DOE/EIA-0095(98)

\title{
Inventory of Power Plants in the United States
}

\section{As of January 1, 1998}

\section{December 1998}

\author{
Energy Information Administration \\ Office of Coal, Nuclear, Electric \\ and Alternate Fuels \\ U.S. Department of Energy \\ Washington, DC 20585
}

DISTRIBUTION OF THIS DOCLMENT IS UNLIMIED PASTER

This report was prepared by the Energy Information Administration, the independent statistical and analytical agency within the Department of Energy. The information contained herein should not be construed as advocating or reflecting any policy position of the Department of Energy or any other organization. 


\section{Contacts}

Questions regarding this report may be directed to:

Energy Information Administration, EI-53

Electric Power Division

U.S. Department of Energy

1000 Independence Avenue, S.W.

Washington, DC 20585

Questions of a general nature should be directed to:

Robert Schnapp (202/426-1211)

Internet e-mail: robert.schnapp@eia.doe.gov

Director, Electric Power Division

Specific information on the data should be directed to:
Elsie Bess (202/426-1142)

Internet e-mail: elsie.bess@eia.doe.gov, Survey Manager

Other contacts for electric data include:

Capacity at U.S. Nonutility Power Producers:

Betty Williams (202/426-1269)

Internet e-mail: betty.williams@eia.doe.gov,

Electric Utility Demand-Side Management:

Karen McDaniel (202/426-1234)

Internet e-mail: karen.mcdaniel@eia.doe.gov,

\section{Quality}

The Energy Information Administration is committed to quality products and quality service. To ensure that this report meets the highest standards for quality, please forward your comments or suggestions about this publication to Elsie Bess at (202/426-1142) or Internet e-mail: elsie.bess@eia.doe.gov.

For general inquiries about energy data, please contact the National Energy Information Center at (202/586-8800). Internet users may contact the center at: infoctr@eia.doe.gov. 


\section{DISCLAIMER}

This repor was prepared as an account of work sponsored by an agency of the United States Government. Neither the United States Governmeat nor any agency thereof, nor any of their employees, makes any wuranty, express or implied, of assumes any legai liability or responsibility for the sccuracy, compieteness, or usefulness of any information, apparatus, produce, or process disclosed. or represents that its use would not infringe privately owned rights. Reference berein to any specific commercial product, process, or service by trade name. tradenarte tnanufac. turer, or otherwise does not necessarily constinute or imply its endorsement. recommendation, or favoring by the United States Governmeat or any agency thereof. The views and opinions of authors expressed herein do not necerarily state or reflect those of the. United States Governmeat or any agency thereof. 


\section{DISCLAIMER}

Portions of this document may be illegible in electronic image products. Images are produced from the best available original document. 


\section{Contents}

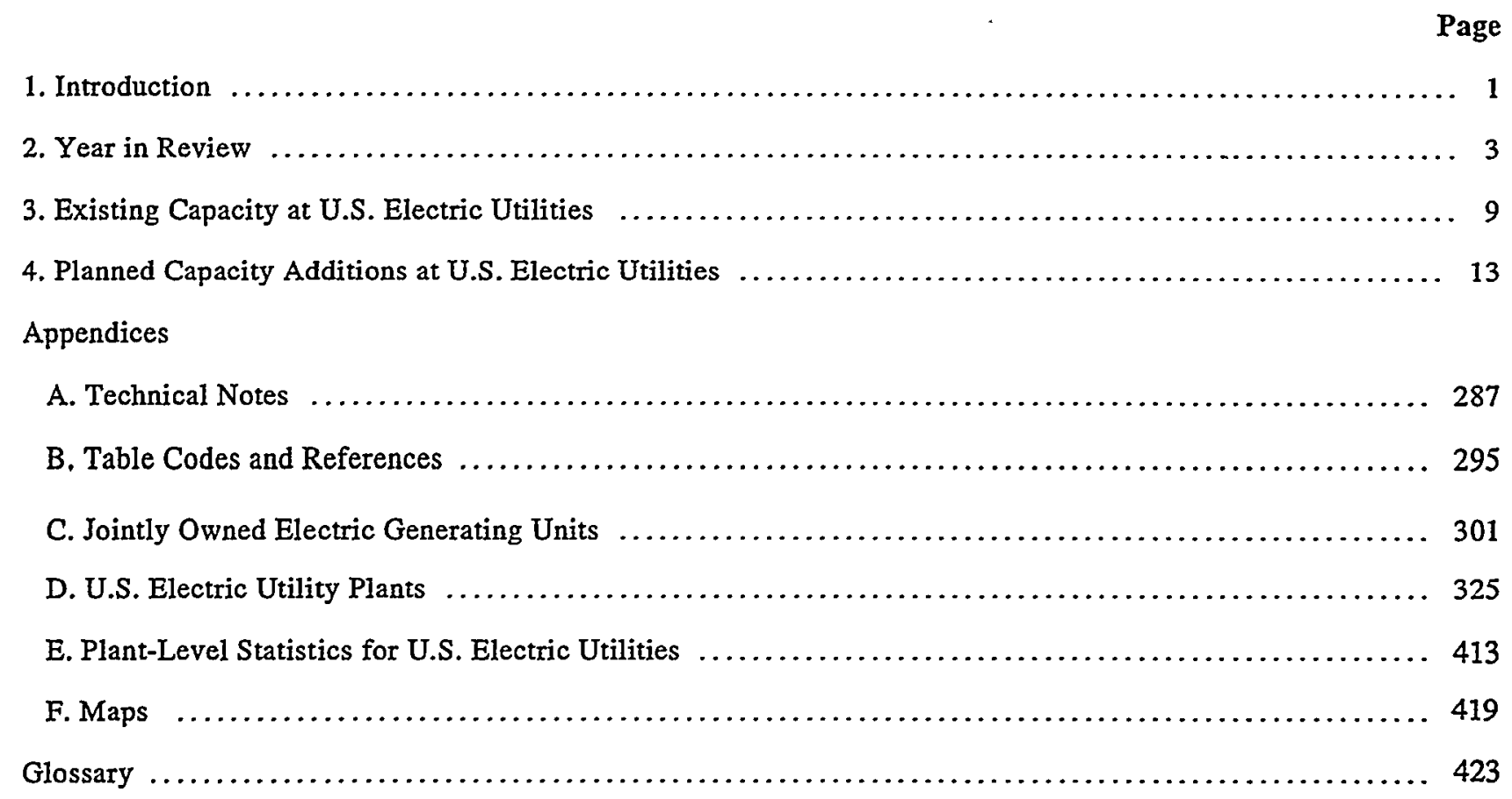




\section{Tables}

Page

1. Existing Capacity and Planned Capacity Additions at U.S. Electric Utilities and Nonutility Power

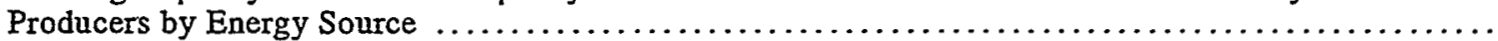

2. Capacity Additions and Retirements at U.S. Electric Utilities by Energy Source, 1997 ............

3. Combined Cycle Existing Capacity and Planned Capacity Additions at U.S. Electric Utilities by Prime

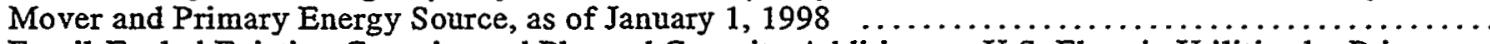

4. Fossil-Fueled Existing Capacity and Planned Capacity Additions at U.S. Electric Utilities by Prime

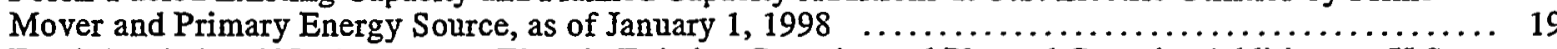

5. Fossil-Fueled and Nuclear Steam-Electric Existing Capacity and Planned Capacity Additions at U.S. Electric Utilities, as of January 1, 1998

6. Existing Capacity at U.S. Electric Utilities by Prime Mover and Energy Source, as of January 1, 1998

7. Planned Capacity Additions at U.S. Electric Utilities, 1998 Through 2007, as of January 1, $1998 \ldots \ldots$

8. Planned Coal- and Petroleum-Fired Capacity Additions at U.S. Electric Utilities, 1998 Through 2007,

9. Planned Gas-Fired and Hydroelectric Capacity Additions at U.S. Electric Utilities, 1998 Through 2007 , Planned Nuclear and Other Capacity Additions at U.S. Electric Utilities, 1998 Through 2007 , as of January 1, 1998

11. Planned Capacity Retirements at U. Electric Utilities, 1998 Trough 2007 as of J............. 22

12. Planned Coal- and Petroleum-Fired Capacity Retirements at U.S. Electric Utilities, 1998 Through 2007 ,

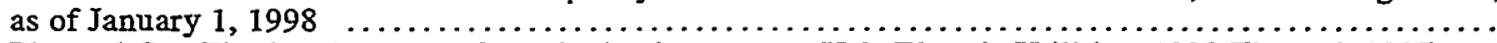

13. Planned Gas-Fired and Nuclear Capacity Retirements at U.S. Electric Utilities, 1998 Through 2007, as of January 1,1998

Existing Capacity and Planned Capacity Additions at U.S. Electric Utilities by Energy Source, North

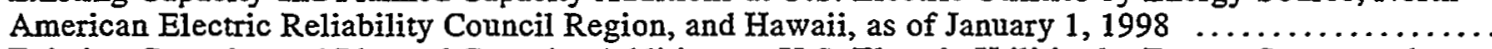

15. Existing Capacity and Planned Capacity Additions at U.S. Electric Utilities by Energy Source and

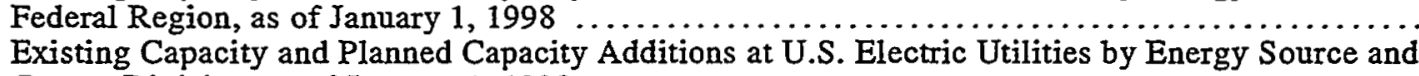

16. Existing Capacity and Planned Capacity Additions at U.S. Electric Utilities by Energy Source and

17. Existing Capacity and Planned Capacity Additions at U.S. Electric Utilities by Energy Source and State, as of January 1, 1998

18. Generating Units that Started Operation at U.S. Electric Utilities by State, Company, and Plant, 1997

19. Generating Units Retired from Service at U.S. Electric Utilities by State, Company, and Plant, $1997 \quad . .48$

20. Existing Generating Units at U.S. Electric Utilities by State, Company, and Plant, as of January 1, 199851

21. Existing Generating Units Powered by Renewable Energy Sources at U.S. Electric Utilities by State, Company, and Plant, as of January 1, 1998

22. Planned Generating Unit Changes at U.S. Electric Utilities by State, Company, and Plant, 1998

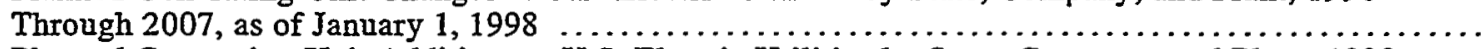

23. Planned Generating Unit Additions at U.S. Electric Utilities by State, Company, and Plant, 1998

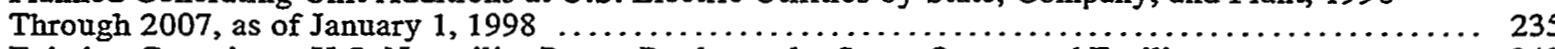

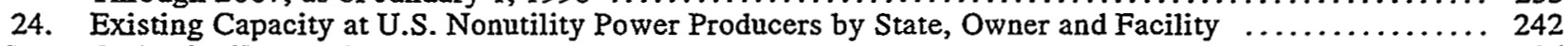

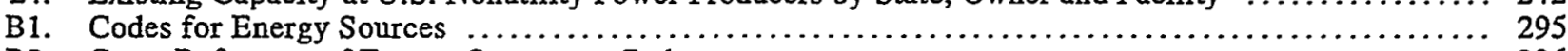

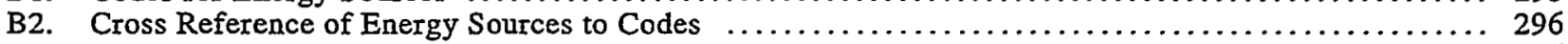

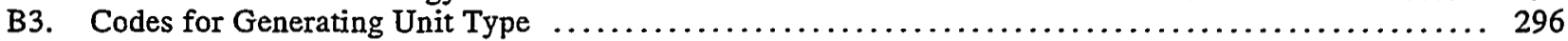

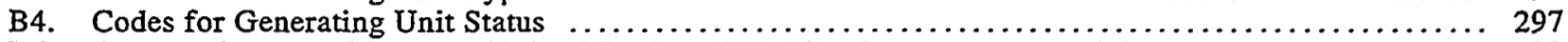

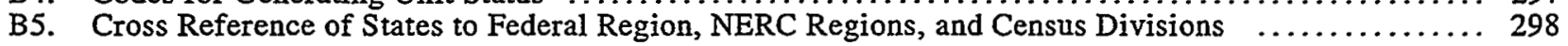

C1. Jointly Owned Electric Generating Units by State, Company, and Plant, as of January 1, $1998 \quad \ldots \ldots . .302$

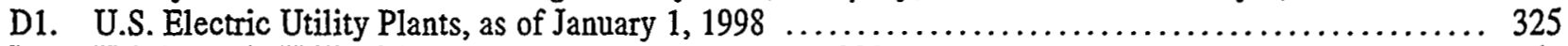

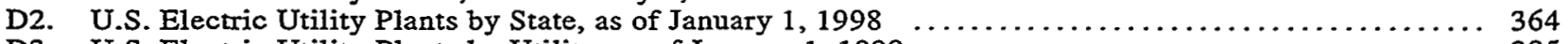

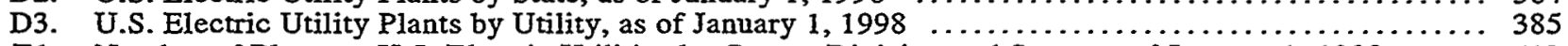

E1. Number of Plants at U.S. Electric Utilities by Census Division and State, as of January 1, $1998 \ldots \ldots \ldots 413$

E2. Existing Capacity at U.S. Electric Utilities by Census Division, State, and Prime Mover, as of January

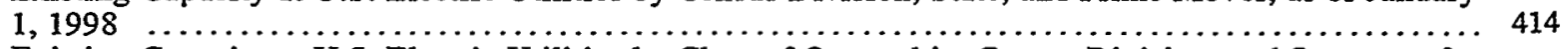

E3. Existing Capacity at U.S. Electric Utilities by Class of Ownership, Census Division, and State, as of

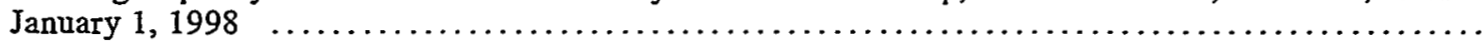




\section{Illustrations}

Page

1. Share of Capacity at U.S. Electric Utilities by Energy Source, as of January 1, $1998 \ldots \ldots \ldots \ldots \ldots \ldots \ldots$

2. Share of Capacity at U.S. Electric Utilities by Prime Mover, as of January 1, $1998 \ldots \ldots \ldots \ldots \ldots \ldots \ldots$

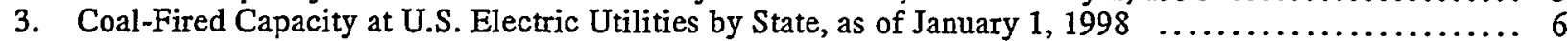

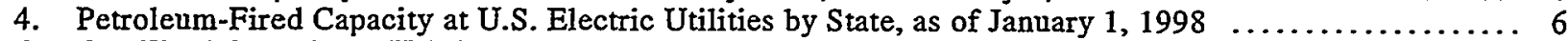

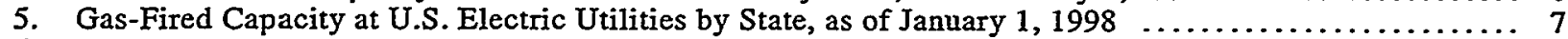

6. Hydroelectric Capacity at U.S. Electric Utilities by State, as of January $1,1998 \ldots \ldots \ldots \ldots \ldots \ldots \ldots \ldots$

7. Nuclear Capacity at U.S. Electric Utilities by State, as of January $1,1998 \ldots \ldots \ldots \ldots \ldots \ldots \ldots \ldots \ldots$

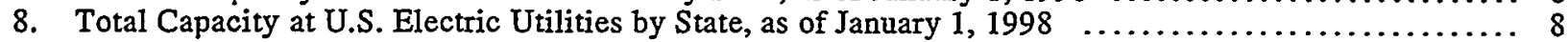

9. Existing Capacity at U.S. Electric Utilities by Prime Mover and Initial Year of Commercial Operation,

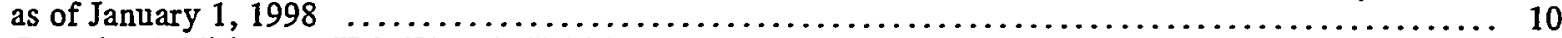

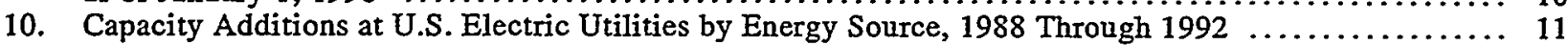

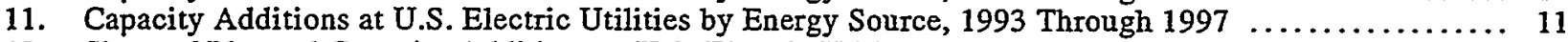

12. Share of Planned Capacity Additions at U.S. Electric Utilities by Energy Source, 1998 Through 2007 . 13

13. Planned Capacity Additions at U.S. Electric Utilities by Energy Source, 1998 Through 2002 ....... 15

14. Planned Capacity Additions at U.S. Electric Utilities by Energy Source, 2003 Through $2007 \ldots \ldots \ldots \ldots$

15. Planned Capacity Additions of More Than 1,000 Megawatts at U.S. Electric Utilities by Utility, 1998

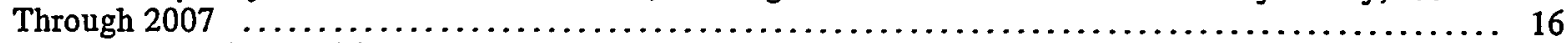

16. Planned Capacity Additions at U.S. Electric Utilities by State, 1998 Through $2007 \ldots \ldots \ldots \ldots \ldots \ldots \ldots \ldots \ldots$

F1. North American Electric Reliability Council Regions for the Contiguous United States and Alaska ... 419

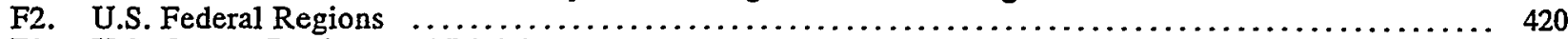

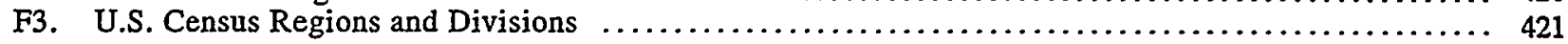




\section{Introduction}

The Inventory of Power Plants in the United States provides annual statistics on generating units operated by electric utilities in the United States (the 50 States and the District of Columbia). Statistics presented in this report reflect the status of generating units as of January 1, 1998. The publication also provides a 10 -year outlook for generating unit additions and generating unit changes.

This report is prepared annually by the Electric Power Division; Office of Coal, Nuclear, Electric and Alternate Fuels; Energy Information Administration (EIA); U.S. Department of Energy (DOE). Data summarized in this report are useful to a wide audience including Congress; Federal and State agencies; the electric utility industry; and the general public. Data presented in this report were assembled and published by the EIA to fulfill its data collection and dissemination responsibilities as specified in the Federal Energy Administration Act of 1974 (Public Law 93-275) as amended.

Chapter 2. "Year in Review" contains aggregate statistics on capacity at various regional levels and at the national level for existing and planned generating unit additions. Aggregate data on capacity at the national level are presented by energy source and prime mover. Aggregate data on capacity at various regional levels are presented by primary energy source. Planned capacity additions and retirements are summarized by year for 1998 through 2007.

Chapter 3. "Existing Capacity at U.S. Electric Utilities" contains data on existing generating units as of January 1, 1998 and generating units that were retired from service during 1997. A summary of generating unit additions by energy source during 1997 is also included.

Chapter 4. "Planned Capacity Additions at U.S. Electric Utilities" contains information regarding generating units scheduled to start commercial operation from 1998 through 2007. This chapter also contains data about proposed changes (modifications and changes in status) to existing and previously retired generating units.

This is a report of electric utility data; in cases where summary data or nonconfidential data of nonutilities are presented, it is specifically noted as nonutility data.
Generally, tables in this publication that contain electric utility capacity data present three measures of generator capacity --generator nameplate capacity, net summer capability, and net winter capability. However, the EIA uses net summer capability as its statistic for analyzing electric utility capacity. Therefore, all discussion of electric utility generating capacity in this publication refers to net summer capability, unless otherwise stated. For an explanation of the three measures of generator capacity, see Appendix A, Technical Notes, "Explanatory Notes." Additionally, any discussion of generator capacity by energy source is based on the primary energy source used by the respective generating unit.

\section{Data Sources}

Data published in the Inventory of Power Plants in the United States were compiled from the Form EIA-860, "Annual Electric Generator Report," filed annually with the EIA, directly by electric utilities, or through an agent of their choice, such as the respondent's regional electric reliability council. Since data requested in Form EIA-860 are also requested by the regional councils on Form EIA-411, "Coordinated Bulk Power Supply Program," Item 3, respondents who report data for Form EIA-411 can fulfill their reporting requirements for Form EIA- 860 by reporting these data to their regional councils. The regional councils use these data for their planning process and regional analysis. The Form EIA-411 data are submitted annually to the North American Electric Reliability Council (NERC) by the regional councils. NERC, in turn, forwards these data electronically to the EIA. For 1998, 78 percent of responses were submitted directly to the EIA in hardcopy form and 22 percent were submitted electronically by NERC.

Updates made during the past year for inclusion in this publication are as follows: (1) changes that reflect construction or modification within power plants or changes in power plant operations (includes the installation of new generators; the retirement of existing generators; the use of a primary energy source for dual-fired units different from that reported in the past; and the modification of generators, such as the rewinding of stators or the retrofitting of associated generator equipment), (2) corrections to previously reported data that were incorrect, (3) deletion of respondents that do not meet the reporting requirements of Form EIA-860, (4) deletion of capacity when generators previously owned and operated by electric utilities are sold to nonutilities, and (5) the inclusion of new respondents. 



\section{Year in Review}

As of January 1, 1998, the existing capacity' of U.S. electric utilities totaled 711,889 megawatts (Table 1). Based on primary energy source, coal-fired capacity represented 43 percent $(302,866$ megawatts) of the Nation's existing capacity (Figure 1). Gas-fired capacity accounted for 19 percent (136,957 megawatts); nuclear, 14 percent (99,716 megawatts); renewable energy sources, ${ }^{2} 11$ percent $(78,300$ megawatts); petroleum, 10 percent $(69,539$ megawatts $)$; and pumped storage hydroelectric, 3 percent $(19,310$ megawatts). The distribution of capacity by state for the various energy sources is shown in Figures 3 through 7. Figure 8 shows the distribution of total U.S. capacity by state.

Of the existing capacity, conventional steam-electric units accounted for 62 percent (441,847 megawatts). Nuclear units accounted for 14 percent; hydroelectric (conventional), 11 percent; gas turbine, 8 percent; pumped storage hydroelectric, 3 percent; combined cycle, 2 percent; internal combustion, geothermal, solar, wind and other, 1 percent (Figure 2).

Of the 441,847 megawatts of conventional steamelectric capacity, 106,815 megawatts were in dualfired generators, capable of using petroleum and gas; 38,046 megawatts of the 73,183 megawatts combined capacity for gas turbine, combined cycle and internal combustion units were dual-fired units.

In $1997,2,556$ megawatts in new units started commercial operation (Table 2). Eighty-one percent $(2,078$ megawatts) of this new capacity is in gas turbine and combined cycle units -- 76 percent fired by gas and waste heat and 5 percent petroleum-fired; the remaining 19 percent is in internal combustion, steam-electric, hydroelectric and wind units. (Table 18).

For the 1998 through 2007 forecast period, electric utilities reported plans to add 45,056 megawatts of generating capacity in new units to their systems. Eighty-eight percent of this total represents gas-fired capacity. Data reported on Form EIA- 860 show that in 1991 gas replaced coal as the dominant energy source in electric utilities' mix of planned capacity additions. These planned gas-fired capacity additions are primarily in short construction lead-time generation resources, such as gas turbine and combined cycle units -- a reflection of today's changing electric industry's effect on electric utilities' practices in planning new capacity.

In addition to adding new generators to their capacity, electric utilities are using other means to meet future load requirements. These include a mix of capability increases in existing generators, repowering and life extension of existing units, purchases from nonutility power producers and demand-side management programs.

Several types of changes in existing generating units were proposed for the ten-year period. These proposed changes include fuel changes, reratings, repowering or life extension, deactivation, change of ownership and retirements (Table 22). More than 7,000 megawatts are a part of utilities' planned sales of their generating assets to nonutility power producers. Another 12,000 megawatts are utilities' planned retirements.

Nonutilities are expected to supply a significant portion of the generating capacity needed to meet energy requirements of electric utilities (Table 24). The contribution of nonutility capacity ${ }^{3}$ to total electricity supply has increased significantly over the past several years and is expected to continue to increase with the existence of economic incentives and the need for additional generating capacity to meet expected industry demands. Data for 1997 show that nonutility capacity totals 74 gigawatts (Table 1 ) for a gross generation of 384,707 gigawatthours with sales to electric utilities of 223,467 gigawathours. Nonutility power producers project that nonutility capacity will be fueled mostly by gas and renewable energy sources. Nonutility capacity additions ${ }^{4}$ planned for 1998 through 2001 total about 10 gigawatts $^{5}$ (Table 1), while electric utilities have planned to add about 14 gigawatts of new capacity (generator nameplate capacity) during this same period (Table 7).

Electric utilities continue to have demand-side management (DSM) programs aimed at reducing electricity use by implementing conservation and load management. The objective of most DSM programs is to provide cost-effective . energy and capacity resources that postpone the need for construction of

I In all cases, capacity is net summer capability, unless noted otherwise.

2 Renewable energy sources include water (conventional hydroelectric), geothermal, biomass, solar and wind.

3 Capacity for nonutility power producer facilities is generator nameplate capacity. For more information on nonutility capacity, see Electric Power Annual 1997, Volume 2, DOE/EIA-0348(97)/2 (Washington, DC, October 1998).

4 These data represent planned capacity additions for which a proposed date of operation in 1998, 1999, 2000 or 2001 was reported. These data may differ from other nonutility planned capacity additions summarized in other reports that additionally include planned capacity additions for which a proposed date of operation was not reported.

s Source: Energy Information Administration, Form EIA-867, "Annual Nonutility Power Producer Report." 
new power plants by modifying the growth in demand and energy use. Final data show the total potential peakload reductions for DSM in 1997 were 41 gigawatts; the total energy savings were 56 billion kilowattthours and total cost was $\$ 1,636$ million dollars. ${ }^{6}$

6 Source: Energy Information Administration, Form EIA-861, "Annual Electric Utility Report."

4 Energy Information Administration/Inventory of Power Plants in the United States as of January 1, 1998 
Figure 1. Share of Capacity at U.S. Electric Utilities by Energy Source, as of January 1, 1998

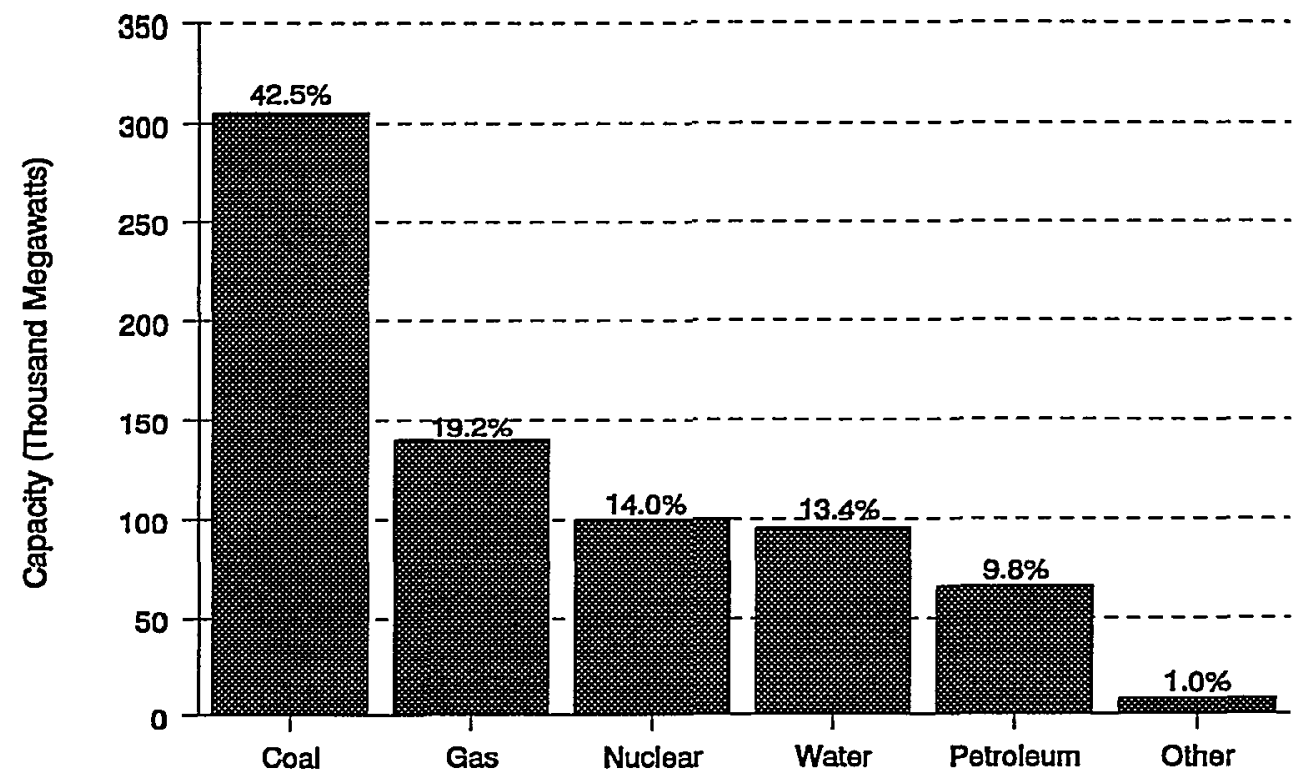

Notes: $\bullet$ Capacity is net summer capability. $\bullet$ Other includes waste heat, geothermal, wood, wood waste, nonwood waste, solar, wind, multi-fuel, methane, and hot nitrogen. $\bullet$ Total may not equal sum of components due to independent rounding. $\bullet$ See Appendix A, Technical Notes, for explanation of reporting date.

Figure 2. Share of Capacity at U.S. Electric Utilities by Prime Mover, as of January 1, 1998

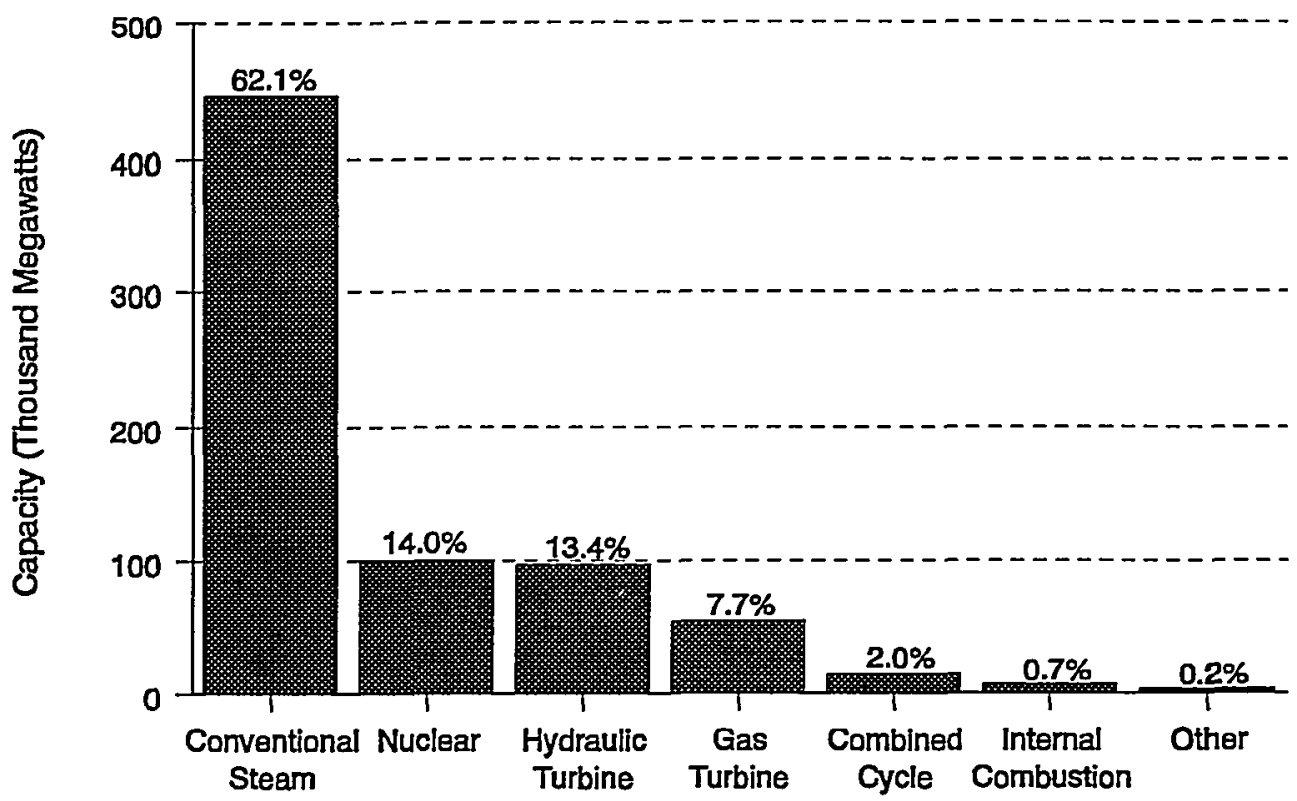

Notes: -Capacity is net summer capability. •Conventional steam includes wood, wood waste, and nonwood waste. - Other includes waste heat, geothermal, wood, wood waste, nonwood waste, solar, wind, expander turbine, and reciprocating engine. • Total may not equal sum of components due to independent rounding. • See Appendix A, Technical Notes, for explanation of reporting date.

Source: Energy Information Administration, Form EIA-860, "Annual Electric Generator Report." 
Figure 3. Coal-Fired Capacity at U.S. Electric Utilities by State, as of January 1, 1998

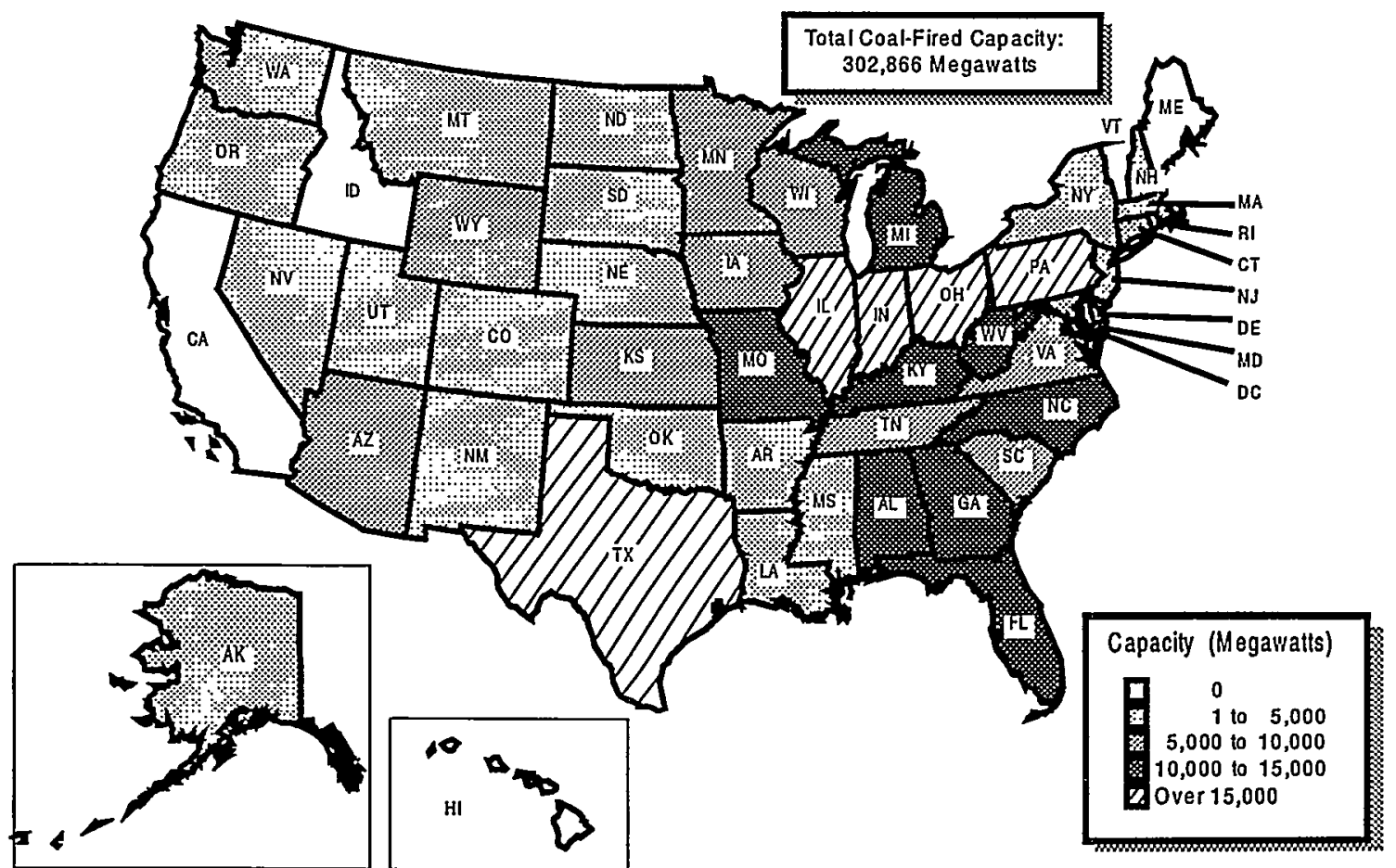

Notes: - Capacity is net summer capability. - See Appendix A, "Technical Notes," for explanation of reporting date. Source: Energy Information Administration, Form EIA-860, "Annual Electric Generator Report."

Figure 4. Petroleum-Fired Capacity at U.S. Electric Utilities by State, as of January 1, 1998

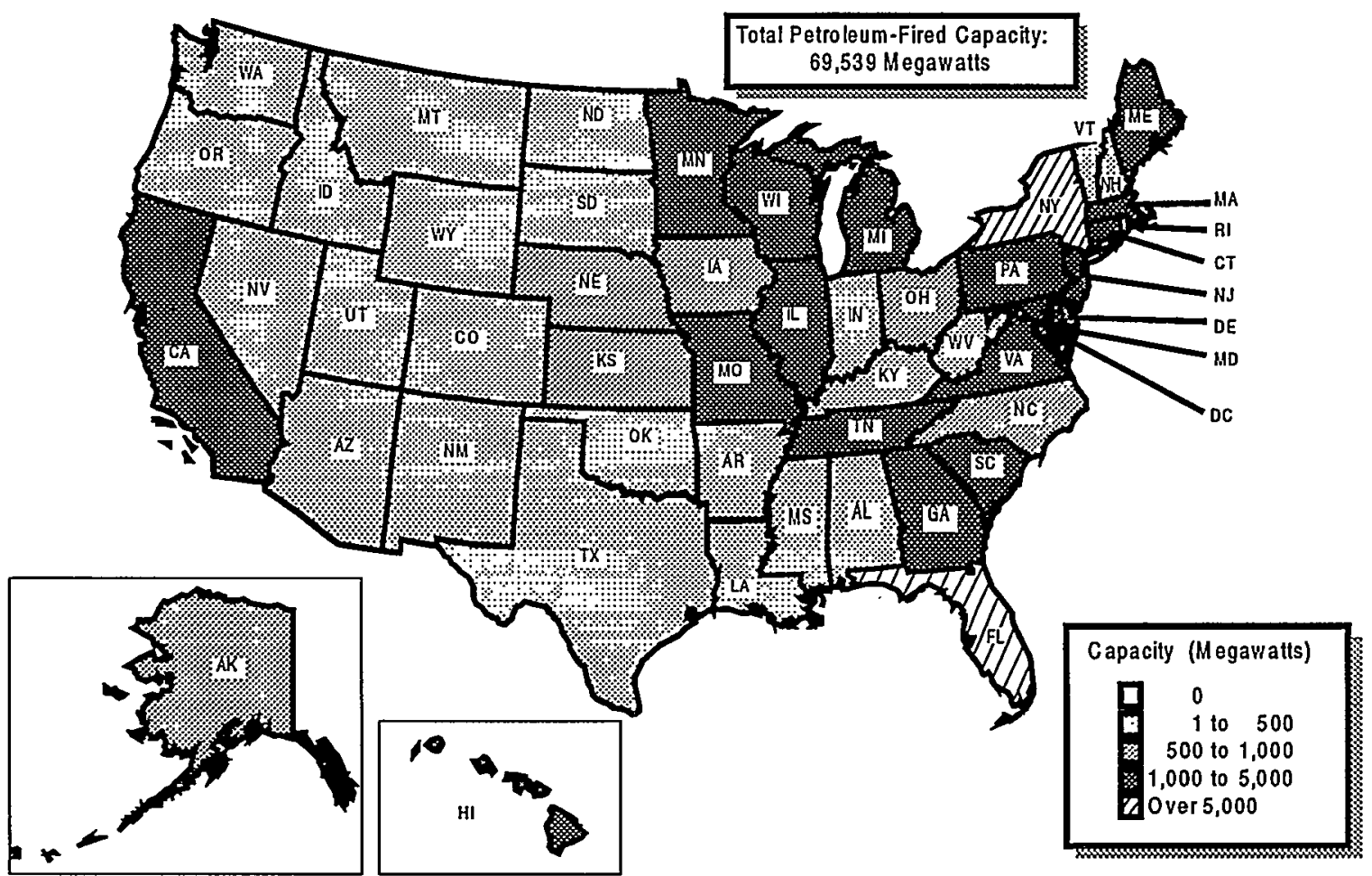

Notes: - Capacity is net summer capability. - See Appendix A, "Technical Notes," for explanation of reporting date. Source: Energy Information Administration, Form EIA-860, "Annual Electric Generator Report." 
Figure 5. Gas-Fired Capacity at U.S. Electric Utilities by State, as of January 1, 1998

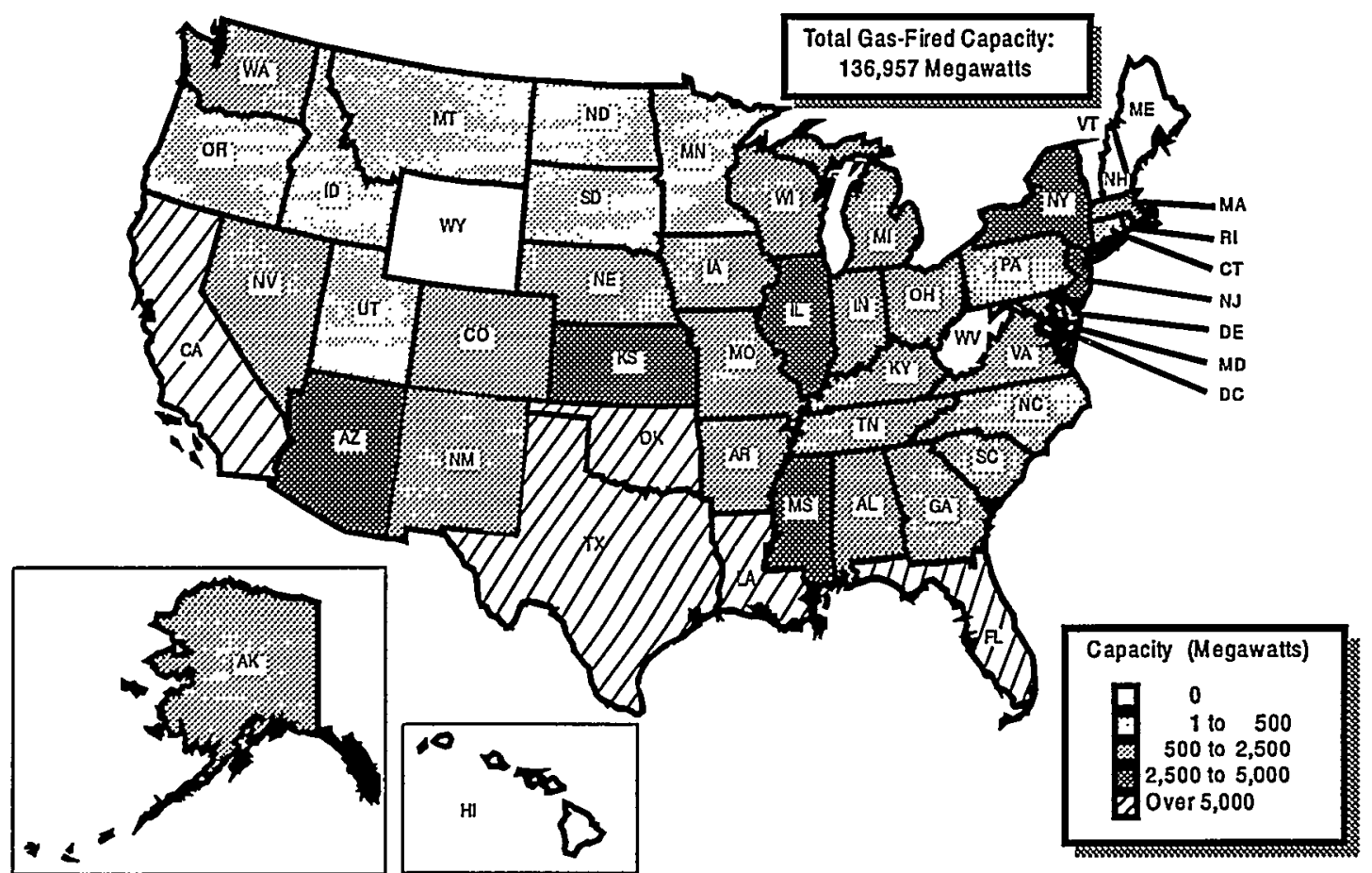

Notes: - Capacity is net summer capability. - See Appendix A, "Technical Notes," for explanation of reporting date. Source: Energy Information Administration, Form ElA-860, "Annual Electric Generator Report."

Figure 6. Hydroelectric Capacity at U.S. Electric Utilities by State, as of January 1, 1998

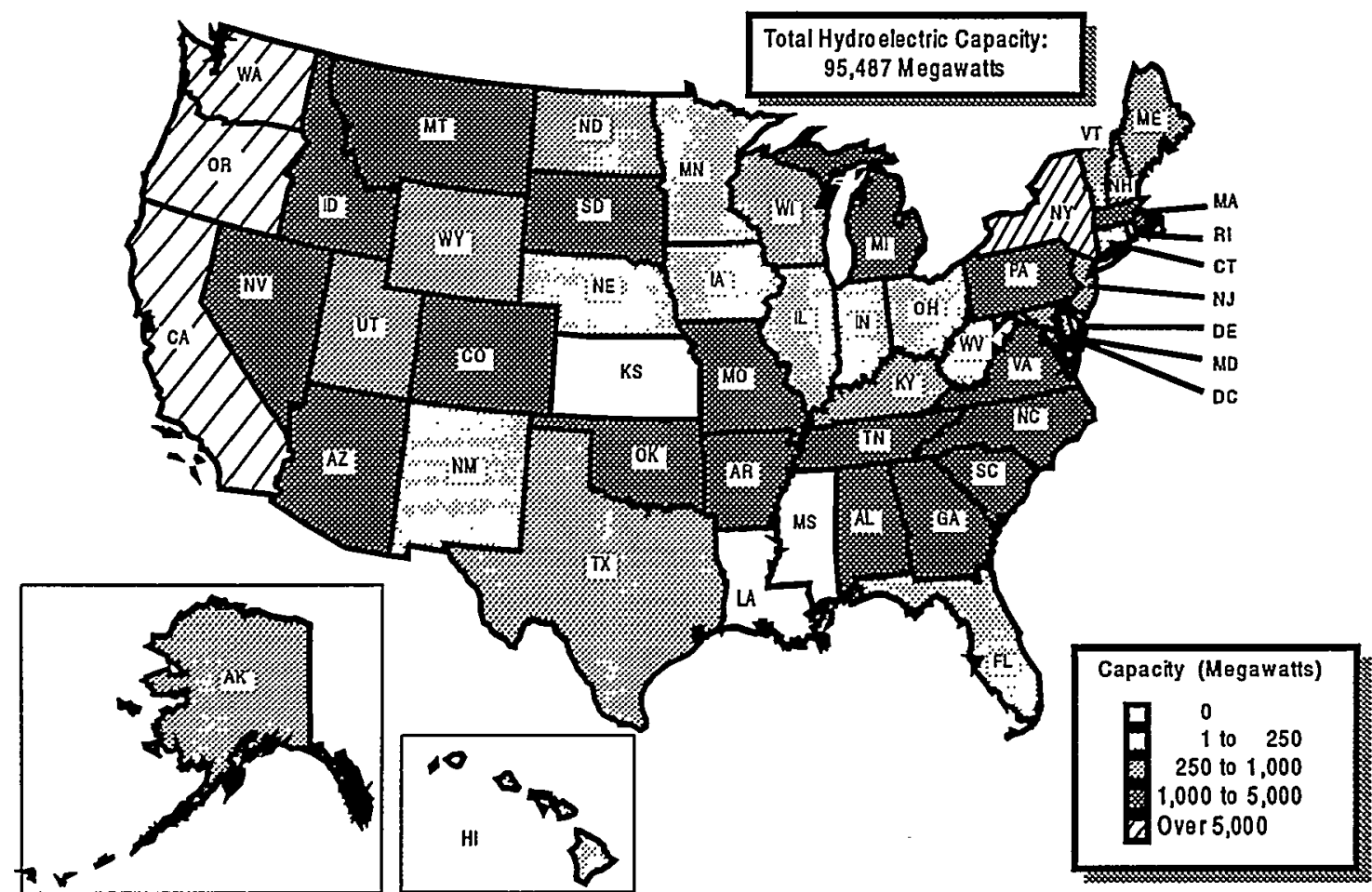

Notes: - Capacity is net summer capability. - See Appendix A, "Technical Notes," for explanation of reporting date.

Source: Energy Information Administration, Form EIA-860, 'Annual Electric Generator Report.' 
Figure 7. Nuclear Capacity at U.S. Electric Utilities by State, as of January 1, 1998

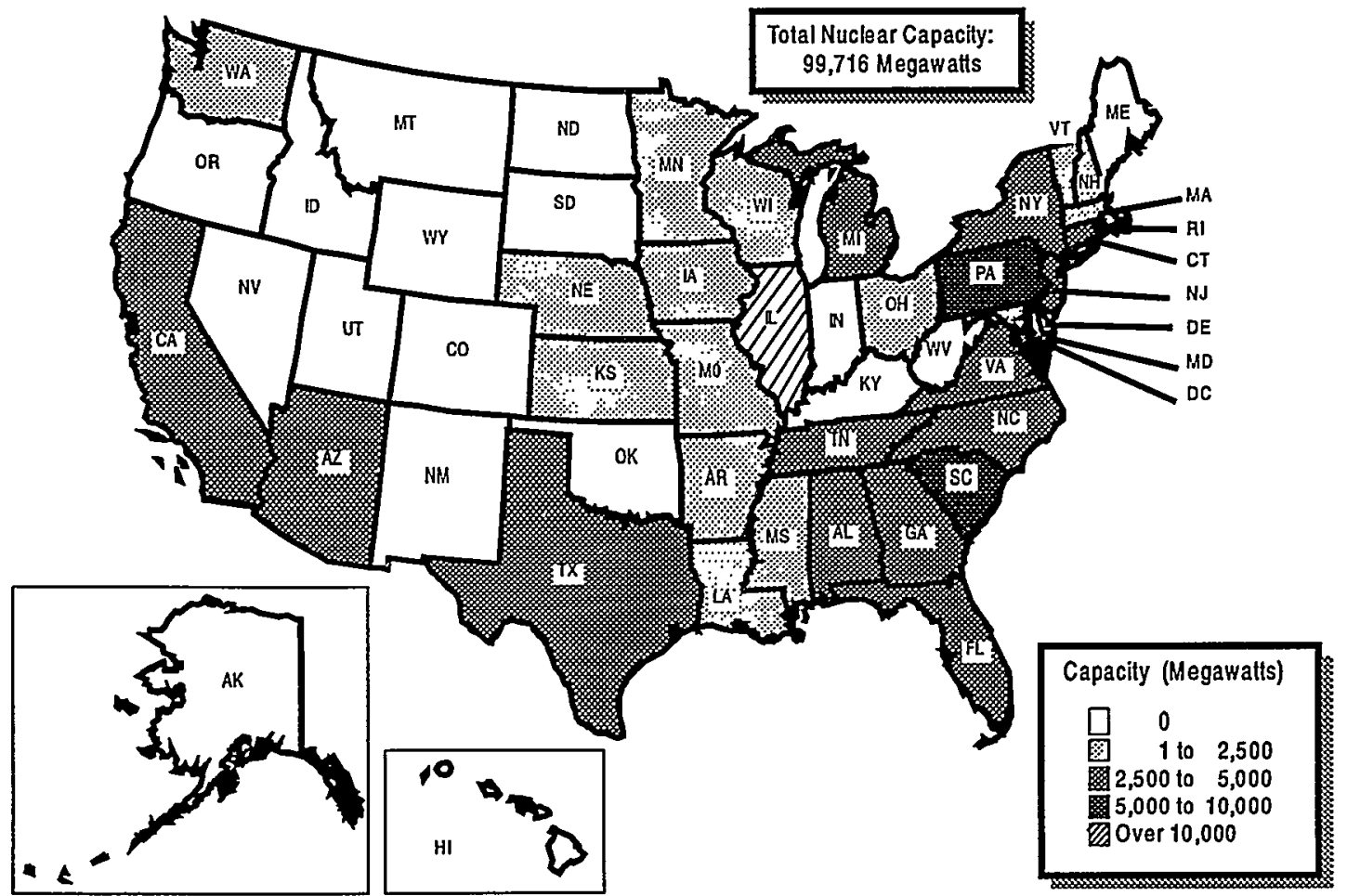

Notes: - Capacity is net summer capability. - See Appendix A, "Technical Noles," for explanation of repoting date.

Source: Energy Information Administration, Form EIA-860, "Annual Electric Generator Report."

Figure 8. Total Capacity at U.S. Electric Utilities by State, as of January 1, 1998

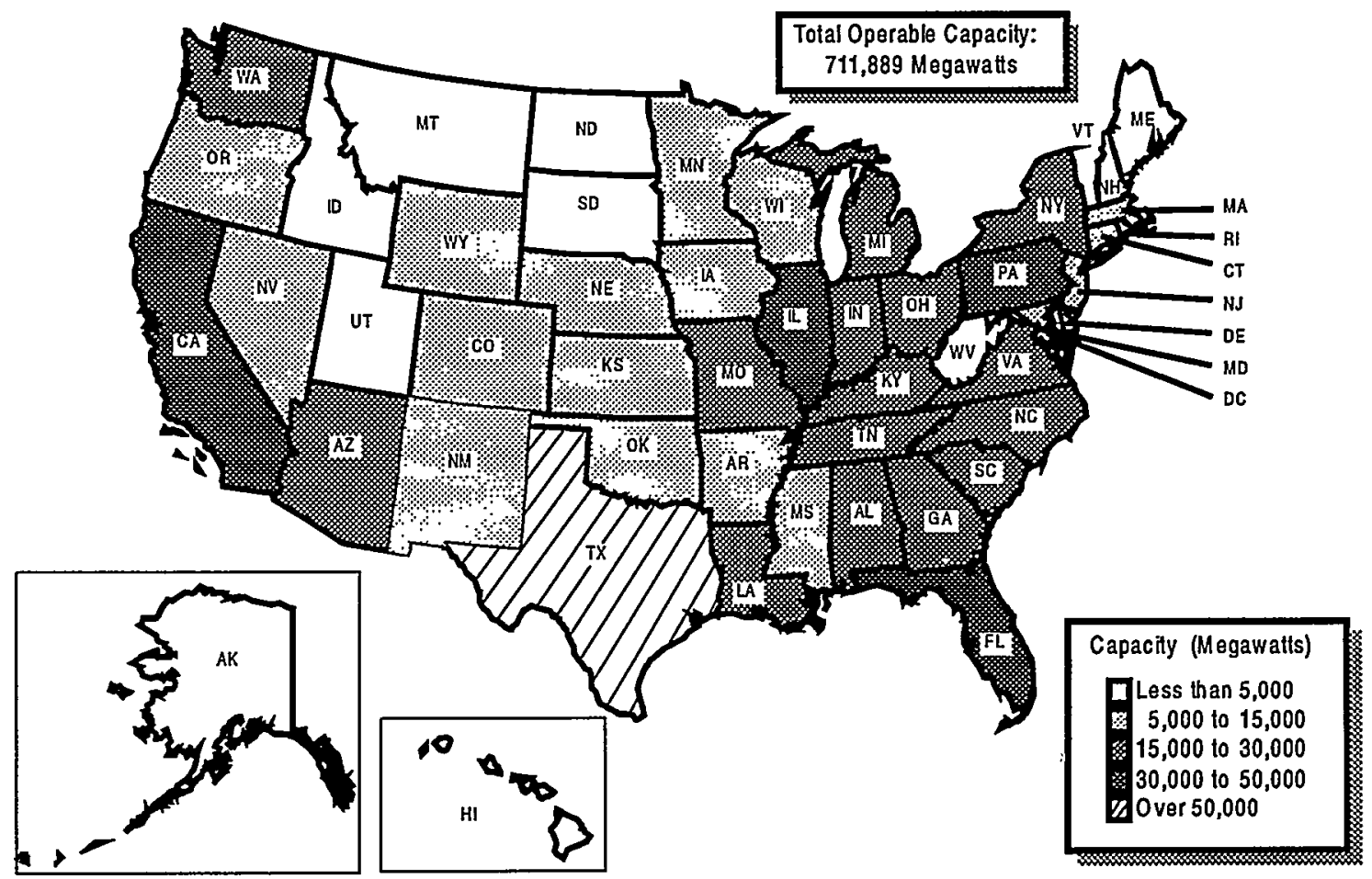

Notes: - Capacity is net sum mer capability. - See Appendix A, "Technical Notes," for explanation of reporting date. Source: Energy Information Administration, Form EIA-860, "Annual Electric Generator Report." 


\section{Existing Capacity at U.S. Electric Utilities}

As of January 1, 1998, the existing capacity ${ }^{7}$ of generating units operated by U.S. electric utilities totaled 711,889. megawatts (Table 1). The active generating capacity (capacity that was either operating, available to operate, or on short-term scheduled or forced outage) totaled 697,124 megawatts. The inactive capacity that was on long-term scheduled or forced outage totaled 9,012 megawatts; the inactive capacity that was in cold standby status (deactivated) totaled 5,754 megawatts.

Conventional steam-electric capacity, accounted for 62 percent ( 441,847 megawatts) of operable capacity; nuclear, 14 percent $(99,716$ megawatts); hydroelectric (conventional), 11 percent (76,177 megawatts); gas turbine and internal combustion, 8 percent (59,298 megawatts); hydroelectric (pumped storage), 3 percent (19,310 megawatts); combined cycle, 2 percent $(13,885$ megawatts); and geothermal, solar, and wind, less than 1 percent (1,641 megawatts) (Table 6). Existing electric generating capacity by prime mover and initial year of commercial operation is presented in Figure 9.

The generating capacity of new units brought on line in 1997 totaled 2,556 megawatts (Table 2). Seventy-six percent of this new capacity is in gasfired gas turbine and combined cycle units (including waste heat steam parts). Such gas-fired capacity additions are expected to dominate capacity additions over the next ten years. The remaining 24 percent in new capacity is comprised of internal combustion units, a petroleum-fired gas turbine unit, gas-fired steamelectric units that are not combined cycle, conventional hydroelectric and wind units. (Table 18).
Included in the newly added gas-fired capacity is Florida Power Corporation's Tiger Bay combined cycle unit which was formerly a part of nonutility capacity. It consists of 2 generators -- a 140-megawatt gas turbine and a 66-megawatt waste heat steamelectric generator. Combined cycle plants were also installed by Sacramento Utility District (241 megawatts) and Public Utility District No.1 of Clark County in Washington (248 megawatts). Virginia Electric and Power Company's 400-megawatt Bell Mead plant which is a part of the capacity added in 1997 was also formerly a part of nonutility capacity. Bell Mead, a gas-fired plant, has 2 gas turbines and one steam generator. In addition to the 60 megawatts of conventional hydroelectric capacity that came on line in 1997, other renewable capacity reported as starting commercial operation in 1997 includes Green Mountain Power Corporation's (VT) Searsburg Wind Turbine (6 megawatts) and Jacksonville Electric Authority's Girvin internal combustion unit (3 megawatts) powered by methane. Electric utility generating capacity additions by energy source are presented for the 1988 through 1997 period in Figures 10 and 11.

Elecíric utilities reported 1,993 megawatts of capacity retired in 1997 (Table 2). This retired capacity includes 937 megawatts in 2 nuclear units -- Maine Yankee Atomic Power Company's Maine Yankee unit (870 megawatts) and Consumers Energy Company's Big Rock Point unit (67 megawatts). Fossil-fueled steam-electric units accounted for 900 megawatts of the retired capacity with an average size of 53 megawatts.

Electric utilities have scheduled 12,479 megawatts of the existing capacity for retirement over the next ten years (Table 11).

7 In all cases, capacity is net summer capability, unless noted otherwise. 
Figure 9. Existing Capacity at U.S. Electric Utilities by Prime Mover and Initial Year of Commercial Operation, as of January 1, 1998

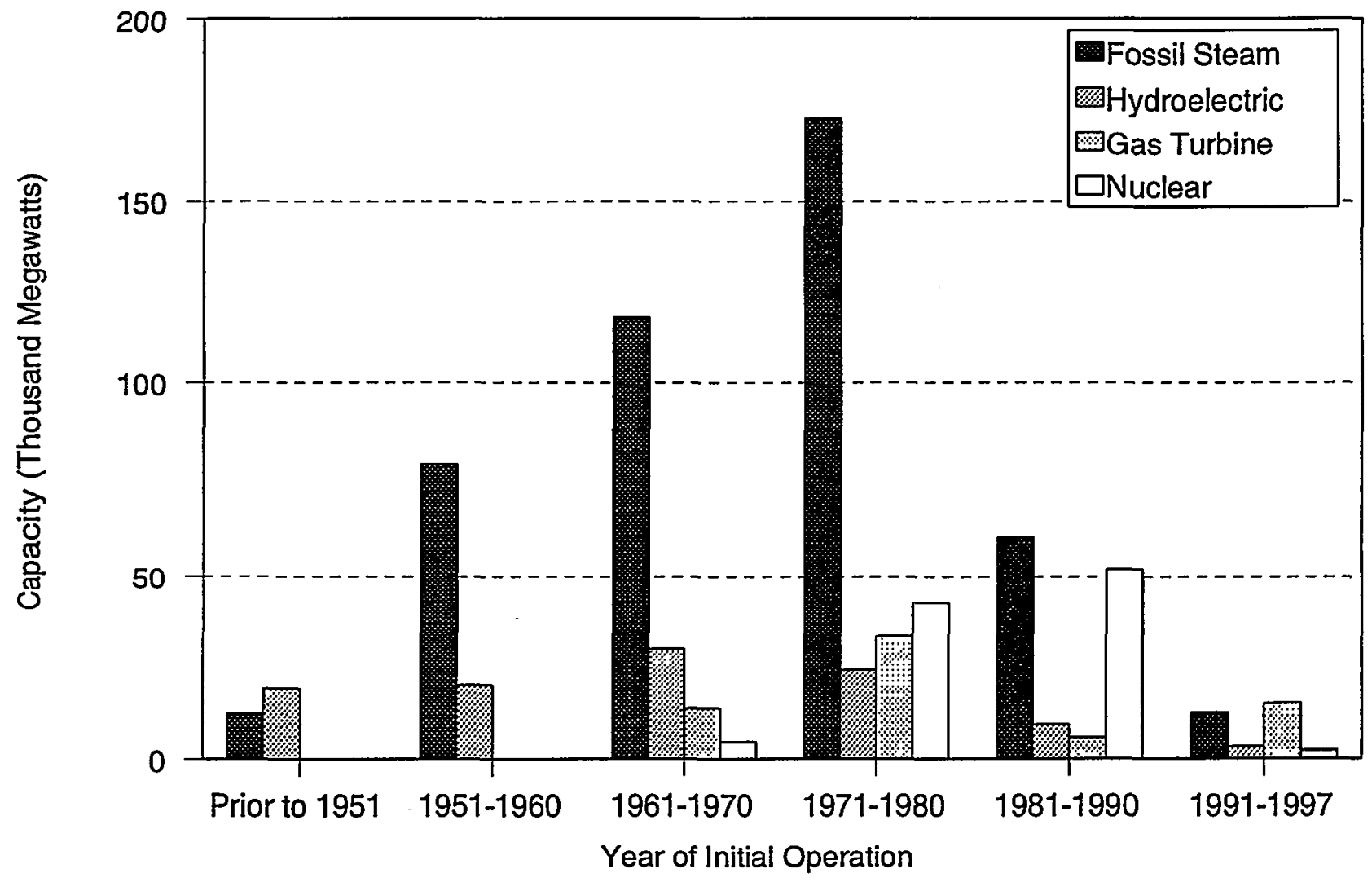

Notes: • Capacity is net summer capability. • Fossil Steam includes wood, wood waste, and nonwood waste. $\bullet$ Combined cycle parts are included appropriately with steam and gas turbine; internal combustion is not shown as it is less than one percent of the total capacity. - See Appendix A, Technical Notes, for explanation of reporting date. $\bullet$ Initial year of operation is the year of initial commercial operation. Prior to the 1996 publication (as of 1/1/96), initial year of operation is the initial year in which the generator/capacity was available to provide power to the grid.

Source: Energy Information Administration, Form ElA-860, "Annual Electric Generator Report." 
Figure 10. Capacity Additions at U.S. Electric Utilities by Energy Source, 1988-1992

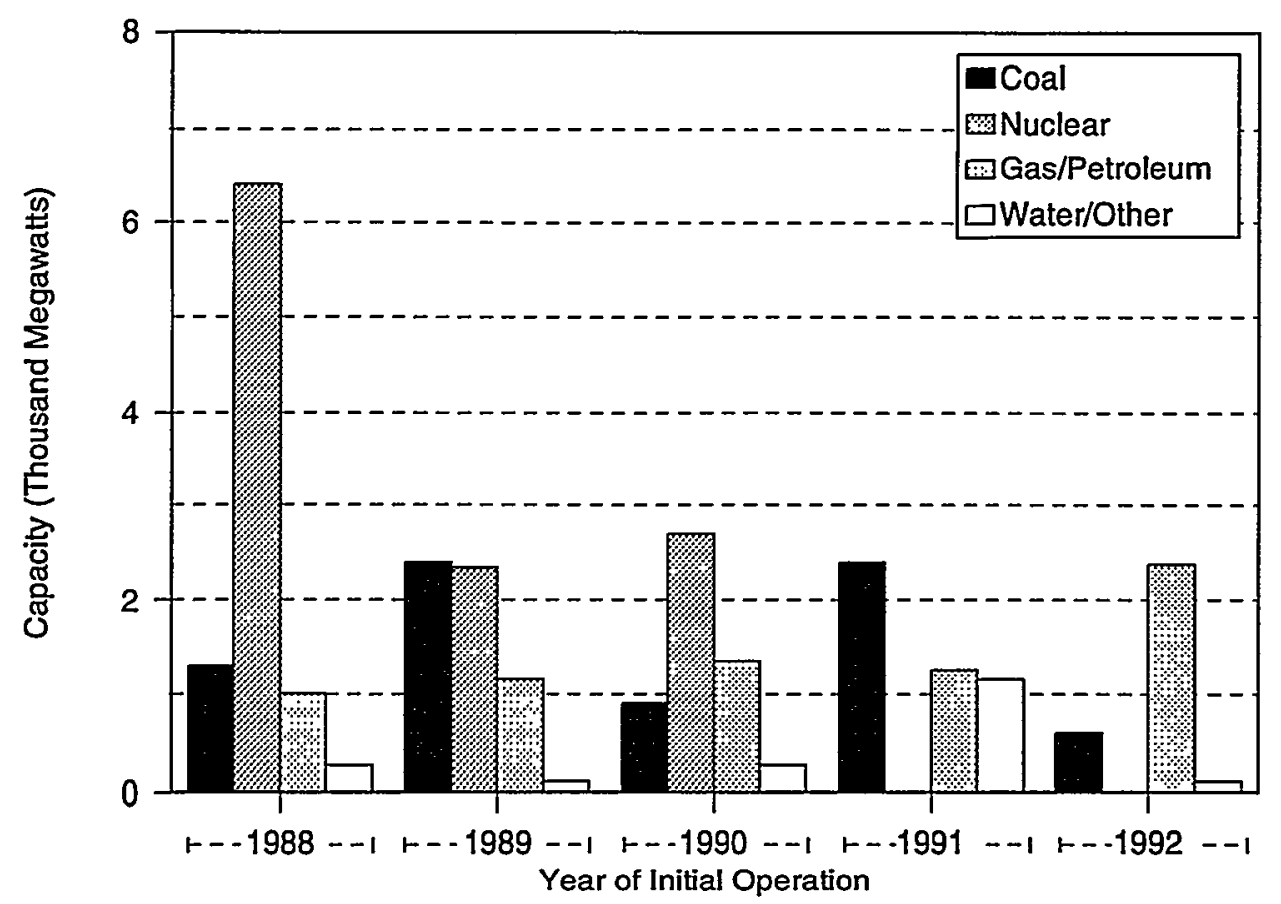

Notes: - Capacity is net summer capability. $\bullet$ Other includes geothermal, wood, wood waste, nonwood waste, solar, and wind. - Initial year of operation is the year of initial commercial operation. Prior to the 1996 publication (as of 1/1/96), initial year of operation is the initial year in which the generator/capacity was available to provide power to the grid.

Source: Energy Information Administration, Form EIA-860, "Annual Electric Generator Report."

Figure 11. Capacity Additions at U.S. Electric Utilities by Energy Source, 1993-1997

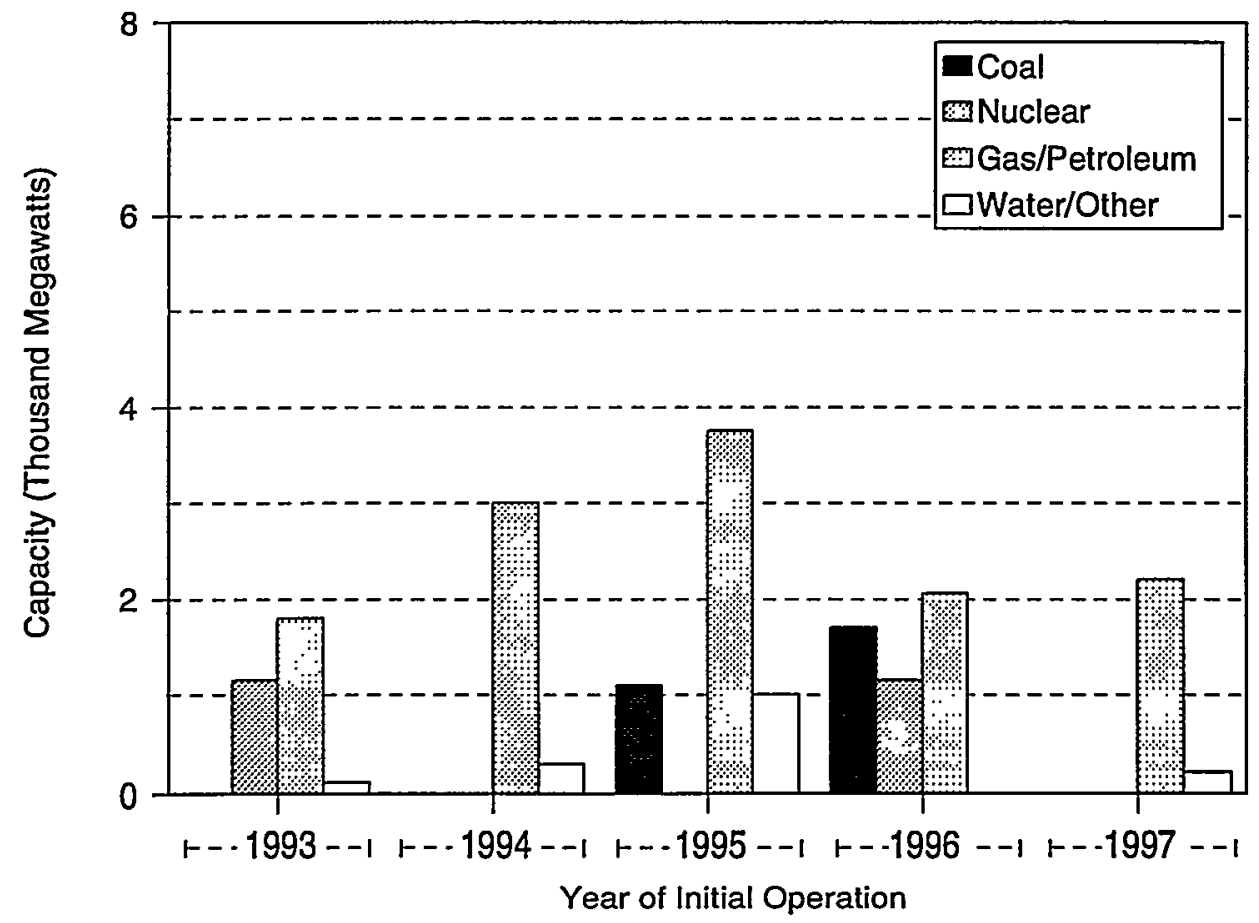

Notes: • Capacity is net summer capability. • Other includes geothermal, wood, wood waste, nonwood waste, solar, and wind. - Initial year of operation is the year of initial commercial operation. Prior to the 1996 publication (as of 1/1/96), initial year of operation is the initial year in which the generator/capacity was available to provide power to the grid.

Source: Energy Information Administration, Form EIA-860, "Annual Electric Generator Report." 



\section{Planned Capacity Additions at U.S. Electric Utilities}

Electric utilities have planned to install 45,056 megawatts of capacity in their systems during the next 10 years (Figures 13 and 14). This proposed new capacity includes generators that were in testing phase, under construction, and in various stages of planning as of January $1,1998 .{ }^{8}$ Of the 45,056 megawatts of proposed new capacity in new generating units, 1 percent (315 megawatts) had construction complete and was in the testing phase. Four percent (1,713 megawatts) was under construction and 95 percent $(43,028$ megawatts) was in various stages of planning. These proposed plans for 45,056 megawatts of capacity are in 316 new units. Additional capacity that electric utilities will realize through repowering or upgrading of their existing plants, or capacity that is owned and operated by nonutility generators is not included in these plans.

Gas-fired capacity $(39,679$ megawatts) represents 88 percent of the total planned capacity. Eighty-six percent $(38,778$ megawatts) of new capacity will be in gas turbine and combined cycle units. Coal-fired units represent 5 percent (2,444 megawatts) of capacity additions (Figure 12). The remainder of planned additions will be in steam-electric units not operating in combined cycle, hydroelectric (including pumped storage), internal combustion, solar, wind and fuel cell units (Table 23).

Figure 12. Share of Planned Capacity Additions at U.S. Electric Utilities by Energy Source, 1998 Through 2007

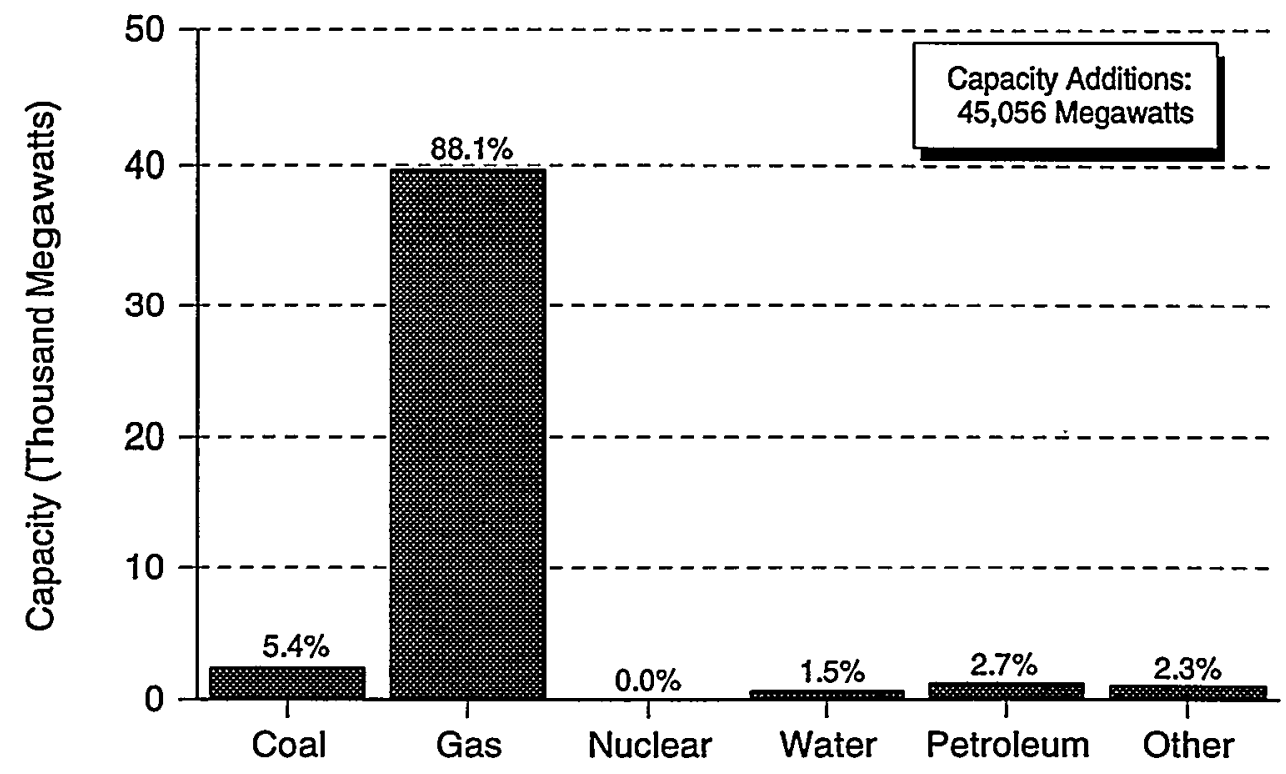

Notes: -Capacity is net summer capability. $\bullet$ Other includes waste heat, solar, and wind. $\bullet$ Total may not equal sum of components due to independent rounding. • Plans are as of January 1, 1998; see Appendix A, Technical Notes, for explanation of reporting date.

Source: Energy Information Administration, Form ElA-860, "Annual Electric Generator Report."

\footnotetext{
${ }^{8}$ Some electric utilities reported plans for new capacity additions that are excluded from the 10 -year forecast presented in this publication. These include capacity reported as "unspecified resources," which refers to capacity that will likely be needed but for which electric utilities have not determined whether the capacity will be utility-built or purchased from nonutilities. Also excluded from the 10-year forecast is capacity reported by electric utilites, for which the choice of technology and/or fuel has not been determined by the utility.
} 
During the next 10 years, new construction by electric utilities will primarily be in gas turbine and combined cycle units because these units have lower installation costs and shorter lead-times for installation. Such planned construction shows the electric utilities' continued reliance on short leadtime resources, as additional capacity is needed. At least 1,000 megawatts of gas turbine or combined cycle capacity in new units are planned in each of 12 States--Alabama, Arizona, Florida, Georgia, Illinois, Indiana, Kentucky, Maryland, North Carolina, Ohio, South Carolina and Wisconsin.

Some of the proposed gas turbines will operate in simple cycle; others are a part of new combined cycle projects and some are a part of electric utilitis' repowering projects. The most common type of repowering reported by electric utilities is reconfiguring an existing steam-electric plant with a new combustion technology and adding a gas turbine.
Most clean coal projects planned and undertaken by utilities were fluidized bed combustion and integrated coal gasification. These technologies improve power plant efficiency, help clean the air, and allow greater use of high-sulfur coal. Current 10-year plans include a single unit of 183 megawatts of fluidized bed combustion capacity at City of Lakeland's C.D. McIntosh, Jr., Unit 4 in Florida. Electric utilities have planned and are engaged in clean coal projects to comply with stricter environmental requirements proposed by the Clean Air Act Amendment.

Renewable-powered capacity (exclusive of hydroelectric) planned for installation during the next ten years include 10 megawatts of photovoltaic in Arizona and Wisconsin (Table 23) and 10 megawatts of wind capacity in Wisconsin. Other activities planned and undertaken by electric utilities to provide an adequate and reliable supply of electricity include purchases from nonutility power producers, demand-side management programs and life extension/refurbishment and upgrading of existing resources. 
Figure 13. Planned Capacity Additions at U.S. Electric Utilities by Energy Source, 1998 Through 2002

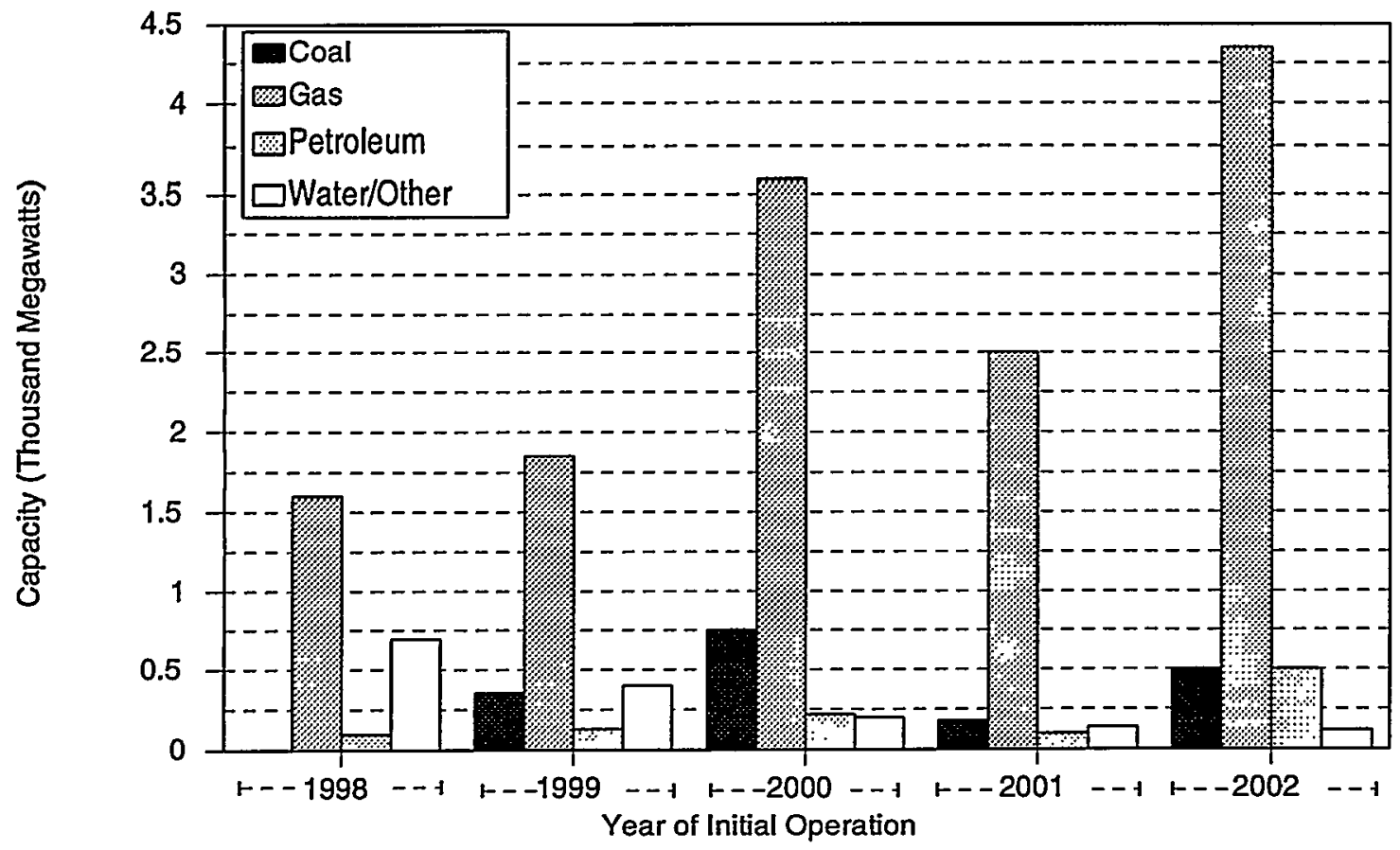

Notes: $\bullet$ Capacity is net summer capability. $\bullet$ Other includes waste heat, solar, and wind. $\bullet$ Plans are as of January 1, 1998; see Appendix A, Technical Notes, for explanation of reporting date.

Source: Energy Information Administration, Form EIA-860, "Annual Electric Generator Report."

Figure 14. Planned Capacity Additions at U.S. Electric Utilities by Energy Source, 2003 Through 2007

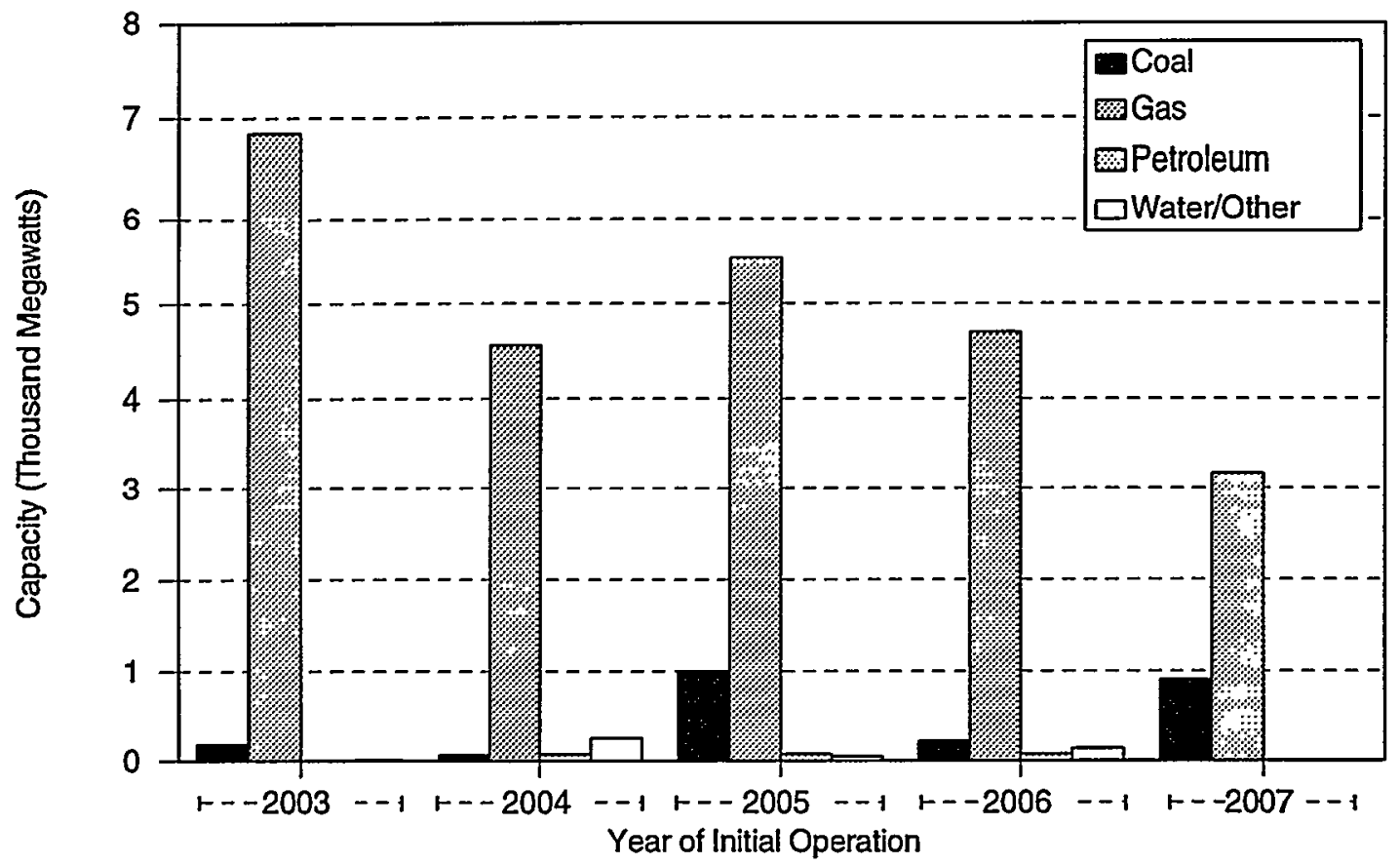

Notes: $\bullet$ Capacity is net summer capability. $\bullet$ Other includes waste heat, solar, and wind. $\bullet$ Plans are as of January 1, 1998; see Appendix A, Technical Notes, for explanation of reporting date.

Source: Energy Information Administration, Form EIA-860, "Annual Electric Generator Report." 
Figure 15. New Generator Planned Capacity Additions of More Than 1,000 Megawatts at U.S. Electric Utilities by Utility, 1998 Through 2007

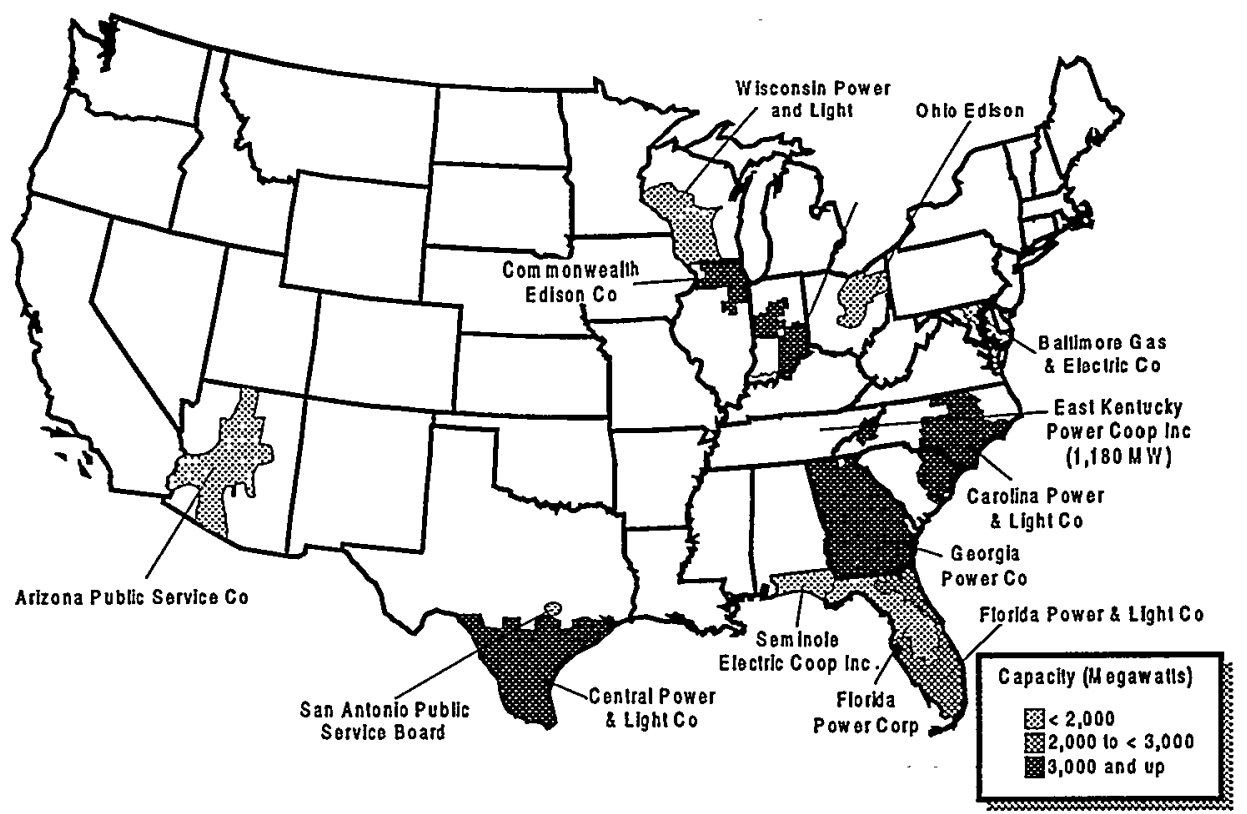

Notes: • Capacity is net summer capability. • Fossil Steam includes wood, wood waste, and nonwood waste. $\bullet$ Combined cycle and internal combustion are not shown as they are only two percent of the total capacity. $\bullet$ See Appendix A, Technical Notes, for explanation of reporting date. - Initial year of operation is the year of initial commercial operation. Prior to the 1996 publication (as of $1 / 1 / 96$ ), initial year of operation is the initial year in which the generator/capacity was available to provide power to the grid.

Source: Energy Information Administration, Form EIA-860, "Annual Electric Generator Report."

Figure 16. Planned Capacity Additions at U.S. Electric Utilities by State, 1998 Through 2007

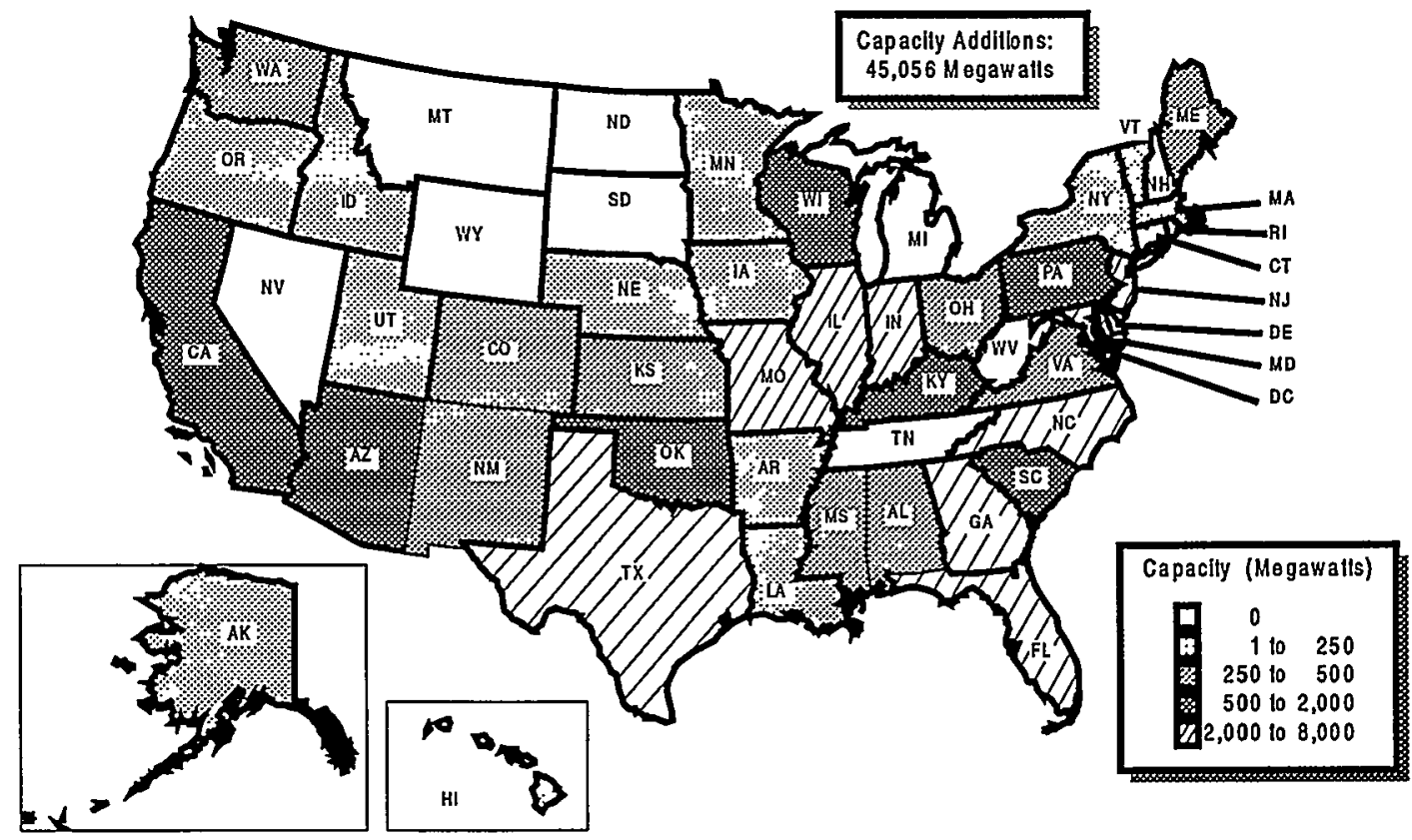

Notes: •Capacity is net summer capability. •Plans are as of January 1, 1998; see Appendix A, Technical Notes, for explanation of reporting date.

Source: Energy Information Administration, Form EIA-860, "Annual Electric Generator Report." 
Table 1. Existing Capacity and Planned Capacity Additions at U.S. Electric Utilities and Nonutility Power Producers by Energy Source

\begin{tabular}{|c|c|c|c|c|c|c|c|c|}
\hline \multirow[b]{2}{*}{$\begin{array}{l}\text { Primary Energy } \\
\text { Source }\end{array}$} & \multicolumn{4}{|c|}{ Existingl } & \multicolumn{4}{|c|}{ Phnned Additions (1998-2007) } \\
\hline & $\begin{array}{l}\text { Number } \\
\text { of Units }\end{array}$ & $\begin{array}{c}\text { Generator } \\
\text { Nameplate } \\
\text { Capacity } \\
\text { (megawatts) }\end{array}$ & $\begin{array}{l}\text { Net Summer } \\
\text { Capability } \\
\text { (megawatts) }\end{array}$ & $\begin{array}{c}\text { Net Winter } \\
\text { Capability } \\
\text { (megawatts) }\end{array}$ & $\begin{array}{l}\text { Number } \\
\text { of Units }\end{array}$ & $\begin{array}{c}\text { Generator } \\
\text { Namephte } \\
\text { Capacity } \\
\text { (megawatts) }\end{array}$ & $\begin{array}{l}\text { Net Summer } \\
\text { Capability } \\
\text { (megawatts) }\end{array}$ & $\begin{array}{l}\text { Net Winter } \\
\text { Capability } \\
\text { (megawatts) }\end{array}$ \\
\hline \multicolumn{9}{|l|}{ Electric Utilities } \\
\hline (as of January 1, 1998) & 10,421 & 754,925 & 711,889 & 725,904 & 316 & 52,044 & 45,056 & 50,124 \\
\hline Coal & 1,198 & 325,001 & 302,866 & 304,914 & 8 & 2,559 & 2,444 & 2,444 \\
\hline Petroleum............................................. & 3,321 & 76,511 & 69,539 & 75,564 & 52 & 1,444 & 1,239 & 1,412 \\
\hline Gas ${ }^{2}$ & 2,148 & 147,260 & 136,957 & $14], 933$ & 212 & 46,181 & 39,679 & 44,476 \\
\hline \multicolumn{9}{|l|}{ Water (Pumped Storage } \\
\hline Hydroelectric) & 141 & 18,669 & 19,310 & 19,282 & 5 & 504 & 509 & 519 \\
\hline Nuclear ${ }^{3} \ldots$ & 107 & 107,632 & 99,716 & 100,896 & - & - & - & $\overline{-1}$ \\
\hline 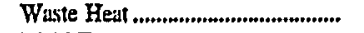 & 60 & 4,130 & 4,979 & 5,360 & 11 & 1,174 & 1,012 & 1,103 \\
\hline 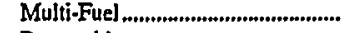 & & 221 & 209 & 212 & - & - & 一 & - \\
\hline $\begin{array}{l}\text { Renewable ............................................. } \\
\text { Water (Conventiona! }\end{array}$ & 3,438 & 75,487 & 78,300 & 77,729 & 28 & 182 & 174 & 169 \\
\hline 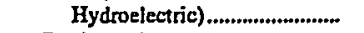 & 3,352 & 73,202 & 76,177 & 75,617 & 22 & 160 & 152 & 147 \\
\hline Geothermal ............................................ & 27 & 1,746 & 1,622 & $\mathrm{I}, 622$ & - & - & - & - \\
\hline Nonwood Waste 4 .......................... & $2 \mathrm{I}$ & 259 & 235 & 235 & $\mathbf{l}$ & 2 & 2 & 2 \\
\hline Solar & 11 & 5 & 5 & 5 & 4 & 10 & 10 & 10 \\
\hline 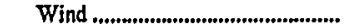 & 19 & 14 & 14 & 14 & 1 & 10 & 10 & 10 \\
\hline \multirow[t]{3}{*}{ Wood and Wood Waste4 ............ } & 8 & 261 & 247 & 237 & - & - & - & - \\
\hline & \multicolumn{5}{|c|}{ Existing } & \multicolumn{3}{|c|}{ Planned Additions (1998-2001) } \\
\hline & $\begin{array}{l}\text { Num } \\
\text { of } 0\end{array}$ & & $\begin{array}{c}\text { Generator } \\
\text { Nameplate } \\
\text { Capacity } \\
\text { (megawatts) }\end{array}$ & \multicolumn{2}{|c|}{$\begin{array}{c}\text { Net Summer } \\
\text { Capobility } \\
\text { (megawatts) }\end{array}$} & $\begin{array}{l}\text { Number } \\
\text { of Units }\end{array}$ & \multicolumn{2}{|c|}{$\begin{array}{c}\text { Generator } \\
\text { Nameplate } \\
\text { Capacity } \\
\text { (megawatts) }\end{array}$} \\
\hline 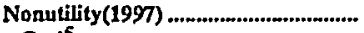 & \multicolumn{2}{|c|}{5,112} & 74,021 & \multicolumn{2}{|c|}{66,624} & 136 & \multicolumn{2}{|r|}{10,203} \\
\hline Coal 5 & & 11,236 & \multicolumn{2}{|c|}{10,465} & 5 & \multicolumn{2}{|r|}{409} \\
\hline 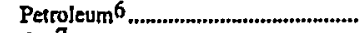 & \multirow{2}{*}{\multicolumn{2}{|c|}{$\begin{array}{r}440 \\
429\end{array}$}} & 2,994 & \multicolumn{2}{|c|}{2,735} & 2 & \multicolumn{2}{|r|}{340} \\
\hline 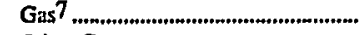 & & & 30,476 & \multicolumn{2}{|c|}{26,369} & so & \multicolumn{2}{|r|}{6,118} \\
\hline 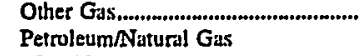 & \multicolumn{2}{|c|}{43} & 273 & \multicolumn{2}{|c|}{253} & 一 & \multicolumn{2}{|r|}{ - } \\
\hline (Combined) & \multirow{2}{*}{\multicolumn{2}{|c|}{$\begin{array}{r}424 \\
1,031\end{array}$}} & 9.767 & \multicolumn{2}{|c|}{8,541} & 2! & \multicolumn{2}{|r|}{2,605} \\
\hline Hydroelectric .......................................... & & & 3,776 & & 516 & 17 & & 67 \\
\hline 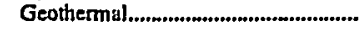 & & 77 & 1,303 & & 32 & 3 & & 15 \\
\hline Sular & & 9 & 354 & & 329 & 一 & & - \\
\hline 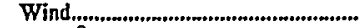 & & 73 & 1,607 & & 507 & 4 & & 183 \\
\hline Wood & & 71 & 7,181 & & 783 & I & & 4 \\
\hline 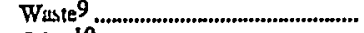 & & 34 & 3,715 & & 438 & 23 & & 83 \\
\hline Other IO & & 60 & 1,340 & & 253 & 10 & & 379 \\
\hline
\end{tabular}

1 Existing capacity totals include a J3-megawatt expander turbine fueled by hot nitrogen.

2 Includes gus-fueled fuel cell units.

3 Existing espacity includes Commonwealth Edison Company's Zion I and 2 nuclear units which were retired from service in January 1998.

4 Biomass, including landfill methane gas.

5 Includes anthracite culm and coal waste.

6 Includes petroleum coke, diesel, kerosene, and petroleum sludge and tar.

7 Includes natural gus, butane, methane, propane, waste heat and waste gases.

8 Includes wood waste, peat, wood liquors, railroad ties, pitch and wood sludge.

9 Includes municipal solid waste, agricultural waste, straw, tires, landfill gases and other waste.

10 Includes hydrogen, sulfur, batteries, and chemicals.

Notes: Data for Form ElA-860 are final, and data for Form EIA-867 are preliminary. The Form ElA-860 was revised during 1995 to collect electric utility dats us of January 1 of the reporting yeur, where "reporting year" is the calendar year in which the report is required to be filed with the Energy Information Administration. These data reflect the status of electrie power plants/generators as of January 1: however, dynamic data are based on oceur-

rences in the previous calendar year (e.g., capabilities and energy sources based on test and consumption in the previous year). *Nonutility existing capacity and planned capacity additions include all facilities with a combined generator nameplate capacity of 1 or more megawatts. Totals may not equal sum of cumponents because of independent rounding. Report."

Sources: Energy Information Administration, Form ElA-860, “Annual Electric Generutor Report" and Form ElA-867, “Annual Nonutility Power Producer 
Table 2. Capacity Additions and Retirements at U.S. Electric.Utilities by Energy Source, 1997

\begin{tabular}{|c|c|c|c|c|c|c|c|c|}
\hline \multirow[b]{2}{*}{$\begin{array}{l}\text { Primary Energy } \\
\text { Source }\end{array}$} & \multicolumn{4}{|c|}{ Additions } & \multicolumn{4}{|c|}{ Retirements } \\
\hline & $\begin{array}{l}\text { Number } \\
\text { of Units }\end{array}$ & $\begin{array}{c}\text { Generator } \\
\text { Nameplate } \\
\text { Capacity } \\
\text { (megawatts) }\end{array}$ & $\begin{array}{c}\text { Net Summer } \\
\text { Capability } \\
\text { (megawatts) }\end{array}$ & $\begin{array}{c}\text { Net Winter } \\
\text { Capability } \\
\text { (megawatts) }\end{array}$ & $\begin{array}{l}\text { Number } \\
\text { of Units }\end{array}$ & $\begin{array}{c}\text { Generator } \\
\text { Nameplate } \\
\text { Capacity } \\
\text { (megawatts) }\end{array}$ & $\begin{array}{c}\text { Net Summer } \\
\text { Copability } \\
\text { (megawatts) }\end{array}$ & $\begin{array}{l}\text { Net Winter } \\
\text { Capability } \\
\text { (megawatts) }\end{array}$ \\
\hline US. Total & 62 & 2,918 & 2,556 & 2,723 & 71 & 2,127 & 1,993 & 2,026 \\
\hline Coal & - & - & - & - & 6 & 281 & 293 & 294 \\
\hline Petroleum & 24 & 199 & 176 & 201 & 43 & 445 & 372 & 394 \\
\hline 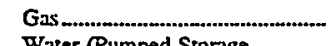 & 25 & 2,475 & 2,154 & 2,295 & 18 & 405 & 390 & 392 \\
\hline $\begin{array}{l}\text { Water (Pumped Storage } \\
\text { Hydroelectric)...................... }\end{array}$ & - & - & - & - & $\overline{2}$ & $\overline{995}$ & $\overline{937}$ & $\overline{946}$ \\
\hline 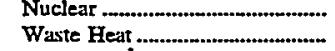 & $\overline{3}$ & $\overline{171}$ & 157 & $\overline{158}$ & $\stackrel{2}{-}$ & 995 & 937 & $\begin{array}{r}946 \\
-\end{array}$ \\
\hline 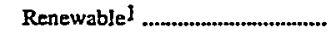 & 10 & 73 & 69 & 69 & 2 & 1 & 1 & J \\
\hline
\end{tabular}

1 Includes conventional hydroelectric, geothermal, biomass (wood, wood waste, nonwood waste), solar, and wind.

Notes: Total may not equal the sum of components because of independent rounding. The Form EIA-860 was revised during 1995 to collect data as of January 1 of the reporting year, where "reporting year" is the calendar year in which the report is required to be filed with the Energy Information Administration. These data reflect the status of electric power plants/generators as of January 1; however, dynamic data are based on occurrences in the previous calendar year (e.g., capabilities and energy sources based on test and consumption in the previous year).

Source: Energy Information Administration, Form ElA-860, "Annual Electric Generator Report."

Table 3. Combined Cycle Existing Capacity and Planned Capacity Additions at U.S. Electric Utilities by Prime Mover and Primary Energy Source, as of January 1, 1998

\begin{tabular}{|c|c|c|c|c|c|c|c|c|}
\hline \multirow[b]{2}{*}{$\begin{array}{l}\text { Prime Mover } \\
\text { Energy Source }\end{array}$} & \multicolumn{4}{|c|}{ Existing } & \multicolumn{4}{|c|}{ Planned Additionsl } \\
\hline & $\begin{array}{l}\text { Number } \\
\text { of Units }\end{array}$ & $\begin{array}{l}\text { Generator } \\
\text { Nameplate } \\
\text { Capacity } \\
\text { (megawatts) }\end{array}$ & $\begin{array}{l}\text { Net Summer } \\
\text { Capability } \\
\text { (megawatts) }\end{array}$ & $\begin{array}{l}\text { Net Winter } \\
\text { Capability } \\
\text { (megawatts) }\end{array}$ & $\begin{array}{l}\text { Number } \\
\text { of Units }\end{array}$ & $\begin{array}{l}\text { Generator } \\
\text { Nameplate } \\
\text { Capacity } \\
\text { (megawatts) }\end{array}$ & $\begin{array}{c}\text { Net Summer } \\
\text { Capability } \\
\text { (megawatts) }\end{array}$ & $\begin{array}{c}\text { Net Winter } \\
\text { Capability } \\
\text { (megawatts) }\end{array}$ \\
\hline 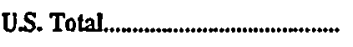 & 202 & 16,224 & 13,885 & 15,146 & 62 & 17,501 & 15,051 & 16,451 \\
\hline Steam & 74 & 5,875 & 6,595 & 7,020 & 37 & 13,844 & 11,905 & 13,013 \\
\hline$\left.\mathrm{Coal}\right|^{2} \ldots$ & 2 & 439 & 339 & 350 & - & - & - & - \\
\hline Petroleum & 2 & 212 & 209 & 209 & - & - & - & - \\
\hline$G_{a s}{ }^{3} \ldots \ldots \ldots$ & 10 & 1,093 & 1,067 & 1,101 & 27 & 12,708 & 10,929 & J1,945 \\
\hline 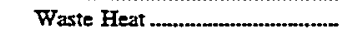 & 60 & 4,130 & 4,979 & 5,360 & 10 & 1,136 & 977 & 1,068 \\
\hline 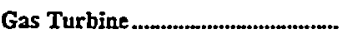 & 128 & 10,349 & 7,291 & 8,127 & 25 & 3,658 & 3,146 & 3,438 \\
\hline 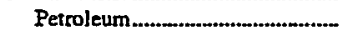 & 19 & 863 & 706 & 904 & 4 & 86 & 74 & 81 \\
\hline 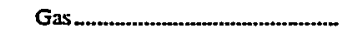 & 109 & 9,485 & 6,585 & 7,222 & 21 & 3,572 & 3,071 & 3,357 \\
\hline
\end{tabular}

1 Planned additions are for 1998 through 2007.

2 Integrated coal gasification combined cycle.

3 Includes a 143-megawatt integrated coal gasification combined cycle unit.

Notes: - Total may not equal the sum of components because of independent rounding. The Form ElA-860 was revised during 1995 to collect data as of January I of the reporting year, where "reporting year" is the calendar year in which the report is required to be filed with the Energy Information Administration. These data reflect the status of electric power plants/generators as of January l: however, dynamic data are based on occurrences in the previous calendar year (e.g., capabilities and energy sources based on test and consumption in the previous year).

Source: Energy Information Administration, Form ElA-860, "Annual Electric Generator Report." 
Table 4. Fossil-Fueled Existing Capacity and Planned Capacity Additions at U.S. Electric Utilities by Prime Mover and Primary Energy Source, as of January 1, 1998

\begin{tabular}{|c|c|c|c|c|c|c|c|c|}
\hline \multirow[b]{2}{*}{$\begin{array}{l}\text { Prime Mover } \\
\text { Energy Source }\end{array}$} & \multicolumn{4}{|c|}{ Existingl } & \multicolumn{4}{|c|}{ Phnned Additions 2} \\
\hline & $\begin{array}{l}\text { Number } \\
\text { of Units }\end{array}$ & $\begin{array}{c}\text { Generator } \\
\text { Nameplate } \\
\text { Capacity } \\
\text { (megawatts) }\end{array}$ & $\begin{array}{l}\text { Net Summer } \\
\text { Capability } \\
\text { (megawatts) }\end{array}$ & $\begin{array}{l}\text { Net Winter } \\
\text { Capability } \\
\text { (megawatts) }\end{array}$ & $\begin{array}{l}\text { Number } \\
\text { of Units }\end{array}$ & $\begin{array}{c}\text { Generator } \\
\text { Nameplate } \\
\text { Capacity } \\
\text { (megawatts) }\end{array}$ & $\begin{array}{l}\text { Net Summer } \\
\text { Capability } \\
\text { (megawntts) }\end{array}$ & $\begin{array}{c}\text { Net Winter } \\
\text { Capability } \\
\text { (megawatts) }\end{array}$ \\
\hline 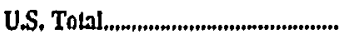 & 6,667 & 548,771 & 509,363 & 522,412 & 272 & 50,184 & 43,361 & 48,333 \\
\hline 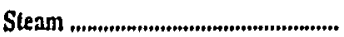 & 2,102 & 470,222 & 442,779 & 445,177 & 45 & 18,518 & 16,397 & 17,446 \\
\hline 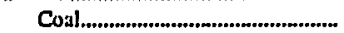 & 1,198 & 325,001 & 302,866 & 304,914 & 8 & 2,559 & 2,444 & 2,444 \\
\hline 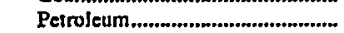 & 214 & 41,989 & 39,605 & 39,809 & - & - & - & - \\
\hline Gas $\ldots$ & 690 & 103,233 & 100,309 & 300,454 & 37 & 15,959 & 13,953 & 15,002 \\
\hline \multicolumn{9}{|l|}{ Gas Turbined } \\
\hline Internal Combustion.................. & 4,563 & 78,549 & 66,583 & 77,235 & 226 & 31,663 & 26,962 & 30,884 \\
\hline Petroleum.......................................... & 3,107 & 34,522 & 29,935 & 35,756 & 52 & 1,444 & 1,239 & 1,412 \\
\hline Gas & 1,456 & 44,027 & 36,648 & 41,479 & 174 & 30,219 & 25,723 & 29,472 \\
\hline
\end{tabular}

1 Existing capacity totals include gas-fueled fuel cell units.

2 Planned additions are for 1998 through 2007 . Totals include one 2.9 megawatts fuel cell unit.

Notes: Total may not equal the sum of components because of independent rounding. The Form ElA-860 was revised during 1995 to collect data as of January $l$ of the reporting year, where "reporting year" is the calendar year in which the report is required to be filed with the Energy Information Administration. These data reflect the status of electrie power plants/generatos as of January l: however, dynamic data are based on oceurrences in the previous calendar year (e.g., cupabilities and energy sources based on test and consumption in the previous year).

Source: Energy Information Administration, Form EJA-860, "Annual Electric Generator Report."

Table 5. Fossil-Fueled and Nuclear Steam-Electric Existing Capacity and Planned Capacity Additions at U.S. Electric Utilities, as of January 1, 1998

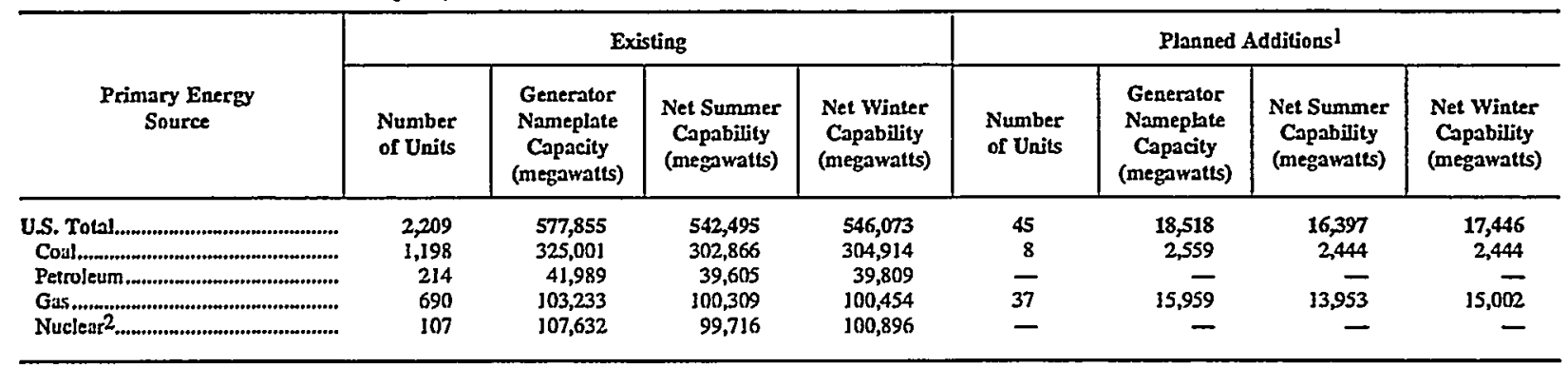

1 Planned additions are for 1998 through 2007.

2 Existing capacity includes Commonwealth Edison Company's Zion 1 and 2 nuclear units which were retired from service in January 1998.

Notes: -Total may not equal the sum of components because of independent rounding. The Form EIA-860 was revised during 1995 to collect data as of January $l$ of the reporting year, where "reporting year" is the ealendar year in which the report is required to be filed with the Energy Information Administration. These data reflect the status of electric power plants/generators as of January d: however, dynamic data are based on occurrences in the previous calendar year (e.g., capabilities and energy sources based on test and consumption in the previous year). Source: Energy Information Administration, Form ElA-860, "Annual Electric Generator Report." 
Table 6. Existing Capacity at U.S. Electric Utilities by Prime Mover and Energy Source, as of January 1, 1998

\begin{tabular}{|c|c|c|c|c|}
\hline $\begin{array}{l}\text { Prime Mover } \\
\text { Energy Source }\end{array}$ & $\begin{array}{l}\text { Number } \\
\text { of Units }\end{array}$ & $\begin{array}{c}\text { Generator } \\
\text { Nameplate } \\
\text { Capacity } \\
\text { (megawatts) }\end{array}$ & $\begin{array}{l}\text { Net Summer } \\
\text { Capability } \\
\text { (megawatts) }\end{array}$ & $\begin{array}{c}\text { Net Winter } \\
\text { Capability } \\
\text { (megawatts) }\end{array}$ \\
\hline U.S. Total ${ }^{1}$ & 10,421 & 754,925 & 711,889 & 725,904 \\
\hline Steam ${ }^{2}$ & 2,117 & 469,210 & 441,847 & 444,192 \\
\hline 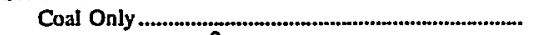 & 911 & 276,895 & 258,045 & 259.959 \\
\hline Other Solids Only ${ }^{3}$ & 15 & 334 & 304 & 294 \\
\hline Petroleum Only & 137 & 22,476 & 21,173 & 21,230 \\
\hline Gas Only & 117 & 10,840 & 10,389 & 10,320 \\
\hline Other Solids/Coal ${ }^{3} \ldots$ & 1 & 2 & 2 & 2 \\
\hline Solids/Petroleum 4 & 72 & 10,796 & 10,056 & 10,149 \\
\hline Solids/Gas4 & 232 & 36,763 & 34,331 & 34,359 \\
\hline 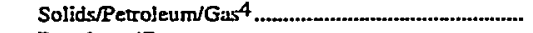 & 1 & 558 & 523 & 523 \\
\hline 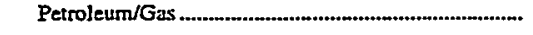 & 624 & 110,324 & 106,815 & 107,144 \\
\hline 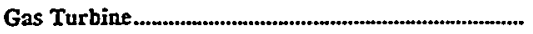 & 1,549 & 63,131 & 54,574 & 64,335 \\
\hline 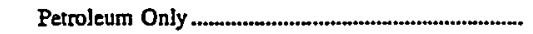 & 625 & 22,802 & 19,581 & 23,889 \\
\hline Gas Only & 179 & 5,776 & 5,061 & 5,577 \\
\hline 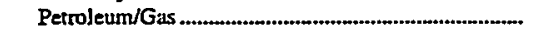 & 745 & 34,554 & 29,933 & 34,869 \\
\hline 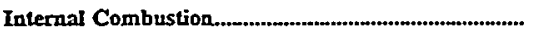 & 2,892 & 5,075 & 4,724 & 4,780 \\
\hline Petroleum Only & 1,799 & 2,671 & 2,523 & 2,548 \\
\hline 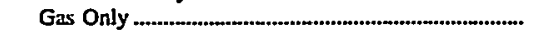 & 48 & 66 & 57 & 58 \\
\hline Petroleum/Gas & 1,044 & 2,335 & 2,141 & 2,171 \\
\hline Other Solids Only ${ }^{3} \ldots \ldots \ldots$ & 1 & 3 & 3 & 3 \\
\hline 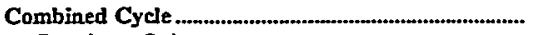 & 202 & 16,224 & 13,885 & 15,146 \\
\hline Petroleum Only & 11 & 470 & 390 & 429 \\
\hline 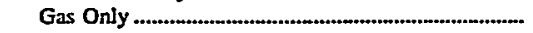 & 29 & 2,331 & 2,206 & 2,289 \\
\hline Coal/Petroletum & 1 & 326 & 250 & 250 \\
\hline 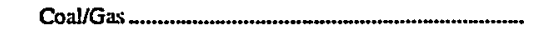 & 1 & 113 & 89 & 100 \\
\hline 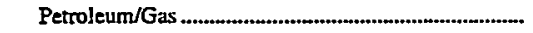 & 100 & 8,852 & 5,972 & 6,719 \\
\hline Waste Heat & 60 & 4,130 & 4,979 & 5,360 \\
\hline Nuclear ${ }^{5}$ & 107 & 107,632 & 99,716 & 100,896 \\
\hline Hydroelectric (Conventional) & 3,352 & 73,202 & 76,177 & 75,617 \\
\hline Hydroelectric (Pumped Storage) & 141 & 18,669 & 19,310 & 19,282 \\
\hline Geothermal & 27 & 1,746 & 1,622 & 1,622 \\
\hline Solar & 11 & 5 & 5 & 5 \\
\hline Wind & 19 & 14 & 14 & 14 \\
\hline
\end{tabular}

1 Totals include a 13-megawatt expander turbine fueled by hot nitrogen and a 2-megawatt reciprocating engine fueled by landfill methane gas.

2 Totals include 7 multi-fueled units totaling 209 megawatts.

3 Includes wood, wood waste, and nonwood waste.

4 Includes coal, wood, wood waste, and nonwood waste.

5 Existing capacity includes Commonwealth Edison Company's Zion 1 and 2 nuclear units which were retired from service in January 1998.

Notes: Operable capacity includes 2 gas-fueled fuel-cell units totaling 0.4 megawarts. Total may not equal the sum of cumponents beenuse of independent rounding. Sufficient data are not available to determine which units can bum more than one energy source without an appreciable loss in capability when buming the alternate energy source. This table provides a distribution of generating capability by energy source that the units are capable of using. The Form ElA-860 was revised during 1995 to collect data as of January 1 of the reporting year, where "reporting year" is the calendar year in which the report is required to be filed with the Energy Information Administration. These data reflect the status of electric power plants/generators as of January 1; however, dynamic data are based on occurrences in the previous calendar year (e.g., capabilities and energy sources based on test and consumption in the previous year).

Source: Energy Information Administration, Form EIA-860, "Annual Electric Generator Report." 
Table 7. Planned Capacity Additions at U.S. Electric Utilities, 1998 Through 2007, as of January 1, 1998

\begin{tabular}{|c|c|c|c|c|c|}
\hline Year & $\begin{array}{l}\text { Number } \\
\text { of Units }\end{array}$ & & $\begin{array}{l}\text { Generator } \\
\text { Nameplate } \\
\text { Capacity } \\
\text { (megawatts) }\end{array}$ & $\begin{array}{l}\text { Net Summer } \\
\text { Capability } \\
\text { (megawatts) }\end{array}$ & $\begin{array}{l}\text { Net Winter } \\
\text { Capability } \\
\text { (megawatts) }\end{array}$ \\
\hline US. Total & 316 & & 52,044 & 45,056 & 50,124 \\
\hline 1998 & 60 & $\cdot$ & 2,020 & 1,790 & 1,963 \\
\hline 1999 & 25 & & 2,298 & 2,016 & 2,229 \\
\hline 2000 & 31 & & 3,875 & 3,325 & 3,741 \\
\hline 2001 & 31 & & 5,843 & 5,023 & 5,554 \\
\hline 2012 & 35 & & 5,978 & 5,112 & 5,826 \\
\hline 2003 & 34 & & 8,201 & 7,053 & 7,939 \\
\hline 2004 & 26 & & 5,707 & 4,923 & 5,480 \\
\hline 2005 & 31 & & 7,576 & 6,642 & 7,254 \\
\hline 20066 & 22 & & 5,879 & 5,098 & 5,642 \\
\hline 2007 & 21 & & 4,667 & 4,075 & 4,496 \\
\hline
\end{tabular}

Notes: Total may not equal the sum of components because of independent rounding. The Form EIA-860 was revised during 1995 to collect data as of January 1 of the reporting year, where "reporting year" is the culendar year in which the report is required to be filed with the Energy Information Adminjstration. These data reflect the status of electric power plants/generators as of January 1: however, dynamic data are based on occurrences in the previous calendar year (e.g., capabilities and energy sources bused on test and consumption in the previous year).

Source: Energy Information Administration, Form ElA-860, "Annual Electric Generator Report."

Table 8. Planned Coal- and Petroleum-Fired Capacity Additions at U.S. Electric Utilities, 1998 Through 2007, as of January 1, 1998

\begin{tabular}{|c|c|c|c|c|c|c|c|c|}
\hline \multirow[b]{2}{*}{ Year } & \multicolumn{4}{|c|}{ Coal } & \multicolumn{4}{|c|}{ Petroleum } \\
\hline & $\begin{array}{l}\text { Number } \\
\text { of Units }\end{array}$ & $\begin{array}{l}\text { Generator } \\
\text { Nameplate } \\
\text { Capacity } \\
\text { (megawatts) }\end{array}$ & $\begin{array}{l}\text { Net Summer } \\
\text { Capability } \\
\text { (megawatts) }\end{array}$ & $\begin{array}{l}\text { Net Winter } \\
\text { Capability } \\
\text { (megawatts) }\end{array}$ & $\begin{array}{l}\text { Number } \\
\text { of Units }\end{array}$ & $\begin{array}{l}\text { Generator } \\
\text { Nameplate } \\
\text { Capacity } \\
\text { (megawatts) }\end{array}$ & $\begin{array}{l}\text { Net Summer } \\
\text { Capability } \\
\text { (megawatts) }\end{array}$ & $\begin{array}{c}\text { Net Winter } \\
\text { Capability } \\
\text { (megawatts) }\end{array}$ \\
\hline U.S. Total............. & 8 & 2,559 & 2,444 & 2,444 & 52 & 1,444 & 1,239 & 1,412 \\
\hline 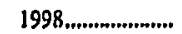 & - & 一 & 一 & 一 & 34 & 225 & 201 & 219 \\
\hline 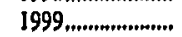 & I & 9] & 91 & 91 & 5 & 169 & 144 & 166 \\
\hline 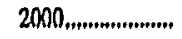 & - & 一 & 一 & - & 4 & 269 & 229 & 263 \\
\hline $2001, \ldots . . . . . . . . . . . . .$. & - & - & - & - & 1 & 83 & $7]$ & 81 \\
\hline $20002 \ldots \ldots \ldots \ldots . . . . . . . . .$. & - & - & - & - & 4 & 444 & 378 & 435 \\
\hline $2003 . . . . . . . . . . . . . . . . .$. & 1 & 183 & 383 & 183 & $\mathbf{J}$ & 5 & 5 & 5 \\
\hline $2004 \ldots \ldots . . . . . . . . . . . . .$. & 1 & 60 & 60 & 60 & 1 & 83 & 71 & 81 \\
\hline 2005 & 2 & 1,046 & 1,000 & 1,000 & 1 & 83 & 71 & 8] \\
\hline $2006 \ldots \ldots . . . . . . . . . . . . . . . .$. & 1 & 233 & 210 & 210 & 1 & 83 & 71 & 8] \\
\hline $2007, \ldots . . . . . . . . . . . . .$. & 2 & 946 & 900 & 900 & - & 一 & - & - \\
\hline
\end{tabular}

Notes: Total may not equal the sum of components bezause of independent counding. The Form ElA-860 was revised during 1995 to collect data us of January $I$ of the reporting year, where "reporting year" is the calendar year in which the report is required to be filed with the Energy Information Administration. These data reflect the status of electric power plants/generators as of January 1: however, dynamic data are based on oecurrences in the previous calendar year (e.g., capabilities and energy sources based on test and consumption in the previous year).

Source: Energy Information Administration, Form EIA-860, "Annual Electric Generator Report." 
Table 9. Planned Gas-Fired and Hydroelectric Capacity Additions at U.S. Electric Utilities, 1998 Through 2007, as of January 1, 1998

\begin{tabular}{|c|c|c|c|c|c|c|c|c|}
\hline \multirow[b]{2}{*}{ Year } & \multicolumn{4}{|c|}{ Gas } & \multicolumn{4}{|c|}{ Hydroelectric] } \\
\hline & $\begin{array}{l}\text { Number } \\
\text { of Units }\end{array}$ & $\begin{array}{c}\text { Generator } \\
\text { Nameplate } \\
\text { Capacity } \\
\text { (megawatts) }\end{array}$ & $\begin{array}{l}\text { Net Summer } \\
\text { Capability } \\
\text { (megawatts) }\end{array}$ & $\begin{array}{l}\text { Net Winter } \\
\text { Capability } \\
\text { (megawatts) }\end{array}$ & $\begin{array}{l}\text { Number } \\
\text { of Units }\end{array}$ & $\begin{array}{c}\text { Generator } \\
\text { Nameplate } \\
\text { Capacity } \\
\text { (megawatts) }\end{array}$ & $\begin{array}{l}\text { Net Summer } \\
\text { Capability } \\
\text { (megawatts) }\end{array}$ & $\begin{array}{c}\text { Net Winter } \\
\text { Capability } \\
\text { (megawatts) }\end{array}$ \\
\hline 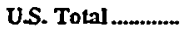 & 212 & 46,181 & 39,679 & 44,476 & 27 & 664 & 661 & 666 \\
\hline 1998....................... & 12 & 1,303 & 1,114 & 1,257 & 12 & 378 & 377 & 381 \\
\hline 1999................. & 14 & $\mathrm{I}, 697$ & 1,457 & 1,634 & 3 & 205 & 207 & 211 \\
\hline 2000 & 21 & 3,538 & 3,031 & 3,414 & 3 & 22 & 20 & 20 \\
\hline $2001 \ldots \ldots \ldots \ldots$ & 23 & 5,313 & 4,567 & 5,052 & 2 & 3 & 2 & 2 \\
\hline $2002 \ldots \ldots \ldots \ldots$ & 29 & 5,523 & 4,723 & 5,381 & 2 & 11 & 11 & 10 \\
\hline $2003 \ldots \ldots \ldots$ & 31 & 7,995 & 6,850 & 7,734 & - & - & - & - \\
\hline $2004 \ldots \ldots$ & 22 & 5,278 & 4,546 & 5,070 & - & - & - & - \\
\hline 2005 ......................... & 22 & 6,401 & 5,528 & 6,130 & 5 & 45 & 43 & 42 \\
\hline $2006 \ldots$ & 19 & 5,413 & 4,689 & 5,209 & 二 & - & - & - \\
\hline $2007 \ldots \ldots \ldots \ldots$ & 19 & 3,721 & 3,175 & 3,596 & 一 & - & 一 & - \\
\hline
\end{tabular}

1 Includes both conventional and pumped storage.

Notes: -Total may not equal the sum of components because of independent rounding. The Form ElA-860 was revised during 1995 to collect data as of January 1 of the reporting year, where "reporting year" is the calendar year in which the report is required to be filed with the Energy Information Administration. These data reflect the status of electric power plants/generators as of January l: however, dynamic data are based on occurrences in the previous calendar year (e.g., capabilities and energy sources based on test and consumption in the previous year).

Source: Energy Information Administration, Form EJA-860, "Annual Electric Generator Report."

Table 10. Planned Nuclear and Other Capacity Additions at U.S. Electric Utilities, 1998 Through 2007, as of January 1, 1998

\begin{tabular}{|c|c|c|c|c|c|c|c|c|}
\hline \multirow[b]{2}{*}{ Year } & \multicolumn{4}{|c|}{ Nuclear } & \multicolumn{4}{|c|}{ Other! } \\
\hline & $\begin{array}{l}\text { Number } \\
\text { of Units }\end{array}$ & $\begin{array}{c}\text { Generator } \\
\text { Nameplate } \\
\text { Capacity } \\
\text { (megawatts) }\end{array}$ & $\begin{array}{c}\text { Net Summer } \\
\text { Capability } \\
\text { (megawatts) }\end{array}$ & $\begin{array}{l}\text { Net Winter } \\
\text { Capability } \\
\text { (megawatts) }\end{array}$ & $\begin{array}{l}\text { Number } \\
\text { of Units }\end{array}$ & $\begin{array}{c}\text { Generator } \\
\text { Nameplate } \\
\text { Capacity } \\
\text { (megawatts) }\end{array}$ & $\begin{array}{c}\text { Net Summer } \\
\text { Capability } \\
\text { (megawates) }\end{array}$ & $\begin{array}{c}\text { Net Winter } \\
\text { Capability } \\
\text { (megawatts) }\end{array}$ \\
\hline U.S. Total .................. & - & - & 一 & - & 17 & 1,196 & 1,034 & 1,125 \\
\hline 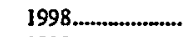 & - & 一 & 一 & 一 & 2 & 113 & 97 & 106 \\
\hline 1999 & - & - & - & - & 2 & 136 & 117 & 328 \\
\hline 2000 & - & 一 & - & 一 & 3 & 47 & 44 & 45 \\
\hline $2001 \ldots$ & 一 & 一 & - & - & 5 & 444 & 384 & 418 \\
\hline $2002 \ldots$ & 一 & 一 & 一 & 一 & - & - & - & - \\
\hline $2003 \ldots$ & - & 一 & 一 & - & I & 18 & 15 & 17 \\
\hline $2004 \ldots . . . . . . . . . . . . . . .$. & - & 一 & - & 一 & 2 & 286 & 246 & 269 \\
\hline $2005 \ldots$ & 一 & 一 & 一 & - & 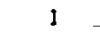 & l & 1 & 1 \\
\hline $2006 \ldots \ldots \ldots$ & - & 一 & 一 & 一 & 1 & 150 & 129 & 141 \\
\hline 2007 & - & - & - & - & - & - & - & - \\
\hline
\end{tabular}

1 Includes geothemal, biomass (wood, wood waste, nonwood waste), waste heat, solar, and wind.

Notes: -Total may not equal the sum of components becuuse of independent rounding. The Form ElA-860 was revised during 1995 to collect data as of January 1 of the reporting year, where "reporting year" is the calendar year in which the report is required to be filed with the Energy Information Administration. These data reflect the status of electric power plants/generators as of January I: however, dynamic data are based on occurrences in the previous calendar year (e.g., capabilities and energy sources based on test and consumption in the previous year).

Source: Energy Information Administration, Form EIA-860, "Annual Electric Generator Report." 
Table 11. Planned Capacity Retirements at U.S. Electric Utilities, 1998 Through 2007, as of January 1, 1998

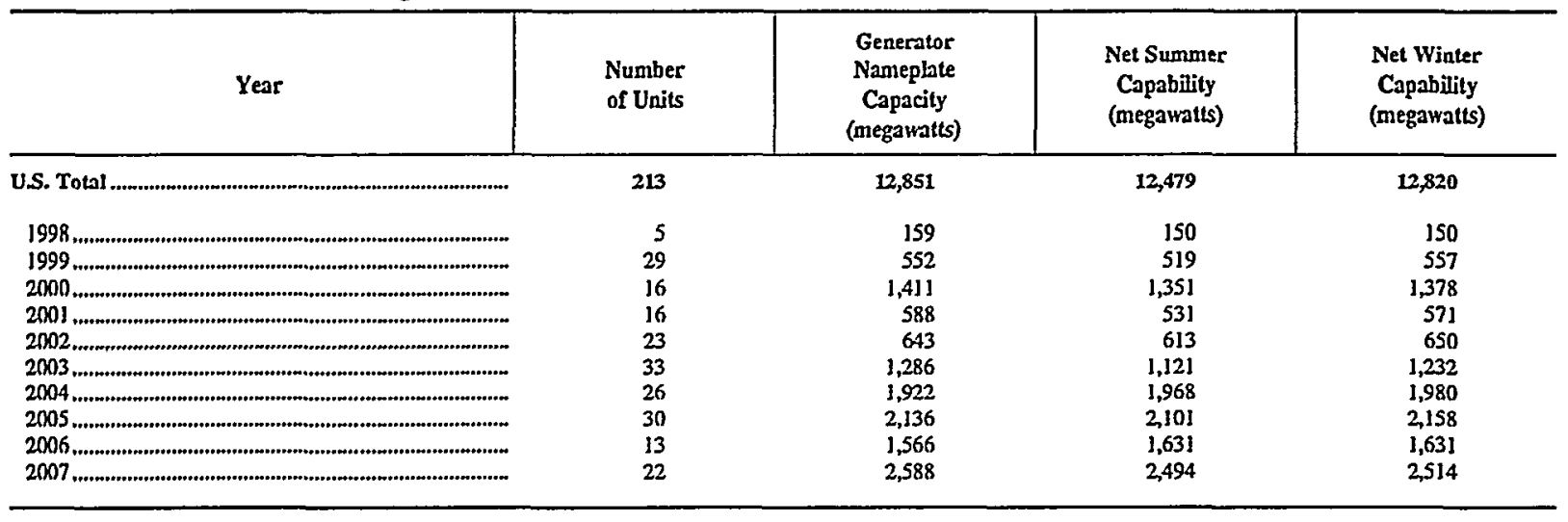

Note: Total may not equal the sum of components because of independent rounding. The Form EIA-860 was revised during 3995 to collect data as of January $\mathrm{l}$ of the reporting year, where "reporting year" is the calendar year in which the report is required to be filed with the Energy Information Administration. These data reflect the sturus of electric power planti/generators as of January l: however, dynamic data are based on occurrences in the previous calendar year (e,g., capabilities and energy sources based on teat and consumption in the previous year).

Source: Energy Information Administration, Form EIA-860, “Annual Electric Generator Report."

Table 12. Planned Coal- and Petroleum-Fired Capacity Retirements at U.S. Electric Utilities, 1998 Through 2007, as of January 1, 1998

\begin{tabular}{|c|c|c|c|c|c|c|c|c|}
\hline \multirow[b]{2}{*}{ Year } & \multicolumn{4}{|c|}{ Coal } & \multicolumn{4}{|c|}{ Petroleum } \\
\hline & $\begin{array}{l}\text { Number } \\
\text { of Units }\end{array}$ & $\begin{array}{c}\text { Generator } \\
\text { Nameplate } \\
\text { Capacity } \\
\text { (megawatts) }\end{array}$ & $\begin{array}{l}\text { Net Summer } \\
\text { Capability } \\
\text { (megawatts) }\end{array}$ & $\begin{array}{l}\text { Net Winter } \\
\text { Capability } \\
\text { (megawatts) }\end{array}$ & $\begin{array}{l}\text { Number } \\
\text { of Uaits }\end{array}$ & $\begin{array}{c}\text { Generator } \\
\text { Nameplate } \\
\text { Capacity } \\
\text { (megawatts) }\end{array}$ & $\begin{array}{c}\text { Net Summer } \\
\text { Capability } \\
\text { (megawatts) }\end{array}$ & $\begin{array}{c}\text { Net Winter } \\
\text { Capability } \\
\text { (megawatts) }\end{array}$ \\
\hline U.S. Total .............. & 19 & 2,339 & 2,292 & 2,315 & 93 & 2,302 & 2,080 & 2,185 \\
\hline $1998 \ldots \ldots . . . . . . . . . . . . . . . .$. & - & - & - & 一 & 2 & 2 & 2 & 2 \\
\hline $1999, \ldots \ldots . . . . . . . . . . . . . .$. & 1 & 30 & 27 & 28 & 19 & 122 & 120 & 129 \\
\hline 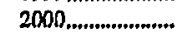 & 3 & J66 & 162 & 162 & 9 & 484 & 450 & 459 \\
\hline $2001, \ldots . . . . . . . . . . . . . . .$. & 2 & 218 & 196 & 199 & 6 & 39 & 17 & 18 \\
\hline 2002 & - & - & - & - & 12 & 190 & 165 & 188 \\
\hline $2003, \ldots \ldots \ldots$ & - & - & - & - & 13 & 603 & 518 & 557 \\
\hline $2004 \ldots \ldots \ldots . . . . . . . . . . . .$. & 3 & 159 & 168 & 168 & 17 & 591 & 531 & 543 \\
\hline $2005, \ldots \ldots \ldots \ldots$ & 5 & 610 & 564 & 582 & 7 & 178 & 177 & 190 \\
\hline 2006 & 4 & 644 & 647 & 647 & j & 4 & 4 & 4 \\
\hline $2007 \ldots . . . . . . . . . . . . . . . . .$. & 1 & 511 & 528 & 528 & 7 & 108 & 95 & 96 \\
\hline
\end{tabular}

Notes: -Total may not equal the sum of components because of independent rounding. The Form EIA-860 was revised during I995 to collect data as of January 1 of the reporing year, where "reporting year" is the calendar year in which the report is required to be filed with the Energy Information Ad ministration. These data reflect the status of electric power plants/generatoss as of January 1; however, dynamic data are based on occutrences in the previous calendar year (e.g., capabilities and energy sources based on test and consumption in the previous year).

Source: Energy Information Administration, Form ElA-860, "Annual Electric Generator Report." 
Table 13. Planned Gas-Fired and Nuclear Capacity Retirements at U.S. Electric Utilities, 1998 Through 2007, as of January 1, 1998

\begin{tabular}{|c|c|c|c|c|c|c|c|c|}
\hline \multirow[b]{2}{*}{ Year } & \multicolumn{4}{|c|}{ Gas } & \multicolumn{4}{|c|}{ Nuclear } \\
\hline & $\begin{array}{l}\text { Number } \\
\text { of Units }\end{array}$ & $\begin{array}{l}\text { Generator } \\
\text { Nameplate } \\
\text { Capacity } \\
\text { (megawatts) }\end{array}$ & $\begin{array}{c}\text { Net Summer } \\
\text { Capability } \\
\text { (megawatts) }\end{array}$ & $\begin{array}{l}\text { Net Winter } \\
\text { Capability } \\
\text { (megawatts) }\end{array}$ & $\begin{array}{l}\text { Number } \\
\text { of Units }\end{array}$ & $\begin{array}{l}\text { Generator } \\
\text { Nameplate } \\
\text { Capacity } \\
\text { (megawatts) }\end{array}$ & $\begin{array}{l}\text { Net Summer } \\
\text { Capability } \\
\text { (megawatts) }\end{array}$ & $\begin{array}{c}\text { Net Winter } \\
\text { Capability } \\
\text { (megawatts) }\end{array}$ \\
\hline U.S. Total ............. & 99 & 6,757 & 6,726 & 6,903 & 2 & 1,452 & 1,381 & 1,418 \\
\hline $1998 \ldots$ & 3 & 157 & 148 & 148 & - & $\rightarrow$ & - & - \\
\hline 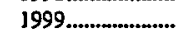 & 9 & 400 & 373 & 400 & - & - & - & - \\
\hline $2000 \ldots \ldots \ldots \ldots$ & 3 & 120 & 120 & 120 & 了 & 641 & 619 & 637 \\
\hline $2001 \ldots$ & 8 & 351 & 318 & 354 & - & - & - & - \\
\hline $2002 \ldots \ldots . . . . . . . . . . .$. & 11 & 452 & 447 & 462 & $\longrightarrow$ & - & - & 一 \\
\hline 2003 & 20 & 683 & 603 & 675 & - & - & - & - \\
\hline $2004 \ldots$ & 6 & 1,172 & 1,269 & 1,269 & - & - & - & - \\
\hline $2005 \ldots$ & 18 & 1,348 & 1,360 & 1,386 & - & - & - & - \\
\hline $2006 \ldots \ldots$ & 8 & 918 & 980 & 980 & 一 & - & - & - \\
\hline $2007 \ldots$ & 13 & 1,157 & 1,109 & 1,109 & 了 & 812 & 762 & 781 \\
\hline
\end{tabular}

Notes: Total may not equal the sum of components because of independent rounding. The Form ElA-860 was revised during 1995 to collect dat as of January 1 of the reporting year, where "reporting year" is the calendar year in which the report is required to be filed with the Energy Information Administration. These data reflect the status of electric power plants/generatos as of January 1: however, dynamic data are bused on occurrences in the previous calendar year (e.g., capabilities and energy sources based on test and consumption in the previous year).

Source: Energy Information Administration, Form EIA-860, "Annual Electric Generator Report." 
Table 14. Existing Capacity and Planned Capacity Additions at U.S. Electric Utilities by Energy Source, North American Electric Reliability Council Region, and Hawaii, as of January 1, 1998

\begin{tabular}{|c|c|c|c|c|c|c|c|c|}
\hline \multirow[b]{2}{*}{$\begin{array}{l}\text { NERC Region and Hawaii } \\
\text { Primary Energy } \\
\text { Source }\end{array}$} & \multicolumn{4}{|c|}{ Existingl } & \multicolumn{4}{|c|}{ Planned Additions 12} \\
\hline & $\begin{array}{l}\text { Number } \\
\text { of Units }\end{array}$ & $\begin{array}{l}\text { Generator } \\
\text { Nameplate } \\
\text { (megawatts) }\end{array}$ & $\begin{array}{l}\text { Summer } \\
\text { Capability } \\
\text { (nlegawatts) }\end{array}$ & $\begin{array}{c}\text { Winter } \\
\text { Capability } \\
\text { (megawatts) }\end{array}$ & $\begin{array}{l}\text { Number } \\
\text { of Units }\end{array}$ & $\begin{array}{l}\text { Generator } \\
\text { Namephate } \\
\text { (megawatts) }\end{array}$ & $\begin{array}{c}\text { Summer } \\
\text { Capability } \\
\text { (megawatts) }\end{array}$ & $\begin{array}{c}\text { Winter } \\
\text { Capability } \\
\text { (megawatts) }\end{array}$ \\
\hline U.S. Total ${ }^{3}$ & 10,421 & 754,925 & 711,889 & 725,904 & 316 & 52,044 & 45,056 & 50,124 \\
\hline 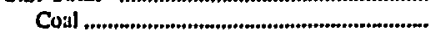 & 1,198 & 325,001 & 302,866 & 304,914 & 8 & 2,559 & 2,444 & 2,444 \\
\hline 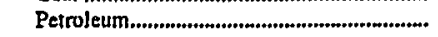 & 3,321 & 76,511 & 69,539 & 75,564 & 52 & 1,444 & 1,239 & 1,412 \\
\hline 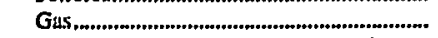 & 2,148 & 147,260 & 136,957 & 141,933 & 212 & $46,18 \mathrm{I}$ & 39,679 & 44,476 \\
\hline Water(Pumped Storage Hydruelectric) & 141 & 18,669 & 19,310 & 19,282 & 5 & 504 & 509 & 519 \\
\hline Water(Conventiona! Hydroelectric)........... & 3,352 & 73,202 & 76,177 & 75,617 & 22 & 160 & 152 & $\mathrm{j} 47$ \\
\hline 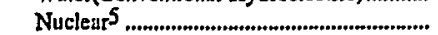 & 107 & 107,632 & 99,716 & 100,896 & - & - & - & - \\
\hline 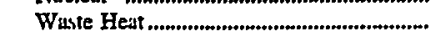 & 60 & 4,130 & 4,979 & 5,360 & 11 & 1,174 & 1,012 & 1,103 \\
\hline 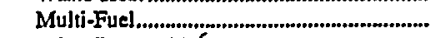 & 7 & 221 & 209 & 212 & - & - & - & - \\
\hline Other Renewable & 81 & 2,281 & 2,119 & 2,109 & 5 & 20 & 20 & 20 \\
\hline 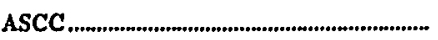 & 565 & 1,949 & 1,750 & 1,881 & 6 & 12 & 11 & 12 \\
\hline 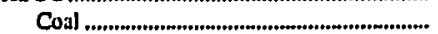 & 5 & 54 & 54 & 54 & - & - & - & - \\
\hline 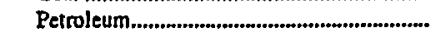 & 468 & 615 & 575 & 615 & 2 & 11 & 10 & 11 \\
\hline 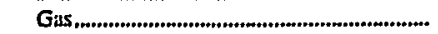 & 30 & 810 & 674 & 753 & - & - & - & - \\
\hline Wuter(Pumped Storage Hydroelectric) & - & - & - & - & - & - & - & - \\
\hline Water(Conventional Hydruelectric)........... & 57 & 369 & 362 & 368 & 4 & 1 & 1 & 1 \\
\hline Nuclear & - & - & - & - & - & - & - & - \\
\hline 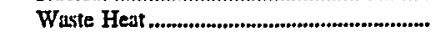 & 2 & 102 & 85 & 91 & - & - & - & - \\
\hline 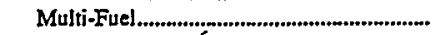 & - & - & - & - & - & - & - & - \\
\hline 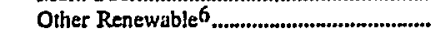 & 3 & $\star$ & 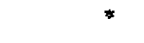 & * & - & 一 & - & - \\
\hline ECAR & 1,113 & 111,748 & 102,518 & 104,424 & 59 & 9,694 & 8,258 & 9,443 \\
\hline 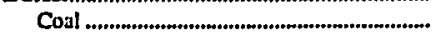 & 347 & 89,683 & 82,563 & 83,398 & - & - & - & - \\
\hline 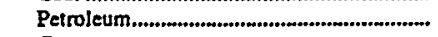 & 310 & $5,09 \mathrm{~J}$ & 4,539 & 4,897 & 1 & 2 & 2 & 2 \\
\hline 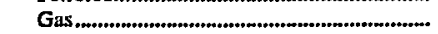 & 155 & 5,185 & 4,571 & 5,136 & 54 & 9,500 & 8,087 & 9,261 \\
\hline Wuter(Pumped Storage Hydruelectric) & 9 & 2,226 & 2,117 & 2,117 & - & - & - & - \\
\hline Water(Conventional Hydroelectric)............ & 281 & 1,197 & 1,043 & 1,075 & 3 & 43 & 40 & 39 \\
\hline 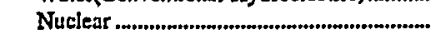 & 8 & 8,276 & 7,594 & 7,711 & - & - & - & - \\
\hline 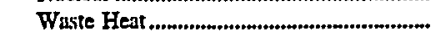 & - & - & - & - & 1 & 150 & 129 & 141 \\
\hline 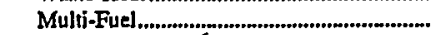 & - & - & - & - & - & - & - & - \\
\hline Other Renewable 6 & 3 & 90 & 90 & 90 & - & - & 一 & - \\
\hline ERCOT & 345 & 56,136 & 53,711 & 53,973 & 13 & 5,027 & 4,679 & 4,729 \\
\hline 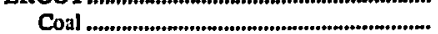 & 27 & 16,063 & 15,156 & 15,177 & 3 & 1,592 & 1,500 & 1,500 \\
\hline 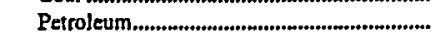 & 26 & 54 & 46 & 48 & - & - & - & - \\
\hline 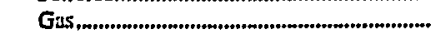 & 249 & 34,357 & 33,173 & 33,413 & 10 & 3,435 & 3,179 & 3,229 \\
\hline Water(Pumped Storage Hydruelectric) & - & - & - & - & - & - & - & - \\
\hline Water(Conventional Hydroelectric)............ & 35 & 297 & 326 & 326 & - & - & - & - \\
\hline 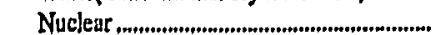 & 4 & 5,139 & 4,800 & 4,800 & - & - & - & - \\
\hline Waste Heat ............................................................. & 2 & 226 & 208 & 208 & - & - & - & - \\
\hline 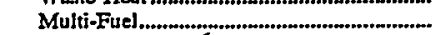 & - & - & - & - & - & - & - & - \\
\hline Other Renewable6. & 2 & 1 & 1 & 1 & - & - & - & - \\
\hline FRCC4 & 319 & 35,616 & 32,616 & 34,395 & 30 & 8,381 & 7,208 & 7,987 \\
\hline 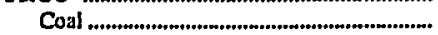 & 21 & 8,867 & 8,106 & 8,248 & 1 & 183 & 183 & 183 \\
\hline 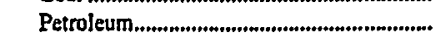 & 129 & 12,784 & 11,594 & 12,352 & 2 & 41 & 35 & 40 \\
\hline Gas, & 122 & 7,678 & 5,486 & 5,945 & 25 & 7,872 & 6,745 & 7,496 \\
\hline Water(Purnped Storage Hydroelectric) & 2 & 250 & 276 & 276 & - & - & - & - \\
\hline Water(Conventional Hydroejectric)............ & 25 & 786 & 868 & 880 & - & - & - & - \\
\hline 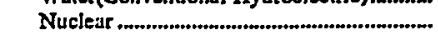 & 5 & 4,110 & 3,876 & 3,975 & - & - & - & - \\
\hline 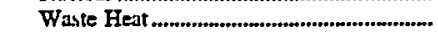 & 15 & 1,140 & 2,410 & 2,719 & 2 & 285 & 245 & 268 \\
\hline 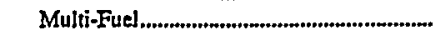 & - & - & - & - & - & - & - & - \\
\hline 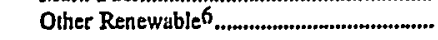 & - & - & - & - & - & - & - & - \\
\hline 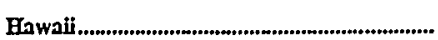 & 86 & $-1,555$ & 1,499 & 1,499 & 8 & 170 & 145 & 161 \\
\hline 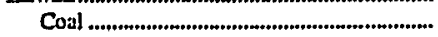 & - & - & - & - & - & - & - & - \\
\hline 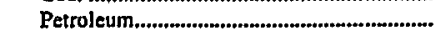 & 81 & 1,534 & 1,477 & 1,477 & 6 & 134 & 114 & 127 \\
\hline 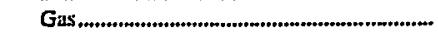 & - & - & - & - & - & - & - & - \\
\hline Water(Pumped Storage Hydroelectric) & - & - & - & - & - & - & - & - \\
\hline Water(Conventional Hydroelectric)............. & 4 & 3 & 3 & 3 & - & - & - & - \\
\hline
\end{tabular}

See footnotes at end of table. 
Table 14. Existing Capacity and Planned Capacity Additions at U.S. Electric Utilities by Energy Source, North American Electric Reliability Council Region, and Hawaii, as of January 1, 1998 (Continued)

\begin{tabular}{|c|c|c|c|c|c|c|c|c|}
\hline \multirow{2}{*}{$\begin{array}{c}\text { NERC Region and Hawaii } \\
\text { Primary Energy } \\
\text { Source }\end{array}$} & \multicolumn{4}{|c|}{ Existing] } & \multicolumn{4}{|c|}{ Planned Additionsl 2} \\
\hline & $\begin{array}{l}\text { Number } \\
\text { of Units }\end{array}$ & $\begin{array}{c}\text { Generator } \\
\text { Nameplate } \\
\text { (megawatts) }\end{array}$ & $\begin{array}{c}\text { Summer } \\
\text { Capability } \\
\text { (megawatts) }\end{array}$ & $\begin{array}{c}\text { Winter } \\
\text { Capability } \\
\text { (megawatts) }\end{array}$ & $\begin{array}{l}\text { Number } \\
\text { of Units }\end{array}$ & $\begin{array}{l}\text { Generator } \\
\text { Namephate } \\
\text { (megawatts) }\end{array}$ & $\begin{array}{c}\text { Summer } \\
\text { Capability } \\
\text { (megawatts) }\end{array}$ & $\begin{array}{c}\text { Winter } \\
\text { Capability } \\
\text { (niegawatts) }\end{array}$ \\
\hline \multicolumn{9}{|l|}{ Hawaii (Continued) } \\
\hline Waste Heat & 1 & 18 & 18 & 18 & 2 & 36 & 31 & 34 \\
\hline Multä-Fuel & - & - & - & - & - & - & - & - \\
\hline Other Renewable 6 & - & - & - & - & - & - & - & - \\
\hline MAIN & 767 & 56,429 & 52,093 & 53,255 & 47 & 6,799 & 5,824 & 6,675 \\
\hline 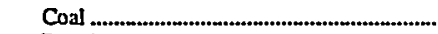 & 131 & 29,942 & 27,836 & 28,025 & 1 & 60 & 60 & 60 \\
\hline 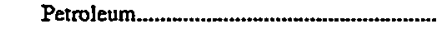 & 231 & 4,088 & 3,648 & 4,007 & 4 & 147 & 126 & 144 \\
\hline 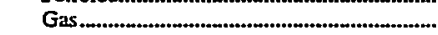 & 165 & 4,769 & 4,424 & 4,846 & 38 & 6,376 & 5,419 & 6,248 \\
\hline Water(Pumped Storage Hydruelectric) & 2 & 408 & 350 & 275 & j & 204 & 206 & 210 \\
\hline Water(Conventional Hydroelectric)........... & 220 & 668 & 649 & 645 & - & - & - & - \\
\hline Nuclear 5 & 17 & 16,553 & 15,184 & 15,455 & - & - & - & - \\
\hline Waste Heat & - & - & - & - & - & - & - & - \\
\hline Multi-Fuel. & - & - & - & - & - & - & - & - \\
\hline Other Renewable 6 & 1 & 2 & 2 & 2 & 2 & 11 & 1] & נ1 \\
\hline MAAC......... & 459 & 57,217 & $\mathbf{5 3 , 5 8 8}$ & 56,067 & 12 & 1,589 & 1,364 & 1,510 \\
\hline Coal & 68 & 20,346 & 18,898 & 19,136 & - & - & - & - \\
\hline 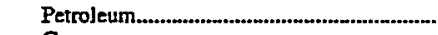 & 246 & 11,662 & 10,832 & 12,114 & 3 & 226 & 193 & 221 \\
\hline Gas & 67 & 8,100 & 7,532 & 8,163 & 6 & 946 & 812 & 896 \\
\hline Water(Pumped Storage Hydroelectic) & 14 & 1,609 & 1,719 & $\mathrm{~J}, 719$ & - & - & - & - \\
\hline Water(Conventional Hydroelectric)............ & 47 & 1,130 & 1,153 & 1,169 & - & - & - & - \\
\hline Nuclear & 13 & 13,686 & 12,913 & 13,201 & - & - & - & - \\
\hline 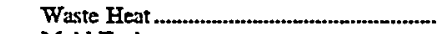 & 4 & 685 & 541 & 564 & 3 & 418 & 359 & 393 \\
\hline Multi-Fuel & - & - & - & - & - & - & - & - \\
\hline Other Renewable6 & - & - & - & - & - & - & - & - \\
\hline MAPP & 1,274 & 36,203 & 34,820 & 35,524 & 14 & 135 & 120 & 132 \\
\hline 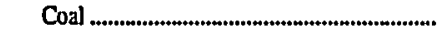 & 128 & 22,327 & 21,828 & 21,738 & - & - & - & - \\
\hline 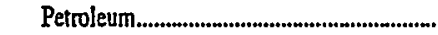 & 635 & 3,798 & 3,441 & 4,075 & 10 & 29 & 28 & 28 \\
\hline Gas....... & 256 & 2,916 & 2,595 & 2,686 & 4 & 106 & 92 & 104 \\
\hline Water(Pumped Storage Hydroelectric) & - & & & & - & - & - & - \\
\hline Water(Conventional Hydroelectric)............ & 22] & 3,028 & 3,173 & 3,173 & - & - & - & - \\
\hline Nuclear & 6 & 3,686 & 3,357 & 3,427 & - & - & - & - \\
\hline 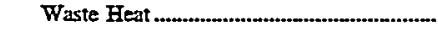 & 4 & 34 & 31 & 28 & - & - & - & - \\
\hline 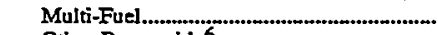 & 7 & 221 & 209 & 212 & - & - & - & - \\
\hline 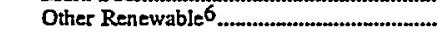 & 16 & 193 & 185 & 185 & - & - & - & - \\
\hline NPCC...... & 1,230 & 54,289 & 51,406 & 53,398 & 10 & 173 & 154 & 163 \\
\hline 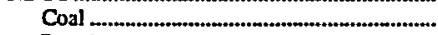 & 47 & 6,803 & 6,580 & 6,676 & - & - & - & - \\
\hline Petroleum & 422 & 23,213 & 21,446 & 22,854 & 4 & 8 & 8 & 8 \\
\hline Gas..... & 57 & 5,116 & 4,979 & 5,209 & 1 & 120 & 103 & 113 \\
\hline Water(Pumped Storage Hydroelectric) & 24 & 2,693 & 2,938 & $2,99]$ & - & - & - . & - \\
\hline Water(Conventional Hydroelectric)........ & 652 & 5,280 & $5,30 \mathrm{~J}$ & 5.359 & 5 & 45 & 43 & 42 \\
\hline Nuclear & 12 & 10,909 & 9,919 & 10,054 & - & - & - & - \\
\hline 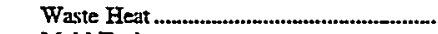 & 3 & 186 & 158 & 169 & - & - & - & - \\
\hline 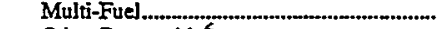 & - & - & - & - & - & - & - & - \\
\hline Other Renewable 6 & 13 & 89 & 86 & 87 & - & - & - & - \\
\hline SERC 4 & 1,250 & 167,570 & 155,786 & 158,434 & 63 & 14,997 & 12,893 & 14,393 \\
\hline 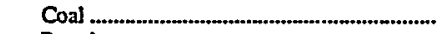 & 248 & 78,888 & 72,852 & 73,416 & 1 & 91 & 91 & 91 \\
\hline Petroleum & 233 & 10,156 & 8,799 & 9,777 & 16 & 843 & 718 & 826 \\
\hline Gas & 227 & 27,201 & 24,974 & 26,216 & 42 & 13,763 & 11,781 & 13,167 \\
\hline Water(Pumped Storage Hydruelectric) & 29 & 6,665 & 6,667 & 6,667 & 4 & 300 & 303 & 309 \\
\hline Water(Conventiona! Hydroelectric).......... & 468 & 10,287 & 10,571 & 10,299 & - & - & - & - \\
\hline Nuclear & 33 & 34,074 & 31,652 & 31,787 & - & - & - & - \\
\hline Waste Heat & 8 & 297 & 268 & 269 & - & - & - & - \\
\hline 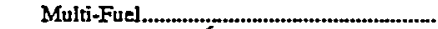 & - & - & - & - & - & - & - & - \\
\hline Other Renewable 6 & 4 & 3 & 3 & 3 & - & - & - & - \\
\hline $\operatorname{SPP}^{3} \ldots$ & 1,024 & 44,643 & 42,871 & 43,070 & 20 & 1,764 & 1,506 & 1,725 \\
\hline Coal & 69 & 20,545 & 19,501 & 19,514 & - & - & - & - \\
\hline Petroleum & 377 & $1,43]$ & 1,301 & 1,365 & 3 & 4 & 4 & 4 \\
\hline 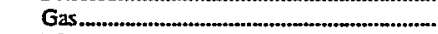 & 467 & 18,477 & 17,755 & 17,910 & 13 & 1,687 & 1,434 & 1,653 \\
\hline Water(Pumped Storage Hydroelectric) & 14 & 509 & 505 & 505 & - & - & - & - \\
\hline Water(Conventional Hydroelectrie)............ & 94 & 2,408 & 2,612 & 2,554 & 3 & 35 & 33 & 32 \\
\hline
\end{tabular}

See foomotes at end of table. 
Table 14. Existing Capacity and Planned Capacity Additions at U.S. Electric Utilities by Energy Source, North American Electric Reliability Council Region, and Hawaii, as of January 1, 1998 (Continued)

\begin{tabular}{|c|c|c|c|c|c|c|c|c|}
\hline \multirow[b]{2}{*}{$\begin{array}{c}\text { NERC Region and Hawaii } \\
\text { Primary Energy } \\
\text { Source }\end{array}$} & \multicolumn{4}{|c|}{ Existing] } & \multicolumn{4}{|c|}{ Phnned Additionsl 2} \\
\hline & $\begin{array}{l}\text { Number } \\
\text { of Units }\end{array}$ & $\begin{array}{l}\text { Generator } \\
\text { Nameplate } \\
\text { (megawatts) }\end{array}$ & $\begin{array}{c}\text { Summer } \\
\text { Capability } \\
\text { (megawatts) }\end{array}$ & $\begin{array}{c}\text { Winter } \\
\text { Capability } \\
\text { (megawatts) }\end{array}$ & $\begin{array}{l}\text { Number } \\
\text { of Units }\end{array}$ & $\begin{array}{l}\text { Generator } \\
\text { Nameplate } \\
\text { (megawatts) }\end{array}$ & $\begin{array}{c}\text { Summer } \\
\text { Capability } \\
\text { (megawatts) }\end{array}$ & $\begin{array}{c}\text { Winter } \\
\text { Capability } \\
\text { (megawatts) }\end{array}$ \\
\hline \multicolumn{9}{|l|}{ SPP3 (Continued) } \\
\hline 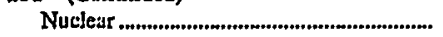 & 1 & 1,236 & $J, 163$ & 1,187 & 一 & - & - & - \\
\hline Waste Heat ......................................................... & 1 & 26 & 21 & 23 & 1 & 38 & 35 & 36 \\
\hline 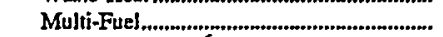 & - & - & - & - & - & - & - & - \\
\hline 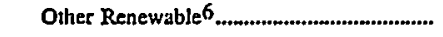 & - & - & - & - & - & - & - & - \\
\hline 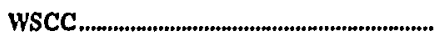 & 1,989 & 131,568 & 129,232 & 129,984 & 34 & 3,303 & 2,892 & 3,194 \\
\hline 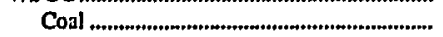 & 107 & 31,484 & 29,492 & 29,531 & 2 & 633 & 610 & 610 \\
\hline 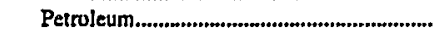 & 163 & 2,086 & 1,840 & 1,983 & 1 & $*$ & 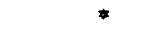 & * \\
\hline 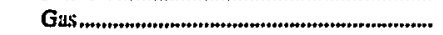 & 353 & 32,650 & 30,795 & 31,658 & 19 & 2,377 & 2,026 & 2,309 \\
\hline Water(Pumped Storage Hydroelectric) & 47 & 4,310 & 4,738 & 4,732 & - & - & - & - \\
\hline Water(Conventional Hydroelectric)............ & 1,248 & 47,750 & $50,1] 16$ & 49,764 & 7 & 36 & 34 & 33 \\
\hline 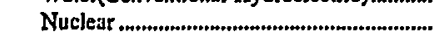 & 8 & 9,964 & 9,258 & 9,300 & - & - & - & - \\
\hline 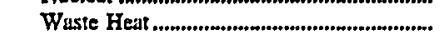 & 20 & 1,417 & 1,238 & 1,271 & 2 & 247 & 212 & 232 \\
\hline 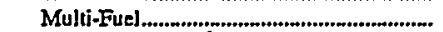 & 二 & - & 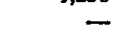 & - & - & - & - & - \\
\hline Other Renewable & 39 & 1,903 & 1,752 & 1,742 & 3 & 9 & 9 & 9 \\
\hline
\end{tabular}

I NERC region totals ate aggregates based on the assignment of units/capacity to the NERC region with which the utility operating the unit is associuted.

2 Planned additions are for 1998 through 2007.

3 Existing capacity totals include a 13-megawatt expander turbine fueled by hot nitrogen.

4 The Florida Reliability Coordinating Council (FRCC) became effective January 1, 1997. The data pertaining to FRCC and the Southeastem Eleetric Reliability Council (SERC) as of January I, 1997 have been revised. The revised data are included in Appendix A Technical Notes, "Quality of Data."

5 Includes Commonwealth Edison Company's Zion 1 and 2 nuclear units which were retired from service in Januury 1998.

6 Includes geothermal, biomass (wood, wood waste, nonwood waste), solar, and wind.

* Less than 0.5 megawatts.

Notes: -NERC $=$ North American Electric Reliability Council. -See NERC Map in Appendix F. -The Form EIA-860 was revised during 1995 to collect data as of January 1 of the reporting year, where "reporting year" is the calendar year in which the report is required to be filed with the Energy Information Administration. These data reflect the status of electric power plants/generators as of January 1 : however, dynamic data are based on occurrences in the previous calendar year (e.g., capabilities and energy sources based on test and consumption in the previous year).

Source: Energy Information Administration, Form EIA-860, "Annual Electric Generator Report." 
Table 15. Existing Capacity and Planned Capacity Additions at U.S. Electric Utilities by Energy Source and Federal Region, as of January 1, 1998

\begin{tabular}{|c|c|c|c|c|c|c|c|c|}
\hline \multirow[b]{2}{*}{$\begin{array}{c}\text { Federal Region } \\
\text { Primary Energy } \\
\text { Source }\end{array}$} & \multicolumn{4}{|c|}{ Existing } & \multicolumn{4}{|c|}{ Planned Additions 1} \\
\hline & $\begin{array}{l}\text { Number } \\
\text { of Units }\end{array}$ & $\begin{array}{l}\text { Generator } \\
\text { Nameplate } \\
\text { Capacity } \\
\text { (megawatts) }\end{array}$ & $\begin{array}{l}\text { Net Summer } \\
\text { Capability } \\
\text { (megawatts) }\end{array}$ & $\begin{array}{l}\text { Net Winter } \\
\text { Capability } \\
\text { (megawatts) }\end{array}$ & $\begin{array}{l}\text { Number } \\
\text { of Units }\end{array}$ & $\begin{array}{c}\text { Generator } \\
\text { Nameplate } \\
\text { Capacity } \\
\text { (megawatts) }\end{array}$ & $\begin{array}{l}\text { Net Summer } \\
\text { Capability } \\
\text { (megawatts) }\end{array}$ & $\begin{array}{c}\text { Net Winter } \\
\text { Capability } \\
\text { (megawatts) }\end{array}$ \\
\hline U.S. Total 2 & 10,421 & 754,925 & 711,889 & 725,904 & 316 & $\mathbf{5 2 , 0 4 4}$ & 45,056 & 50,124 \\
\hline 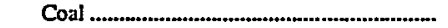 & 1,198 & $325,00]$ & 302,866 & 304,914 & 8 & 2,559 & 2,444 & 2,444 \\
\hline 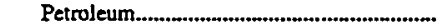 & 3,321 & 76,511 & 69,539 & 75,564 & 52 & 1,444 & 1,239 & 1,412 \\
\hline 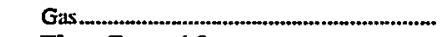 & 2,148 & 147,260 & 136,957 & 141,933 & 212 & 46,181 & 39,679 & 44,476 \\
\hline $\begin{array}{l}\text { Water (Pumped Storage } \\
\text { Hydroelectric) } \\
\text { Water (Conventional }\end{array}$ & 141 & 18,669 & 19,310 & 19,282 & 5 & 504 & 509 & 519 \\
\hline Hydroelectric) & 3,352 & 73,202 & $76, \mathrm{J77}$ & 75,617 & 22 & 160 & 152 & 147 \\
\hline Nuclear ${ }^{3}$ & 107 & 107,632 & 99,716 & 100,896 & - & - & - & - \\
\hline 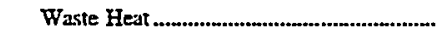 & 60 & 4,130 & 4,979 & 5,360 & 11 & 1,174 & 1,012 & 1,103 \\
\hline 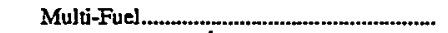 & 7 & 221 & 209 & 212 & - & - & - & - \\
\hline Other Renewable 4 & 81 & 2,281 & 2,119 & 2,109 & $s$ & 20 & 20 & 20 \\
\hline Federal Region 1 & 654 & 22,071 & 21,281 & 22,174 & 8 & 170 & 151 & 159 \\
\hline Coal & 15 & 2,773 & 2,700 & 2,800 & - & - & - & - \\
\hline 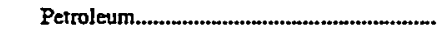 & 221 & 9,165 & 8,587 & 9,067 & 2 & 5 & 5 & 5 \\
\hline Gas & 22 & 1,847 & 1,737 & 1,896 & 1 & 120 & 103 & 113 \\
\hline Water (Pumped Storage & & & & & & & & \\
\hline $\begin{array}{l}\text { Hydroelectic) } \\
\text { Water (Conventional }\end{array}$ & 8 & 1,453 & 1,658 & 1,711 & 一 & - & - & 一 \\
\hline Hydroelectric) & 367 & 1,330 & 1,445 & 1,475 & 5 & 45 & 43 & 42 \\
\hline 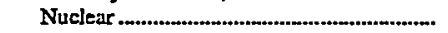 & 6 & 5,285 & 4,958 & 5,021 & - & - & - & - \\
\hline 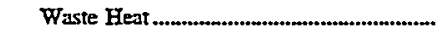 & 2 & 130 & 110 & 117 & - & - & - & - \\
\hline 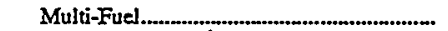 & 一 & - & - & - & - & - & - & - \\
\hline Other Renewable 4 & 13 & 89 & 86 & 87 & - & - & - & - \\
\hline Federal Region 2 & 669 & 46,474 & 43,668 & 45,897 & 2 & 3 & 3 & 3 \\
\hline 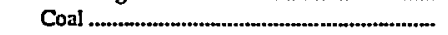 & 39 & 5,717 & 5,515 & 5,534 & - & - & - & - \\
\hline 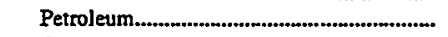 & 250 & 17,882 & 16,673 & 18,217 & 2 & 3 & 3 & 3 \\
\hline Gas & 62 & 6,945 & 6,707 & 7,158 & - & 一 & 一 & - \\
\hline $\begin{array}{l}\text { Water (Pumped Storage } \\
\text { Hydroelectric) }\end{array}$ & 19 & 1,627 & 1.680 & 1.680 & - & - & - & - \\
\hline Water (Conventional & & & & & & & & - \\
\hline Hydroelectric) & 285 & 3,950 & 3,855 & 3,884 & - & - & - & - \\
\hline 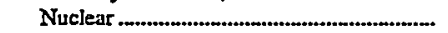 & 10 & 9,770 & 8,823 & 8,983 & - & - & - & - \\
\hline 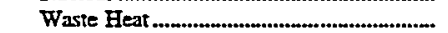 & 4 & 581 & 414 & 441 & - & - & - & - \\
\hline 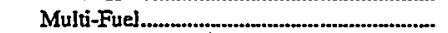 & - & - & - & - & - & - & - & - \\
\hline 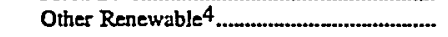 & - & - & - & - & - & - & - & - \\
\hline Federal Region 3 & 611 & 83,488 & 77,791 & 79,995 & 15 & 1,788 & 1,535 & 1,697 \\
\hline Coal & 139 & 45,619 & 42,532 & 43,180 & - & - & - & - \\
\hline Petroleum & 245 & 10,710 & 9,596 & $\mathrm{~J} 0,409$ & 3 & 226 & 193 & 22] \\
\hline 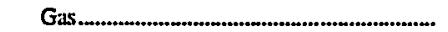 & 57 & 6,293 & 5,632 & 6,127 & 8 & 1,144 & 982 & 1,082 \\
\hline Water (Pumped Storage & & & & & & & & \\
\hline Hydroelectric) & 20 & 3,570 & 3,664 & 3,664 & - & - & - & - \\
\hline Water (Conventional & & & & & & & & \\
\hline 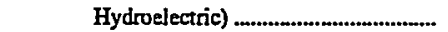 & 129 & 1,942 & 1,990 & 2,038 & 1 & 1 & 1 & 1 \\
\hline 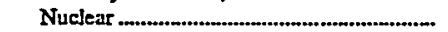 & 15 & $15,04]$ & $.14,073$ & 14,273 & $\ldots$ & - & - & - \\
\hline 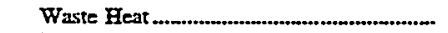 & 3 & 314 & 304 & 304 & 3 & 418 & 359 & 393 \\
\hline 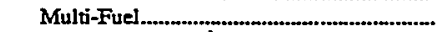 & - & - & - & - & $二$ & - & $\div$ & - \\
\hline Other Renewable 4 & 3 & * & * & $*$ & - & - & 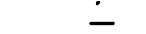 & - \\
\hline Federal Region 4 & 1,447 & 172,629 & 159,378 & 163,464 & 110 & 25,895 & 22,253 & 24,801 \\
\hline 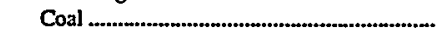 & $28]$ & 85,785 & 78,434 & 79,096 & 2 & 274 & 274 & 274 \\
\hline 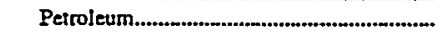 & 312 & 20,404 & 18,071 & 19,707 & 18 & 884 & 753 & 866 \\
\hline Gas. & 293 & $-78,984$ & 15,857 & 17,372 & $\ddot{83}$ & 24,002 & 20,549 & 22,942 \\
\hline Water (Pumped Storage & & & & & & & & \\
\hline Hydroelectric) & 25 & 4,814 & 4,843 & 4,843 & 4 & 300 & 303 & 309 \\
\hline Water (Conventional & & & & & & & & \\
\hline Hydroelectric) & 483 & 10,880 & 11,169 & 10,896 & - & - & - & - \\
\hline 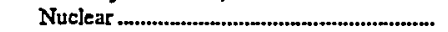 & 30 & 30,449 & 28,431 & 28,665 & - & - & - & - \\
\hline 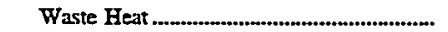 & 22 & 1,309 & 2,570 & 2,882 & 3 & 435 & 374 & 409 \\
\hline
\end{tabular}

See footnotes at end of table. 
Table 15. Existing Capacity and Planned Capacity Additions at U.S. Electric Utilities by Energy Source and Federal Region, as of January 1, 1998 (Continued)

\begin{tabular}{|c|c|c|c|c|c|c|c|c|}
\hline \multirow[b]{2}{*}{$\begin{array}{c}\text { Federal Region } \\
\text { Primary Energy } \\
\text { Source }\end{array}$} & \multicolumn{4}{|c|}{ Existing } & \multicolumn{4}{|c|}{ Planned Additions 1} \\
\hline & $\begin{array}{l}\text { Number } \\
\text { of Units }\end{array}$ & $\begin{array}{c}\text { Generator } \\
\text { Nameplate } \\
\text { Capacity } \\
\text { (niegawatts) }\end{array}$ & $\begin{array}{c}\text { Net Summer } \\
\text { Capability } \\
\text { (megawatts) }\end{array}$ & $\begin{array}{l}\text { Net Winter } \\
\text { Capability } \\
\text { (megnwatts) }\end{array}$ & $\begin{array}{l}\text { Number } \\
\text { of Units }\end{array}$ & $\begin{array}{c}\text { Generator } \\
\text { Namephate } \\
\text { Capacity } \\
\text { (megawatts) }\end{array}$ & $\begin{array}{c}\text { Net Summer } \\
\text { Capability } \\
\text { (megawatts) }\end{array}$ & $\begin{array}{l}\text { Net Winter } \\
\text { Capability } \\
\text { (megawatts) }\end{array}$ \\
\hline \multicolumn{9}{|l|}{$\begin{array}{l}\text { Federal Region } 4 \text { (Continued) } \\
\text { Multi-Fuel. }\end{array}$} \\
\hline 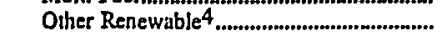 & $\overline{1}$ & $\overline{3}$ & $\overline{3}$ & $\overline{3}$ & 二 & 二 & 二 & $=$ \\
\hline 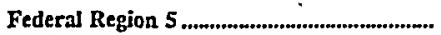 & 2,055 & 133,655 & 123,348 & 126298 & 83 & 13,111 & 11.162 & 12.848 \\
\hline 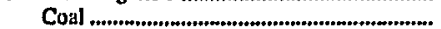 & 410 & 87,481 & 81,176 & 81,754 & ] & 60 & 60 & 60 \\
\hline 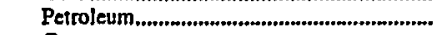 & 675 & 9,666 & 8,734 & 9,730 & 5 & 12 & 12 & 12 \\
\hline & 367 & 9,567 & 8,650 & 9,595 & 72 & 12,984 & 11,037 & 12,725 \\
\hline \multicolumn{2}{|l|}{$\begin{array}{l}\text { Water (Pumped Storage } \\
\text { Hydroelectric) .............................n...... }\end{array}$} & $\{, 979$ & $\mathbb{1 , 8 7 2}$ & 1,872 & - & - & - & - \\
\hline Hydroelectric) ........................................... & 551 & 1,169 & 1,053 & 1,071 & 2 & 42 & 40 & 39 \\
\hline 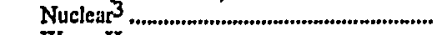 & 25 & 23,497 & 21,577 & 21,988 & - & - & - & - \\
\hline 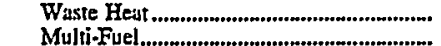 & 1 & 12 & 10 & 10 & 二 & $\overline{-}$ & $\bar{z}$ & 二 \\
\hline 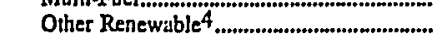 & $\overline{19}$ & 285 & 277 & 277 & $\overline{2}$ & $\overline{11}$ & $\overline{11}$ & $\overline{11}$ \\
\hline \multicolumn{9}{|l|}{ Federal Region $\sigma^{2}$} \\
\hline 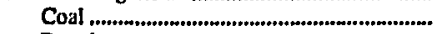 & 71 & 37,509 & 35,654 & 35,679 & 4 & 1,825 & 1,710 & 1,710 \\
\hline 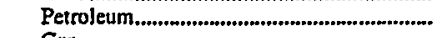 & 98 & 483 & 445 & 447 & - & - & & \\
\hline \multicolumn{9}{|l|}{ Water (Pumped Storage } \\
\hline \multicolumn{9}{|l|}{$\begin{array}{l}\text { Hydroelectric) ........ } \\
\text { Water (Conventional }\end{array}$} \\
\hline \multirow{2}{*}{\multicolumn{9}{|c|}{ Hydroelectric) (....................................... }} \\
\hline \multirow{2}{*}{\multicolumn{9}{|c|}{ Nuclear }} \\
\hline & & & & & & & & \\
\hline 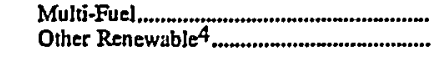 & $\overline{2}$ & $\overline{1}$ & $\overline{1}$ & $\overline{1}$ & 二 & $\overline{-}$ & 二 & - \\
\hline Federal Region 7 & 1,415 & 42,795 & 39,996 & 40,396 & 23 & 1,239 & 1,091 & 1,225 \\
\hline 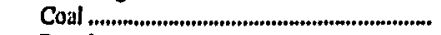 & 125 & 26,414 & 25,009 & 24,950 & - & - & - & - \\
\hline 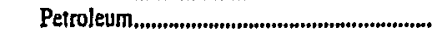 & 752 & 3,469 & 3,129 & 3,443 & 13 & 170 & 148 & 166 \\
\hline 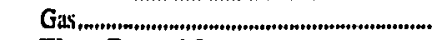 & 445 & 6,843 & 6,125 & 6,282 & 9 & 865 & 737 & 848 \\
\hline $\begin{array}{l}\text { Water (Pumped Storage } \\
\text { Hydroejectric) } \\
\text { Water (Conventional }\end{array}$ & 9 & 601 & 567 & 492 & 1 & 204 & 206 & 210 \\
\hline \multicolumn{9}{|l|}{ 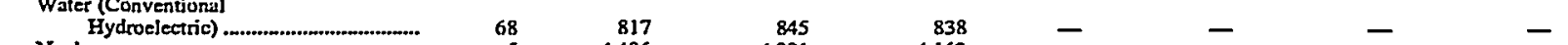 } \\
\hline \multirow{2}{*}{\multicolumn{9}{|c|}{ Wuclear }} \\
\hline & & 23 & 21 & 18 & - & - & - & - \\
\hline \multirow{2}{*}{\multicolumn{9}{|c|}{ 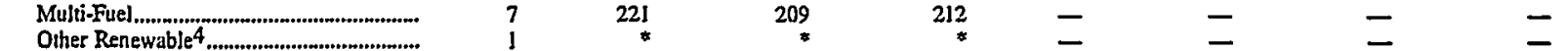 }} \\
\hline & i & $*$ & 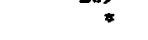 & $*$ & - & - & - & - \\
\hline 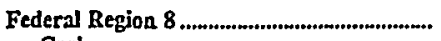 & 572 & 31,459 & 30,442 & 30,582 & 10 & 966 & 885 & 939 \\
\hline 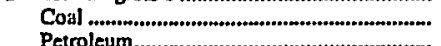 & 85 & 22,947 & 21,832 & 21,896 & 1 & 400 & 400 & 400 \\
\hline 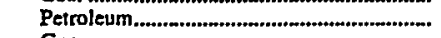 & 124 & 729 & 618 & 732 & i & 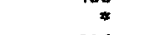 & $*$ & 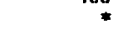 \\
\hline Gas....................................... & 75 & 1,316 & 1,262 & 1,295 & 4 & 316 & 270 & 304 \\
\hline $\begin{array}{l}\text { Water (Pumped Storuge } \\
\text { Hydroelectric) ......... }\end{array}$ & 6 & 509 & 563 & 563 & - & - & - & - \\
\hline Water (Conventional & & & & & & & & \\
\hline Hydroelectric) ........................................... & 275 & 5,918 & 6,132 & $6,06 \mathrm{I}$ & 2 & 3 & 2 & 2 \\
\hline 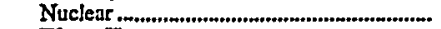 & - & - & - & - & - & & & \\
\hline 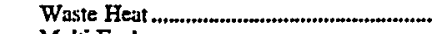 & - & - & - & - & 2 & 247 & 212 & 232 \\
\hline 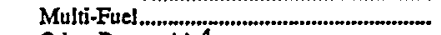 & - & $\overrightarrow{0}$ & - & - & - & - & - & - \\
\hline 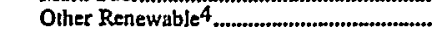 & 7 & 40 & 35 & 35 & - & - & 二 & - \\
\hline 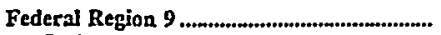 & 984 & 68,691 & 66,110 & 66,864 & 25 & 2,119 & 1,808 & 2,057 \\
\hline 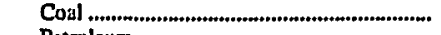 & 23 & 8,632 & 8,062 & 8,073 & - & $\overline{-1}$ & $\overline{-}$ & $\bar{n}$ \\
\hline 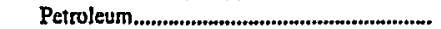 & 168 & 3,202 & 2,941 & 3,003 & 6 & 134 & 114 & 127 \\
\hline Gas, ...., & 242 & 28,688 & 27,133 & 27,748 & 14 & 1,941 & 1,653 & 1,887 \\
\hline $\begin{array}{l}\text { Water (Pumped Storage } \\
\text { Hydroelectric) .................................... }\end{array}$ & 36 & 3,541 & 3,915 & 3,909 & - & - & - & - \\
\hline Water (Conventional & & & & & & & & \\
\hline 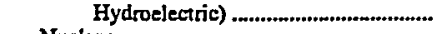 & 466 & $\begin{array}{r}13,268 \\
8769\end{array}$ & 13,564 & 13,579 & - & - & - & - \\
\hline Nuclear & $\begin{array}{r}7 \\
15\end{array}$ & $\begin{array}{r}8,764 \\
879\end{array}$ & 8,088 & $\begin{array}{r}8,130 \\
825\end{array}$ & 3 & $\overline{36}$ & $\overline{31}$ & $\overline{34}$ \\
\hline & & & & & & 20 & & \\
\hline
\end{tabular}

See foutnotes at end of table. 
Table 15. Existing Capacity and Planned Capacity Additions at U.S. Electric Utilities by Energy Source and Federal Region, as of January 1, 1998 (Continued)

\begin{tabular}{|c|c|c|c|c|c|c|c|c|}
\hline \multirow[b]{2}{*}{$\begin{array}{c}\text { Federal Region } \\
\text { Primary Energy } \\
\text { Source }\end{array}$} & \multicolumn{4}{|c|}{ Existing } & \multicolumn{4}{|c|}{ Planned Additions] } \\
\hline & $\begin{array}{l}\text { Number } \\
\text { of Units }\end{array}$ & $\begin{array}{c}\text { Generator } \\
\text { Nameplate } \\
\text { Capacity } \\
\text { (megawatts) }\end{array}$ & $\begin{array}{c}\text { Net Summer } \\
\text { Capability } \\
\text { (megawatts) }\end{array}$ & $\begin{array}{l}\text { Net Winter } \\
\text { Capability } \\
\text { (megawatts) }\end{array}$ & $\begin{array}{l}\text { Number } \\
\text { of Units }\end{array}$ & $\begin{array}{c}\text { Generator } \\
\text { Nameplate } \\
\text { Capacity } \\
\text { (megawatts) }\end{array}$ & $\begin{array}{l}\text { Net Summer } \\
\text { Capability } \\
\text { (megawatts) }\end{array}$ & $\begin{array}{l}\text { Nel Winter } \\
\text { Capability } \\
\text { (megawatts) }\end{array}$ \\
\hline \multicolumn{9}{|l|}{ Federal Region 9 (Continued) } \\
\hline 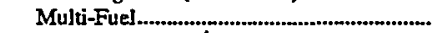 & - & - & - & - & - & - & - & - \\
\hline 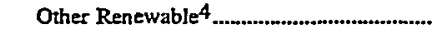 & 27 & 1,717 & 1,597 & 1,597 & 3 & 9 & 9 & 9 \\
\hline Federal Region 10 & 1,154 & 38,851 & 40,136 & 40,193 & 11 & 45 & 43 & 42 \\
\hline 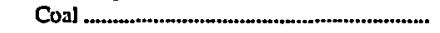 & 10 & 2,124 & 1,952 & 1,952 & 一 & - & 一 & - \\
\hline 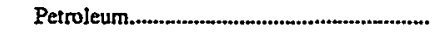 & 476 & 798 & 745 & 808 & 2 & 11 & 10 & 11 \\
\hline Gas & 47 & 2,476 & 2,143 & 2,414 & - & 一 & 一 & - \\
\hline Water (Pumped Storage & & & & & & & & \\
\hline $\begin{array}{l}\text { Hydruelectric) } \\
\text { Water (Conventional }\end{array}$ & 5 & 261 & 261 & 261 & $一$ & 一 & 一 & 一 \\
\hline 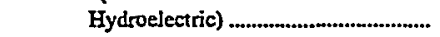 & 598 & 31,311 & 33,304 & 33,013 & 9 & 35 & 33 & 32 \\
\hline 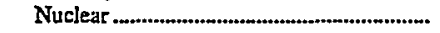 & $\mathbf{1}$ & 1,200 & 1,170 & 1,170 & - & - & - & - \\
\hline 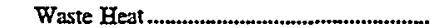 & 5 & 532 & 439 & 463 & - & - & - & - \\
\hline 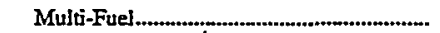 & 一 & - & - & - & 一 & 一 & - & - \\
\hline Other Renewable 4 & 8 & 146 & 120 & 110 & 一 & - & 一 & - \\
\hline
\end{tabular}

1 Planned additions are for 1998 through 2007.

2. Existing capacity totals include a 13-megawatt expander turbine fueled by hot nitrogen.

3 Existing capacity includes Commonwealth Edison Company's Zion 1 and 2 nuclear units which were retired from service in January 1998.

4 Includes geothermal, biomass (wood, wood waste, nonwood waste), solar, and wind.

* Less than 0.5 megawatts.

Notes: Total may not equal the sum of components because of independent rounding. - See Federal Region Map in Appendix F. - The Form ElA. 860 was revised during 1995 to collect data as of January 1 of the reporting year, where "reporting year" is the calendar year in which the report is required to be filed with the Energy Information Administration. These data reflect the status of electric power plants/generators as of January 1: however, dynamic data ate based on occurrences in the previous calendac year (e.g., capabilities and energy sources based on test and consumption in the previous year).

Source: Energy Information Administration, Form EIA-860, "Annual Electric Generator Report." 
Table 16. Existing Capacity and Planned Capacity Additions at U.S. Electric Utilities by Energy Source and Census Division, as of January 1, 1998

\begin{tabular}{|c|c|c|c|c|c|c|c|c|}
\hline \multirow[b]{2}{*}{$\begin{array}{c}\text { Census Division } \\
\text { Primary Energy } \\
\text { Source }\end{array}$} & \multicolumn{4}{|c|}{ Existing } & \multicolumn{4}{|c|}{ Planned Additions! } \\
\hline & $\begin{array}{l}\text { Number } \\
\text { of Units }\end{array}$ & $\begin{array}{c}\text { Generator } \\
\text { Nameplate } \\
\text { Capacity } \\
\text { (megawatts) }\end{array}$ & $\begin{array}{l}\text { Net Summer } \\
\text { Capability } \\
\text { (megawatts) }\end{array}$ & $\begin{array}{l}\text { Net Winter } \\
\text { Capability } \\
\text { (megawatts) }\end{array}$ & $\begin{array}{l}\text { Number } \\
\text { of Units }\end{array}$ & $\begin{array}{c}\text { Generator } \\
\text { Namepbate } \\
\text { Capacily } \\
\text { (megawatts) }\end{array}$ & $\begin{array}{l}\text { Net Summer } \\
\text { Capability } \\
\text { (megawatts) }\end{array}$ & $\begin{array}{l}\text { Net Winter } \\
\text { Capability } \\
\text { (negawats) }\end{array}$ \\
\hline U.S. Total $2 \ldots \ldots \ldots$ & 10,421 & 754,925 & 711,889 & 725,904 & 316 & 52,044 & 45,056 & 50,124 \\
\hline 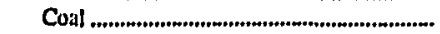 & 1,198 & 325,001 & 302,866 & 304,914 & 8 & 2,559 & 2,444 & 2,444 \\
\hline 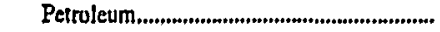 & 3,321 & 76,511 & 69,539 & 75,564 & 52 & 1,444 & 1,239 & 1,412 \\
\hline Gas & 2,148 & 147,260 & 136,957 & 141,933 & 212 & 46,181 & 39,679 & 44,476 \\
\hline $\begin{array}{l}\text { Water (Pumped Storage } \\
\text { Hydroelectic) .................................... } \\
\text { Water (Conventional }\end{array}$ & 14] & 18,669 & 19,310 & 19,282 & 5 & 504 & 509 & 519 \\
\hline Hydroelectric) .............................................. & 3,352 & 73,202 & 76,177 & 75,617 & 22 & 160 & 152 & 147 \\
\hline Nuclear ${ }^{3} \ldots$ & 107 & 107,632 & 99,716 & 100,896 & - & - & - & - \\
\hline 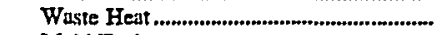 & 60 & 4,130 & 4,979 & 5,360 & 11 & 1,174 & 1,012 & 1,103 \\
\hline Multi-Fuel ..................................................... & 7 & 221 & 209 & 212 & - & - & - & - \\
\hline 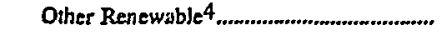 & 81 & 2,281 & 2,119 & 2,109 & 5 & 20 & 20 & 20 \\
\hline 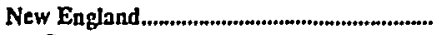 & 654 & 22,071 & 21,281 & 22,174 & 8 & 170 & 151 & 159 \\
\hline 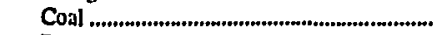 & 15 & 2,773 & 2,700 & 2,800 & - & - & - & - \\
\hline 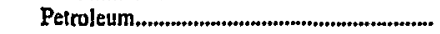 & 221 & 9,165 & 8,587 & 9,067 & 2 & 5 & 5 & 5 \\
\hline 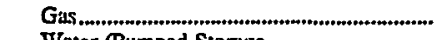 & 22 & 1,847 & 1,737 & 1,896 & 1 & 120 & 103 & 113 \\
\hline $\begin{array}{l}\text { Water (Pumped Storage } \\
\quad \text { Hydroelectric) ........................................ } \\
\text { Water (Conventional }\end{array}$ & 8 & 1,453 & 1,658 & 1,711 & - & - & - & - \\
\hline 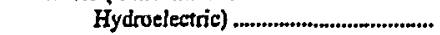 & 367 & 1,330 & 1,445 & 1,475 & 5 & 45 & 43 & 42 \\
\hline 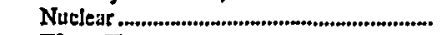 & 6 & 5,285 & 4,958 & 5,021 & - & - & - & - \\
\hline 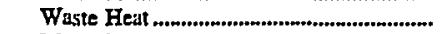 & 2 & 130 & 110 & 117 & - & - & - & - \\
\hline 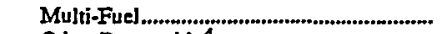 & - & - & - & - & - & - & - & - \\
\hline Other Renewable4 & 13 & 89 & 86 & 87 & - & - & - & - \\
\hline 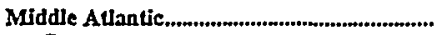 & 901 & 83,359 & 77,494 & 80,752 & 4 & 201 & 173 & 189 \\
\hline 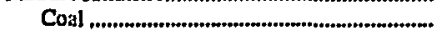 & 97 & 24,924 & 22,901 & 23,271 & - & - & - & - \\
\hline 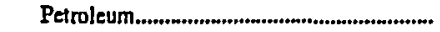 & 355 & 21,660 & $19,88 \mathrm{I}$ & 21,904 & 2 & 3 & 3 & 3 \\
\hline Gas , . & 77 & $9,43 \mathrm{~J}$ & 8,990 & 9,481 & 2 & 198 & 170 & 186 \\
\hline $\begin{array}{l}\text { Water (Pumped Storage } \\
\quad \text { Hydrolectric) } \\
\text { Water (Conventional }\end{array}$ & 30 & 2,849 & 2,999 & 2,999 & - & - & - & - \\
\hline Hydroelectric) ............................................. & 319 & 4,586 & 4,478 & 4,523 & - & - & - & - \\
\hline 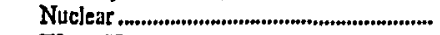 & 19 & 19,328 & 37,829 & 18,134 & - & - & - & - \\
\hline 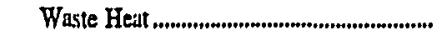 & 4 & 581 & 414 & 44] & - & - & - & - \\
\hline 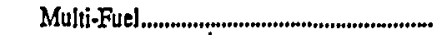 & - & - & - & - & - & - & - & - \\
\hline 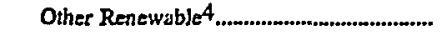 & - & - & - & - & - & - & - & - \\
\hline East North Centenl ......................................... & 1,714 & 124,076 & 114,132 & 116,807 & 79 & 13,103 & 11,153 & 12,840 \\
\hline 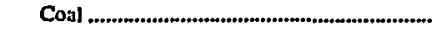 & 368 & 81,648 & 75,365 & 75,953 & 1 & 60 & 60 & 60 \\
\hline 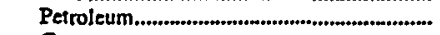 & 513 & 8,460 & 7,632 & 8,411 & 2 & 7 & 6 & 7 \\
\hline Gas & 301 & 9,065 & 8,197 & 9,130 & 71 & 12,981 & 11,034 & 12,722 \\
\hline Water (Pumped Storage & & & & & & & & \\
\hline $\begin{array}{l}\text { Hydroelectric) } \\
\text { Water (Conventional }\end{array}$ & 6 & 1,979 & 1,872 & 1,872 & - & - & - & - \\
\hline Hydroelectic) , & 497 & 3,028 & 913 & 929 & 2 & 42 & 40 & 39 \\
\hline 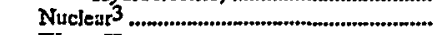 & 22 & 21,746 & 20,005 & 20,362 & - & - & - & - \\
\hline 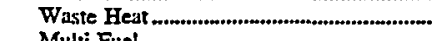 & - & - & - & - & - & - & - & - \\
\hline 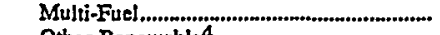 & - & $-\overline{1}$ & $-\overline{0}$ & $\overline{1}$ & - & $\overline{1}$ & $\overline{1}$ & $\overline{1}$ \\
\hline Other Renewable & 7 & 151 & 15] & 151 & 2 & 11 & 11 & 11 \\
\hline 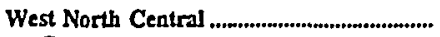 & 1,867 & 60,261 & 56,872 & 57,630 & 27 & 1,247 & 1,099 & 1,233 \\
\hline 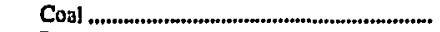 & 183 & 37,012 & 35,349 & 35,311 & - & - & - & - \\
\hline 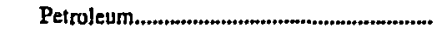 & 965 & 5,181 & 4,624 & 5,242 & 16 & 175 & 153 & 172 \\
\hline 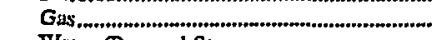 & 524 & 7,713 & 6,950 & 7,086 & 10 & 868 & 740 & 851 \\
\hline $\begin{array}{l}\text { Water (Pumped Storage } \\
\text { Hydroelectric) } \\
\text { Water (Conventional }\end{array}$ & 9 & 601 & 567 & 492 & 1 & 204 & 206 & 210 \\
\hline 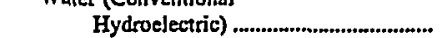 & 153 & 3,207 & 3,352 & 3,345 & - & - & - & - \\
\hline 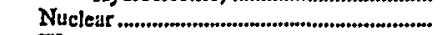 & 8 & 6,157 & 5,663 & 5,788 & - & - & - & - \\
\hline 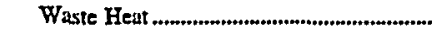 & 4 & 34 & 31 & 28 & - & - & - & - \\
\hline
\end{tabular}

Sec footnotes at end of table. 
Table 16. Existing Capacity and Planned Capacity Additions at U.S. Electric Utilities by Energy Source and Census Division, as of January 1, 1998 (Continued)

\begin{tabular}{|c|c|c|c|c|c|c|c|c|}
\hline \multirow[b]{2}{*}{$\begin{array}{c}\text { Census Division } \\
\text { Primary Energy } \\
\text { Source }\end{array}$} & \multicolumn{4}{|c|}{ Existing } & \multicolumn{4}{|c|}{ Phaned Additions! } \\
\hline & $\begin{array}{l}\text { Number } \\
\text { of Units }\end{array}$ & $\begin{array}{c}\text { Generator } \\
\text { Nameplate } \\
\text { Capacity } \\
\text { (megawatts) }\end{array}$ & $\begin{array}{l}\text { Net Summer } \\
\text { Capability } \\
\text { (megawatls) }\end{array}$ & $\begin{array}{l}\text { Net Winter } \\
\text { Capability } \\
\text { (megawatts) }\end{array}$ & $\begin{array}{l}\text { Number } \\
\text { of Units }\end{array}$ & $\begin{array}{c}\text { Generator } \\
\text { Nameplate } \\
\text { Capacity } \\
\text { (megawatts) }\end{array}$ & $\begin{array}{l}\text { Net Summer } \\
\text { Capability } \\
\text { (megawatts) }\end{array}$ & $\begin{array}{c}\text { Net Winter } \\
\text { Capability } \\
\text { (megawatts) }\end{array}$ \\
\hline \multicolumn{9}{|l|}{ West North Central (Continued) } \\
\hline 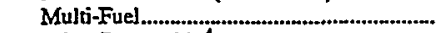 & 7 & 221 & 209 & 212 & - & - & - & - \\
\hline Other Renewable 4 & 13 & 134 & 126 & 126 & 一 & 一 & - & - \\
\hline South Athantic. & 1,340 & 152,350 & 142,325 & 146,723 & 86 & 22,050 & 18,959 & 21,126 \\
\hline 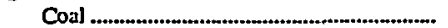 & 223 & 71,613 & 67,425 & 67,979 & 2 & 274 & 274 & 274 \\
\hline 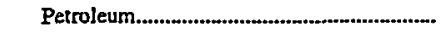 & 414 & 25,646 & 23,091 & 24,845 & 16 & 1,100 & 937 & 1,078 \\
\hline 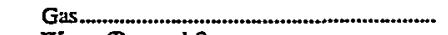 & 240 & 16,007 & 12,704 & 14,283 & 58 & 19,672 & 16,840 & 18,804 \\
\hline \multicolumn{9}{|l|}{ Water (Pumped Storage } \\
\hline \multicolumn{9}{|l|}{ Water (Conventional } \\
\hline Hydroelectric) & 381 & 6,276 & 6,567 & 6,571 & $\mathbf{J}$ & 1 & J & 1 \\
\hline 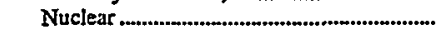 & 27 & 25,617 & 24,068 & 24,266 & 一 & - & - & - \\
\hline 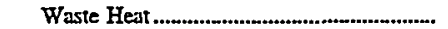 & 21 & 1,557 & 2,810 & 3,120 & 5 & 703 & 604 & 661 \\
\hline 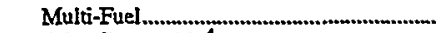 & - & - & - & - & 一 & - & - & - \\
\hline 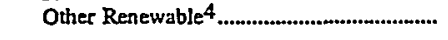 & 4 & 3 & 3 & 3 & 一 & - & - & 一 \\
\hline 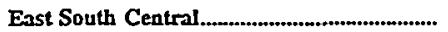 & 486 & 66,882 & 61,019 & 61,881 & 37 & 5,435 & 4,658 & 5,185 \\
\hline 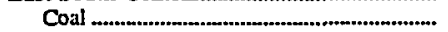 & 139 & 40,584 & 36,155 & 36,560 & - & - & - & - \\
\hline 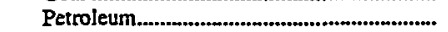 & 38 & 1,692 & 1,368 & 1,584 & 5 & 9 & 9 & 9 \\
\hline Gas............................................................ & 95 & 6,784 & 6,501 & 6,893 & 31 & 5,276 & 4,520 & 5,035 \\
\hline \multicolumn{9}{|l|}{ Water (Pumped Storage } \\
\hline \multicolumn{9}{|l|}{ Water (Conventional } \\
\hline 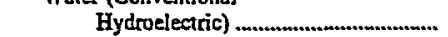 & 197 & 5,910 & 5,969 & 5,725 & - & - & - & - \\
\hline 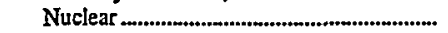 & 9 & 10,316 & 9,430 & 9,521 & 一 & - & - & 一 \\
\hline 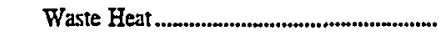 & 4 & 66 & 64 & 66 & 1 & 150 & 129 & 141 \\
\hline 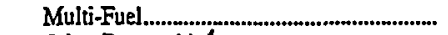 & - & - & 一 & - & 一 & - & - & - \\
\hline 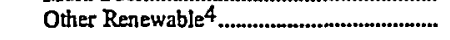 & - & 一 & - & 一 & 一 & - & - & 一 \\
\hline West South Central2 $2 \ldots \ldots \ldots$ & 804 & 109,184 & 104,555 & 104,852 & 22 & 5,656 & 5,220 & 5,342 \\
\hline Coal & 58 & 33,214 & 31,753 & 31,778 & 3 & 1,592 & 1,500 & 1,500 \\
\hline 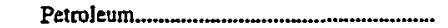 & 91 & 454 & 423 & 423 & - & - & - & - \\
\hline Gus & 510 & 63,062 & 60,519 & 60,848 & 15 & 3,991 & 3,652 & 3,774 \\
\hline \multicolumn{9}{|l|}{ Water (Pumped Storage } \\
\hline \multicolumn{9}{|l|}{ Water (Conventional } \\
\hline Hydroelectric) & 124 & 2,559 & 2,759 & 2,701 & 3 & 35 & 33 & 32 \\
\hline 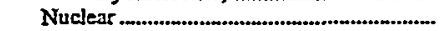 & 8 & 9,219 & 8,505 & 8,505 & - & - & 二 & - \\
\hline 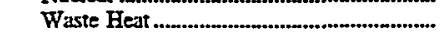 & 3 & 346 & 294 & 294 & 了 & 38 & 35 & 36 \\
\hline 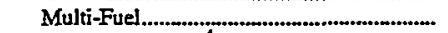 & - & - & - & - & - & - & - & - \\
\hline Other Renewable 4 & 2 & ] & 1 & 1 & 一 & - & - & - \\
\hline \multicolumn{9}{|l|}{ 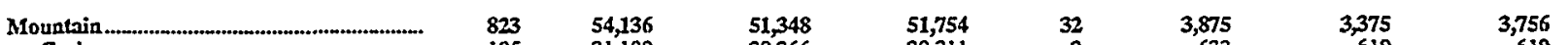 } \\
\hline 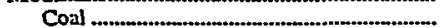 & 105 & 31,109 & 29,266 & 29,311 & 2 & 633 & 630 & 610 \\
\hline Petroleum & 109 & 601 & 548 & 601 & 1 & * & * & * \\
\hline Gas & 168 & 7,595 & 6,772 & 7,274 & 22 & 2,983 & 2,541 & 2,902 \\
\hline \multicolumn{9}{|l|}{ Water (Pumped Storage } \\
\hline \multirow{2}{*}{\multicolumn{9}{|c|}{ Water (Conventional }} \\
\hline & & & & & & & & \\
\hline Nuclear & $\begin{array}{r}4 \sqrt{4} \\
3\end{array}$ & $\begin{array}{l}9,099 \\
4,210\end{array}$ & $\begin{array}{r}10,013 \\
3,778\end{array}$ & 3,820 & -2 & - & $\underline{2}$ & $\underline{2}$ \\
\hline 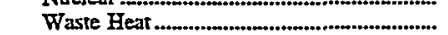 & 4 & 186 & 185 & 185 & $\overline{2}$ & $\overline{247}$ & 212 & 232 \\
\hline Multi-Fuel. & - & - & - & - & - & - & - & 二 \\
\hline Other Renewable 4 & 8 & 40 & 35 & 35 & 3 & 9 & 9 & 9 \\
\hline 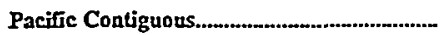 & 1,169 & 79,002 & 79,519 & 79,855 & 7 & 125 & 110 & 121 \\
\hline Coal & 5 & 2,070 & 1,898 & 1,898 & - & - & - & - \\
\hline 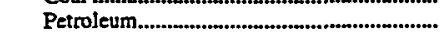 & 54 & 1,405 & 1,237 & 1,297 & - & - & - & - \\
\hline 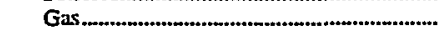 & 181 & 24,946 & 23,913 & 24,289 & 2 & 92 & 78 & 90 \\
\hline \multicolumn{9}{|l|}{ Water (Pumped Storage } \\
\hline Hydroelectric) & 35 & 3,612 & 3,991 & 3,985 & 一 & - & - & - \\
\hline Water (Conventional & & & & & & & & \\
\hline 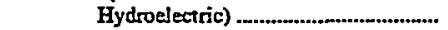 & 839 & 38,236 & 40,313 & 40,197 & 5 & 34 & 32 & 31 \\
\hline 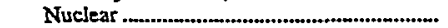 & 5 & 5,755 & 5,480 & 5,480 & - & - & - & - \\
\hline 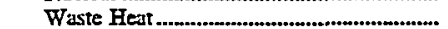 & 15 & 1,111 & 967 & 1,000 & - & - & - & - \\
\hline
\end{tabular}

See footnoter at end of table. 
Table 16. Existing Capacity and Planned Capacity Additions at U.S. Electric Utilities by Energy Source and Census Division, as of January 1, 1998 (Continued)

\begin{tabular}{|c|c|c|c|c|c|c|c|c|}
\hline \multirow[b]{2}{*}{$\begin{array}{c}\text { Census Division } \\
\text { Primary Energy } \\
\text { Source }\end{array}$} & \multicolumn{4}{|c|}{ Existing } & \multicolumn{4}{|c|}{ Planned Additions! } \\
\hline & $\begin{array}{l}\text { Number } \\
\text { of Units }\end{array}$ & $\begin{array}{l}\text { Generator } \\
\text { Nameplate } \\
\text { Capacity } \\
\text { (megawatts) }\end{array}$ & $\begin{array}{l}\text { Net Summer } \\
\text { Capability } \\
\text { (megawatts) }\end{array}$ & $\begin{array}{l}\text { Net Winter } \\
\text { Capability } \\
\text { (megawatts) }\end{array}$ & $\begin{array}{l}\text { Number } \\
\text { of Units }\end{array}$ & $\begin{array}{l}\text { Generator } \\
\text { Nameplate } \\
\text { Capacity } \\
\text { (megawatts) }\end{array}$ & $\begin{array}{l}\text { Net Summer } \\
\text { Capability } \\
\text { (megawatis) }\end{array}$ & $\begin{array}{l}\text { Net Winter } \\
\text { Capability } \\
\text { (megawatts) }\end{array}$ \\
\hline \multicolumn{9}{|l|}{ Pacific Contiguous (Continued) } \\
\hline 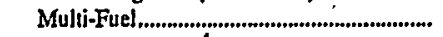 & - & - & - & - & - & 一 & - & 一 \\
\hline Other Renewable4 & 31 & 1,864 & 1,717 & 1,707 & - & 一 & 一 & 一 \\
\hline 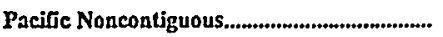 & 663 & 3,604 & 3,345 & 3,476 & 14 & 181 & 157 & 173 \\
\hline 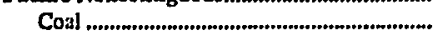 & 5 & 54 & 54 & 54 & - & - & - & - \\
\hline Petroleum.......................................................... & 561 & 2,249 & 2,149 & 2,189 & 8 & 144 & 125 & 138 \\
\hline Water (Pumped Storage & 30 & 810 & 674 & 753 & - & - & - & - \\
\hline 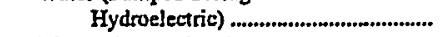 & $一$ & - & 一 & - & - & 一 & - & - \\
\hline Water (Conventional & & & & & & & & \\
\hline Hydroelectric) & 61 & 372 & 366 & 371 & 4 & 1 & 1 & 1 \\
\hline 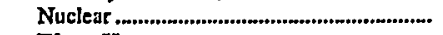 & - & - & - & - & - & - & - & - \\
\hline 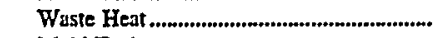 & 3 & 120 & 103 & 109 & 2 & 36 & 31 & 34 \\
\hline 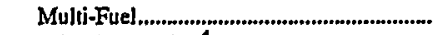 & - & - & - & - & - & 一 & 一 & 一 \\
\hline 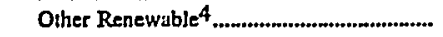 & 3 & $\star$ & * & * & 一 & 一 & - & - \\
\hline
\end{tabular}

1 Planned additions are for 1998 through 2007.

2 Existing capacity totals include a 13-megawatt expander turbine fueled by hot nitrogen.

3 Existing eapacity includes Commonwealth Edison Company's Zion I and 2 nuclear units which were retired from service in January 1998.

4 Includes geothermal, biomass (wood, wood waste, nonwood waste), solar, and wind.

* Less than 0.5 megawatts.

Notes: Total may not equal the sum of components because of independent rounding. *See Census division map in Appendix F. The Form EIA860 was revised during 1995 to collect dats as of January 1 of the reporting year, where "reporting year" is the calendar year in which the report is required to be filed with the Energy Information Administration. These data reflect the status of electric power plants/generators as of January l: however, dynamic data are based on occurtences in the previous calendar year (e.g., capabilities and energy sources based on test and consumption in the previous yest).

Source: Energy Information Administration, Form ElA-860, "Annual Electric Generator Report." 
Table 17. Existing Capacity and Planned Capacity Additions at U.S. Electric Utilities by Energy Source and State, as of January 1, 1998

\begin{tabular}{|c|c|c|c|c|c|c|c|c|}
\hline \multirow[b]{2}{*}{$\begin{array}{c}\text { State } \\
\text { Primary Energy } \\
\text { Source }\end{array}$} & \multicolumn{4}{|c|}{ Existing } & \multicolumn{4}{|c|}{ Planned Additions] } \\
\hline & $\begin{array}{l}\text { Number } \\
\text { of Units }\end{array}$ & $\begin{array}{c}\text { Generator } \\
\text { Nameplate } \\
\text { Capacity } \\
\text { (megawatts) }\end{array}$ & $\begin{array}{l}\text { Net Summer } \\
\text { Capability } \\
\text { (megawatts) }\end{array}$ & $\begin{array}{l}\text { Net Winter } \\
\text { Capability } \\
\text { (megawatts) }\end{array}$ & $\begin{array}{l}\text { Number } \\
\text { of Units }\end{array}$ & $\begin{array}{c}\text { Generator } \\
\text { Nameplate } \\
\text { Capacity } \\
\text { (megawatts) }\end{array}$ & $\begin{array}{l}\text { Net Summer } \\
\text { Capability } \\
\text { (megawatts) }\end{array}$ & $\begin{array}{c}\text { Net Winter } \\
\text { Capability } \\
\text { (megawatts) }\end{array}$ \\
\hline U.S. Total $2 \ldots \ldots . . . . . . . . . . .$. & 10,421 & 754,925 & 711,889 & 725,904 & 316 & 52,044 & 45,056 & 50,124 \\
\hline Coal & 1,198 & 325,001 & 302,866 & 304,914 & 8 & 2,559 & 2,444 & 2,444 \\
\hline 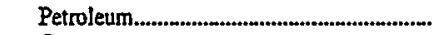 & 3,321 & 76,511 & 69,539 & 75,564 & 52 & 1,444 & 1,239 & 1,412 \\
\hline Gas & 2,148 & 147,260 & 136,957 & 141,933 & 212 & 46,181 & 39,679 & 44,476 \\
\hline $\begin{array}{l}\text { Hydroelectric) } \\
\text { Water (Conventional }\end{array}$ & 141 & 18,669 & 19,310 & 19,282 & 5 & 504 & 509 & 519 \\
\hline 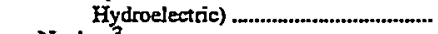 & 3,352 & 73,202 & 76,177 & 75,617 & 22 & 160 & 152 & 147 \\
\hline Nuclear ${ }^{3}$ & 107 & 107,632 & 99,716 & 100,896 & - & - & - & - \\
\hline Waste Heat & 60 & 4,130 & 4,979 & 5,360 & 11 & 1,174 & 1,012 & $\mathrm{I}, \mathrm{J} 03$ \\
\hline 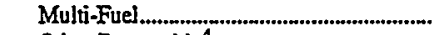 & 7 & 221 & 209 & 212 & - & - & - & - \\
\hline 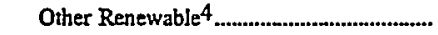 & 81 & 2,281 & 2,119 & 2,109 & 5 & 20 & 20 & 20 \\
\hline Alabama .......... & 157 & 22,242 & 20,840 & 20,993 & 10 & 1,800 & 1,548 & 1,701 \\
\hline Coal ....................... & 38 & 12,316 & 11,286 & 11,342 & - & - & - & - \\
\hline Petroleum............................... & ] & $2 \mathrm{I}$ & 16 & 20 & - & - & - & - \\
\hline 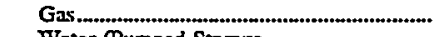 & 21 & 1,728 & 1,663 & 1,858 & 10 & 1,800 & 1,548 & 1,701 \\
\hline Water (Pumped Storage & & & & & & & & \\
\hline $\begin{array}{l}\text { Hydroelectric) .......... } \\
\text { Water (Conventional }\end{array}$ & - & - & - & - & - & - & - & - \\
\hline $\begin{array}{l}\text { Water (Conventional } \\
\text { Hydroelectric) }\end{array}$ & & & & & & & & \\
\hline 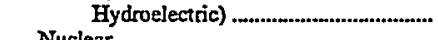 & 89 & 2,904 & 2,959 & 2,858 & - & - & - & - \\
\hline Nuclear & 5 & 5,233 & 4,873 & 4,873 & - & - & - & - \\
\hline Waste Heat ............................ & 3 & 40 & 43 & 43 & - & - & - & - \\
\hline 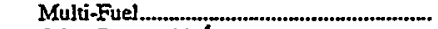 & - & - & - & - & - & - & - & - \\
\hline 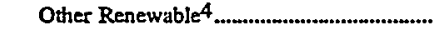 & - & - & - & - & - & - & - & - \\
\hline Alaska & 565 & 1,949 & 1,750 & 1,881 & 6 & 12 & 11 & 12 \\
\hline Coal & 5 & 54 & 54 & 54 & - & $\overline{1}$ & $\overline{-}$ & $\overline{-}$ \\
\hline 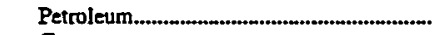 & 468 & 615 & 575 & 615 & 2 & 11 & 10 & 11 \\
\hline Gas & 30 & 810 & 674 & 753 & - & - & - & - \\
\hline Water (Pumped Storage & & & & & & & & \\
\hline $\begin{array}{l}\text { Hydroelectric) } \\
\text { Water (Conventional }\end{array}$ & - & - & - & - & - & - & - & - \\
\hline $\begin{array}{l}\text { Water (Conventional } \\
\text { Hydroelectric) }\end{array}$ & 57 & 369 & 362 & 368 & & I & 1 & 1 \\
\hline Nuclear & - & - & - & - & - & - & - & - \\
\hline 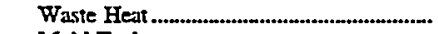 & 2 & 102 & 85 & 91 & - & - & - & - \\
\hline Multi-Fuel. & - & $=$ & - & $=$ & 一 & - & - & - \\
\hline 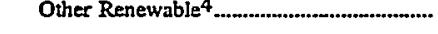 & 3 & * & * & * & 一 & - & - & - \\
\hline Arizona ... & 129 & 16,642 & 15,164 & 15,531 & 15 & 1,858 & 1,584 & 1,806 \\
\hline Coal & I4 & 5,749 & 5,256 & 5,256 & - & - & - & - \\
\hline 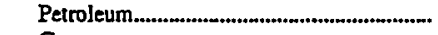 & 10 & 288 & 248 & 268 & - & - & - & - \\
\hline Gas & 54 & 3,503 & 2,989 & 3,294 & 12 & 1,849 & 1,575 & 1,797 \\
\hline Water (Pumped Storage & & & & & & & & \\
\hline Hydroelectric) ........ & 6 & 189 & 385 & 185 & - & - & - & - \\
\hline Water (Conventional & & & & & & & & \\
\hline 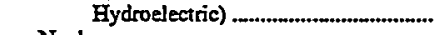 & 41 & 2,704 & 2,708 & 2,708 & - & - & - & - \\
\hline Nuclear & 3 & 4,210 & 3,778 & 3,820 & - & - & - & - \\
\hline Waste Heat & - & - & - & - & - & - & - & - \\
\hline Multi-Fuel. & - & - & - & - & $\rightarrow$ & - & - & - \\
\hline 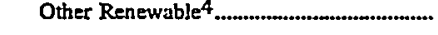 & 1 & * & * & - & 3 & 9 & 9 & 9 \\
\hline Arkansas. & 105 & 9,808 & 9,688 & 9,688 & 3 & 35 & 33 & 32 \\
\hline Coal & 5 & 3,911 & 3,865 & 3,865 & - & - & - & - \\
\hline 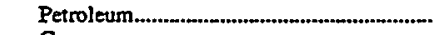 & 36 & 325 & 308 & 308 & - & - & - & - \\
\hline Gas & 19 & 2,530 & 2,494 & 2,494 & - & - & - & - \\
\hline $\begin{array}{l}\text { Water (Pumped Storage } \\
\text { Hydroelectric) }\end{array}$ & & & & & & & & \\
\hline $\begin{array}{l}\text { Hydroelectric) } \\
\text { Water (Conventional }\end{array}$ & 1 & 28 & 28 & 28 & - & - & - & - \\
\hline 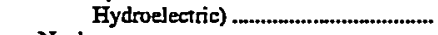 & 42 & 3,168 & 1,298 & 1,298 & 3 & 35 & 33 & 32 \\
\hline Nuclear & 2 & 1,845 & 1,694 & 1,694 & - & - & - & - \\
\hline Waste Heat & - & - & - & - & - & - & - & - \\
\hline 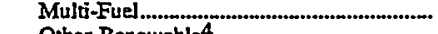 & - & - & - & - & - & - & - & - \\
\hline Other Renewable 4 & - & - & - & - & - & - & - & - \\
\hline Califoraia & 690 & 44,493 & 43,709 & 43,994 & 2 & 92 & 78 & 90 \\
\hline Coal & - & - & - & - & - & - & - & - \\
\hline
\end{tabular}

See footnotes at end of table. 
Table 17. Existing Capacity and Planned Capacity Additions at U.S. Electric Utilities by Energy Source and State, as of January 1, 1998 (Continued)

\begin{tabular}{|c|c|c|c|c|c|c|c|c|}
\hline \multirow[b]{2}{*}{$\begin{array}{c}\text { Slate } \\
\text { Primary Energy } \\
\text { Source }\end{array}$} & \multicolumn{4}{|c|}{ Existing } & \multicolumn{4}{|c|}{ Planned Additions! } \\
\hline & $\begin{array}{l}\text { Number } \\
\text { of Units }\end{array}$ & $\begin{array}{c}\text { Generator } \\
\text { Nameplate } \\
\text { Capacity } \\
\text { (megawatts) }\end{array}$ & $\begin{array}{l}\text { Net Summer } \\
\text { Capability } \\
\text { (megawatts) }\end{array}$ & $\begin{array}{l}\text { Net Winter } \\
\text { Capability } \\
\text { (megawatts) }\end{array}$ & $\begin{array}{l}\text { Number } \\
\text { of Units }\end{array}$ & $\begin{array}{c}\text { Generator } \\
\text { Namephte } \\
\text { Capacity } \\
\text { (megawatts) }\end{array}$ & $\begin{array}{l}\text { Net Summer } \\
\text { Capability } \\
\text { (miegawatts) }\end{array}$ & $\begin{array}{c}\text { Net Winter } \\
\text { Copability } \\
\text { (megawatts) }\end{array}$ \\
\hline \multicolumn{9}{|l|}{ California (Continued) } \\
\hline Water (Pumped Storage & $\begin{array}{l}48 \\
166\end{array}$ & $\begin{array}{r}1,226 \\
23,447\end{array}$ & $\begin{array}{l}1,072 \\
22,581\end{array}$ & $\begin{array}{r}1,109 \\
22,804\end{array}$ & $\overline{2}$ & $\overline{92}$ & $\overline{78}$ & $\overline{90}$ \\
\hline 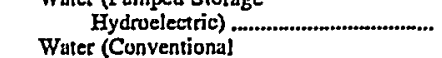 & 30 & 3,352 & 3,730 & 3,724 & - & - & - & - \\
\hline Hydruelectric) ............................................ & 404 & 9,515 & 9,807 & 9,821 & - & - & - & - \\
\hline 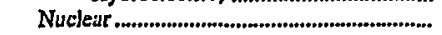 & 4 & 4,555 & 4,310 & 4,310 & - & - & - & - \\
\hline Waste Heat......................................................... & 12 & 681 & 613 & 628 & - & - & - & - \\
\hline Multi-Fuel.................................................... & - & - & - & - & - & - & - & - \\
\hline 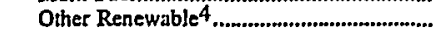 & 26 & 1,717 & 1,597 & 1,597 & - & - & - & - \\
\hline Colorado.......... & 164 & 6,979 & 6,850 & 6,912 & 6 & 562 & 482 & 535 \\
\hline 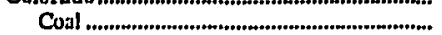 & 31 & 5,126 & 4,954 & 4,954 & - & - & - & - \\
\hline 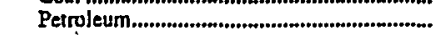 & 50 & 175 & 177 & $\begin{aligned} 204 \\
204\end{aligned}$ & $\overline{1}$ & 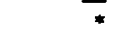 & 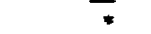 & * \\
\hline 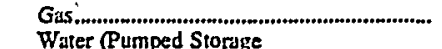 & 35 & 555 & 541 & 588 & 3 & 315 & 269 & 303 \\
\hline 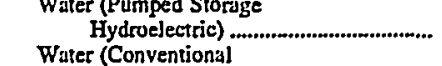 & 5 & 509 & 563 & 563 & - & - & - & - \\
\hline 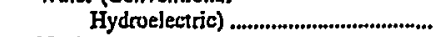 & 43 & 616 & 615 & 604 & - & - & - & - \\
\hline Nuclear & - & - & - & - & - & - & - & - \\
\hline Waste Heat .................................................. & - & - & - & - & 2 & 247 & 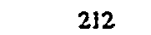 & 232 \\
\hline 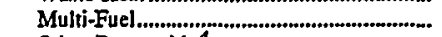 & - & - & - & - & - & - & - & - \\
\hline Other Renewable & - & - & - & $一$ & - & - & - & - \\
\hline 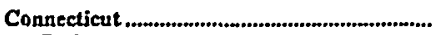 & 84 & 6,609 & 6,294 & 6,533 & - & - & - & - \\
\hline 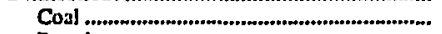 & 1 & 400 & 385 & 400 & - & - & - & - \\
\hline 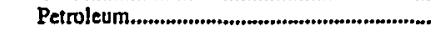 & 40 & 2,879 & 2,801 & 2,944 & - & - & - & - \\
\hline 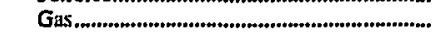 & 6 & 373 & 341 & 381 & - & - & - & - \\
\hline $\begin{array}{l}\text { Water (Pumped Siorage } \\
\text { Hydroelectric) }\end{array}$ & & & & & & & & \\
\hline $\begin{array}{l}\text { Hydroelectric) } \\
\text { Water (Conventional }\end{array}$ & 2 & 7 & 6 & 6 & - & - & - & - \\
\hline 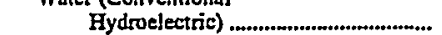 & 32 & 125 & 130 & 134 & - & - & - & - \\
\hline 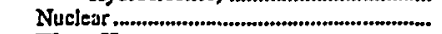 & 3 & 2,824 & 2,631 & 2,668 & - & - & - & - \\
\hline Waste Heat ............................................... & - & - & - & - & - & - & - & - \\
\hline Multi-Fuel................................................. & - & - & - & - & - & - & - & - \\
\hline Other Renewable & - & - & - & - & - & - & - & - \\
\hline 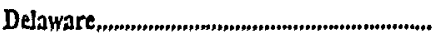 & 30 & 2,293 & 2,277 & 2,343 & 2 & 178 & 151 & 174 \\
\hline 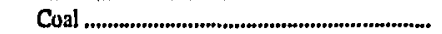 & 6 & 1,034 & 1,019 & 1,027 & - & - & - & - \\
\hline 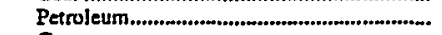 & 20 & 788 & & 775 & - & - & - & - \\
\hline 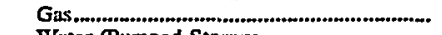 & 3 & 331 & 336 & 366 & 2 & 178 & 151 & 174 \\
\hline $\begin{array}{l}\text { Water (Pumped Storage } \\
\text { Hydroelectric) }\end{array}$ & - & 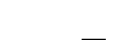 & - & - & - & - & 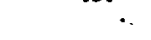 & - \\
\hline 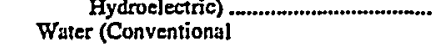 & - & - & - & - & - & - & - & - \\
\hline 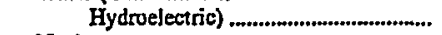 & - & - & - & - & - & - & - & - \\
\hline Nuclear & - & - & - & - & - & - & - & - \\
\hline 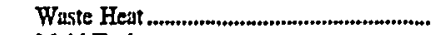 & 1 & 160 & 175 & 175 & - & - & - & - \\
\hline 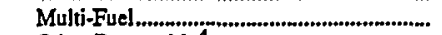 & - & - & - & - & - & - & - & - \\
\hline 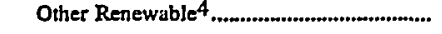 & - & - & - & - & - & - & - & - \\
\hline Distriet of Columbia ............................................. & 4 & 868 & 806 & 870 & - & - & - & - \\
\hline 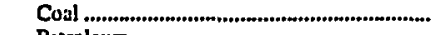 & - & 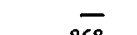 & $\overline{0}$ & & - & - & - & - \\
\hline 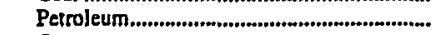 & 4 & 868 & 806 & 870 & - & - & - & - \\
\hline Gas, & - & - & - & - & - & - & - & - \\
\hline Water (Pumped Storage & 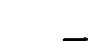 & - & 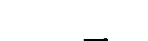 & - & 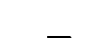 & & 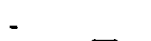 & \\
\hline $\begin{array}{l}\text { Hydroelectric) } \\
\text { Water (Conventiona! }\end{array}$ & - & - & - & - & - & - & - & - \\
\hline 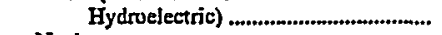 & - & - & - & - & - & - & - & - \\
\hline Nuclear & - & - & - & - & - & - & - & - \\
\hline 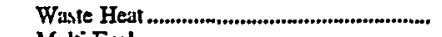 & - & - & - & - & - & - & - & - \\
\hline 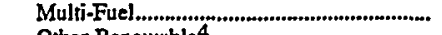 & - & - & - & - & - & - & - & - \\
\hline 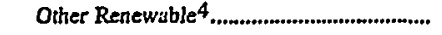 & - & - & - & - & - & - & - & - \\
\hline Florida & 348 & 40,379 & 36,727 & 38,595 & 34 & 8,958 & 7,705 & 8,531 \\
\hline 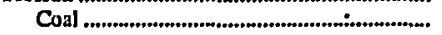 & 31 & 11,798 & 10,823 & 10,965 & j & 383 & 183 & 183 \\
\hline
\end{tabular}

See footnotes at end of table. 


\section{Table 17. Existing Capacity and Planned Capacity Additions at U.S. Electric Utilities by Energy Source and State, as of January 1, 1998 (Continued)}

\begin{tabular}{|c|c|c|c|c|c|c|c|c|}
\hline \multirow[b]{2}{*}{$\begin{array}{c}\text { State } \\
\text { Primary Energy } \\
\text { Source }\end{array}$} & \multicolumn{4}{|c|}{ Existing } & \multicolumn{4}{|c|}{ Planned Additions! } \\
\hline & $\begin{array}{l}\text { Number } \\
\text { of Units }\end{array}$ & $\begin{array}{l}\text { Generator } \\
\text { Nameplate } \\
\text { Capacity } \\
\text { (megawatts) }\end{array}$ & $\begin{array}{l}\text { Net Summer } \\
\text { Capability } \\
\text { (megawatts) }\end{array}$ & $\begin{array}{l}\text { Net Winter } \\
\text { Capability } \\
\text { (megawatts) }\end{array}$ & $\begin{array}{l}\text { Number } \\
\text { of Units }\end{array}$ & $\begin{array}{l}\text { Generator } \\
\text { Nameplate } \\
\text { Capacity } \\
\text { (megawatts) }\end{array}$ & $\begin{array}{l}\text { Net Summer } \\
\text { Capability } \\
\text { (megawatts) }\end{array}$ & $\begin{array}{c}\text { Net Winter } \\
\text { Capability } \\
\text { (megawatts) }\end{array}$ \\
\hline \multicolumn{9}{|l|}{ Florida (Continued) } \\
\hline 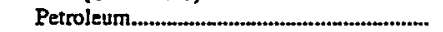 & 154 & 14,962 & 13,493 & 14,326 & 3 & 45 & 38 & 44 \\
\hline Waster Pumped Storage & 136 & 8,323 & 6,075 & 6,560 & 28 & 8,446 & 7,239 & 8,036 \\
\hline $\begin{array}{l}\text { Hydroelectic) } \\
\text { Water (Conventiongl }\end{array}$ & $\longrightarrow$ & 一 & 一 & 一 & - & - & - & - \\
\hline Hydroelectric) & 6 & 42 & 47 & 47 & - & - & - & - \\
\hline 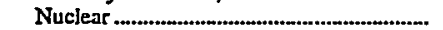 & 5 & 4,110 & 3,876 & 3,975 & - & - & - & - \\
\hline 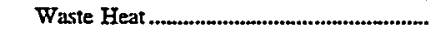 & 15 & 1,140 & 2,410 & 2,719 & 2 & 285 & 245 & 268 \\
\hline Multi-Fuel & - & - & - & - & - & - & - & - \\
\hline 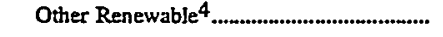 & 1 & 3 & 3 & 3 & - & - & - & - \\
\hline Georgia & 215 & 24,613 & 23,147 & 23,617 & 10 & 5,100 & 4,416 & 4,881 \\
\hline Coal & 39 & 14,549 & 13,222 & 13,222 & - & - & - & - \\
\hline 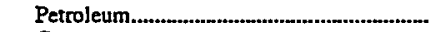 & 30 & 1,386 & 1,228 & 1,525 & - & - & - & - \\
\hline 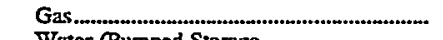 & 25 & 1,345 & 1,281 & 1,438 & 6 & 4,800 & 4,113 & 4,572 \\
\hline $\begin{array}{l}\text { Water (Pumped Storage } \\
\text { Hydroelectric) } \\
\text { Water (Conventional }\end{array}$ & 5 & 1,098 & 1,124 & 1,124 & 4 & 300 & 303 & 309 \\
\hline Hydroelectric) & 112 & 2,193 & 2,337 & 2,353 & - & - & - & - \\
\hline Nuclear & 4 & 4,042 & 3,955 & 3,955 & - & 一 & - & - \\
\hline 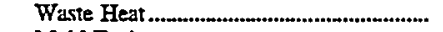 & 一 & - & - & - & - & - & - & - \\
\hline 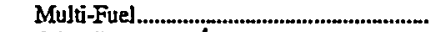 & - & - & - & - & - & - & - & - \\
\hline 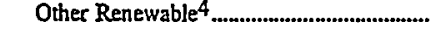 & 一 & - & - & 一 & 一 & 一 & 一 & 一 \\
\hline 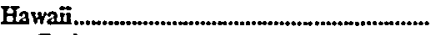 & 98 & 1,655 & 1,595 & 1,595 & 8 & 170 & 145 & 161 \\
\hline 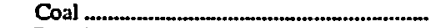 & - & - & - & - & - & - & - & - \\
\hline 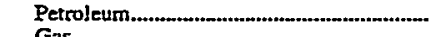 & 93 & 1,634 & 1,574 & 1,574 & 6 & 134 & 114 & 127 \\
\hline Gas & 一 & - & - & - & - & - & - & - \\
\hline Water (Pumped Storage & & & & & & & & \\
\hline Hydroelectric) & - & 一 & 一 & 一 & 一 & 一 & - & 一 \\
\hline Water (Conventional & & & & & & & & \\
\hline Hydroelectric) ...................................... & 4 & 3 & 3 & 3 & - & 一 & - & 一 \\
\hline Nuclear & $\longrightarrow$ & $\overline{10}$ & - & $\overline{10}$ & - & $\overline{a s}$ & $\overline{21}$ & $\overline{2}$ \\
\hline 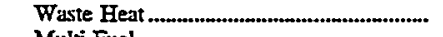 & 1 & 18 & 18 & 18 & 2 & 36 & 31 & 34 \\
\hline 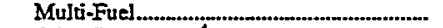 & - & - & - & - & - & - & - & - \\
\hline 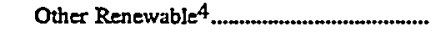 & - & - & - & - & 一 & 一 & 一 & - \\
\hline Idaho & 110 & 2,393 & 2,576 & 2,451 & - & - & - & - \\
\hline Coal & - & - & - & - & - & - & - & - \\
\hline 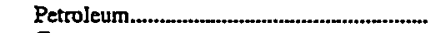 & 2 & 5 & 6 & 6 & - & - & - & - \\
\hline Gas & 2 & 167 & 136 & 176 & - & - & - & - \\
\hline Water (Pumped Storage & & & & & & & & \\
\hline $\begin{array}{l}\text { Hydroelectric) } \\
\text { Water (Conventional }\end{array}$ & - & - & - & 一 & 一 & - & - & - \\
\hline $\begin{array}{l}\text { Water (Conventional } \\
\text { Hydroelectric) }\end{array}$ & 106 & 2,221 & 2,435 & 2,269 & - & - & - & - \\
\hline Nuclear & - & - & - & - & - & - & - & - \\
\hline 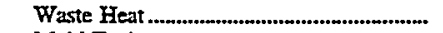 & 一 & - & 一 & - & 一 & - & - & - \\
\hline 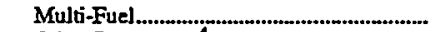 & 一 & 一 & - & - & - & 一 & - & - \\
\hline Other Renewable $4 \ldots \ldots$ & - & 一 & - & 一 & - & $\omega$ & - & - \\
\hline Illinois & 334 & 37,130 & 33,549 & 34,270 & 30 & 4,961 & 4,218 & 4,862 \\
\hline Coal & 58 & 17,220 & 15,339 & 15,446 & - & - & - & - \\
\hline Petroleum. & 125 & 3,020 & 2,671 & 2,868 & l & 5 & 5 & 5 \\
\hline Gas & 126 & 3,141 & 2,917 & 3,116 & 29 & 4,957 & 4,213 & 4,857 \\
\hline Water (Pumped Storage & & & & & & & & \\
\hline 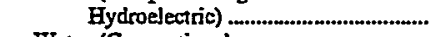 & 一 & - & - & - & - & 一 & 一 & 一 \\
\hline Water (Conventional & & & & & & & & \\
\hline 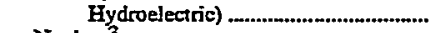 & 12 & 14 & 13 & 13 & - & - & - & - \\
\hline Nuclear ${ }^{3}$ & 13 & 13,734 & 12,609 & 12,826 & - & - & - & 一 \\
\hline 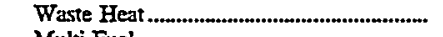 & 一 & - & - & - & - & 一 & - & - \\
\hline 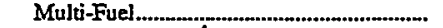 & - & - & - & - & - & - & - & - \\
\hline 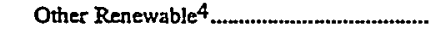 & 一 & - & - & - & - & - & - & - \\
\hline Indiana & 157 & 22,485 & 20,200 & 20,531 & 18 & 4,662 & 3,963 & 4,569 \\
\hline Coal & 75 & 20,366 & 18,426 & 18,550 & - & - & - & - \\
\hline
\end{tabular}

See footnotes at end of table. 
Table 17. Existing Capacity and Planned Capacity Additions at U.S. Electric Utilities by Energy Source and State, as of January 1, 1998 (Continued)

\begin{tabular}{|c|c|c|c|c|c|c|c|c|}
\hline \multirow[b]{2}{*}{$\begin{array}{c}\text { State } \\
\text { Primary Energy } \\
\text { Source }\end{array}$} & \multicolumn{4}{|c|}{ Existing } & \multicolumn{4}{|c|}{ Phanned Additions I } \\
\hline & $\begin{array}{l}\text { Number } \\
\text { of Units }\end{array}$ & $\begin{array}{c}\text { Generator } \\
\text { Nameplate } \\
\text { Capacity } \\
\text { (megawatts) }\end{array}$ & $\begin{array}{l}\text { Net Summer } \\
\text { Capability } \\
\text { (megawatts) }\end{array}$ & $\begin{array}{l}\text { Net Winter } \\
\text { Capability } \\
\text { (megawatts) }\end{array}$ & $\begin{array}{l}\text { Number } \\
\text { of Units }\end{array}$ & $\begin{array}{c}\text { Generator } \\
\text { Namephte } \\
\text { Capacity } \\
\text { (megawatts) }\end{array}$ & $\begin{array}{l}\text { Net Summer } \\
\text { Capability } \\
\text { (megawatts) }\end{array}$ & $\begin{array}{l}\text { Net Winter } \\
\text { Capability } \\
\text { (megawatts) }\end{array}$ \\
\hline \multicolumn{9}{|l|}{ Indians (Continued) } \\
\hline 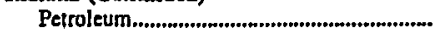 & 37 & 519 & 486 & 539 & - & - & - & - \\
\hline Gat, & 24 & 1,510 & 1,230 & 1,383 & 18 & 4,662 & 3,963 & 4,569 \\
\hline $\begin{array}{l}\text { Water (Pumped Storage } \\
\text { Hydroelectric) } \\
\text { Water (Conventional }\end{array}$ & - & - & - & - & - & 一 & - & 一 \\
\hline Hydroejectric) & 21 & 89 & 59 & 59 & - & - & - & - \\
\hline Nuclear & - & - & - & 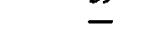 & 二 & $=$ & - & - \\
\hline Waste Heat ...................................................... & - & - & - & - & - & - & 一 & 一 \\
\hline 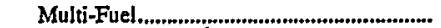 & - & $\rightarrow$ & - & - & - & - & - & - \\
\hline 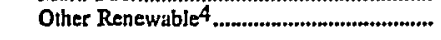 & - & - & - & - & 一 & - & 一 & 一 \\
\hline 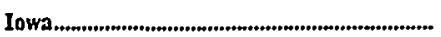 & 403 & 8,867 & 8,238 & 8,429 & 6 & 19 & 18 & 18 \\
\hline 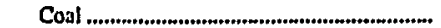 & 42 & 5,829 & 5,573 & 5,568 & - & - & - & - \\
\hline 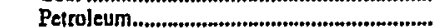 & 254 & 994 & 872 & 1,009 & 6 & 19 & 18 & 18 \\
\hline GuS..............., & 67 & 1,068 & 892 & 953 & - & - & - & - \\
\hline Water (Pumped Storage & & & & & & & & \\
\hline $\begin{array}{l}\text { Hydroelectric) ..................................... } \\
\text { Water (Conventional }\end{array}$ & 一 & 一 & 一 & 一 & - & - & - & 一 \\
\hline 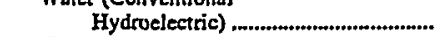 & 28 & 135 & 136 & 135 & - & - & - & - \\
\hline 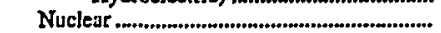 & 1 & 597 & 535 & 535 & - & 二 & - & - \\
\hline 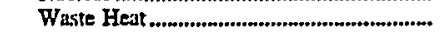 & 3 & 23 & 2] & 18 & - & - & 一 & 一 \\
\hline 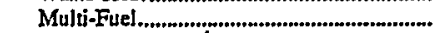 & 7 & 221 & 209 & 212 & - & - & ـ & - \\
\hline 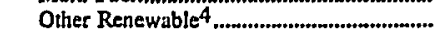 & j & * & 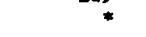 & 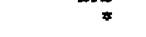 & 一 & 一 & 一 & - \\
\hline 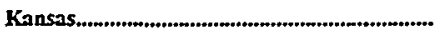 & 415 & 10,466 & 9,786 & 9,871 & 3 & 117 & 99 & 114 \\
\hline Coal & 20 & 5,691 & 5,364 & 5,373 & 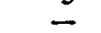 & - & - & 114 \\
\hline 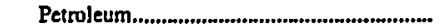 & 212 & 59] & 510 & 525 & 2 & 1 & I & 1 \\
\hline 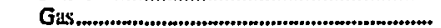 & 182 & 2,949 & 2,749 & 2,786 & l & 116 & 98 & 113 \\
\hline Water (Pumped Storage & & & & & & & & \\
\hline $\begin{array}{l}\text { Hydruelectric) ............................................. } \\
\text { Water (Conventional }\end{array}$ & 一 & - & - & - & - & - & 一 & 一 \\
\hline 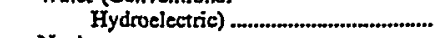 & 一 & - & 一 & - & 一 & $\longrightarrow$ & 一 & - \\
\hline 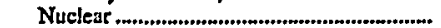 & .1 & 1,236 & 1,163 & I, 187 & - & - & - & - \\
\hline Waste Heat & - & - & - & - & - & - & - & 一 \\
\hline 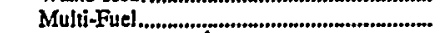 & - & - & - & - & - & - & - & 一 \\
\hline Other Renewable ${ }^{4} \ldots$ & - & - & - & - & 一 & 一 & - & 一 \\
\hline 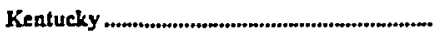 & 113 & 17,728 & 15,660 & 15,910 & 20 & 2,846 & 2,431 & 2,742 \\
\hline Coal & 58 & 16,098 & 14,135 & 34,331 & - & - & - & - \\
\hline 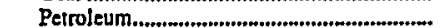 & 15 & 228 & 186 & 200 & - & - & - & - \\
\hline 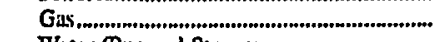 & 10 & 632 & 548 & 610 & 19 & 2,696 & 2,302 & 2,601 \\
\hline Water (Pumped Storage & & & & & & & & \\
\hline Hydroelectric) & 一 & 一 & - & - & 一 & - & 一 & - \\
\hline Water (Conventional & & & & & & & & \\
\hline 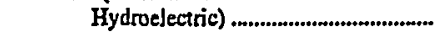 & 30 & 770 & 791 & 768 & 一 & - & - & - \\
\hline 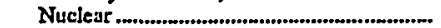 & - & - & - & - & - & - & - & - \\
\hline 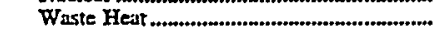 & - & - & - & - & 1 & 150 & 129 & 141 \\
\hline 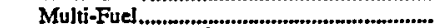 & - & - & - & - & - & - & - & - \\
\hline 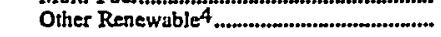 & - & - & - & - & - & 二 & - & 一 \\
\hline 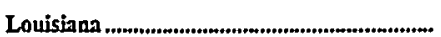 & 110 & 18,469 & 17,079 & 17,080 & 3 & 287 & 247 & 280 \\
\hline 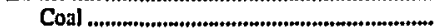 & 6 & 3,726 & 3,453 & 3,453 & - & - & - & - \\
\hline 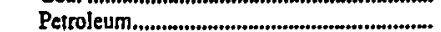 & j & 16 & 16 & 16 & - & - & - & - \\
\hline GuS, & 101 & 12,491 & 11,599 & 11,600 & 2 & 249 & 212 & 244 \\
\hline Water (Pumped Storage & & & & & & & & \\
\hline $\begin{array}{l}\text { Hydroelectric) } \\
\text { Water (Conventional }\end{array}$ & - & - & - & - & 一 & 一 & 一 & - \\
\hline 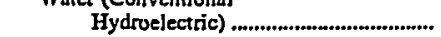 & - & - & - & - & - & 一 & - & - \\
\hline Nuclear & 2 & 2,236 & 2,011 & 2,011 & - & - & - & - \\
\hline 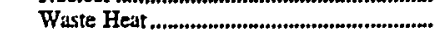 & 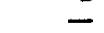 & - & - & - & 1 & 38 & 35 & 36 \\
\hline Multi-Fuel, & - & 一 & - & - & - & - & - & - \\
\hline 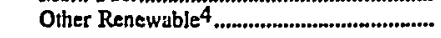 & - & 一 & - & - & - & 一 & - & - \\
\hline 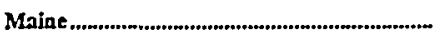 & 185 & 1,501 & 1,498 & 1,532 & $\mathbf{s}$ & 45 & 43 & 42 \\
\hline 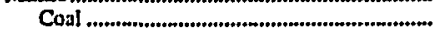 & - & - & - & - & - & - & - & - \\
\hline
\end{tabular}

See footnotes at end of table. 
Table 17. Existing Capacity and Planned Capacity Additions at U.S. Electric Utilities by Energy Source and State, as of January 1, 1998 (Continued)

\begin{tabular}{|c|c|c|c|c|c|c|c|c|}
\hline \multirow[b]{2}{*}{$\begin{array}{c}\text { State } \\
\text { Primary Energy } \\
\text { Source }\end{array}$} & \multicolumn{4}{|c|}{ Existing } & \multicolumn{4}{|c|}{ Planned Additions $\mathbf{I}$} \\
\hline & $\begin{array}{l}\text { Number } \\
\text { of Units }\end{array}$ & $\begin{array}{c}\text { Generator } \\
\text { Nameplate } \\
\text { Capacity } \\
\text { (megawatts) }\end{array}$ & $\begin{array}{c}\text { Net Summer } \\
\text { Capability } \\
\text { (megawatts) }\end{array}$ & $\begin{array}{l}\text { Net Winter } \\
\text { Capability } \\
\text { (megawatts) }\end{array}$ & $\begin{array}{l}\text { Number } \\
\text { of Units }\end{array}$ & $\begin{array}{c}\text { Generator } \\
\text { Nameplate } \\
\text { Capacity } \\
\text { (megawatts) }\end{array}$ & $\begin{array}{l}\text { Net Summer } \\
\text { Capability } \\
\text { (megawatts) }\end{array}$ & $\begin{array}{l}\text { Net Winles } \\
\text { Capability } \\
\text { (megawatts) }\end{array}$ \\
\hline \multicolumn{9}{|l|}{ Maine (Continued) } \\
\hline 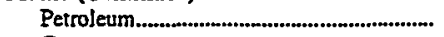 & 43 & 1,089 & 1,064 & 1,085 & 一 & 一 & 一 & - \\
\hline $\begin{array}{l}\text { Gas } \\
\text { Water (Pumped Storage }\end{array}$ & 一 & - & 一 & 一 & - & - & 一 & 一 \\
\hline 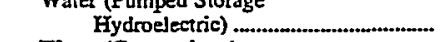 & 一 & - & - & - & - & 一 & - & - \\
\hline Water (Conventional & & & & & & & & \\
\hline Hydroelectric) & 141 & 380 & 404 & 418 & 5 & 45 & 43 & 42 \\
\hline 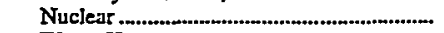 & - & - & - & $\longrightarrow$ & - & - & 一 & - \\
\hline 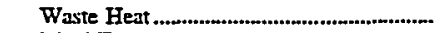 & - & - & $\longrightarrow$ & - & - & 一 & 一 & 一 \\
\hline 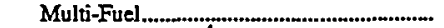 & - & - & - & - & - & - & - & - \\
\hline Other Renewable 4 & 1 & 32 & 30 & 30 & - & - & $一$ & - \\
\hline 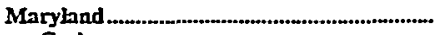 & 105 & 11,892 & 11,101 & 11,510 & 10 & 1,411 & 1,213 & 1,336 \\
\hline Coal & 15 & 4,943 & 4,647 & 4,703 & - & - & - & - \\
\hline 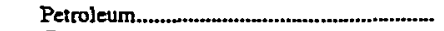 & 52 & 2,830 & 2,631 & 2,752 & 3 & 226 & 193 & 221 \\
\hline Gas & 23 & 1,797 & $1,6] 8$ & 1,793 & 4 & 768 & 660 & 722 \\
\hline \multicolumn{9}{|l|}{ Water (Pumped Storage } \\
\hline Hydroelectric) ....................................... & - & - & - & - & - & - & - & - \\
\hline \multicolumn{9}{|l|}{ Water (Conventional } \\
\hline Hydroelectric) & 13 & 494 & 530 & 531 & - & - & 一 & - \\
\hline Nuclear & 2 & 1,829 & 1,675 & 1,730 & - & - & - & - \\
\hline 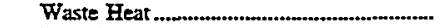 & - & - & - & - & 3 & 418 & 359 & 393 \\
\hline 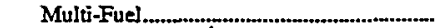 & - & - & - & - & - & - & - & - \\
\hline 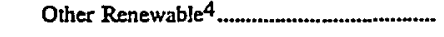 & 一 & 一 & 一 & - & - & - & - & - \\
\hline 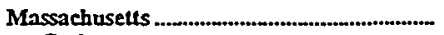 & 191 & 9,706 & 9,442 & 9,847 & 3 & 125 & 108 & 118 \\
\hline Coal & 9 & 1,764 & 1,737 & 1,783 & 二 & - & - & - \\
\hline 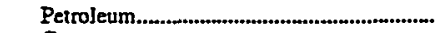 & 95 & 4,525 & 4,094 & 4,345 & 2 & 5 & 5 & 5 \\
\hline Gas & 13 & 984 & 976 & 1,020 & 1 & 120 & 103 & 113 \\
\hline \multicolumn{9}{|l|}{ Water (Pumped Storage } \\
\hline 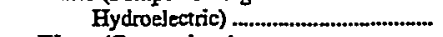 & 6 & 1,446 & 1,652 & 1,705 & 一 & 一 & 一 & 一 \\
\hline \multicolumn{9}{|l|}{ Water (Conventional } \\
\hline Hydroelectric) & 57 & 201 & 203 & 208 & - & - & - & 一 \\
\hline Nuclear & 1 & 655 & 669 & 669 & $\longrightarrow$ & - & - & - \\
\hline 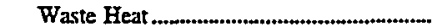 & 2 & 130 & 110 & 117 & - & - & - & - \\
\hline 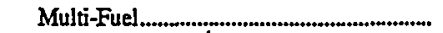 & - & - & - & - & - & 一 & - & 一 \\
\hline Other Renewable 4 & 8 & - & $\$$ & 1 & 一 & 一 & - & - \\
\hline 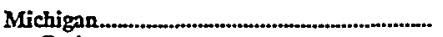 & 556 & 23,917 & 21,909 & 22,296 & - & $\longrightarrow$ & 一 & 一 \\
\hline Coal & 75 & 12,892 & 11,796 & {$[1,84]$} & 一 & 一 & - & - \\
\hline Petroleum & 169 & 2,883 & 2,617 & 2,716 & - & - & - & - \\
\hline 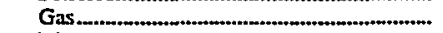 & 79 & 1,570 & 1,445 & 1,597 & - & - & - & - \\
\hline \multicolumn{9}{|l|}{ Water (Pumped Storage } \\
\hline \multirow{2}{*}{\multicolumn{9}{|c|}{$\begin{array}{l}\text { Hydroelectric) } \\
\text { Water (Conventional }\end{array}$}} \\
\hline & & & & & & & & \\
\hline Hydroelectric) & 223 & 343 & 257 & 265 & - & - & - & - \\
\hline 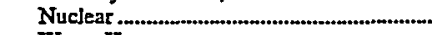 & 4 & 4,251 & 3,922 & 4,004 & - & 一 & - & 一 \\
\hline Waste Heat & - & - & - & - & - & - & - & 一 \\
\hline 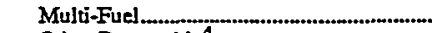 & - & - & - & - & 一 & 一 & 一 & 一 \\
\hline Other Renewable 4 & - & - & - & - & - & 一 & - & 一 \\
\hline \multicolumn{9}{|l|}{ Minnesota } \\
\hline Coal & 42 & 5,833 & 5,811 & 5,802 & - & - & - & 一 \\
\hline 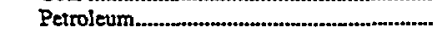 & 162 & 1,206 & 1,102 & 1,319 & 3 & 5 & 5 & 5 \\
\hline 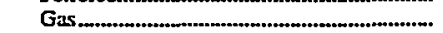 & 66 & 502 & 454 & 465 & 1 & 3 & 3 & 3 \\
\hline \multicolumn{9}{|l|}{ Water (Pumped Storage } \\
\hline Hydroelectric) & 一 & - & - & 一 & 一 & - & - & - \\
\hline \multicolumn{9}{|l|}{ Water (Conventiona] } \\
\hline 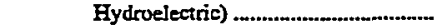 & 54 & 142 & 142 & 142 & $\rightarrow$ & - & - & - \\
\hline Nuclear & 3 & 1,751 & 1,572 & 1,626 & - & - & - & - \\
\hline 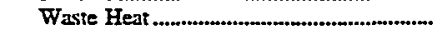 & 1 & 12 & 10 & 10 & - & 一 & 一 & - \\
\hline 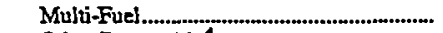 & - & $\rightarrow$ & - & - & - & 一 & - & - \\
\hline Other Renewable 4 & 12. & 134 & 126 & 126 & - & - & 一 & 一 \\
\hline Mississippi & 54 & 7,381 & 7,159 & 7,203 & 7 & 789 & 680 & 742 \\
\hline Coal & 6 & 2,150 & 2,130 & 2,130 & - & - & - & - \\
\hline
\end{tabular}

See footnotes at end of table. 
Table 17. Existing Capacity and Planned Capacity Additions at U.S. Electric Utilities by Energy Source and State, as of January 1, 1998 (Continued)

\begin{tabular}{|c|c|c|c|c|c|c|c|c|}
\hline \multirow[b]{2}{*}{$\begin{array}{c}\text { State } \\
\text { Primary Energy } \\
\text { Source }\end{array}$} & \multicolumn{4}{|c|}{ Existing } & \multicolumn{4}{|c|}{ Planned Additions! } \\
\hline & $\begin{array}{l}\text { Number } \\
\text { of Units }\end{array}$ & $\begin{array}{c}\text { Generator } \\
\text { Nameplate } \\
\text { Capacity } \\
\text { (megawatts) }\end{array}$ & $\begin{array}{l}\text { Net Summer } \\
\text { Capability } \\
\text { (megawatts) }\end{array}$ & $\begin{array}{l}\text { Net Winter } \\
\text { Capability } \\
\text { (megawatts) }\end{array}$ & $\begin{array}{l}\text { Number } \\
\text { of Units }\end{array}$ & $\begin{array}{c}\text { Generator } \\
\text { Namephte } \\
\text { Capacily } \\
\text { (megawatts) }\end{array}$ & $\begin{array}{l}\text { Net Summer } \\
\text { Capability } \\
\text { (megawatls) }\end{array}$ & $\begin{array}{l}\text { Net Winter } \\
\text { Capability } \\
\text { (nlegawatts) }\end{array}$ \\
\hline \multicolumn{9}{|l|}{ Mississippi (Continued) } \\
\hline 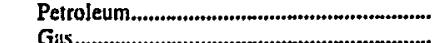 & 2 & 30 & 31 & 31 & 5 & 9 & 9 & 99 \\
\hline Wals...n. Pumped Storage & 44 & 3,803 & 3,776 & 3,819 & 2 & 780 & 671 & 733 \\
\hline $\begin{array}{l}\text { Hydroelectic)....... } \\
\text { Water (Conventiona! }\end{array}$ & - & - & - & - & - & - & - & - \\
\hline Hydroelectric) ........................................ & - & - & - & - & - & - & - & - \\
\hline 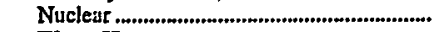 & 1 & 1,373 & $\$, 200$ & 1,200 & - & - & - & - \\
\hline 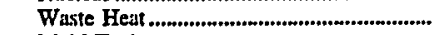 & i & 26 & 21 & 23 & - & - & - & - \\
\hline 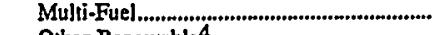 & - & - & - & - & - & - & - & - \\
\hline 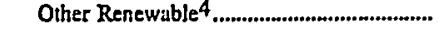 & - & - & - & - & - & - & - & - \\
\hline 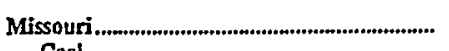 & 344 & 17,481 & 16,212 & 16,349 & 10 & 996 & 880 & 986 \\
\hline 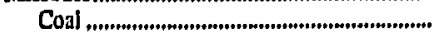 & 48 & 11,727 & 10,920 & 30,968 & - & - & - & - \\
\hline 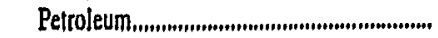 & 179 & 1,277 & 1,200 & 1,295 & 4 & 145 & 124 & 142 \\
\hline 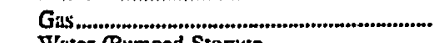 & 87 & 2,142 & 1,839 & 1,884 & 5 & 647 & 550 & 634 \\
\hline \multicolumn{9}{|l|}{ Water (Pumped Stordge } \\
\hline \multicolumn{9}{|l|}{ Water (Conventional } \\
\hline Hydroelectric) & 20 & 499 & 543 & 536 & - & - & - & - \\
\hline 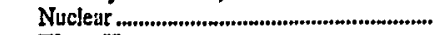 & $\mathrm{J}$ & 1,236 & 1,143 & 1,174 & - & - & - & - \\
\hline 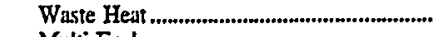 & - & - & - & - & - & - & - & - \\
\hline 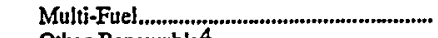 & - & - & - & - & - & - & - & - \\
\hline 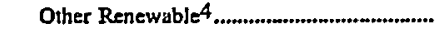 & - & - & - & - & - & - & - & - \\
\hline \multicolumn{9}{|l|}{ 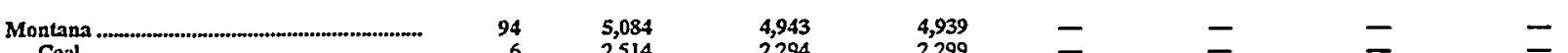 } \\
\hline 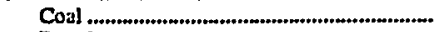 & 6 & 2,514 & 2,294 & 2,299 & - & - & - & - \\
\hline 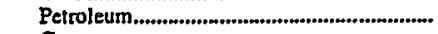 & 3 & 5 & 5 & 5 & - & - & - & - \\
\hline \multicolumn{5}{|l|}{ Water (Pumped Storige } & - & - & & \\
\hline Hydroelectric) & - & - & - & - & - & - & - & - \\
\hline \multicolumn{9}{|l|}{ Water (Conventional } \\
\hline Hydroelectric) ............................................ & 83 & 2,488 & 2,591 & 2,564 & - & - & - & 二 \\
\hline Nuclear & - & - & - & - & 一 & - & - & - \\
\hline 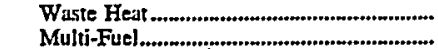 & - & - & - & - & - & 二 & - & - \\
\hline & $\bar{z}$ & $=$ & $=$ & - & - & $=$ & - & - \\
\hline & - & - & - & - & - & - & - & - \\
\hline \multicolumn{2}{|l|}{ Nebraska.................................................................... } & 5,980 & 5,760 & 5,747 & 4 & 108 & 93 & 106 \\
\hline Coal $\ldots$ & 15 & 3,168 & 3,152 & 3,041 & - & $=$ & - & -5 \\
\hline 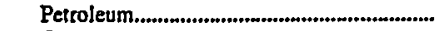 & 107 & 607 & 547 & 614 & 1 & 5 & 4 & 5 \\
\hline 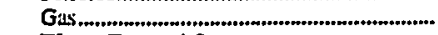 & 109 & 684 & 644 & 659 & 3 & 103 & 89 & 101 \\
\hline \multicolumn{9}{|l|}{ Water (Pumped Storage } \\
\hline \multicolumn{9}{|l|}{$\begin{array}{l}\text { Hydroelectric) } \\
\text { Water (Conventional }\end{array}$} \\
\hline \multirow{2}{*}{\multicolumn{9}{|c|}{ Hydroelectric) ........................................... }} \\
\hline \multirow{2}{*}{\multicolumn{9}{|c|}{ Nucleat }} \\
\hline & - & - & - & - & - & - & - & - \\
\hline & - & - & - & - & - & - & - & - \\
\hline \multicolumn{9}{|l|}{ 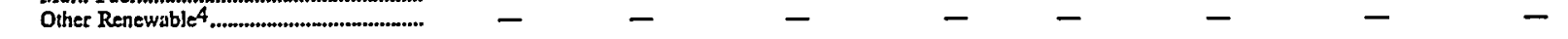 } \\
\hline Nevada & 67 & 5,901 & 5,642 & $\mathbf{5 , 7 4 5}$ & - & - & - & - \\
\hline 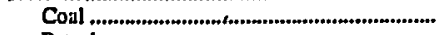 & 9 & 2,883 & 2,806 & 2,817 & - & - & - & - \\
\hline 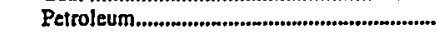 & 17 & 55 & 46 & 51 & - & - & - & - \\
\hline Gas & 22 & 1,738 & 1,564 & 1,651 & - & - & - & - \\
\hline $\begin{array}{l}\text { Water (Pumped Storage } \\
\text { Hydroelectric) }\end{array}$ & - & - & - & - & - & - & - & - \\
\hline $\begin{array}{l}\text { Hydroelectric) } \\
\text { Water (Conventional }\end{array}$ & - & - & - & - & - & & & - \\
\hline Hydruelectric) & 17 & 1,046 & 1,046 & 1,047 & - & - & - & - \\
\hline 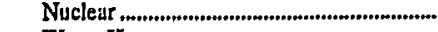 & $\overline{0}$ & $\overline{-1}$ & $\overline{100}$ & $\overline{170}$ & - & - & - & - \\
\hline 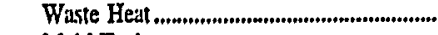 & 2 & 180 & 179 & 179 & - & - & - & - \\
\hline Multi-Fuel ..., & - & - & - & - & - & - & - & - \\
\hline Other Renewable 4 & - & - & - & - & - & - & - & - \\
\hline 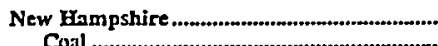 & 44 & $\begin{array}{r}2,614 \\
609\end{array}$ & $\begin{array}{r}2,512 \\
578\end{array}$ & $\begin{aligned} 2,586 \\
617\end{aligned}$ & 二 & 二 & $\overline{-}$ & $\overline{-}$ \\
\hline Coal & & 609 & $5 / 8$ & 617 & - & - & - & - \\
\hline
\end{tabular}

See footnotes at end of table. 
Table 17. Existing Capacity and Planned Capacity Additions at U.S. Electric Utilities by Energy Source and State, as of January 1, 1998 (Continued)

\begin{tabular}{|c|c|c|c|c|c|c|c|c|}
\hline \multirow[b]{2}{*}{$\begin{array}{c}\text { State } \\
\text { Primary Energy } \\
\text { Source }\end{array}$} & \multicolumn{4}{|c|}{ Existing } & \multicolumn{4}{|c|}{ Plnnned Additions ? } \\
\hline & $\begin{array}{l}\text { Number } \\
\text { of Units }\end{array}$ & $\begin{array}{l}\text { Generator } \\
\text { Nameplate } \\
\text { Capacity } \\
\text { (megawatts) }\end{array}$ & $\begin{array}{l}\text { Net Summer } \\
\text { Capability } \\
\text { (megawatts) }\end{array}$ & $\begin{array}{l}\text { Net Winter } \\
\text { Capability } \\
\text { (megawatts) }\end{array}$ & $\begin{array}{l}\text { Number } \\
\text { of Units }\end{array}$ & $\begin{array}{c}\text { Generator } \\
\text { Nameplate } \\
\text { Capacity } \\
\text { (megawatts) }\end{array}$ & $\begin{array}{l}\text { Net Summer } \\
\text { Capability } \\
\text { (megawatts) }\end{array}$ & $\begin{array}{l}\text { Net Winter } \\
\text { Capability } \\
\text { (megawatts) }\end{array}$ \\
\hline \multicolumn{9}{|l|}{ New Hampshire (Continued) } \\
\hline 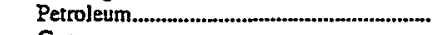 & 6 & 509 & 489 & 519 & - & - & - & - \\
\hline Gas & - & - & - & - & - & - & - & - \\
\hline Water (Pumped Storage & & & & & & & & \\
\hline $\begin{array}{l}\text { Hydroelectric) } \\
\text { Water (Conventional }\end{array}$ & - & - & - & - & - & - & - & - \\
\hline $\begin{array}{l}\text { Water (Conventional } \\
\text { Hydroelectric) }\end{array}$ & & & & & & & & \\
\hline Hydroelectric) & 32 & 254 & 284 & 288 & $\rightarrow$ & - & - & - \\
\hline Nuclear & 1 & 1,242 & 1,162 & 1,162 & - & - & - & - \\
\hline Waste Hest ..................................................... & - & - & - & - & - & - & - & - \\
\hline 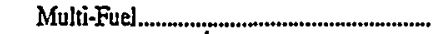 & - & - & - & - & - & - & - & - \\
\hline Other Renewable ${ }^{4} \ldots$ & - & - & - & - & - & - & - & - \\
\hline \multirow{2}{*}{\multicolumn{9}{|c|}{ 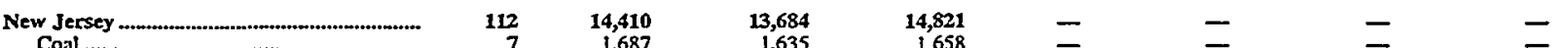 }} \\
\hline & 7 & 1,687 & 1,635 & 1,658 & - & - & - & - \\
\hline 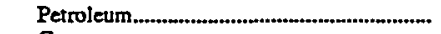 & 65 & 3,939 & 3,915 & 4,531 & - & - & - & - \\
\hline 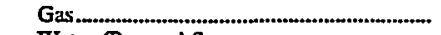 & 30 & 3,726 & 3,506 & 3,893 & - & - & - & - \\
\hline \multicolumn{9}{|l|}{ Water (Pumped Storage } \\
\hline $\begin{array}{l}\text { Hydroelectric) ......... } \\
\text { Water (Conventional }\end{array}$ & 3 & 387 & 400 & 400 & - & - & - & - \\
\hline $\begin{array}{l}\text { Water (Conventional } \\
\text { Hydroelectric) }\end{array}$ & - & - & - & - & - & - & - & - \\
\hline 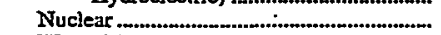 & 4 & 4,146 & 3,862 & 3,950 & - & $\overline{-}$ & 二 & 二 \\
\hline 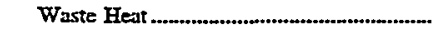 & 3 & 525 & 366 & 389 & - & - & - & - \\
\hline 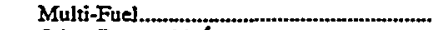 & - & - & - & - & - & - & - & - \\
\hline 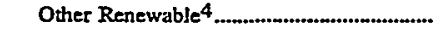 & - & - & - & - & - & - & - & - \\
\hline New Mexico. & 56 & 5,627 & 5,183 & 5,189 & 7 & 1,051 & 905 & 1,012 \\
\hline Coal & 13 & 4,295 & 3,901 & 3,901 & 1 & 233 & 210 & 210 \\
\hline 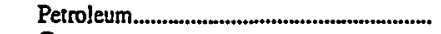 & 7 & 30 & 23 & 24 & - & - & - & - \\
\hline Gas........................................... & 28 & 1,239 & 1,194 & 1,198 & 6 & 818 & 695 & 802 \\
\hline \multicolumn{9}{|l|}{ Water (Pumped Storage } \\
\hline \multicolumn{9}{|l|}{$\begin{array}{l}\text { Hydroelectric) } \\
\text { Water (Conventional }\end{array}$} \\
\hline \multicolumn{9}{|l|}{ Hydroelectric) } \\
\hline \multicolumn{9}{|l|}{ Nuclear } \\
\hline Waste Heat & 2 & 6 & 6 & 6 & - & - & - & - \\
\hline \multirow{2}{*}{\multicolumn{9}{|c|}{$\begin{array}{l}\text { Multi-Fuel } \\
\text { Other Renewable4. }\end{array}$}} \\
\hline & - & - & - & - & - & - & - & - \\
\hline \multicolumn{9}{|l|}{ New York } \\
\hline Coal & 32 & 4,030 & 3,880 & 3,876 & - & - & - & - \\
\hline 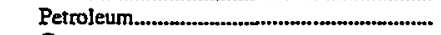 & 185 & 13,944 & 12,759 & 13,687 & 2 & 3 & 3 & 3 \\
\hline Gas & 32 & 3,219 & 3,201 & 3,265 & - & - & - & - \\
\hline \multicolumn{9}{|l|}{ Water (Pumped Storage } \\
\hline $\begin{array}{l}\text { Hydroelectric) } \\
\text { Water (Conventional }\end{array}$ & 16 & 1,240 & 1,280 & 1,280 & - & - & - & - \\
\hline 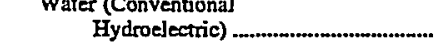 & 285 & 3,950 & 3,855 & 3,884 & - & - & - & - \\
\hline Nuclear & 6 & 5,624 & 4,961 & 5,033 & - & - & - & - \\
\hline 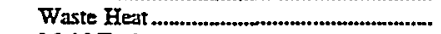 & 1 & 56 & 48 & 52 & - & - & - & - \\
\hline Multi-Fuel & - & - & - & - & - & - & - & - \\
\hline 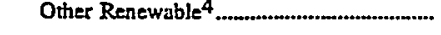 & - & - & - & - & - & - & - & - \\
\hline 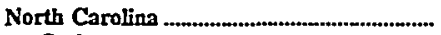 & 187 & 21,964 & 21,054 & 21,591 & 14 & 4,966 & 4,239 & 4,795 \\
\hline & 45 & 12,451 & 12,440 & 12,513 & - & - & - & - \\
\hline 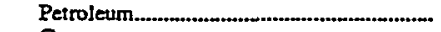 & 40 & 952 & 791 & 914 & - & - & - & $\bar{x}$ \\
\hline Gas & 24 & 1,779 & 1,415 & 1,799 & 14 & 4,966 & 4,239 & 4,795 \\
\hline Water (Pumped Storage & & & & & & & & \\
\hline Hydroelectric) & - & - & - & - & - & - & - & - \\
\hline Water (Conventional & & & & & & & & \\
\hline 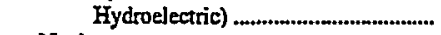 & 70 & 1,497 & 1,564 & 1,520 & - & - & - & - \\
\hline 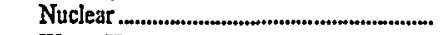 & 5 & $-5,182$ & 4,749 & 4,749 & - & - & - & - \\
\hline 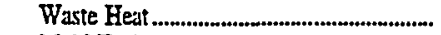 & 3 & 103 & 96 & 97 & - & - & - & - \\
\hline 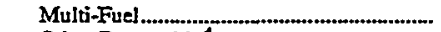 & - & - & - & - & - & - & - & - \\
\hline Other Renewable 4 & - & - & - & - & - & - & - & - \\
\hline North Dakota & 47 & 4,913 & 4,733 & 4,760 & - & - & - & - \\
\hline Coal & 14 & 4,265 & 4,061 & 4,071 & - & - & - & - \\
\hline
\end{tabular}

See foomotes at end of table. 
Table 17. Existing Capacity and Planned Capacity Additions at U.S. Electric Utilities by Energy Source and State, as of January 1, 1998 (Continued)

\begin{tabular}{|c|c|c|c|c|c|c|c|c|}
\hline \multirow[b]{2}{*}{$\begin{array}{c}\text { State } \\
\text { Primary Energy } \\
\text { Source }\end{array}$} & \multicolumn{4}{|c|}{ Existing } & \multicolumn{4}{|c|}{ Planned Additions! } \\
\hline & $\begin{array}{l}\text { Number } \\
\text { of Units }\end{array}$ & $\begin{array}{c}\text { Generator } \\
\text { Nameplate } \\
\text { Capacity } \\
\text { (megawatts) }\end{array}$ & $\begin{array}{c}\text { Net Summer } \\
\text { Capability } \\
\text { (megawatts) }\end{array}$ & $\begin{array}{l}\text { Net Winter } \\
\text { Capability } \\
\text { (megawatts) }\end{array}$ & $\begin{array}{l}\text { Number } \\
\text { of Units }\end{array}$ & $\begin{array}{l}\text { Generator } \\
\text { Nameplate } \\
\text { Capacity } \\
\text { (megawatts) }\end{array}$ & $\begin{array}{c}\text { Net Summer } \\
\text { Capability } \\
\text { (mtgawatts) }\end{array}$ & $\begin{array}{l}\text { Net Winter } \\
\text { Capability } \\
\text { (megawatts) }\end{array}$ \\
\hline \multicolumn{9}{|l|}{ North Dakota (Continued) } \\
\hline Petroleum................................ & 26 & 121 & 117 & 135 & - & - & - & - \\
\hline Gas............................................................... & 2 & 10 & 9 & 10 & - & - & - & - \\
\hline $\begin{array}{l}\text { Water (Pumped Storage } \\
\text { Hydroelectric) .......... }\end{array}$ & - & - & - & - & - & - & - & - \\
\hline Water (Conventional & & & & & & & & \\
\hline 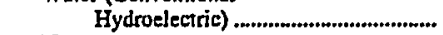 & $s$ & 517 & 545 & 545 & - & - & - & - \\
\hline 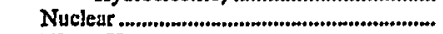 & - & - & - & - & - & - & - & - \\
\hline 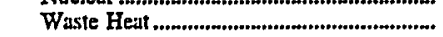 & - & - & - & - & - & - & - & 二 \\
\hline 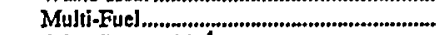 & - & - & - & - & - & - & - & - \\
\hline Other Renewable4. & - & - & - & - & - & - & - & 二 \\
\hline \multicolumn{9}{|l|}{ 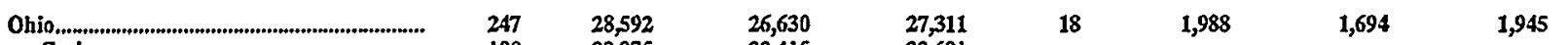 } \\
\hline 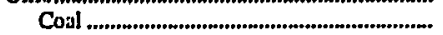 & 108 & 23,975 & 22,415 & 22,691 & - & - & - & - \\
\hline Petroleum................................................ & 81 & 947 & 805 & 971 & 1 & 2 & 2 & 2 \\
\hline Gas & 39 & 1,273 & 1,154 & 1,352 & 15 & 1,944 & 1,652 & 1,905 \\
\hline \multicolumn{9}{|l|}{ Water (Pumped Storage } \\
\hline Hydroelectric) ........... & - & - & - & - & - & - & - & - \\
\hline \multicolumn{9}{|l|}{ Water (Conventional } \\
\hline Hydroelectric) .............................................. & 14 & 129 & 123 & 130 & 2 & 42 & 40 & 39 \\
\hline 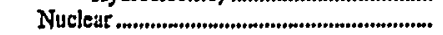 & 2 & 2,178 & 2,042 & 2,077 & - & - & - & - \\
\hline Waste Heat .............................................................. & - & - & - & - & - & - & - & - \\
\hline Multi-Fuel................................................................ & - & - & - & - & - & - & - & - \\
\hline Other Renewable4........................... & 3 & 90 & 90 & 90 & - & - & - & - \\
\hline \multicolumn{9}{|l|}{ Oklahoma } \\
\hline 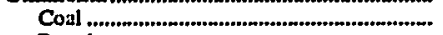 & 10 & 5,144 & 4,848 & 4,852 & - & - & - & - \\
\hline 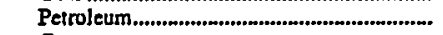 & 29 & 73 & 62 & 62 & - & - & - & - \\
\hline 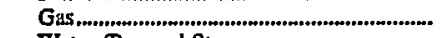 & 78 & 7,235 & 6,986 & 7,052 & 1 & 146 & 124 & 143 \\
\hline $\begin{array}{l}\text { Water (Pumped Storage } \\
\text { Hydroelectric) }\end{array}$ & 6 & 288 & 260 & 260 & - & - & - & - \\
\hline \multicolumn{9}{|l|}{ Water (Conventiona) } \\
\hline Hydroelectric) ............................................. & 32 & 756 & 775 & 775 & - & - & - & - \\
\hline Nuclear ..................................................... & - & - & - & - & - & - & - & - \\
\hline 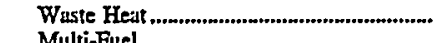 & - & - & - & - & - & - & - & - \\
\hline $\begin{array}{l}\text { Multi-Fuel... } \\
\text { Other Renewable4. }\end{array}$ & $\bar{Z}$ & $\bar{Z}$ & $\bar{z}$ & $\bar{z}$ & $\bar{z}$ & $\bar{z}$ & $\bar{z}$ & $\bar{z}$ \\
\hline \multirow{2}{*}{\multicolumn{9}{|c|}{ 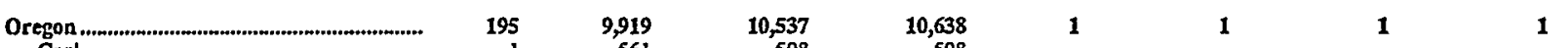 }} \\
\hline & & & 10,537 & & & & & \\
\hline 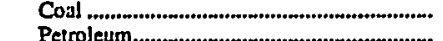 & 1 & 561 & 508 & 508 & - & - & - & - \\
\hline & 2 & 113 & 103 & 136 & - & - & - & - \\
\hline \multirow{2}{*}{\multicolumn{9}{|c|}{ Water (Pumped Storage }} \\
\hline & & & & & & & & \\
\hline \multicolumn{9}{|l|}{ 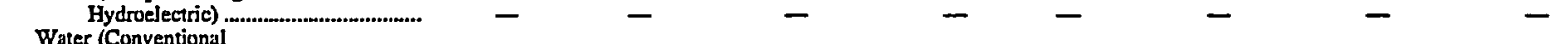 } \\
\hline \multicolumn{9}{|l|}{$\begin{array}{l}\text { Water (Conventional } \\
\text { Hydroelectric) }\end{array}$} \\
\hline \multirow{2}{*}{\multicolumn{2}{|c|}{ Nuclear }} & & & - & - & - & - & - \\
\hline & & 430 & 354 & 372 & - & - & - & - \\
\hline & - & - & & & - & - & - & - \\
\hline 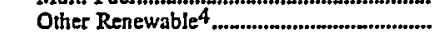 & 3 & 54 & 37 & 37 & - & - & 二 & - \\
\hline 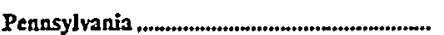 & 232 & 36,885 & 33,825 & 34,855 & 2 & 198 & 170 & 186 \\
\hline 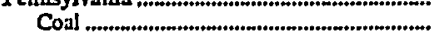 & 58 & 19,207 & 17,386 & 17,737 & - & - & - & - \\
\hline 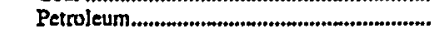 & 105 & 3,777 & 3,208 & 3,687 & - & - & - & - \\
\hline 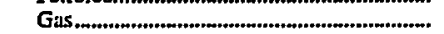 & 15 & 2,486 & 2,283 & 2,323 & 2 & 198 & 170 & 186 \\
\hline Water (Pumped Storage & 1 & 1792 & 1210 & & & & & \\
\hline $\begin{array}{l}\text { Hydroelectric) } \\
\text { Wuter (Conventional }\end{array}$ & 11 & 1,222 & 1,319 & 1,319 & - & - & - & - \\
\hline 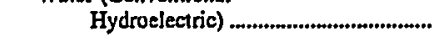 & 34 & 636 & 623 & 638 & - & - & - & - \\
\hline 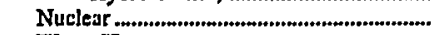 & 9 & 9,557 & 9,006 & 9,151 & - & - & - & - \\
\hline 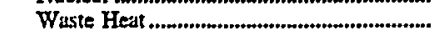 & - & - & - & - & - & - & - & - \\
\hline 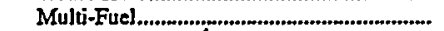 & - & - & - & - & - & - & - & - \\
\hline 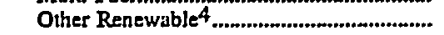 & - & - & - & - & - & - & - & - \\
\hline 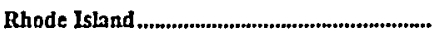 & 16 & 511 & 441 & 516 & - & - & - & - \\
\hline 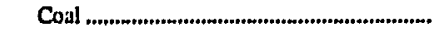 & - & - & - & - & - & - & - & - \\
\hline
\end{tabular}

See footnotes at end of table. 
Table 17. Existing Capacity and Planned Capacity Additions at U.S. Electric Utilities by Energy Source and State, as of January 1, 1998 (Continued)

\begin{tabular}{|c|c|c|c|c|c|c|c|c|}
\hline \multirow[b]{2}{*}{$\begin{array}{c}\text { State } \\
\text { Primary Energy } \\
\text { Source }\end{array}$} & \multicolumn{4}{|c|}{ Existing } & \multicolumn{4}{|c|}{ Planned Additions 1} \\
\hline & $\begin{array}{l}\text { Number } \\
\text { of Units }\end{array}$ & $\begin{array}{c}\text { Generator } \\
\text { Nameplate } \\
\text { Capacity } \\
\text { (megawatts) }\end{array}$ & $\begin{array}{c}\text { Net Summer } \\
\text { Capability } \\
\text { (megawatts) }\end{array}$ & $\begin{array}{l}\text { Net Winter } \\
\text { Capability } \\
\text { (megawatts) }\end{array}$ & $\begin{array}{l}\text { Number } \\
\text { of Units }\end{array}$ & $\begin{array}{c}\text { Generator } \\
\text { Nameplate } \\
\text { Capacity } \\
\text { (megawatts) }\end{array}$ & $\begin{array}{c}\text { Net Summer } \\
\text { Capability } \\
\text { (megawatts) }\end{array}$ & $\begin{array}{c}\text { Net Winter } \\
\text { Capability } \\
\text { (megawatts) }\end{array}$ \\
\hline \multicolumn{9}{|l|}{ Rhode Island (Continued) } \\
\hline 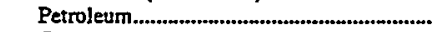 & 12 & 20 & 20 & 20 & - & - & - & - \\
\hline 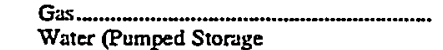 & 3 & 489 & 420 & 495 & - & 一 & - & - \\
\hline $\begin{array}{l}\text { Hydroelectric) } \\
\text { Water (Conventional }\end{array}$ & - & - & - & - & $\multimap$ & $\longrightarrow$ & - & - \\
\hline Hydroelectric) & 1 & 2 & ] & 1 & - & - & - & - \\
\hline Nuclear & - & - & - & - & - & 一 & - & - \\
\hline 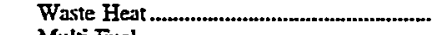 & 一 & - & 一 & 一 & 一 & 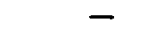 & - & - \\
\hline 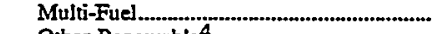 & 一 & - & 一 & - & - & - & - & - \\
\hline Other Renewable ${ }^{4}$ & 一 & - & - & - & - & - & - & - \\
\hline 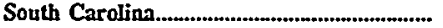 & 211 & 18,791 & 17,431 & 17,780 & 15 & 1,436 & 1,234 & 1,409 \\
\hline 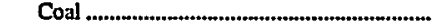 & 27 & 6,403 & 5,794 & 5,836 & 1 & 91 & 91 & 91 \\
\hline 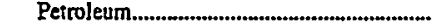 & 50 & 1,413 & 1,192 & 1,358 & 10 & 830 & 705 & 813 \\
\hline 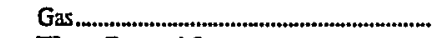 & 13 & 753 & 585 & 682 & 4 & 515 & 438 & 505 \\
\hline \multicolumn{9}{|l|}{ Water (Pumped Storage } \\
\hline Hydroelectric) .................................... & 16 & 2,186 & 2,187 & 2,187 & - & - & 一 & - \\
\hline 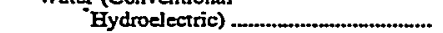 & 98 & 1,237 & 1,252 & 1,252 & - & - & - & - \\
\hline Nuclear & 7 & 6,799 & 6,421 & 6,465 & - & - & - & 二 \\
\hline 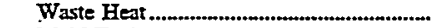 & - & - & - & - & - & $\rightarrow$ & - & - \\
\hline Multi-Fuel & - & - & - & - & - & $\rightarrow$ & - & - \\
\hline 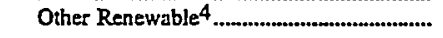 & - & - & 一 & - & 一 & - & 一 & - \\
\hline 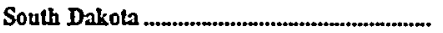 & 64 & 2,974 & 2,927 & 2,983 & - & - & - & - \\
\hline Coal & 2 & 500 & 467 & 488 & - & - & - & - \\
\hline 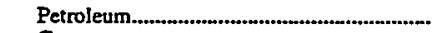 & 25 & 385 & 276 & 346 & - & - & 一 & - \\
\hline \\
\hline Hydroelectric) & - & - & - & - & - & - & 一 & 一 \\
\hline \multicolumn{9}{|l|}{ Water (Conventiona! } \\
\hline Hydroelectric) & 26 & 1,731 & 1,820 & j,820 & - & - & - & - \\
\hline 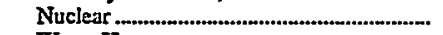 & - & - & - & - & - & 一 & - & 二 \\
\hline 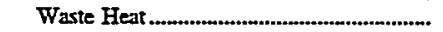 & - & - & - & - & - & 一 & - & - \\
\hline 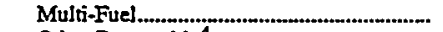 & - & - & - & - & - & 一 & - & 一 \\
\hline 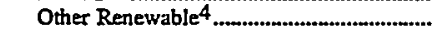 & 一 & - & - & - & - & 一 & - & - \\
\hline \multicolumn{9}{|l|}{ 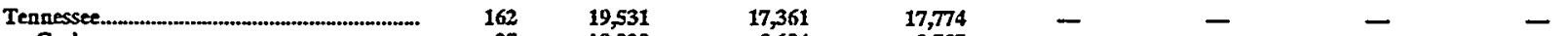 } \\
\hline Coal & 37 & 10,020 & 8,604 & 8,757 & - & - & - & 一 \\
\hline 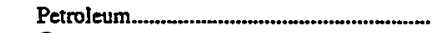 & 20 & 1,413 & 1,135 & 1,333 & - & - & - & - \\
\hline 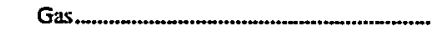 & 20 & 621 & 514 & 606 & - & - & - & - \\
\hline \multicolumn{9}{|l|}{ Water (Pumped Storage } \\
\hline Hydroelectric) & 4 & 1,530 & 1,532 & 1,532 & - & 一 & - & - \\
\hline \multicolumn{9}{|l|}{ Water (Conventional } \\
\hline Hydroelectric) & 78 & 2,236 & 2,219 & 2,098 & - & - & - & - \\
\hline 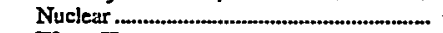 & 3 & $3,71]$ & 3,357 & 3,448 & - & - & - & - \\
\hline 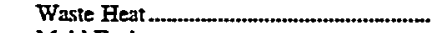 & - & - & - & - & - & 一 & - & - \\
\hline Multi-Fuel. & - & - & - & 一 & - & - & - & - \\
\hline 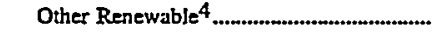 & - & - & - & - & - & - & - & 一 \\
\hline \multicolumn{9}{|l|}{ Texas ${ }^{2} \ldots \ldots \ldots$} \\
\hline 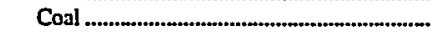 & 37 & 20,433 & 19,587 & 19,608 & 3 & 1,592 & 1,500 & 1,500 \\
\hline 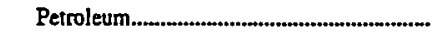 & 25 & 40 & 37 & 37 & $\therefore$ & - & - & - \\
\hline Gas & 312 & 40,805 & 39,439 & 39,702 & 12 & 3,596 & $3,3] 6$ & 3,387 \\
\hline \multicolumn{9}{|l|}{ Water (Pumped Storage } \\
\hline Hydroelectric) & - & - & - & - & - & - & - & 一 \\
\hline \multicolumn{9}{|l|}{ Water (Conventional } \\
\hline Hydroelectric) & 50 & 634 & 686 & 628 & - & - & - & - \\
\hline Nuclear & 4 & 5,139 & 4,800 & 4,800 & - & - & - & - \\
\hline 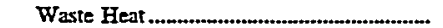 & 3 & 346 & 294 & 294 & - & - & - & - \\
\hline Multi-Fuel & - & - & - & - & - & - & - & - \\
\hline Other Renewable 4 & 2 & 1 & 1 & 1 & - & - & - & - \\
\hline 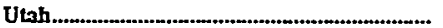 & 147 & 5,131 & 4,945 & 4,944 & 4 & 403 & 403 & 403 \\
\hline 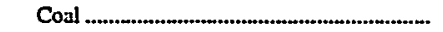 & 11 & 4,468 & 4,318 & 4,338 & 1 & 400 & 400 & 400 \\
\hline
\end{tabular}

See footnotes at end of table. 
Table 17. Existing Capacity and Planned Capacity Additions at U.S. Electric Utilities by Energy Source and State, as of January 1, 1998 (Continued)

\begin{tabular}{|c|c|c|c|c|c|c|c|c|}
\hline \multirow[b]{2}{*}{$\begin{array}{c}\text { State } \\
\text { Primary Energy } \\
\text { Source }\end{array}$} & \multicolumn{4}{|c|}{ Existing } & \multicolumn{4}{|c|}{ Planned Additions! } \\
\hline & $\begin{array}{l}\text { Number } \\
\text { of Units }\end{array}$ & $\begin{array}{l}\text { Generator } \\
\text { Nameplate } \\
\text { Capacity } \\
\text { (megawatts) }\end{array}$ & $\begin{array}{l}\text { Net Summer } \\
\text { Capability } \\
\text { (megawatts) }\end{array}$ & $\begin{array}{l}\text { Net Winter } \\
\text { Capability } \\
\text { (megawatts) }\end{array}$ & $\begin{array}{l}\text { Number } \\
\text { of Units }\end{array}$ & $\begin{array}{c}\text { Generator } \\
\text { Nameplate } \\
\text { Capacity } \\
\text { (megawatts) }\end{array}$ & $\begin{array}{l}\text { Net Summer } \\
\text { Capability } \\
\text { (megawatis) }\end{array}$ & $\begin{array}{l}\text { Net Winter } \\
\text { Capability } \\
\text { (megawatts) }\end{array}$ \\
\hline \multicolumn{9}{|l|}{ Utah (Continued) } \\
\hline 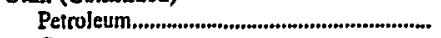 & 15 & 34 & 33 & 34 & - & - & - & - \\
\hline 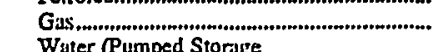 & 25 & 316 & 296 & 296 & $\mathrm{~J}$ & 1 & $\mathbf{l}$ & 1 \\
\hline 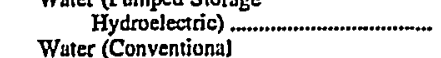 & 1 & $\star$ & * & * & - & - & - & - \\
\hline 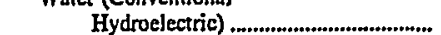 & 88 & 273 & 263 & 242 & 2 & 3 & 2 & 2 \\
\hline 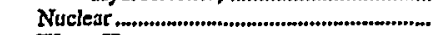 & - & - & - & - & - & - & - & - \\
\hline 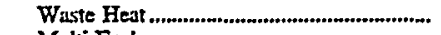 & - & - & - & - & - & - & - & - \\
\hline 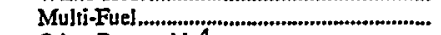 & - & - & - & - & - & - & - & - \\
\hline 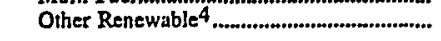 & 7 & 40 & 35 & 35 & - & - & - & - \\
\hline 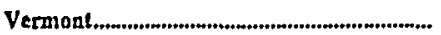 & 134 & 1,131 & 1,094 & 1,159 & - & - & - & - \\
\hline Coal & $\bar{c}$ & - & - & $\overline{-\infty}$ & - & - & - & - \\
\hline 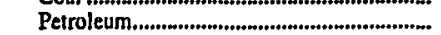 & 25 & 144 & 119 & 155 & - & - & - & 二 \\
\hline Gas ............................................................ & - & - & - & - & - & - & - & - \\
\hline 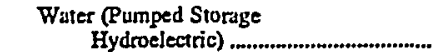 & - & - & - & - & - & - & - & - \\
\hline Water (Conventional & - & & - & - & - & - & - & - \\
\hline Hydroelectric) ...................................... & 104 & 368 & 423 & 426 & - & - & - & - \\
\hline 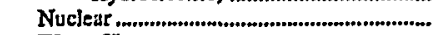 & 1 & 563 & 496 & 522 & - & - & - & - \\
\hline 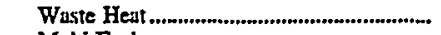 & - & - & - & - & - & - & - & - \\
\hline 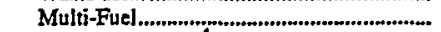 & - & - & - & - & - & - & - & - \\
\hline 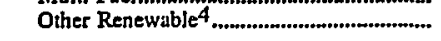 & 4 & 56 & 56 & 56 & - & - & - & - \\
\hline Virginia & 184 & 16,393 & 15,291 & 15,766 & 1 & 1 & $\mathbf{1}$ & 1 \\
\hline 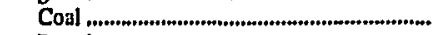 & 26 & 5,397 & 5,099 & 5,184 & - & - & - & - \\
\hline Petroleum & 63 & 2,429 & 2,192 & 2,309 & - & - & - & - \\
\hline 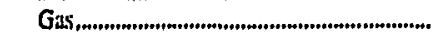 & 16 & 1,699 & 1,395 & 1,645 & - & - & - & - \\
\hline \multicolumn{9}{|l|}{ Water (Pumped Storage } \\
\hline $\begin{array}{l}\text { Hydroelectric) } \\
\text { Water........ }\end{array}$ & 9 & 2,348 & 2,345 & 2,345 & - & - & - & - \\
\hline $\begin{array}{l}\text { Water (Conventional } \\
\text { Hydroelectric) }\end{array}$ & 61 & 712 & 740 & 762 & 1 & 1 & 1 & 1 \\
\hline 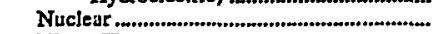 & 4 & 3,655 & 3,392 & 3,392 & - & - & - & - \\
\hline 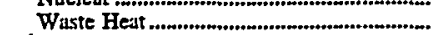 & 2 & 154 & 129 & 129 & 二 & 二 & - & - \\
\hline 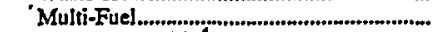 & - & - & - & - & - & - & - & - \\
\hline 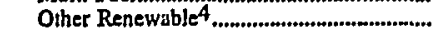 & 3 & * & * & * & - & - & - & - \\
\hline \multicolumn{9}{|l|}{ Washington ............................................................ } \\
\hline 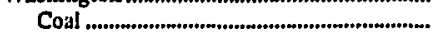 & 4 & 1,510 & 1,390 & 1,390 & - & - & - & - \\
\hline Petroleum........ & 4 & 65 & 62 & 71 & - & - & - & - \\
\hline \multirow{2}{*}{\multicolumn{9}{|c|}{ Water (Pumped Storage }} \\
\hline & 5 & 261 & 261 & & - & - & - & \\
\hline \multicolumn{9}{|l|}{ Water (Conventional } \\
\hline 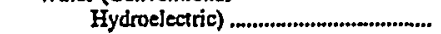 & 260 & 20,559 & 21,470 & 21,339 & 4 & 33 & 31 & 30 \\
\hline 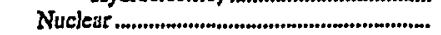 & 1 & 1,200 & 1,170 & 1,170 & - & - & - & - \\
\hline 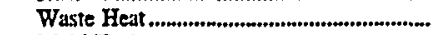 & - & - & - & - & - & - & - & - \\
\hline 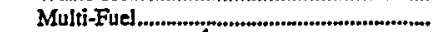 & - & - & - & - & - & - & - & - \\
\hline 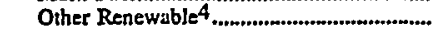 & 2 & 93 & $\overline{83}$ & 73 & - & - & - & - \\
\hline \multicolumn{9}{|l|}{ 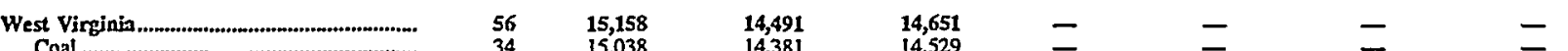 } \\
\hline Coal & 34 & 15,038 & 14,381 & 14,529 & - & - & - & - \\
\hline 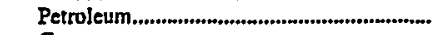 & 1 & 19 & 12 & 16 & - & - & - & - \\
\hline 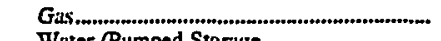 & - & - & - & - & - & - & - & - \\
\hline \multicolumn{9}{|l|}{ Water (Pumped Storage } \\
\hline \multicolumn{9}{|l|}{$\begin{array}{l}\text { Hydroelectric) } \\
\text { Wat......................... }\end{array}$} \\
\hline Hydroejectric) & 21 & 101 & 98 & 106 & - & - & - & - \\
\hline 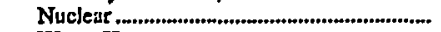 & - & - & - & - & - & - & - & - \\
\hline 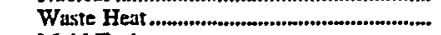 & - & - & - & - & - & - & - & - \\
\hline 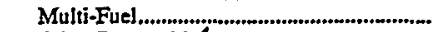 & - & - & - & - & - & - & - & - \\
\hline 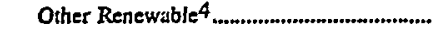 & - & - & - & - & - & - & - & - \\
\hline 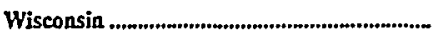 & 420 & 11,952 & 11,845 & 12,400 & 13 & 1,492 & 1,279 & 1,464 \\
\hline 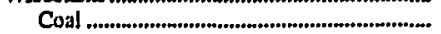 & 52 & 7,194 & 7,389 & 7,424 & 1 & 60 & 60 & 60 \\
\hline
\end{tabular}

Ste footnotes at end of table. 
Table 17. Existing Capacity and Planned Capacity Additions.at U.S. Electric Utilities by Energy Source and State, as of January 1, 1998 (Continued)

\begin{tabular}{|c|c|c|c|c|c|c|c|c|}
\hline \multirow[b]{2}{*}{$\begin{array}{c}\text { State } \\
\text { Primary Energy } \\
\text { Source }\end{array}$} & \multicolumn{4}{|c|}{ Existing } & \multicolumn{4}{|c|}{ Phanned Additions] } \\
\hline & $\begin{array}{l}\text { Number } \\
\text { of Units }\end{array}$ & $\begin{array}{c}\text { Generator } \\
\text { Nameplate } \\
\text { Capacity } \\
\text { (megawatts) }\end{array}$ & $\begin{array}{c}\text { Net Summer } \\
\text { Capability } \\
\text { (megawatts) }\end{array}$ & $\begin{array}{l}\text { Net Winter } \\
\text { Capability } \\
\text { (megawatts) }\end{array}$ & $\begin{array}{l}\text { Number } \\
\text { of Units }\end{array}$ & $\begin{array}{l}\text { Generator } \\
\text { Nameplate } \\
\text { Capacity } \\
\text { (megawatts) }\end{array}$ & $\begin{array}{l}\text { Net Summer } \\
\text { Copability } \\
\text { (megawatts) }\end{array}$ & $\begin{array}{c}\text { Net Winter } \\
\text { Capability } \\
\text { (megawatts) }\end{array}$ \\
\hline \multicolumn{9}{|l|}{ Wisconsin (Continued) } \\
\hline 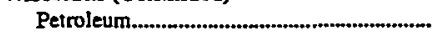 & 101 & 1,091 & 1,053 & 1,316 & - & - & - & - \\
\hline Water Pumped Storage & 33 & 1,572 & 1,450 & 1,682 & 9 & 1,419 & 1,206 & 1,391 \\
\hline $\begin{array}{l}\text { Hydroelectric) } \\
\text { Water (Conventional }\end{array}$ & - & - & 一 & - & - & - & 一 & - \\
\hline 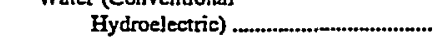 & 227 & 452 & 460 & 462 & 一 & - & 一 & - \\
\hline 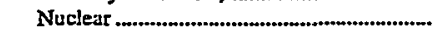 & 3 & 1,583 & 1,432 & 1,455 & - & - & - & - \\
\hline 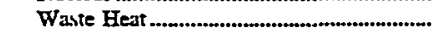 & $工$ & - & - & - & - & 一 & - & - \\
\hline 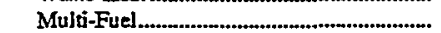 & - & - & - & - & - & - & - & - \\
\hline 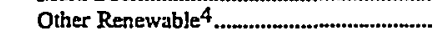 & 4 & 6] & 6] & 6] & 2 & 11 & 11 & 11 \\
\hline 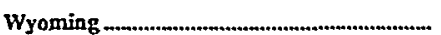 & 56 & 6,378 & 6,044 & 6,042 & - & - & - & - \\
\hline Coal & 2] & 6,075 & 5,737 & 5,746 & 一 & - & - & - \\
\hline 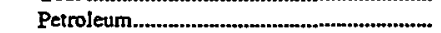 & 5 & 10 & 10 & 10 & - & 一 & - & - \\
\hline $\begin{array}{l}\text { Gus } \\
\text { Whter (Pumped Storage }\end{array}$ & - & - & - & - & - & - & - & - \\
\hline 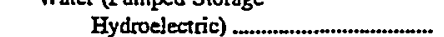 & - & - & - & 一 & - & - & - & - \\
\hline Water (Conventional & & & & & & & & \\
\hline 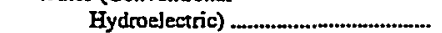 & 30 & 294 & 297 & 286 & 一 & 一 & - & - \\
\hline Nuclear & - & - & - & - & - & - & 一 & - \\
\hline 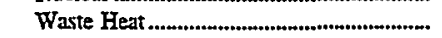 & - & - & 一 & - & - & - & 一 & - \\
\hline 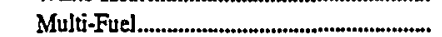 & - & - & - & - & - & - & 一 & 一 \\
\hline Other Renewable 4 & - & - & - & - & - & - & - & - \\
\hline
\end{tabular}

1 Planned additions are for 1998 through 2007.

2 Existing capacity totals include a 13-megawat expander tubine fueled by hot nitrogen.

3 Existing capacity includes Commonwealth Edjson Company's Zion 1 and 2 nuclear units which were retired from service in January 1998.

4 Includes geothermal, biomass (wood, wood waste, nonwood waste), solar, and wind.

* Less than 0.5 megawatts.

Notes: Total may not equal the sum of components because of independent rounding. The Form ElA-860 was revised during 1995 to collect data as of January $l$ of the reporting year, where "reporting year" is the calendar year in which the report is required to be filed with the Energy Information Administration. These data reflect the status of electric power plants/generators as of January 1: however, dynamic data are based on occurrences in the previous calendar year (e.g., capabilities and energy sources based on test and consumption in the previous year). Soure: Energy Information Administration, Form EIA-860, "Annual Electric Generator Report." 


\section{Table 18. Generating Units that Started Operation at U.S. Electric Utilities}

by State, Company, and Plant, 1997

\begin{tabular}{|c|c|c|c|c|c|c|c|}
\hline \multirow[b]{2}{*}{$\begin{array}{c}\text { Slate } \\
\text { Company } \\
\text { Plant (County) }\end{array}$} & \multirow[b]{2}{*}{$\begin{array}{l}\text { Unit } \\
\text { ID }\end{array}$} & \multicolumn{3}{|c|}{ Capacity } & \multirow[b]{2}{*}{$\begin{array}{c}\text { Unit } \\
\text { Type I }\end{array}$} & \multicolumn{2}{|c|}{ Energy Source! } \\
\hline & & $\begin{array}{c}\text { Generator } \\
\text { Nameplate } \\
\text { Capacity } \\
\text { (megawatts) }\end{array}$ & $\begin{array}{l}\text { Net Summer } \\
\text { Capability } \\
\text { (megawatis) }\end{array}$ & $\begin{array}{l}\text { Net Winter } \\
\text { Capability } \\
\text { (megawatts) }\end{array}$ & & Primacy & Alternate \\
\hline \multirow{2}{*}{\multicolumn{8}{|c|}{ Alaska }} \\
\hline & & 4.1 & 4.1 & & & & \\
\hline 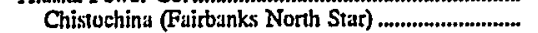 & $2 A$ & .1 & .1 & .1 & IC & FOl & $\mathrm{FO} 2$ \\
\hline 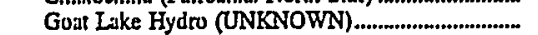 & 1 & 4.0 & 4.0 & 4.0 & HY & Watér & - \\
\hline \multicolumn{8}{|l|}{ 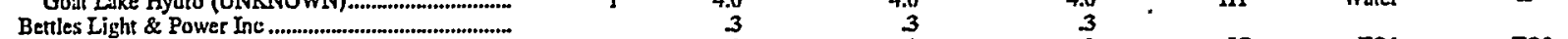 } \\
\hline Bettles Light \& PWr (UNKNOWN) & \multirow[t]{2}{*}{ JA } & 3 & .3 & .3 & IC & FOI & FO2 \\
\hline 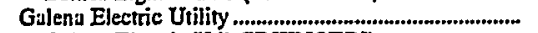 & & .5 & 5 & 5 & & & \\
\hline 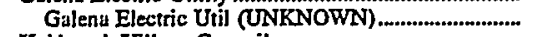 & \multirow[t]{2}{*}{7} & 5 & .5 & 5 & IC & FO2 & - \\
\hline 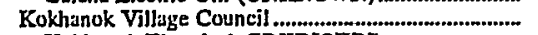 & & 2 & 2 & 2 & & & \\
\hline Kokhanok Electric 1 (UNKNOWN) & \multirow[t]{2}{*}{3} & .2 & .2 & .2 & IC & FOI & - \\
\hline Northway Power \& Light Inc.......................................... & & 1.1 & 1.0 & 1.0 & & & \\
\hline Northway (UNKNOWN) & & .3 & .2 & $\begin{array}{l}.2 \\
.8\end{array}$ & $\begin{array}{l}\text { IC } \\
\text { IC }\end{array}$ & $\begin{array}{l}\text { FO2 } \\
\text { FO2 }\end{array}$ & $\overline{-}$ \\
\hline 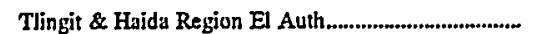 & \multirow[b]{2}{*}{$2 \mathrm{~A}$} & 1.0 & $\ddot{100}$ & 1.0 & & & \\
\hline 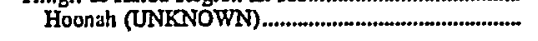 & & 1.0 & 1.0 & 1.0 & IC & $\mathrm{FO2}$ & - \\
\hline \multicolumn{2}{|l|}{ 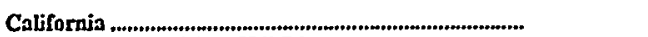 } & 273.7 & 2413 & 241.3 & & & \\
\hline 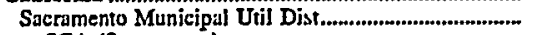 & \multirow[b]{2}{*}{$\begin{array}{l}{ }^{* *} \operatorname{CCCT} \\
{ }^{*} \operatorname{CCST}\end{array}$} & 273.7 & 2413 & 2413 & & & \\
\hline SCA (Sacramento) & & $\begin{array}{l}49.9 \\
49.9\end{array}$ & $\begin{array}{l}39.7 \\
37.6\end{array}$ & $\begin{array}{l}39.7 \\
37.6\end{array}$ & $\underset{\mathrm{CW}}{\mathrm{CT}}$ & $\begin{array}{l}\text { Nat Gas } \\
\text { WH }\end{array}$ & $\underline{-}$ \\
\hline \multirow[t]{2}{*}{ 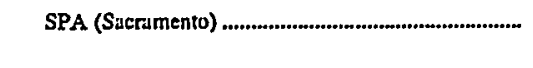 } & $* \approx \mathrm{CCCT}$ & 118.8 & 111.0 & 111.0 & CT & Nar Gas & - \\
\hline & ${ }^{*} \cos \mathrm{C}$ & 55.3 & 53.0 & 53.0 & $\mathrm{CW}$ & WH & - \\
\hline Colorado & & 27.6 & 25.0 & 25.0 & & & \\
\hline 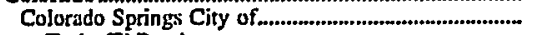 & & 27.6 & 25.0 & 25.0 & & & \\
\hline 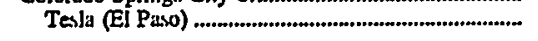 & J & 27.6 & 25.0 & 25.0 & HY & Water & - \\
\hline 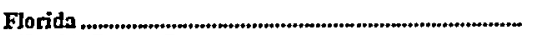 & & 401.0 & 352.0 & 407.0 & & & \\
\hline 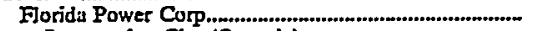 & & 398.0 & 349.0 & 404.0 & & & \\
\hline 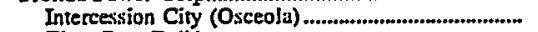 & $*$ *P11 & 165.0 & 143.0 & 168.0 & GT & $\mathrm{FO} 2$ & - \\
\hline 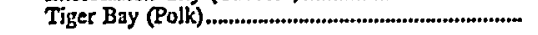 & CTI & 166.9 & 140.0 & 169.0 & $C T$ & Nat Gas & - \\
\hline & CW! & 66.2 & 66.0 & 67.0 & $C W$ & WH & - \\
\hline 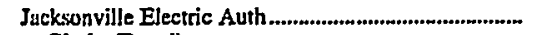 & & 3.0 & 3.0 & 3.0 & & & \\
\hline 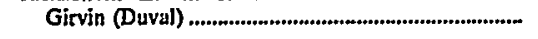 & 1 & 3.0 & 3.0 & 3.0 & IC & Refuse & - \\
\hline Idaho & & 20.3 & 20.3 & 20.3 & & & \\
\hline 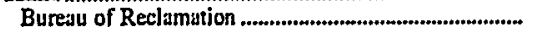 & & 20.0 & 20.0 & 20.0 & & & \\
\hline Minidoka (Minidoka) & 8 & 10.0 & 10.0 & 10.0 & $\mathrm{HY}$ & Water & - \\
\hline & 9 & 10.0 & 10.0 & 10.0 & $\mathbf{H Y}$ & Water & - \\
\hline Fall River Rural Elec Coop Inc ...................................... & & 3 & 3 & 3 & & & \\
\hline Buffalo (Fremont) & 1 & 3 & 3 & 3 & FY & Water & - \\
\hline 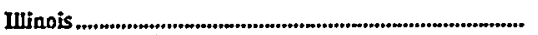 & & 141.1 & 120.5 & 136.5 & & & \\
\hline 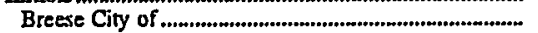 & & 2.5 & 2.5 & 25 & & & \\
\hline 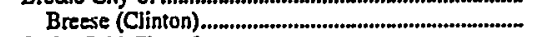 & 6 & 2.5 & 2.5 & 2.5 & IC & FO2 & - \\
\hline 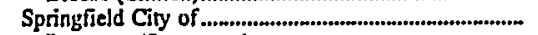 & & 138.6 & 118.0 & 134.0 & & & \\
\hline Interstate (Sangamon) & 1 & 138.6 & 118.0 & 134.0 & GT & Nat Gas & FO2 \\
\hline Iowa & & 5.5 & 5.5 & 5.5 & & & \\
\hline 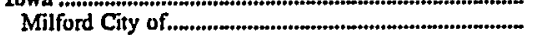 & & 5.5 & 5.5 & 5.5 & & & \\
\hline 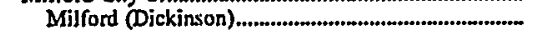 & $s$ & 1.8 & 1.8 & 1.8 & IC & $\mathrm{FO} 2$ & - \\
\hline & 6 & 1.8 & 1.8 & 1.8 & IC & FO2 & - \\
\hline & 7 & 1.8 & 1.8 & 1.8 & IC & $\mathrm{FO2}$ & - \\
\hline 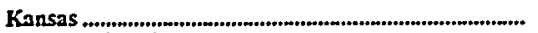 & & 12.8 & 11.5 & 11.5 & & & \\
\hline 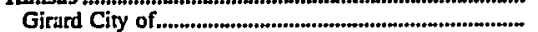 & & 7.3 & 6.5 & 6.5 & & & \\
\hline Girard (Crawford) & 6 & 3.5 & 3.0 & 3.0 & IC & Nat Gai & $\mathrm{FO2}$ \\
\hline & 7 & 3.8 & 3.5 & 3.5 & IC & Nat Gas & $\mathrm{FO} 2$ \\
\hline 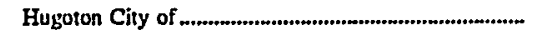 & & 5.5 & 5.0 & 5.0 & & & \\
\hline Huguton 2 (Stevens) & [] & 2.5 & 2.2 & 2.2 & IC & $\mathrm{FO} 2$ & Nat Gas \\
\hline & $\ddot{12}$ & 3.0 & 2.8 & 28 & IC & $\mathrm{FO} 2$ & Nat Gas \\
\hline Minnesota & & 13.4 & 129 & 12.9 & & & \\
\hline 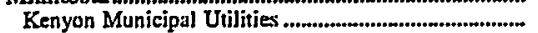 & & 5.5 & 5.5 & 5.5 & & & \\
\hline 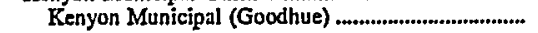 & 5 & 1.8 & 1.8 & 1.8 & IC & $\mathrm{FO} 2$ & - \\
\hline & 6 & 1.8 & 1.8 & 1.8 & IC & $\mathrm{FO2}$ & - \\
\hline & 7 & 1.8 & 1.8 & 3.8 & IC & FO2 & - \\
\hline New Ulm Public Utilities Comm & & 6.0 & 55 & 5.5 & & & \\
\hline 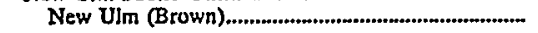 & 6 & 6.0 & 5.5 & 5.5 & ST & Nat Gas & BIT \\
\hline
\end{tabular}

See footnotes at end of table. 
Table 18. Generating Units that Started Operation at U.S. Electric Utilities by State, Company, and Plant, 1997 (Continued)

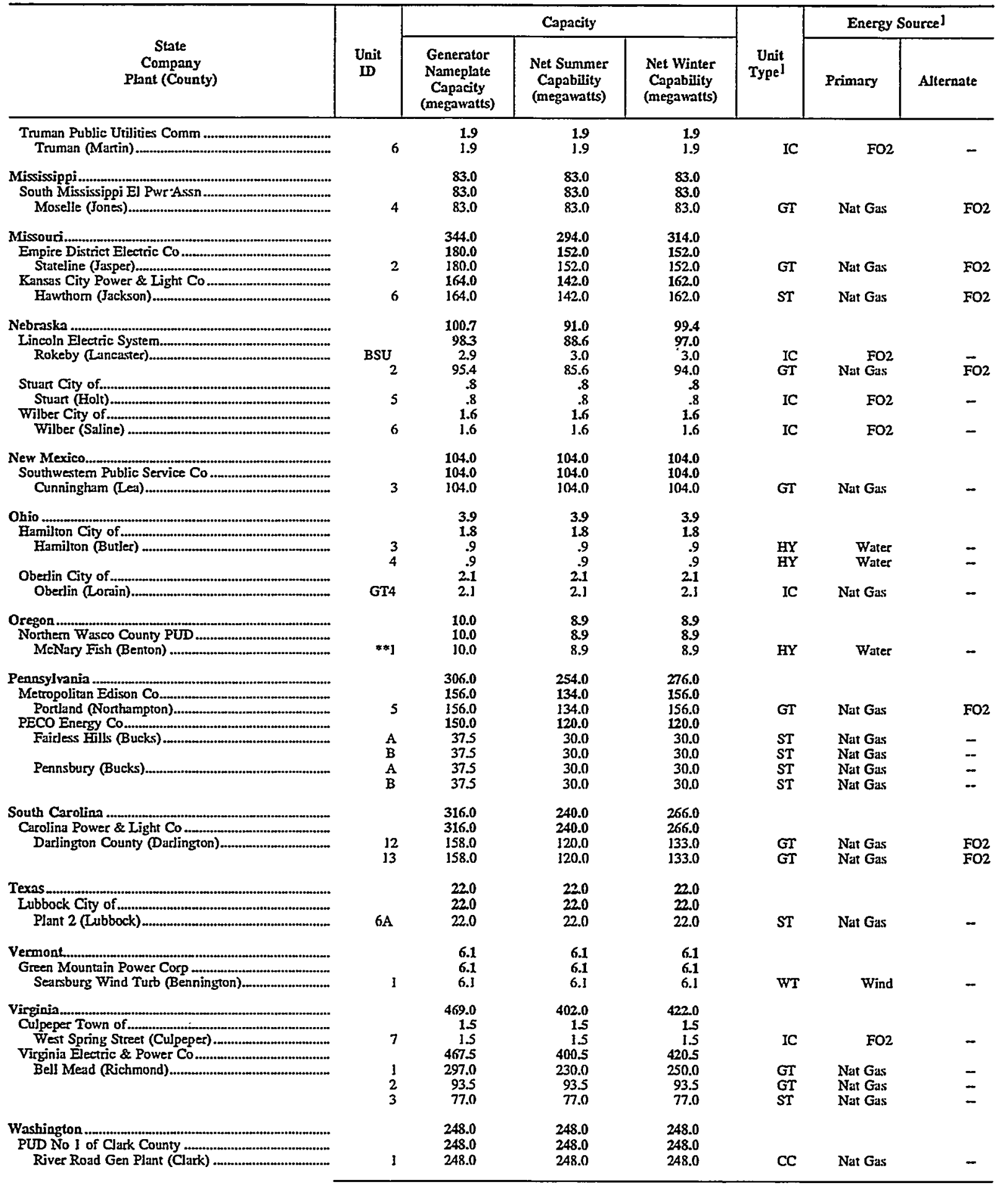

See footnotes at and of table. 
Table 18. Generating Units that Started Operation at U.S. Electric Utilities by State, Company, and Plant, 1997 (Continued)

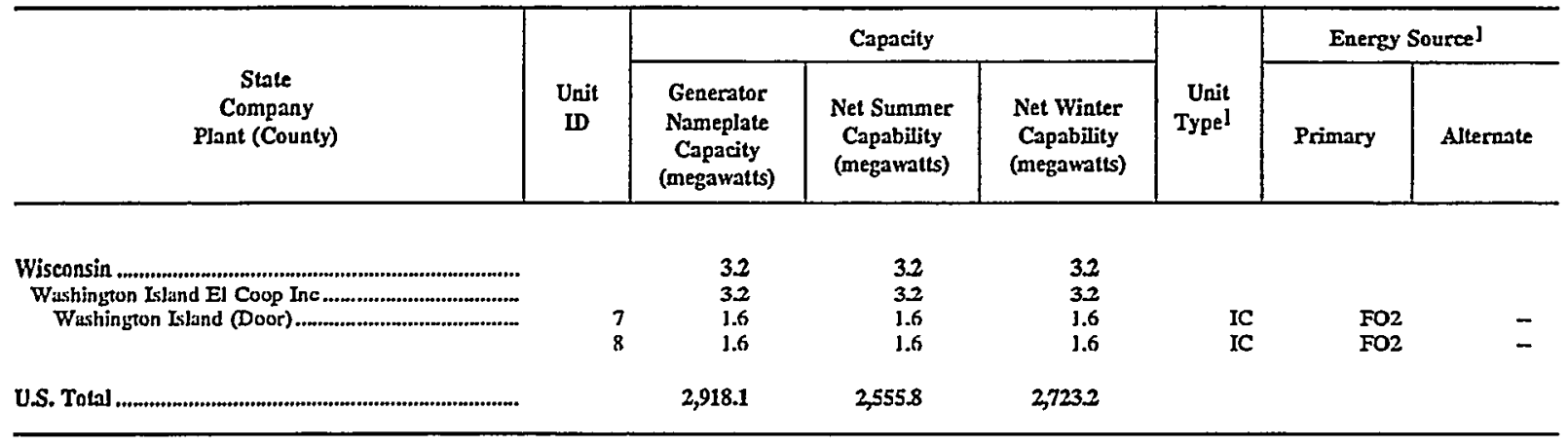

1 See Appendix B for codes.

* A jointly owned unit. See Appendix $C$ for the list of owners.

Note: Total may not equal the sum of components because of independent rounding.

Source: Energy Information Administration, Form EIA-860, "Annual Electric Generator Report." 
Table 19. Generating Units Retired from Service at U.S. Electric Utilities by State, Company, and Plant, 1997

\begin{tabular}{|c|c|c|c|c|c|c|c|c|}
\hline \multirow[b]{2}{*}{$\begin{array}{c}\text { State } \\
\text { Company } \\
\text { Plant (County) }\end{array}$} & \multirow[b]{2}{*}{$\begin{array}{l}\text { Unit } \\
\text { ID }\end{array}$} & \multicolumn{3}{|c|}{ Capacity } & \multirow[b]{2}{*}{$\begin{array}{c}\text { Unit } \\
\text { Type I }\end{array}$} & \multicolumn{2}{|c|}{ Energy Sourcel } & \multirow[b]{2}{*}{$\begin{array}{c}\text { Year } \\
\text { of } \\
\text { Commercial } \\
\text { Operation }\end{array}$} \\
\hline & & $\begin{array}{l}\text { Generator } \\
\text { Nameplate } \\
\text { Capacity } \\
\text { (negawatts) }\end{array}$ & $\begin{array}{l}\text { Net Summer } \\
\text { Capability } \\
\text { (megawatts) }\end{array}$ & $\begin{array}{l}\text { Net Winter } \\
\text { Capability } \\
\text { (megawatts) }\end{array}$ & & Primary & Alternate & \\
\hline \multicolumn{9}{|l|}{ Alaskan } \\
\hline 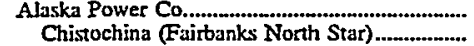 & & $\begin{array}{r}1.3 \\
.1\end{array}$ & $\begin{array}{r}1.3 \\
.3\end{array}$ & $\begin{aligned} 1.3 \\
.3\end{aligned}$ & IC & FOJ & $\mathrm{FO} 2$ & \\
\hline 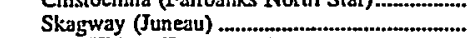 & $\frac{2}{9}$ & 1.3 & 1.3 & 1.3 & IC & $\mathrm{FO} 2$ & FOL & 1977 \\
\hline \multicolumn{9}{|l|}{ 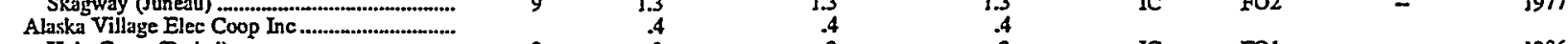 } \\
\hline Holy Cross (Bethel) & 3 & .2 & .2 & .2 & IC & FO1 & - & 1986 \\
\hline \multirow{2}{*}{\multicolumn{9}{|c|}{ 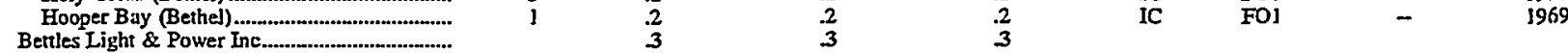 }} \\
\hline & & 3 & 3 & 3 & & & & \\
\hline \multirow{2}{*}{\multicolumn{9}{|c|}{ Galena Electric Utility }} \\
\hline & & & & & & & & \\
\hline \multirow{2}{*}{\multicolumn{9}{|c|}{ 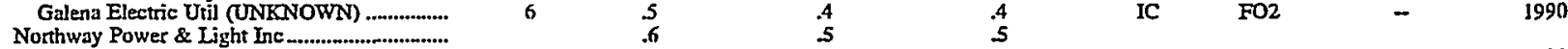 }} \\
\hline & & & & & & & & \\
\hline \multirow{2}{*}{\multicolumn{9}{|c|}{ 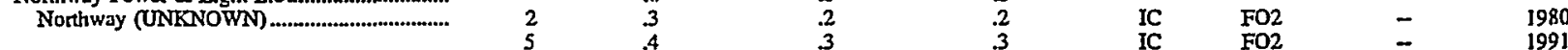 }} \\
\hline & 5 & .4 & .3 & .3 & IC & $\mathrm{FO} 2$ & - & 1991 \\
\hline \multirow{2}{*}{\multicolumn{9}{|c|}{$\begin{array}{l}\text { Perryville Village of } \\
\text { John Deere (UNKNOWN) }\end{array}$}} \\
\hline & 2 & .2 & .2 & .2 & IC & FOI & $\mathrm{FO2}$ & 1992 \\
\hline 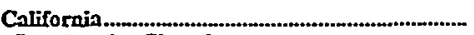 & & 195.4 & 191.0 & 191.0 & & & & \\
\hline Los Angeles City of & & 133.4 & 124.0 & 124.0 & & & & \\
\hline Harbor (Los Angeles) & GT8 & 23.6 & 19.0 & 19.0 & GT & Nat Gas & $\mathrm{FO2}$ & 1972 \\
\hline & GT9 & 23.6 & 19.0 & 19.0 & GT & Nat Gas & $\mathrm{FO} 2$ & 1972 \\
\hline & & 863 & 86.0 & 86.0 & ST & Nat Gas & FO6 & 3948 \\
\hline Pasadena City of & & 60.0 & 65.0 & 65.0 & & & & \\
\hline Glenarm (Los Angeles) & ST8 & 25.0 & 25.0 & 25.0 & ST & Nat Gass & FO6 & 1932 \\
\hline & ST9 & 35.0 & 40.0 & 40.0 & ST & Nat Gas & FO6 & 1949 \\
\hline $\begin{array}{l}\text { Santa Clara City of } \\
\text { SCDP Fuel Cell (Alameda) }\end{array}$ & 1 & 2.0 & $\begin{array}{l}2.0 \\
2.0\end{array}$ & 200 & FC & Nat Gus & $\ldots$ & 1996 \\
\hline Connecticut........... & & 45 & 303 & An 4 & & & & \\
\hline 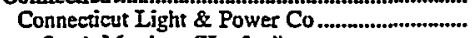 & & 42.5 & 30.3 & 40.4 & & & & \\
\hline 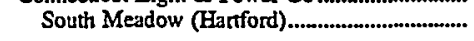 & 15 & 42.5 & 30.3 & 40.4 & GT & Jet Fuel & - & 1996 \\
\hline Forida & & 98.4 & 86.0 & 90.8 & & & & \\
\hline 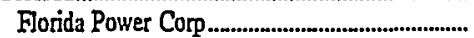 & & 653 & 55.0 & 58.0 & & & & \\
\hline Avon Park (Highlands) & 2 & 46.0 & 40.0 & 40.0 & ST & FO6 & - & 1952 \\
\hline Pont St Joe (Gün) & PI & 19.3 & 15.0 & 18.0 & GT & $\mathrm{FO2}$ & - & 1970 \\
\hline Lakeland City of & & 25.0 & 24.0 & 25.0 & & & & \\
\hline Lassen Memorial (Polk) & 6 & 25.0 & 24.0 & 25.0 & ST & Nat Gas & FO6 & 1959 \\
\hline Starke City of & & 8.1 & $\mathbf{7 . 0}$ & 7.8 & & & & \\
\hline 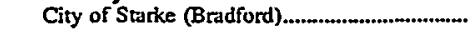 & 1 & 1.3 & 1.0 & 1.0 & IC & Nat Gas & $\mathrm{FO} 2$ & 1983 \\
\hline & 2 & 1.0 & .8 & 1.0 & IC & Nat Gas & FO2 & 1956 \\
\hline & 3 & 1.0 & .8 & 1.0 & IC & Nat Gas & $\mathrm{FO2}$ & 1956 \\
\hline & 4 & 1.0 & .8 & 3.0 & IC & Nat Gas & FO2 & 1956 \\
\hline & 5 & 1.0 & 8 & 1.0 & IC & Nat Gas & FO2 & 1956 \\
\hline & 6 & 1.8 & 1.8 & 1.8 & IC & Nat Gas & $\mathrm{FO} 2$ & 1968 \\
\hline & 7 & 1.0 & 1.0 & 1.0 & IC & FO2 & - & 1972 \\
\hline Hawaii...... & & 14.5 & 13.2 & 13.2 & & & & \\
\hline Hawaii Electric Light Co Inc... & & 11.7 & 11.5 & 11.5 & & & & \\
\hline Kanoelehua (Hawaii).............. & 1 & 11.7 & 11.5 & 11.5 & GT & FO2 & - & 1962 \\
\hline Maui Electric Co Itd ........ & & 2.8 & 1.7 & 1.7 & & & & \\
\hline Ianai City (Maui) ... & L1 & 1.2 & .7 & .7 & IC & $\mathrm{FO} 2$ & - & 1988 \\
\hline & 12 & 1.2 & .7 & .7 & IC & $\mathrm{FO} 2$ & - & 1988 \\
\hline & IA & .4 & .4 & .4 & IC & FO2 & - & 1988 \\
\hline 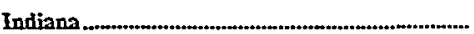 & & 16.6 & 16.5 & 14.4 & & & & \\
\hline Indianapolis Power \& Iight Co...................................... & & 16.6 & 16.5 & 14.4 & & & & \\
\hline Perry K (Murion). & 6 & 5.0 & 4.5 & 4.4 & ST & BIT & - & 1938 \\
\hline Perry W (Marion) & 7 & 11.6 & 120 & 10.0 & ST & BIT & FO2 & 1966 \\
\hline 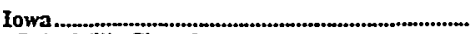 & & 4.1 & 3.9 & 3.9 & & & & \\
\hline Lake Mills City of & & 12 & 1.1 & 1.1 & & & & \\
\hline 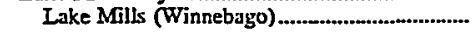 & 2 & .3 & 3 & 3 & IC & FO2 & - & 1937 \\
\hline & 3 & .9 & .8 & .8 & IC & FO2 & Nat Gas & 1956 \\
\hline Story City City of & & .7 & .7 & .7 & & & & \\
\hline 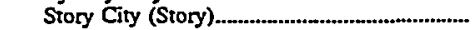 & 5 & .7 & .7 & .7 & IC & $\mathrm{FO} 2$ & Nat Gas & 1954 \\
\hline Strawberty Pojnt City of & & .5 & .4 & .4 & & & & \\
\hline 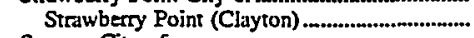 & 5 & .5 & .4 & .4 & IC & FO2 & Nat Gas & 1954 \\
\hline Sumner City of & & 1.7 & 1.7 & 1.7 & & & & \\
\hline
\end{tabular}

See footnotes at end of table. 
Table 19. Generating Units Retired from Service at U.S. Electric Utilities by State, Company, and Plant, 1997 (Continued)

\begin{tabular}{|c|c|c|c|c|c|c|c|c|}
\hline \multirow[b]{2}{*}{$\begin{array}{c}\text { State } \\
\text { Company } \\
\text { Plant (County) }\end{array}$} & \multirow[b]{2}{*}{$\begin{array}{l}\text { Unit } \\
\text { LD }\end{array}$} & \multicolumn{3}{|c|}{ Capacity } & \multirow[b]{2}{*}{$\begin{array}{c}\text { Unit } \\
\text { Type] }\end{array}$} & \multicolumn{2}{|c|}{ Energy Source 1} & \multirow[b]{2}{*}{$\begin{array}{c}\text { Year } \\
\text { of } \\
\text { Commercinl } \\
\text { Operation }\end{array}$} \\
\hline & & $\begin{array}{l}\text { Generstor } \\
\text { Nameplate } \\
\text { Capacity } \\
\text { (nlegawatts) }\end{array}$ & $\begin{array}{l}\text { Net Summer } \\
\text { Capability } \\
\text { (megawatts) }\end{array}$ & $\begin{array}{l}\text { Net Winter } \\
\text { Capability } \\
\text { (megawatts) }\end{array}$ & & Primary & Alternate & \\
\hline Sumner (Bremer).......................................................... & $\begin{array}{l}3 \\
4 \\
5\end{array}$ & $\begin{array}{r}0.7 \\
.3 \\
.7\end{array}$ & $\begin{array}{r}0.7 \\
.3 \\
.7\end{array}$ & $\begin{array}{r}0.7 \\
.3 \\
.7\end{array}$ & $\begin{array}{l}\text { IC } \\
\text { IC } \\
\text { IC }\end{array}$ & $\begin{array}{l}\text { FO2 } \\
\text { FO2 } \\
\text { FO2 }\end{array}$ & $\bar{z}$ & $\begin{array}{l}1946 \\
1939 \\
1951\end{array}$ \\
\hline 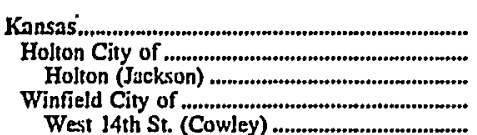 & 5 & $\begin{array}{r}10.9 \\
.9 \\
.9 \\
10.0 \\
10.0\end{array}$ & $\begin{array}{r}12.1 \\
.7 \\
.7 \\
11.5 \\
11.5\end{array}$ & $\begin{array}{r}12.3 \\
.9 \\
.9 \\
11.5 \\
11.5\end{array}$ & IC & FO2 & Nat Gas & 1951 \\
\hline 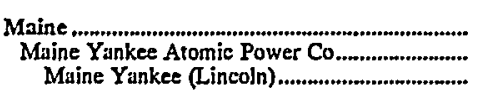 & $\mathrm{J}$ & $\begin{array}{l}920.0 \\
920.0 \\
920.0\end{array}$ & $\begin{array}{l}870.0 \\
870.0 \\
870.0\end{array}$ & $\begin{array}{l}879.0 \\
879.0 \\
879.0\end{array}$ & $\mathrm{NP}$ & Uranium & - & 1972 \\
\hline 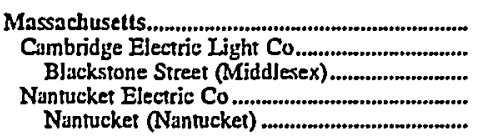 & 3 & $\begin{array}{l}3.8 \\
2.5 \\
2.5 \\
1.3 \\
1.3\end{array}$ & $\begin{array}{l}3.1 \\
1.8 \\
1.8 \\
1.3 \\
1.3\end{array}$ & $\begin{array}{l}3.1 \\
1.8 \\
1.8 \\
1.3 \\
1.3\end{array}$ & ST & $\mathrm{FO} 2$ & Nat Gas & 1930 \\
\hline 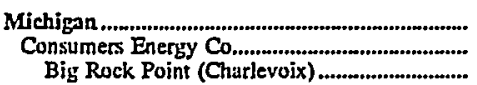 & J & $\begin{array}{l}75.0 \\
75.0 \\
75.0\end{array}$ & $\begin{array}{l}67.0 \\
67.0 \\
67.0\end{array}$ & $\begin{array}{l}67.0 \\
67.0 \\
67.0\end{array}$ & NB & Uranium & - & 1965 \\
\hline 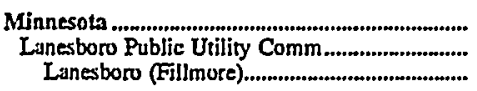 & J & $\begin{array}{l}.4 \\
.4 \\
.4\end{array}$ & $\begin{array}{l}3 \\
3 \\
3\end{array}$ & $\begin{array}{l}3 \\
3 \\
3\end{array}$ & IC & $\mathrm{FO} 2$ & - & 1931 \\
\hline 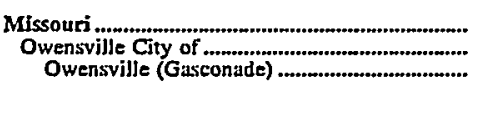 & $\begin{array}{l}1 \\
2 \\
3\end{array}$ & $\begin{array}{l}.5 \\
.5 \\
.2 \\
.2 \\
.2\end{array}$ & $\begin{array}{l}.4 \\
.4 \\
.1 \\
.1\end{array}$ & $\begin{array}{l}.4 \\
.4 \\
.1 \\
.1 \\
.1\end{array}$ & $\begin{array}{l}\text { IC } \\
\text { IC } \\
\text { IC }\end{array}$ & $\begin{array}{l}\text { FO2 } \\
\text { FO2 } \\
\text { FO2 }\end{array}$ & $\bar{z}$ & $\begin{array}{l}1939 \\
1939 \\
1939\end{array}$ \\
\hline 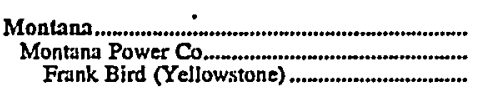 & 1 & $\begin{array}{l}69.0 \\
69.0 \\
69.0\end{array}$ & $\begin{array}{l}70.0 \\
70.0 \\
70.0\end{array}$ & $\begin{array}{l}70.0 \\
70.0 \\
70.0\end{array}$ & ST & Nat Gas & FO6 & 1951 \\
\hline 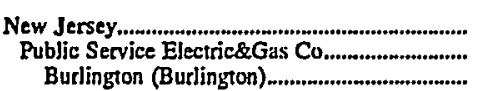 & 7 & $\begin{array}{l}205.0 \\
205.0 \\
205.0\end{array}$ & $\begin{array}{l}180.0 \\
180.0 \\
180.0\end{array}$ & $\begin{array}{l}185.0 \\
185.0 \\
185.0\end{array}$ & ST & FO6 & - & 1955 \\
\hline 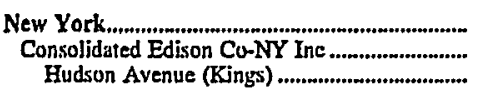 & 10 & $\begin{array}{l}60.0 \\
60.0 \\
60.0\end{array}$ & $\begin{array}{l}44.0 \\
44.0 \\
44.0\end{array}$ & $\begin{array}{l}44.0 \\
44.0 \\
44.0\end{array}$ & ST & FO6 & - & 1951 \\
\hline 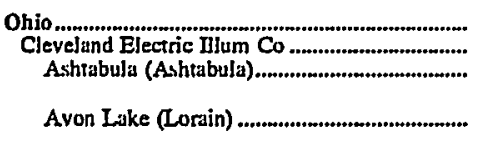 & $\begin{array}{l}8 \\
9 \\
6 \\
7\end{array}$ & $\begin{array}{r}264.0 \\
264.0 \\
46.0 \\
46.0 \\
86.0 \\
86.0\end{array}$ & $\begin{array}{r}276.0 \\
276.0 \\
43.0 \\
43.0 \\
95.0 \\
95.0\end{array}$ & $\begin{array}{r}280.0 \\
280.0 \\
44.0 \\
44.0 \\
96.0 \\
96.0\end{array}$ & $\begin{array}{l}\text { ST } \\
\text { ST } \\
\text { ST } \\
\text { ST }\end{array}$ & $\begin{array}{l}\text { BIT } \\
\text { BIT } \\
\text { BIT } \\
\text { BIT }\end{array}$ & $\bar{z}$ & $\begin{array}{l}1953 \\
1953 \\
1949 \\
1949\end{array}$ \\
\hline 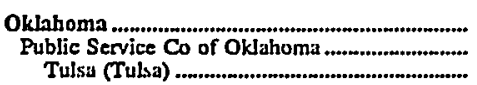 & 3 & $\begin{array}{l}95.0 \\
95.0 \\
95.0\end{array}$ & $\begin{array}{l}85.0 \\
85.0 \\
85.0\end{array}$ & $\begin{array}{l}85.0 \\
85.0 \\
85.0\end{array}$ & ST & Nat Gas & FO2 & 1958 \\
\hline 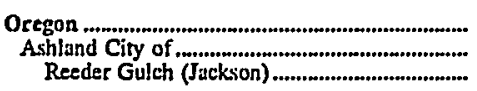 & 1 & $\begin{array}{l}.8 \\
.8 \\
.8\end{array}$ & $\begin{array}{l}.7 \\
.7 \\
.7\end{array}$ & $\begin{array}{l}.7 \\
.7 \\
.7\end{array}$ & HY & Water & - & 1983 \\
\hline 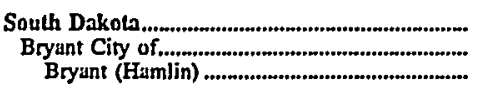 & 2 & $\begin{array}{l}3 \\
3 \\
3\end{array}$ & $\begin{array}{l}3 \\
3 \\
3\end{array}$ & $\begin{array}{l}3 \\
3 \\
3\end{array}$ & IC & FO2 & - & 1951 \\
\hline 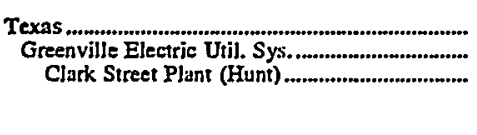 & $\begin{array}{l}\text { ICI } \\
\text { IC2 } \\
\text { IC3 }\end{array}$ & $\begin{array}{r}18.6 \\
18.6 \\
.7 \\
1.0 \\
1.4\end{array}$ & $\begin{array}{r}13.6 \\
13.6 \\
.5 \\
.6 \\
.7\end{array}$ & $\begin{array}{r}13.6 \\
13.6 \\
.5 \\
.6 \\
.7\end{array}$ & $\begin{array}{l}\text { IC } \\
\text { IC } \\
\text { IC }\end{array}$ & $\begin{array}{l}\mathrm{FO} 2 \\
\mathrm{FO} 2 \\
\mathrm{FO} 2 .\end{array}$ & $\bar{z}$ & $\begin{array}{l}1933 \\
1933 \\
1938\end{array}$ \\
\hline
\end{tabular}

See footnutes at end of table. 


\section{Table 19. Generating Units Retired from Service at U.S. Electric Utilities by State, Company, and Plant, 1997 (Continued)}

\begin{tabular}{|c|c|c|c|c|c|c|c|c|}
\hline \multirow[b]{2}{*}{$\begin{array}{c}\text { State } \\
\text { Company } \\
\text { Plant (County) }\end{array}$} & \multirow[b]{2}{*}{$\begin{array}{l}\text { Unit } \\
\text { ID }\end{array}$} & \multicolumn{3}{|c|}{ Capacity } & \multirow[b]{2}{*}{$\begin{array}{c}\text { Unit } \\
\text { TypeI }\end{array}$} & \multicolumn{2}{|c|}{ Energy Source] } & \multirow[b]{2}{*}{$\begin{array}{c}\text { Year } \\
\text { of } \\
\text { Commercin] } \\
\text { Operation }\end{array}$} \\
\hline & & $\begin{array}{c}\text { Generator } \\
\text { Nameplate } \\
\text { Capacity } \\
\text { (megawatts) }\end{array}$ & $\begin{array}{l}\text { Net Sumumer } \\
\text { Copability } \\
\text { (megawntts) }\end{array}$ & $\begin{array}{c}\text { Net Winter } \\
\text { Capability } \\
\text { (megawatts) }\end{array}$ & & Primary & Alternate & \\
\hline & 4 & 1.7 & 1.2 & 1.2 & IC & Nat Gas & - & 1942 \\
\hline & 5 & 20 & 1.2 & 1.2 & IC & Nat Gas & - & 1947 \\
\hline & 6 & 3.5 & 2.7 & 2.7 & IC & FO2 & Nat Gas & 1951 \\
\hline & 7 & 3.3 & 2.9 & 2.9 & IC & FO2 & Nat Gas & 1953 \\
\hline & 8 & 5.0 & 3.8 & 3.8 & IC & $\mathrm{FO} 2$ & Nat Gas & 1961 \\
\hline 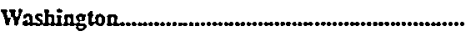 & & 28.5 & 25.6 & 28.5 & & & & \\
\hline Puget Sound Energy Inc. & & 28.5 & 25.6 & 28.5 & & & & \\
\hline South Whidbey (Island) & GT1 & 28.5 & 25.6 & 28.5 & GT & $\mathrm{FO} 2$ & - & 1973 \\
\hline 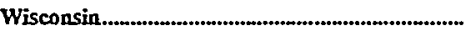 & & .8 & .4 & $\mathbf{5}$ & & & & \\
\hline 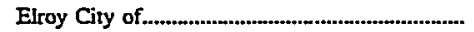 & & 3 & 3 & 3 & & & & \\
\hline Elroy (Juneau) & 4 & .3 & .3 & 3 & IC & $\mathrm{FO} 2$ & - & 1945 \\
\hline Muscoda City of & &. $\mathbf{l}$ & .1 & .1 & & & & \\
\hline Muscoda (Richland) & 2 & .1 & .1 & .1 & IC & $\mathrm{FO} 2$ & - & 1920 \\
\hline 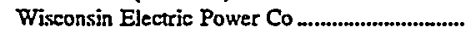 & & .4 & 一 & .1 & & & & \\
\hline Weyauwega (Waupaca) & ] & .4 & 0.0 & ]$. & HY & Water & - & 1930 \\
\hline U.S. Total & & $2,127.1$ & $1,992.5$ & $2,026.5$ & & & & \\
\hline
\end{tabular}

1 See Appendix B for codes.

** A jointly owned unit.

Notes: -Total may not equal the sum of components because of independent rounding. $\bullet 0.0$ capability means no capability during the designated time period.

Source: Energy Information Administration, Form ElA-860, "Annual Electric Generator Report." 
Table 20. Existing Generating Units at U.S. Electric Utilities by State, Company, and Plant, as of January 1, 1998

\begin{tabular}{|c|c|c|c|c|c|c|c|c|c|}
\hline \multirow{2}{*}{$\begin{array}{c}\text { State } \\
\text { Company } \\
\text { Plant (County) }\end{array}$} & \multirow{2}{*}{$\begin{array}{l}\text { Unit } \\
\text { ID }\end{array}$} & \multirow{2}{*}{$\begin{array}{c}\text { Generator } \\
\text { Nameplate } \\
\text { Capacity } \\
\text { (niegawatts) }\end{array}$} & \multirow{2}{*}{$\begin{array}{c}\text { Net Summer } \\
\text { Capability } \\
\text { (megawatts) }\end{array}$} & \multirow{2}{*}{$\begin{array}{l}\text { Net Winter } \\
\text { Capability } \\
\text { (megawatts) }\end{array}$} & \multirow{2}{*}{$\begin{array}{l}\text { Unit } \\
\text { Type] }\end{array}$} & \multicolumn{2}{|c|}{ Energy Sourcel } & \multirow{2}{*}{$\begin{array}{c}\text { Year } \\
\text { of } \\
\text { Commercinl } \\
\text { Operation }\end{array}$} & \multirow{2}{*}{$\begin{array}{c}\text { Unit } \\
\text { Status }\end{array}$} \\
\hline & & & & & & Primary & Alternate & & \\
\hline Alabama & & & & & & & & & \\
\hline 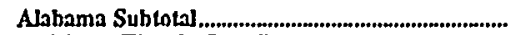 & & $22,242.1$ & $20,839.8$ & $20,993.4$ & & & & 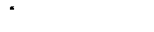 & \\
\hline 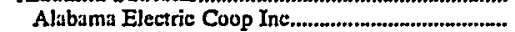 & & 8032 & 804.3 & 8313 & & & & & \\
\hline Charles $R$ Lowman (Washington) & $\frac{1}{2}$ & $\begin{array}{r}66.0 \\
236.0\end{array}$ & $\begin{array}{r}71.0 \\
232.0\end{array}$ & $\begin{array}{r}78.0 \\
235.0\end{array}$ & $\begin{array}{l}\text { ST } \\
\text { ST }\end{array}$ & $\begin{array}{l}\text { BIT } \\
\text { BIT }\end{array}$ & $\overline{-}$ & $\begin{array}{l}1969 \\
1978\end{array}$ & $\begin{array}{l}\text { OP } \\
\text { OP }\end{array}$ \\
\hline & 3 & 236.0 & 238.0 & 240.0 & ST & BIT & - & 1980 & OP \\
\hline 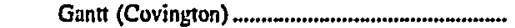 & 3 & 1.2 & 1.2 & 1.2 & HY & Water & - & 1926 & OP \\
\hline & 4 & 3.8 & 1.9 & 1.9 & HY & Water & - & 1985 & OP \\
\hline 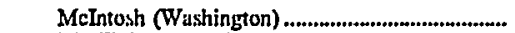 & i & 110.0 & 110.0 & 110.0 & CE & Nat Gas & $\mathrm{FO} 2$ & 1991 & OP \\
\hline McWilliams (Covington) ....................................... & j & 7.5 & 10.0 & 10.0 & $\mathrm{CW}$ & WH & - & 1954 & OP \\
\hline & 2 & 7.5 & 10.0 & 10.0 & CW & WH & - & 1954 & OP \\
\hline & 3 & 25.0 & 23.0 & 23.0 & $\mathrm{CW}$ & WH & - & 1959 & $\mathrm{OP}$ \\
\hline & 4 & 107.0 & 102.0 & 117.0 & CT & Nat Gas & - & 1996 & OP \\
\hline 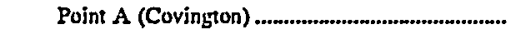 & I & 1.6 & 1.6 & 1.6 & HY & Water & - & 3925 & OP \\
\hline & 2 & 1.6 & 1.6 & 1.6 & HY & Water & - & 1925 & OP \\
\hline & 3 & 2.0 & 2.0 & 2.0 & HY & Water & - & 1949 & OP \\
\hline Alabama Power Co & & $12,875.3$ & $12,379.4$ & $12,445.7$ & & & & & \\
\hline Bankhead Dam (Tuscaloosa)................................. & 1 & 45.1 & 50.0 & 50.0 & HY & Water & - & 1963 & OP \\
\hline 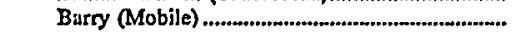 & $\frac{1}{2}$ & 153.1 & $\begin{array}{l}139.6 \\
138.7\end{array}$ & $\begin{array}{l}139.6 \\
138.7\end{array}$ & $\begin{array}{l}\text { ST } \\
\text { ST }\end{array}$ & BIT & Nat Gas & 1954 & OP \\
\hline & $\begin{array}{l}2 \\
3\end{array}$ & $\begin{array}{l}153.1 \\
272.0\end{array}$ & $\begin{array}{l}138.7 \\
255.5\end{array}$ & $\begin{array}{l}138.7 \\
255.5\end{array}$ & $\begin{array}{l}\text { ST } \\
\text { ST }\end{array}$ & $\begin{array}{l}\text { BIr } \\
\text { BIT }\end{array}$ & $\begin{array}{l}\text { Nat Gas } \\
\text { Nat Gas }\end{array}$ & $\begin{array}{l}1954 \\
1959\end{array}$ & $\begin{array}{l}\text { OP } \\
\text { OP }\end{array}$ \\
\hline & 4 & 403.8 & 362.3 & 3623 & ST & BIT & Nat Gas & 1969 & OP \\
\hline & 5 & 788.8 & 750.0 & 750.0 & ST & BIT & Nat Gas & 1971 & OP \\
\hline Chickasaw (Mobile) & & 46.0 & 49.0 & 49.0 & sT & Nat Gas & FO2 & j951 & OP \\
\hline 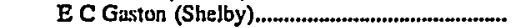 & *GT4 & 21.3 & 15.8 & 20.0 & GT & $\mathrm{FO} 2$ & - & 1970 & OP \\
\hline & "ST4 & 244.8 & 256.8 & 256.8 & ST & BIT & - & 1962 & OP \\
\hline & $* *_{1}$ & 272.0 & 256.5 & 256.5 & ST & BIT & - & 1960 & OP \\
\hline & $* 2$ & 272.0 & 258.8 & 258.8 & ST & BIT & - & 1960 & $\mathbf{O P}$ \\
\hline & $* 3$ & 272.0 & 255.7 & 255.7 & ST & BIT & - & 1961 & OP \\
\hline & 5 & 952.0 & 897.0 & 897.0 & ST & BIT & - & 1974 & OP \\
\hline Gadsden (Etowah) & J & 69.0 & 64.2 & 64.2 & ST & BIT & Nat Gas & 1949 & OP \\
\hline & 2 & 69.0 & 68.7 & 68.7 & ST & BIT & Nat Gas & 1949 & OP \\
\hline Gorgas (Walker) & 6 & 125.0 & 110.8 & 110.8 & ST & BIT & - & 1951 & OP \\
\hline & 7 & 125.0 & 113.0 & 113.0 & ST & BIT & - & 1952 & OP \\
\hline & 8 & 187.5 & 168.1 & 168.1 & ST & BIT & - & 1956 & OP \\
\hline & 9 & 190.4 & 179.] & 179.1 & ST & BIT & - & 1958 & $\mathrm{OP}$ \\
\hline & 10 & 788.8 & 745.8 & 745.8 & ST & BIT & - & 1972 & $O P$ \\
\hline Greene County (Greene) & GT10 & 80.0 & 83.5 & 95.9 & GT & Nat Gas & FO2 & 1996 & OP \\
\hline & GT2 & 80.0 & 83.5 & 95.9 & GT & Nat Gas & FO2 & 1996 & OP \\
\hline & GT3 & 80.0 & 83.5 & 95.9 & $\mathrm{GT}$ & Nat Gas & $\mathrm{FO} 2$ & 1995 & OP \\
\hline & GT4 & 80.0 & 83.5 & 95.9 & $\mathbf{G T}$ & Nat Gas & $\mathrm{FO} 2$ & 1995 & OP \\
\hline & GT5 & 80.0 & 83.5 & 95.9 & GT & Nast Gas & FO2 & 1995 & OP \\
\hline & GT6 & 80.0 & 83.5 & 95.9 & GT & Nat Gas & FO2 & 1995 & OP \\
\hline & GI7 & 80.0 & 83.5 & 95.9 & GT & Nat Gas & FO2 & 1995 & OP \\
\hline & GT8 & 80.0 & 83.5 & 95.9 & GT & Nat Gas & $\mathrm{FO} 2$ & 1996 & OP \\
\hline & GT9 & 80.0 & 835 & 95.9 & GT & Nat Gas & $\mathrm{FO} 2$ & 1996 & OP \\
\hline & $* * !$ & 299.2 & 256.8 & 256.8 & ST & BIT & - & 1965 & $\mathbf{O P}$ \\
\hline & $* 2$ & 269.3 & 255.0 & 255.0 & ST & Nat Gas & FO2 & 1966 & OP \\
\hline 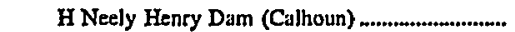 & 1 & 24.3 & 23.3 & 22.3 & HY & Water & - & 1966 & $O P$ \\
\hline & 2 & 24.3 & 23.3 & 22.3 & HY & Water & - & 1966 & OP \\
\hline & 3 & 24.3 & 23.4 & 22.4 & HY & Water & - & 1966 & OP \\
\hline 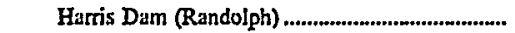 & 1 & 67.5 & 66.0 & 61.5 & HY & Water & - & 1983 & OP \\
\hline & 2 & 67.5 & 66.0 & 615 & $\mathbf{H Y}$ & Water & - & 1983 & op \\
\hline 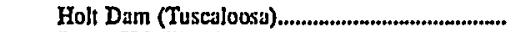 & 1 & 40.0 & 43.0 & 43.0 & HY & Water & - & 1968 & $\mathrm{OP}$ \\
\hline James H Miller Jr (Jefferson)................................. & $* 1$ & 705.5 & 667.2 & 667.2 & ST & BIT & - & 1978 & OP \\
\hline & $=2$ & 705.5 & 667.7 & 667.7 & ST & BIT & - & 1985 & $\mathrm{OP}$ \\
\hline & 3 & 705.5 & 671.4 & 671.4 & ST & BIT & - & 1989 & OP \\
\hline & 4 & 705.5 & 672.J & 672.1 & ST & BIT & - & 1991 & OP \\
\hline 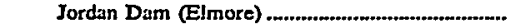 & 1 & 25.0 & 34.0 & 34.5 & $\mathbf{H Y}$ & Water & - & 1929 & OP \\
\hline & 2 & 25.0 & 34.0 & 34.5 & $\mathbf{H Y}$ & Water & - & 1929 & OP \\
\hline & $\overline{3}$ & 25.0 & 34.0 & 34.5 & $\mathbf{B Y}$ & Water & - & 1929 & OP \\
\hline & 4 & 25.0 & 34.0 & 34.5 & HY & Water & - & 1929 & OP \\
\hline Joseph M Farley (Houston) & i & 888.3 & 823.8 & 823.8 & NP & Uranium & - & 1977 & OP \\
\hline & 2 & 888.3 & 854.0 & 854.0 & NP & Uranium & - & $198 \mathrm{I}$ & OP \\
\hline 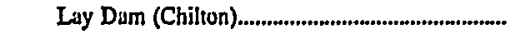 & j & 29.5 & 29.8 & 30.0 & $\mathbf{H Y}$ & Water & - & 1968 & $\mathrm{OP}$ \\
\hline & 2 & 29.5 & 29.8 & 30.0 & HY & Water & - & 1968 & OP \\
\hline & 3 & 29.5 & 29.8 & 30.0 & $\mathbf{H Y}$ & Water & - & 1967 & OP \\
\hline & 4 & 29.5 & 29.8 & 30.0 & HY & Water & - & 1967 & $\overrightarrow{O P}$ \\
\hline & 5 & 29.5 & 29.8 & 30.0 & $\mathbf{H Y}$ & Water & - & 1967 & $O P$ \\
\hline & 6 & 29.5 & 29.8 & 30.0 & $\mathrm{HY}$ & Water & - & 1967 & OP \\
\hline
\end{tabular}

See footnotes at end of table. 
Table 20. Existing Generating Units at U.S. Electric Utilities by State, Company, and Plant, as of January 1, 1998 (Continued)

\begin{tabular}{|c|c|c|c|c|c|c|c|c|c|}
\hline \multirow{2}{*}{$\begin{array}{c}\text { State } \\
\text { Company } \\
\text { Plant (County) }\end{array}$} & \multirow{2}{*}{$\begin{array}{l}\text { Unit } \\
\text { ID }\end{array}$} & \multirow{2}{*}{$\begin{array}{l}\text { Generator } \\
\text { Nameplate } \\
\text { Capacity } \\
\text { (megawatts) }\end{array}$} & \multirow{2}{*}{$\begin{array}{c}\text { Net Summer } \\
\text { Capability } \\
\text { (megawatts) }\end{array}$} & \multirow{2}{*}{$\begin{array}{l}\text { Net Winter } \\
\text { Capability } \\
\text { (megawatts) }\end{array}$} & \multirow{2}{*}{$\begin{array}{r}\text { Unit } \\
\text { Type }\end{array}$} & \multicolumn{2}{|c|}{ Energy Sourcel } & \multirow{2}{*}{$\begin{array}{c}\text { Year } \\
\text { of } \\
\text { Commercial } \\
\text { Operation }\end{array}$} & \multirow{2}{*}{$\begin{array}{c}\text { Unit } \\
\text { Status! }\end{array}$} \\
\hline & & & & & & Primary & Alternate & & \\
\hline Alabama (Continued) & & & & & & & & & \\
\hline Lewis Smith Dam (Walker) & $\begin{array}{l}1 \\
2\end{array}$ & $\begin{array}{l}78.8 \\
78.8\end{array}$ & $\begin{array}{l}90.0 \\
90.0\end{array}$ & $\begin{array}{l}87.0 \\
87.0\end{array}$ & $\begin{array}{l}\mathrm{HY} \\
\mathrm{HY}\end{array}$ & $\begin{array}{l}\text { Water } \\
\text { Water }\end{array}$ & $\overline{-}$ & $\begin{array}{l}1961 \\
1962\end{array}$ & $\begin{array}{l}O P \\
O P\end{array}$ \\
\hline Logan Martin Dam (Talladega)............................. & 1 & 42.8 & 45.0 & 41.7 & $\mathrm{HY}$ & Water & - & 1964 & OP \\
\hline & 2 & 42.8 & 45.0 & 41.7 & HY & Water & - & 1964 & OP \\
\hline & 3 & 428 & 45.0 & 41.7 & HY & Water & - & 1964 & OP \\
\hline 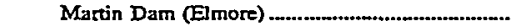 & 1 & 33.0 & 34.2 & 29.8 & $\mathbf{H Y}$ & Water & - & 3927 & OP \\
\hline & 2 & 33.0 & 34.2 & 29.8 & $\mathbf{H Y}$ & Water & - & 1927 & OP \\
\hline & $\begin{array}{l}3 \\
4\end{array}$ & 33.0 & 34.2 & $\begin{array}{l}29.8 \\
497\end{array}$ & $\mathbf{H Y}$ & Water & - & 1927 & OP \\
\hline Mitchell Dam (Cousi) & 4 & 20.0 & 19.5 & $\begin{array}{l}49.7 \\
19.5\end{array}$ & $\begin{array}{l}\mathrm{HY} \\
\mathrm{HY}\end{array}$ & $\begin{array}{l}\text { Water } \\
\text { Water }\end{array}$ & $\overline{-}$ & $\begin{array}{l}1952 \\
1949\end{array}$ & $\begin{array}{l}O P \\
O P\end{array}$ \\
\hline & $s$ & 50.0 & 48.8 & 49.2 & HY & Water & - & 1985 & OP \\
\hline & 6 & 50.0 & 48.8 & 492 & HY & Water & - & 1985 & $\mathrm{OP}$ \\
\hline & 7 & 50.0 & 48.8 & 49.2 & HY & Water & - & 1985 & OP \\
\hline Thurlow Dam (Elmore) & I & 25.0 & 33.6 & 34.1 & HY & Water & - & 1931 & OP \\
\hline & 2 & 25.0 & 33.6 & 34.1 & $\mathbf{H Y}$ & Water & - & 1931 & OP \\
\hline & 3 & 8.0 & 10.8 & 10.9 & HY & Water & - & 1931 & OP \\
\hline Walter Bouldin Dam (Elmore) ................................. & 1 & 75.0 & 75.7 & 76.0 & $\mathrm{HY}$ & Water & - & 1967 & $O P$ \\
\hline & 2 & 75.0 & 75.7 & 76.0 & HY & Water & - & 1967 & OP \\
\hline & 3 & 75.0 & 75.7 & 76.0 & HY & Water & - & 1967 & OP \\
\hline 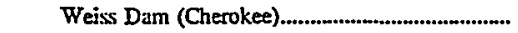 & 1 & 29.3 & 24.7 & 22.3 & $\mathrm{HY}$ & Water & - & 1962 & OP \\
\hline & 2 & 29.3 & 24.7 & 22.3 & HY & Water & - & 196] & OP \\
\hline & 3 & 29.3 & 24.7 & 22.3 & HY & Water & - & 1961 & OP \\
\hline Yates Dam (Elmore) & 1 & 16.0 & 225 & 22.5 & HY & Water & - & 1928 & OP \\
\hline & 2 & 16.0 & 22.5 & 225 & HY & Water & - & 1928 & OP \\
\hline Tennessee Valley Authority & & $8,420.6$ & $7,513.1$ & $\mathbf{7 , 5 7 3 . 4}$ & & & & & \\
\hline 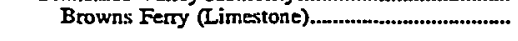 & 1 & 1152.0 & 1065.0 & 1065.0 & NB & Uranium & - & 3974 & os \\
\hline & $\begin{array}{l}2 \\
3\end{array}$ & $\begin{array}{l}1152.0 \\
11520\end{array}$ & 1065.0 & 1065.0 & NB & Uranium & $\overline{-}$ & 1975 & OP \\
\hline Colbert (Colbert) & & J152.0 & 1055.0 & 1065.0 & NB & Uranium & - & 1977 & OP \\
\hline Colbert (Colbert) & $\begin{array}{l}\text { GT1 } \\
\text { GT2 }\end{array}$ & $\begin{array}{l}59.5 \\
59.5\end{array}$ & $\begin{array}{l}49.5 \\
49.5\end{array}$ & $\begin{array}{l}58.0 \\
58.0\end{array}$ & $\begin{array}{l}\text { GT } \\
\text { GT }\end{array}$ & $\begin{array}{l}\text { Nat Gas } \\
\text { Nat Gas }\end{array}$ & $\begin{array}{l}\mathrm{FO} 2 \\
\mathrm{FO} 2\end{array}$ & $\begin{array}{l}1972 \\
1972\end{array}$ & $\begin{array}{l}O P \\
O P\end{array}$ \\
\hline & GT3 & 59.5 & 49.5 & 58.0 & GT & Nat Gas & $\mathrm{FO} 2$ & 1972 & OP \\
\hline & GT4 & 59.5 & 49.5 & 58.0 & GT & Nat Gas & $\mathrm{FO} 2$ & 1972 & OP \\
\hline & GT5 & 59.5 & 49.5 & 58.0 & GT & Nat Gas & $\mathrm{FO} 2$ & 1972 & OP \\
\hline & GT6 & 59.5 & 49.5 & 58.0 & GT & Nat Gas & FO2 & 1972 & OP \\
\hline & GI7 & 59.5 & 49.5 & 58.0 & GT & Nat Gas & FO2 & 1972 & OP \\
\hline & GT8 & 59.5 & 49.5 & 58.0 & GT & Nar Gas & $\mathrm{FO} 2$ & 1972 & OP \\
\hline & 1 & 200.0 & 178.0 & 182.0 & ST & BIT & - & 1955 & OP \\
\hline & 2 & 200.0 & 378.0 & 182.0 & ST & BIT & - & 1955 & OP \\
\hline & 3 & 200.0 & 178.0 & 182.0 & ST & BIT & - & 1955 & OP \\
\hline & 4 & 200.0 & 178.0 & 182.0 & ST & BIT & - & 1955 & OP \\
\hline & 5 & 550.0 & 467.0 & 476.0 & ST & BIT & - & 1965 & OP \\
\hline Guntersville (Marshall) & 1 & 28.8 & 30.0 & 28.5 & HY & Water & - & 1939 & OP \\
\hline & 2 & 28.8 & 30.0 & 28.5 & HY & Water & - & 1939 & $O P$ \\
\hline & 3 & 28.8 & 30.0 & 28.5 & $\mathrm{HY}$ & Water & - & 1939 & $O P$ \\
\hline & 4 & 28.8 & 30.0 & 28.5 & $\mathrm{HY}$ & Water & - & 1952 & $O P$ \\
\hline 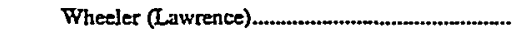 & 1 & 35.1 & 33.3 & 31.3 & $\mathbf{H Y}$ & Water & - & 1936 & OP \\
\hline & 2 & 35.1 & 33.3 & 31.3 & HY & Water & - & 1937 & OP \\
\hline & 3 & 35.1 & 33.3 & 313 & HY & Water & - & 1941 & $O P$ \\
\hline & 4 & 35.1 & 33.3 & 313 & HY & Water & - & 1941 & $O P$ \\
\hline & 5 & 35.1 & 34.5 & 32.3 & $\mathrm{HY}$ & Water & - & 1948 & $O P$ \\
\hline & 6 & 35.1 & 34.5 & 323 & HY & Water & - & 1949 & $O P$ \\
\hline & 7 & 35.1 & 34.5 & 32.3 & HY & Water & - & 1949 & $O P$ \\
\hline & 8 & 35.1 & 34.5 & 323 & $\mathrm{HY}$ & Water & - & 1950 & OP \\
\hline & 9 & 43.7 & 36.3 & 35.0 & $\mathrm{HY}$ & Water & - & 1962 & $O P$ \\
\hline & 10 & 36.0 & 36.3 & 35.0 & HY & Water & - & 1963 & $O P$ \\
\hline & 11 & 36.0 & 36.3 & 35.0 & $\mathrm{HY}$ & Water & - & 1963 & $O P$ \\
\hline Widows Creek (Jackson) & j & 140.6 & 111.0 & 113.0 & ST & BIT & - & 1952 & OP \\
\hline & 2 & 140.6 & 111.0 & 113.0 & ST & BIT & - & 1952 & OP \\
\hline & 3 & 140.6 & 111.0 & II3.0 & $\mathbf{S T}$ & BIT & - & 1952 & OP \\
\hline & 4 & 140.6 & 111.0 & 113.0 & ST & BIT & - & 1953 & OP \\
\hline & 5 & 140.6 & 111.0 & 113.0 & ST & BIT & - & 1954 & OP \\
\hline & 6 & 140.6 & 111.0 & 113.0 & ST & BIT & - & 1954 & OP \\
\hline & 7 & 575.0 & 477.0 & 480.0 & ST & BIT & - & 1961 & OP \\
\hline & 8 & 550.0 & 467.0 & 471.0 & ST & BIT & - & 1965 & OP \\
\hline 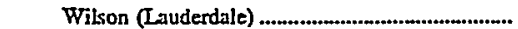 & T & 23.0 & 22.0 & 20.0 & $\mathrm{HY}$ & Water & - & 1925 & OP \\
\hline & 2 & 23.0 & 22.0 & 20.0 & HY & Water & - & 1925 & OP \\
\hline & 3 & 23.0 & 22.0 & 20.0 & $\mathrm{HY}$ & Water & -- & 1925 & OP \\
\hline & 4 & 23.0 & 22.0 & 20.0 & $\mathrm{HY}$ & Water & - & 1925 & $O P$ \\
\hline & 5 & 31.0 & 28.0 & 27.0 & $\mathrm{HY}$ & Water & - & 1925 & OP \\
\hline & 6 & 31.0 & 28.0 & 27.0 & $\mathrm{HY}$ & Water & - & 1925 & OP \\
\hline
\end{tabular}

See footnotes at end of table. 


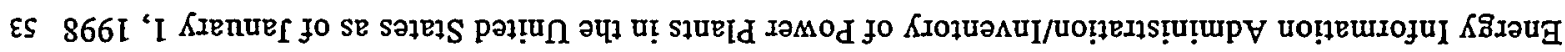

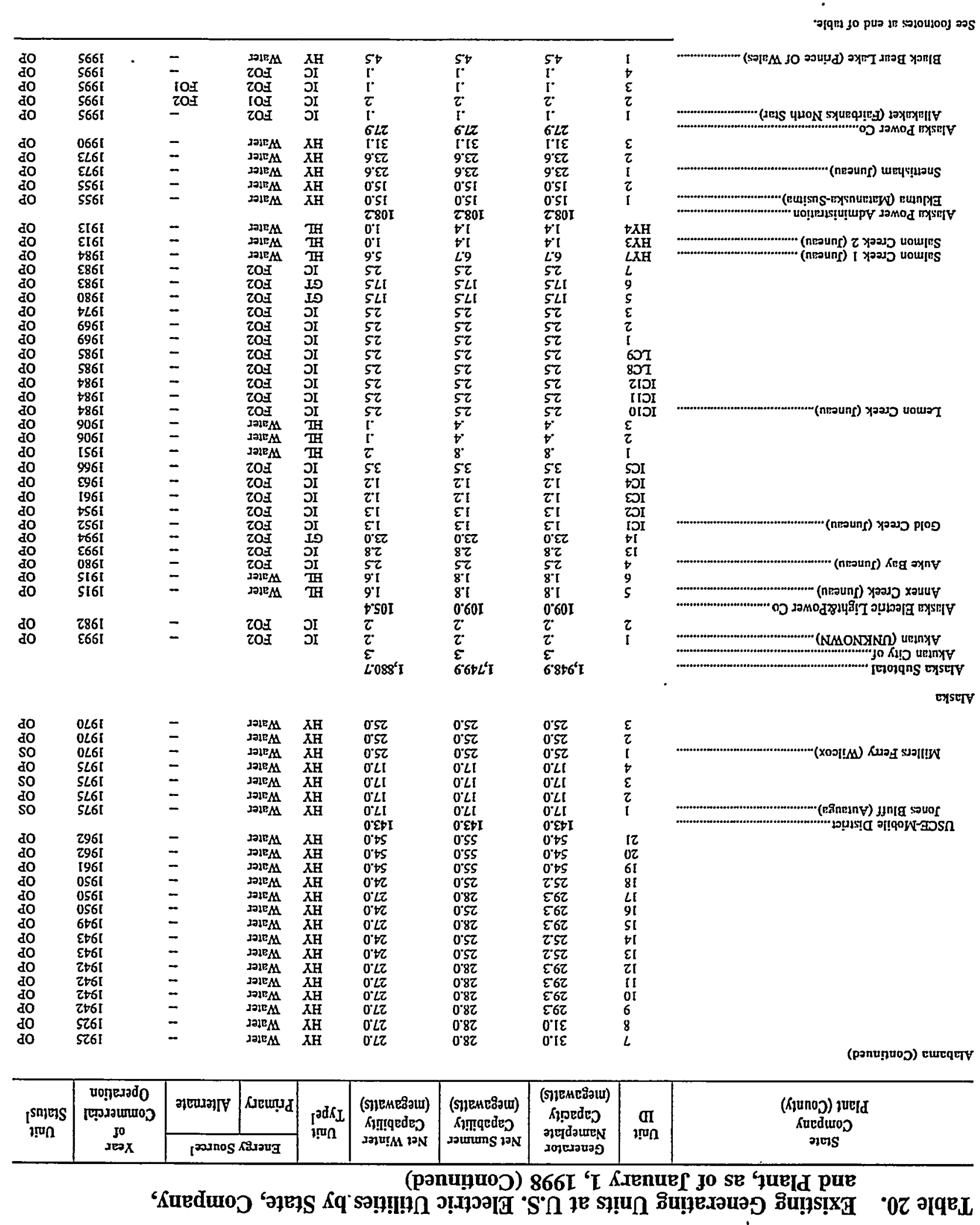


Table 20. Existing Generating Units at U.S. Electric Utilities by State, Company, and Plant, as of January 1, 1998 (Continued)

\begin{tabular}{|c|c|c|c|c|c|c|c|c|c|}
\hline \multirow{2}{*}{$\begin{array}{c}\text { State } \\
\text { Company } \\
\text { Plant (County) }\end{array}$} & \multirow{2}{*}{$\begin{array}{l}\text { Unit } \\
\text { WD }\end{array}$} & \multirow{2}{*}{$\begin{array}{c}\text { Generator } \\
\text { Nameplate } \\
\text { Capacity } \\
\text { (megawatts) }\end{array}$} & \multirow{2}{*}{$\begin{array}{l}\text { Net Summer } \\
\text { Capability } \\
\text { (megawatts) }\end{array}$} & \multirow{2}{*}{$\begin{array}{c}\text { Net Winter } \\
\text { Capability } \\
\text { (negawatts) }\end{array}$} & \multirow{2}{*}{$\begin{array}{c}\text { Unit } \\
\text { Type] }\end{array}$} & \multicolumn{2}{|c|}{ Energy Source] } & \multirow{2}{*}{$\begin{array}{c}\text { Year } \\
\text { of } \\
\text { Commercial } \\
\text { Operation }\end{array}$} & \multirow{2}{*}{$\begin{array}{c}\text { Unit } \\
\text { Status }\end{array}$} \\
\hline & & & & & & Primary & Alternate & & \\
\hline Alaska (Conlinued) & & & & & & & & & \\
\hline Chistochina (Fairbanks North Star) & $2 \mathrm{~A}$ & 0.1 & 0.1 & 0.1 & IC & FOI & FO2 & 1997 & OP \\
\hline & ] & .1 & .1 & .1 & IC & Fol & FO2 & 199] & $\mathrm{OP}$ \\
\hline Coffman Cove (Prince Of Wales) ............................ & $2 \mathrm{~A}_{3}$ & .3 & 3 & 3 & IC & $\begin{array}{l}\text { FO2 } \\
\text { FO2 }\end{array}$ & $\begin{array}{l}\mathrm{FO} 1 \\
\mathrm{FO}\end{array}$ & $\begin{array}{l}1993 \\
1992\end{array}$ & $\begin{array}{l}\text { OP } \\
\text { OP }\end{array}$ \\
\hline Craig (Prince Of Wales) & IC2́ & .3 & 3 & 3 & IC & $\mathrm{FO} 2$ & $\rightarrow$ & 1978 & OP \\
\hline & $3 \mathbf{A}$ & 1.6 & 1.6 & 1.6 & IC & FO2 & - & 199] & OP \\
\hline & I & .7 & .7 & .7 & IC & $\mathrm{FO} 2$ & - & 1984 & OP \\
\hline & 5 & 1.] & 1.1 & 1.1 & IC & FO2 & - & 1983 & $O P$ \\
\hline Dot Lake (Fairbanks North Star) & 1 & .1 & .1 & .3 & IC & $\mathrm{FO} 2$ & FOI & $\begin{array}{l}1989 \\
1990\end{array}$ & OP \\
\hline Eagle (Fairbanks North Star)............................. & I & .2 & .2 & .2 & IC & FOl & $\mathrm{FO} 2$ & 1993 & OP \\
\hline 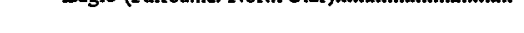 & 2 & .2 & .2 & 2 & IC & FOl & FO2 & 1993 & OP \\
\hline Goat Lake Hydro (UNKNOWN) ........................ & 1 & 4.0 & 4.0 & 4.0 & HY & Water & - & 1997 & OP \\
\hline Healy Lake (Fuisbanks North Star)...................... & IA & * & * & 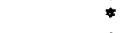 & IC & $\mathrm{FO} 2$ & - & 1995 & OP \\
\hline & 2 & $*$ & * & $\star$ & IC & FOI & $\mathrm{FO} 2$ & 1994 & OP \\
\hline 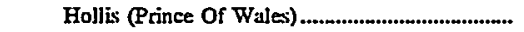 & BB & .1 & .1 & ]$. & IC & FO2 & - & 1996 & OP \\
\hline & $2 \mathrm{~A}$ & .1 & .1 & .1 & IC & FO2 & - & 1995 & OP \\
\hline Hydaburg (Prince Of Wales) & 3 & 3 & 3 & 3 & IC & $\mathrm{FO} 2$ & - & 1983 & OP \\
\hline & 4 & .1 & .1 & .1 & IC & $\mathrm{FO} 2$ & - & 1978 & OP \\
\hline & 5 & .3 & .3 & 3 & IC & $\mathrm{FO} 2$ & - & 1985 & OP \\
\hline & 6 & .4 & .4 & .4 & IC & $\mathrm{FO} 2$ & - & 1990 & OP \\
\hline 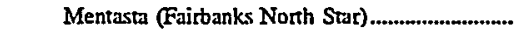 & $\mathbf{I A}$ & .1 & .1 & .1 & IC & FO2 & FOl & 1993 & OP \\
\hline$=\quad 3$ & $3 A$ & .1 & .1 & .1 & IC & FO2 & - & 1996 & OP \\
\hline & 2 & .1 & .1 & . & IC & $\mathrm{FO} 2$ & $\mathrm{FOl}$ & 1992 & OP \\
\hline Skagway (Juneau) & $6 \mathrm{~A}$ & .9 & .9 & .9 & IC & $\mathrm{FO} 2$ & - & 1986 & OP \\
\hline & $7 \mathrm{~A}$ & 1.1 & 1.J & 1.1 & IC & $\mathrm{FO} 2$ & - & 1996 & OP \\
\hline & $8 \mathrm{~A}$ & .5 & .5 & .5 & IC & $\mathrm{FO} 2$ & - & 1991 & OP \\
\hline & 1 & .4 & .4 & .4 & HY & Water & - & 1957 & OP \\
\hline & 2 & .1 & .1 & .1 & $\mathrm{HY}$ & Water & - & 1909 & OP \\
\hline & 3 & 3 & 3 & 3 & HY & Water & - & 1981 & OP \\
\hline & 4 & .2 & .2 & 2 & HY & Water & - & 1987 & OP \\
\hline & 10 & 1.3 & 1.3 & 1.3 & IC & $\mathrm{FO} 2$ & - & 1980 & OP \\
\hline 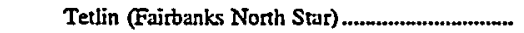 & $1 A$ & .1 & .1 & .1 & IC & $\mathrm{FO} 2$ & FOI & 1993 & OP \\
\hline & 2 & $*$ & $\star$ & $*$ & IC & FOI & $\mathrm{FO} 2$ & 1993 & OP \\
\hline & 3 & .1 & .1 & .1 & IC & $\mathrm{FOl}$ & $\mathrm{FO} 2$ & 1993 & $\mathrm{OP}$ \\
\hline Tok (Faibanks North Star) & $5 \mathrm{~A}$ & 1.1 & 1.1 & 1.1 & IC & $\mathrm{FO} 2$ & - & 1996 & $O P$ \\
\hline & 3 & 3 & 3 & 3 & IC & $\mathrm{FO} 2$ & FOl & 1961 & OP \\
\hline & 6 & 1.0 & 1.0 & 1.0 & IC & $\mathrm{FO} 2$ & FO1 & 1977 & OP \\
\hline & 7 & 1.3 & 1.3 & 1.3 & IC & $\mathrm{FO} 2$ & FO1 & 1984 & OP \\
\hline & 8 & .4 & .4 & .4 & IC & $\mathrm{FO} 2$ & FOI & 1985 & OP \\
\hline & 9 & 9 & 9 & 9 & IC & FO2 & Fol & 1985 & OP \\
\hline & 10 & 1.1 & $1 . J$ & 1.1 & IC & FO2 & FoI & 1989 & OP \\
\hline 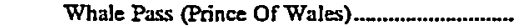 & 1 & .1 & .1 & .1 & IC & FO2 & - & 1995 & OP \\
\hline & 2 & .1 & .1 & .1 & IC & $\mathrm{FO} 2$ & - & 1995 & OP \\
\hline Alaska Village Elec Coop Ine & & 35.1 & 34.9 & 349 & & & & & \\
\hline Alakanuk (Bethel) & IA & 3 & .3 & 3 & IC & FO1 & - & 1986 & OP \\
\hline & 2 & .2 & .2 & 2 & IC & FOI & - & 1970 & OP \\
\hline & 3 & .4 & .4 & .4 & IC & FOI & - & 1974 & OP \\
\hline Ambler (Kobuk) & IC2 & 3 & 3 & 3 & IC & Fol & - & 1985 & OP \\
\hline & $3 \mathrm{~A}$ & .3 & 3 & 3 & IC & FOI & - & 1991 & OP \\
\hline & 1 & .2 & 2 & 2 & IC & Fol & - & 1984 & OP \\
\hline Anvik (Bethel) & $3 A$ & .1 & .1 & .1 & IC & FOI & - & 1992 & OP \\
\hline & J & .1 & .1 & .1 & IC & FOl & - & 1971 & OP \\
\hline & 2 & .1 &.$J$ & .1 & IC & FOl & - & 1969 & OP \\
\hline Brevig Mission (Nome) & J & .2 & .2 & 2 & IC & FoI & - & 1993 & OP \\
\hline & 2 & .2 & .2 & 2 & IC & FOI & - & 1993 & OP \\
\hline & 3 & .1 & .1 & .1 & IC & FOI & - & 1993 & OP \\
\hline Chevak (Bethel) & 1 & .4 & .4 & .4 & IC & FOI & - & 1977 & OP \\
\hline & 2 & .2 & .2 & 2 & IC & Fol & - & 1976 & OP \\
\hline & 3 & .4 & .4 & .4 & IC & Fol & - & 1979 & OP \\
\hline Eek (Bethel) & $2 A$ & .1 & .1 & .1 & IC & Fol & - & 1991 & OP \\
\hline & 1 & .2 & .2 & 2 & IC & FOI & - & 1977 & OP \\
\hline & 3 & .2 & 2 & 2 & IC & FOI & - & 1988 & OP \\
\hline Elim (Norne) & $2 A$ & .2 & .2 & .2 & IC & FOI & - & 1986 & OP \\
\hline & $3 \mathrm{~A}$ & .2 & .2 & .2 & IC & FOI & - & 1991 & OP \\
\hline & J & .2 & .2 & .2 & IC & Fol & ـ & 1975 & OP \\
\hline Emmonak (Bethel) & 2 & 3 & 3 & 3 & IC & Fo] & - & 1977 & $\mathrm{OP}$ \\
\hline & 4 & .4 & .4 & .4 & IC & FOl & - & 1980 & OP \\
\hline & 5 & .6 & 6 & .6 & IC & FOI & - & 1988 & OP \\
\hline & 6 & .9 & 9 & .9 & IC & FOI & - & 1995 & $O P$ \\
\hline
\end{tabular}

See footnotes at end of table. 
Table 20. Existing Generating Units at U.S. Electric Utilities by State, Company, and Plant, as of January 1, 1998 (Continued)

\begin{tabular}{|c|c|c|c|c|c|c|c|c|c|}
\hline \multirow{2}{*}{$\begin{array}{c}\text { State } \\
\text { Company } \\
\text { Plant (County) }\end{array}$} & \multirow{2}{*}{$\begin{array}{l}\text { Unit } \\
\text { ID }\end{array}$} & \multirow{2}{*}{$\begin{array}{c}\text { Generator } \\
\text { Nameplate } \\
\text { Capacity } \\
\text { (megawatts) }\end{array}$} & \multirow{2}{*}{$\begin{array}{c}\text { Net Summer } \\
\text { Capability } \\
\text { (megawatts) }\end{array}$} & \multirow{2}{*}{$\begin{array}{l}\text { Net Winter } \\
\text { Capability } \\
\text { (megawatts) }\end{array}$} & \multirow{2}{*}{$\begin{array}{r}\text { Unit } \\
\text { Typel }\end{array}$} & \multicolumn{2}{|c|}{ Energy Sourcel } & \multirow{2}{*}{$\begin{array}{c}\text { Year } \\
\text { of } \\
\text { Commercial } \\
\text { Operation }\end{array}$} & \multirow{2}{*}{$\begin{array}{c}\text { Unit } \\
\text { Statusl }\end{array}$} \\
\hline & & & & & & Primary & Alternate & & \\
\hline $\begin{array}{l}\text { Alaska (Continued) } \\
\text { Gambell (Nome) }\end{array}$ & $\mathrm{ICI}$ & & & & & & & & \\
\hline & IC2 & $\begin{array}{l}0.3 \\
4\end{array}$ & 0.3 & 0.3 & IC & $\begin{array}{l}\text { Fol } \\
\text { FOI }\end{array}$ & $\overline{-}$ & 1985 & $\mathrm{OP}$ \\
\hline & IC3 & .4 .4 & .4 & .4 & IC & Fol & $\overline{-}$ & 1985 & $O P$ \\
\hline Goodnews Bay (Bethel)........................................... & IC2 & .2 & .2 & .2 & IC & Fol & - & 1985 & OP \\
\hline & $1 \mathrm{~A}$ & .2 & .2 & .2 & IC & FO] & - & 1978 & $O P$ \\
\hline & $3 \mathrm{~A}$ &.$J$ & .1 & .1 & IC & Fo] & - & 1991 & $\mathrm{OP}$ \\
\hline Grayling (Bethel) ............................................................. & IA & .2 & $\ddot{2}$ & .2 & IC & Foj & - & 1987 & OP \\
\hline & $2 \mathrm{~A}$ & .1 & .1 & .1 & IC & FOJ & - & 1991 & $O P$ \\
\hline & 3 & .2 & .2 & .2 & IC & FOI & - & 1969 & OP \\
\hline 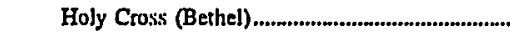 & i & .2 & .2 & .2 & IC & FOI & - & 1977 & $\mathrm{OP}$ \\
\hline & 2 & .2 & .2 & 2 & IC & FOI & - & 1971 & OP \\
\hline Hooper Bay (Bethel)............................................ & 3 & .4 & .4 & .4 & IC & Fol & - & 1975 & $O P$ \\
\hline & $\begin{array}{l}4 \\
5\end{array}$ & .4 & .4 & .4 & IC & FOI & - & 1980 & $\mathrm{OP}$ \\
\hline Huslia (Anchorsge) & $2 \mathrm{~A}^{3}$ & .6 & .6 & .6 & $\begin{array}{l}\text { IC } \\
\text { IC }\end{array}$ & $\begin{array}{l}\text { FOI } \\
\text { FOI }\end{array}$ & $\overline{-}$ & $\begin{array}{l}1991 \\
1987\end{array}$ & $O P$ \\
\hline & 1 & .2 & .2 & 2 & IC & FOl & - & 1969 & OP \\
\hline & 3 & .2 & .2 & 2 & IC & FOl & - & 1984 & $\mathrm{OP}$ \\
\hline Kaltag (Kobuk) ......................................... & IA & .1 &.$J$ & .1 & IC & Fol & - & 1991 & OP \\
\hline & 2 & .2 & .2 & 2 & IC & $\mathrm{FOl}$ & - & 1972 & $O P$ \\
\hline & 3 & 2 & .2 & .2 & IC & FOI & - & 1984 & $O P$ \\
\hline Kiana (Kobuk) ........................................ & IA & 3 & 3 & 3 & IC & Fol & - & 1990 & $O P$ \\
\hline & 2 & .4 & .4 & .4 & IC & Fo] & - & 1977 & OP \\
\hline & 4 & .2 & .2 & 2 & Ic & Fol & - & 1984 & $O P$ \\
\hline Kivalina (Kobuk) ................ & $4 \mathrm{~A}$ & 3 & 3 & .3 & Ic & Fol & - & 1992 & OP \\
\hline & 1 & .2 & .2 & 2 & IC & FOI & - & 1975 & OP \\
\hline & 2 & .3 & 3 & 3 & IC & FOI & - & 1977 & OP \\
\hline & 3 & .2 & .2 & 2 & IC & FOI & - & 1984 & $O P$ \\
\hline 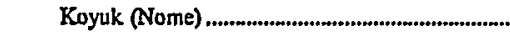 & 1 & .2 & .2 & .2 & IC & FOl & - & 1968 & OP \\
\hline & 2 & .2 & .2 & 2 & IC & FOI & - & 1970 & $\mathrm{OP}$ \\
\hline & 3 & .2 & .2 & 2 & IC & FOI & - & 1970 & OP \\
\hline 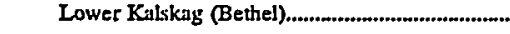 & $2 \mathrm{~A}$ & .2 & .2 & .2 & IC & Fol & - & 1986 & $O P$ \\
\hline & 1 & .2 & .2 & 2 & IC & FO1 & & 1983 & OP \\
\hline & 3 & .2 & .2 & 2 & IC & Fol & - & 1977 & OP \\
\hline Marshall (Bethel) & $2 A$ & .2 & .2 & .2 & IC & Fol & - & 1987 & OP \\
\hline & 1 & .2 & .2 & 2 & IC & Fol & _ & 1970 & $O P$ \\
\hline & 3 & .2 & .2 & 2 & IC & Foi & - & 1970 & OP \\
\hline 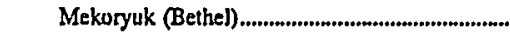 & 1 & .2 & .2 & .2 & IC & Fol & - & 1969 & OP \\
\hline & 2 & .2 & .2 & .2 & IC & Fo1 & . & 1971 & OP \\
\hline & 3 & .2 & .2 & 2 & IC & Fol & - & 1970 & OP \\
\hline Minto (Fairbanks North Star) ...................................... & IC2 & .2 & .2 & .2 & IC & FOI & - & $i 985$ & $O P$ \\
\hline & IC3 & .2 & .2 & .2 & IC & Fol & - & 1985 & OP \\
\hline & IA & .1 & .1 & .1 & IC & Fol & - & 1992 & OP \\
\hline Mountain Village (Bethel).......................................... & 1 & .4 & .4 & .4 & IC & Fol & - & 1984 & OP \\
\hline 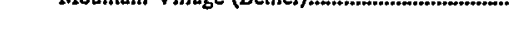 & 3 & 3 & .3 & 3 & IC & FOI & $=$ & 1982 & OP \\
\hline & 4 & .4 & .4 & .4 & IC & Fol & - & 1982 & OP \\
\hline & & .6 & .6 & .6 & IC & Fol & - & 1988 & OP \\
\hline New Stuyahok (Dillingham)....................................... & IC2 & .2 & .2 & .2 & IC & Fol & - & 1984 & $O P$ \\
\hline & IA & .2 & .2 & .2 & IC & FOl & - & 1986 & OP \\
\hline & & .2 & .2 & 2 & IC & Fol & - & 1989 & OP \\
\hline 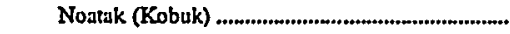 & SA & 3 & .3 & 3 & IC & Fol & - & 1990 & $O P$ \\
\hline & 1 & .2 & .2 & 2 & IC & FOI & - & 1977 & OP \\
\hline & 4 & .2 & .2 & 2 & IC & Fol & - & 1985 & OP \\
\hline 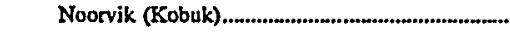 & 1 & .2 & .2 & .2 & IC & Fol & - & 1983 & OP \\
\hline & 2 & .4 & .4 & .4 & IC & Fo1 & - & 1984 & OP \\
\hline & 3 & .4 & .4 & 4 & IC & Fo1 & - & 1984 & OP \\
\hline 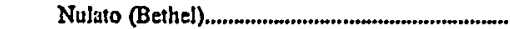 & $3 \mathrm{~A}$ & .3 & 3 & .3 & IC & Fol & - & 1987 & $O P$ \\
\hline & 1 & 3 & 3 & 3 & IC & Fol & _- & 1976 & OP \\
\hline & 2 & .2 & .2 & 2 & IC & Fol & - & 1981 & $O P$ \\
\hline Nunapitchuk (Bethel) & 2 & .4 & .4 & .4 & IC & Fol & - & 1976 & $O P$ \\
\hline & 3 & 3 & $\frac{3}{5}$ & 3 & IC & FOI & - & 1976 & OP \\
\hline & 4 & $s$ & .5 & $s$ & IC & Fol & - & 1986 & OP \\
\hline & 5 & 5 & .4 & .4 & IC & Fol & - & 1994 & OP \\
\hline Old Harbor (Kodjak Island) ........................................... & 1 & .2 & .2 & .2 & IC & Fol & - & 1980 & OP \\
\hline & 2 & .2 & .2 & 2 & IC & Fol & - & 1980 & $O P$ \\
\hline & 3 & .1 & .1 & .1 & IC & Fol & - & 1991 & $O P$ \\
\hline Pilut Station (Bethel) & $2 \mathrm{~A}$ & 3 & 3 & .3 & IC & Fol & - & 1987 & $O P$ \\
\hline & 1 & .2 & .2 & 2 & IC & Fol & - & 1970 & OP \\
\hline & 3 & .2 & .2 & 2 & IC & FOI & - & 1982 & OP \\
\hline 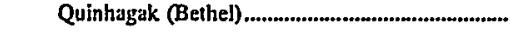 & $3 \mathrm{~A}$ & 3 & 3 & 3 & IC & FOI & - & 1987 & OP \\
\hline & 1 & 3 & 3 & 3 & IC & Fol & - & 1976 & $O P$ \\
\hline
\end{tabular}

See footnotes at end of table. 
Table 20. Existing Generating Units at U.S. Electric Utilities.by State, Company, and Plant, as of January 1, 1998 (Continued)

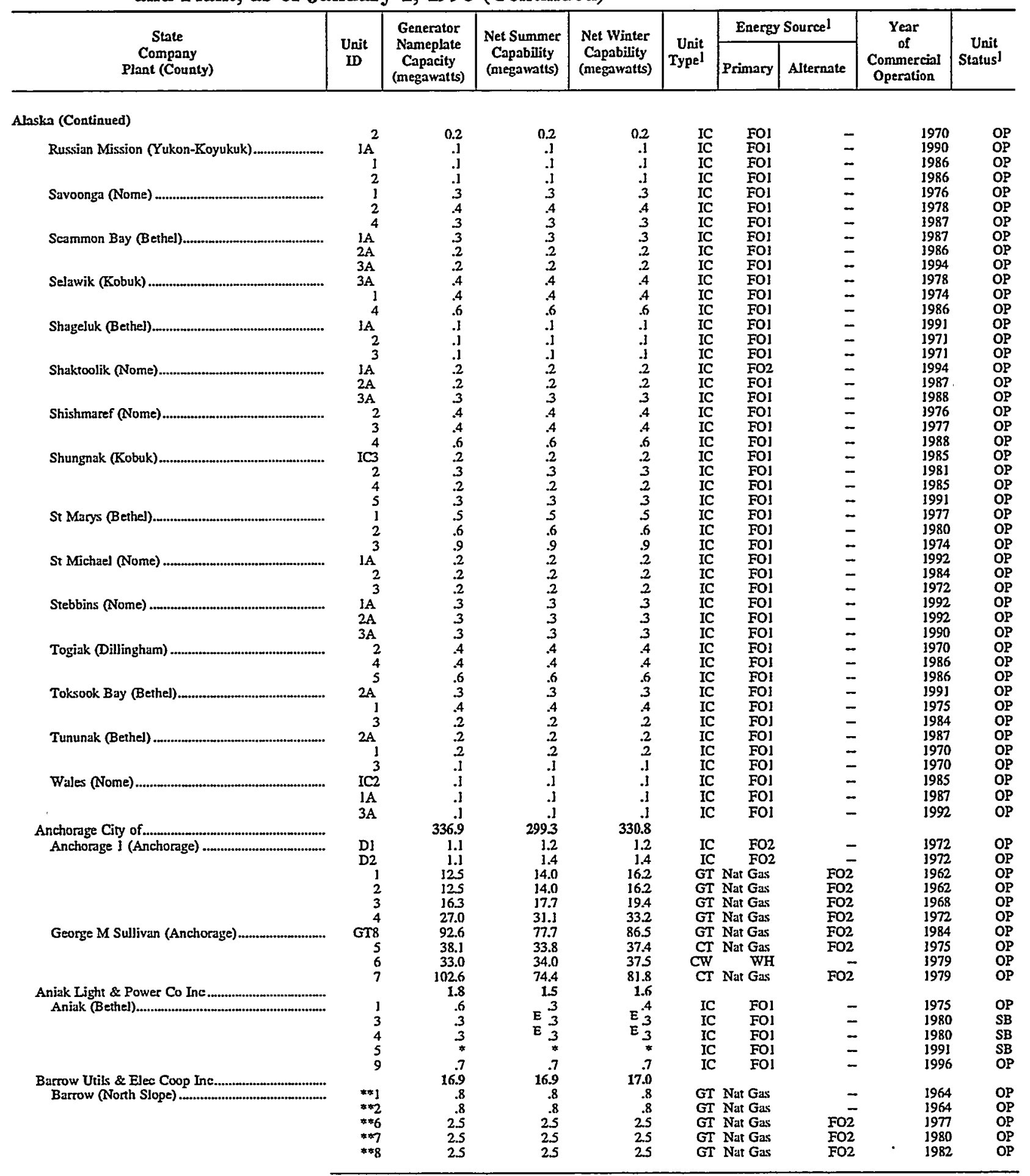

See footnotes at end of table. 
Table 20. Existing Generating Units at U.S. Electric Utilities by State, Company, and Plant, as of January 1, 1998 (Continued)

\begin{tabular}{|c|c|c|c|c|c|c|c|c|c|}
\hline \multirow{2}{*}{$\begin{array}{c}\text { State } \\
\text { Company } \\
\text { Plant (County) }\end{array}$} & \multirow{2}{*}{$\begin{array}{l}\text { Unit } \\
\text { ID }\end{array}$} & \multirow{2}{*}{$\begin{array}{l}\text { Generator } \\
\text { Nameplate } \\
\text { Capacity } \\
\text { (megawatts) }\end{array}$} & \multirow{2}{*}{$\begin{array}{l}\text { Net Summer } \\
\text { Capability } \\
\text { (megawatts) }\end{array}$} & \multirow{2}{*}{$\begin{array}{l}\text { Net Winter } \\
\text { Capability } \\
\text { (megawatts) }\end{array}$} & \multirow{2}{*}{$\begin{array}{l}\text { Unit } \\
\text { TypeI }\end{array}$} & \multicolumn{2}{|c|}{ Energy Sourcel } & \multirow{2}{*}{$\begin{array}{c}\text { Year } \\
\text { of } \\
\text { Commercinl } \\
\text { Operation }\end{array}$} & \multirow{2}{*}{$\begin{array}{c}\text { Unit } \\
\text { Status] }\end{array}$} \\
\hline & & & & & & Primary & Alternate & & \\
\hline \multicolumn{10}{|l|}{ Alaska (Continued) } \\
\hline & $* * 9$ & 1.5 & 1.5 & 1.5 & IC & Nat Gas & - & 1994 & OP \\
\hline & $* * 10$ & 1.5 & 1.5 & 1.5 & IC & Nat Gas & - & 1994 & OP \\
\hline \multirow{7}{*}{ 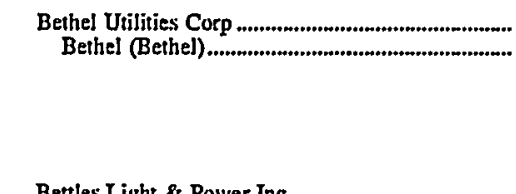 } & II & $\begin{array}{r}4.9 \\
12.6\end{array}$ & $\begin{array}{r}4.9 \\
12.6\end{array}$ & 5.0 & GT & Nat Gas & - & 1996 & OP \\
\hline & 1 & 2.1 & 2.1 & $\begin{array}{r}12.6 \\
2.1\end{array}$ & IC & FO2 & - & 1976 & $\mathbf{O P}$ \\
\hline & 2 & 21 & 2.1 & 2.3 & IC & FO2 & - & 1976 & $O P$ \\
\hline & 3 & 21 & 2.1 & 2.1 & IC & $\mathrm{FO} 2$ & - & 1976 & OP \\
\hline & 4 & 2.1 & 2.1 & 2.1 & IC & $\mathrm{FO} 2$ & - & 1976 & $O P$ \\
\hline & 6 & 21 & 2.J & 2.1 & IC & FO2 & - & 1989 & $O P$ \\
\hline & 7 & 2.1 & 2.3 & 2.1 & IC & $\mathrm{FO} 2$ & - & 1992 & $\mathrm{OP}$ \\
\hline 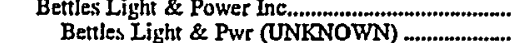 & & .8 & 8 & .8 & & & & 1997 & P \\
\hline 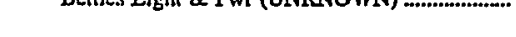 & $\underset{* * 2}{1 A}$ & .3 & .3 & $\frac{3}{3}$ & IC & FOl & $\begin{array}{l}\mathrm{FO} 2 \\
\mathrm{FO} 2\end{array}$ & $\begin{array}{l}1997 \\
1975\end{array}$ & $O P$ \\
\hline & 4 & .2 & .2 & 2 & IC & Fol & FO2 & 1992 & OP \\
\hline Chignik City of & & .6 & 6 & .6 & & & & & \\
\hline East Side Power (UNKNOWN) ..................................... & 4444 & .1 & .1 & .1 & IC & FOI & $\mathrm{FO} 2$ & 1994 & OP \\
\hline West Side Power (UNKNOWN),........................... & 1451 & .2 & .2 & .2 & $\mathrm{IC}$ & Fol & FO2 & 1987 & OP \\
\hline & 1452 & .2 & .2 & .2 & IC & FOI & FO2 & 1989 & OP \\
\hline & 1453 & .2 & .2 & .2 & IC & Fol & FO2 & 1991 & OP \\
\hline 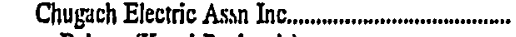 & & 728.0 & 607.4 & 676.5 & & & & & \\
\hline Beluga (Kenai Peninsula) ............................................ & 1 & 18.8 & 14.4 & 19.6 & GT & Nat Gas & - & 1968 & $\mathrm{OP}$ \\
\hline & 2 & 38.8 & 14.4 & 19.6 & GT & Nat Gas & - & 1968 & OP \\
\hline & $\begin{array}{l}3 \\
5\end{array}$ & 65.7 & 58.8 & $\begin{array}{l}68.0 \\
73.3\end{array}$ & GT & $\begin{array}{l}\text { Nat Gas } \\
\text { Natit Gas }\end{array}$ & 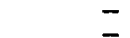 & 1972 & OP \\
\hline & 6 & 85.0 & 68.0 & 69.4 & CT & Nat Gas & - & 1976 & OP \\
\hline & 7 & 85.0 & 68.0 & 71.0 & CT & Nat Gas & - & 1978 & OP \\
\hline & 8 & 68.9 & 51.2 & 53.0 & $\mathrm{CW}$ & WH & - & 1982 & OP \\
\hline 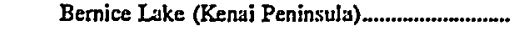 & 2 & 23.0 & 17.2 & 19.5 & GT & Nat Gas & - & 1971 & $O P$ \\
\hline & $\begin{array}{l}3 \\
4\end{array}$ & $\begin{array}{l}320 \\
320\end{array}$ & $\begin{array}{l}24.5 \\
24.5\end{array}$ & $\begin{array}{l}29.6 \\
255\end{array}$ & GT & $\begin{array}{l}\text { Nat Gas } \\
\text { Nat Gas }\end{array}$ & $=$ & 1978 & OP \\
\hline Bradley Lake (Kenai Peninsula) ............................ & i & 57.0 & 54.0 & 60.0 & $\mathrm{HY}$ & Water & - & 1991 & OP \\
\hline Cooper Lake (Kensi Peninsula) & 2 & $\begin{array}{r}57.0 \\
8.3\end{array}$ & $\begin{array}{r}54.0 \\
8.3\end{array}$ & $\begin{array}{r}60.0 \\
83\end{array}$ & HY & $\begin{array}{l}\text { Water } \\
\text { Water }\end{array}$ & 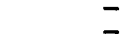 & 1991 & op \\
\hline Cooper Lake (kenal feninsula) ...................... & 2 & 8.3 & 8.3 & 83 & $\mathrm{HY}$ & Water & $\Xi$ & 1961 & OP \\
\hline Intemational (Anchorage) & 1 & 17.6 & 13.8 & 15.0 & GT & Nat Gas & - & 1964 & OP \\
\hline & 2 & 17.6 & 13.8 & 15.1 & GT & Nat Gas & - & 1965 & OP \\
\hline & & 19.0 & 16.7 & 192 & GT & Nat Gas & - & 1969 & OP \\
\hline Soldotna (Kenai Peninsula) ................................... & $* * G T$ I & 37.9 & 37.9 & 42.0 & GT & FO2 & Nat Gas & 1986 & OP \\
\hline 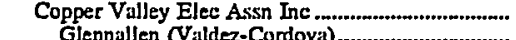 & & 29.6 & 27.7 & 27.7 & & & & & \\
\hline Giennallen (Vialdez-Cordova) .................................... & $\frac{1}{2}$ & $\begin{array}{l}3 \\
3\end{array}$ & $\begin{array}{l}3 \\
3\end{array}$ & $\begin{array}{l}3 \\
3\end{array}$ & IC & $\begin{array}{l}\mathrm{FO} 2 \\
\mathrm{FO} 2\end{array}$ & $\Xi$ & $\begin{array}{l}3959 \\
1959\end{array}$ & $\begin{array}{l}O P \\
O P\end{array}$ \\
\hline & 3 & .6 & 5 & $\vec{s}$ & IC & $\mathrm{FO2}$ & $=$ & 1963 & $O P$ \\
\hline & 4 & .6 & .5 & 5 & IC & $\mathrm{FO} 2$ & - & 1966 & $O P$ \\
\hline & 5 & .6 & 5 & 5 & IC & FO2 & - & 1966 & OP \\
\hline & 6 & 26 & 2.5 & 2.5 & IC & FO2 & - & 1976 & OP \\
\hline Solomon Gulch Valdm-Condovat & 7 & 26 & 2.5 & 25 & IC & $\mathrm{FO2}$ & - & 1976 & OP \\
\hline Solomon Gulch (Valdez-Cordova) ......................... & \#! & 6.0 & 6.0 & 6.0 & HL & Water & - & 1982 & OP \\
\hline 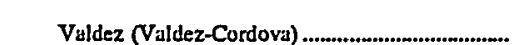 & $* 2$ & 6.0 & 6.0 & 6.0 & HIL & Water & - & 1982 & OP \\
\hline & 1 & .6 & .5 & .5 & IC & FO2 & - & 1967 & OP \\
\hline & 2 & .6 & .5 & 5 & IC & FO2 & - & 1967 & $O P$ \\
\hline & 3 & .6 & .5 & 5 & IC & FO2 & - & 1967 & OP \\
\hline & 4 & 1.8 & 1.5 & 15 & IC & FO2 & - & 1972 & OP \\
\hline & 5 & 2.6 & 2.0 & 2.0 & IC & $\mathrm{FO} 2$ & - & 1975 & OP \\
\hline & 6 & 1.0 & .8 & .8 & IC & $\mathrm{FO} 2$ & - & 1974 & OP \\
\hline & 7 & 28 & 2.8 & 2.8 & GT & FO2 & - & 1974 & OP \\
\hline Cordova Electric Coup Ine...................................... & & 11.7 & 112 & 112 & & & & & \\
\hline 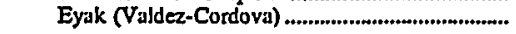 & 1 & 1.9 & 1.9 & 1.9 & IC & $\mathrm{FO} 2$ & - & 1970 & OP \\
\hline & 2 & 3.0 & 2.7 & 2.7 & IC & $\mathrm{FO} 2$ & - & 1973 & OP \\
\hline & , & .6 & $E .6$ & $E_{5}^{.6}$ & $\begin{array}{lll}\text { IC } \\
\text { FY }\end{array}$ & $\mathrm{FO2}$ & - & 1960 & OP \\
\hline Humpback Creek (Valdez-Cordova) ...................... & 2 & $\begin{array}{c}5 \\
5\end{array}$ & E. 5 & $E_{5}^{3}$ & $\mathrm{HY}$ & Water & - & 1991 & OP \\
\hline & $\frac{2}{3}$ & 3 & $\mathrm{E} 2$ & $\mathrm{E}_{2}$ & $\mathrm{HY}$ & Water & - & 1991 & OP \\
\hline & 3 & 25 & .25 & & HY & Water & - & 1991 & OP \\
\hline 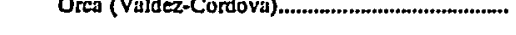 & 3 & 2.5 & 2.5 & 2.5 & IC & FO2 & - & 1984 & OP \\
\hline 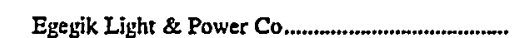 & & $\begin{array}{r}2.4 \\
5\end{array}$ & $\begin{array}{c}2.4 \\
5\end{array}$ & $\begin{array}{c}2.4 \\
5\end{array}$ & IC & FO2 & - & 1984 & OP \\
\hline Egegik (UNKNOWN) & I & .2 & .2 & $\overrightarrow{2}$ & IC & FOl & F02 & 1987 & OP \\
\hline 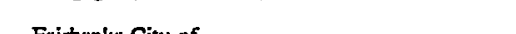 & 2 & .3 & 3 & 3 & IC & Fol & F02 & 1987 & OP \\
\hline Fairbanks Ciry of & & 54,4 & 54.4 & 60.8 & & & & & \\
\hline 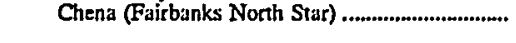 & D2 & 2.8 & 28 & 3.0 & IC & $\mathrm{FO} 2$ & - & 1968 & $O P$ \\
\hline & 1 & 5.0 & 5.0 & 5.0 & ST & SUB & - & 1954 & OP \\
\hline
\end{tabular}

See founutes at end of table. 
Table 20. Existing Generating Units at U.S. Electric Utilities by State, Company, and Plant, as of January 1, 1998 (Continued)

\begin{tabular}{|c|c|c|c|c|c|c|c|c|c|}
\hline \multirow{2}{*}{$\begin{array}{c}\text { State } \\
\text { Company } \\
\text { Plant (County) }\end{array}$} & \multirow{2}{*}{$\begin{array}{l}\text { Unit } \\
\text { ID }\end{array}$} & \multirow{2}{*}{$\begin{array}{c}\text { Generator } \\
\text { Nameplate } \\
\text { Capacity } \\
\text { (megawatts) }\end{array}$} & \multirow{2}{*}{$\begin{array}{l}\text { Net Summer } \\
\text { Capability } \\
\text { (megawatts) }\end{array}$} & \multirow{2}{*}{$\begin{array}{l}\text { Net Winter } \\
\text { Capability } \\
\text { (megawatts) }\end{array}$} & \multirow{2}{*}{$\begin{array}{c}\text { Unit } \\
\text { Type }\end{array}$} & \multicolumn{2}{|c|}{ Energy Sourcel } & \multirow{2}{*}{$\begin{array}{c}\text { Year } \\
\text { of } \\
\text { Commercinl } \\
\text { Operation }\end{array}$} & \multirow{2}{*}{$\begin{array}{c}\text { Unit } \\
\text { Status! }\end{array}$} \\
\hline & & & & & & Primary & Alternate & & \\
\hline Alaska (Continued) & & & & & & & & & \\
\hline & 2 & 2.0 & 2.0 & 2.0 & ST & SUB & - & 1951 & OP \\
\hline & 3 & 1.5 & 1.5 & 15 & ST & SUB & - & 1951 & OP \\
\hline & 5 & 20.0 & 20.0 & 20.0 & ST & SUB & - & 1970 & $O P$ \\
\hline & 6 & 23.1 & & & & & & & \\
\hline $\begin{array}{l}\text { Galena Electric Utility } \\
\text { Galena Electric Util (UNKNOWN) }\end{array}$ & & 4.7 & 4.0 & 4.0 & & & & & \\
\hline & $\begin{array}{l}1 \\
2\end{array}$ & $\begin{array}{l}.9 \\
.9\end{array}$ & $\begin{array}{l}.7 \\
.7\end{array}$ & $\begin{array}{l}.7 \\
.7\end{array}$ & $\begin{array}{l}\text { IC } \\
\text { IC }\end{array}$ & $\begin{array}{l}\text { FO2 } \\
\text { FO2 }\end{array}$ & $\overline{-}$ & $\begin{array}{l}1990 \\
1990\end{array}$ & $\begin{array}{l}\text { OP } \\
\text { OP }\end{array}$ \\
\hline & 3 & .9 & .7 & .7 & IC & $\mathrm{FO} 2$ & - & 1990 & OP \\
\hline & 4 & .9 & .7 & .7 & IC & FO2 & -- & 1990 & OP \\
\hline & 5 & .9 & .7 & .7 & IC & FO2 & - & 1990 & $\mathrm{OP}$ \\
\hline & 7 & .5 & .5 & 5 & IC & $\mathrm{FO} 2$ & - & 1997 & $O P$ \\
\hline 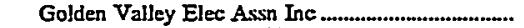 & & 1973 & 171.0 & 198.7 & & & & & \\
\hline Fairbanks (Fairbanks North Star).......................... & GT1 & 17.6 & 16.0 & 18.0 & GT & $\mathrm{FO} 2$ & FO4 & 197] & OP \\
\hline & GT2 & 17.6 & 16.3 & 18.0 & GT & $\mathrm{FO} 2$ & FO4 & 1972 & OP \\
\hline & 5 & 26 & 2.6 & 2.6 & IC & FO2 & - & 1970 & $O P$ \\
\hline & & 2.6 & 2.6 & 2.6 & IC & FO2 & - & 1970 & OP \\
\hline 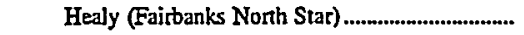 & ICl & 2.5 & 2.5 & 2.5 & IC & $\mathrm{FO} 2$ & - & 1967 & OP \\
\hline & 1 & 25.0 & 25.0 & 25.0 & ST & SUB & - & 1967 & OP \\
\hline North Pole (Eairbanks North Star) ........................ & 1 & 64.7 & 53.0 & 65.0 & GT & F04 & $\cdots$ & 1976 & OP \\
\hline & 2 & 64.7 & 53.0 & 65.0 & GT & FO4 & - & 1977 & OP \\
\hline 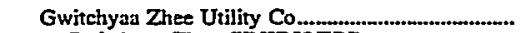 & & 1.4 & .9 & 1.3 & & & & & \\
\hline Gwitchyaa Zhee (UNKNOWN) & 1 & .6 & .4 & .6 & IC & FO2 & - & 1987 & OP \\
\hline & $\begin{array}{l}3 \\
5\end{array}$ & .3 & .2 & $\frac{2}{5}$ & IC & $\begin{array}{l}\mathrm{FO} 2 \\
\mathrm{FO} 2\end{array}$ & $\overline{-}$ & 1984 & $\begin{array}{l}\text { OP } \\
\text { OP }\end{array}$ \\
\hline 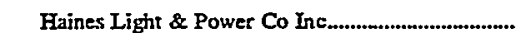 & & $7 \ddot{3}$ & 7.3 & 73 & & & & & \\
\hline Haines (Haines) & IC8A & 1.6 & 1.6 & 1.6 & IC & $\mathrm{FO} 2$ & - & 1996 & $O P$ \\
\hline & $7 A$ & 2.9 & 2.9 & 29 & IC & $\mathrm{FO} 2$ & -- & 1995 & $\mathrm{OP}$ \\
\hline & 5 & .6 & .6 & 6 & IC & $\mathrm{FO} 2$ & - & 1968 & OP \\
\hline & 9 & 1.1 & 1.1 & 1.1 & IC & FO2 & - & 1989 & OP \\
\hline & 10 & 1.1 & 1.1 & 1.1 & IC & FO2 & - & 199] & $\mathrm{OP}$ \\
\hline 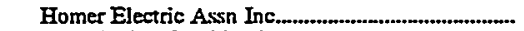 & & 2.1 & 2.1 & 2.1 & & & & & \\
\hline 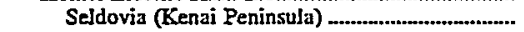 & 1 & .3 & 3 & 3 & IC & FO2 & - & 1964 & OP \\
\hline & 2 & .6 & .6 & .6 & IC & FO2 & - & 1964 & OP \\
\hline & 3 & .6 & .6 & .6 & IC & FO2 & - & 1970 & $\mathrm{OP}$ \\
\hline & 4 & .6 & .6 & 6 & IC & FO2 & - & 1979 & OP \\
\hline Hughes Power \& Light Co & & 2 & 2 & 2 & & & & & \\
\hline Hughes (UNKNOWN) & 3 & .1 & .1 & .1 & IC & FOl & - & 1996 & OP \\
\hline & 4 & .1 & .1 & .1 & IC & FOI & - & 1994 & OP \\
\hline I-N-N Electric Coog Inc & & 1.6 & 1.6 & 1.6 & & & & & \\
\hline 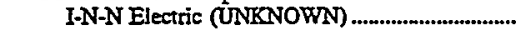 & 1 & .3 & .3 & .3 & IC & FO2 & - & 1983 & OP \\
\hline & 2 & .3 & .3 & 3 & IC & FO2 & - & 1983 & OP \\
\hline & 3 & .3 & .3 & 3 & IC & $\mathrm{FO} 2$ & - & 1983 & OP \\
\hline & 4 & .6 & .6 & 6 & IC & FO2 & - & 1989 & OP \\
\hline Igiugig Electric Co & & .2 & 2 & 2 & & & & & \\
\hline Igiugig (UNKNOWN) & 3179 & .1 &.$j$ & .1 & IC & Fol & FO2 & 1991 & OP \\
\hline & 4045 & * & \# & $\star$ & IC & FOJ & FO2 & 1995 & OP \\
\hline & 4276 & .1 & .1 & .1 & IC & FOl & FO2 & 1993 & $O P$ \\
\hline Ipnatchiaq Electric Co & & 5 & .4 & .4 & & & & & \\
\hline 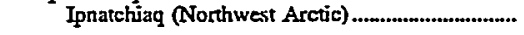 & U00] & .1 & .1 & .1 & IC & Fol & - & 1984 & $O P$ \\
\hline & U002 & .1 & .1 & .1 & IC & Fol & - & 1989 & $\mathrm{OP}_{\mathrm{OP}}$ \\
\hline & U003 & .1 & .1 & .1 & IC & Fol & - & 1992 & $\begin{array}{l}\text { OP } \\
\text { OP }\end{array}$ \\
\hline Ketchikan City of & U004 & .2 & I & .1 & IC & Fol & - & 1984 & OP \\
\hline $\begin{array}{l}\text { Ketchikan City of } \\
\text { Beaver Falls (Retchikan Gateway) }\end{array}$ & & 49.7 & 46.7 & 45.3 & & Wotr & & 1047 & OP \\
\hline & $\begin{array}{l}1 \\
3\end{array}$ & $\begin{array}{l}1.0 \\
22\end{array}$ & $\begin{array}{l}1.0 \\
2.2\end{array}$ & $\begin{array}{l}1.0 \\
1.8\end{array}$ & $\begin{array}{l}\mathrm{HIL} \\
\mathrm{HI}\end{array}$ & $\begin{array}{l}\text { Water } \\
\text { Water }\end{array}$ & $\underline{-}$ & $\begin{array}{l}1947 \\
1954\end{array}$ & OP \\
\hline & 4 & 2.2 & 2.2 & 1.8 & $\mathrm{HL}$ & Water & - & 1954 & $\mathrm{OP}$ \\
\hline 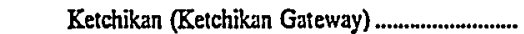 & HY3 & 1.4 & 1.4 & 1.2 & HL & Water & - & 1952 & OP \\
\hline & 4 & 1.4 & 1.4 & 1.2 & 讧 & Warer & - & 1938 & OP \\
\hline & 5 & 1.4 & 1.4 & 12 & HL & Water & - & 1954 & OP \\
\hline S W Bailey (Ketchikan Gateway).................... & l & 4.5 & 3.5 & 3.5 & IC & FO2 & - & 1969 & $\mathrm{OP}$ \\
\hline & 2 & 4.5 & 3.5 & 35 & IC & FO2 & -- & 1970 & OP \\
\hline & 3 & 6.5 & 5.5 & 5.5 & IC & $\mathrm{FO} 2$ & -- & 1976 & OP \\
\hline Silvis (Ketchikan Gateway) & j & 2.1 & 21 & 2.1 & EY & Water & - & 1968 & OP \\
\hline Swan Lake (Ketchikan Gateway)....................... & $* * \mathbf{i}$ & 11.3 & 113 & 11.3 & HI & Water & - & 1984 & op \\
\hline & $=2$ & 11.3 & J]. 3 & 11.3 & FIL & Water & - & 1984 & OP \\
\hline King Cove City of & & 3.5 & 3.1 & 2.2 & & & & & \\
\hline King Cove (UNKNOWN) & 1 & .4 & 3 & .3 & IC & $\mathrm{FO} 2$ & -- & 1980 & OP \\
\hline & 2 & .5 & .5 & 5 & IC & $\mathrm{FO} 2$ & - & 1986 & OP \\
\hline & 3 & .7 & .7 & .7 & IC & $\mathrm{FO} 2$ & - & 1992 & $O P$ \\
\hline & 4 & .8 & .7 & 3 & HY & Water & - & 1995 & \\
\hline
\end{tabular}

See footnotes at end of table. 
Table 20. Existing Generating Units at U.S. Electric Utilities by State, Company, and Plant, as of January 1, 1998 (Continued)

\begin{tabular}{|c|c|c|c|c|c|c|c|c|c|}
\hline \multirow{2}{*}{$\begin{array}{c}\text { State } \\
\text { Company } \\
\text { Plant (County) }\end{array}$} & \multirow{2}{*}{$\begin{array}{l}\text { Unit } \\
\text { ID }\end{array}$} & \multirow{2}{*}{$\begin{array}{c}\text { Generator } \\
\text { Nameplate } \\
\text { Capacity } \\
\text { (megawatts) }\end{array}$} & \multirow{2}{*}{$\begin{array}{l}\text { Net Summer } \\
\text { Capability } \\
\text { (megawatts) }\end{array}$} & \multirow{2}{*}{$\begin{array}{l}\text { Net Winter } \\
\text { Capability } \\
\text { (megawatis) }\end{array}$} & \multirow{2}{*}{\begin{tabular}{|} 
Unit \\
Type $^{1}$
\end{tabular}} & \multicolumn{2}{|c|}{ Energy Source 1} & \multirow{2}{*}{$\begin{array}{c}\text { Year } \\
\text { of } \\
\text { Commercinl } \\
\text { Operation }\end{array}$} & \multirow{2}{*}{$\begin{array}{c}\text { Unit } \\
\text { Status } 1\end{array}$} \\
\hline & & & & & & Primary & Alterrate & & \\
\hline \multicolumn{10}{|l|}{ Alnska (Continued) } \\
\hline \multirow{3}{*}{ 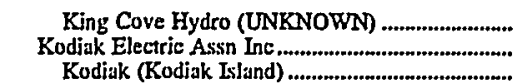 } & 5 & 0.4 & 0.3 & 0.3 & IC & $\mathrm{FO} 2$ & - & 1980 & $O P$ \\
\hline & 4 & $\begin{array}{r}.8 \\
54.9\end{array}$ & 54.7 & $\begin{array}{r}3 \\
54.0\end{array}$ & HY & Water & - & $j 995$ & $\mathrm{OP}$ \\
\hline & 1 & 2.5 & 2.5 & 2.5 & IC & $\mathrm{FO} 2$ & - & 1976 & \\
\hline & 2 & 5,3 & 5.3 & 5.3 & IC & $\mathrm{FO} 2$ & - & 1976 & $O P$ \\
\hline r & 3 & 5,3 & 5.3 & 5.3 & IC & FO2 & - & 1976 & $O P$ \\
\hline & $\begin{array}{l}4 \\
6\end{array}$ & $\begin{array}{l}7.1 \\
2.0\end{array}$ & $\begin{array}{l}7.3 \\
2.0\end{array}$ & $\begin{array}{l}7.1 \\
2.0\end{array}$ & $\begin{array}{l}\text { IC } \\
\text { IC }\end{array}$ & $\begin{array}{l}\mathrm{FO} 2 \\
\mathrm{FO} 2\end{array}$ & $\bar{z}$ & $\begin{array}{l}1981 \\
9968\end{array}$ & $\begin{array}{l}O P \\
O P\end{array}$ \\
\hline & 7 & 20 & 2.0 & 20 & IC & FO2 & - & 1968 & $O P$ \\
\hline & 8 & 27 & 2.0 & 2.0 & IC & $\mathrm{FO} 2$ & - & 1968 & OP \\
\hline & 9 & 20 & 2.0 & 2.0 & IC & FO2 & - & & $O P$ \\
\hline & $j$ & 2.5 & 2.5 & 2.5 & IC & $\mathrm{FO} 2$ & - & 1994 & $O P$ \\
\hline Pon Lions (Kodjak Island)........................................ & 1 & .4 & 3 & $\frac{3}{2}$ & IC & $\mathrm{FO} 2$ & $\ddot{-}$ & 1968 & \\
\hline & $\begin{array}{l}2 \\
3\end{array}$ & $\stackrel{4}{2}$ & .2 & $\frac{2}{2}$ & $\begin{array}{l}\text { IC } \\
\text { IC }\end{array}$ & $\begin{array}{l}\mathrm{FO} 2 \\
\mathrm{FO} 2\end{array}$ & $\bar{z}$ & $\begin{array}{l}1968 \\
1971\end{array}$ & $\begin{array}{l}\text { OP } \\
\text { OP }\end{array}$ \\
\hline & 4 & 2 & .2 & 2 & IC & FO2 & - & 1975 & $O P$ \\
\hline Terror Lake (Kodiak Island) ...................................... & $* * 1$ & 113 & 11.3 & 11.3 & $H Y$ & Water & - & 1984 & $O P$ \\
\hline Kokhanok Village Council & & 113.3 & $\begin{array}{l}11.3 \\
3\end{array}$ & 11.3 & HY & Water & - & 3984 & OP \\
\hline 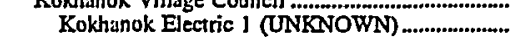 & J & .1 & $\overrightarrow{.1}$ &. $\mathrm{I}$ & IC & FOJ & - & 1992 & \\
\hline & 2 & .1 & .1 &. $\mathrm{I}$ & IC & Fol & - & 1994 & $O P$ \\
\hline & 3 & .2 & .2 & .2 & IC & Fol & - & 1997 & $\mathrm{OP}$ \\
\hline 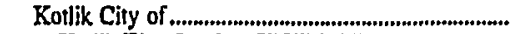 & & .7 & 7 & .7 & & & & & \\
\hline Kollik Ëlec Service (UNKNOWN)........................ & NAI & .2 & .2 & .2 & & Nat Gas & - & 1981 & OP \\
\hline & NA3 & .2 & .2 & .2 & & Nat Gas & - & 1981 & $\mathrm{OP}$ \\
\hline & NA4 & $\frac{3}{2}$ & .3 & 3 & & Nat Gas & - & 3995 & OP \\
\hline Kotzebue Electric Assn Ine ...... & & 11.2 & 10.8 & 10.8 & & 年 & & בנק & \\
\hline Kotzebue (Norhhwest Arctic)............ & $7 \mathrm{~A}$ & 1.1 & 1.1 & 1.1 & IC & $\mathrm{FO} 2$ & - & 1987 & $O P$ \\
\hline & 10 & 2.1 & 2.1 .1 & 2.1 & IC & $\mathrm{FO} 2$ & - & 1983 & OP \\
\hline & 11 & 3.0 & $\begin{array}{l}3.1 \\
1.0\end{array}$ & $\begin{array}{l}3.1 \\
1.0\end{array}$ & IC & $\mathrm{FO} 2$ & & $\begin{array}{l}1987 \\
1994\end{array}$ & $\begin{array}{l}O P \\
O P\end{array}$ \\
\hline & i2 & 1.0 & 1.0 & 3.0 & IC & FO2 & $\overline{-}$ & $\begin{array}{l}1994 \\
1994\end{array}$ & OP \\
\hline & 14 & 2.9 & 25 & 2.5 & IC & FO2 & - & 1994 & OP \\
\hline Kwig Power $\mathrm{Co}_{0}$ & & .4 & 2 & .4 & & & & & \\
\hline Kwig Power Company (UNKNOWN) .................... & 145 & .1 & .1 & .1 & IC & $\mathrm{FO} 2$ & - & 1991 & $\mathrm{OP}$ \\
\hline & 228 & .2 & .1 & .1 & IC & $\mathrm{FO} 2$ & - & 1991 & OP \\
\hline & 245 & .2 & .1 & .1 & IC & FO2 & - & 1989 & OP \\
\hline Larsen Bay City of........................ & & .9 & 6 & .5 & & & & & \\
\hline Cummins (UNKNOWN) ......... & 2 & .2 & .2 & .2 & IC & $\mathrm{FO} 2$ & - & 1984 & $O P$ \\
\hline & 3 & .2 & .2 & 2 & HL & Water & - & 1984 & OP \\
\hline Kato (TNKNOWN) ....................................................... & 1 & 5 & 3 & .1 & HIL & Water & - & 1984 & OP \\
\hline 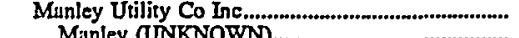 & & .4 & -4 & .4 & & & & & \\
\hline Munley (UNKNOWN) & 2 & 3 & 3 & 3 & IC & F02 & - & 1985 & \\
\hline & 3 & .1 & & .1 & IC & FO2 & - & 1988 & OP \\
\hline & 4 & .1 & .1 & .1 & IC & F02 & - & 1993 & OP \\
\hline Manokotak City of ................................. & & 9 & 2 & 9 & & & & & \\
\hline Manokotak (Bristol Bay) ........................................ & 1 & .1 & .1 & .1 & IC & FOI & - & 1993 & $O P$ \\
\hline & 2 & $\begin{array}{l}3 \\
5\end{array}$ & $\begin{array}{r}3 \\
5\end{array}$ & 3 & IC & Fol & 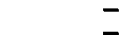 & 1982 & $\mathrm{OP}$ \\
\hline Mutanuskas Electric Assn In & & 2.1 & 2.5 & 21 & IC & Fol & - & 1973 & OP \\
\hline 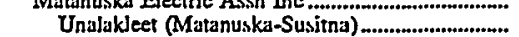 & 1 & 3 & .3 & $\begin{array}{lll}2.1 \\
3\end{array}$ & IC & & - & 1965 & \\
\hline & 2 & 5 & .5 & 5 & IC & FO2 & - & 19 & OP \\
\hline & 3 & .6 & .6 & 6 & IC & $\mathrm{FC}$ & - & & OP \\
\hline & 4 & .6 & 6 & .6 & IC & FO2 & - & & \\
\hline Unalakleet-Wind (Matanuska-Susitna).................. & 1 & * & * & * & WT & Wind & - & 198 & $\mathrm{OP}$ \\
\hline & 2 & * & $*$ & * & WT & Wind & - & & $\mathrm{OP}$ \\
\hline & 3 & * & & 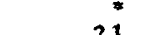 & WT & Wind & - & 1982 & OP \\
\hline 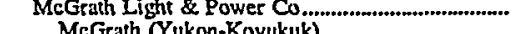 & & 2.1 & 20 & 2.1 & & & & & \\
\hline 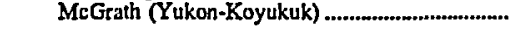 & 3 & 3 & .2 & 2 & IC & FO! & $\mathrm{FO} 2$ & 1979 & OP \\
\hline & 4 & .2 & .2 & 2 & IC & Fol & FC & 19 & \\
\hline & 5 & .6 & .6 & .6 & IC & FOl & & & P \\
\hline & 6 & .7 & .7 & .7 & IC & Fol & & & OP \\
\hline & 7 & .4 & .4 & .4 & IC & FOI & FO2 & 1993 & OP \\
\hline Metlakatla & & 8.2 & 8.2 & 8.2 & & & & & \\
\hline Centennial (Ketchikan Gateway).............................. & IC6 & 3.3 & 3.3 & 3.3 & IC & F02 & - & 1987 & $O P$ \\
\hline Chester Lake (Ketchikan Gateway) ........................ & 1 & 1.0 & 1.0 & 1.0 & HY & Water & - & 1988 & OP \\
\hline Purple Lake (Ketchikan Gateway) .......................... & 1 & 1.3 & 1.3 & 1.3 & HY & Water & - & 1956 & $\mathrm{OP}$ \\
\hline & 2 & 1.3 & 1.3 & 13 & HY & Water & - & 1956 & $O P$ \\
\hline Naknnek Electric Assn In & 3 & $\begin{array}{l}1.3 \\
7.7\end{array}$ & $\begin{array}{l}1.3 \\
7.7\end{array}$ & $\begin{array}{l}13 \\
7.7\end{array}$ & HY & Water & - & 3962 & \\
\hline & & & & & & & & & \\
\hline
\end{tabular}

See footnotes at end of table. 
Table 20. Existing Generating Units at U.S. Electric Utilities by State, Company, and Plant, as of January 1, 1998 (Continued)

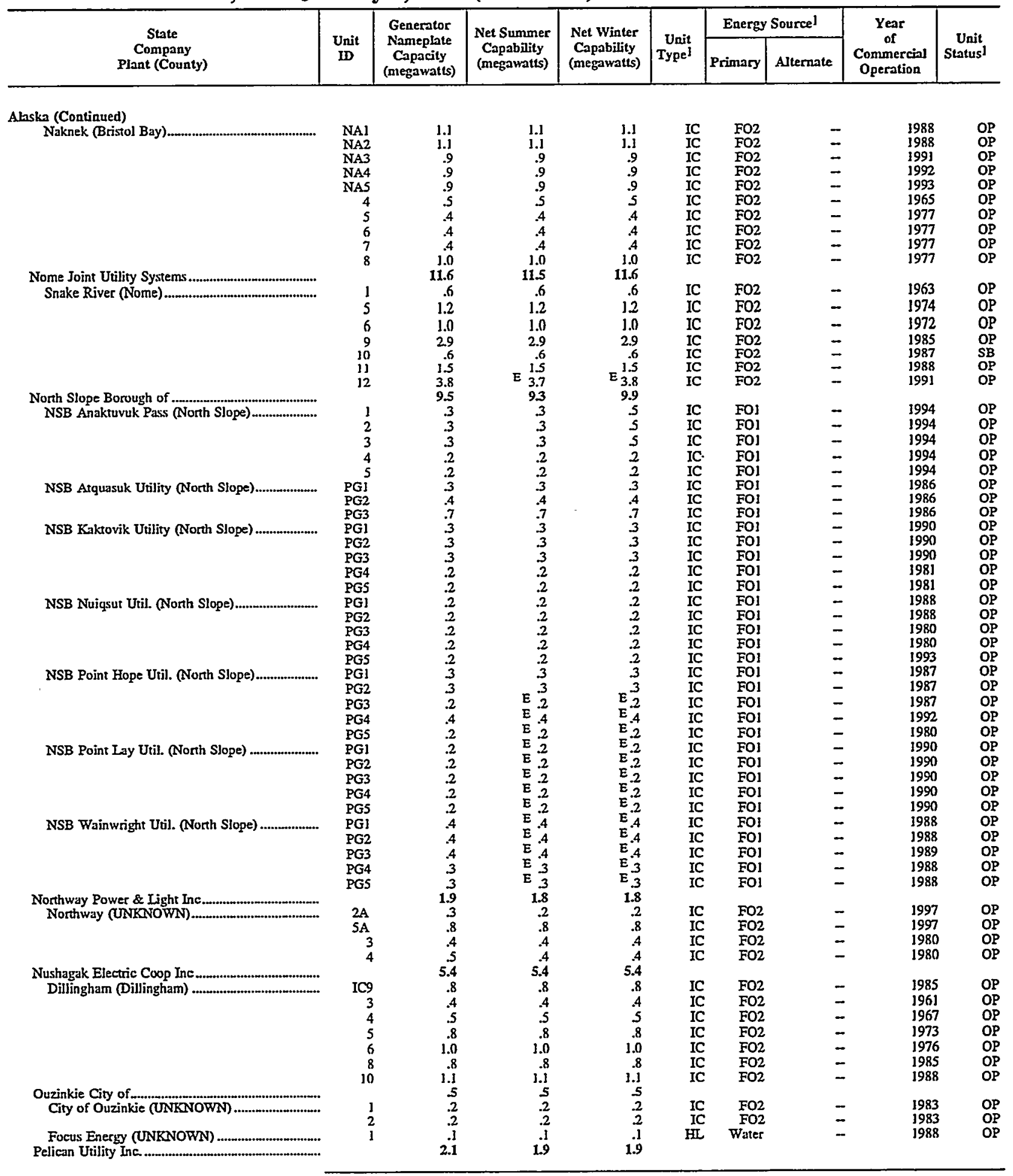

See footnotes at end of table. 
Table 20. Existing Generating Units at U.S. Electric Utilities by State, Company, and Plant, as of January 1, 1998 (Continued)

\begin{tabular}{|c|c|c|c|c|c|c|c|c|c|}
\hline \multirow{2}{*}{$\begin{array}{c}\text { State } \\
\text { Company } \\
\text { Plant (County) }\end{array}$} & \multirow{2}{*}{$\begin{array}{l}\text { Unit } \\
\text { LD }\end{array}$} & \multirow{2}{*}{$\begin{array}{c}\text { Generator } \\
\text { Nameplate } \\
\text { Capacity } \\
\text { (megawatts) }\end{array}$} & \multirow{2}{*}{$\begin{array}{l}\text { Net Summer } \\
\text { Capability } \\
\text { (megawatts) }\end{array}$} & \multirow{2}{*}{$\begin{array}{l}\text { Net Winter } \\
\text { Capability } \\
\text { (megawatls) }\end{array}$} & \multirow{2}{*}{$\begin{array}{c}\text { Unit } \\
\text { Typel }\end{array}$} & \multicolumn{2}{|c|}{ Energy Sourcel } & \multirow{2}{*}{$\begin{array}{c}\text { Year } \\
\text { or } \\
\text { Conmercinl } \\
\text { Operation }\end{array}$} & \multirow{2}{*}{$\begin{array}{c}\text { Unit } \\
\text { Status }\end{array}$} \\
\hline & & & & & & Primary & Alternate & & \\
\hline \multicolumn{10}{|l|}{ Alaskn (Continued) } \\
\hline Pelican (UNKNOWN) & $\mathrm{HCl}$ & 0.6 & 0.5 & 0.5 & HY & Water & - & 1984 & OP \\
\hline & $\mathrm{HC2}$ & .1 & .1 & .1 & HY & Water & - & 1984 & $\mathrm{OP}$ \\
\hline & IC] & 3 & .3 & 3 & $\mathrm{IC}$ & FO2 & - & 1989 & OP \\
\hline & IC2 & .1 & .1 & .1 & IC & $\mathrm{FO} 2$ & - & 1964 & $\mathrm{OP}$ \\
\hline & IC3 & .3 & 2 & .2 & IC & $\mathrm{FO} 2$ & - & 1974 & OP \\
\hline & IC4 & 3 & .3 & 3 & IC & $\mathrm{FO} 2$ & - & 1980 & OP \\
\hline & ICS & .4 & .4 & .4 & IC & FO2 & - & 1990 & OP \\
\hline 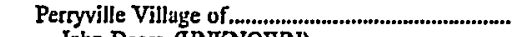 & & 3 & 3 & 3 & & & & & \\
\hline John Deere (UNKNOWN) .................................. & $\begin{array}{l}1 \\
3\end{array}$ & $\begin{array}{l}.2 \\
.1\end{array}$ & .2 & .2 & $\begin{array}{l}\text { IC } \\
\text { IC }\end{array}$ & $\begin{array}{l}\text { FOl } \\
\text { Fol }\end{array}$ & $\begin{array}{l}\mathrm{FO} 2 \\
\mathrm{FO} 2\end{array}$ & $\begin{array}{l}1992 \\
1992\end{array}$ & $\begin{array}{l}O P \\
O P\end{array}$ \\
\hline 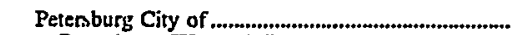 & & 9.8 & 8.5 & 8.5 & & & & 1992 & \\
\hline Petersburg (Wrangell-Petersburg) .......................... & ICI & 2.6 & 2.1 & 2.1 & IC & $\mathrm{FO} 2$ & - & 1972 & OP \\
\hline & IC2 & .4 & .3 & 3 & IC & FO2 & - & 1972 & OP \\
\hline & IC3 & 1.3 & I.I & 1.1 & IC & FO2 & - & 1965 & OP \\
\hline & IC4 & .6 & .6 & .6 & IC & FO2 & - & 1979 & OP \\
\hline & ICS & .8 & .8 & .8 & IC & FO2 & - & 1979 & OP \\
\hline & $\begin{array}{r}\text { IC6 } \\
3\end{array}$ & $\begin{array}{l}2.6 \\
1.6\end{array}$ & 2.1 & 2.1 & IC & FO2 & - & 1993 & OP \\
\hline 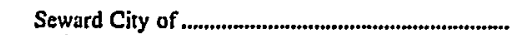 & & 10.5 & 9.5 & 9.9 & HY & & - & 1954 & OP \\
\hline Seward (Kenai Peninsula) & 1 & 1.5 & 1.0 & 1.2 & IC & $\mathrm{FO} 2$ & FOI & 1965 & OP \\
\hline & $\begin{array}{l}2 \\
3\end{array}$ & $\begin{array}{l}1.5 \\
2.5\end{array}$ & $\begin{array}{l}1.0 \\
2.5\end{array}$ & $\begin{array}{l}12 \\
25\end{array}$ & IC & FO2 & $\begin{array}{l}\text { FOl } \\
\text { FOl }\end{array}$ & $\begin{array}{l}1965 \\
1975\end{array}$ & $\begin{array}{l}\text { OP } \\
O P\end{array}$ \\
\hline & 4 & 2.5 & 2.5 & 25 & IC & $\mathrm{FO} 2$ & Fol & $\begin{array}{l}1975 \\
1986\end{array}$ & OP \\
\hline & 5 & 2.5 & 2.5 & 25 & IC & $\mathrm{FO} 2$ & FOl & 1985 & op \\
\hline 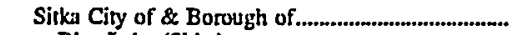 & & 33.7 & 33.7 & 33.7 & & & & & \\
\hline 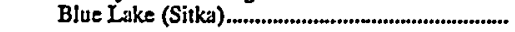 & I & 3.0 & 3.0 & 3.0 & HI & Water & - & 1961 & OP \\
\hline & 2 & 3.0 & 3.0 & 3.0 & HIL & Water & - & 1961 & OP \\
\hline BJue Lake Fish Valve (Sitkis)............................ & NAI & .7 & .7 & .7 & HI & Water & - & 1993 & OP \\
\hline 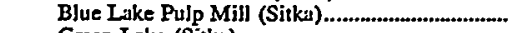 & NA2 & .9 & .9 & .9 & $\mathrm{HL}$ & Water & - & 1993 & OP \\
\hline 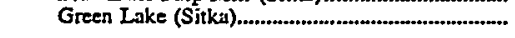 & 1 & 9.3 & 9.3 & 9.3 & $\mathrm{HI}$ & Water & - & 1982 & $O P$ \\
\hline & 2 & 9.3 & 9.3 & 9.3 & HL & Water & - & 1982 & op \\
\hline 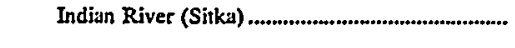 & 1 & $\begin{array}{l}2.0 \\
2.8\end{array}$ & $\begin{array}{l}20 \\
2.8\end{array}$ & 2.0 & IC & $\mathrm{FO} 2$ & $=$ & 1979 & $O P$ \\
\hline & 3 & 28 & $\begin{array}{l}2.8 \\
2.8\end{array}$ & $\begin{array}{l}2.8 \\
2.8\end{array}$ & IC & $\mathrm{FO2}$ & $\overline{-}$ & $\begin{array}{l}1979 \\
1979\end{array}$ & $\begin{array}{l}\text { OP } \\
\text { OP }\end{array}$ \\
\hline 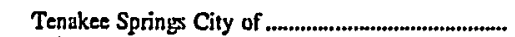 & & 3 & 2 & 2 & & & & & \\
\hline 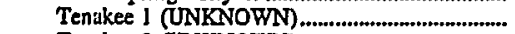 & 1 & .1 & .1 & .1 & IC & FO2 & - & 1992 & OP \\
\hline 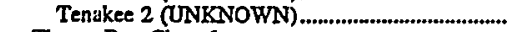 & 2 & .1 & .1 & .1 & IC & FO2 & - & 1993 & OP \\
\hline Thome Bay City of & & 1.4 & 1.4 & 1.4 & & & & & \\
\hline Thome Bay PJant (UNKNOWN) ........................... & 2 & .7 & .7 & .7 & IC & $\mathrm{FO} 2$ & - & 1993 & OP \\
\hline & 3 & 3 & 3 & 3 & IC & FO2 & - & 1987 & OP \\
\hline & 4 & .5 & .5 & $\overrightarrow{5}$ & IC & $\mathrm{FO} 2$ & - & 1996 & OP \\
\hline 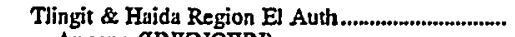 & & 9.6 & 9.0 & 9.0 & & & & & \\
\hline 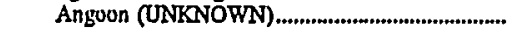 & 1 & .4 & .4 & .4 & IC & $\mathrm{FO} 2$ & - & 1975 & OP \\
\hline & 2 & .3 & 3 & 3 & IC & $\mathrm{FO2}$ & - & 1975 & OP \\
\hline & 3 & .6 & 3 & 3 & IC & FO2 & - & 1990 & OP \\
\hline Chilkat Valley (UNKNOWN) ............................. & $2 \mathrm{~A}$ & 6 & .6 & .6 & IC & $\mathrm{FO} 2$ & - & 1991 & $\mathrm{OP}$ \\
\hline & 1 & .6 & .6 & .6 & IC & $\mathrm{FO} 2$ & - & 1993 & OP \\
\hline Hoonah (UNKNOWN) & $2 A$ & 1.0 & 1.0 & 1.0 & IC & $\mathrm{FO} 2$ & - & 1997 & OP \\
\hline & 1 & .6 & .6 & .6 & IC & FO2 & - & 1977 & OP \\
\hline Kake (UNKNOWN) & $3^{3}$ & .9 & .6 & .6 & IC & FO2 & - & 199j & $O P$ \\
\hline 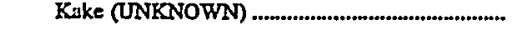 & $3 A_{1}$ & $\begin{array}{l}.9 \\
.6\end{array}$ & $\begin{array}{l}.9 \\
.6\end{array}$ & $\begin{array}{l}9 \\
6\end{array}$ & IC & FO2 & - & 1993 & $O P$ \\
\hline & 2 & .6 & $\begin{array}{r}.6 \\
1.1\end{array}$ & $\begin{array}{r}.6 \\
1.1\end{array}$ & IC & FO2 & - & 1984 & $O P$ \\
\hline & 3 & $\begin{array}{r}1.1 \\
.5\end{array}$ & 1.15 & $\begin{array}{r}1.1 \\
5\end{array}$ & IC & FO2 & - & 1993 & $O P$ \\
\hline 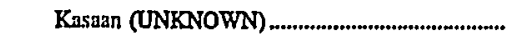 & 1 & 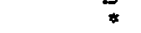 & $\neq$ & * & $\begin{array}{l}\text { IC } \\
\text { IC }\end{array}$ & FO2 & - & 1970 & $\begin{array}{l}O P \\
O P\end{array}$ \\
\hline & 2 & $\bullet$ & $\bullet$ & $*$ & IC & $\mathrm{FO2}$ & $\overline{-}$ & $\begin{array}{l}1984 \\
1984\end{array}$ & $\begin{array}{l}\text { OP } \\
\text { OP }\end{array}$ \\
\hline & 3 & .1 & .] & .1 & IC & $\mathrm{FO2}$ & - & 1978 & OP \\
\hline & 4 & .1 & $\ddot{-1}$ &. & IC & $\mathrm{FO} 2$ & - & 1978 & OP \\
\hline 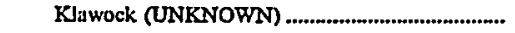 & j & $\ddot{s}$ & .5 & .5 & IC & FO2 & - & 1970 & $O P$ \\
\hline & 2 & .5 & .5 & 5 & IC & $\mathrm{FO} 2$ & - & 1970 & OP \\
\hline & 3 & .1 & .J & .I & IC & $\mathrm{FO2}$ & - & 1955 & OS \\
\hline & 4 & 3 & 3 & 3 & IC & FO2 & - & 1977 & OP \\
\hline 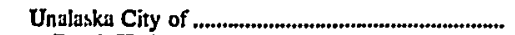 & & 8.0 & 6.4 & 6.4 & & & & & \\
\hline 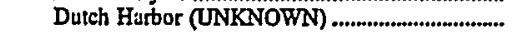 & 1 & 3 & 3 & 3 & IC & $\mathrm{FO} 2$ & - & 1985 & $O P$ \\
\hline & 2 & 3 & 3 & 3 & IC & $\mathrm{FO} 2$ & - & 1987 & $\mathrm{OP}$ \\
\hline & 3 & .7 & .5 & 5 & IC & $\mathrm{FO} 2$ & - & 1986 & $O P$ \\
\hline & 4 & .9 & .7 & .7 & IC & $\mathrm{FO} 2$ & - & 198 & OP \\
\hline . & 5 & .7 & 5 & 5 & IC & $\mathrm{FO} 2$ & - & 1985 & OP \\
\hline & 6 & 1.6 & 1.2 & 1.2 & IC & $\widehat{\mathrm{FO} 2}$ & - & 1985 & $\mathrm{OP}$ \\
\hline & 8 & 1.2 & 1.0 & 1.0 & IC & $\mathrm{FO} 2$ & - & 1989 & $\mathrm{OP}$ \\
\hline
\end{tabular}

See footnotes at end of table. 
Table 20. Existing Generating Units at U.S. Electric Utilities by State, Company, and Plant, as of January 1, 1998 (Continued)

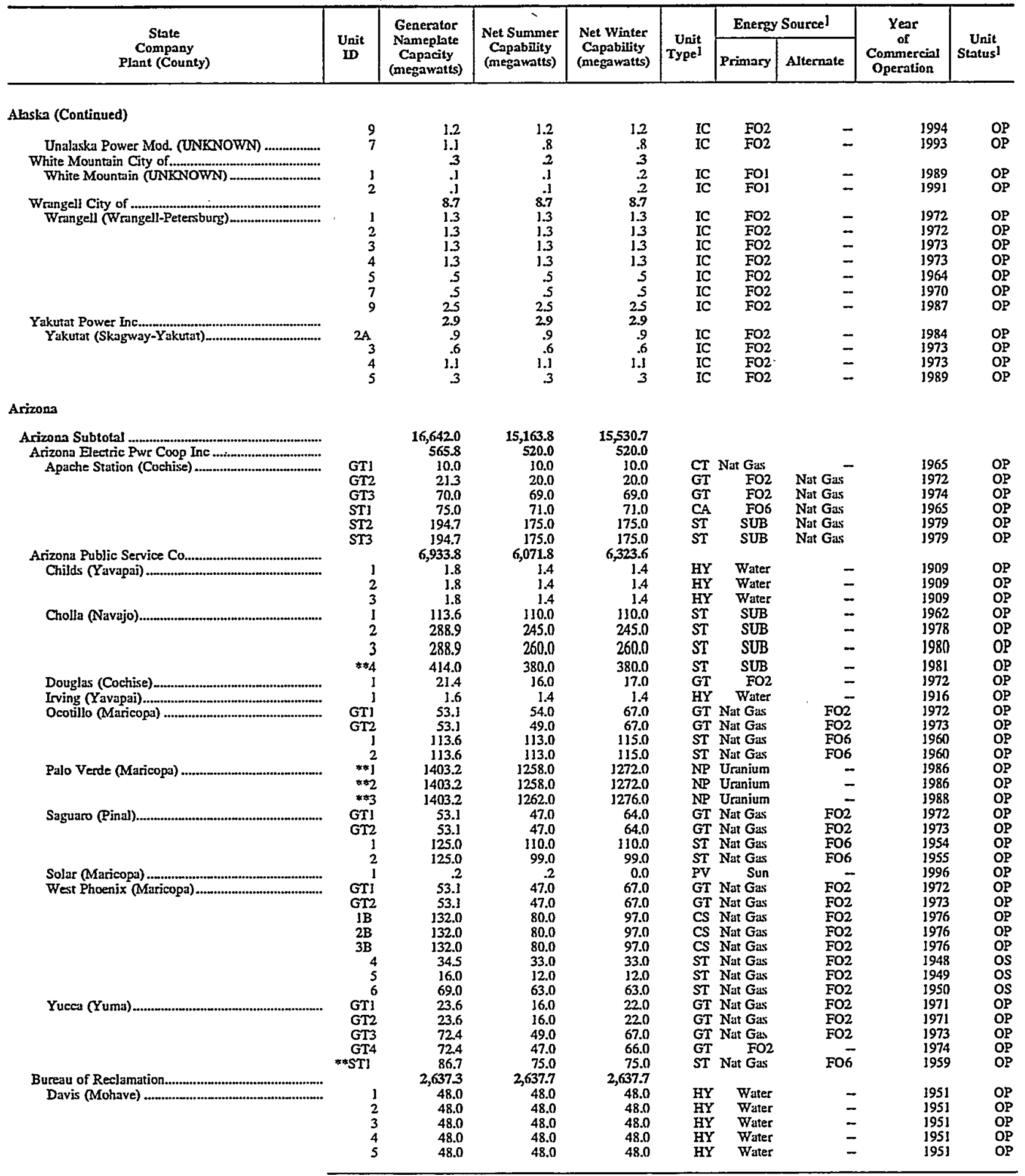

See footnotes at end of table. 
Table 20. Existing Generating Units at U.S. Electric Utilities by State, Company, and Plant, as of January 1, 1998 (Continued)

\begin{tabular}{|c|c|c|c|c|c|c|c|c|c|}
\hline \multirow{2}{*}{$\begin{array}{c}\text { State } \\
\text { Company } \\
\text { PJant (County) }\end{array}$} & \multirow{2}{*}{$\begin{array}{l}\text { Unit } \\
\text { ID }\end{array}$} & \multirow{2}{*}{$\begin{array}{l}\text { Generator } \\
\text { Nameplate } \\
\text { Capacity } \\
\text { (megawatts) }\end{array}$} & \multirow{2}{*}{$\begin{array}{l}\text { Net Summer } \\
\text { Capability } \\
\text { (megawatts) }\end{array}$} & \multirow{2}{*}{$\begin{array}{l}\text { Net Winter } \\
\text { Capability } \\
\text { (megawatts) }\end{array}$} & \multirow{2}{*}{$\begin{array}{c}\text { Unit } \\
\text { Typel }\end{array}$} & \multicolumn{2}{|c|}{ Energy Source] } & \multirow{2}{*}{$\begin{array}{c}\text { Year } \\
\text { of } \\
\text { Commercial } \\
\text { Operation }\end{array}$} & \multirow{2}{*}{$\begin{array}{c}\text { Unit } \\
\text { Stalus }\end{array}$} \\
\hline & & & & & & Primary & Alternate & & \\
\hline Arizona (Continued) & & & & & & & & & \\
\hline Glen Canyon (Coconino) & 1 & 165.0 & 165.0 & 165.0 & HY & Water & - & 1964 & OP \\
\hline & 2 & 157.0 & 157.0 & 157.0 & HY & Water & - & 1964 & OP \\
\hline & $\begin{array}{l}3 \\
4\end{array}$ & 165.0 & 165.0 & 165.0 & HY & $\begin{array}{l}\text { Water } \\
\text { Water }\end{array}$ & $=$ & 1964 & \\
\hline & 5 & 165.0 & 165.0 & 165.0 & HY & $\begin{array}{l}\text { Water } \\
\text { Water }\end{array}$ & $\overline{-}$ & $\begin{array}{l}1965 \\
1965\end{array}$ & $\begin{array}{l}\text { OP } \\
\text { OP }\end{array}$ \\
\hline & 6 & 165.0 & 165.0 & 165.0 & $\mathrm{HY}$ & Water & - & 1965 & $\mathrm{OP}$ \\
\hline & 7 & 157.0 & 157.0 & 357.0 & HY & Water & - & 1966 & OP \\
\hline & 8 & 165.0 & 165.0 & 365.0 & HY & Water & - & 1966 & OP \\
\hline 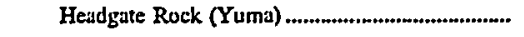 & 1 & 6.5 & 6.5 & 6.5 & HY & Water & - & 1993 & OP \\
\hline & $\begin{array}{l}2 \\
3\end{array}$ & $\begin{array}{l}6.5 \\
6.5\end{array}$ & $\begin{array}{l}6.5 \\
6.5\end{array}$ & $\begin{array}{l}6.5 \\
6.5\end{array}$ & $\begin{array}{l}H Y \\
H Y\end{array}$ & $\begin{array}{l}\text { Water } \\
\text { Water }\end{array}$ & $=$ & $\begin{array}{l}1993 \\
1993\end{array}$ & $\begin{array}{l}O P \\
O P\end{array}$ \\
\hline Hoover (Mohave) & $\mathrm{AO}$ & 2.4 & 28 & 2.8 & HY & Water & - & $\begin{array}{l}1993 \\
1936\end{array}$ & OP \\
\hline 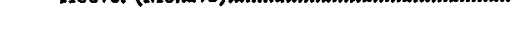 & Al & 130.0 & 130.0 & 130.0 & $\mathbf{H Y}$ & Water & - & 194] & $\mathrm{OP}$ \\
\hline & A2 & 130.0 & 130.0 & 130.0 & $\mathbf{H Y}$ & Water & - & 1942 & OP \\
\hline & A3 & 130.0 & 130.0 & 130.0 & HY & Water & - & 1952 & OP \\
\hline & A4 & 130.0 & 330.0 & 130.0 & HY & Water & - & 1952 & OP \\
\hline & As & J27.0 & 127.0 & 127.0 & HY & Water & - & 1943 & OP \\
\hline & A6 & 130.0 & 130.0 & 130.0 & $\mathbf{H Y}$ & Water & - & 1939 & OP \\
\hline & A7 & 130.0 & 130.0 & 130.0 & HY & Water & - & 1939 & OP \\
\hline & A8 & 61.5 & 61.5 & 61.5 & $\mathbf{H Y}$ & Water & - & 1937 & OP \\
\hline & A9 & 68.5 & 68.5 & 68.5 & HY & Water & - & 1952 & OP \\
\hline & No & 2.4 & 2.4 & 24 & $\mathbf{H Y}$ & Water & - & 1936 & OP \\
\hline 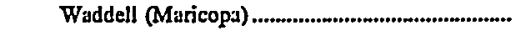 & PG3 & 10.0 & 10.0 & 10.0 & PS & Water & - & 1993 & $O P$ \\
\hline & $\begin{array}{l}\text { PG6 } \\
\text { PG7 }\end{array}$ & 10.0 & 30.0 & 10.0 & PS & Water & - & 1993 & OP \\
\hline & PG7 & 10.0 & 10.0 & 10.0 & PS & Water & - & 1993 & OP \\
\hline & PS1 & 10.0 & 10.0 & 10.0 & PS & Water & - & 1993 & OP \\
\hline Citizens Utilities Co & & 54.4 & 43.9 & 51.0 & & & & & \\
\hline 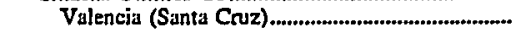 & GTI & 16.8 & 13.5 & 15.8 & GT & Nat Gas & FO2 & 1989 & OP \\
\hline & GT2 & 16.8 & 13.5 & 15.8 & GT & Nat Gas & $\mathrm{FO} 2$ & 1989 & OP \\
\hline & GT3 & 16.8 & 13.5 & 16.0 & GT & Nat Gas & $\mathrm{FO} 2$ & 1989 & OP \\
\hline & 1 & 1.0 & .9 & 9 & IC & FO2 & Nat Gas & 1949 & SB \\
\hline & 2 & 1.0 & .9 & 9 & IC & FO2 & Nat Gas & 1949 & SB \\
\hline & 3 & 1.0 & .9 & .9 & IC & $\mathrm{FO} 2$ & Nat Gas & 1949 & SB \\
\hline & 4 & 1.0 & .9 & 9 & IC & FO2 & Nat Gas & 1949 & SB \\
\hline 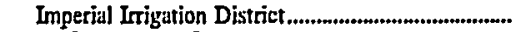 & & 23.4 & 22.0 & 22.0 & & & & & \\
\hline 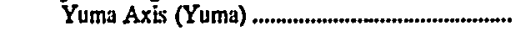 & ] & 23.4 & 220 & 22.0 & GT & $\mathrm{FO} 2$ & - & 1978 & OP \\
\hline 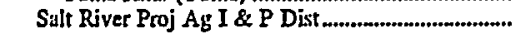 & & $4,808.7$ & $4,416.4$ & $4,524.4$ & & & & & \\
\hline Agua Fria (Maricopa) & AFl & 113.6 & 113.0 & 114.0 & ST & Nat Gas & FO2 & 1958 & OP \\
\hline 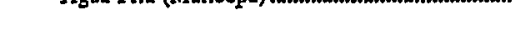 & $\mathrm{AF} 2$ & 133.6 & 113.0 & 114.0 & ST & Nat Gas & $\mathrm{FO} 2$ & 1957 & OP \\
\hline & AF3 & 163.2 & 181.0 & 184.0 & ST & Nat Gas & $\mathrm{FO} 2$ & 196] & OP \\
\hline & AF4 & 80.6 & 72.0 & 87.0 & GT & Nat Gus & FO2 & 1975 & OP \\
\hline & AF5 & 71.2 & 70.0 & 79.0 & GT & Nat Gas & FO2 & 1974 & $O P$ \\
\hline & AF6 & 71.2 & 70.0 & 79.0 & GT & Nat Gas & FO2 & 1974 & OP \\
\hline 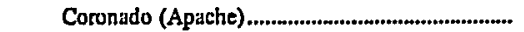 & $\mathrm{CO}]$ & 410.9 & 365.0 & 365.0 & ST & BIT & SUB & 1979 & OP \\
\hline & $\mathrm{CO} 2$ & 410.9 & 365.0 & 365.0 & ST & BIT & SUB & 1980 & OP \\
\hline Crosscut (Muricopa) & $\mathrm{CCl}$ & 7.5 & 8.0 & 8.0 & ST & Nat Gas & FO6 & 1942 & SB \\
\hline & $\mathrm{CC} 2$ & 7.5 & 8.0 & 8.0 & ST & Nat Gus & FO6 & 1942 & SB \\
\hline & $\mathrm{CC} 3$ & 7.5 & 8.0 & 8.0 & ST & Nat Gas & FO6 & 1942 & SB \\
\hline & $\mathrm{CC} 4$ & 7.5 & 8.0 & 8.0 & ST & Nat Gas & FO6 & 1949 & SB \\
\hline & $\operatorname{ccs}$ & 3.0 & 3.0 & 3.0 & HY & Water & - & 1939 & SB \\
\hline 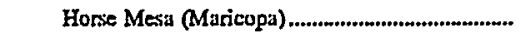 & HMI & 9.9 & 10.0 & 10.0 & HY & Water & $\rightarrow$ & 1927 & OP \\
\hline & HM2 & 9.9 & 10.0 & 10.0 & HY & Water & - & 1927 & OP \\
\hline & HMB & 9.9 & 10.0 & 10.0 & HY & Water & - & 1927 & OP \\
\hline & SM4 & 99.9 & 98.0 & 98.0 & PS & Water & - & 1972 & OP \\
\hline Kyrene (Maricopa) & KYl & 34.5 & 34.0 & 34.0 & ST & Nat Gas & FO6 & 1952 & OP \\
\hline & KY2 & 73.5 & 72.0 & 720 & ST & Nat Gas & FO6 & 1954 & OP \\
\hline & KY4 & 53.1 & 57.0 & 63.0 & GT & Nat Gas & $\mathrm{FO} 2$ & 1971 & OP \\
\hline & KY5 & 60.3 & 51.0 & 61.0 & GT & Nat Gas & $\mathrm{FO2}$ & 1973 & OP \\
\hline & KY6 & 60.3 & 50.0 & 60.0 & GT & Nat Gas & $\mathrm{FO} 2$ & 1973 & OP \\
\hline 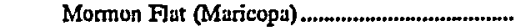 & MF] & 9.2 & 11.0 & 11.0 & HY & Water & - & 1926 & OP \\
\hline & MF2 & 48.6 & 47.0 & 47.0 & PS & Water & - & 1971 & OP \\
\hline Navajo (Coconino) & *NAVI & 803.2 & 755.0 & 755.0 & ST & SUB & - & 1974 & OP \\
\hline & *NAV2 & 803.2 & 720.0 & 720.0 & ST & suB & - & 1975 & OP \\
\hline & *NAV3 & 803.2 & 750.0 & 750.0 & ST & SUB & - & 1976 & OP \\
\hline 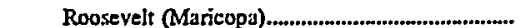 & ROOS & 36.0 & 36.0 & 36.0 & HY & Water & - & 1973 & $O P$ \\
\hline Santun (Maricopa) & STI & 103.5 & 76.0 & 87.0 & $\mathrm{cs}$ & Nat Gas & $\mathrm{FO} 2$ & 3974 & OP \\
\hline & ST2 & 103.5 & 74.0 & 85.0 & CS & Nat Gas & FO2 & 1974. & OP \\
\hline & ST3 & 103.5 & 80.0 & 91.0 & Cs & Nat Gas & $\mathrm{FO} 2$ & 1974 & OP \\
\hline & ST4 & 103.5 & 77.0 & 88.0 & CS & Nat Gas & FO2 & 1975 & OP \\
\hline South Consolidated (Maricopa).............................. & $\mathrm{SCl}$ & 1.4 & 1.4 & 1.4 & $\mathrm{HY}$ & Water & $\therefore$ & 1981 & OP \\
\hline
\end{tabular}

See foutnotes at end of table. 
Table 20. Existing Generating Units at U.S. Electric Utilities by State, Company, and Plant, as of January 1, 1998 (Continued)

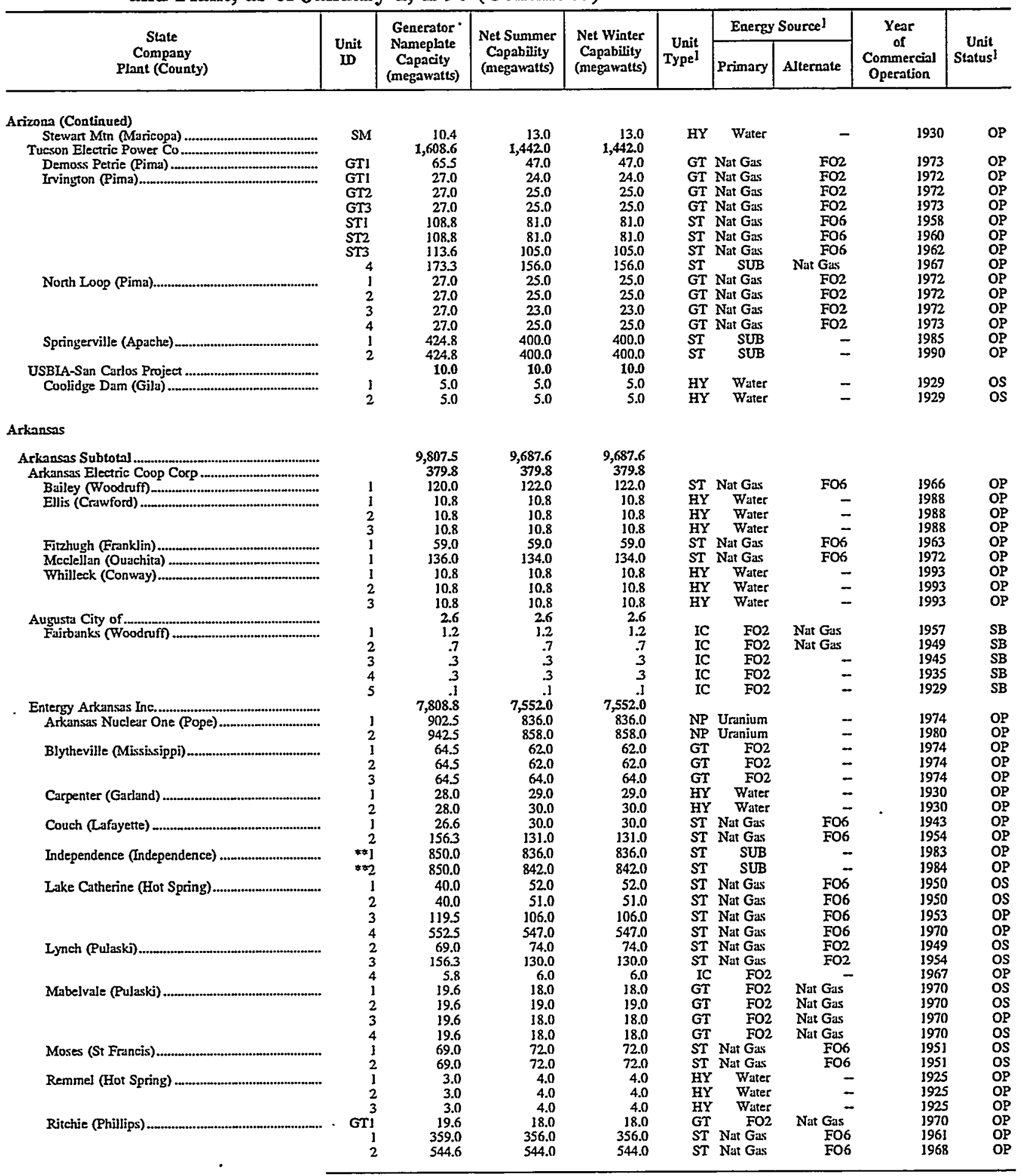

See footnotes at end of table. 
Table 20. Existing Generating Units at U.S. Electric Utilities. by State, Company, and Plant, as of January 1, 1998 (Continued)

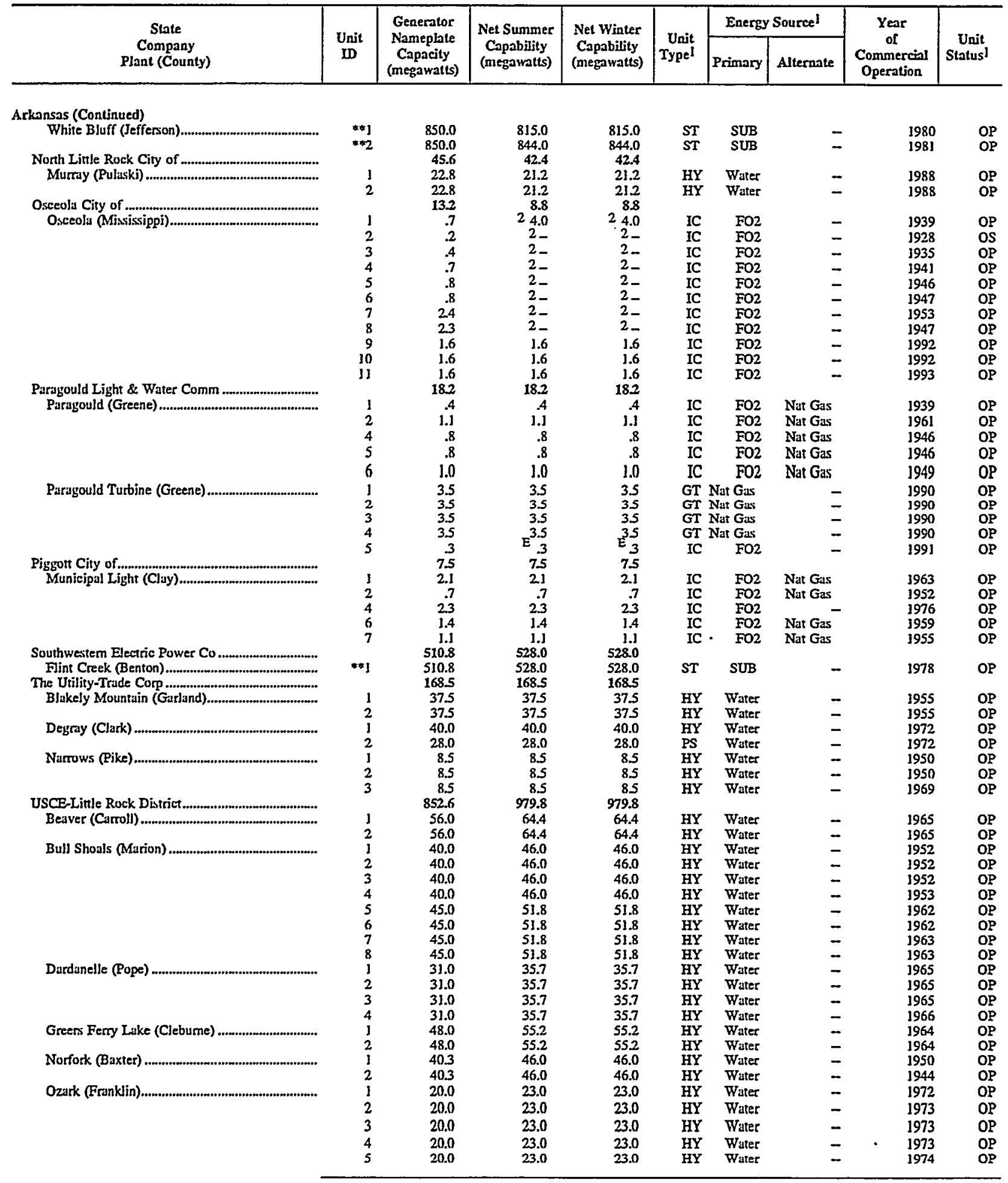

See footnotes at end of table. 
Table 20. Existing Generating Units at U.S. Electric Utilities by State, Company, and Plant, as of January 1, 1998 (Continued)

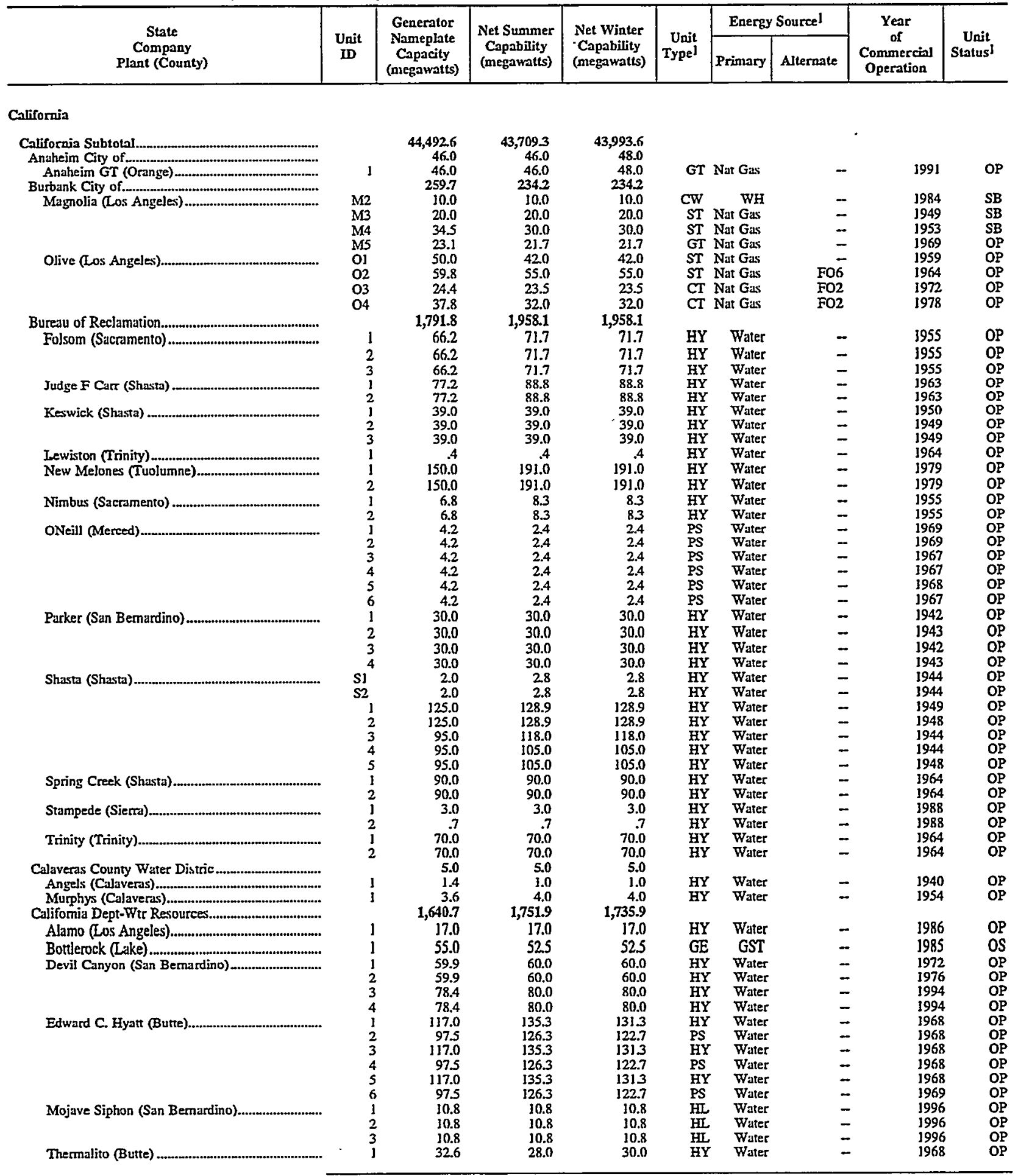

See footnotes at end of table. 
Table 20. Existing Generating Units at U.S. Electric Utilities by State, Company, and Plant, as of January 1, 1998 (Continued)

\begin{tabular}{|c|c|c|c|c|c|c|c|c|c|}
\hline \multirow{2}{*}{$\begin{array}{c}\text { State } \\
\text { Company } \\
\text { Plant (County) }\end{array}$} & \multirow{2}{*}{$\begin{array}{l}\text { Unit } \\
\text { ID }\end{array}$} & \multirow{2}{*}{$\begin{array}{c}\text { Generator } \\
\text { Nameplate } \\
\text { Capacity } \\
\text { (megawatts) }\end{array}$} & \multirow{2}{*}{$\begin{array}{c}\text { Net Summer } \\
\text { Capability } \\
\text { (megawatts) }\end{array}$} & \multirow{2}{*}{$\begin{array}{l}\text { Net Winter } \\
\text { Capability } \\
\text { (megawatts) }\end{array}$} & \multirow{2}{*}{$\begin{array}{r}\text { Unit } \\
\text { Typed }\end{array}$} & \multicolumn{2}{|c|}{ Energy Sourcel } & \multirow{2}{*}{$\begin{array}{c}\text { Xear } \\
\text { of } \\
\text { Commercial } \\
\text { Operation }\end{array}$} & \\
\hline & & & & & & Primary & Alternate & & Status] \\
\hline California (Continued) & & & & & & & & & \\
\hline & 2 & 27.5 & 25.7 & 273 & PS & Water & - & 1968 & OP \\
\hline & 3 & 27.5 & 25.7 & 273 & PS & Water & - & 1968 & OP \\
\hline & 4 & 27.5 & 25.7 & 273 & PS & Water & - & 1968 & OP \\
\hline 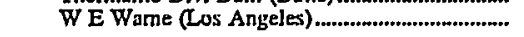 & & 37.1 & 38.0 & 38.0 & HY & Water & - & 1982 & OP \\
\hline & 2 & 37.1 & 38.0 & 38.0 & HY & Water & - & 1983 & OP \\
\hline 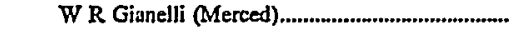 & 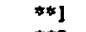 & 53.0 & 51.0 & 51.0 & PS & Water & - & 1968 & OP \\
\hline & $\approx 2$ & 53.0 & 50.0 & 50.0 & PS & Water & - & 1968 & OP \\
\hline & $\$ \$ 3$ & 53.0 & 50.0 & 50.0 & PS & Water & - & 1967 & op \\
\hline & $\approx \% 4$ & 53.0 & 50.0 & 50.0 & PS & Water & - & 1967 & $\mathrm{OP}$ \\
\hline & $* 55$ & 53.0 & S0.0 & 50.0 & PS & Water & - & 1967 & OP \\
\hline & $* *_{6}$ & 53.0 & 50.0 & 50.0 & PS & Water & - & 1967 & OP \\
\hline & $\$ 7$ & 53.0 & 50.0 & 50.0 & PS & Water & - & 1967 & OP \\
\hline & $* \$ 8$ & 53.0 & 50.0 & 50.0 & PS & Water & - & 1967 & OP \\
\hline 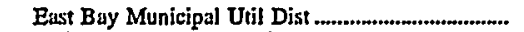 & & 34.4 & 39.3 & 39.3 & & & & & \\
\hline & 2 & 3.6 & 3.6 & 3.6 & HY & Water & - & 1983 & OP \\
\hline & 3 & 3.6 & 3.6 & 3.6 & HY & Water & - & 1983 & $\mathrm{OP}$ \\
\hline 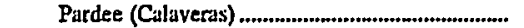 & 1 & 7.5 & 9.4 & 9.4 & HY & Water & - & 1930 & OP \\
\hline & 2 & 7.5 & 9.4 & 9.4 & HY & Water & - & 1930 & OP \\
\hline & 3 & 8.6 & 9.9 & 9.9 & $\mathbf{H Y}$ & Water & - & 1983 & OP \\
\hline 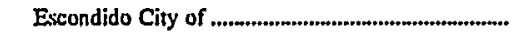 & & 1.8 & 1.8 & 1.8 & & & & & \\
\hline 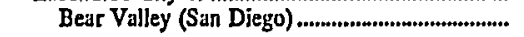 & $\mathrm{HCl}$ & .8 & .8 & .8 & HY & Water & - & 1986 & $\mathrm{OP}$ \\
\hline & $\mathrm{HC2}$ & .8 & .8 & .8 & HY & Water & - & 1986 & $\mathrm{OP}$ \\
\hline Rincon Powet (San Diego)........................................... & 1 & .2 & .2 & .2 & $\mathrm{HY}$ & Water & - & 1915 & $\mathrm{OP}$ \\
\hline & 2 & .2 & .2 & 2 & $\mathrm{HY}$ & Water & - & 1915 & OP \\
\hline Glendale City of & & 282.5 & 263.0 & 282.0 & & & & & \\
\hline 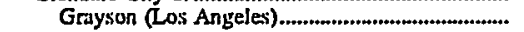 & $8 \mathrm{~A}$ & 26.4 & 26.0 & 30.0 & CT & Nat Gas & FO2 & 1977 & OP \\
\hline & $8 \mathrm{BC}$ & 55.1 & 54.0 & 60.0 & $\mathrm{CT}$ & Nat Gas & FO2 & 1977 & OP \\
\hline & 1 & 20.0 & 20.0 & 20.0 & $\mathbf{C W}$ & WH & - & 1977 & OP \\
\hline & 2 & 20.0 & 20.0 & 20.0 & $C W$ & WH & - & 1977 & $\mathrm{OP}$ \\
\hline & 3 & 20.0 & 20.0 & 21.0 & ST & Nat Gas & MTE & 1953 & OP \\
\hline & 4 & 44.0 & 44.0 & 45.0 & ST & Nat Gas & MTE & 1959 & OP \\
\hline & 5 & 44.0 & 44.0 & 45.0 & ST & Nat Gas & MTE & 1964 & OP \\
\hline & 6 & 220 & 15.0 & 18.0 & GT & Nat Gas & $\mathrm{FO} 2$ & 1972 & OP \\
\hline & 7 & 31.0 & 20.0 & 23.0 & GT & Nat Gas & $\mathrm{FO} 2$ & 1974 & OP \\
\hline 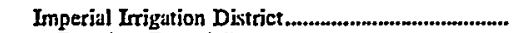 & & 507.1 & 421.7 & 4853 & & & & & \\
\hline & 2 & 23.2 & 20.0 & 20.0 & GT & Nat Gas & FO2 & 1973 & OP \\
\hline & 3 & 23.2 & 20.0 & 20.0 & $\mathbf{G T}$ & Nat Gas & FO2 & 1974 & OP \\
\hline & 4 & 23.2 & 20.0 & 20.0 & GT & Nat Gas & FO2 & 1976 & OP \\
\hline 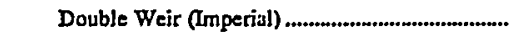 & $i$ & 3 & E 3 & 3 & HY & Water & - & 1961 & $O P$ \\
\hline & 2 & 3 & E 3 & $E_{3}$ & HY & Water & - & 1961 & OP \\
\hline Drop I (Imperial) & 1 & 2.0 & $\mathrm{E} 1 . \overline{7}$ & E ].8 & HY & Water & - & 1984 & OP \\
\hline & 2 & 2.0 & E 1.7 & E 1.8 & HY & Water & - & 1984 & OP \\
\hline & 3 & 20 & E 1.6 & E 1.8 & HY & Water & - & 1984 & OP \\
\hline 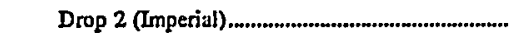 & ] & 5.0 & E 4.0 & E S.I & $\mathrm{HY}$ & Water & - & 1953 & OP \\
\hline & 2 & 5.0 & E 4.0 & $E_{5.1}$ & HY & Water & - & 1953 & OP \\
\hline 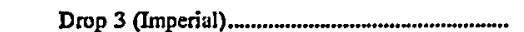 & j & 4.8 & E 4.0 & $E_{4.9}$ & HY & Water & - & 1941 & OP \\
\hline & 2 & 5.0 & E 4.0 & E 5.1 & HY & Water & - & 1966 & OP \\
\hline 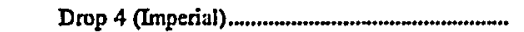 & 1 & 10.0 & E 8.0 & $E_{10.3}$ & HY & Water & - & 1950 & $\mathrm{OP}$ \\
\hline & 2 & 9.6 & E 8.0 & E 9.8 & HY & Water & - & 1941 & OP \\
\hline Drop 5 (Imperial) & 1 & 2.0 & E 1.5 & E 1.8 & FY & Water & - & 1982 & OP \\
\hline & 2 & 2.0 & E is & E 1.8 & $\overrightarrow{H Y}$ & Water & - & 1982 & OP \\
\hline East Highline (Imperial) & 1 & 2.4 & E 1.1 & $\mathrm{E}_{2.2}$ & $\mathbf{H Y}$ & Water & - & 1984 & OP \\
\hline E] Centro (Imperial) & $2 A$ & 89.9 & 84.5 & 88.0 & $\mathrm{CT}$ & Nat Gas & FO2 & 1993 & OP \\
\hline & 2 & 34.5 & 30.7 & 30.7 & $\mathrm{CW}$ & WH & - & 1952 & OP \\
\hline & 3 & 50.0 & 43.6 & 48.0 & ST & Nat Gas & FO6 & 1957 & OP \\
\hline & 4 & 81.6 & 73.9 & 80.0 & ST & Nat Gas & FO6 & 1968 & OP \\
\hline 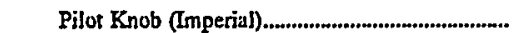 & i & 16.5 & $E 4.0$ & $E_{16.9}$ & $\mathrm{HY}$ & Water & - & 3957 & OP \\
\hline & 2 & 16.5 & E 3.0 & $E_{169}$ & HY & Water & - & 1957 & OP \\
\hline 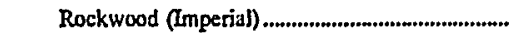 & i & 25.0 & 21.0 & 25.0 & GT & Nat Gas & FO2 & 1979 & $\mathrm{OP}$ \\
\hline & 2 & 25.0 & 21.0 & 25.0 & $\mathbf{G T}$ & $\mathrm{FO} 2$ & - & 1980 & OP \\
\hline 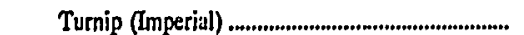 & 1 & .4 & $\mathrm{E}_{.4}$ & $\mathrm{E}_{.4}$ & HY & Water & - & 1964 & OP \\
\hline Kings River Conservation Dist................................. & & 165.0 & 165.0 & 151.8 & & & & & \\
\hline Pine Flat (Fresno) & 1 & 55.0 & E 55.0 & $E_{50.6}$ & HY & Water & - & 1984 & OP \\
\hline & 2 & 55.0 & E 55.0 & E 50.6 & HY & Water & - & 1984 & OP \\
\hline & 3 & 55.0 & E 55.0 & E 50.6 & $\mathbf{H Y}$ & Water & - & 1984 & OP \\
\hline
\end{tabular}

See footnutes at end of table. 
Table 20. Existing Generating Units at U.S. Electric Utilities.by State, Company, and Plant, as of January 1, 1998 (Continued)

\begin{tabular}{|c|c|c|c|c|c|c|c|c|c|}
\hline \multirow{2}{*}{$\begin{array}{c}\text { State } \\
\text { Company } \\
\text { Plant (County) }\end{array}$} & \multirow{2}{*}{$\begin{array}{l}\text { Unit } \\
\text { ID }\end{array}$} & \multirow{2}{*}{$\begin{array}{c}\text { Generator } \\
\text { Nameplate } \\
\text { Capacity } \\
\text { (megawats) }\end{array}$} & \multirow{2}{*}{$\begin{array}{l}\text { Net Summer } \\
\text { Capability } \\
\text { (megawatts) }\end{array}$} & \multirow{2}{*}{$\begin{array}{c}\text { Net Winter } \\
\text { Capability } \\
\text { (megawatts) }\end{array}$} & \multirow{2}{*}{$\begin{array}{r}\text { Unit } \\
\text { TypeI }\end{array}$} & \multicolumn{2}{|c|}{ Energy Sourcel } & \multirow{2}{*}{$\begin{array}{c}\text { Year } \\
\text { of } \\
\text { Commercinl } \\
\text { Operation }\end{array}$} & \\
\hline & & & & & & Primary & Alternate & & \\
\hline California (Continued) & & & & & & & & & \\
\hline Las Angeles City of & & $4,937.3$ & $5,018.1$ & $5,018.1$ & & & & & \\
\hline Big Pine (Inyo) & 1 & & & 3.1 & HI & Water & - & 1925 & OP \\
\hline Castaic (Los Angeles) & j & 212.5 & 240.0 & 240.0 & PS & Water & - & 1973 & OP \\
\hline & 2 & 212.5 & 240.0 & 240.0 & PS & Water & - & 1974 & OP \\
\hline & 3 & 2125 & 240.0 & 240.0 & PS & Water & - & 1977 & OP \\
\hline & 4 & 212.5 & 240.0 & 240.0 & PS & Water & - & 1977 & OP \\
\hline & 5 & 2125 & 240.0 & 240.0 & PS & Water & - & 1978 & OP \\
\hline & 6 & 2125 & 240.0 & 240.0 & PS & Water & - & 3978 & OP \\
\hline ' & 7 & 56.0 & 55.0 & 55.0 & HL & Water & - & 1972 & OP \\
\hline 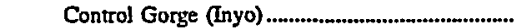 & 1 & 37.5 & 38.0 & 38.0 & HL & Water & - & 1952 & OP \\
\hline 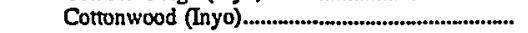 & 1 & 1.2 & 1.4 & 1.4 & HL & Water & - & 1908 & OP \\
\hline & 2 & 1.2 & 1.4 & 1.4 & HL & Water & - & 1909 & OP \\
\hline Division Creek (Inyo) & j & .6 & .7 & .7 & HI & Water & - & 1909 & OP \\
\hline Foothill (Los Angeles) & j & 11.0 & 30.0 & 10.0 & HL & Water & - & 1971 & $\mathrm{OP}$ \\
\hline Franklin (Los Angeles) & 1 & 2.0 & 20 & 2.0 & IIL & Water & - & 1921 & OP \\
\hline 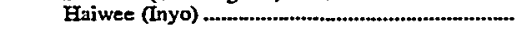 & i & 2.8 & 3.2 & 3.2 & HII & Water & - & 1927 & OP \\
\hline Habor (Tos Anuele) & & 28 & 3.2 & 3.2 & FI & Water & - & 1927 & $O P$ \\
\hline Harbor (Los Angeles) & $\begin{array}{l}\text { Gr6 } \\
\text { GT7 }\end{array}$ & $\begin{array}{l}23.6 \\
23.6\end{array}$ & $\begin{array}{l}19.0 \\
19.0\end{array}$ & $\begin{array}{l}19.0 \\
19.0\end{array}$ & $\begin{array}{l}\text { GT } \\
\text { GT }\end{array}$ & $\begin{array}{l}\text { Nat Gas } \\
\text { Nat Gas }\end{array}$ & $\begin{array}{l}\mathrm{FO} 2 \\
\mathrm{FO} 2\end{array}$ & $\begin{array}{l}1972 \\
1972\end{array}$ & $\begin{array}{l}\text { OP } \\
\text { OP }\end{array}$ \\
\hline & $10 \mathrm{~A}$ & 80.0 & 80.0 & 80.0 & CT & Nat Gas & $\mathrm{FO} 2$ & 1994 & OP \\
\hline & $10 B$ & 80.0 & 80.0 & 80.0 & CT & Nat Gas & $\mathrm{FO2}$ & 1994 & OP \\
\hline & 5 & 86.3 & 86.0 & 86.0 & ST & Nat Gas & FO6 & 1949 & OP \\
\hline & 10 & 80.0 & 80.0 & 80.0 & $\mathrm{CW}$ & WH & - & 1994 & OP \\
\hline Haynes (Los Angeles) & 1 & 230.0 & 222.0 & 222.0 & ST & Nat Gas & F06 & 1962 & OP \\
\hline & 2 & 230.0 & 222.0 & 222.0 & $\mathbf{S T}$ & Nat Gas & FO6 & 1963 & OP \\
\hline & 3 & 230.0 & 222.0 & 222.0 & $\mathbf{S T}$ & Nat Gas & FO6 & 1964 & OP \\
\hline & 4 & 230.0 & 222.0 & 222.0 & ST & Nat Gas & FO6 & 1965 & OP \\
\hline & 5 & 343.0 & 341.0 & 341.0 & ST & Nat Gas & FO6 & 1966 & OP \\
\hline & 6 & 343.0 & 341.0 & 341.0 & $\overline{S T}$ & Nat Gas & FO6 & 1967 & OP \\
\hline Middle Gorge (Mono) & 1 & 37.5 & 38.0 & 38.0 & HIL & Water & - & 1952 & OP \\
\hline 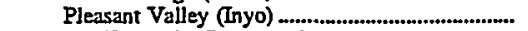 & 1 & 3.2 & 27 & 2.7 & HIL & Water & - & 1958 & OP \\
\hline 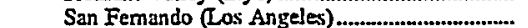 & ] & 2.8 & 3.2 & 3.2 & $\mathrm{HL}$ & Water & - & 1922 & OP \\
\hline & 2 & 28 & 3.2 & 3.2 & HL & Water & - & 1922 & $\mathrm{OP}$ \\
\hline San Francisquito 1 (Los Angeles)........................ & IA & 25.0 & 26.0 & 26.0 & HIL & Water & - & 1983 & OP \\
\hline & 3 & 9.4 & 11.0 & 11.0 & HL & Water & - & 1917 & OP \\
\hline & 4 & 10.0 & 12.5 & 125 & HIL & Water & 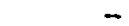 & 1923 & OP \\
\hline & 6 & 25.0 & 26.0 & 26.0 & HI & Water & - & 1987 & OP \\
\hline 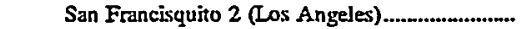 & 1 & 14.0 & 14.5 & 14.5 & HL & Water & - & 1920 & OP \\
\hline & 2 & 14.0 & 14.5 & 14.5 & HL & Water & - & 1920 & OP \\
\hline & 3 & 14.0 & 18.0 & j8.0 & HI & Water & - & 1932 & OP \\
\hline Sawrelle (Los Angeles) & 1 & .6 & .6 & .6 & HY & - Water & - & 1986 & OP \\
\hline Seattergood (Los Angeles) & j & 163.2 & 179.0 & 179.0 & ST & Nat Gas & FO6 & 1958 & OP \\
\hline & 2 & 363.2 & 179.0 & 179.0 & $\mathbf{S T}$ & Nat Gas & FO6 & 1959 & OP \\
\hline & 3 & 496.8 & 445.0 & 445.0 & ST & Nat Gas & - & 1974 & OP \\
\hline Upper Gorge (Mono) & 1 & 37.5 & 36.0 & 36.0 & HI & Water & - & 1953 & OP \\
\hline 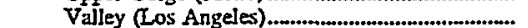 & 1 & 100.0 & 95.0 & 95.0 & ST & Nat Gas & FO6 & 1954 & SB \\
\hline & 2 & 100.0 & 99.0 & 99.0 & ST & Nat Gas & FO6 & 1954 & SB \\
\hline & 3 & 172.8 & 163.0 & 163.0 & ST & Nat Gas & FO6 & 1955 & $\mathrm{OP}$ \\
\hline & 4 & 172.8 & 160.0 & 160.0 & ST & Nat Gas & FO6 & 1956 & OP \\
\hline Merced Irigation District & & 108.0 & 108.5 & 105.6 & & & & & \\
\hline Exchequer (Maripusa) & 1 & 94.5 & 94.5 & 94.5 & HY & Water & - & 1967 & OP \\
\hline Mc Swain (Maripasi) & 1 & 9.0 & 9.0 & 7.0 & HY & Water & - & 1967 & OP \\
\hline Papazian (Fairfield) (Merced) ............................. & 1 & .9 & E 1.0 & E.8 & HY & Water & - & 1983 & OP \\
\hline 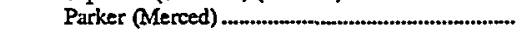 & 1 & 2.7 & E 3.0 & $\mathrm{E}_{2.5}$ & HY & Water & - & 1982 & OP \\
\hline Reta (Cinal Creek) (Merced)............................... & j & 9 & E $] .0$ & E.8 & HY & Water & - & 1983 & OP \\
\hline Metropolitan Water District................................... & & 101.2 & 101.6 & 101.4 & & & & & \\
\hline 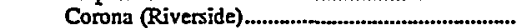 & 1 & 2.9 & 3.0 & 3.0 & HIL & Water & - & 1983 & OP \\
\hline 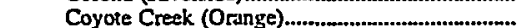 & j & 3.1 & 3.0 & 3.0 & HI & Water & - & 1984 & OP \\
\hline Etiwanda (San Bernardino) & 1 & 23.9 & 23.9 & 23.9 & HL & Water & - & 1994 & OP \\
\hline Foothill Feeder (Los Angeles)............................. & $i$ & 4.5 & 29.0 & 29.0 & HL & Water & - & 1981 & OP \\
\hline & 2 & 4.5 & $2_{-}$ & $2_{-}$ & $\mathrm{HL}$ & Water & - & 1981 & OP \\
\hline 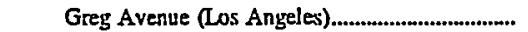 & 1 & 1.0 & 1.0 & 1.0 & HL & Water & - & 1979 & OP \\
\hline 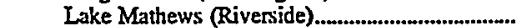 & I & 4.9 & 5.0 & 5.0 & HL & Water & - & 1980 & OP \\
\hline Perris (Riverside) & ] & 7.9 & 8.0 & 8.0 & HI & Water & - & 1983 & OP \\
\hline Red Mountain (San Diego) & 1 & 5.9 & 6.0 & 6.0 & HL & Water & - & 1985 & OP \\
\hline 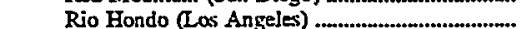 & j & 1.9 & E 1.8 & $E_{1.8}$ & HL & Water & - & 1984 & OP \\
\hline 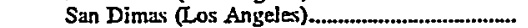 & 1 & 9.9 & J0.0 & 10.0 & HL & Water & - & 1981 & OP \\
\hline 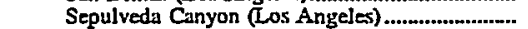 & I & 8.5 & 9.0 & 9.0 & HII & Water & - & 1982 & OP \\
\hline Temescal (Riverside) & j & 2.9 & 3.0 & 3.0 & HI & Water & - & 1983 & $O P$ \\
\hline 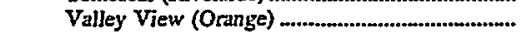 & 1 & 4.1 & E 3.9 & $\mathrm{E}_{3.8}$ & $\mathrm{HL}$ & Water & - & 1985 & OP \\
\hline
\end{tabular}

See footnotes at end of table. 
Table 20. Existing Generating Units at U.S. Electric Utilities by State, Company, and Plant, as of January 1, 1998 (Continued)

\begin{tabular}{|c|c|c|c|c|c|c|c|c|c|}
\hline \multirow{2}{*}{$\begin{array}{c}\text { State } \\
\text { Company } \\
\text { Plant (County) }\end{array}$} & \multirow{2}{*}{$\begin{array}{l}\text { Unit } \\
\text { UD }\end{array}$} & \multirow{2}{*}{$\begin{array}{c}\text { Generator } \\
\text { Nameplate } \\
\text { Capacity } \\
\text { (megawatts) }\end{array}$} & \multirow{2}{*}{$\begin{array}{c}\text { Net Summer } \\
\text { Capability } \\
\text { (megawatts) }\end{array}$} & \multirow{2}{*}{$\begin{array}{l}\text { Net Winter } \\
\text { Capability } \\
\text { (megawatts) }\end{array}$} & \multirow{2}{*}{$\begin{array}{r}\text { Unit } \\
\text { Typel }\end{array}$} & \multicolumn{2}{|c|}{ Energy Sourcel } & \multirow{2}{*}{$\begin{array}{c}\text { Year } \\
\text { of } \\
\text { Commercial } \\
\text { Operation }\end{array}$} & \\
\hline & & & & & & Primary & Alternate & & Status \\
\hline California (Conlinued) & & & & & & & & & \\
\hline 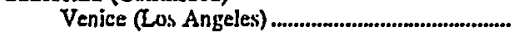 & 1 & 10.1 & 10.0 & 10.0 & HL & Water & - & 1982 & OP \\
\hline Yorba Linda (Orange) ............................................ & j & $\begin{array}{r}5.1 \\
202.0\end{array}$ & $\begin{array}{r}5.0 \\
1632\end{array}$ & $\begin{array}{r}5.0 \\
1752\end{array}$ & HL & Water & - & 1981 & $\mathrm{OP}$ \\
\hline 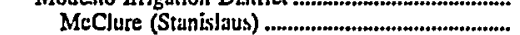 & 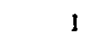 & 71.2 & 56.0 & 61.0 & GT & FO2 & Nat Gas & 1980 & OP \\
\hline & 2 & 71.2 & 56.0 & 61.0 & GT & FO2 & Nat Gas & $198 I$ & OP \\
\hline New Hogan (Calaveras)............................................ & $*$ NAI & 2.0 & 2.0 & 2.0 & $\mathrm{HY}$ & Water & - & I986 & OP \\
\hline & $*$ NA2 & 1.0 & 1.0 & 1.0 & HY & Water & - & 1986 & OP \\
\hline Stone Drop (Stanislaus)............................................. & 1 & .6 & .2 & 2 & $\mathrm{HY}$ & Water & - & 1984 & OP \\
\hline Wood land (Stanislaus) & NAI & 56.0 & 48.0 & 50.0 & GT & Nat Gas & FO2 & 1993 & OP \\
\hline Nevada Irrigation District ........................................... & & 86.2 & 86.1 & 86.2 & & & & & \\
\hline 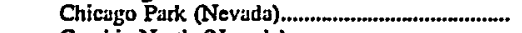 & $2 \mathrm{P}$ & 44.0 & 44.0 & 44.0 & $\mathrm{HY}$ & Water & - & 3965 & OP \\
\hline 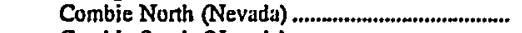 & $6 \mathrm{P}$ & .3 & E 3 & $E_{3}$ & $\mathrm{HY}$ & Water & - & 1987 & OP \\
\hline 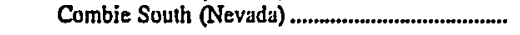 & 1 & .5 & E. .5 & ES & $\mathrm{HY}$ & Water & - & 1984 & $\mathrm{OP}$ \\
\hline & 2 & .5 & E 5 & Es & HY & Water & - & 1984 & OP \\
\hline Dutch Flut 2 (Neysda) & 3 & & E.5 & Es & $\mathrm{HY}$ & Water & - & 1984 & OP \\
\hline $\begin{array}{l}\text { Dutch Flut } 2 \text { (Nevuda) } \\
\text { Rollins (Nevada) }\end{array}$ & 3P & 27.3 & 27.3 & 27.3 & HY & Water & - & 1965 & OP \\
\hline & IP & 12.1 & 12.1 & 12.2 & $\mathrm{HY}$ & Water & - & 1980 & OP \\
\hline Scott Flat (Nevada)........................................... & $7 \mathbf{P}$ & 1.0 & 1.0 & 1.0 & $\overrightarrow{\mathrm{HY}}$ & Water & - & 1985 & OP \\
\hline & & 645.3 & 664.5 & 673.3 & & & & & \\
\hline 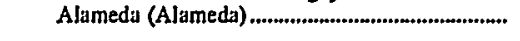 & 1 & 25.2 & 24.7 & 26.2 & GT & Nat Gas & $\mathrm{FO} 2$ & 1986 & $O P$ \\
\hline Geothermal L (Sonoma) & 2 & 25.2 & 25.4 & 27.0 & GT & Nat Gas & FO2 & 1986 & OP \\
\hline 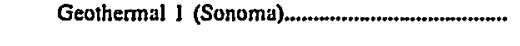 & 1 & 55.0 & 59.0 & 59.0 & GE & GST & - & J983 & OP \\
\hline Geothermal 2 (Sonnome) & 2 & 55.0 & 59.0 & 59.0 & GE & GST & - & 1983 & OP \\
\hline 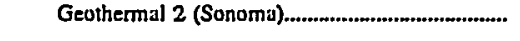 & 3 & 55.0 & 60.0 & 60.0 & GE & GST & - & 1985 & OP \\
\hline & 4 & 55.0 & 60.0 & 60.0 & GE & GST & - & 1986 & OP \\
\hline 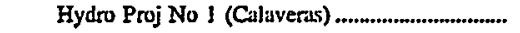 & 1 & 121.5 & 121.5 & 121.5 & HY & Water & - & 1990 & $O P$ \\
\hline & 2 & 121.5 & 121.5 & 1215 & HY & Water & - & 1990 & OP \\
\hline & 3 & 2.7 & 2.7 & 2.7 & HY & Water & - & 19 & OP \\
\hline & 4 & 2.7 & 2.7 & 2.7 & $\mathrm{HY}$ & Water & - & 39 & OP \\
\hline & 5 & 5 & 5 & 5 & HY & Water & - & 19 & $O P$ \\
\hline & 6 & 2 & .2 & 2 & HY & Water & - & 39 & OP \\
\hline 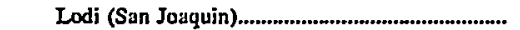 & 1 & 25.2 & 25.9 & 27.0 & GT & Nat Gas & $\mathrm{FO} 2$ & 1986 & OP \\
\hline 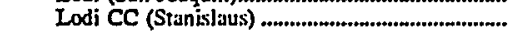 & NAi & 50.0 & 50.0 & 50.0 & GT & Nat Gas & FO2 & 1996 & OP \\
\hline Roseville (Placet) & 1 & 25.2 & 26.0 & 28.3 & GT & Nat Gas & FO2 & 198 & OP \\
\hline & 2 & 25.2 & 25.5 & 27.7 & GT & Nat Gas & $\mathrm{FO} 2$ & 1986 & OP \\
\hline 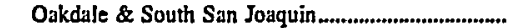 & & 97.3 & 112.7 & 107.7 & & & & & \\
\hline 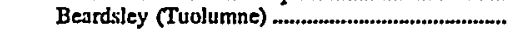 & 1 & 10.0 & 11.0 & 8.0 & $\mathrm{HY}$ & Water & - & 1957 & OP \\
\hline Donnells (Tuolumne) & HI & 54.0 & 67.5 & 67.5 & $\mathrm{HY}$ & Water & - & 1957 & OP \\
\hline 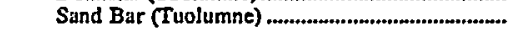 & $* 1$ & 16.2 & 16.2 & 16.2 & HY & Water & - & 1986 & OP \\
\hline 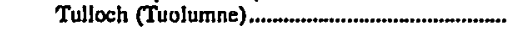 & 1 & 8.6 & 9.0 & 8.0 & $\mathrm{HY}$ & Water & - & 1958 & OP \\
\hline & 2 & 8.6 & 9.0 & 8.0 & $\mathrm{HY}$ & Water & - & 1958 & $\mathrm{OP}$ \\
\hline Oroville-Wyandotte Irrig Dist........................................ & & 103.1 & 94.0 & 92.0 & & & & & \\
\hline 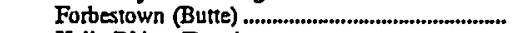 & 1 & 29.0 & 27.0 & 27.0 & HY & Water & - & 1963 & OP \\
\hline 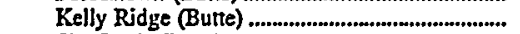 & 1 & 10.0 & 9.0 & 9.0 & HY & Water & - & 1963 & OP \\
\hline Sly Creek (Butte) & 1 & 12.1 & 9.0 & 7.0 & HY & Water & - & 1983 & OP \\
\hline Woodleaf (Butte) & j & 52.0 & 49.0 & 49.0 & HY & Water & - & 1963 & $\mathrm{OP}$ \\
\hline 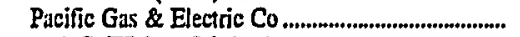 & & $14,058.0$ & $13,638.7$ & $13,636.7$ & & & & & \\
\hline 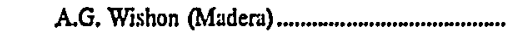 & 1 & 3.2 & 220.0 & 220.0 & HY & Water & - & 1910 & OP \\
\hline & 2 & 3.2 & $2-$ & $2-$ & $\mathrm{HY}$ & Water & - & 191 & OP \\
\hline & 3 & 3.2 & $2-$ & 2 & $\mathbf{H Y}$ & Water & - & j9]. & OP \\
\hline & 4 & 3.2 & $2-$ & $2-$ & HY & Water & - & 191 & OP \\
\hline Alta (Placer) & 1 & 1.0 & 1.0 & 1.0 & $\mathbf{H Y}$ & Water & - & 1902 & $\mathbf{O P}$ \\
\hline & 2 & 1.0 & 1.0 & 1.0 & HY & Water & - & 1902 & OP \\
\hline 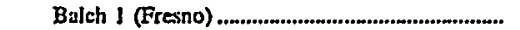 & 1 & 31.0 & 34.0 & 34.0 & $\mathrm{HY}$ & Water & - & 1927 & $\mathrm{OP}$ \\
\hline 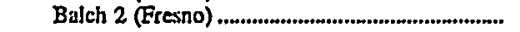 & 2 & 48.6 & 2105.0 & 2105.0 & $\mathrm{HY}$ & Water & - & 1958 & OP \\
\hline & 3 & 48.6 & $2_{-}$ & $2-$ & HY & Water & - & & OP \\
\hline 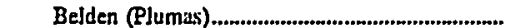 & 1 & 117.9 & 125.0 & 125.0 & HY & Water & - & 1969 & OP \\
\hline 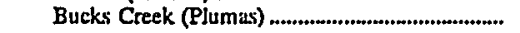 & H] & 33.0 & 265.0 & 265.0 & $\mathbf{H Y}$ & Water & - & 3928 & $\mathrm{OP}$ \\
\hline & H2 & 33.0 & $2-$ & $2-$ & HY & Water & - & 192 & OP \\
\hline Butt Valley (Plumas) & 1 & 40.0 & 40.0 & 40.0 & HY & Water & - & 1958 & OP \\
\hline 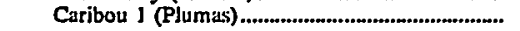 & 1 & 23.9 & 275.0 & 275.0 & $\mathbf{H Y}$ & Water & - & 3921 & OP \\
\hline & 2 & 25.0 & $2-$ & $2-$ & HY & Water & - & 1921 & OP \\
\hline & 3 & 25.0 & $2-$ & $2-$ & HY & Water & - & 1924 & OP \\
\hline 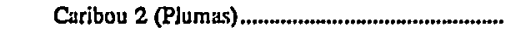 & 4 & 60.3 & 2120.0 & 2120.0 & $\mathrm{HY}$ & Water & - & 1958 & OP \\
\hline & 5 & 57.6 & $2-$ & $2_{-}$ & HY & Water & - & 1958 & \\
\hline Centerville (Butte) & J & 5.5 & 26.4 & 26.4 & HY & Water & - & 1900 & OP \\
\hline & 2 & .9 & $2-$ & 2 & HY & Water & - & 1904 & OP \\
\hline 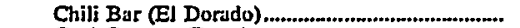 & 1 & 7.0 & 7.0 & $\mathbf{7 . 0}$ & $\mathbf{H Y}$ & Water & - & 1965 & OP \\
\hline 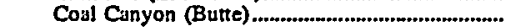 & 1 & 1.0 & .9 & .9 & HY & Water & - & 1907 & OP \\
\hline Coleman (Shista) & 1 & 12.2 & 13.0 & 13.0 & HY & Water & - & 1979 & OP \\
\hline
\end{tabular}

See footnotes at end of table. 
Table 20. Existing Generating Units at U.S. Electric Utilities by State, Company, and Plant, as of January 1, 1998 (Continued)

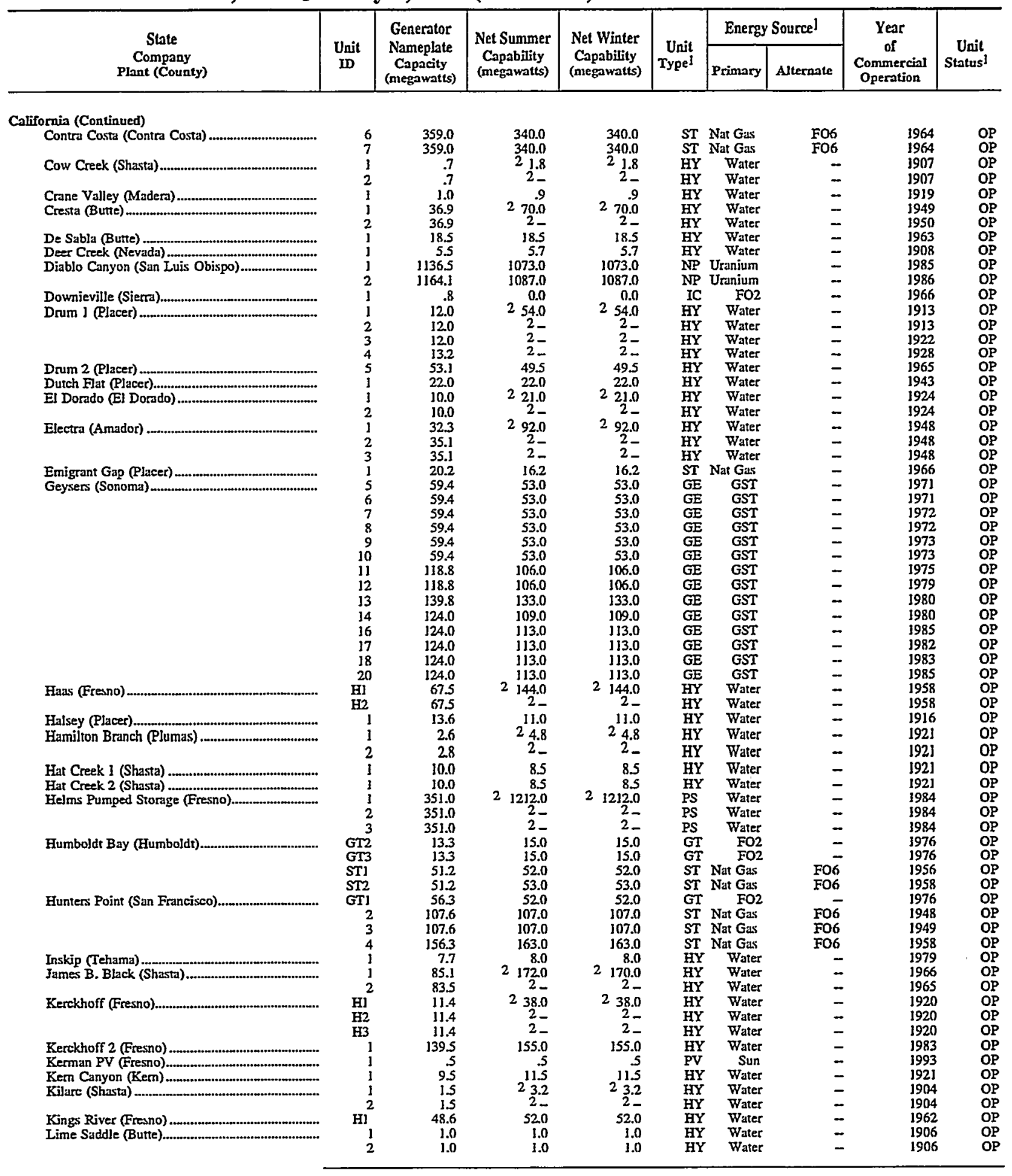

See footnotes at end of table. 
Table 20. Existing Generating Units at U.S. Electric Utilities by State, Company, and Plant, as of January 1, 1998 (Continued)

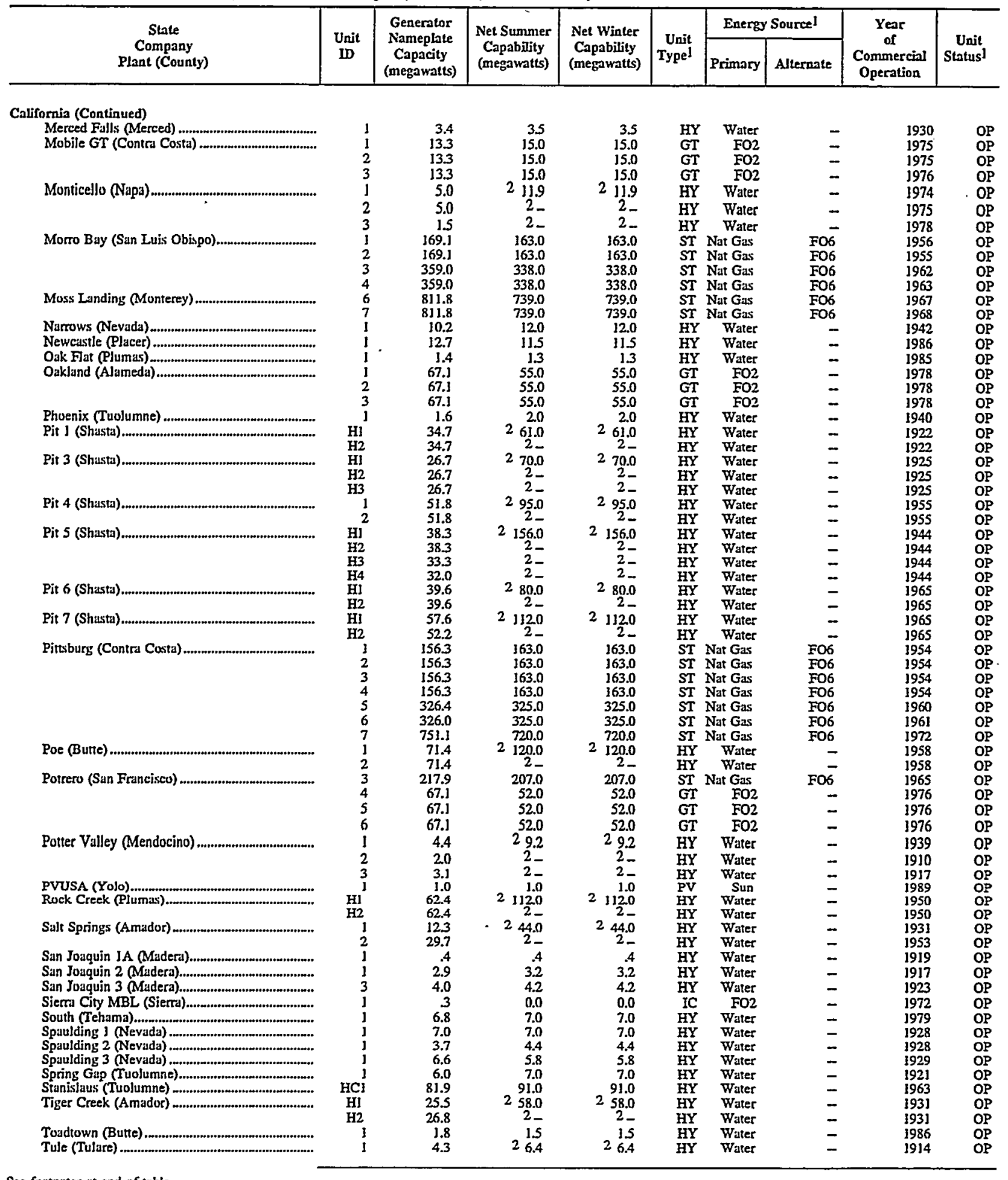

See foutnotes at end of table. 
Table 20. Existing Generating Units at U.S. Electric Utilities by State, Company, and Plant, as of January 1, 1998 (Continued)

\begin{tabular}{|c|c|c|c|c|c|c|c|c|c|}
\hline \multirow{2}{*}{$\begin{array}{c}\text { State } \\
\text { Company } \\
\text { Plant (County) }\end{array}$} & \multirow{2}{*}{$\begin{array}{l}\text { Unit } \\
\text { ID }\end{array}$} & \multirow{2}{*}{$\begin{array}{c}\text { Generator } \\
\text { Nameplate } \\
\text { Capacity } \\
\text { (megawatts) }\end{array}$} & \multirow{2}{*}{$\begin{array}{l}\text { Net Summer } \\
\text { Capability } \\
\text { (megawatts) }\end{array}$} & \multirow{2}{*}{$\begin{array}{l}\text { Net Winter } \\
\text { Capability } \\
\text { (megawatts) }\end{array}$} & \multirow{2}{*}{$\begin{array}{c}\text { Unit } \\
\text { Typel }\end{array}$} & \multicolumn{2}{|c|}{ Energy Source] } & \multirow{2}{*}{$\begin{array}{c}\text { Year } \\
\text { of } \\
\text { Commercial } \\
\text { Operation }\end{array}$} & \\
\hline & & & & & & Primary & Alternate & & \\
\hline Caltrornia (Continued) & & & & & & & & & \\
\hline & 2 & 4.3 & $2-$ & $2-$ & HY & Water & - & 1914 & OP \\
\hline $\begin{array}{l}\text { Volta } 1 \text { (Shasta) } \\
\text { Volta } 2 \text { (Shasta) }\end{array}$ & ] & 8.6 & 9.0 & 9.0 & HY & Water & - & 1980 & $O P$ \\
\hline 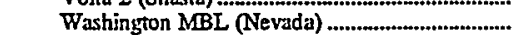 & 1 & $\begin{array}{r}1.0 \\
.3\end{array}$ & $\begin{array}{r}.9 \\
0.0\end{array}$ & 0.0 & IC & $\begin{array}{r}\text { Water } \\
\text { FO2 }\end{array}$ & $\overline{-}$ & $\begin{array}{l}1981 \\
1971\end{array}$ & $\begin{array}{l}\text { OP } \\
\text { OP }\end{array}$ \\
\hline West Point (Amador) & 1 & 13.6 & 14.5 & 14.5 & $\mathrm{HY}$ & Water & - & 1948 & OP \\
\hline 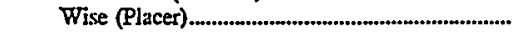 & 1 & 13.6 & 14.0 & 34.0 & HY & Water & - & 1917 & OP \\
\hline & 2 & 29 & 3.1 & 3.] & $\mathrm{HY}$ & Water & - & 1986 & OP \\
\hline 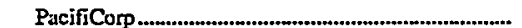 & & 67.2 & 76.2 & 76.7 & & & & & \\
\hline Copco I (Siskiyou) & 1 & 10.0 & 125 & 12.5 & HY & Water & - & 1918 & OP \\
\hline & 2 & 10.0 & 12.5 & 125 & HY & Water & - & 1922 & -OP \\
\hline 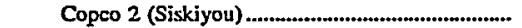 & 1 & 13.5 & 14.8 & 14.8 & $\mathrm{HY}$ & Water & - & 1925 & OP \\
\hline & 2 & 13.5 & 14.8 & 34.8 & HY & Water & - & 1925 & OP \\
\hline Fall Creek (Siskiyou) & ] & .5 & 5 & 5 & HY & Water & - & 1903 & OP \\
\hline & 2 & .5 & .5 & $s$ & HY & Water & $\rightarrow$ & 1907 & OP \\
\hline 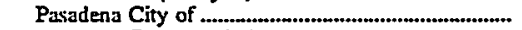 & & 215.8 & 223.7 & 225.7 & & & & & \\
\hline Azusa (Los Angeles) & ] & 3.0 & 2.0 & 2.0 & HY & Water & - & 1949 & OP \\
\hline 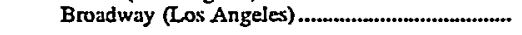 & BI & 40.0 & 45.0 & 45.0 & ST & Nat Gas & FOS & 1955 & OP \\
\hline & B2 & 40.0 & 45.0 & 45.0 & ST & Nat Gas & FO6 & 1957 & OP \\
\hline & B3 & 75.0 & 71.0 & 73.0 & ST & Nat Gas & FO6 & 1965 & OS \\
\hline Glenam (Los Angeles) & GT & 28.9 & 30.4 & 30.4 & GT & Nat Gas & FO2 & 1976 & OP \\
\hline & GT2 & 28.9 & 30.4 & 30.4 & GT & Nat Gas & FO2 & 1976 & OP \\
\hline 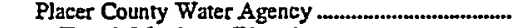 & & 211.2 & 241.8 & 234.5 & & & & & \\
\hline French Meadows (Placer) & ] & 15.3 & 17.0 & 17.0 & HY & Water & - & 1966 & OP \\
\hline Hell Hole (Placer) & 1 & .7 & 5 & .2 & HY & Waier & - & 1983 & OP \\
\hline MIddle Fork (Placer) & 1 & 54.9 & 66.0 & 62.5 & $\mathbf{H Y}$ & Warer & - & 1966 & OP \\
\hline & 2 & 54.9 & 66.0 & 62.5 & $\mathbf{H Y}$ & Water & -- & 1966 & OP \\
\hline Oxbow (Placer) & 1 & 6.1 & 6.0 & 6.0 & HY & Water & - & 1966 & OP \\
\hline Ralston (PJacer) & 1 & 79.2 & 86.3 & 86.3 & $\mathrm{HY}$ & Water & - & 1966 & OP \\
\hline Redding City of & & 98.9 & 94.5 & 1023 & & & & & \\
\hline Redding Power (Shasta) & 1 & 30.0 & 28.0 & 28.0 & ST & Nat Gas & LPG & 1994 & OP \\
\hline . & 2 & 24.0 & 24.0 & 27.6 & GT & Nat Gas & LPG & 1996 & OP \\
\hline & 3 & 24.0 & 24.0 & 27.6 & GT & Nat Gas & LPG & 1996 & OP \\
\hline & 4 & $\mathbf{3 7 . 6}$ & 17.6 & 17.6 & GT & Nat Gas & LPG & 1996 & OP \\
\hline Whiskeytown (Shasta) & 1 & 3.2 & & 1.6 & HY & Water & - & 1986 & OP \\
\hline 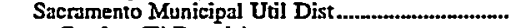 & & $1,275.8$ & $1,171.3$ & $1,171.3$ & & & & & \\
\hline 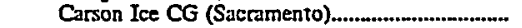 & $*$ GTP & 54.0 & 43.3 & 43.3 & GT & Nat Gas & - & 1995 & OP \\
\hline & $* \mathbf{*}$ & 54.0 & 41.3 & 41.3 & CT & Nat Gas & MTE & 1995 & OP \\
\hline & $=2$ & 17.5 & 16.6 & 16.6 & CW & WH & - & 1995 & OP \\
\hline 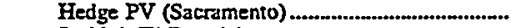 & 1 & .2 & .2 & .2 & PV & Sun & - & 1994 & OP \\
\hline Jaybird (El Dorado) & Hl & 77.0 & 75.0 & 75.0 & HY & Water & - & 196] & OP \\
\hline & H2 & 77.0 & 77.0 & 77.0 & $\mathbf{H Y}$ & Water & - & 1962 & OP \\
\hline Jones Fork (El Dorado) & 1 & 11.5 & 11.5 & 11.5 & HY & Water & - & 1985 & OP \\
\hline Kaiser FC (Sacramento) & 1 & 2 & 2 & .2 & FC & Nat Gas & - & 1994 & OP \\
\hline 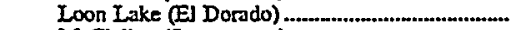 & HI & 82.0 & 820 & 82.0 & HY & Water & - & 1971 & $\mathrm{OP}$ \\
\hline 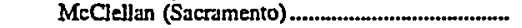 & I & 74.2 & 49.0 & 49.0 & GT & Nat Gas & $\mathrm{FO} 2$ & 1986 & OP \\
\hline Robbs Peak (El Dorado) & ] & 29.5 & 25.0 & 25.0 & HY & Water & - & 1965 & OP \\
\hline Slab Creek (El Dorado) & ] & .5 & .4 & .4 & HY & Water & - & 1983 & OS \\
\hline Solano Wind (Solano) & ] & 6.8 & 6.8 & 6.8 & WT & Wind & - & 1994 & OP \\
\hline Solar (Sacramento) & 1 & 1.0 & 1.0 & 1.0 & PV & Sun & - & 1984 & OP \\
\hline & 2 & 1.0 & 1.0 & 1.0 & PV & Sun & - & 1986 & OP \\
\hline SCA (Sacramento) & *CCCT & 49.9 & 39.7 & 39.7 & CT & Nat Gas & - & 1997 & OP \\
\hline & ${ }^{*} \operatorname{CcsT}$ & 49.9 & 37.6 & 37.6 & $\mathbf{C W}$ & WH & - & 1997 & OP \\
\hline SMUD GEO (Sonoma) & 1 & 78.0 & 720 & 72.0 & GE & GST & - & 1983 & OP \\
\hline SMUD HQ (Sacramento) & 1 & .2 & .2 & .2 & FC & Nat Gas & - & 1994 & OP \\
\hline SPA (Sacramento) & ${ }^{*} \mathrm{CCCT}$ & 118.8 & $1] 1.0$ & 111.0 & CT & Nat Gas & - & 1997 & OP \\
\hline & ${ }^{*} \operatorname{CCST}$ & 553 & 53.0 & 53.0 & $\mathbf{C W}$ & WH & - & 1997 & OP \\
\hline 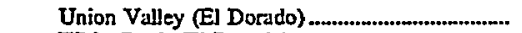 & 1 & 46.7 & 46.7 & 46.7 & HY & Water & - & 1963 & OP \\
\hline 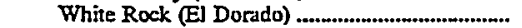 & $\mathrm{Hl}$ & 115.0 & 1120 & 112.0 & $\mathbf{H Y}$ & Water & - & 1968 & OP \\
\hline & H2 & 115.0 & 112.0 & 1120 & HY & Water & - & 1968 & OP \\
\hline 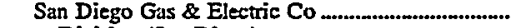 & & 2,3262 & $2,206.0$ & $2,269.0$ & & & & & \\
\hline 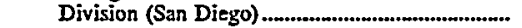 & 1 & 18.0 & 16.0 & 19.0 & GT & $\mathrm{FO} 2$ & - & 1968 & OP \\
\hline El Cajon (San Diego) & 1 & 18.0 & 16.0 & 20.0 & GT & Nat Gas & FO2 & 1968 & OP \\
\hline Encina (San Diego) & GT1 & 18.0 & 16.0 & 18.0 & GT & Nat Gas & $\mathrm{FO} 2$ & 1968 & OP \\
\hline & STI & 110.3 & 107.0 & 107.0 & ST & Nat Gas & FO6 & 1954 & OP \\
\hline & 2 & 110.3 & 304.0 & 104.0 & ST & Nat Gas & FO6 & 1956 & OP \\
\hline
\end{tabular}

See footnotes at end of table. 
Table 20. Existing Generating Units at U.S. Electric Utilities by State, Company, and Plant, as of January 1, 1998 (Continued)

\begin{tabular}{|c|c|c|c|c|c|c|c|c|c|}
\hline \multirow{2}{*}{$\begin{array}{c}\text { State } \\
\text { Company } \\
\text { Plant (County) }\end{array}$} & \multirow{2}{*}{$\begin{array}{l}\text { Unit } \\
\text { ID }\end{array}$} & \multirow{2}{*}{$\begin{array}{c}\text { Generator } \\
\text { Nameplate } \\
\text { Capacity } \\
\text { (megawatts) }\end{array}$} & \multirow{2}{*}{$\begin{array}{l}\text { Net Summer } \\
\text { Copability } \\
\text { (megawatts) }\end{array}$} & \multirow{2}{*}{$\begin{array}{l}\text { Net Winter } \\
\text { Capability } \\
\text { (megawatts) }\end{array}$} & \multirow{2}{*}{$\begin{array}{c}\text { Unit } \\
\text { TypeJ }\end{array}$} & \multicolumn{2}{|c|}{ Energy Sourcel } & \multirow{2}{*}{$\begin{array}{c}\text { Year } \\
\text { or } \\
\text { Commercial } \\
\text { Operation }\end{array}$} & \multirow{2}{*}{$\begin{array}{c}\text { Unit } \\
\text { Status! }\end{array}$} \\
\hline & & & & & & Primary & Alternate & & \\
\hline California (Continued) & & & & & & & & & \\
\hline & 3 & 110.3 & 110.0 & 110.0 & ST & Nat Gas & F06 & 1958 & OP \\
\hline & 4 & 306.0 & 300.0 & 300.0 & ST & Nat Gas & FO6 & 1973 & $O P$ \\
\hline & 5 & 345.6 & 330.0 & 330.0 & ST & Nat Gas & FO6 & 1978 & OP \\
\hline 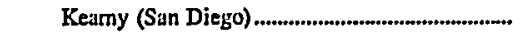 & 1 & 20.7 & 17.0 & 20.0 & GT & Nat Gas & FO2 & 1972 & $\begin{array}{l}\text { OP } \\
\text { OP }\end{array}$ \\
\hline & $\begin{array}{l}2 \\
3\end{array}$ & $\begin{array}{l}72.0 \\
72.0\end{array}$ & $\begin{array}{l}66.0 \\
66.0\end{array}$ & $\begin{array}{l}78.0 \\
78.0\end{array}$ & $\begin{array}{l}\text { GT } \\
\text { GI }\end{array}$ & $\begin{array}{l}\text { Nat Gas } \\
\text { Nat Gas }\end{array}$ & $\begin{array}{l}\text { FO2 } \\
\text { FO2 }\end{array}$ & $\begin{array}{l}1969 \\
1969\end{array}$ & $\begin{array}{l}\text { OP } \\
\text { OP }\end{array}$ \\
\hline Miramar (San Diego) & 1 & 47.2 & 39.0 & 47.0 & GT & Nat Gas & FO2 & 1972 & OP \\
\hline 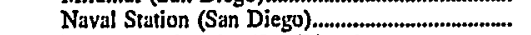 & j & 28.3 & 23.0 & 29.0 & $\mathrm{GT}$ & Nat Gas & $\mathrm{FO} 2$ & 1976 & OP \\
\hline Naval Training Cre (San Diego) .......................... & 了 & 18.0 & 16.0 & 20.0 & GT & Nat Gas & FO2 & 1968 & OP \\
\hline 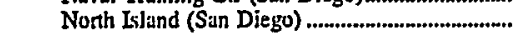 & j & 26.J & 20.0 & 22.0 & GT & $\mathrm{FO} 2$ & - & 1972 & OP \\
\hline & 2 & 26.1 & 38.0 & 22.0 & $\mathrm{GT}$ & Nat Gas & $\mathrm{FO} 2$ & 1972 & OP \\
\hline 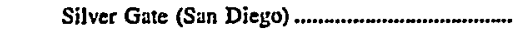 & 1 & 40.0 & 40.0 & 40.0 & ST & $\mathrm{FO} 2$ & Nat Gas & 1943 & SB \\
\hline & 2 & 69.0 & 62.0 & 62.0 & ST & FO2 & Nat Gas & 1948 & SB \\
\hline & 3 & 69.0 & 64.0 & 64.0 & ST & $\mathrm{FO2}$ & Nat Gas & 1950 & SB \\
\hline & 4 & 69.0 & 64.0 & 64.0 & ST & $\mathrm{FO} 2$ & Nat Gas & 1952 & SB \\
\hline South Bay (San Diego) & GTI & 18.6 & 19.0 & 22.0 & GI & Jet Fuel & - & 1966 & OP \\
\hline & ST1 & 136.0 & 146.0 & 146.0 & $S T$ & Nat Gas & FO6 & 1960 & $O P$ \\
\hline & 2 & 136.0 & 150.0 & 150.0 & ST & Nat Gas & FO6 & 1962 & OP \\
\hline & 3 & 201.6 & 175.0 & 175.0 & ST & Nat Gas & FO6 & 1964 & $O P$ \\
\hline & 4 & 240.3 & 222.0 & 222.0 & $S T$ & Nat Gas & FO6 & 1971 & OP \\
\hline 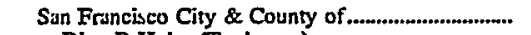 & & 386.1 & 385.1 & 385.1 & & & & & \\
\hline 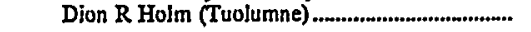 & 1 & 82.5 & 78.4 & 78.4 & HY & Water & - & 1960 & OP \\
\hline & 2 & 82.5 & 78.4 & 78.4 & HY & Water & - & 1960 & OP \\
\hline Moccasin (Tuolumne) & 1 & 50.0 & 51.8 & 51.8 & HY & Water & - & 1969 & OP \\
\hline & 2 & 50.0 & 51.8 & 51.8 & HY & Water & - & 1969 & OP \\
\hline 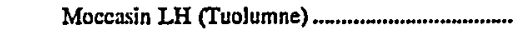 & 1 & 2.9 & 2.9 & 2.9 & $\mathrm{HY}$ & Water & - & 1987 & $\mathrm{OP}$ \\
\hline R C Kitkwood (Tuolumne) & $\mathrm{i}$ & 38.8 & 38.8 & 38.8 & $\mathrm{HY}$ & Water & - & 1967 & OP \\
\hline & 2 & 38.8 & 38.8 & 38.8 & HY & Water & - & 1967 & OP \\
\hline & 3 & 40.6 & 44.3 & 443 & HY & Water & - & 1987 & $O P$ \\
\hline 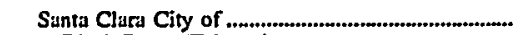 & & 106.1 & 95.0 & 105.9 & & & & & \\
\hline 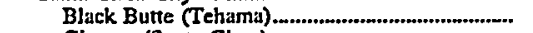 & 1 & 6.2 & 6.2 & 6.2 & $\mathrm{HY}$ & Water & - & 1988 & OS \\
\hline 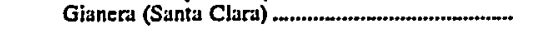 & 3 & 32.3 & 26.0 & 32.0 & GT & Nat Gas & FO2 & 1987 & \\
\hline & $\mathrm{NAl}^{2}$ & 32.3 & $\begin{array}{l}26.0 \\
23.5\end{array}$ & 32.0 & GT & Nat Gas & FO2 & 1986 & $\begin{array}{l}\text { OP } \\
\text { OP }\end{array}$ \\
\hline $\begin{array}{l}\text { Grizzly (Plumas) } \\
\text { High Line (Glenn) }\end{array}$ & & 22.0 & 23.5 & 22.4 & HY & Water & - & 1993 & $\begin{array}{l}\text { OP } \\
\text { OP }\end{array}$ \\
\hline & 1 & 5 & 5 & .5 & HY & Water & - & 1989 & OP \\
\hline Sunta Clara Cogen (Santa Clara) .......................... & $\frac{1}{2}$ & 3.9 & 3.9 & 3.9 & $\mathrm{GT}$ & Nat Gas & - & 1982 & $\begin{array}{l}\text { OP } \\
\text { OP }\end{array}$ \\
\hline & & 3.9 & 3.9 & 3.9 & GT & Nat Gas & - & 1982 & OP \\
\hline Stony Gorge (Glenn) & 1 & 2.5 & 2.5 & 2.5 & HY & Water & - & 1986 & $\begin{array}{l}\text { OP } \\
\text { OP }\end{array}$ \\
\hline Sierra Pacific Power Co... & 2 & 2.5 & 2.5 & 25 & $\mathbf{H Y}$ & Water & - & 1986 & OP \\
\hline Sierra Pacific Power Co... & & 25.3 & 23.5 & 25.0 & & & & & \\
\hline 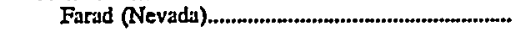 & 1 & 1.4 & 1.3 & 1.3 & HY & Water & - & 1933 & $\begin{array}{l}\text { OP } \\
\text { OP }\end{array}$ \\
\hline & 2 & 1.4 & 1.3 & 13 & HY & Water & - & 1933 & $O P$ \\
\hline Kings Beach (Placer) & 1 & 2.8 & 26 & 2.8 & IC & $\mathrm{FO2}$ & - & 1969 & $O P$ \\
\hline & 2 & 2.8 & 2.6 & 2.8 & IC & $\mathrm{FO2}$ & - & 1969 & \\
\hline & $\begin{array}{l}3 \\
4\end{array}$ & 28 & 2.6 & 2.8 & IC & FO2 & - & 1969 & $\begin{array}{l}\text { OP } \\
\text { OP }\end{array}$ \\
\hline & $\begin{array}{l}4 \\
5\end{array}$ & 2.8 & $\begin{array}{l}2.6 \\
2.6\end{array}$ & 2.8 & IC & FO2 & $\overline{-}$ & 1969 & $\begin{array}{l}\text { OP } \\
\text { OP }\end{array}$ \\
\hline & $\begin{array}{l}5 \\
6\end{array}$ & $\begin{array}{l}2.8 \\
2.8\end{array}$ & $\begin{array}{l}2.0 \\
2.6\end{array}$ & $\begin{array}{l}2.8 \\
2.8\end{array}$ & IC & $\begin{array}{l}\mathrm{FO} 2 \\
\mathrm{FO} 2\end{array}$ & $\bar{z}$ & $\begin{array}{l}1969 \\
1969\end{array}$ & OP \\
\hline Portola (PJumas) & ] & 2.0 & 1.8 & 2.0 & IC & FO2 & - & 1965 & OP \\
\hline & 2 & 20 & 1.8 & 2.0 & IC & FO2 & - & 1965 & OP \\
\hline & 3 & 20 & 1.8 & 2.0 & IC & $\mathrm{FO} 2$ & - & 1965 & OP \\
\hline 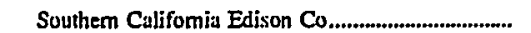 & & $14,014.5$ & $13,609.2$ & $13,725.1$ & & & & & \\
\hline 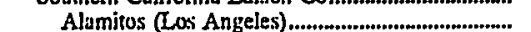 & 1 & 163.2 & 175.0 & 175.0 & ST & Nat Gas & FO4 & 1956 & OP \\
\hline & 2 & 163.2 & 175.0 & 175.0 & ST & Nat Gas & FO4 & 1957 & OP \\
\hline & 3 & 333.0 & 320.0 & 320.0 & ST & Nat Gas & F04 & 1961 & OP \\
\hline & 4 & 333.0 & 320.0 & 320.0 & ST & Nat Gas & FO4 & 1962 & $\mathrm{OP}$ \\
\hline & 5 & 495.0 & 480.0 & 480.0 & SI & Nat Gas & FO4 & 1966 & OP \\
\hline & 6 & 495.0 & 480.0 & 480.0 & ST & Nat Gas & FO4 & 1966 & $O P$ \\
\hline & 7 & 338.1 & 133.0 & 147.0 & GT & Nat Gas & Jet Fuel & & OP \\
\hline Big Creek 1 (Fresno) & i & 20.0 & 17.5 & 17.5 & $\mathbf{H Y}$ & Water & - & 1913 & OP \\
\hline & 2 & 35.8 & 17.0 & 17.0 & HY & Water & & 1913 & OP \\
\hline & 3 & 14.0 & 17.2 & 172 & HY & Water & - & 1923 & OP \\
\hline & 4 & 28.0 & 31.2 & 312 & HY & Water & - & 1925 & OP \\
\hline Big Creek 2 (Fresno) & 3 & 15.8 & 15.8 & 15.8 & HY & Water & - & 1913 & OP \\
\hline & 4 & 15.8 & 15.6 & 35.6 & $\mathrm{HY}$ & Water & - & 1914 & $\mathrm{OP}$ \\
\hline & 5 & 17.5 & 16.9 & 16.9 & HY & Water & - & 1921 & OP \\
\hline & 6 & 17.5 & j8.8 & 38.8 & $\mathrm{HY}$ & Water & - & 1925 & OP \\
\hline Big Creek 2A (Fresno) & 1 & 55.0 & 49.3 & 49.3 & HY & Water & - & 1928 & OP \\
\hline & 2 & 55.0 & 49.2 & 492 & HY & Water & - & 1928 & $\mathrm{OP}$ \\
\hline Big Creek 3 (Fresno) & $\mathrm{j}$ & 34.0 & 34.5 & 34.5 & $\mathrm{HY}$ & Water & - & 1923 & $O P$ \\
\hline
\end{tabular}

See footnotes at end of table. 
Table 20. Existing Generating Units at U.S. Electric Utilities by State, Company, and Plant, as of January 1, 1998 (Continued)

\begin{tabular}{|c|c|c|c|c|c|c|c|c|c|}
\hline \multirow{2}{*}{$\begin{array}{c}\text { State } \\
\text { Company } \\
\text { Plant (County) }\end{array}$} & \multirow{2}{*}{$\begin{array}{c}\text { Unit } \\
\text { ID }\end{array}$} & \multirow{2}{*}{$\begin{array}{c}\text { Generator } \\
\text { Nameplate } \\
\text { Capacity } \\
\text { (megawatts) }\end{array}$} & \multirow{2}{*}{$\begin{array}{l}\text { Net Summer } \\
\text { Capability } \\
\text { (megawatts) }\end{array}$} & \multirow{2}{*}{$\begin{array}{l}\text { Net Winter } \\
\text { Capability } \\
\text { (megawatts) }\end{array}$} & \multirow{2}{*}{$\begin{array}{r}\text { Unit } \\
\text { Type }\end{array}$} & \multicolumn{2}{|c|}{ Energy Source] } & \multirow{2}{*}{$\begin{array}{c}\text { Year } \\
\text { of } \\
\text { Commercial } \\
\text { Operation }\end{array}$} & \\
\hline & & & & & & Primary & Alternate & & \\
\hline California (Continued) & & & & & & & & & \\
\hline & 2 & 34.0 & 34.5 & 34.5 & HY & Water & - & 1923 & OP \\
\hline & 3 & 34.0 & 34.3 & 34.3 & $\mathrm{HY}$ & Water & - & 1923 & $\mathrm{OP}$ \\
\hline & 4 & 36.0 & 40.5 & 405 & $\mathrm{HY}$ & Water & $\ldots$ & 1948 & $\mathrm{OP}$ \\
\hline & 5 & 36.5 & 38.1 & 38.1 & HY & Water & - & 1980 & OP \\
\hline Big Creek 4 (Madera) & 1 & 50.0 & so.1 & 50.1 & HY & Water & - & 1951 & OP \\
\hline Biy Creek 8 (Fresno) & 2 & 420 & 50.1 & 50.1 & HY & Water & - & 1951 & $\begin{array}{l}\text { OP } \\
\text { OP }\end{array}$ \\
\hline Dig Creex o (Fresno) .................................. & 2 & $\begin{array}{l}30.0 \\
45.0\end{array}$ & $\begin{array}{l}25.8 \\
38.7\end{array}$ & $\begin{array}{l}25.8 \\
38.7\end{array}$ & $\begin{array}{l}\text { HY } \\
\text { HY }\end{array}$ & $\begin{array}{l}\text { Water } \\
\text { Water }\end{array}$ & $\overline{-}$ & $\begin{array}{l}1921 \\
1929\end{array}$ & $\begin{array}{l}\text { OP } \\
\text { OP }\end{array}$ \\
\hline Bishop Creek 2 (Inyo) & $j$ & 2.5 & 2.5 & 2.5 & $\mathrm{HY}$ & Water & - & 1908 & OP \\
\hline & 2 & 2.5 & 2.5 & 25 & $\mathbf{H Y}$ & Water & - & 1908 & $\mathrm{OP}$ \\
\hline & 3 & 2.3 & 2.5 & 25 & $\mathrm{HY}$ & Water & - & 1911 & OP \\
\hline 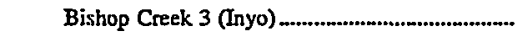 & 1 & 2.8 & 2.6 & 2.6 & $\mathrm{HY}$ & Water & - & 1913 & OP \\
\hline & 2 & 2.2 & 2.6 & 2.6 & $\mathbf{H Y}$ & Water & - & 1913 & OP \\
\hline & 3 & 22 & 2.7 & 2.7 & HY & Water & - & 1913 & OP \\
\hline Bishop Creek 4 (Inyo) & 1 & 1.0 & 1.0 & 1.0 & $\mathbf{H Y}$ & Water & -- & 1905 & OP \\
\hline & 2 & 1.0 & 3.0 & J.0 & $\mathrm{HY}$ & Water & - & 1905 & OP \\
\hline & 3 & 1.8 & 2.0 & 2.0 & $\mathbf{H Y}$ & Water & - & 1906 & OP \\
\hline & 4 & 1.8 & 2.0 & 2.0 & HY & Water & - & 1907 & OP \\
\hline & 5 & 1.8 & 2.0 & 2.0 & $\mathbf{H Y}$ & Water & - & 1909 & $O P$ \\
\hline Bishop Creek 5 (Inyo) & ] & 2.0 & 20 & 2.0 & $\mathrm{HY}$ & Water & - & 1943 & OP \\
\hline & 2 & 1.5 & 1.8 & 1.8 & HY & Water & - & 1919 & OP \\
\hline Bishop Creek 6 (Inyo) & j & 3.6 & 20 & 2.0 & HY & Water & - & 1913 & $O P$ \\
\hline Borel (Kem) & 1 & 3.0 & $2 I$ & 2.1 & HY & Water & - & 1904 & $O P$ \\
\hline & 2 & 3.0 & 2.5 & 2.5 & HY & Water & - & 1904 & OP \\
\hline & 3 & 6.0 & 6.4 & 6.4 & $\mathrm{HY}$ & Water & - & 1932 & OP \\
\hline 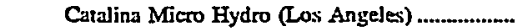 & HY1 & 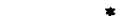 & $*$ & * & HI, & Water & - & 1984 & $O P$ \\
\hline & HY2 & $*$ & $=$ & * & HI & Water & - & 1985 & OP \\
\hline & HY3 & .1 & .1 &.$J$ & HIL & Water & - & 1985 & OP \\
\hline 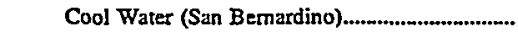 & $3 \mathrm{~A}$ & 83.0 & 68.0 & 73.0 & $\overline{C T}$ & Nat Gas & $\mathrm{FO2}$ & 1978 & OP \\
\hline & $3 \mathrm{~B}$ & 83.0 & 68.0 & 73.0 & CT & Nat Gas & FO2 & 1978 & OP \\
\hline & $3 C$ & 124.0 & 105.0 & 110.0 & $C W$ & WH & - & 1978 & OP \\
\hline & $4 A$ & 83.0 & 68.0 & 73.0 & $C T$ & Nat Gas & $\mathrm{FO} 2$ & 1978 & OP \\
\hline & $4 \mathrm{~B}$ & 83.0 & 68.0 & 73.0 & $\mathrm{CT}$ & Nat Gas & $\mathrm{FO} 2$ & 1978 & OP \\
\hline & $4 \mathrm{C}$ & 124.0 & 105.0 & 110.0 & CW & WH & - & 1978 & OP \\
\hline & 1 & 65.3 & 65.0 & 65.0 & ST & Nat Gas & FO4 & 1961 & OP \\
\hline & 2 & 81.6 & 81.0 & 81.0 & ST & Nat Gas & FO4 & 1964 & OP \\
\hline 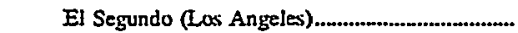 & 1 & 156.3 & 175.0 & 175.0 & sT & Nat Gas & FO4 & 1955 & OP \\
\hline & 2 & 156.3 & 175.0 & 375.0 & ST & Nat Gas & $\mathrm{FO4}$ & 1956 & OP \\
\hline & 3 & 3420 & 335.0 & 335.0 & ST & Nat Gas & FO4 & 1964 & OP \\
\hline & 4 & 342.0 & 335.0 & 335.0 & $\mathrm{ST}$ & Nat Gas & FO4 & 1965 & OP \\
\hline Ellwood (Santa Barbara) & I & 56.7 & 48.0 & 53.0 & GT & Nat Gas & - & 1974 & OP \\
\hline Etiwanda (San Bemardino) & GTS & 138.1 & 126.0 & 142.0 & GT & Nat Gas & Jet Fuel & 1969 & OP \\
\hline & ] & 1225 & 132.0 & 132.0 & ST & Nat Gas & FO4 & 1953 & OP \\
\hline & 2 & 122.5 & 132.0 & 132.0 & ST & Nat Gas & FO4 & 1953 & OP \\
\hline & 3 & 333.0 & 320.0 & 320.0 & ST & Nat Gas & FO4 & 1963 & $O P$ \\
\hline & 4 & 333.0 & 320.0 & 320.0 & ST & Nat Gas & F04 & 1963 & OP \\
\hline Fontana (San Bemardino) & j & 1.5 & .9 & .9 & $\mathrm{HY}$ & Water & - & 3917 & OP \\
\hline & 2 & 1.5 & 1.0 & 1.0 & $\mathbf{H Y}$ & Water & - & 1917 & OP \\
\hline 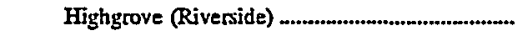 & 1 & 34.5 & 32.0 & 32.0 & ST & Nat Gas & FO4 & 1952 & OP \\
\hline & $i$ & 34.5 & 33.0 & 33.0 & ST & Nat Gas & FO4 & 1952 & OP \\
\hline & 3 & 50.0 & 44.0 & 44.0 & ST & Nat Gas & FO4 & 1953 & OP \\
\hline & 4 & 50.0 & 45.0 & 45.0 & ST & Nat Gas & $\mathrm{FO} 4$ & 1955 & OP \\
\hline Huntington Beach (Orange) & GTS & 138.1 & 133.0 & 147.0 & GT & Nat Gas & Jet Fuel & 1969 & OP \\
\hline & J & 217.6 & 215.0 & 215.0 & ST & Nat Gas & FO4 & 1958 & OP \\
\hline & 2 & 217.6 & 215.0 & 215.0 & ST & Nat Gas & $\mathrm{FO4}$ & 1958 & OP \\
\hline & 3 & 217.6 & 215.0 & 215.0 & ST & Nat Gas & FO4 & 3961 & os \\
\hline & 4 & 217.6 & 225.0 & 225.0 & ST & Nat Gas & FO4 & 1961 & os \\
\hline 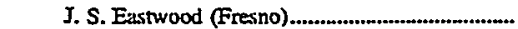 & 1 & 199.8 & 207.0 & 207.0 & PS & Water & - & 1987 & OP \\
\hline 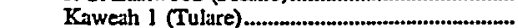 & 1 & 2.3 & 2.1 & 2.1 & HY & Water & - & 1929 & OP \\
\hline 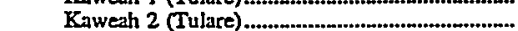 & 2 & 1.8 & 2.3 & 2.3 & $\mathrm{HY}$ & Water & - & 1929 & OP \\
\hline 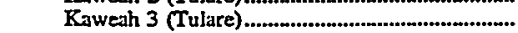 & ] & 2.4 & 2.4 & 2.4 & HY & Water & - & 1913 & OP \\
\hline & 2 & 24 & 2.1 & 2.1 & HY & Water & - & 3913 & OP \\
\hline Kem River l (Kern) & j & 6.2 & 6.2 & 6.2 & HY & Water & _ & 1907 & OP \\
\hline & 2 & 6.2 & 6.2 & 62 & HX & Water & - & 1907 & OP \\
\hline & 3 & 6.2 & 6.2 & 6.2 & $\mathrm{HY}$ & Water & - & 1907 & OP \\
\hline & 4 & 6.2 & 6.2 & 6.2 & HY & Water & - & 1907 & OP \\
\hline Ken River $3(\mathrm{Ken})$ & j & 20.5 & 18.4 & 18.4 & HY & Water & _ & 392] & OP \\
\hline & 2 & 19.7 & 18.4 & 18.4 & HX & Water & _ & 192] & OP \\
\hline 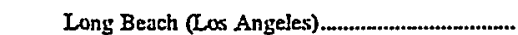 & CTI & 63.0 & 56.5 & 60.0 & $\mathrm{CI}$ & Nat Gas & $\mathrm{FO} 2$ & 1976 & OP \\
\hline & CT2 & 63.0 & 56.5 & 60.0 & CT & Nat Gas & $\mathrm{FO} 2$ & 1976 & OP \\
\hline
\end{tabular}

See footnotes at end of table. 
Table 20. Existing Generating Units at U.S. Electric Utilities by State, Company, and Plant, as of January 1, 1998 (Continued)

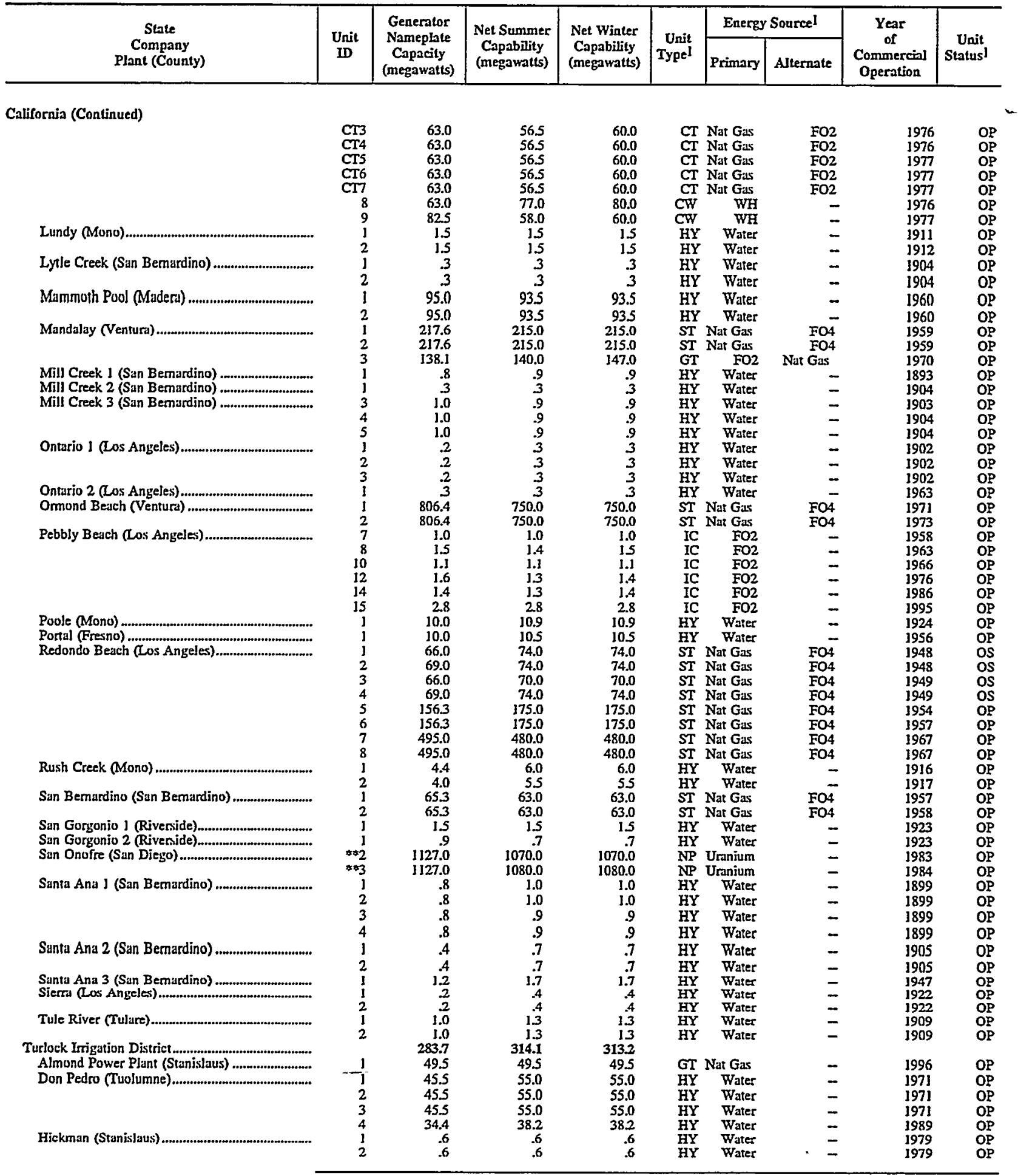

Sec footnotes at end of table. 
Table 20. Existing Generating Units at U.S. Electric Utilities by State, Company, and Plant, as of January 1, 1998 (Continued)

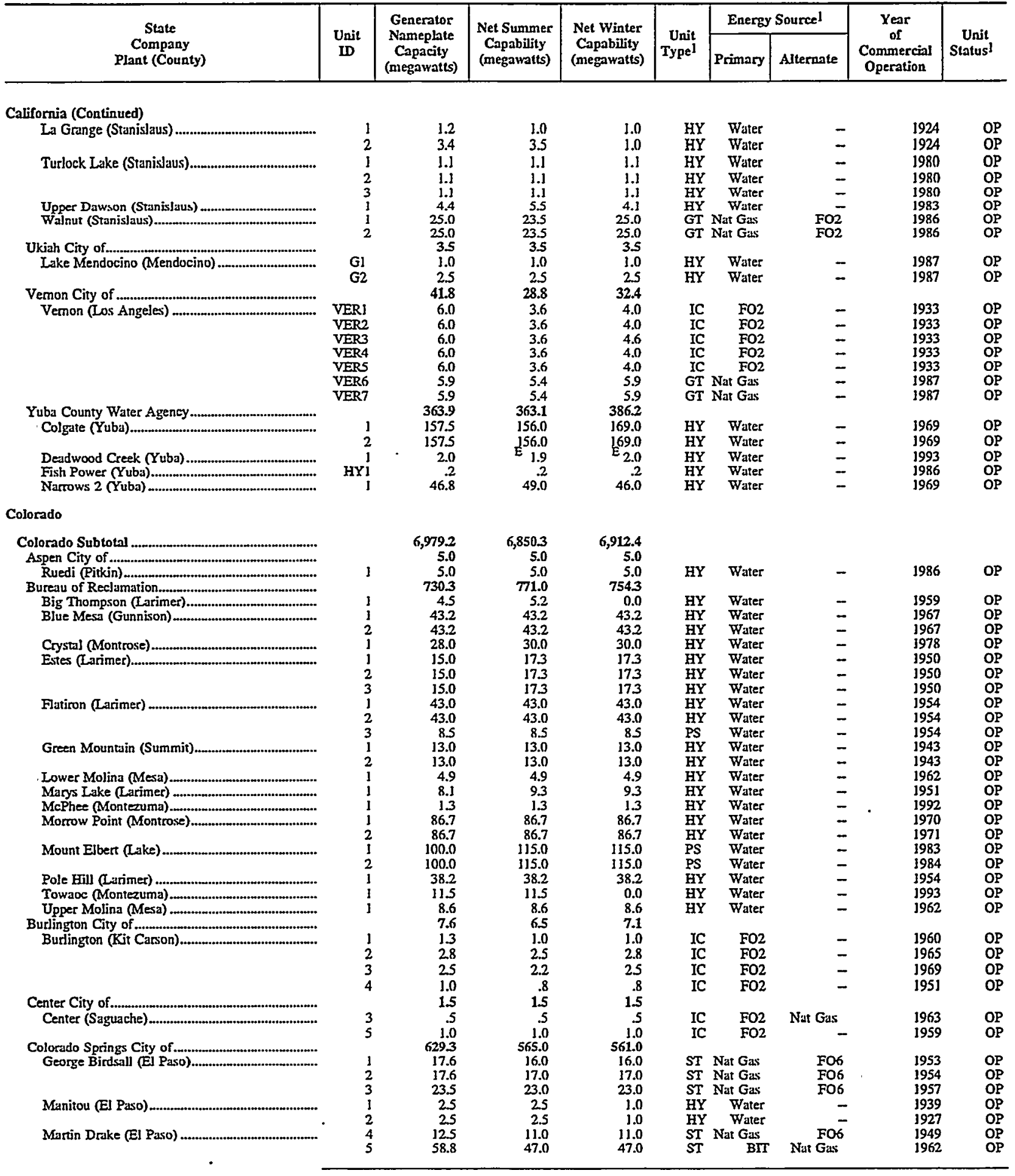

See footnotes at end of table. 
Table 20. Existing Generating Units at U.S. Electric Utilities by State, Company, and Plant, as of January 1, 1998 (Continued)

\begin{tabular}{|c|c|c|c|c|c|c|c|c|c|}
\hline \multirow{2}{*}{$\begin{array}{c}\text { State } \\
\text { Company } \\
\text { Plant (County) }\end{array}$} & \multirow{2}{*}{$\begin{array}{l}\text { Unit } \\
\text { ID }\end{array}$} & \multirow{2}{*}{$\begin{array}{l}\text { Generator } \\
\text { Nameplate } \\
\text { Capacity } \\
\text { (megawatts) }\end{array}$} & \multirow{2}{*}{$\begin{array}{c}\text { Net Summer } \\
\text { Capability } \\
\text { (megawatts) }\end{array}$} & \multirow{2}{*}{$\begin{array}{l}\text { Net Winter } \\
\text { Capability } \\
\text { (megawatts) }\end{array}$} & \multirow{2}{*}{$\begin{array}{l}\text { Unit } \\
\text { TypeI }\end{array}$} & \multicolumn{2}{|c|}{ Energy Sourcel } & \multirow{2}{*}{$\begin{array}{c}\text { Year } \\
\text { of } \\
\text { Commercinl } \\
\text { Operation }\end{array}$} & \multirow{2}{*}{$\begin{array}{c}\text { Unit } \\
\text { Status } 1\end{array}$} \\
\hline & & & & & & Primary & Alternate & & \\
\hline \multicolumn{10}{|l|}{ Colorado (Continued) } \\
\hline & 6 & 88.2 & 79.0 & 79.0 & ST & BIT & Nat Gas & 1968 & OP \\
\hline & 7 & 147.0 & 133.0 & 133.0 & ST & BIT & Nat Gas & 1974 & $\mathrm{OP}$ \\
\hline 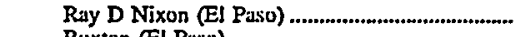 & 1 & 230.0 & 208.0 & 208.0 & sT & BIT & - & 1980 & OP \\
\hline Ruxton (El Pais) & I & 1.3 & 1.0 & 0.0 & $\mathrm{HY}$ & Water & - & 3925 & OP \\
\hline Tesla (El Paso) .......................................................... & 1 & 27.6 & 25.0 & 25.0 & $\mathrm{HY}$ & Water & - & 1997 & OP \\
\hline 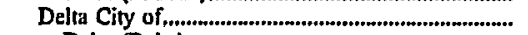 & & 5.0 & 4.7 & 4.8 & & & & 1000 & 0. \\
\hline Delta (Delta) & 1 & .8 & .8 & .8 & & Nat Gas & FO2 & 1945 & OP \\
\hline & 2 & .4 & .4 & .4 & & Nat Gas & FO2 & 1939 & $O P$ \\
\hline & 3 & .2 & .2 & 2 & IC & FO2 & - & 1938 & $O P$ \\
\hline & 4 & .1 & .1 & .1 & IC & $\mathrm{FO} 2$ & - & 1937 & $O P$ \\
\hline & 5 & .1 &.$j$ & .1 & IC & FO2 & - & 1937 & $\mathrm{OP}$ \\
\hline & 6 & 1.2 & 1.2 & 12 & & Nat Gas & FO2 & 1949 & $O P$ \\
\hline & 7 & 21 & 1.9 & 2.0 & IC & Nat Gas & $\mathrm{FO} 2$ & 1956 & OP \\
\hline Haxtun Town of & & 3 & 3 & 3 & & & & & \\
\hline 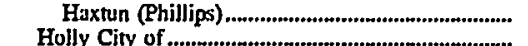 & 3 & .3 & .3 & .3 & IC & FO2 & - & 1947 & OP \\
\hline 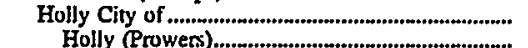 & & 1.3 & 1.3 & 13 & & & & & \\
\hline 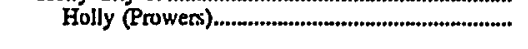 & 1 & .3 & 3 & .3 & IC & Nat Gas & - & 1950 & SB \\
\hline & 2 & .3 & 3 & 3 & IC & Nat Gas & - & 1950 & SB \\
\hline 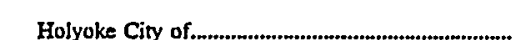 & & .8 & 1.8 & .8 & IC & Fol & - & 1993 & SB \\
\hline Holyoke Chy or & 1 & $\begin{array}{r}1.0 \\
.2\end{array}$ & .2 & $\begin{array}{r}1.0 \\
.2\end{array}$ & $\mathrm{Xc}$ & & & & ת \\
\hline & 2 & 3 & 3 & 3 & IC & $\begin{array}{l}\mathrm{FO} 2 \\
\mathrm{FO} 2\end{array}$ & 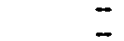 & $\begin{array}{l}1933 \\
1937\end{array}$ & $\underset{O P}{O P}$ \\
\hline$\therefore \quad-$ & 3 & .5 & 5 & 5 & IC & FO2 & - & 1940 & OP \\
\hline Julesburg City of .....i. & & 3.7 & 3.1 & 3.1 & & & & 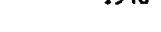 & 01 \\
\hline 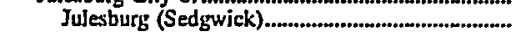 & 1 & .9 & .8 & .8 & IC & $\mathrm{FO} 2$ & Nat Gas & 1951 & OP \\
\hline & 2 & .9 & $\begin{array}{l}.8 \\
.2\end{array}$ & $\begin{array}{l}.8 \\
2\end{array}$ & IC & $\begin{array}{l}\mathrm{FO} 2 \\
\mathrm{FO2}\end{array}$ & $\overline{-}$ & 1949 & OP \\
\hline & 3 & .3 & .2 & 2 & IC & FO2 & - & 1945 & OP \\
\hline & 4 & 1.3 & 1.2 & 12 & IC & $\mathrm{FO2}$ & Nat Gas & 1964 & OP \\
\hline 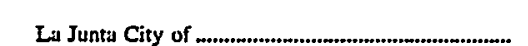 & 5 & 19.2 &. .2 & $16 \frac{2}{2}$ & IC & FO2 & - & 1946 & OP \\
\hline La Junta (Otero)............................................................ & 1 & .7 & E.6 & E.6 & IC & $\mathrm{FO} 2$ & - & 1939 & os \\
\hline & 2 & .7 & $s$ & 5 & IC & $\mathrm{FO} 2$ & Nat Gas & 1939 & SB \\
\hline & 3 & .4 & .4 & .4 & IC & FO2 & Nat Gas & 1939 & SB \\
\hline & 4 & l.1 & 1.0 & 1.0 & IC & Nat Gas & FO2 & 1942 & SB \\
\hline & 5 & 1.3 & $\mathrm{E}_{1.2}$ & $\mathrm{E}_{1.2}$ & IC & Nat Gas & $\mathrm{FO} 2$ & 1950 & os \\
\hline & 6 & 3.0 & 2.5 & 25 & IC & Nat Gas & $\mathrm{FO} 2$ & 1958 & SB \\
\hline & 7 & 3.5 & 3.0 & 3.0 & IC & Nat Gas & $\mathrm{FO} 2$ & 1962 & SB \\
\hline & 8 & 3.5 & 3.0 & 3.0 & IC & Nat Gas & $\mathrm{FO} 2$ & 1962 & SB \\
\hline 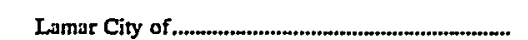 & & $\begin{array}{r}5.1 \\
35.0\end{array}$ & $\begin{array}{r}4.0 \\
39.0\end{array}$ & $\begin{array}{r}4.0 \\
39.0\end{array}$ & & Nat Gas & $\mathrm{FO} 2$ & 1970 & SB \\
\hline Lamar PIt (Prowers)................................................. & ICI & 1.0 & 1.0 & 1.0 & IC & $\mathrm{FO} 2$ & _ & 1949 & OP \\
\hline & IC2 & 1.0 & 1.0 & 1.0 & IC & FO2 & _ & 1946 & OP \\
\hline & 2 & 3.0 & 3.0 & 3.0 & ST & Nat Gas & FO2 & 1939 & os \\
\hline & 3 & 5.0 & 6.0 & 6.0 & ST & Nat Gas & FO2 & 1952 & os \\
\hline & 4 & 25.0 & 28.0 & 28.0 & ST & Nat Gas & FO2 & 1972 & OP \\
\hline 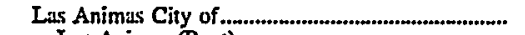 & & 5.6 & 5.1 & 5.1 & & & & & \\
\hline 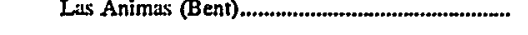 & $\frac{1}{2}$ & $\frac{3}{3}$ & -3 & 3 & IC & $\mathrm{FO} 2$ & - & 1941 & OP \\
\hline & 2 & 3 & $\begin{array}{r}3.3 \\
1.0\end{array}$ & $\begin{array}{r}3 \\
1.0\end{array}$ & IC & FO2 & $\mathrm{FO}^{-}$ & 1941 & OP \\
\hline & 5 & 1.0 & 1.0 & $\begin{array}{l}1.0 \\
3.0\end{array}$ & IC & Nat Gas & FO2 & & SB \\
\hline & 6 & 3.0 & 25 & 25 & & Nat Gas & FO2 & 1951 & SB \\
\hline & & 3.0 & 6 & 6 & IC & Nat Gas & FO2 & 1967 & SB \\
\hline Longmont City of of & 1 & 3 & 3 & 3 & HY & & 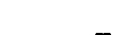 & 1911 & \\
\hline & 2 & 3 & 3 & 3 & HY & $\begin{array}{l}\text { Water } \\
\text { Water }\end{array}$ & $\Xi$ & 1911 & OP \\
\hline 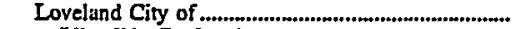 & & .9 & 9 & .9 & & & & & \\
\hline 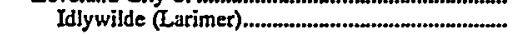 & J & .5 & .5 & s. & HY & Water & - & 1983 & $\mathrm{OP}$ \\
\hline & $?$ & & & & HY & Water & 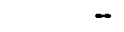 & 1983 & OP \\
\hline 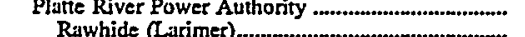 & 1 & 285.1 & $\begin{array}{l}262.0 \\
262.0\end{array}$ & 262.0 & ST & SUB & FO2 & 1984 & $O P$ \\
\hline Public Service Co of Colorado............................... & & $3,611.9$ & $3,604.4$ & $3,666.5$ & & & & 19004 & Or \\
\hline 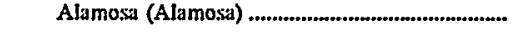 & Cr! & 16.6 & 14.0 & 17.0 & GT & $\mathrm{FO} 2$ & Nat Gas & 1973 & $\mathrm{OP}$ \\
\hline & CT2 & 16.6 & 16.0 & 19.0 & GT & $\mathrm{FO2}$ & Nat Gas & 1977 & OP \\
\hline Amer (Sun Migued),.......................................................... & 1 & 3.6 & 3.8 & 3.8 & HY & Water & & 1906 & OP \\
\hline 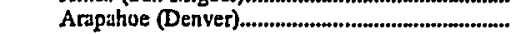 & $\mathrm{i}$ & 44.0 & 45.0 & 45.0 & ST & & Nat Gas & 1950 & OP \\
\hline & 2 & 44.0 & 45.0 & 45.0 & ST & BIT & Nat Gas & 1951 & $O P$ \\
\hline & 3 & 44.0 & 45.0 & 45.0 & $\mathbf{S T}$ & BIT & Nat Gas & 1951 & OP \\
\hline & 4 & 100.0 & 111.0 & 111.0 & ST & BIT & Nat Gas & 1955 & $O P$ \\
\hline 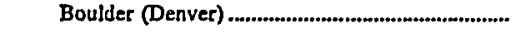 & 1 & 30.0 & 5.0 & 10.0 & $\mathrm{HY}$ & Water & - & 1911 & $O P$ \\
\hline & 2 & 10.0 & 5.0 & 10.0 & $\mathrm{HY}$ & Water & $=$ & 1911 & $O P$ \\
\hline 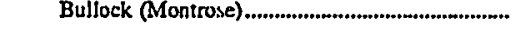 & 1 & 6.0 & 6.0 & 6.0 & ST & Nat Gas & BIT & 1951 & SB \\
\hline
\end{tabular}

See footnotes at end of table. 
Table 20. Existing Generating Units at U.S. Electric Utilities by State, Company, and Plant, as of January 1, 1998 (Continued)

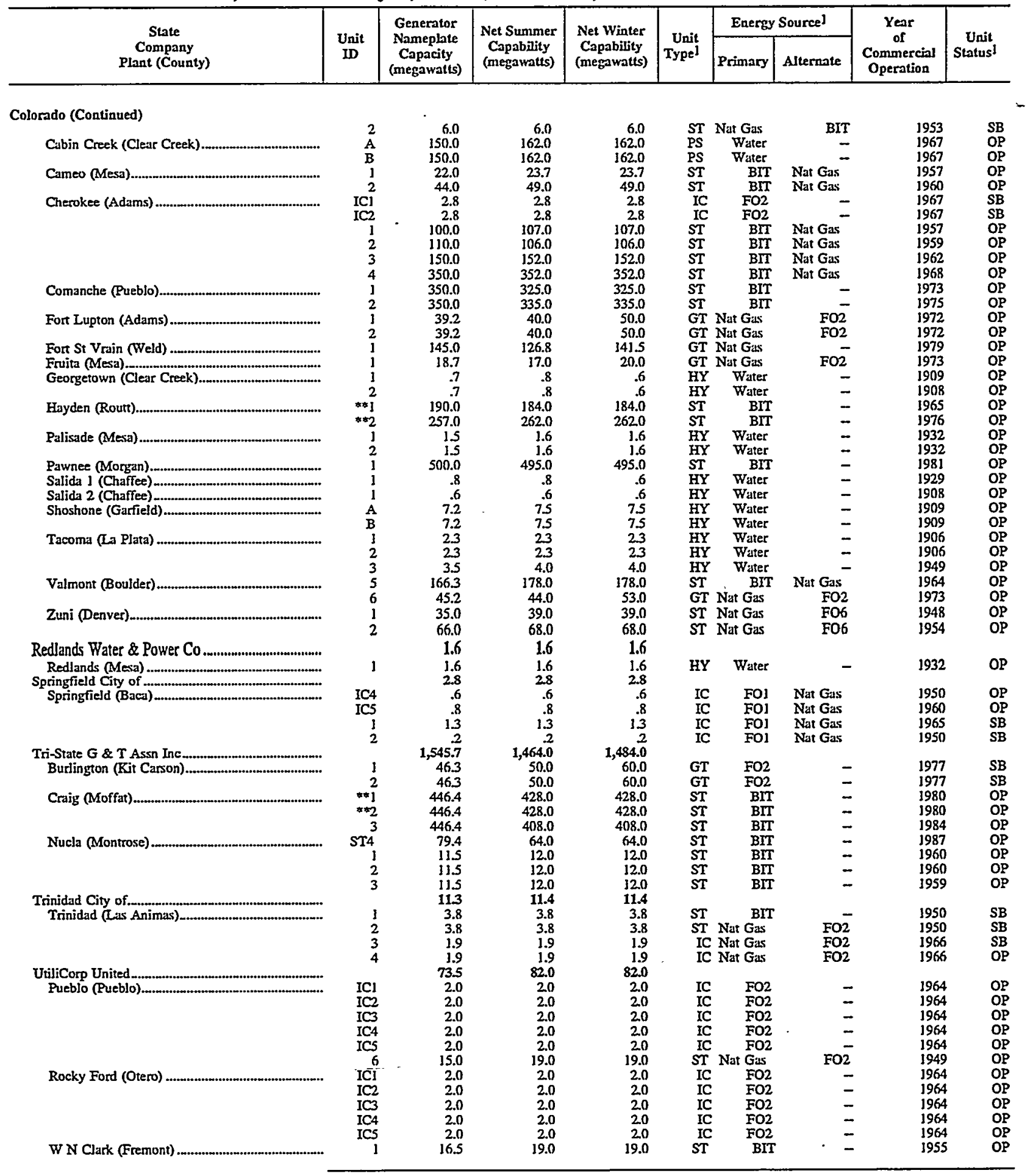

See footnotes at end of table. 
Table 20. Existing Generating Units at U.S. Electric Utilities.by State, Company, and Plant, as of January 1, 1998 (Continued)

\begin{tabular}{|c|c|c|c|c|c|c|c|c|c|}
\hline \multirow{2}{*}{$\begin{array}{c}\text { State } \\
\text { Company } \\
\text { Plant (County) }\end{array}$} & \multirow{2}{*}{$\begin{array}{l}\text { Unit } \\
\text { ID }\end{array}$} & \multirow{2}{*}{$\begin{array}{c}\text { Generator } \\
\text { Nameplate } \\
\text { Capacity } \\
\text { (megawatts) }\end{array}$} & \multirow{2}{*}{$\begin{array}{l}\text { Net Summer } \\
\text { Capability } \\
\text { (megawatts) }\end{array}$} & \multirow{2}{*}{$\begin{array}{l}\text { Net Winter } \\
\text { Capability } \\
\text { (megawatts) }\end{array}$} & \multirow{2}{*}{\begin{tabular}{|} 
Uait \\
Type
\end{tabular}} & \multicolumn{2}{|c|}{ Energy Sourcel } & \multirow{2}{*}{$\begin{array}{c}\text { Year } \\
\text { of } \\
\text { Commercinl } \\
\text { Operation }\end{array}$} & \multirow{2}{*}{$\begin{array}{c}\text { Unit } \\
\text { Status }\end{array}$} \\
\hline & & & & & & Primary & Allernate & & \\
\hline \multicolumn{10}{|l|}{ Colorado (Continued) } \\
\hline 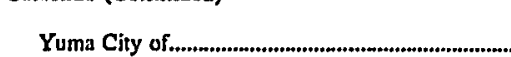 & 2 & $\begin{array}{r}22.0 \\
1.2\end{array}$ & $\begin{array}{r}24.0 \\
1.0\end{array}$ & $\begin{array}{r}24.0 \\
1.0\end{array}$ & ST & BIT & - & 1959 & OP \\
\hline 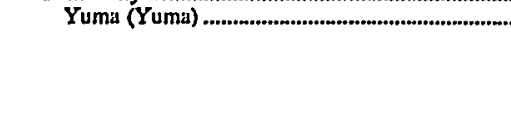 & $\begin{array}{l}1 \\
2 \\
3 \\
4\end{array}$ & $\begin{array}{l}.1 \\
.2 \\
.4 \\
.6\end{array}$ & $\begin{array}{l}.1 \\
.3 \\
.3 \\
.6\end{array}$ & $\begin{array}{l}.1 \\
.1 \\
3 \\
.6\end{array}$ & $\begin{array}{l}\text { IC } \\
\text { IC } \\
\text { IC } \\
\text { IC }\end{array}$ & $\begin{array}{l}\mathrm{FO} 2 \\
\text { FO2 } \\
\text { FO2 } \\
\text { FO2 }\end{array}$ & $\begin{array}{l}\bar{z} \\
\overline{-}\end{array}$ & $\begin{array}{l}1937 \\
1937 \\
1938 \\
1948\end{array}$ & $\begin{array}{l}\text { SB } \\
\text { SB } \\
\text { SB } \\
\text { SB }\end{array}$ \\
\hline \multicolumn{10}{|l|}{ Connecticul } \\
\hline $\begin{array}{l}\text { Connecticut Subtotal } \\
\text { Connecticut Light \& Power Co }\end{array}$ & & $\begin{array}{l}6,608.5 \\
2,510.3\end{array}$ & $\begin{array}{l}6,294.0 \\
2,431.2\end{array}$ & $\begin{array}{l}6,533.2 \\
2,580.3\end{array}$ & & & & & \\
\hline Buntam (Litchfield).............................................. & 1 & 3 & .1 & -3 & HY & Water & - & 1905 & OP \\
\hline \multirow{6}{*}{ 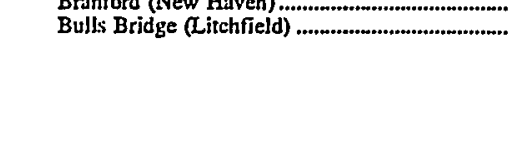 } & 10 & 18.6 & 14.9 & 38.8 & JE & Jet Fuel & - & 1969 & OP \\
\hline & $* * 1$ & 1.2 & $\begin{array}{l}1.4 \\
1.4\end{array}$ & $\begin{array}{l}1.4 \\
1.4\end{array}$ & $\underset{H Y}{H Y}$ & Water & $\overline{-}$ & 1903 & \\
\hline & $* *_{2}$ & $\begin{array}{l}1.2 \\
1.2\end{array}$ & $\begin{array}{l}1.4 \\
1.4\end{array}$ & $\begin{array}{l}1.4 \\
1.4\end{array}$ & $\begin{array}{l}\mathrm{HY} \\
\mathbf{H Y}\end{array}$ & $\begin{array}{l}\text { Water } \\
\text { Water }\end{array}$ & $\overline{-}$ & $\begin{array}{l}1903 \\
1903\end{array}$ & $\begin{array}{l}\text { OP } \\
\text { OP }\end{array}$ \\
\hline & $* *_{4}^{4}$ & 1.2 & 3.4 & 1.4 & HY & Water & - & 1903 & OP \\
\hline & $* * 5$ & 1.2 & 0.4 & 1.4 & $\mathrm{HY}$ & Water & - & 1903 & OP \\
\hline & $* * 6$ & 1.2 & 1.4 & 1.4 & $\mathrm{HY}$ & Water & - & 1903 & OP \\
\hline 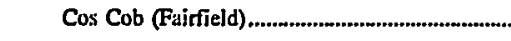 & 10 & 21.3 & 37.9 & 23.3 & JE & Jet Fuel & - & 1969 & OP \\
\hline & II & 21.3 & 37.1 & 22.4 & 正 & Jet Fuel & - & 1969 & OP \\
\hline & 12 & 21.3 & 16.4 & 22.8 & JE & Jet Fuel & - & 1969 & OP \\
\hline Devon (New Haven) & $* * 7$ & 103.5 & 107.0 & 109.0 & ST & Nat Gas & FO6 & 1956 & OP \\
\hline & $\$ 88$ & 103.5 & 107.0 & 109.0 & ST & Nat Gas & FO6 & 1958 & OP \\
\hline & $* * 10$ & 16.3 & 17.2 & 19.2 & JE & Jet Fuel & $\mathrm{FO} 2$ & 1966 & OP \\
\hline & 11 & 41.6 & 32.0 & 40.4 & GT & Nat Gas & FO2 & 1988 & OP \\
\hline & 12 & 41.6 & 30.9 & 40.1 & GT & Nat Gas & $\mathrm{FO} 2$ & 1996 & OP \\
\hline & 13 & 41.6 & 31.9 & 41.0 & GT & Nar Gas & $\mathrm{FO2}$ & 3996 & $O P$ \\
\hline & 14 & 41.6 & 32.1 & 41.8 & GT & Nat Gas & $\mathrm{FO} 2$ & 1996 & $O P$ \\
\hline Falls Village (Litchfield) & 1 & 3.0 & 3.3 & 3.7 & HY & Water & - & 1914 & OP \\
\hline 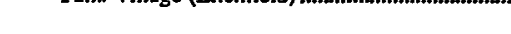 & 2 & 3.0 & 3.3 & 3.7 & HY & Wuter & - & 1914 & OP \\
\hline & 3 & 3.0 & 3.3 & 3.7 & HY & Water & - & 1914 & OP \\
\hline Franklin Drive (Litchfield) & 19 & 18.6 & 17.2 & 18.3 & $\mathrm{JE}$ & Jet Fuel & - & 1968 & OP \\
\hline 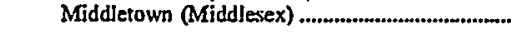 & 1 & 69.0 & 66.4 & 70.0 & $\mathrm{sT}$ & F06 & - & 1954 & OP \\
\hline & $* \approx_{2}^{2}$ & 113.6 & 117.0 & 120.0 & ST & F06 & - & 1958 & OP \\
\hline & $* *_{3}$ & 239.4 & 236.0 & 245.0 & ST & Fo6 & - & 1964 & OP \\
\hline & $* \approx 4$ & 414.9 & 400.0 & 4020 & ST & FO6 & - & 1973 & OP \\
\hline & $* 10$ & 18.6 & 17.2 & 192 & $\mathrm{JE}$ & Jet Fuel & - & 1966 & OP \\
\hline Montville (New London) & $* \$ 5$ & 75.0 & 81.0 & 82.0 & ST & F06 & Nat Gas & 1954 & OP \\
\hline & $* 6$ & 414.9 & 410.0 & 410.0 & ST & Fo6 & - & 197I & OP \\
\hline & $\$ 10$ & 2.8 & 2.8 & 2.8 & IC & FO2 & - & 1967 & $O P$ \\
\hline & $* *] 1$ & 28 & 2.8 & 2.8 & IC & $\mathrm{FO} 2$ & - & 1967 & OP \\
\hline Norwalk Harbor (Fairfield) ....................................... & $* * 1$ & 163.2 & 1620 & 164.0 & ST & FO6 & - & 1960 & $\mathrm{OP}$ \\
\hline & $* 2$ & 163.2 & 168.0 & 1720 & ST & Fo6 & - & 963 & $O P$ \\
\hline & 10 & 16.3 & 11.8 & 17.0 & GT & FO2 & - & 1966 & $\mathrm{OP}$ \\
\hline Robertsville (Litchfield).............................................. & 1 & 3 & .2 & 3 & $\mathrm{HY}$ & Water & - & 3924 & OP \\
\hline & 2 & .3 & .2 & 3 & $\mathrm{HY}$ & Water & - & 1924 & OP \\
\hline 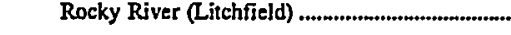 & 1 & 3.5 & 3.0 & 3.0 & PS & Water & - & 1929 & OP \\
\hline & 2 & 3.5 & 3.0 & 3.0 & PS & Water & - & 1928 & $O P$ \\
\hline & 3 & 24.0 & 23.4 & 24.4 & $\mathrm{HY}$ & Water & - & 1928 & OP \\
\hline Scotland Dam (Windham) & I & 2.0 & 1.7 & 2.2 & $\mathrm{HY}$ & Water & - & 1937 & $\mathrm{OP}$ \\
\hline Shepaug (New Haven) & $* * 1$ & 37.2 & 43.0 & 43.4 & $\mathrm{HY}$ & Water & - & 1955 & $\mathrm{OP}$ \\
\hline South Meadow (Eantord) & ji & 41.9 & 38.8 & 49.0 & $J E$ & Jet Fuel & - & 1970 & $O P$ \\
\hline & 12 & 41.9 & 39.0 & 49.0 & $J E$ & Jet Fuel & - & 1970 & OP \\
\hline & 13 & 41.9 & 39.0 & 48.6 & $\sqrt{E}$ & Jet Fuel & - & 1970 & $O P$ \\
\hline & 14 & 41.9 & 39.0 & 49.0 & JE & Jet Fuel & - & 1970 & OP \\
\hline 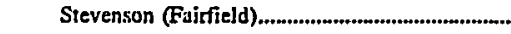 & 1 & 7.5 & 7.1 & 7.1 & $\mathrm{HY}$ & Water & - & 1919 & $O P$ \\
\hline & 2 & 7.5 & 7.1 & 7.1 & $\mathrm{HY}$ & Water & - & 1919 & $O P$ \\
\hline & 3 & 7.5 & 7.1 & 7.1 & HY & Wuter & _- & 1919 & OP \\
\hline & 4 & 8.0 & 7.6 & 7.6 & HY & Water & - & 1936 & OP \\
\hline Tuftrille (New London) & 1 & .4 & .4 & .4 & HY & Water & - & 1926 & OP \\
\hline & 2 & 3 & .4 & .4 & $\mathrm{HY}$ & Water & - & 1906 & OP \\
\hline & 3 & .4 & .4 & .4 & $\mathrm{HY}$ & Water & - & 1906 & OP \\
\hline & 4 & .4 & .4 & .4 & $\mathrm{HY}$ & Water & - & 1949 & OP \\
\hline & 5 & .4 & .4 & .4 & HY & Water & - & 1949 & $O P$ \\
\hline 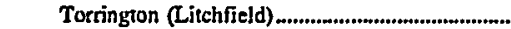 & 10 & 38.6 & 17.2 & 21.8 & $J$ & Jet Fuel & - & 1967 & OP \\
\hline Tunnel (New London) & 1 & 1.0 & .8 & 1.1 & $\mathrm{HY}$ & Water & - & 1919 & $O P$ \\
\hline & 2 & 1.0 & .8 & 1.1 & HY & Water & ـ & 1949 & OP \\
\hline & 10 & 18.6 & 16.9 & 20.8 & $\mathrm{JE}$ & Jet Fuel & - & 1969 & OP \\
\hline 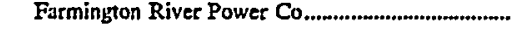 & & 8.0 & 8.0 & 8.0 & & & & • & \\
\hline
\end{tabular}

See foutnotes at end of table. 
Table 20. Existing Generating Units at U.S. Electric Utilities by State, Company, and Plant, as of January 1, 1998 (Continued)

\begin{tabular}{|c|c|c|c|c|c|c|c|c|c|}
\hline \multirow{2}{*}{$\begin{array}{c}\text { State } \\
\text { Company } \\
\text { Plant (County) }\end{array}$} & \multirow{2}{*}{$\begin{array}{c}\text { Unit } \\
\text { ID }\end{array}$} & \multirow{2}{*}{$\begin{array}{c}\text { Generator } \\
\text { Nameplate } \\
\text { Capacity } \\
\text { (megawatts) }\end{array}$} & \multirow{2}{*}{$\begin{array}{l}\text { Net Summer } \\
\text { Capability } \\
\text { (megawatis) }\end{array}$} & \multirow{2}{*}{$\begin{array}{c}\text { Net Winter } \\
\text { Capability } \\
\text { (megawatts) }\end{array}$} & \multirow{2}{*}{$\begin{array}{r}\text { Unit } \\
\text { Typel }\end{array}$} & \multicolumn{2}{|c|}{ Energy Sourcel } & \multirow{2}{*}{$\begin{array}{c}\text { Year } \\
\text { of } \\
\text { Commercial } \\
\text { Operation }\end{array}$} & \multirow{2}{*}{$\begin{array}{c}\text { Unit } \\
\text { Statusl }\end{array}$} \\
\hline & & & & & & Primary & Alternate & & \\
\hline \multicolumn{10}{|l|}{ Connecticut (Continued) } \\
\hline Rainbow (Hartford) & 1 & 4.0 & 4.0 & 4.0 & HY & Water & - & 1925 & OP \\
\hline 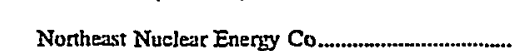 & 2 & $\begin{array}{r}4.0 \\
2,824.5\end{array}$ & $\begin{array}{r}4.0 \\
2,631.3\end{array}$ & $\begin{array}{r}4.0 \\
2,667.9\end{array}$ & HY & Water & $\rightarrow$ & 1925 & OP \\
\hline Millstone (New London) & 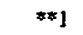 & 661.5 & 641.0 & 647.7 & NB & Uranium & - & 1970 & os \\
\hline & $\star \star 2$ & 909.9 & 870.6 & 874.5 & NP & Uranium & - & 1975 & OS \\
\hline & $* * 3$ & 1253.1 & 1119.6 & 3145.7 & NP & Uranium & - & 1986 & OS \\
\hline Nonwich City of & & 19.8 & 183 & 21.4 & & & & & \\
\hline North Main Street (New London).......................... & 5 & 16.8 & 15.3 & I8.4 & GT & $\mathrm{FO} 2$ & - & 1972 & OP \\
\hline Oceum (New London) & 1 & .8 & .8 & .8 & $\mathbf{H Y}$ & Water & - & 1936 & OP \\
\hline 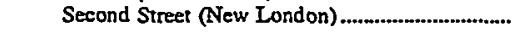 & 1 & .4 & .4 & .4 & HY & Water & - & 1927 & os \\
\hline & 2 & .4 & .4 & .4 & HY & Water & - & 1927 & OP \\
\hline 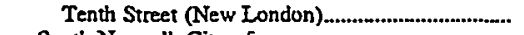 & 1 & 1.4 & 1.4 & 1.4 & HY & Water & - & 1967 & OP \\
\hline 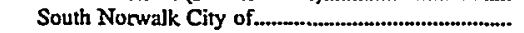 & & 17.3 & 16.1 & 16.7 & & & & & \\
\hline 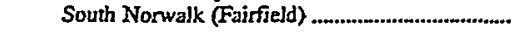 & 了 & 5.0 & 5.0 & 5.1 & IC & $\mathrm{FO} 2$ & - & 1972 & op \\
\hline & 2 & 2.0 & 1.8 & 1.9 & IC & $\mathrm{FO} 2$ & - & 1940 & OP \\
\hline & 3 & 2.0 & 1.9 & 1.9 & IC & FO2 & - & 1942 & OP \\
\hline & 4 & 3.3 & 3.1 & 3.3 & IC & FO2 & - & 1951 & OP \\
\hline & 5 & 4.0 & 3.3 & 3.4 & IC & FO2 & - & 1960 & OP \\
\hline & 6 & 1.0 & 1.1 & 1.1 & IC & FO2 & - & 1990 & OP \\
\hline United Illuminating Co & & $1,206.1$ & $1,166.7$ & $1,216.5$ & & & & & \\
\hline 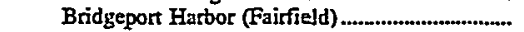 & ] & 81.5 & 76.0 & 85.0 & ST & FO6 & - & 1957 & SB \\
\hline 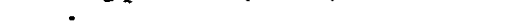 & 2 & 179.5 & 370.0 & 170.0 & ST & FO6 & - & 1961 & oP \\
\hline & 3 & 399.5 & 385.0 & 400.0 & ST & BIT & FO6 & 1968 & OP \\
\hline & 4 & 18.6 & 36.2 & 20.5 & JE & Jet Fuel & - & 1967 & OP \\
\hline English (New Haven) & 7 & 30.0 & 34.1 & 35.0 & ST & FO6 & - & 1948 & SB \\
\hline & 8 & 36.8 & 38.5 & 40.0 & ST & FO6 & - & 1953 & SB \\
\hline New Hiven Harbor (New Haven)......................... & $* * 1$ & 460.3 & 447.0 & 466.0 & ST & FO6 & Nat Gas & 1975 & OP \\
\hline 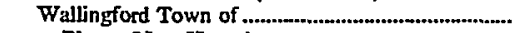 & & 225 & 22.5 & 225 & & & & & \\
\hline 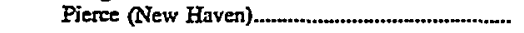 & 1 & 7.5 & 7.5 & 7.5 & ST & FO4 & - & 1953 & OS \\
\hline & 2 & 7.5 & 7.5 & 7.5 & ST & FO4 & - & 1953 & OP \\
\hline & 3 & 7.5 & 7.5 & 75 & $S T$ & FO4 & - & 1953 & OP \\
\hline Delaware & & & & & & & & & \\
\hline Delaware Subtotal & & $2,292.6$ & $2,276.7$ & $2,342.9$ & & & & & \\
\hline 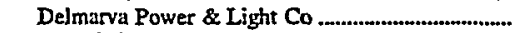 & & $2,086.5$ & 2,0920 & $2,151.0$ & & & & & \\
\hline 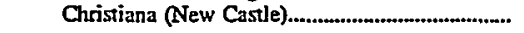 & 11 & 26.6 & 22.5 & 25.0 & GT & $\mathrm{FO} 2$ & - & 1973 & OP \\
\hline & 14 & 28.0 & 22.5 & 25.0 & GT & $\mathrm{FO} 2$ & - & 1973 & $\mathbf{O P}$ \\
\hline 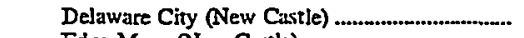 & 10 & 18.6 & 16.0 & 18.0 & GT & FO2 & - & 1968 & OP \\
\hline Edge Moor (New Castle) & 3 & 75.0 & 84.0 & 86.0 & ST & BIT & - & 1954 & $O P$ \\
\hline & 4 & 176.8 & 168.0 & 174.0 & ST & BIT & - & 1966 & OP \\
\hline & 5 & 446.0 & 445.0 & 446.0 & ST & FO6 & - & 1973 & OP \\
\hline & 10 & 12.5 & 13.0 & 15.0 & GT & $\mathrm{FO} 2$ & - & 1963 & OP \\
\hline Hay Road (New Castle) & 1 & 103.5 & 1320 & 122.0 & CT & Nat Gas & KER & 1989 & OP \\
\hline & 2 & 103.5 & 1]2.0 & 122.0 & CT & Nat Gus & KER & 1989 & $\mathbf{O P}$ \\
\hline & 3 & 103.5 & 112.0 & 122.0 & CT & Nat Gas & KER & 1991 & $\mathbf{O P}$ \\
\hline & 4 & 160.0 & 175.0 & 175.0 & $\mathbf{C W}$ & WH & - & 1993 & $\mathbf{O P}$ \\
\hline Indian River (Sussex) & 1 & 81.6 & 91.0 & 91.0 & ST & BIT & - & 1957 & OP \\
\hline & 2 & 81.6 & 91.0 & 91.0 & ST & BIT & - & 1959 & $\mathbf{O P}$ \\
\hline & 3 & 176.8 & J65.0 & 165.0 & ST & BIT & F06 & 1970 & OP \\
\hline & 4 & 4424 & 420.0 & 420.0 & $S \mathbf{T}$ & BIT & - & 1980 & OP \\
\hline & 10 & 18.6 & 37.0 & 21.0 & GT & $\mathrm{FO} 2$ & - & 1967 & OP \\
\hline 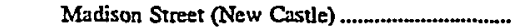 & 1 & 11.5 & 11.0 & 14.0 & GT & FO2 & - & 1962 & OP \\
\hline 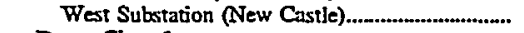 & I & 20.0 & 15.0 & 19.0 & GT & FO2 & - & 1964 & OP \\
\hline 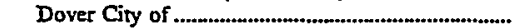 & & 196.3 & 175.0 & 1820 & & & & & \\
\hline McKee Run (Kent) & 了 & 18.8 & 37.0 & 17.0 & ST & FO6 & Nat Gas & 1962 & OP \\
\hline & 2 & 18.8 & 17.0 & 17.0 & ST & FO6 & Nat Gas & 1962 & OP \\
\hline & 3 & 113.6 & 102.0 & 102.0 & ST & FO6 & Nat Gas & 1975 & OP \\
\hline Van Sant Station (Kent) & 1 & 45.1 & 39.0 & 46.0 & GT & $\mathrm{FO} 2$ & Nat Gas & 1991 & OP \\
\hline 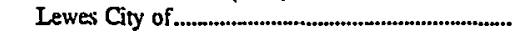 & & 2.0 & 1.8 & 2.1 & & & & & \\
\hline Lewes (Sussex) & 7 & 1.0 & .9 & 1.0 & IC & $\mathrm{FO} 2$ & - & 1993 & OP \\
\hline & 8 & 1.0 & .9 & 1.0 & IC & FO2 & - & 1993 & OP \\
\hline Seaford City of & & 7.8 & 7.8 & 7.8 & & & & & \\
\hline Seaford (Sussex) & 1 & 1.4 & 1.4 & J.4 & IC & FO2 & - & 1958 & OP \\
\hline & 2 & 1.4 & 1.4 & 1.4 & IC & FO2 & - & 3954 & OP \\
\hline & 3 & 1.1 & I.1 & 1.1 & IC & FO2 & - & 1950 & OP \\
\hline & 5 & .8 & .8 & .8 & IC & FO2 & - & 1947 & $\mathrm{OP}$ \\
\hline & 6 & 20 & 2.0 & 2.0 & IC & FO2 & - & 1962 & OP \\
\hline & 7 & 1.1 & 1.1 & 1.1 & IC & FO2 & - & 1989 & OP \\
\hline
\end{tabular}

See footnotes at end of table. 
Table 20. Existing Generating Units at U.S. Electric Utilities by State, Company, and Plant, as of January 1, 1998 (Continued)

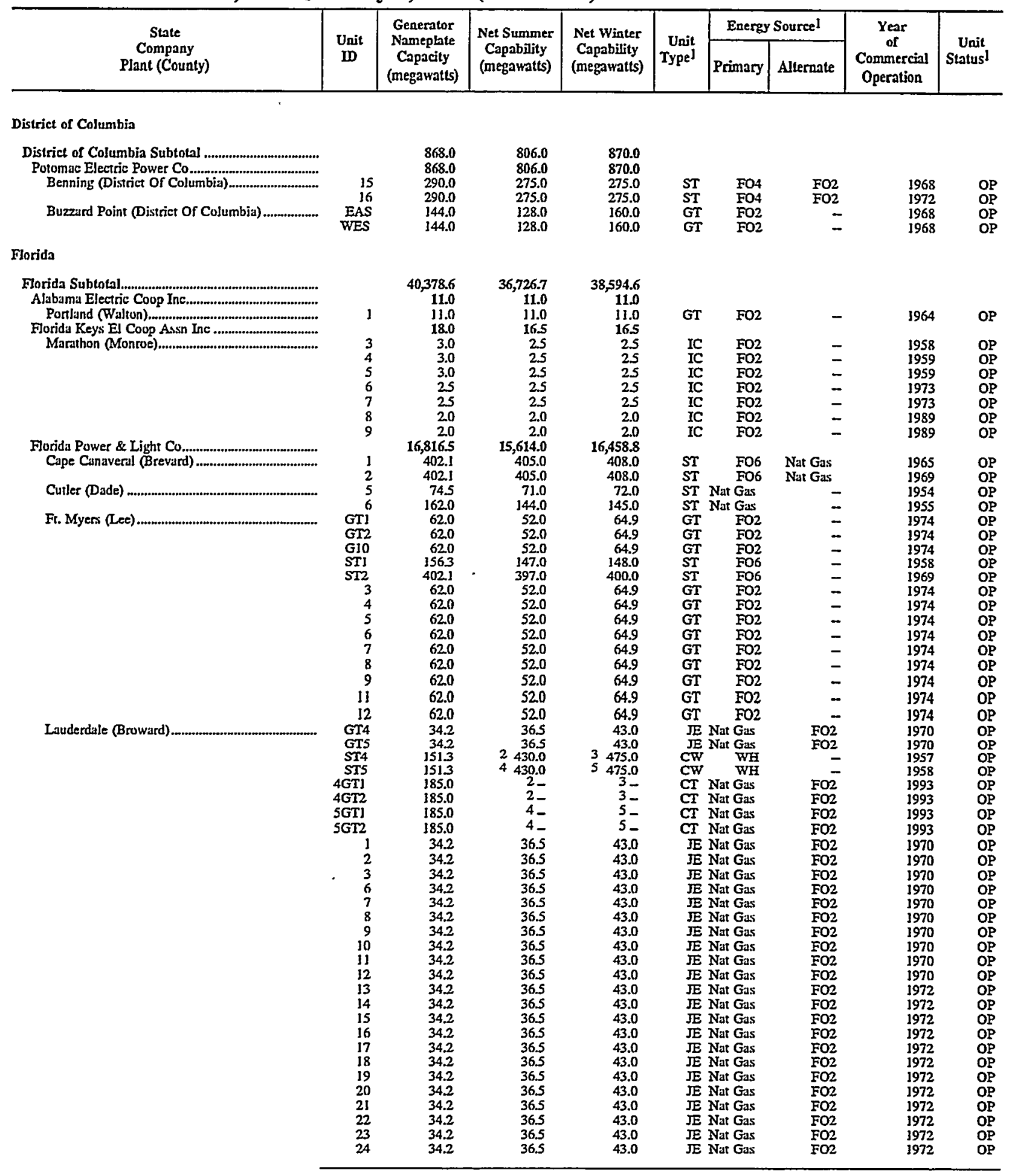

See foornotes at end of table. 
Table 20. Existing Generating Units at U.S. Electric Utilities by State, Company, and Plant, as of January 1, 1998 (Continued)

\begin{tabular}{|c|c|c|c|c|c|c|c|c|c|}
\hline \multirow{2}{*}{$\begin{array}{c}\text { State } \\
\text { Company } \\
\text { Plant (County) }\end{array}$} & \multirow{2}{*}{$\begin{array}{l}\text { Unit } \\
\text { ID }\end{array}$} & \multirow{2}{*}{$\begin{array}{c}\text { Generator } \\
\text { Nameplate } \\
\text { Capacity } \\
\text { (megawatts) }\end{array}$} & \multirow{2}{*}{$\begin{array}{c}\text { Net Summer } \\
\text { Capability } \\
\text { (megawatts) }\end{array}$} & \multirow{2}{*}{$\begin{array}{l}\text { Net Winter } \\
\text { Capability } \\
\text { (megawatts) }\end{array}$} & \multirow{2}{*}{$\begin{array}{r}\text { Unit } \\
\text { Type] }\end{array}$} & \multicolumn{2}{|c|}{ Energy Sourcel } & \multirow{2}{*}{$\begin{array}{c}\text { Year } \\
\text { of } \\
\text { Commercial } \\
\text { Operation }\end{array}$} & \multirow{2}{*}{$\begin{array}{c}\text { Unit } \\
\text { Status! }\end{array}$} \\
\hline & & & & & & Primary & Alternate & & \\
\hline \multicolumn{10}{|l|}{ Florida (Continued) } \\
\hline 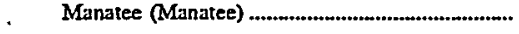 & 1 & 863.3 & 819.0 & 826.0 & ST & FO6 & - & 1976 & OP \\
\hline " & 2 & 863.3 & 819.0 & 826.0 & ST & FO6 & - & 1977 & OP \\
\hline Martin (Martin) & 3GTI & 204.0 & $\begin{array}{l}6- \\
6-\end{array}$ & $\begin{array}{l}7- \\
7-\end{array}$ & CT & Nat Gas & FO2 & 1994 & OP \\
\hline & $3 S T$ & 204.0 & $6430 . \overline{0}$ & 7490.0 & CW & Nat was & ros & 1994 & OP \\
\hline & $\begin{array}{l}4 G T I \\
4 G T 2\end{array}$ & $\begin{array}{l}204.0 \\
204.0\end{array}$ & $\begin{array}{l}8- \\
8-\end{array}$ & $\begin{array}{l}9- \\
9-\end{array}$ & $\begin{array}{l}\mathrm{CT} \\
\mathrm{CI}\end{array}$ & $\begin{array}{l}\text { Nat Gas } \\
\text { Nat Gas }\end{array}$ & $\begin{array}{l}\text { FO2 } \\
\text { FO2 }\end{array}$ & $\begin{array}{l}1994 \\
1994\end{array}$ & $\begin{array}{l}O P \\
O P\end{array}$ \\
\hline & $4 S T$ & 204.0 & 8430.0 & 9490.0 & CW & WH & - & 1994 & OP \\
\hline & $\begin{array}{l}1 \\
2\end{array}$ & $\begin{array}{l}863.3 \\
863.3\end{array}$ & $\begin{array}{l}814.0 \\
816.0\end{array}$ & $\begin{array}{l}821.0 \\
833.0\end{array}$ & $\begin{array}{l}\text { ST } \\
\text { ST }\end{array}$ & $\begin{array}{l}\text { Nat Gas } \\
\text { Nat Gas }\end{array}$ & $\begin{array}{l}\text { FO6 } \\
\text { FO6 }\end{array}$ & $\begin{array}{l}1980 \\
1981\end{array}$ & $\begin{array}{l}\text { OP } \\
\text { OP }\end{array}$ \\
\hline Port Everylades (Broward) ...................................... & GTi & 34.2 & 36.5 & 43.0 & $\mathrm{JE}$ & Nat Gas & $\mathrm{FO} 2$ & 1971 & OP \\
\hline & $\begin{array}{l}\text { GI2 } \\
\text { GI3 }\end{array}$ & $\begin{array}{l}34.2 \\
34.2\end{array}$ & $\begin{array}{l}36.5 \\
36.5\end{array}$ & $\begin{array}{r}43.0 \\
43.0\end{array}$ & $\frac{J E}{J E}$ & $\begin{array}{l}\text { Nat Gas } \\
\text { Nat Gas }\end{array}$ & $\begin{array}{l}\text { FO2 } \\
\text { FO2 }\end{array}$ & $\begin{array}{l}1971 \\
1971\end{array}$ & $\begin{array}{l}O P \\
O P\end{array}$ \\
\hline & GT4 & 34.2 & 36.5 & 43.0 & $\mathrm{JE}$ & Nat Gus & FO2 & 1971 & $O P$ \\
\hline & GT5 & 34.2 & 36.5 & 43.0 & JE & Nat Gas & $\mathrm{FO2}$ & 1971 & OP \\
\hline & $\begin{array}{l}\text { ST1 } \\
\text { ST2 }\end{array}$ & $\begin{array}{l}225.3 \\
225.3\end{array}$ & $\begin{array}{l}221.0 \\
222.0\end{array}$ & $\begin{array}{l}222.0 \\
223.0\end{array}$ & $\begin{array}{l}S T \\
S T\end{array}$ & $\begin{array}{l}\text { F06 } \\
\text { F06 }\end{array}$ & $\begin{array}{l}\text { Nat Gas } \\
\text { Nat Gas }\end{array}$ & $\begin{array}{l}1960 \\
1961\end{array}$ & $\begin{array}{l}\text { OP } \\
\text { OP }\end{array}$ \\
\hline & ST3 & 402.1 & 389.0 & 391.0 & ST & FO6 & Nat Gas & 1964 & OP \\
\hline & ST4 & 402.1 & 395.0 & 397.0 & ST & FO6 & Nat Gas: & 1965 & OP \\
\hline & 6 & 34.2 & 36.5 & 43.0 & JE & Nat Gas & $\mathrm{FO} 2$ & 1971 & OP \\
\hline & 7 & 34.2 & 36.5 & 43.0 & $J E$ & Nat Gas & $\mathrm{FO} 2$ & 1971 & OP \\
\hline & 8 & 34.2 & 36.5 & 43.0 & JE & Nat Gas & $\mathrm{FO} 2$ & 1971 & OP \\
\hline & 9 & 34.2 & 36.5 & 43.0 & $\mathrm{JE}$ & Nat Gas & FO2 & 1971 & $O P$ \\
\hline & 10 & 34.2 & 36.5 & 43.0 & $\mathrm{JE}$ & Nat Gas & $\mathrm{FO} 2$ & 1971 & OP \\
\hline & $\begin{array}{l}11 \\
12\end{array}$ & $\begin{array}{l}34.2 \\
34.2\end{array}$ & $\begin{array}{l}36.5 \\
36.5\end{array}$ & 43.0 & $J E$ & Nat Gas & FO2 & $\begin{array}{l}1971 \\
1971\end{array}$ & OP \\
\hline \multirow[t]{6}{*}{ Putnam (Putnam) } & IGTI & 85.0 & $10-$ & $11-$ & CT & Nat Gas & FO2 & 1978 & OP \\
\hline & $1 G T 2$ & 85.0 & $10-$ & $11-$ & $\mathrm{CT}$ & Nat Gas & $\mathrm{FO} 2$ & 1978 & OP \\
\hline & IST & 120.0 & 10249.0 & 11297.0 & $\mathrm{CA}$ & WH & Nat Gas & 1978 & $O P$ \\
\hline & $2 G T I$ & 85.0 & $12-$ & $13-$ & $\mathrm{CT}$ & Nat Gas & FO2 & 1977 & OP \\
\hline & 2GT2 & 85.0 & $12-$ & $13 \ldots$ & CT & Nat Gas & $\mathrm{FO2}$ & 1977 & OP \\
\hline & $2 S T$ & 120.0 & 12249.0 & 13297.0 & CA & WH & Nat Gas & 1977 & OP \\
\hline Riviera (Palm Beach) & 3 & 310.4 & 290.0 & 292.0 & ST & FO6 & Nat Gas & 1962 & OP \\
\hline & 4 & 310.4 & 290.0 & 292.0 & ST & FO6 & Nat Gas & 1963 & OP \\
\hline Sanford (Volusia) & 3 & 156.3 & 153.0 & 155.0 & ST & FO6 & Nat Gas & 1959 & OP \\
\hline & 4 & 436.1 & 383.0 & 387.0 & ST & FO6 & Nat Gus & 1969 & OP \\
\hline & 5 & 436.1 & 390.0 & 394.0 & ST & FO6 & Nat Gas & 1974 & $O P$ \\
\hline St. Lucie (St Lucie) & 1 & 8500 & 839.0 & 853.0 & NP & Uranium & - & 1976 & OP \\
\hline & $=2$ & 850.0 & 839.0 & 853.0 & $\mathbf{N P}$ & Uranium & - & 1983 & OP \\
\hline Turkey Point (Dade) & ICl & 2.8 & 28 & 2.8 & IC & FO2 & - & 1968 & OP \\
\hline & IC2 & 2.8 & 2.8 & 2.8 & IC & $\mathrm{FO} 2$ & - & 1968 & OP \\
\hline & IC3 & 2.8 & 2.8 & 28 & IC & $\mathrm{FO} 2$ & - & 1968 & OP \\
\hline & IC4 & 2.8 & 2.8 & 2.8 & IC & FO2 & - & 1968 & $O P$ \\
\hline & STJ & 402.1 & 410.0 & 411.0 & $S T$ & FO6 & Nat Gas & 1967 & OP \\
\hline & ST2 & 402.1 & 400.0 & 403.0 & $S T$ & FO6 & Nat Gas & 1968 & OP \\
\hline & 3 & 760.0 & 693.0 & 717.0 & $\mathrm{NP}$ & Uranjum & - & 1972 & $O P$ \\
\hline & 4 & 760.0 & 693.0 & 717.0 & NP & Uranium & - & 1973 & OP \\
\hline & 5 & 28 & 2.8 & 2.8 & IC & $\mathrm{FO} 2$ & - & 1968 & OP \\
\hline 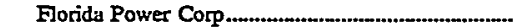 & & $8,244.0$ & $7,183.0$ & $\mathbf{7 , 7 9 7 . 0}$ & & & & & \\
\hline Anclote (Pasco) & J & 556.2 & 503.0 & $5 \mathrm{j} 7.0$ & ST & FO6 & - & 1974 & OP \\
\hline & 2 & 556.2 & 503.0 & 517.0 & ST & FO6 & - & 1978 & OP \\
\hline 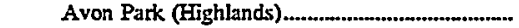 & P] & 33.8 & 29.0 & 32.0 & JE & FO2 & Nat Gas & 1968 & OP \\
\hline & P2 & 33.8 & 29.0 & 32.0 & $\sqrt{E}$ & FO2 & - & 1968 & OP \\
\hline Bayboro (Pinellas) & P] & 56.7 & 47.0 & 58.0 & $\mathrm{JE}$ & FO2 & - & 1973 & OP \\
\hline & 22 & 56.7 & 47.0 & 58.0 & $\mathrm{JE}$ & FO2 & - & 1973 & OP \\
\hline & 23 & 56.7 & 47.0 & 58.0 & $\mathrm{JE}$ & FO2 & - & 1973 & OP \\
\hline & P4 & 56.7 & 47.0 & 58.0 & $\mathrm{JE}$ & $\mathrm{FO} 2$ & - & 1973 & OP \\
\hline Crystal River (Citnus) & ST4 & 739.3 & 697.0 & 737.0 & ST & BIT & - & 1982 & $O P$ \\
\hline & & 440.6 & 369.0 & 373.0 & ST & BIT & - & 1966 & OP \\
\hline & 2 & 523.8 & 464.0 & 469.0 & ST & BIT & - & 1969 & OP \\
\hline & $* 3$ & 890.5 & 812.0 & 835.0 & $\underset{\sim T}{N P}$ & Uranium & - & 1977 & OP \\
\hline & 5 & 739.3 & 697.0 & 717.0 & ST & BIT & - & 1984 & $O P$ \\
\hline Debary (Volusia) & $\mathrm{Pl}$ & 66.9 & 54.0 & 65.0 & GT & FO2 & - & 1976 & OP \\
\hline & 2 & 66.9 & 54.0 & 65.0 & GT & $\mathrm{FO} 2$ & - & 1976 & OP \\
\hline & 3 & 66.9 & 54.0 & 65.0 & GT & FO2 & - & 1975 & OP \\
\hline & 4 & 66.9 & 54.0 & 65.0 & $\mathrm{GT}$ & $\mathrm{FO} 2$ & - & 1976 & OP \\
\hline & $s$ & 66.9 & 54.0 & 65.0 & GI & $\mathrm{FO} 2$ & - & 1975 & OP \\
\hline & 6 & 66.9 & 54.0 & 65.0 & $\mathrm{GT}$ & $\mathrm{FO} 2$ & - & $j 976$ & OP \\
\hline & 7 & $1] 5.0$ & 83.0 & 99.0 & $\mathrm{GT}$ & $\mathrm{FO} 2$ & Nat Gas & 1992 & OP \\
\hline & 8 & 115.0 & 83.0 & 99.0 & $G T$ & FO2 & - & 1992 & OP \\
\hline
\end{tabular}

See footnotes at end of table. 
Table 20. Existing Generating Units at U.S. Electric Utilities by State, Company, and Plant, as of January 1, 1998 (Continued)

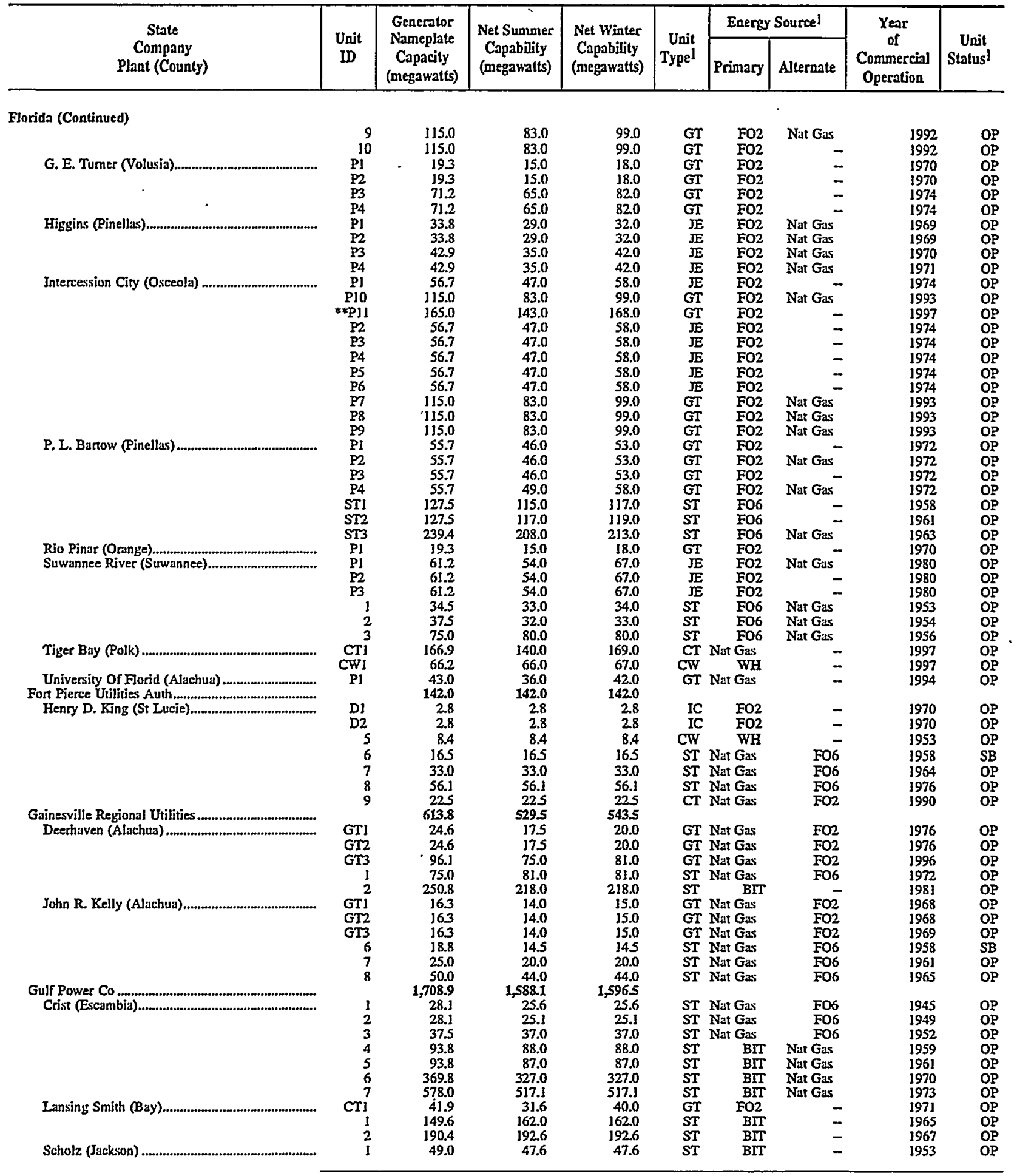

See footnotes at end of tuble. 
Table 20. Existing Generating Units at U.S. Electric Utilities by State, Company, and Plant, as of January 1, 1998 (Continued)

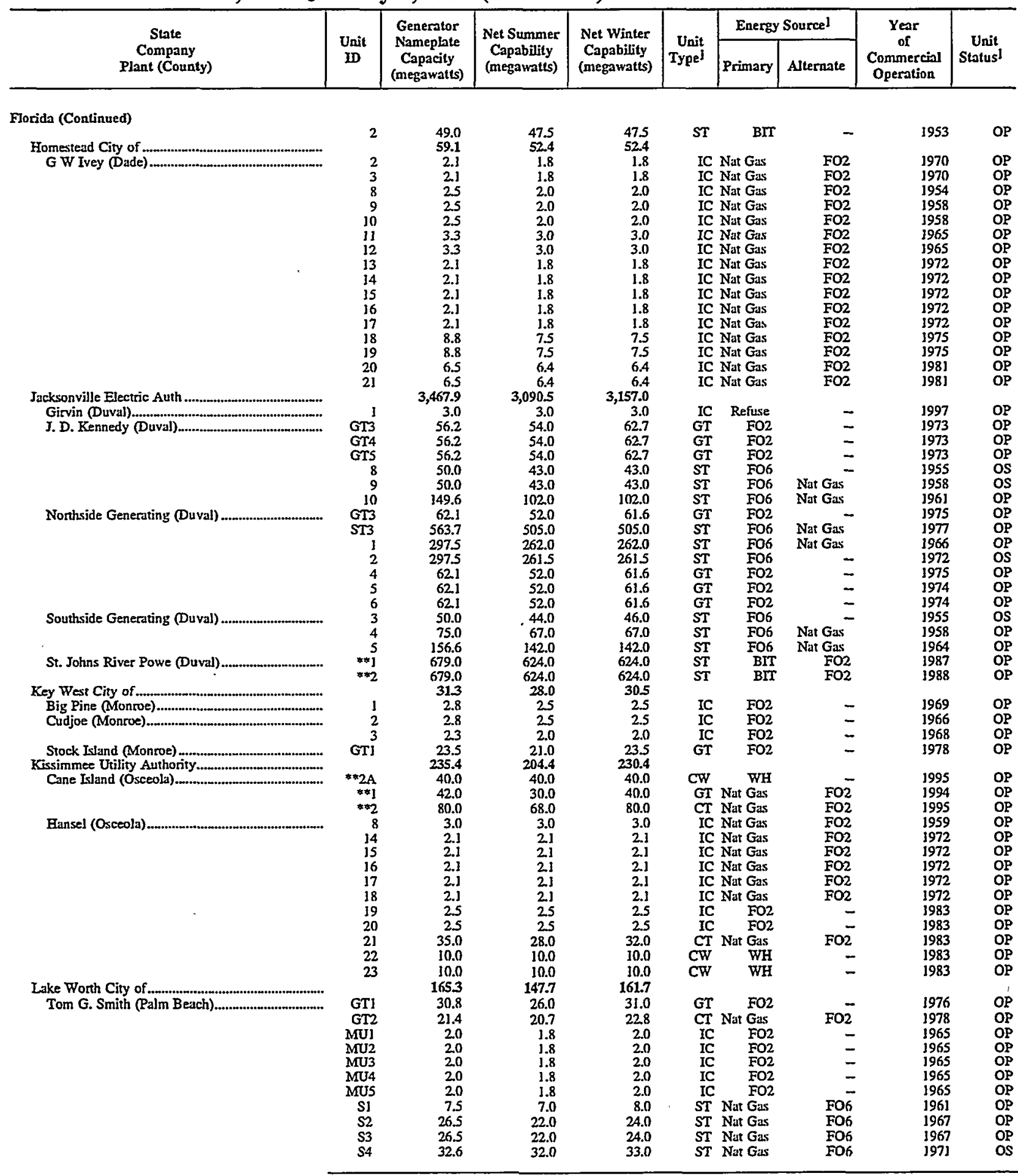

See footnotes at end of table. 
Table 20. Existing Generating Units at U.S. Electric Utilities by State, Company, and Plant, as of January 1, 1998 (Continued)

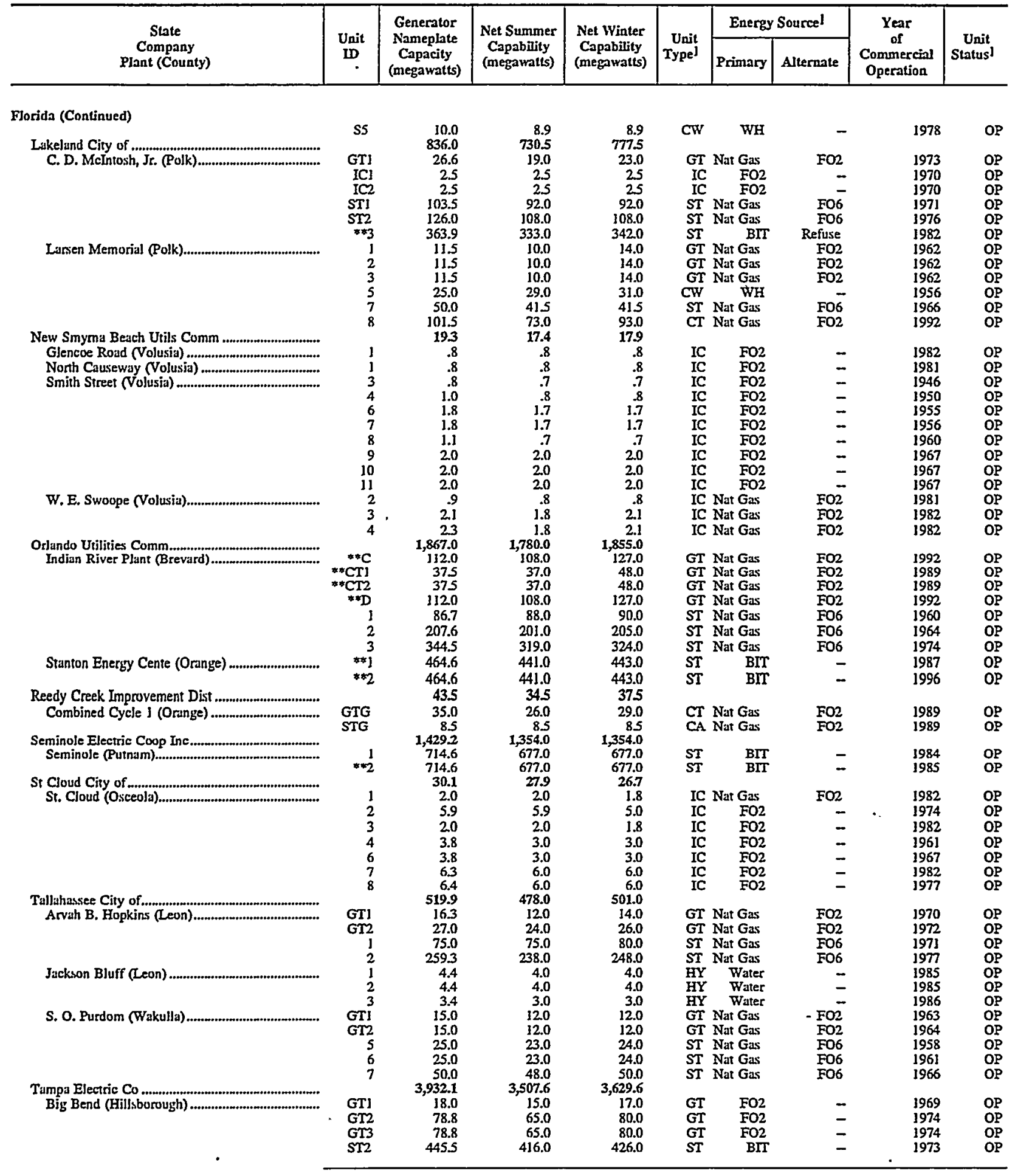

See footnotes at end of table. 
Table 20. Existing Generating Units at U.S. Electric Utilities by State, Company, and Plant, as of January 1, 1998 (Continued)

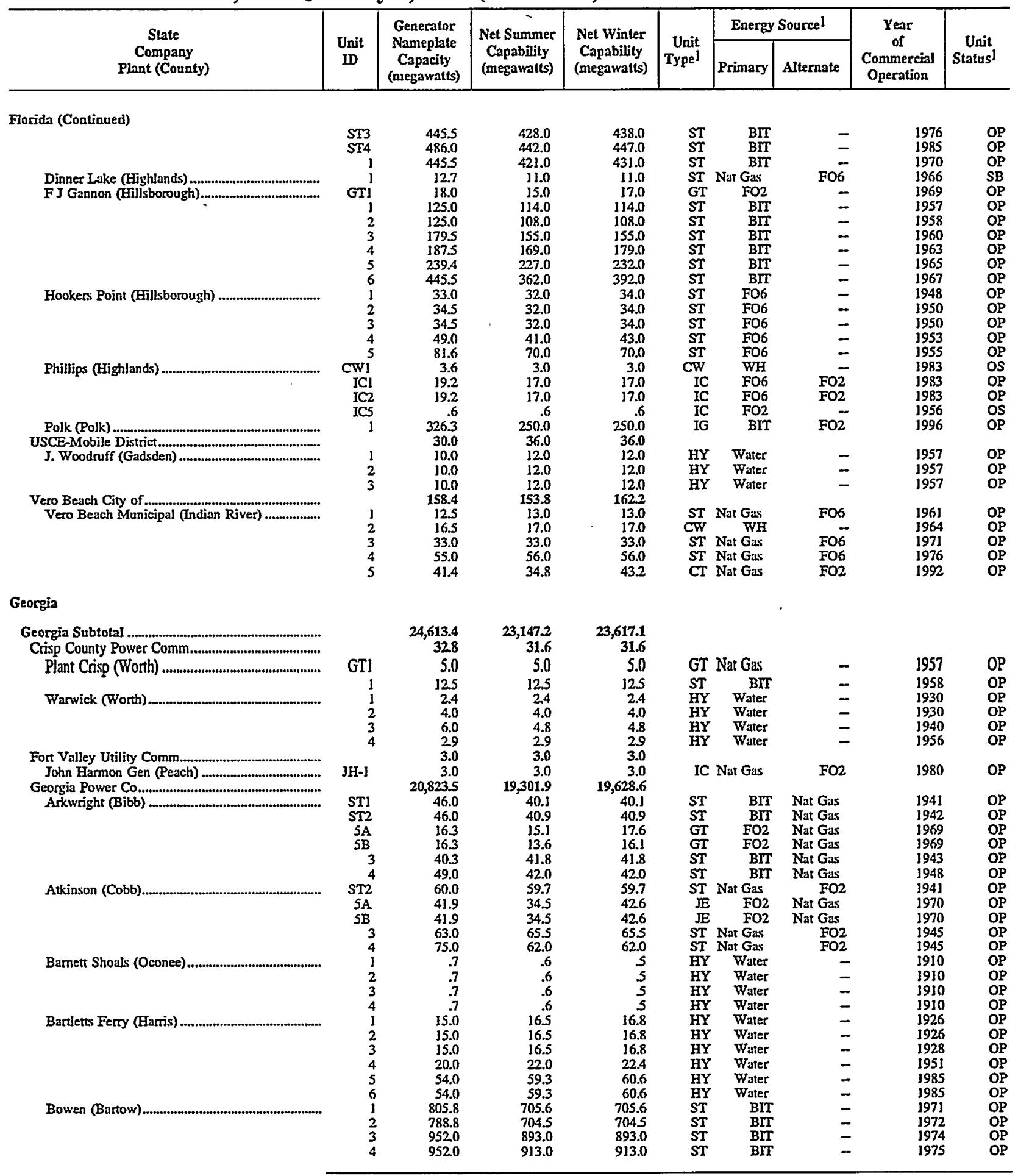

See footnotes at end of table. 
Table 20. Existing Generating Units at U.S. Electric Utilities by State, Company, and Plant, as of January 1, 1998 (Continued)

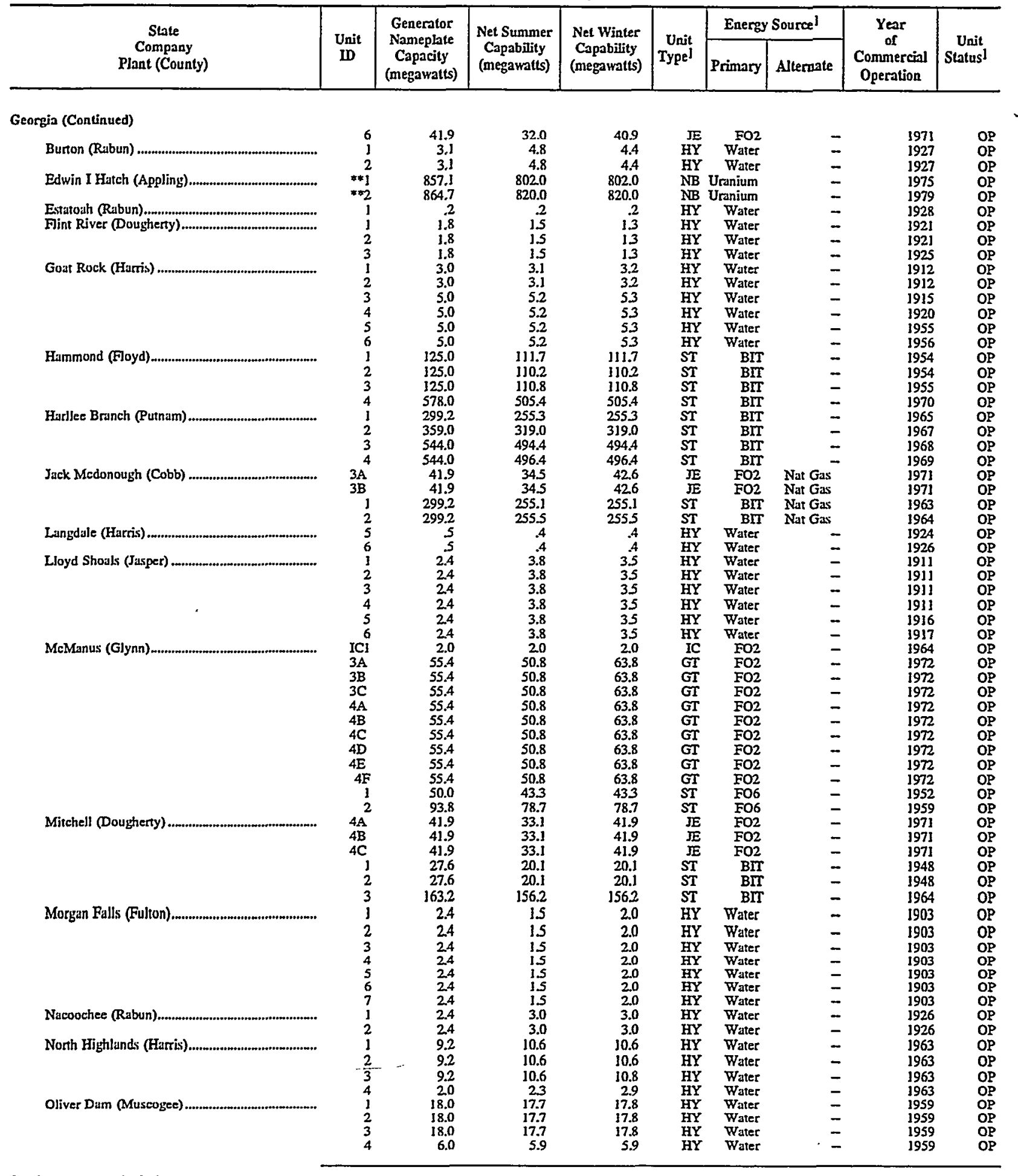

See footnotes at end of table. 
Table 20. Existing Generating Units at U.S. Electric Utilities by State, Company, and Plant, as of January 1, 1998 (Continued)

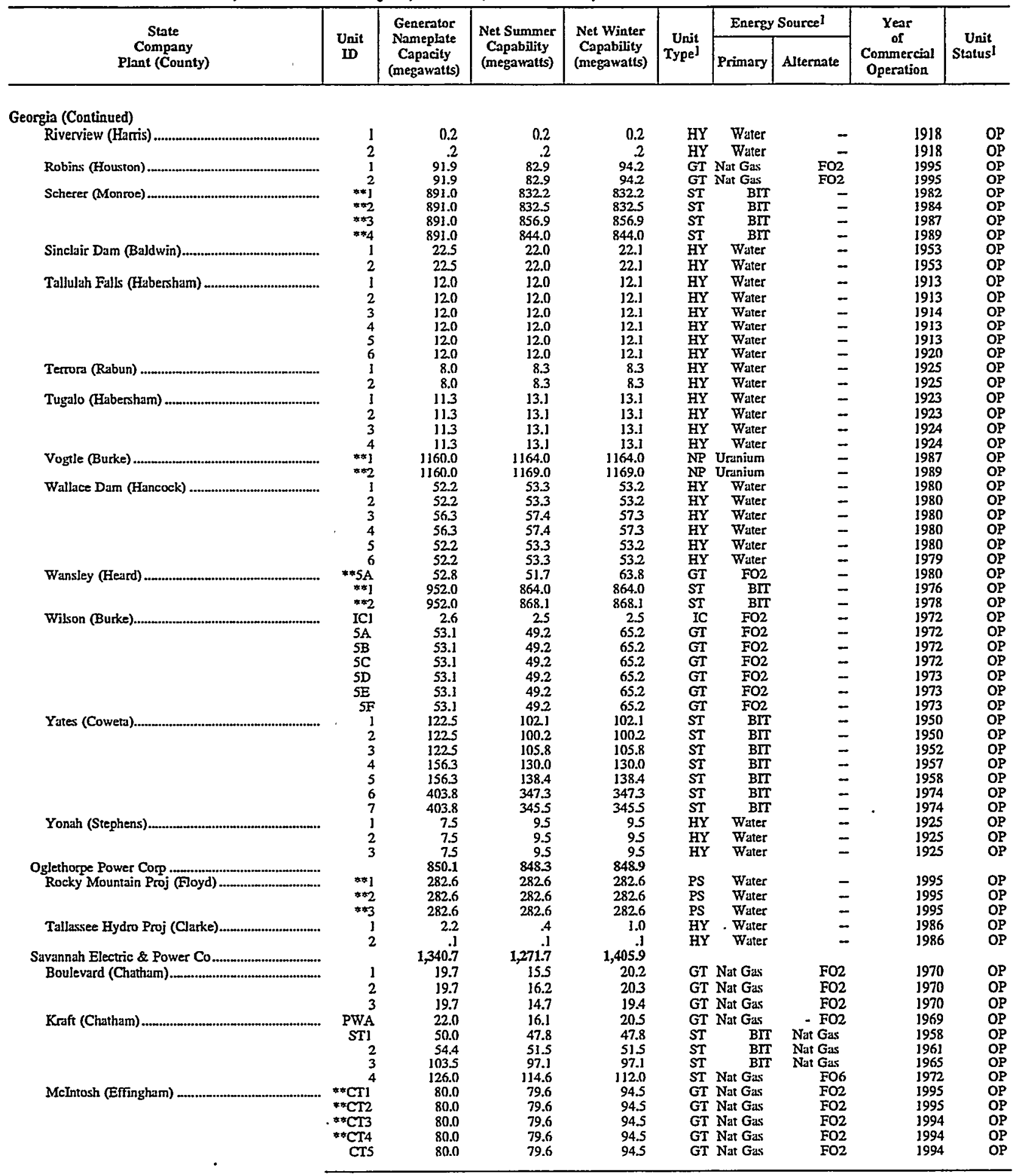

See footnotes at end of table. 
Table 20. Existing Generating Units at U.S. Electric Utilities by State, Company, and Plant, as of January 1, 1998 (Continued)

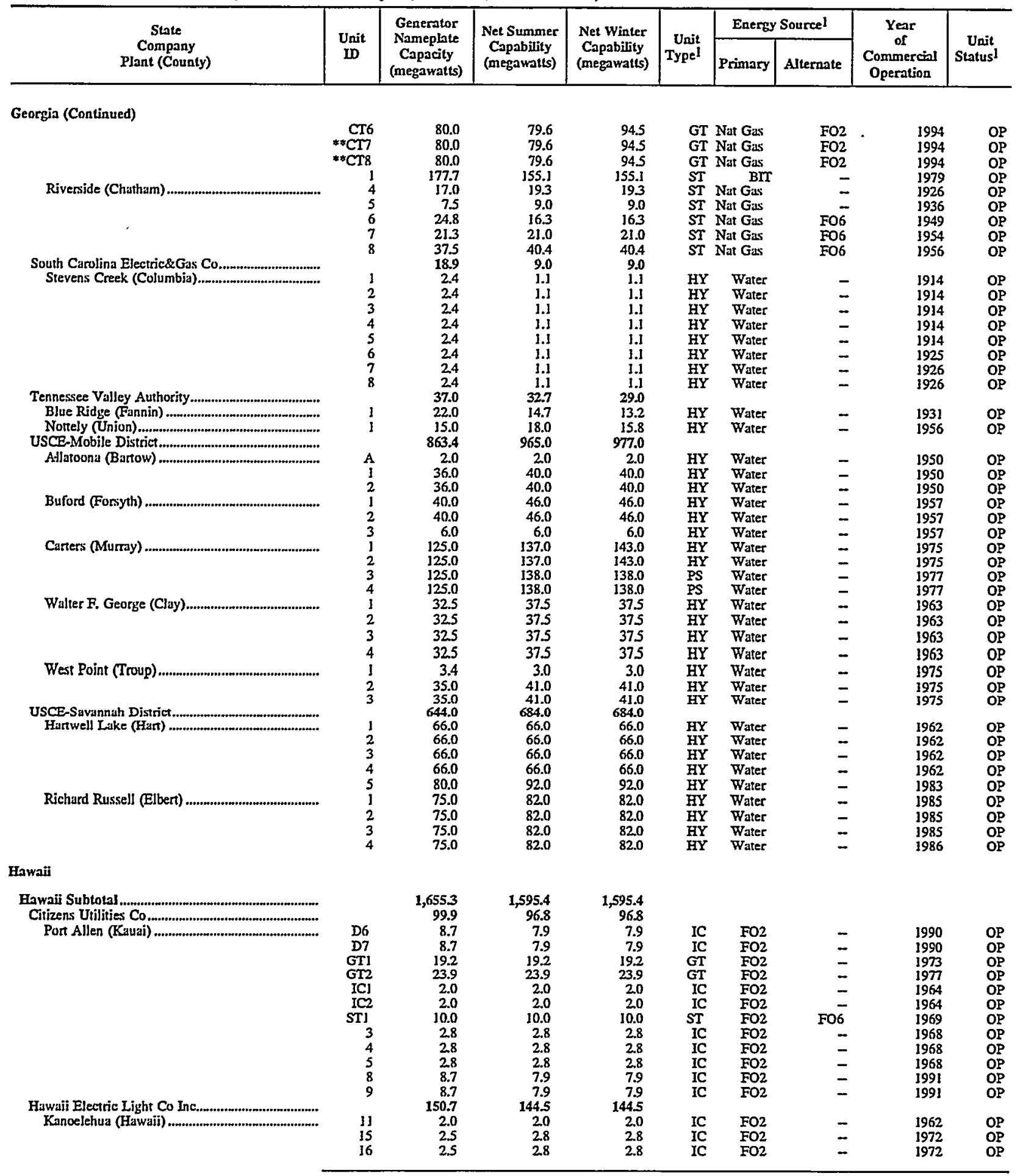

See foonutes at end of table. 
Table 20. Existing Generating Units at U.S. Electric Utilities by State, Company, and Plant, as of January 1, 1998 (Continued)

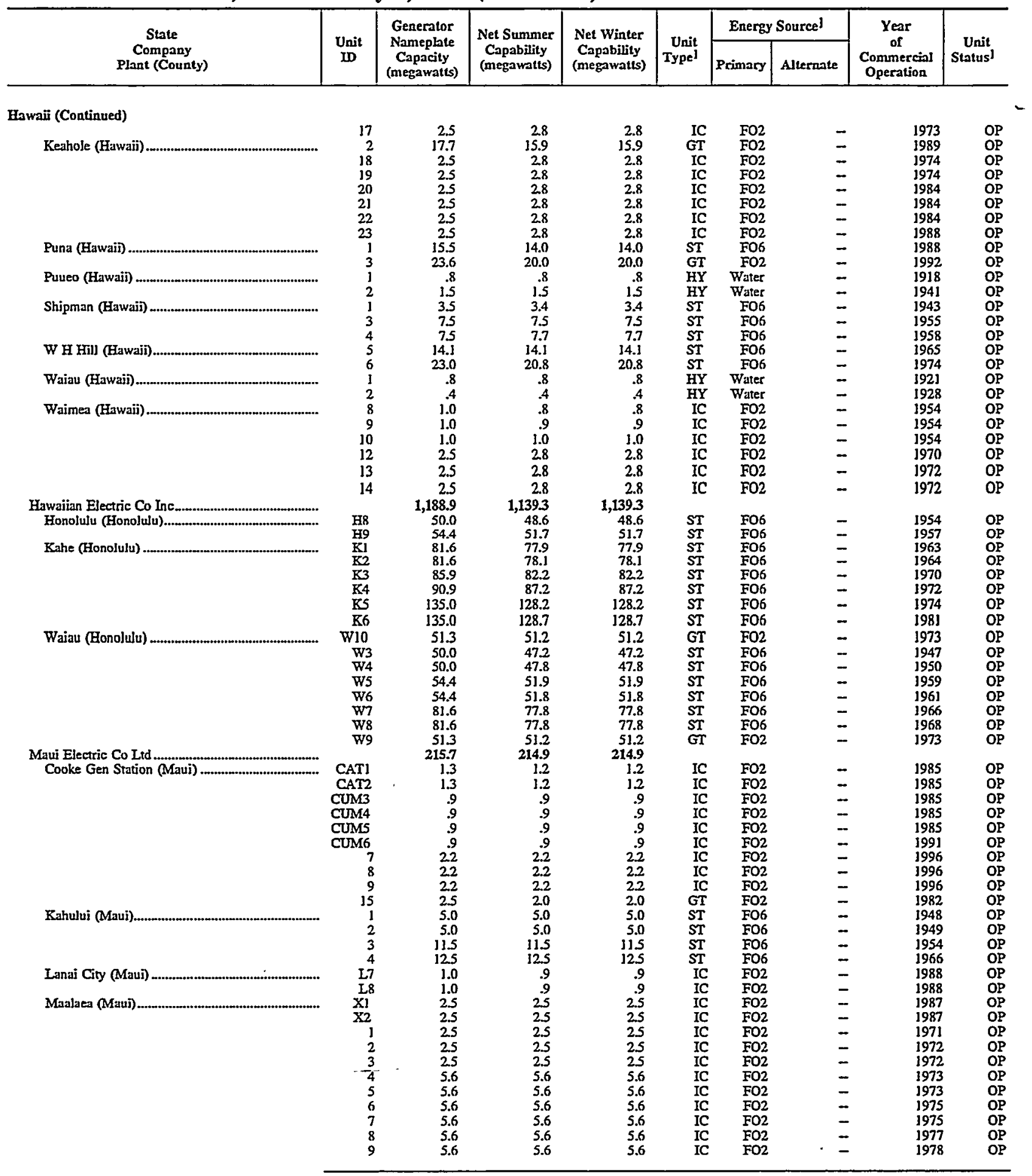

See footnotes at end of table. 
Table 20. Existing Generating Units at U.S. Electric Utilities. by State, Company, and Plant, as of January 1, 1998 (Continued)

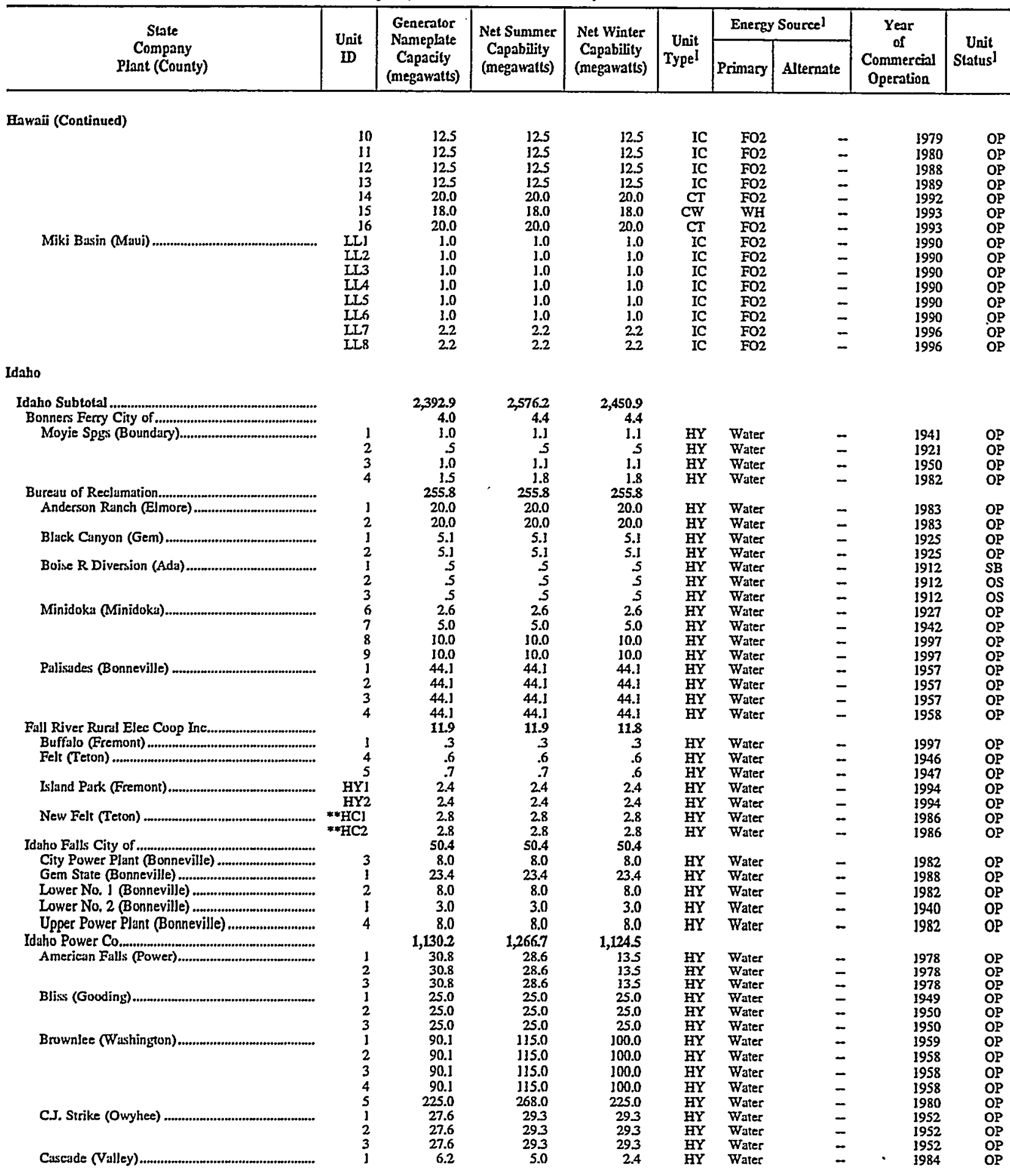

See footnotes at end of table. 
Table 20. Existing Generating Units at U.S. Electric Utilities by State, Company, and Plant, as of January 1, 1998 (Continued)

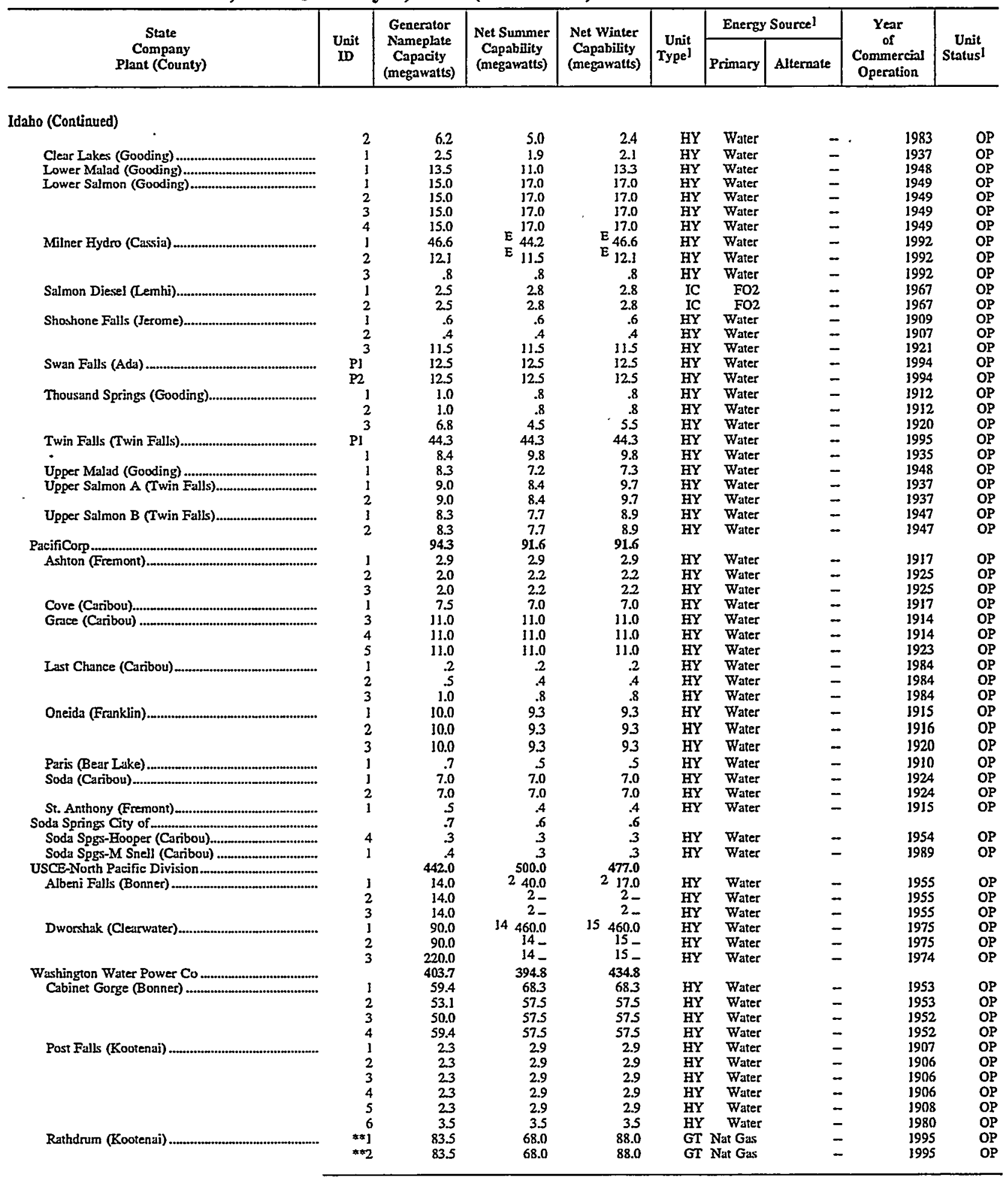

See footnotes at end of table. 
Table 20. Existing Generating Units at U.S. Electric Utilities by State, Company, and Plant, as of January 1, 1998 (Continued)

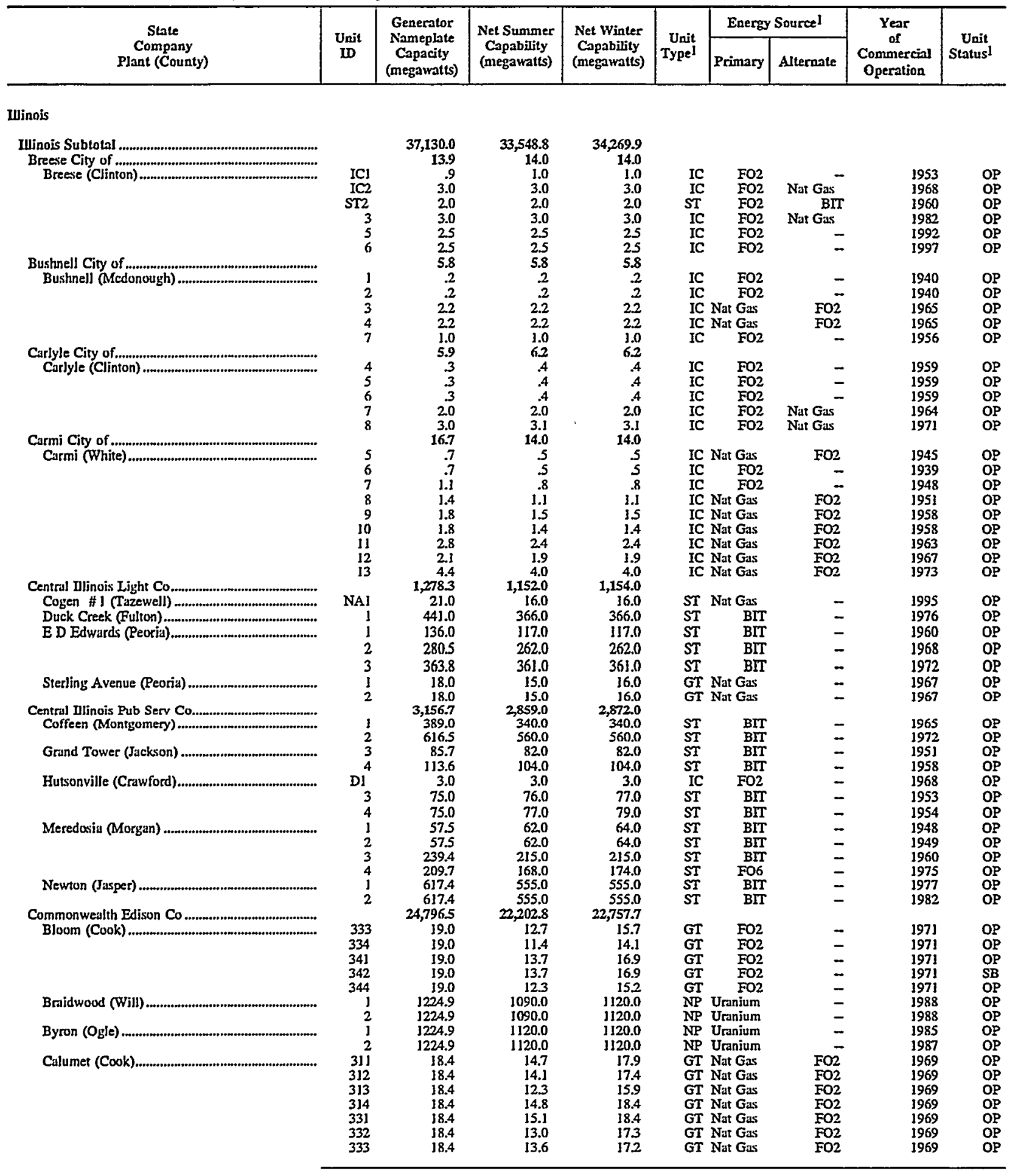

See fooknotes at end of table. 
Table 20. Existing Generating Units at U.S. Electric Utilities by State, Company, and Plant, as of January 1, 1998 (Continued)

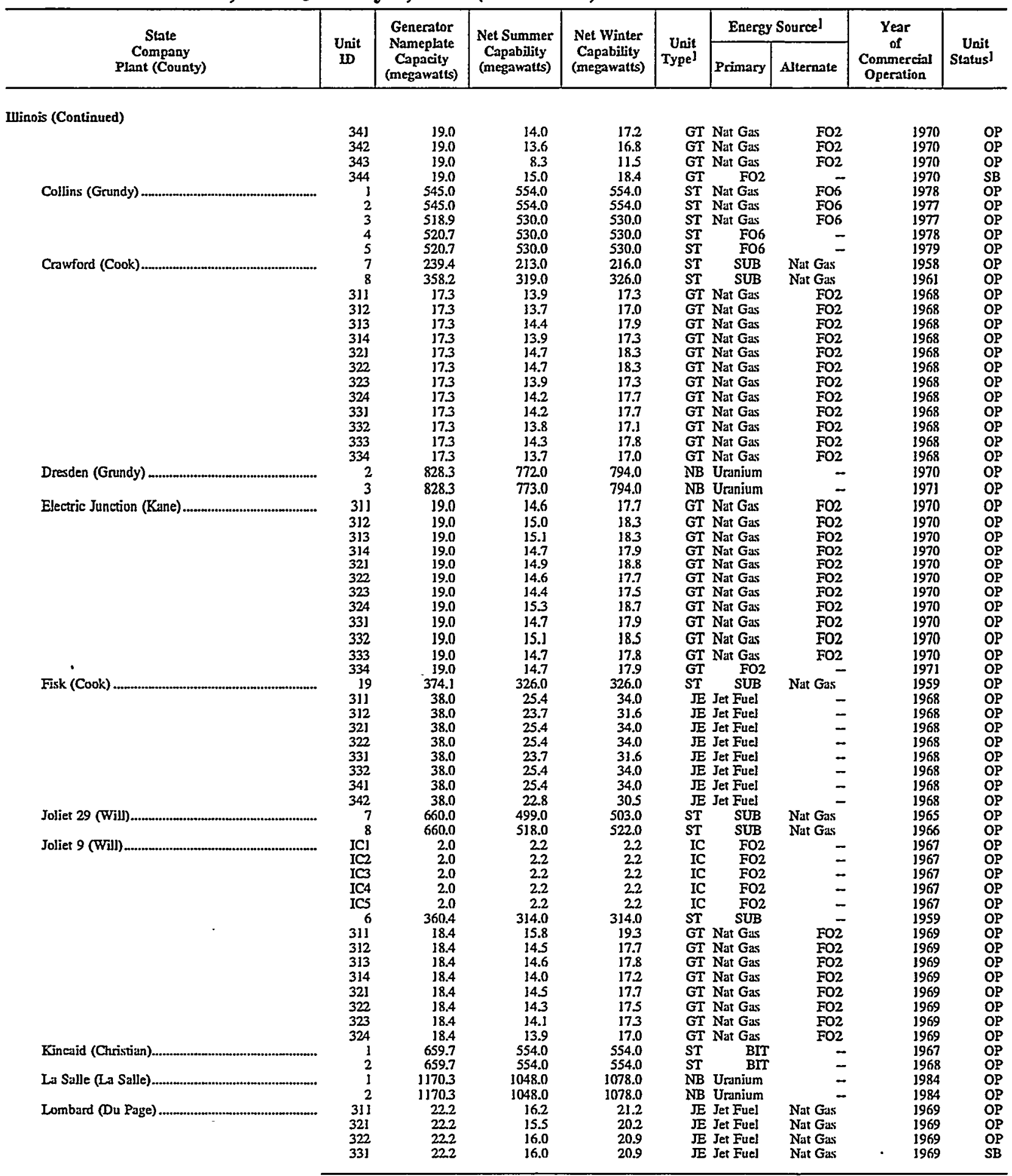

See foornoies at end of table. 
Table 20. Existing Generating Units at U.S. Electric Utilities by State, Company, and Plant, as of January 1, 1998 (Continued)

\begin{tabular}{|c|c|c|c|c|c|c|c|c|c|}
\hline \multirow{2}{*}{$\begin{array}{c}\text { State } \\
\text { Company } \\
\text { Plant (County) }\end{array}$} & \multirow{2}{*}{$\begin{array}{l}\text { Unit } \\
\text { ID }\end{array}$} & \multirow{2}{*}{$\begin{array}{l}\text { Generator } \\
\text { Namephate } \\
\text { Capacity } \\
\text { (megawatts) }\end{array}$} & \multirow{2}{*}{$\begin{array}{l}\text { Net Summer } \\
\text { Capability } \\
\text { (megawatts) }\end{array}$} & \multirow{2}{*}{$\begin{array}{l}\text { Net Winter } \\
\text { Capability } \\
\text { (megawatts) }\end{array}$} & \multirow{2}{*}{$\begin{array}{r}\text { Unit } \\
\text { Type }\end{array}$} & \multicolumn{2}{|c|}{ Energy Sourcel } & \multirow{2}{*}{$\begin{array}{c}\text { Year } \\
\text { of } \\
\text { Commercial } \\
\text { Operation }\end{array}$} & \multirow{2}{*}{$\begin{array}{c}\text { Unit } \\
\text { Statusl }\end{array}$} \\
\hline & & & & & & Primary & Alternate & & \\
\hline \multicolumn{10}{|l|}{ Ulinois (Continued) } \\
\hline Powerton (Tazewell) & $\begin{array}{l}5 \\
6\end{array}$ & $\begin{array}{l}892.8 \\
892.8\end{array}$ & $\begin{array}{l}769.0 \\
769.0\end{array}$ & $\begin{array}{l}769.0 \\
769.0\end{array}$ & $\begin{array}{l}\text { ST } \\
\text { ST }\end{array}$ & SUBB & - & 1972 & OP \\
\hline 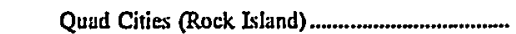 & $*{ }_{1}$ & 828.3 & 769.0 & 789.0 & NB & Uranium & - & 1972 & OP \\
\hline & $=2$ & 828.3 & 769.0 & 789.0 & $\mathbf{N B}$ & Uranium & - & 1972 & OP \\
\hline 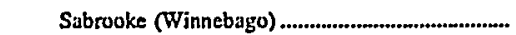 & 311 & 18.4 & 128 & 16.1 & GT & $\mathrm{FO} 2$ & - & 1969 & OP \\
\hline & 312 & 18.4 & 12.4 & 15.6 & GT & FO2 & _ & 1969 & $\mathrm{OP}$ \\
\hline & 32] & 18.4 & 11.4 & 15.2 & GT & $\mathrm{FO} 2$ & - & 1969 & OP \\
\hline & 322 & 18.4 & 13.5 & 16.9 & GT & $\mathrm{FO} 2$ & - & 1969 & $O P$ \\
\hline & 33] & 19.0 & 11.0 & 13.8 & GT & FO2 & - & 1970 & OP \\
\hline & 332 & 19.0 & 12.8 & 16.1 & GT & $\mathrm{FO} 2$ & - & 1970 & $O P$ \\
\hline & 34] & 19.0 & 12.5 & 14.0 & GT & $\mathrm{FO} 2$ & - & 1970 & $O P$ \\
\hline 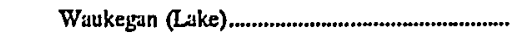 & 6 & 121.0 & 100.0 & 100.0 & ST & SUB & - & 1952 & OP \\
\hline & 7 & 326.4 & 328.0 & 328.0 & $S T$ & SUB & - & 1958 & OP \\
\hline & 8 & 355.3 & 361.0 & 361.0 & ST & SUB & Nat Gas & 1962 & OP \\
\hline & 31] & 38.0 & 24.6 & 33.9 & $\mathrm{JE}$ & Jet Fuel & - & 1968 & OP \\
\hline & 312 & 38.0 & 28.5 & 37.4 & $\mathrm{JE}$ & Jet Fuel & - & 1968 & $O P$ \\
\hline & 32] & 38.0 & 28.5 & 37.4 & $\mathrm{JE}$ & Jet Fuel & - & 1968 & $O P$ \\
\hline & 322 & 38.0 & 26.7 & 35.0 & $\sqrt{E}$ & Jet Fuel & - & 1968 & OP \\
\hline Will County (Will)...... & 1 & 187.5 & 151.0 & 156.0 & ST & SUB & - & 1955 & OP \\
\hline & $\frac{2}{2}$ & 183.8 & 148.0 & 154.0 & ST & SUB & - & 1955 & OP \\
\hline & 3 & 299.2 & 251.0 & 262.0 & ST & SUB & - & 1957 & OP \\
\hline & 4 & 598.4 & 510.0 & 520.0 & ST & SUB & - & 1963 & OP \\
\hline 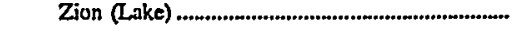 & 1 & 1098.0 & 1040.0 & 1040.0 & NP & Uranium & - & 1973 & OP \\
\hline 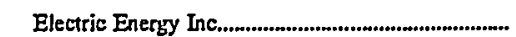 & & $\begin{array}{l}1098.0 \\
1,1003\end{array}$ & $\begin{array}{l}104014.0 \\
1,014\end{array}$ & $\begin{array}{l}1040.0 \\
1,014.0\end{array}$ & $\mathrm{NP}$ & Uranium & - & 1974 & OP \\
\hline Joppa Steam (Massac) .............................................. & $* * 1$ & 183.4 & 169.0 & 169.0 & ST & BIT & Nat Gas & 1953 & OP \\
\hline & $* 2$ & 183.4 & 169.0 & 369.0 & ST & BIT & - & 1953 & OP \\
\hline & $* * 3$ & 183.4 & 169.0 & 169.0 & ST & BIT & - & 1954 & OP \\
\hline & $* * 4$ & 183.4 & 169.0 & 369.0 & ST & BIT & Nat Gas & 1954 & OP \\
\hline & $=5$ & 183.4 & 169.0 & 369.0 & $\mathbf{S T}$ & BIT & - & 1955 & $O P$ \\
\hline & $* \% 6$ & 183.4 & 169.0 & 169.0 & ST & BIT & - & 1955 & OP \\
\hline 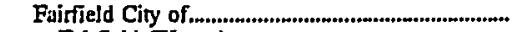 & & 7.5 & 7.5 & 7.5 & & & & & \\
\hline 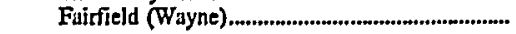 & ICS & 2.4 & 24 & 2.4 & IC & Nat Gas & $\mathrm{FO} 2$ & 1967 & OP \\
\hline & IC6 & 2.4 & 2.4 & 24 & IC & Nat Gas & $\mathrm{FO2}$ & 1967 & $O P$ \\
\hline & IC7 & 2.7 & 2.7 & 27 & IC & FO2 & - & 1979 & OP \\
\hline 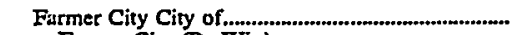 & & 7.0 & 5.7 & 5.7 & & & & & \\
\hline Furmer Ciry (De Wir) & 1 & 1.5 & 1.3 & 13 & IC & Nat Gas & FO2 & 1967 & OP \\
\hline & $\frac{2}{4}$ & 1.1 & .9 & $\begin{array}{l}9 \\
7\end{array}$ & $\begin{array}{l}\text { IC } \\
\text { IC }\end{array}$ & $\begin{array}{l}\text { FO2 } \\
\text { FO2 }\end{array}$ & $=$ & $\begin{array}{l}1963 \\
1951\end{array}$ & $\begin{array}{l}O P \\
O P\end{array}$ \\
\hline & 5 & 3.5 & 2.8 & 2.8 & IC & Nat Gas & $\mathrm{FO} 2$ & 1974 & OP \\
\hline Freeburg Village of & & 7.1 & 7.1 & 7.1 & & & & & \\
\hline 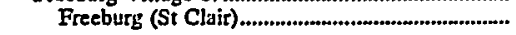 & IC6 & 2.6 & 26 & 2.6 & IC & Nat Gas & FO2 & 1986 & OP \\
\hline & J & .5 & 5 & 5 & IC & Nat Gas & $\mathrm{FO} 2$ & 1948 & $O P$ \\
\hline & 2 & .5 & .5 & .5 & IC & Nat Gas & FO2 & 1948 & OP \\
\hline & 3 & .6 & .6 & .6 & IC & FO2 & - & 1953 & $O P$ \\
\hline & 4 & 1.0 & 1.0 & 1.0 & IC & $\mathrm{FO} 2$ & - & 1959 & $O P$ \\
\hline & 5 & 1.9 & 1.9 & 1.9 & IC & Nat Gas & $\mathrm{FO} 2$ & 1966 & OP \\
\hline Geneseo City of & & 23.0 & 18.8 & 18.8 & & & & & \\
\hline 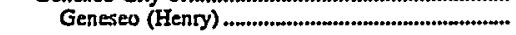 & 1 & 5.6 & 4.5 & 4.5 & IC & Nat Gas & $\mathrm{FO} 2$ & 1974 & OP \\
\hline & 2 & 3.5 & 2.8 & 2.8 & IC & Nat Gas & FO2 & 1967 & OP \\
\hline & 3 & 3.5 & 2.8 & 2.8 & IC & Nat Gas & $\mathrm{FO} 2$ & 1966 & OP \\
\hline & 4 & 20 & 2.0 & 2.0 & Ic & Nat Gas & $\mathrm{FO} 2$ & 1957 & $O P$ \\
\hline & 6 & 1.0 & .8 & .8 & IC & F02 & - & 1947 & OP \\
\hline & 7 & 3.0 & 2.4 & 2.4 & IC & Nat Gas & $\mathrm{FO} 2$ & 196] & OP \\
\hline & 8 & 4.4 & 3.5 & 35 & IC & F02 & Nat Gas & 1990 & OP \\
\hline 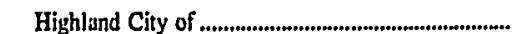 & & 17.7 & 17.6 & 17.6 & & & & & \\
\hline Highland (Madision) ........................................ & IC3 & 4.4 & 4.4 & 4.4 & IC & Nat Gas & & 1971 & $\mathrm{OP}$ \\
\hline & IC4 & 4.4 & 4.4 & 4.4 & IC & Nat Gas & $\mathrm{FO} 2$ & 1971 & $\mathrm{OP}$ \\
\hline & $\begin{array}{l}5 \\
6\end{array}$ & $\frac{21}{2.1}$ & 2.0 & 2.0 & IC & $\begin{array}{l}\text { Nat Gas } \\
\text { Nat Gas }\end{array}$ & $\mathrm{FO2}$ & $\begin{array}{l}1967 \\
1968\end{array}$ & OP \\
\hline & 9 & 1.6 & 1.6 & 1.6 & IC & FO2 & - & 1993 & OP \\
\hline & 10 & 1.6 & 1.6 & 1.6 & IC & $\mathrm{FO} 2$ & - & 1993 & OP \\
\hline & 11 & 1.6 & 1.6 & 1.6 & IC & $\mathrm{FO2}$ & - & 1993 & $O P$ \\
\hline 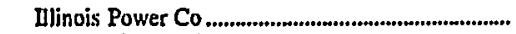 & & $4,919.7$ & 4,5712 & $4,668.2$ & & & & & \\
\hline 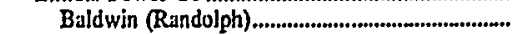 & 1 & 623.1 & 575.0 & 584.0 & ST & BIT & - & 1970 & $\mathrm{OP}$ \\
\hline & 2 & 634.5 & 581.0 & 588.0 & ST & BIT & - & 1973 & OP \\
\hline & & 634.5 & 595.0 & 602.0 & ST & BIT & - & 1975 & OP \\
\hline Clinton (De Witt) & $* 1$ & 984.9 & 930.0 & 944.0 & NB & Uranium & - & 1987 & OP \\
\hline Havana (Mason) & 1 & 46.0 & 47.6 & 48.4 & ST & FO6 & - & 1947 & SB \\
\hline & 2 & 46.0 & 47.6 & 48.4 & ST & FO6 & - & 1947 & SB \\
\hline
\end{tabular}

Sec footnotes at end of table. 
Table 20. Existing Generating Units at U.S. Electric Utilities by State, Company, and Plant, as of January 1, 1998 (Continued)

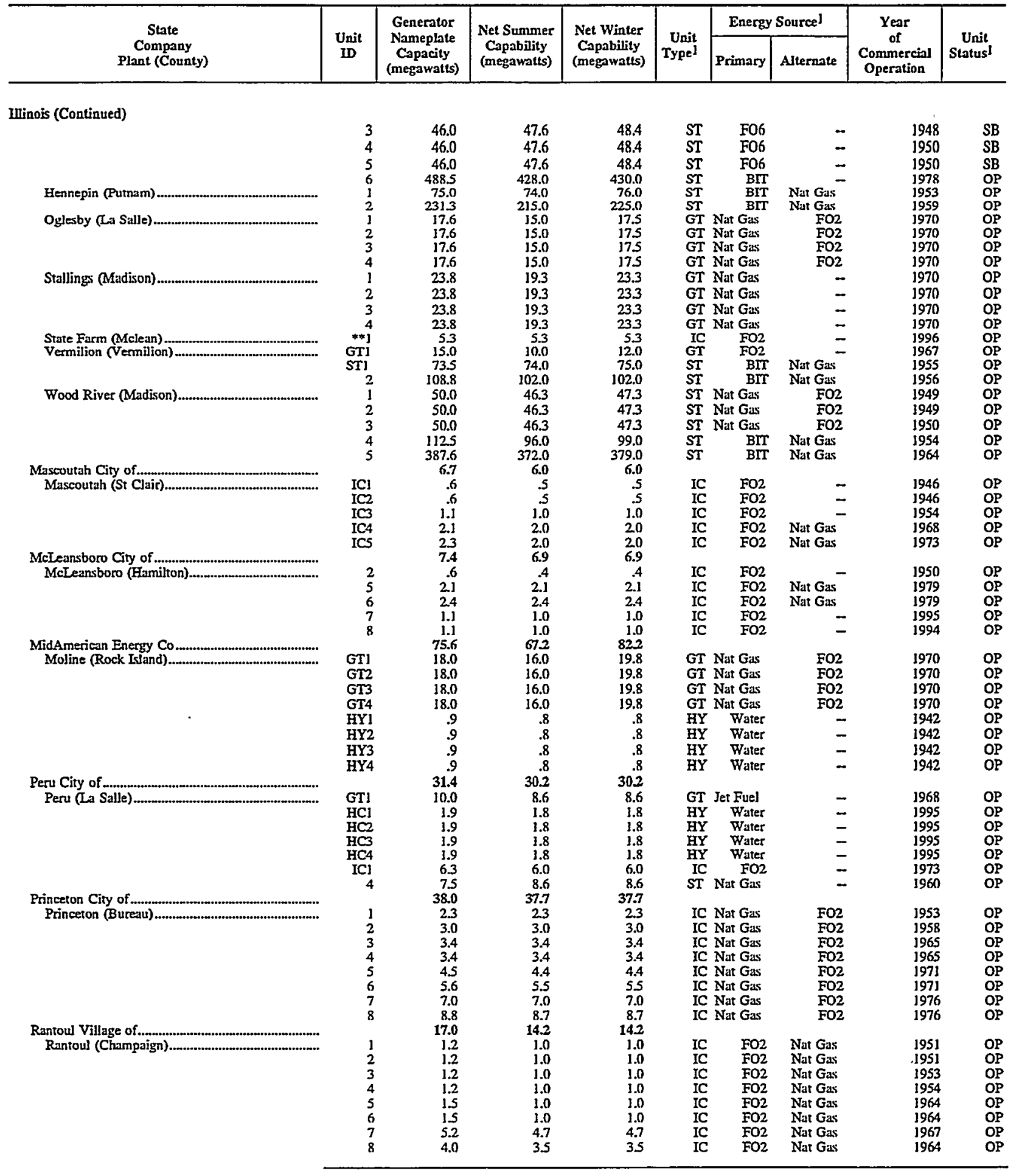

See footnotes at end of table. 
Table 20. Existing Generating Units at U.S. Electric Utilities by State, Company, and Plant, as of January 1, 1998 (Continued)

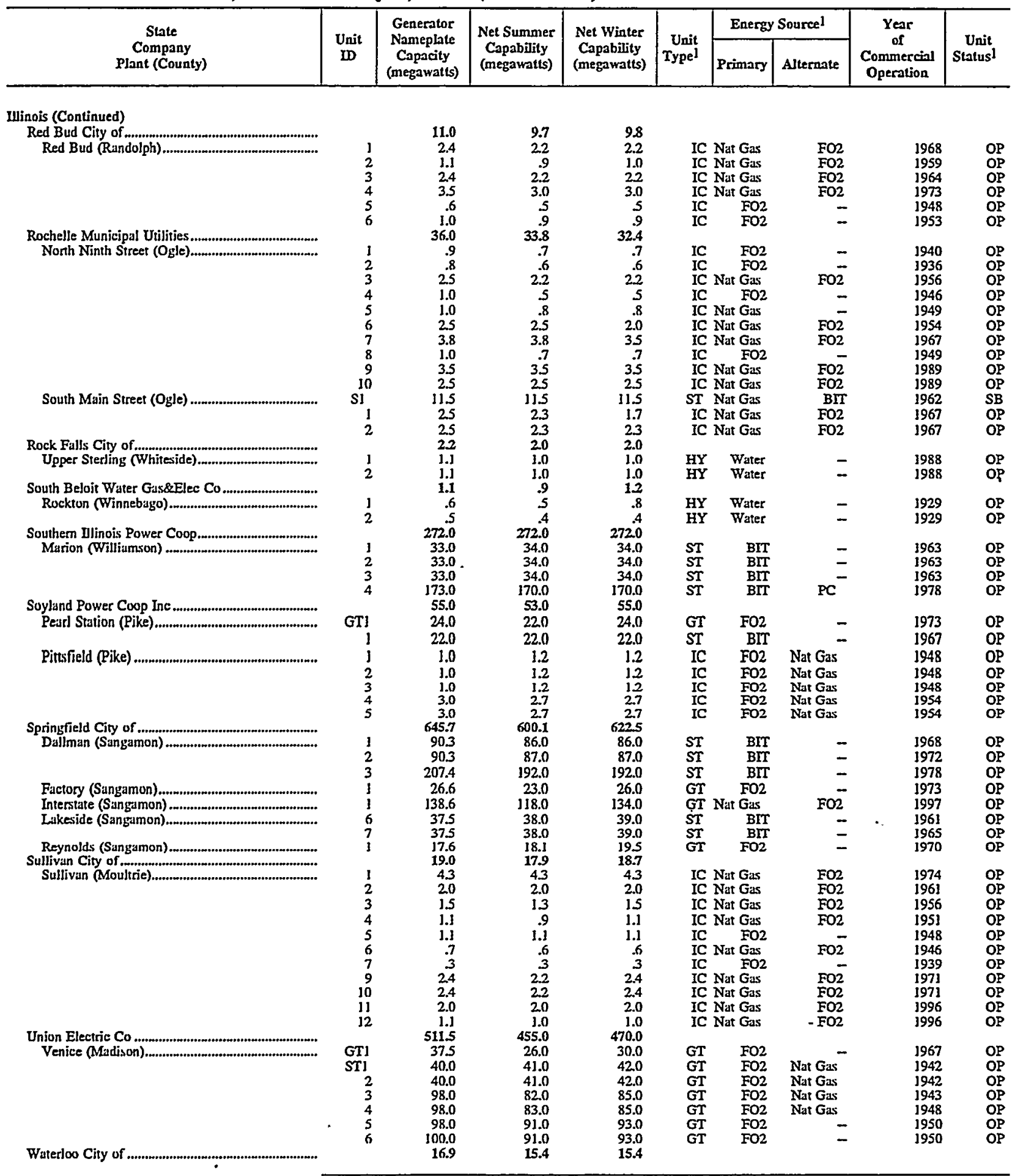

Sec footnotes at end of table. 
Table 20. Existing Generating Units at U.S. Electric Utilities by State, Company, and Plant, as of January 1, 1998 (Continued)

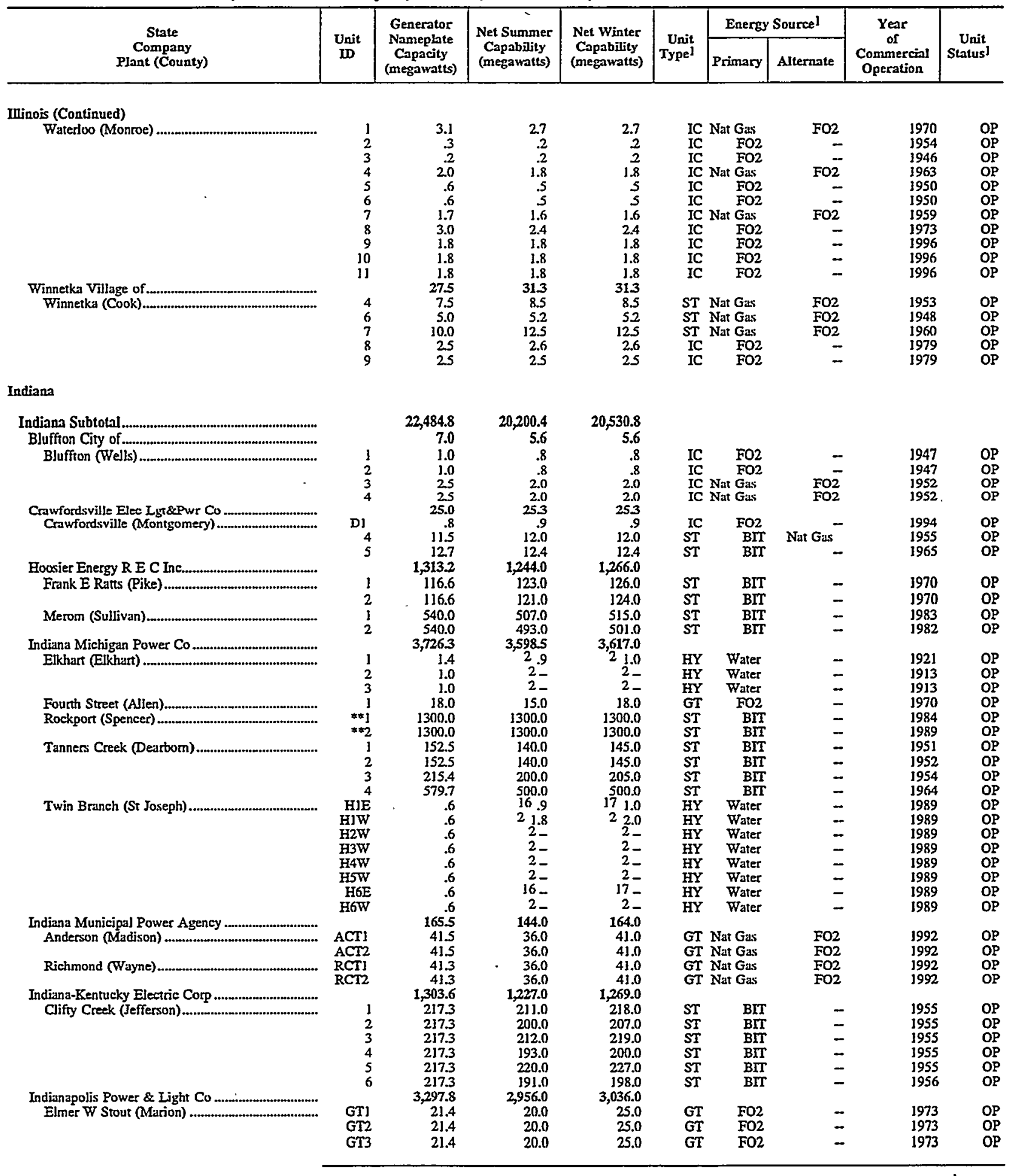

See foornotes at end of table. 
Table 20. Existing Generating Units at U.S. Electric Utilities by State, Company, and Plant, as of January 1, 1998 (Continued)

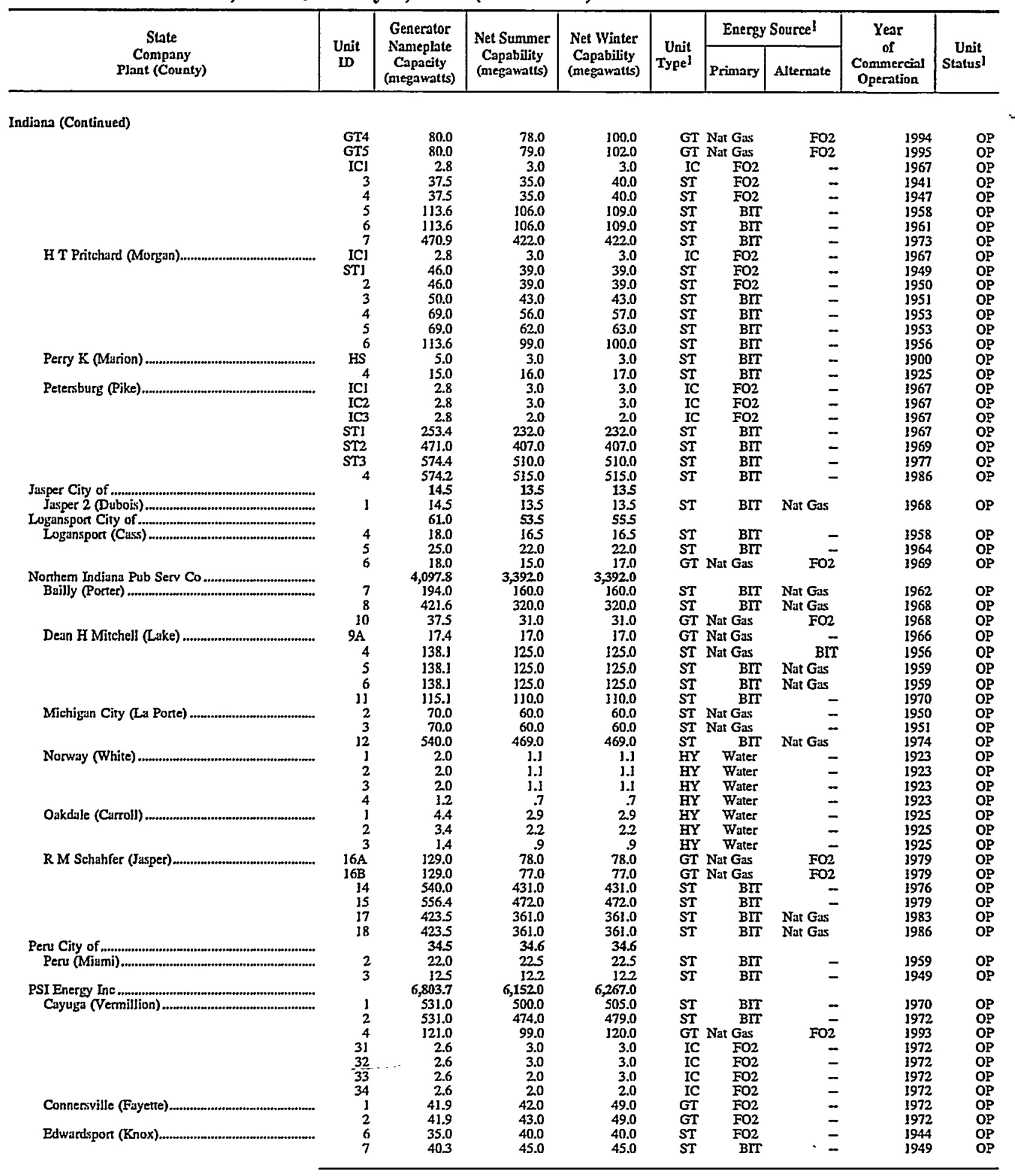

Sec footnotes at end of table. 
Table 20. Existing Generating Units at U.S. Electric Utilities by State, Company, and Plant, as of January 1, 1998 (Continued)

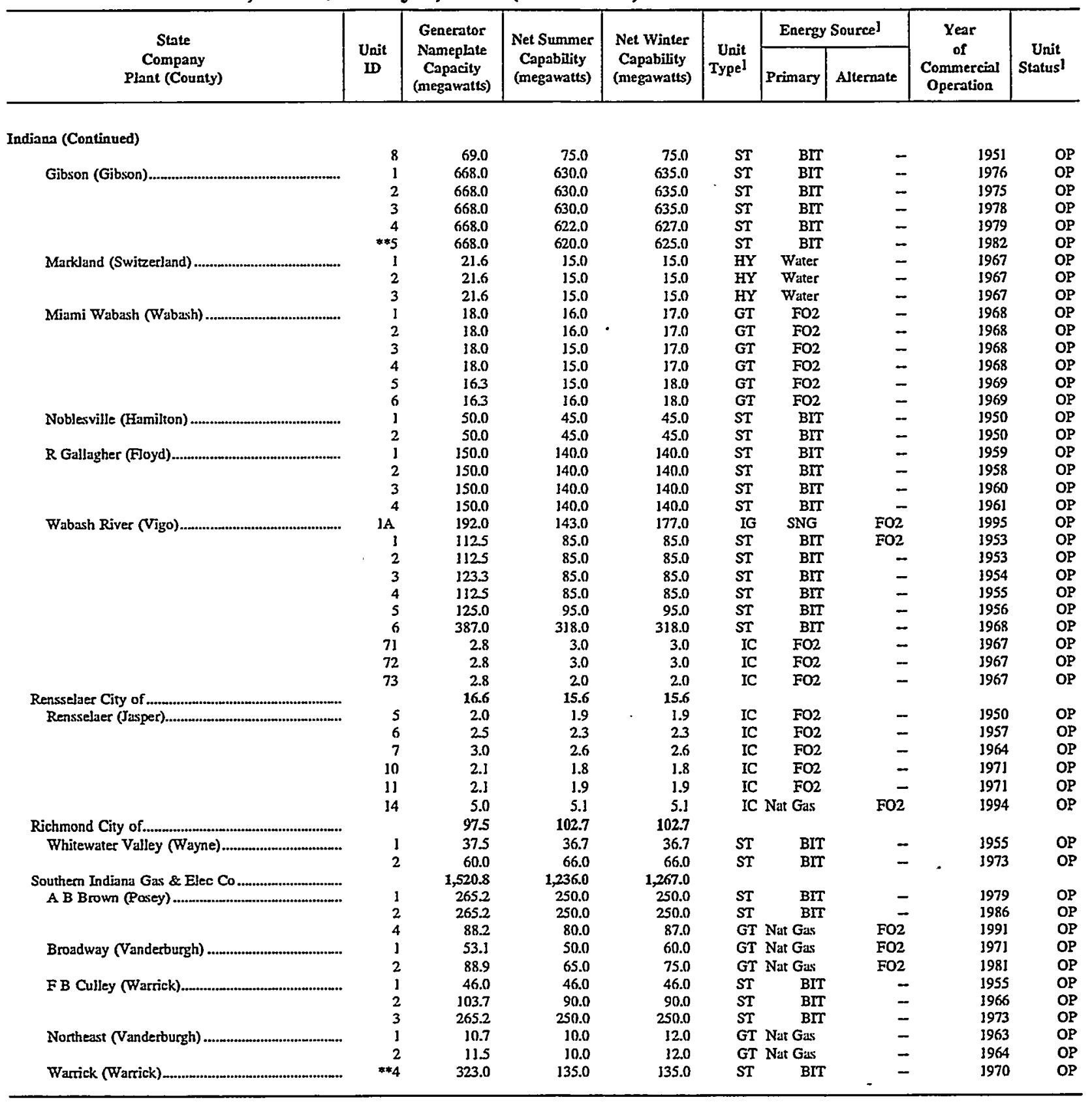

See foomotes at end of table. 
Table 20. Existing Generating Units at U.S. Electric Utilities by State, Company, and Plant, as of January 1, 1998 (Continued)

\begin{tabular}{|c|c|c|c|c|c|c|c|c|c|}
\hline \multirow{2}{*}{$\begin{array}{c}\text { State } \\
\text { Company } \\
\text { Plant (County) }\end{array}$} & \multirow{2}{*}{$\begin{array}{l}\text { Unit } \\
\text { W }\end{array}$} & \multirow{2}{*}{$\begin{array}{c}\text { Generator } \\
\text { Nameplate } \\
\text { Capacity } \\
\text { (megawatts) }\end{array}$} & \multirow{2}{*}{$\begin{array}{c}\text { Net Summer } \\
\text { Capability } \\
\text { (megawatts) }\end{array}$} & \multirow{2}{*}{$\begin{array}{l}\text { Net Winter } \\
\text { Capability } \\
\text { (megawatls) }\end{array}$} & \multirow{2}{*}{$\begin{array}{r}\text { Unit } \\
\text { Type1 }\end{array}$} & \multicolumn{2}{|c|}{ Energy Sourcel } & \multirow{2}{*}{$\begin{array}{c}\begin{array}{c}\text { Year } \\
\text { of } \\
\text { Commercinl } \\
\text { Operation }\end{array} \\
\end{array}$} & \multirow{2}{*}{$\begin{array}{c}\text { Unit } \\
\text { Status } 1\end{array}$} \\
\hline & & & & & & Primary & Alternate & & \\
\hline \multicolumn{10}{|l|}{ Iowa } \\
\hline 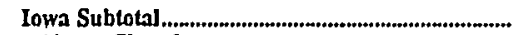 & & $8,867.1$ & $8,237.7$ & $8,429.1$ & & & & * & \\
\hline Algona City of & & 19.3 & 18.6 & 18.6 & & & & & \\
\hline & 3 & .7 & .6 & .6 & IC & $\mathrm{FO} 2$ & Nat Gas & 1938 & OP \\
\hline & 4 & 1.0 & .8 & .8 & IC & $\mathrm{FO2}$ & Nat Gas & 1941 & OP \\
\hline & 5 & 1.5 & 1.1 & I.I & IC & FO2 & Nat Gas & 1947 & OP \\
\hline & 6 & 3.2 & 3.2 & 3.2 & IC & $\mathrm{FO2}$ & Nat Gas & 1965 & OP \\
\hline & 7 & 4.1 & 4.1 & 4.1 & IC & $\mathrm{FO} 2$ & Nat Gas & 1970 & OP \\
\hline & & $\begin{array}{l}4.4 \\
4.4\end{array}$ & $\begin{array}{l}4.4 \\
4.4\end{array}$ & $\begin{array}{l}4.4 \\
4.4\end{array}$ & IC & $\mathrm{FO} 2$ & Nat Gas & 1994 & OP \\
\hline Alta City of & & 22 & $\begin{array}{l}4.4 \\
2.0\end{array}$ & 2.1 & IC & FO2 & Nat Gas & 1994 & op \\
\hline 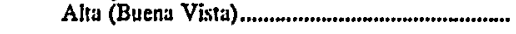 & 1 & 1.0 & 1.0 & 1.0 & IC & $\mathrm{FO} 2$ & - & 1947 & OP \\
\hline 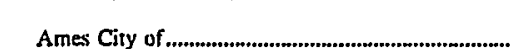 & 3 & 1.2 & 1.0 & $\begin{aligned} 1.1 \\
1130\end{aligned}$ & IC & FO2 & Nat Gas & 1990 & OP \\
\hline 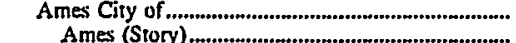 & & 120.0 & 111.0 & 113.0 & & & & & \\
\hline 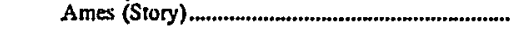 & $\begin{array}{l}7 \\
8\end{array}$ & $\begin{array}{l}33.0 \\
65.0\end{array}$ & $\begin{array}{l}30.0 \\
65.0\end{array}$ & $\begin{array}{l}30.0 \\
65.0\end{array}$ & ST & SUB & Refuse & 1968 & OP \\
\hline Ames-GT (Story) ............................................................. & GTi & 22.0 & 16.0 & $\begin{array}{l}18.0 \\
18.0\end{array}$ & GT & $\begin{array}{l}\text { SUB } \\
\text { FO2 }\end{array}$ & Refuse & $\begin{array}{l}1982 \\
1972\end{array}$ & $\begin{array}{l}O P \\
O P\end{array}$ \\
\hline Anita City of & & .7 & 5 & .7 & & & - & & \\
\hline 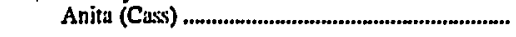 & I & .2 & .1 & .2 & IC & $\mathrm{FO} 2$ & - & 1939 & OP \\
\hline & 2 & .2 & .2 & $\frac{2}{2}$ & IC & $\mathrm{FO} 2$ & - & 1939 & OP \\
\hline & 3 & .4 & .2 & 3 & IC & FO2 & - & 1951 & OP \\
\hline 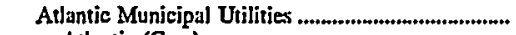 & & 92 & 9.0 & 9.0 & & & & ... & \\
\hline Atlantic (Cass) & 1 & 4.2 & 4.0 & 4.0 & & Nat Gas & $\mathrm{FO} 2$ & 1966 & $O P$ \\
\hline 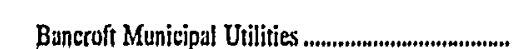 & 2 & 5.0 & 5.0 & 5.0 & ST & Nat Gas & FO6 & 1958 & SB \\
\hline 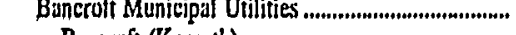 & & 1.6 & 1.5 & 1.5 & & & & & \\
\hline 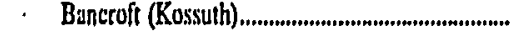 & 1 & .2 & .2 & .2 & IC & FO2 & - & 1939 & $O P$ \\
\hline & 2 & .2 & .2 & 2 & IC & FO2 & - & 1939 & OP \\
\hline & 3 & 3 & 3 & $\frac{3}{3}$ & IC & $\mathrm{FO} 2$ & - & 1941 & OP \\
\hline & 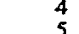 & 3 & 3 & 3 & IC & $\mathrm{FO} 2$ & - & 1948 & OP \\
\hline & 5 & 6.9 & $\begin{aligned} .6 \\
5.9\end{aligned}$ & 5.9 & IC & FO2 & - & 1954 & OP \\
\hline 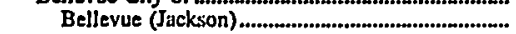 & 1 & .6 & 5 & .5 & IC & $\mathrm{FO} 2$ & - & 1947 & OP \\
\hline & 4 & .8 & .6 & 6 & IC & $\mathrm{FO} 2$ & - & 1963 & OP \\
\hline & 5 & .9 & .8 & .8 & IC & FO2 & - & 1953 & $O P$ \\
\hline & 6 & 3.0 & 2.4 & 2.4 & IC & $\mathrm{FO} 2$ & Nat Gas & 1971 & $O P$ \\
\hline & 7 & 0.6 & 1.6 & 1.6 & IC & FO2 & - & 1992 & OP \\
\hline 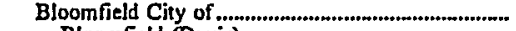 & & 8.6 & 6.8 & 6.8 & & & & & \\
\hline 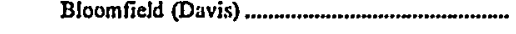 & 1 & 2.8 & 23 & 23 & IC & Nat Gas & FO2 & 1975 & OP \\
\hline & 2 & 27 & $\stackrel{.2}{2.0}$ & 20 & IC & $\mathrm{FO2}$ & $\mathrm{FO}^{-}$ & 1945 & OP \\
\hline & $\begin{array}{l}3 \\
4\end{array}$ & $\begin{array}{r}27 \\
3\end{array}$ & $\begin{array}{l}2.0 \\
3\end{array}$ & $\begin{array}{r}2.0 \\
3\end{array}$ & Ic & Nat Gas & $\mathrm{FO2}$ & 1964 & OP \\
\hline & 5 & .9 & .8 & .8 & IC & $\begin{array}{l}\text { FO2 } \\
\text { Nat Gas }\end{array}$ & $\mathrm{FO}^{-}$ & & OP \\
\hline & 6 & 1.5 & 1.2 & 12 & IC & $\begin{array}{l}\text { Nat Gas } \\
\text { Nat Gas }\end{array}$ & $\mathrm{FO2}$ & 1951 & OP \\
\hline Brooklyn City of .......................... & & & & & 10 & Nat Gas & FO2 & 1958 & OP \\
\hline 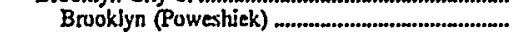 & & 2.4 & 2 & 2.4 & & & & & \\
\hline 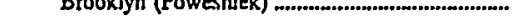 & 1 & .2 & 2 & .2 & IC & FO2 & - & 1940 & OP \\
\hline & 2 & .2 & .2 & 2 & IC & $\mathrm{FO} 2$ & - & 1940 & OP \\
\hline & 3 & .3 & 3 & 3 & IC & $\mathrm{FO} 2$ & - & 1947 & OP \\
\hline & 4 & .6 & .6 & .6 & IC & Nat Gas & $\mathrm{FO} 2$ & 1955 & OP \\
\hline & 5 & 1.1 & 1.1 & 1.1 & IC & Nat Gas & $\mathrm{FO2}$ & 1964 & OP \\
\hline Cascade Municipal Utilities ........................................... & & 3.6 & 32 & 3.4 & & & & & \\
\hline Cascade (Dubuque) & J & .8 & .7 & .8 & IC & $\mathrm{FO} 2$ & Nat Gas & 1957 & OP \\
\hline & 2 & 2.1 & 1.9 & 2.0 & IC & $\mathrm{FO} 2$ & Nat Gas & 1971 & OP \\
\hline & 4 & .7 & 75 & .97 & IC & FO2 & Nat Gas & 1951 & OP \\
\hline Cedar Falls City of ....................... & & 74.6 & 75.2 & 78.1 & & & & & \\
\hline 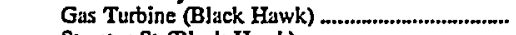 & & 23.1 & 18.7 & 25.0 & GT & Nat Gas & FO2 & 1968 & OP \\
\hline Streeter St (Black Hiwk)......................................... & 6 & 16.5 & 20.0 & 16.5 & ST & Nat Gas & BIT & 1963 & OP \\
\hline & 7 & 35.0 & & & ST & BIT & Nat Gas & 1973 & OP \\
\hline $\begin{array}{l}\text { Central Iowa Power Coop } \\
\text { Fair Station Muscatine) }\end{array}$ & & $\begin{array}{r}149.0 \\
25.0\end{array}$ & $\begin{array}{r}151.1 \\
23.4\end{array}$ & 1662 & & & & & \\
\hline & $* * 2$ & $\begin{array}{l}25.0 \\
37.5\end{array}$ & $\begin{array}{l}23.4 \\
41.0\end{array}$ & $\begin{array}{l}24.0 \\
420\end{array}$ & ST & $\begin{array}{l}\text { BIT } \\
\text { BIT }\end{array}$ & $\begin{array}{l}\text { Nat Gas } \\
\text { Nat Gas }\end{array}$ & 1967 & OP \\
\hline 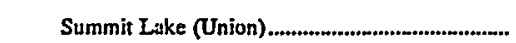 & GTI & 30.0 & 31.0 & $\begin{array}{l}42.0 \\
39.5\end{array}$ & CT & $\mathrm{FO} 2$ & Nat Gas & 1973 & OP \\
\hline & GT2 & 30.0 & 30.0 & 38.4 & CT & $\mathrm{FO} 2$ & Nat Gas & 1975 & OP \\
\hline & IC] & 1.0 & .9 & .9 & IC & $\mathrm{FO} 2$ & - & 1948 & OP \\
\hline & IC2 & 1.0 & 1.1 & 1.1 & Ic & $\mathrm{FO2}$ & - & 1948 & OP \\
\hline & IC4 & 1.0 & 1.1 & 1.1 & IC & $\mathrm{FO} 2$ & - & 1948 & OP \\
\hline & ICS & 1.0 & 1.1 & 1.1 & IC & $\mathrm{FO2}$ & - & 1948 & $O P$ \\
\hline & 1 & 7.5 & 6.9 & 5.8 & CW & WH & - & 1951 & $O P$ \\
\hline & 2 & 7.5 & 7.0 & 5.9 & $\mathrm{CW}$ & WH & _ & 1951 & OP \\
\hline & 3 & 7.5 & 7.6 & 6.4 & $\mathrm{CW}$ & WH & - & 1957 & OP \\
\hline Coggon City of & & 1.5 & 1.5 & 1.5 & & & & & \\
\hline
\end{tabular}

See footnotes at end of table. 
Table 20. Existing Generating Units at U.S. Electric Utilities by State, Company, and Plant, as of January 1, 1998 (Continued)

\begin{tabular}{|c|c|c|c|c|c|c|c|c|c|}
\hline \multirow{2}{*}{$\begin{array}{c}\text { State } \\
\text { Company } \\
\text { Plant (County) }\end{array}$} & \multirow{2}{*}{$\begin{array}{c}\text { Unit } \\
\text { ID }\end{array}$} & \multirow{2}{*}{$\begin{array}{c}\text { Generator } \\
\text { Nameplate } \\
\text { Capacity } \\
\text { (megawatts) }\end{array}$} & \multirow{2}{*}{$\begin{array}{l}\text { Net Summer } \\
\text { Capability } \\
\text { (megawatts) }\end{array}$} & \multirow{2}{*}{$\begin{array}{c}\text { Net Winter } \\
\text { Capabjlity } \\
\text { (megawatts) }\end{array}$} & \multirow{2}{*}{$\begin{array}{r}\text { Unit } \\
\text { Typel }\end{array}$} & \multicolumn{2}{|c|}{ Energy SourceI } & \multirow{2}{*}{$\begin{array}{c}\text { Year } \\
\text { of } \\
\text { Commercial } \\
\text { Operation }\end{array}$} & \multirow{2}{*}{$\begin{array}{c}\text { Unit } \\
\text { Status! }\end{array}$} \\
\hline & & & & & & Primary & Alternate & & \\
\hline Iowa (Continued) & & & & & & & & & \\
\hline Coggon (Linn) & $\begin{array}{r}\mathrm{ICl} \\
3 \\
4\end{array}$ & $\begin{array}{r}0.7 \\
.2 \\
.7\end{array}$ & $\begin{array}{r}0.7 \\
.2 \\
.7\end{array}$ & $\begin{array}{r}0.7 \\
2 \\
.7\end{array}$ & $\begin{array}{l}\text { IC } \\
\text { IC } \\
\text { IC }\end{array}$ & $\begin{array}{l}\mathrm{FO} 2 \\
\mathrm{FO} 2 \\
\mathrm{FO} 2\end{array}$ & $\overline{-}$ & $\begin{array}{l}1957 \\
1945 \\
1987\end{array}$ & $\begin{array}{l}\text { OP } \\
\text { OP } \\
\text { OP }\end{array}$ \\
\hline 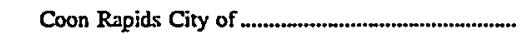 & & 4.0 & 3.0 & 3.0 & & & & & \\
\hline 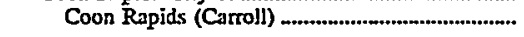 & 4 & .7 & .5 & 5 & IC & $\mathrm{FO} 2$ & - & 1944 & OP \\
\hline & 5 & .7 & .5 & 5 & IC & $\mathrm{FO} 2$ & - & 1948 & OP \\
\hline & 6 & 1.2 & 1.0 & 1.0 & IC & FO2 & Nat Gas & 1956 & OP \\
\hline & 7 & 1.4 & 1.0 & 1.0 & IC & FO2 & Nat Gas & 1987 & OP \\
\hline Com Belt Power Coop & & 85.6 & 86.3 & 87.0 & & & & & \\
\hline Earl F Wisdom (Clay) ............................................ & 1 & 33.0 & 37.3 & 38.0 & ST & BIT & Nat Gas & 1960 & OP \\
\hline 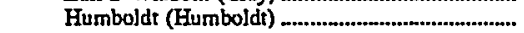 & 1 & 9.4 & 9.0 & 9.0 & ST & BIT & Nat Gas & 1950 & SB \\
\hline & 2 & 9.4 & 9.0 & 9.0 & ST & BIT & Nat Gas & 1950 & SB \\
\hline & 3 & 13.5 & 12.5 & 12.5 & ST & BIT & Nat Gas & 195] & SB \\
\hline & 4 & 20.3 & 18.5 & 18.5 & ST & BIT & Nat Gas. & 1953 & SB \\
\hline Coming City of & & 6.4 & 6.4 & 6.4 & & & & & \\
\hline Coming (Adams) & 1 & .7 & .7 & .7 & IC & $\mathrm{FO} 2$ & - & 1945 & OP \\
\hline & $i$ & 1.0 & 1.0 & 3.0 & $\mathrm{IC}$ & $\mathrm{FO} 2$ & - & 1950 & OP \\
\hline & 3 & 1.4 & 1.4 & 1.4 & IC & $\mathrm{FO} 2$ & - & 1955 & OP \\
\hline & 4 & .5 & .5 & 5 & IC & $\mathrm{FO} 2$ & - & 1938 & OP \\
\hline & $s$ & 29 & 2.9 & 2.9 & IC & $\mathrm{FO} 2$ & - & 3975 & OP \\
\hline 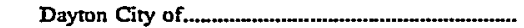 & & 1.4 & 1.4 & 1.4 & & & & & \\
\hline Dayton (Webster) & 1 & .7 & .7 & .7 & IC & $\mathrm{FO} 2$ & Nat Gas & & \\
\hline & $\begin{array}{l}2 \\
3\end{array}$ & $\begin{array}{l}4 \\
2\end{array}$ & $\begin{array}{r}.4 \\
2\end{array}$ & .4 & IC & FO2 & Nat Gas & $\begin{array}{l}1951 \\
1047\end{array}$ & OP \\
\hline & 4 & .2 & .2 & .2 & IC & $\mathrm{FO} 2$ & - & 1947 & $O P$ \\
\hline Durant City of & & $\ddot{32}$ & 3.2 & 3.2 & & $\mathrm{FO2}$ & - & 1939 & \\
\hline Durant (Cedar) & $6 \mathrm{~A}$ & 2.1 & 2.1 & 2.1 & IC & FO2 & Nat Gas & 1970 & oP \\
\hline & 4 & .6 & .6 & .6 & IC & FO2 & - & 1954 & OP \\
\hline & 5 & .6 & .6 & .6 & IC & $\mathrm{FO} 2$ & - & 1958 & OP \\
\hline Estherville City of & & 17.6 & 15.4 & 15.6 & & & & & \\
\hline 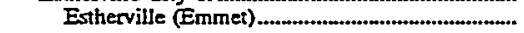 & 2 & 1.6 & 1.1 & 1.1 & IC & FO2 & - & 1946 & OP \\
\hline & 3 & 3.0 & 2.7 & 2.8 & IC & $\mathrm{FO} 2$ & Nat Gas & 1960 & OP \\
\hline & 4 & 4.0 & 3.6 & 3.6 & IC & $\mathrm{FO} 2$ & Nat Gas & 1969 & OP \\
\hline & 5 & 4.0 & 3.6 & 3.6 & $\mathrm{IC}$ & $\mathrm{FO2}$ & Nat Gas & 1969 & OP \\
\hline & 6 & 20 & 1.7 & 1.7 & IC & FO2 & - & 1950 & $O P$ \\
\hline & 7 & 3.0 & 2.7 & 2.8 & IC & $\mathrm{FO} 2$ & Nat Gas & 1960 & OP \\
\hline Forest City City of & & 14.5 & 14.1 & 14.1 & & & & & \\
\hline Forest City (Winnebago) & 1 & 1.3 & 1.3 & 1.3 & IC & FO2 & - & 1958 & OP \\
\hline & 2 & 2.8 & 2.5 & 25 & IC & $\mathrm{FO} 2$ & - & 1965 & OP \\
\hline & 3 & 3.5 & 3.5 & 3.5 & IC & $\mathrm{FO} 2$ & - & 1968 & OP \\
\hline & 4 & 6.3 & 6.2 & 62 & IC & FO2 & - & 1946 & OP \\
\hline & 5 & .7 & .7 & .7 & IC & FO2 & - & 3950 & OP \\
\hline Gowrie Municipal Utilities & & 3.3 & 2.8 & 2.8 & & & & & \\
\hline 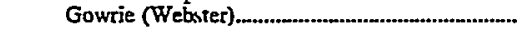 & 1 & 1.3 & 1.0 & 1.0 & IC & FO2 & - & 1959 & OP \\
\hline & 4 & .8 & .8 & .8 & IC & $\mathrm{FO} 2$ & - & 1954 & SB \\
\hline & 5 & 1.3 & 1.0 & 1.0 & IC & $\mathrm{FO} 2$ & - & 1968 & OP \\
\hline Graettinger City of & & 1.8 & 1.7 & 1.8 & & & & & \\
\hline 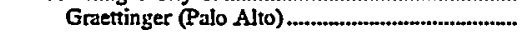 & 1 & .2 & .2 & .2 & IC & $\mathrm{FO} 2$ & - & 1942 & os \\
\hline & 4 & 5 & .4 & .4 & IC & $\mathrm{FO} 2$ & - & 1957 & OP \\
\hline & 5 & 1.1 & 1.0 & 12 & IC & $\mathrm{FO} 2$ & - & 1990 & OP \\
\hline Grand Junction City of & & 4.1 & $\mathbf{3 . 7}$ & 3.7 & & & & & \\
\hline 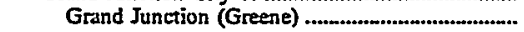 & 1 & .6 & .5 & 5 & IC & $\mathrm{FO} 2$ & Nat Gas & 1952 & OP \\
\hline & 2 & 1.8 & 1.6 & 1.6 & IC & $\mathrm{FO} 2$ & & 1994 & OP \\
\hline & 6 & 1.8 & 1.6 & 1.6 & IC & $\mathrm{FO} 2$ & - & 1994 & OP \\
\hline Greenfield City of & & 6.1 & 5.6 & 5.8 & & & & & \\
\hline Greenfield (Adair) & 3 & 1.3 & 1.0 & 1.1 & IC & $\mathrm{FO2}$ & - & 1952 & OP \\
\hline & 4 & 1.8 & 1.9 & 1.9 & IC & $\mathrm{FO} 2$ & - & 1961 & OP \\
\hline & 5 & 3.0 & 2.8 & 2.8 & IC & FO2 & - & 1973 & op \\
\hline Grundy Center City of & & 8.8 & 8.8 & 8.8 & & & & & \\
\hline 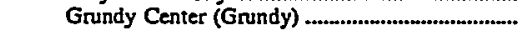 & ICl & 2.3 & 2.3 & 2.3 & IC & $\mathrm{FO2}$ & Nat Gas & 1963 & $\mathbf{O P}$ \\
\hline & $\mathrm{IC2}$ & 3.5 & 3.5 & 3.5 & IC & $\mathrm{FO} 2$ & Nat Gas & 1972 & $\mathrm{OP}$ \\
\hline & IC3 & 3.0 & 3.0 & 3.0 & IC & $\mathrm{FO} 2$ & Nat Gas & 1990 & OP \\
\hline Hartley Ciny of & & 1.7 & 1.7 & 1.7 & & & & & \\
\hline Hartley (O Brien) & 1 & 1.0 & 1.0 & 1.0 & IC & $\mathrm{FO}_{2}$ & - & 1953 & OP \\
\hline & 2 & .7 & .7 & .7 & IC & $\mathrm{FO} 2$ & - & 1947 & OP \\
\hline 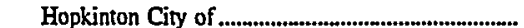 & & 4.6 & 4.5 & 4.6 & & & & & \\
\hline Hopkinton (Delaware) & $\mathrm{IC} 2$ & 1.7 & 1.7 & 1.7 & IC & $\mathrm{FO2}$ & - & 1994 & OP \\
\hline & IC3 & 1.3 & 1.2 & 1.3 & IC & FO2 & - & 1983 & $\mathrm{OP}$ \\
\hline & 1 & 1.6 & 1.6 & 1.6 & IC & $\mathrm{FO2}$ & - & 1973 & OP \\
\hline 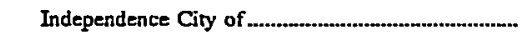 & & 18.4 & 16.7 & 16.7 & & & & & \\
\hline
\end{tabular}

See footnotes at end of table. 
Table 20. Existing Generating Units at U.S. Electric Utilities.by State, Company, and Plant, as of January 1, 1998 (Continued)

\begin{tabular}{|c|c|c|c|c|c|c|c|c|c|}
\hline \multirow{2}{*}{$\begin{array}{c}\text { State } \\
\text { Company } \\
\text { Plant (County) }\end{array}$} & \multirow{2}{*}{$\begin{array}{l}\text { Unit } \\
\text { ID }\end{array}$} & \multirow{2}{*}{$\begin{array}{c}\text { Generator } \\
\text { Nameplate } \\
\text { Capacity } \\
\text { (megawatts) }\end{array}$} & \multirow{2}{*}{$\begin{array}{l}\text { Net Summer } \\
\text { Capability } \\
\text { (megawatts) }\end{array}$} & \multirow{2}{*}{$\begin{array}{l}\text { Net Winter } \\
\text { Capability } \\
\text { (megawatts) }\end{array}$} & \multirow{2}{*}{$\begin{array}{r}\text { Unit } \\
\text { Type }\end{array}$} & \multicolumn{2}{|c|}{ Energy Sourced } & \multirow{2}{*}{$\begin{array}{c}\text { Year } \\
\text { of } \\
\text { Commercial } \\
\text { Operation }\end{array}$} & \multirow{2}{*}{$\begin{array}{c}\text { Unit } \\
\text { Statusl }\end{array}$} \\
\hline & & & & & & Primary & Alternate & & \\
\hline Iowa (Continued) & & & & & & & & & \\
\hline Independence (Buchanan)............... & 1 & 2.5 & 24 & 2.4 & IC & FO2 & Nat Gas & 1957 & \\
\hline & 2 & .7 & .4 & .4 & IC & FO2 & & 1939 & OP \\
\hline & 4 & 1.0 & .8 & .8 & IC & $\mathrm{FO2}$ & - & 1949 & OP \\
\hline & 5 & 1.0 & .8 & .8 & ic & FO2 & - & 1949 & $O P$ \\
\hline & 6 & 3.2 & 2.8 & 2.8 & IC & FO2 & Nat Gas & 1964 & OP \\
\hline & $?$ & 6.3 & 5.8 & 5.8 & IC & $\mathrm{FO} 2$ & Nat Gas & 1973 & OP \\
\hline & $\begin{array}{l}8 \\
0\end{array}$ & 1.9 & $\begin{array}{l}1.9 \\
1.9\end{array}$ & 1.9 & IC & $\mathrm{FO} 2$ & - & 1996 & $\begin{array}{l}\text { OP } \\
\text { OP }\end{array}$ \\
\hline Indianola Municjpal Utilities...................................... & & 34.5 & 30.6 & 362 & IC & FO2 & - & 1996 & \\
\hline 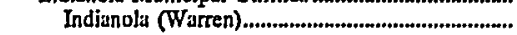 & 1 & .8 & .6 & .6 & IC & $\mathrm{FO} 2$ & - & 1946 & OP \\
\hline & 2 & 1.4 & 1.2 & 13 & IC & FO2 & Nat Gas & 1949 & $O P$ \\
\hline & 3 & I.I & .8 & .8 & IC & FO2 & Nat Gas & 1953 & OP \\
\hline & 4 & 1.5 & 1.2 & 13 & Ic & $\mathrm{FO} 2$ & Nat Gas & 1963 & OP \\
\hline & 5 & 4.0 & 3.5 & 35 & IC & $\mathrm{FO} 2$ & Nat Gas & 1966 & $O P$ \\
\hline & 6 & 5.1 & 4.8 & 4.8 & IC & FO2 & Nat Gas & 1970 & $O P$ \\
\hline & 7 & 20.6 & 18.5 & 24.0 & GT & FO2 & - & 1977 & OP \\
\hline 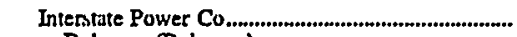 & & 746.4 & 7103 & 6927 & & & & & \\
\hline Dubuque (Dubuque) & ICl & 2.0 & 23 & 2.0 & IC & $\mathrm{FO2}$ & - & 1966 & OP \\
\hline & IC2 & 2.0 & 2.3 & 2.0 & IC & $\mathrm{FO} 2$ & - & 1966 & OP \\
\hline & ST2 & 15.0 & 13.0 & 13.0 & ST & BIT & Nat Gas & 1929 & $O P$ \\
\hline & 3 & 28.8 & 30.0 & 30.0 & ST & BIT & Nat Gas & 1952 & $O P$ \\
\hline & 4 & 37.5 & 35.0 & 35.0 & ST & BIT & Nat Gas & 1959 & $O P$ \\
\hline 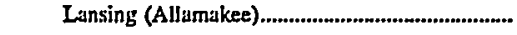 & ICl & 1.0 & 1.0 & 1.0 & IC & $\mathrm{FO2}$ & - & 1970 & $O P$ \\
\hline & IC2 & 1.0 & 1.0 & 1.0 & IC & $\mathrm{FO} 2$ & - & $197 !$ & OP \\
\hline & 1 & 15.0 & 15.5 & 155 & ST & BIT & - & 1948 & OP \\
\hline & 2 & 11.5 & 10.7 & 10.7 & ST & BIT & - & 1949 & OP \\
\hline & 3 & 37.5 & 33.8 & 33.8 & ST & BIT & - & 1957 & OP \\
\hline & 4 & 274.5 & 260.0 & 255.0 & ST & SUB & ـ & 1977 & OP \\
\hline 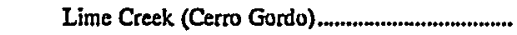 & j & 41.4 & 35.0 & 38.0 & GT & FO2 & - & 1991 & OP \\
\hline & 2 & 41.4 & 35.0 & 38.0 & GT & FO2 & - & 1991 & OP \\
\hline M L Kspp (Clinton)......................... & 1 & 18.8 & 38.0 & 0.0 & ST & Nat Gas & - & 1947 & $\mathrm{OP}$ \\
\hline New Albin (Allamakee) & 2 & 218.5 & 217.0 & 217.0 & ST & BrT & Nat Gas & 1967 & $O P$ \\
\hline 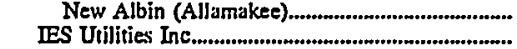 & I & $\begin{array}{r}.7 \\
1,742.1\end{array}$ & 1.542 .7 & $\begin{array}{r}.7 \\
1,513.6\end{array}$ & IC & $\mathrm{FO} 2$ & - & 1970 & OP \\
\hline Agency GT (Des Moines) ............................. & 1 & 17.5 & 13.4 & 18.4 & GT & Nat Gas & $\mathrm{FO} 2$ & 1992 & OP \\
\hline & 2 & 37.5 & 15.2 & 20.2 & GT & Nat Gas & $\mathrm{FO} 2$ & 1990 & $\mathrm{OP}$ \\
\hline & 3 & 17.5 & 15.1 & 20.1 & GT & Nat Gas & $\mathrm{FO} 2$ & 1990 & OP \\
\hline & 4 & 17.5 & 14.7 & 19.7 & GT & Nat Gas & $\mathrm{FO2}$ & 1990 & OP \\
\hline Ames (Story) & j & 1.0 & 1.0 & 1.0 & IC & $\mathrm{FO} 2$ & - & 1960 & OP \\
\hline & 2 & 1.0 & 1.0 & 1.0 & IC & $\mathrm{FO} 2$ & - & 1960 & OP \\
\hline Anamosa (Jone:) .................................... & $\mathrm{HCl}$ & 3 & 3 & 3 & $\mathrm{HY}$ & Water & - & 1990 & OP \\
\hline Burlington (Des Moines) & GTJ & 22.5 & 14.2 & 0.0 & GT & Nat Gas & FO2 & 1971 & $\mathrm{OP}$ \\
\hline & GT2 & 22.5 & 14.2 & 0.0 & GT & Gas & $\mathrm{FO} 2$ & 1971 & $\mathrm{OP}$ \\
\hline & GT3 & 22.5 & 13.8 & 0.0 & GT & Nat & FO2 & $7 !$ & OP \\
\hline & GT4 & 22.5 & 14.8 & 0.0 & GT & Nat Gas & FO2 & & OI \\
\hline & 1 & 2120 & 211.8 & $2 \mathrm{~J} 1.8$ & ST & SUB & BIT & & OP \\
\hline 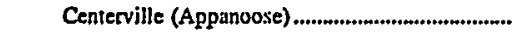 & j & 2.0 & 2.1 & 2.1 & IC & FO2 & - & 1963 & $O P$ \\
\hline & 2 & 20 & 2.1 & 2.1 & $\mathrm{IC}$ & FO2 & - & 1963 & o. \\
\hline & 3 & & 2.1 & 2.1 & IC & $\mathrm{FO} 2$ & - & 1963 & \\
\hline Duane Amold (Linn) ................................................... & $* * 1$ & 597.2 & 535.0 & 535.0 & NB & Uranium & - & 1975 & OP \\
\hline Grinnel] Gt (Poweshick)...................... & 1 & 22.3 & 23.2 & 0.0 & GT & & - & 30 & OP \\
\hline & 2 & 22.3 & 23.2 & 0.0 & GT & & - & & 0 \\
\hline 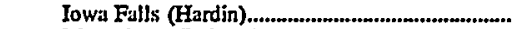 & 1 & 5 & 5 & 5 & HY & Water & - & 1926 & OP \\
\hline 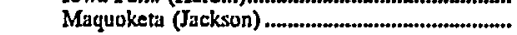 & i & .6 & .6 & .6 & $\mathrm{HY}$ & Water & - & 1924 & $O P$ \\
\hline & 2 & .6 & .6 & .6 & $\mathrm{HY}$ & Water & - & 1924 & OP \\
\hline 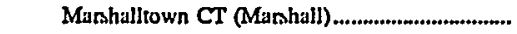 & IC] & 2.5 & 2.0 & 2.0 & IC & $\mathrm{FO} 2$ & - & 1941 & OP \\
\hline & IC2 & 2.5 & 1.9 & 1.9 & IC & $\mathrm{FO} 2$ & - & 19 & $O P$ \\
\hline & 1 & 67.4 & 53.6 & 70.3 & GT & FO2 & - & 1978 & OP \\
\hline & 2 & 67.4 & 53.4 & 70.1 & GT & Fo & - & 78 & OP \\
\hline & 3 & 67.4 & 52 & 69.3 & GT & FO & - & 78 & OP \\
\hline 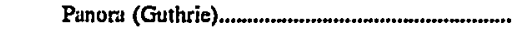 & 1 & 1.5 & 1.5 & 1.5 & IC & FO2 & - & 1988 & 0 \\
\hline & 2 & 3.0 & 1.0 & 1.0 & IC & $\mathrm{FO} 2$ & - & 1988 & \\
\hline Prairie Creck (Linn) & 1 & 23.0 & 38.8 & 18.8 & ST & SUB & BIT & 1950 & OP \\
\hline & 2 & 23.0 & 38.8 & 38.8 & ST & SUB & BIT & 1951 & 0 \\
\hline & 3 & 50.0 & 42.4 & 42.4 & ST & so & BIT & 1958 & $O P$ \\
\hline & 4 & 148 & 139.0 & 139.0 & ST & SUB & BIT & 1967 & \\
\hline 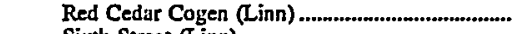 & 1 & 22.5 & 18.8 & 22.7 & GT & Nat Gas & - & 1996 & OP \\
\hline 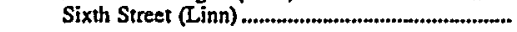 & 1 & 10.0 & 3.0 & 6.0 & ST & BIT & Refuse & 1921 & $O P$ \\
\hline & 2 & 6.0 & 3.0 & 3.0 & $\mathrm{CH}$ & MF & - & 1930 & OP \\
\hline & 4 & 15.0 & 16.0 & 16.0 & $\mathrm{CH}$ & MF & - & 1942 & \\
\hline
\end{tabular}

See footnotes at end of table. 
Table 20. Existing Generating Units at U.S. Electric Utilities by State, Company, and Plant, as of January 1, 1998 (Continued)

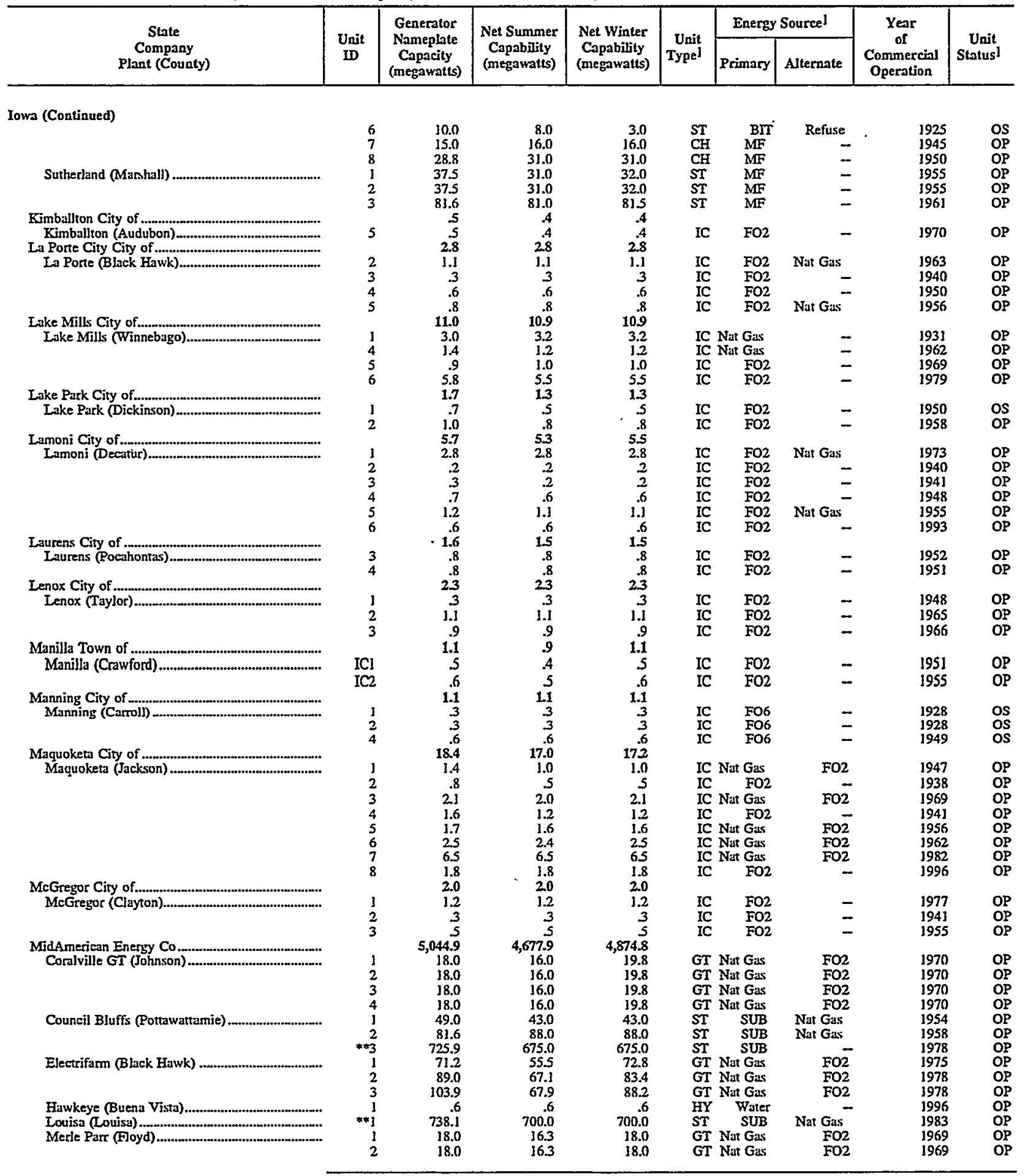

See footnotes at end of table. 
Table 20. Existing Generating Units at U.S. Electric Utilities by State, Company, and Plant, as of January 1, 1998 (Continued)

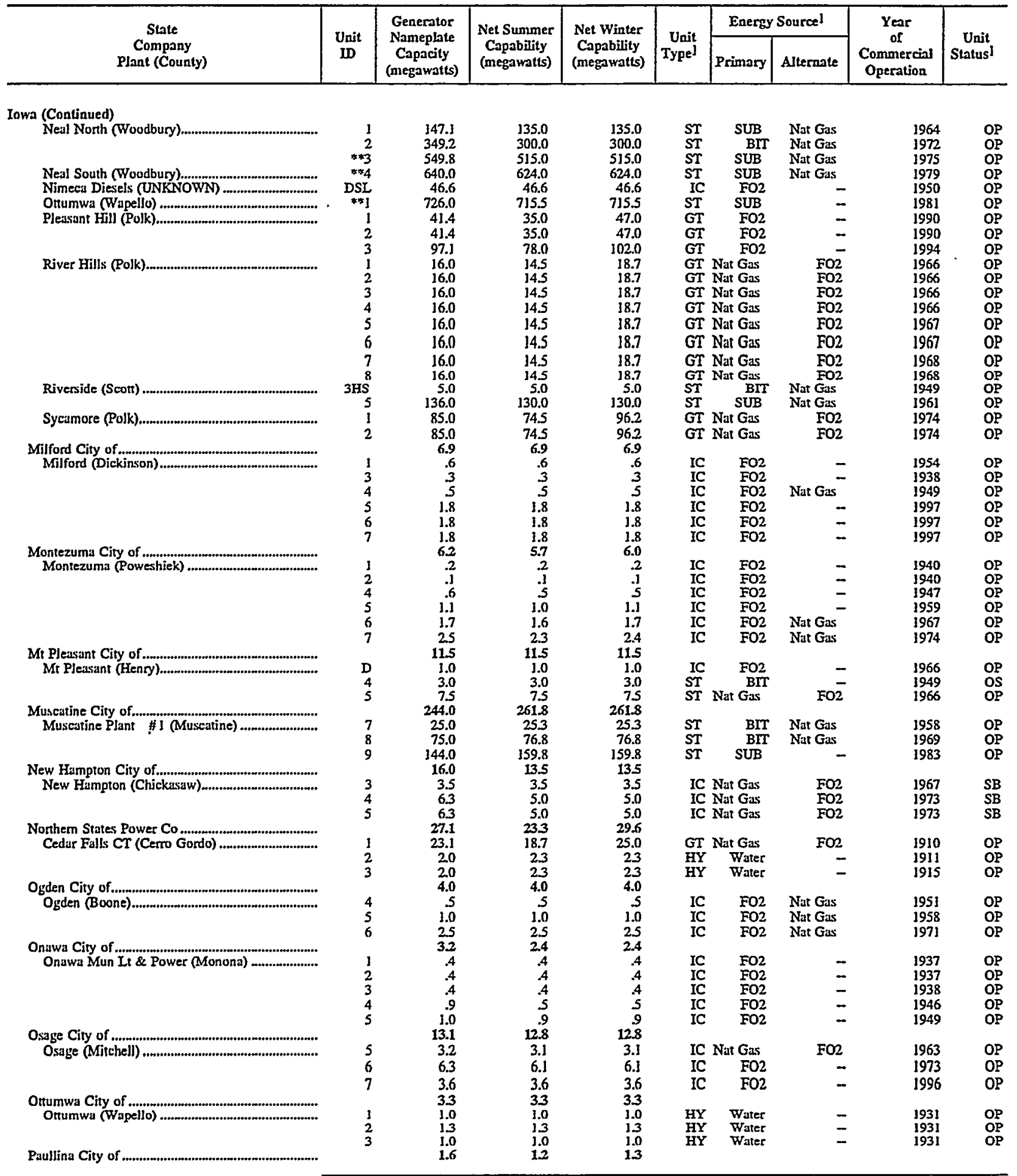

See footnotes at end of table. 
Table 20. Existing Generating Units at U.S. Electric Utilities.by State, Company, and Plant, as of January 1, 1998 (Continued)

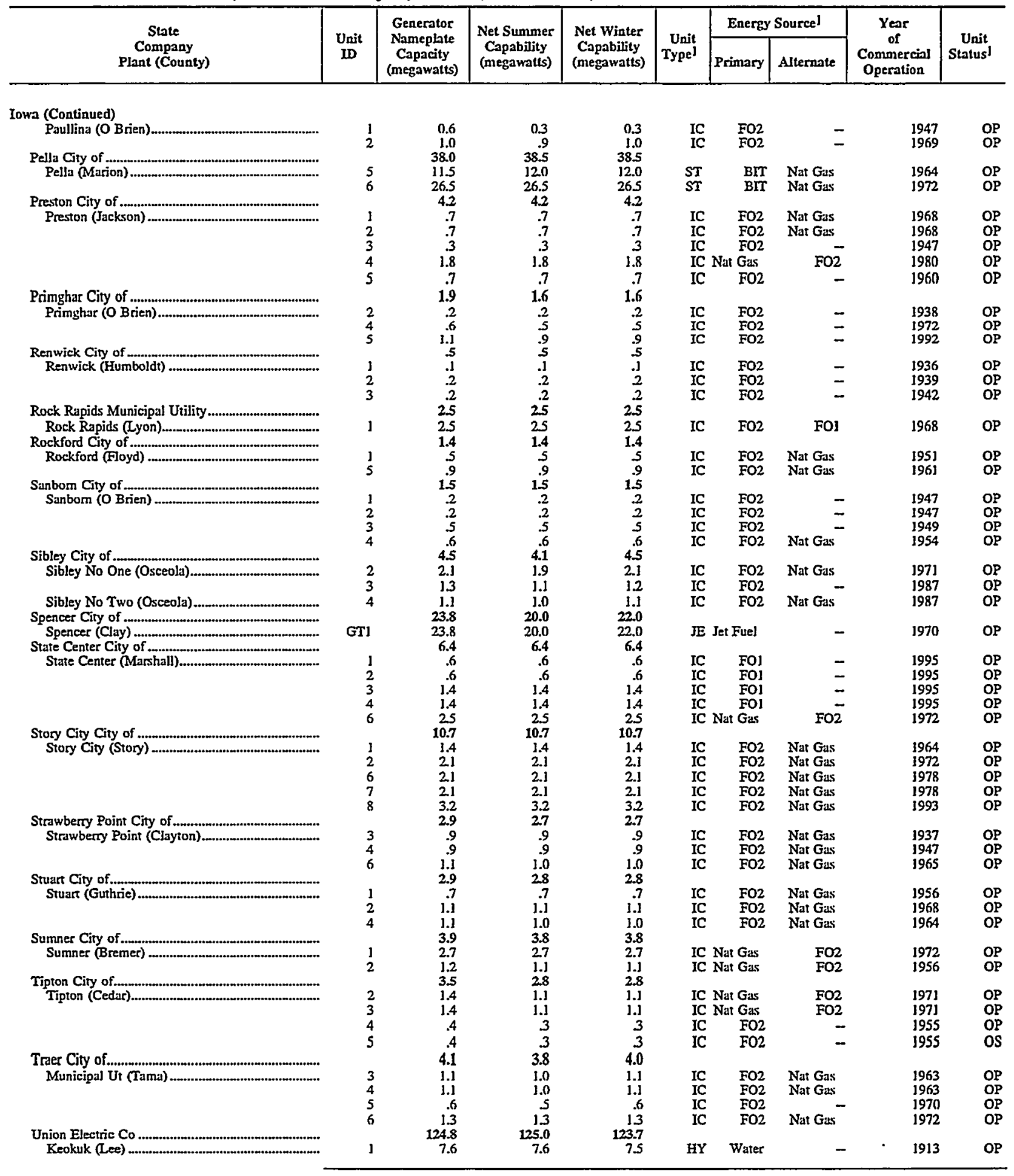

See footnotes at end of table. 
Table 20. Existing Generating Units at U.S. Electric Utilities by State, Company, and Plant, as of January 1, 1998 (Continued)

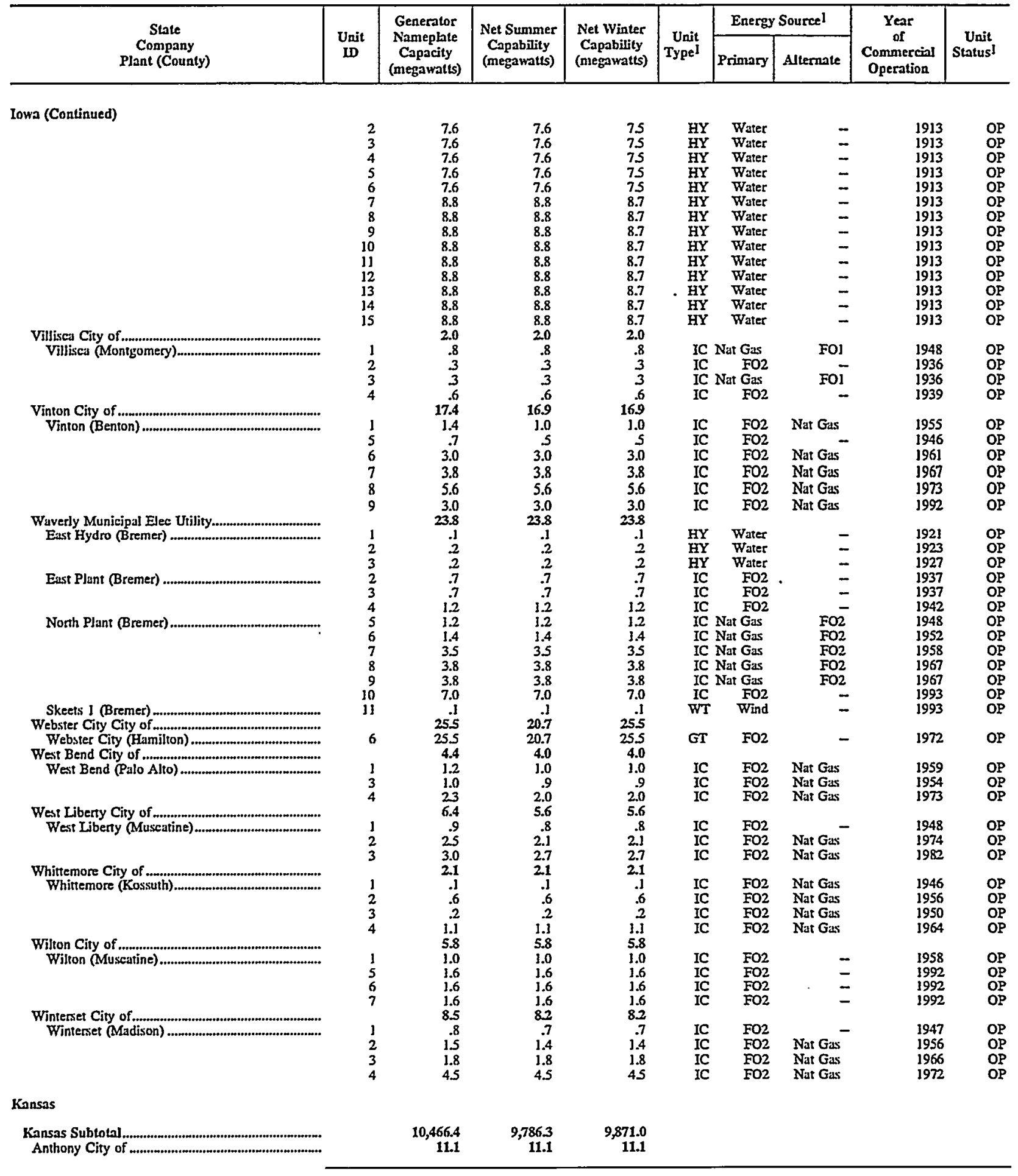

See footnotes at end of table. 
Table 20. Existing Generating Units at U.S. Electric Utilities by State, Company, and Plant, as of January 1, 1998 (Continued)

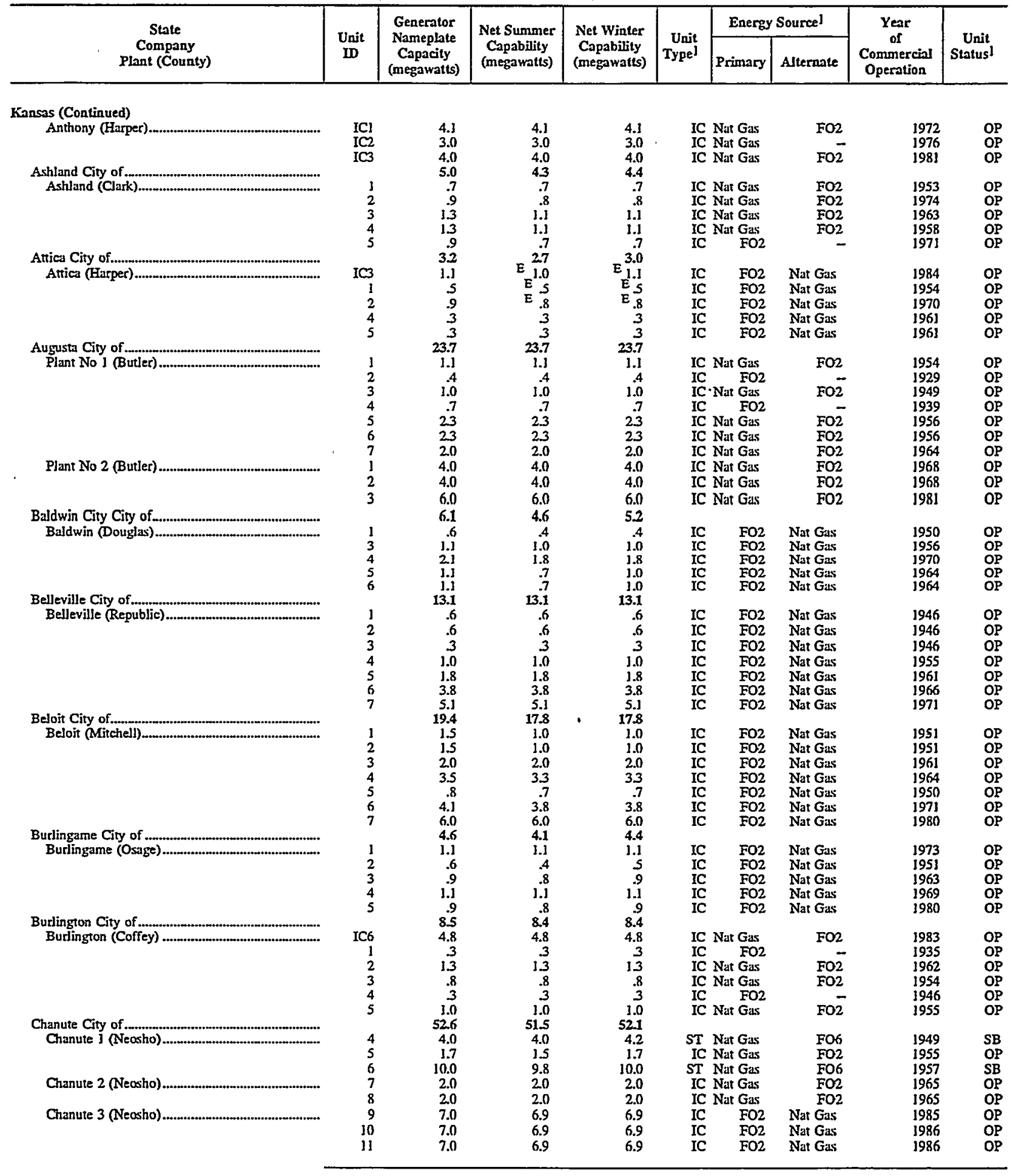

See footnotes at end of table. 
Table 20. Existing Generating Units at U.S. Electric Utilities by State, Company, and Plant, as of January 1, 1998 (Continued)

\begin{tabular}{|c|c|c|c|c|c|c|c|c|c|}
\hline \multirow{2}{*}{$\begin{array}{c}\text { State } \\
\text { Company } \\
\text { Plant (County) }\end{array}$} & \multirow{2}{*}{$\begin{array}{l}\text { Unit } \\
\text { ID }\end{array}$} & \multirow{2}{*}{$\begin{array}{l}\text { Generator } \\
\text { Nameplate } \\
\text { Capacity } \\
\text { (megawatts) }\end{array}$} & \multirow{2}{*}{$\begin{array}{l}\text { Net Sumumer } \\
\text { Capability } \\
\text { (megawatts) }\end{array}$} & \multirow{2}{*}{$\begin{array}{l}\text { Net Winter } \\
\text { Capability } \\
\text { (megawatts) }\end{array}$} & \multirow{2}{*}{$\begin{array}{l}\text { Unit } \\
\text { Type] }\end{array}$} & \multicolumn{2}{|c|}{ Energy Sourcel } & \multirow{2}{*}{\begin{tabular}{c|} 
Year \\
of \\
Commercial \\
Operation
\end{tabular}} & \\
\hline & & & & & & Primary & Alternate & & Status 1 \\
\hline Kansas (Continued) & & & & & & & & & \\
\hline & 12 & 6.0 & 5.5 & 5.5 & IC & FO2 & - & 1991 & $\mathrm{OP}$ \\
\hline & 13 & 6.0 & 6.0 & 6.0 & IC & FO2 & - & 1991 & $\mathrm{OP}$ \\
\hline 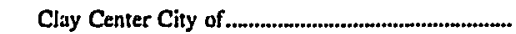 & & 24.6 & 24.5 & 24.5 & & & & & \\
\hline 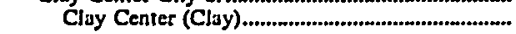 & ICl & .9 & .9 & .9 & & Nat Gas & $\mathrm{FO} 2$ & 1958 & OP \\
\hline & & & & & & Nat Gas & $\mathrm{FO} 2$ & 1966 & OP \\
\hline & IC3 & 5.j & 5.0 & 5.0 & IC & Nat Gas & $\mathrm{FO2}$ & 1972 & OP \\
\hline & IC4 & 3.5 & 3.5 & 3.5 & IC & Nat Gas & FO2 & 1996 & $\mathrm{OP}$ \\
\hline , & ICS & 3.5 & 3.5 & 3.5 & IC & Nat Gas & FO2 & 1996 & OP \\
\hline 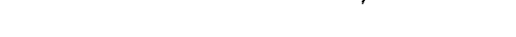 & 4 & 1.5 & 1.5 & 1.5 & $S T$ & Nat Gas & Fos & 1942 & OP \\
\hline & $\begin{array}{l}5 \\
6\end{array}$ & $\begin{array}{l}3.0 \\
5.0\end{array}$ & $\begin{array}{l}3.0 \\
5.0\end{array}$ & $\begin{array}{l}3.0 \\
50\end{array}$ & $\stackrel{\mathbf{S T}}{\mathbf{S T}}$ & Nat Gas & Fos & 1948 & OP \\
\hline Coffeyville City of & & 58.8 & $\begin{array}{r}5.0 \\
55.5\end{array}$ & $\begin{array}{r}5.0 \\
56.7\end{array}$ & ST & Nat Gas & FOS & 1961 & OP \\
\hline 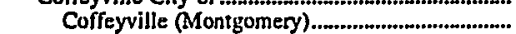 & 6 & 18.8 & 17.5 & 18.5 & ST & Nat Gas & - & 1956 & OP \\
\hline & 7 & 40.0 & 38.0 & 382 & ST & Nat Gas & - & 1973 & $\mathrm{OP}$ \\
\hline 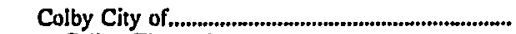 & & 17.4 & 13.6 & 13.6 & & & & & \\
\hline 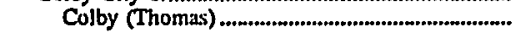 & 3 & 2.5 & 1.8 & 1.8 & IC & $\mathrm{FO} 2$ & Nat Gas & 1963 & OP \\
\hline & 4 & 1.8 & 1.3 & 13 & IC & FO2 & Nat Gas & 1958 & OP \\
\hline & 5 & 1.4 & 1.0 & 1.0 & IC & FO2 & Nat Gas & 1958 & OP \\
\hline & 6 & 4.5 & 3.5 & 35 & IC & FO2 & Nat Gas & 1971 & $\mathrm{OP}$ \\
\hline & 7 & 4.5 & 3.5 & 35 & IC & $\mathrm{FO} 2$ & Nat Gas & 1971 & $O P$ \\
\hline & 8 & 2.8 & 2.5 & 25 & IC & FO2 & Nat Gas & 1971 & $O P$ \\
\hline 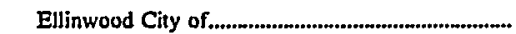 & & 8.5 & $\mathbf{7 . 7}$ & $\mathbf{7 . 7}$ & & & & & \\
\hline 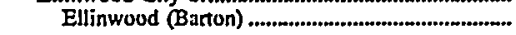 & 1 & 2.1 & 1.9 & 1.9 & IC & $\mathrm{FO} 2$ & Nat Gas & 1965 & OP \\
\hline & 2 & 1.4 & 1.3 & 13 & IC & FO2 & Nat Gas & 1957 & OP \\
\hline & 3 & .6 & .5 & 5 & IC & FO2 & Nat Gas & 1948 & $O P$ \\
\hline & 4 & 1.1 & 1.0 & 1.0 & IC & FO2 & Nat Gas & 1953 & OP \\
\hline & 5 & 3.3 & 3.0 & 3.0 & IC & $\mathrm{FO} 2$ & Nat Gas & 1971 & $O P$ \\
\hline 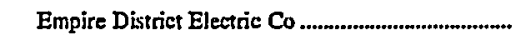 & & 132.6 & 136.0 & 136.0 & & & & & \\
\hline 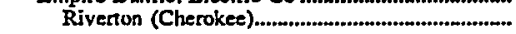 & 7 & 37.5 & 38.0 & 38.0 & ST & SUB & BIT & 1950 & OP \\
\hline & 8 & 50.0 & 54.0 & 54.0 & ST & SUB & BIT & 1954 & OP \\
\hline & 9 & 12.5 & 12.0 & 12.0 & GT & Nat Gas & FO2 & 1964 & $\mathrm{OP}$ \\
\hline & 10 & 16.3 & 16.0 & 16.0 & GT & Nat Gas & $\mathrm{FO} 2$ & 1988 & OP \\
\hline & ii & 16.3 & 16.0 & 16.0 & GT & Nat Gas & $\mathrm{FO} 2$ & 1988 & OP \\
\hline 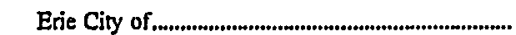 & & 4.8 & 4.4 & 4.4 & & & & & \\
\hline 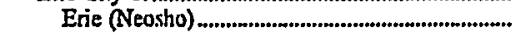 & 1 & .7 & .6 & .6 & IC & $\mathrm{FO} 2$ & - & 1953 & $\mathrm{OP}$ \\
\hline & 3 & 13 & 1.0 & 1.0 & IC & FO2 & - & 1958 & $O P$ \\
\hline & 4 & 1.5 & 1.5 & 1.5 & IC & FO2 & - & 1964 & OP \\
\hline & 5 & 1.0 & 1.0 & 1.0 & ic & FO2 & _ & 1992 & OP \\
\hline & 6 & .4 & 3 & 3 & Ic & $\mathrm{FO} 2$ & - & 1992 & OP \\
\hline Fredonia City of & & 7.4 & 7.0 & 7.0 & & & & & \\
\hline Fredonia (Wilson) ........................................................ & ICS & .9 & .9 & .9 & IC & FO2 & Nat Gas & 1978 & $\mathrm{OP}$ \\
\hline & IC6 & .9 & .9 & .9 & IC & FO2 & Nat Gas & 1978 & OP \\
\hline & IC7 & .7 & .7 & .7 & Ic & FO2 & Nat Gas & 1978 & OP \\
\hline & IC8 & .9 & .9 & .9 & IC & FO2 & Nat Gas & 1980 & OP \\
\hline & IC9 & .9 & 8 & .8 & IC & $\mathrm{FO} 2$ & Nat Gas & 1980 & $\mathrm{OP}$ \\
\hline & 1 & .9 & .8 & .8 & Ic & $\mathrm{FO} 2$ & Nat Gas & 1948 & OP \\
\hline & 2 & 1.3 & 1.3 & 13 & IC & FO2 & Nat Gas & 1953 & OP \\
\hline & 3 & .4 & .3 & 3 & IC & FO2 & Nat Gas & 1927 & op \\
\hline & 4 & .6 & .5 & 5 & IC & FO2 & Nat Gas & 1931 & $\mathrm{OP}$ \\
\hline Gardner City of & & 39.2 & 31.0 & 31.0 & & & & & \\
\hline Gardner (Johnson) & CTI & 19.6 & 15.0 & 15.0 & GT & F02 & Nat Gas & 1990 & op \\
\hline & CT2 & 19.6 & 16.0 & 16.0 & GT & $\mathrm{FO} 2$ & Nat Gas & 1990 & OP \\
\hline Gamett Ciry of & & 9.3 & 8.4 & 8.4 & & & & & \\
\hline Gamett Municipal (Anderson)................................. & ICS & 2.4 & 22 & 2.2 & & Nat Gas & FO2 & 1981 & op \\
\hline & IC6 & 2.5 & 2.3 & 2.3 & & FO2 & & 1978 & OP \\
\hline & 1 & 1.5 & 1.4 & 1.4 & & Nat Gas & $\mathrm{FO} 2$ & 1961 & og \\
\hline & 2 & .4 & .4 & .4 & IC & & - & 1930 & op \\
\hline & 3 & 1.5 & 1.4 & 1.4 & IC & Nat Gas & $\mathrm{FO} 2$ & 1955 & OP \\
\hline & 4 & 1.0 & .9 & .9 & IC & Nat Gas & $\mathrm{FO} 2$ & 1948 & $\mathrm{OP}$ \\
\hline Girand City of & & 10.9 & 9.4 & 98 & & & & & \\
\hline 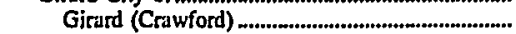 & 1 & 1.4 & 1.1 & 1.3 & IC & Nat Gas & FO2 & 1955 & OP \\
\hline & 4 & 23 & 1.8 & 2.0 & Ic & Nat Gas & $\mathrm{FO} 2$ & 1962 & OP \\
\hline & 6 & 3.5 & 3.0 & 3.0 & IC & Nat Gas & Fo2 & 1997 & $O P$ \\
\hline & 7 & 3.8 & 3.5 & 3.5 & IC & Nar Gas & FO2 & 1997 & OP \\
\hline Goodland Ciry of & & 18.9 & 16.5 & 17.7 & & & & & \\
\hline 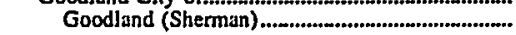 & 3 & .8 & .8 & & IC & $\mathrm{FO} 2$ & - & 1939 & og \\
\hline & 5 & 1.3 & 9 & 1.0 & IC & Nar Gas & $\mathrm{FO} 2$ & 1950 & OP \\
\hline & 6 & 23 & 2.0 & 2.2 & IC & Nat Gas & $\mathrm{FO} 2$ & 1962 & op \\
\hline & 7 & 2.3 & 2.0 & 2.2 & IC & Nat Gas & FO2 & 1966 & $\mathrm{OP}$ \\
\hline & 8 & 5.0 & 4.6 & 4.8 & IC & Nat Gas & $\mathrm{FO} 2$ & 1975 & op \\
\hline
\end{tabular}

See footnotes at end of table. 
Table 20. Existing Generating Units at U.S. Electric Utilities by State, Company, and Plant, as of January 1, 1998 (Continued)

\begin{tabular}{|c|c|c|c|c|c|c|c|c|c|}
\hline \multirow{2}{*}{$\begin{array}{c}\text { State } \\
\text { Company } \\
\text { Plant (County) }\end{array}$} & \multirow{2}{*}{$\begin{array}{l}\text { Unit } \\
\text { ID }\end{array}$} & \multirow{2}{*}{$\begin{array}{l}\text { Generator } \\
\text { Nameplate } \\
\text { Capacity } \\
\text { (megawatts) }\end{array}$} & \multirow{2}{*}{$\begin{array}{l}\text { Net Summer } \\
\text { Capability } \\
\text { (megawatts) }\end{array}$} & \multirow{2}{*}{$\begin{array}{c}\text { Net Winter } \\
\text { Capability } \\
\text { (megnwatts) }\end{array}$} & \multirow{2}{*}{$\begin{array}{r}\text { Unit } \\
\text { Typel }\end{array}$} & \multicolumn{2}{|c|}{ Energy Sourcel } & \multirow{2}{*}{$\begin{array}{c}\text { Year } \\
\text { of } \\
\text { Commercial } \\
\text { Operation }\end{array}$} & \multirow{2}{*}{$\begin{array}{c}\text { Unit } \\
\text { Status }\end{array}$} \\
\hline & & & & & & Primary & Alternate & & \\
\hline Kansas (Continued) & & & & & & & & & \\
\hline & $\begin{array}{l}10 \\
11 \\
12\end{array}$ & $\begin{array}{l}2.1 \\
4.3 \\
1.0\end{array}$ & $\begin{array}{r}1.8 \\
3.6 \\
.9\end{array}$ & $\begin{array}{l}2.1 \\
3.8 \\
1.0\end{array}$ & $\begin{array}{l}\text { IC } \\
\text { IC } \\
\text { IC }\end{array}$ & $\begin{array}{l}\text { Nat Gas } \\
\text { Nat Gas } \\
\text { Nat Gas }\end{array}$ & $\begin{array}{l}\text { FO2 } \\
\text { FO2 } \\
\text { FO2 }\end{array}$ & $\begin{array}{l}1971 \\
1978 \\
1995\end{array}$ & $\begin{array}{l}\text { OP } \\
\text { OP } \\
\text { OP }\end{array}$ \\
\hline 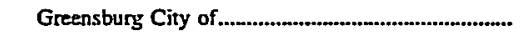 & & $\mathbf{7 . 8}$ & 7.4 & 7.4 & & & & & \\
\hline Greensburg (Kiowa) & ] & 2.1 & 2.0 & 2.0 & IC & Nat Gus & $\mathrm{FO} 2$ & 1966 & OP \\
\hline & 3 & 1.1 & 1.1 & 1.3 & IC & Nat Gas & FO2 & 1963 & OP \\
\hline & 4 & 1.1 & 1.1 & 1.1 & IC & Nat Gas & FO2 & 1956 & $\mathrm{OP}$ \\
\hline & 5 & 2.1 & 1.9 & 1.9 & IC & Nat Gas & FO2 & 1972 & $\mathrm{OP}$ \\
\hline & 6 & 1.4 & 1.3 & 13 & IC & Nat Gas & FO2 & 1983 & OP \\
\hline Herington City of & & 9.7 & 7.0 & 7.7 & & & & & \\
\hline Herington (Dickinson) & J & 2.1 & 1.6 & 1.8 & IC & Nat Gas & FO2 & 1968 & OP \\
\hline & 2 & 1.4 & 1.0 & 1.1 & IC & Nat Gas & FO2 & 1962 & $\mathrm{OP}$ \\
\hline & 3 & 4.3 & 3.1 & 35 & IC & Nat Gas & $\mathrm{FO2}$ & 1973 & OP \\
\hline & 4 & .8 & 3 & 3 & IC & $\mathrm{FO} 2$ & - & 1947 & SB \\
\hline & 5 & 1.1 & 1.0 & 1.0 & IC & Nat Gas & $\mathrm{FO} 2$ & 1951 & OP \\
\hline Herndon City of & & 3 & 3 & 3 & & & & & \\
\hline 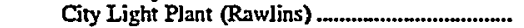 & 1 & 3 & .3 & 3 & IC & $\mathrm{FO} 2$ & - & 1950 & OP \\
\hline 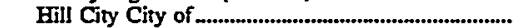 & & 7.3 & 6.4 & 6.5 & & & & & \\
\hline Hill City (Graham) & 1 & 1.4 & 1.2 & 1.2 & IC & Nat Gas & $\mathrm{FO} 2$ & 1962 & OP \\
\hline & 2 & 1.4 & 1.2 & 1.2 & IC & Nat Gas & FO2 & 1962 & OP \\
\hline & 3 & .7 & .6 & .6 & IC & Nat Gas & FO2 & 1952 & OP \\
\hline & 4 & 1.1 & 1.0 & 1.0 & IC & Nat Gas & FO2 & 1967 & op \\
\hline & 5 & 1.4 & 1.3 & 1.3 & IC & Nat Gas & FO2 & 1974 & OP \\
\hline & & 1.4 & 1.3 & 13 & IC & Nat Gas & FO2 & 1974 & OP \\
\hline Hoisington City of & & 142 & 14.4 & 14.4 & & & & & \\
\hline 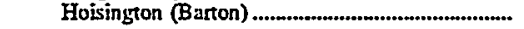 & $2 A$ & 1.0 & 1.2 & 1.2 & IC & FO2 & - & 1996 & OP \\
\hline & 1 & .2 & .2 & 2 & IC & $\mathrm{FO2}$ & - & 1940 & OP \\
\hline & 6 & 2.0 & 2.0 & 2.0 & IC & Nat Gas & $\mathrm{FO} 2$ & 1961 & OP \\
\hline & 7 & 4.0 & 4.0 & 4.0 & IC & Nat Gas & FO2 & 1966 & OP \\
\hline & 8 & 7.0 & 7.0 & 7.0 & IC & Nat Gas & $\mathrm{FO} 2$ & 1981 & OP \\
\hline Holton City of & & 15.4 & 13.5 & 14.8 & & & & & \\
\hline Holton (Jackson) & 6 & 1.8 & 1.4 & 1.8 & IC & $\mathrm{FO} 2$ & Nat Gas & 1958 & OP \\
\hline & 7 & 2.8 & 2.4 & 2.7 & IC & $\mathrm{FO} 2$ & Nat Gas & 1963 & OP \\
\hline & 8 & 4.3 & 3.9 & 4.0 & IC & FO2 & Nat Gas & 1969 & $O P$ \\
\hline & 9 & 2.0 & 1.8 & 2.0 & IC & $\mathrm{FO} 2$ & Nat Gas & 1978 & $O P$ \\
\hline & 10 & 2.0 & 1.8 & 2.0 & IC & $\mathrm{FO2}$ & Nat Gas & 1978 & $\mathrm{OP}$ \\
\hline & 11 & 2.5 & 23 & 2.4 & IC & $\mathrm{FO} 2$ & Nat Gas & 1994 & OP \\
\hline Hugoton City of & & 21.3 & 19.1 & 19.1 & & & & & \\
\hline 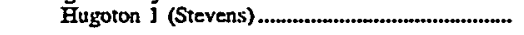 & 1 & .8 & .6 & .6 & IC & $\mathrm{FO2}$ & Nat Gas & 1949 & OP \\
\hline & 2 & .2 & .1 & .1 & IC & FO2 & Nat Gas: & 1929 & OP \\
\hline & 4 & .4 & .4 & .4 & IC & $\mathrm{FO2}$ & Nat Gas & 1940 & OP \\
\hline & 6 & 1.4 & 1.2 & 12 & IC & $\mathrm{FO} 2$ & Nat Gas & 1959 & OP \\
\hline Hugoton 2 (Stevens) & $9 A$ & 4.3 & 4.0 & $4 . \overline{0}$ & IC & FO2 & Nat Gas & 1994 & OP \\
\hline & 7 & 23 & 2.1 & 2.1 & IC & FO2 & Nat Gas & 1964 & OP \\
\hline & 8 & 2.1 & 1.8 & 1.8 & IC & FO2 & Nat Gas & 1971 & OP \\
\hline & 10 & 4.3 & 4.0 & 4.0 & IC & FO2 & Nat Gas & 1983 & OP \\
\hline & 11 & 2.5 & 2.2 & 2.2 & IC & $\mathrm{FO} 2$ & Nat Gas & 1997 & OP \\
\hline & 12 & 3.0 & 2.8 & 2.8 & IC & $\mathrm{FO2}$ & Nat Gas & 1997 & $\mathrm{OP}$ \\
\hline Iola City of & & 28.5 & 30.7 & 30.7 & & & & & \\
\hline Iola (Allen) & 4 & 3.5 & 4.4 & 4.4 & ST & Nat Gas & FOS & 1949 & OP \\
\hline & 5 & 5.0 & 5.4 & 5.4 & ST & Nat Gas & FO5 & 1957 & OP \\
\hline & 6 & 28 & 3.0 & 3.0 & IC & $\mathrm{FO} 2$ & - & 1969 & OP \\
\hline & 7 & 27 & 2.9 & 2.9 & IC & FO2 & - & 1971 & OP \\
\hline & 8 & 28 & 3.0 & 3.0 & IC & FO2 & - & 1976 & OP \\
\hline & 9 & 28 & 3.0 & 3.0 & IC & $\mathrm{FO} 2$ & - & 1977 & OP \\
\hline & 10 & 2.8 & 29 & 2.9 & IC & $\mathrm{FO} 2$ & - & 1981 & OP \\
\hline & ]1] & 2.1 & 2.2 & 2.2 & IC & $\mathrm{FO} 2$ & - & 1988 & OP \\
\hline & 12 & 2.1 & 20 & 2.0 & IC & $\mathrm{FO2}$ & - & 1988 & OP \\
\hline & 13 & 2.1 & 2.] & 2.1 & IC & FO2 & - & 1988 & OP \\
\hline Jetmore City of & & 6.0 & 6.0 & 6.0 & & & & & \\
\hline 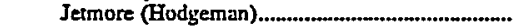 & 1 & 1.0 & 1.0 & 1.0 & IC & $\mathrm{FO} 2$ & Nat Gas & 1960 & OP \\
\hline & 2 & .4 & .4 & .4 & IC & FO2 & Nat Gas & 1951 & OP \\
\hline & 3 & .2 & .2 & 2 & IC & FO2 & Nat Gas & 1946 & OP \\
\hline & 4 & .8 & .8 & .8 & IC & FO2 & Nat Gas & 1964 & OP \\
\hline & 5 & 1.5 & 1.5 & 15 & IC & $\mathrm{FO} 2$ & Nat Gas & 1966 & OP \\
\hline & 6 & 1.2 & 1.2 & 1.2 & IC & FO2 & - & 1966 & OP \\
\hline & 7 & .9 & .9 & .9 & IC & FO2 & - & 1966 & OP \\
\hline 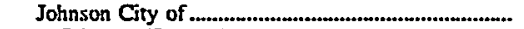 & & 6.8 & 5.5 & 5.5 & & & & & \\
\hline Johnson (Stanton) & IC6 & 1.5 & 1.3 & 1.3 & IC & $\mathrm{FO2}$ & Nat Gas & 1986 & OP \\
\hline & 1 & .6 & .6 & .6 & IC & FO2 & Nat Gas & 1959 & OP \\
\hline
\end{tabular}

See footnotes at end of table. 
Table 20. Existing Generating Units at U.S. Electric Utilities by State, Company, and Plant, as of January 1, 1998 (Continued)

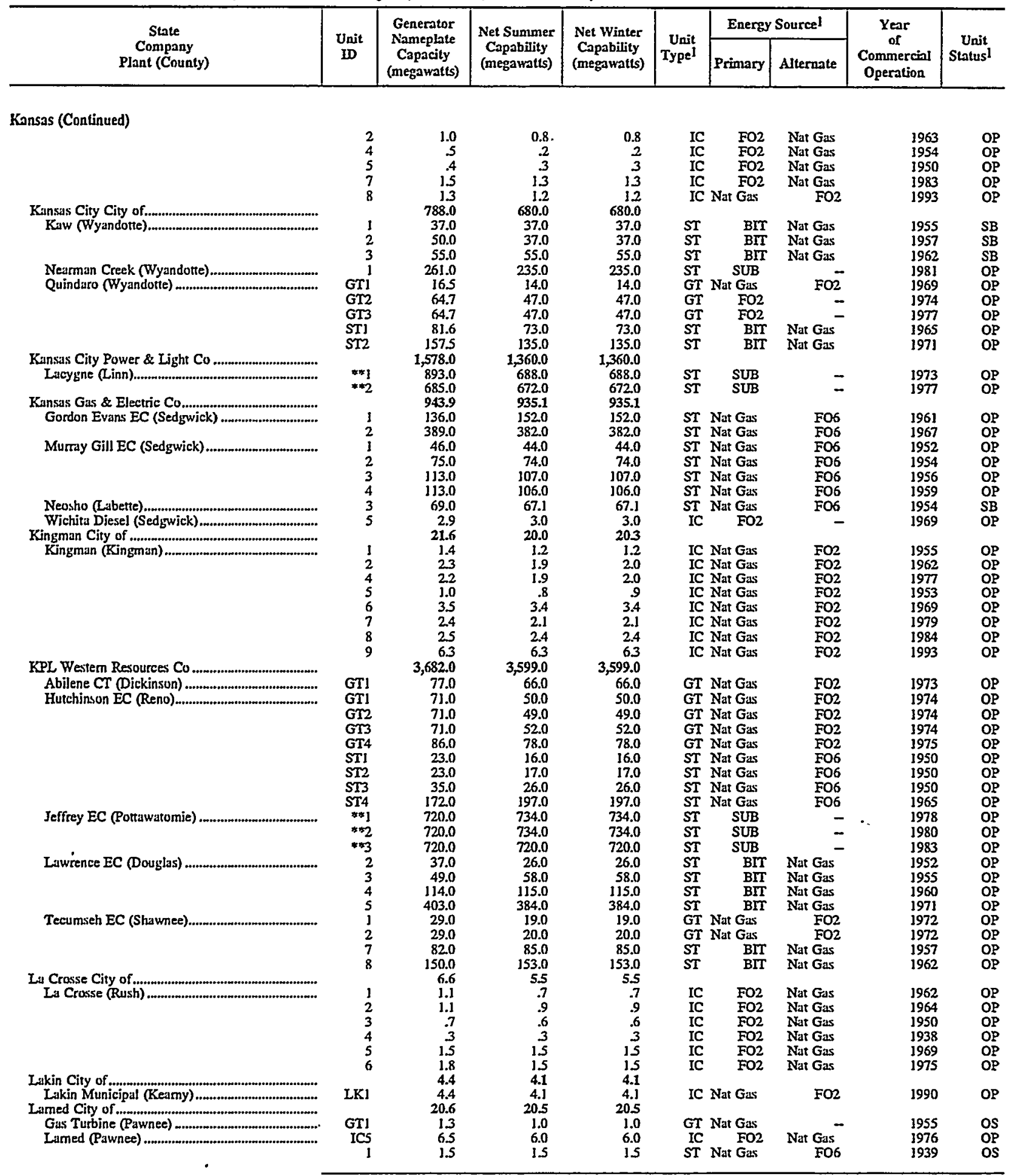

See footnotes at end of table. 
Table 20. Existing Generating Units at U.S. Electric Utilities by State, Company, and Plant, as of January 1, 1998 (Continued)

\begin{tabular}{|c|c|c|c|c|c|c|c|c|c|}
\hline \multirow{2}{*}{$\begin{array}{c}\text { State } \\
\text { Company } \\
\text { Plant (County) }\end{array}$} & \multirow{2}{*}{$\begin{array}{l}\text { Unit } \\
\text { ID }\end{array}$} & \multirow{2}{*}{$\begin{array}{c}\text { Generator } \\
\text { Nameplate } \\
\text { Capacity } \\
\text { (megawatts) }\end{array}$} & \multirow{2}{*}{$\begin{array}{c}\text { Net Summer } \\
\text { Capability } \\
\text { (megawatts) }\end{array}$} & \multirow{2}{*}{$\begin{array}{l}\text { Net Winter } \\
\text { Capability } \\
\text { (megawatts) }\end{array}$} & \multirow{2}{*}{$\begin{array}{l}\text { Unit } \\
\text { Type }\end{array}$} & \multicolumn{2}{|c|}{ Energy Source! } & \multirow{2}{*}{$\begin{array}{c}\text { Year } \\
\text { of } \\
\text { Commercial } \\
\text { Operation }\end{array}$} & \multirow{2}{*}{$\begin{array}{c}\text { Unit } \\
\text { Status } 1\end{array}$} \\
\hline & & & & & & Primary & Alternate & & \\
\hline Kansas (Continued) & & & & & & & & & \\
\hline & $\frac{2}{3}$ & $\begin{array}{l}3.0 \\
8.3\end{array}$ & $\begin{array}{l}3.0 \\
9.0\end{array}$ & $\begin{array}{l}3.0 \\
9.0\end{array}$ & $\begin{array}{l}\text { ST } \\
\text { ST }\end{array}$ & $\begin{array}{l}\text { Nat Gas } \\
\text { Nat Gas }\end{array}$ & $\begin{array}{l}\text { FO6 } \\
\text { F06 }\end{array}$ & $\begin{array}{l}1948 \\
1966\end{array}$ & $\begin{array}{l}\text { OS } \\
\text { OP }\end{array}$ \\
\hline Lincoln Center City of & & 10.7 & 9.1 & 9.1 & & & & & \\
\hline Lincoln (Lincoln) & 1 & 1.3 & 1.1 & 1.1 & IC & Nat Gas & $\mathrm{FO} 2$ & 1964 & OP \\
\hline & 2 & 1.3 & 1.1 & 1.1 & IC & Nat Gas & $\mathrm{FO} 2$ & 1964 & $\mathrm{OP}$ \\
\hline$\cdot$ & 4 & .8 & .6 & .6 & IC & Nat Gas & FO2 & 3958 & $O P$ \\
\hline & 5 & 1.3 & 1.1 & 1.1 & IC & Nat Gas & FO2 & 1960 & OP \\
\hline & $\begin{array}{l}6 \\
7\end{array}$ & 2.5 & 2.2 & 2.2 & IC & $\quad \mathrm{FO} 2$ & Nat Gas & 1979 & OP \\
\hline McPherson City of & & 197.0 & 182.4 & 206.6 & IC & & Nat Gas & & \\
\hline McPherson 2 (Mcphersion) & GTI & 56.4 & 529 & 60.0 & GT & Nat Gas & FO2 & 1973 & OP \\
\hline & GT2 & 56.4 & 50.9 & 60.0 & GT & $\mathrm{FO} 2$ & & 1976 & OP \\
\hline & GT3 & 57.6 & 52.0 & 60.0 & Gr & Nat Gas & $\mathrm{FO} 2$ & 3979 & OP \\
\hline Meade Civy of & 1 & $\begin{array}{r}26.6 \\
82\end{array}$ & 26.6 & 26.6 & ST & Nat Gas & FO6 & 1963 & OP \\
\hline $\begin{array}{l}\text { Meade City of } \\
\text { Meade (Meade) }\end{array}$ & 2 & 8.2 & $\begin{array}{r}7.7 \\
.8\end{array}$ & $\begin{array}{r}8.2 \\
9\end{array}$ & & & & & \\
\hline & 3 & $\therefore$ & 8 & 9 & IC & F02 & Nat Gas & 1951 & OP \\
\hline & 4 & 1.4 & 1.3 & $\begin{array}{l}1.1 \\
1.4\end{array}$ & IC & $\mathrm{FO} 2$ & $\begin{array}{l}\text { Nat Gas } \\
\text { Nat Gass }\end{array}$ & 1957 & OP \\
\hline & 5 & 2.1 & 2.0 & 2.2 & IC & $\mathrm{FO} 2$ & Nat Gas & 1965 & $O P$ \\
\hline & 6 & 27 & 2.5 & 2.7 & IC & $\mathrm{FO} 2$ & Nat Gas & 1972 & OP \\
\hline 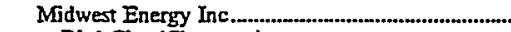 & & 35.7 & 32.0 & 32.0 & & & & & \\
\hline Bird City (Cheyenne) & ] & 2.0 & 2.0 & 2.0 & IC & $\mathrm{FO} 2$ & - & 1965 & $O P$ \\
\hline & & 2.0 & 2.0 & 2.0 & IC & FO2 & & 3966 & OP \\
\hline 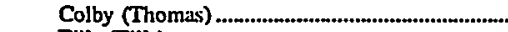 & GT1 & 16.0 & 13.0 & 13.0 & GT & Nat Gas & $\mathrm{FO} 2$ & 1970 & OP \\
\hline Ellis (Ellis) & J & 1.0 & 1.0 & 1.0 & IC & Nat Gas & $\mathrm{FO} 2$ & 1960 & OP \\
\hline & 2 & 20 & 2.0 & 2.0 & IC & Nat Gas & FO2 & 1965 & OP \\
\hline & 3 & .6 & 5 & $s$ & IC & Nat Gas & FO2 & 1947 & OP \\
\hline & 4 & .6 & .5 & 5 & IC & Nat Gas & $\mathrm{FO} 2$ & 1954 & OP \\
\hline & 5 & 1.6 & 1.0 & 1.0 & IC & Nat Gas & & 1973 & OP \\
\hline Great Bend (Barton) & ] & 1.0 & 1.0 & 1.0 & IC & Nat Gas & $\mathrm{FO} 2$ & 1947 & OP \\
\hline & 2 & 1.0 & 1.0 & 1.0 & IC & Nat Gas & $\mathrm{FO} 2$ & 1947 & OP \\
\hline & 3 & 1.0 & 1.0 & 1.0 & IC & Nat Gas & $\mathrm{FO} 2$ & 1949 & OP \\
\hline & 4 & 1.0 & 1.0 & 1.0 & IC & Nat Gas & $\mathrm{FO} 2$ & 1949 & OP \\
\hline & 5 & 3.0 & 3.0 & 3.0 & IC & Nat Gas & $\mathrm{FO} 2$ & 3954 & OP \\
\hline & 6 & 3.0 & 3.0 & 3.0 & IC & Nat Gas & FO2 & 1954 & OP \\
\hline 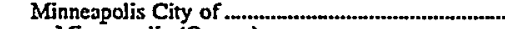 & & 102 & 9.0 & 9.0 & & & & & \\
\hline Minneapolis (Ontawa) & 1 & .4 & .4 & .4 & IC & FO2 & $0^{-}$ & 1936 & OP \\
\hline & 2 & .7 & 5 & 5 & IC & & FO2 & 1947 & OP \\
\hline & 3 & 1.3 & 1.2 & 12 & IC & Nat Gas & $\mathrm{FO} 2$ & 396] & $O P$ \\
\hline & 4 & .7 & .6 & .6 & IC & Nat Gas & FO2 & 1955 & OP \\
\hline & 5 & 2.1 & 1.8 & 1.8 & IC & Nat Gas & FO2 & 1966 & OP \\
\hline & 6 & 3.0 & 2.8 & 2.8 & IC & Nat Gas & $\mathrm{FO} 2$ & 1972 & OP \\
\hline & 7 & 20 & 1.8 & 1.8 & IC & FO2 & - & 1989 & $\mathrm{OP}$ \\
\hline Mulvane City of & & 6.3 & 6.9 & 6.9 & & & & & \\
\hline 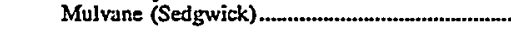 & 1 & .4 & 3 & 3 & IC & $\mathrm{FO} 2$ & - & 1949 & $\mathrm{OP}$ \\
\hline & & 3 & .3 & .4 & IC & FO2 & - & 1945 & OP \\
\hline & 3 & 1.4 & 1.6 & 1.6 & IC & Nat Gas & FO2 & 1963 & OP \\
\hline & 4 & 1.4 & 1.5 & 1.5 & IC & FO2 & Nat Gas & 1958 & $O P$ \\
\hline & 5 & .8 & .8 & .8 & IC & FO2 & Nat Gas & 1967 & $O P$ \\
\hline & 6 & 2.1 & 2.3 & 23 & IC & FO2 & Nat Gas & 1967 & OP \\
\hline Neodesha City of................. & & 8.2 & 7.8 & 7.8 & & & & & \\
\hline Neodesha (Wilson) & 5 & 1.3 & 1.0 & 1.0 & IC & F02 & Nat Gas & 1952 & OP \\
\hline & 6 & 23 & 2.2 & 2.2 & IC & FO2 & Nat Gas & 1956 & OP \\
\hline & 7 & 2.0 & 2.0 & 2.0 & IC & FO2 & Nat Gas & 1962 & OP \\
\hline & 8 & 2.7 & 2.6 & 2.6 & IC & $\mathrm{FO} 2$ & Nat Gas & 1968 & OP \\
\hline Notton City of .................. & & 11.3 & 10.1 & 10.1 & & & & & \\
\hline Norton (Norton) & 1 & 1.0 & .9 & .9 & IC & Nat Gas & $\mathrm{FO} 2$ & 1955 & OP \\
\hline & 2 & 1.5 & 1.4 & 1.4 & IC & Nat Gas & $\mathrm{FO} 2$ & 1960 & $O P$ \\
\hline & 3 & 28 & 2.5 & 25 & IC & Nat Gas & $\mathrm{FO} 2$ & 1963 & $O P$ \\
\hline & 4 & 3.5 & 3.2 & 3.2 & IC & Nat Gas & FO2 & 1968 & OP \\
\hline & 5 & 2.5 & 2.3 & 2.3 & IC & FO2 & - & 1977 & OP \\
\hline Oakley City of & & 82 & 7.5 & 7.8 & & & & & \\
\hline Oakely $(\log a n)$ & $\frac{1}{2}$ & 1.4 & 1.3 & 1.3 & IC & $\mathrm{FO} 2$ & Nat Gas & 1961 & $O P$ \\
\hline & 2 & .4 & $\frac{3}{5}$ & .4 & IC & FO2 & Nat Gas ${ }^{-}$ & 1948 & $\begin{array}{l}O P \\
O P \\
O P\end{array}$ \\
\hline & 3 & .6 & $\begin{array}{l}.5 \\
.9\end{array}$ & $\begin{array}{l}5 \\
9\end{array}$ & IC & FO2 & $\begin{array}{l}\text { Nat Gas } \\
\text { Nat Gas }\end{array}$ & 1951 & OP \\
\hline & $\frac{4}{5}$ & .9 & $\begin{array}{r}.9 \\
1.4\end{array}$ & 15 & IC & FO2 & $\begin{array}{l}\text { Nat Gas } \\
\text { Nat Gas }\end{array}$ & 1956 & $P$ \\
\hline & 5 & 1.5 & 1.4 & 1.5 & IC & FO2 & Nat Gas & 1965 & OP \\
\hline & 6 & 3.4 & 3.2 & 33 & IC & FO2 & Nat Gas & 1973 & OP \\
\hline 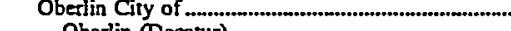 & & 7.0 & 5.6 & 5.6 & & & & & \\
\hline Obedin (Decatur) & 1 & 1.1 & .9 & .9 & IC & Nat Gas & FO2 & 1956 & OP \\
\hline
\end{tabular}

See foomotes at end of table. 
Table 20. Existing Generating Units at U.S. Electric Utilities by State, Company, and Plant, as of January 1, 1998 (Continued)

\begin{tabular}{|c|c|c|c|c|c|c|c|c|c|}
\hline \multirow{2}{*}{$\begin{array}{c}\text { State } \\
\text { Company } \\
\text { Plant (County) }\end{array}$} & \multirow{2}{*}{$\begin{array}{l}\text { Unit } \\
\text { ID }\end{array}$} & \multirow{2}{*}{$\begin{array}{c}\text { Generator } \\
\text { Nameptate } \\
\text { Capacity } \\
\text { (megawatts) }\end{array}$} & \multirow{2}{*}{$\begin{array}{c}\text { Net Summer } \\
\text { Capability } \\
\text { (megawatts) }\end{array}$} & \multirow{2}{*}{$\begin{array}{l}\text { Net Winter } \\
\text { Capability } \\
\text { (megawatts) }\end{array}$} & \multirow{2}{*}{$\begin{array}{r}\text { Unit } \\
\text { Type }\end{array}$} & \multicolumn{2}{|c|}{ Energy Sourcel } & \multirow{2}{*}{$\begin{array}{c}\text { Year } \\
\text { of } \\
\text { Commercinl } \\
\text { Operation }\end{array}$} & \multirow{2}{*}{$\begin{array}{c}\text { Unit } \\
\text { Status }\end{array}$} \\
\hline & & & & & & Primary & Alternate & & \\
\hline Kansas (Continued) & & & & & & & & & \\
\hline & 2 & 0.8 & 0.6 & 0.6 & & Nat Gas & FO2 & 1954 & OP \\
\hline & 4 & 1.5 & 1.2 & 12 & & Nat Gas & $\mathrm{FO} 2$ & 1967 & OP \\
\hline & 5 & 20 & 3.6 & 1.6 & & Nat Gas & $\mathrm{FO} 2$ & 1973 & OP \\
\hline & 6 & 1.5 & 1.2 & 12 & IC & Nat Gas & $\mathrm{FO} 2$ & 1963 & OP \\
\hline Osage City City of & & 9.5 & 8.2 & 8.2 & & & & $\cdots$ & \\
\hline 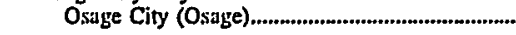 & IC6 & 1.1 & .9 & .9 & IC & FO2 & Nat Gas & 1983 & OP \\
\hline & 1 & 1.1 & $\therefore 9$ & 9 & IC & FO2 & Nat Gas & 1955 & OP \\
\hline & 2 & 3.3 & 1.1 & 1.1 & IC & $\mathrm{FO} 2$ & Nat Gas & 1960 & OP \\
\hline & 4 & 21 & 1.9 & 1.9 & IC & $\mathrm{FO2}$ & Nat Gas & 1967 & OP \\
\hline & 5 & 21 & 1.9 & 1.9 & IC & $\mathrm{FO} 2$ & Nat Gas & 1970 & OP \\
\hline & 7 & 3.8 & 1.5 & 15 & IC & $\mathrm{FO} 2$ & Nat Gas & 3984 & $O P$ \\
\hline Osawatomie City of & & 7.0 & 5.9 & 6.0 & & & & & \\
\hline 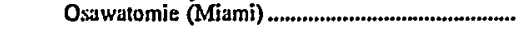 & 2 & 2.3 & 1.8 & 1.9 & IC & FO2 & Nat Gas & 1957 & OP \\
\hline & 3 & .4 & .3 & 3 & IC & FO2 & & 1934 & os \\
\hline & 4 & 1.2 & 1.0 & 1.0 & IC & FO2 & Nat Gas & 1950 & OP \\
\hline & 5 & 3.1 & 2.8 & 2.8 & IC & FO2 & Nat Gas & 1966 & OP \\
\hline Osbome City of & & 7.2 & 6.1 & 6.7 & & & & & \\
\hline Osbome (Osbome) & 1 & 2.3 & 1.8 & 2.0 & IC & $\mathrm{FO} 2$ & Nat Gas & 1967 & OP \\
\hline & $\frac{2}{3}$ & 2.0 & 1.8 & 2.0 & IC & $\mathrm{FO2}$ & Nat Gas & 1963 & $O P$ \\
\hline & $\begin{array}{l}3 \\
6\end{array}$ & $\begin{array}{r}1.1 \\
.5\end{array}$ & $\begin{array}{l}.7 \\
.5\end{array}$ & $\begin{array}{r}.9 \\
-5\end{array}$ & IC & Nar $\mathrm{Fa}_{2}$ & Nat Gas _ & $\begin{array}{l}1957 \\
1992\end{array}$ & OP \\
\hline & 7 & 5 & .5 & $s$ & IC & Nat Gas & - & 1992 & OP \\
\hline$\cdot$ & 8 & .8 & .8 & .8 & IC & Nat Gas & - & 1994 & OP \\
\hline Ottawa City of & & 30.8 & 27.9 & 29.6 & & & & & \\
\hline Ottawa (Franklin) & GT1 & 11.5 & 9.0 & 10.5 & GT & Nat Gas & - & 1967 & OP \\
\hline & IC3 & 3.8 & 3.7 & 3.7 & IC & Nat Gas & $\mathrm{FO} 2$ & 1962 & $\mathrm{OP}$ \\
\hline & IC4 & 3.5 & 3.4 & 3.5 & IC & Nar Gas & FO2 & 1958 & OP \\
\hline & IC6 & 6.0 & 5.9 & 6.0 & IC & Nat Gas & FO2 & 198] & OP \\
\hline & IC7 & 6.0 & 5.9 & 6.0 & IC & Nat Gas & $\mathrm{FO} 2$ & 198] & OP \\
\hline Oxford City of & & 5.5 & 3.1 & 3.1 & & & & & \\
\hline City of Oxford (Sumner) & $\frac{1}{2}$ & 3.1 & $\begin{array}{l}.6 \\
.6\end{array}$ & $\begin{array}{l}.6 \\
.6\end{array}$ & $\begin{array}{l}\text { IC } \\
\text { IC }\end{array}$ & $\begin{array}{l}\mathrm{FO} 2 \\
\text { FO2 }\end{array}$ & $\overline{-}$ & $\begin{array}{l}1986 \\
1986\end{array}$ & $\begin{array}{l}\text { OP } \\
\text { OP }\end{array}$ \\
\hline & 3 & 3.1 & .6 & .6 & IC & $\mathrm{FO} 2$ & - & 1986 & OP \\
\hline & 4 & I.I & .6 & .6 & IC & $\mathrm{FO} 2$ & - & 1990 & OP \\
\hline & 5 & 1.1 & .6 & .6 & IC & FO2 & - & 1990 & OP \\
\hline Pratt City of & & 31.5 & 31.3 & 324 & & & & & \\
\hline 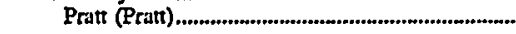 & IC] & 1.5 & 1.5 & 1.5 & IC & $\mathrm{FO} 2$ & Nat Gas & 1958 & OP \\
\hline & $\frac{1}{3}$ & 3.0 & $E_{5.8}$ & $E_{3.1}$ & $\underset{S T}{S T}$ & $\mathrm{FO} 2$ & Nat Gas & 1938 & OP \\
\hline & $\frac{3}{5}$ & 5.0 & $\begin{array}{r}5.8 \\
130\end{array}$ & 5.8 & ST & $\mathrm{FO} 2$ & Nat Gas & 1953 & OP \\
\hline & 5 & 14.0 & 13.0 & 14.0 & $S T$ & $\mathrm{FO} 2$ & Nat Gas & 1965 & OP \\
\hline Pratt 2 (Pratt) & IC2 & 8.0 & 8.0 & 8.0 & IC & : Nat Gas & FO2 & 1994 & OP \\
\hline 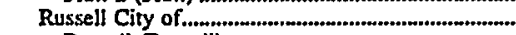 & & 30.4 & 26.4 & 26.6 & & & & & \\
\hline Russell (Russell) & 1 & 3.4 & 2.7 & 2.8 & IC & Nat Gas & FO2 & 1956 & OP \\
\hline & 2 & 3.0 & 2.5 & 2.5 & IC & Nat Gas & $\mathrm{FO} 2$ & 1958 & OP \\
\hline & 3 & .8 & 5 & .6 & IC & Nat Gas & $\mathrm{FO} 2$ & 1957 & OP \\
\hline & 4 & 5.0 & 4.5 & 4.5 & IC & Nat Gas & $\mathrm{FO} 2$ & 1965 & OP \\
\hline & 5 & 25 & 1.8 & 1.8 & IC & Nat Gas & $\mathrm{FO} 2$ & 1951 & OP \\
\hline & 7 & 3.5 & 3.0 & 3.0 & IC & Nat Gas & $\mathrm{FO} 2$ & 1971 & OP \\
\hline & 8 & 2.5 & 2.5 & 25 & Ic & $\mathrm{FO} 2$ & - & 1978 & OP \\
\hline & 9 & 2.5 & 2.5 & 25 & IC & FO2 & - & 1981 & OP \\
\hline & 11 & 3.6 & 3.2 & 3.2 & IC & Nat Gas & FO2 & 1994 & OP \\
\hline & 12 & 3.6 & 3.2 & 3.2 & IC & Nat Gas & FO2 & 1994 & OP \\
\hline 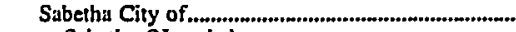 & & 18.0 & 15.2 & 152 & & & & & \\
\hline Subetha (Nemaha) & ICI0 & 2.5 & 2.1 & 2.1 & IC & F02 & Nat Gas & 1990 & OP \\
\hline & IC9 & 1.1 & 1.0 & 1.0 & IC & $\mathrm{FO2}$ & Nat Gas & 1985 & OP \\
\hline & 1 & .6 & .4 & .4 & IC & $\mathrm{FO} 2$ & & 1937 & SB \\
\hline & 2 & 1.5 & 1.3 & 13 & IC & $\mathrm{FO} 2$ & Nat Gas & 1957 & OP \\
\hline & 3 & .8 & .6 & .6 & IC & $\mathrm{FO} 2$ & Nat Gas & 1947 & OP \\
\hline & 4 & 1.0 & .8 & .8 & IC & $\mathrm{FO} 2$ & Nat Gas & 1950 & OP \\
\hline & 5 & 1.4 & 1.3 & 1.3 & IC & $\mathrm{FO} 2$ & Nat Gas & 196] & OP \\
\hline & 6 & 1.4 & 1.3 & 1.3 & IC & FO2 & Nat Gas & 1967 & OP \\
\hline & 7 & 22 & 1.8 & 1.8 & IC & FO2 & Nat Gas & 1970 & OP \\
\hline & 8 & 25 & 2.1 & 2.1 & IC & FO2 & Nat Gas & 1978 & OP \\
\hline & $\pi$ & 3.0 & 27 & 2.7 & IC & $\mathrm{FO} 2$ & Nat Gas & 1992 & $O P$ \\
\hline Sharon Springs City of & & 3.1 & 2.9 & 3.0 & & & & & \\
\hline 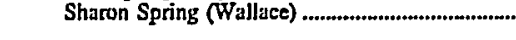 & $\frac{1}{2}$ & 1.0 & .9 & 1.0 & IC & FO2 & Nat Gas & 1970 & $O P$ \\
\hline & 2 & 1.0 & 1.0 & $\begin{array}{r}1.0 \\
4\end{array}$ & IC & FO2 & $\begin{array}{l}\text { Nat Gas } \\
\text { Nat Gas }\end{array}$ & $\begin{array}{l}1964 \\
1958\end{array}$ & 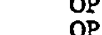 \\
\hline & 3 & .4 & .4 & .4 & IC & FO2 & Nat Gas & 1958 & $\mathrm{OP}$ \\
\hline & 4 & .7 & .6 & .6 & IC & F02 & Nat Gas & 1951 & OP \\
\hline 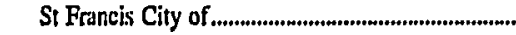 & & 5.9 & 5.9 & 5.9 & & & & & \\
\hline
\end{tabular}

See footnotes at end of table. 
Table 20. Existing Generating Units at U.S. Electric Utilities by State, Company, and Plant, as of January 1, 1998 (Continued)

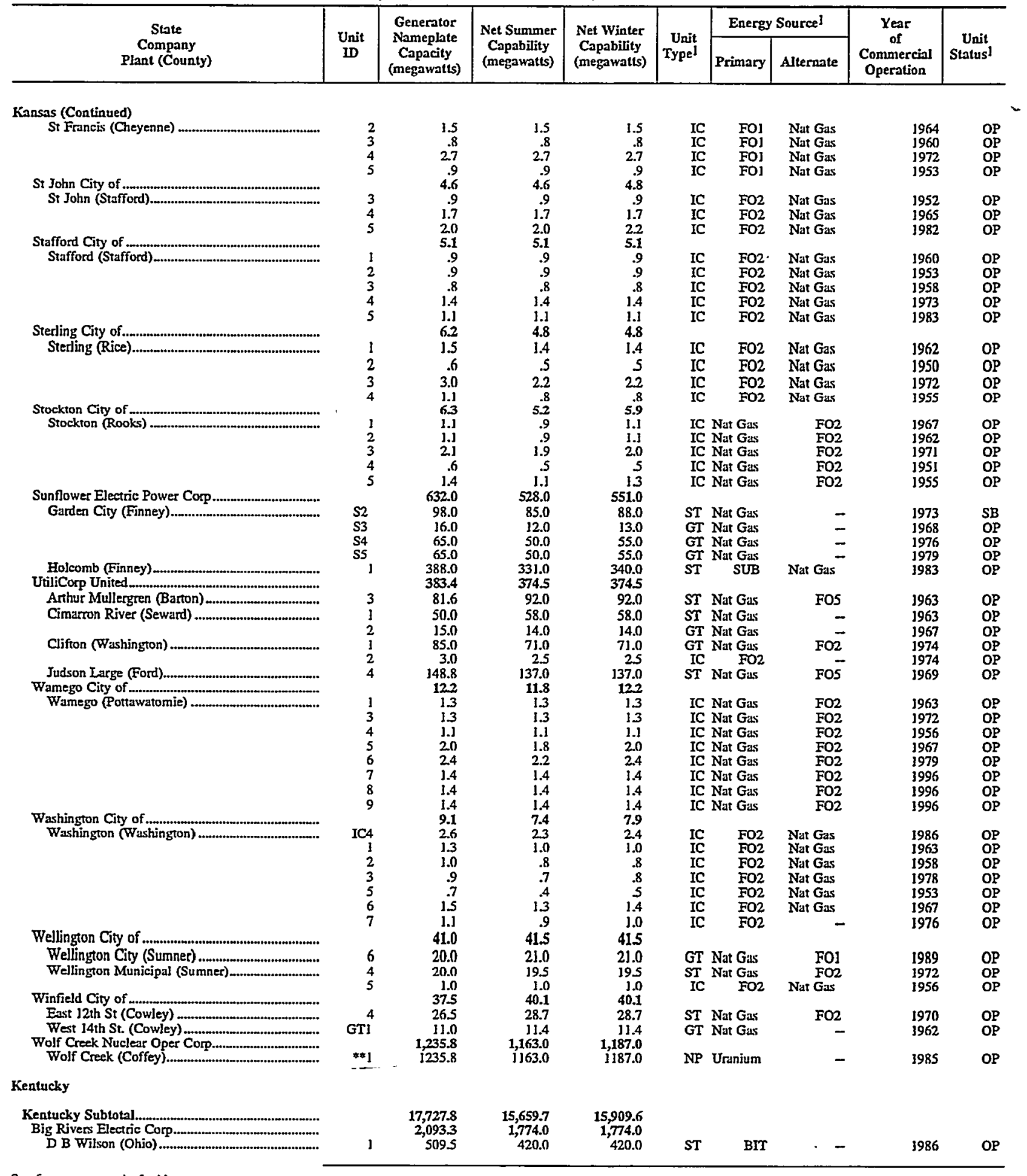

See footnotes at end of table. 
Table 20. Existing Generating Units at U.S. Electric Utilities.by State, Company, and Plant, as of January 1, 1998 (Continued)

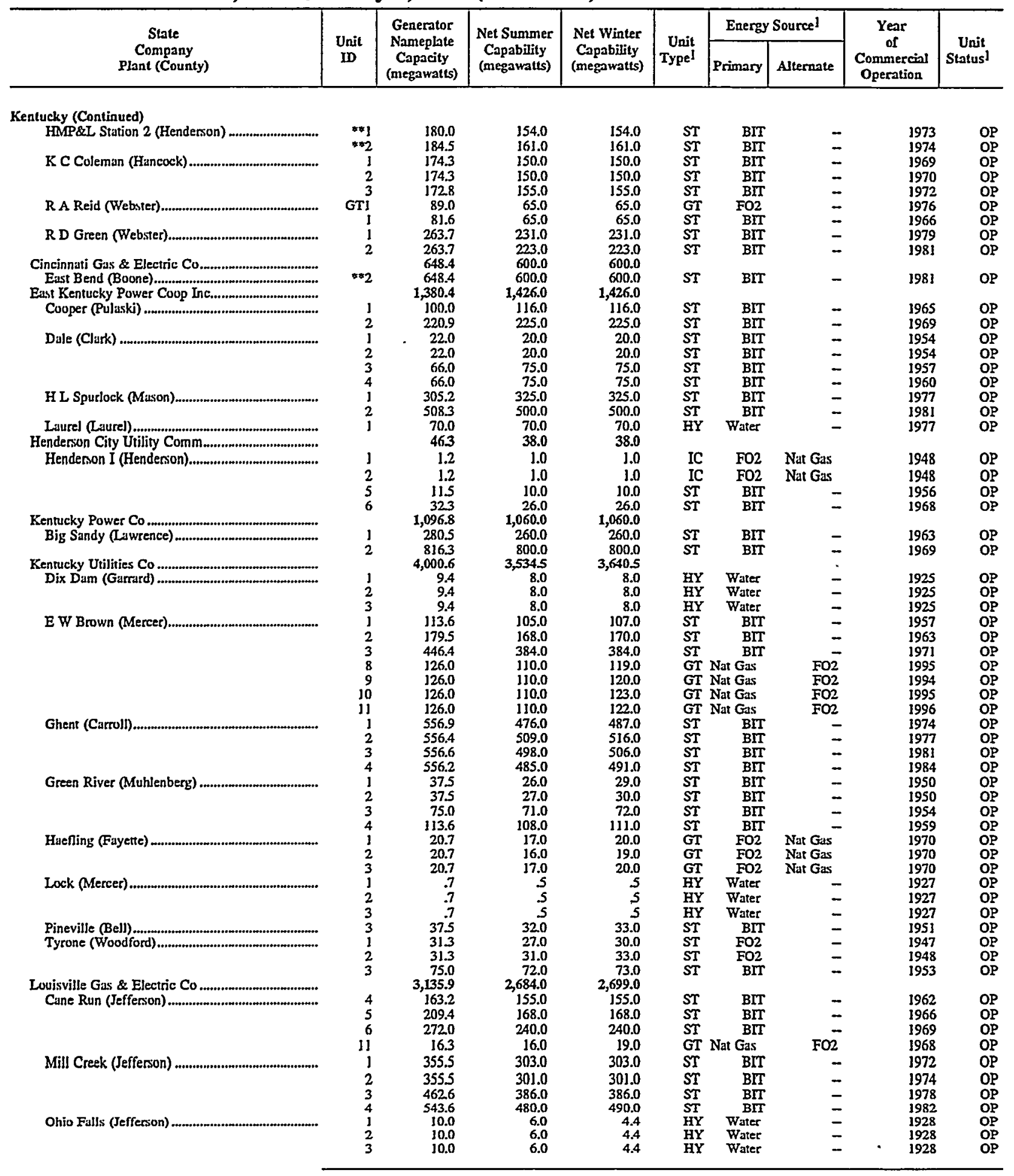

See foornotes at end of table. 
Table 20. Existing Generating Units at U.S. Electric Utilities by State, Company, and Plant, as of January 1, 1998 (Continued)

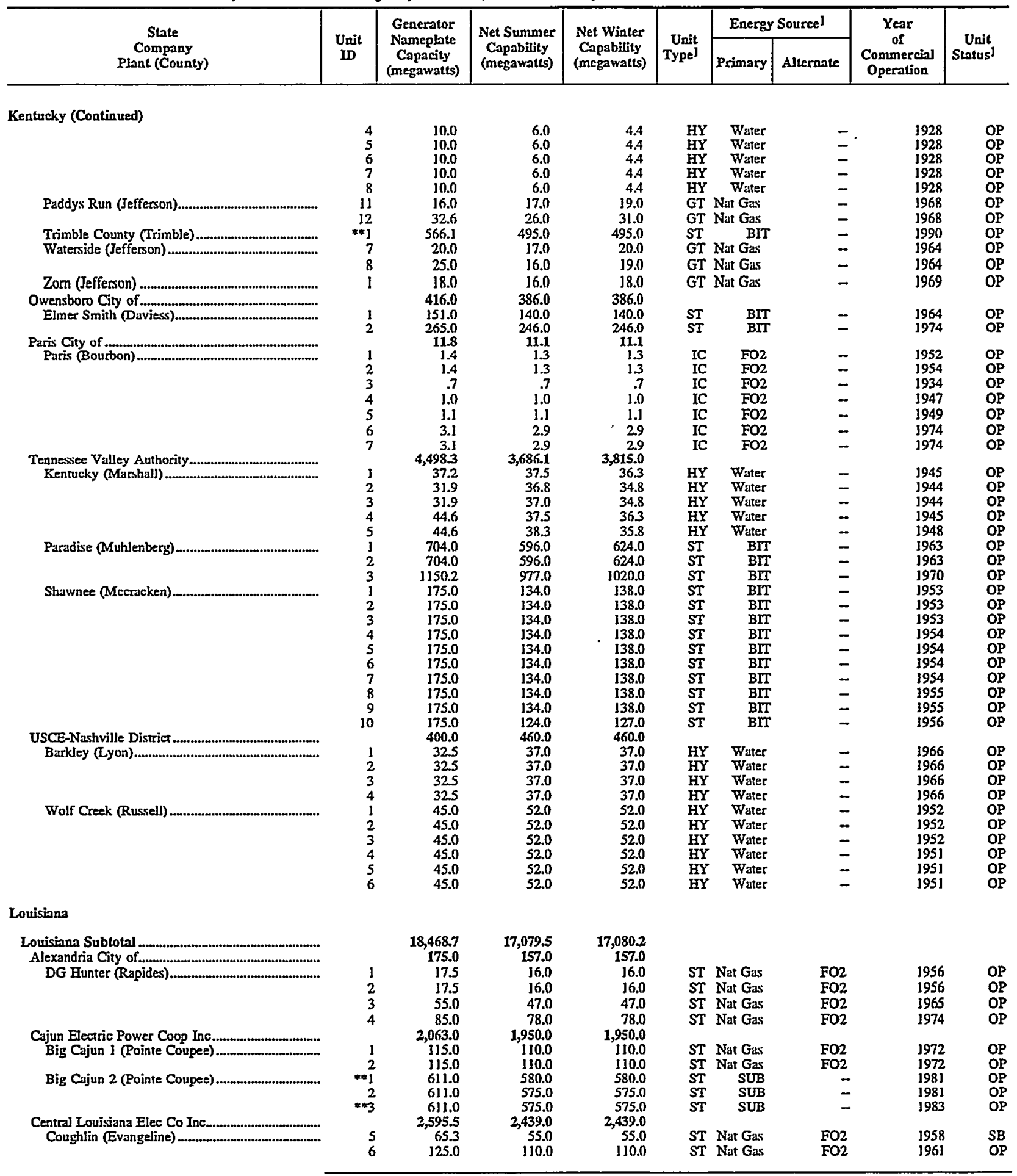

See footnotes at end of table. 
Table 20. Existing Generating Units at U.S. Electric Utilities by State, Company, and Plant, as of January 1, 1998 (Continued)

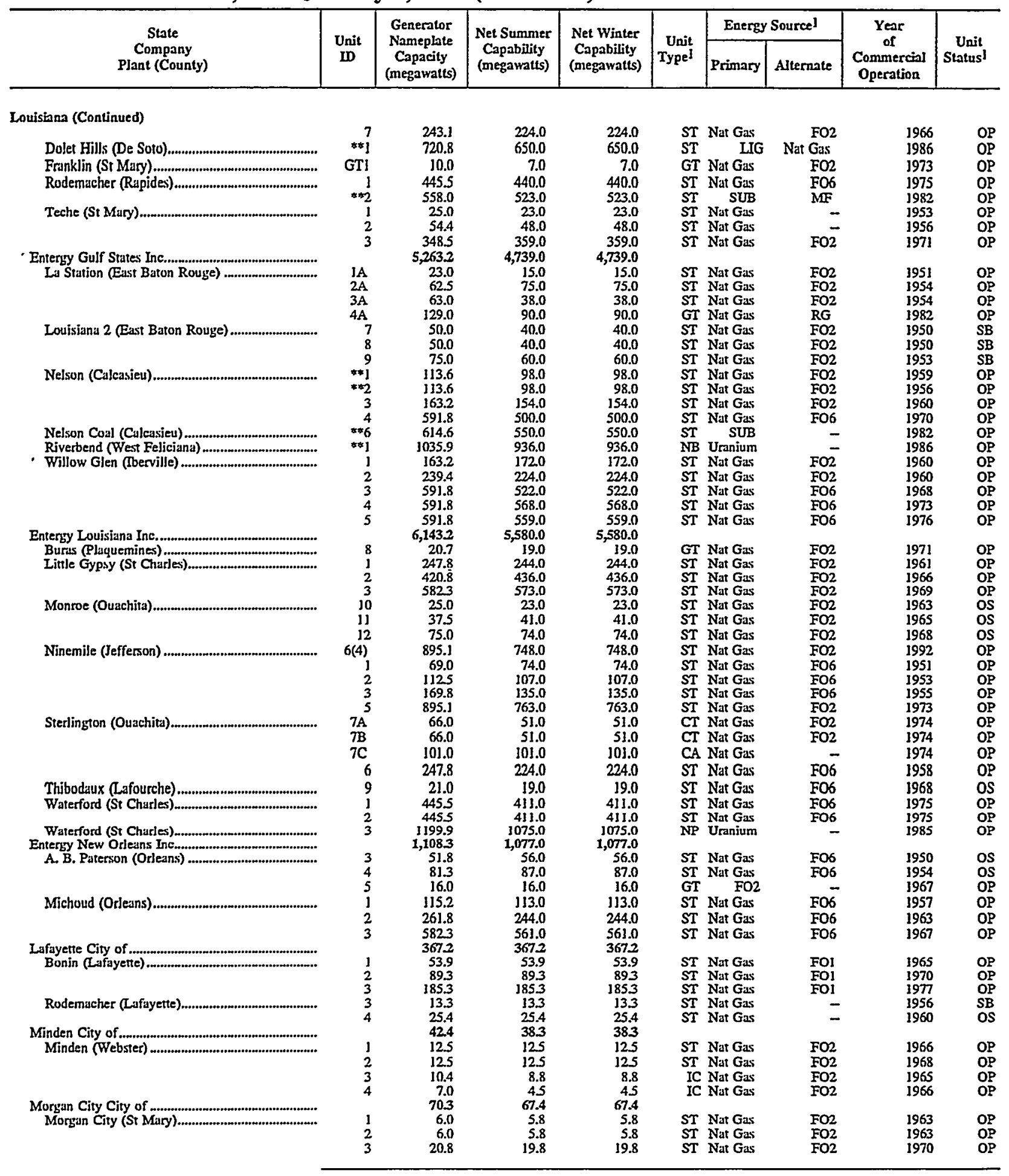

See footnotes at end of table. 
Table 20. Existing Generating Units at U.S. Electric Utilities by State, Company, and Plant, as of January 1, 1998 (Continued)

\begin{tabular}{|c|c|c|c|c|c|c|c|c|c|}
\hline \multirow{2}{*}{$\begin{array}{c}\text { State } \\
\text { Company } \\
\text { Plant (County) }\end{array}$} & \multirow{2}{*}{$\begin{array}{c}\text { Unit } \\
\text { WD }\end{array}$} & \multirow{2}{*}{$\begin{array}{c}\text { Generator } \\
\text { Nameplate } \\
\text { Capacity } \\
\text { (megawatts) }\end{array}$} & \multirow{2}{*}{$\begin{array}{c}\text { Net Summer } \\
\text { Capability } \\
\text { (megawatts) }\end{array}$} & \multirow{2}{*}{$\begin{array}{l}\text { Net Winter } \\
\text { Capability } \\
\text { (megawatts) }\end{array}$} & \multirow{2}{*}{$\begin{array}{r}\text { Unit } \\
\text { Typel }\end{array}$} & \multicolumn{2}{|c|}{ Energy Source! } & \multirow{2}{*}{$\begin{array}{c}\text { Year } \\
\text { of } \\
\text { Commercial } \\
\text { Operation }\end{array}$} & \multirow{2}{*}{$\begin{array}{c}\text { Unit } \\
\text { Status! }\end{array}$} \\
\hline & & & & & & Primary & Altermate & & \\
\hline \multicolumn{10}{|l|}{ Louisiana (Continued) } \\
\hline 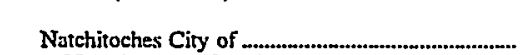 & 4 & $\begin{array}{l}37.5 \\
53.0\end{array}$ & $\begin{array}{l}36.0 \\
53.0\end{array}$ & $\begin{array}{l}36.0 \\
53.0\end{array}$ & ST & Nat Gas & FO2 & 1970 & OP \\
\hline 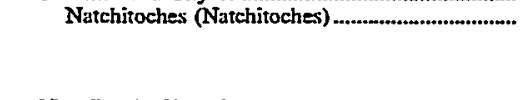 & $\begin{array}{r}* 22 \\
* * 8 \\
* * 9 \\
* * 10\end{array}$ & $\begin{array}{r}10.0 \\
6.0 \\
11.5 \\
25.5\end{array}$ & $\begin{array}{r}10.0 \\
6.0 \\
11.5 \\
25.5\end{array}$ & $\begin{array}{r}10.0 \\
6.0 \\
11.5 \\
25.5\end{array}$ & $\begin{array}{l}\text { IC } \\
\text { ST } \\
\text { ST } \\
\text { ST }\end{array}$ & $\begin{array}{l}\text { Nat Gas } \\
\text { Nat Gas } \\
\text { Nat Gas } \\
\text { Nat Gas }\end{array}$ & $\begin{array}{l}\mathrm{FO} 2 \\
\text { FO2 } \\
\text { FO2 } \\
\text { FO2 }\end{array}$ & $\begin{array}{l}1942 \\
1962 \\
1966 \\
1972\end{array}$ & $\begin{array}{l}\text { OP } \\
\text { OP } \\
\text { OP } \\
\text { OP }\end{array}$ \\
\hline New Roads City of & & 9.5 & 8.7 & 9.4 & & & & & \\
\hline New Roads (Pointe Coupet) & $\begin{array}{l}1 \\
2 \\
3 \\
4 \\
5 \\
6\end{array}$ & $\begin{array}{r}2.3 \\
.7 \\
1.1 \\
1.7 \\
1.7 \\
2.0\end{array}$ & $\begin{array}{r}2.1 \\
.6 \\
1.0 \\
1.6 \\
1.6 \\
1.8\end{array}$ & $\begin{array}{r}2.3 \\
.6 \\
1.1 \\
1.7 \\
1.7 \\
2.0\end{array}$ & $\begin{array}{l}\text { IC } \\
\text { IC } \\
\text { IC } \\
\text { IC } \\
\text { IC } \\
\text { IC }\end{array}$ & $\begin{array}{l}\text { Nat Gas } \\
\text { Nat Gas } \\
\text { Nat Gas } \\
\text { Nat Gas } \\
\text { Nat Gas } \\
\text { Nat Gas }\end{array}$ & $\begin{array}{l}\mathrm{FO} 2 \\
\mathrm{FO} 2 \\
\mathrm{FO} 2 \\
\mathrm{FO} 2 \\
\mathrm{FO} 2 \\
\mathrm{FO} 2\end{array}$ & $\begin{array}{l}1965 \\
1953 \\
1957 \\
1957 \\
1951 \\
1971\end{array}$ & $\begin{array}{l}\text { OP } \\
\text { OP } \\
\text { OP } \\
\text { OP } \\
\text { OP } \\
\text { OP }\end{array}$ \\
\hline Plaquemine City of & & 44.0 & 44.0 & 44.0 & & & & & \\
\hline Plaquemine (Tberville) & $\begin{array}{l}1 \\
2\end{array}$ & $\begin{array}{l}20.0 \\
24.0\end{array}$ & $\begin{array}{l}20.0 \\
24.0\end{array}$ & $\begin{array}{l}20.0 \\
24.0\end{array}$ & $\begin{array}{l}\text { ST } \\
\text { ST }\end{array}$ & $\begin{array}{l}\text { Nat Gas } \\
\text { Nat Gas }\end{array}$ & $\overline{-}$ & $\begin{array}{l}1971 \\
1976\end{array}$ & $\begin{array}{l}\text { OP } \\
\text { OP }\end{array}$ \\
\hline 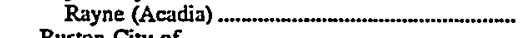 & 8 & 4.1 & 2.5 & 2.5 & IC & Nat Gas & $\mathrm{FO2}$ & 1969 & OP \\
\hline 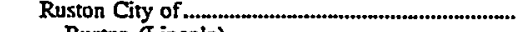 & & 90.5 & 85.0 & 85.0 & & & & & \\
\hline Ruston (Lincoln) & $\begin{array}{r}1 \\
2 \\
3 \\
0900 \\
1070 \\
1700\end{array}$ & $\begin{array}{r}12.6 \\
26.8 \\
41.5 \\
3.4 \\
5.0 \\
1.2 \\
340.0\end{array}$ & $\begin{array}{r}12.0 \\
25.0 \\
40.0 \\
3.0 \\
4.0 \\
3.0 \\
383.0\end{array}$ & $\begin{array}{r}12.0 \\
25.0 \\
40.0 \\
3.0 \\
4.0 \\
1.0 \\
383.0\end{array}$ & $\begin{array}{l}\text { ST } \\
\text { ST } \\
\text { ST } \\
\text { IC } \\
\text { IC } \\
\text { IC }\end{array}$ & $\begin{array}{l}\text { Nat Gas } \\
\text { Nat Gas } \\
\text { Nat Gas } \\
\text { Nat Gas } \\
\text { Nat Gas } \\
\text { Nat Gas }\end{array}$ & $\begin{array}{l}\text { FO2 } \\
\text { FO2 } \\
\text { FO2 } \\
\text { FO2 } \\
\text { FO2 } \\
\text { FO2 }\end{array}$ & $\begin{array}{l}1963 \\
1968 \\
1974 \\
1954 \\
1959 \\
1951\end{array}$ & $\begin{array}{l}\text { OP } \\
\text { OP } \\
\text { OP } \\
\text { OP } \\
\text { OP } \\
\text { OP }\end{array}$ \\
\hline Assenal Hill (Caddo) & 5 & 100.0 & 110.0 & 110.0 & ST & Nat Gas & - & 1960 & OP \\
\hline 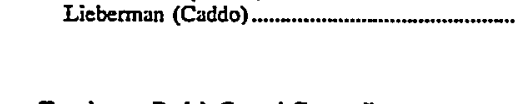 & $\begin{array}{l}1 \\
2 \\
3 \\
4\end{array}$ & $\begin{array}{r}20.0 \\
20.0 \\
100.0 \\
100.0\end{array}$ & $\begin{array}{r}25.0 \\
26.0 \\
112.0 \\
110.0\end{array}$ & $\begin{array}{r}25.0 \\
26.0 \\
112.0 \\
110.0\end{array}$ & $\begin{array}{l}\text { ST } \\
\text { ST } \\
\text { ST } \\
\text { ST }\end{array}$ & $\begin{array}{l}\text { Nat Gas } \\
\text { Nat Gas } \\
\text { Nat Gus } \\
\text { Nat Gas }\end{array}$ & $\begin{array}{l}- \\
\text { FO6 } \\
\text { F06 }\end{array}$ & $\begin{array}{l}1947 \\
1949 \\
1957 \\
1959\end{array}$ & $\begin{array}{l}\text { OP } \\
\text { OP } \\
\text { OP } \\
\text { OP }\end{array}$ \\
\hline Terrebonne Parish Consol Gov & & 99.4 & 88.4 & 88.4 & & & & & \\
\hline 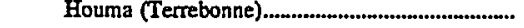 & 6 & 1.4 & 1.0 & 1.0 & IC & Nat Gas & $\mathrm{FO} 2$ & 3948 & OS \\
\hline 1 & 7 & 1.4 & 1.0 & 1.0 & IC & Nat Gas & $\mathrm{FO2}$ & 3948 & os \\
\hline & 8 & 1.4 & 1.0 & 1.0 & IC & Nat Gas & FO2 & 1948 & OS \\
\hline & 9 & 28 & 25 & 2.5 & IC & Nat Gas & FO2 & 1953 & OS \\
\hline & 10 & 4.5 & 3.7 & 3.7 & IC & Nat Gas & $\mathrm{FO2}$ & 1958 & os \\
\hline & 11 & 4.5 & 3.7 & 3.7 & IC & Nat Gas & $\mathrm{FO2}$ & 1958 & OS \\
\hline & 15 & 25.5 & 23.5 & 23.5 & ST & Nat Gas & - & 1972 & OP \\
\hline & 16 & 40.8 & 38.6 & 38.6 & ST & Nat Gas & - & 1977 & $O P$ \\
\hline \multicolumn{10}{|l|}{ Maine } \\
\hline 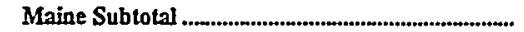 & & $1,500.9$ & $1,497.8$ & 1,5322 & & & & & \\
\hline Bangor Hydro-Electric Co & & 103.3 & 102.2 & 105.7 & & & & & \\
\hline Bar Harbor (Hancock) & 1 & 2.0 & 2.0 & 2.3 & IC & $\mathrm{FO} 2$ & - & $196]$ & OP \\
\hline & 2 & 20 & 2.0 & 2.1 & IC & FO2 & - & j961 & OP \\
\hline & 3 & 2.0 & 2.0 & 2.] & IC & FO2 & - & $196 !$ & OP \\
\hline & 4 & 20 & 2.0 & 2.1 & IC & $\mathrm{FO} 2$ & - & 1961 & OP \\
\hline Eastport (Washington) ............................................. & J & 1.0 & .9 & $\mathbf{3 . 0}$ & IC & FO2 & - & 1948 & OP \\
\hline & 2 & 1.0 & .9 & 1.0 & IC & FO2 & - & 1949 & $\mathrm{OP}$ \\
\hline & 3 & 20 & 2.0 & 2.1 & IC & FO2 & - & 1949 & OP \\
\hline 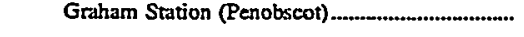 & 4 & 18.8 & 17.7 & 18.2 & $S T$ & FO6 & - & 1957 & SB \\
\hline 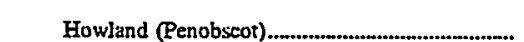 & 5 & 27.2 & $\begin{array}{r}27.6 \\
.6\end{array}$ & 29.0 & ST & F06 & - & 1964 & SB \\
\hline & $\begin{array}{l}1 \\
2\end{array}$ & .6 & .6 & .6 & $\mathrm{HY}$ & Water & - & 1921 & OP \\
\hline & $\begin{array}{l}2 \\
3\end{array}$ & .6 & .6 & 6 & HY & Water & - & 1916 & OP \\
\hline Medway (Penobscot) & $\mathrm{HCl}$ & $\dddot{7}$ & .7 & .0 & HY & Water & - & 1916 & OP \\
\hline & $\mathrm{HC}$ & .7 & .7 & $\ddot{7}$ & HY & $\begin{array}{l}\text { Watex } \\
\text { Water }\end{array}$ & $\overline{-}$ & $\begin{array}{l}1923 \\
1923\end{array}$ & OP \\
\hline & $\mathrm{HC} 3$ & .7 & .7 & .7 & $\mathrm{HY}$ & Water & - & 1925 & $\mathrm{OP}$ \\
\hline & $\mathrm{HC} 4$ & .7 & .7 & .7 & HY & Water & - & $\mathrm{j} 925$ & OP \\
\hline & IC] & 2.0 & 2.0 & 2.1 & IC & FO2 & - & 1960 & OP \\
\hline & IC2 & 2.0 & 2.0 & 21 & IC & FO2 & - & 1960 & OP \\
\hline & IC3 & 2.0 & 2.0 & 2.1 & IC & $\mathrm{FO} 2$ & - & 1960 & OP \\
\hline & IC4 & 2.0 & 2.0 & 2.1 & IC & FO2 & - & 1960 & op \\
\hline & 5 & .7 & .7 & .7 & HY & Water & - & 1925 & \\
\hline Milford (Penobscot) & 3 & J.6 & 1.6 & 1.6 & HY & Water & - & 1956 & OP \\
\hline & 4 & 1.6 & 1.6 & 1.6 & HY & Water & - & 1949 & OP \\
\hline
\end{tabular}

See footnotes at end of table. 
Table 20. Existing Generating Units at U.S. Electric Utilities by State, Company, and Plant, as of January 1, 1998 (Continued)

\begin{tabular}{|c|c|c|c|c|c|c|c|c|c|}
\hline \multirow{2}{*}{$\begin{array}{c}\text { State } \\
\text { Company } \\
\text { PJant (County) }\end{array}$} & \multirow{2}{*}{$\begin{array}{l}\text { Unit } \\
\text { ID }\end{array}$} & \multirow{2}{*}{$\begin{array}{c}\text { Generator } \\
\text { Nameplate } \\
\text { Capacity } \\
\text { (megawatts) }\end{array}$} & \multirow{2}{*}{$\begin{array}{l}\text { Net Summer } \\
\text { Capability } \\
\text { (megawatts) }\end{array}$} & \multirow{2}{*}{$\begin{array}{l}\text { Net Winter } \\
\text { Capability } \\
\text { (megawatts) }\end{array}$} & \multirow{2}{*}{$\begin{array}{l}\text { Unit } \\
\text { Type] }\end{array}$} & \multicolumn{2}{|c|}{ Energy Sourcel } & \multirow{2}{*}{$\begin{array}{c}\text { Year } \\
\text { of } \\
\text { Commercial } \\
\text { Operation }\end{array}$} & \\
\hline & & & & & & Primary & Alternate & & \\
\hline Maine (Continued) & & & & & & & & & \\
\hline & 5 & 1.6 & 1.6 & 1.6 & HY & Water & - & 1942 & OP \\
\hline & 6 & 1.6 & 1.6 & 1.6 & HY & Water & _ & 1943 & OP \\
\hline 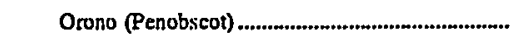 & 1 & $S$ & .5 & 5 & HY & Water & - & 1911 & OP \\
\hline & $\begin{array}{l}2 \\
3\end{array}$ & 5 & 5 & 5 & HY & & - & 1949 & OP \\
\hline & 4 & .17 & .7 & .7 & HY & $\begin{array}{l}\text { Water } \\
\text { Water }\end{array}$ & - & $\begin{array}{l}1949 \\
1949\end{array}$ & $\begin{array}{l}\text { OP } \\
\text { OP }\end{array}$ \\
\hline Stillwater (Penobscut) ............................................. & $j$ & .5 & .5 & .5 & HY & Water & - & 1949 & $\mathrm{OP}$ \\
\hline & 2 & .5 & .5 & $S$ & HY & Water & - & 1949 & OP \\
\hline & 3 & .5 & .5 & $s$ & HY & Water & - & 1949 & OP \\
\hline & 4 & .6 & .6 & .6 & HY & Water & - & 1949 & OP \\
\hline Veazie A (Penubscot) & 1 & .6 & .6 & .6 & HY & Water & - & 1933 & OP \\
\hline & 2 & 3 & 3 & 3 & HY & Water & - & 1920 & OP \\
\hline & 3 & 3 & 3 & 3 & HY & Water & - & 1920 & $\mathrm{OP}$ \\
\hline & 4 & 3 & 3 & 3 & HY & Water & - & 1920 & OP \\
\hline & 7 & 3 & 3 & 3 & HY & Water & - & 1920 & OP \\
\hline & 8 & 3 & 3 & 3 & HY & Water & - & 1920 & OP \\
\hline & 9 & 3 & 3 & 3 & HY & Water & - & 1920 & OP \\
\hline & 10 & 3 & .3 & 3 & HY & Water & - & 1920 & OP \\
\hline & 1] & 3 & 3 & 3 & HY & Water & - & 1920 & OP \\
\hline & 12 & 3 & 3 & 3 & $H X$ & Water & - & 1920 & $\mathrm{OP}$ \\
\hline & 13 & 3 & 3 & 3 & HY & Water & - & 1920 & OP \\
\hline & 14 & 3 & 3 & 3 & HY & Water & - & 1920 & OP \\
\hline & 15 & .6 & .6 & .6 & $\mathrm{HY}$ & Water & - & 1914 & OP \\
\hline 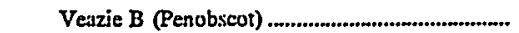 & 16 & 1.5 & 1.5 & 1.5 & HY & Water & - & 1938 & OP \\
\hline & 17 & I.5 & 1.5 & 1.5 & HY & Water & - & 1938 & OP \\
\hline 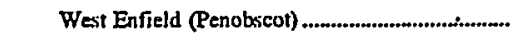 & 1 & 6.5 & 6.5 & 6.5 & HY & Water & - & 1988 & OP \\
\hline & 2 & 6.5 & 6.5 & 6.5 & HY & Water & - & 1988 & OP \\
\hline Central Maine Power Co & & $1,359.0$ & $1,355.4$ & $1,386.2$ & & & & & \\
\hline 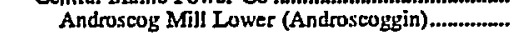 & 1 & 3 & 0.0 & 3 & HY & Water & - & 1986 & OP \\
\hline Androscoggin 3 (Androscoggin) ......................... & j & 3.6 & 4.0 & 4.0 & HY & Water & - & 1928 & OP \\
\hline Aroostook Valley (Aroostook) & j & 32.0 & 29.5 & 29.5 & ST & WD & - & 1994 & OP \\
\hline Bar Mills (York) & j & 2.0 & 20 & 2.0 & HY & Water & - & 1956 & OP \\
\hline & 2 & 2.0 & 2.0 & 2.0 & HY & Water & - & 1956 & OP \\
\hline Bates Mill Lower (Androscoggin) .......................... & 1 & 5 & 0.0 & 5 & HY & Water & ـ & 1986 & $\mathrm{OP}$ \\
\hline Bates Mill Upper (Androscoggin) ....................... & $i$ & 1.2 & 0.0 & .9 & $\mathrm{HY}$ & Water & - & 1986 & OP \\
\hline & 2 & 1.2 & 1.7 & 1.7 & HY & Water & - & 1910 & OP \\
\hline & 3 & 1.2 & 1.6 & 1.6 & HY & Water & - & 1910 & OP \\
\hline & 4 & 1.2 & 1.7 & 1.7 & HY & Water & - & 1910 & OP \\
\hline & 5 & 1.2 & 1.8 & 1.8 & HY & Water & - & 1910 & OP \\
\hline & 6 & 1.2 & 1.7 & 1.7 & HY & Water & - & 1910 & OP \\
\hline 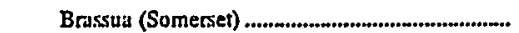 & I & 4.0 & 3.7 & 3.7 & $\mathbf{H Y}$ & Water & - & 1989 & OP \\
\hline 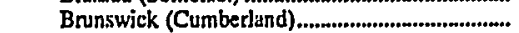 & 1 & 12.6 & 13.3 & 13.3 & HY & Water & - & 1982 & OP \\
\hline & 2 & 3.5 & 3.5 & 3.5 & HY & Water & - & 1983 & OP \\
\hline & 3 & 3.5 & 3.5 & 35 & HY & Water & - & 1983 & OP \\
\hline Cape Gas Turbine (Cumberland) & GT4 & 17.6 & 16.5 & 20.6 & GT & FO2 & - & 1970 & $\mathrm{OP}$ \\
\hline 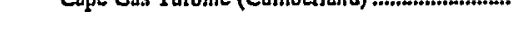 & GT5 & 17.6 & 16.4 & 20.8 & GT & $\mathrm{FO} 2$ & - & 1970 & OP \\
\hline Cataract (York) & 1 & 6.7 & 8.0 & 8.0 & HY & Water & - & 1937 & OP \\
\hline Cataract W Channel (York) & i & 5 & .4 & 4 & HY & Water & - & 1983 & OP \\
\hline & 2 & 5 & .4 & 4 & HY & Water & - & 1983 & $\overline{O P}$ \\
\hline 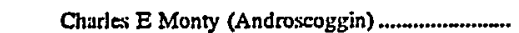 & NAI & 14.2 & 11.4 & 14.0 & HY & Water & - & 1990 & OP \\
\hline & NA2 & 14.2 & II.4 & 14.0 & HY & Water & - & 1990 & OP \\
\hline Continental Mills (Androscoggin) ........................ & 1 & .4 & .4 & 4 & HY & Water & - & 1920 & OP \\
\hline & 2 & .4 & .4 & .4 & HY & Water & - & 1920 & OP \\
\hline & 3 & 4 & .4 & $\ddot{4}$ & HY & Water & _ & 1920 & OP \\
\hline & 5 & .2 & 0.0 & 2 & HY & Water & - & 1920 & OP \\
\hline & 6 & .2 & 0.0 & 2 & HY & Water & _ & 1920 & OP \\
\hline Deer Rips (Androscogrin) & 1 & .6 & .6 & .6 & HY & Water & - & 1903 & OP \\
\hline & 2 & .6 & .6 & .6 & $\mathrm{HY}$ & Water & - & 1903 & OP \\
\hline & 3 & .9 & .9 & .9 & HY & Water & - & 1906 & OP \\
\hline & 4 & .8 & .8 & .8 & HY & Water & - & 1911 & OP \\
\hline & 5 & .8 & .8 & .8 & HY & Water & _ & 1913 & OP \\
\hline & 6 & 1.8 & 1.8 & 1.8 & HY & Water & ـ & 1919 & OP \\
\hline & 7 & 1.0 & 1.0 & 1.0 & HY & Water & _ & 1924 & OP \\
\hline Fon Halifax (Kennebec) & $A$ & .8 & .9 & .9 & HY & Water & - & 1908 & OP \\
\hline & B & .8 & .9 & .9 & $\mathrm{HY}$ & Water & - & 1908 & $\mathrm{OP}$ \\
\hline
\end{tabular}

See footnotes at end of table. 
Table 20. Existing Generating Units at U.S. Electric Utilities by State, Company, and Plant, as of January 1, 1998 (Continued)

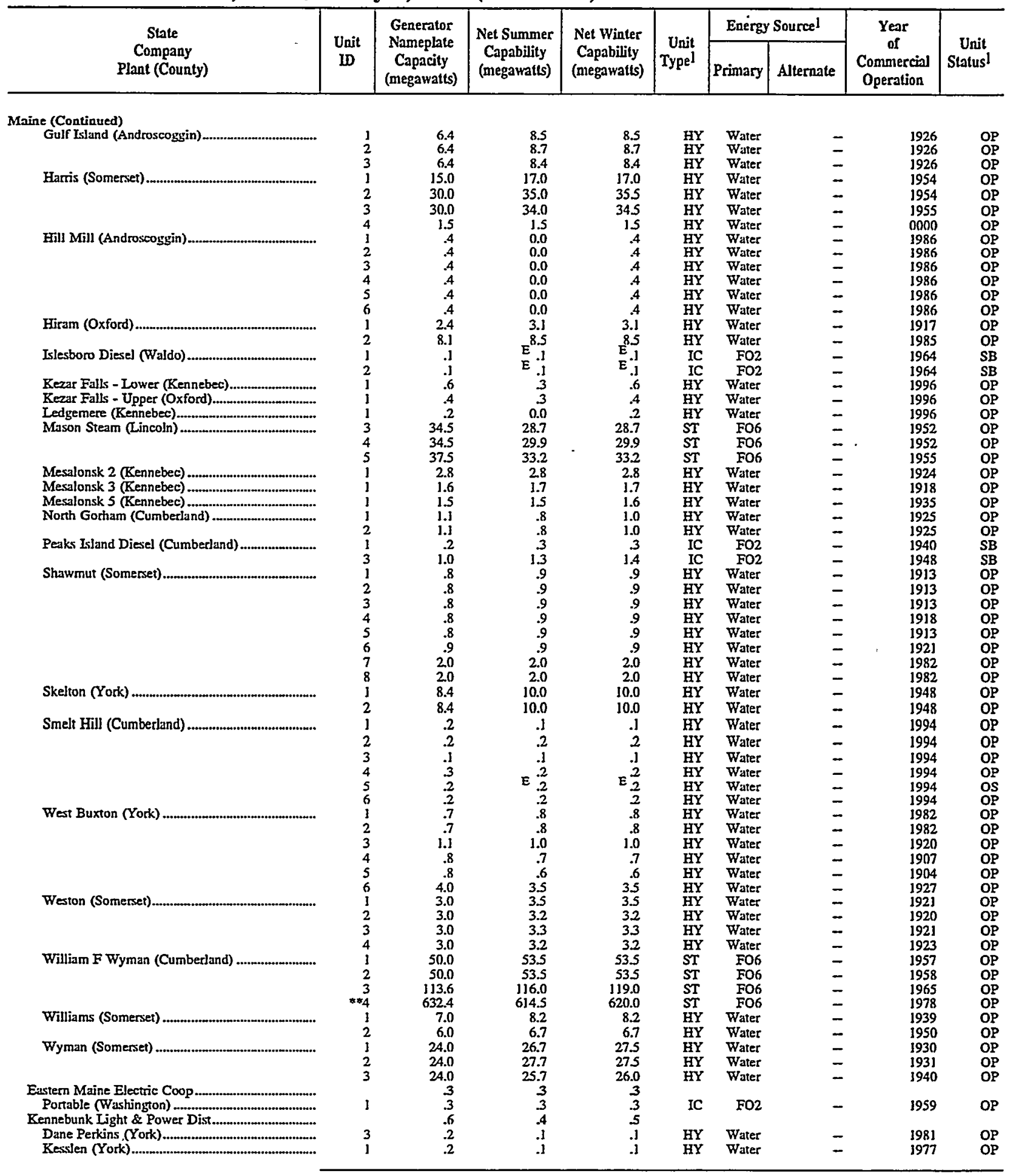

See footnotes at end of table. 
Table 20. Existing Generating Units at U.S. Electric Utilities by State, Company, and Plant, as of January 1, 1998 (Continued)

\begin{tabular}{|c|c|c|c|c|c|c|c|c|c|}
\hline \multirow{2}{*}{$\begin{array}{c}\text { State } \\
\text { Company } \\
\text { Plant (County) }\end{array}$} & \multirow{2}{*}{$\begin{array}{l}\text { Unit } \\
\text { ID }\end{array}$} & \multirow{2}{*}{$\begin{array}{c}\text { Generator } \\
\text { Nameplate } \\
\text { Capacity } \\
\text { (megawatts) }\end{array}$} & \multirow{2}{*}{$\begin{array}{l}\text { Net Summer } \\
\text { Capability } \\
\text { (megawatts) }\end{array}$} & \multirow{2}{*}{$\begin{array}{l}\text { Net Winter } \\
\text { Capability } \\
\text { (megawatts) }\end{array}$} & \multirow{2}{*}{$\begin{array}{c}\text { Unit } \\
\text { Typel }\end{array}$} & \multicolumn{2}{|c|}{ Energy Source] } & \multirow{2}{*}{$\begin{array}{c}\text { Year } \\
\text { of } \\
\text { Commercial } \\
\text { Operation }\end{array}$} & \multirow{2}{*}{$\begin{array}{c}\text { Unit } \\
\text { Status }\end{array}$} \\
\hline & & & & & & Primary & Alternate & & \\
\hline \multicolumn{10}{|l|}{ Maine (Continued) } \\
\hline 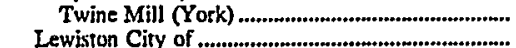 & 2 & 0.3 & 0.2 & 0.2 & HY & Water & - & 1981 & OP \\
\hline 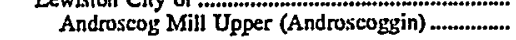 & 1 & .7 & .7 & .7 & HY & Water & - & 1986 & OP \\
\hline & 2 & .5 & .5 & 5 & $\mathrm{HY}$ & Water & - & 1986 & $O P$ \\
\hline 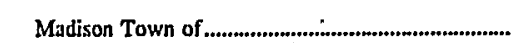 & & .5 & 35 & 3 & HY & Water & - & 1986 & OP \\
\hline Norridgewock (Sumerset) ........................................ & 1 & .2 & .2 & .2 & $\begin{array}{ll}\mathrm{HY} \\
\mathrm{HY}\end{array}$ & $\begin{array}{l}\text { Water } \\
\text { Wher }\end{array}$ & - & 1904 & OP \\
\hline \multirow{9}{*}{ 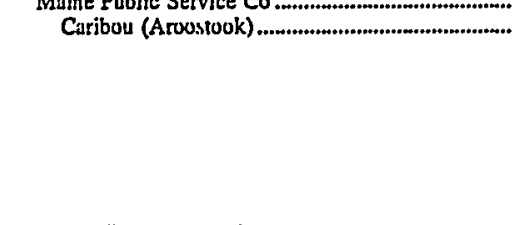 } & & 34.9 & 36.6 & 36.6 & & & & & \\
\hline & HYI & .4 & .5 & .5 & HY & Water & - & 1926 & OP \\
\hline & HY2 & .4 & $S$ & $s$ & HY & Water & - & 1926 & OP \\
\hline & IC2 & 2.8 & 2.6 & 2.6 & IC & F02 & - & 1948 & $\mathrm{OP}$ \\
\hline & ST2 & 11.5 & 14.0 & 14.0 & ST & F06 & - & 1955 & SB \\
\hline & 1 & 7.5 & 9.0 & 9.0 & ST & FO6 & - & 1950 & SB \\
\hline & 3 & 28 & 2.6 & 2.6 & IC & FO2 & - & 1948 & OP \\
\hline & 4 & 1.0 & 1.0 & 1.0 & IC & FO2 & - & 1948 & $\mathrm{OP}$ \\
\hline & 5 & 1.0 & 1.0 & 1.0 & IC & $\mathrm{FO} 2$ & - & 1951 & OP \\
\hline 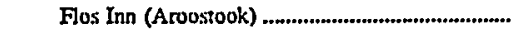 & ICO & 2.0 & 1.4 & 1.4 & IC & $\mathrm{FO} 2$ & - & 1965 & OP \\
\hline & IC3 & 2.0 & 1.4 & 1.4 & IC & FO2 & - & 1973 & \\
\hline & I & 20 & 1.4 & 1.4 & IC & $\mathrm{FO} 2$ & - & 1959 & OP \\
\hline Syua Pan (Arroostook).................................................. & 1 & 1.5 & 1.4 & 1.4 & HY & Water & - & 1941 & OP \\
\hline Matinicus Plantation Elec Co .............................................. & & 3 & 3 & 3 & & & & & \\
\hline 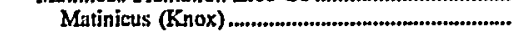 & 1 & .1 & .1 & .1 & IC & FOl & - & 1983 & OP \\
\hline & 2 & .1 & .1 & .1 & IC & Fol & - & 1983 & op \\
\hline & 3 & .1 & .1 & .1 & IC & FOI & - & 1983 & OP \\
\hline & 4 & .2 & .2 & 2 & IC & FOI & - & 1977 & OP \\
\hline Swans Island Electric Coop Inc................................. & & 4 & .4 & .4 & & & & & \\
\hline 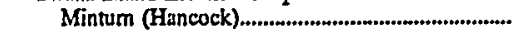 & 1 & .1 & .1 & .1 & IC & $\mathrm{FO} 2$ & - & 1950 & OP \\
\hline & $\frac{2}{3}$ & .12 & $\frac{1}{2}$ & $\frac{1}{2}$ & IC & $\begin{array}{l}\text { FO2 } \\
\text { FO2 }\end{array}$ & $\bar{z}$ & 1950 & $\begin{array}{l}\text { OP } \\
\text { OP }\end{array}$ \\
\hline Maryland & & & & & & & & & \\
\hline 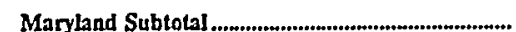 & & $11,892,1$ & $11,101.2$ & $11,509.7$ & & & & & \\
\hline 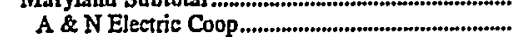 & & 1.7 & 1.7 & 1.7 & & & & & \\
\hline 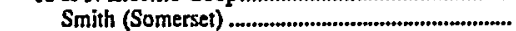 & 2 & 5 & .5 & .5 & IC & FO2 & - & 1969 & OP \\
\hline & 3 & 1.2 & 1.2 & 12 & IC & FO2 & - & 1994 & OP \\
\hline Baltimore Gas \& Electric Co & & $5,903.7$ & $5,538.9$ & $5,759.4$ & & & & & \\
\hline Brandon Shores (Anne Arundel) & 1 & 685.1 & 650.0 & 670.0 & ST & BIT & - & 1984 & OP \\
\hline & $2^{2}$ & 685.1 & 646.0 & 670.0 & ST & BIT & - & 1991 & OP \\
\hline C P Crane (Battimore) & GT $]$ & 16.0 & 14.0 & .17 .0 & GT & FO2 & - & 1967 & OP \\
\hline & & 190.4 & 190.0 & 190.0 & ST & BIT & - & 1961 & OP \\
\hline & 2 & 209.4 & 195.0 & 195.0 & ST & BIT & - & 1963 & OP \\
\hline 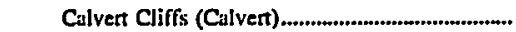 & 1 & 918.0 & 835.0 & 865.0 & $\mathbf{N P}$ & Uranium & - & 1975 & OP \\
\hline & 2 & 910.7 & 840.0 & 865.0 & $\mathrm{NP}$ & Uranium & - & 1977 & OP \\
\hline 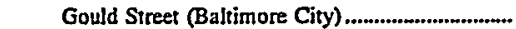 & 3 & 103.5 & 104.0 & 104.0 & ST & FO6 & Nat Gas & 1952 & OP \\
\hline Herbert A Wagner (Anne Anundel) ........................... & GTI & 16.0 & 14.0 & 17.0 & GT & FO2 & - & 1967 & $O P$ \\
\hline & 1 & 132.8 & 137.0 & 138.0 & ST & Nat Gas & Fo6 & 1956 & OP \\
\hline & 2 & 136.0 & 135.0 & 135.0 & ST & BIT & - & 1959 & OP \\
\hline & 3 & 359.0 & 324.0 & 332.0 & ST & BIT & - & 1966 & OP \\
\hline & 4 & 414.7 & 410.0 & 415.0 & ST & F06 & _ & 1972 & OP \\
\hline Notch Cliff (Baltimure) ............................................ & GT] & 18.0 & 16.0 & 17.0 & GT & Nat Gas & - & 1969 & OP \\
\hline & GT2 & 18.0 & 16.0 & 17.0 & GT & Nat Gas & - & 1969 & OP \\
\hline & GT3 & 18.0 & 16.0 & 17.0 & GT & Nat Gas & - & 1969 & OP \\
\hline & GT4 & 18.0 & 16.0 & 17.0 & GT & Nat Gas & - & 1969 & OP \\
\hline & GTS & 18.0 & 16.0 & 17.0 & GT & Nat Gas & - & 1969 & OP \\
\hline & GT6 & 18.0 & 16.0 & 17.0 & GT & Nat Gas & - & 1969 & OP \\
\hline & GT7 & 18.0 & 16.0 & 17.0 & GT & Nat Gas & - & 1969 & OP \\
\hline & GT8 & 18.0 & 16.0 & 17.0 & GT & Nat Gas & - & 1969 & OP \\
\hline 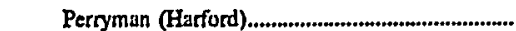 & GTI & 53.1 & 520 & 61.0 & GT & FO2 & - & 1972 & OP \\
\hline & GT2 & 53.1 & 52.0 & 61.0 & GT & FO2 & - & 1972 & OP \\
\hline & GT3 & 53.1 & 52.0 & 61.0 & GT & FO2 & - & 1972 & OP \\
\hline & GT4 & 53.1 & 52.0 & 61.0 & GT & $\mathrm{FO} 2$ & - & 1972 & OP \\
\hline & s & 130.4 & 130.9 & 131.4 & $\mathrm{CT}$ & Nat Gas & - & 1995 & OP \\
\hline & 51 & 192.0 & 1420 & 173.0 & CT & Nat Gas & $\mathrm{FO} 2$ & 1995 & $\mathrm{OP}$ \\
\hline Philadelphia Road (Baltimore City)........................ & & & 16.0 & 17.0 & GT & $\mathrm{FO} 2$ & - & 1970 & OP \\
\hline 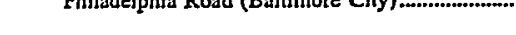 & GT2 & 20.7 & 16.0 & 17.0 & GT & FO2 & - & 1970 & $O P$ \\
\hline & GT3 & 20.7 & 16.0 & 17.0 & GT & FO2 & - & 1970 & OP \\
\hline & 4 & 20.7 & 16.0 & 17.0 & GT & $\mathrm{FO} 2$ & - & 1970 & OP \\
\hline 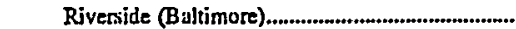 & GT6 & 121.5 & 129.0 & 133.0 & $J E$ & Nat Gas & KER & 1970 & OP \\
\hline
\end{tabular}

See footnotes at end of table. 
Table 20. Existing Generating Units at U.S. Electric Utilities by State, Company, and Plant, as of January 1, 1998 (Continued)

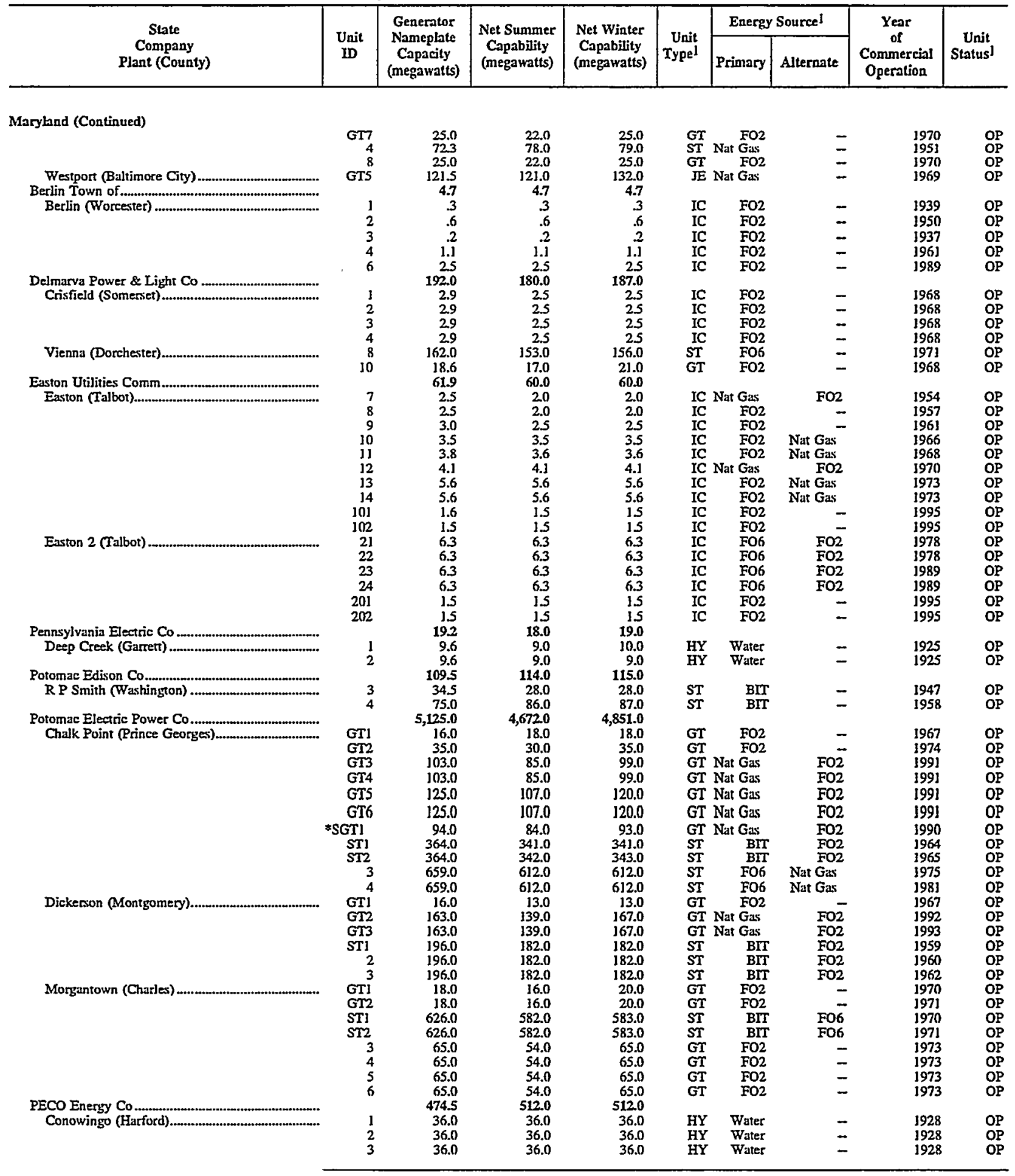

See footnotes at end of table. 
Table 20. Existing Generating Units at U.S. Electric Utilities by State, Company, and Plant, as of January 1, 1998 (Continued)

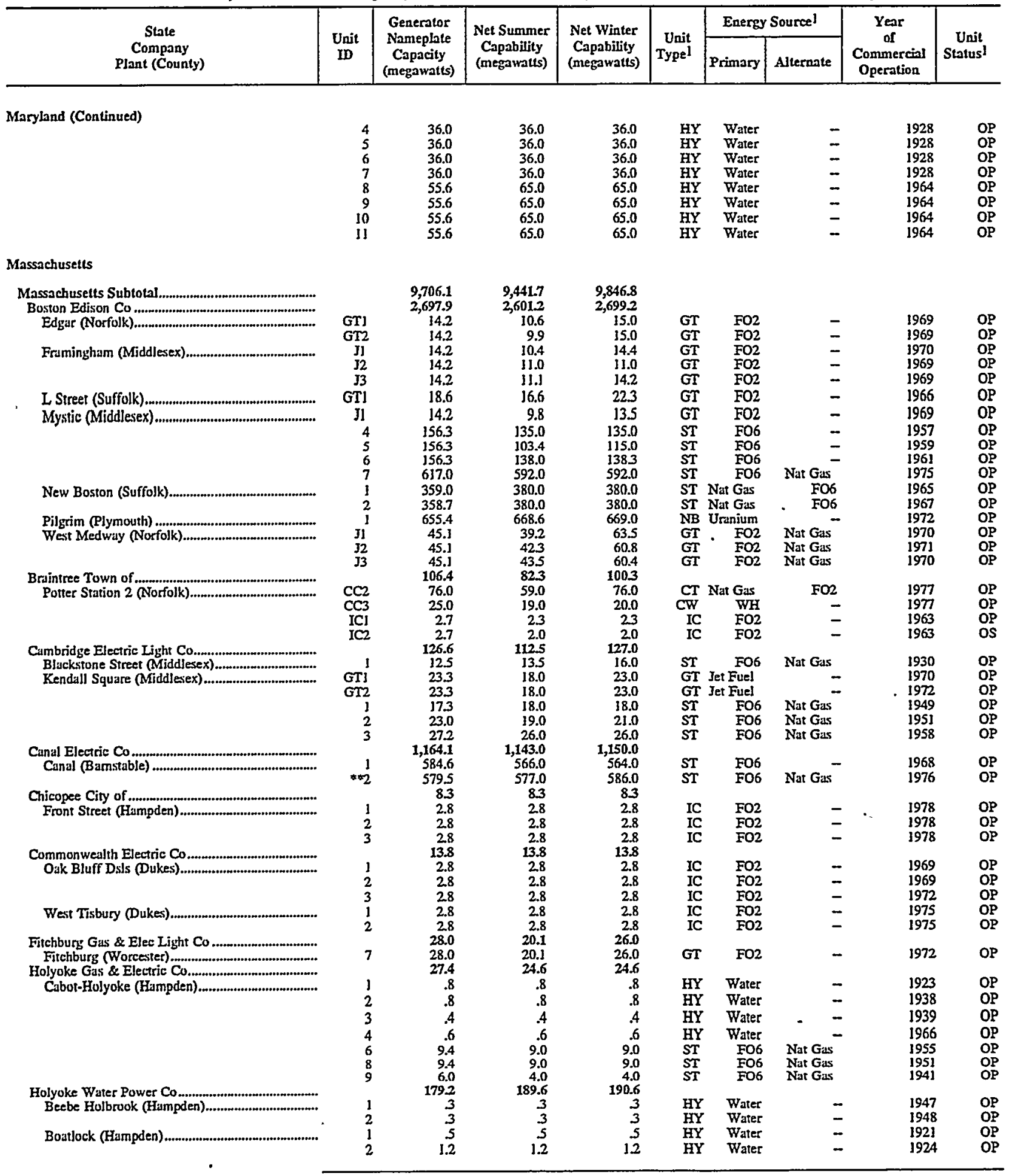

See footnotes at end of table. 
Table 20. Existing Generating Units at U.S. Electric Utilities by State, Company, and Plant, as of January 1, 1998 (Continued)

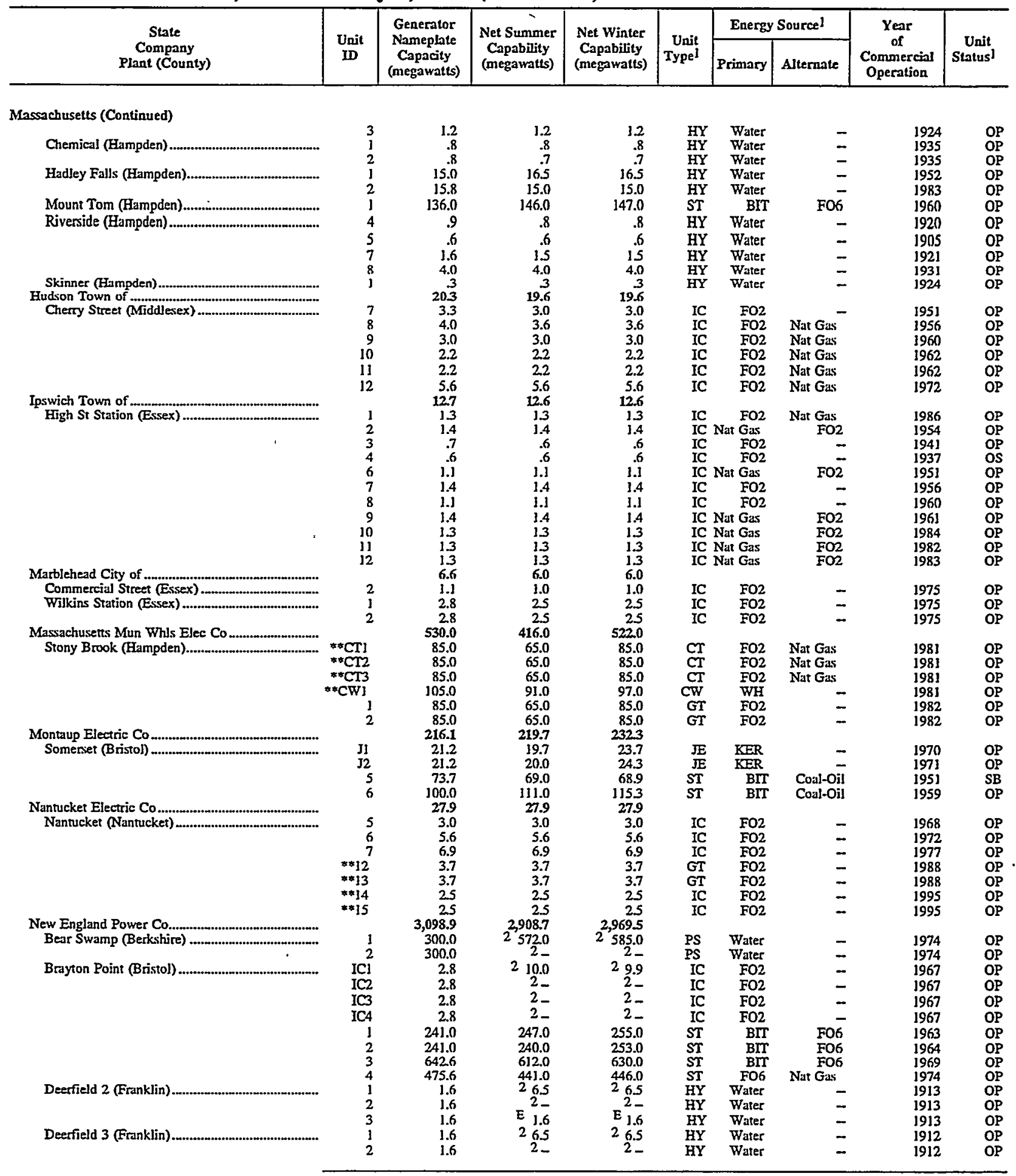

See footnotes at end of table. 
Table 20. Existing Generating Units at U.S. Electric Utilities by State, Company, and Plant, as of January 1, 1998 (Continued)

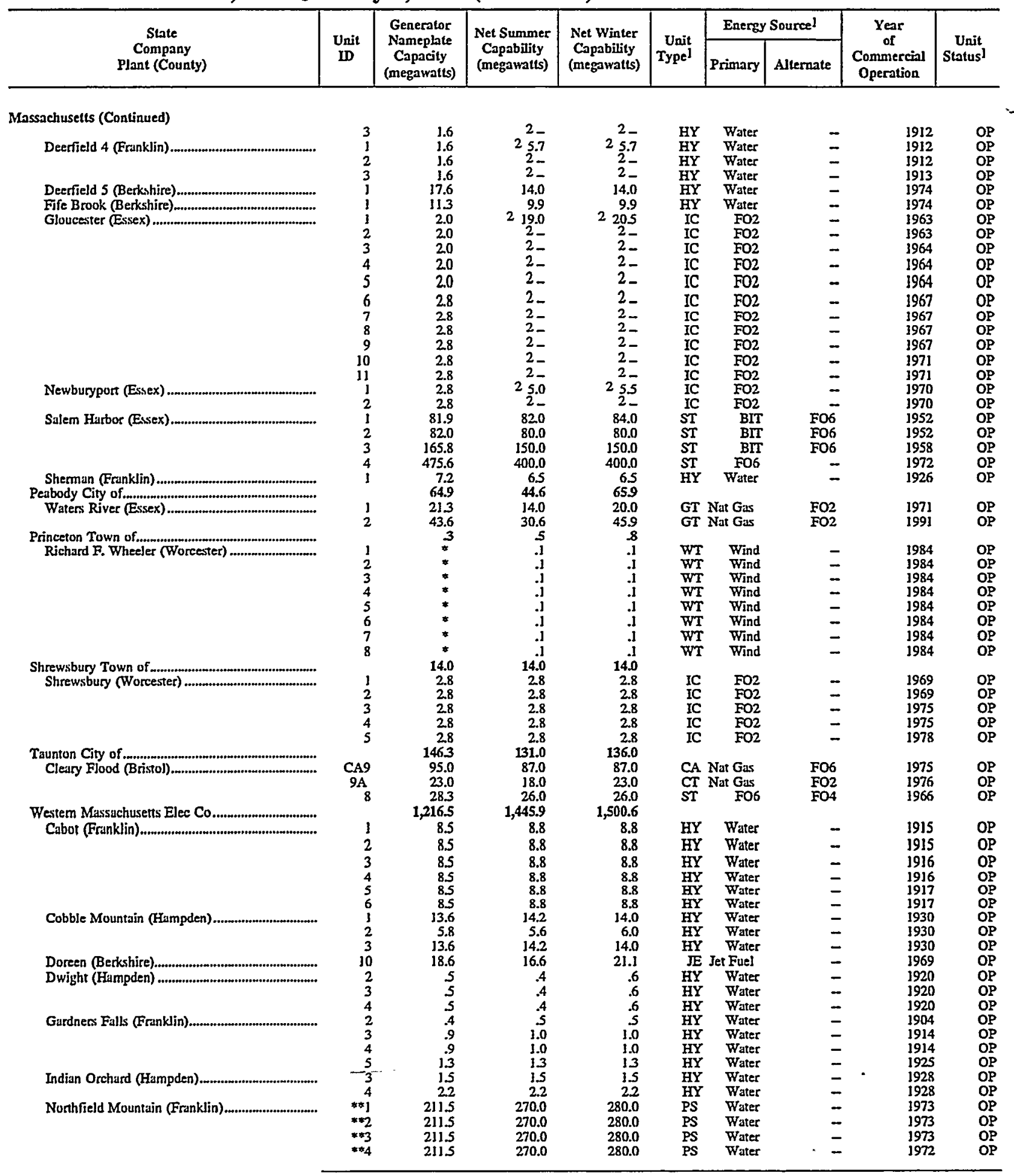

See foutnotes at end of table. 
Table 20. Existing Generating Units at U.S. Electric Utilities by State, Company, and Plant, as of January 1, 1998 (Continued)

\begin{tabular}{|c|c|c|c|c|c|c|c|c|c|}
\hline \multirow{2}{*}{$\begin{array}{c}\text { State } \\
\text { Company } \\
\text { Plant (County) }\end{array}$} & \multirow{2}{*}{$\begin{array}{l}\text { Unit } \\
\mathbf{W}\end{array}$} & \multirow{2}{*}{$\begin{array}{c}\text { Generator } \\
\text { Namephite } \\
\text { Capacity } \\
\text { (megawatts) }\end{array}$} & \multirow{2}{*}{$\begin{array}{l}\text { Net Summer } \\
\text { Capability } \\
\text { (megawatts) }\end{array}$} & \multirow{2}{*}{$\begin{array}{l}\text { Net Winter } \\
\text { Capability } \\
\text { (megawatts) }\end{array}$} & \multirow{2}{*}{$\begin{array}{l}\text { Unit } \\
\text { Type! }\end{array}$} & \multicolumn{2}{|c|}{ Energy Sourcel } & \multirow{2}{*}{$\begin{array}{c}\text { Year } \\
\text { of } \\
\text { Commercial } \\
\text { Operation }\end{array}$} & \multirow{2}{*}{$\begin{array}{c}\text { Unit } \\
\text { Status }\end{array}$} \\
\hline & & & & & & Primary & Alternate & & \\
\hline \multicolumn{10}{|l|}{ Massachusetts (Continued) } \\
\hline Putts Bridge (Hampden) & $\begin{array}{l}2 \\
3\end{array}$ & $\begin{array}{l}1.6 \\
1.6\end{array}$ & $\begin{array}{l}1.9 \\
1.9\end{array}$ & $\begin{array}{l}2.1 \\
2.1\end{array}$ & $\begin{array}{l}\text { HY } \\
\text { HY }\end{array}$ & $\begin{array}{l}\text { Water } \\
\text { Water }\end{array}$ & $=$ & 1918 & OP \\
\hline Red Bridge (Hampden) & 3 & 1.8 & .2 & 2.1 & HY & Water & $\overline{-}$ & 1934 & OP \\
\hline Turners Falls (Franklin) & 1 & 1.4 & 1.9 & 1.9 & HY & Water & - & 1913 & OP \\
\hline & 2 & .4 & .4 & .4 & HY & Water & - & 1913 & OP \\
\hline & 3 & 1.3 & 1.3 & 13 & HY & Water & - & 1910 & OP \\
\hline & 5 & 1.3 & 1.4 & 1.4 & HY & Water & - & 1905 & OP \\
\hline & $?$ & 1.3 & $\mathrm{J.4}$ & 1.4 & HY & Water & - & 1905 & OP \\
\hline 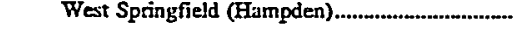 & 1 & 46.0 & 51.2 & 51.2 & ST & F06 & - & 1949 & os \\
\hline & 2 & 50.0 & 51.2 & 512 & ST & FO6 & - & 1952 & os \\
\hline & 3 & 113.6 & 107.0 & 107.0 & ST & FO6 & Nat Gas & 1957 & OP \\
\hline & 10 & 18.6 & 17.2 & 19.0 & JE & Jet Fuel & - & 1968 & OP \\
\hline Woodland Road (Berkshire)................................... & 10 & 18.6 & 16.6 & 20.4 & $\mathrm{JE}$ & Jet Fuel & - & 1969 & OP \\
\hline 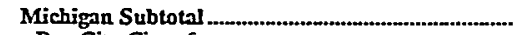 & & $23,917.2$ & $21,908.5$ & $22,295.6$ & & & & & \\
\hline Bay City City of & & 283 & 28.3 & 28.3 & & & & & \\
\hline 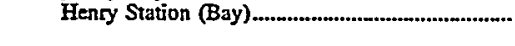 & GEN3 & 7.8 & 7.8 & 7.8 & IC & $\mathrm{FO} 2$ & - & 1993 & OP \\
\hline & GaN4 & $\begin{array}{r}7.8 \\
50\end{array}$ & 7.8 & 7.8 & IC & FO2 & - & 1993 & OP \\
\hline Saginaw Station (Bay) & GENI & 5.8 & 5.8 & 5.8 & IC & $\mathrm{FO2}$ & - & 1980 & OP \\
\hline Clinton Village of & GEN2 & $\begin{array}{l}7.0 \\
4.3\end{array}$ & $\begin{array}{l}7.0 \\
4.3\end{array}$ & $\begin{array}{l}7.0 \\
4.3\end{array}$ & IC & FO2 & - & 1984 & OP \\
\hline Cinton (Lenawee) & 1 & .5 & .5 & .5 & IC & $\mathrm{FO} 2$ & - & 1939 & OP \\
\hline & 2 & 5 & .5 & 5 & IC & FO2 & - & 1939 & OP \\
\hline & 3 & .4 & .4 & $s$ & IC & FO2 & - & 1955 & OP \\
\hline & 4 & .4 & .4 & .4 & IC & FO2 & - & 1955 & OP \\
\hline & 5 & .4 & .4 & .4 & IC & FO2 & - & 1955 & OP \\
\hline & 6 & 2.0 & 2.0 & 2.0 & IC & Nat Gas & $\mathrm{FO} 2$ & 1978 & OP \\
\hline Cloverland Eletric Coop & & 15.0 & 12.7 & 12.7 & & & & & \\
\hline Dafter (Chippewg) & 1 & 1.0 & .9 & .9 & IC & $\mathrm{FO} 2$ & - & 1955 & OP \\
\hline & 2 & 1.0 & .9 & 9 & IC & FO2 & - & 1955 & OP \\
\hline & 3 & 1.0 & .9 & 9 & IC & $\mathrm{FO} 2$ & - & 1955 & OP \\
\hline & 4 & 3.0 & 2.5 & 25 & IC & FO2 & - & 1960 & OP \\
\hline & 5 & 3.0 & 2.5 & 25 & IC & FO2 & - & 1960 & OP \\
\hline Detour (Chippewa) & 6 & 3.0 & 25 & 2.5 & IC & FO2 & - & 1973 & OP \\
\hline & 7 & 3.0 & 2.5 & 2.5 & IC & FO2 & - & 1976 & OP \\
\hline 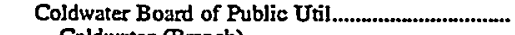 & & 23.8 & 23.8 & 23.8 & & & & & \\
\hline Coldwater (Branch) & IC4 & 2.5 & 25 & 2.5 & IC & $\mathrm{FO} 2$ & - & 1974 & OP \\
\hline & ICS & 6.0 & 6.0 & 6.0 & IC & Nat Gas & FO2 & 1978 & OP \\
\hline & ST4 & 3.0 & 3.0 & 3.0 & ST & BIT & - & 1940 & os \\
\hline & STS & 3.0 & 3.0 & 3.0 & ST & BIT & - & 1962 & os \\
\hline & 1 & .8 & .8 & .8 & IC & $\mathrm{FO} 2$ & - & 1948 & SB \\
\hline & 3 & 3.5 & 3.5 & 3.5 & IC & Nat Gas & $\mathrm{FO} 2$ & 1969 & OP \\
\hline & 6 & $\begin{array}{r}5.0 \\
7000\end{array}$ & 5.0 & 5.0 & ST & BIT & - & 1962 & os \\
\hline Consumers Energy Co & & $7,602.8$ & $7,162.5$ & $7,274.5$ & & & & & \\
\hline Alcona (Alcona) & 1 & 4.0 & 1.5 & 1.6 & HY & Water & - & 1924 & OP \\
\hline & 2 & 4.0 & 1.5 & 1.6 & HY & Water & - & 1924 & OP \\
\hline Allegan Dam (Allegan) & 1 & 5 & .2 & 3 & HY & Water & - & 1935 & OP \\
\hline & 2 & .9 & .4 & .6 & HY & Water & - & 1935 & OP \\
\hline & 3 & 1.2 & 6 & 9 & HYY & Water & - & 1945 & OP \\
\hline B C Cobb (Muskegon) & 4 & 156.3 & 150.0 & 150.0 & ST & BIT & - & 1956 & OP \\
\hline & 5 & 156.3 & 150.0 & I50.0 & ST & BIT & - & 1957 & $O P$ \\
\hline 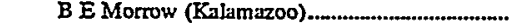 & A & 17.5 & 14.0 & 17.0 & GT & Nat Gas & - & 1968 & OP \\
\hline & $\mathbf{B}$ & 17.5 & 14.0 & 17.0 & GT & Nat Gas & - & 1969 & OP \\
\hline C W Tippy (Manistee) & 1 & 6.7 & 1.8 & 2.3 & HY & Water & - & 1918 & OP \\
\hline & 2 & 6.7 & 1.8 & 2.3 & HY & Water & - & 1918 & OP \\
\hline & 3 & 6.7 & 1.8 & 2.3 & HY & Water & - & 1918 & OP \\
\hline Cooke (Iosco) & 1 & 3.0 & 1.5 & 1.5 & HY & Water & - & 1911 & OP \\
\hline & 2 & 3.0 & 3.0 & 3.0 & HY & Water & - & 1911 & OP \\
\hline & 3 & 3.0 & 3.0 & 3.0 & HY & Water & - & 1911 & OP \\
\hline Croton (Newaygo) & 1 & 3.0 & 1.0 & 1.6 & HY & Water & - & 1907 & OP \\
\hline & 2 & 3.0 & 1.0 & 1.6 & HY & Water & - & 1907 & OP \\
\hline & 3 & 1.4 & .4 & .7 & $\mathrm{HY}$ & Water & - & 1915 & OP \\
\hline & 4 & 1.4 & .4 & 7 & $\mathrm{HY}$ & Water & - & 1912 & OP \\
\hline Dan E Kam (Bay) & 1 & 265.0 & 255.0 & 255.0 & ST & BIT & - & 1959 & $O P$ \\
\hline & 2 & 265.0 & 260.0 & 260.0 & ST & BIT & - & 1961 & OP \\
\hline & 3 & 605.0 & 638.0 & 638.0 & ST & FO6 & - & 1975 & OP \\
\hline & 4 & 626.3 & 638.0 & 638.0 & ST & Nat Gas & FO6 & 1977 & OP \\
\hline
\end{tabular}

See footnotes at end of table. 
Table 20. Existing Generating Units at U.S. Electric Utilities by State, Company, and Plant, as of January 1, 1998 (Continued)

\begin{tabular}{|c|c|c|c|c|c|c|c|c|c|}
\hline \multirow{2}{*}{$\begin{array}{c}\text { State } \\
\text { Contpany } \\
\text { Plant (County) }\end{array}$} & \multirow{2}{*}{$\begin{array}{l}\text { Unit } \\
\text { ID }\end{array}$} & \multirow{2}{*}{$\begin{array}{l}\text { Generator } \\
\text { Nameplate } \\
\text { Capacity } \\
\text { (megawatts) }\end{array}$} & \multirow{2}{*}{$\begin{array}{c}\text { Net Summer } \\
\text { Capability } \\
\text { (megawatts) }\end{array}$} & \multirow{2}{*}{$\begin{array}{l}\text { Net Winter } \\
\text { Capability } \\
\text { (megawatts) }\end{array}$} & \multirow{2}{*}{$\begin{array}{r}\text { Unit } \\
\text { Typel }\end{array}$} & \multicolumn{2}{|c|}{ Energy Sourcel } & \multirow{2}{*}{$\begin{array}{c}\text { Year } \\
\text { of } \\
\text { Commercial } \\
\text { Operation }\end{array}$} & \\
\hline & & & & & & Primary & Alternate & & \\
\hline Michigan (Continued) & & & & & & & & & \\
\hline 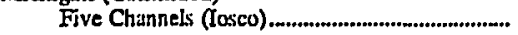 & 1 & 3.0 & 3.0 & 3.0 & HY & Water & - & 1912 & OP \\
\hline & 2 & 3.0 & 3.0 & 3.0 & HY & Water & - & 1912 & OP \\
\hline 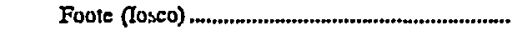 & 1 & 3.0 & 1.4 & 1.5 & HY & Water & - & 1918 & OP \\
\hline & $\begin{array}{l}2 \\
3\end{array}$ & $\begin{array}{l}3.0 \\
3.0\end{array}$ & $\begin{array}{l}1.4 \\
1.4\end{array}$ & $\begin{array}{l}1.5 \\
1.5\end{array}$ & $\begin{array}{l}\mathrm{HY} \\
\mathrm{HY}\end{array}$ & $\begin{array}{l}\text { Water } \\
\text { Water }\end{array}$ & $\bar{z}$ & $\begin{array}{l}1918 \\
1918\end{array}$ & $\begin{array}{l}\text { OP } \\
\text { OP }\end{array}$ \\
\hline Gaylord (Otsego) & j & 17.5 & 14.0 & 37.0 & GT & Nat Gas & $\mathrm{FO} 2$ & 1966 & OP \\
\hline & 2 & 17.5 & 14.0 & 17.0 & $\mathrm{GT}$ & Nat Gas & FO2 & 1966 & $\mathrm{OP}$ \\
\hline & 3 & 17.5 & 14.0 & 17.0 & GT & Nat Gas & FO2 & 1966 & $\mathrm{OP}$ \\
\hline & 4 & 17.5 & 14.0 & 17.0 & GT & Nat Gas & FO2 & 1966 & OP \\
\hline & $\mathbf{s}$ & 20.6 & 14.0 & 17.0 & GT & Nat Gas & FO2 & 1968 & OP \\
\hline 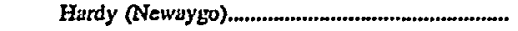 & 1 & 10.0 & jo.j & 30.3 & $\overrightarrow{H Y}$ & Water & - & 1931 & OP \\
\hline & 2 & 10.0 & 10.1 & 10.1 & HY & Water & - & 1931 & OP \\
\hline & 3 & 10.0 & 10.1 & 10.] & HY & Water & - & 1931 & OP \\
\hline 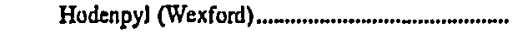 & 1 & 8.5 & 2.3 & 2.8 & HY & Water & - & 1925 & OP \\
\hline & 2 & 8.5 & 2.3 & 2.8 & HY & Water & - & 1925 & OP \\
\hline 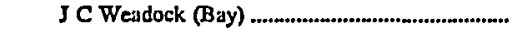 & A & 20.6 & 13.0 & 17.0 & GT & Nat Gas & - & 1968 & OP \\
\hline & 7 & 156.3 & 155.0 & 155.0 & ST & BIT & - & 1955 & OP \\
\hline & 8 & 156.3 & 155.0 & 155.0 & ST & BIT & - & 1958 & OP \\
\hline 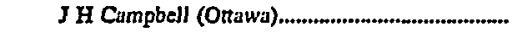 & A & 20.6 & 13.0 & 37.0 & GT & $\mathrm{FO} 2$ & - & 1968 & OP \\
\hline & 1 & 265.0 & 254.0 & 254.0 & ST & BIT & - & 1962 & OP \\
\hline . & 2 & 385.0 & 355.0 & 360.0 & $\mathbf{S T}$ & BIT & - & 1967 & OP \\
\hline & **3 & 871.0 & 790.0 & 790.0 & ST & BIT & - & 1980 & OP \\
\hline 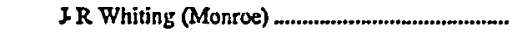 & $\bar{A}$ & 20.6 & 13.0 & 17.0 & GT & $\mathrm{FO} 2$ & - & 1968 & OP \\
\hline & 1 & 300.0 & 95.0 & 95.0 & ST & BIT & - & 1952 & $O P$ \\
\hline & 2 & 100.0 & 95.0 & 95.0 & ST & BIT & - & 1952 & OP \\
\hline & 3 & 125.0 & 120.0 & 120.0 & ST & BIT & - & 1953 & OP \\
\hline Loud (Iosco) & j & 2.0 & 22 & 2.2 & HY & Water & - & 1913 & OP \\
\hline & 2 & 2.0 & 2.2 & 2.2 & HY & Water & - & 1913 & OP \\
\hline 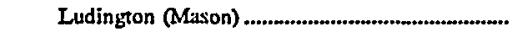 & $* \pi 1$ & 329.8 & 312.0 & 312.0 & PS & Water & - & 1973 & OP \\
\hline & $* 2$ & 329.8 & 312.0 & 3120 & PS & Water & - & 1973 & OP \\
\hline & $* 3$ & 329.8 & 312.0 & 3120 & PS & Water & - & 1973 & OP \\
\hline & $* * 4$ & 329.8 & 312.0 & 3120 & PS & Water & - & 1973 & OP \\
\hline & $\Rightarrow \pi$ & 329.8 & 312.0 & 3120 & PS & Water & - & 1973 & $\mathrm{OP}$ \\
\hline & $* \$ 6$ & 329.8 & 312.0 & 312.0 & PS & Water & - & 1973 & OP \\
\hline Mio (Oscoda) & 1 & 2.5 & .8 & .8 & HY & Water & - & 1916 & OP \\
\hline & 2 & 2.5 & .8 & .8 & HY & Water & - & 1916 & OP \\
\hline 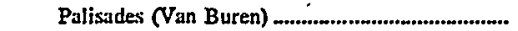 & 1 & $8 1 \longdiv { 1 . 7 }$ & 7620 & 781.0 & NP & Uranium & - & 1972 & OP \\
\hline Rogets (Mecosta) & 3 & 1.7 & .4 & .8 & HY & Water & - & 1922 & OP \\
\hline & 2 & 1.7 & .4 & .8 & HY & Water & - & 3922 & OP \\
\hline & 3 & 1.7 & .4 & .8 & HY & Water & - & 1922 & OP \\
\hline & 4 & 1.7 & .4 & .8 & HY & Water & - & 1922 & OP \\
\hline Strais: (Emmet) & 1 & 25.0 & 16.0 & 21.0 & GT & Nat Gas & - & 1969 & OP \\
\hline 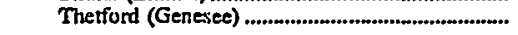 & 1 & 37.3 & 30.0 & 37.0 & GI & Nat Gas & - & 1970 & OP \\
\hline & 2 & 37.3 & 29.0 & 37.0 & GT & Nat Gas & - & 1970 & $O P$ \\
\hline & 3 & 37.3 & 30.0 & 37.0 & GT & Nat Gas & - & 1970 & OP \\
\hline & 4 & 37.3 & 30.0 & 37.0 & GT & Nat Gas & - & 1970 & OP \\
\hline & 5 & 17.6 & 15.0 & 17.0 & GT & Nat Gas & $\mathrm{FO} 2$ & 1971 & OP \\
\hline & 6 & 17.6 & 15.0 & 17.0 & GT & Nat Gas & FO2 & 1971 & $O P$ \\
\hline & 7 & 17.6 & 14.0 & 17.0 & GT & Nat Gas & FO2 & 1971 & $O P$ \\
\hline & 8 & 17.6 & 15.0 & 18.0 & GT & Nat Gas & FO2 & 1971 & OP \\
\hline & 9 & 17.6 & 14.0 & 17.0 & GT & Nat Gas & $\mathrm{FO} 2$ & 1971 & $\mathrm{OP}$ \\
\hline Webber (Ionia) & 1 & 3.3 & .6 & 1.3 & HY & Water & - & 1907 & $\mathrm{OP}$ \\
\hline & 2 & 1.0 & 3 & .6 & HY & Water & - & 1949 & OP \\
\hline Croswell City of & & 5.2 & 52 & 5.2 & & & & & \\
\hline 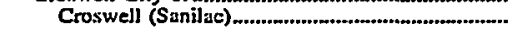 & 1 & .6 & .6 & .6 & IC & FOJ & Nat Gas & 1982 & \\
\hline & 2 & .7 & .7 & 7 & IC & Fol & Nat Gas & 1984 & $O P$ \\
\hline & 3 & 1.2 & 1.2 & 1.2 & IC & Fol & & 1988 & OP \\
\hline & 4 & 1.4 & 1.4 & 1.4 & IC & Fol & Nat Gas & 1990 & OP \\
\hline & 5 & 1.4 & 1.4 & 1.4 & IC & FOI & Nat Gas & 1996 & OP \\
\hline Crystal Falls City of & & 1.0 & 1.0 & 1.0 & & & & & \\
\hline 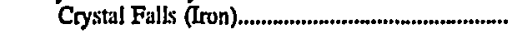 & 1 & 3 & 3 & 3 & HY & Water & - & $19] 4$ & OP \\
\hline & 2 & 3 & 3 & 3 & HY & Water & - & 1924 & OP \\
\hline & .3 & .4 & .4 & .4 & $\mathrm{HY}$ & Water & - & 1954 & OP \\
\hline 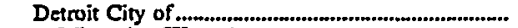 & & 189.0 & 179.0 & 184.0 & & & & & \\
\hline 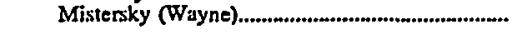 & GT! & 35.0 & 25.0 & 30.0 & GT & FO2 & - & 1974 & OP \\
\hline & 5 & 44.0 & 44.0 & 44.0 & $\mathbf{S T}$ & FO6 & - & 1950 & OP \\
\hline & 6 & 50.0 & 50.0 & 50.0 & ST & FO6 & - & 1958 & OP \\
\hline & 7 & 60.0 & 60.0 & 60.0 & ST & FO6 & Nat Gas & 1979 & $O P$ \\
\hline Detroit Edison Co ........................................................... & & $11,451.6$ & $10,279.0$ & $10,445.0$ & & & & & \\
\hline 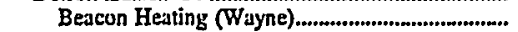 & 25 & 20.0 & 18.0 & 18.0 & ST & Nat Gas & $\mathrm{FO} 2$ & 1959 & OP \\
\hline
\end{tabular}

See footnotes at end of table. 
Table 20. Existing Generating Units at U.S. Electric Utilities by State, Company, and Plant, as of January 1, 1998 (Continued)

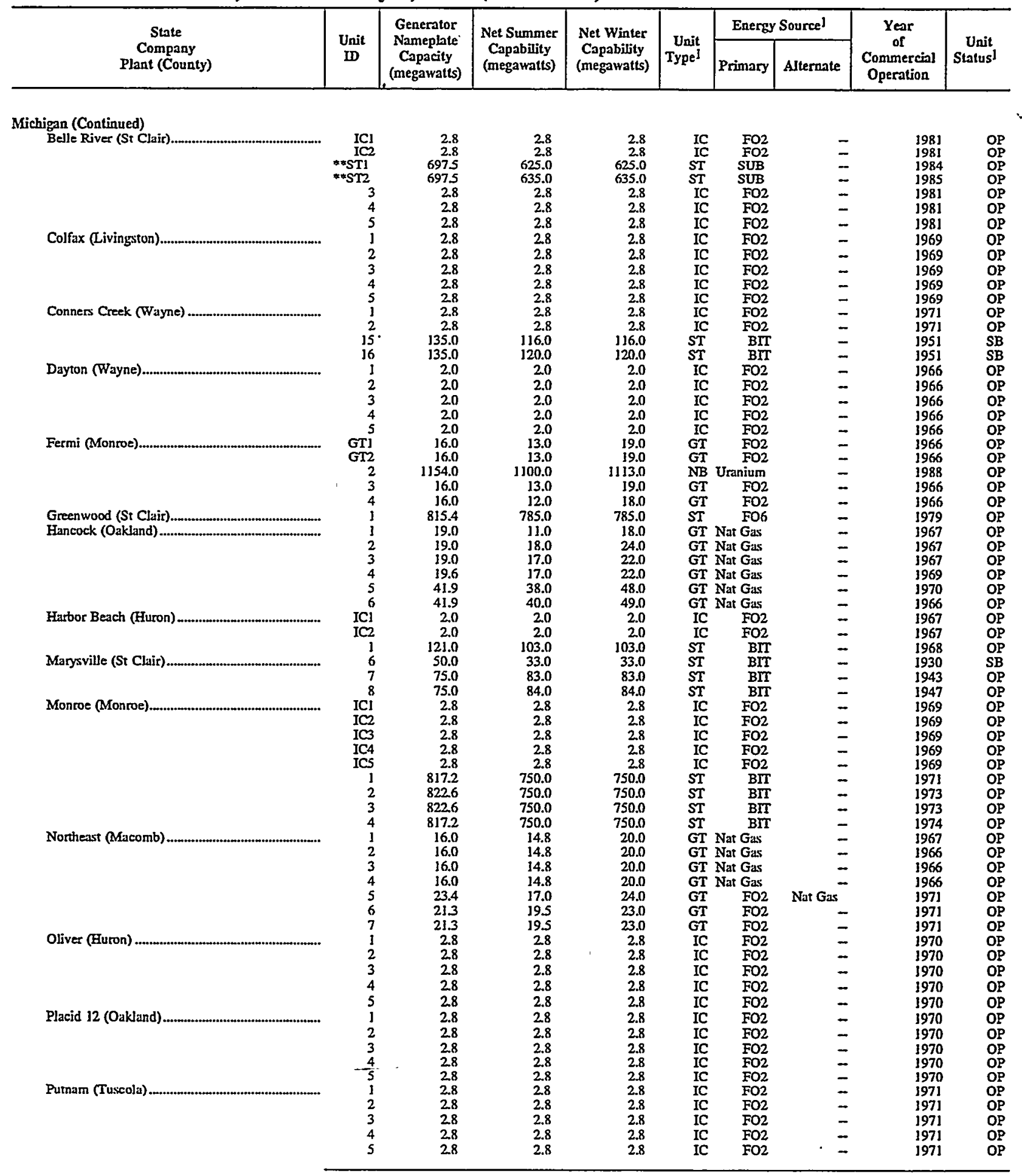

See foomotes at end of table. 
Table 20. Existing Generating Units at U.S. Electric Utilities by State, Company, and Plant, as of January 1, 1998 (Continued)

\begin{tabular}{|c|c|c|c|c|c|c|c|c|c|}
\hline \multirow{2}{*}{$\begin{array}{c}\text { State } \\
\text { Company } \\
\text { Plant (County) }\end{array}$} & \multirow{2}{*}{$\begin{array}{l}\text { Unit } \\
\text { ID }\end{array}$} & \multirow{2}{*}{$\begin{array}{c}\text { Genemator } \\
\text { Nameplate } \\
\text { Capacity } \\
\text { (negawatts) }\end{array}$} & \multirow{2}{*}{$\begin{array}{c}\text { Net Summer } \\
\text { Capability } \\
\text { (megawatts) }\end{array}$} & \multirow{2}{*}{$\begin{array}{c}\text { Net Winter } \\
\text { Capability } \\
\text { (megawatts) }\end{array}$} & \multirow{2}{*}{$\begin{array}{r}\text { Unit } \\
\text { Type }\end{array}$} & \multicolumn{2}{|c|}{ Energy Source! } & \multirow{2}{*}{$\begin{array}{c}\text { Year } \\
\text { of } \\
\text { Commerciol } \\
\text { Operation }\end{array}$} & \multirow{2}{*}{$\begin{array}{c}\text { Unit } \\
\text { Status } 1\end{array}$} \\
\hline & & & & & & Primary & Alternate & & \\
\hline $\begin{array}{l}\text { Michigan (Continued) } \\
\text { River Rouge (Wayne) }\end{array}$ & & & & & & & & & \\
\hline River Rouge (Wayne) .................................................. & ICl & 2.8 & 2.8 & 2.8 & IC & FO2 & - & 1967 & OP \\
\hline & IC2 & 2.8 & $\begin{array}{l}2.8 \\
2.8\end{array}$ & $\begin{array}{l}28 \\
28\end{array}$ & IC & $\mathrm{FO} 2$ & 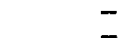 & 1967 & \\
\hline & IC4 & 2.8 & 2.8 & 28 & IC & FO2 & $\bar{z}$ & 1967 & $\begin{array}{l}O P \\
O P\end{array}$ \\
\hline & $i$ & 282.6 & 399.0 & 206.0 & ST & FO6 & - & 1956 & SB \\
\hline & 2 & 292.5 & 238.0 & 247.0 & ST & BIT & Fo6 & 1957 & OP \\
\hline & 3 & 358.1 & 262.0 & 270.0 & ST & BIT & Fo6 & 1958 & OP \\
\hline 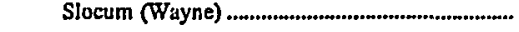 & 1 & 2.8 & 28 & 2.8 & IC & FO2 & - & 1968 & OP \\
\hline & $\frac{2}{3}$ & 28 & 2.8 & 2.8 & IC & FO2 & - & 1968 & $\begin{array}{l}O P \\
O P\end{array}$ \\
\hline & 4 & 28 & 2.8 & 2.8 & IC & $\begin{array}{l}\text { FO2 } \\
\text { FO2 }\end{array}$ & $\bar{z}$ & $\begin{array}{l}1968 \\
1968\end{array}$ & $\begin{array}{l}\mathrm{OP} \\
\mathrm{OP}\end{array}$ \\
\hline & $s$ & 2.8 & 2.8 & 2.8 & IC & FO2 & - & 1968 & OP \\
\hline 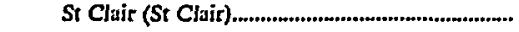 & $12 \mathrm{~A}$ & 2.8 & 28 & 2.8 & IC & FO2 & - & 1970 & $O P$ \\
\hline & $12 \mathrm{~B}$ & 2.8 & $\begin{array}{r}2.8 \\
1630\end{array}$ & $\begin{array}{r}28 \\
1630\end{array}$ & IC & $\mathrm{FO} 2$ & FOs & 1970 & $\underset{O P}{O P}$ \\
\hline & 1 & 168.8 & 163.0 & 163.0 & ST & BIT & Fo6 & 1953 & $O P$ \\
\hline & 2 & 156.3 & 162.0 & 162.0 & ST & BIT & FO6 & 1953 & OP \\
\hline & 3 & 156.3 & 163.0 & 163.0 & ST & BIT & FO6 & 1954 & OP \\
\hline & 4 & I68.8 & 162.0 & 162.0 & ST & BIT & FO6 & 1954 & OP \\
\hline & 5 & 357.8 & 250.0 & 250.0 & $\mathbf{S T}$ & FO6 & - & 1959 & SB \\
\hline & 6 & 3528 & 294.0 & 294.0 & $\underset{\Omega T}{S T}$ & $\mathrm{BIT}$ & - & 1961 & OP \\
\hline & $7^{7}$ & 544.5 & 435.0 & 435.0 & $\stackrel{S T}{S T}$ & $\mathrm{BIT}$ & $\operatorname{Nat} \mathrm{G}^{-}-$ & 1969 & $\begin{array}{l}O P \\
O P\end{array}$ \\
\hline & J] & 18.6 & 19.0 & 23.0 & GT & $\mathrm{FO} 2$ & Nat Gas & 1968 & OP \\
\hline Superior (Washtenaw) n............................................. & 1 & 16.0 & 13.0 & 19.0 & GT & FO2 & - & 1966 & OP \\
\hline & 2 & 36.0 & 13.0 & 19.0 & GT & FO2 & - & 1966 & OP \\
\hline & 3 & 16.0 & 13.0 & 19.0 & GT & FO2 & - & 1966 & OP \\
\hline & 4 & 16.0 & 13.0 & 19.0 & GT & FO2 & - & 1966 & OP \\
\hline Trenton Channel (Wayne) .......................................... & 7 & 120.0 & 105.0 & 105.0 & ST & BIT & $\mathrm{FO} 2$ & 1949 & OP \\
\hline & 8 & 120.0 & 105.0 & 105.0 & ST & BIT & F02 & 1950 & OP \\
\hline & 9 & 535.5 & 515.0 & 515.0 & ST & BIT & - & 1968 & OP \\
\hline Wilmot (Tuscola) & 1 & 2.8 & 28 & 2.8 & IC & $\mathrm{FO} 2$ & - & 1968 & OP \\
\hline & $\frac{2}{2}$ & 28 & 2.8 & 2.8 & IC & FO2 & - & 1968 & OP \\
\hline & $\begin{array}{l}3 \\
4\end{array}$ & 2.8 & $\begin{array}{l}2.8 \\
2.8\end{array}$ & $\begin{array}{l}2.8 \\
2.8\end{array}$ & IC & $\mathrm{FO} 2$ & 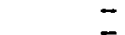 & 1968 & $\begin{array}{l}\text { OP } \\
\text { OP }\end{array}$ \\
\hline & 5 & 2.8 & 2.8 & $\begin{array}{l}2.8 \\
2.8\end{array}$ & $\begin{array}{l}\text { IC } \\
\text { IC }\end{array}$ & FO2 & $\overline{-}$ & $\begin{array}{l}1968 \\
1968\end{array}$ & \\
\hline 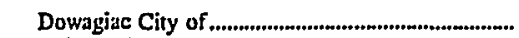 & & 3.9 & 3.1 & 3.1 & IC & FuL & & 1700 & \\
\hline 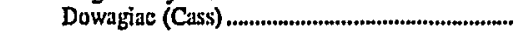 & 1 & I.I & 1.0 & 1.0 & IC & Nat Gas & FO2 & 1962 & OP \\
\hline & 2 & .6 & .4 & .4 & IC & FO2 & - & 1945 & $S B$ \\
\hline & 4 & 1.J & .9 & .9 & IC & $\mathrm{FO} 2$ & - & 1941 & SB \\
\hline & 5 & 3.1 & .9 & .9 & IC & FO2 & - & 1949 & OP \\
\hline Edison Sault Electric Co......... & & 46.8 & 34.4 & 33.0 & & & & & \\
\hline Edison Sault (Chippewa) & 6 & .6 & .4 & .4 & HY & Water & - & 1963 & $\mathrm{OP}$ \\
\hline & 7 & .6 & .4 & .4 & HY & Water & - & 1963 & op \\
\hline & 8 & .6 & .4 & .4 & HY & Water & - & 1963 & OP \\
\hline & 9 & .6 & .4 & .4 & HY & Water & - & 1963 & OP \\
\hline & 10 & 6 & 4 & .4 & HY & Water & - & 1963 & OP \\
\hline & 1) & .6 & .4 & .4 & HY & Water & - & 1963 & OP \\
\hline & 12 & .6 & .4 & .4 & HY & Water & - & 1963 & OP \\
\hline & 13 & .6 & .4 & .4 & HY & Water & - & 1963 & OP \\
\hline & 14 & .6 & .4 & .4 & HY & Water & - & 1963 & $O P$ \\
\hline & is & .6 & .4 & .4 & $\mathrm{HY}$ & Water & - & 19 & $O P$ \\
\hline & 16 & .6 & .4 & .4 & HY & Water & - & 1963 & OP \\
\hline & 17 & .6 & .4 & .4 & HY & Water & - & 1963 & OP \\
\hline & 18 & .6 & .4 & .4 & HY & Water & - & 1963 & OP \\
\hline & 19 & .6 & .4 & .4 & $\mathrm{HY}$ & Water & - & 1963 & $O P$ \\
\hline & 20 & .6 & .4 & .4 & HY & Water & - & 1963 & OP \\
\hline & 21 & .6 & .4 & .4 & HY & Water & - & 1963 & $O P$ \\
\hline & 22 & .6 & .4 & .4 & $\mathrm{HY}$ & Water & - & 19 & OP \\
\hline & 23 & .6 & .4 & .4 & HY & Water & - & 19 & OP \\
\hline & 24 & .6 & .4 & .4 & $\mathrm{HY}$ & Water & - & 1963 & OP \\
\hline & 25 & .6 & .4 & .4 & $H Y$ & Water & - & 1963 & OP \\
\hline & 26 & .6 & .4 & .4 & HY & Water & - & 1963 & OP \\
\hline & 27 & .6 & .4 & .4 & HY & Water & - & 1963 & $O P$ \\
\hline & 28 & .6 & .4 & .4 & HY & Water & - & 1963 & OP \\
\hline & 29 & .6 & .4 & .4 & HY & Water & - & 1963 & $O P$ \\
\hline . & 30 & .6 & .4 & .4 & HY & Water & - & 1963 & OP \\
\hline & 31 & .6 & .4 & .4 & $\mathrm{HY}$ & Water & - & 1963 & OP \\
\hline & 32 & . $\quad .6$ & .4 & .4 & HY & Water & - & 1963 & OP \\
\hline & 33 & .6 & .4 & .4 & $\mathrm{HY}$ & Water & - & 1963 & $O P$ \\
\hline & 34 & .6 & .4 & .4 & HY & Water & - & 1963 & OP \\
\hline & 35 & .6 & .4 & .4 & HY & Water & - & 1963 & OP \\
\hline
\end{tabular}

See footnotes at end of table. 
Table 20. Existing Generating Units at U.S. Electric Utilities.by State, Company, and Plant, as of January 1, 1998 (Continued)

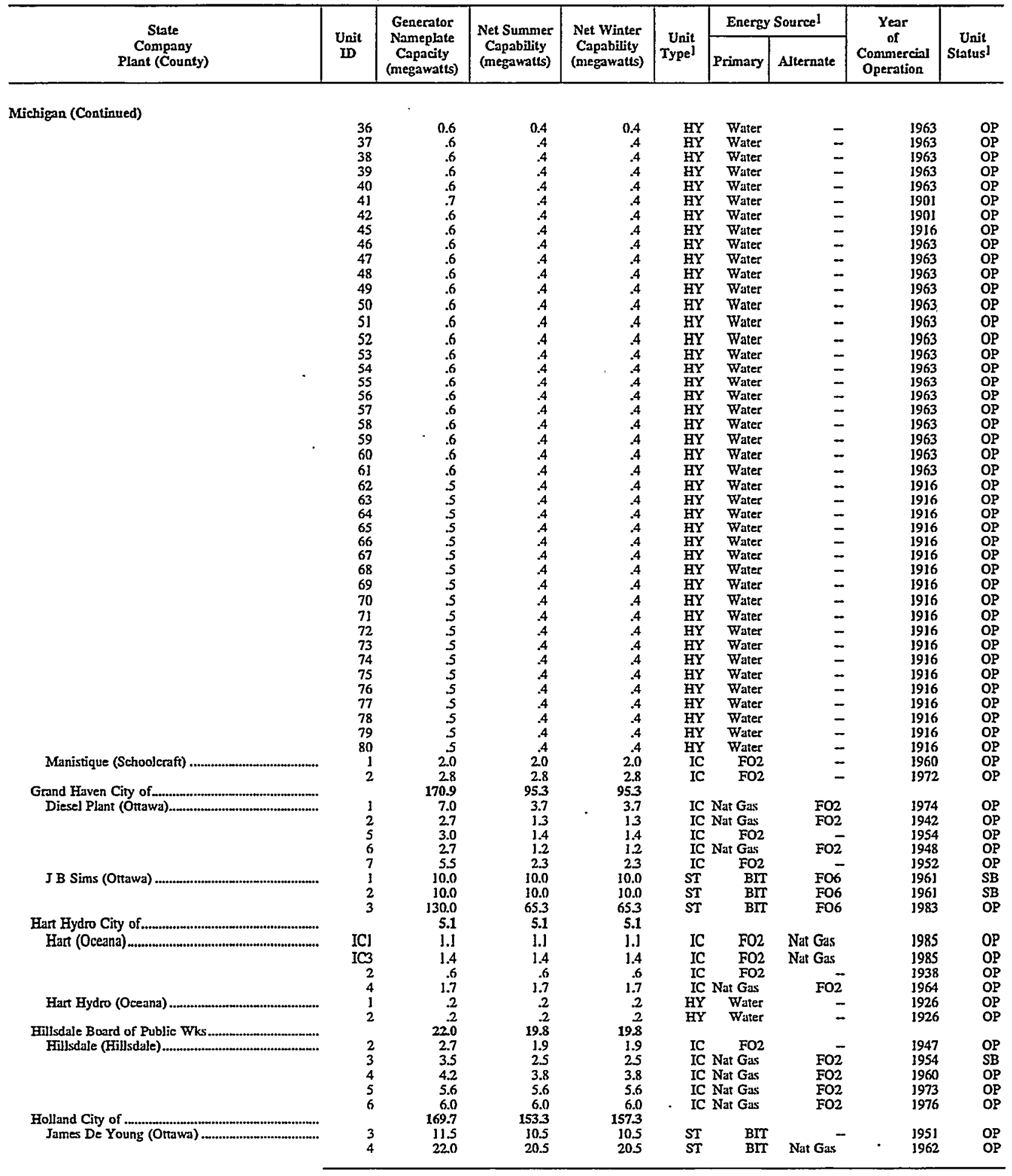

See footnotes at end of table. 
Table 20. Existing Generating Units at U.S. Electric Utilities by State, Company, and Plant, as of January 1, 1998 (Continued)

\begin{tabular}{|c|c|c|c|c|c|c|c|c|c|}
\hline \multirow{2}{*}{$\begin{array}{c}\text { State } \\
\text { Company } \\
\text { Plant (County) }\end{array}$} & \multirow{2}{*}{$\begin{array}{l}\text { Unit } \\
\text { ID }\end{array}$} & \multirow{2}{*}{$\begin{array}{c}\text { Generator } \\
\text { Nanteplate } \\
\text { Capacity } \\
\text { (megawatts) }\end{array}$} & \multirow{2}{*}{$\begin{array}{l}\text { Net Summer } \\
\text { Capability } \\
\text { (megawatts) }\end{array}$} & \multirow{2}{*}{$\begin{array}{l}\text { Net Winter } \\
\text { Copability } \\
\text { (megawatts) }\end{array}$} & \multirow{2}{*}{$\begin{array}{l}\text { Unit } \\
\text { Type] }\end{array}$} & \multicolumn{2}{|c|}{ Energy Source? } & \multirow{2}{*}{$\begin{array}{c}\text { Year } \\
\text { of } \\
\text { Commercinl } \\
\text { Operation }\end{array}$} & \multirow{2}{*}{$\begin{array}{c}\text { Unit } \\
\text { Status! }\end{array}$} \\
\hline & & & & & & Primary & Alternate & & \\
\hline \multicolumn{10}{|l|}{ Michigan (Continued) } \\
\hline & 5 & 29.4 & 27.0 & 27.0 & ST & BFT & - & 1969 & OP \\
\hline Sixth Street (Ottawa) & I & 24.0 & 20.0 & 24.0 & GT & $\mathrm{FO} 2$ & - & 1974 & OP \\
\hline 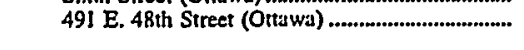 & $\begin{array}{l}7 \\
8\end{array}$ & $\begin{array}{l}41.4 \\
41.4\end{array}$ & $\begin{array}{l}37.7 \\
37.7\end{array}$ & $\begin{array}{l}37.7 \\
37.7\end{array}$ & $\begin{array}{l}\text { GT } \\
\text { GT }\end{array}$ & $\begin{array}{l}\text { Nat Gas } \\
\text { Nat Gas }\end{array}$ & $\begin{array}{l}\text { FO2 } \\
\text { FO2 }\end{array}$ & $\begin{array}{l}1992 \\
1992\end{array}$ & $\begin{array}{l}\text { OP } \\
\text { OP }\end{array}$ \\
\hline Indiana Michigan Power Co ........................................... & & $2,296.6$ & $2,068.9$ & $2,119.2$ & & & & & \\
\hline 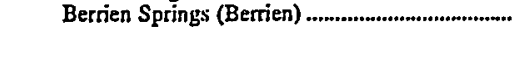 & $\begin{array}{l}1 \mathrm{~A} \\
2 \mathrm{~A}\end{array}$ & $\begin{array}{r}.6 \\
.6\end{array}$ & $\begin{array}{r}27.2 \\
2-\end{array}$ & $\begin{array}{r}27.2 \\
2-\end{array}$ & $\begin{array}{l}\mathbf{H Y} \\
\mathbf{H Y}\end{array}$ & $\begin{array}{l}\text { Water } \\
\text { Water }\end{array}$ & - & $\begin{array}{l}1996 \\
1996\end{array}$ & OP \\
\hline & $\begin{array}{l}3 \mathrm{~A} \\
4 \mathrm{~A}\end{array}$ & .6 & $\begin{array}{l}2- \\
2-\end{array}$ & $\begin{array}{l}2- \\
2-\end{array}$ & $\begin{array}{l}\mathbf{H Y} \\
\mathbf{H Y}\end{array}$ & $\begin{array}{l}\text { Water } \\
\text { Water }\end{array}$ & $\overline{-}$ & $\begin{array}{l}1996 \\
1996\end{array}$ & $\begin{array}{l}O P \\
O P\end{array}$ \\
\hline & 5 & .6 & $2-$ & $2-$ & $\mathbf{H Y}$ & Water & $\overline{-}$ & $\begin{array}{l}1996 \\
1996\end{array}$ & OP \\
\hline & 6 & .6 & $2-$ & $2-$ & HY & Water & - & 1996 & OP \\
\hline & 7 & .6 & $2-$ & $2-$ & HY & Water & - & 1996 & OP \\
\hline & 8 & .6 & $2-$ & $2-$ & HY & Water & - & 1996 & OP \\
\hline & 9 & .6 & $2-$ & $2-$ & HY & Water & - & 1996 & OP \\
\hline & 10 & .6 & $2-$ & $2-$ & HY & Water & - & 1996 & OP \\
\hline & J] & .6 & $2-$ & $2-$ & HY & Water & - & 1996 & OP \\
\hline Buchanan (Berrien) & 12 & .6 & $2 \frac{2}{17}$ & 225 & HY & Water & - & 1996 & OP \\
\hline & 1 & 4.1 & $\begin{array}{l}21.7 \\
2-\end{array}$ & $\begin{array}{l}22.0 \\
2-\end{array}$ & HY & Water & - & 1919 & OP \\
\hline & 2 & 0.0 & $\begin{array}{l}2- \\
2-\end{array}$ & $\begin{array}{l}2_{-} \\
2-\end{array}$ & HY & Water & - & 1919 & OP \\
\hline & 3 & 0.0 & $2-$ & $\begin{array}{l}2- \\
2-\end{array}$ & HY & Water & - & 1919 & OP \\
\hline & 4 & 0.0 & $2-$ & $2-$ & HY & Water & - & 1919 & OP \\
\hline & 5 & 0.0 & $2-$ & $2-$ & HY & Water & - & 1919 & OP \\
\hline & 6 & 0.0 & $2-$ & $2-$ & HY & Water & - & 1919 & OP \\
\hline & 7 & 0.0 & $2-$ & $2-$ & HY & Water & - & 1927 & OP \\
\hline & 8 & 0.0 & $2-$ & $2-$ & HY & Water & - & 1927 & OP \\
\hline & 9 & 0.0 & $2-$ & $2-$ & HY & Water & - & 1927 & OP \\
\hline & 10 & 0.0 & $2-$ & $2-$ & HY & Water & - & 1927 & OP \\
\hline Donald C Cook (Berrien) & 1 & 1152.0 & 1000.0 & 1020.0 & $\mathrm{NP}$ & Uranium & - & 1975 & OP \\
\hline 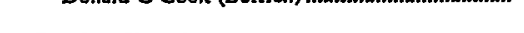 & 2 & $j 133.3$ & 1060.0 & 1090.0 & NP & Uranium & - & 1978 & OP \\
\hline 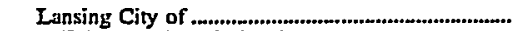 & & 529.7 & 5153 & 530.9 & & & & & \\
\hline 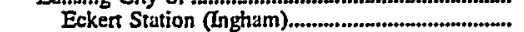 & 1 & 44.0 & 41.9 & 45.6 & ST & BIT & - & 1954 & OP \\
\hline & 2 & 44.0 & 42.5 & 46.7 & ST & BIT & - & 1958 & OP \\
\hline & 3 & 47.0 & 45.5 & 47.8 & ST & BIT & - & 1960 & OP \\
\hline & 4 & 80.0 & 76.4 & 78.8 & ST & BII & - & 1964 & OP \\
\hline & $\dot{s}$ & 80.0 & 76.9 & 785 & ST & BIT & - & 1968 & OP \\
\hline & 6 & 80.0 & 76.5 & 77.1 & ST & . BIT & - & 1970 & OP \\
\hline Erickson (Eatun) & i & 154.7 & 155.8 & 156.4 & ST & BIT & - & 1973 & OP \\
\hline & $\begin{array}{l}4 \\
5\end{array}$ & 1.5 & $\begin{array}{l}1.4 \\
1.1\end{array}$ & 3.4 & $\begin{array}{l}\text { IC } \\
\text { IC }\end{array}$ & $\begin{array}{l}\text { FO2 } \\
\text { Nat Gas }\end{array}$ & $\mathrm{FO}_{2}$ & 1965 & $\begin{array}{l}\text { OP } \\
\text { OP }\end{array}$ \\
\hline & 6 & J.1 & 1.1 & 1.1 & IC & $\begin{array}{l}\text { Nat Gas } \\
\text { Nat Gas }\end{array}$ & $\begin{array}{l}\mathrm{FO} 2 \\
\mathrm{FO} 2\end{array}$ & 1956 & OP \\
\hline & 7 & 1.4 & 1.4 & 1.4 & IC & Nat Gas & FO2 & 1973 & OP \\
\hline Marquette City of & & 104.0 & 103.0 & 104.0 & & & & & \\
\hline Frank J Russell (Marquette) & 1 & .7 & .7 & .7 & HY & Water & - & 1924 & OP \\
\hline Plant Four (Marquette) & GTI & 24.0 & 23.0 & 24.0 & $\mathrm{GT}$ & FO2 & - & 1979 & OP \\
\hline 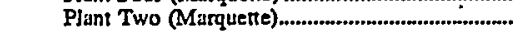 & 1 & 1.6 & 1.6 & 1.6 & HY & Water & - & 1919 & $O P$ \\
\hline & 2 & 1.6 & 1.6 & 1.6 & HY & Water & - & 1922 & OP \\
\hline 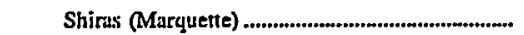 & 1 & 12.5 & 125 & 12.5 & ST & BIT & - & 1967 & OP \\
\hline & 2 & 19.6 & 19.6 & 19.6 & ST & BIT & - & 1972 & OP \\
\hline & 3 & 44.0 & 44.0 & 44.0 & ST & SUB & - & 1983 & OP \\
\hline Marshall City of & & 11.9 & 10.8 & 10.8 & & & & & \\
\hline Marshall (Calhoun) & $\mathrm{IC} 2$ & 1.1 & .9 & .9 & IC & FO2 & Nat Gas & 1953 & OP \\
\hline & IC3 & 2.j & 1.9 & 1.9 & IC & FO2 & Nat Gas & 1973 & OP \\
\hline & ICA & 1.0 & .7 & .7 & IC & FO2 & & 1942 & OP \\
\hline & ICS & 1.7 & 1.4 & 3.4 & IC & FO2 & Nat Gas & 1948 & OP \\
\hline & IC6 & 5.7 & 5.6 & 5.6 & IC & FO2 & Nat Gus & 1978 & OP \\
\hline & 1 & .2 & .2 & .2 & $\mathrm{HY}$ & Water & - & 1928 & OP \\
\hline & 3 & $\ddot{\mathbf{I}}$ & .1 & .1 & HY & Water & - & 1929 & OP \\
\hline Michigan Power Co & & 2.9 & 1.7 & 2.0 & & & & & \\
\hline 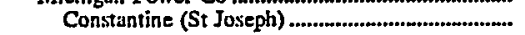 & 1 & 3 & 2.9 & 21.0 & HY & Water & - & 1923 & OP \\
\hline & 2 & .3 & $2-$ & $2-$ & HY & Water & - & 1923 & OP \\
\hline & 3 & .3 & $2-$ & $2-$ & $\mathrm{HY}$ & Water & - & 1929 & $O P$ \\
\hline & 4 & 3 & ${ }^{2}-$ & $2-$ & HY & Water & - & 1923 & OP \\
\hline 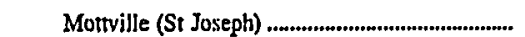 & I & .4 & 3.9 & 31.0 & $\mathrm{HY}$ & Water & - & 1923 & OP \\
\hline & 2 & .4 & $3-$ & $3-$ & $\mathrm{HY}$ & Water & - & 1923 & $\mathrm{OP}$ \\
\hline & 3 & .4 & $3-$ & 3 & $\mathrm{HY}$ & Water & - & 1923 & $\mathrm{OP}$ \\
\hline & 4 & .4 & 3 & 3 & $\mathrm{HY}$ & Water & - & 1923 & $O P$ \\
\hline Michigan South Central Pwr Agy ............................. & & 55.0 & 50.0 & 55.0 & & & & & \\
\hline 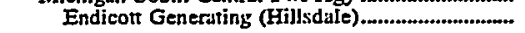 & 1 & 55.0 & 50.0 & 55.0 & ST & BIT & FO2 & 1982 & OP \\
\hline
\end{tabular}

See footnotes at end of table. 
Table 20. Existing Generating Units at U.S. Electric Utilities by State, Company, and Plant, as of January 1, 1998 (Continued)

\begin{tabular}{|c|c|c|c|c|c|c|c|c|c|}
\hline \multirow{2}{*}{$\begin{array}{c}\text { State } \\
\text { Company } \\
\text { PJant (County) }\end{array}$} & \multirow{2}{*}{$\begin{array}{l}\text { Unit } \\
\text { WD }\end{array}$} & \multirow{2}{*}{$\begin{array}{c}\text { Generator } \\
\text { Nameplate } \\
\text { Capacity } \\
\text { (megawatts) }\end{array}$} & \multirow{2}{*}{$\begin{array}{c}\text { Net Summer } \\
\text { Capability } \\
\text { (megawatus) }\end{array}$} & \multirow{2}{*}{$\begin{array}{c}\text { Net Winter } \\
\text { Capability } \\
\text { (megawatts) }\end{array}$} & \multirow{2}{*}{$\begin{array}{r}\text { Unit } \\
\text { Type }\end{array}$} & \multicolumn{2}{|c|}{ Energy Sourcel } & \multirow{2}{*}{$\begin{array}{c}\text { Year } \\
\text { of } \\
\text { Commercial } \\
\text { Operation }\end{array}$} & \\
\hline & & & & & & Primary & Alternate & & Status 1 \\
\hline Michigan (Continued) & & & & & & & & & \\
\hline Newberty Water \& Light B ourd & & 5.6 & 4.5 & 4.5 & & & & & \\
\hline 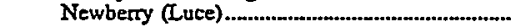 & I & 3.1 & 2.5 & 2.5 & IC & FO2 & - & 1974 & OP \\
\hline & 2 & .7 & .5 & $s$ & IC & FO2 & - & 1948 & OP \\
\hline & 4 & 1.8 & 1.5 & 15 & IC & FO2 & - & 1988 & OP \\
\hline 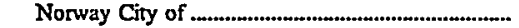 & & 5.6 & 4.7 & 4.7 & & & & & \\
\hline Norway (Dickinson) & 1 & 2.0 & 1.5 & 1.5 & HY & Water & - & 1905 & OP \\
\hline & 2 & 1.2 & 1.2 & 1.2 & HY & Water & - & 1905 & OP \\
\hline & 3 & 1.2 & E 1.1 & $E_{1.3}$ & HY & Water & - & 1988 & OP \\
\hline & 4 & 1.2 & .9 & .9 & HY & Water & - & 1986 & OP \\
\hline Portland City of & & 3.5 & 3.2 & 32 & & & & & \\
\hline 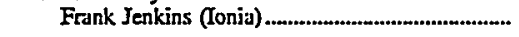 & 3 & 3 & .3 & 3 & IC & FO2 & - & 1935 & OP \\
\hline & 4 & .8 & .8 & .8 & IC & FO2 & - & 1950 & OP \\
\hline & 5 & 2.0 & 1.7 & 1.7 & IC & $\mathrm{FO} 2$ & Nat Gas & 1995 & OP \\
\hline Portland (Ionia) & ] & .1 & .1 & .1 & HY & Water & - & 1930 & $O P$ \\
\hline Sebewaing City of & & 13.5 & 12.4 & 13.4 & & & & & \\
\hline 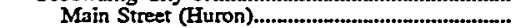 & 1 & 1.0 & .9 & 1.0 & IC & Nat Gas & $\mathrm{FO} 2$ & 1961 & OP \\
\hline & 2 & .9 & .8 & .9 & IC & FO2 & - & 1947 & OP \\
\hline & 3 & 1.1 & 1.1 & 1.1 & IC & Nat Gas & $\mathrm{FO} 2$ & 1966 & $\mathrm{OP}$ \\
\hline & 4 & 1.4 & 1.3 & 13 & IC & Nat Gas & FO2 & 1966 & OP \\
\hline & 5 & 1.1 & 1.1 & 1.1 & IC & Nat Gas & FO2 & 1979 & OP \\
\hline & 6 & .7 & .6 & .7 & IC & Nat Gas & $\mathrm{FO2}$ & 1967 & OP \\
\hline Pine Street (Huron) & ] & 1.1 & I.I & J.1 & $\mathrm{IC}$ & Nat Gas & FO2 & 1969 & OP \\
\hline & 2 & 3.1 & 1.1. & 3.1 & IC & Nat Gas & FO2 & 1969 & OP \\
\hline & 3 & 1.1 & I.J & 1.1 & IC & $\mathrm{FO} 2$ & - & 1988 & OP \\
\hline & 4 & 1.1 & 1.1 & 1.1 & IC & $\mathrm{FO} 2$ & - & 1988 & OP \\
\hline & 5 & 1.4 & I. 3 & 3.4 & IC & Nat Gas & FO2 & 1996 & OP \\
\hline & 6 & 1.4 & 1.3 & 1.4 & IC & Nat Gas & $\mathrm{FO} 2$ & 1996 & OP \\
\hline St Louis City of & & 4.6 & 4.6 & 4.6 & & & & & \\
\hline St Louis (Gratiot) & 1 & 1.4 & 1.4 & 1.4 & IC & FO2 & Nat Gas & 1958 & OP \\
\hline & 2 & .7 & .7 & .7 & IC & FO2 & - & 1945 & OP \\
\hline & 3 & 1.0 & 1.0 & 1.0 & IC & FO2 & - & 1951 & OP \\
\hline & 5 & .2 & .2 & 3 & HY & Water & - & 1919 & OP \\
\hline & 6 & .2 & .2 & 2 & HY & Water & - & 1919 & OP \\
\hline & 7 & 1.1 & 1.1 & 1.1 & IC & $\mathrm{FO2}$ & Nat Gas & 1996 & OP \\
\hline Sturgis City of & & 12.4 & 112 & 11.2 & & & & & \\
\hline Diesel Plant (St Joseph) & 1 & 1.0 & .8 & .8 & IC & $\mathrm{FO} 2$ & - & 1947 & OP \\
\hline & 2 & 1.0 & .8 & .8 & IC & FO2 & - & 1948 & OP \\
\hline & 4 & $\begin{array}{l}1.0 \\
1.0\end{array}$ & .6 & .6 & IC & $\mathrm{FO2}$ & - & 1947 & OP \\
\hline & 5 & 1.0 & .6 & .6 & IC & FO2 & - & 1947 & OP \\
\hline & 6 & 6.0 & 6.0 & 6.0 & IC & Nat Gas & FO2 & 1981 & OP \\
\hline Hydro Plant (St Joseph) & 1 & .4 & .4 & .4 & HY & Water & - & [91] & OP \\
\hline & 2 & .4 & 4 & .4 & $\mathbf{H Y}$ & Water & - & 1911 & .OP \\
\hline & 3 & .8 & .8 & .8 & $\mathbf{H Y}$ & Water & - & 1983 & OP \\
\hline & 4 & .8 & .8 & .8 & HY & Water & - & 1983 & OP \\
\hline Thumb Electric Coop-Mithigan ......................... & & 11.6 & 10.5 & 10.5 & & & & & \\
\hline 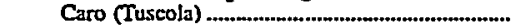 & 1 & 1.3 & 1.0 & 1.0 & IC & $\mathrm{FO} 2$ & - & 1949 & OP \\
\hline & 2 & 1.3 & 1.0 & 1.0 & IC & $\mathrm{FO} 2$ & - & 1949 & $\mathrm{OP}$ \\
\hline & 3 & 1.3 & 1.0 & 1.0 & IC & $\mathrm{FO} 2$ & - & 1952 & OP \\
\hline & 4 & 1.5 & 1.5 & 1.5 & IC & $\mathrm{FO} 2$ & ـ & 1984 & OP \\
\hline Ubly (Huron) & i & .6 & .6 & .6 & $\mathrm{IC}$ & FO2 & - & 1938 & OP \\
\hline & 2 & .7 & .6 & .6 & IC & $\mathrm{FO} 2$ & - & 1938 & OP \\
\hline & 3 & .7 & .7 & .7 & IC & $\mathrm{FO} 2$ & - & 1938 & OP \\
\hline & 4 & 1.0 & 1.0 & 1.0 & IC & FO2 & - & 1947 & OP \\
\hline & 5 & 1.6 & E 3.5 & E 15 & IC & $\mathrm{FO} 2$ & - & 1987 & OP \\
\hline & 6 & 1.5 & 1.5 & 15 & IC & Nat Gas & FO2 & 1993 & OP \\
\hline Traverse City City of & & 32.0 & 36.1 & 363 & & & & & \\
\hline Bayside (Grand Traverse) & 了 & 2.5 & 3.1 & 3.1 & ST & BIT & - & 1946 & OP \\
\hline & 2 & 5.0 & 6.1 & 6.1 & ST & BIT & - & 1950 & OP \\
\hline & 3 & 7.5 & 9.6 & 9.6 & ST & Nat Gas & - & 1954 & OP \\
\hline & 4 & 14.0 & 15.1 & 15.1 & ST & BIT & - & 1968 & OP \\
\hline Boardman (Grand Traverse) ...................................... & $\mathrm{HCl}$ & 1.0 & .8 & 9 & HY & Water & - & 1985 & OP \\
\hline Brown Bridge (Grand Traverse) ......................... & 1 & .4 & .3 & .4 & $\mathbf{H Y}$ & Water & - & 1921 & OP \\
\hline & 2 & 3 & 3 & .4 & HY & Water & - & 1921 & OP \\
\hline Elk Rapids (Antrim) & $* * 3$ & .4 & .2 & .2 & HY & Water & - & 1984 & OP \\
\hline & $* 4$ & .4 & .2 & .2 & HY & Water & - & 1984 & OP \\
\hline Sabin (Grand Traverse) & $\mathrm{HCl}$ & .5 & .4 & $s$ & HY & Water & - & 1985 & $O P$ \\
\hline 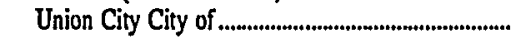 & & 1.3 & 13 & 1.3 & & & & & \\
\hline 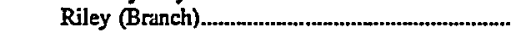 & ] & .3 & .3 & 3 & HY & Water & - & 1922 & OP \\
\hline & 2 & .2 & .2 & 2 & HY & Water & - & 1922 & $O P$ \\
\hline
\end{tabular}

See footnotes at end of table. 
Table 20. Existing Generating Units at U.S. Electric Utilities by State, Company, and Plant, as of January 1, 1998 (Continued)

\begin{tabular}{|c|c|c|c|c|c|c|c|c|c|}
\hline \multirow{2}{*}{$\begin{array}{c}\text { State } \\
\text { Company } \\
\text { Plant (County) }\end{array}$} & \multirow{2}{*}{$\begin{array}{l}\text { Unit } \\
\text { ID }\end{array}$} & \multirow{2}{*}{$\begin{array}{c}\text { Generator } \\
\text { Nameplate } \\
\text { Capacity } \\
\text { (megawatts) }\end{array}$} & \multirow{2}{*}{$\begin{array}{c}\text { Net Summer } \\
\text { Capability } \\
\text { (megawatts) }\end{array}$} & \multirow{2}{*}{$\begin{array}{l}\text { Net Winter } \\
\text { Capability } \\
\text { (nuegawatts) }\end{array}$} & \multirow{2}{*}{$\begin{array}{r}\text { Unit } \\
\text { Typel }\end{array}$} & \multicolumn{2}{|c|}{ Energy Sourcel } & \multirow{2}{*}{$\begin{array}{c}\text { Year } \\
\text { of } \\
\text { Commercial } \\
\text { Operation }\end{array}$} & \multirow{2}{*}{$\begin{array}{c}\text { Unit } \\
\text { Status }\end{array}$} \\
\hline & & & & & & Primary & Alternate & & \\
\hline Michigan (Continued) & & & & & & & & & \\
\hline Union City (Brunch) .................................. & 1 & 0.3 & 0.3 & 0.3 & IC & FO2 & - & 1941 & OP \\
\hline & 2 & 3 & .3 & 3 & IC & $\mathrm{FO} 2$ & $\overline{-}$ & 1941 & $O P$ \\
\hline Upper Peninsula Power Co.............................................. & & 116.5 & 121.6 & 129.0 & & & & & \\
\hline 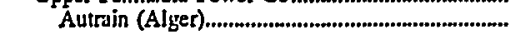 & 1 & .5 & .5 & .5 & HY & Water & - & 1988 & OP \\
\hline Catartet (Marduette) & 2 & .5 & .6 & .6 & HY & $\begin{array}{l}\text { Water } \\
\text { Whor }\end{array}$ & - & 1988 & $O P$ \\
\hline $\begin{array}{l}\text { Catartet (Marquette) } \\
\text { Escanaba (Delta) }\end{array}$ & $* * 1$ & 11.5 & 13.1. & 13.1 & ${ }_{S T}^{M T}$ & $\begin{array}{l}\text { Water } \\
\text { BIT }\end{array}$ & $\overline{-}$ & $\begin{array}{l}1988 \\
1958\end{array}$ & $\begin{array}{l}O P \\
O P\end{array}$ \\
\hline & $* 2$ & 31.5 & 13.2 & 13.2 & ST & BIT & - & 1958 & OP \\
\hline Gladitone (Delta) ........................................................ & 1 & 22.6 & 23.8 & 27.5 & GT & $\mathrm{FO} 2$ & - & 1975 & OP \\
\hline Hoist (Marquette) ................................................... & 1 & 1.0 & 1.0 & 1.0 & HY & Water & - & 1988 & OP \\
\hline & 2 & 1.4 & 1.5 & 15 & HY & Water & - & 1988 & OP \\
\hline & 3 & 20 & 1.8 & 1.8 & HY & Water & - & 1988 & OP \\
\hline John H Warden (Baraga) ............................................. & 1 & 18.8 & 17.7 & 37.7 & ST & Nat Gas & BIT & 1959 & OP \\
\hline Meclure (Marquette) ........................................ & i & 4.0 & 4.3 & 4.3 & $\mathrm{HY}$ & Water & - & 1988 & $O P$ \\
\hline & 2 & 4.0 & 4.4 & 4.4 & HY & Water & - & 1988 & $O P$ \\
\hline Portage (Houghton) & $\overline{1}$ & 22.6 & 23.8 & 27.5 & GT & $\mathrm{FO2}$ & _ & 1973 & OP \\
\hline 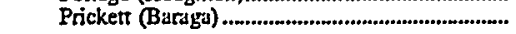 & i & 1.1 & 1.1 & 1.1 & $\mathrm{HY}$ & Water & - & 1931 & OP \\
\hline & 2 & 1.1 & 1.1 & 1.1 & $\mathrm{HY}$ & Water & - & 1931 & OP \\
\hline 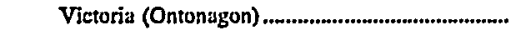 & 1 & 6.0 & 6.2 & 6.2 & HY & Water & - & 1931 & OP \\
\hline & 2 & 6.0 & 6.2 & 62 & HY & Water & - & 1931 & OP \\
\hline USCE-Detroit District ............................................................ & & 18.4 & 20.0 & 20.0 & & & & & \\
\hline Saint Marys Falls (Chippewa) ..................................... & $3 \mathrm{~A}$ & 2.0 & 20 & 2.0 & HY & Water & - & 1954 & $\mathrm{OP}$ \\
\hline & 1 & 4.8 & 5.3 & 53 & $\mathrm{HY}$ & Water & - & 1951 & $O P$ \\
\hline & 2 & 4.8 & 5.3 & 53 & $\mathrm{FY}$ & Water & - & 1951 & OP \\
\hline & 3 & 4.8 & 5.3 & 53 & $\mathrm{HY}$ & Water & - & 1952 & OP \\
\hline & 10 & 2.0 & 20 & 2.0 & $\mathrm{HY}$ & Water & - & 1932 & os \\
\hline Wisconsin Electric Power Co & & 705.8 & 684.3 & 685.6 & & & & & \\
\hline 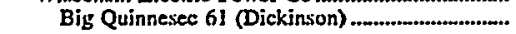 & 4 & 1.8 & 1.5 & 1.2 & HY & Water & - & 1914 & OP \\
\hline & 5 & 1.8 & 1.5 & 1.2 & $\mathrm{BY}$ & Water & - & 1914 & OP \\
\hline 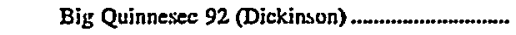 & 1 & 8.0 & 7.5 & 8.0 & $\mathrm{HY}$ & Water & - & 1949 & $\mathrm{OP}$ \\
\hline & 2 & 8.0 & 7.5 & 8.0 & $\mathrm{HY}$ & Water & - & 1949 & $\mathrm{OP}$ \\
\hline 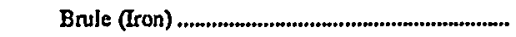 & I & 1.3 & 2.3 & 21.2 & $\mathrm{HY}$ & Water & - & 1919 & OP \\
\hline & 2 & 2.0 & $2-$ & $2-$ & $\mathrm{HY}$ & Water & - & 1919 & OP \\
\hline & 3 & 20 & $2-$ & $2-$ & HY & Water & - & 1921 & OP \\
\hline Chalk Hill (Menuminee)............................................... & 1 & 2.6 & 26.0 & 26.0 & HY & Water & - & 1927 & OP \\
\hline 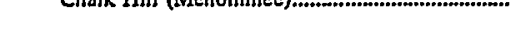 & 2 & 2.6 & $2-$ & $2-$ & HY & Water & - & 1927 & OP \\
\hline & 3 & 2.6 & $2^{2}-$ & $2_{-}$ & $\mathrm{HY}$ & Water & - & 1927 & OP \\
\hline 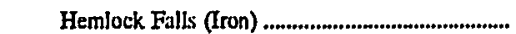 & $i$ & 2.8 & 1.2 & 2.0 & $\mathrm{HY}$ & Water & - & 1953 & $O P$ \\
\hline 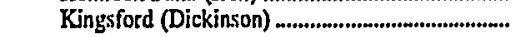 & $i$ & 2.4 & 26.0 & 26.0 & HY & Water & - & 1924 & OP \\
\hline & $i$ & 2.4 & $2-$ & $2_{-}$ & $\mathrm{HY}$ & Water & - & 1924 & OP \\
\hline & 3 & 24 & $2-$ & $2^{2}$ & HY & Water & - & 1924 & OP \\
\hline Lower Paint (Iron) .................................................... & & & .1 & .1 & & Water & - & 1952 & $\mathrm{OP}$ \\
\hline 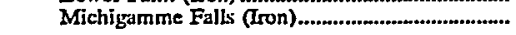 & j & 4.8 & 28.8 & 28.8 & $\mathbf{H Y}$ & Water & - & 1953 & OP \\
\hline & & & & $2-$ & $\mathrm{HY}$ & Water & - & 1953 & OP \\
\hline Peavy Falls (Iron) & 1 & 6.0 & 7.5 & 7.5 & $\mathrm{EY}$ & Water & - & 1943 & OP \\
\hline & 2 & 6.0 & 7.5 & 75 & HY & Water & - & 1943 & OP \\
\hline Presque Isle (Marquette)................................................. & 1 & 25.0 & 25.0 & 25.0 & ST & BIT & - & 1955 & OP \\
\hline & 2 & 37.5 & 37.0 & 37.0 & ST & BIT & - & 1962 & OP \\
\hline & 3 & 54.4 & 58.0 & 58.0 & ST & BIT & - & 1964 & OP \\
\hline & 4 & 57.8 & 58.0 & 58.0 & ST & BIT & - & 1966 & OP \\
\hline & 5 & 90.0 & 87.0 & 87.0 & ST & BIT & - & 1974 & OP \\
\hline & 6 & 90.0 & 90.0 & 90.0 & ST & BIT & - & 1975 & OP \\
\hline & 7 & 90.0 & 85.0 & 85.0 & ST & SUB & - & 1978 & OP \\
\hline & 8 & 90.0 & 85.0 & 85.0 & ST & SUB & - & 1978 & OP \\
\hline & 9 & 90.0 & 88.0 & 88.0 & ST & SUB & - & 1979 & OP \\
\hline Sturgeun (Dickinson) ............................................... & 1 & .8 & .4 & .4 & HY & Water & - & 1923 & OP \\
\hline 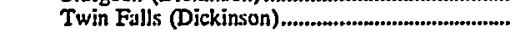 & i & 1.2 & 26.0 & 26.0 & $\mathrm{HY}$ & Water & - & 1913 & OP \\
\hline & 2 & 1.2 & $2-$ & $2-$ & $\mathrm{HY}$ & Water & - & 1913 & OP \\
\hline & 3 & 1.2 & $2-$ & $2_{-}$ & $\mathrm{HY}$ & Water & - & 3913 & $O P$ \\
\hline & 4 & 1.2 & $2-$ & $2-$ & HY & Water & _ & 1916 & $O P$ \\
\hline & 5 & 1.2 & $2-$ & 2 & $\mathrm{HY}$ & Water & - & 1916 & OP \\
\hline 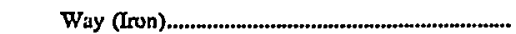 & 1 & 1.8 & .8 & .9 & HY & Water & - & 1949 & OP \\
\hline White Rapids (Menominee) & 1 & 3.0 & 42.9 & 42.9 & $\mathrm{HY}$ & Water & - & 1927 & OP \\
\hline & 2 & 20 & 42.0 & 42.0 & $\mathrm{HY}$ & Water & -- & 1927 & OP \\
\hline & $\overline{3}$ & $\overline{3.0}$ & 42.9 & 42.9 & $\mathrm{HY}$ & Water & -- & 1927 & OP \\
\hline Wisconsin Public Service Corp....................................... & & 7.5 & 3.8 & 3.9 & & & & & \\
\hline 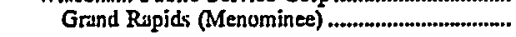 & 1 & 1.1 & .6 & .6 & HY & Water & - & 1930 & OP \\
\hline & 2 & 1.1 & 6 & .6 & HY & Water & - & 1910 & $O P$ \\
\hline & 3 & 1.5 & .8 & .8 & HY & Water & - & 1912 & OP \\
\hline
\end{tabular}

See footnotes at end of table. 
Table 20. Existing Generating Units at U.S. Electric Utilities by State, Company, and Plant, as of January 1, 1998 (Continued)

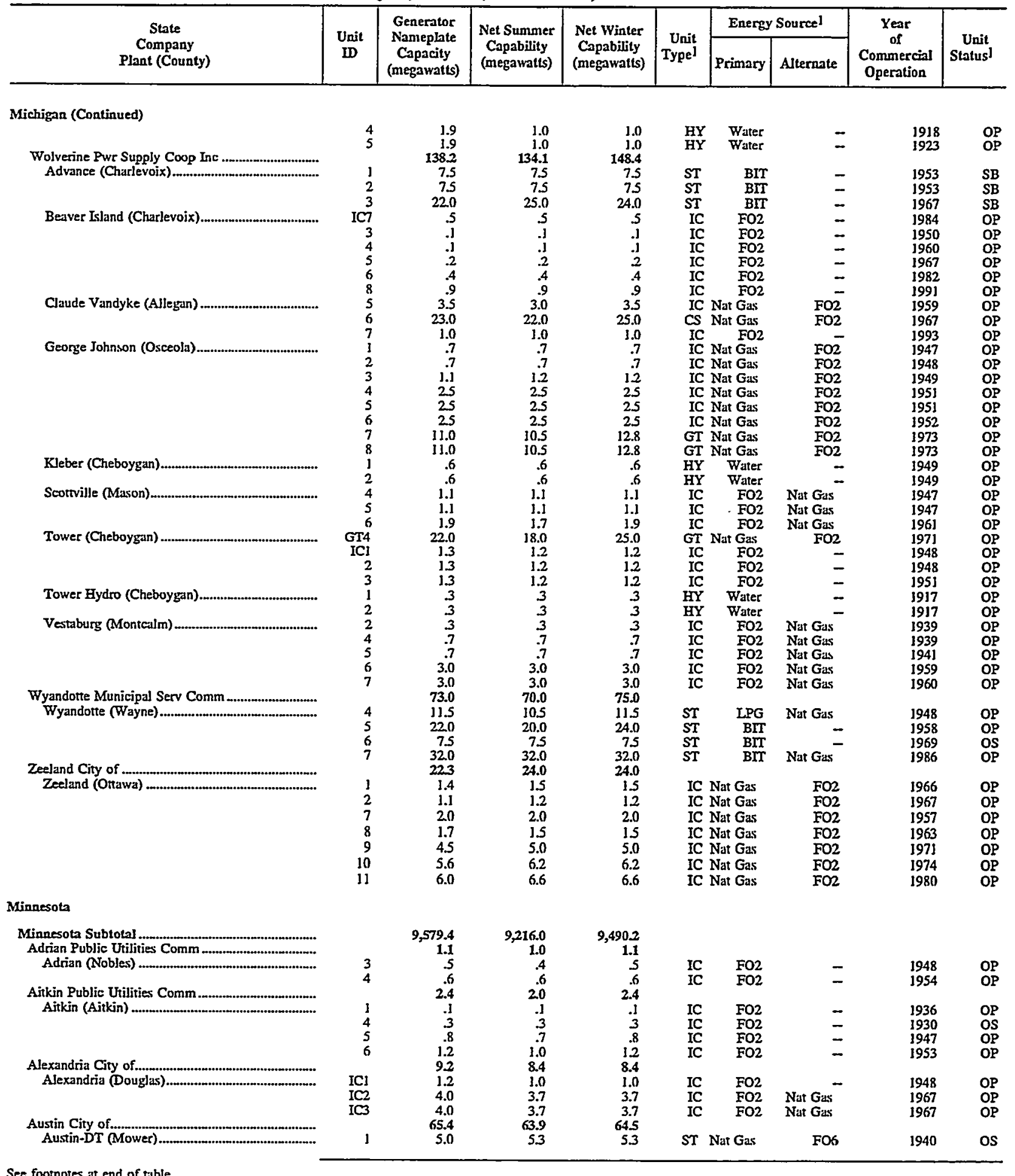


Table 20. Existing Generating Units at U.S. Electric Utilities by State, Company, and Plant, as of January 1, 1998 (Continued)

\begin{tabular}{|c|c|c|c|c|c|c|c|c|c|}
\hline \multirow{2}{*}{$\begin{array}{c}\text { State } \\
\text { Company } \\
\text { Plant (County) }\end{array}$} & \multirow{2}{*}{$\begin{array}{l}\text { Unit } \\
\text { ID }\end{array}$} & \multirow{2}{*}{$\begin{array}{l}\text { Generator } \\
\text { Nameplate } \\
\text { Capacity } \\
\text { (megawatts) }\end{array}$} & \multirow{2}{*}{$\begin{array}{l}\text { Net Summer } \\
\text { Capability } \\
\text { (megawatts) }\end{array}$} & \multirow{2}{*}{$\begin{array}{l}\text { Net Winter } \\
\text { Capability } \\
\text { (megawatts) }\end{array}$} & \multirow{2}{*}{$\begin{array}{l}\text { Unit } \\
\text { Type }\end{array}$} & \multicolumn{2}{|c|}{ Eneray Sourcel } & \multirow{2}{*}{$\begin{array}{c}\text { Year } \\
\text { of } \\
\text { Commercial } \\
\text { Operation }\end{array}$} & \multirow{2}{*}{$\begin{array}{c}\text { Unit } \\
\text { Status! }\end{array}$} \\
\hline & & & & & & Primary & Alternate & & \\
\hline Minnesota (Continued) & & & & & & & & & \\
\hline & 2 & 3.5 & 3.5 & 3.5 & ST & Nat Gas & FO6 & 1935 & os \\
\hline & 3 & 7.5 & 8.8 & 8.8 & ST & Nat Gas & F06 & 1946 & os \\
\hline & 4 & 11.5 & 12.2 & 12.2 & ST & Nat Gas & FO6 & 1955 & os \\
\hline & 5 & 6.0 & 4.8 & 5.4 & GT & Nat Gas & & $196 !$ & $\mathrm{OP}$ \\
\hline 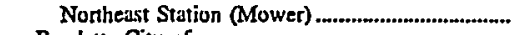 & J & 31.9 & 29.3 & 29.3 & ST & BIT & Nat Gas & 1971 & OP \\
\hline Baudette City of & & 1.9 & 1.9 & 1.9 & & & & & \\
\hline Baudette (Lake Of The Woods) & 2 & 1.1 & 1.1 & j.1 & IC & FO2 & - & 1960 & OP \\
\hline 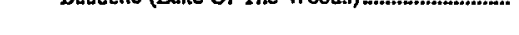 & 3 & .2 & .2 & 2 & IC & FO2 & - & 1936 & OP \\
\hline & 4 & .3 & 3 & 3 & IC & $\mathrm{FO} 2$ & - & 1946 & OP \\
\hline & 5 & .3 & 3 & 3 & IC & FO2 & - & 1950 & OP \\
\hline 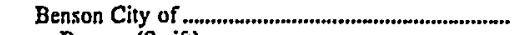 & & 3.1 & 3.1 & 3.1 & & & & & \\
\hline 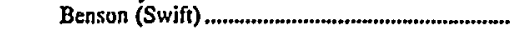 & 3 & 3 & 3 & 3 & IC & $\mathrm{FO} 2$ & - & 1936 & OP \\
\hline & 4 & .6 & .6 & .6 & IC & $\mathrm{FO} 2$ & - & 1939 & op \\
\hline & 5 & .9 & .9 & 9 & Ic & $\mathrm{FO2}$ & - & 1948 & OP \\
\hline & 6 & 1.3 & 1.3 & 13 & IC & FO2 & - & 1955 & OP \\
\hline 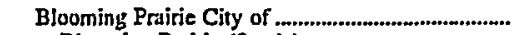 & & 3.6 & 3.6 & 3.6 & & & & & \\
\hline Blooming Prairie (Steele) .............................................. & l & .3 & 3 & 3 & IC & $\mathrm{FO} 2$ & - & 1937 & OP \\
\hline & 2 & .7 & .7 & .7 & IC & $\mathrm{FO} 2$ & - & 1947 & OP \\
\hline & & 1.4 & 1.4 & 1.4 & IC & $\mathrm{FO2}$ & - & 1957 & OP \\
\hline & 4 & 1.2 & 1.2 & 1.2 & IC & $\mathrm{FO2}$ & - & 1974 & OP \\
\hline 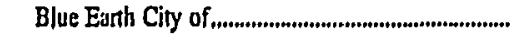 & & 8.1 & 8.1 & 8.1 & & & & & \\
\hline Blue Eath (Furibault)............................................... & ICI & 1.5 & 1.5 & 1.5 & IC & $\mathrm{FO} 2$ & Nar Gas & 1960 & OP \\
\hline & IC & 3.6 & 3.6 & 1.6 & IC & $\mathrm{FO} 2$ & - & 1993 & op \\
\hline & ICA & 1.6 & 1.6 & 1.6 & IC & $\mathrm{FO} 2$ & $=$ & 1993 & OP \\
\hline & IC6 & $\begin{array}{l}1.6 \\
1.8\end{array}$ & $\begin{array}{l}1.6 \\
1.8\end{array}$ & $\begin{array}{l}1.6 \\
1.8\end{array}$ & IC & $\begin{array}{ll}\mathrm{FO} 2 \\
\mathrm{FO} 2\end{array}$ & $\bar{z}$ & $\begin{array}{l}1993 \\
1996\end{array}$ & $O P$ \\
\hline 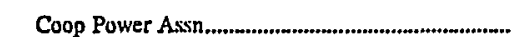 & & 47.6 & 47.3 & 50.0 & & & & & \\
\hline 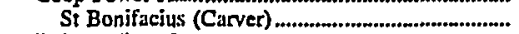 & 1 & 47.6 & 47.3 & 50.0 & GT & FO2 & - & 1978 & OP \\
\hline Deluno City of & & 8.7 & 8.7 & 8.7 & & & & & \\
\hline Dejano (Wright) & $\cdot 1$ & 1,1 & 1.1 & 1.1 & IC & $\mathrm{FO} 2$ & $m^{-}$ & 1951 & OP \\
\hline & $\begin{array}{l}2 \\
3\end{array}$ & $\begin{array}{l}1.1 \\
1.4\end{array}$ & $\begin{array}{l}1.1 \\
1.4\end{array}$ & 1.14 & $\begin{array}{l}\text { IC } \\
\text { IC }\end{array}$ & $\begin{array}{l}\text { Nat Gas } \\
\text { Nat Gas }\end{array}$ & $\begin{array}{l}\mathrm{FO} 2 \\
\mathrm{FO} 2\end{array}$ & $\begin{array}{l}1972 \\
1973\end{array}$ & OP \\
\hline & 5 & .8 & .8 & .8 & IC & FO2 & 50 & 1946 & OP \\
\hline & 6 & 1.3 & 1.3 & 13 & IC & FO2 & - & 1989 & OP \\
\hline & 7 & 3.0 & 3.0 & 3.0 & IC & $\mathrm{FO2}$ & - & 1994 & OP \\
\hline 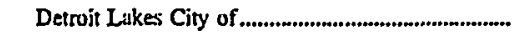 & & 12.5 & 10.0 & 10.0 & & & & & \\
\hline Detroit Lakes (Becker) ....................................................... & 1 & 12.5 & 10.0 & 10.0 & $\mathrm{JE}$ & FOI & - & 1968 & OP \\
\hline Elk River City of & & 9.1 & 9.1 & 9.1 & & & & & \\
\hline Elk River (Sherbume) .............................................. & $\frac{1}{2}$ & .6 & .6 & .6 & $\begin{array}{l}\text { IC } \\
\text { IC }\end{array}$ & $\mathrm{FO2}$ & 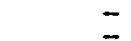 & 1948 & OP \\
\hline & 2 & 3.6 & 3.6 & 3.6 & IC & $\mathrm{FO2}$ & $\mathrm{FO}^{-}$ & 1948 & OP \\
\hline & 4 & $\begin{array}{lll}3.0 \\
5.0\end{array}$ & $\begin{array}{l}3.0 \\
50\end{array}$ & 50 & IC & Nat Gas & $\mathrm{FOz}$ & 1962 & $\mathrm{OP}$ \\
\hline Fairfax City of..... & & 5.0 & 5.0 & 5.0 & & Nat Gas & Fo2 & 1972 & OP \\
\hline & & 1.7 & 1.7 & 1.7 & & & & & \\
\hline 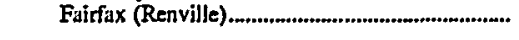 & 1 & .9 & .9 & .9 & IC & $\mathrm{FO} 2$ & - & 1948 & OP \\
\hline & 2 & .2 & .2 & 2 & IC & $\mathrm{FO} 2$ & - & 1935 & SB \\
\hline & 4 & .6 & .6 & .6 & IC & FO2 & - & 1940 & OP \\
\hline Faimunt Public Utilities Comm................................... & & 35.5 & 34.3 & 343 & & & & $\because$ & \\
\hline Fajmont (Mirtin) & 3 & 5.0 & 4.5 & 4.5 & ST & Nat Gas & - & 1945 & $O P$ \\
\hline & 4 & 5.0 & 4.7 & 4.7 & ST & Nat Gas & & 1949 & OP \\
\hline & 5 & 12.5 & 12.3 & 12.3 & ST & Nat Gas & - & 1959 & OP \\
\hline & 6 & 6.5 & 6.5 & 6.5 & IC & $\mathrm{FO} 2$ & Nat Gas & 1975 & OP \\
\hline & 7 & 6.5 & 6.3 & 6.3 & IC & FO2 & Nat Gas & 1975 & OP \\
\hline Glencoe Light \& Power Comm................................... & & 26.6 & 21.3 & 21.3 & & & & & \\
\hline 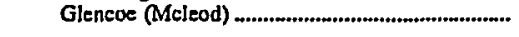 & 5 & 1.4 & 1.1 & 1.1 & IC & Nat Gas & F02 & 1957 & OP \\
\hline & 6 & 1.4 & 1.1 & 1.1 & IC & Nat Gas & FO2 & 1961 & OP \\
\hline & 7 & 4.1 & 3.3 & 3.3 & IC & Nat Gas & FO2 & 1966 & OP \\
\hline & 8 & 5.6 & 4.5 & 4.5 & IC & Nat Gas & Fo2 & 1969 & OP \\
\hline & 9 & 7.2 & 5.7 & 5.7 & IC & Nat Gas & $\mathrm{FO} 2$ & 1973 & $O P$ \\
\hline & 10 & 7.1 & 5.7 & 5.7 & IC & FO2 & - & 1985 & OP \\
\hline 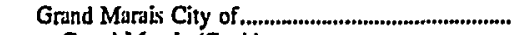 & & 3.5 & 3.3 & 3.3 & & & & & \\
\hline Grand Marais (Cook)......................................................... & 2 & .7 & .7 & .7 & IC & $\mathrm{FO} 2$ & - & 1956 & OP \\
\hline & 3 & 3 & .2 & .2 & IC & $\mathrm{FO} 2$ & - & 1947 & OP \\
\hline & 4 &.$J$ & .1 & .1 & IC & $\mathrm{FO2}$ & - & 1940 & $O P$ \\
\hline & 5 & 1.J & 1.1 & 1.1 & Ic & $\mathrm{FO} 2$ & - & 1962 & $O P$ \\
\hline & 6 & 1.2 & 1.2 & 1.2 & IC & FO2 & - & 1969 & OP \\
\hline Granite Fulls City of ........................ & & 1.4 & 1.2 & 1.2 & & & & & \\
\hline Granite Falls (Chippewa)....................... & HC3 & .9 & .7 & .7 & HY & Water & - & 1986 & op \\
\hline & 1 & 3 & .3 & 3 & $\mathrm{HY}$ & Water & - & 1940 & OP \\
\hline & & 3 & .3 & 3 & $\mathrm{HY}$ & Water & - & 1932 & OP \\
\hline Halstud City of & & 1.1 & 1.1 & 1.1 & & & & & \\
\hline
\end{tabular}

See, footnotes at end of table. 
Table 20. Existing Generating Units at U.S. Electric Utilities by State, Company, and Plant, as of January 1, 1998 (Continued)

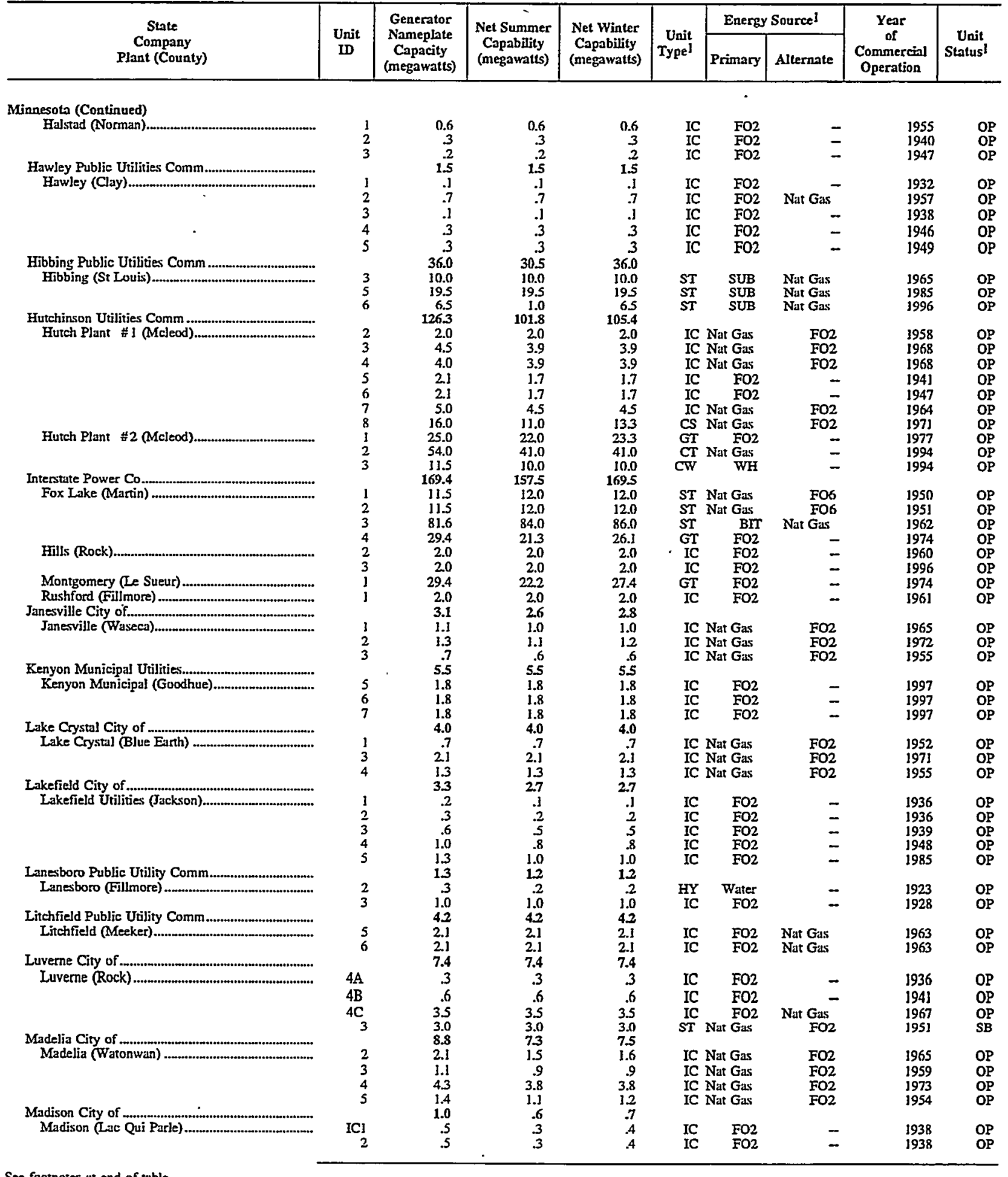

See footnotes at end of table. 
Table 20. Existing Generating Units at U.S. Electric Utilities by State, Company, and Plant, as of January 1, 1998 (Continued)

\begin{tabular}{|c|c|c|c|c|c|c|c|c|c|}
\hline \multirow{2}{*}{$\begin{array}{c}\text { State } \\
\text { Company } \\
\text { Plant (County) }\end{array}$} & \multirow{2}{*}{$\begin{array}{l}\text { Unit } \\
\text { ID }\end{array}$} & \multirow{2}{*}{$\begin{array}{c}\text { Generator } \\
\text { Nameplate } \\
\text { Capacity } \\
\text { (megawatts) }\end{array}$} & \multirow{2}{*}{$\begin{array}{l}\text { Net Summer } \\
\text { Capability } \\
\text { (megawatts) }\end{array}$} & \multirow{2}{*}{$\begin{array}{l}\text { Net Winter } \\
\text { Capability } \\
\text { (megawatts) }\end{array}$} & \multirow{2}{*}{$\begin{array}{l}\text { Unit } \\
\text { Type] }\end{array}$} & \multicolumn{2}{|c|}{ Energy Sourcel } & \multirow{2}{*}{$\begin{array}{c}\text { Year } \\
\text { of } \\
\text { Commercial } \\
\text { Operation }\end{array}$} & \multirow{2}{*}{$\begin{array}{c}\text { Unit } \\
\text { Status }\end{array}$} \\
\hline & & & & & & Primary & Alternate & & \\
\hline Minnesota (Continued) & & & & & & & & & \\
\hline 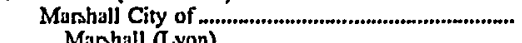 & & 16.5 & 15.5 & 19.0 & & & & & \\
\hline 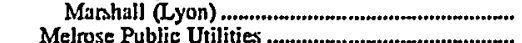 & 6 & 16.5 & 15.5 & 19.0 & GT & FO2 & - & 1969 & OP \\
\hline & & 8.3 & 7.8 & 7.8 & & & & & \\
\hline Melrose (Steams) & $\begin{array}{l}1 \\
2\end{array}$ & $\begin{array}{l}1.0 \\
1.1\end{array}$ & .8 & .8 & $\begin{array}{l}\text { IC } \\
\text { IC }\end{array}$ & $\begin{array}{l}\text { FO2 } \\
\text { FO2 }\end{array}$ & $\overline{-}$ & $\begin{array}{l}1945 \\
1948\end{array}$ & $\begin{array}{l}O P \\
O P\end{array}$ \\
\hline & 3 & 3.0 & 3.0 & 3.0 & IC & FO2 & Nat Gas & 1969 & OP \\
\hline & 4 & 3.0 & 3.0 & 3.0 & IC & FO2 & Nat Gas & 1969 & OP \\
\hline 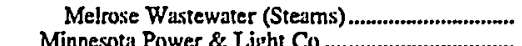 & EG & $\frac{.2}{9}$ & $137 . .2$ & $\begin{array}{r}.2 \\
13758\end{array}$ & IC & MTE & - & 1990 & OP \\
\hline Minnesota Power \& Light Co .................................... & & $1,431.9$ & $1,375.8$ & $1,375.8$ & & & & & \\
\hline 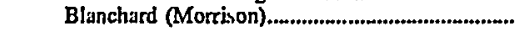 & $\frac{1}{2}$ & $\begin{array}{l}6.0 \\
6.0\end{array}$ & $\begin{array}{l}5.8 \\
5.8\end{array}$ & $\begin{array}{l}5.8 \\
5.8\end{array}$ & $\underset{H Y}{\mathrm{HY}}$ & $\begin{array}{l}\text { Water } \\
\text { Water }\end{array}$ & 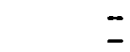 & $\begin{array}{l}1925 \\
1925\end{array}$ & $\begin{array}{l}O P \\
O P\end{array}$ \\
\hline & 3 & 6.0 & 6.0 & 6.0 & HY & Water & - & 1988 & $O P$ \\
\hline Clay Boswell (Itasea)................................................... & **D4 & .9 & .9 & .9 & IC & FO2 & - & 1980 & $\mathrm{OP}$ \\
\hline & 1 & 75.0 & 69.0 & 69.0 & ST & SUB & - & 1958 & OP \\
\hline & 2 & 75.0 & 69.0 & 69.0 & ST & SUB & - & 1960 & OP \\
\hline & 3 & 364.5 & 350.0 & 350.0 & ST & SUB & - & 1973 & OP \\
\hline & $* \$ 4$ & 558.0 & 535.0 & 535.0 & ST & SUB & - & 1980 & OP \\
\hline 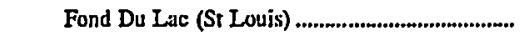 & 1 & 12.0 & 11.2 & 11.2 & HY & Water & - & 1924 & $O P$ \\
\hline 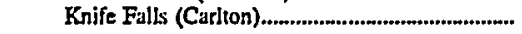 & I & .8 & .6 & .6 & HY & Water & - & 1922 & OP \\
\hline & 2 & .8 & .6 & 6 & HY & Water & - & 1922 & OP \\
\hline & 3 & .8 & .6 & .6 & HY & Water & - & 1922 & OP \\
\hline Little Falls (Morrison) …............................................. & 1 & .8 & .8 & .8 & $\mathrm{HY}$ & Water & - & 1919 & OP \\
\hline 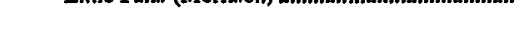 & 2 & .8 & .8 & 8 & $\mathrm{HY}$ & Water & - & 1919 & OP \\
\hline & 3 & 1.0 & 1.0 & 1.1 & HY & Water & $=$ & 1920 & OP \\
\hline & 4 & 1.2 & 1.4 & 1.4 & HY & Water & - & 1979 & OP \\
\hline & 5 & .4 & 3 & 3 & $\mathrm{HY}$ & Water & - & 1906 & OP \\
\hline & 6 & .4 & 3 & 3 & HY & Water & - & 1906 & OP \\
\hline 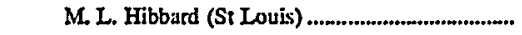 & 1 & 25.0 & 25.0 & 25.0 & ST & FO6 & - & 1931 & os \\
\hline - & 2 & 25.0 & 25.0 & 25.0 & ST & FO6 & - & 1943 & os \\
\hline & 3 & 35.3 & 32.6 & 32.6 & ST & WD & BIT & 1949 & OP \\
\hline & 4 & 37.5 & 39.0 & 39.0 & ST & SUB & Nat Gas & 1951 & os \\
\hline 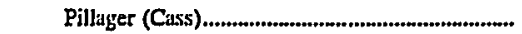 & $\mathrm{j}$ & .8 & .9 & .9 & $\mathrm{HY}$ & Water & - & 3917 & OP \\
\hline & 2 & .8 & .9 & .9 & HY & Water & - & 1917 & OP \\
\hline 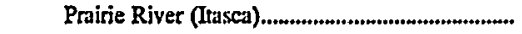 & 1 & .7 & .5 & .5 & HY & Water & - & 1920 & OP \\
\hline & 2 & .4 & .4 & .4 & HY & Water & - & 1920 & $\mathrm{OP}$ \\
\hline Scanlon (Carlton) & 1 & .4 & .4 & .4 & $\mathrm{HY}$ & Water & - & 1923 & OP \\
\hline & 2 & .4 & .4 & .4 & HY & Water & - & 1923 & $\mathrm{OP}$ \\
\hline & $\tilde{3}$ & .4 & .4 & .4 & HY & Water & - & 1923 & OP \\
\hline & 4 & .4 & .4 & .4 & HY & Water & - & 1923 & OP \\
\hline Syl Laskin (St Louis) & 1 & 58.0 & 55.0 & 55.0 & ST & SUB & - & 1953 & OP \\
\hline & 2 & 58.0 & 55.0 & 55.0 & ST & SUB & - & 1953 & OP \\
\hline Sylvan (Cass) ............. & 1 & .6 & .6 & .6 & HY & Water & - & 1913 & OP \\
\hline & 2 & 6 & .6 & 6 & HY & Water & - & 1913 & OP \\
\hline & 3 & .6 & .6 & .6 & HY & Water & - & 1915 & OP \\
\hline Thomson (Carlion) & 1 & 13.0 & 125 & 12.5 & HY & Water & - & 1907 & OP \\
\hline 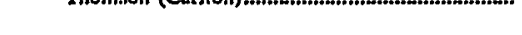 & 2 & 13.0 & 12.5 & 12.5 & HY & Water & - & 1907 & $O P$ \\
\hline & 3 & 13.0 & 12.5 & 12.5 & HY & Water & - & 1907 & OP \\
\hline & 4 & 10.8 & 32.5 & 125 & HY & Water & - & 1914 & $O P$ \\
\hline & 5 & 10.8 & 32.5 & 125 & HY & Water & - & 1919 & OP \\
\hline & 6 & 120 & 12.5 & 125 & HY & Water & - & 1949 & OP \\
\hline 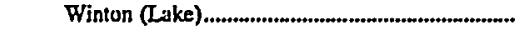 & 2 & 2.0 & 2.0 & 2.0 & HY & Water & - & 3923 & OP \\
\hline & 3 & 20 & 2.0 & 2.0 & HY & Water & - & 1923 & OP \\
\hline Sity of & & 35.0 & 29.3 & 32.6 & & & & & \\
\hline 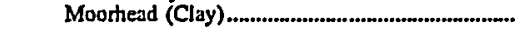 & 6 & 10.0 & 6.3 & 9.6 & GT & FO2 & - & 1961 & OP \\
\hline & 7 & 25.0 & 23.0 & 23.0 & ST & IIG & - & 1970 & SB \\
\hline Moose Lake Water \& Light Comm ............................ & & & 3.6 & 3.6 & & & & & \\
\hline Moose Lake (Carlton) & 1 & 1.3 & 1.3 & 1.3 & & Nat Gas & $\mathrm{FO} 2$ & 1973 & $\mathrm{OP}$ \\
\hline & 2 & 1.0 & 1.0 & 1.0 & & Nat Gas & $\mathrm{FO} 2$ & 1952 & $O P$ \\
\hline & 4 & 1.3 & 1.3 & 13 & & Nat Gas & $\mathrm{FO2}$ & 1963 & OP \\
\hline 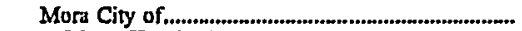 & & 13.9 & 12.6 & 13.1 & & & & & \\
\hline Mora (Kanabec) & 2 & 1.1 & .9 & .9 & & Nat Gas & FO2 & 1957 & OP \\
\hline & 5 & 5.8 & 5.7 & 5.7 & & Nat Gas & FO2 & 1972 & OP \\
\hline & 6 & 7.0 & 6.0 & 6.5 & IC & Nat Gas & FO2 & 1975 & OP \\
\hline 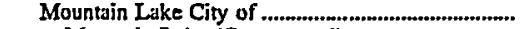 & & 4.6 & 4.0 & 4.3 & & & & & \\
\hline 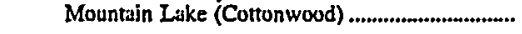 & $-\overline{2}$ & 1.1 & 1.0 & 1.1 & IC & $\mathrm{FO} 2$ & - & 1954 & $O P$ \\
\hline & 4 & 21 & 1.8 & 1.9 & IC & FO2 & - & 1968 & OP \\
\hline & 5 & 3.4 & 1.3 & 13 & IC & FO2 & - & 1959 & OP \\
\hline 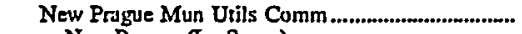 & & 18.3 & 18.0 & 18.0 & & & & & \\
\hline 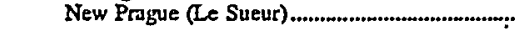 & $\frac{1}{2}$ & $\begin{array}{l}1.4 \\
4.4\end{array}$ & $\begin{array}{l}1.0 \\
4.4\end{array}$ & $\begin{array}{l}1.0 \\
4.4\end{array}$ & IC & Nat Gas & FO2 & $\begin{array}{l}1948 \\
1978\end{array}$ & $\begin{array}{l}O P \\
O P\end{array}$ \\
\hline
\end{tabular}

See footnotes at end of table. 
Table 20. Existing Generating Units at U.S. Electric Utilities by State, Company, and Plant, as of January 1, 1998 (Continued)

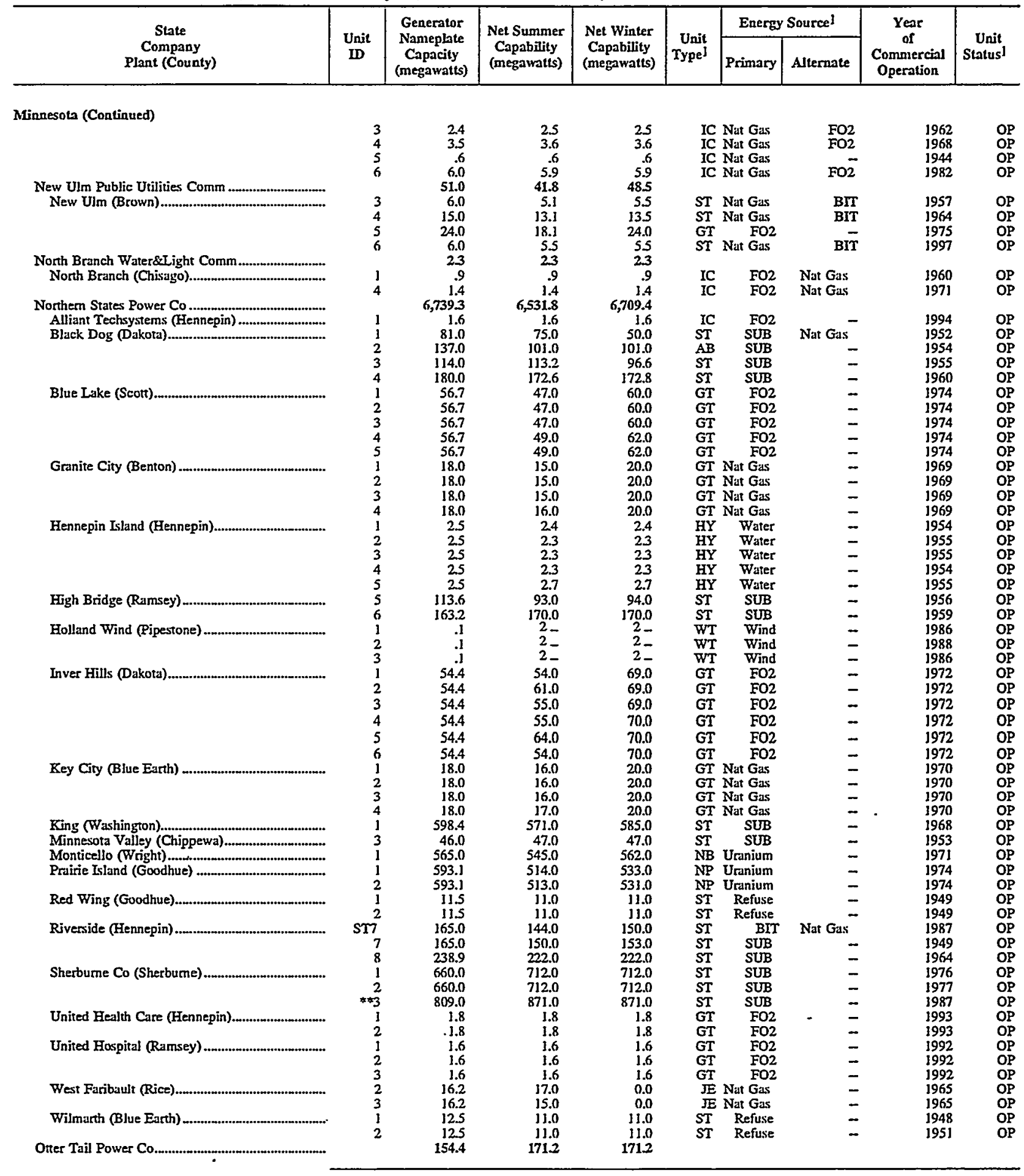

See footnotes at end of table. 
Table 20. Existing Generating Units at U.S. Electric Utilities by State, Company, and Plant, as of January 1, 1998 (Continued)

\begin{tabular}{|c|c|c|c|c|c|c|c|c|c|}
\hline \multirow{2}{*}{$\begin{array}{c}\text { State } \\
\text { Company } \\
\text { Plant (County) }\end{array}$} & \multirow{2}{*}{$\begin{array}{l}\text { Unit } \\
\text { DD }\end{array}$} & \multirow{2}{*}{$\begin{array}{c}\text { Generator } \\
\text { Nameplate } \\
\text { Capacity } \\
\text { (megawatts) }\end{array}$} & \multirow{2}{*}{$\begin{array}{l}\text { Net Summer } \\
\text { Capability } \\
\text { (megawatts) }\end{array}$} & \multirow{2}{*}{$\begin{array}{l}\text { Net Winter } \\
\text { Capability } \\
\text { (megawatts) }\end{array}$} & \multirow{2}{*}{$\begin{array}{c}\text { Unit } \\
\text { Typel }\end{array}$} & \multicolumn{2}{|c|}{ Energy Sourcel } & \multirow{2}{*}{$\begin{array}{c}\text { Year } \\
\text { of } \\
\text { Commercial } \\
\text { Operation }\end{array}$} & \\
\hline & & & & & & Primary & Alternale & & \\
\hline Minnesota (Continued) & & & & & & & & & \\
\hline Bemidji Hydro (Beltrami) ..................................... & 1 & 0.2 & 0.2 & 0.2 & HY & Water & - & 1929 & $O P$ \\
\hline & 2 & .5 & .6 & .6 & HY & Water & - & 1907 & OP \\
\hline Dayton Hollow (Otter Tail) .................................... & ] & 5 & .6 & 6 & HY & Water & - & 1928 & OP \\
\hline Fergus Control Crr (Orter Tail)................................ & ] & 2.0 & 20 & 2.0 & IC & FO2 & - & 1995 & OP \\
\hline 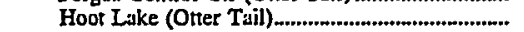 & HI & 1.0 & .8 & .8 & HY & Water & - & 1914 & OP \\
\hline & 1 & 7.5 & 7.6 & 7.6 & ST & SUB & - & 1948 & OP \\
\hline & $\begin{array}{l}2 \\
3\end{array}$ & $\begin{array}{l}54.4 \\
750\end{array}$ & $\begin{array}{l}63.8 \\
82.7\end{array}$ & $\begin{array}{l}63.8 \\
82.7\end{array}$ & $\begin{array}{l}\text { ST } \\
\text { ST }\end{array}$ & & $\overline{-}$ & 1959 & $O P$ \\
\hline Pistah (Otter Tajl) & 3 & $\begin{array}{r}75.0 \\
.5\end{array}$ & $\begin{array}{r}02.1 \\
.7\end{array}$ & $\begin{array}{r}82.1 \\
.7\end{array}$ & HY & $\begin{array}{l}\text { SUB } \\
\text { Water }\end{array}$ & $\overline{-}$ & $\begin{array}{l}1964 \\
1918\end{array}$ & OP \\
\hline Potlatch Cogen (Bejtrami) & $* * 1$ & 11.3 & 10.8 & 10.8 & ST & WD & - & 1992 & OP \\
\hline 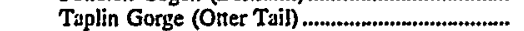 & 1 & .6 & .5 & .5 & HY & Water & - & 1925 & OP \\
\hline Wright (Oter Tuil) & I & .4 & .5 & 5 & $\mathbf{H Y}$ & Water & - & 1922 & OP \\
\hline 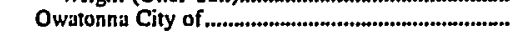 & & 45.0 & 443 & 49.3 & & 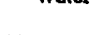 & & 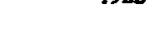 & \\
\hline Owatonna (Steele) & 5 & 6.0 & 9.0 & 9.0 & ST & Nat Gas & - & 1957 & SB \\
\hline & 6 & 20.0 & 20.5 & 20.5 & ST & Nat Gas & - & 1969 & OP \\
\hline & 7 & 19.0 & 14.9 & 19.9 & GT & Nat Gas & $\mathrm{FO2}$ & 1982 & $\mathbf{O P}$ \\
\hline Preston Public Utilities Comm ....................................... & & 4.5 & 4.0 & 4.0 & & & & & \\
\hline Preston (Fillmore) & 1 & 1 & .1 & .3 & IC & FO2 & - & 1935 & OP \\
\hline & 2 & .2 & .2 & 2 & IC & FO2 & - & 1935 & OP \\
\hline & 3 & 3 & 3 & 3 & IC & FO2 & - & 1939 & OP \\
\hline & 4 & .7 & .6 & 6 & IC & FO2 & - & 1949 & OP \\
\hline - & 5 & 1.1 & .8 & .8 & IC & $\mathrm{FO} 2$ & - & 1954 & OP \\
\hline & 6 & 21 & 2.1 & 2.1 & IC & Nat Gas & $\mathrm{FO} 2$ & 1974 & OP \\
\hline 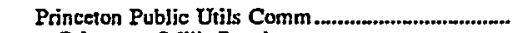 & & 7.6 & 6.6 & 6.6 & & & & & \\
\hline Princeton (Mille Lues) & 1 & .1 & ]$. & .1 & IC & FO2 & - & 1938 & OP \\
\hline & 2 & .1 & .1 & .1 & IC & $\mathrm{FO} 2$ & - & 1938 & OP \\
\hline & 3 & 24 & 2.2 & 2.2 & IC & $\mathrm{FO} 2$ & - & 1978 & OP \\
\hline & 4 & 1.2 & 1.0 & 1.0 & IC & FO2 & Nat Gas & 1967 & OP \\
\hline & 5 & 1.0 & .8 & .8 & IC & FO2 & Nat Gas & 1953 & OP \\
\hline & 6 & 2.8 & 2.5 & 2.5 & IC & FO2 & Nat Gas & 1963 & OP \\
\hline Redwood Falls Public Util Comm n........................... & & 8.5 & 7.9 & 7.9 & & & & & \\
\hline Redwood Falls (Redwood) & 1 & 5 & 3 & .3 & HY & Water & - & 1930 & OP \\
\hline & 6 & 2.2 & 2.1 & 2.1 & IC & FO2 & Nat Gas & 1970 & OP \\
\hline & 7 & 5.8 & 5.5 & 5.5 & IC & FO2 & Nat Gas & 1974 & OP \\
\hline Rochester Public Utilities & & 136.7 & 136.2 & 146.8 & & & & & \\
\hline Cascade Creek (Olmsted) & I & 35.0 & 27.9 & 38.0 & GT & FO2 & - & 1975 & OP \\
\hline 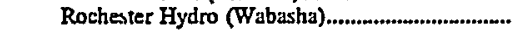 & 1 & 1.3 & 1.3 & 1.3 & HY & Water & - & 1984 & OP \\
\hline & 2 & 1.3 & 13 & 13 & $\mathrm{HY}$ & Water & $0-$ & 1984 & OP \\
\hline 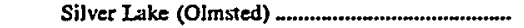 & $\mathbf{I}$ & 8.0 & 9.1 & 9.1 & ST & BIT & Nat Gas & 1948 & OP \\
\hline & 2 & 120 & 13.8 & 13.8 & ST & BIT & Nat Gas & 1953 & OP \\
\hline & 3 & 25.0 & 22.5 & 23.0 & ST & BIT & Nat Gas & 1962 & OP \\
\hline & 4 & 54.0 & 60.3 & 603 & ST & BIT & Nat Gas & 1969 & $\mathbf{O P}$ \\
\hline 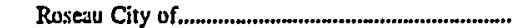 & & 3.1 & 3.0 & 3.0 & & & & & \\
\hline Roseau (Rosesu) & I & 1.4 & 1.4 & 1.4 & IC & $\mathrm{FO} 2$ & - & 1956 & OP \\
\hline & 2 & i.j & 1.1 & 1.1 & IC & FO2 & - & 1949 & OP \\
\hline & 3 & .6 & .6 & .6 & IC & FO2 & - & 1946 & OP \\
\hline 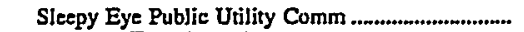 & & 72 & 72 & 72 & & & & & \\
\hline 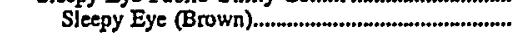 & IC4 & $1 . \overline{8}$ & 1.8 & 1.8 & IC & $\mathrm{FO} 2$ & - & 1995 & OP \\
\hline & 2 & 20 & 2.0 & 2.0 & ST & Nat Gas & - & 1946 & OP \\
\hline & 3 & 1.5 & 1.5 & 1.5 & IC & $\mathrm{FO} 2$ & Nat Gas & 1961 & OP \\
\hline & 5 & 1.8 & 1.8 & 1.8 & IC & $\mathrm{FO} 2$ & - & 1996 & OP \\
\hline 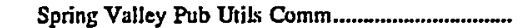 & & 3.9 & 3.5 & 3.5 & & & & & \\
\hline 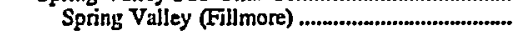 & 1 & .8 & 5 & 5 & IC & $\mathrm{FO} 2$ & - & 1949 & OP \\
\hline & 2 & 1.1 & 1.0 & 1.0 & IC & FO2 & Nat Gas & 1952 & OP \\
\hline & 3 & 2.0 & 2.0 & 2.0 & IC & $\mathrm{FO} 2$ & Nat Gas & 1960 & OP \\
\hline Springfield Public Utili Comm ..................................... & & 7.8 & 7.8 & 7.8 & & & & & \\
\hline Springfield (Brown) & 3 & 2.0 & 2.0 & 2.0 & ST & BIT & $\mathrm{FO2}$ & 1946 & OP \\
\hline & 4 & 4.0 & 4.0 & 4.0 & ST & BIT & $\mathrm{FO} 2$ & 1961 & OP \\
\hline & 5 & 1.8 & 1.8 & 1.8 & IC & $\mathrm{FO} 2$ & - & 1994 & OP \\
\hline 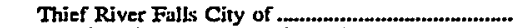 & & 6.5 & 5.9 & 5.9 & & & & & \\
\hline 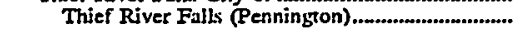 & HY1 & 3 & 3 & 3 & $\mathrm{HY}$ & Water & - & 1927 & OP \\
\hline & HY2 & 3 & 3 & 3 & $\mathbf{H Y}$ & Water & - & 1927 & OP \\
\hline & ICI & 2.2 & 2.0 & 2.0 & IC & $\mathrm{FO2}$ & - & 1956 & OP \\
\hline & IC2 & 1.2 & 1.1 & 1.1 & IC & FO2 & - & 1952 & OP \\
\hline & IC3 & 1.1 & 1.0 & 1.0 & IC & FO2 & - & 1941 & OP \\
\hline & IC4 & 1.4 & 1.3 & 1.3 & IC & $\mathrm{FO} 2$ & - & 1948 & OP \\
\hline 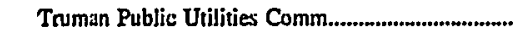 & & 6.1 & 5.8 & 5.8 & & & & & \\
\hline Truman (Martin) & 1 & .2 & .2 & .2 & IC & FO2 & Nat Gas & 1938 & OP \\
\hline & 2 & .2 & .2 & 2 & IC & FO2 & Nat Gas & 1938 & OP \\
\hline
\end{tabular}

See footnotes at end of table. 
Table 20. Existing Generating Units at U.S. Electric Utilities by State, Company, and Plant, as of January 1, 1998 (Continued)

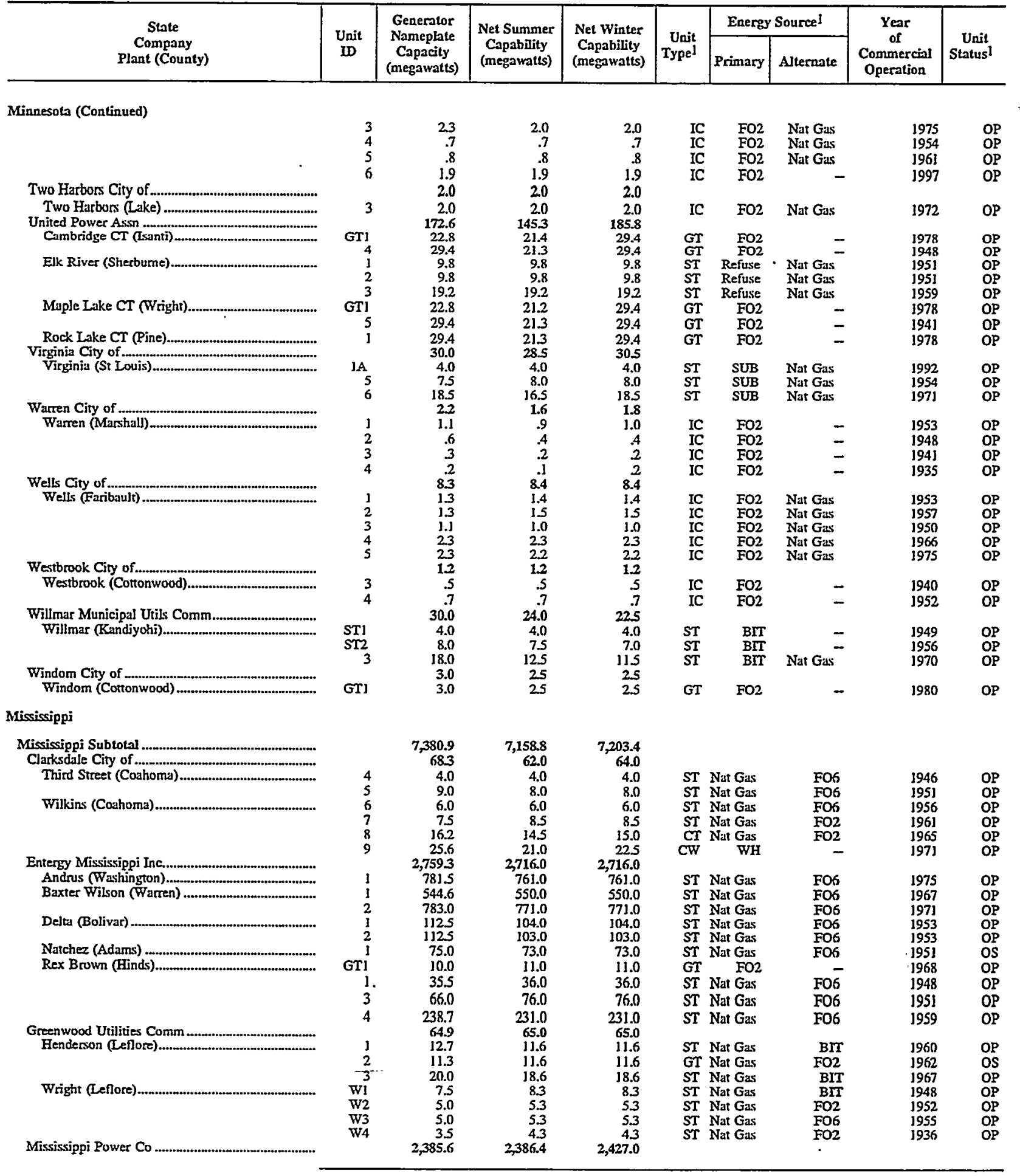

See footnotes at end of table. 
Table 20. Existing Generating Units at U.S. Electric Utilities.by State, Company, and Plant, as of January 1, 1998 (Continued)

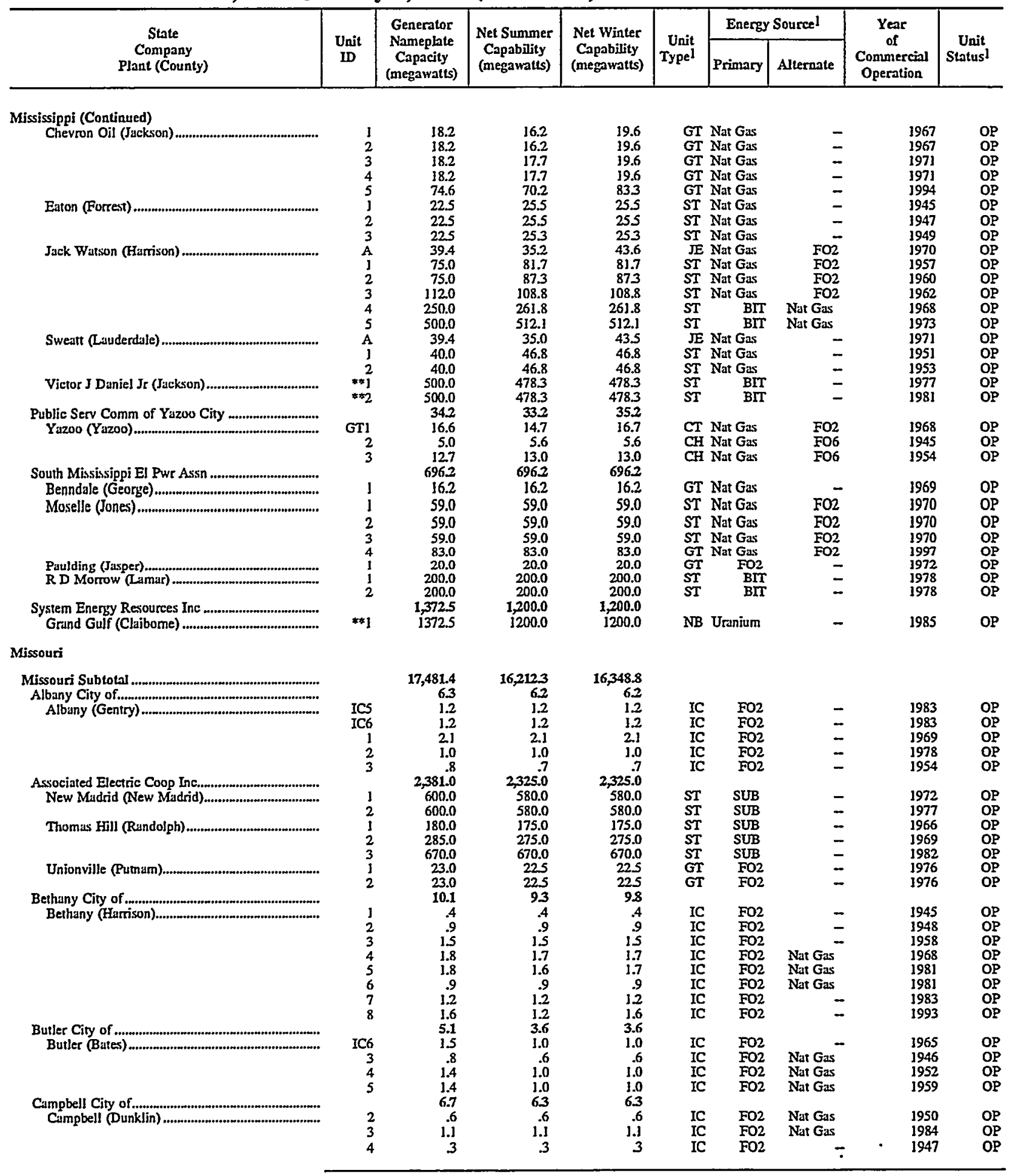

See footnotes at end of table. 
Table 20. Existing Generating Units at U.S. Electric Utilities by State, Company, and Plant, as of January 1, 1998 (Continued)

\begin{tabular}{|c|c|c|c|c|c|c|c|c|c|}
\hline \multirow{2}{*}{$\begin{array}{c}\text { State } \\
\text { Company } \\
\text { Plant (County) }\end{array}$} & \multirow{2}{*}{$\begin{array}{l}\text { Unit } \\
\text { ID }\end{array}$} & \multirow{2}{*}{$\begin{array}{c}\text { Generator } \\
\text { Nameplate } \\
\text { Capacity } \\
\text { (megawatts) }\end{array}$} & \multirow{2}{*}{$\begin{array}{c}\text { Net Summer } \\
\text { Capability } \\
\text { (megawatts) }\end{array}$} & \multirow{2}{*}{$\begin{array}{l}\text { Net Winter } \\
\text { Copability } \\
\text { (megawatts) }\end{array}$} & \multirow{2}{*}{$\begin{array}{l}\text { Unit } \\
\text { TypeI }\end{array}$} & \multicolumn{2}{|c|}{ Energy Source] } & \multirow{2}{*}{$\begin{array}{c}\text { Year } \\
\text { of } \\
\text { Commercial } \\
\text { Operation }\end{array}$} & \\
\hline & & & & & & Primary & Alternate & & Status $]^{1}$ \\
\hline Missouri (Continued) & & & & & & & & & \\
\hline & 5 & 1.4 & 1.4 & 1.4 & IC & $\mathrm{FO} 2$ & - & 1987 & OP \\
\hline & 6 & 1.6 & 1.5 & is & IC & FO2 & - & 1988 & OP \\
\hline 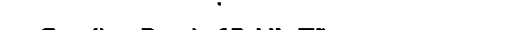 & 7 & 1.8 & 1.5 & 15 & IC & $\mathrm{FO} 2$ & - & 1990 & OP \\
\hline 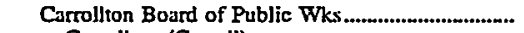 & & 22.2 & 21.1 & 21.2 & & & & & \\
\hline 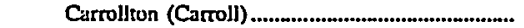 & 1 & .4 & .4 & .4 & IC & FO2 & - & 1941 & OP \\
\hline & 2 & .4 & .4 & .4 & IC & $\mathrm{FO} 2$ & - & 1941 & OP \\
\hline & 3 & 1.8 & 1.8 & 1.8 & IC & Nat Gas & FO2 & 1947 & OP \\
\hline & 4 & .8 & .7 & .8 & IC & Nat Gas & FO2 & 1963 & OP \\
\hline & 5 & .9 & .9 & .9 & IC & Nat Gas & FO2 & 1951 & OP \\
\hline & 6 & 1.1 & 1.0 & $1 . I$ & IC & Nat Gas & $\mathrm{FO} 2$ & 1956 & OP \\
\hline & 7 & 2.5 & 2.5 & 2.5 & IC & Nat Gas & FO2 & 1959 & OP \\
\hline & 8 & 4.1 & 3.8 & 3.8 & IC & Nat Gas & FO2 & 1966 & OP \\
\hline & 9 & 4.J & 3.8 & 3.8 & IC & Nat Gas & FO2 & 1970 & $O P$ \\
\hline & 10 & 6.2 & 6.0 & 6.0 & IC & Nat Gas & $\mathrm{FO} 2$ & 1972 & $O P$ \\
\hline Carthage City of & & 41.8 & 35.7 & 35.7 & & & & & \\
\hline & 7 & 3.0 & 2.2 & 2.2 & IC & Nat Gas & FO2 & 1949 & OP \\
\hline & 8 & 3.3 & 2.5 & 2.5 & IC & Nat Gas & $\mathrm{FO2}$ & 1952 & $O P$ \\
\hline & 9 & 5.0 & 4.0 & 4.0 & IC & Nat Gas & FO2 & 1957 & OP \\
\hline & 10 & 7.0 & 6.0 & 6.0 & IC & Nat Gus & $\mathrm{FO} 2$ & 1965 & OP \\
\hline & 11 & 4.5 & 4.0 & 4.0 & IC & Nat Gas & FO2 & 1970 & $O P$ \\
\hline & 12 & 4.5 & 4.0 & 4.0 & IC & Nat Gas & $\mathrm{FO} 2$ & $197\rfloor$ & OP \\
\hline - & 13 & 6.0 & 5.5 & 5.5 & IC & Nat Gas & FO2 & 1976 & $O P$ \\
\hline & 14 & 6.0 & 5.5 & 5.5 & IC & Nat Gas & FO2 & 1976 & OP \\
\hline 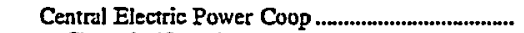 & & 59.0 & 66.0 & 68.0 & & & & & \\
\hline 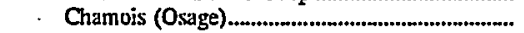 & 1 & 15.0 & 17.0 & 18.0 & sT & BIT & - & 1953 & OP \\
\hline & 2 & 44.0 & 49.0 & 50.0 & ST & BIT & PC & 1960 & OP \\
\hline Chillicothe City of & & 91.0 & 83.0 & 91.0 & & & & & \\
\hline 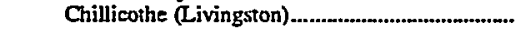 & GTI & 40.0 & 36.0 & 40.0 & GT & Nat Gas & Jet Fuel & 1986 & OP \\
\hline & GT2 & 40.0 & 36.0 & 40.0 & GT & Nat Gas & Jet Fuel & 1986 & OP \\
\hline & 5 & 5.0 & 5.0 & 5.0 & ST & BIT & - & 1948 & OP \\
\hline & 6 & 6.0 & 6.0 & 6.0 & ST & BIT & - & 1958 & $O P$ \\
\hline 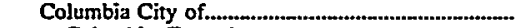 & & 86.0 & 86.0 & 86.0 & & & & & \\
\hline Columbia (Boone) & 5 & 16.5 & 16.5 & 16.5 & ST & BIT & $\overrightarrow{-}$ & 1957 & OP \\
\hline & 6 & 125 & 12.5 & 125 & GT & Nat Gas & FO2 & 1963 & OP \\
\hline & 7 & 22.0 & 22.0 & 22.0 & ST & BIT & - & 1965 & OP \\
\hline & 8 & 35.0 & 35.0 & 35.0 & GT & Nat Gas & $\mathrm{FO} 2$ & 1970 & OP \\
\hline Empire Energy Center (Jasper) ............................ & ] & 129.0 & 90.0 & 90.0 & $\mathrm{GT}$ & Nat Gas & $\mathrm{FO} 2$ & 1978 & OP \\
\hline & 2 & 129.0 & 90.0 & 90.0 & GT & Nat Gas & $\mathrm{FO} 2$ & 1981 & OP \\
\hline 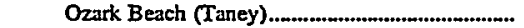 & 1 & 4.0 & 4.0 & 4.0 & HY & Water & - & 1931 & OP \\
\hline & 2 & 4.0 & 4.0 & 4.0 & HY & Water & - & 1931 & OP \\
\hline & 3 & 4.0 & 4.0 & 4.0 & HY & Water & - & 1931 & OP \\
\hline & 4 & 4.0 & 4.0 & 4.0 & HY & Water & - & 1931 & OP \\
\hline Stateline (Jasper) & 1 & 123.0 & 101.0 & 101.0 & GT & Nat Gas & $\mathrm{FO} 2$ & 1995 & OP \\
\hline & 2 & 180.0 & 152.0 & 152.0 & GT & Nat Gas & $\mathrm{FO2}$ & 1997 & OP \\
\hline Fayette City of & & 11.0 & 9.9 & 9.9 & & & & & \\
\hline 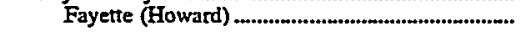 & GTI & 3.5 & 3.2 & 3.2 & IC & FO2 & Nat Gas & 1985 & OP \\
\hline & GT2 & 3.5 & 3.2 & 3.2 & IC & FO2 & Nat Gas & 1985 & OP \\
\hline & GT3 & 2.9 & 2.4 & 2.4 & IC & FO2 & Nat Gas & 1985 & OP \\
\hline & GT4 & 1.1 & 1.1 & 1.] & IC & FO2 & Nat Gas & 1985 & OP \\
\hline Fulton City of & & 327 & 29.6 & 33.8 & & & & & \\
\hline Fulton (Callaway) & GT4 & 18.1 & 15.0 & 18.0 & GT & Nat Gas & $\mathrm{FO} 2$ & 1972 & OP \\
\hline & ICl & 4.2 & 4.2 & 4.5 & IC & Nat Gas & $\mathrm{FO} 2$ & 1966 & OP \\
\hline & IC2 & 4.2 & 4.2 & 4.5 & IC & Nat Gas & FO2 & 1966 & OP \\
\hline & IC3 & 6.3 & 6.3 & 6.8 & IC ? & Nat Gas & $\mathrm{FO} 2$ & 1975 & OP \\
\hline Gallatin City of & & 6.5 & 6,3 & 6.3 & & & & & \\
\hline Gallatin (Daviess) & IC4 & 2.5 & 25 & 2.5 & IC & $\mathrm{FO} 2$ & - & 1983 & $O P$ \\
\hline & IC6 & 2.5 & 2.5 & 25 & IC & FO2 & - & $19 \pi$ & OP \\
\hline & 2 & .2 & .2 & 2 & IC & $\mathrm{FO} 2$ & - & 1939 & $\mathrm{OP}$ \\
\hline & 3 & .2 & .2 & 2 & IC & FO2 & - & 1947 & OP \\
\hline & 5 & 1.1 & 1.0 & 1.0 & IC & FO2 & - & 1960 & OP \\
\hline 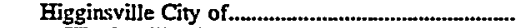 & & 44.9 & 41.5 & 44.0 & & & & & \\
\hline 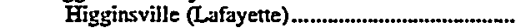 & I & .8 & .6 & .6 & IC & FO2 & - & 1945 & OP \\
\hline & 2 & & 1.0 & 1.0 & IC & $\mathrm{FO} 2$ & - & 1947 & OP \\
\hline & 3 & 24 & 2.4 & 2.4 & IC & $\mathrm{FO} 2$ & Nat Gas & 1981 & $O P$ \\
\hline & 4 & 40.0 & 37.5 & 40.0 & GT & Nat Gas & FO2 & 1996 & OP \\
\hline 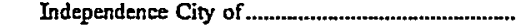 & & 339.0 & 288.0 & 288.0 & & & & & \\
\hline
\end{tabular}

See footnotes at end of table. 
Table 20. Existing Generating Units at U.S. Electric Utilities by State, Company, and Plant, as of January 1, 1998 (Continued)

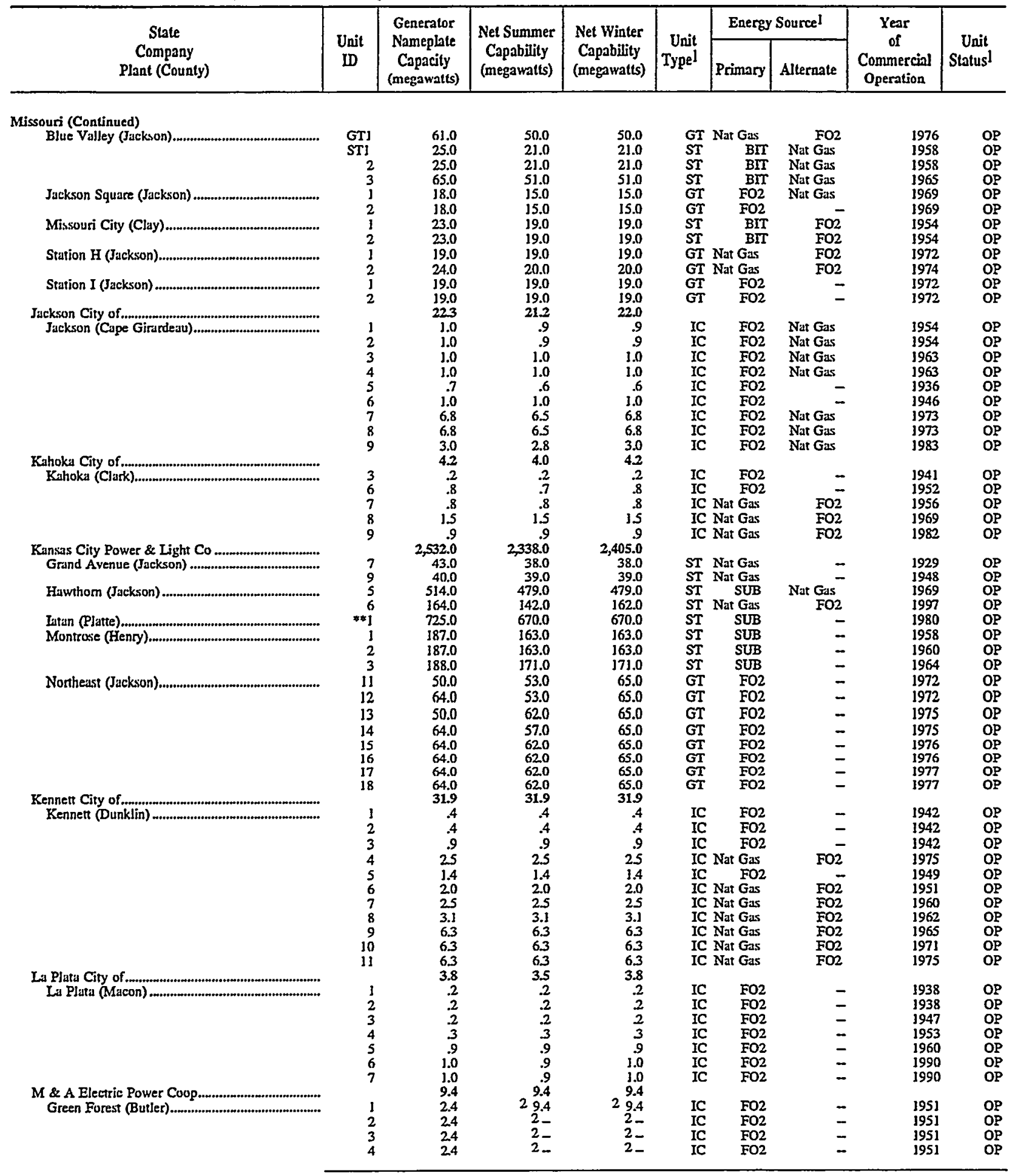

See footnotes at end of table. 
Table 20. Existing Generating Units at U.S. Electric Utilities. by State, Company, and Plant, as of January 1, 1998 (Continued)

\begin{tabular}{|c|c|c|c|c|c|c|c|c|c|}
\hline \multirow{2}{*}{$\begin{array}{c}\text { State } \\
\text { Company } \\
\text { Plant (County) }\end{array}$} & \multirow{2}{*}{$\begin{array}{l}\text { Unit } \\
\text { DD }\end{array}$} & \multirow{2}{*}{$\begin{array}{c}\text { Generator } \\
\text { Nameplate } \\
\text { Capacity } \\
\text { (megawatts) }\end{array}$} & \multirow{2}{*}{$\begin{array}{l}\text { Net Summer } \\
\text { Capability } \\
\text { (megawatts) }\end{array}$} & \multirow{2}{*}{$\begin{array}{l}\text { Net Winter } \\
\text { Capability } \\
\text { (megawatts) }\end{array}$} & \multirow{2}{*}{$\begin{array}{r}\text { Unit } \\
\text { Type }\end{array}$} & \multicolumn{2}{|c|}{ Energy Sourcel } & \multirow{2}{*}{$\begin{array}{c}\text { Year } \\
\text { of } \\
\text { Commercial } \\
\text { Operation }\end{array}$} & \multirow{2}{*}{$\begin{array}{c}\text { Unit } \\
\text { Status }\end{array}$} \\
\hline & & & & & & Primary & Alternate & & \\
\hline $\begin{array}{l}\text { Missouri (Continued) } \\
\text { Macon Ciry of ......... }\end{array}$ & & 11.3 & 10.2 & 10.2 & & & & & \\
\hline Macon (Macon) & 1 & 5.2 & 4.8 & 4.8 & IC & FO2 & Nat Gas & 1962 & OP \\
\hline & 3 & 5.0 & 4.6 & 4.6 & IC & FO2 & Nat Gas & 1971 & OP \\
\hline 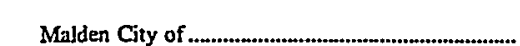 & 4 & $\begin{array}{r}1.1 \\
17.4\end{array}$ & $\begin{aligned} .88 \\
16.0\end{aligned}$ & $\begin{array}{r}.8 \\
16.0\end{array}$ & IC & FO2 & - & 1985 & OP \\
\hline Malden (Dunklin) & $2 \mathrm{~A}$ & 1.8 & 1.8 & 1.8 & IC & $\mathrm{FO} 2$ & - & 1996 & OP \\
\hline & $3 \mathrm{~A}$ & 1.8 & 1.8 & 1.8 & IC & $\mathrm{FO} 2$ & - & 1996 & OP \\
\hline & $4 \mathrm{~A}$ & 1.8 & 1.8 & 1.8 & IC & FO2 & - & 1996 & OP \\
\hline & 1 & 1.4 & 1.2 & 1.2 & IC & Nat Gas & FO2 & [95] & OP \\
\hline & 5 & 1.4 & 1.2 & 1.2 & IC & Nat Gas & FO2 & 1957 & OP \\
\hline & 6 & 2.1 & 1.8 & 1.8 & IC & Nat Gas & FO2 & 1963 & OP \\
\hline & 7 & 2.8 & 2.5 & 2.5 & IC & Nat Gas & FO2 & 1973 & OP \\
\hline & 8 & 4.3 & 3.8 & 3.8 & IC & Nat Gas & FO2 & 1973 & OP \\
\hline 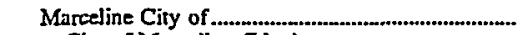 & & 2.9 & 2.5 & 2.5 & & & & 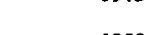 & \\
\hline City of Marceline (Linn) & 1 & 1.3 & 1.1 & 1.1 & IC & FO4 & - & 1989 & $O P$ \\
\hline & 3 & 1.3 & 1.0 & 1.0 & IC & FO4 & - & 1959 & OP \\
\hline Marshall City of ........ & 4 & 573 & .4 & 58.4 & IC & FO4 & - & 1995 & OP \\
\hline Mashall City of & GIJ & 15.2 & 12.0 & 17.0 & GT & Nar Gas & - & 1972 & OP \\
\hline & 3 & 4.0 & 3.9 & 3.9 & ST & Nat Gas & - & 3948 & OP \\
\hline & 4 & 6.0 & 5.9 & 5.9 & ST & BIT & Nat Gas & 1956 & OP \\
\hline & 5 & 16.5 & J6.0 & 16.2 & ST & BIT & Nat Gas & 1967 & OP \\
\hline & 7 & 1.0 & .9 & .9 & IC & $\mathrm{FO} 2$ & - & 1988 & OP \\
\hline & 8 & 1.0 & 9 & 9 & IC & $\mathrm{FO} 2$ & - & 1988 & OP \\
\hline & 9 & 1.0 & .9 & .9 & IC & $\mathrm{FO} 2$ & - & 1988 & OP \\
\hline & 10 & 6.3 & 6.3 & 6.3 & IC & Nat Gas & FO2 & 1990 & OP \\
\hline & 11 & 63 & 6.3 & 6.3 & IC & Nat Gas & FO2 & 1994 & OP \\
\hline Memphis City of & & 9.1 & 8.5 & 8.5 & & & & & \\
\hline 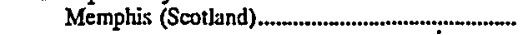 & 1 & .7 & .6 & .6 & IC & Nat Gas & FO2 & 1972 & OP \\
\hline & 3 & .2 & .2 & .2 & IC & F02 & - & 1945 & OP \\
\hline & 6 & .9 & .8 & .8 & IC & $\mathrm{FO} 2$ & - & 1957 & OP \\
\hline & 7 & 1.1 & 1.0 & 1.0 & IC & FO2 & - & 1960 & OP \\
\hline & 8 & 1.4 & 1.3 & 13 & IC & Nat Gas & FO2 & 1966 & OP \\
\hline & 9 & 1.4 & $=1.3$ & 1.3 & IC & Nat Gas & FO2 & 1972 & OP \\
\hline & 10 & 1.0 & E 1.0 & $\mathrm{E}_{1.0}$ & IC & FO2 & - & 1989 & OP \\
\hline & 11 & 1.0 & $E_{E}^{1.0}$ & $E_{1.0}$ & IC & FO2 & - & 1989 & OP \\
\hline & 12 & .5 & $\mathrm{E}_{.4}$ & E.5 & IC & $\mathrm{FO} 2$ & - & 1989 & OP \\
\hline & 13 & 1.0 & 1.0 & 1.0 & IC & FO2 & - & 1990 & $O P$ \\
\hline Monroe City City of ............................. & & 15.5 & 15.1 & 15.5 & & & & & \\
\hline Monroe (Monroe) & 1 & .7 & .7 & .7 & IC & FO2 & - & 1940 & OP \\
\hline & 2 & 1.4 & 1.4 & 1.4 & IC & FO2 & Nat Gas & 1955 & OP \\
\hline & 3 & 1.2 & 1.2 & 1.2 & IC & Nat Gas & FO2 & 1964 & OP \\
\hline & 4 & 1.1 & 1.1 & I.I & IC & Nat Gas & FO2 & 1958 & OP \\
\hline & 5 & 20 & 1.6 & 2.0 & IC & FO2 & Nat Gas & 1985 & OP \\
\hline & 6 & 2.1 & 2.1 & 2.1 & IC & Nat Gas & $\mathrm{FO} 2$ & 1971 & OP \\
\hline & 7 & 2.3 & 2.3 & 23 & IC & Nat Gas & $\mathrm{FO} 2$ & 1973 & OP \\
\hline & 8 & 1.6 & 1.6 & 1.6 & IC & FO2 & - & 1988 & OP \\
\hline & 9 & 1.6 & 1.6 & 1.6 & IC & FO2 & - & 1988 & OP \\
\hline & 10 & 1.6 & 1.6 & 1.6 & IC & FO2 & - & 1988 & OP \\
\hline 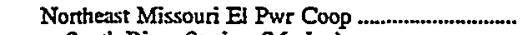 & & 7.3 & 6.6 & 6.6 & & & & & \\
\hline South River Station (Marion) & ICI & 2.4 & 22 & 2.2 & IC & FO2 & Nat Gas & 1951 & OP \\
\hline & IC2 & 2.4 & 2.2 & 2.2 & IC & FO2 & Nat Gas & $195 !$ & OP \\
\hline & IC3 & 2.4 & 2.2 & 2.2 & IC & FO2 & Nat Gas & 1951 & OP \\
\hline Odessa City of & & 8.2 & 7.2 & 72 & & & & & \\
\hline Odessa (Lafayette) & IC4 & .9 & .8 & .8 & IC & & Nat Gas & 1986 & $O P$ \\
\hline & J & .7 & .6 & .6 & IC & $\mathrm{FO} 2$ & & 1946 & OP \\
\hline & 2 & .3 & .3 & 3 & IC & FO2 & - & 1939 & OP \\
\hline & 3 & 2.1 & 1.8 & 1.8 & IC & FO2 & Nat Gas & 1965 & OP \\
\hline & 5 & 1.3 & 1.0 & 1.0 & IC & $\mathrm{FO} 2$ & Nat Gas. & 1957 & $O P$ \\
\hline & 6 & 3.0 & 2.7 & 2.7 & IC & FO2 & Nat Gas & 1981 & OP \\
\hline Owensville City of & & 2.7 & 2.6 & 2.6 & & & & & \\
\hline 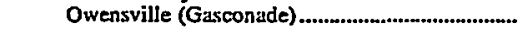 & $4 \mathrm{~A}$ & 1.4 & 1.3 & 1.3 & IC & FO2 & - & 1989 & OP \\
\hline 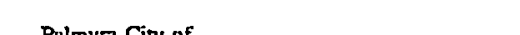 & 5 & 1.4 & 1.3 & 13 & IC & FO2 & - & 1966 & OP \\
\hline Palmyra City of & & 16.4 & 15.5 & 16.0 & & & & & \\
\hline 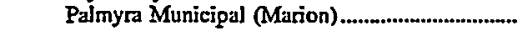 & IC7 & 2.1 & 1.8 & 2.0 & IC & FO2 & Nat Gas & 1985 & OP \\
\hline & IC8 & 2.0 & 3.8 & 1.9 & IC & $\mathrm{FO} 2$ & Nat Gas & 1985 & OP \\
\hline & 1 & .5 & 5 & $s$ & IC & FO2 & Nat Gas & 1939 & OP \\
\hline & 2 & 5 & .5 & 5 & IC & FO2 & Nat Gas & 1959 & OP \\
\hline & 3 & 1.5 & 3.2 & 1.4 & IC & $\mathrm{FO} 2$ & Nat Gas & 1966 & OP \\
\hline & 4 & .8 & .8 & .8 & IC & $\mathrm{FO} 2$ & Nat Gas & 3959 & OP \\
\hline
\end{tabular}

See footnotes at end of table. 
Table 20. Existing Generating Units at U.S. Electric Utilities by State, Company, and Plant, as of January 1, 1998 (Continued)

\begin{tabular}{|c|c|c|c|c|c|c|c|c|c|}
\hline \multirow{2}{*}{$\begin{array}{c}\text { State } \\
\text { Company } \\
\text { PJant (County) }\end{array}$} & \multirow{2}{*}{$\begin{array}{c}\text { Unit } \\
\text { ID }\end{array}$} & \multirow{2}{*}{$\begin{array}{c}\text { Generator } \\
\text { Nameplate } \\
\text { Capacity } \\
\text { (megawatts) }\end{array}$} & \multirow{2}{*}{$\begin{array}{l}\text { Net Summer } \\
\text { Capability } \\
\text { (megawatts) }\end{array}$} & \multirow{2}{*}{$\begin{array}{l}\text { Net Winter } \\
\text { Capability } \\
\text { (megawatts) }\end{array}$} & \multirow{2}{*}{$\begin{array}{c}\text { Unit } \\
\text { Type! }\end{array}$} & \multicolumn{2}{|c|}{ Energy Sourcel } & \multirow{2}{*}{$\begin{array}{c}\text { Year } \\
\text { of } \\
\text { Commercin] } \\
\text { Operation }\end{array}$} & \multirow{2}{*}{$\begin{array}{c}\text { Unit } \\
\text { Status }\end{array}$} \\
\hline & & & & & & Primary & Alternate & & \\
\hline \multicolumn{10}{|l|}{ Missouri (Continued) } \\
\hline & 6 & 2]$. & 2.1 & 2.1 & IC & $\mathrm{FO} 2$ & Nat Gas & 1971 & $O P$ \\
\hline Palmyra Municipal 2 (Marion).................................. & ICI0 & $\begin{array}{l}3.5 \\
3.5\end{array}$ & $\begin{array}{l}3.5 \\
3.5\end{array}$ & $\begin{array}{l}3.5 \\
3.5\end{array}$ & IC & $\mathrm{FO} 2$ & Nat Gas & $199]$ & $O P$ \\
\hline Poplar Bluff City of ......................... & & 14.0 & 13.8 & 143 & & & Nat Gax & 1991 & \\
\hline Poplar Bluff Gen (Butler)................ & $\frac{1}{2}$ & $\begin{array}{l}7.0 \\
7.0\end{array}$ & $\begin{array}{l}6.9 \\
6.9\end{array}$ & 7.2 & $\begin{array}{l}\text { IC } \\
\text { IC }\end{array}$ & $\begin{array}{l}\text { FO2 } \\
\text { FO2 }\end{array}$ & $\begin{array}{l}\text { Nat Gas } \\
\text { Nat Gas }\end{array}$ & $\begin{array}{l}1976 \\
j 976\end{array}$ & $\begin{array}{l}O P \\
O P\end{array}$ \\
\hline 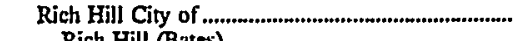 & & 1.1 & $E^{10}$ & $\begin{array}{ll}1.0 \\
E\end{array}$ & & & & & \\
\hline 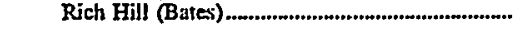 & $\frac{1}{2}$ & .2 & $\mathrm{E} .2$ & $E_{2}^{2}$ & $\begin{array}{l}\text { IC } \\
\text { IC }\end{array}$ & $\begin{array}{l}\mathrm{FO} 2 \\
\mathrm{FO} 2\end{array}$ & $\bar{z}$ & $\begin{array}{l}1934 \\
1935\end{array}$ & $\begin{array}{l}\text { OS } \\
\text { os }\end{array}$ \\
\hline & 3 & .2 & E.2 & $E_{2}$ & IC & $\mathrm{FO} 2$ & - & 1949 & os \\
\hline & 4 & .5 & Es & $E_{S}$ & IC & FO2 & - & 1956 & os \\
\hline \multirow{7}{*}{ 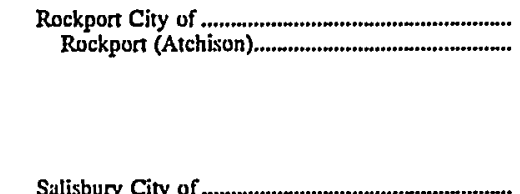 } & & 5.9 & 5.5 & 5.5 & & & & & \\
\hline & 1 & 1.1 & 1.1 & 3.1 & & Nat Gas & $\mathrm{FO} 2$ & 1964 & $O P$ \\
\hline & $\begin{array}{l}2 \\
3\end{array}$ & $\begin{array}{r}1.3 \\
.5\end{array}$ & $\begin{array}{l}1.1 \\
.4\end{array}$ & $\begin{aligned} 1.1 \\
.4\end{aligned}$ & $\begin{array}{l}\text { IC } \\
\text { IC }\end{array}$ & $\begin{array}{l}\text { Nat Gas } \\
\text { FO2 }\end{array}$ & FO2 & $\begin{array}{l}1964 \\
1959\end{array}$ & $\begin{array}{l}\text { OP } \\
\text { OP }\end{array}$ \\
\hline & 4 & .4 & 3 & 3 & IC & FO2 & - & 1940 & OP \\
\hline & 5 & 1.4 & 1.3 & 13 & & Nat Gas & $\mathrm{FO} 2$ & 1972 & $\mathrm{OP}$ \\
\hline & 6 & 1.4 & 1.3 & 13 & IC & Nat Gas & FO2 & 1972 & OP \\
\hline & & 6.9 & 4.5 & 4.5 & & & & & \\
\hline 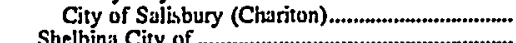 & 1 & 6.9 & 4.5 & 4.5 & IC & FO2 & - & 1983 & OP \\
\hline Shelbina City of & & 10.0 & 10.0 & 10.0 & & & & & \\
\hline Shelbina Power \# 1 (Shelby)......................................... & GI & 3.0 & 3.0 & 3.0 & IC & $\mathrm{FO} 2$ & MF & 1981 & $O P$ \\
\hline Shelbina Power $\# 2$ (Shelby).................................. & G3 & $\begin{array}{l}1.8 \\
1.8\end{array}$ & $\begin{array}{l}1.8 \\
1.8\end{array}$ & $\begin{array}{l}1.8 \\
1.8\end{array}$ & IC & $\begin{array}{l}\text { FO2 } \\
\text { FO2 }\end{array}$ & $\overline{-}$ & $\begin{array}{l}1989 \\
1992\end{array}$ & $\begin{array}{l}O P \\
O P\end{array}$ \\
\hline 5 & G4 & 1.8 & 1.8 & 1.8 & IC & $\mathrm{FO} 2$ & - & 1992 & OP \\
\hline & G5 & 1.8 & 1.8 & 1.8 & IC & $\mathrm{FO} 2$ & - & 1992 & OP \\
\hline 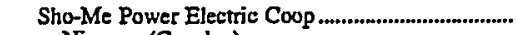 & & 3.0 & 3.0 & 3.0 & & & & & \\
\hline Niangua (Camden) & $\begin{array}{l}1 \\
2\end{array}$ & $\begin{array}{l}1.5 \\
1.5\end{array}$ & $\begin{array}{l}1.5 \\
1.5\end{array}$ & is & $\begin{array}{l}\mathrm{HY} \\
\mathrm{HY}\end{array}$ & $\begin{array}{l}\text { Water } \\
\text { Water }\end{array}$ & $\overline{-}$ & $\begin{array}{l}1930 \\
1930\end{array}$ & $\begin{array}{l}\text { OP } \\
\text { OP }\end{array}$ \\
\hline 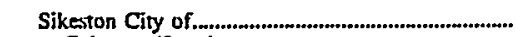 & & 265.3 & 226.3 & 226.3 & & & & & \\
\hline Coleman $(S \operatorname{con})$ & ICl & 2.0 & 20 & 2.0 & IC & FO2 & - & 1965 & OP \\
\hline & IC2 & 2.3 & 2.3 & 23 & IC & $\mathrm{FO} 2$ & - & 1967 & OP \\
\hline Sikeston (Scom)..... & I & 261.0 & 222.0 & 222.0 & ST & BIT & - & 1981 & OP \\
\hline 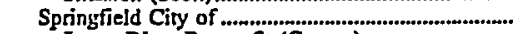 & & 860.4 & 667.0 & 667.0 & & & & & \\
\hline James Rjver Power St (Greene) ................................... & GTI & 96.0 & 75.0 & 75.0 & GT & Nat Gas & FO2 & 1989 & OP \\
\hline & GT2 & 101.5 & 74.0 & 74.0 & $\underset{\mathcal{G T}}{\mathbf{G T}}$ & Nat Gas & - & 1992 & OP \\
\hline & 1 & 22.0 & 21.0 & 21.0 & $\underset{\mathrm{ST}}{\mathrm{ST}}$ & BIT & - & 1957 & OP \\
\hline & 2 & 22.0 & 21.0 & 21.0 & ST & BIT & - & 1957 & OP \\
\hline & 3 & 58.0 & 42.0 & 42.0 & ST & BIT & - & 1960 & OP \\
\hline & 4 & 76.0 & 58.0 & 58.0 & ST & BIT & - & 1964 & OP \\
\hline & 5 & 128.0 & 97.0 & 97.0 & ST & BIT & Nat Gas & 1970 & OP \\
\hline Main Street (Greene) ................................................. & 1 & 15.3 & 13.0 & 33.0 & GT & FO2 & - & 1968 & OP \\
\hline Southwest Power St. (Greene) ...................................... & GTI & 57.0 & 44.0 & 44.0 & GT & Nat Gas & FO2 & 1983 & OP \\
\hline & ST] & 233.0 & 178.0 & 378.0 & ST & SUB & Nat Gas & 1976 & OP \\
\hline & 2 & 51.6 & 44.0 & 44.0 & ST & Nat Gas & - & 1983 & OP \\
\hline St Joseph Light \& Power Co...................................... & & 2733 & 257.0 & 2620 & & & & & \\
\hline Lake Road (Buchanan) & ] & 23.0 & 19.7 & 17.2 & $\mathrm{CH}$ & Nat Gas & F06 & 1950 & $O P$ \\
\hline & 2 & 25.0 & 25.0 & 21.8 & & Nat Gas & FO6 & 1958 & $\mathrm{OP}$ \\
\hline & $\overline{3}$ & 12.5 & 10.3 & 9.0 & ST & Nat Gas & FO6 & 1962 & OP \\
\hline & 4 & 90.0 & 97.0 & 97.0 & ST & SUB & Nat Gas & 1966 & OP \\
\hline & 5 & 85.0 & 63.0 & 69.0 & GT & Nat Gas & FO2 & 1974 & $\mathrm{OP}$ \\
\hline & 6 & 18.9 & 21.0 & 24.0 & $\mathrm{JE}$ & $\mathrm{FO} 2$ & - & 1989 & OP \\
\hline & 7 & 18.9 & 21.0 & 24.0 & $\mathrm{JE}$ & $\mathrm{FO} 2$ & - & 1990 & OP \\
\hline Stunberny City of & & 5.1 & 4.8 & 4.8 & & & & & \\
\hline 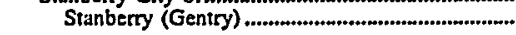 & ICS & .4 & 3 & 3 & IC & $\mathrm{FO} 2$ & - & 1958 & OP \\
\hline & IC6 & 1.9 & 0.8 & 1.8 & IC & & $\mathrm{FO} 2$ & 1979 & $O P$ \\
\hline & j & 1.1 & j.I & i.l & IC & Nat Gas & FO2 & 1963 & OP \\
\hline & 2 & 1.1 & 1.1 & 3.1 & IC & Nat Gas & FO2 & 1967 & OP \\
\hline & 3 & 3 & .3 & 3 & IC & FO2 & - & 1945 & OP \\
\hline & 4 & .3 & .3 & 3 & IC & FO2 & - & 1953 & OP \\
\hline Trenton Municipal Utilities.......... & & 19.0 & 18.4 & 18.4 & & & & & \\
\hline 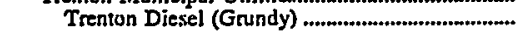 & 1 & .4 & .3 & .3 & IC & $\mathrm{FO} 2$ & - & 1937 & OP \\
\hline & 2 & .4 & 3 & 3 & IC & & - & 1937 & OP \\
\hline & 4 & 1.0 & .9 & 9 & IC & FO2 & - & 1945 & OP \\
\hline & 5 & 1.1 & 1.0 & 1.0 & IC & FO2 & Nat Gas & 1948 & OP \\
\hline & 6 & 1.3 & 1.2 & 12 & IC & $\mathrm{FO} 2$ & Nat Gas & 1958 & OP \\
\hline & 7 & 1.0 & .9 & .9 & IC & FO2 & Nat Gas & 1966 & OP \\
\hline 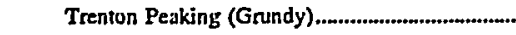 & I & 2.8 & 2.8 & 2.8 & IC & $\mathrm{FO} 2$ & - & 1974 & $O P$ \\
\hline & 2 & 2.8 & 2.8 & 2.8 & IC & $\mathrm{FO} 2$ & - & 1974 & OP \\
\hline & 3 & 2.8 & 2.8 & 2.8 & IC & FO2 & - & 1974 & OP \\
\hline
\end{tabular}

See footnotes at end of tuble. 
Table 20. Existing Generating Units at U.S. Electric Utilities by State, Company, and Plant, as of January 1, 1998 (Continued)

\begin{tabular}{|c|c|c|c|c|c|c|c|c|c|}
\hline \multirow{2}{*}{$\begin{array}{c}\text { State } \\
\text { Company } \\
\text { Plant (County) }\end{array}$} & \multirow{2}{*}{$\begin{array}{l}\text { Unit } \\
\text { ID }\end{array}$} & \multirow{2}{*}{$\begin{array}{c}\text { Generator } \\
\text { Nameplate } \\
\text { Capacity } \\
\text { (megawatts) }\end{array}$} & \multirow{2}{*}{$\begin{array}{l}\text { Net Summer } \\
\text { Capability } \\
\text { (megawatts) }\end{array}$} & \multirow{2}{*}{$\begin{array}{c}\text { Net Winter } \\
\text { Capability } \\
\text { (megawatts) }\end{array}$} & \multirow{2}{*}{$\begin{array}{l}\text { Unit } \\
\text { Type! }\end{array}$} & \multicolumn{2}{|c|}{ Energy Sourcel } & \multirow{2}{*}{$\begin{array}{c}\text { Year } \\
\text { of } \\
\text { Commercinl } \\
\text { Operation }\end{array}$} & \\
\hline & & & & & & Primary & Alternate & & \\
\hline Missouri (Continued) & & & & & & & & & \\
\hline & 4 & 2.8 & 2.8 & 2.8 & IC & $\mathrm{FO} 2$ & - & 1974 & OP \\
\hline Union Electric Co & 5 & $\begin{array}{r}2.8 \\
7.911 .4\end{array}$ & $\begin{array}{r}2.8 \\
7.344 .0\end{array}$ & $\begin{array}{r}2.8 \\
7383.0\end{array}$ & IC & FO2 & - & 1975 & OP \\
\hline Callaway (Callaway) & I & 1235.8 & 1143.0 & 1174.0 & $\mathbf{N P}$ & Uranium & - & 1984 & OP \\
\hline 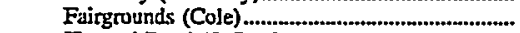 & ; & 68.3 & 55.0 & 62.0 & GT & $\mathrm{FO} 2$ & - & 1974 & OP \\
\hline 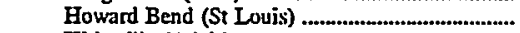 & $i$ & 47.4 & 43.0 & 47.0 & $J E$ & $\mathrm{FO} 2$ & - & 1973 & OP \\
\hline Kirksville (Aduir) & $i$ & 15.0 & 13.0 & 15.0 & GT & Nat Gas & - & 1967 & OP \\
\hline 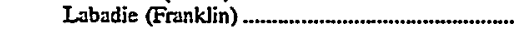 & $i$ & 573.8 & 574.0 & 575.0 & ST & BIT & - & 1970 & OP \\
\hline & 2 & 573.8 & 574.0 & 575.0 & ST & BIT & - & $197 \mathrm{I}$ & OP \\
\hline & 3 & 621.0 & 576.0 & 577.0 & ST & BIT & - & 1972 & OP \\
\hline & 4 & 621.0 & 576.0 & 577.0 & ST & BIT & - & 1973 & OP \\
\hline 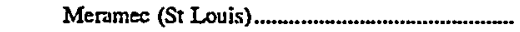 & GT1 & 62.0 & 55.0 & 62.0 & GT & $\mathrm{FO} 2$ & - & 1974 & OP \\
\hline & 1 & 137.5 & 132.0 & 134.0 & ST & BIT & Nat Gas & 1953 & OP \\
\hline & 2 & 137.5 & 132.0 & 134.0 & ST & BIT & Nat Gas & 1954 & OP \\
\hline & 3 & 289.0 & 277.0 & 279.0 & ST & BIT & Nat Gas & 1959 & OP \\
\hline & 4 & 359.0 & 335.0 & 344.0 & ST & BIT & - & 1961 & OP \\
\hline Mexico (Audrain) & 1 & 60.7 & 55.0 & 62.0 & GT & $\mathrm{FO2}$ & - & 1978 & OP \\
\hline Moberly (Randolph) & 1 & 60.6 & 55.0 & 62.0 & GT & FO2 & - & 1978 & OP \\
\hline 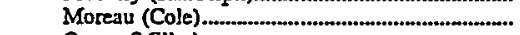 & ] & 60.9 & 55.0 & 62.0 & $\mathrm{GT}$ & $\mathrm{FO2}$ & - & 1978 & OP \\
\hline 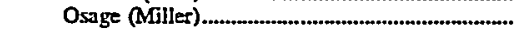 & j & 27.5 & 28.0 & 27.1 & $\mathbf{H Y}$ & Water & - & 1931 & OP \\
\hline & 2 & 27.5 & 28.0 & 27.1 & HY & Water & - & 1931 & OP \\
\hline & 3 & 27.5 & 28.0 & 27.1 & HY & Water & - & 1931 & OP \\
\hline & 4 & 27.5 & 28.0 & 27.1 & $\mathbf{H Y}$ & Water & - & 1931 & OP \\
\hline & 5 & 27.5 & 28.0 & 27.1 & HY & Water & - & 1931 & OP \\
\hline & 6 & 27.5 & 28.0 & 27.1 & HY & Water & - & 1931 & OP \\
\hline & 7 & 21.5 & 21.9 & 212 & $\mathrm{HY}$ & Water & - & 1953 & OP \\
\hline & 8 & 21.5 & 21.9 & 21.2 & HY & Water & - & $\cdot 1953$ & OP \\
\hline Rush Island (Jefferson) & I & 621.0 & 578.0 & 584.0 & ST & BIT & - & 1976 & OP \\
\hline & 2 & 621.0 & 578.0 & 584.0 & ST & $\mathrm{BIT}$ & - & 1977 & OP \\
\hline Sioux (St Charles) & ] & 549.8 & 475.0 & 482.0 & ST & BIT & - & 1967 & OP \\
\hline & 2 & 549.8 & $\mathbf{4 7 5 . 0}$ & 482.0 & ST & BIT & - & 1968 & OP \\
\hline Taum Sauk (Reynolds) ............................................. & ] & 204.0 & 175.0 & 137.5 & PS & Warer & - & 1963 & OP \\
\hline & 2 & 204.0 & 175.0 & 137.5 & PS & Water & - & 1963 & OP \\
\hline Viaduct (Cape Girardeau) & 1 & 30.6 & 26.0 & 30.0 & GT & Nat Gas & - & 1967 & OP \\
\hline 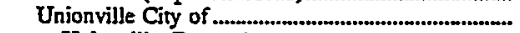 & & 9.1 & 8.2 & 8.2 & & & & . & 2 \\
\hline Unionville (Putnam) & 1 & .8 & .6 & .6 & IC & $\mathrm{FO} 2$ & - & 1970 & OP \\
\hline & 2 & 1.8 & 1.8 & 1.8 & IC & FO2 & Nat Gas & 1975 & OP \\
\hline & 3 & 3 & .3 & 3 & IC & $\mathrm{FO2}$ & - & 1935 & OP \\
\hline & 4 & 1.0 & .9 & .9 & IC & $\mathrm{FO} 2$ & - & 1970 & OP \\
\hline & 5 & .4 & .4 & .4 & IC & FO2 & - & 1955 & OP \\
\hline & 6 & .4 & .4 & .4 & IC & FO2 & - & 1955 & OP \\
\hline & 7 & 1.1 & .9 & .9 & IC & FO2 & - & 1962 & OP \\
\hline & 8 & 1.4 & 1.1 & 1.1 & IC & FO2 & Nat Gas & 1967 & OP \\
\hline & 9 & 20 & 2.0 & 2.0 & IC & FO2 & - & 1994 & OP \\
\hline UtiliCorp United Inc & & 918.9 & 887.7 & 887.7 & & & & & \\
\hline Greenwood (Jackson) & 1 & 61.0 & 62.3 & 62.3 & GT & Nat Gas & FO2 & 1975 & OP \\
\hline & 2 & 61.0 & 60.9 & 60.9 & GT & Nat Gas & FO2 & 1975 & OP \\
\hline & 3 & 61.0 & 61.9 & 61.9 & GI & Nat Gas & FO2 & 1977 & OP \\
\hline & 4 & 61.0 & 62.4 & 62.4 & $\mathrm{GT}$ & Nat Gas & $\mathrm{FO} 2$ & 1979 & OP \\
\hline 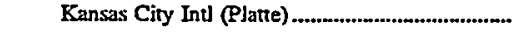 & ] & 18.0 & 17.5 & 17.5 & $\mathrm{JE}$ & Nat Gas & - & 1977 & OP \\
\hline & 2 & 18.0 & 14.6 & 14.6 & JE & Nat Gas & - & 1977 & OP \\
\hline Nevada (Vemon) & 1 & 22.0 & 20.3 & 20.3 & GI & $\mathrm{FO} 2$ & - & 1974 & OP \\
\hline Ralph Green (Cass) & CT1 & 19.9 & 19.0 & 19.0 & $\mathrm{GT}$ & Nat Gas & - & 1996 & OP \\
\hline & 3 & 74.0 & 73.7 & 73.7 & GT & Nat Gas & $\mathrm{FO} 2$ & 1981 & OP \\
\hline Sibley (Jackson) & 1 & SS.0 & 527 & 52.7 & ST & BIT & - & 1960 & OP \\
\hline & 2 & 50.0 & 52.7 & 52.7 & ST & BIT & - & 1962 & OP \\
\hline & 3 & 418.0 & 389.7 & 389.7 & ST & BII & - & 1969 & OP \\
\hline 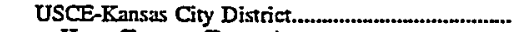 & & 207.0 & 240.7 & 240.7 & & & & & \\
\hline Harry Truman (Benton) & 1 & 27.0 & 31.0 & 31.0 & PS & Water & - & 1982 & os \\
\hline & 2 & 27.0 & 31.0 & 31.0 & PS & Water & - & 1982 & os \\
\hline & 3 & 27.0 & 31.0 & 31.0 & PS & Water & - & 1982 & OP \\
\hline & 4 & 27.0 & 31.0 & 31.0 & PS & Water & - & 1982 & OP \\
\hline & $s$ & 27.0 & 31.0 & 31.0 & PS & Water & - & 1981 & OP \\
\hline & 6 & 27.0 & 31.0 & 31.0 & PS & Water & - & 1979 & OP \\
\hline 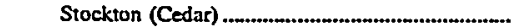 & J & 45.2 & 54.7 & 54.7 & HY & Water & - & 1973 & OP \\
\hline 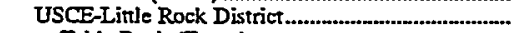 & & 200.0 & 230.0 & 230.0 & & & & & \\
\hline Table Rock (Taney) & $\mathbf{J}$ & 50.0 & 57.5 & 57.5 & HY & Water & - & 1959 & OP \\
\hline & 2 & 50.0 & S7.5 & 575 & $\mathrm{HY}$ & Water & - & 1959 & OP \\
\hline & 3 & 50.0 & 57.5 & 57.5 & $\mathrm{HY}$ & Water & - & 1961 & $\mathrm{OP}$ \\
\hline & 4 & 50.0 & 57.5 & 57.5 & $\mathrm{HY}$ & Water & - & 1961 & OP \\
\hline
\end{tabular}

See footnotes at end of table. 
Table 20. Existing Generating Units at U.S. Electric Utilities by State, Company, and Plant, as of January 1, 1998 (Continued)

\begin{tabular}{|c|c|c|c|c|c|c|c|c|c|c|}
\hline \multirow{2}{*}{$\begin{array}{c}\text { State } \\
\text { Company } \\
\text { Plant (County) }\end{array}$} & \multirow{2}{*}{$\begin{array}{l}\text { Unit } \\
\text { ID }\end{array}$} & \multirow{2}{*}{$\begin{array}{c}\text { Generator } \\
\text { Nameplate } \\
\text { Capacity } \\
\text { (nregawatts) }\end{array}$} & \multirow{2}{*}{$\begin{array}{l}\text { Net Summer } \\
\text { Capability } \\
\text { (megawatts) }\end{array}$} & \multirow{2}{*}{$\begin{array}{l}\text { Net Winter } \\
\text { Capability } \\
\text { (megawatts) }\end{array}$} & \multirow{2}{*}{$\begin{array}{l}\text { Unit } \\
\text { Type1 }\end{array}$} & \multicolumn{3}{|c|}{ Energy Sourcel } & \multirow{2}{*}{$\begin{array}{c}\begin{array}{c}\text { Year } \\
\text { of } \\
\text { Conmercial } \\
\text { Operation }\end{array} \\
\end{array}$} & \multirow{2}{*}{$\begin{array}{l}\text { Unit } \\
\text { Status' }\end{array}$} \\
\hline & & & & & & Primary & Alternate & & & \\
\hline $\begin{array}{l}\text { Missouri (Continued) } \\
\text { USCE-St Louis District }\end{array}$ & & & & & & & & & & \\
\hline 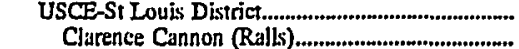 & 1 & 58.0 & 58.0 & 58.0 & & Water & & & & \\
\hline 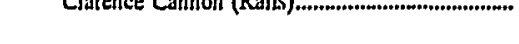 & 2 & 31.0 & 31.0 & 31.0 & $\begin{array}{l}\text { MI } \\
\text { PS }\end{array}$ & $\begin{array}{l}\text { Water } \\
\text { Water }\end{array}$ & & $\overline{-}$ & 1984 & OP \\
\hline Vandalia City of .............. & & 9.5 & 8.1 & 8.1 & & & & & & \\
\hline Vandalia (Audrain) ...................................................... & $4 \mathrm{~A}$ & 1.3 & 1.0 & 1.0 & IC & $\mathrm{FO} 2$ & & - & 1996 & OP \\
\hline & SA & 1.3 & 1.0 & 1.0 & IC & $\mathrm{FO2}$ & & - & 1996 & $O P$ \\
\hline & 1 & 1.3 & 1.0 & 1.0 & IC & $\mathrm{FO2}$ & & - & 1967 & $\mathrm{OP}$ \\
\hline & 8 & 1.0 & .8 & .8 & IC & $\mathrm{FO2}$ & & - & 1957 & $\mathrm{OP}$ \\
\hline & 9 & 1.4 & 1.2 & 1.2 & IC & $\mathrm{FO2}$ & & - & 1977 & OP \\
\hline & 10 & 1.4 & 1.1 & 1.1 & IC & $\mathrm{FO} 2$ & & - & 1984 & $\mathrm{OP}$ \\
\hline & ij & 1.0 & 1.0 & 1.0 & IC & $\mathrm{FO} 2$ & & - & 1993 & OP \\
\hline & 12 & 1.0 & 1.0 & 1.0 & IC & $\mathrm{FO} 2$ & & - & 1993 & OP \\
\hline Montana & & & & & & & & & & \\
\hline Mnntana Subtotal...................... & & $5,084.0$ & $4,943.0$ & $4,939,2$ & & & & & & \\
\hline 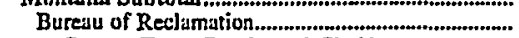 & & 728.0 & 773.1 & 773.1 & & & & & & \\
\hline Canyon Ferry (Lewis And Clark) ............................... & 1 & 16.7 & 19.2 & 19.2 & HY & Water & & - & 1953 & OP \\
\hline & 2 & 16.7 & 19.2 & 19.2 & $\mathrm{HY}$ & Water & & - & 1954 & OP \\
\hline & 3 & 36.7 & 19.2 & 19.2 & $\mathrm{HY}$ & Water & & - & 1954 & $\mathrm{OP}$ \\
\hline 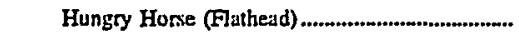 & I & j07.0 & 307.0 & 107.0 & $\mathrm{HY}$ & Water & & - & 1952 & OP \\
\hline & 2 & 107.0 & 107.0 & $\mathbf{I 0 7 . 0}$ & HY & Water & & - & 3952 & OP \\
\hline & 3 & 107.0 & 107.0 & 107.0 & HY & Water & & - & 1953 & OP \\
\hline & 4 & 107.0 & 307.0 & 107.0 & HY & Water & & - & 1953 & OP \\
\hline Yellowrail (Big Hom) & 1 & 62.5 & 71.9 & 71.9 & $\mathrm{HY}$ & Water & & - & 1966 & OP \\
\hline & 2 & 62.5 & 71.9 & 71.9 & HY & Water & & - & 1966 & OP \\
\hline & 3 & 62.5 & 71.9 & 71.9 & HY & Water & & - & 1966 & $\mathrm{OP}$ \\
\hline & 4 & 62.5 & 71.9 & 71.9 & $\mathrm{HY}$ & Water & & - & 1966 & OP \\
\hline 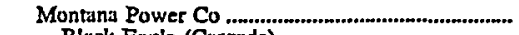 & & $3,047.7$ & $2,697.3$ & $2,709.0$ & & & & & & \\
\hline Black Eagle (Caseade) & 1 & 7.8 & $2 \frac{13.6}{2-6}$ & $2 \frac{13.4}{2}$ & $\stackrel{\mathrm{HY}}{\mathrm{HY}}$ & $\begin{array}{l}\text { Water } \\
\text { Water }\end{array}$ & & $z$ & $\begin{array}{l}1927 \\
1927\end{array}$ & $\begin{array}{l}O P \\
O P\end{array}$ \\
\hline & 2 & $\begin{array}{l}7.8 \\
5.6\end{array}$ & $2-$ & $2=$ & $\mathrm{HY}$ & $\begin{array}{l}\text { Water } \\
\text { Whtrer }\end{array}$ & & $\overline{-}$ & 1927 & $\begin{array}{l}O P \\
O P\end{array}$ \\
\hline 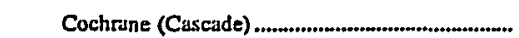 & 1 & 24.0 & 222.6 & 222.3 & $\begin{array}{l}\text { HY } \\
\text { HY }\end{array}$ & $\begin{array}{l}\text { Water } \\
\text { Water }\end{array}$ & & $\overline{-}$ & $\begin{array}{l}1927 \\
1958\end{array}$ & op \\
\hline & 2 & 24.0 & $2-$ & $2-$ & HY & Water & & - & 1958 & $O P$ \\
\hline Colstrip (Rosebud) & $\approx 1$ & 358.4 & 307.0 & 307.0 & ST & SUB & & - & 1975 & OP \\
\hline & **2 & 358.4 & 307.0 & 307.0 & ST & SUB & & - & 1976 & $O P$ \\
\hline & $* * 3$ & 778.0 & 740.0 & 740.0 & ST & SUB & & - & 3984 & $O P$ \\
\hline & $* * 4$ & 778.0 & 740.0 & 740.0 & ST & SUB & & - & $j 986$ & $O P$ \\
\hline Corette (Yellowstone) ...................... & 1 & 191.0 & 156.0 & 156.0 & ST & SUB & & _ & 1968 & OP \\
\hline 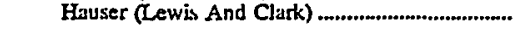 & 1 & 2.8 & 230.1 & $2 \frac{12.4}{2}$ & $\mathrm{HY}$ & Water & & - & 1911 & OP \\
\hline & 2 & 28 & $2-$ & & $\mathbf{H Y}$ & Water & & - & 1911 & OP \\
\hline & 3 & 28 & $2-$ & $2-$ & HY & Wa & & - & 19 & $\mathrm{OP}$ \\
\hline & 4 & 28 & $2-$ & $2-$ & HY & Wat & & - & 19. & OP \\
\hline & 5 & 28 & $2-$ & $2-$ & HY & Water & & - & 1911 & OP \\
\hline & 6 & 3.0 & $2-$ & $2-$ & HY & Water & & - & 1915 & $O P$ \\
\hline Holter (Lewis And Clark) ...................................... & 1 & 9.6 & 220.7 & 2262 & $\mathrm{HY}$ & Water & & - & 1918 & $O P$ \\
\hline & 2 & 9.6 & $2-$ & & $\mathrm{HY}$ & Water & & - & 1918 & OP \\
\hline & 3 & 9.6 & 2- & 2- & $\mathrm{HY}$ & Water & & - & 19]. & OP \\
\hline & 4 & 9.6 & $2_{-}$ & $2_{-}$ & $\mathrm{HY}$ & Water & & - & 1918 & OP \\
\hline 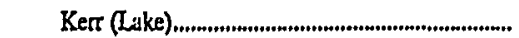 & ] & 70.6 & 2180.0 & 2180.0 & $\mathrm{HL}$ & Water & & - & 1938 & OP \\
\hline & 2 & 70.6 & $2_{-}$ & & $\mathrm{HL}$ & Water & & _- & 1949 & $\mathrm{OP}$ \\
\hline & 3 & 70.6 & 2 & 2 & $\mathrm{HI}$ & Water & & _ & 1954 & OP \\
\hline Lake (Teton) & 1 & 2.8 & 2.8 & 2.8 & IC & $\mathrm{FO2}$ & & - & 1967 & OP \\
\hline 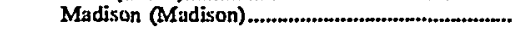 & 1 & 2.3 & 26.6 & 2 s..9 & HII & Wuter & & - & 190 & OP \\
\hline & 2 & 23 & $2-$ & $2-$ & EII & Wat & & - & 198 & os \\
\hline & 3 & 23 & $2-$ & $2-$ & HII & Wat & & - & 19 & OP \\
\hline & 4 & 23 & $2-$ & $2-$ & $\mathbf{H L}$ & Water & & - & 1908 & OP \\
\hline Milltown (Missoula) & 1 & .6 & 22.6 & 22.3 & $\mathrm{HY}$ & Water & & - & 1908 & $O P$ \\
\hline & 2 & .6 & $2-$ & & $\mathrm{HY}$ & Water & & - & 1908 & OP \\
\hline & 3 & .6 & 2- & 2- & $\mathrm{HY}$ & Wat & & - & 19 & OP \\
\hline & 4 & .6 & $2-$ & $2-$ & HY & Water & - & - & 19 & OP \\
\hline & 5 & .6 & $2-$ & $2=$ & $\mathrm{HY}$ & Wat & & - & 192 & OP \\
\hline Morony (Caseade) & 1 & 22.5 & 222.1 & $2 \frac{22.2}{2}$ & HYY & Water & & - & 19. & OP \\
\hline & 2 & 22.5 & & $2=$ & HY & Water & & - & 1930 & OP \\
\hline Mystic (Stillwatet) & 1 & 5,0 & 231.5 & 211.5 & HI & Water & & - & 1925 & $\mathrm{OP}$ \\
\hline & 2 & 5,0 & $2-$ & $2-$ & HIL & Water & & - & 1925 & OP \\
\hline 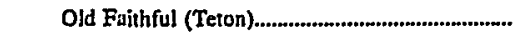 & 1 & 1.0 & & 1.0 & IC & FO2 & & - & 1979 & OP \\
\hline & 2 & 1.0 & 1.0 & 1.0 & IC & FO2 & & - & 1979 & OP \\
\hline 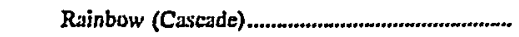 & j & 4.0 & 224.5 & 2253 & $\mathrm{HL}$ & Water & & - & 1910 & $O P$ \\
\hline & 2 & 4.0 & $2-$ & $2_{-}^{2}$ & HL & Water & & - & 1910 & OP \\
\hline
\end{tabular}

See footnotes at end of table. 
Table 20. Existing Generating Units at U.S. Electric Utilities by State, Company, and Plant, as of January 1, 1998 (Continued)

\begin{tabular}{|c|c|c|c|c|c|c|c|c|c|}
\hline \multirow{2}{*}{$\begin{array}{c}\text { State } \\
\text { Company } \\
\text { Plant (County) }\end{array}$} & \multirow{2}{*}{$\begin{array}{l}\text { Unit } \\
\text { ID }\end{array}$} & \multirow{2}{*}{$\begin{array}{l}\text { Generator } \\
\text { Nameplate } \\
\text { Capacity } \\
\text { (negawatts) }\end{array}$} & \multirow{2}{*}{$\begin{array}{l}\text { Net Summer } \\
\text { Capability } \\
\text { (megawatts) }\end{array}$} & \multirow{2}{*}{$\begin{array}{l}\text { Net Winter } \\
\text { Capability } \\
\text { (niegawatts) }\end{array}$} & \multirow{2}{*}{$\begin{array}{c}\text { Unit } \\
\text { Typel }\end{array}$} & \multicolumn{2}{|c|}{ Energy Sourcel } & \multirow{2}{*}{$\begin{array}{c}\text { Year } \\
\text { of } \\
\text { Commercial } \\
\text { Operation }\end{array}$} & \multirow{2}{*}{$\begin{array}{c}\text { Unit } \\
\text { Statusl }\end{array}$} \\
\hline & & & & & & Primary & Allernate & & \\
\hline Montana (Continued) & & & & & & & & & \\
\hline & 3 & 4.0 & $2-$ & $2-$ & HL & Water & - & 1910 & OP \\
\hline & 4 & 4.0 & $2-$ & $2-$ & HL & Water & - & 1910 & OP \\
\hline & 5 & 4.0 & $2-$ & $2-$ & HL & Water & - & 1910 & OP \\
\hline & 6 & 4.0 & $2-$ & 2 & HL & Water & - & 1910 & OP \\
\hline & 7 & 5.8 & $2-$ & $2-$ & HL & Water & - & 1917 & OP \\
\hline & 8 & 5.8 & $2-$ & $2-$ & HIL & Water & - & 1917 & $\mathrm{OP}$ \\
\hline 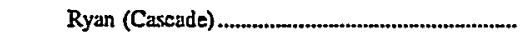 & 1 & 8.0 & 256.9 & 257.0 & HY & Water & - & 1915 & OP \\
\hline & 2 & 8.0 & $2-$ & $2-$ & $\mathrm{HY}$ & Water & - & 1915 & $O P$ \\
\hline & 3 & 8.0 & $\begin{array}{l}2- \\
2-\end{array}$ & $\begin{array}{l}2- \\
2-\end{array}$ & $\hat{H Y}$ & Water & - & 3915 & OP \\
\hline & 4 & 8.0 & & $\frac{2}{2}-$ & $\mathrm{HY}$ & Water & - & 1915 & $O P$ \\
\hline & 5 & $\begin{array}{l}8.0 \\
8.0\end{array}$ & $\begin{array}{l}2- \\
2-\end{array}$ & $\begin{array}{l}2- \\
2-\end{array}$ & HY & Water & - & 1916 & OP \\
\hline Thompson Falls (Sanders) & 6 & $\begin{array}{l}8.0 \\
7.0\end{array}$ & 2350 & 2395 & $\begin{array}{l}\mathrm{HY} \\
\mathrm{HY}\end{array}$ & Water & - & 1916 & OP \\
\hline & 2 & $\begin{array}{l}7.0 \\
7.0\end{array}$ & $\begin{array}{l}3.1 \\
2-\end{array}$ & 2 & $\begin{array}{l}\text { HY } \\
\text { HYY }\end{array}$ & $\begin{array}{l}\text { Water } \\
\text { Water }\end{array}$ & - & $\begin{array}{l}1917 \\
1917\end{array}$ & $\begin{array}{l}\text { OP } \\
\text { OP }\end{array}$ \\
\hline & 3 & 7.0 & $2-$ & 2 & HY & $\begin{array}{l}\text { Water } \\
\text { Water }\end{array}$ & $\overline{-}$ & $\begin{array}{l}1917 \\
1916\end{array}$ & OP \\
\hline & 4 & 7.0 & $2-$ & $2-$ & HY & Water & - & 1916 & OP \\
\hline & 5 & 7.0 & $2-$ & $2-$ & $H Y$ & Water & - & 1915 & $O P$ \\
\hline & 6 & 7.0 & $2-$ & $2_{-}$ & $\mathrm{HY}$ & Water & - & 1915 & OP \\
\hline & 7 & 50.0 & 36.4 & 36.4 & HY & Water & - & 1995 & OP \\
\hline 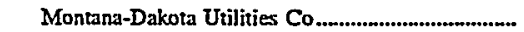 & & 127.4 & 972 & 120.6 & & & & & \\
\hline Glendive GT (Dawson) & GT1 & 48.0 & 31.2 & 42.0 & GT & Nat Gas & $\mathrm{FO} 2$ & 1979 & OP \\
\hline Lewis \& Clark (Richland) & 3 & 50.0 & 44.4 & 49.2 & ST & IIG & Nat Gas & 1958 & OP \\
\hline Miles City GT (Custer) & ] & 29.4 & 21.6 & 29.4 & GT & Nat Gas & $\mathrm{FO} 2$ & 1972 & $\mathrm{OP}$ \\
\hline Pacificorp... & & 42 & 42 & 42 & & & & & \\
\hline Big Fork (Flathead) & 1 & 1.7 & 1.7 & 1.7 & HY & Water & - & 1924 & OP \\
\hline & 2 & 1.7 & 1.7 & 1.7 & HY & Water & - & 1929 & OP \\
\hline & 3 & .8 & .8 & 8 & HY & Water & - & 1910 & OP \\
\hline USBLA-Mission Valley Power ................................. & & .4 & 4 & .4 & & & & & \\
\hline Hellroaring Hydro (Lake) & 1 & .2 & .2 & .2 & HY & Water & - & 1916 & OP \\
\hline & 2 & .2 & .2 & 2 & $\mathrm{HY}$ & Water & -- & 1916 & OP \\
\hline USCE-Missouri River District & & 1853 & 213.0 & 213.0 & & & & & \\
\hline Fort Peck (Mecone) & 1 & 43.5 & 50.0 & 50.0 & HY & Water & - & 1943 & OP \\
\hline & 2 & 18.3 & 21.0 & 21.0 & HY & Water & - & 1948 & OP \\
\hline & 3 & 43.5 & 50.0 & 50.0 & $\mathrm{HY}$ & Water & - & 1951 & $\mathrm{OP}$ \\
\hline & 4 & 40.0 & 46.0 & 46.0 & HY & Water & - & 1961 & OP \\
\hline & 5 & 40.0 & 46.0 & 46.0 & HY & Water & - & 1961 & OP \\
\hline 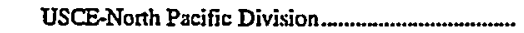 & & 525.0 & 603.8 & 565.0 & & & & & \\
\hline Libby (Lincoln) & 1 & 105.0 & 2603.8 & 2565.0 & HY & Water & - & 1975 & OP \\
\hline & $\dot{2}$ & 105.0 & $2-$ & $2-$ & HY & Water & - & 3975 & OP \\
\hline & 3 & 105.0 & $2-$ & $2-$ & HY & Water & - & 1976 & OP \\
\hline & 4 & 105.0 & $2-$ & 2 - & HY & Water & -- & 1976 & OP \\
\hline & 5 & 105.0 & 2 & $2_{-}$ & $\mathrm{HY}$ & Water & - & 1984 & OP \\
\hline 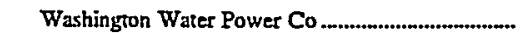 & & 466.2 & 554.0 & 554.0 & & & & & \\
\hline Noxon Rapids (Sanders) & ] & 91.8 & 107.5 & 107.5 & HY & Water & - & 1959 & OP \\
\hline & 2 & 76.8 & 107.5 & 107.5 & HY & Water & - & 1959 & OP \\
\hline & 3 & 91.8 & 107.5 & 1075 & HY & Water & - & 1959 & OP \\
\hline & 4 & 91.8 & 107.5 & 1075 & $\mathrm{HY}$ & Water & - & 1960 & OP \\
\hline & 5 & 114.0 & 124.0 & 124.0 & HY & Water & - & 1977 & OP \\
\hline Nebraskn & & & & & & & & & \\
\hline 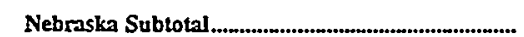 & & $5,980.0$ & $5,760.2$ & $5,747.3$ & & & & & \\
\hline Ansley City of & & 1.5 & 1.5 & 1.5 & & & & & \\
\hline Ansley (Custer) & 2 & .6 & .6 & .6 & & Nat Gas & - & 1963 & OP \\
\hline & 3 & .9 & 9 & 9 & $\mathrm{IC}$ & Nat Gas & - & 1969 & OP \\
\hline Anold Village of & & 12 & 1.1 & 1.1 & & & & & \\
\hline 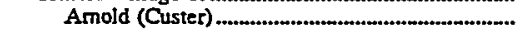 & 1 & .6 & 5 & .5 & IC & $\mathrm{FO} 2$ & - & 1960 & OP \\
\hline & 2 & .2 & E.1 & E.] & IC & $\mathrm{FO} 2$ & - & 1928 & os \\
\hline & 3 & .2 & 2 & $\ddot{2}$ & IC & $\mathrm{FO} 2$ & - & 1941 & OP \\
\hline & 4 & 3 & 3 & 3 & IC & FO2 & - & 1949 & OP \\
\hline Aubum City of & & 18.9 & 17.6 & 18.9 & & & & & \\
\hline Aubum (Nemaha) & $4 \mathrm{~A}$ & 3.8 & 3.8 & 3.8 & & Nat Gas & $\mathrm{FO} 2$ & 1993 & \\
\hline & 1 & 2.4 & 2.2 & 2.4 & & Nat Gas & $\mathrm{FO} 2$ & 1982 & OP \\
\hline & 2 & 1.0 & .9 & 1.0 & & Nat Gas & $\mathrm{FO} 2$ & 1949 & OP \\
\hline & 5 & 3.4 & 3.1 & 3.4 & & Nat Gas & FO2 & 1973 & OP \\
\hline & 6 & 2.8 & 2.5 & 2.8 & & Nat Gas & FO2 & 1967 & OP \\
\hline & 7 & 5.6 & 5.2 & 5.6 & IC & Nat Gas & $\mathrm{FO} 2$ & 1987 & OP \\
\hline Beaver City City of & & 2.1 & 1.9 & 2.0 & & & & & \\
\hline 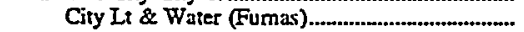 & J & .5 & .5 & .5 & IC & $\mathrm{FO} 2$ & Nat Gas & 1957 & OP \\
\hline & 2 & .4 & 3 & .4 & IC & Nat Gas & $\mathrm{FO} 2$ & 1963 & OP \\
\hline
\end{tabular}

See foomotes at end of table. 
Table 20. Existing Generating Units at U.S. Electric Utilities by State, Company, and Plant, as of January 1, 1998 (Continued)

\begin{tabular}{|c|c|c|c|c|c|c|c|c|c|}
\hline \multirow{2}{*}{$\begin{array}{c}\text { State } \\
\text { Company } \\
\text { Plant (County) }\end{array}$} & \multirow{2}{*}{$\begin{array}{l}\text { Unit } \\
\text { WD }\end{array}$} & \multirow{2}{*}{$\begin{array}{c}\text { Generator } \\
\text { Nameplate } \\
\text { Capacity } \\
\text { (megawatts) }\end{array}$} & \multirow{2}{*}{$\begin{array}{l}\text { Net Summer } \\
\text { Capability } \\
\text { (megawatts) }\end{array}$} & \multirow{2}{*}{$\begin{array}{l}\text { Net Winter } \\
\text { Capability } \\
\text { (megawatts) }\end{array}$} & \multirow{2}{*}{$\begin{array}{r}\text { Unit } \\
\text { Type! }\end{array}$} & \multicolumn{2}{|c|}{ Energy Sourcel } & \multirow{2}{*}{$\begin{array}{c}\text { Year } \\
\text { of } \\
\text { Commercinl } \\
\text { Operation }\end{array}$} & \multirow{2}{*}{$\begin{array}{c}\text { Unit } \\
\text { Status } 1\end{array}$} \\
\hline & & & & & & Primary & Alternate & & \\
\hline \multicolumn{10}{|l|}{ Nebraska (Continued) } \\
\hline & 3 & 0.3 & 0.3 & 0.3 & IC & FO2 & - & 1947 & OP \\
\hline \multirow{2}{*}{ 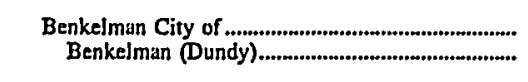 } & & .99 & .99 & .99 & IC & Nat Gas & FO2 & 1967 & OP \\
\hline & 1 & .9 & .8 & .8 & IC & $\mathrm{FO} 2$ & - & 1952 & OP \\
\hline Blue Hill City of & & .3 & 12 & 3 & IC & FO2 & - & 1941 & os \\
\hline City Light \& Water (Webstes) & 1 & .9 & .8 & .8 & IC & FO2 & _ & 1987 & OP \\
\hline 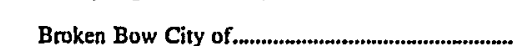 & 2 & .4 & .4 & .4 & IC & FO2 & - & 1987 & $O P$ \\
\hline 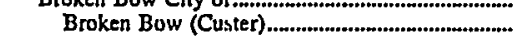 & 1 & $\begin{aligned} 8.7 \\
.5\end{aligned}$ & $\begin{array}{c}8.5 \\
5\end{array}$ & $\begin{array}{r}8.5 \\
5\end{array}$ & xc & $\mathrm{FO} 2$ & - & 1936 & $O P$ \\
\hline & 2 & 3.5 & 3.5 & 35 & IC & Nat Gas & $\mathrm{FO} 2$ & 1970 & OP \\
\hline & 3 & .8 & .7 & .7 & & Nat Gas & $\mathrm{FO} 2$ & 1945 & OP \\
\hline & 4 & .8 & .8 & .8 & & Nat Gas & $\mathrm{FO} 2$ & 1951 & OP \\
\hline & 5 & 1.0 & 1.0 & 1.0 & IC & Nat Gas & FO2 & 1951 & OP \\
\hline & 6 & 2.1 & 2.0 & 2.0 & IC & Nat Gas & $\mathrm{FO2}$ & 1961 & OP \\
\hline 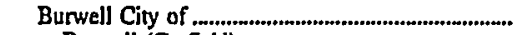 & & 4.1 & 4.1 & 4.1 & & & & & \\
\hline Burwell (Garfield) & 1 & 1.4 & 1.4 & 1.4 & IC & Nat Gas & FO2 & 1972 & OP \\
\hline & 2 & 1.1 & 3.3 & 1.1 & IC & Nat Gas & FO2 & 1968 & OP \\
\hline & 4 & .7 & .7 & .7 & IC & FO2 & FO2 & $\begin{array}{l}1960 \\
1955\end{array}$ & $\begin{array}{l}\text { OP } \\
\text { OP }\end{array}$ \\
\hline Callaway Village of & & .9 & $\ddot{8}$ & $\ddot{8}$ & & & & & \\
\hline Callaway (Custer) .............................................................. & 1 & .2 & .2 & .2 & IC & $\mathrm{FO} 2$ & - & 1948 & OP \\
\hline & 2 & .2 & .2 & $\stackrel{2}{5}$ & IC & FO2 & - & 1950 & OP \\
\hline & & 3.0 & 2.5 & 2.5 & IC & FO2 & - & 1960 & OP \\
\hline 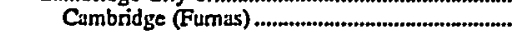 & 1 & .8 & .7 & .7 & IC & FO2 & _ & 1957 & OP \\
\hline & 2 & .9 & .8 & $\ddot{8}$ & IC & FO2 & - & 1963 & OP \\
\hline & 3 & 1.4 & 1.2 & 1.2 & IC & $\mathrm{FO} 2$ & - & 1971 & OP \\
\hline Campbell Village of & & 1.2 & 1.2 & 1.2 & & & & & \\
\hline & IC4 & 1.1 & 1.0 & 1.0 & IC & $\mathrm{FO} 2$ & - & 1983 & OP \\
\hline & $\frac{1}{2}$ & .1 &.$j$ & .1 & IC & $\begin{array}{ll}\mathrm{FO2} \\
\mathrm{FO} 2\end{array}$ & $\overline{-}$ & $\begin{array}{l}1927 \\
1937\end{array}$ & $\stackrel{O P}{O P}$ \\
\hline & 3 & 2138 & .1 & .1 & IC & FO2 & - & 1946 & OP \\
\hline 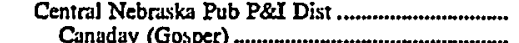 & & 213.8 & 199.0 & 199.0 & & & & & \\
\hline $\begin{array}{l}\text { Canaday (Gosper) } \\
\text { Jeffrey (Lincoln) }\end{array}$ & 1 & 108.8 & 107.0 & 107.0 & ST & Nat Gas & FO6 & 1958 & OP \\
\hline & $\mathrm{i}$ & 9.0 & 9.0 & 9.0 & HY & Water & - & 1941 & OP \\
\hline Johnson 1 (Gosner) & 2 & 9.0 & 9.0 & 9.0 & HY & Water & - & 1941 & op \\
\hline & ] & 9.0 & 9.0 & 9.0 & HY & Water & - & 1941 & OP \\
\hline 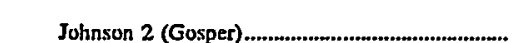 & 2 & 9.0 & 9.0 & 9.0 & HY & Water & - & 1941 & op \\
\hline & 3 & $\begin{array}{l}19.0 \\
50.0\end{array}$ & $\begin{array}{l}18.0 \\
380\end{array}$ & 38.0 & $\mathrm{HY}$ & Water & - & 1941 & OP \\
\hline 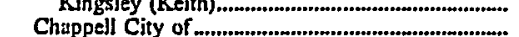 & $\mathbf{s}$ & $\begin{array}{r}50.0 \\
1.4\end{array}$ & $\begin{array}{r}38.0 \\
12\end{array}$ & 38.0 & HY & Water & - & 1984 & OP \\
\hline Chappell (Deuel) & 1 & $\begin{array}{r}1.4 \\
2\end{array}$ & $\frac{12}{2}$ & 1.2 & TC & & & & \\
\hline & 5 & 1.2 & .2 & .2 & IC & Fol & - & 1947 & OP \\
\hline Crete Ciry of.......... & & 15.7 & 152 & $\begin{array}{l}1.0 \\
162\end{array}$ & & Fol & & 1982 & OP \\
\hline Crete Mun Power (Saline).................................... & 1 & .4 & .4 & .4 & IC & $\mathrm{FO} 2$ & - & 1939 & OP \\
\hline & 2 & 1.4 & 1.4 & 1.4 & IC & Nat Gas & $\mathrm{FO} 2$ & 1955 & OP \\
\hline & 3 & 1.0 & .9 & 1.0 & IC & Nat Gas & $\mathrm{FO} 2$ & $195]$ & OP \\
\hline & 4 & $1 . J$ & 1.0 & 1.1 & & Nat Gas & $\mathrm{FO} 2$ & 1947 & $O P$ \\
\hline & 5 & 25 & 2.4 & 2.6 & IC & Nat Gas & $\mathrm{FO} 2$ & 1963 & $O P$ \\
\hline & 6 & 3.3 & 2.8 & 33 & IC & Nat Gas & FO2 & 1965 & OP \\
\hline & 7 & 6.0 & 6.4 & 6.4 & IC & Nat Gas & $\mathrm{FO} 2$ & 1973 & OP \\
\hline $\begin{array}{l}\text { Curtis City of. } \\
\text { Cuntis (Frontier) }\end{array}$ & & 3.4 & 3.0 & 3.0 & & & & & \\
\hline & 2 & .9 & .8 & .8 & IC & Nat Gas & FO2 & 1955 & OP \\
\hline & 3 & 1.1 & 1.0 & 1.0 & IC & Nat Gas & FO2 & 1969 & OP \\
\hline & 4 & 1.4 & 1.2 & 12 & IC & Nat Gas & FO2 & 1975 & OP \\
\hline 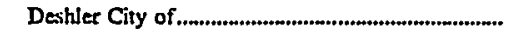 & & 1.6 & 1.2 & 12 & & & & & \\
\hline 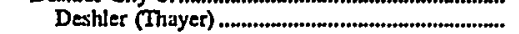 & 1 & .3 & .2 & .2 & IC & Fol & - & 1938 & OP \\
\hline & 2 & .4 & .2 & 2 & IC & Fol & - & 1950 & OP \\
\hline & 3 & .2 & .2 & 2 & IC & FOI & - & 1935 & OP \\
\hline & 4 & .7 & .6 & .6 & IC & FOI & - & 1956 & OP \\
\hline Emerson City of & & 1.7 & 1.7 & 1.7 & & & & & \\
\hline Emerson (Dixon).......................................................... & 2 & 1.1 & 1.1 & 1.j & & Nat Gas & FO2 & 1968 & OP \\
\hline & 3 & .1 & .1 & .1 & IC & FO2 & - & 1947 & $\mathrm{OP}$ \\
\hline & -1 & .5 & .5 & 5 & IC & Nat Gas & $\mathrm{FO} 2$ & 1960 & OP \\
\hline Fairbury Ciry of & & 19.0 & 18.8 & 195 & & & & & \\
\hline Fairbury (Jeffersion) & 1 & 4.0 & 3.8 & 4.0 & ST & Nat Gas & FO6 & 1948 & OP \\
\hline & 2 & 25 & 2.5 & 25 & $\mathbf{S T}$ & Nat Gas & FOS & 1938 & OP \\
\hline & 4 & 125 & 12.5 & 13.0 & ST & Nat Gas & FOS & 1965 & OP \\
\hline Falls City City of & & 223 & 20.6 & 20.6 & & & & & \\
\hline
\end{tabular}

See foutnotes at end of table. 
Table 20. Existing Generating Units at U.S. Electric Utilities by State, Company, and Plant, as of January 1, 1998 (Continued)

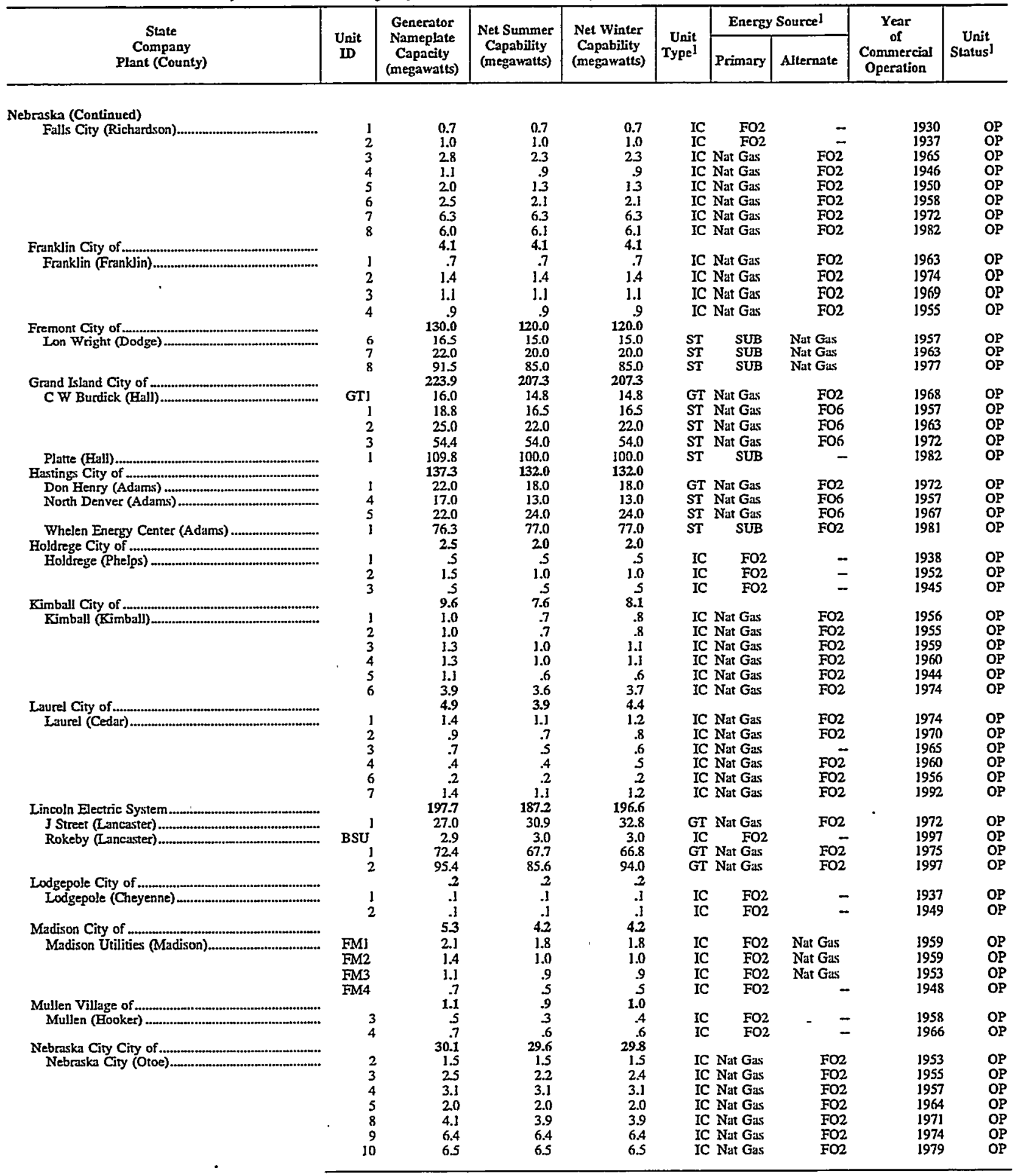

See footnotes at end of table. 
Table 20. Existing Generating Units at U.S. Electric Utilities by State, Company, and Plant, as of January 1, 1998 (Continued)

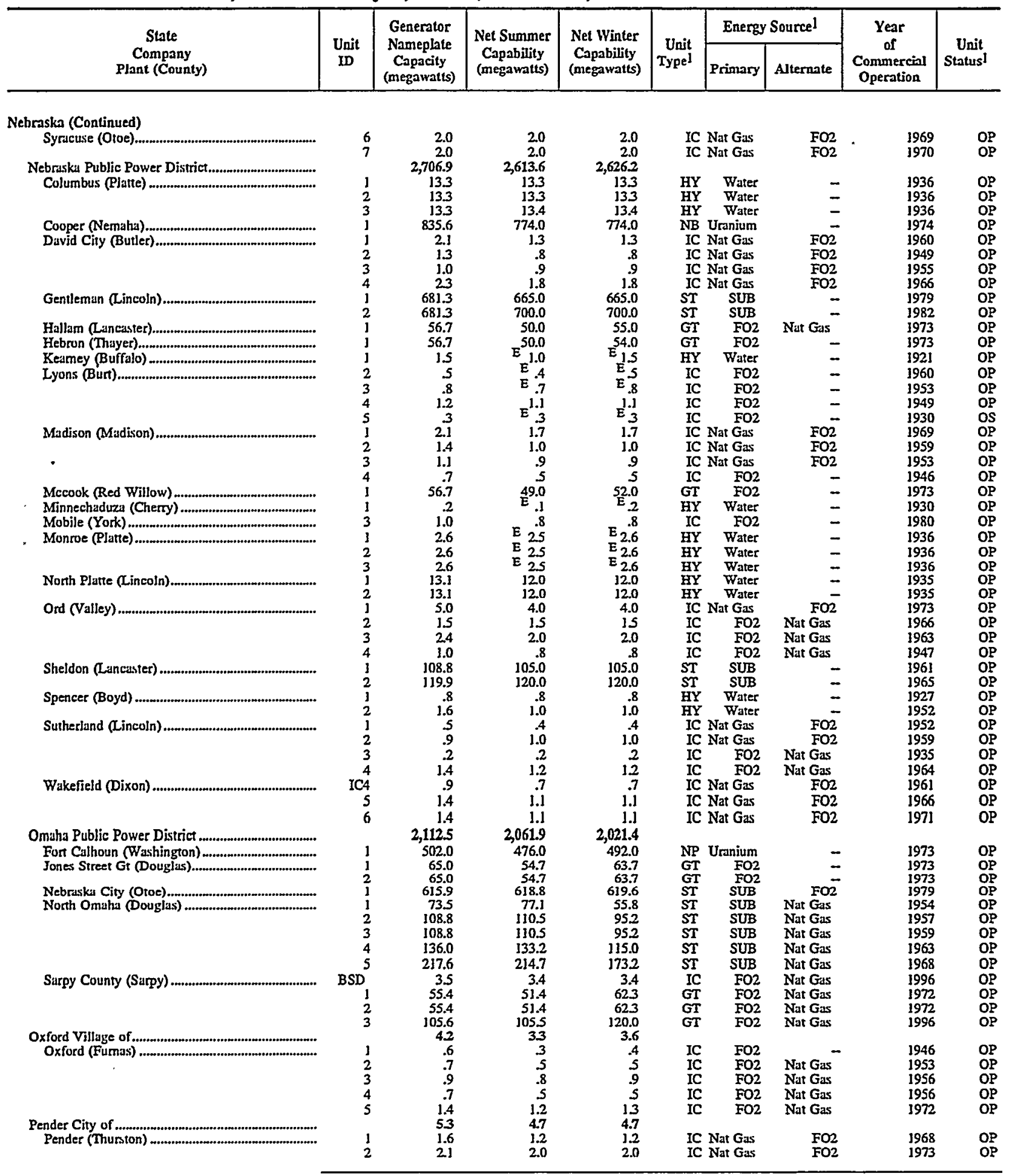

See footnotes at end of table. 
Table 20. Existing Generating Units at U.S. Electric Utilities by State, Company, and Plant, as of January 1, 1998 (Continued)

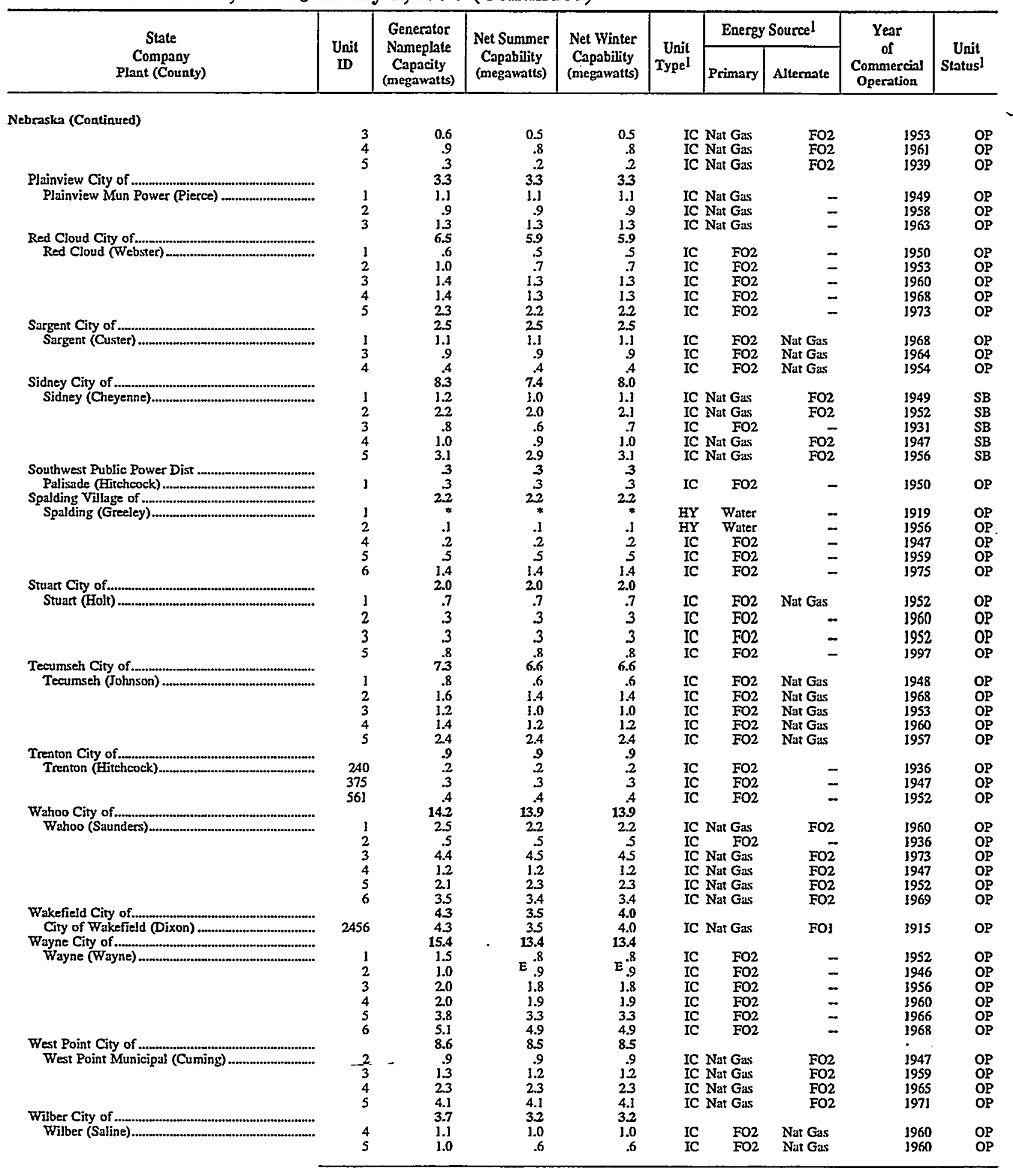

See footnotes at end of table. 
Table 20. Existing Generating Units at U.S. Electric Utilities by State, Company, and Plant, as of January 1, 1998 (Continued)

\begin{tabular}{|c|c|c|c|c|c|c|c|c|c|}
\hline \multirow{2}{*}{$\begin{array}{c}\text { State } \\
\text { Company } \\
\text { Plant (County) }\end{array}$} & \multirow{2}{*}{$\begin{array}{c}\text { Unit } \\
\text { W }\end{array}$} & \multirow{2}{*}{$\begin{array}{l}\text { Generator } \\
\text { Nameplate } \\
\text { Capacity } \\
\text { (megawatts) }\end{array}$} & \multirow{2}{*}{$\begin{array}{l}\text { Net Summer } \\
\text { Capability } \\
\text { (megawatts) }\end{array}$} & \multirow{2}{*}{$\begin{array}{l}\text { Net Winter } \\
\text { Capability } \\
\text { (megawatts) }\end{array}$} & \multirow{2}{*}{$\begin{array}{r}\text { Unit } \\
\text { Type }\end{array}$} & \multicolumn{2}{|c|}{ Energy Source] } & \multirow{2}{*}{$\begin{array}{c}\text { Year } \\
\text { of } \\
\text { Commercial } \\
\text { Operation }\end{array}$} & \multirow{2}{*}{$\begin{array}{c}\text { Unit } \\
\text { Status } 1\end{array}$} \\
\hline & & & & & & Prinary & Alernate & & \\
\hline \multicolumn{10}{|l|}{ Nebraska (Continued) } \\
\hline & 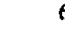 & 1.6 & 1.6 & 1.6 & IC & FO2 & - & 1997 & OP \\
\hline 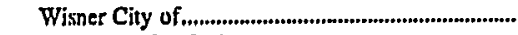 & & 1.9 & 1.9 & 1.9 & & & & & \\
\hline 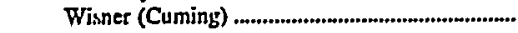 & 1 & .6 & .6 & .6 & IC & $\mathrm{FO} 2$ & - & 1954 & OP \\
\hline & 2 & .5 & 5 & 5 & IC & $\mathrm{FO} 2$ & - & 1947 & OP \\
\hline & 3 & .8 & .8 & .8 & IC & FO2 & - & 1969 & OP \\
\hline
\end{tabular}

See footnotes at end of table. 
Table 20. Existing Generating Units at U.S. Electric Utilities by State, Company, and Plant, as of January 1, 1998 (Continued)

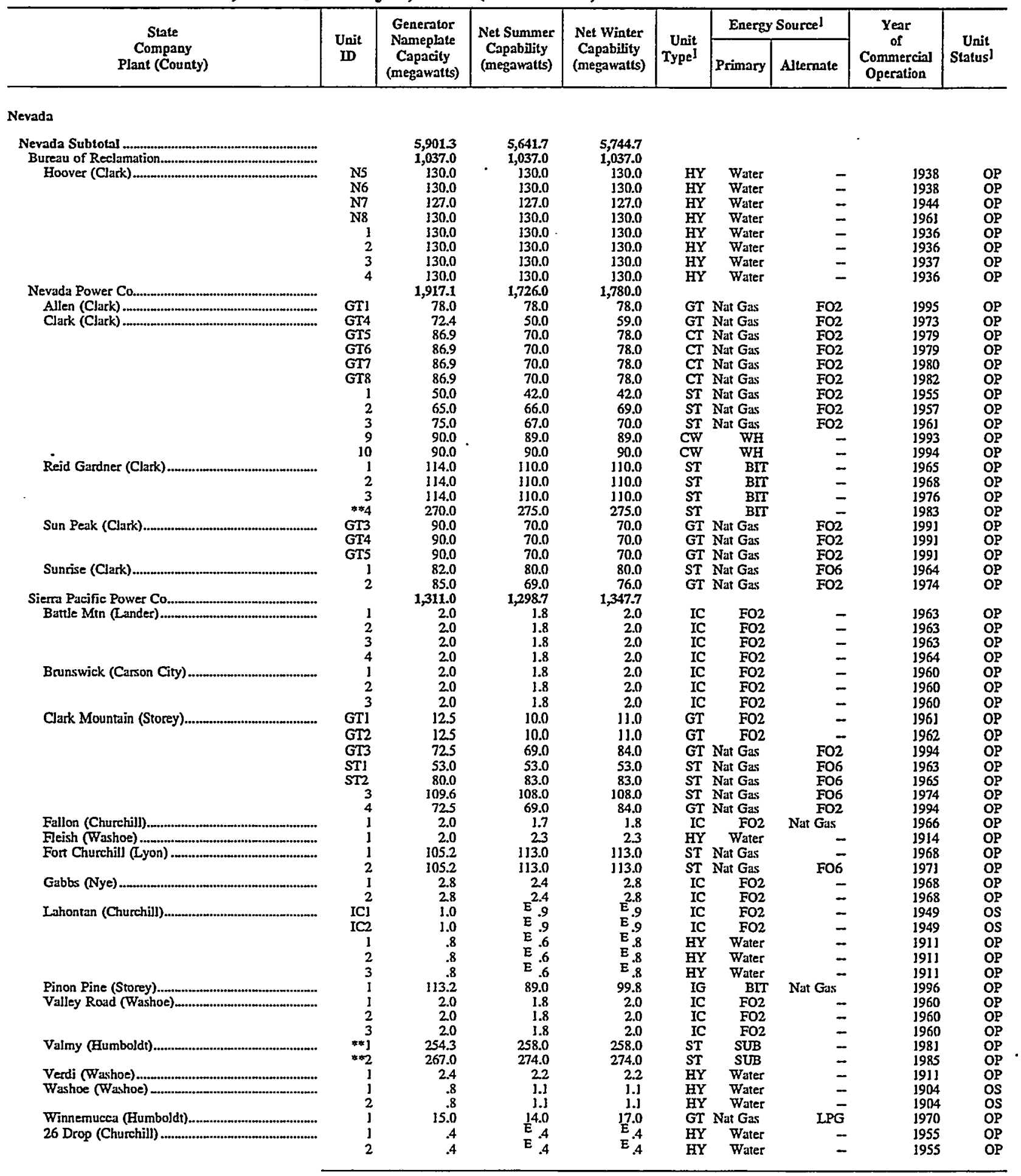

See footnotes at end of table. 
Table 20. Existing Generating Units at U.S. Electric Utilities by State, Company, and Plant, as of January 1, 1998 (Continued)

\begin{tabular}{|c|c|c|c|c|c|c|c|c|c|}
\hline \multirow{2}{*}{$\begin{array}{c}\text { State } \\
\text { Company } \\
\text { Plant (County) }\end{array}$} & \multirow{2}{*}{$\begin{array}{l}\text { Unit } \\
\text { DD }\end{array}$} & \multirow{2}{*}{$\begin{array}{l}\text { Generator } \\
\text { Naneplate } \\
\text { Capacity } \\
\text { (megawatts) }\end{array}$} & \multirow{2}{*}{$\begin{array}{c}\text { Net Summer } \\
\text { Capability } \\
\text { (megawatts) }\end{array}$} & \multirow{2}{*}{$\begin{array}{l}\text { Net Winter } \\
\text { Capability } \\
\text { (megawatts) }\end{array}$} & \multirow{2}{*}{$\begin{array}{r}\text { Unit } \\
\text { Type }\end{array}$} & \multicolumn{2}{|c|}{ Energy Sourcel } & \multirow{2}{*}{$\begin{array}{c}\text { Year } \\
\text { of } \\
\text { Commercinal } \\
\text { Operation }\end{array}$} & \multirow{2}{*}{$\begin{array}{c}\text { Unit } \\
\text { Status }\end{array}$} \\
\hline & & & & & & Primary & Alteraate & & \\
\hline 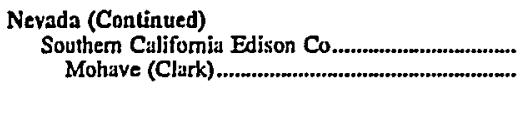 & $* * 1$ & $\begin{array}{r}1,636.2 \\
818.1 \\
818.1\end{array}$ & $\begin{array}{r}1,580.0 \\
790.0 \\
790.0\end{array}$ & $\begin{array}{r}1,580.0 \\
790.0 \\
790.0\end{array}$ & $\begin{array}{l}S T \\
S T\end{array}$ & $\begin{array}{l}\text { BIT } \\
\text { BIT }\end{array}$ & $\begin{array}{l}\text { Nat Gas } \\
\text { Nat Gas }\end{array}$ & $\begin{array}{l}1971 \\
1971\end{array}$ & $\begin{array}{l}O P \\
O P\end{array}$ \\
\hline \multicolumn{10}{|l|}{ New Hampshire } \\
\hline \multirow{2}{*}{ 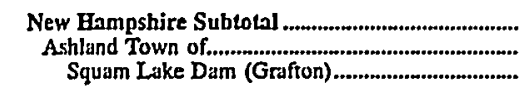 } & & $\begin{array}{r}2,613.9 \\
.1\end{array}$ & $\begin{array}{r}2,511.9 \\
.1\end{array}$ & $\begin{array}{r}2,585.7 \\
.1\end{array}$ & & & & & \\
\hline & $\frac{1}{2}$ & 188.4 & & 220.8 & $\begin{array}{l}\mathrm{HY} \\
\mathrm{HY}\end{array}$ & $\begin{array}{l}\text { Water } \\
\text { Water }\end{array}$ & $\overline{-}$ & $\begin{array}{l}1982 \\
1982\end{array}$ & $\begin{array}{l}O P \\
O P\end{array}$ \\
\hline 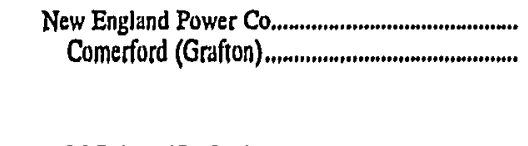 & $\begin{array}{l}1 \\
2 \\
3 \\
4\end{array}$ & $\begin{array}{l}35.1 \\
35.1 \\
35.1 \\
35.1\end{array}$ & $\begin{array}{r}2164.0 \\
2- \\
2= \\
2=\end{array}$ & $\begin{array}{r}2 \text { I64.0 } \\
2- \\
2- \\
2-\end{array}$ & $\begin{array}{l}\mathrm{HY} \\
\mathrm{HY} \\
\mathrm{HY}\end{array}$ & $\begin{array}{l}\text { Water } \\
\text { Water } \\
\text { Water } \\
\text { Water }\end{array}$ & $\bar{z}$ & $\begin{array}{l}1930 \\
1930 \\
1930 \\
1930\end{array}$ & $\begin{array}{l}O P \\
O P \\
O P \\
O P\end{array}$ \\
\hline \multirow[t]{2}{*}{ 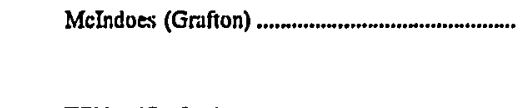 } & $\begin{array}{l}1 \\
2 \\
3\end{array}$ & $\begin{array}{l}2.7 \\
27 \\
27\end{array}$ & $\begin{array}{r}2 \begin{array}{l}13.0 \\
2 \\
2-\end{array} \\
2-\end{array}$ & $\begin{array}{rl}2 & 13.0 \\
2 & -0 \\
2 & -\end{array}$ & $\begin{array}{l}\mathrm{HY} \\
\mathrm{HY}\end{array}$ & $\begin{array}{l}\text { Water } \\
\text { Water } \\
\text { Wutter }\end{array}$ & $\bar{z}$ & $\begin{array}{l}1931 \\
1931 \\
1931\end{array}$ & $\begin{array}{l}O P \\
O P \\
O P\end{array}$ \\
\hline & 4 & 27 & $2-$ & $2-$ & HY & $\begin{array}{l}\text { Water } \\
\text { Water }\end{array}$ & $\bar{z}$ & $\begin{array}{l}1931 \\
1931\end{array}$ & $\begin{array}{l}\text { OP } \\
\text { OP }\end{array}$ \\
\hline \multirow[t]{2}{*}{ Wilder (Grafton) ......................................................... } & $\begin{array}{l}1 \\
2\end{array}$ & $\begin{array}{l}16.2 \\
18.0\end{array}$ & $\begin{array}{r}242.5 \\
2-\end{array}$ & $\begin{array}{r}343.9 \\
3-\end{array}$ & $\begin{array}{l}\mathrm{HY} \\
\mathrm{HY}\end{array}$ & $\begin{array}{l}\text { Water } \\
\text { Water }\end{array}$ & $\overline{-}$ & $\begin{array}{l}1950 \\
1950\end{array}$ & $\begin{array}{l}O P \\
O P\end{array}$ \\
\hline & 3 & 3.2 & $2^{2}-$ & $3-$ & HY & Water & - & 1987 & OP \\
\hline \multirow{3}{*}{ 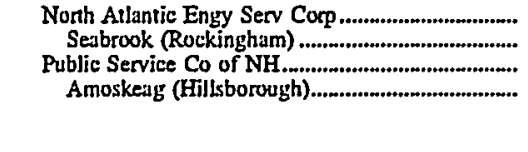 } & 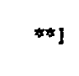 & $\begin{aligned} 1,242.0 \\
1242.0 \\
1,183.5\end{aligned}$ & $\begin{array}{r}1,162.0 \\
1162.0 \\
1,130.4\end{array}$ & $\begin{array}{l}1,162.0 \\
1162.0 \\
1,202.8\end{array}$ & NP & Uranium & - & 1990 & OP \\
\hline & $\begin{array}{l}1 \\
2\end{array}$ & $\begin{array}{l}6.0 \\
5.0\end{array}$ & $\begin{array}{r}6.3 \\
5.5\end{array}$ & $\begin{array}{l}6.3 \\
5.5\end{array}$ & $\begin{array}{l}\mathrm{HY} \\
\mathrm{HY}\end{array}$ & $\begin{array}{l}\text { Water } \\
\text { Water }\end{array}$ & - & $\begin{array}{l}1924 \\
1922\end{array}$ & $\begin{array}{l}O P \\
O P\end{array}$ \\
\hline & 3 & 5.0 & 5.8 & 5.8 & $\mathrm{HY}$ & Water & - & 1922 & OP \\
\hline \multirow[t]{2}{*}{ 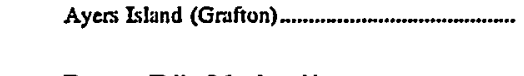 } & $\frac{1}{2}$ & 2.8 & $\begin{array}{l}3.0 \\
3.0\end{array}$ & $\begin{array}{l}3.0 \\
3.0\end{array}$ & HY & $\begin{array}{l}\text { Water } \\
\text { Water }\end{array}$ & $z$ & 1925 & $O P$ \\
\hline & & 28 & 3.0 & 3.0 & HY & Water & - & 1925 & $O P$ \\
\hline Eastman Falls (Merrimuck) ...................................... & 1 & 1.8 & 1.9 & 1.9 & $\mathrm{HY}$ & Water & - & 1937 & $O P$ \\
\hline \multirow[t]{4}{*}{ Garvins Falls (Mertimack) ............................................ } & 2 & $\begin{array}{l}4.6 \\
3.4\end{array}$ & $\begin{array}{l}4.6 \\
3.3\end{array}$ & $\begin{array}{l}4.6 \\
3.3\end{array}$ & $\begin{array}{l}\text { HY } \\
\text { HY }\end{array}$ & $\begin{array}{l}\text { Water } \\
\text { Water }\end{array}$ & $\bar{z}$ & $\begin{array}{l}1983 \\
1981\end{array}$ & $\begin{array}{l}\text { OP } \\
\text { OP }\end{array}$ \\
\hline & 2 & 3.4 & 3.3 & 3.3 & HY & Water & - & 1981 & OP \\
\hline & 3 & 24 & 2.5 & 2.5 & $\mathrm{HY}$ & Water & - & 1925 & OP \\
\hline & 4 & 3.2 & 3.0 & 3.0 & $\mathrm{HY}$ & Water & - & 1925 & OP \\
\hline \multirow[t]{3}{*}{ 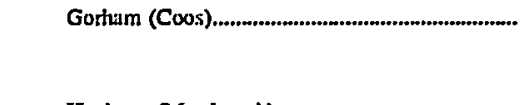 } & 1 & 4 & .3 & 3 & $\mathrm{HY}$ & Water & - & 1917 & $O P$ \\
\hline & 2 & .4 & 3 & 3 & HY & Water & - & 1917 & OP \\
\hline & 3 & .7 & .8 & .8 & $\mathrm{HY}$ & Water & - & 1923 & OP \\
\hline Hooksent (Mertimack) & 4 & .78 & .8 & .8 & $\mathrm{HY}$ & Water & - & 1923 & OP \\
\hline Jackman (Hillsborough) ....................................... & i & 3.0 & 1.9 & 1.9 & HY & Water & - & 1927 & OP \\
\hline 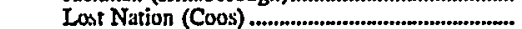 & & 3.2 & 137 & 3.6 & $H Y$ & Water & - & 1926 & OP \\
\hline \multirow{5}{*}{ 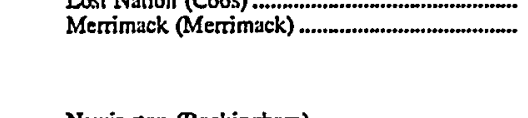 } & GT1 & 18.0 & 13.7 & 18.6 & GT & FO2 & - & 1969 & OP \\
\hline & $\begin{array}{l}\text { GT1 } \\
\text { GT2 }\end{array}$ & $\begin{array}{l}18.6 \\
18.6\end{array}$ & $\begin{array}{l}17.0 \\
17.0\end{array}$ & $\begin{array}{l}21.5 \\
23.5\end{array}$ & $\begin{array}{l}\text { GT } \\
\text { GT }\end{array}$ & Jet Fuel & $=$ & 1968 & $\mathrm{OP}$ \\
\hline & 1 & 113.6 & 112.5 & 121.0 & ST & BIT & - & 1960 & $O P$ \\
\hline & 2 & 345.6 & 320.0 & 349.5 & ST & BIT & - & 1968 & OP \\
\hline & 1 & 414.0 & 406.0 & 415.0 & ST & FO6 & Nat Gas & 1974 & OP \\
\hline 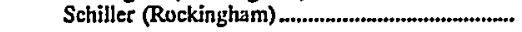 & GTl & 21.3 & 17.0 & 18.0 & GT & Jet Fuel & Nat Gas & 1970 & OP \\
\hline & 4 & 50.0 & 47.5 & 48.0 & ST & BIT & FO6 & 1952 & OP \\
\hline & 5 & 50.0 & 49.6 & 49.6 & ST & BIT & F06 & 1955 & OP \\
\hline & 6 & 50.0 & 48.0 & 49.0 & ST & BIT & F06 & 1957 & OP \\
\hline Smith (Coos) & 1 & 15.0 & 11.3 & 14.2 & HY & Water & - & 1948 & OP \\
\hline White Lake (Carroll) ................................................. & GTI & 18.6 & 18.1 & 22.3 & GT & Jet Fuel & - & 1968 & OP \\
\hline New Jersey & & & & & & & & & \\
\hline $\begin{array}{l}\text { New Jersey Subtolal } \\
\text { Aulantic Cy Electic Co }\end{array}$ & & $\begin{array}{r}14,410.4 \\
1,308.8\end{array}$ & $\begin{array}{r}13,683.6 \\
1,188.0\end{array}$ & $\begin{array}{r}14,820.6 \\
1,295.0\end{array}$ & & & & & \\
\hline B L England (Cape May) & IC] & 2.0 & $\begin{aligned} 2, x 000 \\
2.0\end{aligned}$ & 2.0 & IC & FO2 & - & 1961 & OP \\
\hline & ICE & $\begin{array}{l}2.0 \\
2.0\end{array}$ & 20 & 20 & IC & FO2 & $=$ & $\begin{array}{l}1961 \\
1961\end{array}$ & $O P$ \\
\hline & IC4 & 2.0 & 2.0 & 20 & IC & $\mathrm{FO2}$ & $=$ & 1961 & $O P$ \\
\hline & I & 136.0 & 129.0 & 129.0 & ST & BIT & FO6 & 1962 & OP \\
\hline & 2 & 163.2 & 155.0 & 155.0 & ST & BIT & Fo6 & 1964 & OP \\
\hline & 3 & 176.4 & IS5.0 & 160.0 & ST & FO6 & - & 1974 & OP \\
\hline 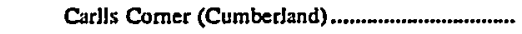 & I & 41.9 & 36.0 & 43.0 & GT & Nat Gas & KER & 1973 & op \\
\hline & 2 & 41.9 & 37.0 & 43.0 & GT & Nat Gas & KER & 1973 & OP \\
\hline 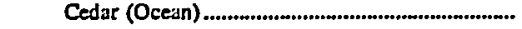 & $\mathbf{I}$ & 41.9 & 46.0 & 52.0 & GT & KER & - & 1972 & $O P$ \\
\hline
\end{tabular}

See footnotes at end of table. 
Table 20. Existing Generating Units at U.S. Electric Utilities. by State, Company, and Plant, as of January 1, 1998 (Continued)

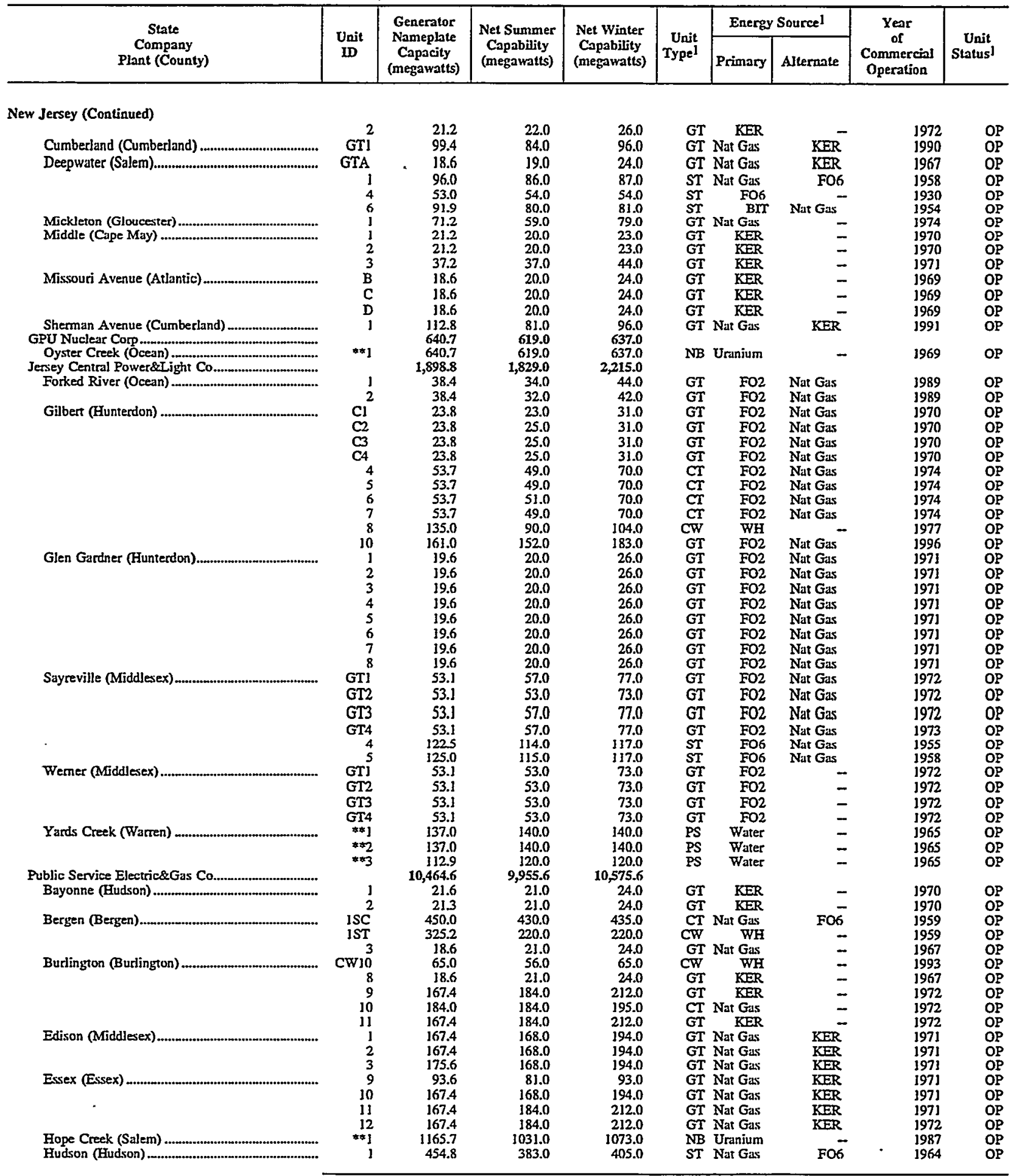

See footnotes at end of table. 
Table 20. Existing Generating Units at U.S. Electric Utilities by State, Company, and Plant, as of January 1, 1998 (Continued)

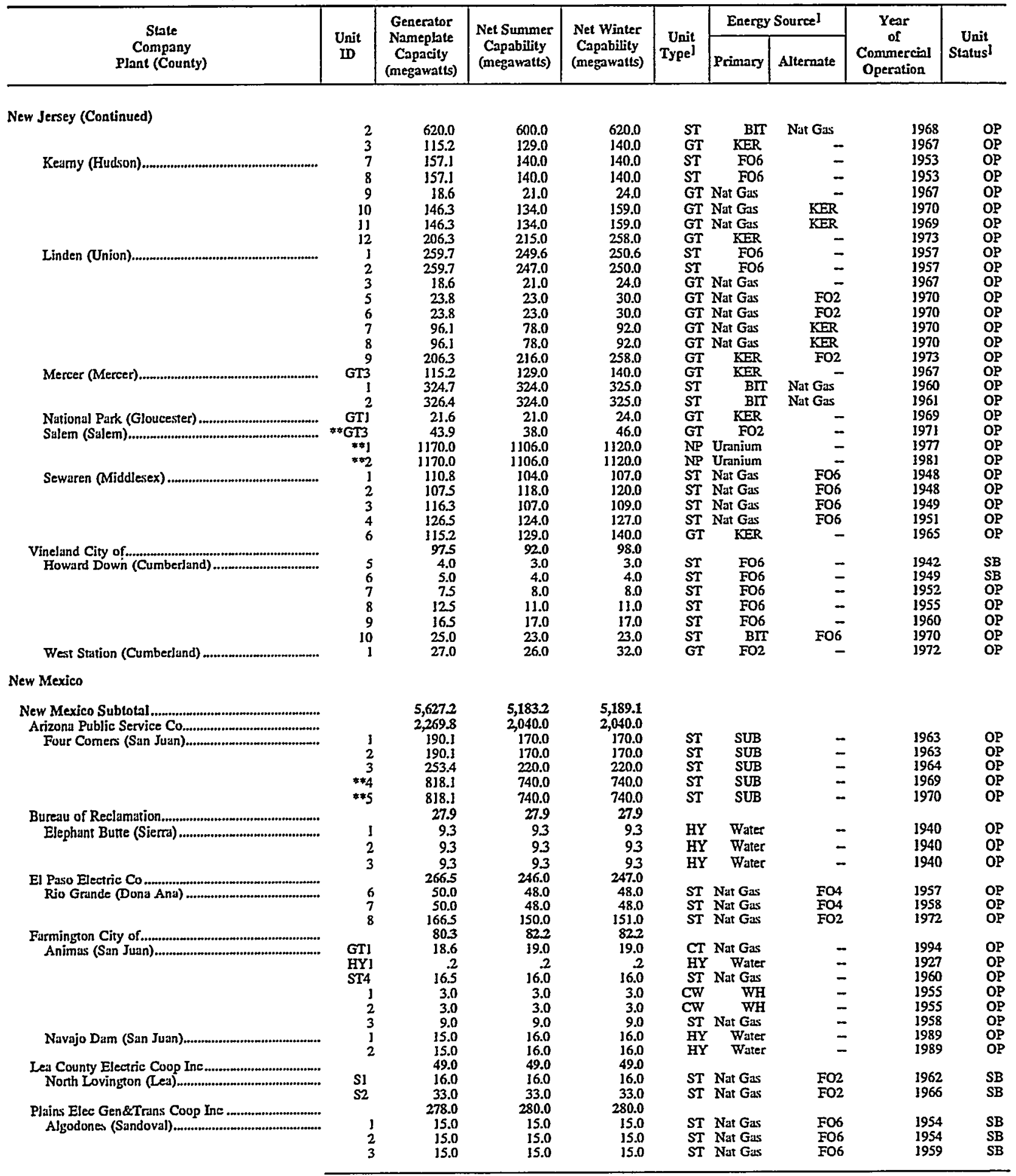

See footnotes at end of table. 
Table 20. Existing Generating Units at U.S. Electric Utilities by State, Company, and Plant, as of January 1, 1998 (Continued)

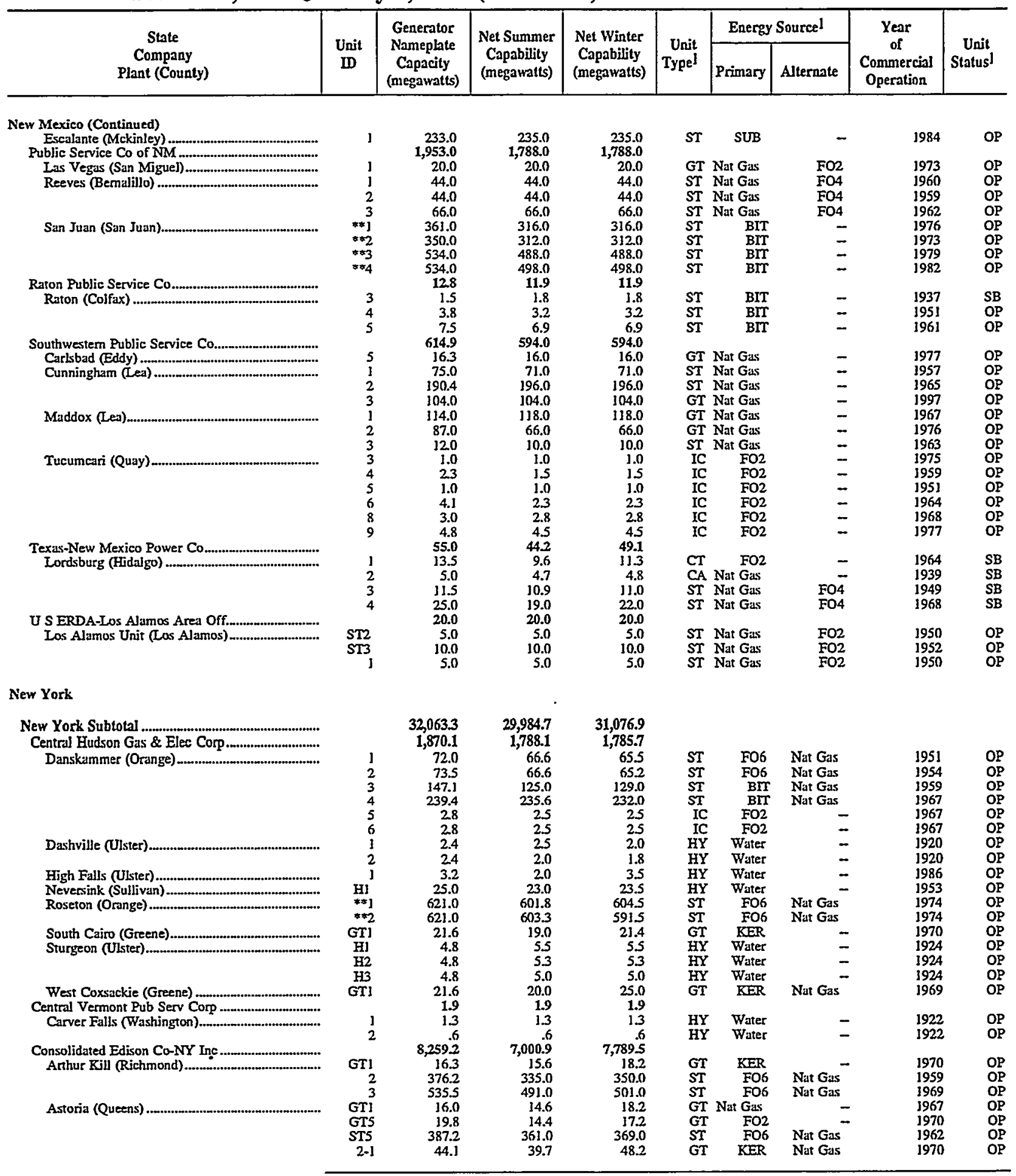

See foomotes at end of table. 
Table 20. Existing Generating Units at U.S. Electric Utilities by State, Company, and Plant, as of January 1, 1998 (Continued)

\begin{tabular}{|c|c|c|c|c|c|c|c|c|c|}
\hline \multirow{2}{*}{$\begin{array}{c}\text { State } \\
\text { Company } \\
\text { PIant (County) }\end{array}$} & \multirow{2}{*}{$\begin{array}{l}\text { Unit } \\
\text { ID }\end{array}$} & \multirow{2}{*}{$\begin{array}{l}\text { Generator } \\
\text { Nameplate } \\
\text { Capacity } \\
\text { (megawatts) }\end{array}$} & \multirow{2}{*}{$\begin{array}{l}\text { Net Summer } \\
\text { Capability } \\
\text { (megawatts) }\end{array}$} & \multirow{2}{*}{$\begin{array}{l}\text { Net Winter } \\
\text { Capability } \\
\text { (megawatts) }\end{array}$} & \multirow{2}{*}{$\begin{array}{c}\text { Unit } \\
\text { Type] }\end{array}$} & \multicolumn{2}{|c|}{ Energy Sourcel } & \multirow{2}{*}{$\begin{array}{c}\text { Year } \\
\text { of } \\
\text { Commercial } \\
\text { Operation }\end{array}$} & \multirow{2}{*}{$\begin{array}{c}\text { Unit } \\
\text { Status }\end{array}$} \\
\hline & & & & & & Primary & Alteraate & & \\
\hline (1) & 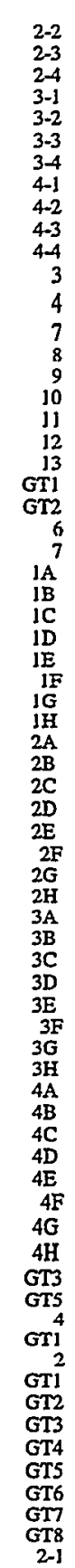 & 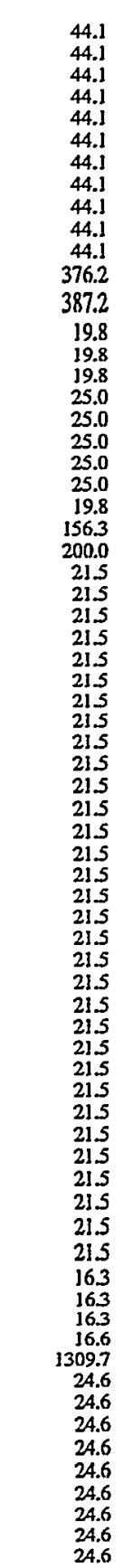 & $\begin{array}{r}40.4 \\
40.7 \\
38.1 \\
39.2 \\
39.2 \\
41.6 \\
40.2 \\
41.0 \\
39.8 \\
40.7 \\
31.5 \\
353.0 \\
361.0 \\
13.5 \\
13.6 \\
13.9 \\
0.0 \\
21.0 \\
20.5 \\
22.5 \\
20.5 \\
15.3 \\
130.0 \\
170.0 \\
17.0 \\
17.3 \\
15.0 \\
16.4 \\
13.5 \\
14.7 \\
15.4 \\
16.4 \\
16.3 \\
15.7 \\
14.8 \\
17.0 \\
17.4 \\
16.9 \\
15.3 \\
17.8 \\
16.7 \\
17.2 \\
17.2 \\
14.7 \\
16.9 \\
16.2 \\
16.4 \\
15.3 \\
12.4 \\
13.4 \\
15.8 \\
15.2 \\
16.5 \\
15.3 \\
15.9 \\
12.9 \\
16.1 \\
15.7 \\
17.0 \\
14.6 \\
14.2 \\
\end{array}$ & $\begin{array}{r}50.2 \\
48.7 \\
47.8 \\
46.4 \\
46.4 \\
47.4 \\
47.4 \\
47.8 \\
48.1 \\
49.1 \\
48.5 \\
361.0 \\
369.0 \\
16.1 \\
17.1 \\
17.2 \\
29.4 \\
28.2 \\
27.9 \\
28.1 \\
27.4 \\
20.2 \\
134.0 \\
175.0 \\
23.4 \\
22.6 \\
22.5 \\
22.4 \\
22.7 \\
22.4 \\
22.3 \\
22.7 \\
22.6 \\
22.3 \\
251.0 \\
24.7 \\
23.4 \\
23.4 \\
24.3 \\
24.3 \\
24.3 \\
23.5 \\
23.8 \\
25.3 \\
23.3 \\
22.3 \\
23.2 \\
22.2 \\
22.5 \\
22.4 \\
22.8 \\
22.4 \\
22.4 \\
22.7 \\
23.6 \\
23.2 \\
22.7 \\
20.8 \\
23.7 \\
22.9 \\
23.0 \\
22.9 \\
24.2 \\
23 \\
\end{array}$ & 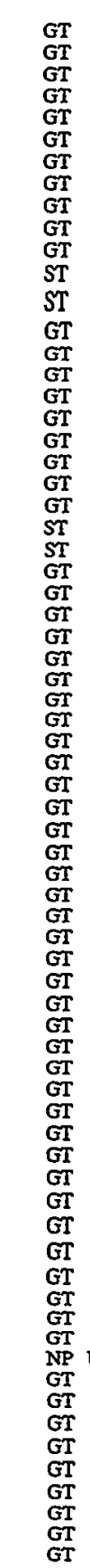 & $\begin{array}{c}\text { KER } \\
\text { KER } \\
\text { KER } \\
\text { KER } \\
\text { KER } \\
\text { KER } \\
\text { KER } \\
\text { KER } \\
\text { KER } \\
\text { KER } \\
\text { KER } \\
\text { FO6 } \\
\text { FO6 } \\
\text { FO2 } \\
\text { FO2 } \\
\text { FO2 } \\
\text { FO2 } \\
\text { FO2 } \\
\text { FO2 } \\
\text { FO2 } \\
\text { FO2 } \\
\text { FO2 } \\
\text { FO6 } \\
\text { FO6 } \\
\text { FO2 } \\
\text { FO2 } \\
\text { FO2 } \\
\text { FO2 } \\
\text { FO2 } \\
\text { FO2 } \\
\text { FO2 } \\
\text { FO2 } \\
\text { FO2 } \\
\text { FO2 } \\
\text { FO2 } \\
\text { FO2 } \\
\text { KER } \\
\text { KER } \\
\text { KEER } \\
\text { KERR } \\
\text { KER } \\
\text { KER } \\
\text { KER } \\
\text { KER } \\
\text { KERR }\end{array}$ & 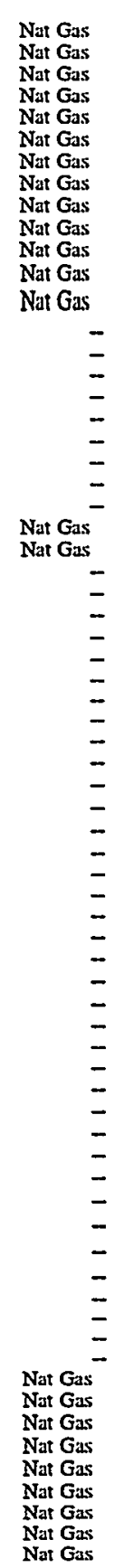 & $\begin{array}{l}1970 \\
1970 \\
1970 \\
1970 \\
1970 \\
1970 \\
1970 \\
1970 \\
1970 \\
1970 \\
1970 \\
1958 \\
1961 \\
1970 \\
1970 \\
1970 \\
1971 \\
1971 \\
1971 \\
1971 \\
1971 \\
1970 \\
1951 \\
1955 \\
1971 \\
1971 \\
1971 \\
1971 \\
1971 \\
1971 \\
1971 \\
1971 \\
1971 \\
1971 \\
1971 \\
1971 \\
1971 \\
1971 \\
1971 \\
1971 \\
1971 \\
1971 \\
1971 \\
1971 \\
1971 \\
1971 \\
1971 \\
1971 \\
1971 \\
1971 \\
1971 \\
1971 \\
1971 \\
1971 \\
1971 \\
1971 \\
1970 \\
1970 \\
1970 \\
1969 \\
1973 \\
1972 \\
1972 \\
1972 \\
1972 \\
1972 \\
1972 \\
1972 \\
1972 \\
1972\end{array}$ & $\begin{array}{l}O P \\
O P \\
O P \\
O P \\
O P \\
O P \\
O P \\
O P \\
O P \\
O P \\
O P \\
O P \\
O P \\
O P \\
O P \\
O P \\
O P \\
O P \\
O P \\
O P \\
O P \\
O P \\
O P \\
O P \\
O P \\
O P \\
O P \\
O P \\
O P \\
O P \\
O P \\
O P \\
O P \\
O P \\
O P \\
O P \\
O P \\
O P \\
O P \\
O P \\
O P \\
O P \\
O P \\
O P \\
O P \\
O P \\
O P \\
O P \\
O P \\
O P \\
O P \\
O P \\
O P \\
O P \\
O P \\
O P \\
O P \\
O P \\
O P \\
O P \\
O P \\
O P \\
O P \\
O P \\
O P \\
O P \\
O P \\
O P \\
O P \\
O P \\
O P \\
O P \\
O P \\
O P\end{array}$ \\
\hline
\end{tabular}

See footnotes at end of table. 
Table 20. Existing Generating Units at U.S. Electric Utilities by State, Company, and Plant, as of January 1, 1998 (Continued)

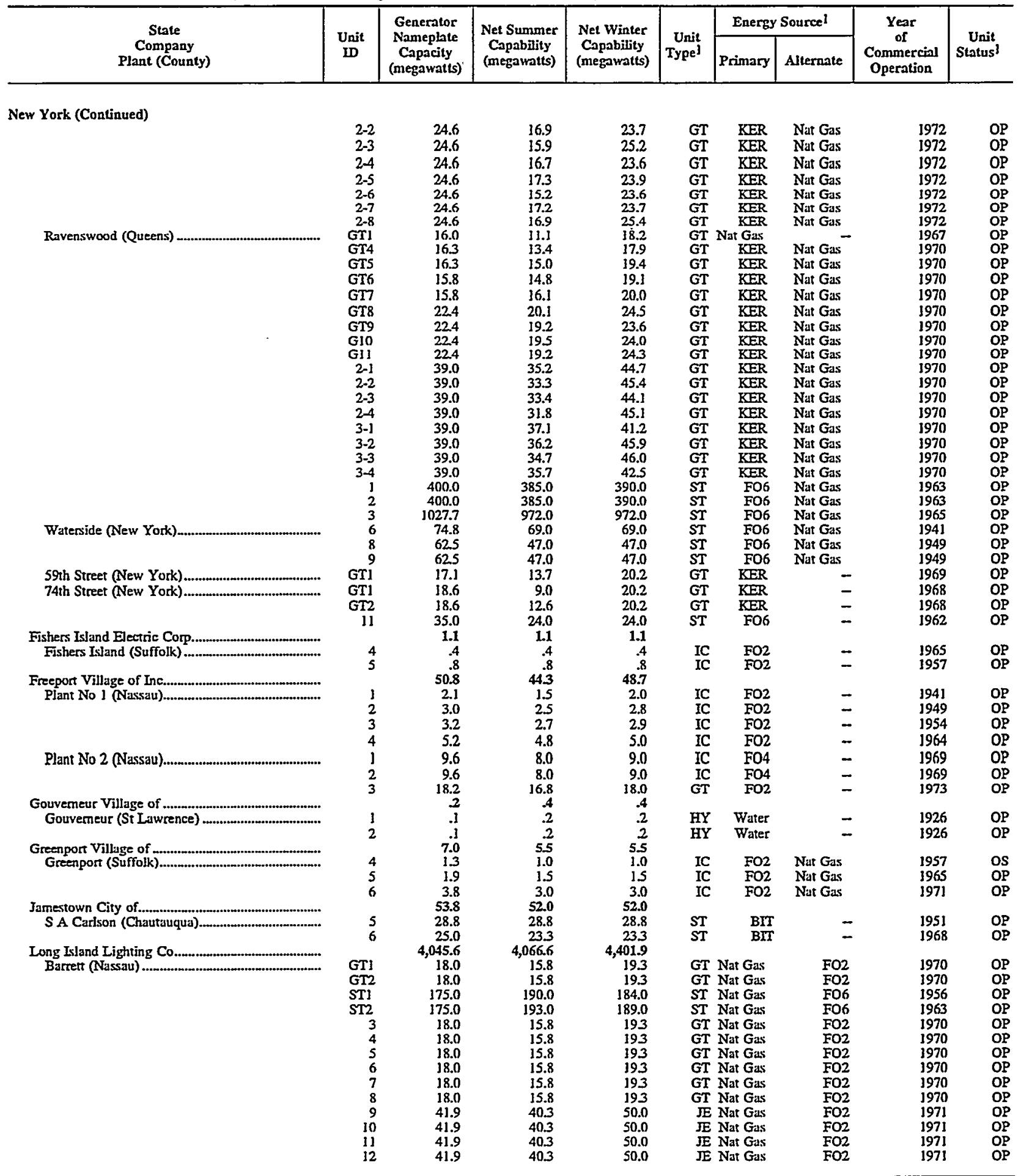

See footnotes at end of table. 
Table 20. Existing Generating Units at U.S. Electric Utilities by State, Company, and Plant, as of January 1, 1998 (Continued)

\begin{tabular}{|c|c|c|c|c|c|c|c|c|c|}
\hline \multirow{2}{*}{$\begin{array}{c}\text { State } \\
\text { Company } \\
\text { Plant (County) }\end{array}$} & \multirow{2}{*}{$\begin{array}{l}\text { Unit } \\
\text { ID }\end{array}$} & \multirow{2}{*}{$\begin{array}{c}\text { Generator } \\
\text { Nameplate } \\
\text { Capacity } \\
\text { (megawatts) }\end{array}$} & \multirow{2}{*}{$\begin{array}{l}\text { Net Summer } \\
\text { Capability } \\
\text { (megawatts) }\end{array}$} & \multirow{2}{*}{$\begin{array}{l}\text { Net Winter } \\
\text { Capability } \\
\text { (megawatts) }\end{array}$} & \multirow{2}{*}{$\begin{array}{c}\text { Unit } \\
\text { TypeI }\end{array}$} & \multicolumn{2}{|c|}{ Energy Sourcel } & \multirow{2}{*}{$\begin{array}{c}\text { Year } \\
\text { of } \\
\text { Commercinl } \\
\text { Operation }\end{array}$} & \\
\hline & & & & & & Primary & Alternate & & \\
\hline New York (Continued) & & & & & & & & & \\
\hline 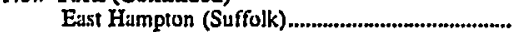 & I & 21.3 & 20.0 & 24.0 & GT & $\mathrm{FO} 2$ & - & 1970 & OP \\
\hline & 2 & 2.0 & 2.0 & 2.0 & IC & FO2 & - & 1962 & OP \\
\hline & 3 & 2.0 & 2.0 & 2.0 & IC & $\mathrm{FO} 2$ & - & 1962 & OP \\
\hline & 4 & 2.0 & 2.0 & 2.0 & IC & $\mathrm{FO} 2$ & - & 1962 & $\mathrm{OP}$ \\
\hline 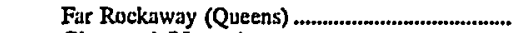 & 4 & 100.0 & 106.0 & 110.0 & ST & Nat Gas & F06 & 1953 & OP \\
\hline 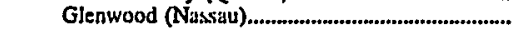 & GT2 & 55.0 & 53.5 & 66.5 & GT & $\mathrm{FO} 2$ & - & 1972 & OP \\
\hline & GT3 & 55.0 & 53.5 & 66.5 & GT & FO2 & - & 1972 & $O P$ \\
\hline & I & 16.0 & 15.0 & 19.0 & GT & $\mathrm{FO} 2$ & - & 1967 & OP \\
\hline * & 4 & 100.0 & 109.0 & 109.0 & ST & Nat Gas & - & 1952 & OP \\
\hline & 5 & 100.0 & 111.0 & 110.0 & ST & Nat Gas & - & 1954 & OP \\
\hline Holtsville (Suffolk) .................................................... & 1 & 56.7 & 51.5 & 66.4 & JE & $\mathrm{FO} 2$ & - & 1974 & $O P$ \\
\hline & 2 & 56.7 & 51.5 & 66.4 & JE & $\mathrm{FO} 2$ & - & 1974 & $O P$ \\
\hline & 3 & 56.7 & 51.5 & 66.4 & $\mathrm{JE}$ & FO2 & - & 1974 & $\mathrm{OP}$ \\
\hline & 4 & 56.7 & 51.5 & 66.4 & $\mathrm{JE}$ & FO2 & - & 1974 & OP \\
\hline & $\begin{array}{l}7 \\
8\end{array}$ & $\begin{array}{l}56.7 \\
56.7\end{array}$ & $\begin{array}{l}51.5 \\
51.5\end{array}$ & $\begin{array}{l}66.4 \\
66.4\end{array}$ & JE & $\mathrm{FO} 2$ & $\overline{-}$ & $\begin{array}{l}1975 \\
1975\end{array}$ & $O P$ \\
\hline & $\begin{array}{l}8 \\
9\end{array}$ & $\begin{array}{l}50.8 \\
56.7\end{array}$ & $\begin{array}{l}51.5 \\
53.5\end{array}$ & $\begin{array}{l}66.4 \\
66.4\end{array}$ & $\frac{\mathrm{JE}}{\mathrm{JE}}$ & $\mathrm{FO2}$ & $\underline{-}$ & $\begin{array}{l}1975 \\
1975\end{array}$ & OP \\
\hline & 10 & 56.7 & 515 & 66.4 & $\mathrm{JE}$ & $\begin{array}{l}\mathrm{FO2} \\
\mathrm{FO2}\end{array}$ & - & 1975 & OP \\
\hline 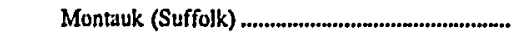 & 2 & 2.0 & 20 & 2.0 & IC & FO2 & - & 1962 & OP \\
\hline & 3 & 20 & 2.0 & 2.0 & IC & FO2 & - & 1965 & OP \\
\hline & 4 & 20 & 2.0 & 2.0 & IC & $\mathrm{FO} 2$ & - & 1965 & OP \\
\hline Northport (Suffolk) & GTI & 16.0 & 15.0 & 19.0 & GT & FO2 & - & 1967 & OP \\
\hline & ST1 & 375.0 & 381.0 & 355.0 & ST & FO6 & - & 1967 & OP \\
\hline & 2 & 375.0 & 381.0 & 377.0 & ST & Nat Gas & F06 & 1968 & OP \\
\hline & 3 & 375.0 & 381.0 & 375.0 & ST & FO6 & - & 1972 & OP \\
\hline & 4 & 375.0 & 381.0 & 386.0 & ST & Nat Gas & F06 & 1977 & op \\
\hline 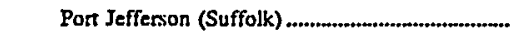 & GTi & 16.0 & 15.0 & 19.0 & GT & FO2 & roo & 1966 & OP \\
\hline & STI & 44.0 & E 42.3 & E 42.5 & ST & FO6 & - & 1948 & SB \\
\hline & 2 & 44.0 & $E_{42.3}$ & $E_{42.5}$ & ST & Fo6 & - & 1950 & SB \\
\hline & 3 & 175.0 & 191.0 & 188.0 & ST & Nat Gas & F06 & 1958 & OP \\
\hline & 4 & 175.0 & 191.0 & 192.0 & ST & FO6 & - & 1960 & OP \\
\hline 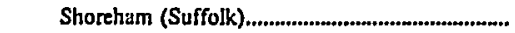 & GII & 52.9 & 49.0 & 63.0 & GT & FO2 & - & 1971 & OP \\
\hline & GT2 & 18.6 & 18.0 & 21.0 & GT & FO2 & - & 1966 & OP \\
\hline South Hampton (Suffolk) & 1 & 11.5 & 11.0 & 15.0 & GT & $\mathrm{FO} 2$ & - & 1963 & OP \\
\hline 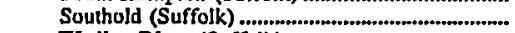 & 了 & 14.0 & 11.0 & 17.0 & GT & FO2 & - & 1964 & OP \\
\hline 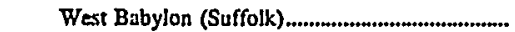 & 4 & 52.4 & 47.0 & 66.0 & GT & $\mathrm{FO} 2$ & - & 1971 & OP \\
\hline 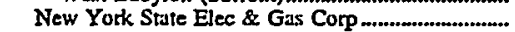 & & $1,495.2$ & $1,495.4$ & $1,499.5$ & & & & & \\
\hline Cadyville (Clinton) & 了 & 1.2 & 1.5 & 1.2 & HY & Water & - & 192] & OP \\
\hline & 2 & 1.2 & 1.5 & 12 & HY & Water & - & 1921 & OP \\
\hline & 3 & 3.1 & 4.0 & 3.6 & $\mathrm{HY}$ & Water & - & 1986 & OP \\
\hline Goudey (Broome) & 7 & 43.8 & 43.0 & 43.0 & ST & BIT & - & 1943 & OP \\
\hline & 8 & 75.0 & 83.0 & 83.0 & ST & BrT & - & 1951 & OP \\
\hline Greenidge (Yates) & 3 & 50.0 & 54.0 & 55.0 & ST & BIT & - & 1950 & SB \\
\hline & 4 & 112.5 & 305.0 & 106.0 & ST & BIT & WD & 1953 & OP \\
\hline 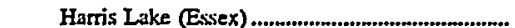 & 1 & 1.8 & 1.8 & 1.6 & IC & $\mathrm{FO} 2$ & - & 1967 & $O P$ \\
\hline Hickling (Steuben) & 1 & 37.5 & 37.5 & 37.5 & ST & BIT & WD & 1948 & SB \\
\hline & $i$ & 49.0 & 49.0 & 45.0 & ST & BIT & WD & 1952 & OP \\
\hline 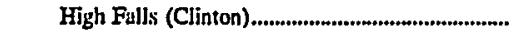 & 1 & 4.0 & 4.4 & 4.4 & HY & Water & - & 1948 & $\mathrm{OP}$ \\
\hline & 2 & 4.0 & 4.4 & 4.4 & HY & Water & - & 1949 & OP \\
\hline & 3 & 7.0 & 7.2 & 72 & HY & Water & - & 1956 & OP \\
\hline 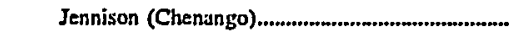 & ] & 37.5 & 33.0 & 36.0 & ST & BIT & WD & 1945 & OP \\
\hline & 2 & 37.5 & 34.0 & 37.0 & ST & BIT & WD & 1950 & OP \\
\hline Kent Falls (Clinton) & $\mathrm{j}$ & 3.2 & 3.0 & 2.8 & HY & Water & - & 1928 & OP \\
\hline & 2 & 3.2 & 3.0 & 2.8 & HY & Water & - & 1928 & op \\
\hline & 3 & 6.0 & 6.0 & 5.4 & HY & Water & - & 1985 & OP \\
\hline 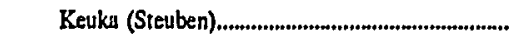 & 1 & 2.0 & 1.5 & 1.8 & HY & Water & - & 1928 & OP \\
\hline Kintigh (Niagara) & $i$ & 655.1 & 675.0 & 675.0 & ST & $\mathrm{BIT}$ & - & 1984 & $\mathrm{OP}$ \\
\hline Mechanicyille (Saratoga)....................................... & i & 8.3 & 8.0 & 9.5 & HY & Water & - & 1983 & $\mathrm{OP}$ \\
\hline & & 8.3 & 8.0 & 95 & HY & Water & - & 1983 & OP \\
\hline Mill C (Clinton) & $-\frac{2}{1}$ & 1.0 & 1.0 & .8 & HY & Water & - & 1944 & OP \\
\hline & 2 & 3.3 & 1.3 & .8 & HY & Water & - & 1943 & OP \\
\hline & 3 & 3.8 & 3.8 & 3.4 & $\mathbf{H Y}$ & Water & - & 1984 & OP \\
\hline 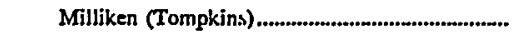 & $\mathrm{ICl}$ & 2.8 & 2.8 & 2.9 & IC & $\mathrm{FO2}$ & - & 1967 & OP \\
\hline & IC2 & 2.8 & 2.8 & 2.9 & IC & $\mathrm{FO} 2$ & - & 1967 & OP \\
\hline & 1 & 155.3 & 150.0 & 149.0 & ST & BIT & - & 1955 & OP \\
\hline
\end{tabular}

See footnotes at end of table. 
Table 20. Existing Generating Units at U.S. Electric Utilities by State, Company, and Plant, as of January 1, 1998 (Continued)

\begin{tabular}{|c|c|c|c|c|c|c|c|c|c|}
\hline \multirow{2}{*}{$\begin{array}{c}\text { State } \\
\text { Company } \\
\text { Plant (County) }\end{array}$} & \multirow{2}{*}{$\begin{array}{l}\text { Unit } \\
\text { ID }\end{array}$} & \multirow{2}{*}{$\begin{array}{l}\text { Generator } \\
\text { Nameplate } \\
\text { Capacity } \\
\text { (megawatts) }\end{array}$} & \multirow{2}{*}{$\begin{array}{c}\text { Net Summer } \\
\text { Capability } \\
\text { (megawatts) }\end{array}$} & \multirow{2}{*}{$\begin{array}{l}\text { Net Winter } \\
\text { Capability } \\
\text { (megawatts) }\end{array}$} & \multirow{2}{*}{$\begin{array}{c}\text { Unit } \\
\text { Typel }\end{array}$} & \multicolumn{2}{|c|}{ Energy Source? } & \multirow{2}{*}{$\begin{array}{c}\text { Year } \\
\text { of } \\
\text { Commercial } \\
\text { Operation }\end{array}$} & \\
\hline & & & & & & Primary & Alternate & & \\
\hline New York (Continued) & & & & & & & & & \\
\hline & 2 & 167.2 & 156.0 & 156.0 & ST & BTT & - & 1958 & OP \\
\hline Rainbow Falls (Clinton) & 1 & 1.3 & 1.5 & 1.5 & HY & Water & - & 1926 & OP \\
\hline & 2 & 1.3 & 1.5 & 1.5 & HY & Water & - & 1927 & OP \\
\hline & 2 & 2.0 & 1.9 & 2.1 & HY & Water & - & 1917 & OP \\
\hline & 4 & 2.0 & 1.9 & 2.1 & HY & Water & - & 1917 & OP \\
\hline Waterloo (Seneca) & 2 & .5 & .5 & .5 & HY & Water & - & 1915 & OP \\
\hline & 3 & .5 & .5 & $S$ & HY & Water & - & 1915 & OP \\
\hline & 4 & .5 & .5 & 5 & HY & Water & - & 1915 & OP \\
\hline Niagara Mohawk Power Corp & & $6,240.9$ & $5,791.8$ & $5,725.1$ & & & & & \\
\hline Albany (Albany) & ICl & .7 & .7 & .7 & IC & $\mathrm{FO} 2$ & $\overline{-}$ & 1967 & OP \\
\hline & $\begin{array}{l}1 \\
2\end{array}$ & $\begin{array}{l}300.0 \\
100.0\end{array}$ & $\begin{array}{l}95.0 \\
92.8\end{array}$ & $\begin{array}{l}95.0 \\
95.0\end{array}$ & $\begin{array}{l}\text { ST } \\
\text { ST }\end{array}$ & $\begin{array}{l}\text { Nat Gas } \\
\text { Nat Gas }\end{array}$ & $\begin{array}{l}\text { FO6 } \\
\text { FO6 }\end{array}$ & $\begin{array}{l}1952 \\
1952\end{array}$ & $\begin{array}{l}\text { OP } \\
\text { OP }\end{array}$ \\
\hline & 3 & 300.0 & 95.0 & 95.0 & ST & Nat Gas & FO6 & 1953 & OP \\
\hline & 4 & 100.0 & 95.0 & 873 & ST & Nat Gas & FO6 & 1954 & OP \\
\hline Baldwinsville (Onondaga) ....................................... & 1 & 3 & .2 & .3 & HY & Water & - & 1927 & OP \\
\hline & 2 & 3 & .2 & 3 & HY & Water & - & 1927 & OP \\
\hline Beardslee (Herkimer) .............................................. & I & 10.0 & 7.7 & 8.1 & HY & Water & - & 1924 & OP \\
\hline & 2 & 10.0 & 7.7 & 8.1 & $\mathrm{HY}$ & Water & - & 1924 & OP \\
\hline Beebee Island (Jefferson) & $* 1$ & 4.0 & 3.3 & 3.3 & HY & Water & - & 1968 & OP \\
\hline & $* 2$ & 4.0 & 3.3 & 3.3 & $\mathbf{H Y}$ & Water & - & 1963 & OP \\
\hline Belfort (Lewis) & $\bar{j}$ & .4 & .4 & .4 & HY & Water & - & 1903 & OP \\
\hline & 2 & .6 & .6 & .7 & HY & Water & - & 1915 & OP \\
\hline & 3 & 1.0 & 1.0 & 1.0 & HY & Water & - & 1918 & OP \\
\hline 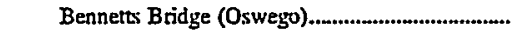 & 1 & 6.4 & 7.1 & 7.2 & HY & Water & - & 1970 & OP \\
\hline & 2 & 6.4 & 7.1 & 7.2 & HY & Water & - & 1970 & OP \\
\hline & 3 & 7.0 & 7.8 & 7.9 & HY & Water & - & 1966 & OP \\
\hline & 4 & 7.0 & 7.8 & 7.9 & HY & Water & - & 1964 & OP \\
\hline Black River (Jefferion) & I & 2.0 & 2.] & 2.3 & HY & Water & - & 1920 & OP \\
\hline & 2 & 2.0 & 2.1 & 23 & $\mathbf{H Y}$ & Water & - & 1920 & OP \\
\hline & 3 & 2.0 & 2.1 & 2.3 & HY & Water & -- & 1920 & OP \\
\hline Blake (St Lawrence) & 1 & 14.4 & 15.0 & 15.0 & HY & Water & - & 1957 & OP \\
\hline Browns Falls (St Lawrence)................................. & 1 & 7.5 & 8.1 & 8.4 & HY & Water & - & 1923 & OP \\
\hline & 2 & 7.5 & 8.1 & 8.4 & HY & Water & - & 1923 & OP \\
\hline C R Huntley (Erie) & ICI & .7 & -7 & .7 & IC & FO2 & - & 1967 & OP \\
\hline & $\$ 68$ & 217.6 & 192.0 & 191.0 & ST & BIT & - & 1958 & op \\
\hline & 66 & 100.0 & 93.0 & 93.0 & ST & BIT & - & 1954 & OP \\
\hline & 67 & 217.6 & 193.0 & 189.0 & ST & BIT & - & 1957 & OP \\
\hline Chusm (Franklin) & 1 & 1.0 & ].1 & 1.1 & HY & Water & - & 1913 & OP \\
\hline & 2 & 1.0 & 1.1 & I.I & $\mathrm{HY}$ & Water & - & 1913 & OP \\
\hline & 3 & 1.4 & 1.5 & 1.5 & HY & Water & - & 1926 & OP \\
\hline Colton (St Lawrence) & 1 & 10.0 & 9.5 & 9.5 & $\mathrm{HY}$ & Water & - & 1962 & OP \\
\hline & 2 & 10.0 & 9.5 & 9.5 & HY & Water & - & 1918 & OP \\
\hline & 3 & 10.0 & 9.5 & 9.5 & HY & Water & - & 1928 & OP \\
\hline Deferiet (Jefferson) & 1 & 3.6 & 3.5 & 3.5 & $\mathrm{HY}$ & Water & - & 1925 & OP \\
\hline & 2 & 3.6 & 3.5 & 3.5 & $\mathrm{HY}$ & Water & - & 1925 & OP \\
\hline & 3 & 3.6 & 3.5 & 3.5 & HY & Water & - & 1925 & OP \\
\hline Dunkitk (Chautauqua) & IC2 & 5 & .5 & 5 & IC & $\mathrm{FO2}$ & - & 1990 & OP \\
\hline & ST4 & 218.0 & 189.5 & 2028 & ST & BIT & - & 1960 & OP \\
\hline & 1 & 96.0 & 95.8 & 91.0 & ST & BIT & - & 1950 & OP \\
\hline & 2 & 96.0 & 99.5 & 92.0 & ST & BIT & - & 1950 & OP \\
\hline & 3 & 218.0 & 196.5 & 207.3 & ST & BIT & - & 1959 & OP \\
\hline E J West (Saratoga) & ] & 10.0 & 9.8 & 9.6 & HY & Water & - & 1930 & OP \\
\hline & 2 & 10.0 & 9.8 & 9.6 & HY & Water & - & 1930 & OP \\
\hline 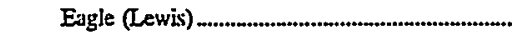 & ] & 1.3 & 1.2 & 1.2 & HY & Water & - & 1914 & OP \\
\hline & 2 & 1.4 & 1.3 & 13 & HY & Water & - & 1915 & OP \\
\hline & 3 & 1.4 & 1.3 & 13 & HY & Water & - & 1919 & OP \\
\hline & 4 & 2.1 & 2.0 & 1.9 & HY & Water & - & 1925 & OP \\
\hline East Norfolk (St Lawrence) & 1 & 3.0 & 3.6 & 3.5 & HY & Water & - & 1928 & $\mathbf{O P}$ \\
\hline Eel Weir (St Lawrence) & 1 & .5 & .4 & .4 & $\mathrm{HY}$ & Water & - & 1928 & OP \\
\hline & 2 & 1.1 & .8 & .8 & $\mathrm{HY}$ & Water & - & 1938 & OP \\
\hline & 3 & 1.1 & $\ddot{8}$ & .8 & HY & Water & - & 1938 & OP \\
\hline 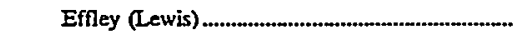 & $\overrightarrow{1}$ & .4 & E. .4 & $E_{.4}$ & $\mathrm{HY}$ & Water & - & 1902 & os \\
\hline & 2 & .4 & .4 & 5 & HY & Water & - & 1907 & OP \\
\hline & 3 & .6 & .6 & .7 & $\mathrm{HY}$ & Water & - & 1910 & OP \\
\hline & 4 & 1.6 & 1.6 & 1.8 & $\mathrm{HY}$ & Water & - & 1923 & OP \\
\hline
\end{tabular}

See footnotes at end of table. 
Table 20. Existing Generating Units at U.S. Electric Utilities by State, Company, and Plant, as of January 1, 1998 (Continued)

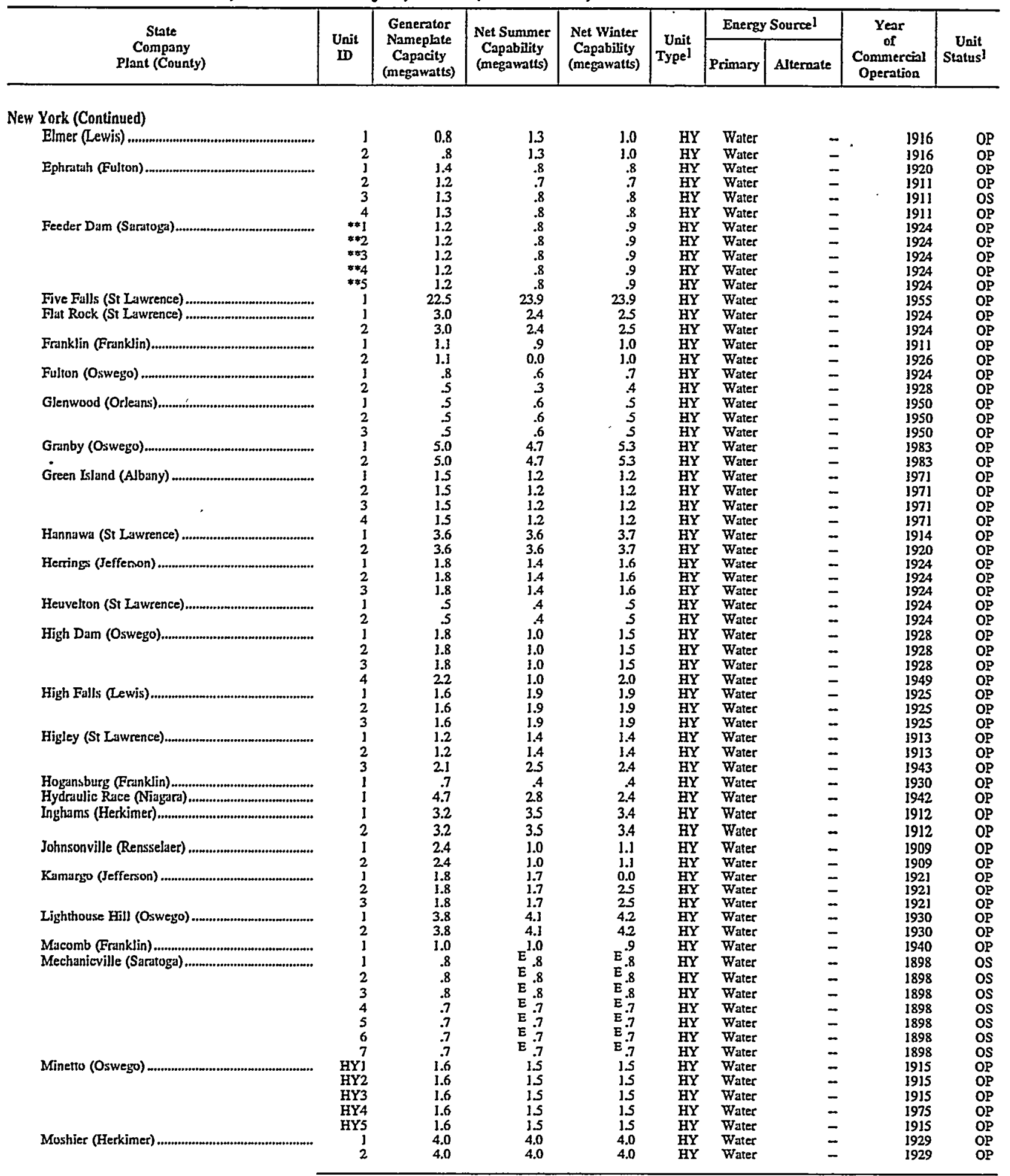

See foornotes at end of table. 
Table 20. Existing Generating Units at U.S. Electric Utilities by State, Company, and Plant, as of January 1, 1998 (Continued)

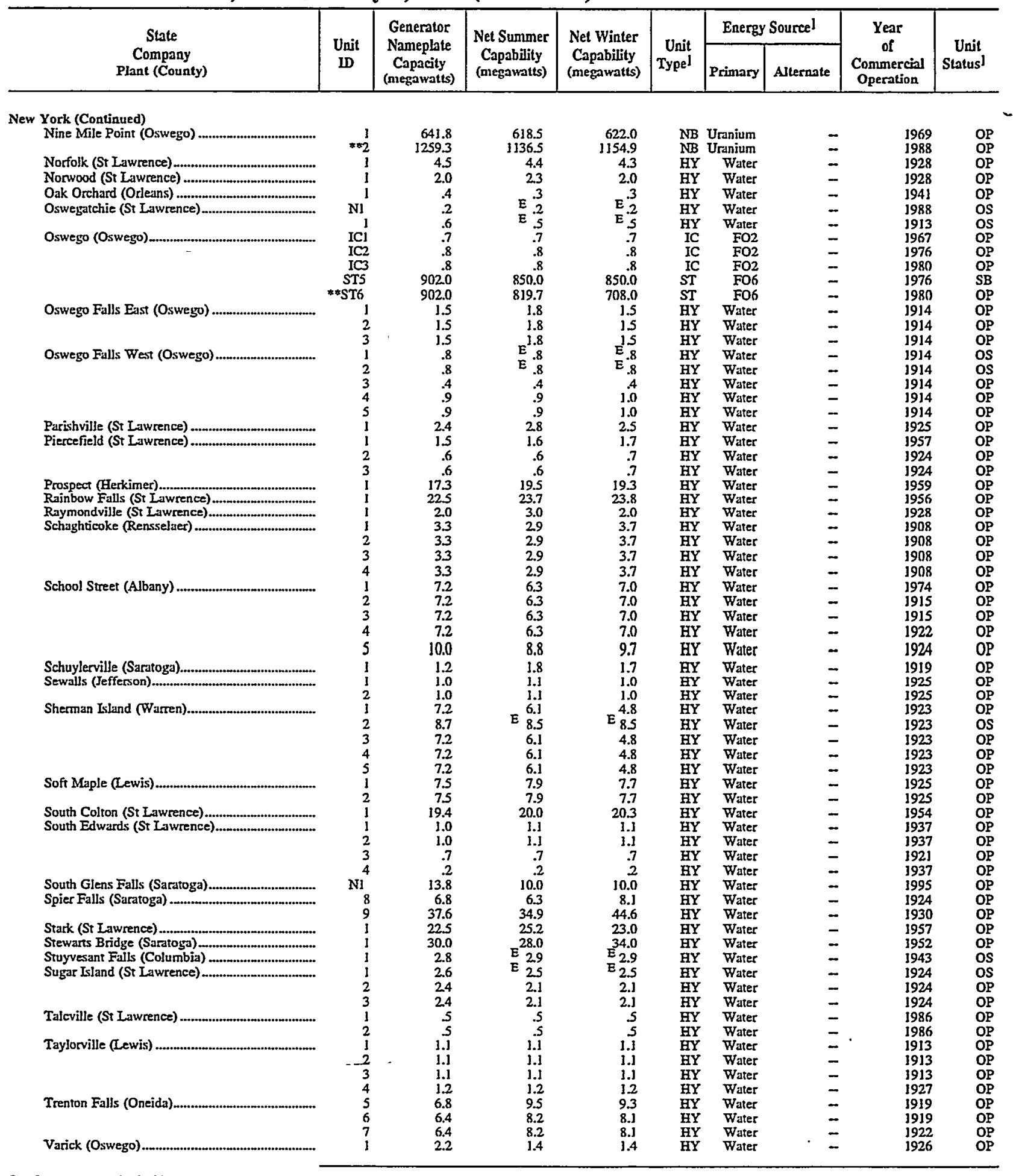

See footnotes at end of table. 
Table 20. Existing Generating Units at U.S. Electric Utilities.by State, Company, and Plant, as of January 1, 1998 (Continued)

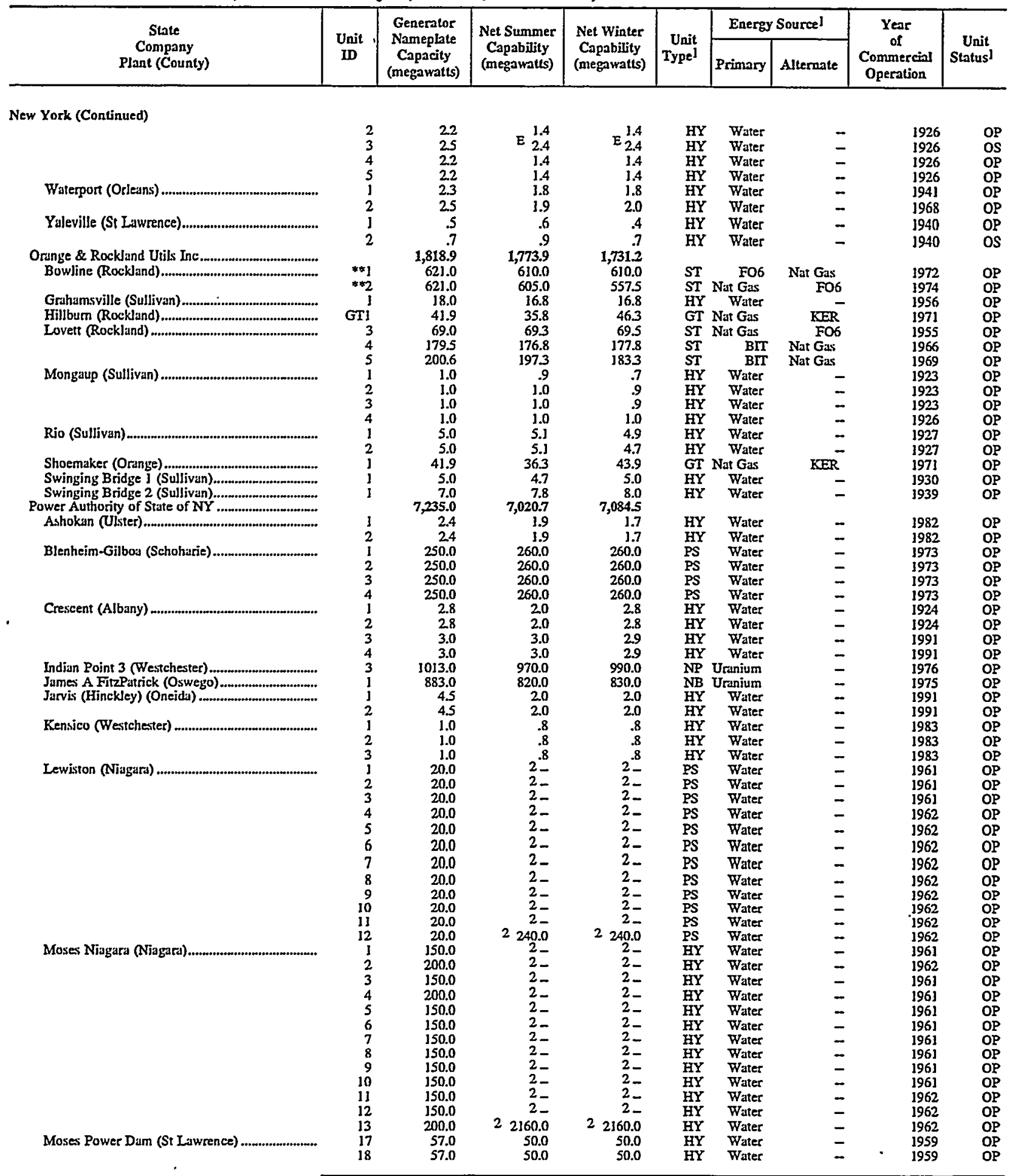

See footnotes at end of table. 
Table 20. Existing Generating Units at U.S. Electric Utilities by State, Company, and Plant, as of January 1, 1998 (Continued)

\begin{tabular}{|c|c|c|c|c|c|c|c|c|c|}
\hline \multirow{2}{*}{$\begin{array}{c}\text { Shate } \\
\text { Company } \\
\text { Plant (County) }\end{array}$} & \multirow{2}{*}{$\begin{array}{c}\text { Unit } \\
\text { ID }\end{array}$} & \multirow{2}{*}{$\begin{array}{c}\text { Generator } \\
\text { Nameplate } \\
\text { Capacity } \\
\text { (megawatts) }\end{array}$} & \multirow{2}{*}{$\begin{array}{l}\text { Net Summer } \\
\text { Capability } \\
\text { (megawatts) }\end{array}$} & \multirow{2}{*}{$\begin{array}{c}\text { Net Winter } \\
\text { Capability } \\
\text { (megawatts) }\end{array}$} & \multirow{2}{*}{$\begin{array}{c}\text { Unit } \\
\text { Typel }\end{array}$} & \multicolumn{2}{|c|}{ Energy Sourcel } & \multirow{2}{*}{$\begin{array}{c}\text { Year } \\
\text { of } \\
\text { Commercial } \\
\text { Operation }\end{array}$} & \multirow{2}{*}{$\begin{array}{c}\text { Unit } \\
\text { Status }\end{array}$} \\
\hline & & & & & & Primary & Alternate & & \\
\hline New York (Continued) & & & & & & & & & \\
\hline & 19 & 57.0 & 50.0 & 50.0 & HY & Water & - & 1959 & OP \\
\hline & 20 & 57.0 & 50.0 & 50.0 & HY & Water & - & 1959 & OP \\
\hline & 21 & 57.0 & 50.0 & 50.0 & $\mathrm{HY}$ & Water & - & 1959 & OP \\
\hline & 23 & 57.0 & 50.0 & 50.0 & $\mathrm{HY}$ & Water & - & 1959 & OP \\
\hline & 24 & 57.0 & 50.0 & 50.0 & $\mathrm{HY}$ & Water & - & 1958 & $O P$ \\
\hline & 25 & 57.0 & 50.0 & 50.0 & $\mathrm{HY}$ & Water & - & 1958 & OP \\
\hline & 26 & 57.0 & 50.0 & 50.0 & $\mathrm{HY}$ & Water & - & 1958 & OP \\
\hline & 27 & 57.0 & 50.0 & 50.0 & $\mathrm{HY}$ & Water & - & 1958 & $\mathrm{OP}$ \\
\hline & 28 & 57.0 & 50.0 & 50.0 & $\mathrm{HY}$ & Water & - & 1958 & $O P$ \\
\hline & 29 & 57.0 & 50.0 & So. 0 & $H Y$ & Water & - & 1958 & OP \\
\hline & 30 & 57.0 & 50.0 & So.0 & HY & Water & - & 1958 & OP \\
\hline & $3 I$ & 57.0 & 50.0 & S0.0 & $\mathrm{HY}$ & Water & - & 1958 & $\mathrm{OP}$ \\
\hline & 32 & 57.0 & So.0 & 50.0 & HY & Water & - & 1958 & OP \\
\hline & NA2 & 56.0 & 48.4 & 52.3 & $C W$ & WH & - & 1994 & OP \\
\hline Vischer Ferry (Saratoga) & 1 & 2.8 & 20 & 2.8 & HY & Water & - & 1924 & OP \\
\hline & 2 & 2.8 & 2.0 & 2.8 & $\mathrm{HY}$ & Water & - & 1924 & OP \\
\hline & 3 & 3.0 & 3.0 & 2.9 & $\mathrm{HY}$ & Water & _ & 199] & OP \\
\hline & 4 & 3.0 & 3.0 & 2.9 & HY & Water & - & 1991 & OP \\
\hline 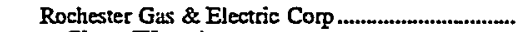 & & 9442 & 902.6 & 910.6 & & & & & \\
\hline 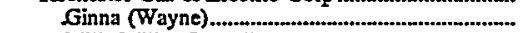 & l & 517.1 & 485.0 & 485.0 & NP & Uranium & - & 1970 & OP \\
\hline Mills Mills 172 (Allegany) & J & .2 & .2 & .2 & $\mathrm{HY}$ & Water & - & 1925 & OP \\
\hline 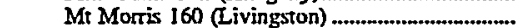 & j & .3 & 3 & .3 & $\mathrm{HY}$ & Water & - & 1916 & OP \\
\hline Rochester 2 (Monroe) & i & 6.5 & 6.0 & 6.0 & HY & Water & - & 1960 & OP \\
\hline 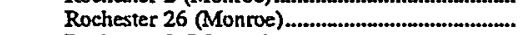 & l & 3.0 & 2.0 & 2.0 & $\mathrm{HY}$ & Water & - & 1952 & OP \\
\hline Rochester 3 (Monroe) & 12 & 81.6 & 80.0 & 80.0 & ST & BIT & - & 1959 & OP \\
\hline & 13 & 19.0 & 14.0 & 18.0 & GT & FO2 & - & 1969 & OP \\
\hline Rochester 5 (Monroe) & HYI & 12.9 & 11.0 & 14.0 & HY & Water & - & 1927 & OP \\
\hline & HY3 & 18.0 & 17.0 & 17.0 & $\mathrm{HY}$ & Water & - & 1918 & OP \\
\hline & 2 & 12.9 & 11.0 & 12.0 & $\mathrm{HY}$ & Water & - & 1918 & OP \\
\hline Rochester 7 (Monroe) & $\vec{j}$ & 46.0 & 47.0 & 47.0 & ST & BIT & - & 1948 & OP \\
\hline & 2 & 62.5 & 68.0 & 65.0 & ST & BII & - & 1950 & OP \\
\hline & 3 & 62.5 & 65.0 & 65.0 & ST & BII & - & 1953 & OP \\
\hline & 4 & 81.6 & 80.0 & 80.0 & ST & BIT & - & 1957 & OP \\
\hline Rochester 9 (Monroe) & 2 & 19.0 & 15.0 & 18.0 & GT & Nat Gas & - & 1969 & OP \\
\hline Charles $P$, keller (Nassau) & 7 & 2.0 & 2.0 & 2.0 & IC & $\mathrm{FO} 2$ & - & 1942 & OP \\
\hline & 8 & 27 & 2.7 & 2.7 & IC & $\mathrm{FO} 2$ & - & 1950 & OP \\
\hline & 9 & 3.2 & 3.2 & 3.2 & IC & $\mathrm{FO} 2$ & Nat Gas & 1954 & OP \\
\hline & 10 & 3.2 & 3.2 & 3.2 & IC & $\mathrm{FO} 2$ & Nat Gas & 3954 & OP \\
\hline & ]1 & 5.2 & 5.2 & 5.2 & IC & $\mathrm{FO2}$ & Nat Gas & 1962 & OP \\
\hline & 12 & 5.5 & 5.5 & 5.5 & IC & FO2 & Nat Gas & 3967 & OP \\
\hline & 13 & 5.5 & 5.5 & 5.5 & IC & FO2 & Nat Gas & 1974 & $\mathrm{OP}$ \\
\hline & 14 & 6.2 & 6.2 & 6.2 & IC & $\mathrm{FO} 2$ & Nat Gas & 1994 & OP \\
\hline Springville Village of & & .6 & 5 & 5 & & & & & \\
\hline Springville (Cattaraugus) & I & 3 & 3 & 3 & HY & Water & - & 1925 & OP \\
\hline & 2 & .3 & 3 & 3 & $\mathrm{HY}$ & Water & - & 1924 & OP \\
\hline Watertown City of & & 5.4 & 5.4 & 5.4 & & & & & \\
\hline City of Watertown (Jefferson). & 1 & 1.8 & 1.8 & 1.8 & $\mathbf{H Y}$ & Water & - & 1924 & OP \\
\hline & 2 & 1.8 & 1.8 & 1.8 & $\mathbf{H Y}$ & Water & ـ & 1924 & OP \\
\hline & 3 & 1.8 & 1.8 & 1.8 & $\mathbf{H Y}$ & Water & - & 1924 & OP \\
\hline North Carolinn & & & & & & & & & \\
\hline 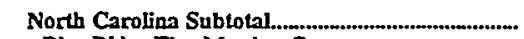 & & $21,964.2$ & $21,054.2$ & $21,591.2$ & & & & & \\
\hline 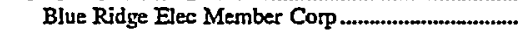 & & 2 & 2 & 2 & & & & & \\
\hline Sharp Falls (Ashe) & 1 & & .2 & & HY & Water & - & 1931 & OP \\
\hline 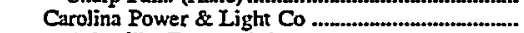 & & $8,774.6$ & $8,279.0$ & $8,467.0$ & & & & & \\
\hline 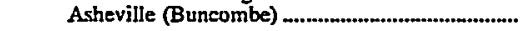 & 1 & 206.6 & 198.0 & 200.0 & ST & BIT & - & 1964 & $O P$ \\
\hline & 2 & 207.0 & 194.0 & 194.0 & ST & BIT & - & 1971 & $O P$ \\
\hline 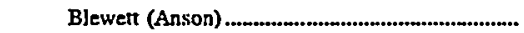 & GT1 & 17.5 & 13.0 & 17.0 & GT & $\mathrm{FO} 2$ & - & 1971 & OP \\
\hline & GT2 & 17.5 & 13.0 & 17.0 & GT & $\mathrm{FO} 2$ & - & 1971 & $O P$ \\
\hline & GT3 & 17.5 & 13.0 & 17.0 & GT & $\mathrm{FO} 2$ & - & 1971 & $O P$ \\
\hline & GT4 & 17.5 & 13.0 & 37.0 & GT & FO2 & - & 1971 & OP \\
\hline & 1 & 3.2 & 3.3 & 4.2 & $\mathrm{HY}$ & Water & - & 1912 & OP \\
\hline & 2 & 3.2 & 3.3 & 4.2 & $\mathrm{HY}$ & Water & - & 1912 & OP \\
\hline
\end{tabular}

See footnotes at end of table. 
Table 20. Existing Generating Units at U.S. Electric Utilities by State, Company, and Plant, as of January 1, 1998 (Continued)

\begin{tabular}{|c|c|c|c|c|c|c|c|c|c|}
\hline \multirow{2}{*}{$\begin{array}{c}\text { State } \\
\text { Company } \\
\text { Plant (County) }\end{array}$} & \multirow{2}{*}{$\begin{array}{l}\text { Unit } \\
\text { WD }\end{array}$} & \multirow{2}{*}{$\begin{array}{c}\text { Generator } \\
\text { Nameplate } \\
\text { Capacity } \\
\text { (megawalts) }\end{array}$} & \multirow{2}{*}{$\begin{array}{l}\text { Net Summer } \\
\text { Capability } \\
\text { (megawatts) }\end{array}$} & \multirow{2}{*}{$\begin{array}{l}\text { Net Winter } \\
\text { Capability } \\
\text { (megawatts) }\end{array}$} & \multirow{2}{*}{$\begin{array}{c}\text { Unit } \\
\text { Typel }\end{array}$} & \multicolumn{2}{|c|}{ Energy Sourcel } & \multirow{2}{*}{$\begin{array}{c}\text { Year } \\
\text { of } \\
\text { Commercinl } \\
\text { Operation }\end{array}$} & \\
\hline & & & & & & Primary & Alternate & & Stalus ${ }^{l}$ \\
\hline North Carolina (Continued) & & & & & & & & & \\
\hline & 3 & 3.2 & 3.4 & 4.2 & HY & Water & - & $\cdot 1912$ & OP \\
\hline & 4 & 5.0 & 4.0 & 42 & HY & Water & - & 1912 & OP \\
\hline & 5 & 5.0 & 4.0 & 4.2 & HY & Water & - & 1912 & OP \\
\hline & 6 & 5.0 & 4.0 & 4.2 & HY & Water & - & 1912 & OP \\
\hline 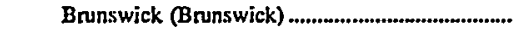 & $* * 1$ & 895.0 & 820.0 & 820.0 & NB & Uranium & - & 1977 & OP \\
\hline & $* \approx 2$ & 895.0 & 811.0 & 811.0 & NB & Uranium & - & 1975 & OP \\
\hline Cape Fear (Chatham) & $1 \mathbf{A}$ & 18.0 & 14.0 & 18.0 & CT & $\mathrm{FO} 2$ & - & 1969 & OP \\
\hline & $1 \mathrm{~B}$ & $\begin{array}{l}18.0 \\
18.0\end{array}$ & $\begin{array}{l}14.0 \\
14.0\end{array}$ & $\begin{array}{l}18.0 \\
18.0\end{array}$ & CT & $\mathrm{FO2}$ & - & 1969 & $\begin{array}{l}\text { OP } \\
\text { OP }\end{array}$ \\
\hline & $2 B$ & 18.0 & $\begin{array}{l}14.0 \\
14.0\end{array}$ & $\begin{array}{l}18.0 \\
18.0\end{array}$ & $\begin{array}{l}C T \\
C T\end{array}$ & $\begin{array}{l}\mathrm{FO} 2 \\
\mathrm{FO2}\end{array}$ & Z & $\begin{array}{l}1969 \\
1969\end{array}$ & $\begin{array}{l}\text { OP } \\
\text { OP }\end{array}$ \\
\hline & J & 15.0 & 14.0 & 17.0 & $C W$ & WH & 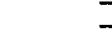 & $\begin{array}{l}1909 \\
1923\end{array}$ & OP \\
\hline & 2 & 15.0 & 34.0 & 17.0 & $C W$ & WH & - & 1924 & OP \\
\hline - & 5 & 140.6 & 143.0 & 348.0 & ST & BIT & - & 1956 & $O P$ \\
\hline & 6 & $\mathrm{~J} 63.3$ & 173.0 & 375.0 & ST & BIT & - & 1958 & OP \\
\hline Harris (Wake) & **I & 951.0 & 860.0 & 860.0 & NP & Uranium & - & 1987 & OP \\
\hline L V Sunon (New Hanover) & GTA & 37.5 & 26.0 & 33.0 & GT & $\mathrm{FO} 2$ & - & 1969 & OP \\
\hline & GTB & 37.5 & 25.0 & 33.0 & GT & FO2 & - & 1969 & OP \\
\hline & GTI & 16.3 & 13.0 & 18.0 & GT & $\mathrm{FO} 2$ & - & 1968 & OP \\
\hline & 1 & 103.5 & 97.0 & 305.0 & ST & BIT & - & 1954 & OP \\
\hline & 2 & 103.5 & 106.0 & 108.0 & ST & BIT & - & 1955 & OP \\
\hline & 3 & 446.6 & 410.0 & 416.0 & ST & BIT & - & 1972 & $O P$ \\
\hline Lee (Wayne) & GTI & 16.3 & 14.0 & 18.0 & GT & FO2 & - & 1968 & OP \\
\hline & GT2 & 30.0 & 27.0 & 320 & GT & FO2 & - & 1971 & OP \\
\hline & GT3 & 30.0 & 25.0 & 320 & GT & FO2 & - & 1971 & OP \\
\hline & GT4 & 30.0 & 25.0 & 32.0 & GT & $\mathrm{FO} 2$ & - & 1971 & OP \\
\hline & 1 & 75.0 & 79.0 & 84.0 & ST & BIT & - & 1952 & OP \\
\hline & 2 & 75.0 & 76.0 & 80.0 & ST & BIT & - & 1951 & OP \\
\hline & 3 & 252.5 & 252.0 & 257.0 & ST & BIT & - & 1962 & $\mathrm{OP}$ \\
\hline Marshall (Madison) & $\mathrm{HCl}$ & 2.5 & 2.5 & 2.5 & $\mathrm{HY}$ & Water & - & 3985 & OP \\
\hline - & $\mathrm{HC2}$ & 2.5 & 2.5 & 25 & $\hat{H Y}$ & Water & - & 1985 & $\mathrm{OP}$ \\
\hline Miyo (Pesson) & $=* \pi !$ & 735.8 & 745.0 & 750.0 & ST & BIT & - & 3983 & OP \\
\hline 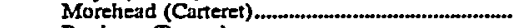 & GTI & 16.3 & 15.0 & 18.0 & GI & FO2 & - & 1968 & OP \\
\hline Roxboro (Person) & GT! & 16.3 & 15.0 & 18.0 & GT & FO2 & . & 1968 & OP \\
\hline & 1 & 410.9 & 385.0 & 390.0 & ST & BIT & - & 1966 & $O P$ \\
\hline & 2 & 657.0 & 670.0 & 675.0 & ST & BIT & - & 1968 & OP \\
\hline & 3 & 745.2 & 707.0 & 715.0 & ST & BIT & - & 1973 & OP \\
\hline & $* * 4$ & .745 .2 & 700.0 & 710.0 & ST & BIT & - & 1980 & $O P$ \\
\hline Tillery (Montgomery) & I & 22.0 & 21.0 & 21.0 & HY & Water & - & 1928 & OP \\
\hline & 2 & 18.0 & 18.5 & 18.5 & EY & Water & - & 1928 & $O P$ \\
\hline & 3 & 220 & 21.0 & 21.0 & $\mathbf{H Y}$ & Water & - & 1928 & OP \\
\hline & 4 & 220 & 25.5 & 25.5 & FY & Water & & 1960 & OP \\
\hline 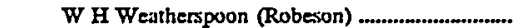 & GTI & 39.7 & 35.0 & 42.0 & GT & $\mathrm{FO} 2$ & Nat Gas & 1970 & OP \\
\hline & GT2 & 39.7 & 35.0 & 42.0 & GT & FO2 & Nat Gas & 1970 & OP \\
\hline & GT3 & 48.6 & 34.0 & 42.0 & GT & $\mathrm{FO2}$ & Nat Gas & 1971 & OP \\
\hline & GT4 & 48.6 & 34.0 & 42.0 & GT & $\mathrm{FO2}$ & Nat Gas & 1971 & OP \\
\hline & 1 & 46.0 & 49.0 & 49.0 & ST & BIT & 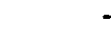 & 1949 & OP \\
\hline & 2 & 46.0 & 49.0 & 49.0 & ST & BIT & - & 1950 & OP \\
\hline & 3 & 73.5 & 78.0 & 79.0 & ST & BIT & . & 1952 & OP \\
\hline 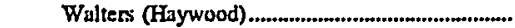 & 1 & 36.0 & 35.0 & 33.3 & HY & Water & - & 1930 & OP \\
\hline & 2 & 36.0 & 35.0 & 333 & HY & Water & - & 1930 & OP \\
\hline & 3 & 36.0 & 35.0 & 333 & HY & Water & - & 1930 & OP \\
\hline Caseade Power Co & & .8 & 8 & .8 & & & & & \\
\hline 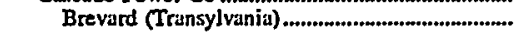 & 1 & .4 & .4 & .4 & HY & Water & - & 1922 & OP \\
\hline & 2 & & .4 & .4 & HY & Water & - & 1931 & OP \\
\hline Duke Power Co & & $12,060.4$ & $11,590.4$ & $11,974.4$ & & & & & \\
\hline Belews Creek (Stokes) & 1 & 1080.1 & 1120.0 & 1120.0 & ST & BIT & & 1974 & OP \\
\hline & 2 & 1080.1 & 1120.0 & 1120.0 & ST & BIT & - & 1975 & $\mathrm{OP}$ \\
\hline Bridgewater (Burke) & 1 & 10.0 & 11.5 & 11.5 & $\mathrm{HY}$ & Waier & - & 1919 & oP \\
\hline & 2 & 10.0 & 11.5 & 11.5 & HY & Water & - & 1919 & OP \\
\hline Buck (Rowan) & 3 & 80.0 & 75.0 & 75.0 & ST & BIT & - & 1941 & $O P$ \\
\hline & 4 & 40.0 & 38.0 & 38.0 & ST & BII & & 1942 & $O P$ \\
\hline & 5 & 125.0 & 128.0 & 128.0 & ST & BII & . & 1953 & OP \\
\hline & 6 & 125.0 & 128.0 & 128.0 & ST & BIT & - & 1953 & OP \\
\hline & 7 & 34.9 & 31.0 & 31.0 & GT & FO2 & Nat Gas & 1970 & $\mathrm{OP}$ \\
\hline & 8 & 34.9 & 31.0 & 31.0 & GT & $\mathrm{FO} 2$ & Nat Gas & 1970 & OP \\
\hline & 9 & 34.9 & 31.0 & 31.0 & GT & $\mathrm{FO} 2$ & Nat Gas & 1970 & OP \\
\hline 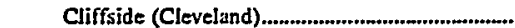 & j & 40.0 & 38.0 & 38.0 & ST & BIT & - & 1940 & OP \\
\hline & 2 & 40.0 & 38.0 & 38.0 & ST & BIT & . & 1940 & $O P$ \\
\hline & 3 & 65.0 & 61.0 & 61.0 & ST & BIT & - & 1948 & OP \\
\hline & 4 & 65.0 & 61.0 & 61.0 & ST & BIT & . & 1948 & OP \\
\hline
\end{tabular}

See footnotes at end of table. 
Table 20. Existing Generating Units at U.S. Electric Utilities by State, Company, and Plant, as of January 1, 1998 (Continued)

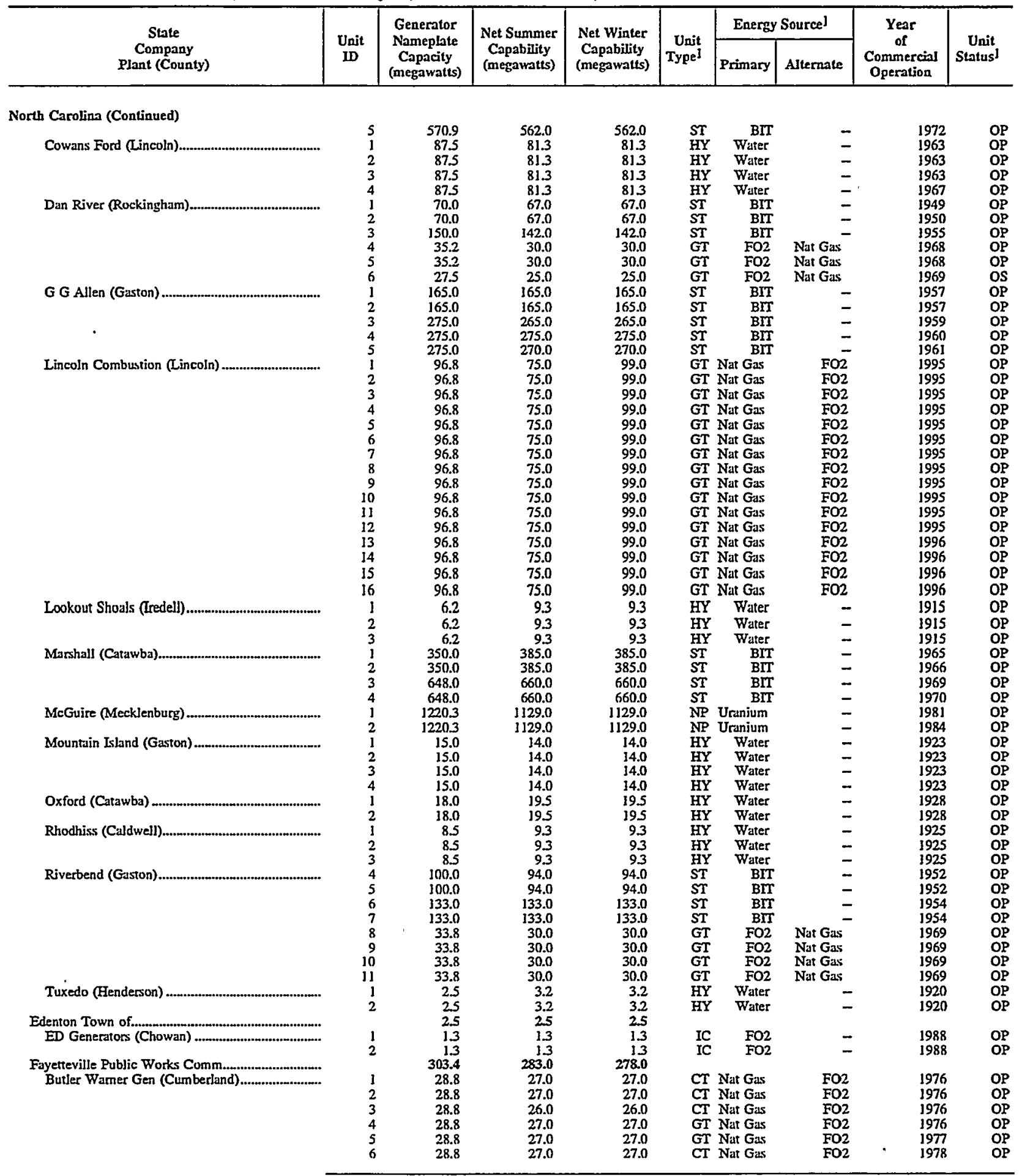

See footnotes at end of table. 
Table 20. Existing Generating Units at U.S. Electric Utilities by State, Company, and Plant, as of January 1, 1998 (Continued)

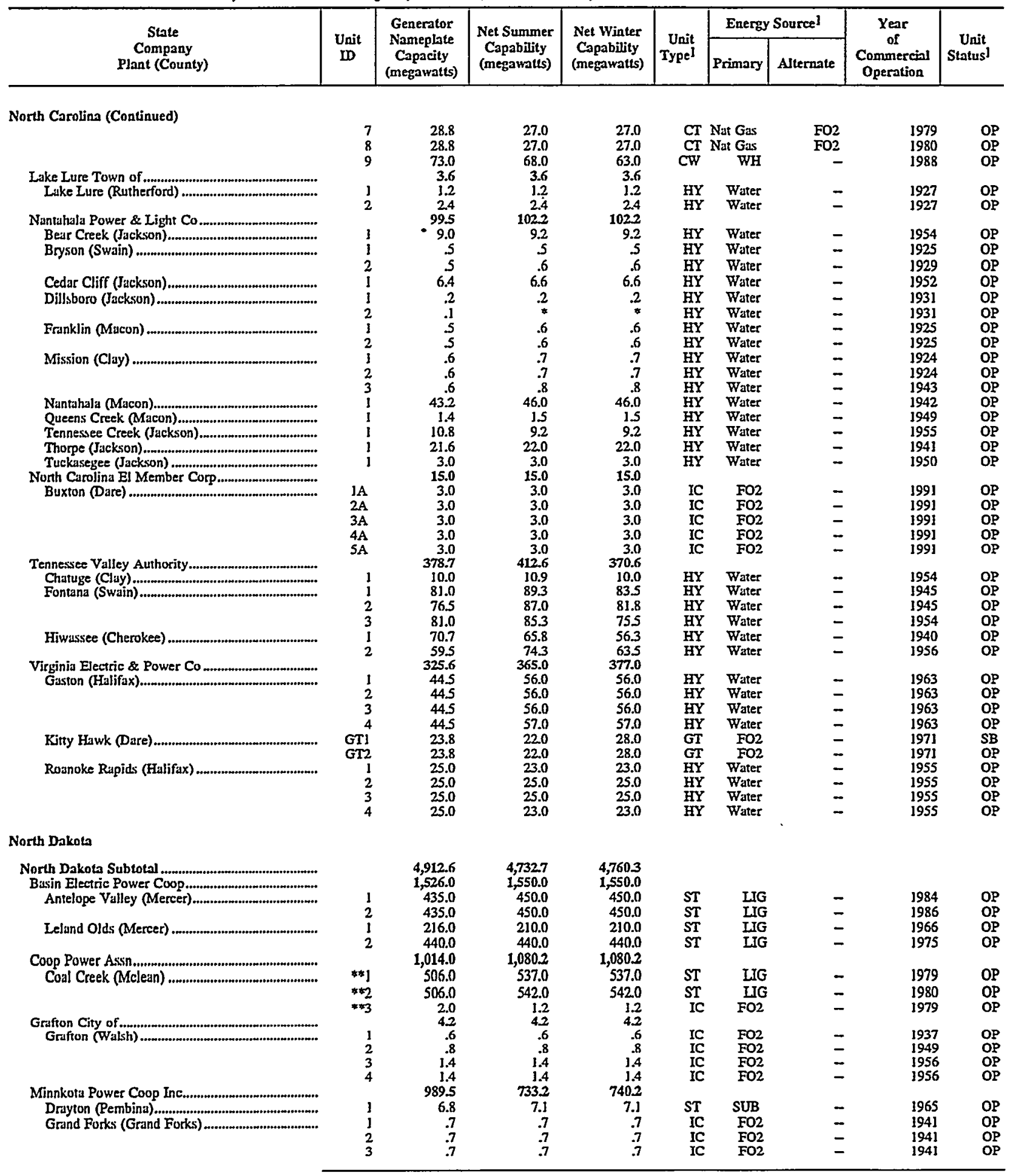

See footnotes at end of table. 
Table 20. Existing Generating Units at U.S. Electric Utilities by State, Company, and Plant, as of January 1, 1998 (Continued)

\begin{tabular}{|c|c|c|c|c|c|c|c|c|c|}
\hline \multirow{2}{*}{$\begin{array}{c}\text { State } \\
\text { Company } \\
\text { PInnt (County) }\end{array}$} & \multirow{2}{*}{$\begin{array}{l}\text { Unit } \\
\text { ID }\end{array}$} & \multirow{2}{*}{$\begin{array}{l}\text { Generator } \\
\text { Nameplate } \\
\text { Capacity } \\
\text { (megawatts) }\end{array}$} & \multirow{2}{*}{$\begin{array}{c}\text { Net Summer } \\
\text { Capability } \\
\text { (megawatts) }\end{array}$} & \multirow{2}{*}{$\begin{array}{c}\text { Net Winter } \\
\text { Capability } \\
\text { (megawatts) }\end{array}$} & \multirow{2}{*}{$\begin{array}{c}\text { Unit } \\
\text { Typel }\end{array}$} & \multicolumn{2}{|c|}{ Energy Source! } & \multirow{2}{*}{$\begin{array}{c}\text { Year } \\
\text { of } \\
\text { Commercin } \\
\text { Operation }\end{array}$} & \multirow{2}{*}{$\begin{array}{c}\text { Unit } \\
\text { StatusI }\end{array}$} \\
\hline & & & & & & Primary & Alternate & & \\
\hline \multicolumn{10}{|l|}{ North Dakota (Continued) } \\
\hline & 4 & 1.0 & 1.0 & 1.0 & IC & $\mathrm{FO} 2$ & - & 1946 & OP \\
\hline & 5 & 1.0 & 1.0 & 1.0 & IC & $\mathrm{FO} 2$ & - & 1946 & $O P$ \\
\hline & 6 & 1.0 & 1.0 & 1.0 & IC & $\mathrm{FO} 2$ & - & 1946 & OP \\
\hline & 7 & 1.] & 1.1 & 1.1 & IC & $\mathrm{FO} 2$ & - & 1949 & $\mathrm{OP}$ \\
\hline & 8 & 1.] & 1.1 & 1.1 & IC & F02 & - & 1949 & OP \\
\hline & 9 & 1.1 & 1.1 & 1.1 & IC & $\mathrm{FO} 2$ & - & 1949 & OP \\
\hline & 10 & I.J & i.j & j.j & IC & $\mathrm{FO} 2$ & - & 1949 & OP \\
\hline & 11 & I.j. & 1.1 & 1.1 & IC & $\mathrm{FO} 2$ & - & 1949 & $O P$ \\
\hline Hanwood (Cass) ............. & 1 & 1.6 & 1.5 & 1.5 & IC & $\mathrm{FO2}$ & $\bar{z}$ & 1947 & $\begin{array}{ll}O P P \\
O P\end{array}$ \\
\hline & 3 & 1.6 & 1.6 & 1.6 & IC & $\mathrm{FO} 2$ & - & 1947 & $O P$ \\
\hline 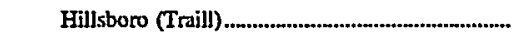 & 1 & 13.3 & 13.3 & 13.3 & ST & suB & - & 1986 & $O P$ \\
\hline Milton R Young (Oliver)........................................ & 1 & 477.0 & 250.0 & 250.0 & ST & LIG & - & 1970 & OP \\
\hline & $* 2$ & 477.0 & 448.0 & 455.0 & ST & $\overline{\text { LIG }}$ & - & 1977 & OP \\
\hline \multirow{2}{*}{\multicolumn{10}{|c|}{ 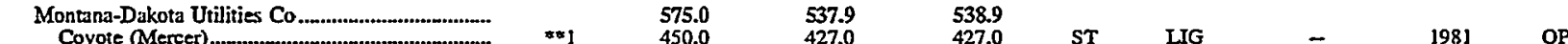 }} \\
\hline & $=1$ & 450.0 & 427.0 & 427.0 & ST & LIG & - & 1981 & OP \\
\hline 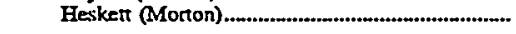 & 1 & 40.0 & 28.4 & 28.4 & ST & IIG & - & 1954 & OP \\
\hline & 2 & 75.0 & 73.6 & 73.6 & ST & LIG & - & 1963 & OP \\
\hline Williston (Williams) …….......................................... & 2 & 5.0 & 4.5 & 5.0 & GT & Nat Gas & - . & 1953 & OP \\
\hline & 3 & 5.0 & 4.5 & 5.0 & GT & Nat Gas & - & 1953 & OP \\
\hline Nodak Electric Coop Inc. ................................................ & & .5 & 5 & 5 & & & & & \\
\hline Mobile (Grand Forks) & 2 & .4 & .4 & .4 & IC & $\mathrm{FO} 2$ & - & 1959 & OP \\
\hline 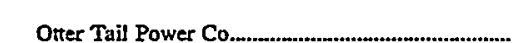 & 4 & 48.1 & 4.15 & 58.1 & IC & FO2 & - & 1977 & OP \\
\hline Jamestown (Stutsman) & 1 & 24.1 & 20.6 & 29.3 & GT & $\mathrm{FO} 2$ & - & 1976 & OP \\
\hline & 2 & $\begin{array}{r}24.1 \\
235.5\end{array}$ & 20.9 & 29.4 & GT & $\mathrm{FO} 2$ & - & 1978 & OP \\
\hline $\begin{array}{l}\text { United Power Assn } \\
\text { Standard Station (Mercer) }\end{array}$ & 1 & 235.5 & 237.5 & 239.9 & & & & & \\
\hline & $\frac{1}{2}$ & $\begin{array}{r}88.0 \\
48.0\end{array}$ & $\begin{array}{r}385.1 \\
52.4\end{array}$ & $\begin{array}{r}187.5 \\
52.4\end{array}$ & $\begin{array}{l}\text { ST } \\
\text { ST }\end{array}$ & $\begin{array}{l}\text { LIG } \\
\text { FOl }\end{array}$ & $\overline{-}$ & $\begin{array}{l}1967 \\
1967\end{array}$ & $\begin{array}{l}\text { OP } \\
\text { OP }\end{array}$ \\
\hline 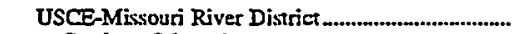 & & 517.0 & 545.0 & 545.0 & & & & & \\
\hline 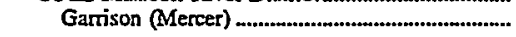 & 1 & 109.0 & 109.0 & 109.0 & HY & Water & - & 1956 & OP \\
\hline & 2 & 109.0 & 309.0 & 109.0 & $\mathrm{HY}$ & Water & - & 1956 & OP \\
\hline & 3 & 109.0 & 309.0 & 109.0 & $\mathrm{HY}$ & Water & - & 1956 & $O P$ \\
\hline & 4 & 95.0 & 109.0 & 109.0 & HY & Water & - & 1960 & OP \\
\hline & 5 & 95.0 & 309.0 & 309.0 & HY & Water & - & 1960 & OP \\
\hline 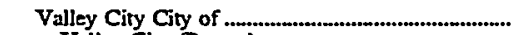 & & 2.7 & 27 & 2.7 & & & & & \\
\hline Valley City (Bames) & IC] & 1.4 & 1.4 & 1.4 & IC & FO2 & - & 1962 & SB \\
\hline & IC2 & 1.4 & 1.4 & 1.4 & IC & FO2 & - & 1962 & SB \\
\hline Ohio & & & & & & & & & \\
\hline Ohio Subtotal............................. & & $28,592.0$ & $26,629.6$ & $27,310.9$ & & & & & \\
\hline American Mun Power-Ohio Inc......................... & & 213.2 & 212.3 & 2123 & & & & & \\
\hline Richard Gorsuch (Washington) & & & 53.0 & 53.0 & & BIT & - & 1988 & \\
\hline & $\approx 2$ & 53.3 & 53.0 & 53.0 & ST & BIT & - & 1988 & $O P$ \\
\hline & **3 & 53.3 & 53.0 & 53.0 & ST & $\mathrm{BIT}$ & - & 1988 & OP \\
\hline & $* *_{4}$ & 53.3 & 53.3 & 53.3 & ST & BIT & - & 1988 & $\mathrm{OP}$ \\
\hline Arcanum City of & & 13 & 13 & 13 & & & & & \\
\hline Arcanum (Darke) ........................ & 1 & .8 & .8 & .8 & IC & $\mathrm{FO} 2$ & - & 1951 & OP \\
\hline & 2 & .6 & .6 & .6 & IC & $\mathrm{FO} 2$ & - & 1946 & OP \\
\hline Bowling Green City of ............... & & 8.8 & 8.8 & 8.8 & & & & & \\
\hline Bowling Green (Wood) ........................ & 1 & 1.6 & 1.6 & 1.6 & GT & $\mathrm{FO} 2$ & - & 1993 & $\mathrm{OP}$ \\
\hline & 2 & 7.2 & 7.2 & 7.2 & GT & $\mathrm{FO} 2$ & - & 1995 & OP \\
\hline 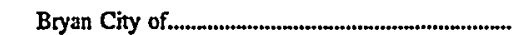 & & 43.8 & 44.4 & 44.4 & & & & & \\
\hline Auglaize Hydro (Defrance) & 1 & .7 & .7 & .7 & HY & Water & - & 1986 & $\mathrm{OP}$ \\
\hline & 2 & 1.0 & 1.0 & 1.0 & $\mathrm{HY}$ & Water & - & 1986 & os \\
\hline & 3 & 1.4 & 1.3 & 13 & $\mathrm{HY}$ & Water & - & 1992 & $\mathrm{OP}$ \\
\hline & 4 & .7 & .7 & .7 & HY & Water & - & 1987 & $O P$ \\
\hline & $s$ & .7 & .7 & $\ddot{7}$ & $\mathrm{HY}$ & Water & - & 1988 & OP \\
\hline Bryan (Williams) & 1 & 15.8 & 16.0 & 16.0 & GT & Nat Gas & $\mathrm{FO} 2$ & 1970 & $O P$ \\
\hline & 2 & 16.0 & 16.0 & 16.0 & GT & Nat Gas & $\mathrm{FO} 2$ & 1988 & OP \\
\hline & 5 & 25 & 2.0 & 2.0 & IC & FO2 & - & 1948 & OP \\
\hline & 6 & 5.0 & 6.0 & 6.0 & GT & Nat Gas & $\mathrm{FO2}$ & 1963 & OP \\
\hline Cardinal Operating $\mathrm{Co}_{0}$ & & $1,880.5$ & $1,800.0$ & $1,830.0$ & & & & & \\
\hline 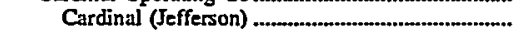 & $* * 1$ & & 585.0 & 600.0 & ST & BIT & - & 1967 & OP \\
\hline & $\rightarrow 2$ & 615.2 & 585.0 & 600.0 & ST & BIT & - & 1967 & OP \\
\hline & $=\$ 3$ & 650.0 & 630.0 & 630.0 & ST & BIT & - & 1977 & $O P$ \\
\hline Cineinnati Gas \& EJectric Co & & $4,808.2$ & 4,5024 & $4,726.1$ & & & & & \\
\hline 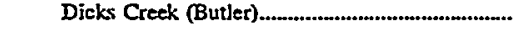 & $\frac{1}{3}$ & $\begin{array}{r}100.0 \\
16.5\end{array}$ & $\begin{array}{l}920 \\
14.2\end{array}$ & $\begin{array}{r}110.0 \\
195\end{array}$ & $\underset{G T}{J E}$ & $\begin{array}{l}\text { Nat Gas } \\
\text { Nat Gass }\end{array}$ & $\begin{array}{l}\mathrm{FO} 2 \\
\mathrm{FO} 2\end{array}$ & $\begin{array}{l}1965 \\
1969\end{array}$ & $\begin{array}{l}O P \\
O P\end{array}$ \\
\hline
\end{tabular}

See footnotes at end of table. 
Table 20. Existing Generating Units at U.S. Electric Utilities by State, Company, and Plant, as of January 1, 1998 (Continued)

\begin{tabular}{|c|c|c|c|c|c|c|c|c|c|}
\hline \multirow{2}{*}{$\begin{array}{c}\text { State } \\
\text { Company } \\
\text { Plant (County) }\end{array}$} & \multirow{2}{*}{$\begin{array}{l}\text { Unit } \\
\text { ID }\end{array}$} & \multirow{2}{*}{$\begin{array}{l}\text { Generator } \\
\text { Nameplate } \\
\text { Capacity } \\
\text { (megawatts) }\end{array}$} & \multirow{2}{*}{$\begin{array}{l}\text { Net Summer } \\
\text { Capability } \\
\text { (megawatts) }\end{array}$} & \multirow{2}{*}{$\begin{array}{l}\text { Net Winter } \\
\text { Capability } \\
\text { (megawatts) }\end{array}$} & \multirow{2}{*}{$\begin{array}{c}\text { Unit } \\
\text { Type! }\end{array}$} & \multicolumn{2}{|c|}{ Eaergy Sourcel } & \multirow{2}{*}{$\begin{array}{c}\text { Year } \\
\text { of } \\
\text { Commercial } \\
\text { Operation }\end{array}$} & \multirow{2}{*}{$\begin{array}{c}\text { Unit } \\
\text { Status] }\end{array}$} \\
\hline & & & & & & Primary & Alternate & & \\
\hline Ohio (Continued) & & & & & & & & & \\
\hline & 4 & 21.3 & 15.0 & 21.4 & GT & FO2 & - & 1969 & OP \\
\hline Miami Fort (Hamilton) & 5 & $\begin{array}{l}21.3 \\
165\end{array}$ & $\begin{array}{l}15.0 \\
142\end{array}$ & $\begin{array}{l}21.4 \\
19.5\end{array}$ & $G T$ & FO2 & - & 1969 & OP \\
\hline 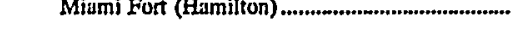 & GT4 & $\begin{array}{l}16.5 \\
16.5\end{array}$ & $\begin{array}{l}14.2 \\
14.2\end{array}$ & $\begin{array}{l}19.5 \\
19.5\end{array}$ & $\begin{array}{l}\text { GT } \\
\text { GT }\end{array}$ & $\begin{array}{l}\mathrm{FO} 2 \\
\mathrm{FO} 2\end{array}$ & $\overline{-}$ & $\begin{array}{l}1971 \\
1971\end{array}$ & $\begin{array}{l}O P \\
O P\end{array}$ \\
\hline & GT5 & $\mathrm{j} 6.5$ & 14.2 & 19.5 & GT & $\mathrm{FO} 2$ & - & 1971 & OP \\
\hline ' & GT6 & 16.5 & 14.2 & 19.5 & GT & FO2 & - & 1971 & OP \\
\hline & $\begin{array}{l}5 \\
6\end{array}$ & $\begin{array}{l}100.0 \\
168.0\end{array}$ & $\begin{array}{r}80.0 \\
163.0\end{array}$ & $\begin{array}{r}80.0 \\
163.0\end{array}$ & $\begin{array}{l}\text { ST } \\
\text { ST }\end{array}$ & $\begin{array}{l}\text { BIT } \\
\text { BII }\end{array}$ & $\overline{-}$ & $\begin{array}{l}1949 \\
1960\end{array}$ & $\begin{array}{l}O P \\
O P\end{array}$ \\
\hline & $\Rightarrow 7$ & 512.1 & 500.0 & 500.0 & ST & BII & $\overline{-}$ & 1975 & OP \\
\hline & $\approx * 8$ & 512.2 & 500.0 & 500.0 & ST & BIT & - & 1978 & OP \\
\hline 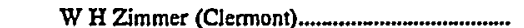 & $*$ STI & 1425.6 & 1300.0 & 1300.0 & ST & BIT & - & 1991 & OP \\
\hline 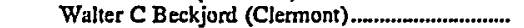 & GTl & 52.9 & 46.6 & 61.2 & GT & FO2 & - & 1972 & OP \\
\hline & GT2 & 52.9 & 46.6 & 61.2 & GT & FO2 & - & 1972 & OP \\
\hline & GT3 & 529 & 46.6 & 61.2 & GT & FO2 & - & 1972 & OP \\
\hline & GT4 & 52.9 & 46.6 & 61.2 & GT & $\mathrm{FO} 2$ & - & 1972 & OP \\
\hline & 1 & 100.0 & 94.0 & 94.0 & ST & $\mathrm{BIT}$ & - & 1952 & OP \\
\hline & 2 & 100.0 & 94.0 & 94.0 & ST & BIT & - & 3953 & $O P$ \\
\hline & 3 & 125.0 & 128.0 & 128.0 & $S T$ & BIT & - & 1954 & OP \\
\hline & 4 & 365.0 & 150.0 & 150.0 & ST & BIT & - & 1958 & OP \\
\hline & 5 & 240.0 & 238.0 & 238.0 & ST & BIT & - & 1962 & OP \\
\hline & $\star * 6$ & 434.0 & 414.0 & 420.0 & ST & BIT & - & 1969 & $\mathrm{OP}$ \\
\hline Woodsdale (Butler) & GT1 & 81.6 & 77.0 & 94.0 & GT & Nat Gas & PRO & 3993 & OP \\
\hline & GT2 & 81.6 & 77.0 & 94.0 & GT & Nat Gas & PRO & 1992 & OP \\
\hline & GT3 & 81.6 & 77.0 & 94.0 & GT & Nat Gas & PRO & 1992 & OP \\
\hline & GT4 & 81.6 & 77.0 & 94.0 & GT & Nat Gas & PRO & 1992 & OP \\
\hline & GTS & 81.6 & 77.0 & 94.0 & GT & Nat Gas & PRO & 1992 & OP \\
\hline & GT6 & 81.6 & 77.0 & 94.0 & GT & Nat Gas & PRO & 1992 & OP \\
\hline Cleveland City of & & 208.0 & 208.0 & 214.0 & & & & & \\
\hline Collinwood (Cuyahoga) & 3 & 16.0 & 16.0 & 18.0 & GT & Nat Gas & $\mathrm{FO} 2$ & 1971 & OP \\
\hline 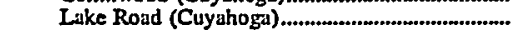 & 8 & 25.0 & 25.0 & 25.0 & ST & BIT & - & 1941 & os \\
\hline & 9 & 25.0 & 25.0 & 25.0 & ST & BIT & - & 1953 & os \\
\hline & 10 & 25.0 & 25.0 & 25.0 & sT & BIT & - & 1953 & os \\
\hline & 11 & 85.0 & 85.0 & 85.0 & ST & BII & - & 1967 & os \\
\hline West 4lst Street (Cuyahoga) & 1 & 16.0 & 36.0 & 18.0 & GT & Nat Gas & FO2 & 1970 & $\mathrm{OP}$ \\
\hline & 2 & 16.0 & 16.0 & 18.0 & GT & Nat Gas & $\mathrm{FO} 2$ & 1970 & OP \\
\hline Cleveland Electric Ilum Co & & $3,769.6$ & $3,527.0$ & $3,574.0$ & & & & & \\
\hline 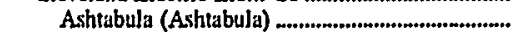 & 5 & 256.0 & 243.0 & 244.0 & ST & BIT & - & 1958 & OP \\
\hline Eastlake (Lake) & 1 & 123.0 & 129.0 & 132.0 & ST & BIT & - & 1953 & $\mathrm{OP}$ \\
\hline 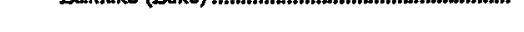 & 2 & 123.0 & 129.0 & 132.0 & $\mathbf{S T}$ & BIT & - & 1953 & OP \\
\hline & 3 & 123.0 & 129.0 & 132.0 & ST & BIT & - & 1954 & OP \\
\hline & 4 & 208.0 & 238.0 & 240.0 & ST & BIT & - & 3956 & OP \\
\hline & *\$5 & 680.0 & 597.0 & 597.0 & $\mathbf{S T}$ & BIT & - & 1972 & OP \\
\hline & 6 & 320 & 24.0 & 29.0 & GT & FO2 & - & 1973 & OP \\
\hline Lake Shore (Cuyahoga) & ICl & 2.0 & 2.0 & 2.0 & - IC & FO2 & - & 1966 & OP \\
\hline & $\mathrm{IC} 2$ & 2.0 & 2.0 & 20 & IC & $\mathrm{FO2}$ & - & 1966 & OP \\
\hline & 18 & 256.0 & 245.0 & 245.0 & ST & BIT & - & 1962 & SB \\
\hline Perry (Lake) & 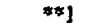 & 1252.6 & 1169.0 & 1194.0 & NB & Uranium & - & 1987 & OP \\
\hline 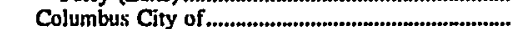 & & 95.4 & 95.4 & 95.4 & & & & & \\
\hline 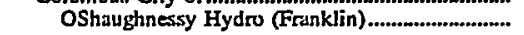 & 1 & 1.4 & 1.4 & 1.4 & HY & Water & - & 1988 & OP \\
\hline & 2 & 4.0 & 4.0 & 4.0 & $\mathrm{HY}$ & Water & - & 1988 & $O P$ \\
\hline 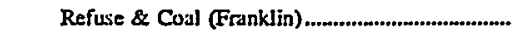 & $\mathbf{J}$ & 30.0 & 30.0 & 30.0 & ST & Refuse & - & 1983 & os \\
\hline & 2 & 30.0 & 30.0 & 30.0 & ST & Refuse & - & 1983 & os \\
\hline & 3 & 30.0 & 30.0 & 30.0 & ST & Refuse & - & 1983 & os \\
\hline 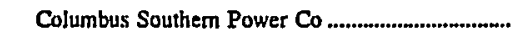 & & $2,281.2$ & $2,015.0$ & $2,045.0$ & & & & & \\
\hline Conesville (Coshocton) & ] & 148.0 & 115.0 & 125.0 & ST & BIT & - & 1959 & OP \\
\hline & 2 & 136.0 & 115.0 & 125.0 & ST & BIT & - & 1957 & $\mathrm{OP}$ \\
\hline & 3 & 161.5 & 165.0 & 165.0 & ST & BIT & - & 1962 & $\mathrm{OP}$ \\
\hline & $* * 4$ & 841.5 & 780.0 & 780.0 & ST & BIT & - & 1973 & OP \\
\hline & 5 & 444.0 & 375.0 & 375.0 & ST & BIT & - & 1976 & OP \\
\hline & 6 & 444.0 & 375.0 & 375.0 & ST & BIT & - & 1978 & OP \\
\hline 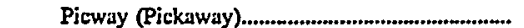 & 5 & 106.3 & 90.0 & 100.0 & ST & BIT & - & 1955 & OP \\
\hline 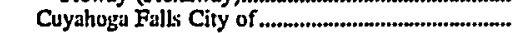 & & 9.0 & 9.0 & 9.0 & & & & & \\
\hline 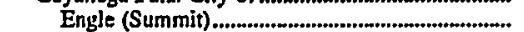 & 16 & & 9.0 & 9.0 & GT & FO2 & - & 1989 & OP \\
\hline Dayton Power \& Light Co & & 3,9592 & $3,678.0$ & $3,753.0$ & & & & & \\
\hline Frank M Tait (Montgomery).............................. & GTI & 103.5 & 87.0 & 100.0 & GT & Nat Gas & $\mathrm{FO} 2$ & 1995 & OP \\
\hline & GT2 & 106.3 & 89.0 & 1020 & GI & Nat Gas & FO2 & 1996 & OP \\
\hline & ICl & 2.8 & 2.5 & 25 & IC & FO2 & - & 1967 & OP \\
\hline & IC2 & 2.8 & 2.5 & 25 & IC & $\mathrm{FO}_{2}$ & - & 1967 & OP \\
\hline
\end{tabular}

See footnotes at end of table. 


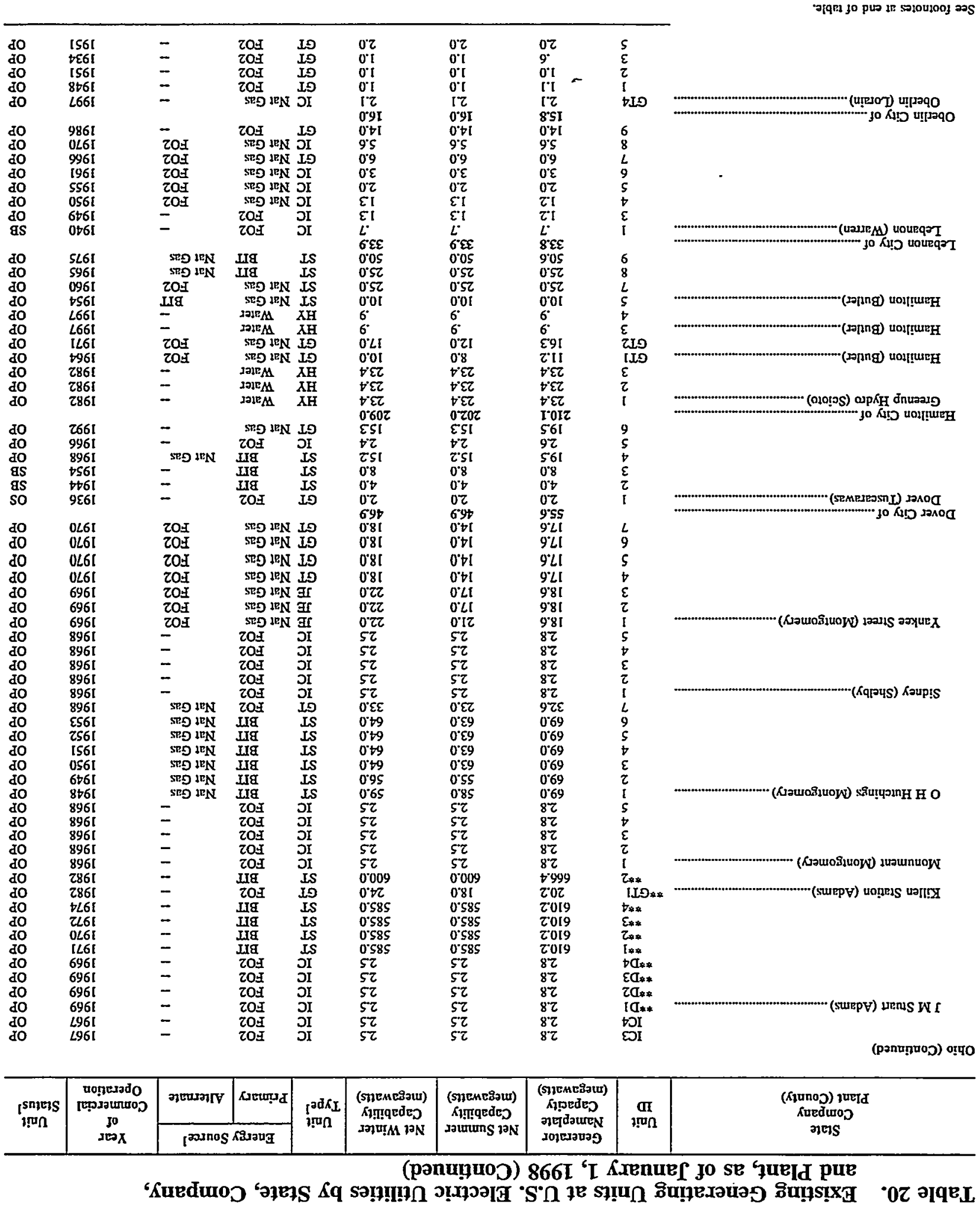


Table 20. Existing Generating Units at U.S. Electric Utilities by State, Company, and Plant, as of January 1, 1998 (Continued)

\begin{tabular}{|c|c|c|c|c|c|c|c|c|c|}
\hline \multirow{2}{*}{$\begin{array}{c}\text { State } \\
\text { Company } \\
\text { Plant (County) }\end{array}$} & \multirow{2}{*}{$\begin{array}{l}\text { Unit } \\
\text { ID }\end{array}$} & \multirow{2}{*}{$\begin{array}{c}\text { Generator } \\
\text { Nameplate } \\
\text { Capacity } \\
\text { (megawatts) }\end{array}$} & \multirow{2}{*}{$\begin{array}{c}\text { Net Summer } \\
\text { Capability } \\
\text { (megawatts) }\end{array}$} & \multirow{2}{*}{$\begin{array}{l}\text { Net Winter } \\
\text { Capability } \\
\text { (megawatts) }\end{array}$} & \multirow{2}{*}{$\begin{array}{l}\text { Unit } \\
\text { Typel }\end{array}$} & \multicolumn{2}{|c|}{ Energy Source! } & \multirow{2}{*}{$\begin{array}{c}\text { Year } \\
\text { of } \\
\text { Commercinl } \\
\text { Operation }\end{array}$} & \multirow{2}{*}{$\begin{array}{c}\text { Unit } \\
\text { Status! }\end{array}$} \\
\hline & & & & & & Primary & Alternate & & \\
\hline Ohio (Continued) & & & & & & & & & \\
\hline & 6 & 2.5 & 2.0 & 2.0 & GT & $\mathrm{FO} 2$ & Nat Gas & 1958 & OP \\
\hline & 7 & 2.7 & 3.0 & 3.0 & GT & $\mathrm{FO} 2$ & Nat Gas & 3961 & $\mathrm{OP}$ \\
\hline & 8 & 3.0 & 3.0 & 3.0 & GT & $\mathrm{FO} 2$ & Nat Gas & 1966 & OP \\
\hline & 9 & .4 & .4 & .4 & $\mathbf{G T}$ & Nat Gas & - & 1990 & OP \\
\hline & 30 & & 3271.5 & $\begin{array}{r}.5 \\
3392.0\end{array}$ & $\mathrm{GT}$ & Nat Gas & $\rightarrow$ & 1990 & OP \\
\hline 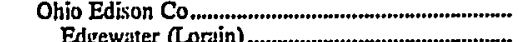 & $\star * \mathrm{MTA}$ & $\begin{array}{r}3,713.1 \\
28.8\end{array}$ & $\begin{array}{r}3,271.0 \\
19.0\end{array}$ & $\begin{array}{r}3,392.0 \\
24.0\end{array}$ & GT & F02 & - & 1973 & OP \\
\hline 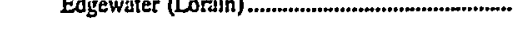 & $*$ CTA & $\begin{array}{l}28.8 \\
-\quad 28.8\end{array}$ & 19.0 & 24.0 & GT & $\mathrm{FO2}$ & - & 1973 & OP \\
\hline & & 113.6 & 100.0 & 100.0 & ST & Nat Gas & $\mathrm{FO} 2$ & 1957 & \\
\hline Mad River (Clark) ..................................................... & ${ }^{*}$ CTA & 27.0 & 25.0 & 30.0 & GT & $\mathrm{FO} 2$ & - & 1972 & OP \\
\hline Niles Mahoning) & $*$ * CTB & 27.0 & 25.0 & 30.0 & GT & FO2 & $\rightarrow$ & 1972 & OP \\
\hline Niles (Mahoning) & $*$ *TA & 27.0 & 25.0 & 30.0 & Gr & FO2 & - & 1972 & OP \\
\hline & 1 & 132.8 & 69.0 & 108.0 & ST & BIT & Refuse & 1954 & OP \\
\hline & 2 & 1328 & 69.0 & 108.0 & ST & BIT & - & 1954 & OP \\
\hline 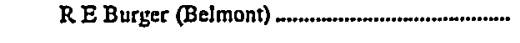 & $\because A 1$ & 2.5 & 20 & 2.0 & IC & $\mathrm{FO} 2$ & - & 1972 & $\begin{array}{l}\text { OP } \\
\text { OP }\end{array}$ \\
\hline & $\begin{array}{l}* * \mathrm{~B} 1 \\
* * \mathrm{~B} 2\end{array}$ & $\begin{array}{l}2.5 \\
2.5\end{array}$ & $\begin{array}{l}2.0 \\
3.0\end{array}$ & $\begin{array}{l}2.0 \\
3.0\end{array}$ & $\begin{array}{l}\text { IC } \\
\text { IC }\end{array}$ & $\begin{array}{l}\mathrm{FO} 2 \\
\mathrm{FO} 2\end{array}$ & $\overline{-}$ & $\begin{array}{l}1972 \\
1972\end{array}$ & $\begin{array}{l}\mathrm{OP} \\
\mathrm{OP}\end{array}$ \\
\hline & 3 & 303.5 & 94.0 & 94.0 & ST & BIT & - & 1950 & OP \\
\hline & 4 & 156.3 & 156.0 & 156.0 & ST & BIT & - & 1955 & OP \\
\hline & 5 & 156.3 & 156.0 & 156.0 & ST & BIT & - & 1955 & OP \\
\hline 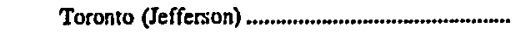 & 5 & 35.0 & 420 & 42.0 & ST & BIT & Refuse & 1940 & SB \\
\hline & 6 & 69.0 & 65.0 & 65.0 & ST & BII & - & 1949 & SB \\
\hline & 7 & 69.0 & 65.0 & 65.0 & ST & BIT & - & 1949 & SB \\
\hline W H Sammis (Jefferson) & $* A 1$ & 2.5 & 3.0 & 3.0 & IC & $\mathrm{FO2}$ & - & 1972 & OP \\
\hline & $* * \mathrm{~B} 1$ & 2.5 & 3.0 & 3.0 & IC & FO2 & - & 1972 & OP \\
\hline & $\approx \mathrm{B} 2$ & 2.5 & 3.0 & 3.0 & IC & FO2 & - & 1972 & OP \\
\hline & $* * \mathrm{~B} 3$ & 2.5 & 2.0 & 2.0 & IC & $\mathrm{FO} 2$ & - & 1972 & OP \\
\hline & $* *_{\mathrm{B} 4}$ & 2.5 & 2.0 & 2.0 & IC & FO2 & - & 1972 & OP \\
\hline & I & 190.4 & 180.0 & 180.0 & ST & BIT & - & 1959 & oP \\
\hline & 2 & 190.4 & 180.0 & 180.0 & ST & BIT & - & 1960 & OP \\
\hline & 3 & 190.4 & 180.0 & 180.0 & ST & BIT & - & 19 & OP \\
\hline & 4 & 190.4 & 180.0 & 180.0 & ST & BIT & - & 1962 & OP \\
\hline & 5 & 334.1 & 300.0 & 300.0 & ST & BIT & - & 1967 & OP \\
\hline & 6 & 680.0 & 600.0 & 600.0 & ST & BIT & - & 1969 & OP \\
\hline & $=07$ & 680.0 & 600.0 & 600.0 & ST & BTT & - & 1971 & OP \\
\hline 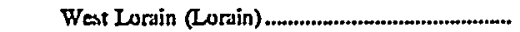 & IA & 65.3 & 51.0 & 60.0 & GT & $\mathrm{FO} 2$ & - & 1983 & OP \\
\hline & IB & 65.3 & 51.0 & 60.0 & Gr & FO2 & - & 1973 & OP \\
\hline 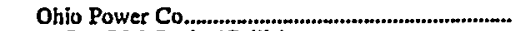 & & $4,177.1$ & $4,006,4$ & $4,073.0$ & & & & & \\
\hline 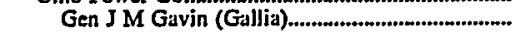 & 1 & 1300.0 & 1300.0 & 1300.0 & ST & BIT & - & 1974 & OP \\
\hline & 2 & 1300.0 & 1300.0 & 1300.0 & ST & BIT & - & 1975 & OP \\
\hline 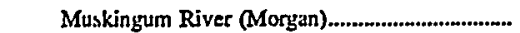 & 1 & 219.7 & 190.0 & 205.0 & ST & BIT & - & 1953 & OP \\
\hline & 2 & 219.7 & 190.0 & 205.0 & SI & BIT & - & 1954 & OP \\
\hline & 3 & 237.5 & 205.0 & 215.0 & ST & BIT & - & 1957 & OP \\
\hline & 4 & 237.5 & 205.0 & 215.0 & ST & BIT & - & 1958 & OP \\
\hline & $s$ & 615.2 & 575.0 & 585.0 & ST & BIT & - & 1968 & OP \\
\hline Rucine (Mejgs) & 1 & 23.8 & 20.7 & 24.0 & HY & Water & - & 1983 & OP \\
\hline 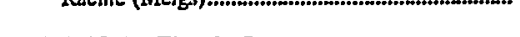 & 2 & 23.8 & 20.7 & 24.0 & HY & Water & - & 1982 & OP \\
\hline Ohio Valley Electric Corp & & 1,0863 & $1,028.0$ & $1,072.0$ & & & & & \\
\hline 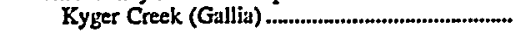 & 1 & 217.3 & 213.0 & 221.0 & ST & BIT & - & 1955 & OP \\
\hline & 2 & 217.3 & 203.0 & 212.0 & ST & BIT & - & 1955 & $O P$ \\
\hline & 3 & 217.3 & 201.0 & 210.0 & ST & BIT & - & 3955 & OP \\
\hline & 4 & 217.3 & 205.0 & 214.0 & ST & BIT & - & 1955 & OP \\
\hline & 5 & 217.3 & 206.0 & 215.0 & ST & BIT & - & 1955 & OP \\
\hline Orville City of & & 84.5 & 74.5 & 745 & & & & & \\
\hline 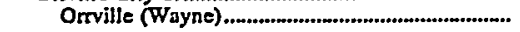 & 7 & 5.0 & 5.0 & 5.0 & ST & BIT & - & 1949 & \\
\hline & 8 & 7.5 & 7.5 & 7.5 & ST & BIT & - & 1955 & SB \\
\hline & 9 & 220 & 12.0 & 12.0 & ST & BIT & - & 1961 & OP \\
\hline & 10 & 25.0 & 25.0 & 25.0 & ST & BII & - & 1971 & OP \\
\hline & j] & 25.0 & 25.0 & 25.0 & ST & BIT & - & 1971 & OP \\
\hline Painesville City of.......... & & 53.5 & $\mathbf{5 3 . 5}$ & 535 & & & & & \\
\hline Painesville (Lake) & ST2 & 7.5 & 7.5 & 7.5 & ST & BIT & $-\quad-$ & 1933 & OP \\
\hline & 3 & 7.5 & 7.5 & 7.5 & ST & BIT & $\mathrm{FO} 2$ & 1953 & OP \\
\hline & 5 & 16.5 & 16.5 & 16.5 & ST & BIT & $\mathrm{FO} 2$ & 1965 & OP \\
\hline & 7 & 22.0 & 22.0 & 22.0 & ST & BIT & FO2 & 1990 & OP \\
\hline 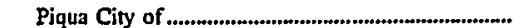 & & 86.1 & 863 & 863 & & & & & \\
\hline Piqua (Miami) & 3 & 4.0 & 4.0 & 4.0 & $\mathrm{CH}$ & BIT & $\mathrm{FO2}$ & 1940 & OP \\
\hline & 4 & 7.5 & 7.5 & 75 & $\mathrm{CH}$ & BIT & $\mathrm{FO} 2$ & 1947 & OP \\
\hline & 5 & 1.0 & 1.0 & 1.0 & $\mathrm{CH}$ & BIT & $\mathrm{FO} 2$ & 1947 & OP \\
\hline & 6 & 125 & 32.5 & 12.5 & $\mathrm{CH}$ & BIT & $\mathrm{FO} 2$ & 1951 & OP \\
\hline & 7 & 20.0 & 20.0 & 20.0 & ST & BIT & FO2 & 1961 & OP \\
\hline
\end{tabular}

See footnotes at end of table. 
Table 20. Existing Generating Units at U.S. Electric Utilities by State, Company, and Plant, as of January 1, 1998 (Continued)

\begin{tabular}{|c|c|c|c|c|c|c|c|c|c|}
\hline \multirow{2}{*}{$\begin{array}{c}\text { State } \\
\text { Company } \\
\text { Plant (County) }\end{array}$} & \multirow{2}{*}{$\begin{array}{c}\text { Unit } \\
\text { ID }\end{array}$} & \multirow{2}{*}{$\begin{array}{c}\text { Generator } \\
\text { Nameplate } \\
\text { Capacity } \\
\text { (megawatts) }\end{array}$} & \multirow{2}{*}{$\begin{array}{l}\text { Net Summer } \\
\text { Capability } \\
\text { (megawatts) }\end{array}$} & \multirow{2}{*}{$\begin{array}{l}\text { Net Winter } \\
\text { Capability } \\
\text { (megawatts) }\end{array}$} & \multirow{2}{*}{$\begin{array}{r}\text { Unit } \\
\text { Type] }\end{array}$} & \multicolumn{2}{|c|}{ Energy Source] } & \multirow{2}{*}{$\begin{array}{c}\text { Year } \\
\text { of } \\
\text { Commercinl } \\
\text { Operation }\end{array}$} & \multirow{2}{*}{$\begin{array}{c}\text { Unit } \\
\text { Status } 1\end{array}$} \\
\hline & & & & & & Primary & Alternate & & \\
\hline \multicolumn{10}{|l|}{ Ohio (Continued) } \\
\hline & 8 & 20.0 & 20.0 & 20.0 & GT & $\mathrm{FO} 2$ & $=\bar{n}$ & 1972 & OP \\
\hline & 10 & $\begin{array}{r}4.0 \\
.8\end{array}$ & $\begin{array}{r}4.0 \\
.8\end{array}$ & $\begin{array}{r}4.0 \\
.8\end{array}$ & $\begin{array}{l}\text { ST } \\
\text { ST }\end{array}$ & $\begin{array}{l}\text { BIT } \\
\text { BIT }\end{array}$ & $\begin{array}{l}\mathrm{FO2} \\
\mathrm{FO} 2\end{array}$ & $\begin{array}{l}1947 \\
1987\end{array}$ & $\begin{array}{l}\text { OP } \\
\text { OP }\end{array}$ \\
\hline 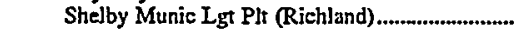 & $\mathrm{ICl}$ & 3.0 & 3.0 & 3.0 & IC & FO2 & Nat Gas & 1963 & OP \\
\hline & 1 & 12.5 & 12.0 & 12.0 & ST & BIT & $\mathrm{FO} 2$ & 1967 & OP \\
\hline & 2 & 12.5 & 12.0 & 12.0 & ST & BIT & $\mathrm{FO} 2$ & 1973 & OP \\
\hline & 3 & 5.0 & 5.0 & 5.0 & ST & BIT & - & 1948 & os \\
\hline & & 7.0 & 7.0 & 7.0 & ST & BIT & - & 1954 & OP \\
\hline St Marys City of & & 33.4 & 30.5 & 30.5 & & & & & \\
\hline 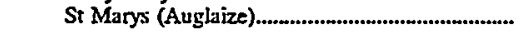 & AUX & .9 & .8 & .8 & GT & $\mathrm{FO} 2$ & - & 1967 & OP \\
\hline & & 2.5 & 1.9 & 1.9 & ST & BIT & - & 1946 & os \\
\hline & 5 & 6.0 & 5.8 & 5.8 & ST & BIT & - & 1957 & os \\
\hline & 6 & 10.0 & 30.0 & 10.0 & ST & BIT & - & 1967 & OP \\
\hline Toledo Edison Co & & $1,716.7$ & 1,6320 & $1,663.0$ & & & & & \\
\hline Acme (Lucas) & 2 & 72.0 & 720 & 72.0 & ST & BIT & - & 1951 & SB \\
\hline Bay Shore (lucas) & GI1 & 16.0 & 16.0 & 17.0 & GT & FO2 & - & 1967 & OP \\
\hline & 1 & 140.6 & 132.0 & 136.0 & ST & BIT & - & 1955 & OP \\
\hline & 2 & 140.6 & 134.0 & 138.0 & ST & BIT & - & 1959 & OP \\
\hline & 3 & 140.6 & 142.0 & 142.0 & ST & BIT & - & 1963 & OP \\
\hline & 4 & 217.6 & 213.0 & 215.0 & ST & BIT & - & 1968 & OP \\
\hline Davis-Besse (Ottawa) & $\approx 1$ & 925.2 & 873.0 & 883.0 & NP & Uranium & - & 1977 & OP \\
\hline Richland (Defiance) & 1 & 15.0 & 11.0 & 14.0 & GT & $\mathrm{FO2}$ & Nat Gas & 1965 & OP \\
\hline & 2 & 15.0 & 11.0 & 14.0 & GT & Nat Gas & FO2 & 1966 & OP \\
\hline & 3 & 15.0 & 11.0 & 14.0 & GT & Nat Gas & $\mathrm{FO2}$ & 1966 & OP \\
\hline Stryker (Williams) & 1 & 19.0 & 17.0 & 18.0 & GT & $\mathrm{FO} 2$ & - & 1968 & OP \\
\hline 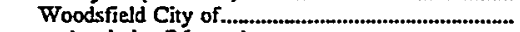 & & 8.0 & 80 & 8.0 & & & & & \\
\hline 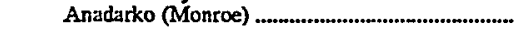 & 6 & .6 & .6 & .6 & GT & FO2 & Nat Gas & 1949 & SB \\
\hline & 7 & 1.3 & 1.3 & 13 & GT & EO2 & Nat Gas & 1957 & SB \\
\hline & 8 & 1.5 & 1.5 & 1.5 & GT & $\mathrm{FO} 2$ & Nat Gas & 1965 & $S B$ \\
\hline & 9 & 2.2 & 2.2 & 2.2 & GT & $\mathrm{FO} 2$ & Nat Gas & 1971 & SB \\
\hline & 10 & 1.2 & 1.2 & 1.2 & GT & FO2 & Nat Gas & 1983 & SB \\
\hline & 11 & 3.2 & 1.2 & 1.2 & GT & FO2 & Nat Gas & 1983 & SB \\
\hline Oklahoma & & & & & & & & & \\
\hline Cushing (Payne) & ] & 2.5 & 1.9 & 1.9 & IC & $\mathrm{FO} 2$ & Nat Gas & 1956 & OP \\
\hline & 2 & 1.0 & .8 & .8 & IC & FO2 & Nat Gas & 1949 & OP \\
\hline & 3 & .5 & .4 & .4 & IC & FO2 & Nat Gas & 1936 & OP \\
\hline & 4 & .5 & .4 & .4 & IC & $\mathrm{FO} 2$ & Nat Gas & 1936 & OP \\
\hline & 5 & .5 & .4 & .4 & IC & FO2 & Nat Gas & 1936 & OP \\
\hline & 6 & .8 & .6 & .6 & IC & $\mathrm{FO} 2$ & Nat Gas & 1939 & $O P$ \\
\hline & 7 & 25 & 1.9 & 1.9 & IC & FO2 & Nat Gas & 1956 & OP \\
\hline & 8 & 2.5 & 1.9 & 1.9 & IC & $\mathrm{FO} 2$ & Nat Gas & 1956 & OP \\
\hline & 9 & 3.0 & 2.3 & 23 & IC & FO2 & Nat Gas & 1965 & OP \\
\hline & 10 & 4.5 & 3.5 & 3.5 & IC & $\mathrm{FO} 2$ & Nat Gas & 1972 & OP \\
\hline & 1] & 6.3 & 5.8 & 5.8 & IC & $\mathrm{FO} 2$ & Nat Gas & 1988 & OP \\
\hline Fairview City of & & 25 & 2.1 & 2.1 & & & & & \\
\hline Fairview (Major) & J & .1 & .1 & .1 & IC & FO2 & - & 1924 & OP \\
\hline & 2 & .5 & .4 & 4 & IC & FO2 & - & 1926 & OP \\
\hline & 4 & .8 & .7 & .7 & IC & $\mathrm{FO} 2$ & - & 1948 & $O P$ \\
\hline & 5 & 1.0 & .9 & .9 & IC & $\mathrm{FO} 2$ & Nat Gas & 1954 & OP \\
\hline Grand River Dam Authority ...................................... & & $1,514.5$ & 1,4803 & $1,480.3$ & & & & & \\
\hline GRDA (Mayes) & 1 & 490.0 & 490.0 & 490.0 & ST & BIT & Nat Gas & 1981 & $\mathrm{OP}$ \\
\hline & $=2$ & 520.0 & 520.0 & 520.0 & ST & BIT & Nat Gas & 1985 & OP \\
\hline Markham (Mayes) & 1 & 30.0 & 28.5 & 28.5 & HY & Water & - & 1964 & OP \\
\hline & 2 & 30.0 & 28.5 & 28.5 & $\mathrm{HY}$ & Water & - & 1964 & $O P$ \\
\hline & 3 & 30.0 & 28.5 & 285 & $\mathrm{HY}$ & Water & - & 1964 & $O P$ \\
\hline & 4 & 30.0 & 28.5 & 28.5 & HY & Water & - & 1964 & OP \\
\hline Pensacola (Mayes) & A & .5 & .5 & .5 & HY & Water & - & 1940 & OP \\
\hline & j & 36.0 & 16.0 & 16.0 & $\mathrm{HY}$ & Water & - & 1940 & OP \\
\hline & 2 & 16.0 & 16.0 & 16.0 & HY & Water & - & 1940 & OP \\
\hline & 3 & 16.0 & 16.0 & 36.0 & $\mathrm{HY}$ & Water & - & 1940 & OP \\
\hline & 4 & 16.0 & 16.0 & 36.0 & $\mathrm{HY}$ & Water & - & 1940 & OP \\
\hline & 5 & 16.0 & 16.0 & 16.0 & HY & Water & - & 1946 & OP \\
\hline & 6 & 36.0 & 16.0 & 16.0 & $\mathrm{HY}$ & Water & - & 1952 & $O P$ \\
\hline
\end{tabular}

See footnotes at end of table. 
Table 20. Existing Generating Units at U.S. Electric Utilities by State, Company, and Plant, as of January 1, 1998 (Continued)

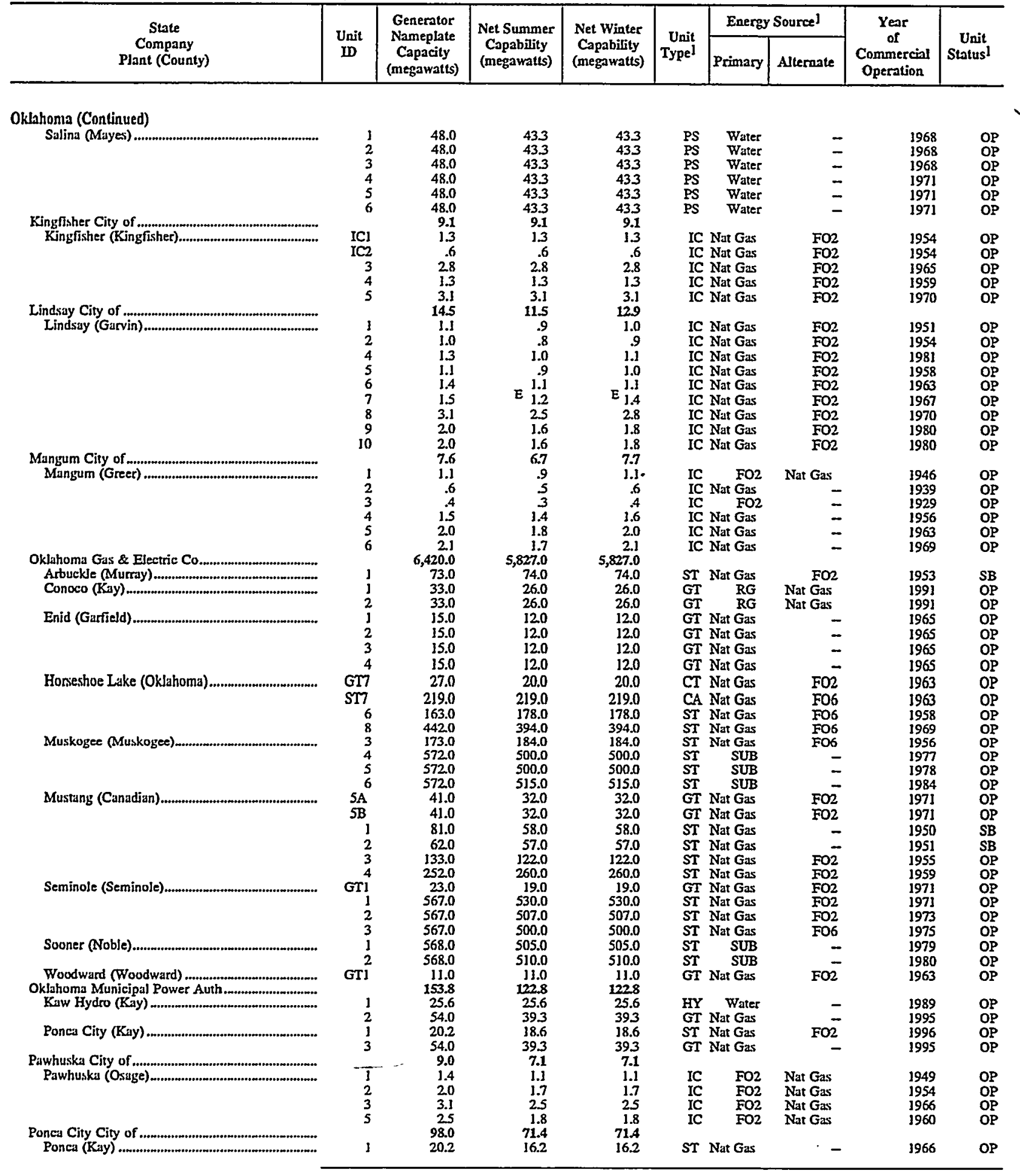

See footnotes at end of table. 
Table 20. Existing Generating Units at U.S. Electric Utilities by State, Company, and Plant, as of January 1, 1998 (Continued)

\begin{tabular}{|c|c|c|c|c|c|c|c|c|c|}
\hline \multirow{2}{*}{$\begin{array}{c}\text { State } \\
\text { Company } \\
\text { Plant (County) }\end{array}$} & \multirow{2}{*}{$\begin{array}{l}\text { Unit } \\
\text { ID }\end{array}$} & \multirow{2}{*}{$\begin{array}{l}\text { Generator } \\
\text { Nanieplate } \\
\text { Capacity } \\
\text { (megawatts) }\end{array}$} & \multirow{2}{*}{$\begin{array}{l}\text { Net Summer } \\
\text { Capability } \\
\text { (megawatts) }\end{array}$} & \multirow{2}{*}{$\begin{array}{l}\text { Net Winter } \\
\text { Capability } \\
\text { (megawatts) }\end{array}$} & \multirow{2}{*}{$\begin{array}{c}\text { Unit } \\
\text { Type }\end{array}$} & \multicolumn{2}{|c|}{ Energy Sourcel } & \multirow{2}{*}{$\begin{array}{c}\text { Year } \\
\text { of } \\
\text { Commercinl } \\
\text { Operation }\end{array}$} & \multirow{2}{*}{$\begin{array}{c}\text { Unit } \\
\text { Status! }\end{array}$} \\
\hline & & & & & & Primary & Alternate & & \\
\hline Okbahoma (Continued) & & & & & & & & & \\
\hline & 2 & 48.0 & 34.4 & 34.4 & ST & Nat Gas & - & 1977 & OP \\
\hline Ponca Diesel (Kay) & 1 & 7.0 & 4.3 & 4.3 & IC & FO2 & Nat Gas & 1961 & OP \\
\hline & 4 & 2.8 & 1.6 & 1.6 & IC & Nat Gas & - & 1949 & OP \\
\hline & 5 & 1.5 & 1.0 & 1.0 & IC & Nat Gas & - & 1937 & os \\
\hline & 6 & 1.7 & 1.1 & 1.] & IC & Nat Gas & - & 1947 & OP \\
\hline & 7 & 3.3 & 2.6 & 2.6 & IC & Nat Gas & - & 1952 & OP \\
\hline & 8 & 4.0 & 3.2 & 3.2 & IC & Nat Gas & - & 1954 & OP \\
\hline & 9 & $\mathbf{7 . 0}$ & 4.9 & 4.9 & IC & Nat Gas & - & 1956 & OP \\
\hline & 10 & 2.5 & 2.1 & 2.1 & IC & $\mathrm{FO} 2$ & - & 1964 & OP \\
\hline 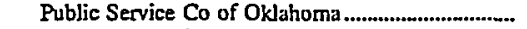 & & $3,627.0$ & $3,719.0$ & $3,719.0$ & & & & & \\
\hline 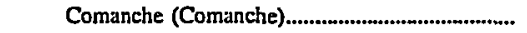 & ICl & 4.0 & 4.0 & 4.0 & IC & $\mathrm{FO} 2$ & - & 1962 & OP \\
\hline & ]GJ & 85.0 & 78.0 & 78.0 & CT & Nat Gas & - & 1973 & OP \\
\hline & JG2 & 85.0 & 78.0 & 78.0 & $\mathrm{CT}$ & Nat Gas & - & 1973 & OP \\
\hline & is & 106.8 & 117.0 & 117.0 & CA & Nat Gas & - & 1974 & OP \\
\hline Northeastem (Rogers) & ICI & 4.6 & 4.0 & 4.0 & IC & $\mathrm{FO} 2$ & - & 1980 & OP \\
\hline & 1 & 170.0 & 157.0 & 157.0 & ST & Nat Gas & $\mathrm{FO} 2$ & 196] & OP \\
\hline & 2 & 441.8 & 480.0 & 480.0 & ST & Nat Gas & $\mathrm{FO} 2$ & 1970 & OP \\
\hline & 3 & 441.2 & 450.0 & 450.0 & ST & SUB & Nat Gas & 1979 & OP \\
\hline & 4 & 441.2 & 450.0 & 450.0 & ST & SUB & Nat Gas & 1980 & OP \\
\hline Riverside (Tulsa) & $\mathrm{ICl}$ & 2.8 & 2.8 & 2.8 & IC & $\mathrm{FO} 2$ & - & 1976 & OP \\
\hline & 1 & 441.4 & 457.0 & 457.0 & ST & Nat Gas & $\mathrm{FO} 2$ & 1974 & OP \\
\hline & 2 & 441.2 & 459.0 & 459.0 & ST & Nat Gas & FO2 & 1976 & OP \\
\hline Southwestem (Caddo) & ICI & 2.0 & 20 & 2.0 & IC & $\mathrm{FO} 2$ & - & 1962 & OP \\
\hline & 1 & 80.3 & 80.0 & 80.0 & ST & Nat Gas & $\mathrm{FO} 2$ & 1952 & OP \\
\hline & 2 & 80.3 & 80.0 & 80.0 & ST & Nat Gas & FO2 & 1954 & OP \\
\hline & 3 & 288.4 & 315.0 & 315.0 & ST & Nat Gas & FO2 & 1967 & OP \\
\hline Tulsa (Tulsa) & ICl & 8.3 & 8.3 & 8.3 & IC & $\mathrm{FO} 2$ & - & 1967 & OP \\
\hline - & 2 & 170.0 & 165.0 & 165.0 & ST & Nat Gas & FO2 & 1956 & OP \\
\hline & 4 & 370.0 & 165.0 & 165.0 & ST & Nat Gas & FO2 & 1958 & OP \\
\hline 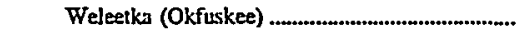 & ICl & 4.0 & 4.0 & 4.0 & IC & $\mathrm{FO} 2$ & - & 1963 & OP \\
\hline & 4 & 53.0 & 55.0 & 55.0 & GT & Nat Gas & FO2 & 1975 & OP \\
\hline & 5 & 53.0 & 54.0 & 54.0 & GT & Nat Gas & FO2 & 1976 & OP \\
\hline & 6 & 53.0 & 54.0 & 54.0 & GT & Nat Gas & FO2 & 1976 & OP \\
\hline 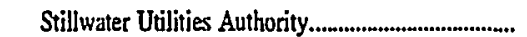 & & 22.7 & 23.9 & 23.9 & & & & & \\
\hline Boomer Iake (Payne) . & 1 & 10.0 & 11.0 & 31.0 & ST & Nat Gas & FO2 & 1956 & OP \\
\hline & 2 & 12.7 & 12.9 & 12.9 & ST & Nat Gas & FO2 & 1959 & OP \\
\hline 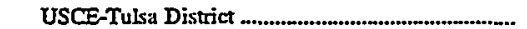 & & 514.1 & $\mathbf{5 3 9 . 0}$ & 539.0 & & & & & \\
\hline Broken Bow (Mecurtain) .......................................... & 1 & 50.0 & 57.5 & 57.5 & $\mathrm{HY}$ & Water & - & 1970 & OP \\
\hline & 2 & 50.0 & 57.5 & 57.5 & HY & Water & - & 1970 & OP \\
\hline Eufaula (Haskell) & 1 & 30.0 & 30.0 & 30.0 & HY & Water & - & 1964 & OP \\
\hline & 2 & 30.0 & 30.0 & 30.0 & HY & Water & - & 1964 & OP \\
\hline & 3 & 30.0 & 30.0 & 30.0 & HY & Water & - & 1964 & OP \\
\hline Fort Gibson (Cherokee) & $\mathbf{l}$ & 11.3 & 125 & 12.5 & HY & Water & - & 1953 & OP \\
\hline & 2 & 11.3 & 12.5 & 125 & HY & Water & - & 1953 & OP \\
\hline & 3 & 11.3 & 12.5 & 125 & HY & Water & - & 1953 & OP \\
\hline & 4 & 11.3 & 12.5 & 12.5 & HY & Water & - & 1953 & OP \\
\hline 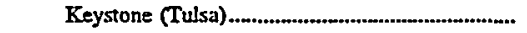 & 1 & 35.0 & 35.0 & 35.0 & HY & Water & - & 1968 & OP \\
\hline & 2 & 35.0 & 35.0 & 35.0 & HY & Water & - & 1968 & OP \\
\hline Robert S Kert (Sequoyah) & ] & 27.5 & 28.5 & 28.5 & HY & Water & - & 1971 & OP \\
\hline & 2 & 27.5 & 28.5 & 285 & HY & Water & - & 1971 & OP \\
\hline & 3 & 27.5 & 28.5 & 28.5 & HY & Water & - & 1971 & OP \\
\hline & 4 & 27.5 & 28.5 & 28.5 & HY & Water & - & 1971 & OP \\
\hline Tenkiller Ferry (Sequoyah) & J & 19.6 & 20.0 & 20.0 & HY & Water & - & 1953 & OP \\
\hline & 2 & 19.6 & 20.0 & 20.0 & HY & Water & - & 1953 & OP \\
\hline Webbers Falls (Muskogee) & 1 & 20.0 & 20.0 & 20.0 & HY & Water & - & 1973 & OP \\
\hline & 2 & 20.0 & 20.0 & 20.0 & HY & Water & - & 1973 & OP \\
\hline & 3 & 20.0 & 20.0 & 20.0 & HY & Water & - & 1973 & OP \\
\hline Westem Farmess Elec Coop Inc.............................. & & $1,079.0$ & $1,091.0$ & $1, \mathbf{1 5 9 . 0}$ & & & & & \\
\hline Anadarko (Caddo) & J & 15.0 & 14.0 & 15.0 & ST & Nat Gas & $-\mathrm{FO2}$ & 1953 & SB \\
\hline & 2 & 15.0 & 14.0 & 15.0 & ST & Nat Gas & FO2 & 1953 & SB \\
\hline & 3 & 44.0 & 44.0 & 46.0 & sT & Nat Gas & FO2 & 1959 & OP \\
\hline & 4 & 100.0 & 94.0 & J 14.0 & CS & Nat Gas & FO2 & 1977 & OP \\
\hline & 5 & 100.0 & 94.0 & 114.0 & CS & Nat Gas & FO2 & 1977 & OP \\
\hline & 6 & 100.0 & 94.0 & 114.0 & Cs & Nat Gas & FO2 & 1977 & OP \\
\hline Hugo (Choctaw) & ] & 400.0 & 408.0 & 412.0 & ST & SUB & - & 1982 & OP \\
\hline Mooreland (Woodward) & ] & 45.0 & 50.0 & 50.0 & ST & Nat Gas & -- & 1964 & OP \\
\hline & 2 & 125.0 & 139.0 & 139.0 & ST & Nat Gas & - & 1968 & OP \\
\hline - & 3 & 135.0 & 140.0 & 140.0 & ST & Nat Gas & - & 1975 & OP \\
\hline
\end{tabular}

Sec footnotes at end of table. 
Table 20. Existing Generating Units at U.S. Electric Utilities. by State, Company, and Plant, as of January 1, 1998 (Continued)

\begin{tabular}{|c|c|c|c|c|c|c|c|c|c|}
\hline \multirow{2}{*}{$\begin{array}{c}\text { State } \\
\text { Company } \\
\text { Plant (County) }\end{array}$} & \multirow{2}{*}{$\begin{array}{l}\text { Unit } \\
\text { ID }\end{array}$} & \multirow{2}{*}{$\begin{array}{l}\text { Generator } \\
\text { Nameplate } \\
\text { Capacity } \\
\text { (megawatts) }\end{array}$} & \multirow{2}{*}{$\begin{array}{l}\text { Net Summer } \\
\text { Capability } \\
\text { (megawatis) }\end{array}$} & \multirow{2}{*}{$\begin{array}{l}\text { Net Winter } \\
\text { Capability } \\
\text { (megawatts) }\end{array}$} & \multirow{2}{*}{\begin{tabular}{|} 
Unit \\
Typel
\end{tabular}} & \multicolumn{2}{|c|}{ Energy Sourcel } & \multirow{2}{*}{$\begin{array}{c}\text { Year } \\
\text { of } \\
\text { Commercial } \\
\text { Operation }\end{array}$} & \multirow{2}{*}{$\begin{array}{c}\text { Unit } \\
\text { Status! }\end{array}$} \\
\hline & & & & & & Primary & Alternate & & \\
\hline Oregon & & & & & & & & & \\
\hline 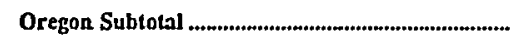 & & $9,919.1$ & $10,536.6$ & $10,638.4$ & & & & & \\
\hline Bureau of Reclamation............................... & & 16.0 & 18.4 & 18.4 & & & & & \\
\hline 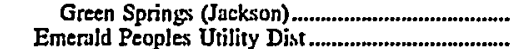 & 1 & $\begin{array}{r}16.0 \\
32\end{array}$ & $\begin{array}{r}18.4 \\
3.2\end{array}$ & $\begin{array}{r}18.4 \\
3.2\end{array}$ & HY & Water & - & 1960 & OP \\
\hline 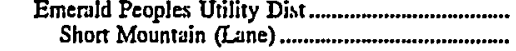 & 1 & .8 & .8 & $\begin{array}{r}3.2 \\
.8\end{array}$ & IC & MTE & - & 1992 & OP \\
\hline & 2 & .8 & .8 & .8 & IC & MTE & - & 1992 & $\mathrm{OP}$ \\
\hline & & .8 & .8 & .8 & IC & MTE & - & 1993 & OP \\
\hline & & 175 & .8 & 8 & IC & MTE & - & 1993 & OP \\
\hline Eugene City of & & 175.0 & 151.0 & 151.0 & & & & & \\
\hline & 1 & 40.0 & 40.8 & 40.8 & HY & Water & - & 1963 & OP \\
\hline & 2 & 40.0 & 40.8 & 40.8 & HY & Water & - & 1963 & OP \\
\hline & 3 & 10.0 & 3.8 & 3.8 & HY & Water & - & 1963 & OP \\
\hline Leaburg (Lane),........................................................... & 1 & 6.0 & 6.0 & 6.0 & HY & Water & - & 1930 & OP \\
\hline & 2 & 7.5 & 7.5 & 7.5 & HY & Water & - & 1950 & $O P$ \\
\hline 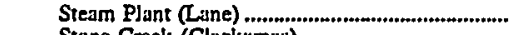 & 3 & 11.5 & 11.5 & 11.5 & ST & WD & - & 3950 & OP \\
\hline 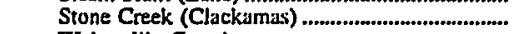 & j & 32.0 & 10.7 & 10.7 & $\mathrm{BY}$ & Water & - & 1994 & $O P$ \\
\hline Walterville (Lune)............................................................ & $i$ & 8.0 & 6.9 & 6.9 & $\hat{H Y}$ & Water & - & 1949 & $O P$ \\
\hline Weyco Energy CTR (Line)........................................ & 4 & 40.0 & 23.0 & 23.0 & ST & Refuse & - & 1976 & $O P$ \\
\hline Idaho Power Co & & 581.5 & 580.8 & 670.0 & 81 & thescos & - & 1070 & \\
\hline Hells Canyon (Wallowa) ........................................... & 1 & 130.5 & 120.3 & 150.0 & $\mathrm{HY}$ & Water & - & 1967 & $\mathrm{OP}$ \\
\hline & 2 & 130.5 & 120.3 & 150.0 & HY & Water & - & 1967 & $O P$ \\
\hline & 3 & 130.5 & 120.3 & 150.0 & $\mathrm{HY}$ & Water & - & 1967 & OP \\
\hline 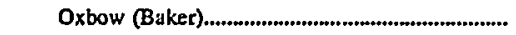 & j & 47.5 & 55.0 & 55.0 & $\mathrm{HY}$ & Water & - & 1961 & OP \\
\hline & 2 & 47.5 & 55.0 & 55.0 & $\mathrm{HY}$ & Water & - & 1961 & OP \\
\hline & 3 & 47.5 & 55.0 & 55.0 & HY & Water & - & 1961 & $\mathrm{OP}$ \\
\hline & 4 & 47.5 & 55.0 & 55.0 & HY & Water & - & 3961 & OP \\
\hline Northem Wasco County PUD ............................................ & & 16.5 & 13.9 & 139 & & & & & \\
\hline MeNary Fish (Benton) & $* * 1$ & 10.0 & 8.9 & 8.9 & $\mathrm{HY}$ & Water & - & 1997 & OP \\
\hline The Dalles Fishway (Wasco) .................................... & j & 6.5 & 5.0 & 5.0 & $\mathrm{HY}$ & Water & - & 1991 & OP \\
\hline 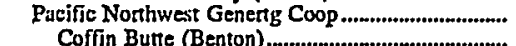 & 1 & 2.2 & 22 & 2.2 & $18 \mathrm{or}$ & Refuse & - & 1995 & $O P$ \\
\hline 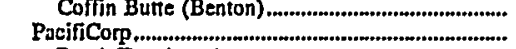 & 1 & 325.3 & 339.2 & 347.6 & 01 & Keruse & - & 1993 & UP \\
\hline Bend (Deschutes) & 1 & .2 & .2 & .2 & HY & Water & - & 1913 & OP \\
\hline & 2 & .4 & .4 & .4 & $\mathrm{HY}$ & Water & - & 1916 & $\mathrm{OP}$ \\
\hline & 3 & .6 & .6 & .6 & HY & Warer & - & 1917 & $\mathrm{OP}$ \\
\hline 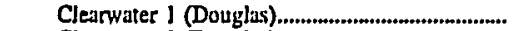 & 1 & 15.0 & 15.0 & 15.0 & $\mathrm{HY}$ & Water & - & 1953 & OP \\
\hline 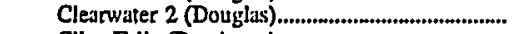 & j & 26.0 & 26.0 & 26.0 & $\mathrm{HY}$ & Water & - & 1953 & OP \\
\hline Cline Falls (Deschutes).................................... & $i$ & 1.0 & $\mathrm{E}_{1.0}$ & $E_{1.0}$ & $\mathrm{HY}$ & Water & - & 1943 & OP \\
\hline 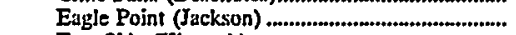 & $i$ & 2.8 & 3.0 & 3.0 & $\mathrm{HY}$ & Water & - & 1957 & OP \\
\hline 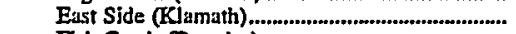 & j & 3.2 & 3.0 & 3.0 & $\mathrm{HY}$ & Water & - & 1924 & OP \\
\hline Fish Creek (Douglas)...................................................... & j & 11.0 & 120 & 12.0 & $\mathrm{HY}$ & Water & - & 1952 & OP \\
\hline 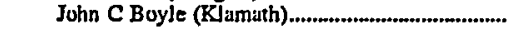 & 1 & 40.0 & 42.0 & 46.0 & HY & Water & - & 1958 & OP \\
\hline & 2 & 40.0 & 42.0 & 44.0 & $\mathrm{HY}$ & Water & - & 1958 & $O P$ \\
\hline 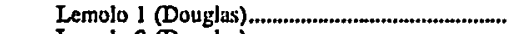 & 1 & 29.0 & 28.0 & 29.0 & $\mathrm{HY}$ & Water & - & 1955 & OP \\
\hline 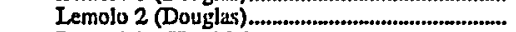 & i & 33.0 & 34.0 & 35.0 & HY & Water & - & 1956 & $O P$ \\
\hline 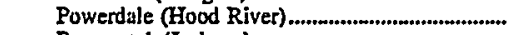 & j & 6.0 & 6.5 & 6.5 & HY & Water & - & 1923 & OP \\
\hline 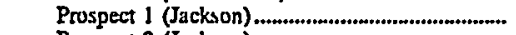 & 1 & 3.8 & 4.7 & 5.0 & HY & Water & - & 1912 & $O P$ \\
\hline 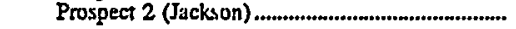 & 1 & 16.0 & 18.0 & 18.0 & HY & Water & - & 1928 & OP \\
\hline & 2 & 16.0 & 18.0 & 18.0 & $\mathrm{HY}$ & Water & - & 1928 & $\mathrm{OP}$ \\
\hline Prospect 3 (Jackson) ..................................................... & ] & 7.2 & 7.5 & 8.0 & HY & Water & - & 1932 & OP \\
\hline Prospect 4 (Jackson) ............................................ & i & 1.0 & 3.0 & 1.0 & HY & Water & - & 1944 & OP \\
\hline Slide Creek (Douglas) ….............................................. & 1 & 18.0 & 18.0 & 18.0 & HY & Water & - & 1951 & $O P$ \\
\hline 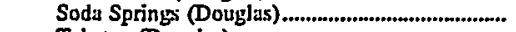 & $\mathbf{l}$ & 11.0 & 11.5 & 11.0 & HY & Water & - & 1952 & OP \\
\hline 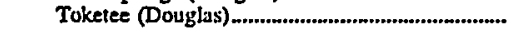 & 1 & 14.2 & 15.0 & 15.0 & HY & Water & - & 3950 & OP \\
\hline & 2 & 14.2 & 15.0 & 15.0 & HY & Water & - & 1949 & $O P$ \\
\hline & 3 & 14.2 & 15.0 & 15.0 & $\mathrm{HY}$ & Water & - & 1950 & OP \\
\hline Wallowa Falls (Wallowa) ......................................... & j & 1.J & .9 & 1.0 & $\mathrm{HY}$ & Water & $=$ & 1921 & OP \\
\hline West Side (KJumath) & 1 & .6 & 1.0 & 1.0 & HY & Water & - & 1908 & OP \\
\hline Porland General Electric Co.................................. & & 2,2782 & $2,126,2$ & $2,228.1$ & & & & & \\
\hline 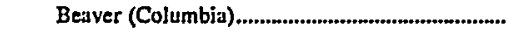 & 1 & 68.3 & 58.7 & 66.7 & CT & Nat Gas & F02 & 1974 & op \\
\hline & 2 & 68.3 & 58.7 & 66.7 & CT & & FO2 & 1974 & OP \\
\hline & 3 & 68.3 & 58.7 & 66.7 & CT & Nat Gas & FO2 & 1974 & OP \\
\hline & 4 & 68.3 & 58.7 & 66.7 & $\overline{C T}$ & Nat Gas & $\mathrm{FO} 2$ & 1974 & $O P$ \\
\hline & 5 & 68.3 & 58.7 & 66.7 & $C T$ & Nat Gas & $\mathrm{FO} 2$ & 1974 & $O P$ \\
\hline & 6 & 68.3 & 58.7 & 66.7 & $\hat{\mathbf{C T}}$ & Nar Gus & $\mathrm{FO} 2$ & 1974 & OP \\
\hline & 7 & 176.4 & 141.0 & 134.0 & $\mathrm{CW}$ & WH & & 1977 & OP \\
\hline 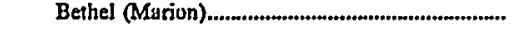 & 1 & 56.7 & 51.5 & 58.0 & Gr & FO2 & Nat Gas & 1973 & $\mathbf{O P}$ \\
\hline & 2 & 56.7 & 51.5 & 58.0 & GT & FO2 & Nat Gas & 1973 & OP \\
\hline 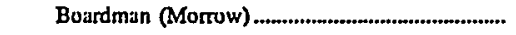 & & 560.5 & 508.0 & 508.0 & SI & BIT & - & 1980 & OP \\
\hline
\end{tabular}

See footnotes at end of table. 
Table 20. Existing Generating Units at U.S. Electric Utilities by State, Company, and Plant, as of January 1, 1998 (Continued)

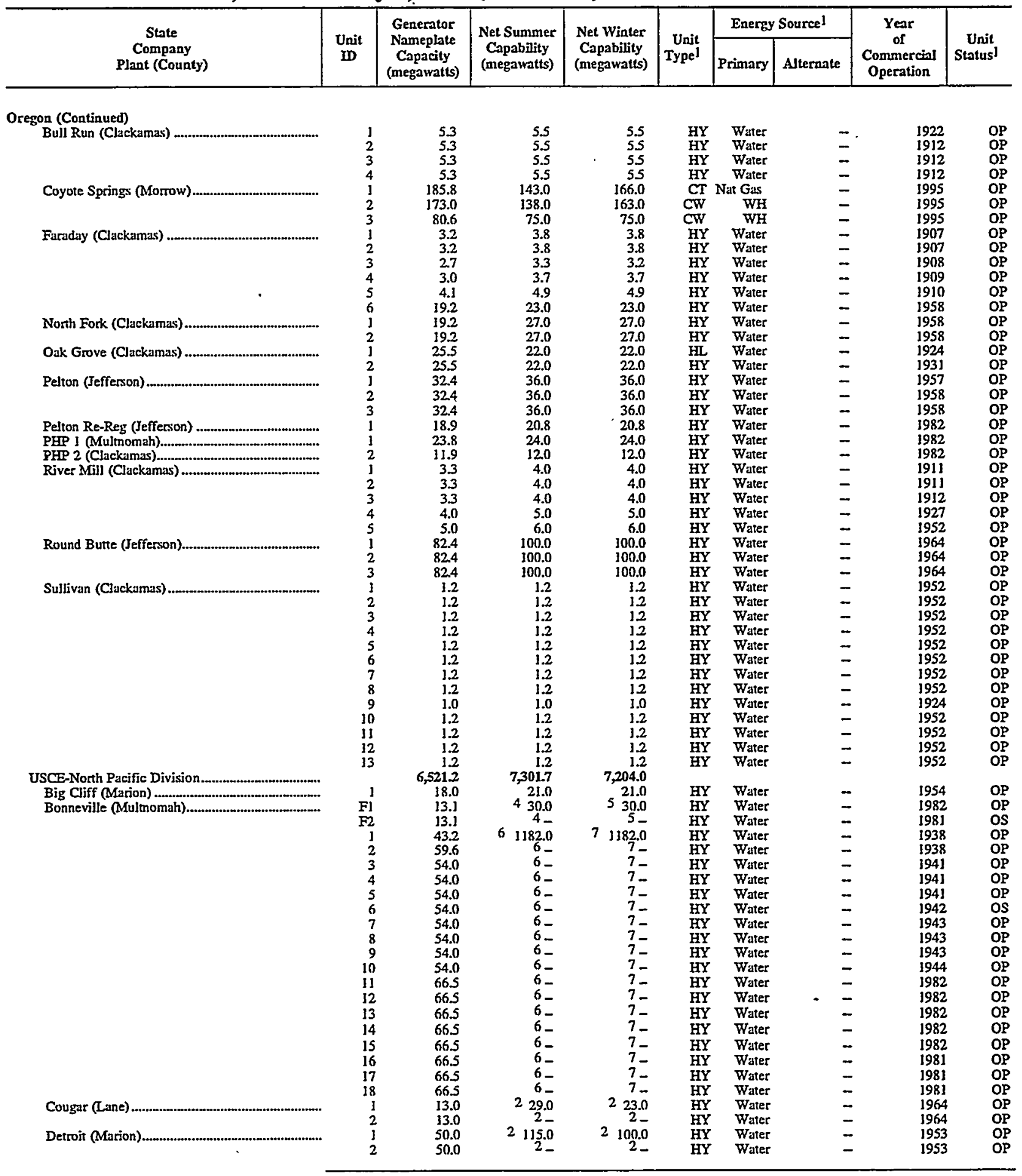

See footnotes at end of table. 
Table 20. Existing Generating Units at U.S. Electric Utilities by State, Company, and Plant, as of January 1, 1998 (Continued)

\begin{tabular}{|c|c|c|c|c|c|c|c|c|c|}
\hline \multirow{2}{*}{$\begin{array}{c}\text { State } \\
\text { Company } \\
\text { Plant (County) }\end{array}$} & \multirow{2}{*}{$\begin{array}{l}\text { Unit } \\
\text { ID }\end{array}$} & \multirow{2}{*}{$\begin{array}{c}\text { Generator } \\
\text { Nameplate } \\
\text { Capacity } \\
\text { (megawatts) }\end{array}$} & \multirow{2}{*}{$\begin{array}{l}\text { Net Summer } \\
\text { Capability } \\
\text { (megawatts) }\end{array}$} & \multirow{2}{*}{$\begin{array}{c}\text { Net Winter } \\
\text { Capability } \\
\text { (megnwatts) }\end{array}$} & \multirow{2}{*}{$\begin{array}{l}\text { Unit } \\
\text { Typel }\end{array}$} & \multicolumn{2}{|c|}{ Energy Source! } & \multirow{2}{*}{$\begin{array}{c}\text { Year } \\
\text { of } \\
\text { Commercinl } \\
\text { Operation }\end{array}$} & \multirow{2}{*}{$\begin{array}{c}\text { Unit } \\
\text { Statusl }\end{array}$} \\
\hline & & & & & & Primary & Alternate & & \\
\hline \multicolumn{10}{|l|}{ Oregon (Continued) } \\
\hline Dexter (Lane) & 1 & 15.0 & 17.0 & 17.0 & HY & Water & - & 1955 & OS \\
\hline Foster (Linn) & $\begin{array}{l}1 \\
2\end{array}$ & $\begin{array}{l}10.0 \\
10.0\end{array}$ & 223.0 & 221.0 & HYY & $\begin{array}{l}\text { Water } \\
\text { Water }\end{array}$ & $\overline{-}$ & $\begin{array}{l}1968 \\
1968\end{array}$ & $\begin{array}{l}\text { OP } \\
\text { OP }\end{array}$ \\
\hline Green Peter $(\operatorname{Linn})$ & j & 40.0 & 292.0 & 276.0 & $\mathbf{H Y}$ & Water & - & 1967 & OS \\
\hline 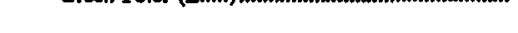 & 2 & 40.0 & $2-$ & $2-$ & HY & Water & - & 1967 & OP \\
\hline 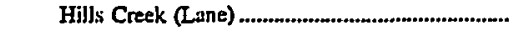 & 1 & 15.0 & 235.0 & 231.0 & $\mathbf{H Y}$ & Water & - & 1962 & OP \\
\hline John Day (Sherman) & 2 & $\begin{array}{r}15.0 \\
1350\end{array}$ & $2 \quad \begin{array}{l}2- \\
24840\end{array}$ & $2 \frac{2}{2}$ & HY & Water & $\overline{-}$ & 1962 & OP \\
\hline 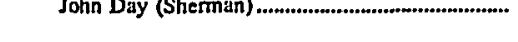 & $\begin{array}{l}1 \\
2\end{array}$ & $\begin{array}{l}135.0 \\
135.0\end{array}$ & $\begin{array}{r}2484.0 \\
2-\end{array}$ & $\begin{array}{r}2484.0 \\
2-\end{array}$ & $\begin{array}{l}\text { HYY } \\
\text { HY }\end{array}$ & $\begin{array}{l}\text { Water } \\
\text { Water }\end{array}$ & $\overline{-}$ & $\begin{array}{l}1968 \\
1968\end{array}$ & $\begin{array}{l}\text { OP } \\
\text { OP }\end{array}$ \\
\hline & 3 & 135.0 & $2-$ & $2-$ & $\mathrm{HY}$ & Water & - & 1968 & OP \\
\hline & 4 & 135.0 & $2-$ & $2-$ & HY & Water & - & 1968 & $\mathrm{OP}$ \\
\hline & 5 & 135.0 & $2-$ & $2-$ & HY & Water & - & 1969 & OP \\
\hline & 6 & 135.0 & $2-$ & $2-$ & HY & Water & - & 1969 & OP \\
\hline & 7 & 135.0 & $2-$ & $2-$ & HY & Water & - & 1969 & OP \\
\hline & 8 & 335.0 & $2-$ & $2-$ & HY & Water & - & 1969 & OP \\
\hline & 9 & 135.0 & $\begin{array}{l}2- \\
2-\end{array}$ & $2-$ & HY & Water & - & 1969 & OP \\
\hline & $\begin{array}{l}10 \\
11\end{array}$ & $\begin{array}{l}135.0 \\
135.0\end{array}$ & $\frac{2}{2-}$ & $\begin{array}{l}2- \\
2-\end{array}$ & $\underset{H Y Y}{H Y}$ & Water & - & $\begin{array}{l}1969 \\
1970\end{array}$ & OP \\
\hline & 12 & 135.0 & $2-$ & $2-$ & $\begin{array}{l}\text { HY } \\
\text { HY }\end{array}$ & $\begin{array}{l}\text { Water } \\
\text { Water }\end{array}$ & $\overline{-}$ & $\begin{array}{l}1970 \\
1970\end{array}$ & OP \\
\hline & 13 & 135.0 & $2-$ & $2-$ & $\mathbf{H Y}$ & Water & - & 1970 & $O P$ \\
\hline & 14 & 135.0 & 2- & $2-$ & HY & Water & - & 1971 & OP \\
\hline & 15 & 135.0 & $2-$ & $2-$ & $\mathrm{HY}$ & Water & - & 1971 & OP \\
\hline & 16 & 135.0 & $2-$ & $2-$ & HY & Water & - & 3971 & OS \\
\hline Lookout Point (Lane) & 1 & 40.0 & 2138.0 & 284.0 & $\mathbf{H Y}$ & Water & - & 1955 & OP \\
\hline & 2 & 40.0 & $2-$ & $2-$ & $\mathbf{H Y}$ & Water & - & 1955 & os \\
\hline & 3 & 40.0 & $2_{-}$ & $2-$ & HY & Water & - & 1955 & OP \\
\hline Lost Creek (Jackson) & I & 24.5 & 248.0 & 248.0 & HY & Water & - & 1977 & OP \\
\hline & 2 & 24.5 & $2-$ & $2-$ & HY & Water & - & 1977 & OP \\
\hline MeNary (Umatilla) & j & 70.0 & 21127.0 & 21127.0 & $\mathbf{H Y}$ & Water & - & 1953 & OP \\
\hline & 2 & 70.0 & $2-$ & & $\mathbf{H Y}$ & Water & - & 1954 & OP \\
\hline & 3 & 70.0 & $2-$ & & $\mathbf{H Y}$ & Water & - & 1954 & OP \\
\hline & 4 & 70.0 & $2-$ & $2-$ & HY & Water & - & 1954 & OP \\
\hline & $\begin{array}{l}5 \\
6\end{array}$ & $\begin{array}{l}70.0 \\
70.0\end{array}$ & $\begin{array}{l}2- \\
2-\end{array}$ & $\begin{array}{l}2- \\
2-\end{array}$ & $\begin{array}{l}H Y \\
H Y\end{array}$ & $\begin{array}{l}\text { Water } \\
\text { Water }\end{array}$ & $=$ & $\begin{array}{l}1954 \\
1955\end{array}$ & OP \\
\hline & 7 & 70.0 & $2-$ & $2-$ & $\begin{array}{l}\text { HY } \\
\text { HY }\end{array}$ & Water & $=$ & 1955 & OP \\
\hline & 8 & 70.0 & $2-$ & $2-$ & HY & Water & - & 1955 & OP \\
\hline & 9 & 70.0 & $2-$ & 2 & $\mathrm{HY}$ & Water & - & 1956 & $O P$ \\
\hline & 10 & 70.0 & $2_{-}$ & $2-$ & $\mathrm{HY}$ & Water & - & 1955 & $O P$ \\
\hline & 11 & 70.0 & $2-$ & $2-$ & $\mathrm{HY}$ & Water & - & 1956 & $\mathrm{OP}$ \\
\hline & 12 & 70.0 & $2-$ & $2-$ & HY & Water & _ & 1956 & OP \\
\hline & 13 & 70.0 & $2-$ & $2-$ & HY & Water & - & 1957 & OP \\
\hline & 14 & 80.5 & $2-$ & $2-$ & $\mathbf{H Y}$ & Water & - & 1957 & OP \\
\hline 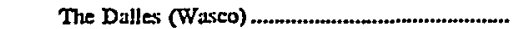 & Fj & 14.0 & 81868.0 & 91868.0 & HY & Water & - & 1957 & os \\
\hline & $\mathrm{F} 2$ & 14.0 & $8-$ & & HY & Water & - & 1957 & OS \\
\hline & 1 & 78.0 & & $9-$ & $\mathrm{HY}$ & Water & - & 3957 & OP \\
\hline & 2 & 78.0 & $8-$ & $9-$ & HY & Water & - & 3957 & OP \\
\hline & 3 & 78.0 & $8-$ & 9- & HY & Water & - & 1958 & OP \\
\hline & 4 & 78.0 & 8 & $9-$ & HY & Water & - & 3958 & $O P$ \\
\hline & 5 & 89.7 & $E_{92.7}$ & $E_{92.0}$ & $\mathrm{HY}$ & Water & - & 1958 & OP \\
\hline & 6 & 78.0 & $8-$ & 9- & HY & Water & - & 1958 & OP \\
\hline & 7 & 78.0 & $8-$ & 9- & HY & Water & - & 1959 & OP \\
\hline & 8 & 78.0 & $8-$ & $9-$ & $\mathrm{HY}$ & Water & - & 1959 & OP \\
\hline & 9 & 78.0 & $8-$ & $9-$ & HY & Water & - & 1959 & OP \\
\hline & 10 & 78.0 & $8-$ & 9- & HY & Water & - & 1959 & $O P$ \\
\hline & 11 & 78.0 & $8-$ & 9- & HY & Water & - & 1960 & os \\
\hline & 12 & 78.0 & $8-$ & 9 & $\mathbf{H Y}$ & Water & - & 1960 & OP \\
\hline & 13 & 78.0 & $8-$ & $9-$ & HY & Water & - & 1960 & OP \\
\hline & 14 & 78.0 & $8_{-}$ & $9-$ & $\mathrm{HY}$ & Water & - & 1960 & OP \\
\hline & 15 & 86.0 & $8_{-}$ & 9- & HY & Water & - & 1973 & $O P$ \\
\hline & 16 & 86.0 & $8_{-}$ & 9 & $\mathrm{HY}$ & Water & - & $j 973$ & $O P$ \\
\hline & 17 & 86.0 & $8-$ & $9-$ & HY & Water & - & 1973 & $\mathrm{OP}$ \\
\hline & 18 & 86.0 & 8 & 9 & HY & Water & - & 1973 & $O P$ \\
\hline & 10 & $\begin{array}{l}60.0 \\
86.0\end{array}$ & $8-$ & 9 & HY & Water & $=$ & 1973 & $O P$ \\
\hline & 37 & 860 & $8-$ & 9 & HY & witer & 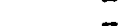 & 1073 & $\mathrm{OP}$ \\
\hline & 20 & 86.0 & $8^{8}-$ & $0^{y^{-}}$ & HY & Water & - & 1973 & OP \\
\hline & 21 & 86.0 & 8- & $9-$ & $\mathrm{HY}$ & Water & - & 1973 & OP \\
\hline & & 86.0 & & & HY & Water & - & 1973 & $\mathrm{OP}$ \\
\hline Pennsylvania & & & & & & & & & \\
\hline Pennsylvania Subtotal & & $36,884.9$ & 33,8253 & $34,855.0$ & & & & & \\
\hline
\end{tabular}

See footnotes at end of table. 
Table 20. Existing Generating Units at U.S. Electric Utilities by State, Company, and Plant, as of January 1, 1998 (Continued)

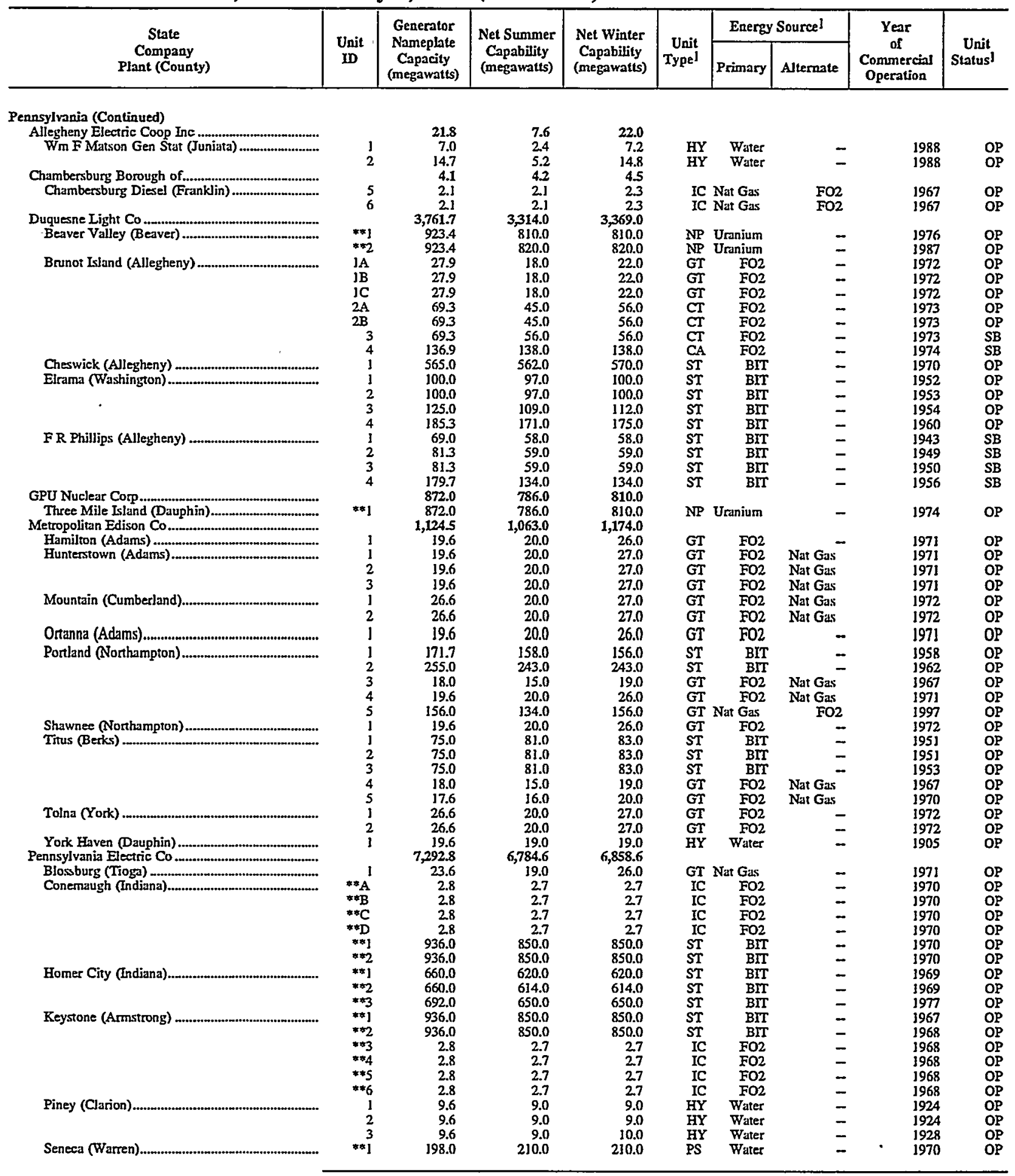

See footnotes at end of table. 
Table 20. Existing Generating Units at U.S. Electric Utilities by State, Company, and Plant, as of January 1, 1998 (Continued)

\begin{tabular}{|c|c|c|c|c|c|c|c|c|c|}
\hline \multirow{2}{*}{$\begin{array}{c}\text { State } \\
\text { Company } \\
\text { Plant (County) }\end{array}$} & \multirow{2}{*}{$\begin{array}{l}\text { Unit } \\
\text { ID }\end{array}$} & \multirow{2}{*}{$\begin{array}{l}\text { Generator } \\
\text { Nameplate } \\
\text { Capacity } \\
\text { (megawatts) }\end{array}$} & \multirow{2}{*}{$\begin{array}{c}\text { Net Summer } \\
\text { Capability } \\
\text { (megawatts) }\end{array}$} & \multirow{2}{*}{$\begin{array}{l}\text { Net Winter } \\
\text { Capability } \\
\text { (megawatts) }\end{array}$} & \multirow{2}{*}{$\begin{array}{l}\text { Unit } \\
\text { Type }\end{array}$} & \multicolumn{2}{|c|}{ Energy Source! } & \multirow{2}{*}{$\begin{array}{c}\text { Year } \\
\text { of } \\
\text { Comnlercial } \\
\text { Operation }\end{array}$} & \multirow{2}{*}{$\begin{array}{l}\text { Unit } \\
\text { Statusl }\end{array}$} \\
\hline & & & & & & Primary & Alternate & & \\
\hline Pennsylvania (Continued) & & & & & & & & & \\
\hline & $m 2$ & 198.0 & 197.0 & 197.0 & PS & Water & - & 1970 & OP \\
\hline Seward (Indiana) & $\approx+3$ & 26.0 & 32.0 & & PS & Water & - & 1970 & $O P$ \\
\hline 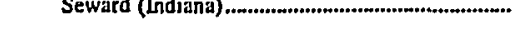 & $\begin{array}{l}4 \\
5\end{array}$ & $\begin{array}{l}62.01 \\
156.2\end{array}$ & $\begin{array}{r}60.0 \\
136.0\end{array}$ & $\begin{array}{r}62.0 \\
137.0\end{array}$ & $\begin{array}{l}S T \\
S T\end{array}$ & $\begin{array}{l}\text { BIT } \\
\text { BIT }\end{array}$ & $\bar{z}$ & $\begin{array}{l}1950 \\
1957\end{array}$ & $\begin{array}{l}\text { OP } \\
\text { OP }\end{array}$ \\
\hline Shawville (Clearfield) & 1 & 125.0 & 1220 & 128.0 & ST & BIT & - & 1954 & $O P$ \\
\hline & 2 & 125.0 & 125.0 & 130.0 & ST & BIT & - & 1954 & OP \\
\hline & 3 & 187.5 & 175.0 & 180.0 & ST & BIT & - & 1959 & OP \\
\hline & 4 & 187.5 & 175.0 & 180.0 & $\operatorname{ST}$ & $\mathrm{BIT}$ & - & 1960 & OP \\
\hline & 5 & 20 & 2.0 & 2.0 & IC & FO2 & - & 1960 & OP \\
\hline & 6 & 20 & 2.0 & 2.0 & IC & FO2 & - & 1960 & OP \\
\hline & 7 & 20 & 2.0 & 2.0 & IC & $\mathrm{FO} 2$ & - & 1960 & OP \\
\hline Warren (Warren) & ] & 42.3 & 41.0 & 41.0 & ST & BIT & - & 1948 & $O P$ \\
\hline & 2 & 42.3 & 41.0 & 41.0 & ST & BIT & - & 1949 & OP \\
\hline & 3 & 53.1 & 57.0 & 79.0 & GI & FO2 & Nat Gas & 1972 & OP \\
\hline Wayne (Crawford) & A & 53.1 & 56.0 & 76.0 & GT & FO2 & - & 1972 & OP \\
\hline Pennsylvania Power \& Ligtt Co.................. & & $8,487.1$ & $7,866.2$ & $8,078.2$ & & & & & \\
\hline 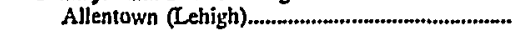 & CT! & 36.0 & 14.0 & 18.0 & GT & FO2 & - & 1967 & OP \\
\hline & CT2 & 16.0 & 14.0 & 18.0 & GT & $\mathrm{FO} 2$ & - & 1967 & OP \\
\hline & CT3 & 16.0 & 14.0 & 18.0 & GT & $\mathrm{FO} 2$ & - & 1967 & $O P$ \\
\hline & CT4 & 16.0 & 14.0 & 18.0 & GT & $\mathrm{FO} 2$ & - & 1967 & OP \\
\hline 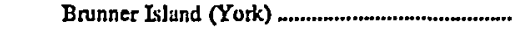 & D] & 2.8 & 28 & 2.8 & IC & $\mathrm{FO2}$ & - & 1967 & OP \\
\hline & D2 & $\begin{array}{l}2.8 \\
2.8\end{array}$ & $\begin{array}{l}2.8 \\
2.7\end{array}$ & $\begin{array}{r}28 \\
27\end{array}$ & $\begin{array}{l}\text { IC } \\
\text { IC }\end{array}$ & $\mathrm{FO2}$ & - & 1967 & $\begin{array}{l}\mathrm{OP} \\
\mathrm{OP}\end{array}$ \\
\hline & D3 & 363.3 & 321.0 & 334.0 & $\underset{\text { ST }}{\text { IC }}$ & FO2 & 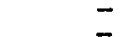 & 1967 & $O P$ \\
\hline & $\frac{1}{2}$ & 405.0 & 378.0 & 390.0 & $\begin{array}{l}\text { ST } \\
\text { ST }\end{array}$ & $\frac{B I T}{B I T}$ & $\overline{-}$ & $\begin{array}{l}1961 \\
1965\end{array}$ & OP \\
\hline & 3 & 790.4 & 735.0 & 745.0 & ST & BIT & $\underline{-}$ & 1969 & OP \\
\hline 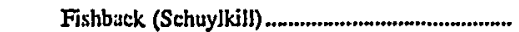 & CT1 & 18.6 & 14.0 & 18.0 & GT & FO2 & - & 1969 & OP \\
\hline & CT2 & 18.6 & 14.0 & 18.0 & GT & $\mathrm{FO} 2$ & - & 1969 & OP \\
\hline Harrisburg (Dauphin) & CTI & 16.0 & 14.0 & 38.0 & GT & $\mathrm{FO} 2$ & - & 1967 & $\mathrm{OP}$ \\
\hline & CT2 & 16.0 & 14.0 & 18.0 & GT & $\mathrm{FO} 2$ & - & 1967 & ${ }_{O P}$ \\
\hline & CT3 & 16.0 & 14.0 & 18.0 & GT & FO2 & - & 1967 & $\mathrm{OP}$ \\
\hline & CT4 & 16.0 & 14.0 & 18.0 & GT & $\mathrm{FO} 2$ & - & 1967 & OP \\
\hline 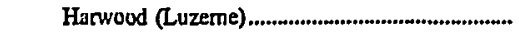 & CTl & 16.0 & 14.0 & 18.0 & GT & FO2 & - & 1967 & OP \\
\hline & CT2 & 16.0 & 14.0 & 18.0 & GT & FO2 & - & 3967 & OP \\
\hline Holtwood (Laneaster) & 3 & 10.4 & 11.0 & Jנ.0 & $\mathrm{HY}$ & Water & - & 1910 & $O P$ \\
\hline & 2 & 10.4 & 31.0 & 31.0 & $\mathrm{HY}$ & Water & - & 1911 & OP \\
\hline & 3 & 10.4 & 31.0 & 11.0 & HY & Water & - & 1911 & OP \\
\hline & 4 & 10.4 & 10.0 & 10.0 & $\mathrm{HY}$ & Water & - & 1911 & $\mathrm{OP}$ \\
\hline & 5 & 10.4 & 10.0 & 10.0 & $\mathrm{HY}$ & Water & - & 1911 & $\mathrm{OP}$ \\
\hline & 6 & 10.4 & 10.0 & 10.0 & $\mathrm{HY}$ & Water & - & 1911 & $O P$ \\
\hline & 7 & 10.4 & 10.0 & 10.0 & $\mathrm{HY}$ & Water & - & 1913 & OP \\
\hline & 8 & 10.4 & 10.0 & 10.0 & $\mathrm{HY}$ & Water & - & 1914 &. $\mathrm{OP}$ \\
\hline & 9 & 120 & 12.0 & 12.0 & $\mathrm{HY}$ & Water & - & 1924 & OP \\
\hline & 10 & 12.0 & 120 & 12.0 & $\mathrm{HY}$ & Water & - & 1924 & OP \\
\hline & J] & .5 & .5 & 5 & $\mathrm{HY}$ & Water & - & 1910 & $O P$ \\
\hline & 13 & 5 & 5 & 5 & $\mathrm{HY}$ & Water & - & 1910 & $O P$ \\
\hline & 17 & 75.0 & 720 & 73.0 & ST & ANT & - & 1954 & $O P$ \\
\hline Jenkins (Luzerne)......................................................... & CTl & 16.0 & 14.0 & 18.0 & GT & FO2 & - & 1969 & OP \\
\hline & CT2 & 16.0 & 14.0 & 18.0 & GT & $\mathrm{FO} 2$ & - & 3969 & OP \\
\hline Lock Haven (Clinton) & GTI & 18.6 & 14.0 & 18.0 & GT & $\mathrm{FO} 2$ & - & 1969 & $\mathrm{OP}$ \\
\hline Martins Creek (Nonthampton) .................................. & DI & 2.8 & 2.5 & 2.5 & IC & FO2 & - & 1967 & $O P$ \\
\hline & D2 & 2.8 & 2.5 & 2.5 & IC & $\mathrm{FO2}$ & - & 1967 & $\mathrm{OP}$ \\
\hline & ] & 156.3 & 140.0 & 150.0 & ST & BIT & - & 1954 & OP \\
\hline & 2 & 1563 & 140.0 & 150.0 & ST & BIT & $m-$ & 1956 & $O P$ \\
\hline & 3 & 850.5 & 807.0 & 807.0 & ST & Nat Gas & FO6 & 1975 & OP \\
\hline & 4 & 850.5 & 785.0 & 785.0 & ST & Nat Gas & FO6 & $19 n$ & OP \\
\hline 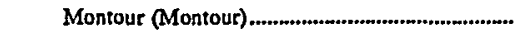 & J & 805.5 & 745.0 & 755.0 & ST & BIT & - & 1972 & OP \\
\hline & 2 & 819.0 & 745.0 & 755.0 & ST & BIT & - & 1973 & of \\
\hline & J1 & 17,2 & 15.0 & 15.0 & ST & BIT & - & 1973 & o \\
\hline 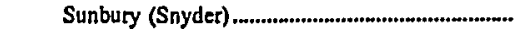 & Dl & 2,8 & 3.0 & 3.0 & IC & $\mathrm{FO} 2$ & - & 1967 & OP \\
\hline & D2 & 2.8 & 3.0 & 3.0 & IC & $\mathrm{FO} 2$ & - & 1967 & OP \\
\hline & I & 75.0 & 70.0 & 76.0 & $\mathbf{C H}$ & ANT & - & 1949 & OP \\
\hline & 2 & 75.0 & & 76.0 & $\mathrm{CH}$ & ANT & - & 1949 & $O P$ \\
\hline & 3 & 103.5 & 94.0 & 103.0 & $\mathrm{CH}$ & BIT & - & 1951 & OP \\
\hline & & 156.3 & 128.0 & 134.0 & ST & BIT & _ & 1953 & OP \\
\hline 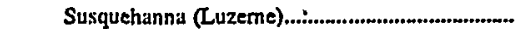 & $=*_{1}$ & 1152.0 & 1090.0 & I 107.0 & NB & Uranium & - & 1983 & $O P$ \\
\hline & $* 2$ & 1152,0 & 1094.0 & 1110.0 & NB & Uranium & - & 1985 & 0 \\
\hline 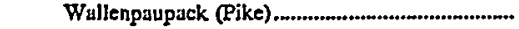 & I & 20.0 & 22.0 & 22.0 & $\mathrm{HY}$ & Water & - & 1926 & OP \\
\hline & 2 & 20.0 & 22.0 & 22.0 & $\mathbf{H Y}$ & Water & - & 1926 & OP \\
\hline West Shore (Dauphin & CTI & 18.6 & 34.0 & 18.0 & GT & FO2 & - & 1969 & OP \\
\hline
\end{tabular}

See footnutes at end of table. 
Table 20. Existing Generating Units at U.S. Electric Utilities by State, Company, and Plant, as of January 1, 1998 (Continued)

\begin{tabular}{|c|c|c|c|c|c|c|c|c|c|}
\hline \multirow{2}{*}{$\begin{array}{c}\text { State } \\
\text { Company } \\
\text { PIant (County) }\end{array}$} & \multirow{2}{*}{$\begin{array}{c}\text { Unit } \\
\text { ID }\end{array}$} & \multirow{2}{*}{$\begin{array}{c}\text { Generator } \\
\text { Nameplate } \\
\text { Capacily } \\
\text { (megawatts) }\end{array}$} & \multirow{2}{*}{$\begin{array}{l}\text { Net Summer } \\
\text { Capability } \\
\text { (negawatts) }\end{array}$} & \multirow{2}{*}{$\begin{array}{c}\text { Net Winter } \\
\text { Capability } \\
\text { (megawatts) }\end{array}$} & \multirow{2}{*}{$\begin{array}{r}\text { Unit } \\
\text { TypeI }\end{array}$} & \multicolumn{2}{|c|}{ Energy Sourcel } & \multirow{2}{*}{$\begin{array}{c}\text { Year } \\
\text { of } \\
\text { Commercial } \\
\text { Operation }\end{array}$} & \\
\hline & & & & & & Primary & Alternate & & \\
\hline Pennsylvania (Continued) & & & & & & & & & \\
\hline & CT2 & 18.6 & 14.0 & 18.0 & GT & FO2 & - & 1969 & OP \\
\hline Williamsport (Lycoming) & Cr] & 16.0 & 14.0 & 18.0 & GT & FO2 & - & 1967 & $\stackrel{O P}{O P}$ \\
\hline 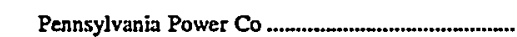 & 212 & $\begin{array}{r}10.0 \\
3,094.1\end{array}$ & $\begin{array}{r}14.0 \\
2,699.0\end{array}$ & $\begin{array}{r}18.0 \\
2,699.0\end{array}$ & GT & $\mathrm{FO} 2$ & - & 1967 & OP \\
\hline Bruce Mansfield (Beiver) & $*$ * ] & 913.8 & 780.0 & 780.0 & $S T$ & BIT & - & 1976 & OP \\
\hline & $* 2$ & 913.8 & 780.0 & 780.0 & $\mathrm{ST}$ & BIT & - & 1977 & OP \\
\hline & $* * 3$ & 913.8 & 800.0 & 800.0 & ST & BIT & - & 1980 & OP \\
\hline New Castle (Luwrence) & 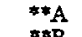 & 2.8 & 3.0 & 3.0 & IC & $\mathrm{FO} 2$ & - & 1968 & OP \\
\hline & $\approx \mathbf{B}$ & 2.8 & 3.0 & 3.0 & IC & $\mathrm{FO} 2$ & - & 1968 & OP \\
\hline & 3 & 97.8 & 98.0 & 98.0 & ST & BIT & - & 1952 & OP \\
\hline & 4 & 113.6 & 98.0 & 98.0 & ST & BIT & - & 1958 & OP \\
\hline & $s$ & 136.0 & 137.0 & 137.0 & ST & BIT & - & 1964 & OP \\
\hline PECO Energy Co & & $9,040.8$ & $8,338.2$ & 8,6992 & & & & & \\
\hline Chester (Delaware) & 7 & 18.6 & 13.0 & 18.0 & GT & $\mathrm{FO} 2$ & - & 1969 & OP \\
\hline & 8 & 38.6 & 13.0 & 18.0 & GT & $\mathrm{FO} 2$ & - & 1969 & OP \\
\hline & 9 & 38.6 & 13.0 & 38.0 & GT & $\mathrm{FO} 2$ & - & 1969 & OP \\
\hline Cromby (Chester) & ICl & 2.8 & 27 & 2.7 & IC & $\mathrm{FO2}$ & - & 1967 & OP \\
\hline & 1 & 187.5 & 144.0 & 147.0 & ST & BIT & FO6 & 1954 & OP \\
\hline & 2 & 230.0 & 201.0 & 211.0 & ST & Nat Gas & FO6 & 1955 & OP \\
\hline Croydon (Bucks) & 11 & 68.3 & 49.0 & 60.0 & GT & FO2 & - & 1974 & OP \\
\hline & 12 & 68.3 & 48.0 & 60.0 & GT & FO2 & - & 1974 & OP \\
\hline & 21 & 68.3 & 45.0 & 59.0 & GT & $\mathrm{FO} 2$ & - & 1974 & OP \\
\hline & 22 & 68.3 & 47.0 & 60.0 & GT & FO2 & - & 1974 & OP \\
\hline & 31 & 68.3 & 47.0 & 60.0 & GT & $\mathrm{FO} 2$ & - & 1974 & OP \\
\hline & 32 & 68.3 & 45.0 & 59.0 & GT & $\mathrm{FO} 2$ & - & 1974 & OP \\
\hline & 41 & 68.3 & 47.0 & 60.0 & GT & FO2 & - & 1974 & OP \\
\hline & 42 & 68.3 & 45.0 & 59.0 & GT & $\mathrm{FO} 2$ & - & 1974 & OP \\
\hline 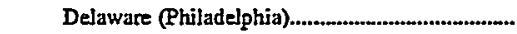 & 1 & 2.8 & 27 & 2.7 & IC & $\mathrm{FO2}$ & - & 1967 & OP \\
\hline n. & 7 & 156.3 & 126.0 & 128.0 & ST & FO6 & - & 1953 & OP \\
\hline " & 8 & 156.3 & 124.0 & 128.0 & ST & Fo6 & - & 1953 & OP \\
\hline & 9 & 21.3 & 17.0 & 20.0 & GT & $\mathrm{FO} 2$ & - & 1970 & OP \\
\hline & 10 & 18.6 & 15.0 & 18.0 & GT & FO2 & - & 1969 & OP \\
\hline & II & 18.6 & 15.0 & 18.0 & GT & FO2 & - & 1969 & OP \\
\hline & 12 & 18.6 & 15.0 & 18.0 & GT & FO2 & - & 1969 & OP \\
\hline 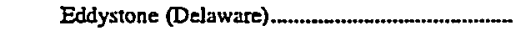 & 1 & 353.6 & 279.0 & 288.0 & ST & BIT & - & 1960 & OP \\
\hline & 2 & 353.6 & 302.0 & 311.0 & ST & BIT & - & 1960 & OP \\
\hline & 3 & 391.0 & 380.0 & 380.0 & ST & FO6 & Nat Gus & 1974 & OP \\
\hline & 4 & 391.0 & 380.0 & 380.0 & ST & FO6 & Nat Gas & 1976 & OP \\
\hline & 10 & 18.6 & 14.0 & 18.0 & GT & FO2 & - & 1967 & OP \\
\hline & 20 & 18.6 & 14.0 & 18.0 & $\mathrm{GT}$ & $\mathrm{FO} 2$ & - & 1967 & OP \\
\hline & 30 & 21.3 & 17.0 & 20.0 & GT & $\mathrm{FO} 2$ & - & 1970 & OP \\
\hline & 40 & 21.3 & 17.0 & 20.0 & GT & FO2 & - & 1970 & OP \\
\hline Fairless Hills (Bucks) & A & 37.5 & 30.0 & 30.0 & ST & Nat Gas & - & 1997 & $\mathrm{OP}$ \\
\hline & $\mathbf{B}$ & 37.5 & 30.0 & 30.0 & $S T$ & Nat Gas & - & 1997 & $O P$ \\
\hline Falls (Bucks) & 1 & 21.3 & 17.0 & 20.0 & GT & $\mathrm{FO} 2$ & - & 1970 & OP \\
\hline & 2 & 21.3 & 16.0 & 20.0 & GT & $\mathrm{FO} 2$ & - & 1970 & OP \\
\hline & 3 & 21.3 & 17.0 & 20.0 & GT & $\mathrm{FO} 2$ & - & 1970 & OP \\
\hline Limerick (Montgomery) & 1 & 1138.5 & 1105.0 & 1123.0 & NB & Uranium & - & 1986 & OP \\
\hline & 2 & 1092.0 & 1115.0 & 1133.0 & NB & Uranium & - & 1990 & OP \\
\hline Moser (Montgomery) & 1 & 21.3 & 16.0 & 20.0 & GT & $\mathrm{FO} 2$ & - & 1970 & OP \\
\hline & 2 & 21.3 & 16.0 & 20.0 & GT & $\mathrm{FO} 2$ & - & 1970 & OP \\
\hline & 3 & 21.3 & 16.0 & 20.0 & GT & FO2 & ـ & 1970 & OP \\
\hline Muddy Run (Lancaster) ......................................... & 1 & 100.0 & 110.0 & 110.0 & PS & Water & - & 1967 & OP \\
\hline & 2 & 100.0 & 110.0 & 110.0 & PS & Water & - & 1967 & OP \\
\hline & 3 & 100.0 & 110.0 & 110.0 & PS & Water & - & 1967 & OP \\
\hline & 4 & 100.0 & 110.0 & 110.0 & PS & Water & - & 1967 & OP \\
\hline & 5 & 100.0 & 110.0 & 110.0 & PS & Water & ـ & 1967 & OP \\
\hline & 6 & 100.0 & 110.0 & 110.0 & PS & Water & - & 1967 & OP \\
\hline & 7 & 100.0 & 110.0 & 110.0 & PS & Water & - & 1968 & OP \\
\hline & 8 & 100.0 & 110.0 & 110.0 & PS & Water & - & 1968 & OP \\
\hline Peach Bottom (York) & $* 2$ & 1152.0 & 1093.0 & 1119.0 & NB & Uranium & - & 1974 & OP \\
\hline & $\star * 3$ & 1152.0 & 3093.0 & 1119.0 & $\mathrm{NB}$ & Uranium & - & 1974 & OP \\
\hline 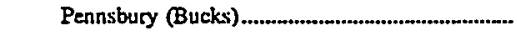 & A & 37.5 & 30.0 & 30.0 & ST & Nat Gas & - & 1997 & OP \\
\hline & B & 37.5 & 30.0 & 30.0 & ST & Nat Gas & - & 1997 & OP \\
\hline & 1 & 3.0 & 3.0 & 3.0 & GT & Nat Gas & - & 1996 & OP \\
\hline & 2 & 3.0 & 3.0 & 3.0 & GT & Nat Gas & - & 1996 & OP \\
\hline Richmond (Philadelphia) & 91 & 65.9 & 48.0 & 66.0 & GT & $\mathrm{FO} 2$ & - & 1973 & $\mathbf{O P}$ \\
\hline & 92 & 65.9 & 48.0 & 66.0 & GT & FO2 & - & 1973 & OP \\
\hline Schuylkill (Philadelphia) & ICI & 2.8 & 2.8 & 2.8 & IC & FO2 & - & 1967 & $O P$ \\
\hline & 1 & 190.4 & 166.0 & 175.0 & ST & F06 & - & 1958 & $O P$ \\
\hline
\end{tabular}

See footnotes at end of table. 
Table 20. Existing Generating Units at U.S. Electric Utilities by State, Company, and Plant, as of January 1, 1998 (Continued)

\begin{tabular}{|c|c|c|c|c|c|c|c|c|c|}
\hline \multirow{2}{*}{$\begin{array}{c}\text { State } \\
\text { Company } \\
\text { Plant (County) }\end{array}$} & \multirow{2}{*}{$\begin{array}{l}\text { Unit } \\
\text { ID }\end{array}$} & \multirow{2}{*}{$\begin{array}{l}\text { Generator } \\
\text { Nameplate } \\
\text { Capacity } \\
\text { (megawatts) }\end{array}$} & \multirow{2}{*}{$\begin{array}{c}\text { Net Summer } \\
\text { Capability } \\
\text { (megawatts) }\end{array}$} & \multirow{2}{*}{$\begin{array}{c}\text { Net Winter } \\
\text { Capability } \\
\text { (megawatts) }\end{array}$} & \multirow{2}{*}{$\begin{array}{l}\text { Unit } \\
\text { Typel }\end{array}$} & \multicolumn{2}{|c|}{ Energy Sourcel } & \multirow{2}{*}{$\begin{array}{c}\text { Year } \\
\text { of } \\
\text { Commercinl } \\
\text { Operation }\end{array}$} & \multirow{2}{*}{$\begin{array}{c}\text { Unit } \\
\text { Statusl }\end{array}$} \\
\hline & & & & & & Primary & Alternate & & \\
\hline \multicolumn{10}{|l|}{ Pennsylvania (Continued) } \\
\hline & 10 & 18.6 & 15.0 & 18.0 & GT & FO2 & - & 1969 & OP \\
\hline & jI & 21.3 & 17.0 & 20.0 & GT & FO2 & - & 1971 & OP \\
\hline \multirow[t]{4}{*}{ Southwark (Philadelphia)............................................... } & 3 & 18.6 & 13.0 & 18.0 & GT & FO2 & - & 1967 & OP \\
\hline & 4 & 18.6 & 14.0 & 38.0 & GT & Fo2 & - & 1967 & OP \\
\hline & 5 & 18.6 & 13.0 & 18.0 & GT & FO2 & - & 1967 & OP \\
\hline & 6 & 18.6 & 14.0 & 18.0 & GT & Fo2 & - & 1968 & OP \\
\hline Sufe Harbor Water Power Corp....................................... & & 417.5 & 417.5 & 417.5 & & r & & & \\
\hline 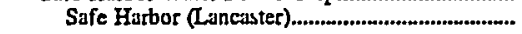 & 1 & 33.0 & 33.0 & 33.0 & HY & Water & - & 1940 & OP \\
\hline & 2 & 33.0 & 33.0 & 33.0 & $\mathrm{HY}$ & Wares & - & 1934 & OP \\
\hline & 3 & 320 & 32.0 & 32.0 & $\mathrm{HY}$ & Water & - & 1931 & OP \\
\hline & 4 & 320 & 32.0 & 32.0 & $\mathrm{HY}$ & Water & - & 1931 & $\mathrm{OP}$ \\
\hline & 5 & 32.0 & 32.0 & 32.0 & HY & Water & - & 1932 & $O P$ \\
\hline & 6 & 320 & 32.0 & 32.0 & $\mathrm{HY}$ & Water & - & 1932 & $\mathrm{OP}$ \\
\hline & 7 & 320 & 32.0 & 32.0 & $\mathrm{HY}$ & Water & - & 1933 & $O P$ \\
\hline & 8 & 37.5 & 37.5 & 37.5 & $\mathrm{HY}$ & Water & - & 1985 & $O P$ \\
\hline & 9 & 37.5 & 37.5 & 37.5 & $\mathrm{HY}$ & Water & - & 1986 & OP \\
\hline & 10 & 37.5 & 37.5 & 37.5 & HY & Water & - & 1985 & $\mathrm{OP}$ \\
\hline & II & 37.5 & 37.5 & 37.5 & HY & Water & $\underline{-}$ & 1986 & $O P$ \\
\hline & 12 & 37.5 & 37.5 & 37.5 & $\mathrm{HY}$ & Water & - & 3985 & $O P$ \\
\hline & 41 & 2.0 & 20 & 2.0 & $\mathrm{HY}$ & Water & - & 1931 & $O P$ \\
\hline & 42 & 2.0 & 20 & 2.0 & $\mathrm{HY}$ & Water & - & i93i & $O P$ \\
\hline 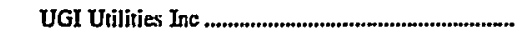 & & 50.0 & 48.0 & 48.0 & & & & & \\
\hline Hunlock Power Sta (Luzeme) ............................. & 3 & 50.0 & 48.0 & 48.0 & ST & ANT & - & 1959 & OP \\
\hline West Penn Power Co & & $2,718.5$ & $2,497.0$ & $2,675.0$ & & & & & \\
\hline Armstrong (Armstrong) & 1 & 163.2 & 1720 & 176.0 & ST & BIT & - & 1958 & OP \\
\hline & 2 & 163.2 & 171.0 & 176.0 & ST & BIT & - & 1959 & $\mathrm{OP}$ \\
\hline Hatfields Ferry (Greene)............................................... & $* * 1$ & 576.0 & 500.0 & 555.0 & ST & BIT & - & 1969 & OP \\
\hline 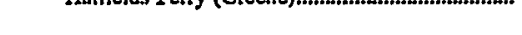 & $* * 2$ & 576.0 & 500.0 & 555.0 & ST & BIT & - & 1970 & OP \\
\hline & $* * 3$ & 576.0 & 500.0 & 550.0 & ST & BIT & $=$ & 3971 & $\mathrm{OP}$ \\
\hline Mitchell (Washington) & 1 & 74.8 & 86.0 & 86.0 & ST & $\mathrm{FO2}$ & - & 1948 & OP \\
\hline & 2 & 74.8 & $\begin{array}{r}86.0 \\
2750\end{array}$ & $\begin{array}{r}86.0 \\
2840\end{array}$ & ST & Nat Gas & FO2 & 1949 & $O P$ \\
\hline & 7 & $\begin{array}{r}29.2 \\
74.8\end{array}$ & 86.0 & 28.0 & & $\underset{\text { BTT }}{\mathrm{BT}}$ & - & 1963 & OP \\
\hline 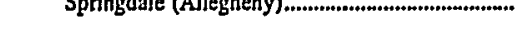 & 8 & $\begin{array}{r}74.8 \\
140.6\end{array}$ & $\begin{array}{r}86.10 \\
121.0\end{array}$ & $\begin{array}{r}86.0 \\
121.0\end{array}$ & $\begin{array}{l}\text { ST } \\
\text { ST }\end{array}$ & $\begin{array}{l}\text { FO6 } \\
\text { Nat Gas }\end{array}$ & $\mathrm{FO} 2$ & $\begin{array}{l}1945 \\
1954\end{array}$ & $\begin{array}{l}S B \\
S B\end{array}$ \\
\hline Rhode Island & & & & & & & & & \\
\hline Rhode Island Subtotal & & 510.9 & 441.2 & 516.4 & & & & & \\
\hline Block Istand Power Co & & 4.0 & 3.5 & 3.7 & & & & & \\
\hline Block Istund (Washington) .................................. & 31 & 1.0 & .8 & .8 & IC & $\mathrm{FO} 2$ & - & 1972 & OP \\
\hline 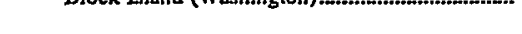 & 13 & .7 & 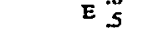 & $\mathrm{E}_{.7}^{0}$ & IC & FO2 & - & 1986 & $O P$ \\
\hline & 14 & .4 & 3 & 3 & IC & FO2 & $=$ & 1981 & OP \\
\hline & 15 & .4 & $\mathrm{E} .3$ & $\mathrm{E}_{.4}^{-4}$ & IC & FO2 & - & 1982 & OP \\
\hline & 17 & 1.6 & 1.6 & 1.6 & IC & FO2 & - & 1987 & OP \\
\hline 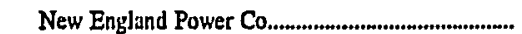 & & 489.2 & 420.0 & 495.0 & & & & & \\
\hline Manchester Street (Providence).......................... & 9 & 159.1 & 340.0 & 165.0 & ST & Nat Gas & F02 & 1941 & OP \\
\hline & 10 & 165.1 & 140.0 & 165.0 & ST & Nat Gas & FO2 & 1947 & OP \\
\hline & il & 165.1 & 340.0 & 165.0 & ST & Nat Gas & $\mathrm{FO2}$ & 1949 & OP \\
\hline Newport Electric Corp & & 163 & 16.3 & 163 & & & & & \\
\hline Eldred (Newport) & 1 & 2.8 & 28 & 2.8 & IC & FO2 & - & 1970 & OP \\
\hline & 2 & 28 & 2.8 & 2.8 & IC & $\mathrm{FO} 2$ & - & 1970 & OP \\
\hline & 3 & 28 & 2.8 & 2.8 & Ic & $\mathrm{FO} 2$ & - & 1978 & OP \\
\hline Jepson (Newpon) ,.......................................................... & 1 & 2.0 & 20 & 2.0 & IC & $\mathrm{FO} 2$ & - & 1960 & OP \\
\hline & 2 & 20 & 2.0 & 2.0 & IC & $\mathrm{FO} 2$ & - & 1960 & OP \\
\hline & 3 & 2.0 & 2.0 & 2.0 & IC & $\mathrm{FO} 2$ & - & 1961 & OP \\
\hline & 4 & 20 & 2.0 & 20 & IC & FO2 & - & 1961 & OP \\
\hline 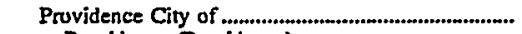 & & 1.5 & 1.5 & 1.5 & & & & & \\
\hline 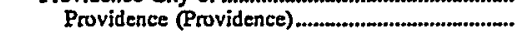 & 1 & 1.5 & E i.s & $E_{1.5}$ & $\mathrm{HY}$ & Water & - & 1930 & os \\
\hline South Carolina & & & & & & & & & \\
\hline 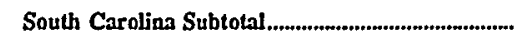 & & $18,790.7$ & $17,430.5$ & $17,780.0$ & & & & & \\
\hline 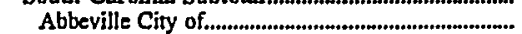 & & 3.7 & 3.7 & 3.7 & & & & & \\
\hline 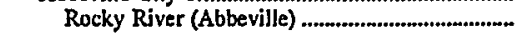 & ICl & 1.1 & 1.1 & 1.1 & IC & FO2 & - & 1946 & OP \\
\hline & 1 & 1.8 & J.8 & 3.8 & HY & Water & - & 1941 & $O P$ \\
\hline & 2 & & .8 & .8 & $\mathrm{HY}$ & Water & - & 1941 & OP \\
\hline Curolina Power \& Light Co & & $2,037.6$ & $1,684.0$ & $1,891.0$ & & & & & \\
\hline 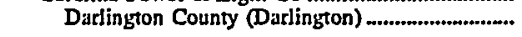 & 1 & 66.8 & 520 & 64.0 & GT & Nat Gas & FO2 & 1974 & $O P$ \\
\hline & $\begin{array}{l}2 \\
3\end{array}$ & $\begin{array}{l}65.8 \\
66.8\end{array}$ & $\begin{array}{l}52.0 \\
52.0\end{array}$ & $\begin{array}{l}64.0 \\
64.0\end{array}$ & $\begin{array}{l}\text { GT } \\
\text { GT }\end{array}$ & Nat GO2 & $\begin{array}{l}\text { IPG } \\
\text { FO2 }\end{array}$ & $\begin{array}{l}1974 \\
1974\end{array}$ & $\begin{array}{l}\text { OP } \\
\text { OP }\end{array}$ \\
\hline
\end{tabular}

See foomotes at end of table. 
Table 20. Existing Generating Units at U.S. Electric Utilities by State, Company, and Plant, as of January 1, 1998 (Continued)

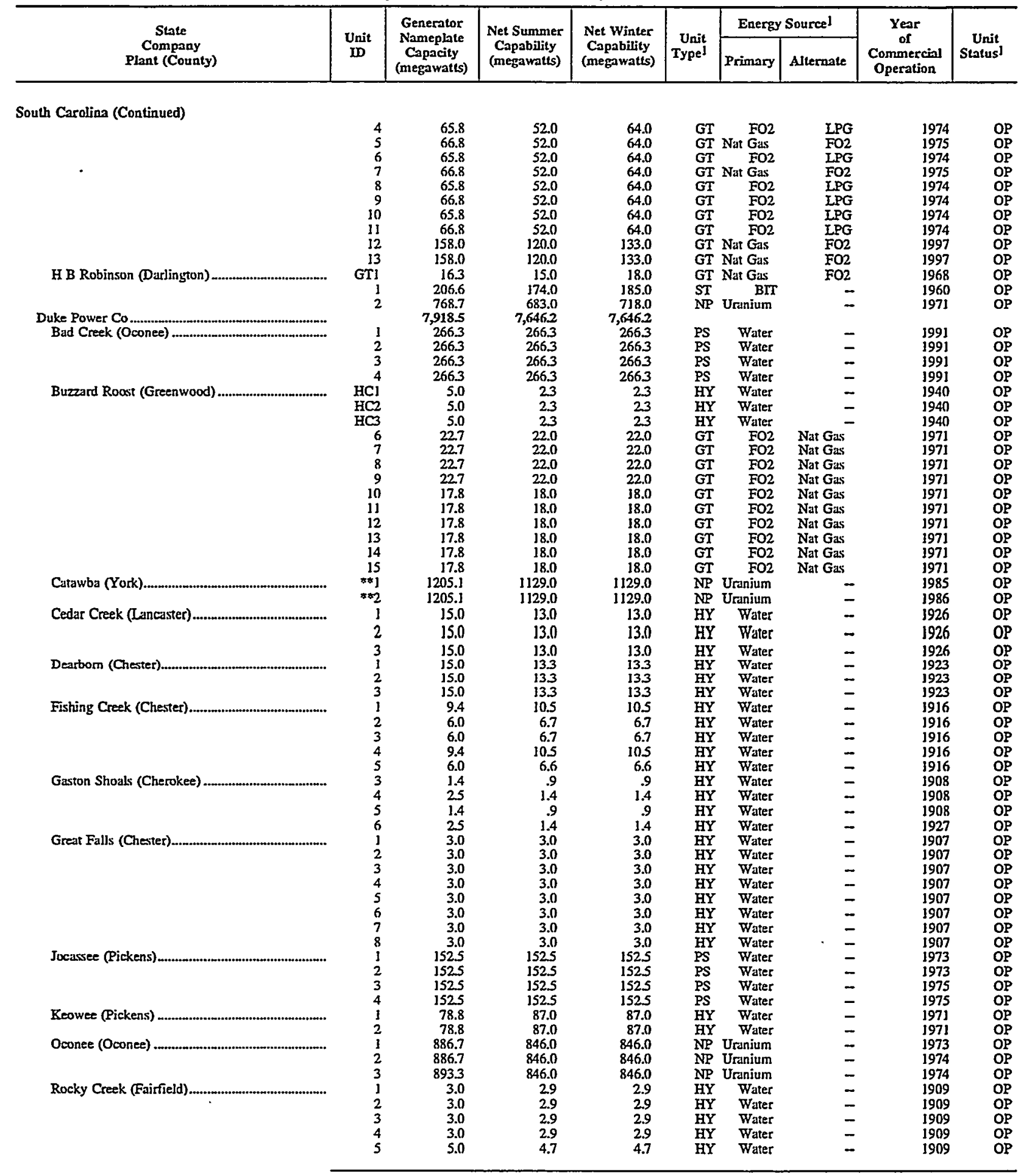

See footnotes at end of table. 
Table 20. Existing Generating Units at U.S. Electric Utilities by State, Company, and Plant, as of January 1, 1998 (Continued)

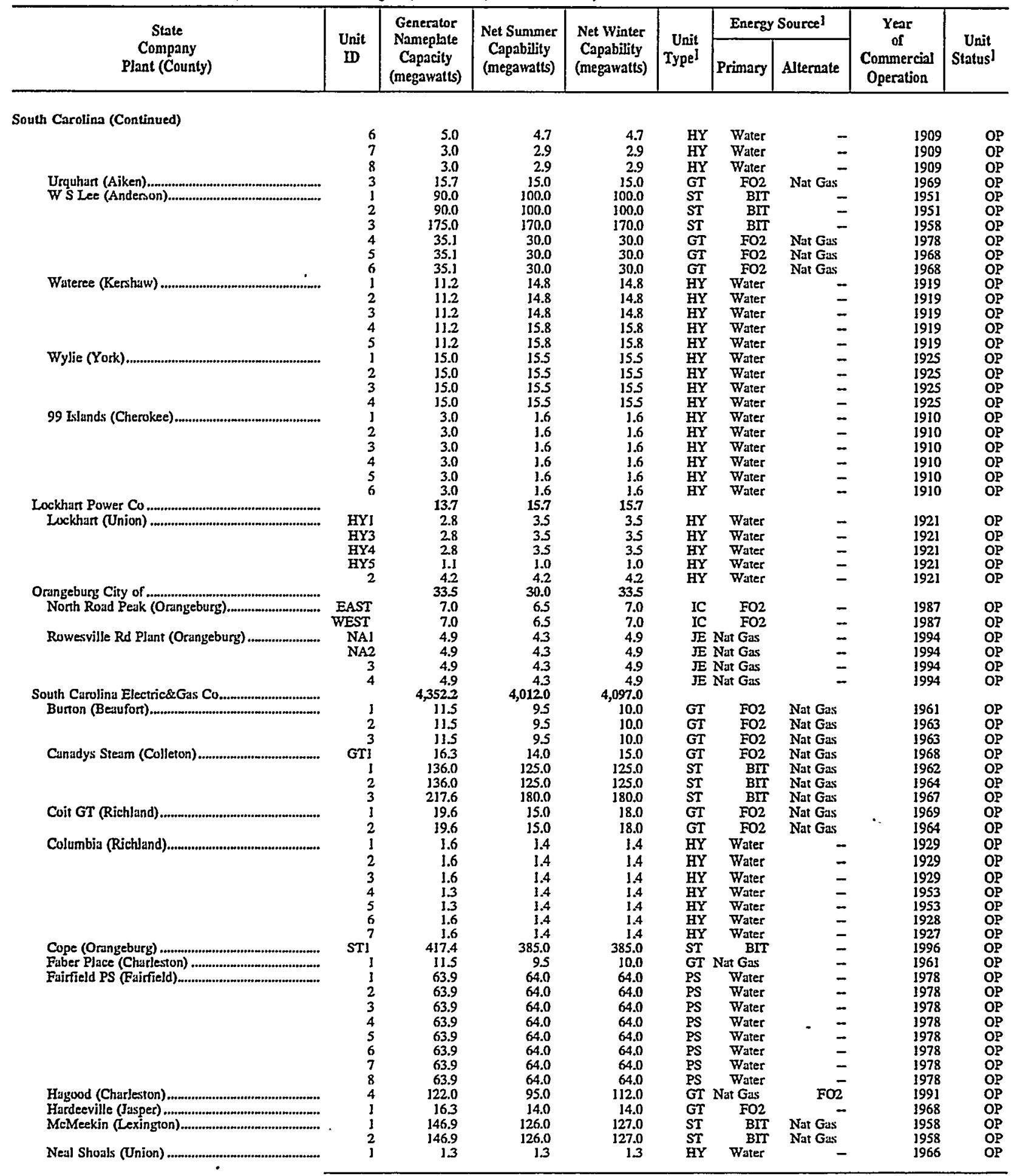

See footnotes ut end of table. 
Table 20. Existing Generating Units at U.S. Electric Utilities by State, Company, and Plant, as of January 1, 1998 (Continued)

\begin{tabular}{|c|c|c|c|c|c|c|c|c|c|}
\hline \multirow{2}{*}{$\begin{array}{c}\text { State } \\
\text { Company } \\
\text { Plant (County) }\end{array}$} & \multirow{2}{*}{$\begin{array}{c}\text { Unit } \\
\text { ID }\end{array}$} & \multirow{2}{*}{$\begin{array}{c}\text { Generator } \\
\text { Nameplate } \\
\text { Capacity } \\
\text { (megawatts) }\end{array}$} & \multirow{2}{*}{$\begin{array}{l}\text { Net Summer } \\
\text { Capability } \\
\text { (megawatts) }\end{array}$} & \multirow{2}{*}{$\begin{array}{l}\text { Net Winter } \\
\text { Capability } \\
\text { (niegawatts) }\end{array}$} & \multirow{2}{*}{$\begin{array}{r}\text { Unit } \\
\text { Type }\end{array}$} & \multicolumn{2}{|c|}{ Energy Source 1} & \multirow{2}{*}{$\begin{array}{c}\text { Year } \\
\text { of } \\
\text { Commercial } \\
\text { Operation }\end{array}$} & \\
\hline & & & & & & Primary & Alternate & & \\
\hline South Carolina (Continued) & & & & & & & & & \\
\hline & 2 & 1.3 & 1.3 & 13 & HY & Water & - & 1966 & OP \\
\hline & 3 & 1.3 & 1.3 & 13 & HY & Water & - & 1966 & OP \\
\hline & 4 & 1.3 & 1.3 & 1.3 & HY & Water & - & 1966 & OP \\
\hline Parr (Fairfield) & 1 & 2.5 & 2.3 & 2.3 & HY & Water & - & 1914 & OP \\
\hline & 2 & 2.5 & 2.3 & 2.3 & HY & Water & - & 1914 & OP \\
\hline . & 3 & 2.5 & 2.3 & 2.3 & HY & Water & - & 1914 & OP \\
\hline & 4 & 2.5 & 2.3 & 2.3 & HY & Water & - & 1914 & OP \\
\hline & 5 & 2.5 & 2.3 & 23 & $\mathrm{HY}$ & Water & - & 1914 & OP \\
\hline & 6 & 2.5 & 2.3 & 23 & HY & Water & - & 1921 & OP \\
\hline Part GT (Fairfield) & GTI & 17.6 & 13.0 & 17.0 & GT & $\mathrm{FO} 2$ & Nat Gas & 1970 & OP \\
\hline & GT2 & 17.6 & 13.0 & 17.0 & GT & $\mathrm{FO} 2$ & Nat Gas & 1970 & OP \\
\hline & GT3 & 19.6 & 17.0 & 21.0 & GT & FO2 & Nat Gus & 1971 & $O P$ \\
\hline & GT4 & 19.6 & 37.0 & 21.0 & GT & $\mathrm{FO} 2$ & Nat Gas & 1971 & OP \\
\hline Saluda (Lexington) & 1 & 32.5 & 34.0 & 34.0 & $\mathrm{HY}$ & Water & - & 1930 & $O P$ \\
\hline & 2 & 32.5 & 34.0 & 34.0 & HY & Water & - & 1930 & $\begin{array}{l}\text { OP } \\
\text { OP }\end{array}$ \\
\hline & 3 & 32.5 & 34.0 & 34.0 & HY & Water & - & 1930 & $\begin{array}{l}O P \\
O P\end{array}$ \\
\hline & 4 & 32.5 & 34.0 & 34.0 & HY & Water & - & 1930 & \\
\hline & $\begin{array}{r}5 \\
* 1\end{array}$ & $\begin{array}{r}67.5 \\
0530\end{array}$ & $\begin{array}{r}70.0 \\
0420\end{array}$ & $\begin{array}{r}70.0 \\
0510\end{array}$ & $\underset{N P}{H Y}$ & $\begin{array}{l}\text { Water } \\
\text { I }\end{array}$ & $\overrightarrow{-}$ & $\begin{array}{l}1971 \\
1984\end{array}$ & $\begin{array}{l}\text { OP } \\
\text { OP }\end{array}$ \\
\hline 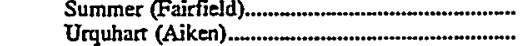 & GTI & $\begin{array}{r}953.9 \\
19.6\end{array}$ & $\begin{array}{r}942.0 \\
14.0\end{array}$ & $\begin{array}{r}951.0 \\
18.0\end{array}$ & $\begin{array}{l}\mathrm{NP} \\
\mathrm{GT}\end{array}$ & $\begin{array}{r}\text { Uranium } \\
\text { FO2 }\end{array}$ & Nat Gas & $\begin{array}{l}1984 \\
1969\end{array}$ & OP \\
\hline & GT2 & 16.3 & 12.0 & 14.0 & GT & FO2 & Nat Gus & 1969 & $O P$ \\
\hline & GT3 & 16.3 & 12.0 & 14.0 & GT & FO2 & Nat Gas & 1994 & $O P$ \\
\hline & 1 & 75.0 & 75.0 & 76.0 & ST & BIT & Nat Gas & 1953 & OP \\
\hline & 2 & 75.0 & 75.0 & 76.0 & $\mathbf{S T}$ & BIT & Nat Gas & 1954 & OP \\
\hline & 3 & 100.0 & 100.0 & 102.0 & ST & $\mathrm{BII}$ & Nat Gas & 1955 & OP \\
\hline USDOU SRS (D-Area) (Aiken) & 1 & 70.0 & 17.0 & 17.0 & SI & $\mathrm{BIT}$ & - & 1995 & OP \\
\hline Wateree (Richland) & 1 & 385.9 & 350.0 & 360.0 & ST & BIT & - & 1970 & OP \\
\hline 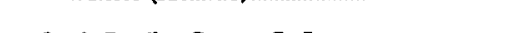 & 2 & 385.9 & 350.0 & 360.0 & ST & BFT & - & 1971 & OP \\
\hline 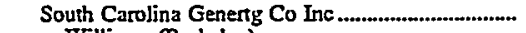 & & 686.5 & 609.0 & 623.0 & & & & & \\
\hline Williams (Berkeley) & STI & 632.7 & 560.0 & 565.0 & ST & BIT & $\lambda-$ & 1973 & OP \\
\hline & 1 & 26.9 & 24.5 & 29.0 & GT & FO2 & Nat Gas & 1972 & OP \\
\hline & 2 & 26.9 & 24.5 & 29.0 & GT & FO2 & Nat Gas & 1972 & OP \\
\hline 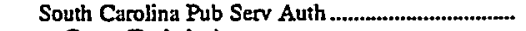 & & $3,463.9$ & $3,149.0$ & $3,189.0$ & & & & & \\
\hline Cross (Berkeley) & ] & 590.9 & 560.0 & 560.0 & ST & BIT & - & 1995 & OP \\
\hline & 2 & 556.2 & 540.0 & 540.0 & ST & BIT & - & 1984 & OP \\
\hline 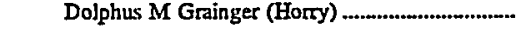 & 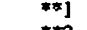 & 81.6 & 85.0 & 85.0 & ST & BIT & - & 1966 & OP \\
\hline & $* 2$ & 81.6 & 85.0 & 85.0 & ST & BIT & - & 1966 & OP \\
\hline Hilton Head (Beaufort) & $*$ * $]$ & 26.6 & 20.0 & 25.0 & GT & $\mathrm{FO} 2$ & - & 1973 & OP \\
\hline & 2 & 26.6 & 20.0 & 25.0 & GT & $\mathrm{FO2}$ & - & 1974 & OP \\
\hline & 3 & 64.7 & 57.0 & 70.0 & GT & FO2 & - & 1979 & OP \\
\hline Jefferies (Berkeley) & HI & 30.6 & 29.3 & 29.3 & $\mathrm{HY}$ & Water & - & 1942 & OP \\
\hline & $\mathrm{H} 2$ & 30.6 & 29.3 & 29.3 & HY & Water & - & 1942 & OP \\
\hline & H3 & 30.6 & 29.3 & 29.3 & HY & Water & - & 1942 & OP \\
\hline & H4 & 30.6 & 29.3 & 29.3 & $\mathbf{H Y}$ & Water & - & 1942 & OP \\
\hline & H6 & 10.2 & 11.0 & 11.0 & $\mathbf{H Y}$ & Water & - & 1942 & OP \\
\hline & 1 & 50.0 & 46.0 & 46.0 & ST & FO6 & - & 1954 & OP \\
\hline & 2 & 50.0 & 46.0 & 46.0 & ST & FO6 & - & 1954 & OP \\
\hline & 3 & 172.8 & 153.0 & 153.0 & ST & BIT & - & 1970 & OP \\
\hline & 4 & 172.8 & 153.0 & 153.0 & ST & BIT & - & 1970 & OP \\
\hline Myrtle Beach (Horry) & 1 & 11.5 & 10.0 & 11.0 & GT & FO2 & - & 1962 & OP \\
\hline & 2 & 11.5 & 10.0 & 11.0 & GT & FO2 & - & 1962 & OP \\
\hline & 3 & 26.6 & 20.0 & 25.0 & GT & FO2 & - & 1972 & OP \\
\hline & 4 & 26.6 & 20.0 & 25.0 & GT & FO2 & - & 1972 & OP \\
\hline " & 5 & 35.3 & 30.0 & 35.0 & GT & $\mathrm{FO2}$ & - & 1976 & OP \\
\hline Spillway (Berkeley) & 1 & 2.0 & 20 & 2.0 & HY & Water & - & 1950 & OP \\
\hline St Stephen (Berkeley) & $* \approx 1$ & 28.0 & 28.0 & 28.0 & HY & Warer & - & 1985 & OP \\
\hline & $\approx 2$ & 28.0 & 28.0 & 28.0 & HY & Water & - & 1985 & OP \\
\hline & $* * 3$ & 28.0 & 28.0 & 28.0 & HY & Water & - & 1985 & OP \\
\hline Winyah (Georgetown) & I & 315.0 & 270.0 & 270.0 & ST & BIT & - & 1975 & OP \\
\hline & 2 & 315.0 & 270.0 & 270.0 & ST & BIT & - & 1977 & OP \\
\hline & 3 & 315.0 & 270.0 & 270.0 & ST & BIT & - & 1980 & OP \\
\hline & 4 & 315.0 & 270.0 & 270.0 & ST & BIT & - & 1981 & OP \\
\hline 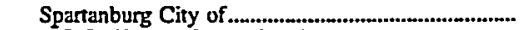 & & 1.0 & 1.0 & 1.0 & & & & & \\
\hline R B Simms (Spartanburg) & 1 & .5 & .5 & .5 & HY & Water & - & 1926 & OP \\
\hline & 2 & .5 & .5 & 5 & HY & Water & - & 1926 & OP \\
\hline 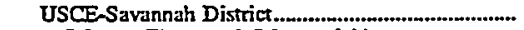 & & 280.0 & 280.0 & 280.0 & & & & & \\
\hline 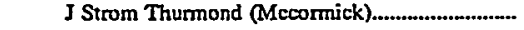 & 1 & 40.0 & 40.0 & 40.0 & HY & Water & - & 1953 & OP \\
\hline & 2 & 40.0 & 40.0 & 40.0 & HY & Water & - & 1953 & OP \\
\hline & 3 & 40.0 & 40.0 & 40.0 & HY & Water & - & 1953 & OP \\
\hline & 4 & 40.0 & 40.0 & 40.0 & HY & Water & - & 1953 & OP \\
\hline
\end{tabular}

See footnotes at end of table. 
Table 20. Existing Generating Units at U.S. Electric Utilities by State, Company, and Plant, as of January 1, 1998 (Continued)

\begin{tabular}{|c|c|c|c|c|c|c|c|c|c|}
\hline \multirow{2}{*}{$\begin{array}{c}\text { State } \\
\text { Company } \\
\text { PJant (County) }\end{array}$} & \multirow{2}{*}{$\begin{array}{l}\text { Unit } \\
\text { ID }\end{array}$} & \multirow{2}{*}{$\begin{array}{l}\text { Generator } \\
\text { Nameplate } \\
\text { Capacity } \\
\text { (megawatts) }\end{array}$} & \multirow{2}{*}{$\begin{array}{l}\text { Net Summer } \\
\text { Capability } \\
\text { (megawatts) }\end{array}$} & \multirow{2}{*}{$\begin{array}{c}\text { Net Winter } \\
\text { Capability } \\
\text { (megawatts) }\end{array}$} & \multirow{2}{*}{$\begin{array}{l}\text { Unit } \\
\text { Type }^{1}\end{array}$} & \multicolumn{2}{|c|}{ Energy Sourcel } & \multirow{2}{*}{$\begin{array}{c}\text { Year } \\
\text { of } \\
\text { Commercinl } \\
\text { Operation }\end{array}$} & \multirow{2}{*}{$\begin{array}{c}\text { Unit } \\
\text { Status! }\end{array}$} \\
\hline & & & & & & Primary & Alternate & & \\
\hline \multicolumn{10}{|l|}{ South Carolina (Continued) } \\
\hline & 5 & 40.0 & 40.0 & 40.0 & HY & Water & - & 1954 & OP \\
\hline & $\begin{array}{l}6 \\
7\end{array}$ & 40.0 & $\begin{array}{l}40.0 \\
40.0\end{array}$ & $\begin{array}{l}40.0 \\
40.0\end{array}$ & $\begin{array}{l}\mathrm{HY} \\
\mathrm{HY}\end{array}$ & $\begin{array}{l}\text { Water } \\
\text { Water }\end{array}$ & $\overline{-}$ & 1954 & $\begin{array}{l}\text { OP } \\
\text { OP }\end{array}$ \\
\hline \multicolumn{10}{|l|}{ South Dakota } \\
\hline South Dakota Subtotal ................................................... & & $2,973.7$ & $2,926.8$ & $2,983.5$ & & & & & \\
\hline 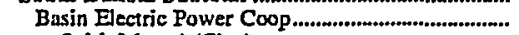 & & 135.0 & 96.0 & 104.0 & & & & & \\
\hline 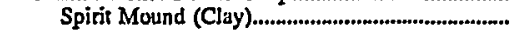 & 1 & 67.5 & 520 & 52.0 & GT & $\mathrm{FO} 2$ & - & 1978 & OP \\
\hline 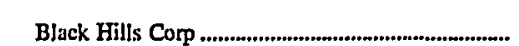 & 2 & $\begin{array}{r}67.5 \\
135.8\end{array}$ & $\begin{array}{l}44.0 \\
99.6\end{array}$ & $\begin{array}{r}52.0 \\
131.6\end{array}$ & GT & FO2 & - & 1978 & OP \\
\hline 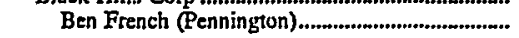 & * *GT1 & 25.2 & 17.0 & 25.0 & GT & FO2 & _- & 1977 & OP \\
\hline & $* * G T 2$ & 252 & 17.0 & 25.0 & GT & $\mathrm{FO} 2$ & - & 1977 & $O P$ \\
\hline & $*$ GT3 & 252 & 17.0 & 25.0 & GT & $\mathrm{FO} 2$ & Nat Gas & 1978 & OP \\
\hline & $*$ GT4 $_{4}$ & 252 & 17.0 & 25.0 & GT & $\mathrm{FO} 2$ & Nat Gas & 1979 & OP \\
\hline & IC] & 2.0 & 2.0 & 20 & IC & FO2 & & 1965 & OP \\
\hline & STl & 25.0 & 21.6 & 21.6 & ST & SUB & Nat Gas & 1961 & OP \\
\hline & 2 & 2.0 & 2.0 & 2.0 & IC & FO2 & - & 1965 & OP \\
\hline & 3 & 20 & 2.0 & 2.0 & IC & $\mathrm{FO} 2$ & _ & 1965 & OP \\
\hline & 4 & 20 & 2.0 & 2.0 & IC & FO2 & - & 1965 & $O P$ \\
\hline & 5 & 2.0 & 2.0 & 2.0 & IC & $\mathrm{FO2}$ & - & 1965 & $\mathrm{OP}$ \\
\hline Missouri Basin Mun Power Agmy.................. & & 67.5 & 42.2 & 54.8 & & & & & \\
\hline Watertown PP (Codington) ..................... & $* * 1$ & 675 & 422 & 54.8 & GT & FO2 & - & 1978 & OP \\
\hline 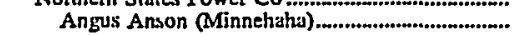 & 1 & 105.0 & 116.0 & 125.0 & GT & Nat Gas & - & 1994 & OP \\
\hline & 2 & 105.0 & 316.0 & 125.0 & GT & Nat Gas & - & 1994 & OP \\
\hline Pathfinder (Minnehaha) ......................................... & i & 75.0 & 61.0 & 0.0 & ST & Nat Gas & - & 1969 & $\mathrm{OP}$ \\
\hline Northwestern Public Service Co................................ & & 119.6 & 107.0 & 125.6 & & & & & \\
\hline Aberdeen CT (Brown) ............................................... & GT1 & 28.8 & 20.3 & 29.4 & GT & $\mathrm{FO} 2$ & - & 1978 & OP \\
\hline Clark (Clark) & 1 & $\begin{array}{l}2.8 \\
2.8\end{array}$ & $\begin{array}{l}27 \\
26\end{array}$ & 2.7 & IC & $\mathrm{FO} 2$ & $\bar{z}$ & 1970 & OP \\
\hline Highmore (Hyde) & $\mathrm{i}$ & .7 .7 & $\begin{array}{r}2.6 \\
.6\end{array}$ & .6 & IC & FO2 & $\Xi$ & 1948 & OP \\
\hline & 2 & 1.4 & 1.2 & 13 & IC & FO2 & - & 1960 & OP \\
\hline & 3 & 2.8 & 2.6 & 2.7 & IC & FO2 & - & 1970 & OP \\
\hline Huron (Beadle)......................................................... & $2 A$ & 42.9 & 43.0 & 49.0 & GT & Nat Gas & $\mathrm{FO} 2$ & 1991 & OP \\
\hline & 1 & 15.0 & 11.8 & 14.8 & GT & Nat Gas & $\mathrm{FO} 2$ & 1961 & OP \\
\hline 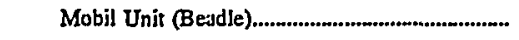 & j & .5 & .5 & .5 & IC & FO1 & - & 1955 & op \\
\hline & 2 & 1.8 & 1.8 & 1.8 & IC & Fol & $n^{-}$ & 1991 & OP \\
\hline 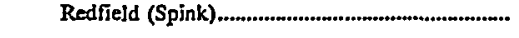 & 1 & 1.4 & 1.3 & 1.3 & IC & Nat Gas & $\mathrm{FO} 2$ & 1962 & OP \\
\hline & 2 & 1.4 & I.3 & 13 & IC & Nat Gas & FO2 & 1962 & OP \\
\hline & 3 & 1.4 & 1.3 & 13 & IC & Nat Gas & $\mathrm{FO} 2$ & 1962 & OP \\
\hline 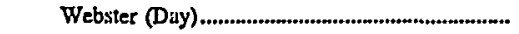 & I & .8 & .7 & .8 & IC & FO2 & - & 1932 & OP \\
\hline & 2 & 2.0 & 1.9 & 1.9 & IC & FO2 & - & 1950 & OP \\
\hline Yankton (Yankton) ................................................ & 1 & 2.3 & 2.3 & 2.3 & IC & Nat Gas & FO2 & 1974 & OP \\
\hline & 2 & 2.8 & 2.7 & 2.7 & IC & Nat Gas & $\mathrm{FO} 2$ & 1974 & $\mathrm{OP}$ \\
\hline & 3 & 6.5 & 6.5 & 65 & IC & Nat Gas & $\mathrm{FO} 2$ & 1975 & OP \\
\hline & 4 & 2,0 & 2.0 & 2.0 & IC & $\mathrm{FO} 2$ & - & 1963 & $O P$ \\
\hline 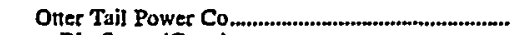 & & 500.1 & 468.7 & 497.2 & & & & & \\
\hline Big Stone (Grant) & $*$ *Dl & 1.0 & 1.1 & 1.1 & ST & $\mathrm{FO} 2$ & - & 1975 & OP \\
\hline & $* * j$ & 475.0 & 445.8 & 466.7 & ST & SUB & - & 1975 & OP \\
\hline 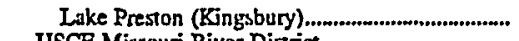 & $i$ & 24.1 & 21.8 & 29.4 & GT & FO2 & - & 1948 & OP \\
\hline USCE-Missouri River Distict .................................... & & $1,730.6$ & $1,820.3$ & $1,820.3$ & & & & & \\
\hline 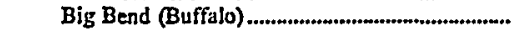 & 1 & 67.3 & 67.0 & 67.0 & $\mathrm{HY}$ & Water & - & 1964 & OP \\
\hline & 2 & 673 & 67.0 & 67.0 & $\mathrm{HY}$ & Water & - & 1964 & OP \\
\hline & 3 & 67.3 & 67.0 & 67.0 & HY & Water & - & 1965 & $O P$ \\
\hline & 4 & 58.5 & 67.0 & 67.0 & HY & Water & - & 1965 & $O P$ \\
\hline & 5 & 58.5 & 67.0 & 67.0 & $\mathrm{HY}$ & Water & - & 1965 & $O P$ \\
\hline & 6 & 58.5 & 67.0 & 67.0 & HY & Water & $=$ & 1965 & $\mathrm{OP}$ \\
\hline & 7 & 58.5 & 67.0 & 67.0 & $\mathrm{HY}$ & Water & - & 1966 & $O P$ \\
\hline & 8 & 58.5 & 67.0 & 67.0 & $\mathrm{HY}$ & Water & - & 1966 & OP \\
\hline FT Randall (Charles Mix) & 1 & 40.0 & 46.0 & 46.0 & $\mathrm{HY}$ & Water & -- & 1954 & $O P$ \\
\hline & 2 & 40.0 & 46.0 & 46.0 & HY & Water & - & 1954 & OP \\
\hline & 3 & 40.0 & 46.0 & 46.0 & HY & Water & - & 1954 & OP \\
\hline & 4 & 40.0 & 46.0 & 46.0 & $\mathrm{HY}$ & Water & - & 1954 & $O P$ \\
\hline & 5 & 40.0 & 46.0 & 46.0 & $\mathrm{HY}$ & Water & - & 1955 & OP \\
\hline & 6 & 40.0 & 46.0 & 46.0 & $\mathrm{HY}$ & Water & - & 1955 & $O P$ \\
\hline & 7 & 40.0 & 46.0 & 46.0 & $\mathrm{HY}$ & Water & - & 1955 & OP \\
\hline & 8 & 40.0 & 46.0 & 46.0 & $\mathrm{HY}$ & Water & - & 3956 & OP \\
\hline Gavins Point (Yunkton) & J & 44.1 & 44.1 & 44.1 & $\mathrm{HY}$ & Water & - & 1956 & OP \\
\hline & 2 & 44.1 & 44.1 & 44.1 & $\mathrm{HY}$ & Water & - & 1956 & $O P$ \\
\hline
\end{tabular}

See footnotes at end of table. 
Table 20. Existing Generating Units at U.S. Electric Utilities by State, Company, and Plant, as of January 1, 1998 (Continued)

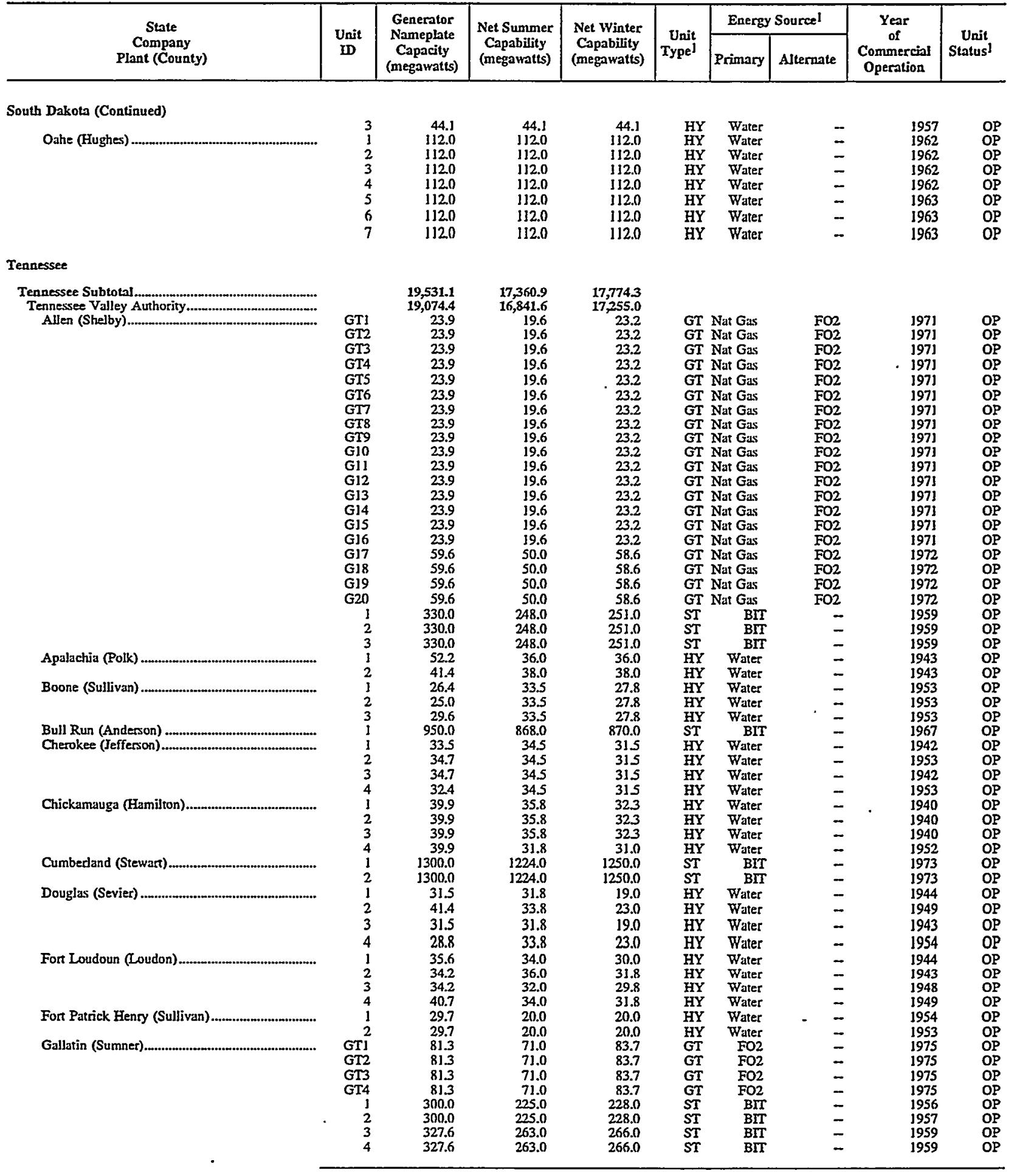

Sec footnotes at end of table. 
Table 20. Existing Generating Units at U.S. Electric Utilities by State, Company, and Plant, as of January 1, 1998 (Continued)

\begin{tabular}{|c|c|c|c|c|c|c|c|c|c|}
\hline \multirow{2}{*}{$\begin{array}{c}\text { State } \\
\text { Company } \\
\text { Plant (County) }\end{array}$} & \multirow{2}{*}{$\begin{array}{c}\text { Unit } \\
\text { w }\end{array}$} & \multirow{2}{*}{$\begin{array}{c}\text { Generator } \\
\text { Nameplate } \\
\text { Capacity } \\
\text { (megawatts) }\end{array}$} & \multirow{2}{*}{$\begin{array}{l}\text { Net Summer } \\
\text { Capability } \\
\text { (megawatts) }\end{array}$} & \multirow{2}{*}{$\begin{array}{c}\text { Net Winter } \\
\text { Capability } \\
\text { (megawatts) }\end{array}$} & \multirow{2}{*}{$\begin{array}{r}\text { Unit } \\
\text { Type! }\end{array}$} & \multicolumn{2}{|c|}{ Energy Sourcel } & \multirow{2}{*}{$\begin{array}{c}\text { Year } \\
\text { of } \\
\text { Commercial } \\
\text { Operation }\end{array}$} & \\
\hline & & & & & & Primary & Alternate & & Status 1 \\
\hline Tennessee (Continued) & & & & & & & & & \\
\hline Great Falls (Wamen) & 1 & 15.4 & 17.0 & 17.0 & HY & Water & - & 1916 & OP \\
\hline & 2 & 18.4 & 20.0 & 20.0 & HY & Water & - & 1924 & OP \\
\hline 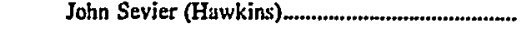 & 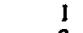 & 200.0 & 176.0 & 178.0 & ST & BIT & - & j95s & OP \\
\hline & $\begin{array}{l}2 \\
3\end{array}$ & $\begin{array}{l}200.0 \\
200.0\end{array}$ & $\begin{array}{l}176.0 \\
376.0\end{array}$ & $\begin{array}{l}178.0 \\
178.0\end{array}$ & $\begin{array}{l}\text { ST } \\
\text { ST }\end{array}$ & $\begin{array}{l}\text { BIT } \\
\text { BIT }\end{array}$ & $\overline{-}$ & $\begin{array}{l}1955 \\
1956\end{array}$ & $\begin{array}{l}\text { OP } \\
\text { OP }\end{array}$ \\
\hline & 4 & 200.0 & 176.0 & 178.0 & ST & BIT & - & 1957 & OP \\
\hline Johnsunville (Humphreys) ...................................... & GT] & 68.0 & 53.2 & 62.4 & GT & FO2 & - & 1975 & $\mathrm{OP}$ \\
\hline & GT2 & 68.0 & 53.2 & 624 & GT & FO2 & - & 1975 & OP \\
\hline & GT3 & 68.0 & 53.2 & 624 & GT & FO2 & - & 1975 & OP \\
\hline & GT4 & 68.0 & 53.2 & 62.4 & GT & $\mathrm{FO} 2$ & - & 1975 & OP \\
\hline & GT5 & 68.0 & 53.2 & 62.4 & GT & FO2 & - & 1975 & OP \\
\hline & GT6 & 68.0 & 53.2 & 62.4 & GT & $\mathrm{FO} 2$ & - & 1975 & OP \\
\hline & GT7 & 68.0 & 53.2 & 624 & GT & FO2 & - & 1975 & op \\
\hline & GT8 & 68.0 & 53.2 & 62.4 & GT & FO2 & - & 1975 & $\mathrm{OP}$ \\
\hline & GT9 & 68.0 & 53.2 & 62.4 & GT & $\mathrm{FO} 2$ & - & 1975 & $O P$ \\
\hline & GI0 & 68.0 & 53.2 & 62.4 & GT & $\mathrm{FO} 2$ & - & 1975 & $\mathrm{OP}$ \\
\hline & GII & 68.0 & 53.2 & 62.4 & GT & $\mathrm{FO} 2$ & - & 1975 & OP \\
\hline & G12 & 68.0 & 53.2 & 62.4 & GT & FO2 & . & 1975 & OP \\
\hline & G13 & 68.0 & 53.2 & 624 & GT & FO2 & - & 1975 & $O P$ \\
\hline & GJ4 & 68.0 & 53.2 & 62.4 & GT & FO2 & - & 1975 & $O P$ \\
\hline & GI5 & 68.0 & 53.2 & 62.4 & GT & $\mathrm{FO} 2$ & - & 1975 & $O P$ \\
\hline & G16 & 68.0 & 53.2 & 62.4 & GT & $\mathrm{FO} 2$ & - & 1975 & OP \\
\hline - & 1 & 125.0 & 107.0 & 113.0 & ST & BIT & - & 1953 & OP \\
\hline & 2 & 125.0 & 107.0 & 113.0 & ST & BIT & - & 1951 & $O P$ \\
\hline & 3 & 125.0 & 107.0 & 113.0 & ST & BIT & - & 1952 & OP \\
\hline & 4 & 125.0 & 107.0 & 313.0 & ST & BIT & - & 1952 & OP \\
\hline & 5 & 147.0 & J07.0 & 113.0 & ST & BIT & - & 1952 & OP \\
\hline & 6 & 147.0 & 107.0 & 113.0 & ST & BIT & - & 1953 & $\mathrm{OP}$ \\
\hline & 7 & 1728 & 141.0 & 144.0 & $S T$ & BIT & - & 1958 & OP \\
\hline & 8 & 172.8 & 141.0 & 144.0 & ST & BIT & - & 1959 & OP \\
\hline & 9 & 1728 & 141.0 & 144.0 & ST & BIT & - & 1959 & OP \\
\hline & 10 & 172.8 & 141.0 & 144.0 & $S T$ & BIT & - & 1959 & OP \\
\hline Kingston (Roane) & 1 & 175.0 & 136.0 & 139.0 & ST & BIT & - & 1954 & OP \\
\hline & 2 & 375.0 & 136.0 & 139.0 & $S T$ & BIT & - & 1954 & OP \\
\hline & 3 & $\$ 75.0$ & 136.0 & 139.0 & ST & BIT & - & 1954 & OP \\
\hline & 4 & 175.0 & 136.0 & 139.0 & ST & BIT & - & 1954 & OP \\
\hline & 5 & 200.0 & $\mathbf{1 7 8 . 0}$ & 180.0 & $\mathbf{S T}$ & BIT & - & 1955 & OP \\
\hline & 6 & 200.0 & 178.0 & 180.0 & ST & BIT & - & 1955 & $\mathrm{OP}$ \\
\hline & 7 & 200.0 & 178.0 & 180.0 & ST & BII & - & 1955 & OP \\
\hline & 8 & 200.0 & 178.0 & 180.0 & ST & BIT & - & 1955 & OP \\
\hline & 9 & 200.0 & 178.0 & 180.0 & ST & BIT & - & 1955 & $O P$ \\
\hline 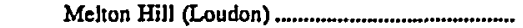 & 1 & 36.0 & 37.0 & 37.0 & HY & Water & - & 3964 & OP \\
\hline & 2 & 36.0 & 35.0 & 35.0 & HY & Water & - & 1964 & OP \\
\hline Nickujack (Marion) & 1 & 27.5 & 25.0 & 25.0 & HY & Water & - & 1968 & OP \\
\hline & 2 & 27.9 & 25.0 & 25.0 & HY & Water & $\ldots$ & 1968 & OP \\
\hline & 3 & 24.3 & 25.0 & 25.0 & HY & Water & - & 1968 & OP \\
\hline & 4 & 24.3 & 25.0 & 25.0 & HY & Water & 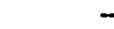 & 1968 & OP \\
\hline Norris (Anderson) & J & 65.7 & 59.8 & 55.3 & HY & Water & - & 1936 & OP \\
\hline & 2 & 65.7 & 59.8 . & 553 & HY & Water & - & 1936 & OP \\
\hline Ocuee 1 (Polk) & l & 3.8 & 5.0 & 5.0 & $\mathbf{H Y}$ & Water & $\ldots$ & 1912 & OP \\
\hline & 2 & 3.8 & 5.0 & 5.0 & $\mathrm{HY}$ & Water & - & 1912 & OP \\
\hline & 3 & 3.8 & 5.0 & 5.0 & $\mathrm{HY}$ & Water & - & 1912 & $\mathrm{OP}$ \\
\hline & 4 & 3.8 & 5.0 & 5.0 & $\mathrm{HY}$ & Water & - & 1912 & OP \\
\hline & 5 & 3.8 & 5.0 & 5.0 & $\mathrm{HY}$ & Water & - & 1914 & OP \\
\hline Ocoee 2 (Polk) & I & 11.5 & 9.0 & 9.0 & $\mathrm{HY}$ & Water & - & 1913 &. $\mathrm{OP}$ \\
\hline & 2 & 11.5 & 10.4 & 10.4 & HY & Water & - & 1913 & OP \\
\hline Ocoee 3 (Polk) & I & 28.8 & 28.0 & 28.0 & HY & Water & - & 1943 & $\mathrm{OP}$ \\
\hline Pickwick (Hardin) & 1 & 40.0 & 33.0 & 31.5 & HY & Water & - & 3938 & OP \\
\hline & 2 & 40.0 & 33.0 & 315 & HY & Water & - & 1938 & OP \\
\hline & 3 & 40.0 & 33.0 & 315 & $\mathbf{H Y}$ & Water & - & 1942 & OP \\
\hline & 4 & 40.0 & 33.0 & 315 & $\mathbf{H Y}$ & Water & - & 1942 & OP \\
\hline & 5 & 40.0 & 35.8 & 33.5 & HY & Water & - & 1952 & OP \\
\hline & 6 & 40.0 & 35.8 & 335 & HY & Water & - & 1952 & OP \\
\hline Raccoon Mountain (Hamilion) ................................ & 1 & 382.5 & 383.0 & 383.0 & PS & Water & - & 1979 & $\mathrm{OP}$ \\
\hline & 2 & 382.5 & 383.0 & 383.0 & PS & Water & - & 1978 & OP \\
\hline & 3 & 382.5 & 383.0 & 383.0 & PS & Water & - & 1979 & OP \\
\hline & 4 & 382.5 & 383.0 & 383.0 & PS & Water & - & 1979 & OP \\
\hline 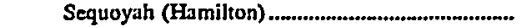 & 1 & 1220.6 & 1119.0 & 1147.0 & NP & Uranium & - & 1981 & $\mathbf{O P}$ \\
\hline & 2 & 1220.6 & 1119.0 & 1147.0 & $\mathrm{NP}$ & Uranjum & - & 1982 & $\mathrm{OP}$ \\
\hline 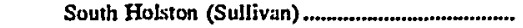 & I & 38.5 & 43.3 & $\mathbf{4 4 . 0}$ & HY & Water & - & 1951 & OP \\
\hline
\end{tabular}

See footnotes at end of table. 
Table 20. Existing Generating Units at U.S. Electric Utilities by State, Company, and Plant, as of January 1, 1998 (Continued)

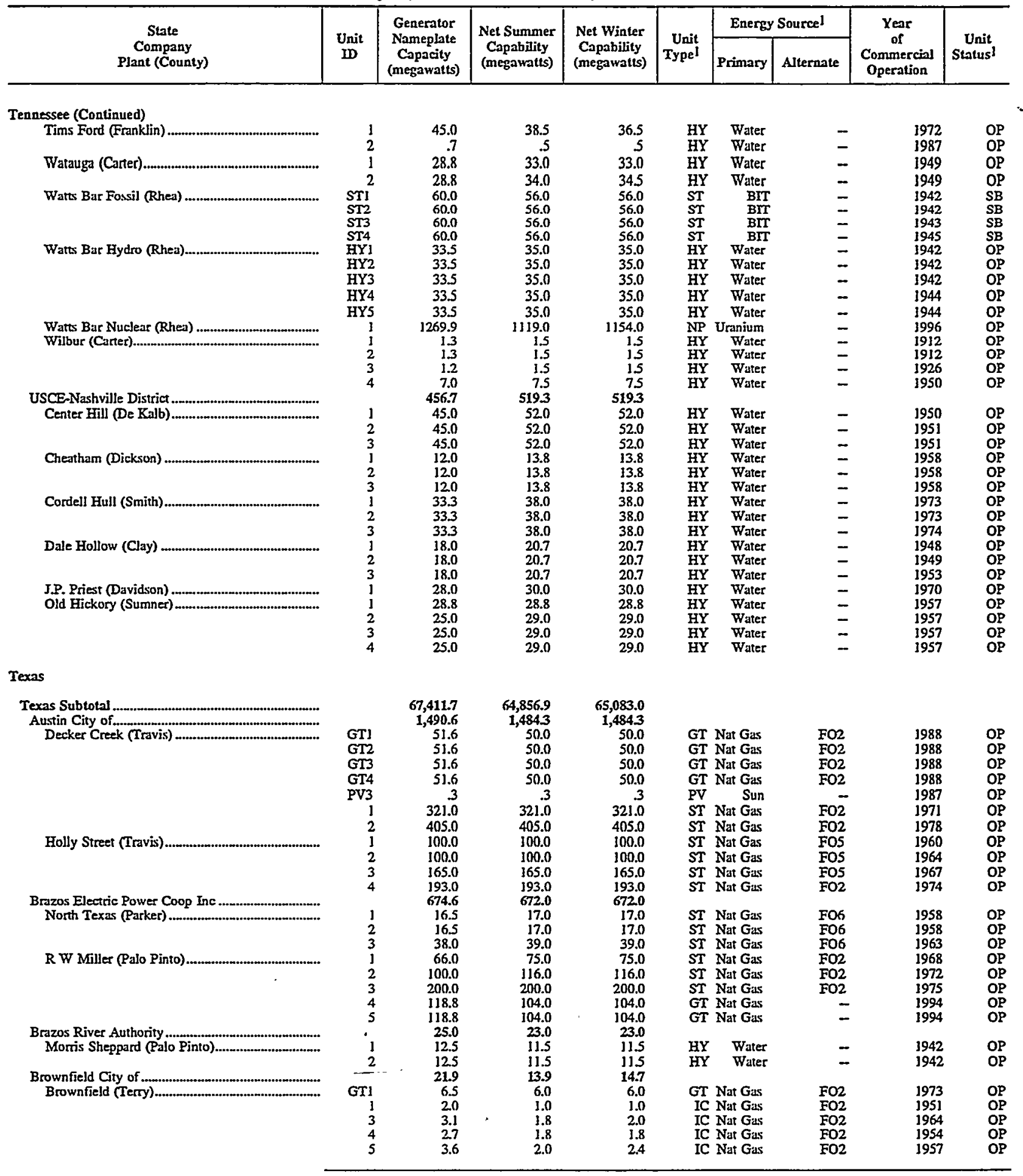

See footnotes at end of table. 
Table 20. Existing Generating Units at U.S. Electric Utilities.by State, Company, and Plant, as of January 1, 1998 (Continued)

\begin{tabular}{|c|c|c|c|c|c|c|c|c|c|}
\hline \multirow{2}{*}{$\begin{array}{c}\text { State } \\
\text { Company } \\
\text { Plant (County) }\end{array}$} & \multirow{2}{*}{$\begin{array}{l}\text { Unit } \\
\text { ID }\end{array}$} & \multirow{2}{*}{$\begin{array}{l}\text { Generator } \\
\text { Nameplate } \\
\text { Capacity } \\
\text { (megawatts) }\end{array}$} & \multirow{2}{*}{$\begin{array}{c}\text { Net Summer } \\
\text { Capability } \\
\text { (megawatts) }\end{array}$} & \multirow{2}{*}{$\begin{array}{c}\text { Net Winter } \\
\text { Capability } \\
\text { (megawatts) }\end{array}$} & \multirow{2}{*}{$\begin{array}{c}\text { Unit } \\
\text { Type } 1\end{array}$} & \multicolumn{2}{|c|}{ Energy Source! } & \multirow{2}{*}{$\begin{array}{c}\text { Year } \\
\text { of } \\
\text { Commercial } \\
\text { Operation }\end{array}$} & \multirow{2}{*}{$\begin{array}{c}\text { Unit } \\
\text { Status! }\end{array}$} \\
\hline & & & & & & Primary & Alternate & & \\
\hline Texas (Continued) & & & & & & & & & \\
\hline & 6 & $\begin{array}{r}4.0 \\
1450\end{array}$ & $\begin{array}{r}1.3 \\
1208\end{array}$ & $\begin{array}{r}1.5 \\
1301\end{array}$ & IC & Nat Gas & FO2 & 1961 & OP \\
\hline 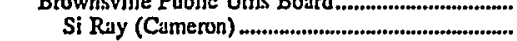 & 5 & 25.0 & $\begin{array}{ll}23.8 \\
23.8\end{array}$ & $\begin{array}{r}130.1 \\
24.1\end{array}$ & ST & Nat Gas & $\mathrm{FO} 2$ & 1952 & $O P$ \\
\hline & 6 & 22.0 & 21.0 & 21.0 & ST & Nat Gas & FO2 & 1959 & $O P$ \\
\hline & 8 & 45.0 & 43.0 & 43.0 & GT & Nat Gas & FO2 & 1973 & OP \\
\hline & 9 & 53.0 & 42.0 & 42.0 & GT & Nat Gas & FO2 & 1996 & OP \\
\hline 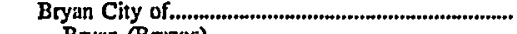 & & 243.0 & 235.0 & 230.0 & & & & & \\
\hline Bryan (Bruzos) & 3 & 13.0 & 120 & 12.0 & ST & Nat Gas & FO2 & 1955 & OP \\
\hline & 4 & 24.0 & 22.0 & 22.0 & ST & Nat Gas & FO2 & 1958 & OP \\
\hline & 5 & 25.0 & 25.0 & 25.0 & ST & Nat Gas & FO2 & 1966 & $\mathrm{OP}$ \\
\hline & 6 & 54.0 & 50.0 & 50.0 & ST & Nat Gas & $\mathrm{FO} 2$ & 1969 & $O P$ \\
\hline 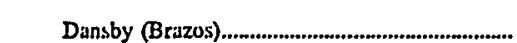 & 3 & 105.0 & $\begin{array}{r}21.0 \\
105.0\end{array}$ & $\begin{array}{r}21.0 \\
100.0\end{array}$ & $\begin{array}{l}\text { GT } \\
\text { ST }\end{array}$ & $\begin{array}{l}\text { Nat Gas } \\
\text { Nat Gas }\end{array}$ & $\begin{array}{l}\mathrm{FO} 2 \\
\mathrm{FO} 2\end{array}$ & $\begin{array}{l}1975 \\
1978\end{array}$ & $O P$ \\
\hline 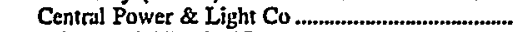 & & $3,527.6$ & $3,754.0$ & $3,754.0$ & & & & & or \\
\hline Barney M Davis (Nueces) & 1 & 323.4 & 344.0 & 344.0 & ST & Nat Gas & FO2 & 1974 & OP \\
\hline & 2 & 323.7 & 353.0 & 353.0 & ST & Nat Gas & FO4 & 1976 & OP \\
\hline Coleto Creek (Goliud) & 3 & 570.1 & 6320 & 632.0 & $\underset{S T}{S T}$ & BIT & $\mathrm{FO}^{-}$ & 1980 & $O P$ \\
\hline 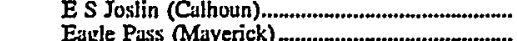 & 1 & $\begin{array}{r}234.9 \\
4.5\end{array}$ & 249.0 & 249.0 & ST & Nat Gas & FO2 & 1971 & OP \\
\hline 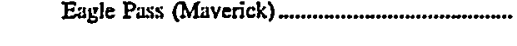 & $\frac{1}{2}$ & $\begin{array}{l}4.5 \\
4.5\end{array}$ & $\begin{array}{l}2.0 \\
2.0\end{array}$ & $\begin{array}{l}2.0 \\
20\end{array}$ & $\begin{array}{l}\mathrm{HY} \\
\mathrm{HY}\end{array}$ & $\begin{array}{c}\text { Water } \\
\text { Water }\end{array}$ & - & 1932 & $O P$ \\
\hline & 3 & $\begin{array}{l}4.5 \\
4.5\end{array}$ & 2.0 & $\begin{array}{l}2.0 \\
2.0\end{array}$ & HY & $\begin{array}{l}\text { Water } \\
\text { Water }\end{array}$ & $\ddot{-}$ & 1932 & 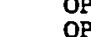 \\
\hline J L Bates (Hidalgo) & $i$ & 66.0 & 72.0 & 72.0 & ST & Nat Gas & FO2 & 1958 & OP \\
\hline & 2 & 100.0 & IJ0.0 & 110.0 & ST & Nat Gas & FO2 & 1960 & $O P$ \\
\hline La Palma (Cameron).... & 4 & 20.0 & 20.0 & 20.0 & ST & Nat Gas & - & 1947 & OP \\
\hline & 5 & 20.0 & 20.0 & 20.0 & si & Nat Gas & - & 1949 & OP \\
\hline & 6 & 153.2 & 155.0 & 155.0 & ST & Nat Gas & $\mathrm{FO} 2$ & 1970 & $O P$ \\
\hline & 7 & 49.1 & 48.0 & 48.0 & GT & Nat Gas & - & 1975 & $\mathrm{OP}$ \\
\hline Laredo (Webb) & 1 & 30.0 & 34.0 & 34.0 & ST & Nat Gas & FO2 & 1951 & $O P$ \\
\hline & 2 & 33.0 & 32.0 & 32.0 & $\underset{\sim T}{S T}$ & Nat Gas & FO2 & 1955 & $O P$ \\
\hline & 3 & 105.3 & 110.0 & 110.0 & ST & Nat Gas & FO2 & 1975 & OP \\
\hline Lon C. Hill (Nueces) .................................................... & 1 & 60.0 & 71.0 & 71.0 & ST & Nat Gas & - & 1954 & $\mathrm{OP}$ \\
\hline & 2 & 66.0 & 71.0 & 71.0 & ST & Nat Gas & - & 1956 & $O P$ \\
\hline & 3 & 150.0 & 152.0 & 152.0 & ST & Nat Gas & FO2 & 1959 & $\mathrm{OP}$ \\
\hline & 4 & 234.9 & 234.0 & 234.0 & ST & Nat Gas & FO2 & 1969 & $\mathrm{OP}$ \\
\hline Nueces Bay (Nueces)....... & 5 & 30.0 & 30.0 & 30.0 & $\underset{\sim T}{S T}$ & Nat Gas & - & 1949 & $O P$ \\
\hline & 6 & 160.0 & 161.0 & 161.0 & $\underset{\sim T}{S T}$ & Nat Gas & FO2 & 1965 & $O P$ \\
\hline & 7 & 323.7 & 368.0 & 368.0 & ST & Nat Gas & FO2 & 1972 & OP \\
\hline Victoria (Victoria) & 4 & 66.0 & 60.0 & 60.0 & $\underset{\mathrm{ST}}{\mathrm{ST}}$ & Nat Gas & $\mathrm{FO} 2$ & 1955 & $O P$ \\
\hline & 5 & 160.0 & 172.0 & 172.0 & ST & Nat Gas & FO2 & 1963 & OP \\
\hline & 6 & 234.9 & 250.0 & 250.0 & ST & Nat Gas & FO2 & I968 & op \\
\hline Coleman City of & & 16.9 & 14.5 & 15.7 & & & & & \\
\hline Coleman $($ Coleman) & IC] & 1.5 & 1.3 & 1.4 & IC & Nat Gas & FO2 & 1955 & OP \\
\hline & IC2 & 1.0 & 1.0 & 1.0 & IC & Nat Gas & FO2 & 1959 & $\mathrm{OP}$ \\
\hline & IC3 & 1.3 & 1.1 & 1.3 & IC & Nat Gas & FO2 & 1951 & OP \\
\hline & IC4 & 1.5 & 1.4 & 3.4 & IC & Nat Gas & FO2 & 1963 & OP \\
\hline & ICS & 2.2 & 1.8 & 1.9 & IC & Nat Gas & FO2 & 1968 & OP \\
\hline & IC6 & 2.5 & 2.3 & 24 & IC & Nat Gas & FO2 & 1973 & $O P$ \\
\hline & IC7 & 1.5 & 1.3 & 1.4 & & Nat Gas & FO2 & 1978 & OP \\
\hline & IC8 & 1.4 & .8 & 1.0 & IC & Nat Gas & FO2 & 1980 & $\mathrm{OP}$ \\
\hline & IC9 & 4.0 & 3.6 & 4.0 & IC & Nat Gas & FO2 & 1986 & OP \\
\hline Denton City of.......................... & & 177.9 & 183.0 & 183.0 & & & & & \\
\hline Lewisville (Dentun) ...................................................... & 1 & 2.8 & 2.8 & 2.8 & $\mathrm{HY}$ & Water & - & 1992 & $O P$ \\
\hline 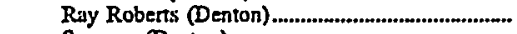 & 1 & 1.2 & 1.2 & 1.2 & $\mathrm{HY}$ & Water & - & 1992 & OP \\
\hline Spencer (Denton) & 1 & 12.7 & 13.0 & 13.0 & ST & Nat Gas & FO2 & 1955 & OP \\
\hline & 2 & & & & ST & Nat Gas & FO2 & 1955 & $\mathrm{OP}$ \\
\hline & 3 & 220 & 27.0 & 27.0 & ST & Nat Gas & FO2 & 1962 & $\mathrm{OP}$ \\
\hline & 4 & 61.2 & 60.0 & 60.0 & ST & Nat Gas & FO2 & 1966 & OP \\
\hline & 5 & 65.5 & 66.0 & 66.0 & ST & Nat Gas & FO2 & 1973 & OP \\
\hline 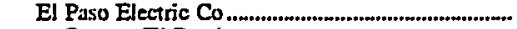 & & 648.9 & 567.0 & 580.0 & & & & & \\
\hline Cupper (El Paso) .............................................................. & 1 & 80.6 & 69.0 & 71.0 & GT & Nat Gas & FO2 & 1980 & OP \\
\hline 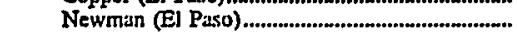 & CT) & 85.0 & 73.0 & 77.0 & CI & Nat Gas & FO2 & 1975 & OP \\
\hline & CT2 & 85.0 & 73.0 & 77.0 & CT & Nat Gas & FO2 & 1975 & $O P$ \\
\hline & 1 & 81.6 & 82.0 & 83.0 & $\mathbf{S T}$ & Nat Gas & FO2 & 1960 & $O P$ \\
\hline & 2 & 81.6 & 81.0 & 82.0 & ST & Nat Gas & FO2 & 1963 & OP \\
\hline & 3 & 115.2 & 103.0 & 104.0 & ST & Nat Gas & FO2 & 1966 & OP \\
\hline & 4 & 120.0 & 86.0 & 86.0 & CW & WH & - & 1975 & OP \\
\hline Electra Ciry of & & 42 & 4.0 & 4.0 & & & & & \\
\hline 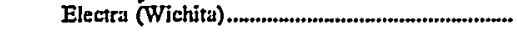 & 3 & .2 & .2 & .2 & IC & Nat Gas & FO2 & 1939 & OP \\
\hline & 4 & .2 & .2 & 2 & IC & Nat Gas & FO2 & 1939 & OP \\
\hline & 5 & .5 & .5 & 5 & IC & Nat Gas & FO2 & 1945 & OP \\
\hline
\end{tabular}

See footnotes at end of table. 
Table 20. Existing Generating Units at U.S. Electric Utilities by State, Company, and Plant, as of January 1, 1998 (Continued)

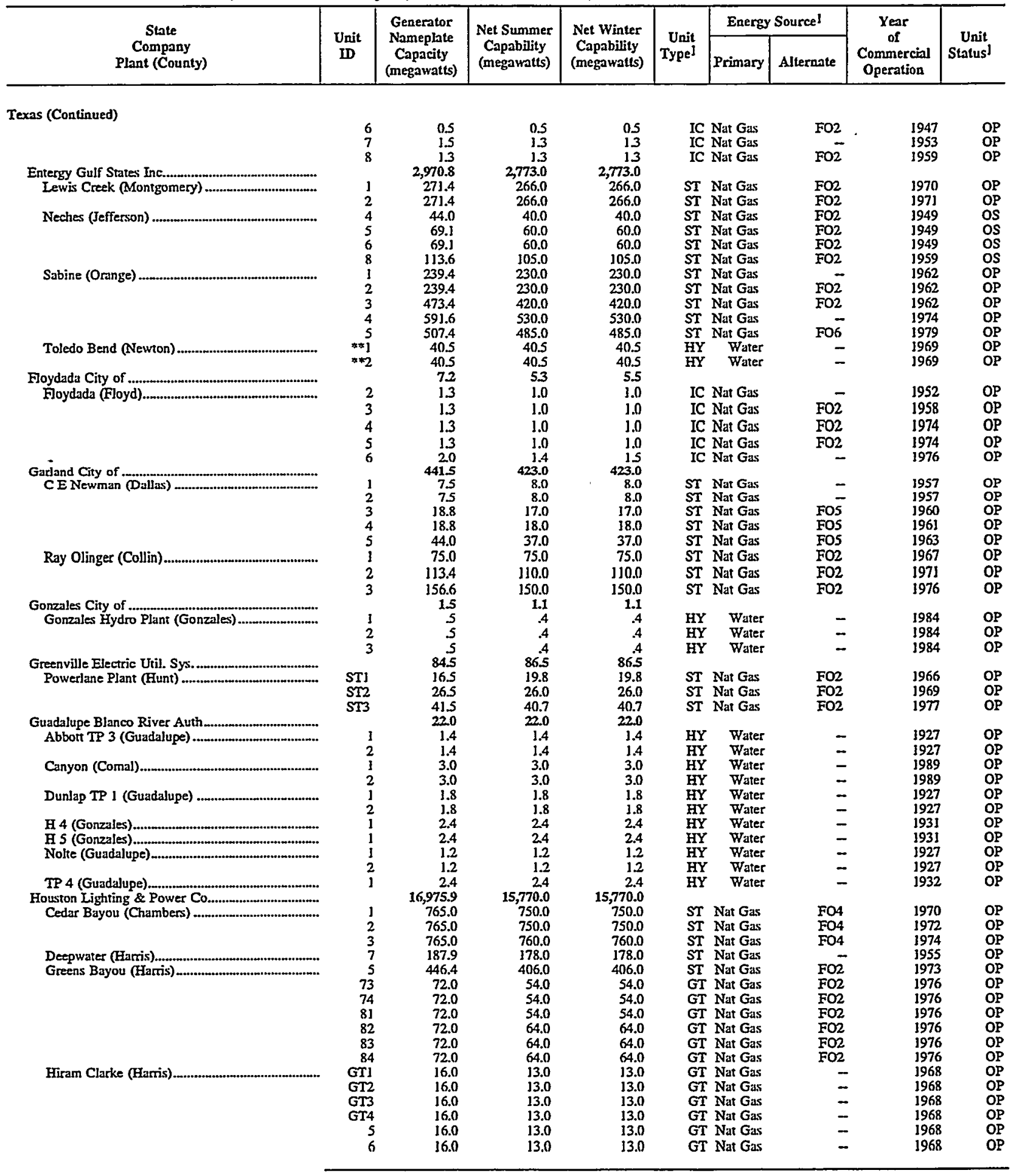

See footnotes at end of table. 
Table 20. Existing Generating Units at U.S. Electric Utilities by State, Company, and Plant, as of January 1, 1998 (Continued)

\begin{tabular}{|c|c|c|c|c|c|c|c|c|c|}
\hline \multirow{2}{*}{$\begin{array}{c}\text { State } \\
\text { Company } \\
\text { Plant (County) }\end{array}$} & \multirow{2}{*}{$\begin{array}{c}\text { Unit } \\
\text { ID }\end{array}$} & \multirow{2}{*}{$\begin{array}{c}\text { Generator } \\
\text { Nameplate } \\
\text { Capacity } \\
\text { (megawatts) }\end{array}$} & \multirow{2}{*}{$\begin{array}{l}\text { Net Summer } \\
\text { Capability } \\
\text { (megawatts) }\end{array}$} & \multirow{2}{*}{$\begin{array}{l}\text { Net Winter } \\
\text { Capability } \\
\text { (megawatts) }\end{array}$} & \multirow{2}{*}{$\begin{array}{l}\text { Unit } \\
\text { Type }\end{array}$} & \multicolumn{2}{|c|}{ Energy Sourcel } & \multirow{2}{*}{$\begin{array}{c}\text { Year } \\
\text { of } \\
\text { Commercial } \\
\text { Operation }\end{array}$} & \multirow{2}{*}{$\begin{array}{c}\text { Unit } \\
\text { Status }\end{array}$} \\
\hline & & & & & & Primary & Alternate & & \\
\hline Texas (Continued) & & & & & & & & & \\
\hline Limestone (Limestone) & 1 & 813.4 & 760.0 & 760.0 & ST & LIG & - & 1985 & OP \\
\hline 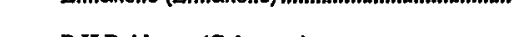 & 2 & 813.4 & 760.0 & 760.0 & ST & - IIG & - & 1986 & OP \\
\hline P H Robinson (Galveston) & 1 & 484.5 & 461.0 & 461.0 & ST & Nat Gas & - & 1966 & OP \\
\hline & $\frac{2}{3}$ & $\begin{array}{l}484.5 \\
580.5\end{array}$ & $\begin{array}{l}461.0 \\
552.0\end{array}$ & $\begin{array}{l}461.0 \\
552.0\end{array}$ & $\begin{array}{l}\text { ST } \\
\text { ST }\end{array}$ & $\begin{array}{l}\text { Nat Gas } \\
\text { Nat Gas }\end{array}$ & $\overline{-}$ & $\begin{array}{l}1967 \\
1968\end{array}$ & $\begin{array}{l}\text { OP } \\
\text { OP }\end{array}$ \\
\hline & 4 & 765.0 & 739.0 & 739.0 & ST & Nat Gas & FO4 & 1973 & $O P$ \\
\hline Sam Bertron (Harris) & GT1 & 32.6 & 23.0 & 23.0 & GT & Nat Gas & - & 1967 & OP \\
\hline & $\begin{array}{l}\text { GT2 } \\
\text { ST1 }\end{array}$ & $\begin{array}{r}16.3 \\
187.9\end{array}$ & $\begin{array}{r}13.0 \\
174.0\end{array}$ & $\begin{array}{r}13.0 \\
174.0\end{array}$ & $\begin{array}{l}\text { GT } \\
\text { ST }\end{array}$ & $\begin{array}{l}\text { Nat Gas } \\
\text { Nat Gas }\end{array}$ & $\mathrm{FO}^{-}$ & $\begin{array}{l}1967 \\
1958\end{array}$ & $\begin{array}{l}\text { OP } \\
\text { OP }\end{array}$ \\
\hline & ST2 & 187.9 & 174.0 & 174.0 & $\begin{array}{l}\text { SI } \\
\text { ST }\end{array}$ & Nat Gas & FO4 & 1956 & OP \\
\hline & 3 & 225.3 & 230.0 & 230.0 & SI & Nat Gas & FO4 & 1959 & OP \\
\hline & 4 & 225.3 & 230.0 & 230.0 & ST & Nat Gas & FO4 & 1960 & OP \\
\hline 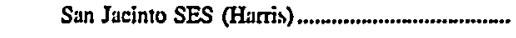 & SJS1 & 88.2 & 81.0 & 81.0 & GT & Nat Gas & - & 1995 & OP \\
\hline & SJS2 & 88.2 & 81.0 & 81.0 & GT & Nat Gas & - & 1995 & OI \\
\hline & $* * 2$ & 1354.3 & 1250.0 & 1250.0 & NP & Uranium & - & 1989 & OP \\
\hline T H Wharton (Harris) & Gl & 16.3 & 13.0 & 13.0 & GT & Nut Gas & - & 1967 & OP \\
\hline & 2 & 247.8 & 229.0 & 229.0 & $\stackrel{\text { ST }}{\text { CW }}$ & Nat Gas & $\mathrm{FO} 2$ & 1960 & OP \\
\hline & $\begin{array}{l}3 \\
4\end{array}$ & $\begin{array}{l}113.1 \\
113.1\end{array}$ & $\begin{array}{l}104.0 \\
104.0\end{array}$ & $\begin{array}{l}104.0 \\
104.0\end{array}$ & CW & WH & - & 1974 & OP \\
\hline & 31 & 113.1 & 58.0 & 104.0 & $\mathrm{CW}$ & WH & - & 1974 & OP \\
\hline & $3 !$ & 51.3 & 57.0 & 57.0 & CT & Nat Gas & - & 1972 & OP \\
\hline & 32 & 51.3 & 57.0 & 57.0 & CT & Nat Gas & - & 1972 & OP \\
\hline & 33 & 51.3 & 57.0 & 57.0 & CT & Nat Gas & - & 1972 & OP \\
\hline & $\begin{array}{l}34 \\
41\end{array}$ & $\begin{array}{l}51.3 \\
51.3\end{array}$ & $\begin{array}{l}57.0 \\
57.0\end{array}$ & $\begin{array}{l}57.0 \\
57.0\end{array}$ & $\underset{C T}{C T}$ & Nat Gas & $=$ & 1972 & OP \\
\hline & 42 & 51.3 & 57.0 & 57.0 & CT & Nat Gas & - & $\begin{array}{l}1972 \\
1972\end{array}$ & OP \\
\hline & 43 & 56.7 & 57.0 & 57.0 & $\mathrm{CT}$ & Nat Gas & - & 1974 & OP \\
\hline & 44 & 56.7 & 57.0 & 57.0 & Cr & Nat Gas & - & 1974 & OP \\
\hline & 51 & 85.0 & 58.0 & 58.0 & GT & Nat Gas & FO2 & 1975 & OP \\
\hline & 52 & 85.0 & 58.0 & 58.0 & GT & Nat Gas & FO2 & 1975 & OP \\
\hline & 53 & 85.0 & 58.0 & 58.0 & GT & Nat Gas & FO2 & 1975 & OP \\
\hline & 54 & 85.0 & 58.0 & 58.0 & $\mathrm{GT}$ & Nat Gas & FO2 & 1975 & $O P$ \\
\hline & 55 & 85.0 & 58.0 & 58.0 & GT & Nat Gas & $\mathrm{FO} 2$ & 1975 & $O P$ \\
\hline & 56 & 85.0 & 58.0 & 58.0 & GT & Nat Gas & FO2 & 1975 & OP \\
\hline 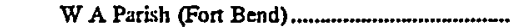 & GT1 & 16.3 & 13.0 & 13.0 & GT & Nat Gas & - & 1967 & OP \\
\hline & 1 & 187.9 & 378.0 & 178.0 & ST & Nat Gas & $\mathrm{FO} 2$ & 1958 & OP \\
\hline & 2 & 187.9 & 178.0 & 178.0 & ST & Nat Gas & $\mathrm{FO} 2$ & 1958 & OP \\
\hline & 5 & 734.1 & 650.0 & 650.0 & ST & SUB & Nat Gas & 1977 & OP \\
\hline & 6 & 734.1 & 650.0 & 650.0 & ST & SUB & Nat Gas & 1978 & OP \\
\hline & 7 & $6] 4.6$ & 560.0 & 560.0 & ST & SUB & - & 1980 & OP \\
\hline & 8 & 6]4.6 & 555.0 & 555.0 & ST & SUB & - & 1982 & OP \\
\hline Webster (Harris) & GT1 & 16.3 & 13.0 & 13.0 & GT & Nat Gas & - & 1967 & OP \\
\hline & 3 & 410.0 & 374.0 & 374.0 & ST & Nat Gas & - & 1965 & OP \\
\hline Intemational Bound \& Wtr Comm & & 97.5 & 109.0 & $\$ 1.0$ & & & & & \\
\hline Amistad Dam \& Power (Val Verde) ..................... & 1 & 33.0 & 35.0 & 16.5 & $\mathbf{H Y}$ & Water & - & 1983 & OP \\
\hline & 2 & 33.0 & 35.0 & 165 & HY & Water & - & 1983 & OP \\
\hline 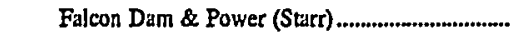 & 1 & 10.5 & 13.0 & 6.0 & HY & Water & - & 1954 & OP \\
\hline & 2 & 10.5 & 13.0 & 6.0 & HY & Water & - & 1954 & OP \\
\hline & 3 & 10.5 & 13.0 & 6.0 & HY & Water & - & 1954 & OP \\
\hline Lower Colorado River Authority & & $3,005.4$ & $2,905.0$ & $2,937.0$ & & & & & \\
\hline Austin (Travis) & 1 & 8.1 & 8.4 & 8.4 & HY & Water & - & 1941 & OP \\
\hline & 2 & 8.1 & 8.9 & 8.9 & $\mathbf{H Y}$ & Water & - & 1941 & OP \\
\hline Buchanan (Bumet) & 1 & 11.3 & 14.7 & 14.7 & HY & Water & - & 1938 & OP \\
\hline & 2 & 11.3 & 14.7 & 14.7 & HY & Water & - & 1938 & OP \\
\hline & 3 & 11.3 & 14.9 & 14.9 & HY & Water & - & 1938 & OP \\
\hline 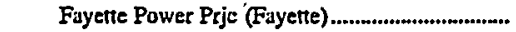 & $* \overline{1}$ & 615.0 & 580.0 & 588.0 & ST & SUB & LIG & 1979 & OP \\
\hline & $* 2$ & 615.0 & 580.0 & 588.0 & SI & SUB & IIG & 1980 & OP \\
\hline & 3 & 460.0 & 435.0 & 440.0 & ST & SUB & IIG & 1988 & OP \\
\hline Granite Shouls (Burnet)......................................... & 1 & 22.5 & 28.0 & 28.0 & $\mathbf{H Y}$ & Water & - & 1951 & OP \\
\hline & 2 & 22.5 & 28.0 & 28.0 & HY & Water & - & 1951 & oP \\
\hline 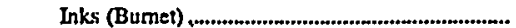 & 1 & 15.0 & 14.0 & 14.0 & $\mathbf{H Y}$ & Water & - & 1938 & OP \\
\hline Marble Falls (Burnet) & $\mathrm{i}$ & 15.0 & 18.2 & 18.2 & $\mathbf{H Y}$ & Water & - & 1951 & OP \\
\hline & 2 & 15.0 & 18.2 & 18.2 & $\mathbf{H Y}$ & Water & - & 1951 & op \\
\hline Marshall Ford (Travis).......................................... & J & 34.0 & 36.0 & 36.0 & HY & Water & - & 1941 & OP \\
\hline & 2 & 225 & 30.0 & 30.0 & HY & Water & - & 1941 & OP \\
\hline & 3 & 34.0 & 36.0 & 36.0 & HY & Water & - & 1941 & OP \\
\hline Sim Gideon (Bastrop) & I & 144.0 & 140.0 & 144.0 & ST & Nat Gas & FO2 & 1965 & OP \\
\hline & 2 & 144.0 & 140.0 & 144.0 & ST & Nat Gas & $\mathrm{FO} 2$ & 1968 & OP \\
\hline
\end{tabular}

See footnotes at end of table. 
Table 20. Existing Generating Units at U.S. Electric Utilities by State, Company, and Plant, as of January 1, 1998 (Continued)

\begin{tabular}{|c|c|c|c|c|c|c|c|c|c|}
\hline \multirow{2}{*}{$\begin{array}{c}\text { State } \\
\text { Company } \\
\text { Plant (County) }\end{array}$} & \multirow{2}{*}{$\begin{array}{c}\text { Unit } \\
\text { ID }\end{array}$} & \multirow{2}{*}{$\begin{array}{c}\text { Generator } \\
\text { Nameplate } \\
\text { Capacity } \\
\text { (megawatts) }\end{array}$} & \multirow{2}{*}{$\begin{array}{l}\text { Net Summer } \\
\text { Capability } \\
\text { (megawatts) }\end{array}$} & \multirow{2}{*}{$\begin{array}{l}\text { Net Winter } \\
\text { Capability } \\
\text { (megawatts) }\end{array}$} & \multirow{2}{*}{$\begin{array}{r}\text { Unit } \\
\text { Type }\end{array}$} & \multicolumn{2}{|c|}{ Energy Sourcel } & \multirow{2}{*}{$\begin{array}{c}\text { Year } \\
\text { of } \\
\text { Commerciol } \\
\text { Operation }\end{array}$} & \multirow{2}{*}{$\begin{array}{c}\text { Unit } \\
\text { Status } 1\end{array}$} \\
\hline & & & & & & Primary & Alternate & & \\
\hline \multicolumn{10}{|l|}{ Texas (Continued) } \\
\hline & 3 & 351.0 & 340.0 & 343.0 & ST & Nat Gas & FO2 & 1972 & \\
\hline 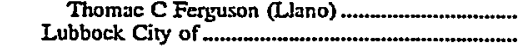 & I & $\begin{array}{l}446.0 \\
238.7\end{array}$ & $\begin{array}{l}420.0 \\
235.6\end{array}$ & $\begin{array}{l}420.0 \\
245.1\end{array}$ & ST & Nat Gas & FO2 & 1974 & OP \\
\hline Brandon Station (Lubbock) & J & 21.0 & 20.0 & 21.5 & GT & Nat Gas & - & 1990 & OP \\
\hline Holly Ave (Lubbock) & GT1 & 12.5 & 11.0 & 12.5 & GT & Nat Gas & - & 1964 & OP \\
\hline & GT2 & 18.5 & 16.0 & 18.5 & GT & Nat Gas & - & 1971 & OP \\
\hline & GT3 & 22.0 & 18.0 & 220 & GT & Nat Gas & - & 1974 & OP \\
\hline & $\begin{array}{l}1 \\
2\end{array}$ & $\begin{array}{l}44.0 \\
53.7\end{array}$ & $\begin{array}{l}50.0 \\
53.6\end{array}$ & $\begin{array}{l}50.0 \\
53.6\end{array}$ & $\begin{array}{l}S T \\
S T\end{array}$ & $\begin{array}{l}\text { Nat Gas } \\
\text { Nat Gas }\end{array}$ & $\mathrm{FO2}$ & 1965 & $\begin{array}{l}O P \\
O P\end{array}$ \\
\hline Plant 2 (Lubbock) & $6 A$ & 22.0 & 220 & 22.0 & ST & Nat Gas & 5 & 1997 & OP \\
\hline & 4 & 11.5 & 11.5 & 11.5 & ST & Nat Gas & - & 1952 & OP \\
\hline & 5 & 11.5 & 11.5 & 115 & ST & Nat Gas & - & 1953 & OP \\
\hline & 7 & 22.0 & 22.0 & 22.0 & ST & Nat Gass & - & 1959 & OP \\
\hline 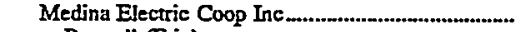 & & 66.0 & 75.0 & 75.0 & & & & & \\
\hline Pearsall (Frio) & $\begin{array}{l}3 \\
2\end{array}$ & $\begin{array}{l}22.0 \\
22.0\end{array}$ & $\begin{array}{l}25.0 \\
25.0\end{array}$ & $\begin{array}{l}25.0 \\
25.0\end{array}$ & $\begin{array}{l}\text { ST } \\
\text { ST }\end{array}$ & $\begin{array}{l}\text { Nat Gas } \\
\text { Nat Gas }\end{array}$ & $\begin{array}{l}\mathrm{FO} 2 \\
\mathrm{FO} 2\end{array}$ & $\begin{array}{l}196] \\
196]\end{array}$ & $\begin{array}{l}\text { OP } \\
\text { OP }\end{array}$ \\
\hline & 3 & 220 & 25.0 & 25.0 & ST & Nat Gas & FO2 & 1961 & OP \\
\hline Robstown City of & & 21.1 & 17.6 & 17.6 & & & & & \\
\hline Robstown (Nueces) & $\begin{array}{l}3 \\
4\end{array}$ & 2.5 & 2.1 & 2.1 & IC & Nat Gas & $\mathrm{FO2}$ & 1958 & $O P$ \\
\hline & 5 & $\begin{array}{l}2.4 \\
2.4\end{array}$ & $\begin{array}{l}2.0 \\
2.0\end{array}$ & $\begin{array}{l}2.0 \\
2.0\end{array}$ & $\begin{array}{l}\text { IC } \\
\text { IC }\end{array}$ & $\begin{array}{l}\text { Nat Gas } \\
\text { Nat Gas }\end{array}$ & $\begin{array}{l}\text { FO2 } \\
\text { FO2 }\end{array}$ & $\begin{array}{l}1979 \\
1979\end{array}$ & $\begin{array}{l}\text { OP } \\
\text { OP }\end{array}$ \\
\hline & 7 & 1.0 & .9 & .9 & IC & Nat Gas & FO2 & 1955 & OP \\
\hline & 8 & 1.0 & .9 & .9 & IC & Nat Gas & $\mathrm{FO} 2$ & 1956 & OP \\
\hline & 9 & 2.6 & 2.2 & 2.2 & IC & Nat Gas & $\mathrm{FO} 2$ & 1962 & OP \\
\hline & 10 & 4.2 & 3.5 & 3.5 & IC & Nar Gas & $\mathrm{FO} 2$ & 1967 & OP \\
\hline & 11 & 5.0 & 4.0 & 4.0 & IC & Nat Gas & $\mathrm{FO2}$ & 1972 & OP \\
\hline 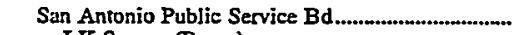 & & $4,022.0$ & $3,725.0$ & $3,725.0$ & & & & & \\
\hline J K Spruce (Bexar) & ] & 546.0 & 530.0 & 530.0 & $\mathbf{S T}$ & SUB & - & 1992 & OP \\
\hline J T Deely (Bexar) & 1 & 446.0 & 405.0 & 405.0 & ST & SUB & - & 1977 & OP \\
\hline Lean Creek (Bexar) & 2 & 446.0 & 405.0 & 405.0 & ST & SUB & - & 1978 & OP \\
\hline Leon Creek (Bexar) & 3 & 75.0 & 65.0 & 65.0 & ST & Nat Gas & - & 1953 & OP \\
\hline & 4 & 114.0 & 95.0 & 95.0 & ST & Nat Gas & - & 1959 & $\mathrm{OP}$ \\
\hline Mission Road (Bexar) ........................................ & 3 & 114.0 & 100.0 & 100.0 & ST & Nat Gas & - & 1958 & OP \\
\hline O W Sommers (Bexar) & 1 & 446.0 & 430.0 & 430.0 & ST & Nat Gas & $\mathrm{FO} 2$ & 1972 & OP \\
\hline & 2 & 446.0 & 420.0 & 420.0 & ST & Nat Gas & $\mathrm{FO2}$ & 1974 & OP \\
\hline V H Braunig (Bexar) & l & 225.0 & 220.0 & 220.0 & ST & Nat Gas & $\mathrm{FO} 2$ & 1966 & OP \\
\hline & 2 & 2520 & 230.0 & 230.0 & ST & Nat Gas & FO2 & 1968 & OP \\
\hline & 3 & 417.0 & 400.0 & 400.0 & ST & Nat Gas & FO2 & 1970 & OP \\
\hline W B Tuttle (Bexar) & $\mathbf{1}$ & 75.0 & 65.0 & 65.0 & ST & Nat Gas & - & 1954 & OP \\
\hline & 2 & 114.0 & 100.0 & 100.0 & ST & Nat Gas & - & 1956 & OP \\
\hline & 3 & 114.0 & 100.0 & 100.0 & ST & Nat Gus & - & 1961 & OP \\
\hline & 4 & 1920 & 160.0 & 160.0 & sT & Nat Gas & - & 1963 & OP \\
\hline 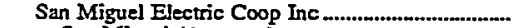 & & 410.0 & 391.0 & 391.0 & & & & & \\
\hline San Migued (Atascosa) & $* * 1$ & 410.0 & 391.0 & 391.0 & ST & LIG & - & 1982 & OP \\
\hline Seguin City of & & 5 & 5 & 5 & & & & & \\
\hline Seguin (Guadalupe) & HYI & 3 & 3 & 3 & $\mathrm{HY}$ & Water & - & 1926 & OP \\
\hline & I-I & $\frac{3}{47}$ & 503 & 543 & IC & $\mathrm{FO2}$ & - & 1900 & OP \\
\hline 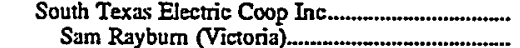 & & $\$ 7.7$ & $\begin{array}{l}50.2 \\
11.0\end{array}$ & 542 & & & & & \\
\hline Sam Raybum (Victoria) & $\frac{1}{2}$ & $\begin{array}{l}11.3 \\
11.3\end{array}$ & 11.0 & $\begin{array}{l}11.0 \\
14.0\end{array}$ & $\begin{array}{l}\text { GT } \\
\text { GT }\end{array}$ & $\begin{array}{l}\text { Nat Gas } \\
\text { Nat Gas }\end{array}$ & $\begin{array}{l}\text { FO4 } \\
\text { FO4 }\end{array}$ & $\begin{array}{l}1964 \\
1964\end{array}$ & $\begin{array}{l}\text { OP } \\
\text { OP }\end{array}$ \\
\hline & 3 & 220 & 25.0 & 26.0 & ST & Nat Gas & FO4 & 1965 & OP \\
\hline & 4 & 1.6 & 1.6 & 1.6 & IC & FO2 & - & 1991 & OP \\
\hline & 5 & 1.6 & 1.6 & 1.6 & IC & FO2 & - & 199] & OP \\
\hline 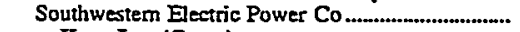 & & $3,423.1$ & $3,660.0$ & $3,660.0$ & & & & & \\
\hline Knox Lee (Gregg) & 2 & 30.0 & 25.0 & 25.0 & ST & Nat Gas & - & 1950 & OP \\
\hline & 3 & 30.0 & 25.0 & 25.0 & ST & Nat Gas & - & 1952 & OP \\
\hline & 4 & 75.0 & 77.0 & 77.0 & ST & Nat Gas & - & 1956 & OP \\
\hline & 5 & 323.7 & 344.0 & 344.0 & ST & Nat Gas & FO6 & 19 & $O P$ \\
\hline Lone Star (Morris) & 1 & 40.0 & So.0 & 50.0 & ST & Nat Gas & $\mathrm{FO2}$ & 1954 & OP \\
\hline Pitkey (Harrison) & $* *]$ & 580.1 & 675.0 & 675.0 & ST & LIG & - & 1985 & OP \\
\hline Welsh (Titus) & 1 & 512.3 & 528.0 & 528.0 & ST & SUB & - & 1977 & $O P$ \\
\hline & 2 & 5123 & 528.0 & 528.0 & ST & SUB & - & 1980 & $\mathrm{OP}$ \\
\hline & 3 & 5123 & 528.0 & 528.0 & ST & SUB & - & 1982 & $\mathrm{OP}$ \\
\hline Wilkes (Marion) & 1 & 160.0 & 175.0 & 175.0 & ST & Nat Gas & FO4 & 1964 & OP \\
\hline & 2 & 323.7 & 357.0 & 357.0 & ST & Nat Gas & - & 1970 & OP \\
\hline & 3 & 323.7 & 348.0 & 348.0 & ST & Nat Gas & - & 1971 & $O P$ \\
\hline Southwestem Public Service Co............................... & & $3,746.4$ & $3,645.0$ & $3,645.0$ & & & & & \\
\hline 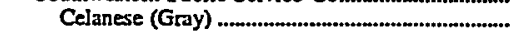 & 1 & 13.0 & 13.0 & 13.0 & 19 OT & 19 or & - & 1964 & $O P$ \\
\hline & 2 & 37.0 & 26.0 & 26.0 & ST & SUB & - & 1979 & OP \\
\hline 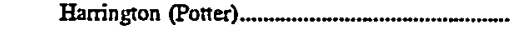 & 1 & 360.0 & 346.0 & 346.0 & sT & SUB & Nat Gas & 1976 & OP \\
\hline
\end{tabular}

See footnotes at end of table. 
Table 20. Existing Generating Units at U.S. Electric Utilities by State, Company, and Plant, as of January 1, 1998 (Continued)

\begin{tabular}{|c|c|c|c|c|c|c|c|c|c|}
\hline \multirow{2}{*}{$\begin{array}{c}\text { State } \\
\text { Company } \\
\text { Plant (County) }\end{array}$} & \multirow{2}{*}{$\begin{array}{l}\text { Unit } \\
\text { WD }\end{array}$} & \multirow{2}{*}{$\begin{array}{l}\text { Generator } \\
\text { Nameplate } \\
\text { Capacity } \\
\text { (megawatts) }\end{array}$} & \multirow{2}{*}{$\begin{array}{l}\text { Net Summer } \\
\text { Capability } \\
\text { (megawatts) }\end{array}$} & \multirow{2}{*}{$\begin{array}{l}\text { Net Winter } \\
\text { Capability } \\
\text { (megawatts) }\end{array}$} & \multirow{2}{*}{$\begin{array}{r}\text { Unit } \\
\text { Type }\end{array}$} & \multicolumn{2}{|c|}{ Energy Source! } & \multirow{2}{*}{$\begin{array}{c}\text { Year } \\
\text { of } \\
\text { Commercinl } \\
\text { Operation }\end{array}$} & \multirow{2}{*}{$\begin{array}{c}\text { Unit } \\
\text { Status }\end{array}$} \\
\hline & & & & & & Primary & Alternate & & \\
\hline Texas (Continued) & & & & & & & & & \\
\hline & 2 & 360.0 & 360.0 & 360.0 & ST & SUB & Nat Gas & 1978 & OP \\
\hline & 3 & 360.0 & 360.0 & 360.0 & ST & SUB & Nat Gas & 1980 & OP \\
\hline 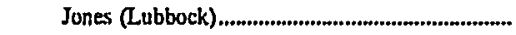 & 1 & 248.0 & 243.0 & 243.0 & ST & Nat Gas & FO2 & 1971 & OP \\
\hline & 2 & 248.0 & 243.0 & 243.0 & ST & Nat Gas & $\mathrm{FO} 2$ & 1974 & OP \\
\hline 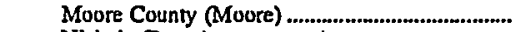 & 3 & 49.0 & 48.0 & 48.0 & GT & - Nat Gas & - & 1954 & OP \\
\hline Nichols (Potter) & 1 & 114.0 & 107.0 & 107.0 & ST & Nat Gas & - & 1960 & OP \\
\hline & 2 & 114.0 & 106.0 & 106.0 & $\underset{\mathscr{S T}}{\mathrm{ST}}$ & Nat Gas & - & 1962 & OP \\
\hline & & 248.0 & 244.0 & 244.0 & ST & Nat Gas & - & 1968 & OP \\
\hline 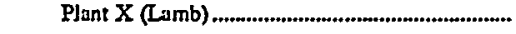 & J & 48.0 & 48.0 & 48.0 & ST & Nat Gas & FO2 & 1952 & OP \\
\hline & 2 & 98.0 & 102.0 & 102.0 & ST & Nat Gas & FO2 & 1953 & $O P$ \\
\hline & 3 & 98.0 & 103.0 & 103.0 & sT & Nat Gas & FO2 & 1955 & OP \\
\hline & 4 & 190.4 & 191.0 & 191.0 & ST & Nat Gas & $\mathrm{FO} 2$ & 1964 & $O P$ \\
\hline Riverview (Hutchinson)........................................... & 6 & 25.0 & 25.0 & 25.0 & GT & Nat Gas & - & 1974 & OP \\
\hline Tolk (Lamb) & l & 568.0 & 540.0 & 540.0 & ST & SUB & Nat Gas & 1982 & OP \\
\hline & 2 & 568.0 & 540.0 & 540.0 & ST & SUB & Nat Gas & 1985 & $\mathrm{OP}$ \\
\hline Texas Municipal Power Agency......................................... & & 480.2 & 462.0 & 4620 & & & & & \\
\hline 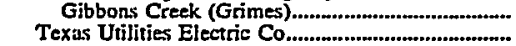 & 1 & $22,233.3$ & $\begin{array}{r}4620 \\
21,225.0\end{array}$ & $\begin{array}{r}462.0 \\
21,450.0\end{array}$ & ST & SUB & Nat Gas & 1983 & OP \\
\hline 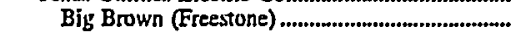 & 1 & 593.4 & 575.0 & 575.0 & ST & LIG & - & 1971 & OP \\
\hline & 2 & 593.4 & 575.0 & 575.0 & ST & LIG & - & 1972 & OP \\
\hline Collin (Collin) & j & 156.3 & 153.0 & 153.0 & ST & Nat Gas & Fos & 1955 & OP \\
\hline 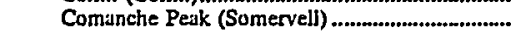 & $\mathrm{j}$ & 1215.0 & 1150.0 & 1150.0 & NP & Uranium & - & 1990 & $O P$ \\
\hline & 2 & 1215.0 & 1150.0 & 1150.0 & NP & Uranium & - & 1993 & OP \\
\hline Dallas (Dallas) ................... & 3 & 78.8 & 75.0 & 75.0 & $\mathbf{s T}$ & Nat Gas & - & 1954 & $O P$ \\
\hline & 9 & 75.0 & 70.0 & 70.0 & $\mathbf{S T}$ & Nat Gas & $-n^{-}$ & 1951 & OP \\
\hline DeCorduva (Hood)........ & CTI & 89.5 & 65.0 & 80.0 & GT & Nat Gas & FO2 & 1990 & OP \\
\hline & CT2 & 89.5 & 65.0 & 80.0 & GT & Nat Gas & $\mathrm{FO} 2$ & 1990 & $O P$ \\
\hline & $\mathrm{CT} 3$ & 89.5 & 65.0 & 80.0 & GT & Nat Gas & $\mathrm{FO} 2$ & 1990 & $O P$ \\
\hline & CT4 & 89.5 & 65.0 & 80.0 & GT & - Nat Gas & FO2 2 & 1990 & OP \\
\hline & i & 799.2 & 838.0 & 818.0 & ST & Nat Gas & FO2 & 1975 & $O P$ \\
\hline Eagle Mountain (Tarrant) ........................................ & j & 122.5 & 135.0 & 115.0 & ST & Nar Gas & Fos & 1954 & $O P$ \\
\hline & 2 & $\begin{array}{l}187.5 \\
3962\end{array}$ & $\begin{array}{l}375.0 \\
375.0\end{array}$ & $\begin{array}{l}175.0 \\
375\end{array}$ & $\begin{array}{l}\text { ST } \\
\text { ST }\end{array}$ & Nat Gas & Fos & 1956 & $O P$ \\
\hline Graham (Young) & $\mathrm{j}$ & 247.8 & 240.0 & 240.0 & ST & Nat Gas & Fos & 1960 & OP \\
\hline & 2 & 387.0 & 390.0 & 390.0 & ST & Nat Gas & FOS & 1969 & $O P$ \\
\hline Handley (Tarrant)............... & j & 43.8 & 45.0 & 45.0 & ST & Nat Gas & 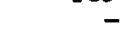 & 1948 & OP \\
\hline 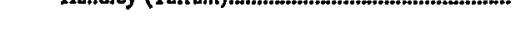 & 2 & 74.8 & 80.0 & 80.0 & ST & Nat Gas & - & 1950 & $O P$ \\
\hline & 3 & 404.8 & 400.0 & 400.0 & ST & Nat Gas & $\mathrm{FO} 2$ & 1963 & $O P$ \\
\hline & 4 & 455.0 & 458.0 & 458.0 & ST & Nat Gas & FO2 & 1976 & $O P$ \\
\hline & 5 & 455.0 & 458.0 & 458.0 & ST & Nat Gas & $\mathrm{FO} 2$ & 1977 & $O P$ \\
\hline Lake Creek (Mclennan)...... & DI & 2.0 & 20 & 2.0 & IC & FO2 & - & 1966 & OP \\
\hline & D2 & 2.0 & 2.0 & 20 & IC & FO2 & - & 1966 & $\mathrm{OP}$ \\
\hline & D3 & 2.0 & 2.0 & 20 & IC & FO2 & - & 1966 & $O P$ \\
\hline & STI & 79.6 & 87.0 & 87.0 & ST & Nat Gas & $\mathrm{FO} 2$ & 1953 & $O P$ \\
\hline & ST2 & 236.0 & 230.0 & 230.0 & ST & Nat Gas & $\mathrm{FO} 2$ & 1959 & $O P$ \\
\hline Lake Hubbard (Dallas) .............. & 1 & 396.5 & 393.0 & 393.0 & ST & Nat Gas & FO2 & 1970 & OP \\
\hline & 2 & 531.0 & 528.0 & 528.0 & ST & Nat Gas & FO2 & 1973 & OP \\
\hline 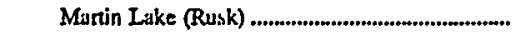 & 1 & 7933 & 750.0 & 750.0 & ST & LIG & - & 1977 & $O P$ \\
\hline & 2 & 793.3 & 750.0 & 750.0 & ST & IIG & - & 1978 & $\mathrm{OP}$ \\
\hline & 3 & 793.3 & 750.0 & 750.0 & ST & LIG & - & 1979 & $O P$ \\
\hline 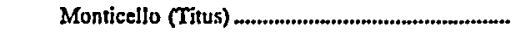 & 1 & 593.4 & 565.0 & 565.0 & ST & LIG & SUB & 1974 & $O P$ \\
\hline & 2 & 593.4 & 565.0 & 565.0 & ST & LIG & SUB & 1975 & OP \\
\hline & & 793.3 & 750.0 & 750.0 & ST & ZIG & SUB & 1978 & OP \\
\hline 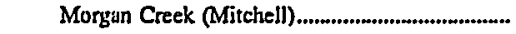 & CTI & 89.5 & 65.0 & 80.0 & GT & Nat Gas & FO2 & 1988 & OP \\
\hline & CT2 & 89.5 & 65.0 & 80.0 & GT & Nat Gas & FO2 & 1988 & OP \\
\hline & CT3 & 89.5 & 65.0 & 80.0 & $\mathrm{GT}$ & Nat Gas & $\mathrm{FO} 2$ & 1988 & $O P$ \\
\hline & CT4 & 89.5 & 65.0 & 80.0 & GT & Nat Gas & FO2 & 1988 & $O P$ \\
\hline & CT5 & 89.5 & 65.0 & 80.0 & GT & Nat Gas & FO2 & 1988 & $O P$ \\
\hline & CT6 & 89.5 & 65.0 & 80.0 & GT & Nat Gas & FO2 & 1988 & $O P$ \\
\hline & 2 & 18.4 & 22.0 & 22.0 & ST & Nat Gas & FOS & 1950 & $\mathrm{OP}$ \\
\hline & 3 & 46.0 & 44.0 & 44.0 & ST & Nat Gas & Fos & 1952 & $O P$ \\
\hline & 4 & 75.0 & 70.0 & 70.0 & ST & Nat Gas & FOS & 1954 & OP \\
\hline & 5 & 170.5 & 175.0 & 175.0 & $\underset{\sim T}{S T}$ & Nat Gas & FOS & 1959 & $O P$ \\
\hline & 6 & 517.5 & 511.0 & 511.0 & ST & Nat Gas & FOS & 1966 & OP \\
\hline 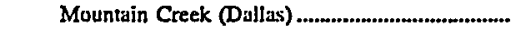 & 2 & 31.2 & 33.0 & 33.0 & ST & Nat Gas & Fos & 1945 & $O P$ \\
\hline & 3 & 75.0 & 70.0 & 70.0 & ST & Nat Gas & Fos & 1949 & OP \\
\hline & 6 & 135.8 & 115.0 & 115.0 & ST & Nat Gas & FOS & 1956 & $O P$ \\
\hline & 7 & 136.0 & 125.0 & 125.0 & ST & Nat Gas & FOS & 1958 & OP \\
\hline & 8 & 580.5 & 550.0 & 550.0 & ST & Nat Gas & FOS & 1967 & OP \\
\hline 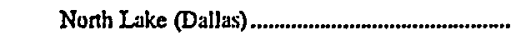 & 1 & 176.8 & 175.0 & 175.0 & ST & Nat Gas & FO2 & 1959 & OP \\
\hline
\end{tabular}

See footnotes at end of table. 
Table 20. Existing Generating Units at U.S. Electric Utilities by State, Company, and Plant, as of January 1, 1998 (Continued)

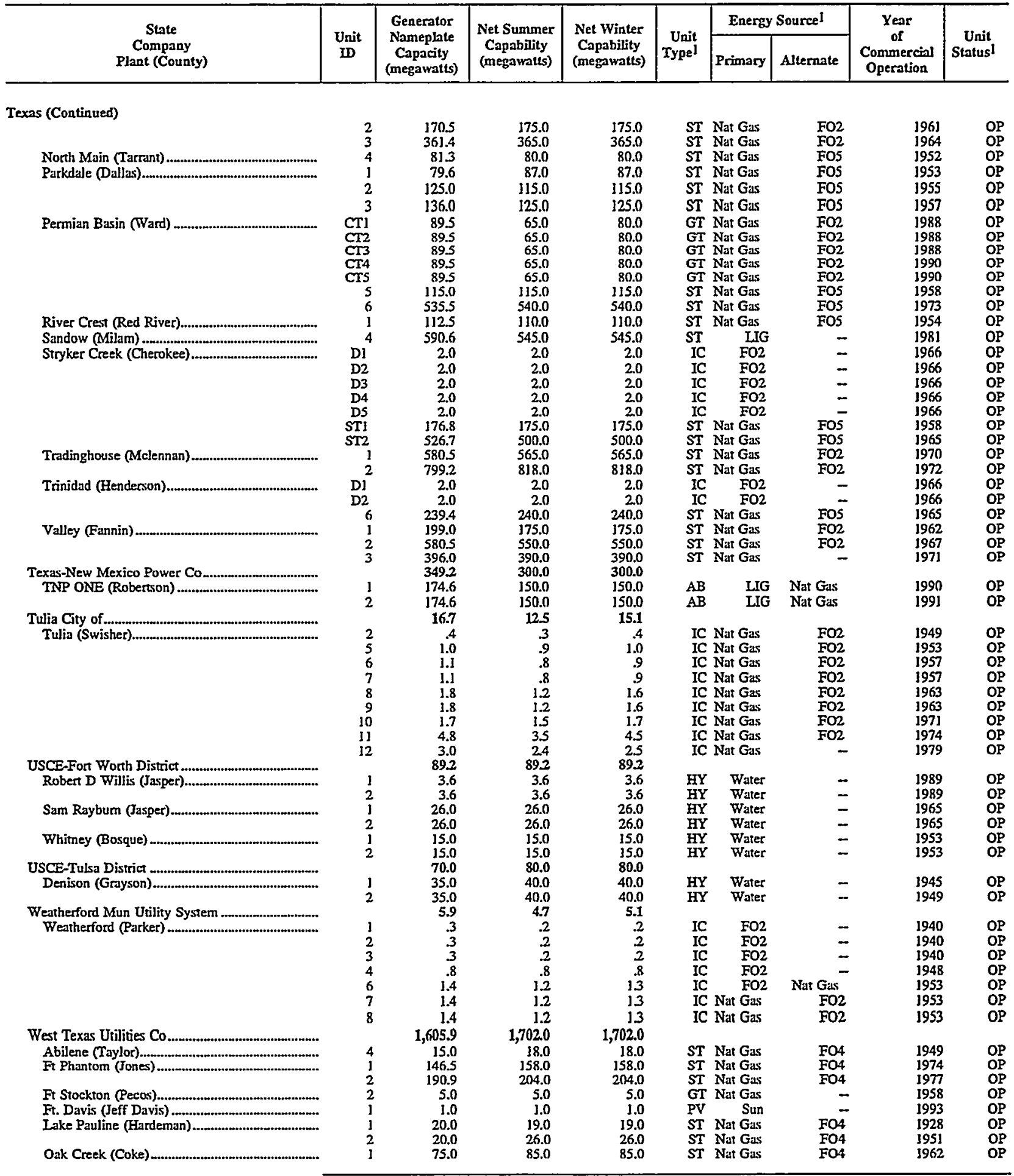

See foomotes at end of table. 
Table 20. Existing Generating Units at U.S. Electric Utilities by State, Company, and Plant, as of January 1, 1998 (Continued)

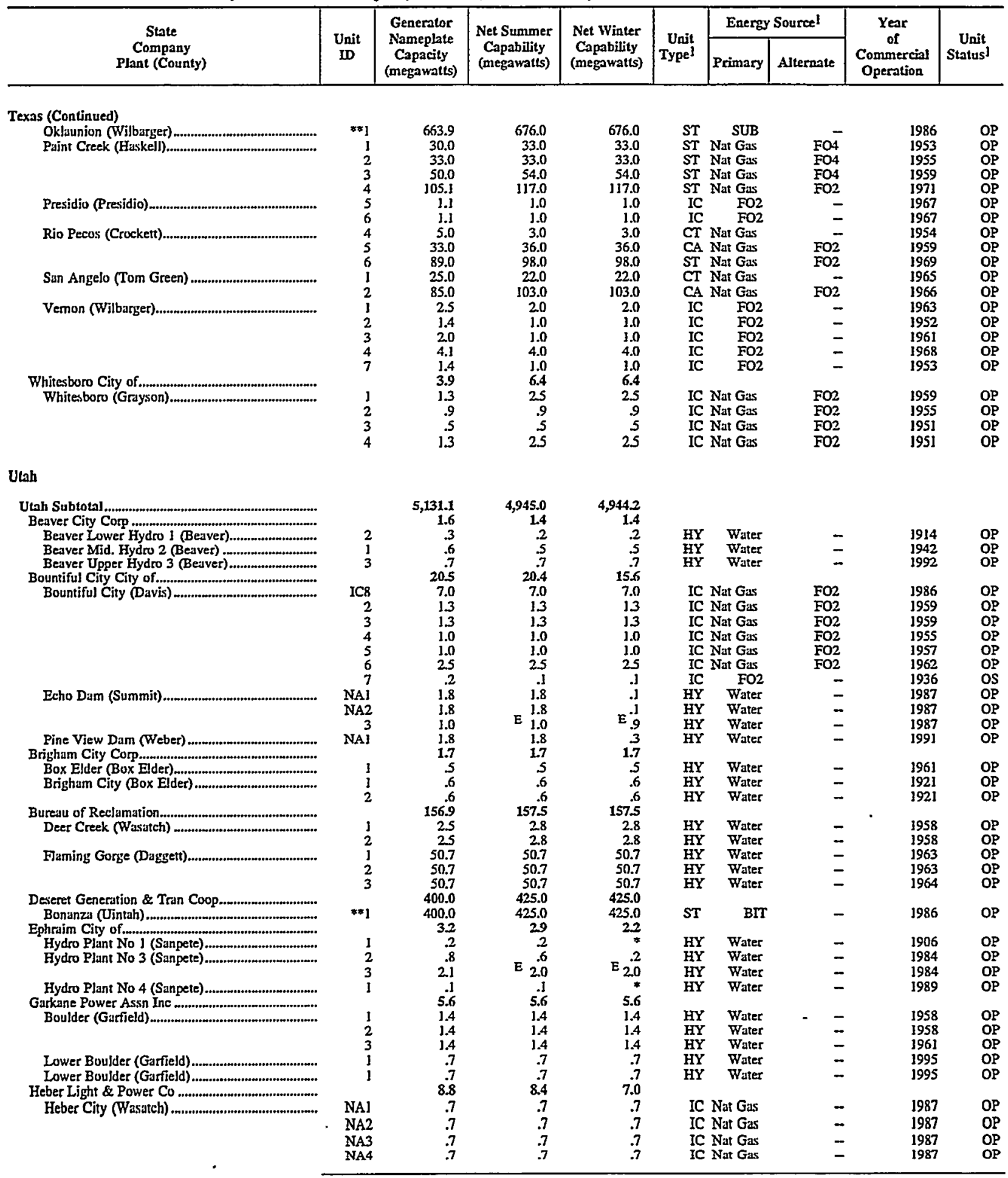

See footnotes at end of table. 
Table 20. Existing Generating Units at U.S. Electric Utilities by State, Company, and Plant, as of January 1, 1998 (Continued)

\begin{tabular}{|c|c|c|c|c|c|c|c|c|c|}
\hline \multirow{2}{*}{$\begin{array}{c}\text { State } \\
\text { Company } \\
\text { Plant (County) }\end{array}$} & \multirow{2}{*}{$\begin{array}{l}\text { Unit } \\
\text { ID }\end{array}$} & \multirow{2}{*}{$\begin{array}{c}\text { Generator } \\
\text { Nanieplate } \\
\text { Capacity } \\
\text { (megawatts) }\end{array}$} & \multirow{2}{*}{$\begin{array}{l}\text { Net Summer } \\
\text { Capability } \\
\text { (megawatts) }\end{array}$} & \multirow{2}{*}{$\begin{array}{l}\text { Nel Winter } \\
\text { Capability } \\
\text { (megawatts) }\end{array}$} & \multirow{2}{*}{$\begin{array}{c}\text { Unit } \\
\text { Type] }\end{array}$} & \multicolumn{2}{|c|}{ Energy Source] } & \multirow{2}{*}{$\begin{array}{c}\text { Year } \\
\text { of } \\
\text { Commercial } \\
\text { Operation }\end{array}$} & \multirow{2}{*}{$\begin{array}{c}\text { Unit } \\
\text { Status! }\end{array}$} \\
\hline & & & & & & Primary & Alternate & & \\
\hline Utah (Continued) & & & & & & & & & \\
\hline & NAS & 0.8 & 0.8 & 0.8 & IC & Nat Gas & - & 1990 & OP \\
\hline & NA7 & 1.6 & 1.6 & 1.6 & IC & $\mathrm{FO} 2$ & - & 1996 & OP \\
\hline 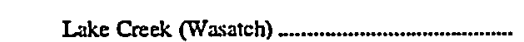 & $\begin{array}{c}\text { NA8 } \\
1\end{array}$ & $\begin{array}{l}1.6 \\
1.5\end{array}$ & 1.5 & $\begin{array}{r}1.5 \\
.3\end{array}$ & $\underset{\mathrm{HL}}{\mathrm{IC}}$ & $\begin{array}{r}\text { FO2 } \\
\text { Water }\end{array}$ & $\overline{-}$ & $\begin{array}{l}1991 \\
1981\end{array}$ & $\begin{array}{l}\text { OP } \\
\text { OP }\end{array}$ \\
\hline 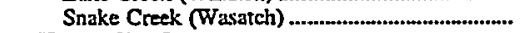 & 1 & .8 & .8 & 3 & HL & Water & - & 1949 & OP \\
\hline Hyrum City Corp & & 5 & .4 & .4 & & & & & \\
\hline 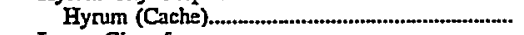 & 1 & .5 & .4 & .4 & $\mathrm{HY}$ & Water & - & 1931 & OP \\
\hline Logan City of & & 15.1 & 13.9 & 9.7 & & & & & \\
\hline 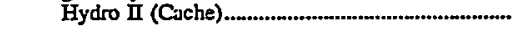 & $\frac{1}{2}$ & $\begin{array}{l}3.3 \\
3.3\end{array}$ & $\begin{array}{l}3.1 \\
3.1\end{array}$ & 1.5 & HY & $\begin{array}{l}\text { Water } \\
\text { Water }\end{array}$ & $\overline{-}$ & 1986 & OP \\
\hline Hydro III (Cache) & HYI & $\begin{array}{r}3.3 \\
.7\end{array}$ & $\begin{aligned} 3.1 \\
.7\end{aligned}$ & $\begin{array}{r}15 \\
.2\end{array}$ & $\begin{array}{l}\text { HY } \\
\text { HY }\end{array}$ & Water & $=$ & $\begin{array}{l}1980 \\
1925\end{array}$ & OP \\
\hline - & HY2 & .7 & .7 & .2 & HY & Water & - & 1925 & OP \\
\hline & $* \pitchfork \mathrm{HY}$ & .1 & 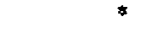 & $\neq$ & HL & Water & - & 1992 & OP \\
\hline Logan City (Cache) & IC2 & .8 & .6 & .6 & IC & $\mathrm{FO2}$ & - & 1927 & OS \\
\hline & IC3 & .8 & .6 & .6 & IC & $\mathrm{FO} 2$ & - & 1927 & os \\
\hline & IC4 & 1.3 & .7 & .8 & IC & $\mathrm{FO} 2$ & - & 1935 & OP \\
\hline & ICSA & 1.0 & 1.1 & 1.1 & IC & FO2 & - & 1990 & OP \\
\hline & ICSB & 1.0 & 1.J & 1.1 & IC & FO2 & $\rightarrow$ & 1990 & OP \\
\hline & IC6 & 2.3 & 2.3 & 23 & IC & $\mathrm{FO} 2$ & - & 1947 & OP \\
\hline Los Angeles City of & & $1,640.0$ & $1,640.0$ & $1,660.0$ & & & & & \\
\hline 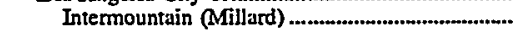 & $* \pm 1$ & 820.0 & 820.0 & 830.0 & ST & BIT & - & 1986 & OP \\
\hline & $\$ 2$ & 820.0 & 820.0 & 830.0 & ST & BIT & - & 1987 & OP \\
\hline Manti City of & & 2.8 & 2.4 & .4 & & & & & \\
\hline 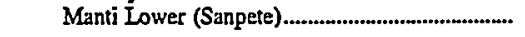 & $\mathrm{HCl}$ & .6 & .6 & .1 & HL & Water & - & 1989 & OP \\
\hline & & .6 & 6 & .1 & HLL & Water & - & 1989 & OP \\
\hline Manti Upper (Sanpete) & $\mathrm{HC} 2$ & 1.0 & .8 & .1 & HLL & Water & - & 1988 & OP \\
\hline & 1 & .6 & .4 & 2 & $\mathrm{HY}$ & Water & - & 1939 & OP \\
\hline $\begin{array}{l}\text { Monroe City of } \\
\text { Iower (Sevier) }\end{array}$ & & .6 & 6 & .6 & & & & & \\
\hline Iower (Sevier) & 1 & 3 & $\mathrm{E}^{.2}$ & $E^{.2}$ & $\mathrm{HL}$ & Water & - & 1928 & OP \\
\hline & 1 & .1 & E.] & E.J & PS & Water & - & 1981 & OP \\
\hline & 1 & .3 & .2 & .2 & HL & Water & - & 1940 & OP \\
\hline Moon Lake Electric Assn Inc & & 2.1 & 2.0 & 2.0 & & & & & \\
\hline Uintah (Duchesne) & $\mathbf{l}$ & .6 & .6 & .6 & $\mathrm{HY}$ & Water & - & 1920 & OP \\
\hline & 2 & .6 & .6 & .6 & HY & Water & - & 1940 & OP \\
\hline 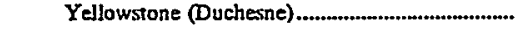 & 1 & .3 & 3 & 3 & HY & Water & - & 1941 & OP \\
\hline & 2 & 3 & 3 & 3 & HY & Water & - & 1941 & OP \\
\hline & 3 & 3 & 3 & 3 & HY & Water & - & 1941 & OP \\
\hline Mt Pleasant City of & & 1.8 & 1.7 & 1.7 & & & & & \\
\hline Lower-Unit (Sanpete) & 1 & .2 & .2 & .1 & HLL & Water & - & 1913 & OP \\
\hline Unit (Sanpete) & 1 & 1.3 & 1.3 & 1.3 & HI & Water & - & 1993 & OP \\
\hline Unit (Sanpete) & 1 & .2 & .1 & 2 & HL & Water & - & 1993 & OP \\
\hline 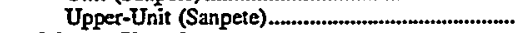 & 1 & .2 & .2 & .2 & HI & Water & - & 1931 & OP \\
\hline Murray City of & & 12.1 & 11.0 & 8.1 & & & & & \\
\hline 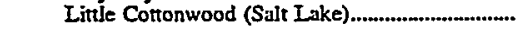 & 1 & 2.5 & 2.5 & .8 & HII & Water & - & 1983 & OP \\
\hline & 2 & 2.5 & 2.5 & .8 & HII & Water & - & 1983 & OP \\
\hline Murray City (Salt Lake) & 3 & 2.2 & 2.0 & 2.0 & IC & Nat Gas & FO2 & 1952 & OP \\
\hline & 4 & 1.0 & .9 & 1.0 & IC & Nat Gas & FO2 & 1948 & OP \\
\hline & 5 & 1.0 & 9 & 1.0 & IC & Nat Gas & FO2 & 1948 & OP \\
\hline & 6 & 3.0 & 2.3 & 25 & IC & Nat Gas & FO2 & 1958 & OP \\
\hline Nephi City Corp & & 7 & 6 & 3 & & & & & \\
\hline Bradley (Juab) & 7122 & .2 & .2 & 1 & HI & Water & - & 1986 & OP \\
\hline 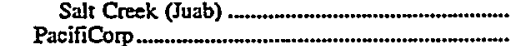 & 7120 & $2,773.4$ & & & HIL & Water & - & 1986 & OP \\
\hline $\begin{array}{l}\text { PacifiCorp...m } \\
\text { Ameriean Fork (Utah) }\end{array}$ & 1 & 1.0 & $\begin{array}{r}2,569.4 \\
.4\end{array}$ & $\begin{array}{r}2,566.9 \\
.4\end{array}$ & HY & Water & & & \\
\hline 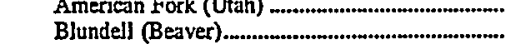 & j & 26.1 & 23.0 & 23.0 & GE & $\begin{array}{l}\text { Water } \\
\text { GST }\end{array}$ & $\overline{-}$ & $\begin{array}{l}1954 \\
1984\end{array}$ & OS \\
\hline $\begin{array}{l}\text { Blundell (Beaver) } \\
\text { Carbon (Carbon) }\end{array}$ & j & 75.0 & 70.0 & 70.0 & ST & BIT & - & $\begin{array}{l}1984 \\
1954\end{array}$ & OP \\
\hline & 2 & 113.6 & 105.0 & 105.0 & ST & BIT & - & $\begin{array}{l}1934 \\
1957\end{array}$ & OP \\
\hline 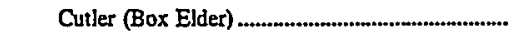 & 1 & 15.0 & 14.6 & 14.6 & HY & Water & - & 1927 & OP \\
\hline & 2 & 15.0 & 14.6 & 14.6 & HY & Water & - & 1927 & OP \\
\hline 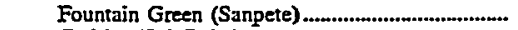 & 1 & .2 & .1 & .1 & HY & Water & - & 1922 & OP \\
\hline 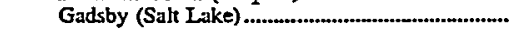 & 1 & 69.0 & 60.0 & 60.0 & ST & Nat Gas & FO6 & 1951 & OP \\
\hline & 2 & 69.0 & 75.0 & 75.0 & ST & Nat Gas & - & 1952 & OP \\
\hline & 3 & 113.6 & 100.0 & 100.0 & ST & Nat Gas & - & 1955 & OP \\
\hline 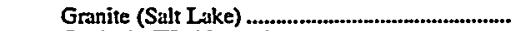 & 1 & 2.0 & 1.2 & 1.2 & HY & Water & - & 1896 & OP \\
\hline Gunlock (Washington) & i & .8 & .5 & .5 & HY & Water & - & 1917 & OP \\
\hline 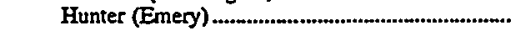 & +1 & 446.4 & 415.0 & 415.0 & ST & BIT & - & 1978 & OP \\
\hline & $* 2$ & 446.4 & 415.0 & 415.0 & ST & BIT & - & 1980 & OP \\
\hline & 3 & 446.4 & 395.0 & 395.0 & ST & BIT & - & 1983 & OP \\
\hline 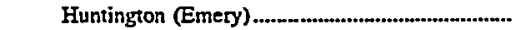 & I & 446.4 & 420.0 & 420.0 & ST & BIT & - & 1977 & OP \\
\hline & 2 & 446.4 & 425.0 & 425.0 & ST & BIT & - & 1974 & OP \\
\hline
\end{tabular}

See footnotes at end of table. 
Table 20. Existing Generating Units at U.S. Electric Utilities by State, Company, and Plant, as of January 1, 1998 (Continued)

\begin{tabular}{|c|c|c|c|c|c|c|c|c|c|}
\hline \multirow{2}{*}{$\begin{array}{c}\text { State } \\
\text { Company } \\
\text { Plant (County) }\end{array}$} & \multirow{2}{*}{$\begin{array}{l}\text { Unit } \\
\text { ID }\end{array}$} & \multirow{2}{*}{$\begin{array}{l}\text { Generator } \\
\text { Nameptate } \\
\text { Capacity } \\
\text { (megawatts) }\end{array}$} & \multirow{2}{*}{$\begin{array}{c}\text { Net Summer } \\
\text { Capability } \\
\text { (megawatts) }\end{array}$} & \multirow{2}{*}{$\begin{array}{l}\text { Net Winter } \\
\text { Capability } \\
\text { (megawatts) }\end{array}$} & \multirow{2}{*}{$\begin{array}{r}\text { Unit } \\
\text { Type }\end{array}$} & \multicolumn{2}{|c|}{ Energy Sourced } & \multirow{2}{*}{$\begin{array}{c}\text { Year } \\
\text { of } \\
\text { Commercinl } \\
\text { Operation }\end{array}$} & \multirow{2}{*}{$\begin{array}{c}\text { Unit } \\
\text { Status }\end{array}$} \\
\hline & & & & & & Primary & Alternate & & \\
\hline \multicolumn{10}{|l|}{ Utah (Continued) } \\
\hline \multirow{3}{*}{$\begin{array}{l}\text { Iittle Mountain (Weber) } \\
\text { Olmitead (Utah) }\end{array}$} & 1 & 16.0 & 14.0 & 14.0 & GT & Nat Gas & FO2 & 1971 & OP \\
\hline & $\frac{1}{2}$ & 2.4 & $\begin{array}{l}24 \\
2.4\end{array}$ & $\begin{array}{l}2.4 \\
2.4\end{array}$ & $\begin{array}{l}\mathrm{HY} \\
\mathrm{HY}\end{array}$ & $\begin{array}{l}\text { Water } \\
\text { Water }\end{array}$ & - & 1904 & $\underset{O P}{O P}$ \\
\hline & 4 & 5.5 & 5.5 & 3.0 & $\mathrm{HY}$ & Water & 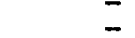 & 1922 & $\mathrm{OP}$ \\
\hline 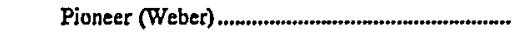 & $i$ & 2.5 & 20 & 2.0 & HYY & Water & - & 1914 & OP \\
\hline & 2 & 2.5 & 2.0 & 2.0 & HY & Water & - & 1914 & OP \\
\hline Sand Cove (Washington) & I & .8 & .5 & .5 & $\mathbf{H Y}$ & Water & - & 1920 & OP \\
\hline 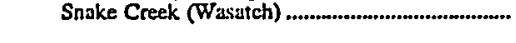 & $\frac{1}{2}$ & .6 & 5 & .5 & $\underset{\mathrm{HY}}{\mathrm{HY}}$ & Water & - & 1910 & $\mathrm{OP}$ \\
\hline 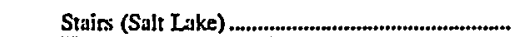 & 3 & 1.0 & .6 & .6 & HY & $\begin{array}{l}\text { Water } \\
\text { Water }\end{array}$ & $\Xi$ & $\begin{array}{l}1930 \\
1914\end{array}$ & $\begin{array}{l}\text { OP } \\
\text { OP }\end{array}$ \\
\hline 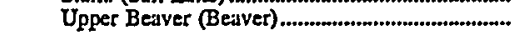 & i & 1.3 & 1.1 & 1.1 & HY & Water & - & 1907 & OP \\
\hline & 2 & 1.2 & 1.J & 1.1 & HY & Water & - & 1907 & OP \\
\hline Veyo (Washington).............. & 1 & .5 & 5 & 5 & HY & Water & - & 1920 & OP \\
\hline 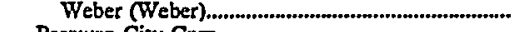 & 1 & 3.9 & 20 & 2.0 & HY & Water & - & 1949 & OP \\
\hline 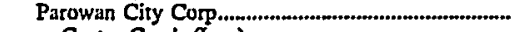 & & 12 & .8 & 5 & & & & & \\
\hline 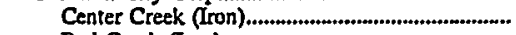 & 1 & .6 & .4 & 3 & HY & Water & - & 1951 & OP \\
\hline 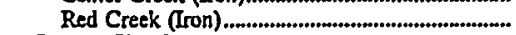 & i & .6 & .4 & 3 & HY & Water & - & 1955 & OP \\
\hline 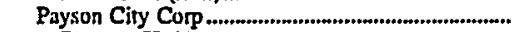 & & 9.8 & 93 & 93 & & & & & \\
\hline 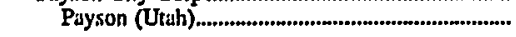 & $86-1$ & 2.7 & 27 & 2.7 & IC & Nat Gas & FOI & 1988 & $O P$ \\
\hline & $86-2$ & 27 & 2.7 & 27 & IC & & $\mathrm{FOI}$ & 1988 & $O P$ \\
\hline & & 20 & 2.0 & 20 & IC & $\begin{array}{l}\text { Nat Gas } \\
\text { Nat Gas }\end{array}$ & FOI & 1995 & OP \\
\hline Provo City Corp......... & & 31.0 & 29.5 & 29.5 & & & & & \\
\hline Bonnett (Besver) ........ & CTl & 8.5 & 7.0 & 7.0 & GE & GST & - & 1989 & OP \\
\hline & OECI & .8 & .8 & .8 & GE & GST & - & 1985 & OP \\
\hline & $\mathrm{OEC2}$ & .8 & .8 & .8 & GE & GST & - & 1985 & OP \\
\hline & OEC3 & .8 & .8 & .8 & GE & GST & - & 1985 & OP \\
\hline & OEC4 & .8 & .8 & .8 & GE & GST & - & 1985 & OP \\
\hline & TTI & 20 & 2.0 & 2.0 & GE & GST & - & 1988 & OP \\
\hline Provo (Utah), & 4 & 7.5 & 7.5 & 7.5 & ST & BIT & - & 1949 & SB \\
\hline & 5 & 2.5 & 2.5 & 25 & IC & FO4 & - & 1980 & $O P$ \\
\hline & 6 & 2.5 & 2.5 & 25 & IC & F04 & - & 1980 & OP \\
\hline & 7 & 2.5 & 2.5 & 25 & IC & F04 & - & 1980 & OP \\
\hline & 8 & 25 & 2.5 & 25 & IC & FO4 & - & 1980 & OP \\
\hline 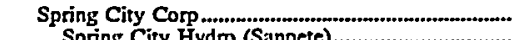 & & & 3 & 3 & & & & & \\
\hline $\begin{array}{l}\text { Sping City Hydro (Sanpete) } \\
\text { Springville City of . }\end{array}$ & 1769 & $\begin{array}{r}3.3 \\
16.5\end{array}$ & $\begin{array}{r}.3 \\
16.5\end{array}$ & $\begin{array}{r}3 \\
16.5\end{array}$ & HL & Water & - & 1920 & OP \\
\hline Bartholomew (Utah) ................................................... & 1 & 5 & 5 & 5 & HIL & Water & - & 1948 & os \\
\hline - & 2 & 1.0 & 1.0 & 1.0 & HIL & Water & - & 1988 & OP \\
\hline Hobble Creek (Utah) & 1 & 3 & 3 & 3 & 正 & Water & - & 1950 & OP \\
\hline Spring Creek (Utah) & 3 & 5 & 5 & .5 & FIL & Water & - & 1987 & OP \\
\hline 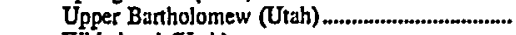 & 1 & .2 & .2 & .2 & $\mathrm{HL}$ & Water & - & 1993 & OP \\
\hline 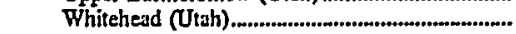 & i & 7.0 & 7.0 & 7.0 & IC & Nat Gas & FO2 & 1986 & OP \\
\hline & 2 & 7.0 & 7.0 & 7.0 & IC & Nat Gas & $\mathrm{FO} 2$ & 1986 & OP \\
\hline & & 15.0 & 15.0 & 15.0 & & & & & \\
\hline 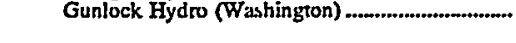 & $\frac{1}{2}$ & $\begin{array}{l}.2 \\
.2\end{array}$ & $\frac{2}{2}$ & $\frac{.2}{2}$ & $\begin{array}{l}\mathrm{HY} \\
\mathrm{HY}\end{array}$ & $\begin{array}{l}\text { Water } \\
\text { Water }\end{array}$ & 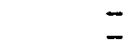 & $\begin{array}{l}1987 \\
1987\end{array}$ & $\begin{array}{l}O P \\
O P\end{array}$ \\
\hline 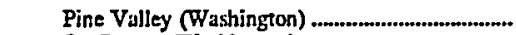 & j & .6 &.$\overline{6}$ &.$\overline{6}$ & HI & Water & - & 1995 & OP \\
\hline 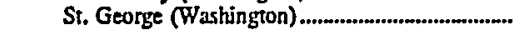 & ]. & 7.0 & 7.0 & 7.0 & IC & $\mathrm{FO} 2$ & - & 1987 & OP \\
\hline & 2 & 7.0 & 7.0 & 7.0 & IC & $\mathrm{FO} 2$ & - & 1987 & OP \\
\hline 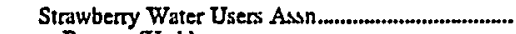 & & 4.2 & 4.1 & 4.1 & & & & & \\
\hline Payson (Utah) & 1 & .4 & 3 & 3 & HY & Water & - & 1941 & OP \\
\hline 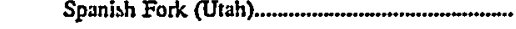 & 1 & 1.8 & 3.8 & 1.8 & $\mathrm{HY}$ & Water & - & 1983 & OP \\
\hline & 2 & 1.8 & 1.8 & 1.8 & $\mathrm{HY}$ & Water & - & 1983 & OP \\
\hline & 3 & 3 & .3 & 3 & HY & Water & - & 1937 & OP \\
\hline 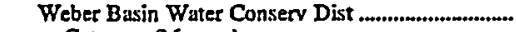 & & 5.9 & 4.8 & 3.2 & & & & & \\
\hline 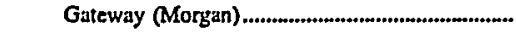 & I & 2.0 & 1.5 & 1.0 & $\mathrm{HY}$ & Water & - & 1958 & $O P$ \\
\hline & & 20 & 1.5 & 1.0 & HY & Water & - & 1958 & $O P$ \\
\hline Wanship (Summit) & $!$ & 1.9 & 1.8 & 1.2 & HY & Water & - & 1958 & OP \\
\hline Vermont & & 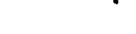 & & & & & & & \\
\hline Vermont Subtotal.............. & & $1,130.9$ & $1,094.4$ & $1,159.4$ & & & & & \\
\hline 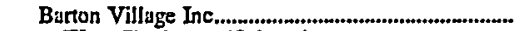 & & & & 2.4 & & & & & \\
\hline West Charleston (Orleans) & ICS & 1.4 & 3.1 & 1.1 & IC & $\mathrm{FO} 2$ & - & 1956 & OP \\
\hline & 1 & .7 & .5 & .7 & HY & Water & - & 1931 & OP \\
\hline & 2 & .7 & 5 & .7 & HY & Water & - & 1948 & OP \\
\hline Burlington City of & & 78.0 & 70.0 & 74.2 & & & & & \\
\hline Burlington G T (Chittenden) ................................... & GT] & 28.0 & 20.0 & 24.2 & GT & $\mathrm{FO} 2$ & - & 1971 & OP \\
\hline 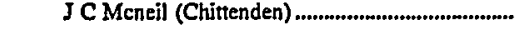 & ${ }^{* * 1} \mathbf{1}$ & 50.0 & 50.0 & 50.0 & ST & WD & Nat Gass & 1984 & OP \\
\hline
\end{tabular}

See foutnotes at end of table. 
Table 20. Existing Generating Units at U.S. Electric Utilities by State, Company, and Plant, as of January 1, 1998 (Continued)

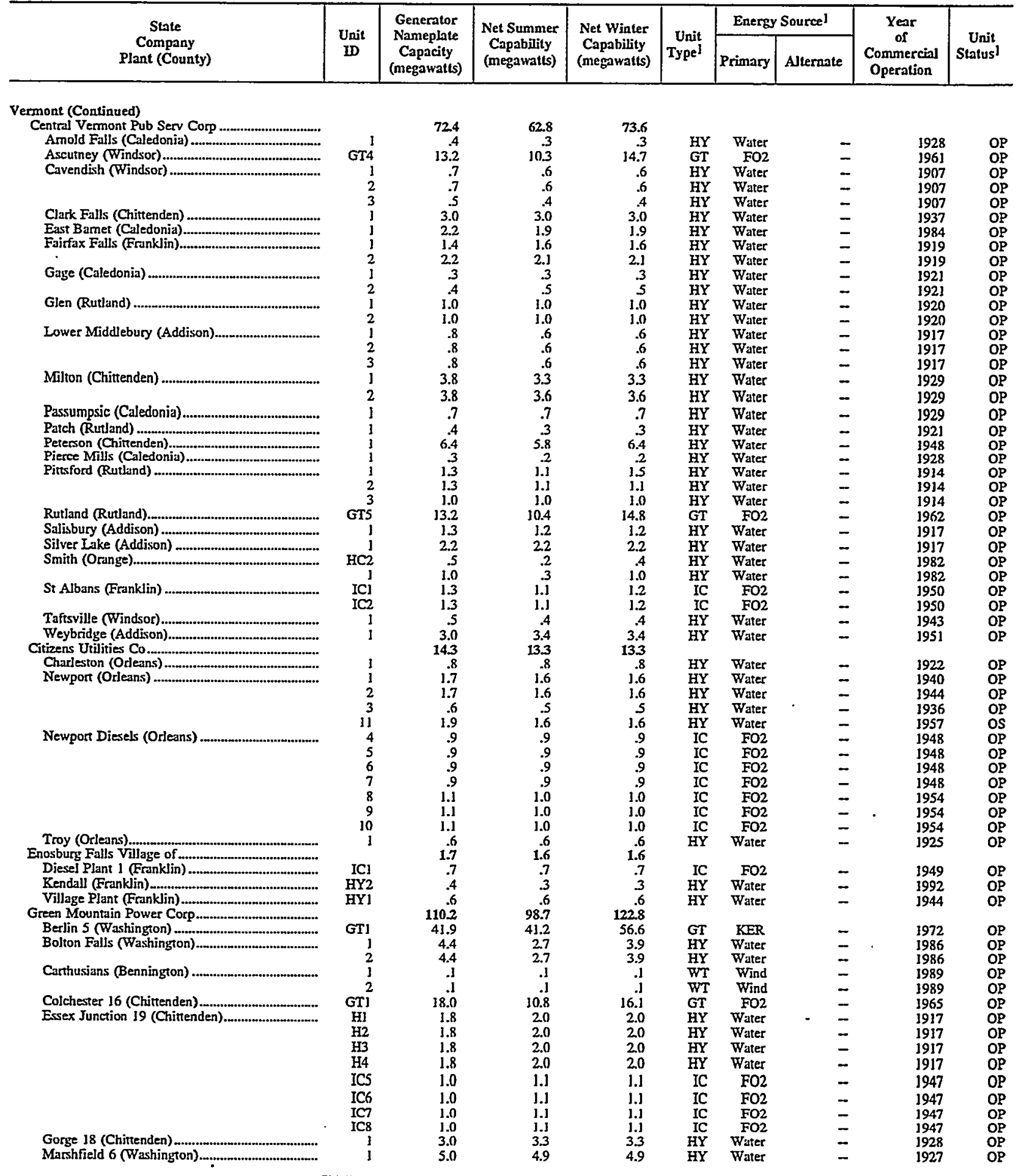

See footnotes at end of table. 
Table 20. Existing Generating Units at U.S. Electric Utilities by State, Company, and Plant, as of January 1, 1998 (Continued)

\begin{tabular}{|c|c|c|c|c|c|c|c|c|c|}
\hline \multirow{2}{*}{$\begin{array}{c}\text { State } \\
\text { Company } \\
\text { Plant (County) }\end{array}$} & \multirow{2}{*}{$\begin{array}{c}\text { Unit } \\
\text { ID }\end{array}$} & \multirow{2}{*}{$\begin{array}{c}\text { Generator } \\
\text { Nameplate } \\
\text { Capacity } \\
\text { (megawatts) }\end{array}$} & \multirow{2}{*}{$\begin{array}{l}\text { Net Summer } \\
\text { Capability } \\
\text { (megawatts) }\end{array}$} & \multirow{2}{*}{$\begin{array}{c}\text { Net Winter } \\
\text { Capability } \\
\text { (megnwatts) }\end{array}$} & \multirow{2}{*}{$\begin{array}{r}\text { Unit } \\
\text { Typel }\end{array}$} & \multicolumn{2}{|c|}{ Energy Sourcel } & \multirow{2}{*}{$\begin{array}{c}\text { Year } \\
\text { of } \\
\text { Commercinl } \\
\text { Operation }\end{array}$} & \multirow{2}{*}{$\begin{array}{c}\text { Unit } \\
\text { Status }\end{array}$} \\
\hline & & & & & & Primary & Alternate & & \\
\hline \multicolumn{10}{|l|}{ Vermont (Continued) } \\
\hline 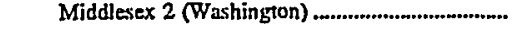 & I & $\begin{array}{l}1.6 \\
1.6\end{array}$ & $\begin{array}{l}1.3 \\
1.3\end{array}$ & $\begin{array}{l}1.7 \\
1.7\end{array}$ & $\begin{array}{l}\text { HY } \\
\text { HY }\end{array}$ & $\begin{array}{l}\text { Water } \\
\text { Water }\end{array}$ & $\underline{-}$ & $\begin{array}{l}1928 \\
1928\end{array}$ & $\begin{array}{l}\text { OP } \\
\text { OP }\end{array}$ \\
\hline Searsburg Wind Turb (Bennington) ....................... & $\bar{l}$ & 6.1 & 6.1 & 6.1 & WT & Wind & - & 1997 & $O P$ \\
\hline 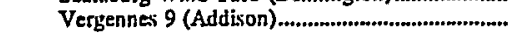 & 1 & .7 & .6 & .6 & HY & Water & - & 1912 & OP \\
\hline & 2 & .7 & .6 & .6 & HY & Water & - & 1912 & OP \\
\hline & 4 & 1.0 & .9 & .9 & HY & Water & - & 1943 & $O P$ \\
\hline & 5 & 20 & 2.1 & 2.1 & IC & FO2 & - & 1963 & OP \\
\hline & 6 & 20 & 2.I & 2.1 & IC & FO2 & - & 1964 & OP \\
\hline Waterbury 22 (Washington) & $\mathbf{1}$ & 5.5 & 5.0 & 5.0 & HY & Water & - & 1953 & $O P$ \\
\hline West Danville 15 (Caledonia) ................................ & 1 & 1.0 & 1.1 & 3.J & $\mathbf{H Y}$ & Water & - & 1917 & OP \\
\hline 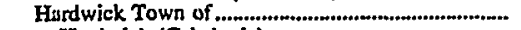 & & 1.6 & 1.3 & 1.4 & & & & & \\
\hline Hardwick (Caledonia) & 1 & .6 & .5 & .6 & IC & FO2 & - & 1948 & OP \\
\hline Wolcott (Lamoille)..................................................... & I & 3.0 & .8 & .8 & HY & Water & - & 196] & OP \\
\hline 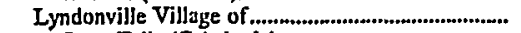 & & 23 & 2.1 & 2.1 & & & & & \\
\hline 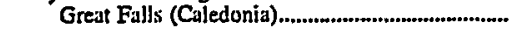 & 1 & 3 & .4 & .4 & $\mathrm{HY}$ & Water & - & 1915 & OP \\
\hline & 2 & .3 & $\therefore 4$ & $\therefore$ & HY & Water & - & 1915 & OP \\
\hline & 3 & 1.3 & 1.0 & 1.0 & HY & Water & - & 1979 & OP \\
\hline Vail (Caledonia) & $\mathbf{l}$ & .4 & .4 & 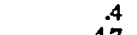 & HY & Water & - & 1949 & OP \\
\hline 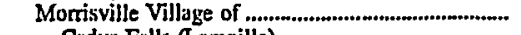 & & 53 & 4.7 & 4.7 & & & & & \\
\hline 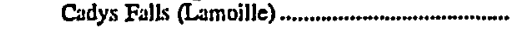 & $\begin{array}{l}1 \\
2\end{array}$ & $\begin{array}{l}.8 \\
.8\end{array}$ & .4 & .4 & HY & Water & - & 1914 & OP \\
\hline 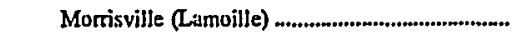 & $\vec{j}$ & .6 & .6 & $\begin{array}{l}.7 \\
.6\end{array}$ & $\begin{array}{l}\text { HY } \\
\text { HY }\end{array}$ & $\begin{array}{l}\text { Water } \\
\text { Water }\end{array}$ & $\overline{-}$ & $\begin{array}{l}1947 \\
1924\end{array}$ & $\begin{array}{l}\text { OP } \\
\text { OP }\end{array}$ \\
\hline - & 2 & 1.2 & 1.2 & 1.2 & $\mathrm{HY}$ & Water & - & 1924 & OP \\
\hline 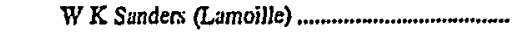 & 1 & 9 & 9 & .9 & $\mathrm{HY}$ & Water & - & 1983 & OP \\
\hline & 2 & .9 & 9 & .9 & HY & Water & - & 1983 & OP \\
\hline New England Power Co & & 243.4 & 310.3 & 307.8 & & & & & \\
\hline Bellows Falls (Windham) & 1 & 13.6 & 248.5 & 2485 & HY & Water & - & 1928 & OP \\
\hline & 2 & 13.6 & $\begin{array}{l}2- \\
2-\end{array}$ & $\begin{array}{l}2- \\
2-\end{array}$ & HY & Water & - & 1928 & OP \\
\hline 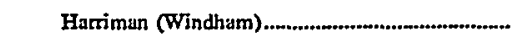 & $\begin{array}{l}3 \\
1\end{array}$ & $\begin{array}{l}13.6 \\
11.2\end{array}$ & 240.5 & 238.0 & $\begin{array}{l}\text { HYY } \\
\text { HY }\end{array}$ & Water & $\overline{-}$ & 1928 & $O P$ \\
\hline 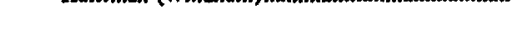 & $\begin{array}{l}2 \\
3\end{array}$ & $\begin{array}{l}11.2 \\
11.2\end{array}$ & $2_{-}^{2-}$ & $2=$ & $\begin{array}{l}\text { HY } \\
H Y Y\end{array}$ & $\begin{array}{l}\text { Water } \\
\text { Water }\end{array}$ & $\bar{z}$ & $\begin{array}{l}1924 \\
1924\end{array}$ & $\begin{array}{l}O P \\
O P\end{array}$ \\
\hline 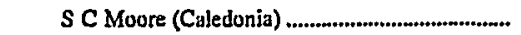 & 1 & 35.1 & 21920 & 21920 & $\begin{array}{l}\text { HY } \\
\text { HY }\end{array}$ & $\begin{array}{l}\text { Water } \\
\text { Water }\end{array}$ & $\bar{z}$ & $\begin{array}{l}1924 \\
1957\end{array}$ & $\begin{array}{l}O P \\
O P\end{array}$ \\
\hline & 2 & 35.1 & $2-$ & $2-$ & HY & Water & - & 1957 & OP \\
\hline & 3 & 35.J & $2-$ & $2-$ & $\mathrm{HY}$ & Water & - & 1957 & OP \\
\hline & 4 & 35.1 & $2-$ & 2 & HY & Water & - & J957 & $O P$ \\
\hline Searsburg (Bennington) & 1 & 4.2 & & 5.0 & HY & Water & - & 1922 & OP \\
\hline 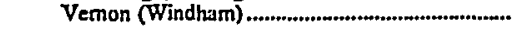 & $\begin{array}{l}1 \\
2\end{array}$ & $\begin{array}{l}2.0 \\
2.0\end{array}$ & $\begin{array}{c}1024.4 \\
10-\end{array}$ & $\begin{array}{ll} & 24.4 \\
& 11\end{array}$ & $\begin{array}{l}\text { HY } \\
\text { HY }\end{array}$ & $\begin{array}{l}\text { Water } \\
\text { Water }\end{array}$ & $\overline{-}$ & $\begin{array}{l}1909 \\
1909\end{array}$ & $\begin{array}{l}\text { OP } \\
\text { OP }\end{array}$ \\
\hline & 3 & 20 & $10-$ & $11-$ & $\mathrm{HY}$ & Water & - & 1909 & OP \\
\hline & 4 & 2.0 & $10-$ & $11-$ & HY & Water & - & 1909 & OP \\
\hline & 5 & 2.0 & $10-$ & II- & HY & Water & - & 1909 & OP \\
\hline & 6 & 2.0 & $10-$ & $11-$ & HY & Water & - & 1910 & OP \\
\hline & 7 & 2.0 & $10-$ & $11-$ & HY & Water & - & 1910 & OP \\
\hline & 8 & 20 & $10-$ & $11-$ & HY & Water & - & 1910 & OP \\
\hline & 9 & 4.2 & $10-$ & $11-$ & $\mathrm{HY}$ & Water & - & 1921 & OP \\
\hline & 10 & 4.2 & $10 \ldots$ & 11 - & HY & Water & - & 3921 & OP \\
\hline 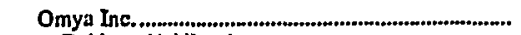 & & 222 & 19.6 & 21.6 & & & & & \\
\hline Bejdens (Addison) & HC3 & 4.1 & 4.1 & 4.1 & HY & Water & - & 1988 & OP \\
\hline & 1 & .8 & .8 & .8 & $\mathbf{H Y}$ & Water & - & 1913 & OP \\
\hline & 2 & .8 & .8 & .8 & HY & Water & - & 1913 & OP \\
\hline 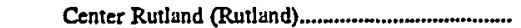 & $\mathrm{l}$ & 3 & 3 & 3 & HY & Water & - & 1898 & OP \\
\hline 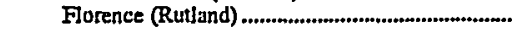 & 1 & 4.6 & 3.3 & 4.3 & GT & $\mathrm{FO} 2$ & - & 1992 & OP \\
\hline & 2 & 4.6 & 3.3 & 43 & GT & FO2 & - & 1992 & OP \\
\hline 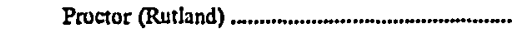 & 1 & 1.7 & 1.7 & 1.7 & $\mathbf{H Y}$ & Water & - & 1927 & OP \\
\hline & 2 & .8 & .8 & .8 & HY & Water & - & 1905 & OP \\
\hline & 3 & .8 & .8 & 8 & HY & Water & - & 1905 & OP \\
\hline & 4 & .8 & .8 & .8 & HY & Water & - & 1905 & OP \\
\hline & 5 & 3.0 & 3.0 & 3.0 & HY & Water & - & 1984 & OP \\
\hline 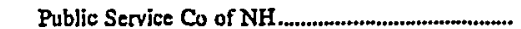 & & 1.1 & 1.1 & 1.1 & & & & & \\
\hline Canaun (Essex) & I & 1.1 & 1.1 & 1.1 & HY & Water & - & 1927 & OP \\
\hline Swanton Village of & & 112 & 102 & 10.2 & & & & & \\
\hline 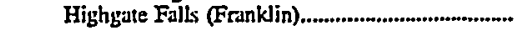 & 1 & 1.2 & 1.1 & 1.1 & HY & Water & - & 1930 & OP \\
\hline & 2 & 1.0 & 1.0 & 1.0 & HY & Water & - & 1923 & op \\
\hline & 3 & 3.2 & 3.1 & 3.1 & HY & Water & - & 1954 & OP \\
\hline & 4 & 5.8 & 5.0 & 5.0 & HY & Water & - & 1990 & OP \\
\hline 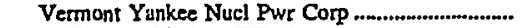 & & 563.4 & 496.0 & 521.8 & & & & & \\
\hline Vermont Yankee (Windham) & $\mathbf{l}$ & 563.4 & 496.0 & 521.8 & NB & Uranium & - & 1972 & OP \\
\hline 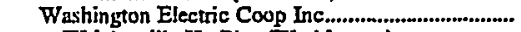 & & 1.0 & .7 & $\mathbf{7}$ & & & & & \\
\hline 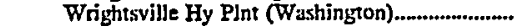 & $\mathbf{J}$ & .1 & .1 & .1 & HY & Water & - & 1985 & OP \\
\hline
\end{tabular}

See footnores at end of table. 
Table 20. Existing Generating Units at U.S. Electric Utilities by State, Company, and Plant, as of January 1, 1998 (Continued)

\begin{tabular}{|c|c|c|c|c|c|c|c|c|c|}
\hline \multirow{2}{*}{$\begin{array}{c}\text { State } \\
\text { Company } \\
\text { Plant (County) }\end{array}$} & \multirow{2}{*}{$\begin{array}{l}\text { Unit } \\
\text { ID }\end{array}$} & \multirow{2}{*}{$\begin{array}{c}\text { Generator } \\
\text { Nameplate } \\
\text { Capacity } \\
\text { (megawatts) }\end{array}$} & \multirow{2}{*}{$\begin{array}{l}\text { Net Summer } \\
\text { Capability } \\
\text { (megawatts) }\end{array}$} & \multirow{2}{*}{$\begin{array}{l}\text { Net Winter } \\
\text { Capability } \\
\text { (megawatts) }\end{array}$} & \multirow{2}{*}{\begin{tabular}{|} 
Unit \\
Type
\end{tabular}} & \multicolumn{2}{|c|}{ Energy Sourcel } & \multirow{2}{*}{$\begin{array}{c}\text { Year } \\
\text { of } \\
\text { Commercial } \\
\text { Operation }\end{array}$} & \multirow{2}{*}{$\begin{array}{c}\text { Unit } \\
\text { Status } 1\end{array}$} \\
\hline & & & & & & Primary & Alternate & & \\
\hline \multicolumn{10}{|l|}{ Vermont (Continued) } \\
\hline & $\frac{2}{3}$ & $\begin{array}{r}0.3 \\
.6\end{array}$ & $\begin{array}{r}0.2 \\
.5\end{array}$ & $\begin{array}{r}0.2 \\
5\end{array}$ & $\begin{array}{l}\mathrm{HY} \\
\mathrm{HY}\end{array}$ & $\begin{array}{l}\text { Water } \\
\text { Water }\end{array}$ & $\overline{-}$ & $\begin{array}{l}1985 \\
1985\end{array}$ & $\begin{array}{l}\text { OP } \\
\text { OP }\end{array}$ \\
\hline \multicolumn{10}{|l|}{ Virgiaia } \\
\hline 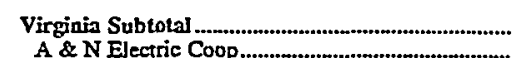 & & $16,393.1$ & $15,291.4$ & $\begin{array}{r}15,766.5 \\
3,9\end{array}$ & & & & & \\
\hline Tangier (Accomack) & 3 & .7 & .7 & .7 & IC & FO2 & - & 1974 & OP \\
\hline & 4 & & .8 & .8 & IC & FO2 & - & 1974 & $\mathrm{OP}$ \\
\hline & 5 & 1.2 & 1.2 & 12 & IC & $\mathrm{FO} 2$ & - & 1993 & OP \\
\hline Appalachian Power Co & & $\begin{array}{r}1.2 \\
1,757.6\end{array}$ & $\begin{array}{r}1.2 \\
1,718.8\end{array}$ & $\begin{array}{r}1.2 \\
1,766.0\end{array}$ & IC & FO2 & - & 1993 & OP \\
\hline 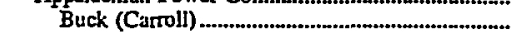 & 1 & 8.5 & 28.6 & $\frac{1}{2} 10.0$ & HY & Water & - & 1912 & OP \\
\hline & 2 & 0.0 & $2_{-}$ & $2-$ & HY & Water & - & 1912 & $\mathrm{OP}$ \\
\hline & 3 & 0.0 & ${ }^{2}-$ & $2-$ & HY & Water & - & 1912 & OP \\
\hline 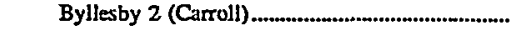 & 1 & 5.4 & 4.3 & 5.0 & HY & Water & - & 1912 & OP \\
\hline & 2 & 5.4 & 4.3 & 5.0 & HY & Water & - & 1912 & $O P$ \\
\hline & 3 & 5.4 & 4.3 & 5.0 & HY & Water & - & $i 912$ & OP \\
\hline & 4 & 5.4 & 4.3 & 5.0 & HY & Water & - & 1912 & OP \\
\hline 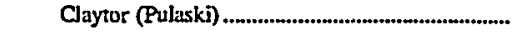 & 1 & 18.8 & 16.4 & 19.0 & HY & Water & - & 1939 & OP \\
\hline & 2 & 18.8 & 16.4 & 19.0 & $\mathrm{HY}$ & Water & - & 1939 & OP \\
\hline & 3 & 18.8 & 36.4 & 19.0 & $\mathrm{HY}$ & Water & - & 1939 & $\mathrm{OP}$ \\
\hline & 4 & 18.8 & 36.4 & 19.0 & HY & Water & - & 1939 & $\mathrm{OP}$ \\
\hline 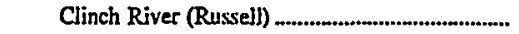 & $\mathrm{j}$ & 237.5 & 230.0 & 235.0 & ST & BIT & - & 1958 & $O P$ \\
\hline & 2 & 237.5 & 230.0 & 235.0 & ST & BIT & - & 3958 & $O P$ \\
\hline & 3 & 237.5 & 230.0 & 235.0 & ST & BIT & $\overline{-}$ & 1961 & $O P$ \\
\hline Glen Lyn (Giles)......... & 5 & 100.0 & 90.0 & 95.0 & ST & BIT & - & 1944 & OP \\
\hline 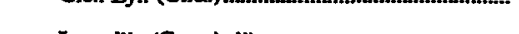 & 6 & 237.5 & 235.0 & 240.0 & ST & BIT & $\overline{-}$ & 1957 & $O P$ \\
\hline Leesville (Campbell) & ] & 20.0 & 17.3 & 20.0 & $\mathrm{HY}$ & Water & - & 1964 & $O P$ \\
\hline & 2 & 20.0 & 17.3 & 20.0 & HY & Water & - & $j 964$ & $\mathrm{OP}$ \\
\hline Niagara (Roanoke)................... & 1 & 2.4 & 22.6 & 23.0 & $\mathrm{HY}$ & Water & - & 9954 & $O P$ \\
\hline & 2 & 0.0 & $2-$ & $2-$ & $\mathrm{HY}$ & Water & - & 1954 & $O P$ \\
\hline Reusens (Campbell) & 1 & 12.5 & 210.4 & 212.0 & $\mathrm{HY}$ & Water & - & 1903 & OP \\
\hline & 2 & 0.0 & & $2-$ & $\mathrm{HY}$ & Water & - & 1903 & $O P$ \\
\hline & 3 & 0.0 & $2-$ & $2-$ & $\mathrm{HY}$ & Water & - & 1903 & $O P$ \\
\hline & 4 & 0.0 & $2-$ & $2-$ & HY & Water & - & 1903 & OP \\
\hline & 5 & 0.0 & $2-$ & $2=$ & $\mathrm{HI}_{\mathrm{H}}$ & $\begin{array}{l}\text { Water } \\
\text { Water }\end{array}$ & $\overline{-}$ & 1903 & OP \\
\hline Smith Mountain (Franklin) & 1 & 66.0 & 70.0 & 70.0 & PS & Water & - & 1965 & OP \\
\hline & 2 & 150.1 & 160.0 & 160.0 & HY & Water & - & 1965 & OP \\
\hline & 3 & 115.3 & 105.0 & 105.0 & PS & Water & - & 1980 & OP \\
\hline & 4 & 150.1 & 160.0 & 160.0 & HY & Water & - & 1966 & OP \\
\hline & 5 & 66.0 & 70.0 & 70.0 & PS & Water & - & 1966 & $\mathrm{OP}$ \\
\hline Bedford Ciry of & & 5.0 & 5.0 & 5.0 & (50 & Walct & - & 1300 & Ur \\
\hline Snowden (Amherst) & 4 & 2.5 & 25 & 2.5 & HY & Water & - & 1987 & OP \\
\hline Craig-Botetourt Electric Coop & 5 & $\begin{array}{r}2.5 \\
3\end{array}$ & $\begin{array}{r}2.5 \\
3\end{array}$ & $\begin{array}{r}2.5 \\
3\end{array}$ & HY & Water & - & 1987 & OP \\
\hline Meadow Creek (Craig) & 1 & 3 & $\overrightarrow{3}$ & $\overrightarrow{3}$ & HY & Water & - & 1938 & OP \\
\hline Culpeper Town of & & 7.8 & 6.5 & $6 . \overline{7}$ & & & & & \\
\hline West Spring Street (Culpeper) & IT & .8 & .5 & $s$ & GT & $\mathrm{FO} 2$ & - & 1974 & $O P$ \\
\hline & $2 \mathrm{~A}$ & 2.0 & 2.0 & 20 & IC & $\mathrm{FO} 2$ & - & 1989 & $O P$ \\
\hline & $2 \mathrm{~T}$ & .8 & 5 & 5 & GT & $\mathrm{FO2}$ & - & 1974 & $\mathrm{OP}$ \\
\hline & 4 & 1.5 & 1.3 & 13 & IC & Nat Gas & FO2 & 1962 & $O P$ \\
\hline & 5 & 1.2 & .8 & .9 & IC & Nat Gas & $\mathrm{FO2}$ & 1959 & OP \\
\hline & 7 & 1.5 & 1.5 & 15 . & IC & $\mathrm{FO} 2$ & - & 1997 & OP \\
\hline Danville City of & & 11.3 & 10.5 & 10.5 & & & & & \\
\hline 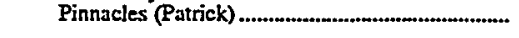 & $\frac{1}{2}$ & 3.8 & 3.5 & 3.5 & $\mathrm{HI}$ & Water & - & 1938 & OP \\
\hline & 2 & $\begin{array}{l}3.8 \\
3.8\end{array}$ & $\begin{array}{l}3.5 \\
3.5\end{array}$ & $\begin{array}{l}35 \\
35\end{array}$ & $\mathrm{HL}$ & Water & $\overline{-}$ & 1938 & OP \\
\hline Delmarva Power \& Light Co & & $\begin{array}{r}3.8 \\
39.0\end{array}$ & $\begin{array}{r}3.5 \\
38.0\end{array}$ & $\begin{array}{r}3.5 \\
45.0\end{array}$ & HL & Water & - & 1938 & OP \\
\hline Bayview (Northampton) & 1 & 2.0 & 2.0 & 2.0 & IC & FO2 & _ & 1963 & OP \\
\hline & 2 & 20 & 2.0 & 2.0 & IC & $\mathrm{FO} 2$ & - & 1963 & OP \\
\hline & 3 & 20 & 2.0 & 2.0 & IC & $\mathrm{FO} 2$ & - & 1963 & OP \\
\hline & 4 & 20 & 2.0 & 2.0 & IC & $\mathrm{FO2}$ & - & 1963 & OP \\
\hline & 5 & 20 & 2.0 & 2.0 & IC & $\mathrm{FO} 2$ & - & 1963 & OP \\
\hline & -6 & 20 & 2.0 & 2.0 & IC & FO2 & - & 1963 & OP \\
\hline Tasley (Accomack) & 10 & 27.0 & 26.0 & 33.0 & GT & FO2 & -- & 1972 & OP \\
\hline Manassas City of & & 34.0 & 32.3 & 32.0 & & & & & \\
\hline Broad Run (Prince William) ..................................... & HI & .5 & $\mathrm{E} .4$ & E.4 & $\mathbf{H Y}$ & Water & - & 1987 & OP \\
\hline & $\mathrm{H} 2$ & 1.0 & E.9 & E.7 & $\mathbf{H Y}$ & Water & - & 1987 & OP \\
\hline Church Street Plant (Prince William) ........................ & Cl & 1.0 & 1.0 & 1.0 & IC & FO2 & - & 1979 & OP \\
\hline
\end{tabular}

See footnotes at end of table. 
Table 20. Existing Generating Units at U.S. Electric Utilities by State, Company, and Plant, as of January 1, 1998 (Continued)

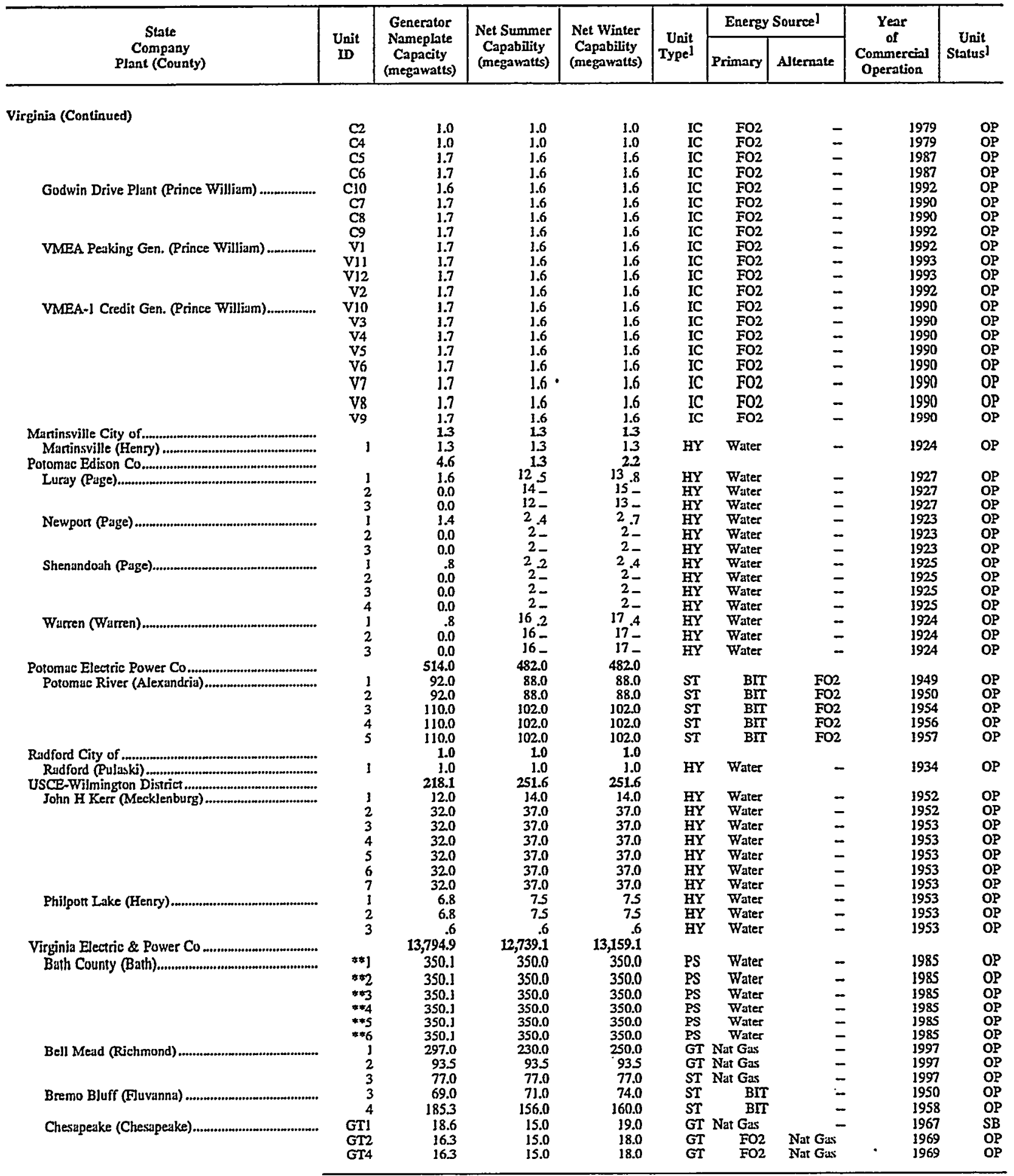

See footnutes at end of table. 
Table 20. Existing Generating Units at U.S. Electric Utilities by State, Company, and Plant, as of January 1, 1998 (Continued)

\begin{tabular}{|c|c|c|c|c|c|c|c|c|c|}
\hline \multirow{2}{*}{$\begin{array}{c}\text { State } \\
\text { Company } \\
\text { Plant (County) }\end{array}$} & \multirow{2}{*}{$\begin{array}{c}\text { Unit } \\
\text { ID }\end{array}$} & \multirow{2}{*}{$\begin{array}{c}\text { Generator } \\
\text { Nameplate } \\
\text { Capacity } \\
\text { (megawatts) }\end{array}$} & \multirow{2}{*}{$\begin{array}{l}\text { Net Summer } \\
\text { Capability } \\
\text { (megawatts) }\end{array}$} & \multirow{2}{*}{$\begin{array}{l}\text { Net Winter } \\
\text { Capability } \\
\text { (megawatts) }\end{array}$} & \multirow{2}{*}{$\begin{array}{r}\text { Unit } \\
\text { Type] }\end{array}$} & \multicolumn{2}{|c|}{ Energy Sourcel } & \multirow{2}{*}{$\begin{array}{c}\text { Year } \\
\text { of } \\
\text { Commercial } \\
\text { Operation }\end{array}$} & \multirow{2}{*}{$\begin{array}{c}\text { Unit } \\
\text { Status! }\end{array}$} \\
\hline & & & & & & Primary & Alternate & & \\
\hline \multicolumn{10}{|l|}{ Virginia (Continued) } \\
\hline & STI & 112.5 & $1] 1.0$ & 111.0 & ST & BIT & - & 1953 & OP \\
\hline & ST2 & 1125 & 111.0 & 111.0 & ST & BIT & - & 1954 & OP \\
\hline & ST4 & 239.4 & 217.0 & 221.0 & ST & BIT & - & 1962 & $\mathrm{OP}$ \\
\hline & 3 & 185.3 & 156.0 & $J 62.0$ & $\mathrm{ST}$ & $\mathrm{BIT}$ & - & 1959 & $\mathrm{OP}$ \\
\hline & 6 & 16.3 & 15.0 & 18.0 & GT & $\mathrm{FO} 2$ & Nat Gas & 1969 & OP \\
\hline & 7 & 23.8 & 21.0 & 29.0 & GT & FO2 & Nat Gas & 1969 & OP \\
\hline & 8 & 23.8 & 21.0 & 29.0 & GT & FO2 & Nat Gas & 1969 & OP \\
\hline & 9 & 23.8 & 21.0 & 29.0 & GT & FO2 & Nat Gas & 1970 & OP \\
\hline 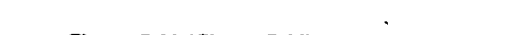 & 30 & 23.8 & 21.0 & 29.0 & GT & $\mathrm{FO} 2$ & Nat Gas & 1970 & OP \\
\hline \multirow[t]{8}{*}{ Chesterfield (Chesterfield) } & CT7 & 236.5 & 197.0 & 232.0 & CT & Nat Gas & $\mathrm{FO} 2$ & 1990 & OP \\
\hline & CT8 & 237.9 & 200.0 & 235.0 & CT & Nat Gas & $\mathrm{FO2}$ & 1992 & OP \\
\hline & $C W 7$ & 74.4 & 62.0 & 62.0 & CW & WH & - & 1990 & $\mathrm{OP}$ \\
\hline & CW8 & 79.2 & 67.0 & 67.0 & $\mathrm{CW}$ & WH & - & 1992 & OP \\
\hline & 3 & 132.5 & 100.0 & 105.0 & ST & BIT & - & 1952 & $\mathrm{OP}$ \\
\hline & 4 & 187.5 & 166.0 & 171.0 & ST & BIT & - & 1960 & OP \\
\hline & 5 & 359.0 & 326.0 & 333.0 & ST & BIT & - & 1964 & $O P$ \\
\hline & 6 & 693.9 & 658.0 & 671.0 & ST & BIT & - & 1969 & OP \\
\hline 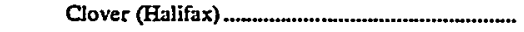 & $* \$ 1$ & 424.0 & 441.0 & 441.0 & $S T$ & BIT & - & 1995 & OP \\
\hline & $\Rightarrow 2$ & 424.0 & 441.0 & 441.0 & ST & BIT & - & 1996 & $O P$ \\
\hline Cushuw (Amhent) & 1 & 1.5 & 1.5 & 1.5 & HY & Water & - & 1930 & OP \\
\hline - & 2 & 1.5 & 1.5 & 15 & HY & Water & - & 1930 & OP \\
\hline & 3 & 1.5 & 1.5 & 15 & HY & Water & - & 1930 & OP \\
\hline & 4 & 1.5 & 1.5 & 15 & HY & Water & - & 1930 & $O P$ \\
\hline & 5 & 1.5 & 1.5 & 15 & $\mathbf{H Y}$ & Water & - & 1930 & OP \\
\hline Darbytown (Henrico) & 1 & 92.1 & 72.0 & 92.0 & GT & Nat Gas & FO2 & 1990 & OP \\
\hline & 2 & 921 & 72.0 & 92.0 & GT & Nat Gas & FO2 & 1990 & OP \\
\hline & 3 & 92.1 & 72.0 & 92.0 & GT & Nat Gas & $\mathrm{FO} 2$ & 1990 & OP \\
\hline & 4 & 92.1 & 72.0 & 92.0 & GT & Nat Gas & $\mathrm{FO} 2$ & 1990 & OP \\
\hline Gravel Neck (Surry) & j & 16.3 & 15.0 & 17.0 & GT & $\mathrm{FO} 2$ & Nat Gas & 1970 & $\mathrm{OP}$ \\
\hline & 2 & 23.8 & 22.0 & 28.0 & GT & $\mathrm{FO} 2$ & Nat Gas & 1970 & $\mathrm{OP}$ \\
\hline & 3 & 92.0 & 73.0 & 92.0 & GT & Nat Gas & $\mathrm{FO} 2$ & 1989 & OP \\
\hline & 4 & 92.0 & 73.0 & 92.0 & GT & Nat Gas & $\mathrm{FO} 2$ & 1989 & OP \\
\hline & 5 & 92.0 & 73.0 & 92.0 & GT & Nat Gas & $\mathrm{FO} 2$ & 1989 & OP \\
\hline & 6 & 920 & 73.0 & 92.0 & GT & Nat Gas & $\mathrm{FO} 2$ & 1989 & $\mathrm{OP}$ \\
\hline 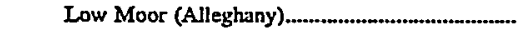 & GT1 & 20.7 & 15.0 & 18.0 & GT & $\mathrm{FO} 2$ & - & 3971 & OP \\
\hline & GT2 & 20.7 & 15.0 & 18.0 & GT & FO2 & - & 1971 & OP \\
\hline & GT3 & 20.7 & 15.0 & 18.0 & GT & FO2 & - & 1971 & OP \\
\hline & GT4 & 20.7 & 15.0 & 18.0 & GT & $\mathrm{FO} 2$ & - & 1971 & OP \\
\hline North Anna (Louisa) & HCi & 1.0 & 1.0 & 1.0 & HY & Water & - & 3987 & OP \\
\hline & SPI & 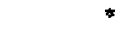 & $\star$ & * & PV & Sun & - & 1985 & OP \\
\hline & SP2 & * & \# & * & PV & Sun & - & 1985 & OP \\
\hline & SP3 & $*$ & * & * & PV & Sun & - & 1985 & OP \\
\hline & $* * 1$ & 979.7 & 893.0 & 893.0 & $\mathrm{NP}$ & Uranium & - & 1978 & OP \\
\hline & $* * 2$ & 979.7 & 897.0 & 897.0 & $\mathbf{N P}$ & Uranium & - & 1980 & OP \\
\hline Northem Neck (Richmond) & GTI & 20.7 & 16.0 & 19.0 & GT & $\mathrm{FO} 2$ & - & 1971 & OP \\
\hline & GT2 & 20.7 & 16.0 & 19.0 & $\mathrm{GT}$ & $\mathrm{FO2}$ & - & 1971 & OP \\
\hline & GT3 & 20.7 & 16.0 & 19.0 & GT & $\mathrm{FO} 2$ & - & 1971 & OP \\
\hline & GT4 & 20.7 & 16.0 & 19.0 & GT & FO2 & - & 1971 & OP \\
\hline Possum Point (Prince William) & GTI & 16.0 & 13.0 & 16.0 & GT & FO2 & - & 1968 & OP \\
\hline & GT2 & 16.0 & 13.0 & 16.0 & GT & FO2 & - & 1968 & OP \\
\hline & GT3 & 16.0 & 13.0 & 16.0 & GT & $\mathrm{FO} 2$ & - & 1968 & OP \\
\hline & GT4 & 16.0 & 13.0 & 16.0 & GT & FO2 & - & 1968 & OP \\
\hline & GT5 & 36.0 & 13.0 & 16.0 & GT & FO2 & - & 1968 & OP \\
\hline & GT6 & 16.0 & 13.0 & 16.0 & GT & FO2 & - & 1968 & OP \\
\hline & J & 69.0 & 74.0 & 74.0 & ST & FO6 & - & 1948 & OP \\
\hline & 2 & 69.0 & 69.0 & 71.0 & ST & FO6 & - & 1951 & OP \\
\hline & 3 & 113.6 & 101.0 & 105.0 & ST & BIT & - & 1955 & OP \\
\hline & 4 & 239.4 & 221.0 & 221.0 & ST & BIT & - & 1962 & OP \\
\hline & 5 & 882.0 & 786.0 & 801.0 & ST & F06 & - & 1975 & OP \\
\hline Surry (Surry) & $\mathbf{1}$ & 847.5 & 801.0 & 801.0 & NP & Uranium & - & 1972 & OP \\
\hline & 2 & 847.5 & 801.0 & 801.0 & $\mathrm{NP}$ & Uranium & - & 1973 & OP \\
\hline Yorktown (York) & 1 & 187.5 & 159.0 & 163.0 & ST & BIT & - & 1957 & OP \\
\hline & 2 & 187.5 & 167.0 & 372.0 & ST & BIT & - & 1959 & OP \\
\hline & 3 & 882.0 & 818.0 & 820.0 & ST & FO6 & - & 1974 & OP \\
\hline
\end{tabular}

See footnotes at end of table. 
Table 20. Existing Generating Units at U.S. Electric Utilities by State, Company, and Plant, as of January 1, 1998 (Continued)

\begin{tabular}{|c|c|c|c|c|c|c|c|c|c|}
\hline \multirow{2}{*}{$\begin{array}{c}\text { State } \\
\text { Company } \\
\text { Plant (County) }\end{array}$} & \multirow{2}{*}{$\begin{array}{l}\text { Unit } \\
\text { D }\end{array}$} & \multirow{2}{*}{$\begin{array}{c}\text { Generator } \\
\text { Nameplate } \\
\text { Capacity } \\
\text { (megawatts) }\end{array}$} & \multirow{2}{*}{$\begin{array}{c}\text { Net Summer } \\
\text { Capability } \\
\text { (megawatts) }\end{array}$} & \multirow{2}{*}{$\begin{array}{l}\text { Net Winter } \\
\text { Capability } \\
\text { (megawatts) }\end{array}$} & \multirow{2}{*}{$\begin{array}{c}\text { Unit } \\
\text { Typel }\end{array}$} & \multicolumn{2}{|c|}{ Energy Source] } & \multirow{2}{*}{$\begin{array}{c}\text { Year } \\
\text { of } \\
\text { Commercinl } \\
\text { Operation }\end{array}$} & \multirow{2}{*}{$\begin{array}{c}\text { Unit } \\
\text { Statusl }\end{array}$} \\
\hline & & & & & & Primary & Altemale & & \\
\hline \multicolumn{10}{|l|}{ Washington } \\
\hline 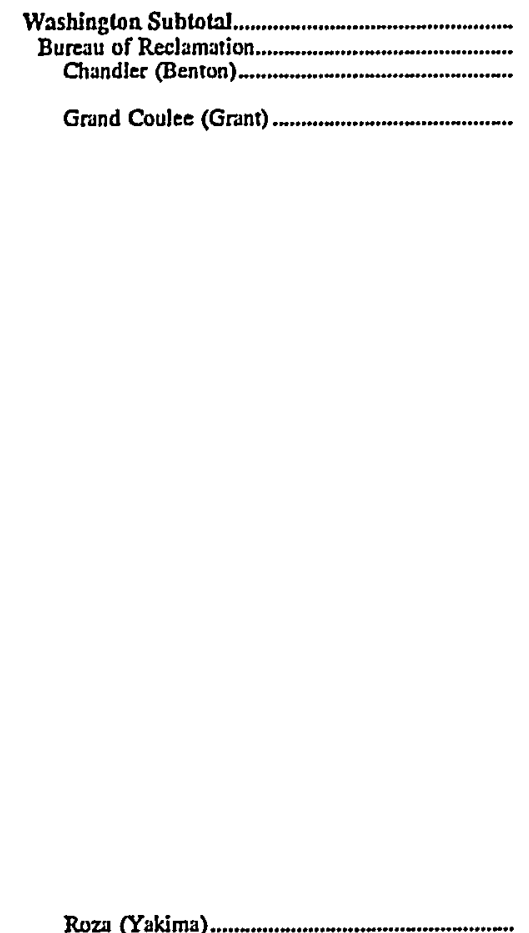 & $\begin{array}{r}1 \\
2 \\
\text { IS1 } \\
\text { IS2 } \\
\text { IS3 } \\
\text { PG10 } \\
\text { PGI1 } \\
\text { PG12 } \\
\text { PG7 } \\
\text { PG8 } \\
\text { PG9 } \\
1 \\
10 \\
11 \\
12 \\
13 \\
14 \\
15 \\
16 \\
17 \\
18 \\
19 \\
2 \\
20 \\
21 \\
22 \\
23 \\
24 \\
3 \\
4 \\
5 \\
6 \\
7 \\
8 \\
9 \\
1\end{array}$ & $\begin{array}{r}24,590.1 \\
6,833.9 \\
6.0 \\
6.0 \\
10.0 \\
10.0 \\
10.0 \\
53.5 \\
53.5 \\
53.5 \\
50.0 \\
50.0 \\
53.5 \\
125.0 \\
125.0 \\
125.0 \\
125.0 \\
125.0 \\
125.0 \\
125.0 \\
125.0 \\
125.0 \\
125.0 \\
600.0 \\
125.0 \\
600.0 \\
600.0 \\
805.0 \\
805.0 \\
805.0 \\
125.0 \\
125.0 \\
125.0 \\
125.0 \\
125.0 \\
125.0 \\
125.0 \\
12.9\end{array}$ & $\begin{array}{r}25,273.4 \\
7,103.9 \\
6.0 \\
6.0 \\
10.0 \\
10.0 \\
10.0 \\
53.5 \\
53.5 \\
53.5 \\
50.0 \\
50.0 \\
53.5 \\
125.0 \\
125.0 \\
125.0 \\
125.0 \\
125.0 \\
125.0 \\
125.0 \\
125.0 \\
125.0 \\
125.0 \\
690.0 \\
125.0 \\
690.0 \\
690.0 \\
805.0 \\
805.0 \\
805.0 \\
125.0 \\
125.0 \\
125.0 \\
125.0 \\
125.0 \\
125.0 \\
125.0 \\
12.9\end{array}$ & $\begin{array}{r}25,223.0 \\
7,103.9 \\
6.0 \\
6.0 \\
10.0 \\
10.0 \\
10.0 \\
53.5 \\
53.5 \\
53.5 \\
50.0 \\
50.0 \\
53.5 \\
125.0 \\
125.0 \\
125.0 \\
125.0 \\
125.0 \\
125.0 \\
125.0 \\
125.0 \\
125.0 \\
125.0 \\
690.0 \\
125.0 \\
690.0 \\
690.0 \\
805.0 \\
805.0 \\
805.0 \\
125.0 \\
125.0 \\
125.0 \\
125.0 \\
125.0 \\
125.0 \\
125.0 \\
12.9\end{array}$ & 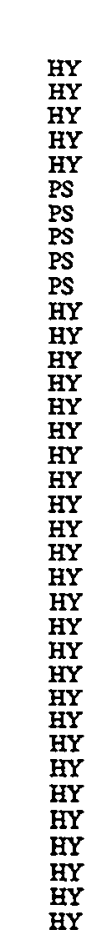 & $\begin{array}{l}\text { Water } \\
\text { Water } \\
\text { Water } \\
\text { Water } \\
\text { Water } \\
\text { Water } \\
\text { Water } \\
\text { Water } \\
\text { Water } \\
\text { Water } \\
\text { Water } \\
\text { Water } \\
\text { Water } \\
\text { Water } \\
\text { Water } \\
\text { Water } \\
\text { Water } \\
\text { Water } \\
\text { Water } \\
\text { Water } \\
\text { Water } \\
\text { Water } \\
\text { Water } \\
\text { Water } \\
\text { Water } \\
\text { Water } \\
\text { Water } \\
\text { Water } \\
\text { Warer } \\
\text { Water } \\
\text { Water } \\
\text { Water } \\
\text { Water } \\
\text { Water } \\
\text { Water } \\
\text { Water }\end{array}$ & 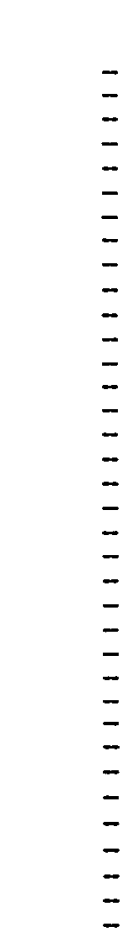 & $\begin{array}{l}1956 \\
1956 \\
1941 \\
1941 \\
1951 \\
1983 \\
1983 \\
1984 \\
1973 \\
1973 \\
1983 \\
1971 \\
1980 \\
1975 \\
1976 \\
1973 \\
1974 \\
1975 \\
1974 \\
1972 \\
1971 \\
1975 \\
1973 \\
1976 \\
1976 \\
1978 \\
1979 \\
1980 \\
1972 \\
1970 \\
1964 \\
1969 \\
1966 \\
1971 \\
1968 \\
1958\end{array}$ & $\begin{array}{l}O P \\
O P \\
O P \\
O P \\
O P \\
O P \\
O P \\
O P \\
O P \\
O P \\
O P \\
O P \\
O P \\
O P \\
O P \\
O P \\
O P \\
O P \\
O P \\
O P \\
O P \\
O P \\
O P \\
O P \\
O P \\
O P \\
O P \\
O P \\
O P \\
O P \\
O P \\
O P \\
O P \\
O P \\
O P \\
O P\end{array}$ \\
\hline $\begin{array}{l}\text { Roza (Yakima) } \\
\text { Centralia City of }\end{array}$ & I & $\begin{array}{l}12.9 \\
12.0\end{array}$ & $\begin{array}{l}12.9 \\
11.4\end{array}$ & $\begin{array}{l}12.9 \\
11.4\end{array}$ & HY & Water & - & 1958 & OP \\
\hline Yelm (Thurston) & $\begin{array}{l}1 \\
2 \\
3\end{array}$ & $\begin{array}{l}3.0 \\
3.0 \\
6.0\end{array}$ & $\begin{array}{l}2.7 \\
2.7 \\
6.0\end{array}$ & $\begin{array}{l}2.7 \\
2.7 \\
6.0\end{array}$ & $\begin{array}{l}\mathrm{HY} \\
\mathrm{HY}\end{array}$ & $\begin{array}{l}\text { Water } \\
\text { Water } \\
\text { Water }\end{array}$ & $\overline{-}$ & $\begin{array}{l}1930 \\
1930 \\
1955\end{array}$ & $\begin{array}{l}\text { OP } \\
\text { OP } \\
\text { OP }\end{array}$ \\
\hline 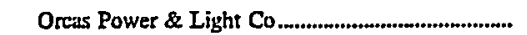 & & 1.0 & 1.0 & 1.0 & & & & & \\
\hline Eastsound (San Juan)................................................ & $\begin{array}{l}4 \\
5\end{array}$ & & $\begin{array}{r}5 \\
5 \\
10703\end{array}$ & $\frac{.5}{5}$ & $\begin{array}{l}\text { IC } \\
\text { IC }\end{array}$ & $\begin{array}{l}\text { FO2 } \\
\text { FO2 }\end{array}$ & $\overline{-}$ & $\begin{array}{l}1948 \\
1948\end{array}$ & $\begin{array}{l}\text { SB } \\
\text { SB }\end{array}$ \\
\hline PacifiCorp & & $2,057.4$ & $\begin{array}{r}1,970.3 \\
670.0\end{array}$ & $\begin{array}{r}1,971.7 \\
670.0\end{array}$ & & & & & \\
\hline Centralia (Lewis) & $* * 1$ & $\begin{array}{l}730.0 \\
730.0\end{array}$ & $\begin{array}{l}670.0 \\
670.0\end{array}$ & $\begin{array}{l}670.0 \\
670.0\end{array}$ & $\begin{array}{l}\text { ST } \\
\text { ST }\end{array}$ & $\begin{array}{l}\text { SUB } \\
\text { SUB }\end{array}$ & $\overline{-}$ & $\begin{array}{l}1972 \\
1973\end{array}$ & $\begin{array}{l}\text { OP } \\
\text { OP }\end{array}$ \\
\hline Condit (Klickitat) & 1 & $\begin{array}{r}4.8 \\
4.8\end{array}$ & 7.5 & 7.5 & $\begin{array}{l}\text { HY } \\
\text { HY }\end{array}$ & $\begin{array}{l}\text { Water } \\
\text { Water }\end{array}$ & $\overline{-}$ & $\begin{array}{l}1913 \\
1913\end{array}$ & $\begin{array}{l}\text { OP } \\
\text { OP }\end{array}$ \\
\hline Merwin (Cowlitz) & $\begin{array}{l}1 \\
2 \\
3\end{array}$ & $\begin{array}{l}45.0 \\
45.0 \\
45.0\end{array}$ & $\begin{array}{l}48.0 \\
48.0 \\
48.0\end{array}$ & $\begin{array}{l}45.0 \\
48.0 \\
48.0\end{array}$ & $\begin{array}{l}\text { HY } \\
\text { HY } \\
\text { HY }\end{array}$ & $\begin{array}{l}\text { Water } \\
\text { Water } \\
\text { Water }\end{array}$ & $\overline{-}$ & $\begin{array}{l}1932 \\
1949 \\
1958\end{array}$ & $\begin{array}{l}\text { OP } \\
\text { OP } \\
\text { OP }\end{array}$ \\
\hline Naches (Yakimi) & 2 & $\begin{array}{r}3.0 \\
3.4\end{array}$ & $\begin{array}{r}40.0 \\
4.0\end{array}$ & $\begin{array}{r}40.0 \\
2.7 \\
4.0\end{array}$ & HY & $\begin{array}{l}\text { Water } \\
\text { Water }\end{array}$ & $\overline{-}$ & $\begin{array}{l}1900 \\
1913\end{array}$ & OP \\
\hline Naches Drop (Yakima) ............................ & 1 & 1.4 & 1.1 & 1.1 & HY & Water & - & 1915 & OP \\
\hline $\begin{array}{l}\text { Skookumchuck (Thurston) } \\
\text { Swift I (Skamanja) }\end{array}$ & HYj1 & $\begin{array}{r}1.0 \\
80.0\end{array}$ & $\begin{array}{r}1.0 \\
89.3\end{array}$ & $\begin{array}{r}1.0 \\
88.0\end{array}$ & $\begin{array}{l}\text { HY } \\
\text { HY }\end{array}$ & $\begin{array}{l}\text { Water } \\
\text { Water }\end{array}$ & $\overline{-}$ & $\begin{array}{l}1990 \\
1958\end{array}$ & $\begin{array}{l}\text { OP } \\
\text { OP }\end{array}$ \\
\hline & HY12 & 80.0 & 89.3 & 88.0 & HY & Water & - & 3958 & OP \\
\hline & $\mathrm{HY} 13$ & 80.0 & 85.0 & 87.0 & $\mathrm{HY}$ & Water & - & 1958 & OP \\
\hline Swift 2 (Cowlitz) & $* 21$ & 35.0 & 34.0 & 36.0 & HY & Water & - & 1959 & OP \\
\hline Yale (Cow]itz) & 1 & $\begin{array}{l}35.0 \\
67.0\end{array}$ & $\begin{array}{l}31.0 \\
67.0\end{array}$ & $\begin{array}{l}34.0 \\
67.0\end{array}$ & $\underset{H Y Y}{H Y}$ & $\begin{array}{l}\text { Water } \\
\text { Water }\end{array}$ & $\overline{-}$ & $\begin{array}{l}1958 \\
1953\end{array}$ & OP \\
\hline Port Anveles City of & 2 & $\begin{array}{r}67.0 \\
.5\end{array}$ & $\begin{array}{r}67.0 \\
5\end{array}$ & $\begin{array}{r}67.0 \\
5\end{array}$ & HY & Water & - & 1953 & OP \\
\hline 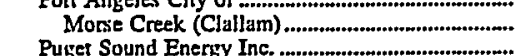 & $\mathrm{MCl}$ & 955.5 & 908.9 & $\begin{array}{r}.5 \\
9853\end{array}$ & HL & Water & - & 1987 & OP \\
\hline $\begin{array}{l}\text { Crystal Mountain (Pjerce) } \\
\text { Electron (Pierce) }\end{array}$ & $\begin{array}{l}1 \\
1\end{array}$ & 2.8 & $\begin{array}{l}2.8 \\
6.0\end{array}$ & 2.8 & $\begin{array}{l}\text { IC } \\
\mathrm{HY}\end{array}$ & $\begin{array}{r}\text { FO2 } \\
\text { Water }\end{array}$ & $\underline{-}$ & $\begin{array}{l}1969 \\
1904\end{array}$ & $\begin{array}{l}\text { SB } \\
\text { OP }\end{array}$ \\
\hline
\end{tabular}

Ste footnotes at end of tuble. 
Table 20. Existing Generating Units at U.S. Electric Utilities. by State, Company, and Plant, as of January 1, 1998 (Continued)

\begin{tabular}{|c|c|c|c|c|c|c|c|c|c|}
\hline \multirow{2}{*}{$\begin{array}{c}\text { State } \\
\text { Company } \\
\text { Plant (County) }\end{array}$} & \multirow{2}{*}{$\begin{array}{l}\text { Unit } \\
\text { ID }\end{array}$} & \multirow{2}{*}{$\begin{array}{c}\text { Generator } \\
\text { Nameplate } \\
\text { Capacity } \\
\text { (megawatts) }\end{array}$} & \multirow{2}{*}{$\begin{array}{l}\text { Net Summer } \\
\text { Capability } \\
\text { (megawatts) }\end{array}$} & \multirow{2}{*}{$\begin{array}{l}\text { Net Winter } \\
\text { Capability } \\
\text { (megawatts) }\end{array}$} & \multirow{2}{*}{$\begin{array}{r}\text { Unit } \\
\text { Typel }\end{array}$} & \multicolumn{2}{|c|}{ Energy Sourcel } & \multirow{2}{*}{$\begin{array}{c}\text { Year } \\
\text { of } \\
\text { Commercial } \\
\text { Operation }\end{array}$} & \\
\hline & & & & & & Primary & Alternate & & Status] \\
\hline Washington (Continued) & & & & & & & & & \\
\hline & 2 & 6.0 & 6.0 & 6.0 & HY & Water & - & 1904 & OP \\
\hline & 3 & 6.0 & 6.0 & 6.0 & $\mathbf{H Y}$ & Water & - & 1904 & OP \\
\hline & 4 & 7.5 & 8.0 & 8.0 & HY & Water & - & 1929 & OP \\
\hline Frederickson (Pierce) & 1 & 84.6 & 79.0 & 89.0 & GT & Nat Gas & $\mathrm{FO} 2$ & 1981 & OP \\
\hline & 2 & 84.6 & 79.0 & 89.0 & GT & Nat Gas & FO2 & 1981 & OP \\
\hline Fredonia (Skagit) & 1 & J23.6 & 108.0 & 123.6 & GT & Nat Gas & $\mathrm{FO} 2$ & 1984 & OP \\
\hline 20 & 2 & 123.6 & 108.0 & 123.6 & GT & Nat Gas & $\mathrm{FO} 2$ & 1984 & OP \\
\hline Lower Baker (Skagit) & 3 & 64.0 & 71.4 & 67.0 & HY & Water & - & 1960 & OP \\
\hline Nooksack (Whatcom) & 1 & 1.5 & 1.8 & 1.8 & HY & Water & - & 1906 & OP \\
\hline 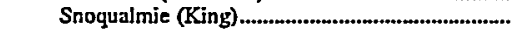 & 1 & 1.5 & 1.8 & 1.8 & HY & Water & - & 1898 & OP \\
\hline & 2 & 1.8 & 1.8 & 1.8 & HY & Water & - & 1898 & OP \\
\hline & 3 & 1.5 & 1.8 & 1.8 & HY & Water & - & 1898 & OP \\
\hline & 4 & 1.5 & 1.8 & 1.8 & HY & Water & - & 1898 & OP \\
\hline & 5 & 5.6 & 5.8 & 5.8 & HY & Water & - & 1905 & OP \\
\hline & 6 & 9.8 & 10.0 & 10.0 & HY & Water & - & 1910 & OP \\
\hline & 7 & 20.3 & 21.0 & 21.0 & HY & Water & - & 1957 & $\mathrm{OP}$ \\
\hline Upper Baker (Whatcom) & 1 & 47.2 & 51.5 & 51.5 & HY & Water & - & 1959 & OP \\
\hline & 2 & 47.2 & 51.5 & 515 & HY & Water & - & 1959 & OP \\
\hline White River (Pierce) & J & 15.0 & 15.0 & 15.0 & HY & Water & - & 1912 & $\mathrm{OP}$ \\
\hline & 2 & 15.0 & 15.0 & 15.0 & HY & Water & - & 1912 & OP \\
\hline & 3 & 20.0 & 20.0 & 20.0 & HY & Water & - & 1918 & OP \\
\hline & 4 & 20.0 & 20.0 & 20.0 & HY & Water & - & 1924 & OP \\
\hline Whitehom (Whatcom) & 1 & 61.2 & 58.0 & 67.5 & GT &. $\mathrm{FO} 2$ & - & 1974 & OP \\
\hline & 2 & 88.9 & 79.0 & 89.0 & GT & Nat Gas & $\mathrm{FO} 2$ & 1981 & OP \\
\hline & 3 & 88.9 & 79.0 & 89.0 & GT & Nat Gas & $\mathrm{FO} 2$ & 1981 & OP \\
\hline 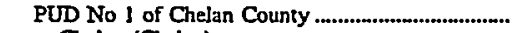 & & $1,951.4$ & $1,951.4$ & $1,951.4$ & & & & & \\
\hline Chelan (Chelan) & $A-1$ & 24.0 & 24.0 & 24.0 & HY & Water & - & 1927 & OP \\
\hline & $A-2$ & 24.0 & 24.0 & 24.0 & HY & Water & - & 1928 & OP \\
\hline Rock Isjand (Chelan) & A & 1.2 & 1.2 & 1.2 & HY & Water & - & 1931 & OP \\
\hline & B-1 & 20.7 & 20.7 & 20.7 & HY & Water & - & 1931 & OP \\
\hline & B-10 & 22.5 & 22.5 & 225 & HY & Water & - & 1953 & OP \\
\hline & B-2 & 20.7 & 20.7 & 20.7 & HY & Water & - & 1931 & $O P$ \\
\hline & B-3 & 15.0 & 15.0 & 15.0 & HYY & Water & - & 1932 & OP \\
\hline & B-4 & 20.7 & 20.7 & 20.7 & $\mathbf{H Y}$ & Water & - & 1932 & OP \\
\hline & B-5 & 22.5 & 22.5 & 22.5 & $\mathbf{H Y}$ & Water & - & 1952 & OP \\
\hline & $\begin{array}{l}\text { B-6 } \\
\text { B-7 }\end{array}$ & $\begin{array}{l}22.5 \\
22.5\end{array}$ & $\begin{array}{l}22.5 \\
22.5\end{array}$ & $\begin{array}{l}22.5 \\
22.5\end{array}$ & $\begin{array}{l}\mathbf{H Y} \\
\mathbf{H Y}\end{array}$ & $\begin{array}{l}\text { Water } \\
\text { Water }\end{array}$ & $\overrightarrow{-}$ & $\begin{array}{l}1952 \\
1952\end{array}$ & $\begin{array}{l}O P \\
O P\end{array}$ \\
\hline & B-8 & 22.5 & 22.5 & 22.5 & $\mathbf{H Y}$ & Water & - & 1953 & $O P$ \\
\hline & B.9 & 22.5 & 22.5 & 225 & $\mathbf{H Y}$ & Water & - & 1953 & $O P$ \\
\hline & U-I & 51.3 & 51.3 & 51.3 & HY & Water & - & 1979 & $O P$ \\
\hline & $\mathrm{U}-2$ & 51.3 & 51.3 & 51.3 & HY & Water & - & 1979 & $O P$ \\
\hline & $\mathrm{U}-\overline{3}$ & 51.3 & 51.3 & 51.3 & $\mathbf{H Y}$ & Water & - & 1979 & OP \\
\hline & $\mathrm{U}-4$ & 51.3 & 51.3 & 51.3 & HY & Water & - & 1979 & $O P$ \\
\hline & U-S & 51.3 & 51.3 & 51.3 & HY & Water & - & 1978 & $O P$ \\
\hline & U-6 & 51.3 & 51.3 & $5] 3$ & HY & Water & - & 1978 & OP \\
\hline & U-7 & 51.3 & 51.3 & 51.3 & HY & Water & - & 1978 & OP \\
\hline & U-8 & 51.3 & 51.3 & 51.3 & HY & Water & - & 1978 & $O P$ \\
\hline 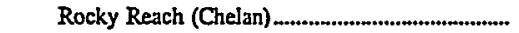 & $C-1$ & 111.2 & 111.2 & 111.2 & $\mathrm{HY}$ & Water & - & 1961 & $\mathrm{OP}$ \\
\hline & $C-10$ & 125.4 & 125.4 & 125.4 & HY & Water & - & 1974 & $\mathrm{OP}$ \\
\hline & C-11 & 125.4 & 125.4 & 125.4 & HY & Water & - & 1974 & OP \\
\hline & C-2 & 111.2 & 111.2 & II].2 & $\mathbf{H Y}$ & Water & - & 1961 & OP \\
\hline & C-3 & 111.2 & 111.2 & 111.2 & $\mathbf{H Y}$ & Water & - & 1961 & OP \\
\hline & $\mathrm{C}-4$ & 111.2 & 111.2 & 111.2 & HY & Water & - & 1961 & OP \\
\hline & C-5 & $1] 1.2$ & 111.2 & II].2 & HY & Water & - & 1961 & OP \\
\hline & C-6 & 111.2 & 111.2 & 111.2 & HY & Water & - & 1961 & OP \\
\hline & C-7 & 111.2 & 111.2 & 111.2 & HY & Water & - & 1961 & OP \\
\hline & C-8 & 125.4 & 125.4 & 125.4 & HY & Water & - & 1973 & OP \\
\hline & C-9 & 125.4 & 125.4 & 125.4 & HY & Water & - & 1973 & OP \\
\hline 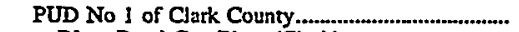 & & 248.0 & 248.0 & 248.0 & & & & & \\
\hline River Rond Gen Plant (Clark)......................... & 1 & 248.0 & 248.0 & 248.0 & $\mathrm{CC}$ & Nat Gas & - & 1997 & OP \\
\hline PUD No 1 of Douglas County & & $\mathbf{7 7 4 . 0}$ & 840.0 & 840.0 & & & & & \\
\hline Wells (Douglas) & U-I & 77.4 & 84.0 & 84.0 & HY & Water & - & 1967 & OP \\
\hline & U-10 & 77.4 & 84.0 & 84.0 & HY & Water & - & 1969 & OP \\
\hline & $U-2$ & 77.4 & 84.0 & 84.0 & HY & Water & - & 1967 & OP \\
\hline & U-3 & 77.4 & 84.0 & 84.0 & HY & Water & - & 1967 & OP \\
\hline & U-4 & 77.4 & 84.0 & 84.0 & $\mathbf{H Y}$ & Water & - & 1967 & OP \\
\hline & U-5 & 77.4 & 84.0 & 84.0 & HY & Water & - & 1967 & OP \\
\hline & $\mathrm{U}-6$ & 77.4 & 84.0 & 84.0 & HY & Water & - & 1967 & OP \\
\hline & U-7 & 77.4 & 84.0 & 84.0 & $\mathrm{HY}$ & Water & - & 1967 & $O P$ \\
\hline & U-8 & 77.4 & 84.0 & 84.0 & HY & Water & - & 1968 & OP \\
\hline
\end{tabular}

See footnotes at end of table. 
Table 20. Existing Generating Units at U.S. Electric Utilities by State, Company, and Plant, as of January 1, 1998 (Continued)

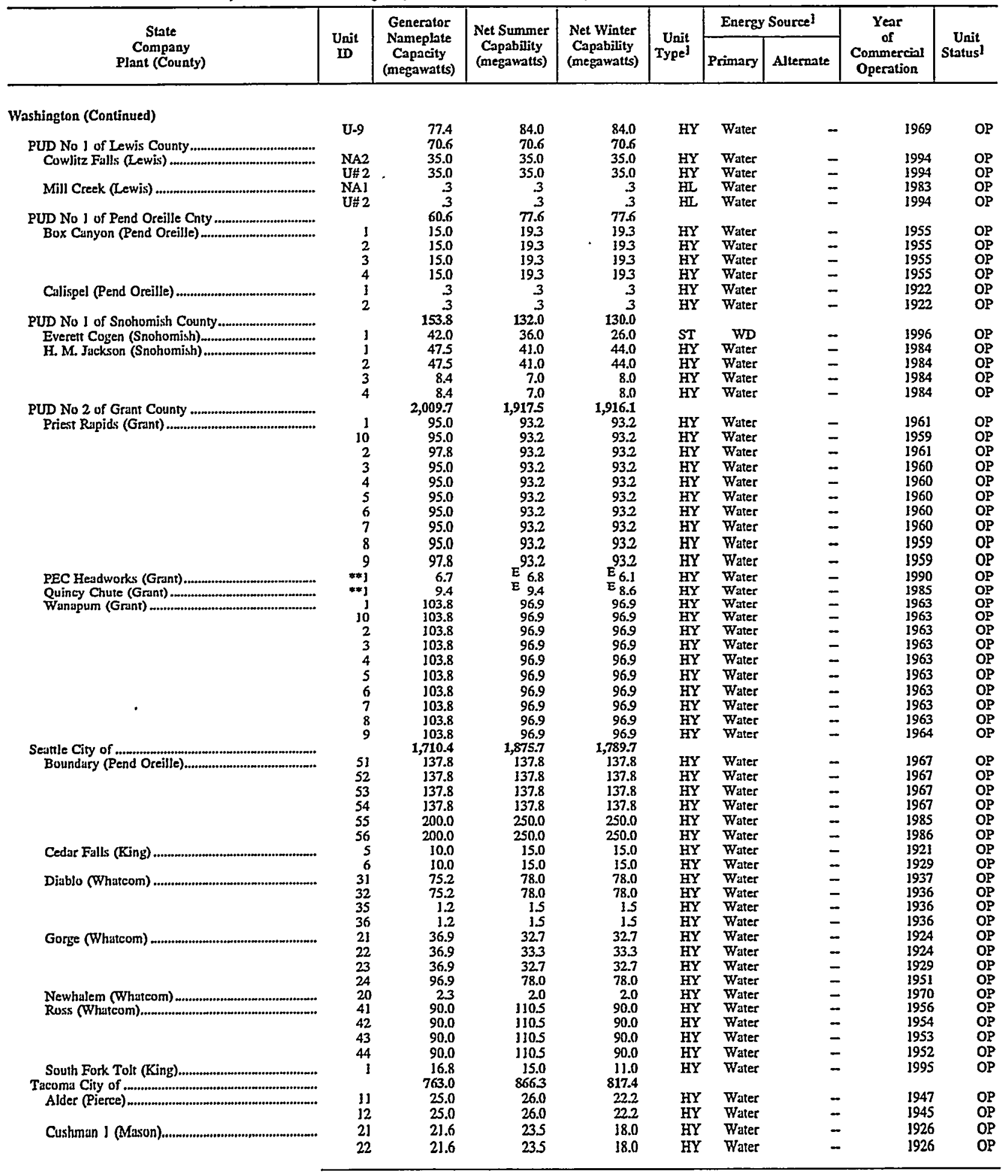

See footnotes at end of table. 
Table 20. Existing Generating Units at U.S. Electric Utilities by State, Company, and Plant, as of January 1, 1998 (Continued)

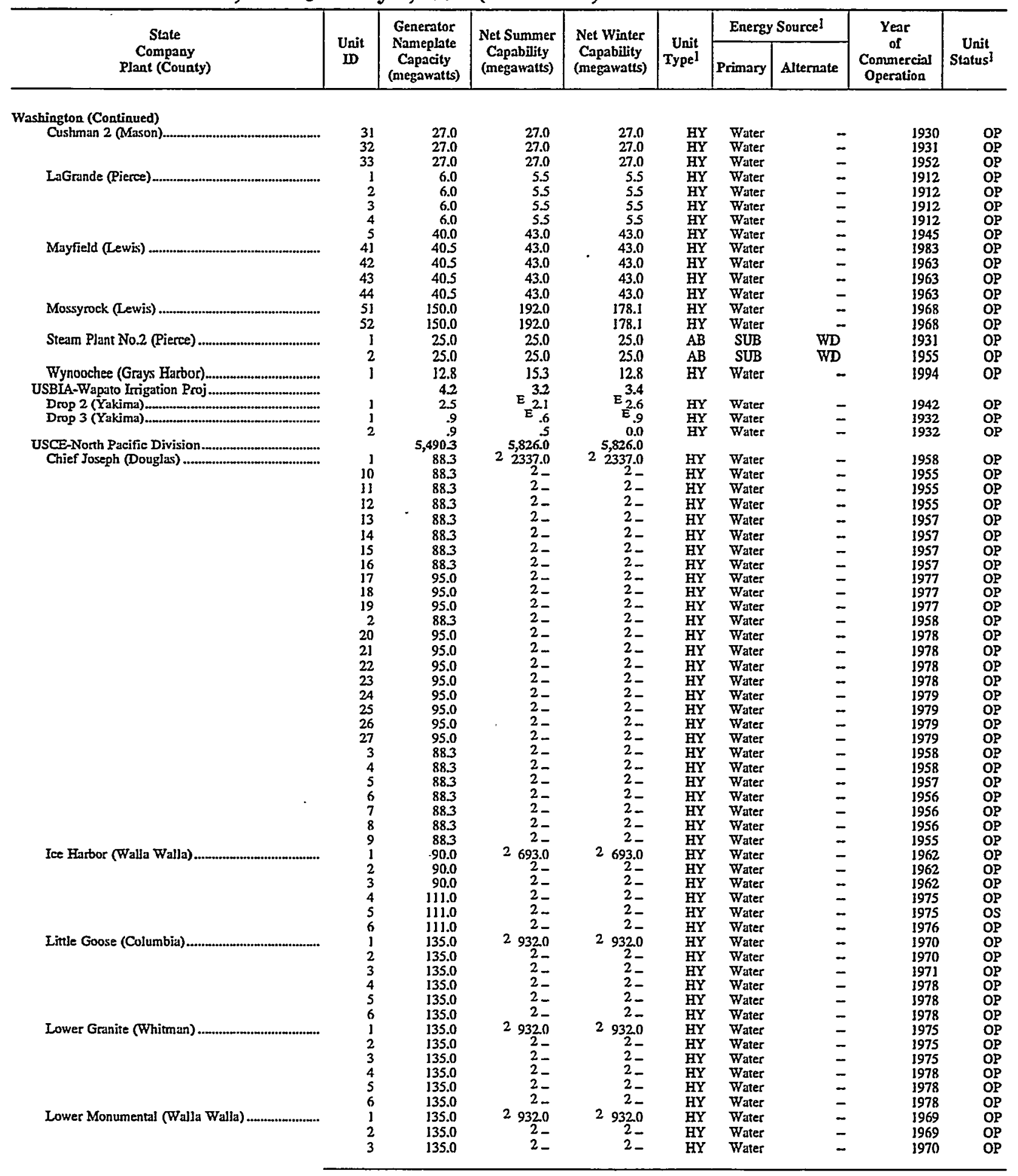

See footnotes at end of table. 
Table 20. Existing Generating Units at U.S. Electric Utilities by State, Company, and Plant, as of January 1, 1998 (Continued)

\begin{tabular}{|c|c|c|c|c|c|c|c|c|c|}
\hline \multirow{2}{*}{$\begin{array}{c}\text { State } \\
\text { Company } \\
\text { Plant (County) }\end{array}$} & \multirow{2}{*}{$\begin{array}{l}\text { Unit } \\
\text { wD }\end{array}$} & \multirow{2}{*}{$\begin{array}{c}\text { Generator } \\
\text { Nameplate } \\
\text { Capacily } \\
\text { (megawatts) }\end{array}$} & \multirow{2}{*}{$\begin{array}{c}\text { Net Summer } \\
\text { Capability } \\
\text { (megawatts) }\end{array}$} & \multirow{2}{*}{$\begin{array}{l}\text { Net Winter } \\
\text { Capability } \\
\text { (megawatts) }\end{array}$} & \multirow{2}{*}{$\begin{array}{l}\text { Unit } \\
\text { Typel }\end{array}$} & \multicolumn{2}{|c|}{ Energy Sourcel } & \multirow{2}{*}{$\begin{array}{c}\text { Year } \\
\text { of } \\
\text { Commercial } \\
\text { Operation }\end{array}$} & \multirow{2}{*}{$\begin{array}{c}\text { Unil } \\
\text { Status! }\end{array}$} \\
\hline & & & & & & Primary & Alternate & & \\
\hline \multicolumn{10}{|l|}{ Washington (Continued) } \\
\hline & 4 & 135.0 & $2-$ & $2-$ & HY & Water & - & 1979 & OP \\
\hline & 5 & 135.0 & $2-$ & $2-$ & $\mathrm{HY}$ & Water & - & 1979 & OP \\
\hline Washington Pub Pwr Supply Sys................................... & 6 & $\begin{array}{r}135.0 \\
12275\end{array}$ & $1300-$ & $22^{2}-$ & HY & Water & - & 1979 & OP \\
\hline 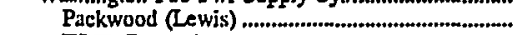 & J & 27.5 & 30.0 & 30.0 & $\mathrm{HY}$ & Water & - & 1964 & OP \\
\hline WNP (Benton) ................................................................... & 2 & 1200.0 & 3130.0 & 1170.0 & $\mathrm{NB}$ & Uranium & - & 1984 & OP \\
\hline Washington Water Power Co ............................... & & 2663 & 269.1 & 279.1 & & Stamoma & - & & \\
\hline Ketrle Falls (Stevens)................................................ & 1 & 50.7 & 47.0 & 47.0 & ST & WD & Nat Gas & 1983 & OP \\
\hline Little Falls (Lincoln) & j & 8.0 & 9.0 & 9.0 & HY & Water & - & 1910 & OP \\
\hline & $\frac{2}{3}$ & 8.0 & 9.0 & 9.0 & $\mathrm{HY}$ & Water & - & 1910 & OP \\
\hline & $\begin{array}{l}3 \\
4\end{array}$ & $\begin{array}{l}8.0 \\
8.0\end{array}$ & $\begin{array}{l}9.0 \\
9.0\end{array}$ & $\begin{array}{l}9.0 \\
9.0\end{array}$ & $\begin{array}{l}\mathrm{HY} \\
\mathrm{HY}\end{array}$ & $\begin{array}{l}\text { Water } \\
\text { Water }\end{array}$ & $\overline{-}$ & $\begin{array}{l}1910 \\
1911\end{array}$ & $\begin{array}{l}O P \\
O P\end{array}$ \\
\hline 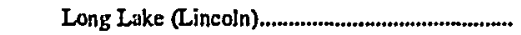 & $\mathrm{j}$ & 17.5 & 18.2 & 18.2 & HY & $\begin{array}{l}\text { Water } \\
\text { Water }\end{array}$ & $\bar{\Xi}$ & $j 915$ & OP \\
\hline & 2 & 17.5 & 38.2 & 182 & $\mathrm{HY}$ & Water & - & 1915 & OP \\
\hline & 3 & 17.5 & 18.2 & 18.2 & HY & Wate & - & 1919 & OP \\
\hline & 4 & 17.5 & 18.2 & 18.2 & $\mathrm{HY}$ & Water & - & 1924 & OP \\
\hline 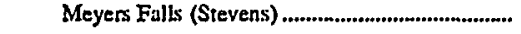 & 1 & .9 & .9 & .9 & HY & Water & - & 1915 & OP \\
\hline & 2 & .3 & .4 & .4 & $\mathrm{HY}$ & Water & - & 1917 & OP \\
\hline Monroe Street (Spokane)............................................. & 6 & 34.8 & 14.8 & 14.8 & $\mathrm{HY}$ & Water & - & 1992 & OP \\
\hline 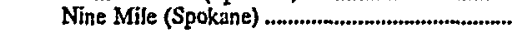 & i & 3.4 & 4.5 & 4.5 & $\mathrm{HY}$ & Water & - & 3910 & OP \\
\hline & 2 & 3.0 & 4.5 & 4.5 & $\mathrm{HY}$ & Water & - & 1908 & OP \\
\hline & $3 \mathrm{~N}$ & 10.0 & 10.0 & 10.0 & $\mathrm{HY}$ & Water & - & 1994 & $\mathrm{OP}$ \\
\hline & $4 \mathbf{N}$ & 10.0 & 10.0 & 10.0 & HY & Water & - & 1994 & OP \\
\hline 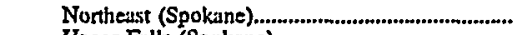 & 1 & 61.2 & 58.0 & 68.0 & GT & Nat Gas & FO2 & 1978 & SB \\
\hline Upper Falls (Spokane) ............................................. & 1 & 10.0 & 10.2 & 10.2 & HY & Water & - & 1922 & OP \\
\hline \multicolumn{10}{|l|}{ West Virginia } \\
\hline 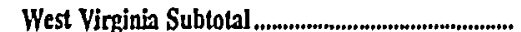 & & $15,157.5$ & $14,490.7$ & $14,650.8$ & & & & & \\
\hline Appalachian Power Co.......... & & $4,715.5$ & $4,634.0$ & $4,651.0$ & & & & & \\
\hline John E Amos (Putnam) & 1 & 816.3 & 800.0 & 800.0 & ST & BIT & - & 1971 & OP \\
\hline & 2 & & & & ST & BIT & - & & OP \\
\hline & $* * 3$ & $\begin{array}{r}1300.0 \\
2107\end{array}$ & $\begin{array}{l}1300.0 \\
1050\end{array}$ & 1300.0 & ST & BIT & - & 1973 & OP \\
\hline 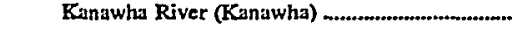 & $\frac{1}{2}$ & $\begin{array}{l}219.7 \\
2197\end{array}$ & 195.0 & 200.0 & $\begin{array}{l}S T \\
S T\end{array}$ & BIT & $\overline{-}$ & 1953 & $O P$ \\
\hline 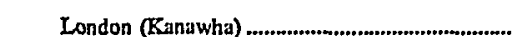 & 1 & $\begin{array}{r}219.7 \\
14.4\end{array}$ & $2_{138}^{J 95.0}$ & $2_{160}^{200.0}$ & ST & $\mathrm{BIT}$ & - & 1953 & op \\
\hline 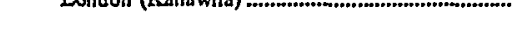 & $\frac{1}{2}$ & $\begin{array}{r}14.4 \\
0.0\end{array}$ & $\frac{13.8}{2}$ & $2-160$ & $\mathrm{HY}$ & $\begin{array}{l}\text { Water } \\
\text { Water }\end{array}$ & $\overline{-}$ & $\begin{array}{l}1935 \\
1935\end{array}$ & $\begin{array}{l}O P \\
O P\end{array}$ \\
\hline & 3 & 0.0 & $2-$ & $2-$ & $\mathbf{H Y}$ & Water & - & 1935 & $\mathrm{OP}$ \\
\hline Marmet (Kanawha) & 1 & 14.4 & 213.8 & 216.0 & $\mathrm{HY}$ & Water & - & 1935 & $\mathrm{OP}$ \\
\hline & 2 & 0.0 & $2-$ & $2-$ & HY & Water & - & 1935 & $\mathrm{OP}$ \\
\hline & 3 & 0.0 & $2-$ & $2-$ & $\mathrm{HY}$ & Water & - & 1935 & OP \\
\hline Mountaineer (1301) (Mason)........... & j & 1300.0 & 1300.0 & 1300.0 & ST & BIT & - & 3980 & $O P$ \\
\hline 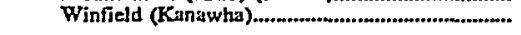 & i & $\mathrm{J4.8}$ & 216.4 & 219.0 & MY & Water & - & 1938 & op \\
\hline & 2 & 0.0 & $2=$ & $2-$ & $\mathrm{HY}$ & Water & - & 1938 & \\
\hline Central Operating Co................................ & & $1,105.6$ & $1,020 . \overline{0}$ & $1,050.0$ & & Water & - & 1938 & OP \\
\hline 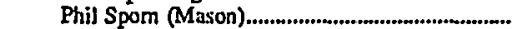 & 1 & IS2.5 & 145.0 & 150.0 & ST & & _ & 1950 & \\
\hline & 2 & 152.5 & 145.0 & 150.0 & $\mathbf{S T}$ & BIT & $=$ & 1950 & OP \\
\hline & 3 & 152.5 & 145.0 & 150.0 & ST & BIT & - & 1951 & OP \\
\hline & 4 & 152.5 & 145.0 & 150.0 & ST & BIT & - & 1952 & OP \\
\hline & 5 & 495.6 & 440.0 & 450.0 & ST & BIT & - & 1960 & $O P$ \\
\hline Monongahela Pow & & 5,1732 & $4,910.0$ & $4,946.0$ & & & & & \\
\hline 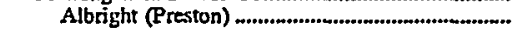 & 1 & 69.0 & 73.0 & 76.0 & ST & BIT & - & 1952 & OP \\
\hline & 2 & 69 & 73.0 & 76.0 & ST & BIT & - & & OP \\
\hline & & 140.3 & 137.0 & 140.0 & ST & BIT & - & 1954 & OP \\
\hline Fort Martin (Monongalia)........ & $* *]$ & 576.0 & 5520 & 552.0 & $S T$ & BIT & - & 1967 & OP \\
\hline & $* 2$ & 576.0 & 555.0 & 555.0 & ST & BIT & - & 19 & OP \\
\hline 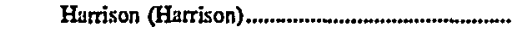 & $*=1$ & 684.0 & 640.0 & 640.0 & $\mathbf{S T}$ & BIT & - & 19 & OP \\
\hline & $* 2$ & & 640 & 640 & $\mathbf{S T}$ & BIT & - & 19 & OP \\
\hline & $* * 3$ & 684 & 640.0 & 640 & ST & BIT & - & 1974 & OP \\
\hline Pleasants (Pleasants) ................................................... & $* \star_{j}$ & 684.0 & 614.0 & 621.0 & ST & BIT & - & 1979 & OP \\
\hline & $=\infty 2$ & 684.0 & 614.0 & 621.0 & ST & BIT & - & 1980 & OP \\
\hline Rivesville (Marion) & 5 & 35.0 & 46.0 & 48.0 & ST & BIT & - & 1943 & OP \\
\hline WIV- & 6 & 74.8 & 91.0 & 94. & ST & BIT & - & 195] & OP \\
\hline Willow Island (Pleasants) .............................................. & J & 50.0 & 54.0 & 55.0 & ST & BIT & - & 1949 & OP \\
\hline & 2 & 163.2 & 181.0 & 188.0 & ST & BIT & - & 1960 & OP \\
\hline 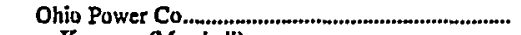 & & $2,345.1$ & $2,200.0$ & $2,230.0$ & & & & & \\
\hline 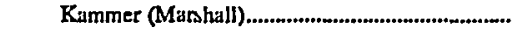 & 1 & 237.5 & 200.0 & 230.0 & ST & BIT & - & 1958 & OP \\
\hline & 2 & 237.5 & 200.0 & 210.0 & $\underset{m}{S T}$ & BIT & - & 1958 & OP \\
\hline & 3 & 237.5 & 200.0 & 210.0 & $S T$ & BIT & - & 1959 & $O P$ \\
\hline
\end{tabular}

See footnotes at end of table. 
Table 20. Existing Generating Units at U.S. Electric Utilities by State, Company, and Plant, as of January 1, 1998 (Continued)

\begin{tabular}{|c|c|c|c|c|c|c|c|c|c|}
\hline \multirow{2}{*}{$\begin{array}{c}\text { State } \\
\text { Company } \\
\text { Plant (County) }\end{array}$} & \multirow{2}{*}{$\begin{array}{l}\text { Unit } \\
\text { ID }\end{array}$} & \multirow{2}{*}{$\begin{array}{l}\text { Generator } \\
\text { Nameplate } \\
\text { Capacity } \\
\text { (megawatls) }\end{array}$} & \multirow{2}{*}{$\begin{array}{l}\text { Net Summer } \\
\text { Capability } \\
\text { (negawatts) }\end{array}$} & \multirow{2}{*}{$\begin{array}{l}\text { Net Winter } \\
\text { Capability } \\
\text { (megawatts) }\end{array}$} & \multirow{2}{*}{$\begin{array}{c}\text { Unit } \\
\text { Type] }\end{array}$} & \multicolumn{2}{|c|}{ Energy Source] } & \multirow{2}{*}{$\begin{array}{c}\text { Year } \\
\text { of } \\
\text { Commercial } \\
\text { Operation }\end{array}$} & \multirow{2}{*}{$\begin{array}{c}\text { Unit } \\
\text { Status } 1\end{array}$} \\
\hline & & & & & & Primary & Alternate & & \\
\hline \multicolumn{10}{|l|}{ West Virginia (Continued) } \\
\hline 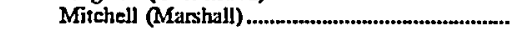 & ] & 816.3 & 800.0 & 800.0 & ST & BIT & - & 1971 & OP \\
\hline & 2 & 816.3 & 800.0 & 800.0 & ST & BIT & - & 1971 & OP \\
\hline Potomac Edison Co & & 5.9 & 1.7 & 2.8 & & & & & \\
\hline 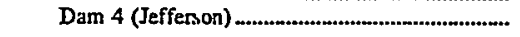 & 1 & 1.9 & 2.6 & 2.9 & HY & Water & -- & 1909 & OP \\
\hline 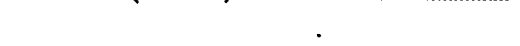 & 2 & 0.0 & $2-$ & $2-$ & HY & Water & - & 1909 & OP \\
\hline • & 3 & 0.0 & $2^{2}-$ & $2-$ & HY & Water & - & 1991 & OP \\
\hline 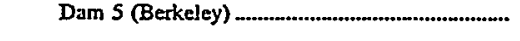 & 1 & 1.1 & 2.3 & 2.5 & HY & Water & - & 1919 & OP \\
\hline Millville (Jefferson) ................................................. & 2 & 0.0 & $2^{2}-$ & $2-$ & HY & Water & - & 1919 & OP \\
\hline & $\begin{array}{l}1 \\
2\end{array}$ & $\begin{array}{l}2.8 \\
0.0\end{array}$ & 2.8 & 21.4 & $\mathbf{H Y}$ & Water & - & 1913 & OP \\
\hline & 3 & & $2-$ & $2_{-}^{2-}$ & $\begin{array}{l}\text { HY } \\
\text { HY }\end{array}$ & Water & - & 1939 & $O P$ \\
\hline Virginia Electric \& Power Co & & $1,761.1$ & $1,673.0$ & $1,719.0$ & & & & 1938 & \\
\hline 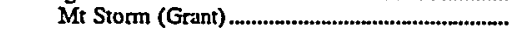 & JEI & 18.6 & 12.0 & 16.0 & GT & Jet Fuel & - & 1967 & SB \\
\hline & 1 & 570.2 & 533.0 & 545.0 & $S T$ & BIT & - & 1965 & OP \\
\hline & 2 & 570.2 & 533.0 & 545.0 & $S T$ & BIT & - & 1966 & OP \\
\hline & 3 & 5220 & 521.0 & 536.0 & ST & BIT & -- & 3973 & OP \\
\hline $\begin{array}{l}\text { North Branch (Grant). } \\
\text { West Penn Power Co }\end{array}$ & 1 & 80.0 & 74.0 & 77.0 & $\mathbf{A B}$ & WC & BrT & 1992 & SB \\
\hline West Penn Power Co ............................ & & 51.2 & $\mathbf{5 2 . 0}$ & 52.0 & & & & & \\
\hline 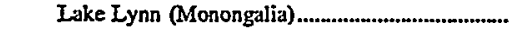 & ] & 12.8 & 13.0 & 13.0 & HY & Water & - & 1926 & OP \\
\hline & 2 & 128 & 13.0 & 13.0 & HY & Water & - & 1926 & OP \\
\hline & 3 & 128 & 13.0 & 13.0 & HY & Water & - & 1926 & OP \\
\hline & & 128 & 13.0 & I3.0 & HY & Water & - & 1926 & OP \\
\hline Wisconsin & & & & & & & & & \\
\hline 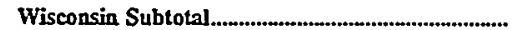 & & $11,952,2$ & $11,845.0$ & $12,400.2$ & & & & & \\
\hline 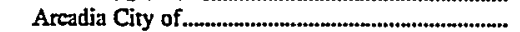 & & 9.1 & 93 & 9.3 & & & & & \\
\hline Arcadia (Trempealeau) & 1 & 1.4 & 1.4 & 1.4 & IC & FO2 & - & 1955 & OP \\
\hline & 2 & 1.0 & 1.0 & 1.0 & IC & $\mathrm{FO2}$ & - & 1948 & OP \\
\hline & 3 & .5 & .4 & .4 & IC & FO2 & - & 1940 & OP \\
\hline & 4 & .2 & 3 & 3 & IC & FO2 & - & 1930 & OP \\
\hline & 5 & 3.1 & 3.1 & 3.1 & IC & FO2 & - & [97] & OP \\
\hline Argyle City of ........................ & 6 & $\begin{array}{l}3.0 \\
2.3\end{array}$ & $\begin{array}{l}3.2 \\
2.3\end{array}$ & 32 & IC & FO2 & - & 1987 & OP \\
\hline Argyle (Lafayette) & 2 & 1.1 & 1.1 & 1.1 & IC & FO2 & - & 1947 & OP \\
\hline & 3 & .1 & $*$ & $*$ & HY & Water & - & 1973 & OP \\
\hline & 4 & 1.1 & 1.2 & 1.2 & IC & $\mathrm{FO} 2$ & - & 1989 & $\mathrm{OP}$ \\
\hline 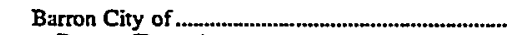 & & 4.2 & 4.2 & 42 & & & & & \\
\hline Batron (Barron) & $\mathrm{H} 2$ & .1 & .1 & ]$. & HY & Water & - & 1923 & OP \\
\hline & 7 & .8 & .8 & .8 & IC & $\mathrm{FO} 2$ & - & 1944 & OP \\
\hline & 8 & 1.3 & 1.3 & 1.3 & IC & $\mathrm{FO} 2$ & - & 1954 & OP \\
\hline & 9 & 20 & 2.0 & 2.0 & IC & FO2 & - & 1960 & $O P$ \\
\hline 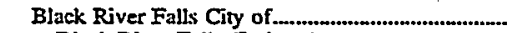 & & 4.0 & 4.0 & 4.0 & & & & & \\
\hline 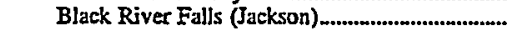 & HYI & .6 & .6 & .6 & HY & Water & - & 1947 & OP \\
\hline & HY2 & 3 & .3 & 3 & HY & Water & - & 1919 & OP \\
\hline & 1 & 3 & 3 & 3 & IC & $\mathrm{FO} 2$ & - & 1941 & SB \\
\hline & 2 & $s$ & .5 & 5 & IC & FO2 & - & 1941 & SB \\
\hline & 3 & .9 & .9 & .9 & IC & FO2 & - & 1949 & SB \\
\hline & 4 & 1.4 & 1.4 & 1.4 & IC & FO2 & - & 1955 & SB \\
\hline Cashton Village of & & 1.9 & 2.0 & 2.0 & & & & & \\
\hline Cashton (Mัonroe) & 3 & .5 & .5 & 5 & IC & FO2 & - & 1932 & OP \\
\hline & 4 & .3 & .3 & 3 & IC & FO2 & - & 1962 & OP \\
\hline & 5 & 1.1 & 1.2 & 1.2 & IC & Nat Gas & FO2 & 1970 & $\mathbf{O P}$ \\
\hline 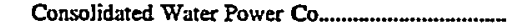 & & 33.3 & 33.0 & 33.0 & & & & & \\
\hline Biron (Wood) & 1 & 1.5 & 1.3 & 1.3 & HY & Water & - & 1916 & OP \\
\hline & 2 & 1.5 & 1.3 & 1.3 & HY & Water & - & 1921 & $O P$ \\
\hline & 3 & .4 & .4 & .4 & HY & Water & - & 1921 & OP \\
\hline & 4 & .4 & .4 & .4 & HY & Water & - & 1896 & $\mathbf{O P}$ \\
\hline & 5 & .5 & .5 & 5 & HY & Water & - & 1896 & OP \\
\hline & 6 & .4 & .4 & .4 & HY & Water & - & 3896 & $\mathrm{OP}$ \\
\hline & 7 & 5 & .5 & 5 & HY & Water & - & 1896 & OP \\
\hline & 8 & .5 & .5 & 5 & HY & Water & - & 1896 & OP \\
\hline & 9 & .9 & .9 & .9 & $\mathrm{HY}$ & Water & - & 1896 & $\mathrm{OP}$ \\
\hline Du Bay (Portage) & 1 & 1.2 & 1.2 & 1.2 & $\hat{\mathrm{HY}}$ & Water & - & 1942 & $\mathrm{OP}$ \\
\hline & 2 & 20 & 2.0 & 2.0 & HY & Water & - & 1942 & $\mathrm{OP}$ \\
\hline & 3 & 20 & 2.0 & 2.0 & $\mathrm{HY}$ & Water & - & 1942 & OP \\
\hline & 4 & 20 & 2.0 & 2.0 & HY & Water & - & 1942 & $O P$ \\
\hline Stevens Point (Portage) & 1 & .8 & .8 & .8 & $\mathbf{H Y}$ & Water & _- & 1938 & $O P$ \\
\hline & 2 & .8 & .8 & 8 & HY & Water & - & 1918 & OP \\
\hline & 3 & .8 & .8 & .8 & HY & Water & - & 1918 & OP \\
\hline
\end{tabular}

See footnotes at end of table. 
Table 20. Existing Generating Units at U.S. Electric Utilities by State, Company, and Plant, as of January 1, 1998 (Continued)

\begin{tabular}{|c|c|c|c|c|c|c|c|c|c|}
\hline \multirow{2}{*}{$\begin{array}{c}\text { State } \\
\text { Company } \\
\text { Plant (County) }\end{array}$} & \multirow{2}{*}{$\begin{array}{l}\text { Unit } \\
\text { ID }\end{array}$} & \multirow{2}{*}{$\begin{array}{c}\text { Generator } \\
\text { Nameplate } \\
\text { Capacily } \\
\text { (megawatts) }\end{array}$} & \multirow{2}{*}{$\begin{array}{l}\text { Net Summer } \\
\text { Capability } \\
\text { (megawatts) }\end{array}$} & \multirow{2}{*}{$\begin{array}{l}\text { Net Winter } \\
\text { Capability } \\
\text { (megawatts) }\end{array}$} & \multirow{2}{*}{$\begin{array}{l}\text { Unit } \\
\text { Type] }\end{array}$} & \multicolumn{2}{|c|}{ Energy Source! } & \multirow{2}{*}{$\begin{array}{c}\text { Year } \\
\text { of } \\
\text { Commercial } \\
\text { Operation }\end{array}$} & \\
\hline & & & & & & Primary & Alternate & & \\
\hline Wisconsin (Continued) & & & & & & & & & \\
\hline & 4 & 0.8 & 0.8 & 0.8 & HY & Water & - & 1918 & OP \\
\hline & 5 & .8 & .8 & .8 & HY & Water & - & 1918 & OP \\
\hline & 6 & .8 & .8 & .8 & $\mathrm{HY}$ & Water & - & 1918 & OP \\
\hline 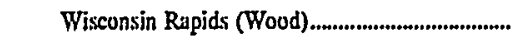 & 1 & 2.3 & 23 & 2.3 & $\mathrm{HY}$ & Water & - & 1920 & OP \\
\hline & 10 & .6 & .6 & .6 & HY & Water & - & 1903 & $\mathrm{OP}$ \\
\hline & 2 & 2.3 & 2.3 & 2.3 & HY & Water & - & 1920 & OP \\
\hline & 3 & .6 & .6 & .6 & $\mathrm{HY}$ & Water & - & 1903 & $\mathrm{OP}$ \\
\hline & 4 & .6 & .6 & .6 & HY & Water & - & 1903 & OP \\
\hline & 5 & .6 & .6 & .6 & HY & Water & - & 1903 & OP \\
\hline & 6 & .3 & 3 & 3 & $\mathrm{HY}$ & Water & - & 1903 & $O P$ \\
\hline & 7 & 6 & 6 & .6 & HY & Water & - & 1903 & OP \\
\hline & 8 & 3 & .3 & 3 & HY & Water & - & 1903 & $\mathrm{OP}$ \\
\hline & 9 & .6 & .6 & .6 & $\mathrm{HY}$ & Water & - & 1903 & OP \\
\hline Wisconsin River Div (Portage) ................................ & 1 & 1.3 & 1.3 & 13 & $\mathrm{HY}$ & Water & - & 1963 & OP \\
\hline & 10 & .4 & .4 & .4 & $\mathrm{HY}$ & Water & - & 1891 & OP \\
\hline & 2 & .6 & .6 & .6 & $\mathrm{HY}$ & Water & - & 1893 & OP \\
\hline & 3 & .6 & .6 & .6 & HY & Water & - & 1891 & OP \\
\hline & 4 & .6 & .6 & .6 & HY & Water & - & 189] & $\mathrm{OP}$ \\
\hline & 5 & .5 & .5 & 5 & $\mathrm{HY}$ & Water & - & 1891 & OP \\
\hline & 6 & 5 & 5 & 5 & $\mathrm{HY}$ & Water & - & 1891 & OP \\
\hline & 7 & 5 & .5 & 5 & $\overline{H Y}$ & Water & - & 1891 & $\mathrm{OP}$ \\
\hline & 8 & .4 & .4 & .4 & HY & Water & - & 1891 & OP \\
\hline & 9 & .4 & .4 & .4 & HY & Water & - & 1891 & OP \\
\hline Cumberland City of & & 12.0 & 11.9 & 11.9 & & & & & \\
\hline Cumberland (Barron) & $\begin{array}{l}1 \\
2\end{array}$ & $\begin{array}{l}.7 \\
3\end{array}$ & $\begin{array}{l}.8 \\
.2\end{array}$ & $\begin{array}{l}.8 \\
2\end{array}$ & $\begin{array}{l}\text { IC } \\
\text { IC }\end{array}$ & $\begin{array}{l}\mathrm{FO} 2 \\
\mathrm{FO} 2\end{array}$ & $\overline{-}$ & $\begin{array}{l}1945 \\
1939\end{array}$ & $\begin{array}{l}O P \\
O P\end{array}$ \\
\hline & 3 & 3 & 3 & 3 & IC & FO2 & - & 1939 & OP \\
\hline & 4 & 1.4 & 1.5 & 15 & IC & FO2 & - & 1954 & OP \\
\hline & 5 & 2.1 & 2.1 & 2.1 & IC & Nat Gas & FO2 & 1966 & OP \\
\hline & 6 & 7.3 & 7.1 & 7.1 & IC & $\mathrm{FO} 2$ & - & 1979 & OP \\
\hline Dahlberg Light \& Power Co & & 10.1 & 10.0 & 10.0 & & & & & \\
\hline 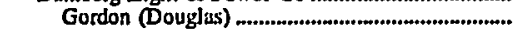 & I & .3 & .1 &. $\mathrm{I}$ & HY & Water & - & 1934 & OP \\
\hline & 2 & .1 & .1 & .1 & HY & Water & - & 1945 & OP \\
\hline & 5 & .7 & .7 & .7 & IC & $\mathrm{FO2}$ & - & 1955 & OP \\
\hline & 6 & .7 & .7 & .7 & IC & $\mathrm{FO} 2$ & - & 1949 & OP \\
\hline 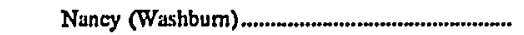 & 1 & 3 & 3 & 3 & $\mathrm{HY}$ & Water & - & 1953 & OP \\
\hline & $\dot{2}$ & .2 & .2 & .2 & HY & Water & - & 1953 & OP \\
\hline 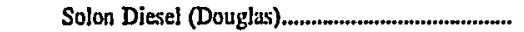 & 1 & 1.0 & 1.0 & 1.0 & IC & $\mathrm{FO2}$ & - & 3988 & OP \\
\hline & 2 & 1.0 & 1.0 & 1.0 & IC & $\mathrm{FO} 2$ & - & 1988 & $O P$ \\
\hline & 3 & 1.0 & 1.0 & 1.0 & IC & FO2 & - & 1989 & OP \\
\hline & 4 & 1.0 & 1.0 & 1.0 & IC & FO2 & - & 1989 & $O P$ \\
\hline & 5 & 1.0 & 1.0 & 1.0 & IC & $\mathrm{FO} 2$ & - & 1989 & $O P$ \\
\hline & 6 & 1.0 & 1.0 & 1.0 & IC & $\mathrm{FO} 2$ & - & 1995 & OP \\
\hline & 7 & 1.0 & 1.0 & 1.0 & IC & $\mathrm{FO} 2$ & - & 1995 & OP \\
\hline & 8 & 1.0 & 1.0 & 1.0 & IC & FO2 & - & 1995 & OP \\
\hline 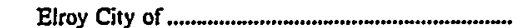 & & 2.1 & 22 & 2.2 & & & & & \\
\hline 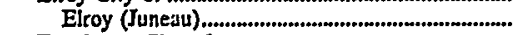 & 5 & 2.1 & 22 & 2.2 & IC & FO2 & - & 1972 & OP \\
\hline Fennimore City of & & 2.1 & 25 & 2.5 & & & & & \\
\hline Fennimore (Grant) & 4 & 1.1 & 1.2 & 1.2 & IC & FO2 & - & 1964 & OP \\
\hline & 5 & 1.0 & 1.3 & 13 & $\mathrm{IC}$ & FO2 & - & 1956 & OP \\
\hline 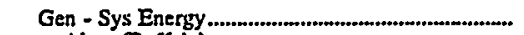 & & 922.6 & 971.9 & 971.9 & & & & & \\
\hline 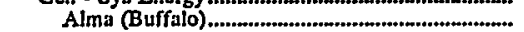 & 1 & 15.0 & 21.0 & 21.0 & ST & BIT & - & 1947 & OP \\
\hline & 2 & 15.0 & 20.2 & 202 & $\mathbf{C H}$ & BIT & - & 1947 & op \\
\hline & 3 & 15.0 & 19.7 & 19.7 & $\mathbf{C H}$ & BIT & - & 1947 & OP \\
\hline & 4 & 50.0 & 54.7 & 54.7 & $\mathbf{C H}$ & BIT & - & 1957 & OP \\
\hline & 5 & 80.0 & 83.9 & 83.9 & ST & BIT & - & 1960 & OP \\
\hline 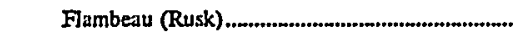 & 1 & 5.0 & 7.1 & 7.1 & HY & Water & - & 1951 & $O P$ \\
\hline & 2 & 5.0 & 7.2 & 72 & $\mathbf{H Y}$ & Water & - & 1951 & OP \\
\hline & 3 & 5.0 & 6.8 & 6.8 & HY & Water & - & 1951 & OP \\
\hline Genos (Vemon) & $*$ **T3 & 345.6 & 374.3 & 374.3 & ST & BIT & SUB & 1969 & OP \\
\hline John P. Madgett (BuffaJo) & 1 & 387.0 & 377.0 & 377.0 & ST & SUB & - & 1979 & OP \\
\hline Gresham Village of ................................................... & & .9 & .7 & .7 & & & & & \\
\hline Lower Weed (Shawano) & I & .5 & 3 & 3 & HY & Water & - & 1967 & OP \\
\hline & $i$ & .1 & .1 & .1 & HY & Water & - & 1967 & $\mathbf{O P}$ \\
\hline 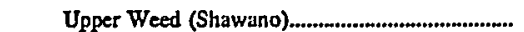 & I & $\ddot{i}$ & .1 & .1 & $\mathbf{H Y}$ & Water & - & 1946 & OP \\
\hline & 2 & .2 & 2 & 2 & HY & Water & - & 1944 & OP \\
\hline 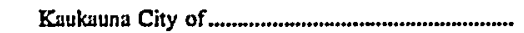 & & 46.3 & 45.5 & $48 . \overline{1}$ & & & & & \\
\hline Combined Locks (Outagamie)............................... & $\mathrm{HCl}$ & 3.1 & 3.1 & 3.1 & HY & Water & - & 1988 & OP \\
\hline & $\mathrm{HC2}$ & 3.1 & 3.3 & 3.1 & HY & Water & - & 1988 & OP \\
\hline 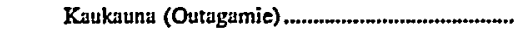 & 1 & 2.4 & 24 & 2.4 & HY & Water & " - & 1940 & OP \\
\hline
\end{tabular}

See footnotes at end of table. 
Table 20. Existing Generating Units at U.S. Electric Utilities by State, Company, and Plant, as of January 1, 1998 (Continued)

\begin{tabular}{|c|c|c|c|c|c|c|c|c|c|}
\hline \multirow{2}{*}{$\begin{array}{c}\text { State } \\
\text { Company } \\
\text { Plant (County) }\end{array}$} & \multirow{2}{*}{$\begin{array}{l}\text { Unit } \\
\text { ID }\end{array}$} & \multirow{2}{*}{$\begin{array}{c}\text { Generator } \\
\text { Nameplate } \\
\text { Capacity } \\
\text { (megawatts) }\end{array}$} & \multirow{2}{*}{$\begin{array}{l}\text { Net Summer } \\
\text { Capability } \\
\text { (megawatts) }\end{array}$} & \multirow{2}{*}{$\begin{array}{l}\text { Net Winter } \\
\text { Capability } \\
\text { (megawatts) }\end{array}$} & \multirow{2}{*}{$\begin{array}{c}\text { Unit } \\
\text { Typel }\end{array}$} & \multicolumn{2}{|c|}{ Energy Sourcel } & \multirow{2}{*}{$\begin{array}{c}\text { Year } \\
\text { of } \\
\text { Commercial } \\
\text { Operation }\end{array}$} & \multirow{2}{*}{$\begin{array}{c}\text { Unit } \\
\text { Status! }\end{array}$} \\
\hline & & & & & & Primary & Alternale & & \\
\hline Wisconsin (Continued) & & & & & & & & & \\
\hline & 2 & 2.4 & 2.4 & 2.4 & HY & Water & - & 1942 & OP \\
\hline Kaukauna Gas \& Diese (Outagamie).................... & $\begin{array}{l}\text { GT] } \\
\text { IC] }\end{array}$ & $\begin{array}{r}18.0 \\
2.0\end{array}$ & $\begin{array}{r}16.5 \\
2.5\end{array}$ & $\begin{array}{r}19.1 \\
2.1\end{array}$ & GT & $\begin{array}{l}\text { Nat Gas } \\
\text { FO2 }\end{array}$ & $\mathrm{FO}_{2}$ & $\begin{array}{l}1969 \\
1966\end{array}$ & $\begin{array}{l}\text { OP } \\
\text { OP }\end{array}$ \\
\hline & $\begin{array}{l}2 \\
3\end{array}$ & $\begin{array}{l}2.0 \\
2.0\end{array}$ & $\begin{array}{l}2.2 \\
2.3\end{array}$ & $\begin{array}{l}2.2 \\
2.3\end{array}$ & IC & $\begin{array}{l}\mathrm{FO} 2 \\
\mathrm{FO} 2\end{array}$ & $=$ & $\begin{array}{l}1966 \\
1966\end{array}$ & $\begin{array}{l}\text { OP } \\
\text { OP }\end{array}$ \\
\hline 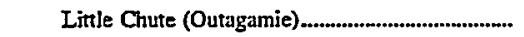 & $j$ & 1.1 & 1.1 & 1.1 & $\mathrm{HY}$ & Water & - & 1948 & OP \\
\hline & 2 & 1.1 & 1.1 & j.j & $\mathrm{HY}$ & Water & - & 1948 & OP \\
\hline & 3 & 1.3 & 1.1 & 1.1 & HY & Water & - & 1948 & OP \\
\hline 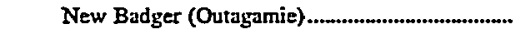 & 1 & 1.8 & 1.8 & 1.8 & HY & Water & - & 1928 & OP \\
\hline & 2 & 1.8 & 3.8 & 1.8 & $\mathrm{HY}$ & Water & - & 1928 & OP \\
\hline 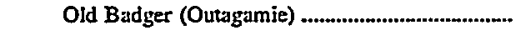 & 3 & 1.0 & 3.0 & 1.0 & HY & Water & - & 1907 & OP \\
\hline 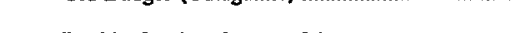 & 4 & 1.0 & 1.0 & 1.0 & $\mathrm{HY}$ & Water & $\rightarrow$ & 1907 & OP \\
\hline Rapide Croche (Outagamie) ................................... & 1 & .6 & .6 & .6 & HY & Water & - & 1926 & OP \\
\hline & 2 & .6 & .6 & .6 & HY & Water & - & 1926 & OP \\
\hline & 3 & .6 & 6 & 6 & $\mathrm{HY}$ & Water & - & 1926 & OP \\
\hline Ia Farge Municipal Electric Co & & 1.9 & 1.6 & 1.6 & & & & & \\
\hline Ia Farge (Vemon) & 2 & 1.9 & 1.6 & 1.6 & IC & $\mathrm{FO2}$ & $\rightarrow$ & 1936 & OP \\
\hline 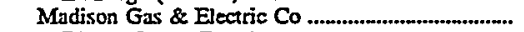 & & 282.5 & 2863 & 312.6 & & & & & \\
\hline 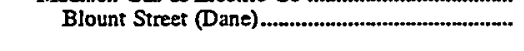 & $\begin{array}{l}1 \\
3\end{array}$ & $\begin{array}{l}12.5 \\
33.0\end{array}$ & $\begin{array}{r}6.9 \\
39.6\end{array}$ & $\begin{array}{r}6.7 \\
41.8\end{array}$ & $\begin{array}{l}\text { ST } \\
\text { ST }\end{array}$ & $\begin{array}{l}\text { BIT } \\
\text { BIT }\end{array}$ & $\begin{array}{l}\text { Nat Gas } \\
\text { Nat Gas }\end{array}$ & $\begin{array}{l}1925 \\
1953\end{array}$ & $\begin{array}{l}\text { OP } \\
\text { OP }\end{array}$ \\
\hline & 4 & 20.0 & 23.1 & $\begin{array}{l}41.8 \\
24.2\end{array}$ & ST & BIT & Nat Gas & 1938 & OP \\
\hline & 5 & 25.0 & 29.4 & 303 & ST & BIT & Nat Gas & 1948 & OP \\
\hline & 6 & 44.0 & 49.3 & 53.0 & ST & BIT & Nat Gas & 1957 & OP \\
\hline & 7 & 44.0 & 48.6 & 52.7 & ST & BIT & Nat Gas & 196] & OP \\
\hline Fitchburg (Dane) & 1 & 27.0 & 20.0 & 23.8 & GT & Nat Gas & $\mathrm{FO} 2$ & 1973 & OP \\
\hline & 2 & 27.0 & 21.2 & 23.1 & GT & Nat Gas & $\mathrm{FO} 2$ & 1973 & OP \\
\hline 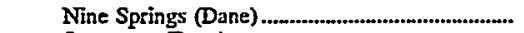 & GT & 14.0 & 13.3 & 37.1 & GT & Nat Gus & Jet Fuel & 3964 & OP \\
\hline 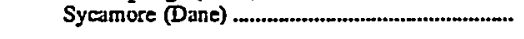 & 1 & 16.0 & 13.9 & 15.8 & GI & Nat Gas & $\mathrm{FO2}$ & 1967 & OP \\
\hline 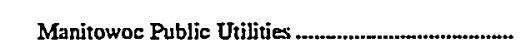 & 2 & 20.0 & 21.1 & 24.2 & GT & Nat Gas & FO2 & 1971 & $O P$ \\
\hline & & 89.5 & 89.5 & 89.5 & & & & & \\
\hline 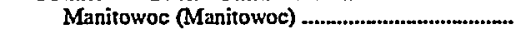 & ICI & 5.3 & 5.3 & 5.3 & IC & Nat Gas & $\mathrm{FO} 2$ & 1985 & $O P$ \\
\hline & $\mathrm{IC}$ & 5.3 & 5.3 & 5.3 & IC & Nat Gas & FO2 & 1985 & OP \\
\hline & 2 & 5.0 & 5.0 & 5.0 & ST & BIT & PC & 1935 & OP \\
\hline & 3 & 10.0 & 10.0 & 10.0 & ST & BIT & PC & 1941 & OP \\
\hline & 4 & 10.0 & 10.0 & 10.0 & ST & BIT & PC & 1950 & OP \\
\hline & 5 & 220 & 22.0 & 22.0 & ST & BIT & PC & 1956 & $O P$ \\
\hline & 6 & 320 & 32.0 & 32.0 & ST & PC & - & 1964 & OP \\
\hline & 3 & 7.5 & 9.3 & 9.4 & ST & BIT & - & 1954 & $O P$ \\
\hline & 4 & 13.7 & 14.8 & 15.0 & ST & BIT & - & 1964 & $O P$ \\
\hline Merrillan Village of & & 1.0 & .9 & .9 & & & & & \\
\hline 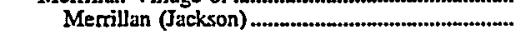 & $\mathrm{HCl}$ & .1 & .1 &.$I$ & HY & Water & - & 1942 & OP \\
\hline & 1 & .8 & .8 & .8 & IC & FO2 & - & 1943 & OP \\
\hline & 2 & .1 & .1 & .1 & HY & Water & - & 1977 & OP \\
\hline Muscoda City of & & 2.1 & 1.5 & 1.5 & & & & $\cdot$ & \\
\hline 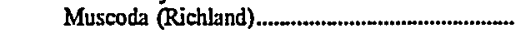 & 1 & .1 & * & $*$ & HY & Water & - & 1934 & OP \\
\hline & 3 & 20 & 1.5 & 1.5 & ST & Refuse & WD & 1989 & os \\
\hline New Lisbon City of & & 4.4 & 4.6 & 4.6 & & & & & \\
\hline New Lisbon (Juneau) & 1 & .1 & .1 & .1 & IC & $\mathrm{FO} 2$ & - & 1930 & OP \\
\hline & 2 & 1.4 & 1.3 & 13 & IC & Nat Gas & - & 1966 & OP \\
\hline & 3 & .2 & .2 & .2 & IC & $\mathrm{FO} 2$ & - & 1936 & op \\
\hline & 4 & .4 & .5 & $s$ & IC & FO2 & _ & 1948 & OP \\
\hline & 5 & 2.4 & 2.6 & 2.6 & IC & Nat Gas & $\mathrm{FO} 2$ & 1977 & OP \\
\hline 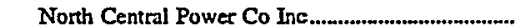 & & 32 & 3.1 & 3.1 & & & & & \\
\hline Arpin Dam (Sawyer) & 1 & .6 & .6 & .6 & $\mathbf{H Y}$ & Water & - & 1971 & OP \\
\hline & 2 & .6 & .6 & 6 & HY & Water & - & 1971 & OP \\
\hline & 3 & 3 & .3 & 3 & HY & Water & - & 1973 & OP \\
\hline East Fork (Sawyer) & 1 & .2 & .2 & .2 & $\mathrm{HY}$ & Water & - & 1973 & OP \\
\hline & 2 & .4 & .4 & .4 & HY & Water & - & 1972 & OP \\
\hline Grimh (Sawyer) & ICI & .8 & .7 & .7 & IC & $\mathrm{FO} 2$ & - & 1951 & OP \\
\hline & 1 & .1 & .1 & .1 & HY & Water & - & 1928 & SB \\
\hline & 3 & 3 & 3 & 3 & $\mathrm{HY}$ & Water & - & 1965 & $\mathrm{SB}$ \\
\hline Northem States Power Co & & 828.3 & 841.4 & 996.7 & & & & & \\
\hline 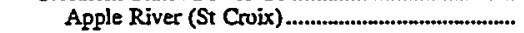 & 1 & .8 & 1.0 & 1.0 & $\mathbf{H Y}$ & Water & - & 1901 & OP \\
\hline & 2 & .8 & .9 & .9 & HY & Water & - & 1901 & OP \\
\hline & 3 & .8 & .9 & .9 & $\mathbf{H Y}$ & Water & - & 1901 & $O P$ \\
\hline & 4 & .8 & E .8 & E.8 & HY & Water & - & 1900 & OP \\
\hline Bay Front (Ashland) & 4 & 20.0 & 20.2 & 20.2 & CH & SUB & - & 1949 & OP \\
\hline
\end{tabular}

See footnotes at end of table. 
Table 20. Existing Generating Units at U.S. Electric Utilities by State, Company, and Plant, as of January 1, 1998 (Continued)

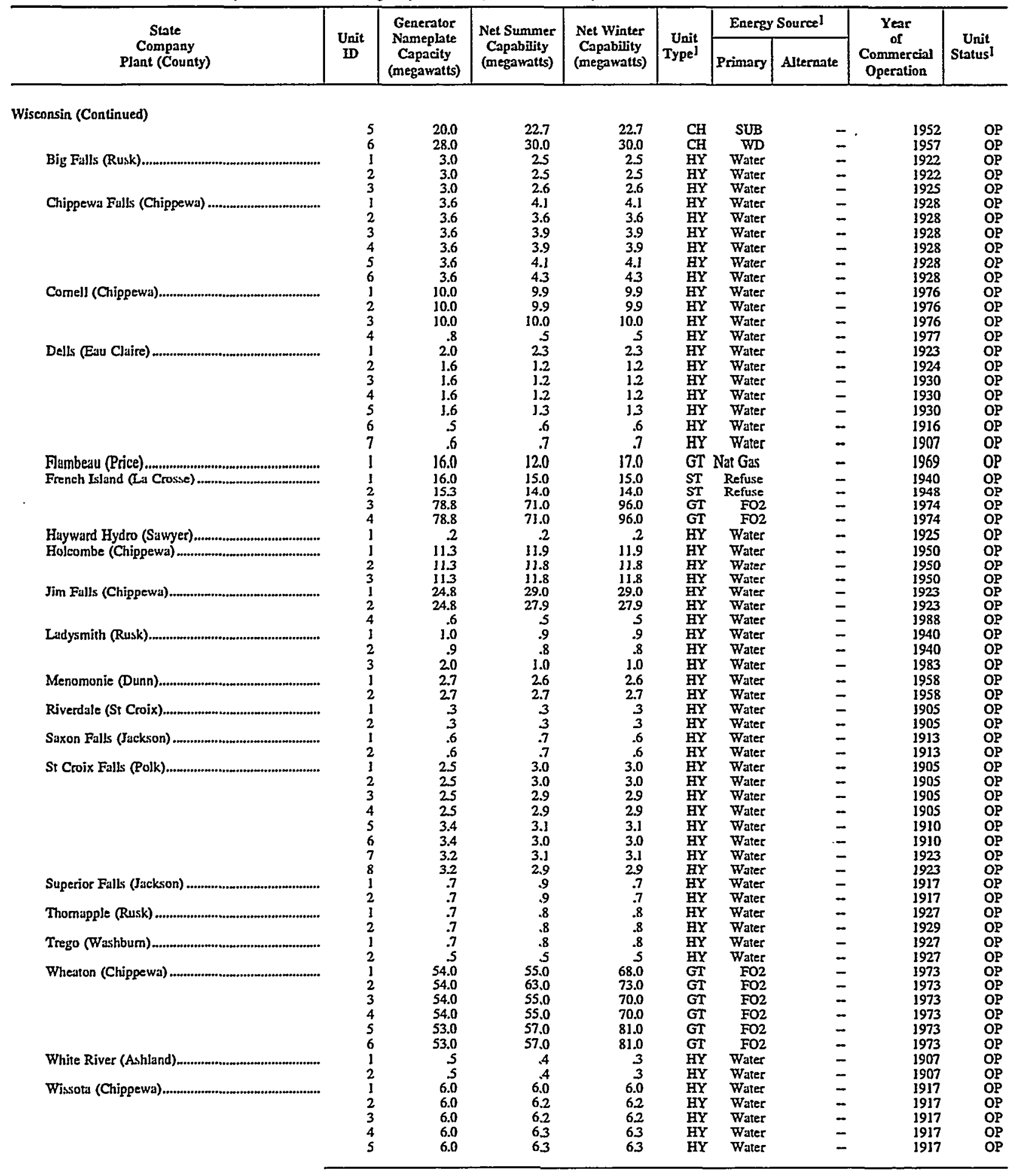

See footnotes at end of table. 
Table 20. Existing Generating Units at U.S. Electric Utilities by State, Company, and Plant, as of January 1, 1998 (Continued)

\begin{tabular}{|c|c|c|c|c|c|c|c|c|c|}
\hline \multirow{2}{*}{$\begin{array}{c}\text { State } \\
\text { Company } \\
\text { Plant (County) }\end{array}$} & \multirow{2}{*}{$\begin{array}{c}\text { Unit } \\
\text { WD }\end{array}$} & \multirow{2}{*}{$\begin{array}{c}\text { Generator } \\
\text { Nameplate } \\
\text { Capacity } \\
\text { (megawatts) }\end{array}$} & \multirow{2}{*}{$\begin{array}{c}\text { Net Summer } \\
\text { Capability } \\
\text { (megawatts) }\end{array}$} & \multirow{2}{*}{$\begin{array}{l}\text { Net Winter } \\
\text { Capability } \\
\text { (megawatts) }\end{array}$} & \multirow{2}{*}{$\begin{array}{c}\text { Unit } \\
\text { Type }\end{array}$} & \multicolumn{2}{|c|}{ Energy Sourcel } & \multirow{2}{*}{$\begin{array}{c}\text { Year } \\
\text { of } \\
\text { Commercial } \\
\text { Operation }\end{array}$} & \multirow{2}{*}{$\begin{array}{c}\text { Unit } \\
\text { Status }\end{array}$} \\
\hline & & & & & & Primary & Alternate & & \\
\hline \multicolumn{10}{|l|}{ Wisconsin (Continued) } \\
\hline Northwestem Wisconsin Elec Co.......................... & 6 & $\begin{array}{r}5.8 \\
22.1\end{array}$ & $\begin{array}{r}6.2 \\
22.0\end{array}$ & $\begin{array}{r}6.2 \\
22.0\end{array}$ & HY & Water & - & 1917 & OP \\
\hline Black Brook Dam (Polk) & ] & .3 & .2 & .2 & $\mathrm{HY}$ & Water & - & 1982 & OP \\
\hline & 2 & .4 & .4 & .4 & HY & Water & - & 1982 & OP \\
\hline 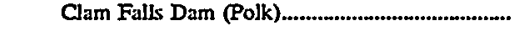 & 1 & .1 & $\mathrm{E}^{.1}$ & $\mathrm{E}^{.1}$ & HY & Water & - & 1917 & os \\
\hline & 2 & .1 & E.I & E.] & HY & Water & - & 1946 & os \\
\hline Clam River Dam (Burnett) .................................... & 1 & .4 & $\stackrel{.4}{4}$ & .4 & $\begin{array}{l}\text { HY } \\
\text { HYY }\end{array}$ & Water & $=$ & 1942 & $O P$ \\
\hline & 3 & 4 & .4 & .4 & HY & $\begin{array}{l}\text { Water } \\
\text { Water }\end{array}$ & $\overline{-}$ & $\begin{array}{l}1942 \\
1967\end{array}$ & OP \\
\hline Danbury Dam (Bumett) & GT] & 6.8 & 7.3 & 7.3 & GT & FO1 & - & 1981 & OP \\
\hline & HY3 & .6 & .6 & .6 & HY & Water & - & 1950 & OP \\
\hline & IC] & .5 & .5 & .5 & IC & FO2 & - & 1982 & OP \\
\hline & IC2 & .6 & .6 & .6 & IC & FO2 & - & 1966 & OP \\
\hline & 1 & .2 & .1 & .1 & HY & Water & - & 1921 & $O P$ \\
\hline & 2 & .3 & .3 & 3 & HY & Water & - & 1927 & OP \\
\hline 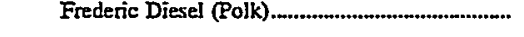 & 2 & .7 & .7 & .7 & IC & FO2 & - & 1948 & $O P$ \\
\hline & 3 & .7 & .7 & .7 & IC & $\mathrm{FO} 2$ & - & 1949 & $O P$ \\
\hline & 4 & .7 & .7 & .7 & IC & FO2 & - & 1955 & OP \\
\hline & 5 & .6 & .6 & .6 & IC & FO2 & - & 1955 & OP \\
\hline & 6 & 1.8 & 1.8 & 1.8 & IC & FO2 & - & 1970 & OP \\
\hline & 7 & 1.8 & 1.8 & 1.8 & IC & $\mathrm{FO} 2$ & - & 1975 & OP \\
\hline Grantsburg Diesel (Bumett) ................................... & IA & .8 & .8 & .8 & IC & FO2 & - & 1995 & OP \\
\hline & 2 & .8 & .8 & .8 & IC & $\mathrm{FO} 2$ & - & 1963 & OP \\
\hline & 3 & 1.0 & .9 & 9 & IC & FO2 & - & 1968 & OP \\
\hline & 4 & 2.3 & 2.0 & 2.0 & IC & FO2 & - & 1975 & OP \\
\hline 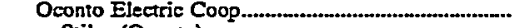 & & 1.0 & 1.0 & 1.0 & & & & & \\
\hline Stiles (Oconto) & 1 & .5 & 5 & $\mathbf{s}$ & $\mathrm{HY}$ & Water & - & 1949 & OP \\
\hline & 2 & 5 & 5 & 5 & HY & Water & - & 1949 & OP \\
\hline Pardeeville Village of & & .1 & 1 & .1 & & & & & \\
\hline Pardecville Hydro (Columbia) & w875 & .1 & .1 & .1 & HY & Water & - & 1945 & OP \\
\hline 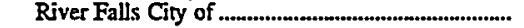 & & 13.6 & 13.2 & 132 & & & & & \\
\hline Junction (Pierce) & 1 & .3 & .2 & .2 & HY & Water & - & 1948 & OP \\
\hline & 2 & .4 & .4 & .4 & IC & FO2 & - & 1929 & OP \\
\hline & 3 & .5 & 5 & 5 & IC & FO2 & - & $194]$ & OP \\
\hline & 4 & 1.1 & 1.1 & 1.1 & IC & FO2 & - & 1948 & OP \\
\hline & 5 & 29 & 2.9 & 2.9 & IC & $\mathrm{FO2}$ & Nat Gas & 1965 & OP \\
\hline & 6 & $\begin{array}{l}2.1 \\
6.0\end{array}$ & $\begin{array}{l}2.1 \\
5.6\end{array}$ & 2.1 & IC. & $\mathrm{FO} 2$ & Nat Gas & 1965 & OP \\
\hline & 8 & $\begin{array}{r}6.0 \\
.3\end{array}$ & $\begin{array}{r}5.6 \\
3\end{array}$ & $\begin{array}{r}5.6 \\
3\end{array}$ & IC & $\begin{array}{l}\mathrm{FO} 2 \\
\mathrm{FO} 2\end{array}$ & Nat Gas _ & $\begin{array}{l}1972 \\
1979\end{array}$ & $\begin{array}{l}O P \\
O P\end{array}$ \\
\hline 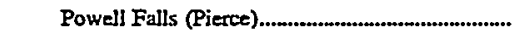 & 1 & .J & .1 & .1 & HY & Water & - & $\begin{array}{l}1919 \\
1948\end{array}$ & op \\
\hline Viola Village of. & & 1.1 & 1.1 & 1.1 & & & & & \\
\hline Viola (Richland) & 1 & .4 & 5 & 5 & IC & FO2 & - & 1948 & OP \\
\hline & 2 & .7 & .6 & .6 & IC & FO2 & - & 1966 & OP \\
\hline 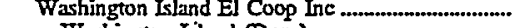 & & 5.1 & 5.1 & 5.1 & & & & & \\
\hline 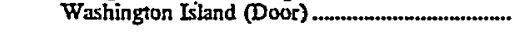 & 2 & .1 & .1 & .1 & IC & $\mathrm{FO} 2$ & - & 1952 & OP \\
\hline & $\begin{array}{l}3 \\
4\end{array}$ & $\begin{array}{l}.1 \\
.3\end{array}$ & .1 & .13 & $\begin{array}{l}\text { IC } \\
\text { IC }\end{array}$ & $\begin{array}{l}\text { FO2 } \\
\text { FO2 }\end{array}$ & $\overline{-}$ & $\begin{array}{l}1945 \\
1951\end{array}$ & $\begin{array}{l}\text { OP } \\
\text { OP }\end{array}$ \\
\hline & 5 & .5 & 5 & 5 & ic & FO2 & - & 1968 & OP \\
\hline & 6 & .9 & .9 & 9 & IC & FO2 & - & 1972 & OP \\
\hline & 7 & 1.6 & 1.6 & 1.6 & IC & $\mathrm{FO} 2$ & - & 1997 & OP \\
\hline & 8 & & 1.6 & 1.6 & IC & $\mathrm{FO2}$ & - & 1997 & OP \\
\hline Wisconsin Electric Power Co & & $5,158.9$ & $4,824.2$ & $5,011.1$ & & & & & \\
\hline Appleton (Outagamie) & 4 & .9 & 21.1 & 21.3 & $\mathrm{HY}$ & Water & - & 1980 & OP \\
\hline & 5 & 5 & $2-$ & $\begin{array}{l}2- \\
2-\end{array}$ & HY & Water & - & 1916 & OP \\
\hline & 6 & .5 & $2-$ & $2-$ & HY & Water & - & 1916 & OP \\
\hline Concond (Jefferson) & 1 & 95.4 & 83.0 & 95.0 & $\mathrm{GI}$ & Nat Gas & $\mathrm{FO2}$ & 1993 & OP \\
\hline & 2 & 95.4 & 83.0 & 95.0 & GT & Nat Gas & $\mathrm{FO} 2$ & 1993 & OP \\
\hline & 3 & 95.4 & 83.0 & 95.0 & GT & Nat Gas & $\mathrm{FO} 2$ & 1994 & OP \\
\hline & 4 & 95.4 & 83.0 & 95.0 & GT & Nat Gas & $\mathrm{FO} 2$ & 1994 & OP \\
\hline Germantown (Washington) & 1 & 61.2 & 53.0 & 65.0 & GT & $\mathrm{FO} 2$ & - & 1978 & OP \\
\hline & 2 & 61.2 & 53.0 & 65.0 & GT & FO2 & - & 1978 & OP \\
\hline & 3 & 61.2 & 53.0 & 65.0 & GT & $\mathrm{FO} 2$ & - & 1978 & OP \\
\hline & 4 & 61.2 & 53.0 & 65.0 & GT & $\mathrm{FO} 2$ & - & 1978 & $\mathbf{O P}$ \\
\hline Milwaukee County (Milwaukee)............................. & NA & 11.0 & 11.0 & 11.0 & ST & BIT & - & 1996 & OP \\
\hline Oconto Fails (Oconto) & $\mathrm{T}$ & .5 & 2.6 & 2.6 & HY & Water & - & 1924 & $\mathrm{OP}$ \\
\hline & $\frac{2}{3}$ & .5 & $\begin{array}{l}2- \\
2-\end{array}$ & $\begin{array}{l}2- \\
2-\end{array}$ & HY & Water & $\bar{z}$ & 1921 & $O P$ \\
\hline & 3 & .4 .4 & $2=\overline{0}$ & $05 \overline{0}$ & HY & Water & - & 1916 & OP \\
\hline Paris (Kenusha) & 1 & 95.4 & 83.0 & 95.0 & GT & Nat Gas & FO2 & 1995 & OP \\
\hline & 2 & 95.4 & 83.0 & 95.0 & GT & Nat Gas & FO2 & 3995 & OP \\
\hline & 3 & 95.4 & 83.0 & 95.0 & GT & Nat Gas & FO2 & 1995 & OP \\
\hline
\end{tabular}

See footnotes at end of table. 
Table 20. Existing Generating Units at U.S. Electric Utilities. by State, Company, and Plant, as of January 1, 1998 (Continued)

\begin{tabular}{|c|c|c|c|c|c|c|c|c|c|}
\hline \multirow{2}{*}{$\begin{array}{c}\text { Slate } \\
\text { Company } \\
\text { Plant (County) }\end{array}$} & \multirow{2}{*}{$\begin{array}{l}\text { Unit } \\
\text { ID }\end{array}$} & \multirow{2}{*}{$\begin{array}{c}\text { Generator } \\
\text { Namephate } \\
\text { Capacity } \\
\text { (megawatts) }\end{array}$} & \multirow{2}{*}{$\begin{array}{l}\text { Net Summer } \\
\text { Capability } \\
\text { (megawatts) }\end{array}$} & \multirow{2}{*}{$\begin{array}{c}\text { Net Winter } \\
\text { Capability } \\
\text { (megawatts) }\end{array}$} & \multirow{2}{*}{$\begin{array}{r}\text { Unit } \\
\text { Typed }\end{array}$} & \multicolumn{2}{|c|}{ Energy Source] } & \multirow{2}{*}{$\begin{array}{c}\text { Year } \\
\text { of } \\
\text { Commercinl } \\
\text { Operation }\end{array}$} & \multirow{2}{*}{$\begin{array}{c}\text { Unit } \\
\text { Status } 1\end{array}$} \\
\hline & & & & & & Primary & Alternate & & \\
\hline \multicolumn{10}{|l|}{ Wisconsin (Continued) } \\
\hline & 4 & 95.4 & 83.0 & 95.0 & GT & Nat Gas & $\mathrm{FO} 2$ & 1995 & OP \\
\hline 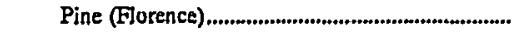 & $\frac{1}{2}$ & 1.8 & ${ }^{2}{ }_{2} .5$ & $\begin{array}{l}21.2 \\
2-\end{array}$ & $\begin{array}{l}\mathrm{HY} \\
\mathrm{HY}\end{array}$ & Water & - & 1922 & OP \\
\hline 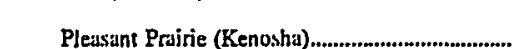 & $\frac{2}{1}$ & $\begin{array}{r}1.8 \\
616.6\end{array}$ & 600.0 & 605.0 & $\begin{array}{l}\text { HY } \\
\text { ST }\end{array}$ & $\begin{array}{c}\text { Water } \\
\text { SUB }\end{array}$ & - & $\begin{array}{l}1922 \\
1980\end{array}$ & $\begin{array}{l}O P \\
O P\end{array}$ \\
\hline & 2 & 616.6 & 600.0 & 605.0 & ST & SUB & - & 1985 & OP \\
\hline & 3 & 2.0 & 2.0 & 2.0 & IC & $\mathrm{FO2}$ & - & 1985 & OP \\
\hline 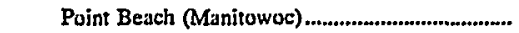 & 1 & 523.8 & 493.0 & 498.0 & NP & Uranium & - & 1970 & OP \\
\hline & $\begin{array}{l}2 \\
5\end{array}$ & $\begin{array}{r}523.8 \\
250\end{array}$ & $\begin{array}{r}441.0 \\
16.0\end{array}$ & $\begin{array}{r}446.0 \\
24.0\end{array}$ & $\begin{array}{l}\text { NP } \\
\text { GT }\end{array}$ & $\begin{array}{l}\text { Uranium } \\
\text { FO2 }\end{array}$ & - & $\begin{array}{l}1972 \\
1969\end{array}$ & OP \\
\hline Pont Washington (Ozaukee)................................... & 1 & 80.0 & 80.0 & 80.0 & ST & BIT & - & 3935 & OP \\
\hline & 2 & 80.0 & 83.0 & 83.0 & ST & BIT & - & 1943 & OP \\
\hline & 3 & 80.0 & 83.0 & 84.0 & ST & BIT & - & 1948 & OP \\
\hline & 4 & 80.0 & 80.0 & 80.0 & ST & BIT & - & 1949 & OP \\
\hline & 6 & 19.6 & 18.0 & 23.0 & GT & FO2 & - & 1969 & OP \\
\hline 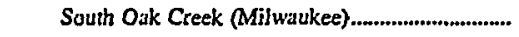 & 5 & 275.0 & 261.0 & 262.0 & ST & BIT & - & 1959 & OP \\
\hline & 6 & $\begin{array}{l}275.0 \\
3176\end{array}$ & 264.0 & 265.0 & ST & BII & - & 1961 & OP \\
\hline & $\begin{array}{l}7 \\
8\end{array}$ & $\begin{array}{l}317.6 \\
324.0\end{array}$ & $\begin{array}{l}298.0 \\
312.0\end{array}$ & $\begin{array}{l}298.0 \\
314.0\end{array}$ & $\begin{array}{l}\text { ST } \\
\text { ST }\end{array}$ & $\begin{array}{l}\text { BIT } \\
\text { BIT }\end{array}$ & $\overline{-}$ & $\begin{array}{l}1965 \\
1967\end{array}$ & $\begin{array}{l}\text { OP } \\
\text { OP }\end{array}$ \\
\hline & 9 & 19.6 & 20.0 & 25.0 & GT & Nat Gas & $\mathrm{FO} 2$ & 1968 & OP \\
\hline Villey (Milwaukee) & 1 & 136.0 & 140.0 & 140.0 & ST & BIT & - & 1968 & OP \\
\hline & 2 & 136.0 & 140.0 & 140.0 & $\mathbf{S T}$ & BIT & - & 1969 & OP \\
\hline & 3 & 2.8 & 3.0 & 3.0 & IC & $\mathrm{FO} 2$ & - & 1969 & OP \\
\hline 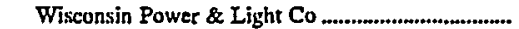 & & $2,759.9$ & $2,916.0$ & $3,016.8$ & & & & & \\
\hline 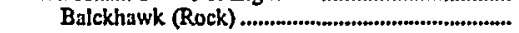 & ] & 5 & .6 & .6 & HY & Water & - & 1928 & OP \\
\hline & 3 & 25.0 & 29.0 & 29.0 & ST & Nat Gas & - & 1946 & OP \\
\hline & 4 & 25.0 & 29.0 & 29.0 & ST & Nat Gas & - & 1948 & OP \\
\hline 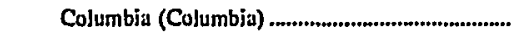 & $* * \mathbf{1}$ & 512.0 & 535.0 & 535.0 & ST & SUB & - & 1975 & OP \\
\hline & $* * 2$ & 511.0 & 535.0 & 535.0 & ST & SUB & - & 1978 & $\mathrm{OP}$ \\
\hline Edgewater (Sheboygan) ........................................... & 3 & 60.0 & 76.0 & 76.0 & ST & BIT & - & 1951 & $O P$ \\
\hline & $* * 4$ & 330.0 & 348.0 & 348.0 & ST & BIT & - & 1969 & OP \\
\hline & $* * 5$ & 380.0 & 408.0 & 408.0 & ST & BIT & - & 1985 & OP \\
\hline 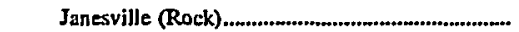 & I & 3 & 3 & 3 & HY & Water & - & 1927 & OP \\
\hline & 2 & 3 & 3 & & $\mathbf{H Y}$ & Water & - & 1927 & OP \\
\hline 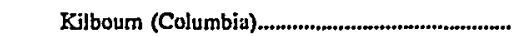 & $\mathrm{HCl}$ & 2.2 & 29.0 & 210.0 & $\mathrm{HY}$ & Water & - & 1926 & OP \\
\hline & HCS & 20 & $2-$ & $2-$ & $\mathrm{HY}$ & Water & - & 1935 & OP \\
\hline & HC6 & 20 & $2-$ & 2 & $\mathrm{HY}$ & Water & - & 1937 & OP \\
\hline & 2 & 20 & $2-$ & 2 & $\mathrm{HY}$ & Water & - & 1939 & OP \\
\hline Nelson Dewey (Grant) & 1 & 100.0 & 113.0 & 113.0 & ST & BIT & SUB & 1959 & OP \\
\hline Doublo Find Du T- & 2 & 100.0 & 113.0 & 114.0 & ST & BIT & SUB & 1962 & OP \\
\hline 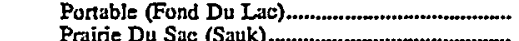 & 4 & .5 & $2 \begin{array}{r}5 \\
200\end{array}$ & 230.5 & IC & $\underset{\text { WO2 }}{\mathrm{Fater}}$ & $\overline{-}$ & 1946 & OP \\
\hline & $\begin{array}{l}1 \\
2\end{array}$ & $\begin{array}{l}2.1 \\
2.8\end{array}$ & $\begin{array}{r}30.0 \\
2-\end{array}$ & $\begin{array}{r}30.0 \\
2-\end{array}$ & $\begin{array}{l}\mathrm{HY} \\
\mathrm{HY}\end{array}$ & $\begin{array}{l}\text { Water } \\
\text { Water }\end{array}$ & $\overline{-}$ & $\begin{array}{l}1914 \\
1915\end{array}$ & $\begin{array}{l}O P \\
O P\end{array}$ \\
\hline & 3 & 4.8 & $2-$ & $2-$ & $\mathrm{HY}$ & Water & - & 1920 & OP \\
\hline & 4 & 4.8 & 2 - & 2- & HY & Water & - & 192 & OP \\
\hline & 5 & 3.5 & 2 & $2-$ & HY & Water & - & 1938 & OP \\
\hline & 6 & 3.5 & $2-$ & $2-$ & $\mathrm{HY}$ & Water & - & 1938 & $\mathrm{OP}$ \\
\hline & 7 & 3.5 & 2- & 2 & HY & Water & _ & 1940 & OP \\
\hline & 8 & 3.5 & $2-$ & $2_{-}$ & HY & Water & - & 1940 & $O P$ \\
\hline Rock River (Rock) & 1 & 75.0 & 82.0 & 82.0 & ST & BIT & - & 1954 & $O P$ \\
\hline & 2 & 75.0 & 82.0 & 83.0 & ST & BIT & - & 1955 & OP \\
\hline & 3 & 27.0 & 26.0 & 36.0 & GT & $\mathrm{FO} 2$ & Nat Gas & 3967 & OP \\
\hline & 4 & 15.0 & 16.0 & 19.8 & GT & $\mathrm{FO2}$ & Nat Gas & 1968 & OP \\
\hline & 5 & 51.0 & 53.0 & 68.0 & $\mathbf{G T}$ & $\mathrm{FO} 2$ & Nat Gas & 1972 & OP \\
\hline & 6 & 51.0 & 53.0 & 68.0 & $\mathbf{G T}$ & $\mathrm{FO} 2$ & Nat Gas & 1972 & $O P$ \\
\hline Shawano (Shawano) & 1 & .8 & .4 & .4 & HY & Water & - & 1928 & OP \\
\hline 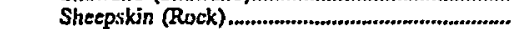 & I & 40.0 & 37.0 & 44.0 & GT & $\mathrm{FO2}$ & Nat Gas & 1971 & OP \\
\hline 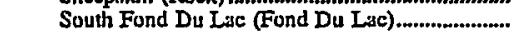 & CTI & 86.0 & 84.0 & 96.0 & GI & Nat Gas & PET & 1993 & OP \\
\hline & CT2 & 86.0 & 85.0 & 95.0 & & Nat Gas & PET & 1994 & OP \\
\hline & CT3 & 86.0 & 84.0 & 96.0 & GT & Nat Gas & PET & 1994 & OP \\
\hline & CT4 & 86.0 & 87.0 & $\mathrm{~J} 00.0$ & GT & Nat Gas & PET & 1996 & OP \\
\hline Wisconsin Public Service Corp & & $1,669.2$ & $1,671.0$ & $1,754.2$ & & & & & \\
\hline 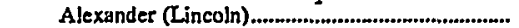 & 1 & 1.4 & .7 & .9 & HY & Water & - & 1925 & OP \\
\hline & 2 & 1.4 & .7 & 9 & HY & Water & - & 1925 & OP \\
\hline & 3 & 1.4 & .7 & .9 & HY & Water & - & 1925 & OP \\
\hline 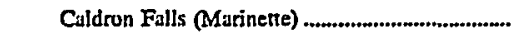 & 1 & 3.2 & 3.4 & 3.5 & HY & Water & - & 1924 & OP \\
\hline & 2 & 3.2 & 3.4 & 3.5 & HY & Water & - & 1924 & OP \\
\hline Eagle River (Vilas) & I & 2.0 & 20 & 2.0 & IC & FO2 & - & 1964 & OP \\
\hline & 2 & 2.0 & 2.0 & 2.0 & IC & $\mathrm{FO} 2$ & - & 1964 & OP \\
\hline 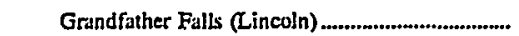 & 1 & 11.0 & 11.2 & 11.2 & HY & Water & - & 1938 & OP \\
\hline & 2 & 6.2 & 6.3 & 6.4 & $\mathbf{H Y}$ & Water & - & 1938 & $O P$ \\
\hline
\end{tabular}

See footnotes at end of table. 
Table 20. Existing Generating Units at U.S. Electric Utilities by State, Company, and Plant, as of January 1, 1998 (Continued)

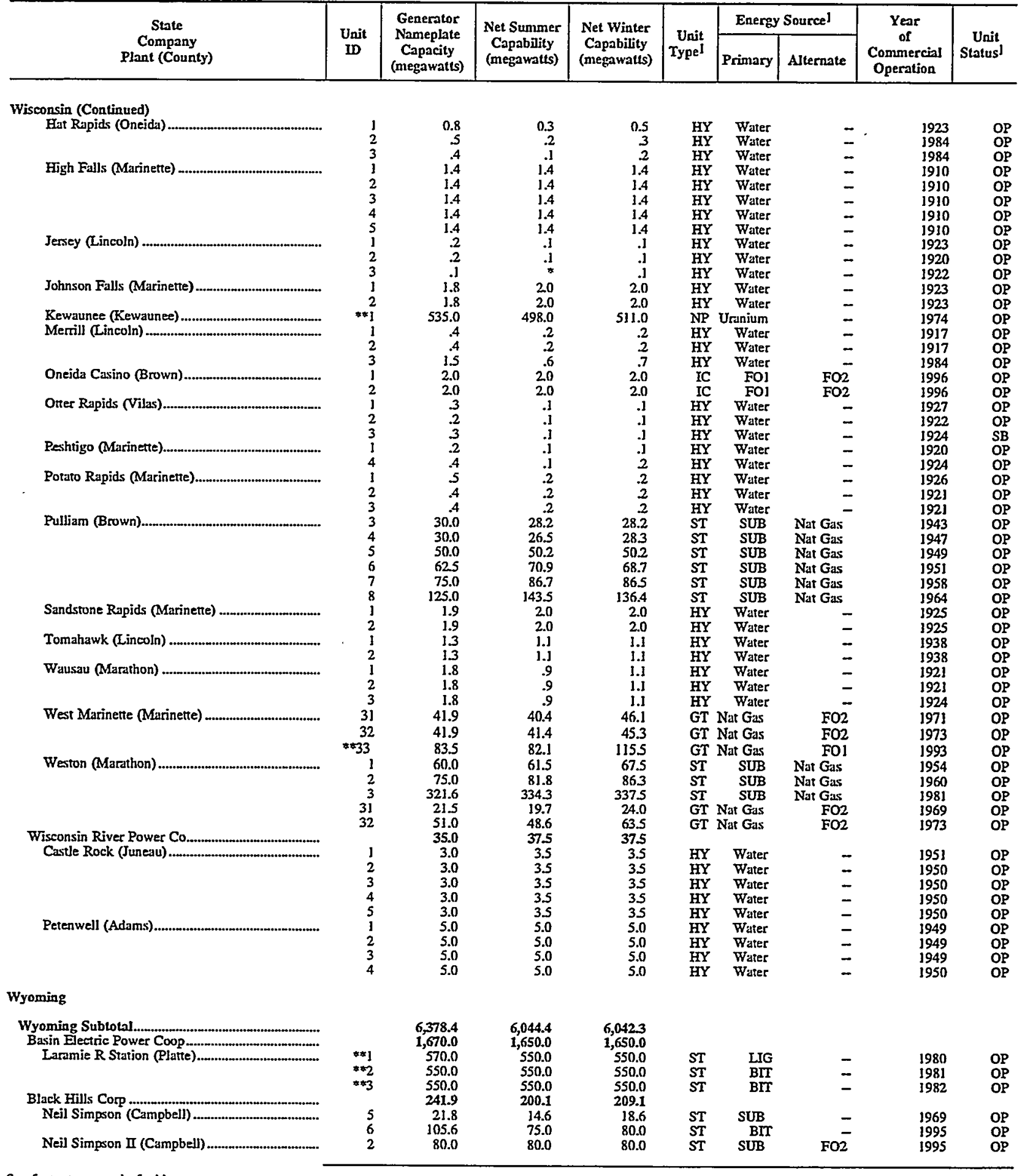

See footnotes at end of table. 
Table 20. Existing Generating Units at U.S. Electric Utilities by State, Company, and Plant, as of January 1, 1998 (Continued)

\begin{tabular}{|c|c|c|c|c|c|c|c|c|c|}
\hline \multirow{2}{*}{$\begin{array}{c}\text { State } \\
\text { Company } \\
\text { PJant (Counly) }\end{array}$} & \multirow{2}{*}{$\begin{array}{c}\text { Unit } \\
\text { ID }\end{array}$} & \multirow{2}{*}{$\begin{array}{c}\text { Generator } \\
\text { Nameplate } \\
\text { Capacity } \\
\text { (megawatts) }\end{array}$} & \multirow{2}{*}{$\begin{array}{l}\text { Net Summer } \\
\text { Capability } \\
\text { (megawatts) }\end{array}$} & \multirow{2}{*}{$\begin{array}{l}\text { Net Winter } \\
\text { Capability } \\
\text { (megawatls) }\end{array}$} & \multirow{2}{*}{$\begin{array}{l}\text { Unit } \\
\text { TypeI }\end{array}$} & \multicolumn{2}{|c|}{ Energy Sourcel } & \multirow{2}{*}{$\begin{array}{c}\text { Year } \\
\text { of } \\
\text { Commercin] } \\
\text { Operation }\end{array}$} & \multirow{2}{*}{$\begin{array}{c}\text { Unit } \\
\text { Status! }\end{array}$} \\
\hline & & & & & & Primary & Alternate & & \\
\hline \multicolumn{10}{|l|}{ Wyoming (Continued) } \\
\hline \multirow[t]{3}{*}{ 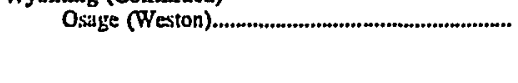 } & J & 11.5 & 10.2 & 10.2 & ST & SUB & - & 1948 & OP \\
\hline & 2 & 11.5 & 10.2 & 10.2 & ST & SUB & - & 1949 & OP \\
\hline & 3 & 11.5 & 10.2 & 10.2 & ST & SUB & - & 1952 & OP \\
\hline Bureau of Reclamarion............... & & 2913 & 295.1 & 284.0 & & & & & \\
\hline \multirow{2}{*}{ Alcova (Natrona) } & 1 & 18.0 & 18.0 & 18.0 & HY & Water & - & 1955 & OP \\
\hline & 2 & 18.0 & 18.0 & 18.0 & HY & Water & - & 1955 & OP \\
\hline \multirow[t]{2}{*}{ Boysen (Fremont) } & 1 & 7.5 & 8.6 & 8.6 & HY & Water & - & 1952 & OP \\
\hline & 2 & 7.5 & 8.6 & 8.6 & HY & Water & - & 1952 & OP \\
\hline \multirow[t]{3}{*}{ 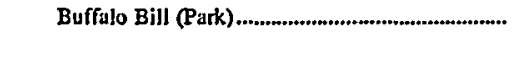 } & 1 & 6.0 & 6.0 & 6.0 & HY & Water & - & 1992 & OP \\
\hline & 2 & 6.0 & 6.0 & 6.0 & HY & Water & - & 1992 & OP \\
\hline & 3 & 6.0 & 6.0 & 6.0 & $\mathrm{HY}$ & Water & - & 1992 & OP \\
\hline Fontenelle (Lincoln)............................................. & 1 & 10.0 & 11.3 & 11.3 & HY & Water & - & 1968 & OP \\
\hline \multirow{2}{*}{ 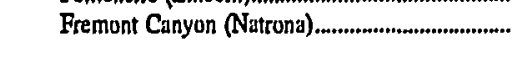 } & $j$ & 33.4 & 33.4 & 33.4 & $\mathrm{HY}$ & Water & - & 1960 & $\mathrm{OP}$ \\
\hline & 2 & 33.4 & 33.4 & 33.4 & HY & Water & - & 1960 & OP \\
\hline 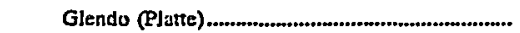 & 1 & 19.0 & $E 19.0$ & E 19.5 & HY & Water & - & 1958 & OP \\
\hline & 2 & 19.0 & E 19.0 & $E_{19.5}$ & HY & Water & - & 1959 & OP \\
\hline 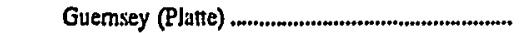 & I & 3.2 & 3.2 & 0.0 & HY & Water & - & 1927 & OP \\
\hline & 2 & 3.2 & 3.2 & 0.0 & HY & Water & - & 1928 & OP \\
\hline Heart Mountain (Park) & 1 & 5.0 & 4.5 & 0.0 & HY & Water & - & 1948 & OP \\
\hline Kortes (Catbon) & $\mathrm{i}$ & 12.0 & 12.2 & 12.2 & HY & Water & - & 1951 & OP \\
\hline & 2 & 120 & 12.2 & 12.2 & HY & Water & _- & 1950 & OP \\
\hline & 3 & 120 & 12.2 & 12.2 & HY & Water & - & 3950 & $\mathbf{O P}$ \\
\hline Pilor Bunte (Fremont) & j & .8 & .6 & 0.0 & HY & Water & _ & 1925 & OP \\
\hline & 2 & .8 & .6 & 0.0 & $\mathrm{HY}$ & Water & - & 1929 & OP \\
\hline 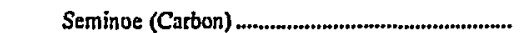 & 1 & 17.0 & 17.2 & 17.2 & $\mathrm{HY}$ & Water & - & 1939 & OP \\
\hline & 2 & 17.0 & 17.2 & 17.2 & HY & Water & - & 1939 & OP \\
\hline & 3 & 17.0 & 17.2 & 172 & $\mathrm{HY}$ & Water & - & 1939 & OP \\
\hline Shoshone (Park) & I & 3.0 & 3.0 & 3.0 & HY & Water & - & 1922 & OP \\
\hline Spinit Mountain (Park) & j & 4.5 & 4.5 & 4.5 & HY & Water & - & 1994 & OP \\
\hline Cheyenne Light Fuel \& Power Co......... & & 10.0 & 10.0 & 10.0 & & & & & \\
\hline Cheyenne Diesel (Luramie) & 1 & 2.0 & 2.0 & 2.0 & IC & FO2 & - & 1963 & SB \\
\hline & 2 & 20 & 2.0 & 2.0 & IC & FO2 & - & 3963 & SB \\
\hline & 3 & 20 & 2.0 & 2.0 & IC & FO2 & _- & 1963 & SB \\
\hline & 4 & 2.0 & 2.0 & 2.0 & IC & $\mathrm{FO} 2$ & - & 1963 & SB \\
\hline & 5 & 2.0 & 2.0 & 2.0 & IC & $\mathrm{FO} 2$ & - & 1963 & SB \\
\hline Lower Valley Power \& Light Inc ............................. & & 1.5 & 1.5 & 1.5 & & & & & \\
\hline 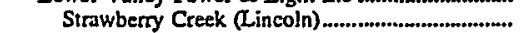 & 1 & 5 & 5 & 5 & $\mathrm{HIL}$ & Water & - & 1951 & OP \\
\hline & 2 & 5 & 5 & 5 & $\mathrm{HL}$ & Water & - & 1951 & OP \\
\hline & 3 & .5 & 5 & 5 & $\mathrm{HL}$ & Water & $\ldots$ & 1951 & OP \\
\hline PacifiCorp, & & $4,163.8$ & $3,887.7$ & $3,887.7$ & & & & & \\
\hline 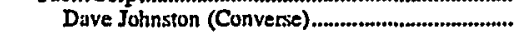 & 1 & 113.6 & 106.0 & 106.0 & ST & SUB & - & 1959 & OP \\
\hline & 2 & 113.6 & 106.0 & 106.0 & ST & SUB & - & 1961 & OP \\
\hline & 3 & 229.5 & 230.0 & 230.0 & ST & SUB & - & 1964 & OP \\
\hline & 4 & 360.0 & 330.0 & 330.0 & ST & SUB & - & 1972 & OP \\
\hline Jim Bridger (Sweetwater) & $\$ 1$ & 560.6 & 520.0 & 520.0 & ST & SUB & - & 1974 & OP \\
\hline & $* 2$ & 577.9 & 520.0 & 520.0 & ST & SUB & - & 1975 & OP \\
\hline & $* \$ 3$ & 577.9 & 520.0 & 520.0 & ST & SUB & - & 1976 & OP \\
\hline & $* 4$ & 560.6 & 520.0 & 520.0 & ST & SUB & _- & 1979 & OP \\
\hline 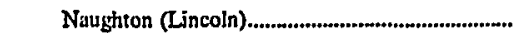 & i & 163.2 & 160.0 & 160.0 & ST & BIT & Nat Gas & 1963 & OP \\
\hline & 2 & 217.6 & 210.0 & 210.0 & ST & BIT & Nat Gas & 1968 & OP \\
\hline & 3 & 326.4 & 330.0 & 330.0 & ST & BIT & Nat Gas & 1971 & OP \\
\hline 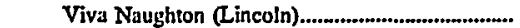 & 1 & .6 & .6 & .6 & HY & Water & - & 1986 & OP \\
\hline & 2 & .2 & 2 & 2 & $\mathrm{HY}$ & Water & - & 1986 & OP \\
\hline 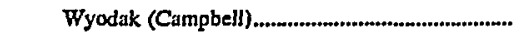 & $*=1$ & 362.1 & 335.0 & 335.0 & ST & SUB & - & 1978 & OP \\
\hline US. Total & & $754,924.7$ & $711,889.4$ & $725,903.8$ & & & & & \\
\hline
\end{tabular}

1 See Appendix B for codes.

2 Individual net summer and winter capabilities for these generatos are not available. Within a plant, reported value is the aggregated capability of all these generutors.

3 through 17: Individual net summer and winter capabilities for these generators are not available. An aggregate net summer capability and an aggregate net winter capability have been reported for generators in several plants or for specific generators within a plant. Generators in this category are denoted by matching footnote numbers to show what generators are aggregated.

** A jointly owned unit. See Appendix $C$ for the list of owners.

- Iess than 0.05 megawatts.

18 A reciprocating engine (with spark plugs) that uses landfill gas to generate electricity.

19 An expander tutbine unit using hot nitrogen.

E Estimated.

Note: 0.0 capability means no capability during the designated time period

Source: Energy Information Administration, Form EIA-860, "Annual Electric Generator Report." 
Table 21. Existing Generating Units Powered by Renewable Energy Sources at U.S. Electric Utilities by State, Company, and Plant, as of January 1, 1998

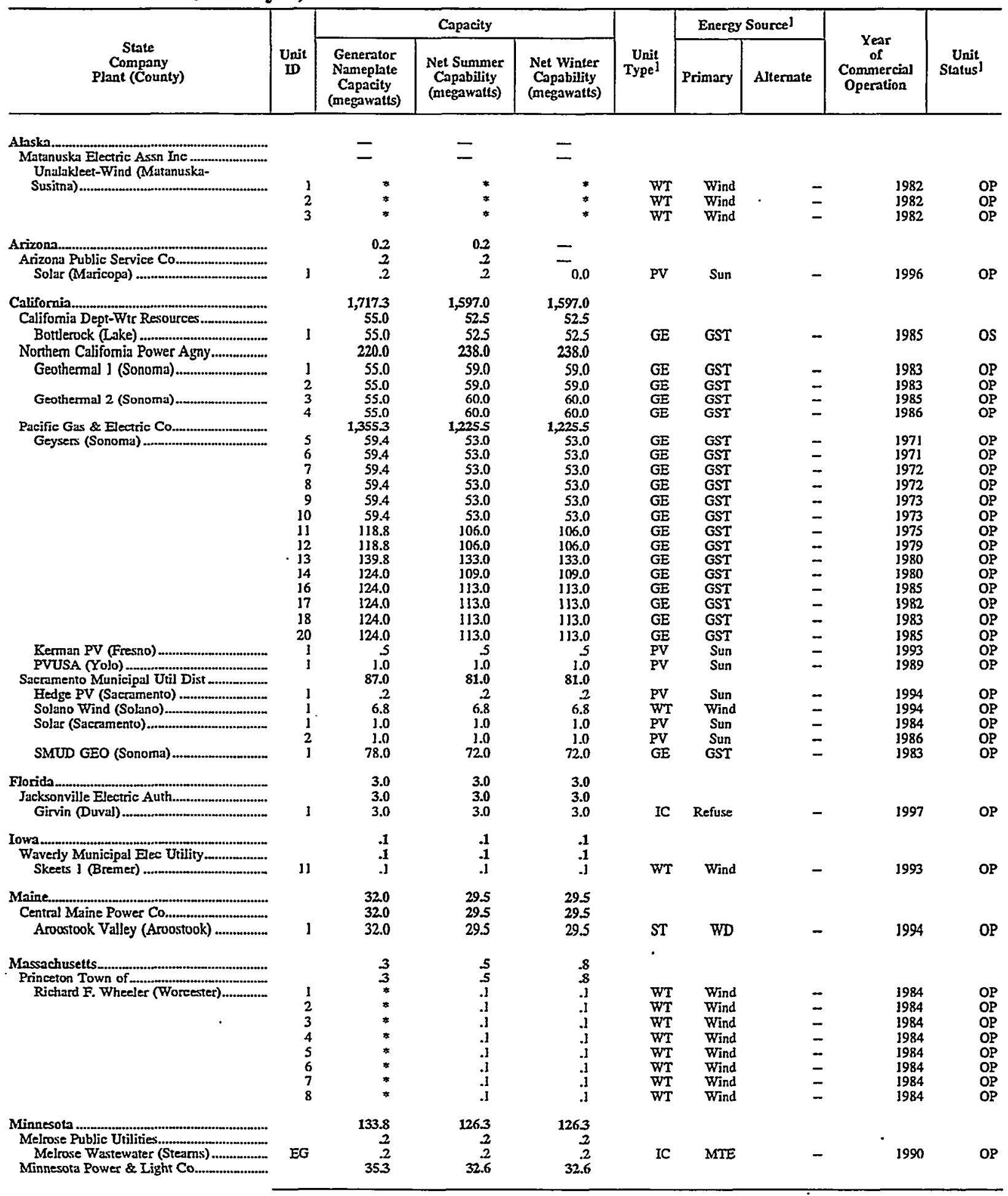

See footnotes at end of tible. 
Table 21. Existing Generating Units Powered by Renewable Energy Sources at U.S. Electric Utilities by State, Company, and Plant, as of January 1, 1998 (Continued)

\begin{tabular}{|c|c|c|c|c|c|c|c|c|c|}
\hline \multirow[b]{2}{*}{$\begin{array}{c}\text { Slate } \\
\text { Company } \\
\text { Plant (County) }\end{array}$} & \multirow[b]{2}{*}{ Unit } & \multicolumn{3}{|c|}{ Capacity } & \multirow[b]{2}{*}{$\begin{array}{r}\text { Unit } \\
\text { Type }\end{array}$} & \multicolumn{2}{|c|}{ Energy Source! } & \multirow[b]{2}{*}{$\begin{array}{c}\text { Year } \\
\text { of } \\
\text { Commercial } \\
\text { Operation }\end{array}$} & \multirow[b]{2}{*}{$\begin{array}{l}\text { Unit } \\
\text { Status }\end{array}$} \\
\hline & & $\begin{array}{c}\text { Generator } \\
\text { Nameplate } \\
\text { Capacity } \\
\text { (megawatts) }\end{array}$ & $\begin{array}{l}\text { Net Summer } \\
\text { Capability } \\
\text { (megawatts) }\end{array}$ & $\begin{array}{c}\text { Net Winter } \\
\text { Capability } \\
\text { (megawatts) }\end{array}$ & & Primary & Allernate & & \\
\hline 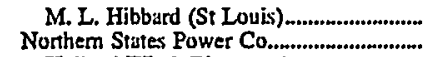 & 3 & $\begin{array}{l}35.3 \\
482\end{array}$ & $\begin{array}{l}32.6 \\
44.0\end{array}$ & $\begin{array}{l}32.6 \\
44.0\end{array}$ & ST & WD & BIT & 1949 & OP \\
\hline Holland Wind (Pipestone)........................... & $\begin{array}{l}1 \\
2 \\
3\end{array}$ & .1 & $\begin{array}{l}2= \\
2= \\
2=\end{array}$ & $\begin{array}{l}2.0 \\
2= \\
2-\end{array}$ & $\begin{array}{l}\text { WT } \\
\text { WT } \\
\text { WT }\end{array}$ & $\begin{array}{l}\text { Wind } \\
\text { Wind } \\
\text { Wind }\end{array}$ & $\bar{z}$ & $\begin{array}{l}1986 \\
1988 \\
1986\end{array}$ & $\begin{array}{l}O P \\
O P \\
O P\end{array}$ \\
\hline 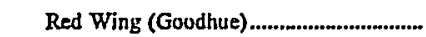 & i & 13.5 & 11.0 & 11.0 & $\mathrm{sT}$ & Refuse & - & 1949 & OP \\
\hline & 2 & 11.5 & 11.0 & 11.0 & ST & Refuse & - & 1949 & OP \\
\hline 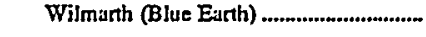 & 1 & 12.5 & 11.0 & 11.0 & ST & Refuse & - & 1948 & op \\
\hline Orter Tail Power Co....................................... & 2 & $\begin{array}{l}12.5 \\
11.3\end{array}$ & $\begin{array}{l}11.0 \\
10.8\end{array}$ & $\begin{array}{l}11.0 \\
10.8\end{array}$ & ST & Refuse & - & 1951 & OP \\
\hline 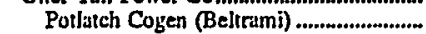 & $* \$ 1$ & 11.3 & 30.8 & 10.8 & ST & WD & - & 1992 & OP \\
\hline 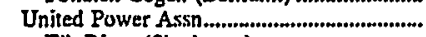 & & 38.8 & 38.8 & $\mathbf{3 8 . 8}$ & 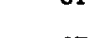 & & & & \\
\hline 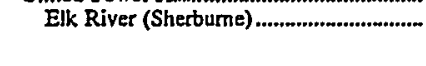 & $\begin{array}{l}1 \\
2\end{array}$ & $\begin{array}{l}9.8 \\
9.8\end{array}$ & $\begin{array}{r}9.8 \\
9.8\end{array}$ & $\begin{array}{r}9.8 \\
9.8\end{array}$ & ST & $\begin{array}{l}\text { Refuse } \\
\text { Refuse }\end{array}$ & $\begin{array}{l}\text { Nat Gas } \\
\text { Nat Gas }\end{array}$ & $\begin{array}{l}1951 \\
1951\end{array}$ & $\begin{array}{ll}\text { OP } \\
\text { OP }\end{array}$ \\
\hline & 3 & 19.2 & 19.2 & 19.2 & ST & Refuse & Nat Gas & 1959 & OP \\
\hline Columbus City of & & $\begin{array}{l}90.0 \\
90.0\end{array}$ & $\begin{array}{l}90.0 \\
90.0\end{array}$ & $\begin{array}{l}90.0 \\
90.0\end{array}$ & & & & & \\
\hline 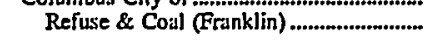 & I & 30.0 & 30.0 & 30.0 & ST & Refuse & - & 1983 & os \\
\hline & 2 & 30.0 & 30.0 & 30.0 & $\stackrel{S T}{S T}$ & Refuse & - & 1983 & OS \\
\hline & & & 30.0 & 30.0 & & Retuse & - & 1980 & 0. \\
\hline Oregon. & & 56.9 & 39.9 & 39.9 & & & & & \\
\hline Emerald Peoples Utility Dist ......................... & & 3.2 & 3.2 & 3.2 & & & & & \\
\hline 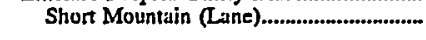 & 1 & .8 & .8 & .8 & IC & MTE & - & 1992 & OP \\
\hline & 2 & .8 & .8 & .8 & IC & MTE & $\overline{-}$ & 1992 & $\operatorname{Oop}^{0}$ \\
\hline & $\begin{array}{l}3 \\
4\end{array}$ & $\begin{array}{l}.8 \\
.8\end{array}$ & $\begin{array}{l}.8 \\
.8\end{array}$ & $\begin{array}{l}.8 \\
.8\end{array}$ & $\begin{array}{l}\text { IC } \\
\text { IC }\end{array}$ & $\begin{array}{l}\text { MTE } \\
\text { MTE }\end{array}$ & $\bar{z}$ & $\begin{array}{l}1993 \\
1993\end{array}$ & OP \\
\hline Eugene City of....................... & & 51.5 & 34.5 & 34.5 & & & & & \\
\hline 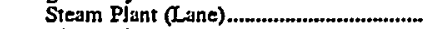 & 3 & 11.5 & 11.5 & 11.5 & ST & WD & - & 1950 & OP \\
\hline Weyco Energy CTR (Lane)............................. & 4 & 40.0 & 23.0 & 23.0 & ST & Refuse & - & 1976 & OP \\
\hline 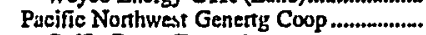 & & 22 & 22 & 22 & & & & & \\
\hline 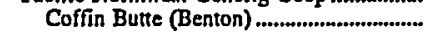 & 1 & 2.2 & $\overline{2.2}$ & $\overline{2.2}$ & OT & Refuse & - & 1995 & OP \\
\hline Texas & & 13 & 13 & 1.3 & & & & & \\
\hline $\begin{array}{l}\text { Austin City of } \\
\text { Decker Creck (Travis). }\end{array}$ & PV3 & $\begin{array}{l}3 \\
3\end{array}$ & $\frac{3}{3}$ & $\frac{3}{3}$ & PV & Sun & - & 1987 & OP \\
\hline West Texas Utilities Co & S v & 1.0 & $1 . \overrightarrow{0}$ & 1.0 & $5 v$ & Sun & - & 1908 & or \\
\hline 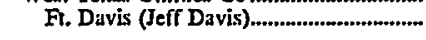 & 1 & 1.0 & 1.0 & 1.0 & PV & Sun & - & 1993 & OP \\
\hline Ulah & & 39.6 & 35.0 & 35.0 & & & & . & \\
\hline PacifílCorp & & 26.1 & 23.0 & 23.0 & & & & & \\
\hline 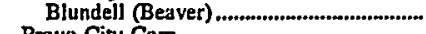 & 1 & 26.1 & 23.0 & 23.0 & GE & GST & - & 1984 & OP \\
\hline 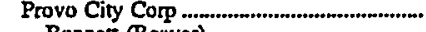 & & 13.5 & 12.0 & 12.0 & & & & & \\
\hline Bonnert (Beaver) .............................................. & CTI & 8.5 & 7.0 & 7.0 & GE & GST & - & 1989 & OP \\
\hline & OECI & .8 & .8 & .8 & GE & GST & - & 1985 & $O P$ \\
\hline & OEC2 & .8 & .8 & .8 & $\mathrm{GE}$ & GST & - & 1985 & OP \\
\hline & OEC 3 & .8 & .8 & .8 & GE & GST & - & 1985 & $O P$ \\
\hline & OEC4 & .8 & .8 & .8 & GE & GST & - & 1985 & $O P$ \\
\hline & TTi & 2.0 & 2.0 & 2.0 & $\mathrm{GE}$ & GST & - & 1988 & OP \\
\hline Vermont .......................................................... & & 56.3 & 56.3 & 563 & & & & & \\
\hline Butlington City of & & 50.0 & 50.0 & 50.0 & & & & & \\
\hline 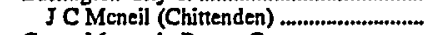 & $*$ * I & 50.0 & 50.0 & 50.0 & ST & WD & Nat Gas & 1984 & OP \\
\hline Green Mountain Power Corp............................ & & 6.3 & 63 & 63 & & & & & \\
\hline Carthusians (Bennington) & 1 & .1 & .1 & .1 & WT & Wind & - & 1989 & OP \\
\hline & 2 & & .1 & .1 & wT & Wind & - & 1989 & OP \\
\hline Seasaburg Wind Tusb (Bennington) & j & 6.1 & 6.1 & 6.1 & WT & Wind & - & 1997 & OP \\
\hline Virginia & & .1 & 1 & 1 & & & & & \\
\hline Virginia Electric \& Power Co ....................... & & .1 & .1 & .1 & & & & & \\
\hline 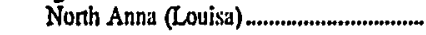 & SPI & * & * & * & PV & Sun & - & 1985 & OP \\
\hline & SP2 & * & * & * & PV & Sun & - & 1985 & OP \\
\hline & SP3 & * & * & * & PV & Sun & - & 1985 & OP \\
\hline Washiagton & & 927 & 83.0 & 73.0 & & & & & \\
\hline PUD No 1 of Snohomish County................. & & 420 & 36.0 & 26.0 & & & & & \\
\hline $\begin{array}{l}\text { Everert Cogen (Snohomish) } \\
\text { washington Water Power Co }\end{array}$ & 1 & $\begin{array}{l}42.0 \\
50.7\end{array}$ & $\begin{array}{l}36.0 \\
47.0\end{array}$ & $\begin{array}{l}26.0 \\
47.0\end{array}$ & ST & WD & - & 1996 & Or \\
\hline Kettle Falls (Stevens) ................................ & 1 & 50.7 & 47.0 & 47.0 & ST & WD & Nat Gas & 1983 & OP \\
\hline
\end{tabular}

See footnotes at end of table. 


\section{Table 21. Existing Generating Units Powered by Renewable Energy Sources} at U.S. Electric Utilities by State, Company, and Plant, as of January 1, 1998 (Continued)

\begin{tabular}{|c|c|c|c|c|c|c|c|c|c|}
\hline \multirow[b]{2}{*}{$\begin{array}{c}\text { State } \\
\text { Company } \\
\text { PLant (County) }\end{array}$} & \multirow[b]{2}{*}{$\begin{array}{l}\text { Unit } \\
\text { ID }\end{array}$} & \multicolumn{3}{|c|}{ Capacity } & \multirow[b]{2}{*}{$\begin{array}{r}\text { Unit } \\
\text { Type! }\end{array}$} & \multicolumn{2}{|c|}{ Energy Sourcel } & \multirow{2}{*}{$\begin{array}{c}\text { Year } \\
\text { of } \\
\text { Commercinl } \\
\text { Operation }\end{array}$} & \multirow[b]{2}{*}{$\begin{array}{c}\text { Unit } \\
\text { Status } 1\end{array}$} \\
\hline & & $\begin{array}{l}\text { Generator } \\
\text { Nameplate } \\
\text { Capacity } \\
\text { (niegawatts) }\end{array}$ & $\begin{array}{l}\text { Net Summer } \\
\text { Capability } \\
\text { (megawatts) }\end{array}$ & $\begin{array}{l}\text { Net Winter } \\
\text { Capability } \\
\text { (megawatts) }\end{array}$ & & Primary & Alternate & & \\
\hline Wisconsin & & 61.3 & 60.5 & 60.5 & & & & & \\
\hline Muscoda City of & & 2.0 & 1.5 & 1.5 & & & & & \\
\hline Muscoda (Richland) & 3 & 2.0 & 1.5 & 1.5 & ST & Refuse & WD & 1989 & os \\
\hline 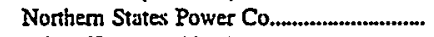 & & 59.3 & 59.0 & 59.0 & & & & & \\
\hline Bay Front (Ashland) & 6 & 28.0 & 30.0 & 30.0 & CH & WD & - & 1957 & OP \\
\hline \multirow[t]{2}{*}{ French Island (La Crosse)......................... } & 1 & 16.0 & 15.0 & 15.0 & ST & Refuse & - & 1940 & OP \\
\hline & 2 & 15.3 & 14.0 & 14.0 & ST & Refuse & - & 1948 & OP \\
\hline US. Total ................... & & $2,284.8$ & $2,122,6$ & $2,112.7$ & & & & & \\
\hline
\end{tabular}

\footnotetext{
1 See Appendix B for codes.

- Less than 0.05 megawatts.

** A jointly owned unit. See Appendix $\mathrm{C}$ for the list of owners.

2 Individual summer and winter capabilities for these generators are not available. Within plant, reported value is the aggregated capability of all these generators.

Notes: This table excludes hydroelectric generating units. The Form EIA-860 was revised during 1995 to collect data as of January 1 of the reporting year, where "reporting year" is the ealendar yeur in which the report is required to be filed with the Energy Information Administration. These data reflect the status of electric power plants/generstors as of January 1: however, dynamic data are based on occurrences in the previous calendar year (e.g., capabilities and energy sources based on test and consumption in the previous year).

Source: Energy Information Administration, Form EIA-860, "Annual Electric Generator Report."
} 
Table 22. Planned Generating Unit Changes at U.S. Electric Utilities by State, Company, and Plant, 1998 Through 2007 as of January 1, 1998

\begin{tabular}{|c|c|c|c|c|c|c|c|}
\hline $\begin{array}{c}\text { State } \\
\text { Company } \\
\text { Plant (County) }\end{array}$ & $\begin{array}{l}\text { Unit } \\
\text { ID }\end{array}$ & $\begin{array}{c}\text { Generator } \\
\text { Nameplate } \\
\text { Capacity } \\
\text { (megawatts) }\end{array}$ & $\begin{array}{c}\text { Net Summer } \\
\text { Capability } \\
\text { (megawatts) }\end{array}$ & $\begin{array}{l}\text { Unit } \\
\text { Typel }\end{array}$ & $\begin{array}{l}\text { Energy } \\
\text { Soureel }\end{array}$ & $\begin{array}{c}\text { Unit } \\
\text { Status! }\end{array}$ & $\begin{array}{c}\text { Year } \\
\text { of } \\
\text { Completion }\end{array}$ \\
\hline \multicolumn{8}{|l|}{ 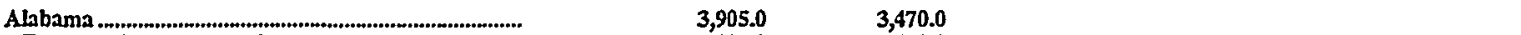 } \\
\hline 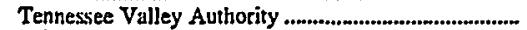 & & $3,905.0$ & $3, \mathbf{4 7 0 . 0}$ & & & & \\
\hline Browns Ferry (Limestone) & $\begin{array}{l}2 \\
3\end{array}$ & $\begin{array}{l}1,152.0 \\
1,152.0\end{array}$ & $\begin{array}{l}1,065.0 \\
1,065.0\end{array}$ & $\begin{array}{l}\text { NB } \\
\text { NB }\end{array}$ & $\begin{array}{l}\text { Uranium } \\
\text { Uranium }\end{array}$ & A & $\begin{array}{l}1999 \\
1998\end{array}$ \\
\hline \multirow[t]{6}{*}{ 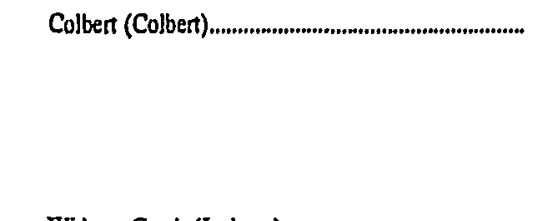 } & GTI & 59.5 & 49.5 & GT & Nat Gas & A & 1998 \\
\hline & GT2 & 59.5 & 49.5 & GT & Nat Gas & A & 1998 \\
\hline & GT3 & 59.5 & 49.5 & GT & Nat Gas & $\ddot{A}$ & 1998 \\
\hline & GT4 & 59.5 & 49.5 & GT & Nat Gas & A & 1998 \\
\hline & GT5 & $\begin{array}{l}59.5 \\
59.5\end{array}$ & $\begin{array}{l}49.5 \\
49.5\end{array}$ & $\underset{\mathbf{G T}}{\mathbf{G T}}$ & $\begin{array}{l}\text { Nat Gas } \\
\text { Nat Gas }\end{array}$ & A & $\begin{array}{l}1998 \\
1998\end{array}$ \\
\hline & GT7 & 59.5 & $\begin{array}{l}49.5 \\
49.5\end{array}$ & GT & Nat Gas & A & 1998 \\
\hline 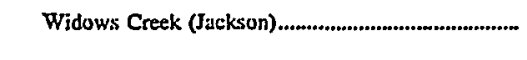 & $\begin{array}{r}318 \\
7 \\
8\end{array}$ & $\begin{array}{r}59.3 \\
575.0 \\
550.0\end{array}$ & $\begin{array}{r}49.5 \\
477.0 \\
467.0\end{array}$ & $\begin{array}{l}\text { ST } \\
\text { ST }\end{array}$ & $\begin{array}{l}\text { Nat Gas } \\
\text { BIT } \\
\text { BIT }\end{array}$ & $\begin{array}{l}\text { A } \\
\text { A } \\
\text { A }\end{array}$ & $\begin{array}{l}1998 \\
1998 \\
2001\end{array}$ \\
\hline \multicolumn{2}{|l|}{ 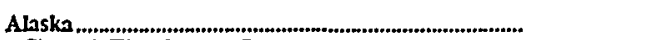 } & 83.0 & 83.0 & & & & \\
\hline \multicolumn{2}{|l|}{ Chugach Electric Assn Inc } & 25.0 & 25.0 & & & & \\
\hline \multirow[t]{2}{*}{ 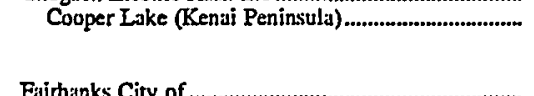 } & $\begin{array}{l}1 \\
1\end{array}$ & 8.3 & $\begin{array}{l}8.3 \\
8.3\end{array}$ & $\begin{array}{l}\text { HY } \\
\text { HY }\end{array}$ & $\begin{array}{l}\text { Water } \\
\text { Water }\end{array}$ & $\begin{array}{l}\text { A } \\
\text { A }\end{array}$ & $\begin{array}{l}1999 \\
1999\end{array}$ \\
\hline \multirow{2}{*}{\multicolumn{2}{|c|}{ Fuibanks City of }} & $\begin{array}{r}8.3 \\
56.9\end{array}$ & $\begin{array}{r}8.3 \\
569\end{array}$ & HY & Water & $A$ & 1999 \\
\hline & & $\begin{array}{r}50.9 \\
5.0\end{array}$ & 5.0 & ST & SUB & $\mathrm{CO}$ & 1998 \\
\hline \multirow{5}{*}{ 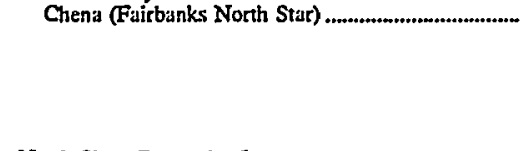 } & 2 & 20 & 20 & ST & SUB & Co & 1998 \\
\hline & 3 & J.5 & 1.5 & ST & SUB & $\mathrm{CO}$ & 1998 \\
\hline & 4 & 5.3 & 5.3 & GT & FO2 & $\mathrm{CO}$ & 1998 \\
\hline & 5 & 20.0 & 20.0 & $\overline{S T}$ & SUB & $\mathrm{CO}$ & 1998 \\
\hline & 6 & 23.1 & 23.1 & GT & $\mathrm{FO} 2$ & $\mathrm{CO}$ & 1998 \\
\hline \multirow{4}{*}{$\begin{array}{l}\text { North Slope Borough of } \\
\text { NSB Nuigsut Util. (North Slope) }\end{array}$} & & .7 & .7 & & & & \\
\hline & PGI & 2 & .2 & IC & FOl & RT & 3999 \\
\hline & PG2 & .2 & 2 & IC & Fol & RT & 1999 \\
\hline & PGS & .2 & .2 & IC & FOI & RT & 1999 \\
\hline \multirow{2}{*}{$\begin{array}{l}\text { Tlingit \& Hajda Region El Auth } \\
\text { Kake (UNKNOWN) }\end{array}$} & & 5 & 5 & & & & \\
\hline & 3 & $s$ & .5 & IC & FO2 & CO & 1998 \\
\hline \multirow{2}{*}{ 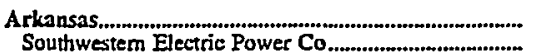 } & & 510.8 & 528.0 & & & & \\
\hline & & 510.8 & 528.0 & & & & \\
\hline Flint Creek (Benton) & $* * 1$ & 510.8 & 528.0 & ST & SUB & $\mathbf{R T}$ & 2007 \\
\hline 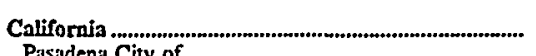 & & 87.8 & 78.7 & & & & \\
\hline \multirow{3}{*}{$\begin{array}{l}\text { Pasadena City of } \\
\text { Glenarm (Los Angeles) }\end{array}$} & & 57.8 & 60.7 & & & & \\
\hline & GT1 & 28.9 & 30.4 & GT & Nat Gas & RP & 2000 \\
\hline & GT2 & 28.9 & 30.4 & GT & Nat Gas & RP & 2000 \\
\hline \multirow{6}{*}{$\begin{array}{l}\text { Vemon City of } \\
\text { Vemon (Los Angeles) }\end{array}$} & & 30.0 & 18.0 & & & & \\
\hline & VER] & 6.0 & 3.6 & IC & FO2 & RT & 3999 \\
\hline & VER2 & 6.0 & 3.6 & IC & FO2 & RT & 2000 \\
\hline & VER3 & 6.0 & 3.6 & IC & FO2 & RT & 2000 \\
\hline & VER4 & 6.0 & 3.6 & IC & FO2 & RT & 2001 \\
\hline & VERS & 6.0 & 3.6 & IC & FO2 & $\mathbf{R T}$ & 2002 \\
\hline \multirow{2}{*}{$\begin{array}{l}\text { Colorado } \\
\text { Plutte River Power Authority }\end{array}$} & & 430.1 & 388.8 & & & & \\
\hline & & 285.1 & 262.0 & & & & \\
\hline \multirow{2}{*}{ Ruwhide (Larimer) } & 1 & 285.1 & 262.0 & ST & SUB & A & 1998 \\
\hline & & 145.0 & 126.8 & & & & \\
\hline Fon St Vrain (Weld) & 1 & 145.0 & 126.8 & GT & Nat Gas & $\mathbf{R P}$ & 1998 \\
\hline Connecticut. & & $3,156.3$ & 2922.4 & & & & \\
\hline Connecticut Light \& Power Co. & & 1663 & 126.9 & & & & \\
\hline Devon (New Haven) & 11 & $\begin{array}{l}4] .6 \\
4] .6\end{array}$ & $\begin{array}{l}32.0 \\
30.9\end{array}$ & $\stackrel{G T}{G T}$ & $\begin{array}{l}\text { Nat Gas } \\
\text { Nat Gas }\end{array}$ & $\begin{array}{l}\text { RT } \\
\text { RT }\end{array}$ & $\begin{array}{l}2001 \\
2001\end{array}$ \\
\hline & 13 & 41.6 & 31.9 & GT & Nat Gas & $\mathrm{RT}$ & 2001 \\
\hline & 14 & 41.6 & 32.1 & GT & Nar Gas & RT & 2001 \\
\hline 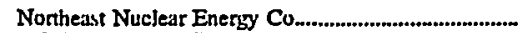 & & $2,824.5$ & $2,631.3$ & & & & \\
\hline 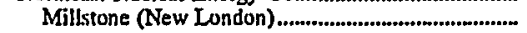 & $* *_{1}$ & 661.5 & 641.0 & NB & Uranium & $\mathbf{R A}$ & 1999 \\
\hline & $* 2$ & 909.9 & 870.6 & NP & Uranium & $\mathbf{R A}$ & 1998 \\
\hline & $* 3$ & $1,253.1$ & $1,119.6$ & NP & Uranium & RA & 1998 \\
\hline 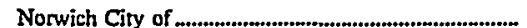 & & 172 & 15.7 & & & & \\
\hline 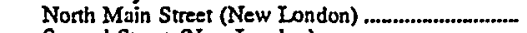 & 5 & 36.8 & 15.3 & GT & $\mathrm{FO2}$ & A & 1998 \\
\hline 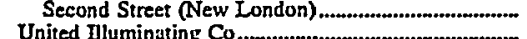 & I & & & HY & Water & $\mathbf{R A}$ & 1998 \\
\hline United Iluminating Co & & 1483 & 148.6 & & & & \\
\hline 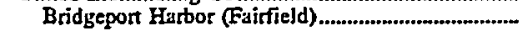 & 1 & 81.5 & 76.0 & ST & FO6 & $\mathbf{M}$ & 1998 \\
\hline
\end{tabular}

See footnotes at end of table. 
Table 22. Planned Generating Unit Changes at U.S. Electric Utilities by State, Company, and Plant, 1998 Through 2007 as of January 1, 1998 (Continued)

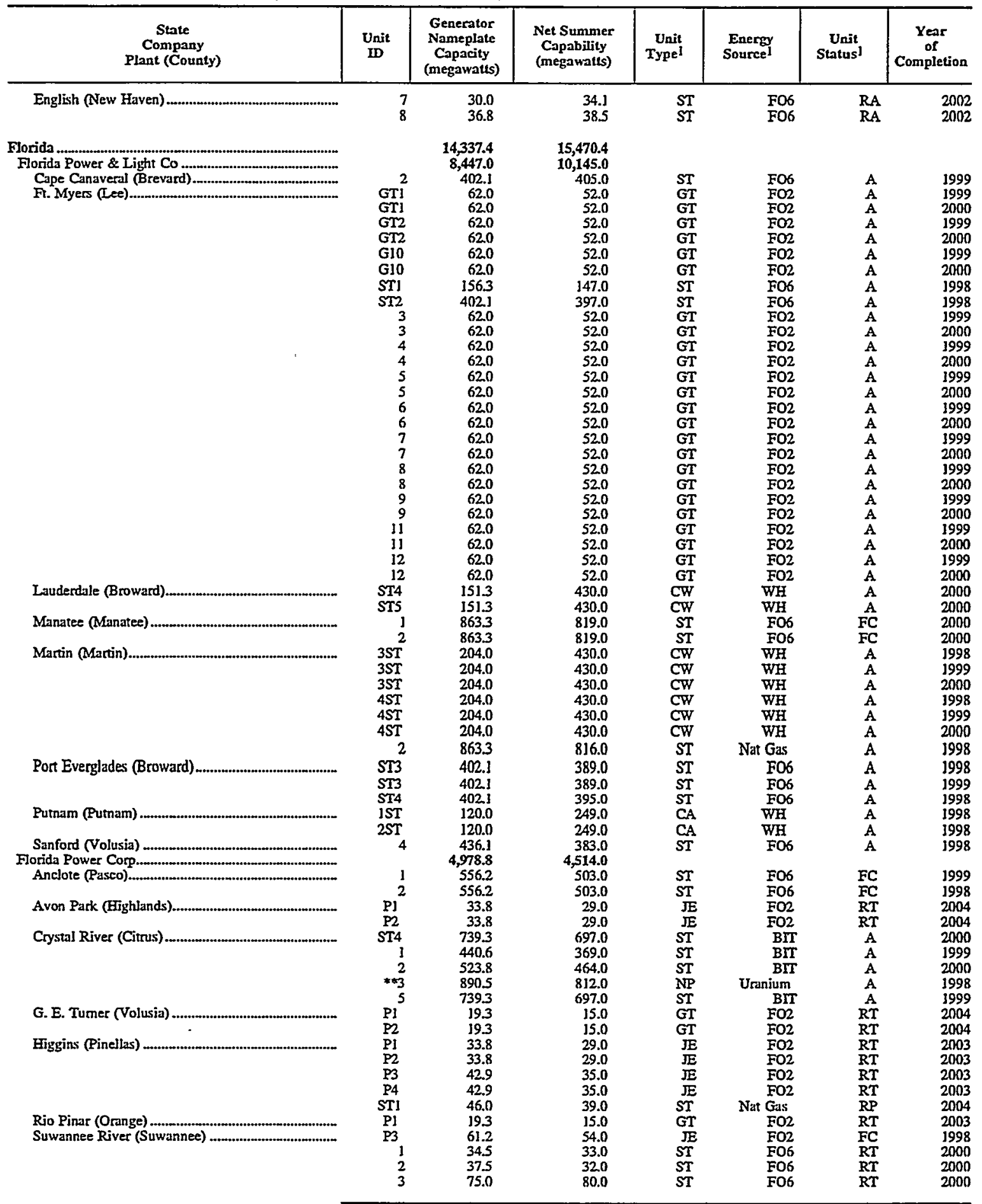

See fooinotes at end of table. 
Table 22. Planned Generating Unit Changes at U.S. Electric Utilities by State, Company, and Plant, 1998 Through 2007 as of January 1, 1998 (Continued)

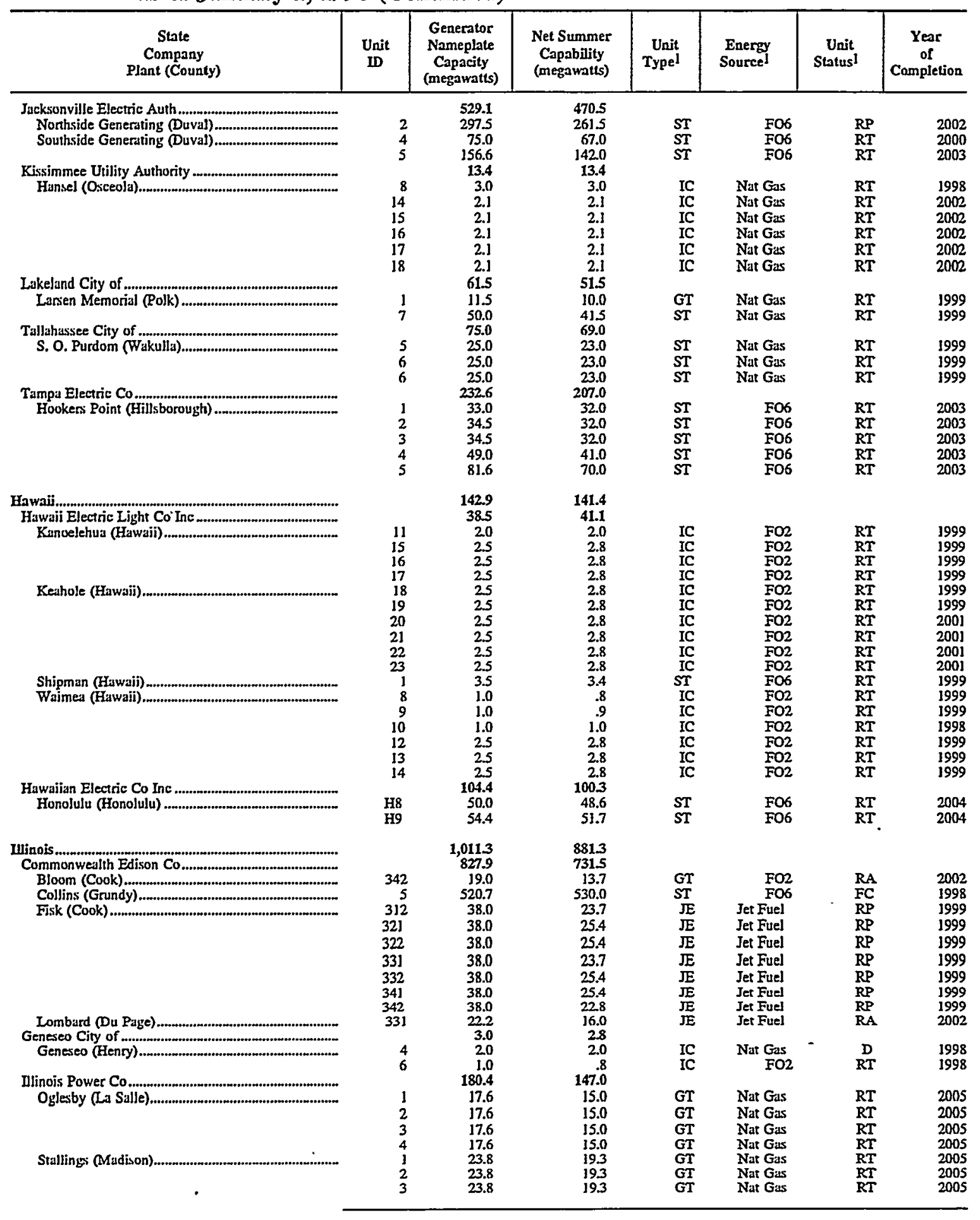

See foutnotes at end of table. 
Table 22. Planned Generating Unit Changes at U.S. Electric Utilities by State, Company, and Plant, 1998 Through 2007 as of January 1, 1998 (Continued)

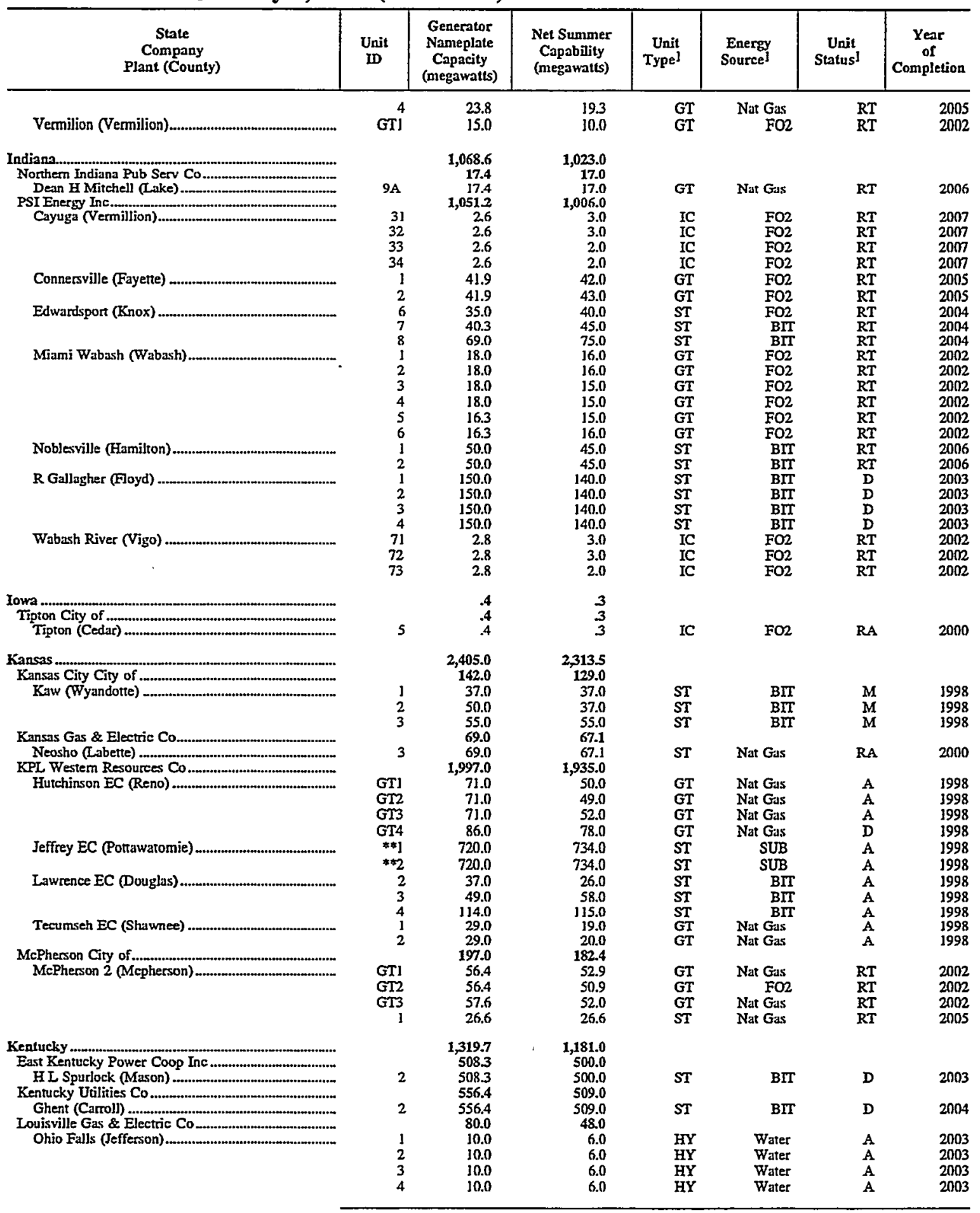

See footnotes at end of tuble. 
Table 22. Planned Generating Unit Changes at U.S. Electric Utilities by State, Company, and Plant, 1998 Through 2007 as of January 1, 1998 (Continued)

\begin{tabular}{|c|c|c|c|c|c|c|c|}
\hline $\begin{array}{c}\text { State } \\
\text { Company } \\
\text { Plant (County) }\end{array}$ & $\begin{array}{l}\text { Unit } \\
\text { ID }\end{array}$ & $\begin{array}{l}\text { Generator } \\
\text { Nameplate } \\
\text { Capacity } \\
\text { (megawatts) }\end{array}$ & $\begin{array}{c}\text { Net Summer } \\
\text { Capability } \\
\text { (megawatts) }\end{array}$ & $\begin{array}{c}\text { Unit } \\
\text { Typel }\end{array}$ & $\begin{array}{l}\text { Energy } \\
\text { Source] }\end{array}$ & $\begin{array}{c}\text { Unit } \\
\text { Statusl }\end{array}$ & $\begin{array}{c}\text { Year } \\
\text { of } \\
\text { Completion }\end{array}$ \\
\hline - & $\begin{array}{l}5 \\
6 \\
7 \\
8\end{array}$ & $\begin{array}{l}10.0 \\
10.0 \\
10.0 \\
10.0\end{array}$ & $\begin{array}{l}6.0 \\
6.0 \\
6.0 \\
6.0\end{array}$ & $\begin{array}{l}\text { HY } \\
\text { HY } \\
\text { HY } \\
\text { HY }\end{array}$ & $\begin{array}{l}\text { Water } \\
\text { Water } \\
\text { Water } \\
\text { Water }\end{array}$ & $\begin{array}{l}A \\
A \\
A \\
A\end{array}$ & $\begin{array}{l}2003 \\
2003 \\
2003 \\
2003\end{array}$ \\
\hline 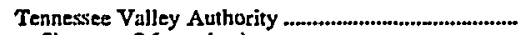 & & 175.0 & 124.0 & & & & \\
\hline 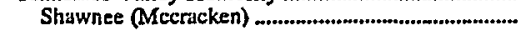 & 10 & 175.0 & 124.0 & ST & BIT & A & 1999 \\
\hline Louisiona & & $1,530.2$ & $1,427.0$ & & & & \\
\hline 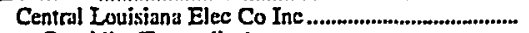 & & 90.3 & 79.0 & & & & \\
\hline Coughlin (Evangeline) & $\begin{array}{l}4 \\
5\end{array}$ & $\begin{array}{r}25.0 \\
65.3\end{array}$ & $\begin{array}{r}24.0 \\
55.0\end{array}$ & $\begin{array}{l}S T \\
S T\end{array}$ & $\begin{array}{l}\text { Nat Gas } \\
\text { Nat Gas }\end{array}$ & $\begin{array}{l}\mathrm{RA} \\
\mathrm{RA}\end{array}$ & $\begin{array}{l}2000 \\
1999\end{array}$ \\
\hline 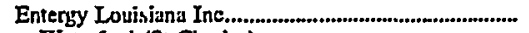 & & $1,199.9$ & $1,075.0$ & & & & \\
\hline 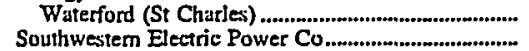 & 3 & $\begin{array}{r}1,199.9 \\
240.0\end{array}$ & $\begin{array}{r}1,075.0 \\
273.0\end{array}$ & NP & Uranium & A & 1999 \\
\hline 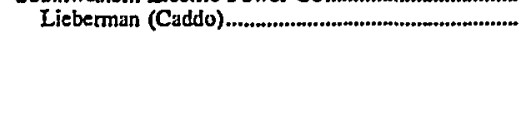 & $\begin{array}{l}1 \\
2 \\
3 \\
4\end{array}$ & $\begin{array}{r}20.0 \\
20.0 \\
100.0 \\
100.0\end{array}$ & $\begin{array}{r}25.0 \\
26.0 \\
112.0 \\
110.0\end{array}$ & $\begin{array}{l}\text { ST } \\
\text { ST } \\
\text { ST } \\
\text { ST }\end{array}$ & $\begin{array}{l}\text { Nat Gas } \\
\text { Nat Gas } \\
\text { Nat Gas } \\
\text { Nat Gas }\end{array}$ & $\begin{array}{l}\text { RT } \\
\text { RT } \\
\text { RT } \\
\text { RT }\end{array}$ & $\begin{array}{l}2005 \\
2007 \\
2004 \\
2004\end{array}$ \\
\hline 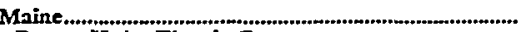 & & 763.6 & 775.1 & & & & \\
\hline Bangor Hydro-Electric Co................. & & 33.0 & 327 & & & & \\
\hline 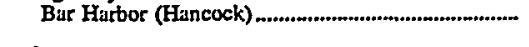 & $\begin{array}{l}1 \\
2\end{array}$ & $\begin{array}{l}2.0 \\
2.0\end{array}$ & $\begin{array}{l}2.0 \\
2.0\end{array}$ & IC & $\begin{array}{l}\mathrm{FO} 2 \\
\mathrm{FO} 2\end{array}$ & $\begin{array}{l}M \\
M\end{array}$ & $\begin{array}{l}2002 \\
2002\end{array}$ \\
\hline 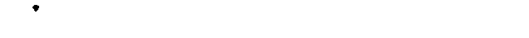 & 3 & 20 & 2.0 & IC & FO2 & $M$ & 2002 \\
\hline & 4 & 20 & 20 & IC & $\mathrm{FO} 2$ & $\mathbf{M}$ & 2002 \\
\hline 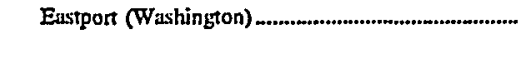 & $\begin{array}{l}1 \\
2 \\
3\end{array}$ & $\begin{array}{l}1.0 \\
1.0 \\
2.0\end{array}$ & $\begin{array}{r}.9 \\
.9 \\
2.0\end{array}$ & $\begin{array}{l}\text { IC } \\
\text { IC } \\
\text { IC }\end{array}$ & $\begin{array}{l}\mathrm{FO} 2 \\
\mathrm{FO} 2 \\
\mathrm{FO} 2\end{array}$ & $\begin{array}{l}\mathrm{M} \\
\mathrm{M} \\
\mathrm{M}\end{array}$ & $\begin{array}{l}2001 \\
2001 \\
2001\end{array}$ \\
\hline Medway (Penobscot) & $\mathrm{ICI}$ & 2.0 & 2.0 & IC & $\mathrm{FO} 2$ & $\mathbf{M}$ & 2002 \\
\hline & IC2 & 2.0 & 2.0 & IC & FO2 & $\mathbf{M}$ & 2002 \\
\hline 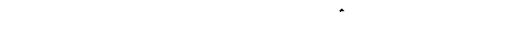 & IC3 & 2.0 & 2.0 & IC & FO2 & $M$ & 2002 \\
\hline & IC4 & 2.0 & 2.0 & IC & FO2 & $\mathbf{M}$ & 2002 \\
\hline West Enfield (Penobscot) ................................................ & $\begin{array}{l}1 \\
2\end{array}$ & $\begin{array}{l}6.5 \\
6.5\end{array}$ & $\begin{array}{l}6.5 \\
6.5\end{array}$ & $\begin{array}{l}\mathrm{HY} \\
\mathrm{HY}\end{array}$ & $\begin{array}{l}\text { Water } \\
\text { Water }\end{array}$ & D & $\begin{array}{l}1998 \\
1998\end{array}$ \\
\hline 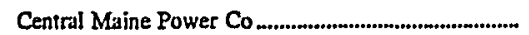 & & 730.6 & 742.4 & & & & \\
\hline Androscog Mill Lower (Androscogyin) ...................... & 1 & 3 & 0.0 & HY & Water & $\mathrm{CO}$ & 1998 \\
\hline Androscoggin 3 (Androscoggin) ................................. & 1 & 3.6 & 4.0 & $\mathrm{HY}$ & Water & co & 1998 \\
\hline 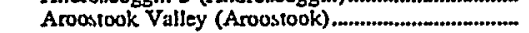 & $i$ & 32.0 & 29.5 & sT & WD & co & 1998 \\
\hline 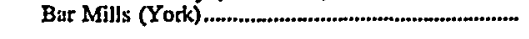 & 1 & 2.0 & 2.0 & HY & Water & CO & 1998 \\
\hline & 2 & 20 & 20 & $\mathrm{HY}$ & Water & $\mathrm{CO}$ & 1998 \\
\hline 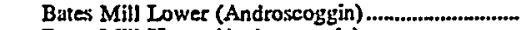 & 1 & 5 & 0.0 & HY & Water & $\mathrm{CO}$ & 1998 \\
\hline Butes Mill Upper (Androscoggin) ............................... & $\frac{1}{2}$ & $\begin{array}{l}1.2 \\
1.5\end{array}$ & 0.0 & HY & $\begin{array}{l}\text { Water } \\
\text { Water }\end{array}$ & $\begin{array}{ll}\mathrm{CO} \\
\mathrm{CO}\end{array}$ & $\begin{array}{l}1998 \\
1998\end{array}$ \\
\hline & 3 & 1.2 & 0.0 & HY & Water & $\mathrm{CO}$ & 1998 \\
\hline 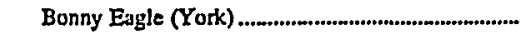 & 1 & 1.2 & 1.7 & HY & Water & co & 1998 \\
\hline & 2 & 1.2 & 1.7 & HY & Water & Co & 1998 \\
\hline & 3 & 1.2 & 1.6 & HY & Water & CO & 1998 \\
\hline & $\begin{array}{l}4 \\
5\end{array}$ & $\begin{array}{l}1.2 \\
1.2\end{array}$ & $\begin{array}{l}1.7 \\
1.8\end{array}$ & $\begin{array}{l}\text { HY } \\
\text { HYY }\end{array}$ & $\begin{array}{l}\text { Water } \\
\text { Water }\end{array}$ & Co & $\begin{array}{l}1998 \\
1998\end{array}$ \\
\hline & 6 & 1.2 & 1.7 & HY & Water & $\mathrm{CO}$ & 1998 \\
\hline Brassua (Somerset) & 1 & 4.0 & 3.7 & HY & Water & co & 1998 \\
\hline 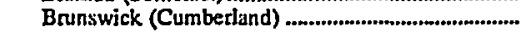 & 1 & 12.6 & 13.3 & HY & Water & Co & 1998 \\
\hline & 2 & 3.5 & 3.5 & HY & Water & CO & 1998 \\
\hline & 3 & 3.5 & 3.5 & HY & Water & $\mathbf{C O}$ & 1998 \\
\hline 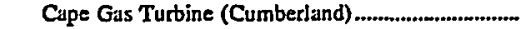 & GT4 & 57.6 & 16.5 & GT & $\mathrm{FO2}$ & $\mathbf{R T}$ & 1999 \\
\hline & GTS & 17.6 & 16.4 & GT & $\mathrm{FO} 2$ & RT & 1999 \\
\hline Cataract (York) & 1 & 6.7 & 8.0 & HY & Water & CO & 1998 \\
\hline 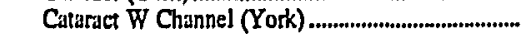 & 1 & .5 & .4 & HY & Water & $\mathrm{CO}$ & 1998 \\
\hline & 2 & 5 & .4 & HY & Water & $\mathrm{CO}$ & 1998 \\
\hline 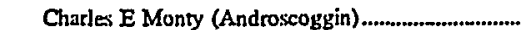 & NAI & 14.2 & 11.4 & $\mathbf{H Y}$ & Water & Co & 1998 \\
\hline & NA2 & 14.2 & 11.4 & $\mathbf{H Y}$ & Water & & 1998 \\
\hline Continental Mills (Androscoggin) & 1 & .4 & .4 & $\mathbf{H Y}$ & Water & co & 1998 \\
\hline & 2 & 4 & .4 & HY & Water & co & 1998 \\
\hline & 3 & .4 & 4 & HY & Water & & 1998 \\
\hline & 5 & 2 & 0.0 & HY & Water & CO & 1998 \\
\hline & 6 & .2 & 0.0 & HY & Water & $\mathrm{CO}$ & 1998 \\
\hline Deer Rjps (Androscogyin) & 1 & .6 & .6 & $\mathbf{H Y}$ & Water & $\mathrm{CO}$ & 1998 \\
\hline & 2 & .6 & .6 & HY & Water & $\mathrm{CO}$ & 1998 \\
\hline & 3 & .9 & .9 & HY & Water & $\mathrm{CO}$ & 1998 \\
\hline & 4 & .8 & .8 & HY & Water & Co & 1998 \\
\hline & 5 & .8 & .8 & HY & Water & Co & 1998 \\
\hline
\end{tabular}

See footnotes at end of table. 
Table 22. Planned Generating Unit Changes at U.S. Electric Utilities by State, Company, and Plant, 1998 Through 2007 as of January 1, 1998 (Continued)

\begin{tabular}{|c|c|c|c|c|c|c|c|}
\hline $\begin{array}{c}\text { State } \\
\text { Company } \\
\text { Plant (County) }\end{array}$ & $\begin{array}{l}\text { Unit } \\
\text { W }\end{array}$ & $\begin{array}{c}\text { Generator } \\
\text { Nameplate } \\
\text { Capncity } \\
\text { (negawatts) }\end{array}$ & $\begin{array}{c}\text { Net Summer } \\
\text { Capability } \\
\text { (negawatts) }\end{array}$ & $\begin{array}{r}\text { Unit } \\
\text { Type }\end{array}$ & $\begin{array}{l}\text { Energy } \\
\text { Sourcel }\end{array}$ & $\begin{array}{c}\text { Unit } \\
\text { Status! }\end{array}$ & $\begin{array}{c}\text { Year } \\
\text { of } \\
\text { Completion }\end{array}$ \\
\hline & $\begin{array}{l}6 \\
7\end{array}$ & $\begin{array}{l}1.8 \\
1.0\end{array}$ & $\begin{array}{l}1.8 \\
1.0\end{array}$ & $\begin{array}{l}\text { HY } \\
\text { HY }\end{array}$ & $\begin{array}{l}\text { Water } \\
\text { Water }\end{array}$ & $\begin{array}{l}\text { CO } \\
\text { CO }\end{array}$ & $\begin{array}{l}1998 \\
1998\end{array}$ \\
\hline \multirow[t]{2}{*}{ 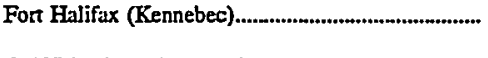 } & A & .8 & .9 & HY & Water & $\mathrm{CO}$ & 1998 \\
\hline & B & .8 & .9 & $\mathbf{H Y}$ & Water & $\mathrm{CO}$ & 1998 \\
\hline \multirow[t]{3}{*}{ Gulf Island (Androscoggin) } & 1 & 6.4 & 8.5 & HY & Water & $\mathrm{CO}$ & 1998 \\
\hline & 2 & 6.4 & 8.7 & HY & Water & $\mathrm{CO}$ & 1998 \\
\hline & 3 & 6.4 & 8.4 & HY & Water & $\mathrm{CO}$ & 1998 \\
\hline \multirow[t]{3}{*}{ Harris (Somerset) } & 1 & 15.0 & 17.0 & HY & Water & $\mathrm{Co}$ & 1998 \\
\hline & 2 & $\begin{array}{l}30.0 \\
30.0\end{array}$ & $\begin{array}{l}35.0 \\
340\end{array}$ & HY & Water & CO & 1998 \\
\hline & 4 & 1.5 & 1.5 & HY & Water & $\mathrm{CO}$ & $\begin{array}{l}1998 \\
1998\end{array}$ \\
\hline \multirow[t]{6}{*}{ Hill Mill (Androscoggin) } & i & .4 & 0.0 & HY & Water & $\mathrm{CO}$ & 1998 \\
\hline & 2 & .4 & 0.0 & HY & Water & $\mathrm{CO}$ & 1998 \\
\hline & 3 & .4 & 0.0 & HY & Water & $\mathrm{CO}$ & 1998 \\
\hline & 4 & .4 & 0.0 & HY & Water & CO & 1998 \\
\hline & 5 & .4 & 0.0 & HY & Water & Co & 1998 \\
\hline & 6 & .4 & 0.0 & HY & Water & Co & 1998 \\
\hline Hiram (Oxford) & 1 & 24 & 3.1 & HY & Water & CO & 1998 \\
\hline & 2 & 8.1 & 8.5 & $\mathbf{H Y}$ & Water & $\mathrm{CO}$ & 1998 \\
\hline \multirow{2}{*}{ Kezar Falls - Lower (Kennebec)................................... } & $\mathbf{l}$ & .6 & 3 & HY & Water & $\mathrm{CO}$ & 1998 \\
\hline & 」 & .6 & 3 & $\mathbf{H Y}$ & Water & A & 1998 \\
\hline \multirow{4}{*}{$\begin{array}{l}\text { Kezar Falls - Upper (Oxford) } \\
\text { Ledgemere (Kennebec) }\end{array}$} & i & .4 & 3 & $\mathbf{H Y}$ & Water & $\mathrm{CO}$ & $j 998$ \\
\hline & 1 & .2 & 0.0 & HY & Water & A & 1998 \\
\hline & 1 & .2 & 0.0 & HY & Water & A & 1998 \\
\hline & J & .2 & 0.0 & HY & Water & $\mathrm{CO}$ & 1998 \\
\hline \multirow[t]{3}{*}{ 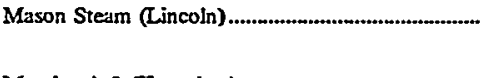 } & 3 & 34.5 & 28.7 & ST & FO6 & co & 1998 \\
\hline & 4 & 34.5 & 29.9 & ST & FO6 & CO & 1998 \\
\hline & 5 & 37.5 & 33.2 & ST & - FO6 & co & 1998 \\
\hline 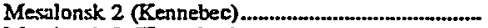 & 1 & 2.8 & 2.8 & HY & Water & Co & 1998 \\
\hline 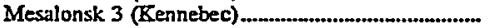 & 1 & 1.6 & 1.7 & HY & Water & $\mathrm{Co}$ & 1998 \\
\hline 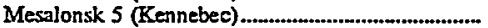 & 1 & 1.5 & 1.5 & $\mathbf{H Y}$ & Water & $\mathrm{Co}$ & 1998 \\
\hline \multirow[t]{6}{*}{ North Gortam (Cumberland) ....................................... } & j & 1.1 & .8 & HY & Water & $\mathbf{A}$ & 1998 \\
\hline & 1 & 1.1 & .8 & HY & Water & $\mathrm{CO}$ & 1998 \\
\hline & 1 & 1.1 & .8 & HY & Water & D & 1998 \\
\hline & 2 & 1.1 & .8 & HY & Water & A & 1998 \\
\hline & $\overline{2}$ & 1.1 & .8 & HY & Water & $\mathrm{CO}$ & 1998 \\
\hline & 2 & 1.1 & .8 & HY & Water & D & 1998 \\
\hline \multirow[t]{8}{*}{ 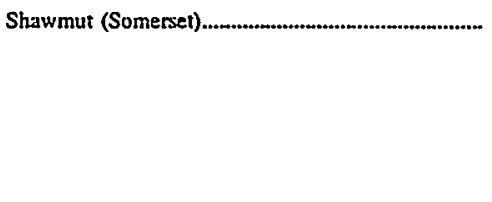 } & 1 & .8 & .9 & HY & Water & $\mathrm{CO}$ & 1998 \\
\hline & 2 & .8 & .9 & HY & Water & Co & 1998 \\
\hline & 3 & .8 & .9 & HY & Water & $\mathrm{CO}$ & 1998 \\
\hline & 4 & .8 & .9 & HY & Water & $\mathrm{Co}$ & 1998 \\
\hline & 5 & .8 & .9 & $\mathbf{H Y}$ & Water & $\mathrm{Co}$ & 1998 \\
\hline & 6 & .9 & .9 & $\hat{\mathbf{H Y}}$ & Water & $\mathrm{CO}$ & 1998 \\
\hline & 7 & 2.0 & 20 & HY & Water & $\mathrm{CO}$ & 1998 \\
\hline & 8 & 20 & 2.0 & $\mathbf{H Y}$ & Water & $\mathrm{CO}$ & 1998 \\
\hline \multirow{2}{*}{ 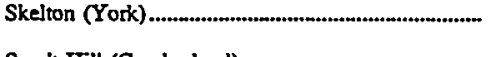 } & I & 8.4 & 10.0 & HY & Water & $\mathrm{CO}$ & 1998 \\
\hline & 2 & 8.4 & 10.0 & HY & Water & co & 1998 \\
\hline 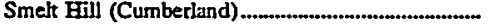 & 1 & 2 & .1 & HY & Water & $\mathrm{CO}$ & 1998 \\
\hline & 2 & .2 & .2 & HY & Water & $\mathrm{Co}$ & 1998 \\
\hline & 3 & II & .1 & HY & Water & Co & 1998 \\
\hline & 4 & 3 & .2 & $\mathrm{HY}$ & Water & $\mathrm{CO}$ & 1998 \\
\hline & 5 & .2 & E .2 & HY & Water & $\mathrm{CO}$ & 1998 \\
\hline & 6 & .2 & .2 & HY & Water & $\mathrm{CC}$ & 1998 \\
\hline West Buxton (York) & I & .7 & .8 & HY & Water & $\mathrm{Co}$ & 1998 \\
\hline & 2 & .7 & .8 & HY & Water & $\mathrm{CO}$ & 1998 \\
\hline & 3 & 1.1 & 1.0 & HY & Water & Co & 1998 \\
\hline & 4 & .8 & .7 & HY & Water & $\mathrm{Co}$ & 1998 \\
\hline & 5 & .8 & .6 & HY & Water & $\mathrm{CO}$ & 1998 \\
\hline & 6 & 4.0 & 3.5 & HY & Water & $\mathrm{C}$ & 1998 \\
\hline Weston (Somerset) & 1 & 3.0 & 3.5 & HY & Water & $\mathrm{CO}$ & 1998 \\
\hline & 2 & 3.0 & 3.2 & HY & Water & $\mathrm{CO}$ & 1998 \\
\hline & 3 & 3.0 & 3.3 & HY & Water & Co & 1998 \\
\hline & 4 & 3.0 & 3.2 & HY & Water & $\mathrm{c}$ & 1998 \\
\hline William F Wyman (Cumberland) & I & 50.0 & 53.5 & ST & FO6 & Co & 1998 \\
\hline & 2 & 50.0 & 53.5 & ST & FO6 & CO & 1998 \\
\hline & 3 & 113.6 & 116.0 & ST & FO6 & $\mathrm{CO}$ & 1998 \\
\hline Williams (Somerset) & 1 & 7.0 & 8.2 & HY & Water & Co & 1998 \\
\hline & 2 & 6.0 & 6.7 & HY & Water & & 1998 \\
\hline 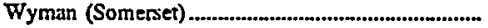 & 1 & 24.0 & 26.7 & HY & Water & Co & 1998 \\
\hline & 2 & 24.0 & 27.7 & $\mathrm{HY}$ & Water & $\mathrm{CO}$ & 1998 \\
\hline & 3 & 24.0 & 25.7 & HY & Water & CO & 1998 \\
\hline
\end{tabular}

See footnotes at end of table. 
Table 22. Planned Generating Unit Changes at U.S. Electric Utilities by State, Company, and Plant, 1998 Through 2007 as of January 1, 1998 (Continued)

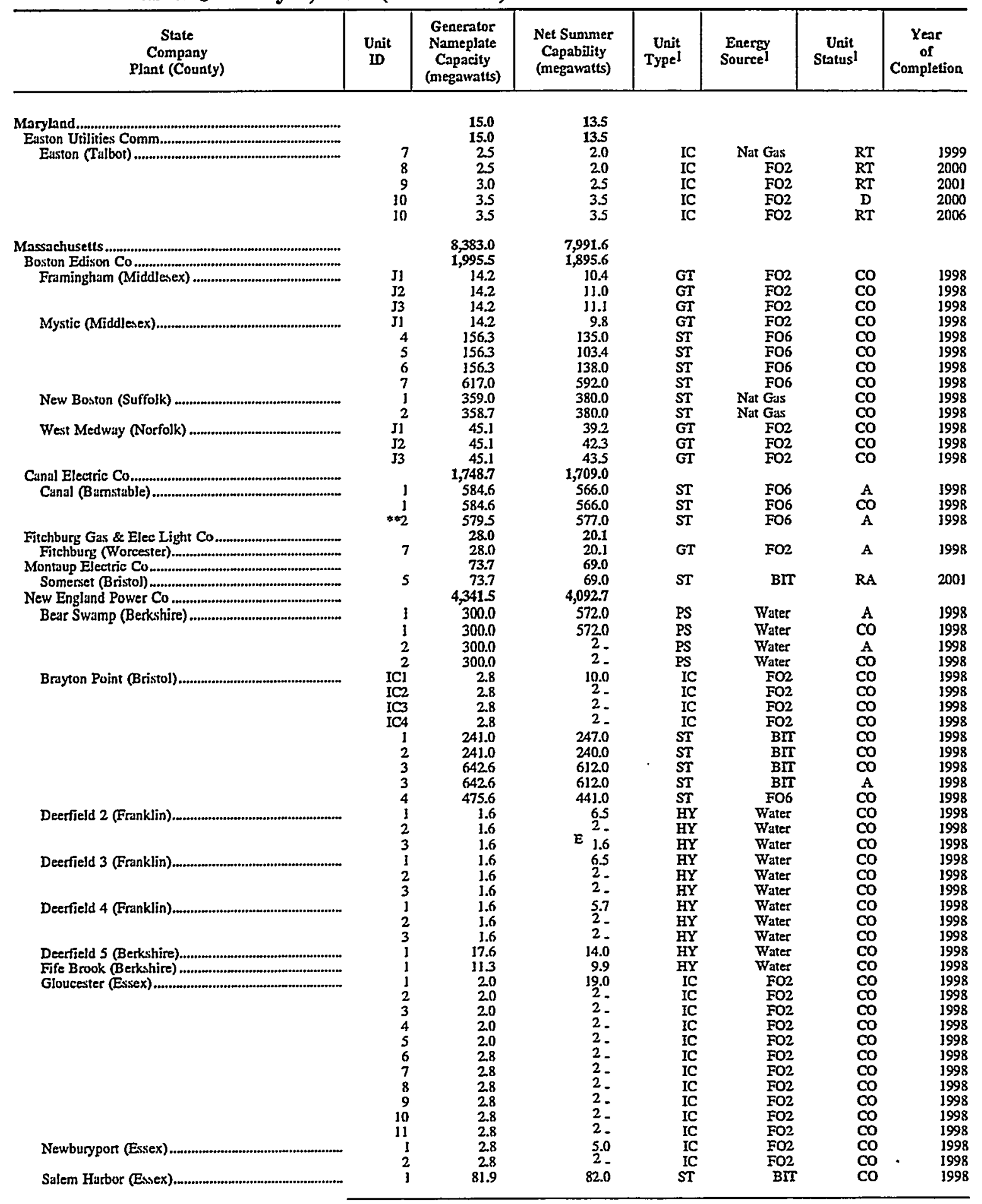

See footnotes at end of table. 
Table 22. Planned Generating Unit Changes at U.S. Electric Utilities by State, Company, and Plant, 1998 Through 2007 as of January 1, 1998 (Continued)

\begin{tabular}{|c|c|c|c|c|c|c|c|}
\hline $\begin{array}{c}\text { State } \\
\text { Company } \\
\text { Plant (County) }\end{array}$ & $\begin{array}{l}\text { Unit } \\
\text { ID }\end{array}$ & $\begin{array}{c}\text { Generator } \\
\text { Nameplate } \\
\text { Capacity } \\
\text { (megawatts) }\end{array}$ & $\begin{array}{l}\text { Net Summer } \\
\text { Capability } \\
\text { (megawatts) }\end{array}$ & $\begin{array}{c}\text { Unit } \\
\text { TypeI }\end{array}$ & $\begin{array}{l}\text { Energy } \\
\text { Source }\end{array}$ & $\begin{array}{c}\text { Unit } \\
\text { Status }\end{array}$ & $\begin{array}{c}\text { Year } \\
\text { of } \\
\text { Completion }\end{array}$ \\
\hline 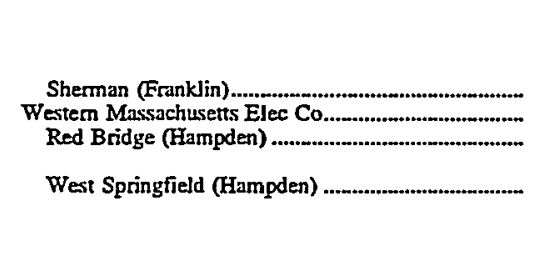 & $\begin{array}{l}3 \\
4 \\
1 \\
1 \\
2 \\
2\end{array}$ & $\begin{array}{r}82.0 \\
165.8 \\
475.6 \\
7.2 \\
195.6 \\
1.8 \\
1.8 \\
46.0 \\
46.0 \\
50.0 \\
50.0\end{array}$ & $\begin{array}{r}80.0 \\
150.0 \\
400.0 \\
6.5 \\
205.2 \\
.2 \\
.2 \\
51.2 \\
51.2 \\
51.2 \\
51.2\end{array}$ & $\begin{array}{l}\text { HY } \\
\text { HY } \\
\text { ST } \\
\text { ST } \\
\text { ST } \\
\text { ST }\end{array}$ & $\begin{array}{r}\text { Water } \\
\text { Water } \\
\text { FO6 } \\
\text { FO6 } \\
\text { FO6 } \\
\text { FO6 }\end{array}$ & $\begin{array}{r}\text { A } \\
\text { A } \\
\text { M } \\
\text { RA } \\
\text { M } \\
\text { RA }\end{array}$ & $\begin{array}{l}1998 \\
1998 \\
1999 \\
1998 \\
1999 \\
1998\end{array}$ \\
\hline 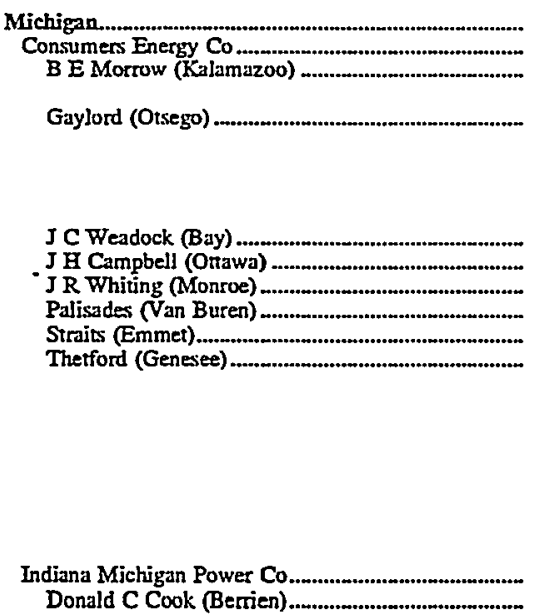 & $\begin{array}{r}A \\
B \\
1 \\
2 \\
3 \\
4 \\
5 \\
A \\
A \\
A \\
\text { J } \\
1 \\
1 \\
2 \\
3 \\
4 \\
5 \\
6 \\
7 \\
8 \\
9\end{array}$ & $\begin{array}{r}2,394.5 \\
1,261.2 \\
17.5 \\
17.5 \\
17.5 \\
17.5 \\
17.5 \\
17.5 \\
20.6 \\
20.6 \\
20.6 \\
20.6 \\
811.7 \\
25.0 \\
37.3 \\
37.3 \\
37.3 \\
37.3 \\
17.6 \\
17.6 \\
17.6 \\
17.6 \\
17.6 \\
1,133.3 \\
1,133.3\end{array}$ & $\begin{array}{r}2,167.0 \\
1,107.0 \\
14.0 \\
14.0 \\
14.0 \\
14.0 \\
14.0 \\
14.0 \\
14.0 \\
13.0 \\
13.0 \\
13.0 \\
762.0 \\
16.0 \\
30.0 \\
29.0 \\
30.0 \\
30.0 \\
15.0 \\
15.0 \\
14.0 \\
15.0 \\
14.0 \\
1,060.0 \\
1,060.0\end{array}$ & $\begin{array}{l}\text { GT } \\
\text { GT } \\
\text { GT } \\
\text { GT } \\
\text { GT } \\
\text { GT } \\
\text { GT } \\
\text { GT } \\
\text { GT } \\
\text { GT } \\
\text { NP } \\
\text { GT } \\
\text { GT } \\
\text { GT } \\
\text { GT } \\
\text { GT } \\
\text { GT } \\
\text { GT } \\
\text { GT } \\
\text { GT } \\
\text { GT }\end{array}$ & $\begin{array}{r}\text { Nat Gas } \\
\text { Nat Gas } \\
\text { Nat Gas } \\
\text { Nat Gas } \\
\text { Nat Gas } \\
\text { Nat Gas } \\
\text { Nat Gas } \\
\text { Nat Gas } \\
\text { FO2 } \\
\text { FO2 } \\
\text { Uranium } \\
\text { Nat Gas } \\
\text { Nat Gas } \\
\text { Nat Gas } \\
\text { Nat Gas } \\
\text { Nat Gas } \\
\text { Nat Gas } \\
\text { Nat Gas } \\
\text { Nat Gas } \\
\text { Nat Gas } \\
\text { Nat Gas } \\
\text { Uranium }\end{array}$ & $\begin{array}{l}\mathrm{RT} \\
\mathrm{RT} \\
\mathrm{RT} \\
\mathrm{RT} \\
\mathrm{RT} \\
\mathrm{RT} \\
\mathrm{RT} \\
\mathrm{RT} \\
\mathrm{RT} \\
\mathrm{RT} \\
\mathrm{RT} \\
\mathrm{RT} \\
\mathrm{RT} \\
\mathrm{RT} \\
\mathrm{RT} \\
\mathrm{RT} \\
\mathrm{RT} \\
\mathrm{RT} \\
\mathrm{RT} \\
\mathrm{RT} \\
\mathrm{RT}\end{array}$ & $\begin{array}{l}2003 \\
2003 \\
2003 \\
2003 \\
2003 \\
2003 \\
2003 \\
2003 \\
2003 \\
2003 \\
2007 \\
2003 \\
2003 \\
2003 \\
2003 \\
2003 \\
2003 \\
2003 \\
2003 \\
2003 \\
2003 \\
1999\end{array}$ \\
\hline 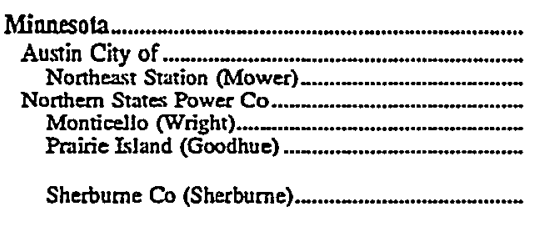 & $\begin{array}{l}1 \\
1 \\
2 \\
1 \\
2\end{array}$ & $\begin{array}{r}3,103.1 \\
31.9 \\
31.9 \\
3,071.2 \\
565.0 \\
593.1 \\
593.1 \\
660.0 \\
660.0\end{array}$ & $\begin{array}{r}3,025.3 \\
29.3 \\
29.3 \\
2,996.0 \\
545.0 \\
514.0 \\
513.0 \\
712.0 \\
712.0\end{array}$ & $\begin{array}{l}\mathrm{NB} \\
\mathrm{NP} \\
\mathrm{NP} \\
\mathrm{ST} \\
\mathrm{ST}\end{array}$ & $\begin{array}{l}\text { BIT } \\
\text { Uranium } \\
\text { Uranium } \\
\text { Uranium } \\
\text { SUB } \\
\text { SUB }\end{array}$ & $\begin{array}{l}\text { A } \\
\text { A } \\
\text { A } \\
\text { A } \\
\text { A }\end{array}$ & $\begin{array}{l}1999 \\
1998 \\
1999 \\
1998 \\
1998\end{array}$ \\
\hline $\begin{array}{l}\text { Mississippi } \\
\text { South Mississippi El Pwr Assn } \\
\text { Moselle (Jones) }\end{array}$ & 3 & $\begin{array}{l}59.0 \\
59.0 \\
59.0\end{array}$ & $\begin{array}{l}59.0 \\
59.0 \\
59.0\end{array}$ & ST & Nat Gas & RP & 2001 \\
\hline 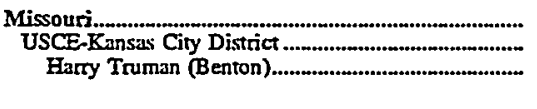 & $\begin{array}{l}1 \\
2\end{array}$ & $\begin{array}{l}53.9 \\
53.9 \\
27.0 \\
27.0\end{array}$ & $\begin{array}{l}62.0 \\
62.0 \\
31.0 \\
31.0\end{array}$ & $\begin{array}{l}\text { PS } \\
\text { PS }\end{array}$ & $\begin{array}{l}\text { Water } \\
\text { Water }\end{array}$ & $\begin{array}{l}\text { RP } \\
\text { RP }\end{array}$ & $\begin{array}{l}1999 \\
1998\end{array}$ \\
\hline $\begin{array}{l}\text { Montana } \\
\text { Montana Power Co } \\
\text { Hauser (Lewis And Clark) }\end{array}$ & $\begin{array}{l}1 \\
2 \\
3 \\
4 \\
5 \\
6 \\
1 \\
2 \\
3 \\
4\end{array}$ & $\begin{array}{r}26.0 \\
26.0 \\
2.8 \\
2.8 \\
2.8 \\
2.8 \\
2.8 \\
3.0 \\
2.3 \\
2.3 \\
2.3 \\
2.3\end{array}$ & $\begin{array}{r}16.7 \\
16.7 \\
10.1 \\
2- \\
2- \\
2- \\
2- \\
2= \\
6.6 \\
2= \\
2- \\
2-\end{array}$ & $\begin{array}{l}\text { HY } \\
\text { HY } \\
\text { HY } \\
\text { HY } \\
\text { HY } \\
\text { HY } \\
\text { HI } \\
\text { HI } \\
\text { HIL } \\
\text { HI }\end{array}$ & $\begin{array}{l}\text { Water } \\
\text { Water } \\
\text { Water } \\
\text { Water } \\
\text { Water } \\
\text { Water } \\
\text { Water } \\
\text { Water } \\
\text { Water } \\
\text { Water }\end{array}$ & $\begin{array}{l}\text { RP } \\
\text { RP } \\
\text { RP } \\
\text { RP } \\
\text { RP } \\
\text { RP } \\
\text { RP } \\
\text { RP } \\
\text { RP } \\
\text { RP }\end{array}$ & $\begin{array}{l}2002 \\
2002 \\
2002 \\
2002 \\
2002 \\
2000 \\
2002 \\
2002 \\
2002 \\
2002\end{array}$ \\
\hline 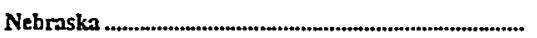 & & 4942 & 475.0 & & & & \\
\hline
\end{tabular}

See footnotes at end of table. 
Table 22. Planned Generating Unit Changes at U.S. Electric Utilities by State, Company, and Plant, 1998 Through 2007 as of January 1, 1998 (Continued)

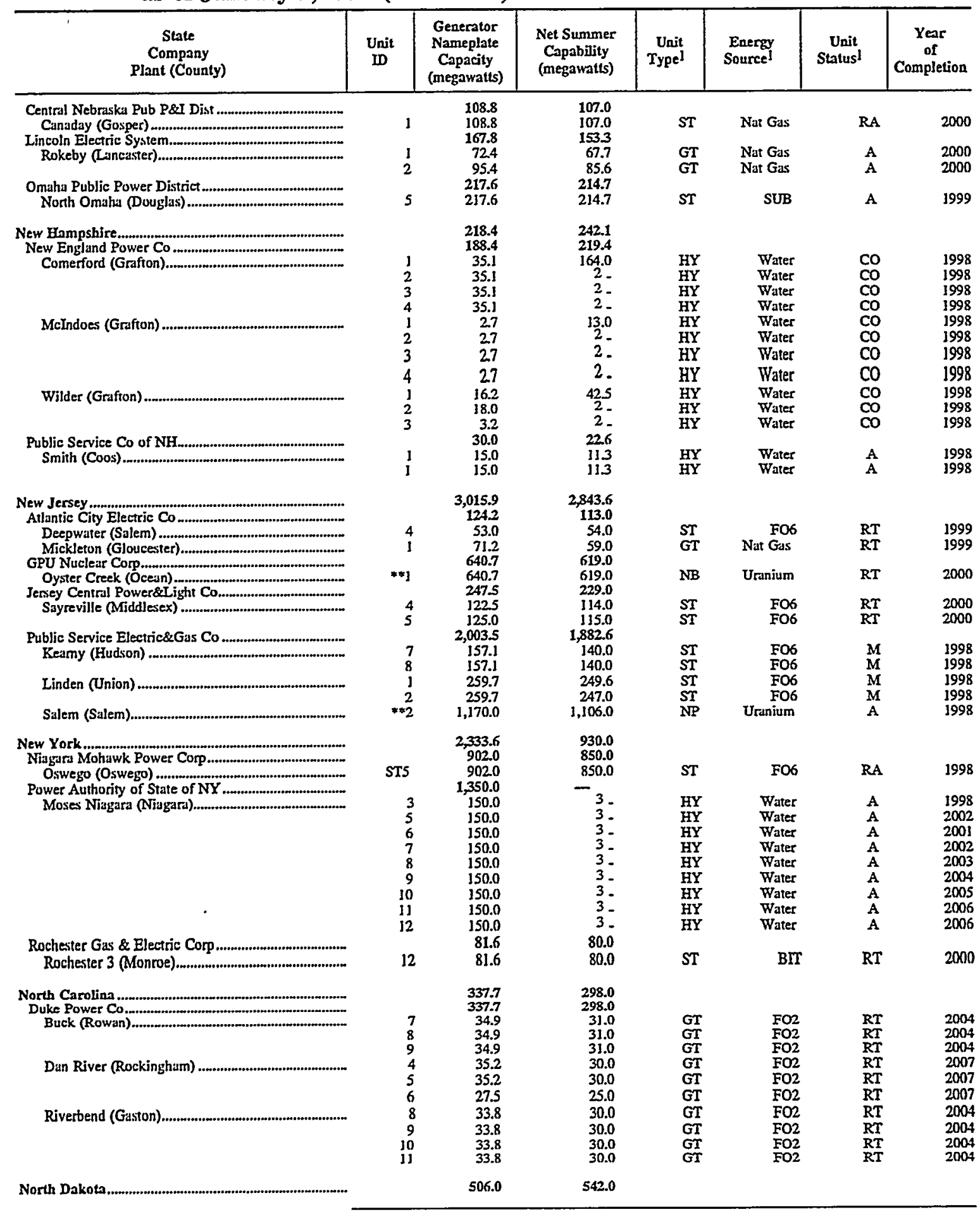

See footnotes at end of table. 
Table 22. Planned Generating Unit Changes at U.S. Electric Utilities by State, Company, and Plant, 1998 Through 2007 as of January 1, 1998 (Continued)

\begin{tabular}{|c|c|c|c|c|c|c|c|}
\hline $\begin{array}{c}\text { State } \\
\text { Company } \\
\text { Plant (County) }\end{array}$ & $\begin{array}{l}\text { Unit } \\
\text { ID }\end{array}$ & $\begin{array}{l}\text { Generator } \\
\text { Nameplate } \\
\text { Capacity } \\
\text { (megawatts) }\end{array}$ & $\begin{array}{l}\text { Net Summer } \\
\text { Capability } \\
\text { (megawatts) }\end{array}$ & $\begin{array}{c}\text { Unit } \\
\text { Type }\end{array}$ & $\begin{array}{l}\text { Energy } \\
\text { Sourcel }\end{array}$ & $\begin{array}{c}\text { Unit } \\
\text { Status }\end{array}$ & $\begin{array}{l}\text { Year } \\
\text { of } \\
\text { Completion }\end{array}$ \\
\hline 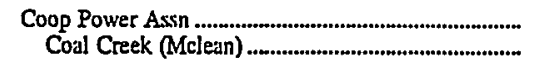 & $* 2$ & $\begin{array}{l}506.0 \\
506.0\end{array}$ & $\begin{array}{l}542.0 \\
542.0\end{array}$ & ST & LIG & A & 1999 \\
\hline 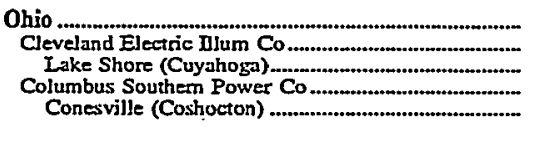 & $\begin{array}{l}5 \\
6\end{array}$ & $\begin{array}{r}1,143.9 \\
256.0 \\
256.0 \\
887.9 \\
444.0 \\
444.0\end{array}$ & $\begin{array}{l}995.0 \\
245.0 \\
245.0 \\
750.0 \\
375.0 \\
375.0\end{array}$ & $\begin{array}{l}\text { ST } \\
\text { ST }\end{array}$ & $\begin{array}{l}\text { BIT } \\
\text { BIT }\end{array}$ & A & $\begin{array}{l}1998 \\
1998\end{array}$ \\
\hline 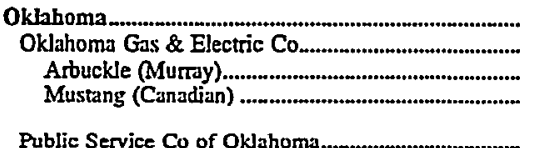 & $\begin{array}{l}1 \\
1 \\
2\end{array}$ & $\begin{array}{r}1,439.8 \\
216.0 \\
73.0 \\
81.0 \\
62.0 \\
223.8\end{array}$ & $\begin{array}{r}1,468.0 \\
189.0 \\
74.0 \\
58.0 \\
57.0 \\
1279.0\end{array}$ & $\begin{array}{l}\text { ST } \\
\text { ST } \\
\text { ST }\end{array}$ & $\begin{array}{l}\text { Nat Gas } \\
\text { Nat Gas } \\
\text { Nat Gas }\end{array}$ & $\begin{array}{l}\mathrm{RP} \\
\mathrm{RP} \\
\mathrm{RP}\end{array}$ & $\begin{array}{l}2005 \\
2005 \\
2004\end{array}$ \\
\hline $\begin{array}{l}\text { Public Service Co of Oklahoma } \\
\text { Northeastem (Rogers) } \\
\text { Southwestem (Caddo) } \\
\text { Weleetka (Okfuskee) }\end{array}$ & $\begin{array}{r}1 \\
2 \\
1 \\
2 \\
3 \\
I C 1 \\
4 \\
5 \\
6\end{array}$ & $\begin{array}{r}1,223.8 \\
170.0 \\
441.8 \\
80.3 \\
80.3 \\
288.4 \\
4.0 \\
53.0 \\
53.0 \\
53.0\end{array}$ & $\begin{array}{r}1,279.0 \\
157.0 \\
480.0 \\
80.0 \\
80.0 \\
315.0 \\
4.0 \\
55.0 \\
54.0 \\
54.0\end{array}$ & $\begin{array}{l}\text { ST } \\
\text { ST } \\
\text { ST } \\
\text { ST } \\
\text { ST } \\
\text { IC } \\
\text { GT } \\
\text { GT } \\
\text { GT }\end{array}$ & $\begin{array}{c}\text { Nat Gas } \\
\text { Nat Gas } \\
\text { Nat Gas } \\
\text { Nat Gas } \\
\text { Nat Gas } \\
\text { FO2 } \\
\text { Nat Gas } \\
\text { Nat Gas } \\
\text { Nat Gas }\end{array}$ & $\begin{array}{l}\text { RT } \\
\text { RT } \\
\text { RT } \\
\text { RT } \\
\text { RT } \\
\text { RT } \\
\text { RT } \\
\text { RT } \\
\text { RT }\end{array}$ & $\begin{array}{l}2005 \\
2004 \\
2000 \\
2001 \\
2006 \\
2005 \\
2004 \\
2005 \\
2005\end{array}$ \\
\hline $\begin{array}{l}\text { Oregon } \\
\text { Porland General Electrie Co } \\
\text { Boardman (Morrow) }\end{array}$ & $\$ \approx 1$ & $\begin{array}{l}560.5 \\
560.5 \\
560.5\end{array}$ & $\begin{array}{l}508.0 \\
508.0 \\
508.0\end{array}$ & ST & BIT & A & 1998 \\
\hline 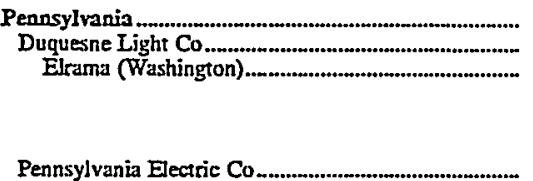 & $\begin{array}{l}1 \\
2 \\
3 \\
4\end{array}$ & $\begin{array}{r}3,534.2 \\
510.3 \\
100.0 \\
100.0 \\
125.0 \\
185.3 \\
302.8\end{array}$ & $\begin{array}{r}3,471.0 \\
474.0 \\
97.0 \\
97.0 \\
109.0 \\
171.0 \\
278.0\end{array}$ & $\begin{array}{l}\text { ST } \\
\text { ST } \\
\text { ST } \\
\text { ST }\end{array}$ & $\begin{array}{l}\text { BIT } \\
\text { BIT } \\
\text { BIT } \\
\text { BIT }\end{array}$ & $\begin{array}{l}\text { RT } \\
\text { RT } \\
\text { RT } \\
\text { RT }\end{array}$ & $\begin{array}{l}2005 \\
2005 \\
2005 \\
2005\end{array}$ \\
\hline Weward (Indiana) & $\begin{array}{l}4 \\
5 \\
1 \\
2\end{array}$ & $\begin{array}{r}62.0 \\
156.2 \\
42.3 \\
42.3\end{array}$ & $\begin{array}{r}60.0 \\
136.0 \\
41.0 \\
41.0\end{array}$ & $\begin{array}{l}\text { ST } \\
\text { ST } \\
\text { ST } \\
\text { ST }\end{array}$ & $\begin{array}{l}\text { BIT } \\
\text { BIT } \\
\text { BIT } \\
\text { BIT }\end{array}$ & $\begin{array}{l}\text { RT } \\
\text { RT } \\
\text { RT } \\
\text { RT }\end{array}$ & $\begin{array}{l}2001 \\
2001 \\
2000 \\
2000\end{array}$ \\
\hline $\begin{array}{l}\text { PECO Energy Co } \\
\text { Limerick (Montgomery) } \\
\text { Muddy Run (Lancaster) } \\
\text { UGI Utilities Inc }\end{array}$ & $\begin{array}{l}1 \\
2 \\
2 \\
4 \\
8\end{array}$ & $\begin{array}{r}2,530.5 \\
1,138.5 \\
1,092.0 \\
100.0 \\
100.0 \\
100.0 \\
50.0\end{array}$ & $\begin{array}{r}2,550.0 \\
1,105.0 \\
1,115.0 \\
110.0 \\
110.0 \\
110.0 \\
48.0\end{array}$ & $\begin{array}{l}\text { NB } \\
\text { NB } \\
\text { PS } \\
\text { PS } \\
\text { PS }\end{array}$ & $\begin{array}{l}\text { Uranium } \\
\text { Uranium } \\
\text { Water } \\
\text { Water } \\
\text { Water }\end{array}$ & $\begin{array}{l}A \\
A \\
A \\
A \\
A\end{array}$ & $\begin{array}{l}1998 \\
1999 \\
1998 \\
1998 \\
1998\end{array}$ \\
\hline 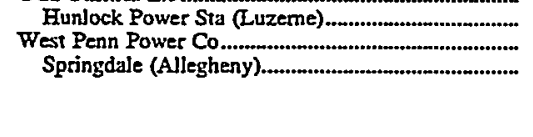 & $\begin{array}{r}\text { CT1 } \\
\text { CT2 } \\
8\end{array}$ & $\begin{array}{r}50.0 \\
140.6 \\
0.0 \\
0.0 \\
140.6\end{array}$ & $\begin{array}{r}48.0 \\
121.0 \\
0.0 \\
0.0 \\
121.0\end{array}$ & $\begin{array}{l}\text { CT } \\
\text { CT } \\
\text { ST }\end{array}$ & ANT & $\begin{array}{l}\text { RP } \\
\text { RP } \\
\text { RP }\end{array}$ & $\begin{array}{l}2001 \\
2001 \\
2001\end{array}$ \\
\hline $\begin{array}{l}\text { Rhode Isband... } \\
\text { New England Power Co } \\
\text { Manchester Street (Providence) }\end{array}$ & $\begin{array}{r}9 \\
10 \\
11\end{array}$ & $\begin{array}{l}489.2 \\
489.2 \\
159.1 \\
165.1 \\
165.1\end{array}$ & $\begin{array}{l}420.0 \\
420.0 \\
140.0 \\
140.0 \\
140.0\end{array}$ & $\begin{array}{l}\text { ST } \\
\text { ST } \\
\text { ST }\end{array}$ & $\begin{array}{l}\text { Nat Gas } \\
\text { Nat Gas } \\
\text { Nat Gass }\end{array}$ & $\begin{array}{l}\mathrm{CO} \\
\mathrm{CO} \\
\mathrm{CO}\end{array}$ & $\begin{array}{l}1998 \\
1998 \\
1998\end{array}$ \\
\hline 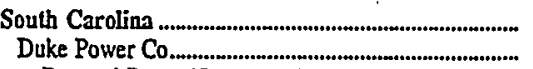 & & $\begin{array}{l}423.2 \\
196.1\end{array}$ & $\begin{array}{l}369.5 \\
178.0\end{array}$ & & & & \\
\hline $\begin{array}{l}\text { Lockhart Power Co } \\
\text { Lockhan (Union) }\end{array}$ & $\begin{array}{l}6 \\
7 \\
8 \\
9 \\
4 \\
5 \\
6\end{array}$ & $\begin{array}{r}22.7 \\
22.7 \\
22.7 \\
22.7 \\
35.1 \\
35.1 \\
35.1 \\
9.5 \\
2.8\end{array}$ & $\begin{array}{r}22.0 \\
22.0 \\
22.0 \\
22.0 \\
30.0 \\
30.0 \\
30.0 \\
11.5 \\
3.5\end{array}$ & $\begin{array}{l}\mathrm{GT} \\
\mathrm{GT} \\
\mathrm{GT} \\
\mathrm{GT} \\
\mathrm{GT} \\
\mathrm{GT} \\
\mathrm{GT}\end{array}$ & $\begin{array}{c}\text { FO2 } \\
\text { FO2 } \\
\text { FO2 } \\
\text { FO2 } \\
\text { FO2 } \\
\text { FO2 } \\
\text { FO2 } \\
\text { Water }\end{array}$ & $\begin{array}{l}\text { RT } \\
\text { RT } \\
\text { RT } \\
\text { RT } \\
\text { RT } \\
\text { RT } \\
\text { RT }\end{array}$ & $\begin{array}{l}2005 \\
2005 \\
2005 \\
2005 \\
2004 \\
2004 \\
2004\end{array}$ \\
\hline
\end{tabular}

See footnotes at end of table. 
Table 22. Planned Generating Unit Changes at U.S. Electric Utilities by State, Company, and Plant, 1998 Through 2007 as of January 1, 1998 (Continued)

\begin{tabular}{|c|c|c|c|c|c|c|c|}
\hline $\begin{array}{c}\text { State } \\
\text { Company } \\
\text { Plant (County) }\end{array}$ & $\begin{array}{l}\text { Unit } \\
\text { ID }\end{array}$ & $\begin{array}{c}\text { Generator } \\
\text { Nameplate } \\
\text { Capacity } \\
\text { (megawatis) }\end{array}$ & $\begin{array}{l}\text { Net Summer } \\
\text { Capability } \\
\text { (megawatts) }\end{array}$ & $\begin{array}{c}\text { Unit } \\
\text { Typel }\end{array}$ & $\begin{array}{l}\text { Energy } \\
\text { Sourcel }\end{array}$ & $\begin{array}{c}\text { Unit } \\
\text { StatusI }\end{array}$ & $\begin{array}{c}\text { Year } \\
\text { of } \\
\text { Completion }\end{array}$ \\
\hline 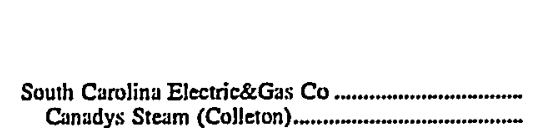 & $\begin{array}{l}\text { HY3 } \\
\text { HY4 } \\
\text { HY5 }\end{array}$ & $\begin{array}{r}2.8 \\
2.8 \\
1.1 \\
217.6 \\
217.6\end{array}$ & $\begin{array}{r}3.5 \\
3.5 \\
1.0 \\
180.0 \\
180.0\end{array}$ & $\begin{array}{l}\mathrm{HY} \\
\mathrm{HY}\end{array}$ & $\begin{array}{l}\text { Water } \\
\text { Water } \\
\text { Water }\end{array}$ & $\begin{array}{l}\text { A } \\
\text { A } \\
A\end{array}$ & $\begin{array}{l}2000 \\
1998 \\
2001\end{array}$ \\
\hline $\begin{array}{l}\text { South Dakota } \\
\text { Otter Tail Power Co } \\
\text { Big Stone (Grant) }\end{array}$ & $* \star{ }^{2} I$ & $\begin{array}{l}475.0 \\
475.0 \\
475.0\end{array}$ & $\begin{array}{l}445.8 \\
445.8 \\
445.8\end{array}$ & $\mathbf{S T}$ & SUB & A & 1998 \\
\hline Gumberland (Stewart) & $\begin{array}{r}\text { GTI } \\
\text { GT2 } \\
\text { GT3 } \\
\text { GT4 } \\
\text { GT5 } \\
\text { GT6 } \\
\text { GT7 } \\
\text { GT8 } \\
\text { GT9 } \\
\text { G10 } \\
\text { G11 } \\
\text { G12 } \\
\text { GI3 } \\
\text { G14 } \\
\text { G15 } \\
\text { G16 } \\
\text { G17 } \\
\text { G18 } \\
\text { G19 } \\
\text { G20 } \\
1 \\
2 \\
3 \\
1 \\
2 \\
\text { GT1 } \\
\text { GT2 } \\
\text { GT3 } \\
\text { GT4 } \\
\text { GT1 } \\
\text { GT1 } \\
\text { GT2 } \\
\text { GI2 } \\
\text { GI3 } \\
\text { GI3 } \\
\text { GT4 } \\
\text { GI4 } \\
\text { GI4 } \\
\text { GT5 } \\
\text { GT5 } \\
\text { GT6 } \\
\text { GT6 } \\
\text { GT7 } \\
\text { GT7 } \\
\text { GT8 } \\
\text { GT8 } \\
\text { GT9 } \\
\text { GT9 } \\
\text { G10 } \\
\text { G10 } \\
\text { G11 } \\
\text { G11 } \\
\text { G12 }\end{array}$ & $\begin{array}{r}9,942.0 \\
9,942.0 \\
23.9 \\
23.9 \\
23.9 \\
23.9 \\
23.9 \\
23.9 \\
23.9 \\
23.9 \\
23.9 \\
23.9 \\
23.9 \\
23.9 \\
23.9 \\
23.9 \\
23.9 \\
23.9 \\
59.6 \\
59.6 \\
59.6 \\
59.6 \\
330.0 \\
330.0 \\
330.0 \\
1,300.0 \\
1,300.0 \\
81.3 \\
81.3 \\
81.3 \\
81.3 \\
68.0 \\
68.0 \\
68.0 \\
68.0 \\
68.0 \\
68.0 \\
68.0 \\
68.0 \\
68.0 \\
68.0 \\
68.0 \\
68.0 \\
68.0 \\
68.0 \\
68.0 \\
68.0 \\
68.0 \\
68.0 \\
68.0 \\
68.0 \\
68.0 \\
68.0 \\
68.0 \\
68.0 \\
68.0 \\
68.0 \\
68.0 \\
68.0 \\
68.0 \\
68.0\end{array}$ & $\begin{array}{r}8,658.0 \\
8,658.0 \\
19.6 \\
19.6 \\
19.6 \\
19.6 \\
19.6 \\
19.6 \\
19.6 \\
19.6 \\
19.6 \\
19.6 \\
19.6 \\
19.6 \\
39.6 \\
39.6 \\
19.6 \\
19.6 \\
50.0 \\
50.0 \\
50.0 \\
50.0 \\
248.0 \\
248.0 \\
248.0 \\
1,224.0 \\
1,224.0 \\
71.0 \\
71.0 \\
71.0 \\
71.0 \\
53.2 \\
53.2 \\
53.2 \\
53.2 \\
53.2 \\
53.2 \\
53.2 \\
53.2 \\
53.2 \\
53.2 \\
53.2 \\
53.2 \\
53.2 \\
53.2 \\
53.2 \\
53.2 \\
53.2 \\
53.2 \\
53.2 \\
53.2 \\
53.2 \\
53.2 \\
53.2 \\
53.2 \\
53.2 \\
53.2 \\
53.2 \\
53.2 \\
53.2 \\
53.2\end{array}$ & 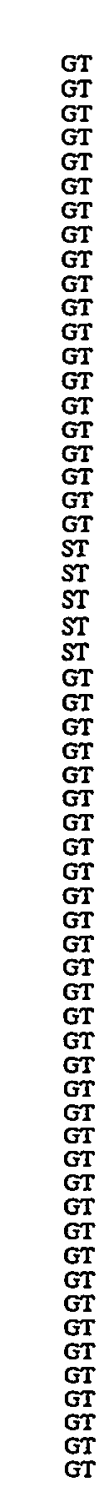 & $\begin{array}{c}\text { Nat Gas } \\
\text { Nat Gas } \\
\text { Nat Gas } \\
\text { Nat Gas } \\
\text { Nat Gas } \\
\text { Nat Gas } \\
\text { Nat Gas } \\
\text { Nat Gas } \\
\text { Nat Gas } \\
\text { Nat Gas } \\
\text { Nat Gas } \\
\text { Nat Gas } \\
\text { Nat Gas } \\
\text { Nat Gas } \\
\text { Nat Gas } \\
\text { Nat Gas } \\
\text { Nat Gas } \\
\text { Nat Gas } \\
\text { Nat Gas } \\
\text { Nat Gas } \\
\text { BIT } \\
\text { BIT } \\
\text { BIT } \\
\text { BIT } \\
\text { BIT } \\
\text { FO2 } \\
\text { FO2 } \\
\text { FO2 } \\
\text { FO2 } \\
\text { FO2 } \\
\text { FO2 } \\
\text { FO2 } \\
\text { FO2 } \\
\text { FO2 } \\
\text { FO2 } \\
\text { FO2 } \\
\text { FO2 } \\
\text { FO2 } \\
\text { FO2 } \\
\text { FO2 } \\
\text { FO2 } \\
\text { FO2 } \\
\text { FO2 } \\
\text { FO2 } \\
\text { FO2 } \\
\text { FO2 } \\
\text { FO2 } \\
\text { FO2 } \\
\text { FO2 } \\
\text { FO2 } \\
\text { FO2 } \\
\text { FO2 } \\
\text { FO2 } \\
\text { FO2 }\end{array}$ & $\begin{array}{l}A \\
A \\
A \\
A \\
A \\
A \\
A \\
A \\
A \\
A \\
A \\
A \\
A \\
A \\
A \\
A \\
A \\
A \\
A \\
A \\
A \\
A \\
A \\
A \\
A \\
A \\
A \\
A \\
A \\
A \\
A \\
A \\
A \\
A \\
A \\
A \\
A \\
A \\
A \\
A \\
A \\
A \\
A \\
A \\
A \\
A \\
A \\
A \\
A \\
A \\
A \\
A \\
A \\
A \\
A \\
A \\
A \\
A \\
A \\
A\end{array}$ & $\begin{array}{l}1998 \\
1998 \\
1998 \\
1998 \\
1998 \\
1998 \\
1998 \\
1998 \\
1998 \\
1998 \\
1998 \\
1998 \\
1998 \\
1998 \\
1998 \\
1998 \\
1998 \\
1998 \\
1998 \\
1998 \\
1999 \\
1999 \\
1999 \\
2000 \\
1999 \\
1998 \\
1998 \\
1998 \\
1998 \\
1998 \\
1999 \\
1998 \\
1999 \\
1998 \\
1999 \\
1998 \\
1999 \\
1998 \\
1999 \\
1998 \\
1999 \\
1998 \\
1999 \\
1998 \\
1999 \\
1998 \\
1999 \\
1998 \\
1999 \\
1998 \\
1999 \\
1998 \\
1999 \\
1998 \\
1999 \\
1998 \\
1999 \\
1998 \\
1999\end{array}$ \\
\hline
\end{tabular}

See footnotes at end of table. 
Table 22. Planned Generating Unit Changes at U.S. Electric Utilities by State, Company, and Plant, 1998 Through 2007 as of January 1, 1998 (Continued)

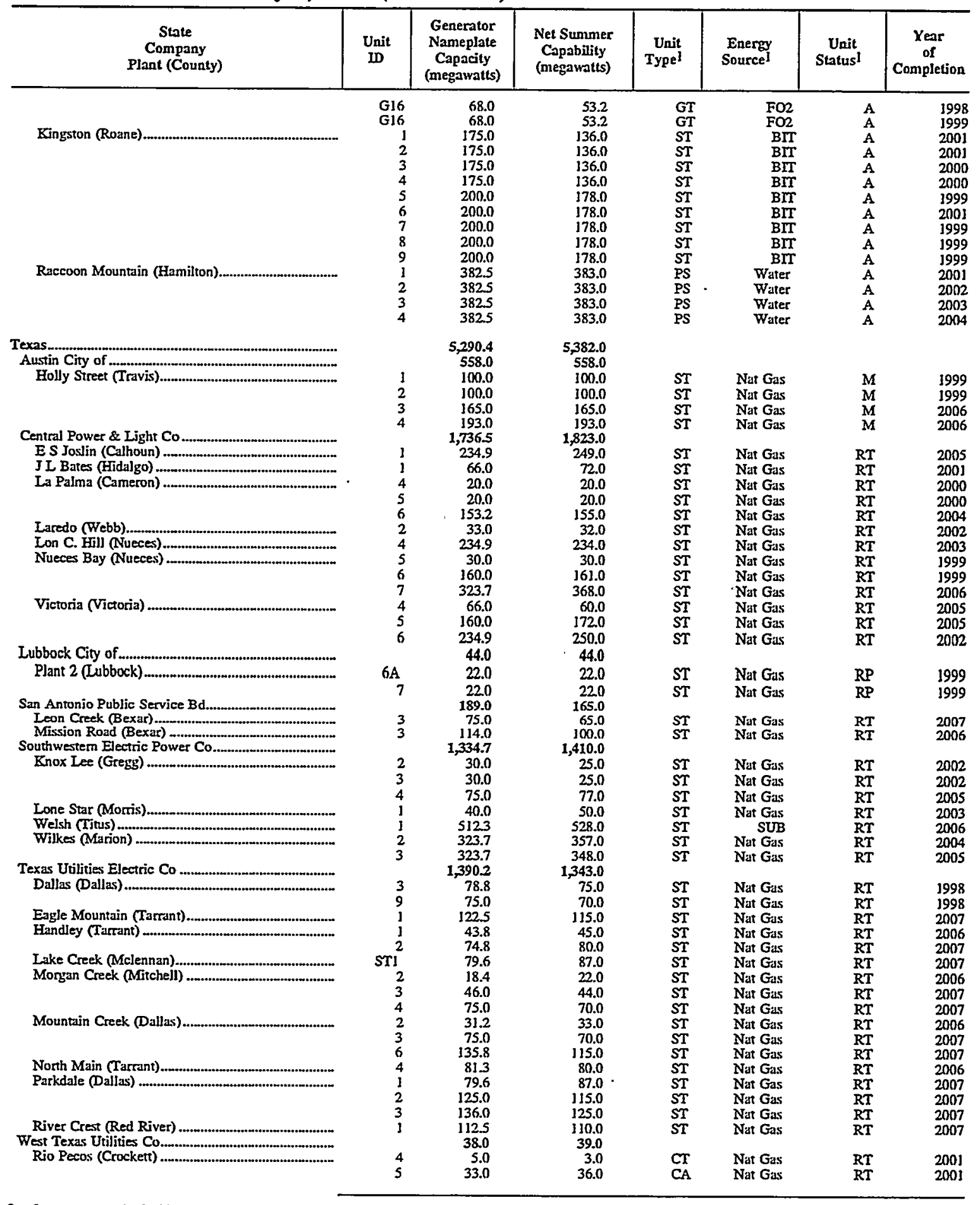

See footnotes at end of table. 
Table 22. Planned Generating Unit Changes at U.S. Electric Utilities by State, Company, and Plant, 1998 Through 2007 as of January 1, 1998 (Continued)

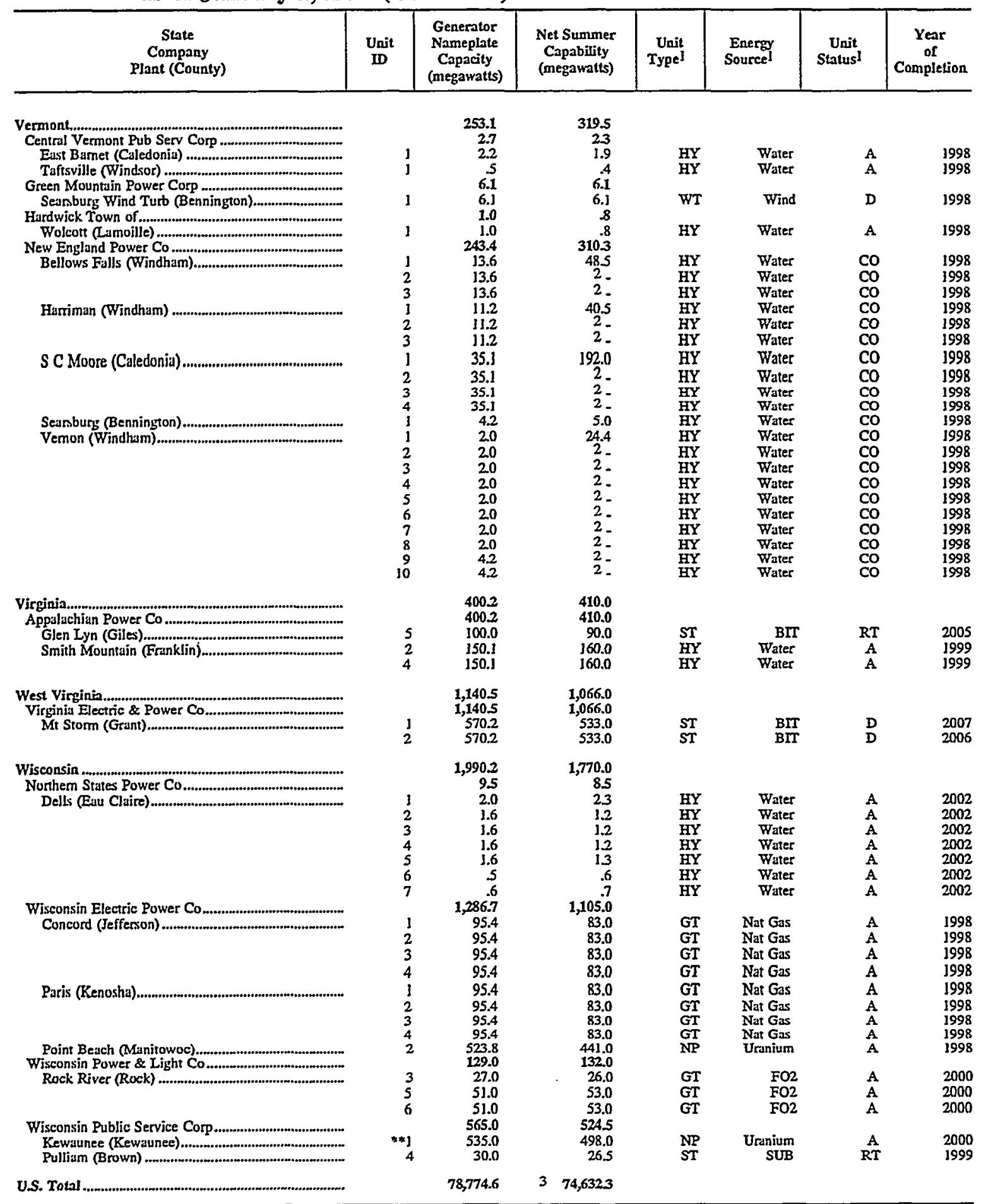

I See Appendix B for codes. 
2 Individual summer and winter capabilities for these generutors are not available. Within plant, reported value is the aggregated capabiltiy of all these generators.

3 Does not include Moses Niagara units that are proposed for capability increase. Individual existing capabilities for these generators are not available.

* Less than 0.05 megawatts.

* A jointly owned unit. See Appendix $C$ for the list of owners.

E Estimated.

Note: The Form EIA-860 was revised during 1995 to collect data as of January 1 of the reporting year, where "reporting year" is the calendar year in which the report is required to be filed with the Energy Information Administration. These data reflect the status of electric power plants/generators as of January 1: however, dynamic data are bused on occurrences in the previous calendar year (e.g., capubilities and energy sources based on test and consumption in the previous year).

Source: Energy Information Administration, Form EIA-860, "Annual Electric Generator Report." 
Table 23. Planned Generating Unit Additions at U.S. Electric Utilities by State, Company, and Plant, 1998 Through 2007 as of January 1, 1998

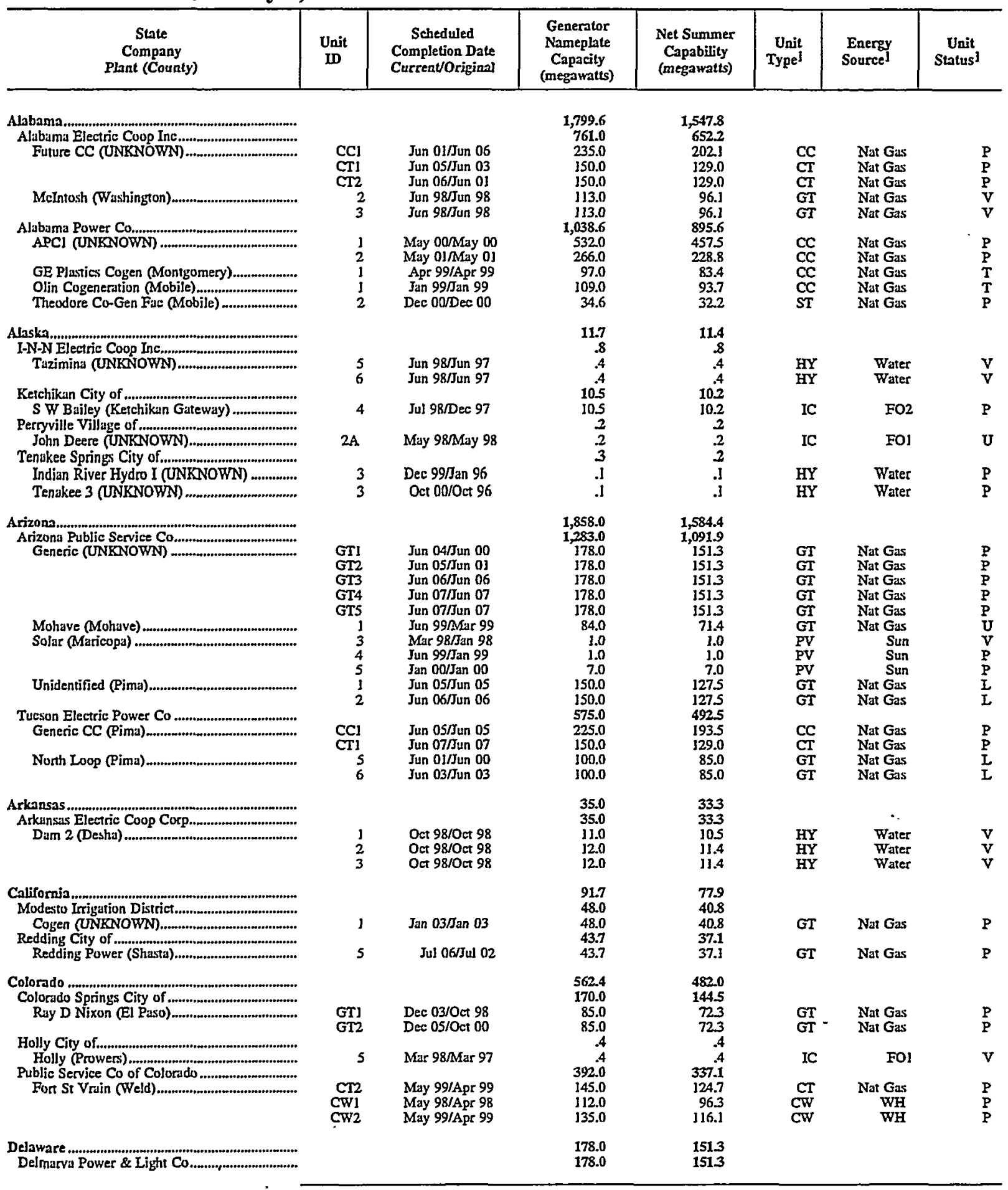

See foutnotes at end of table. 
Table 23. Planned Generating Unit Additions at U.S. Electric Utilities by State, Company, and Plant, 1998 Through 2007 as of January 1, 1998 (Continued)

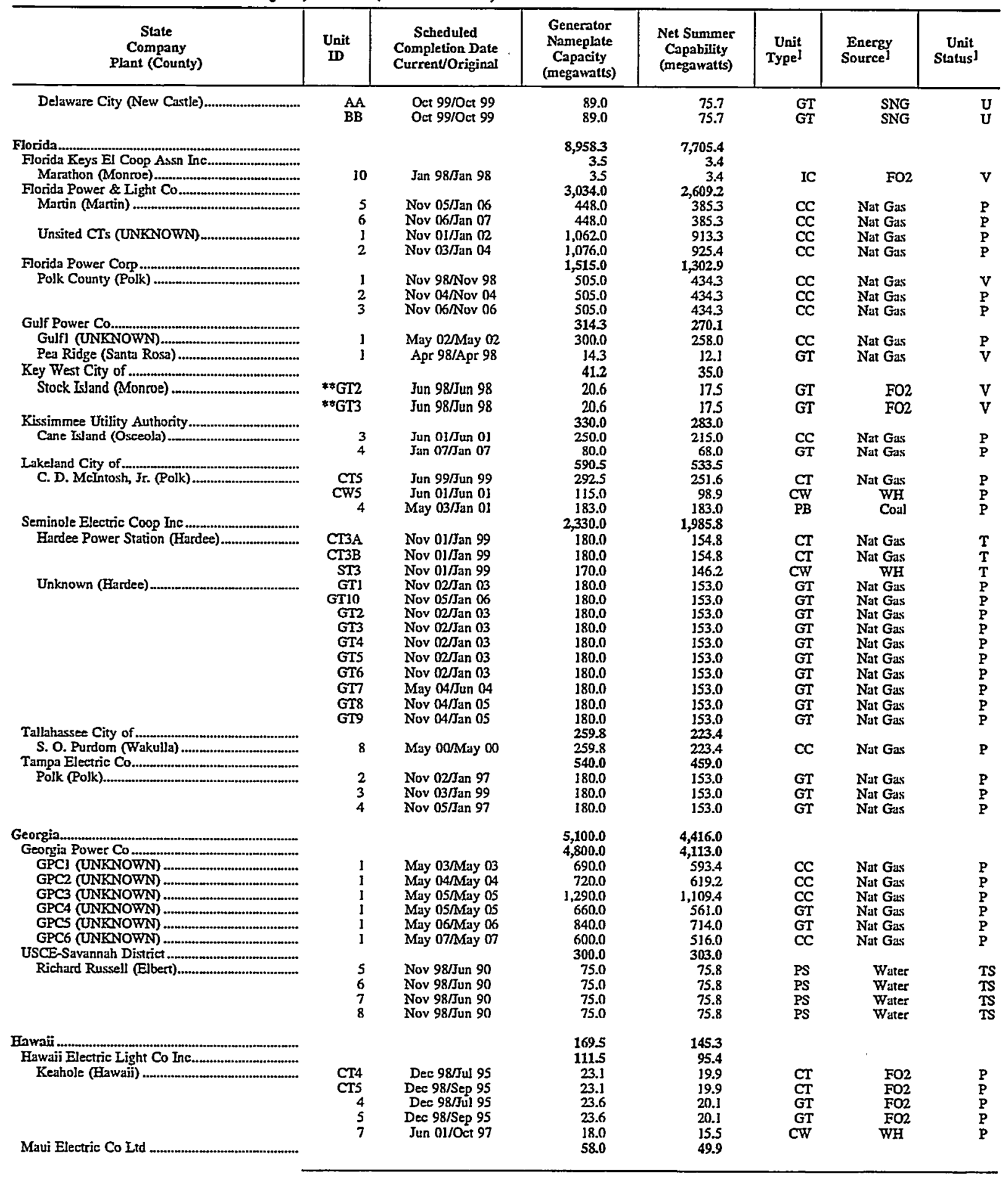

See footnotes at end of table. 
Table 23. Planned Generating Unit Additions at U.S. Electric Utilities by State, Company, and Plant, 1998 Through 2007 as of January 1, 1998 (Continued)

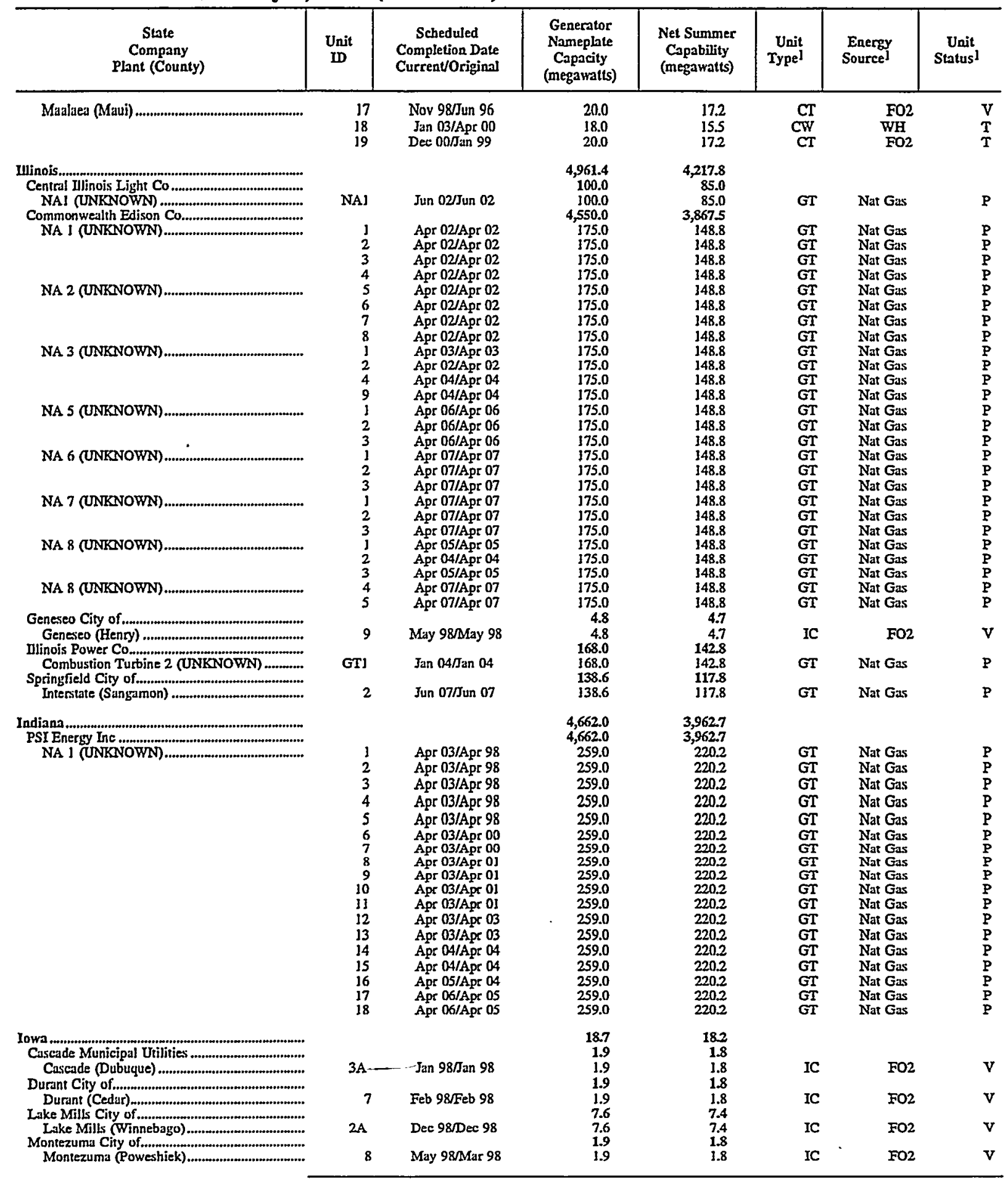

See foutnotes at end of table. 
Table 23. Planned Generating Unit Additions at U.S. Electric Utilities by State, Company, and Plant, 1998 Through 2007 as of January 1, 1998 (Continued)

\begin{tabular}{|c|c|c|c|c|c|c|c|}
\hline $\begin{array}{c}\text { State } \\
\text { Company } \\
\text { Plant (County) }\end{array}$ & $\begin{array}{l}\text { Unit } \\
\text { ID }\end{array}$ & $\begin{array}{l}\text { Scheduled } \\
\text { Completion Date } \\
\text { Current/Original }\end{array}$ & $\begin{array}{c}\text { Generator } \\
\text { Namephate } \\
\text { Capacity } \\
\text { (megawatts) }\end{array}$ & $\begin{array}{l}\text { Net Summer } \\
\text { Capability } \\
\text { (megawatts) }\end{array}$ & $\underset{\text { Type }}{\text { Unit }}$ & $\begin{array}{l}\text { Energy } \\
\text { Sourcel }\end{array}$ & $\begin{array}{c}\text { Unit } \\
\text { Status }\end{array}$ \\
\hline $\begin{array}{l}\text { Osage City of } \\
\text { Osage (Mitchell) } \\
\text { Sumner City of }\end{array}$ & 8 & Apr 98/Apr 98 & $\begin{array}{l}3.6 \\
3.6 \\
1.8\end{array}$ & $\begin{array}{l}3.6 \\
3.6 \\
1.8\end{array}$ & IC & FO2 & Ts \\
\hline 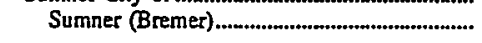 & 6 & Apr 99/Apr 99 & 1.8 & 1.8 & IC & FO2 & $\mathbf{U}$ \\
\hline Kansas... & & & 116.8 & 99.4 & & & \\
\hline 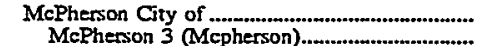 & NA] & $\operatorname{Jan} 99 \pi$ un 98 & 115.6 & 983 & GT & & $p$ \\
\hline 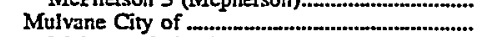 & NAI & & $\begin{aligned} 115.6 \\
1.2\end{aligned}$ & $\begin{array}{r}98.3 \\
1.2\end{array}$ & GT & Nat Gas & $P$ \\
\hline 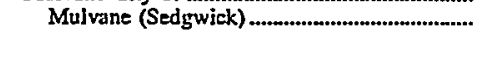 & $\begin{array}{l}7 \\
8\end{array}$ & $\begin{array}{l}\text { Jun } 99 / \text { Jan } 90 \\
\text { Jun } 99 / J \text { an } 90\end{array}$ & $\begin{array}{l}.6 \\
.6\end{array}$ & $\begin{array}{l}.6 \\
.6\end{array}$ & $\begin{array}{l}\text { IC } \\
\text { IC }\end{array}$ & $\begin{array}{l}\text { FO2 } \\
\text { FO2 }\end{array}$ & $\begin{array}{l}\mathrm{v} \\
\mathrm{v}\end{array}$ \\
\hline 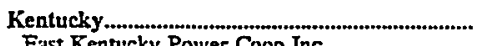 & & & $2,846.0$ & $2,430.8$ & & & \\
\hline Eust Kentucky Power Coop Inc.............................. & & & $1,382.0$ & $1,180.4$ & & & \\
\hline J K Smith (Clark) & $\begin{array}{l}1 \\
2 \\
3 \\
4\end{array}$ & $\begin{array}{l}\text { Sep } 98 / \text { Sep } 98 \\
\text { Sep 98/Sep } 98 \\
\text { Sep 98/Mar } 95 \\
\text { Apr 01/Apr } 98\end{array}$ & $\begin{array}{l}149.0 \\
149.0 \\
149.0 \\
149.0\end{array}$ & $\begin{array}{l}126.7 \\
126.7 \\
126.7 \\
126.7\end{array}$ & $\begin{array}{l}G T \\
G T \\
G T \\
G T\end{array}$ & $\begin{array}{l}\text { GAS } \\
\text { GAS } \\
\text { GAS } \\
\text { GAS }\end{array}$ & $\begin{array}{l}\mathrm{v} \\
\mathrm{v} \\
\mathrm{v} \\
\mathrm{P}\end{array}$ \\
\hline Unknown (UNKNOWN) .................................... & 1 & Apr 03/Apr 01 & 225.0 & 193.5 & CT & GAS & $\mathrm{p}$ \\
\hline & $\begin{array}{l}2 \\
3 \\
4\end{array}$ & $\begin{array}{l}\text { Apr 01/Apr 03 } \\
\text { Apr 02/Apr 03 } \\
\text { Apr 03/Apr 03 }\end{array}$ & $\begin{array}{l}108.0 \\
108.0 \\
120.0\end{array}$ & $\begin{array}{r}91.8 \\
91.8 \\
103.2\end{array}$ & $\begin{array}{l}\text { GT } \\
\text { GT } \\
\text { CT }\end{array}$ & $\begin{array}{l}\text { GAS } \\
\text { GAS } \\
\text { GAS }\end{array}$ & $\begin{array}{l}\mathrm{p} \\
\mathrm{p} \\
\mathrm{P}\end{array}$ \\
\hline & $\begin{array}{l}4 \\
5\end{array}$ & Apr 05/Apr 05 & 225.0 & 193.5 & CT & GAS & $\mathbf{P}$ \\
\hline Kentucky Utilities Co & & & $1,080.0$ & 924.0 & & & \\
\hline 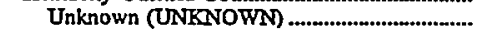 & 1 & Jun 00/Apr 99 & 120.0 & 102.0 & GT & Nat Gas & $\mathbf{P}$ \\
\hline & 2 & Jun 01/Apr 98 & 120.0 & 102.0 & GT & Nat Gas & $\mathrm{P}$ \\
\hline & 3 & Jun $02 / A p r 98$ & 120.0 & 302.0 & GT & Nat Gas & $\mathrm{P}$ \\
\hline & 4 & Jun $03 / A p r ~ 99$ & 120.0 & j02.0 & GT & Nat Gas & $\stackrel{p}{p}$ \\
\hline & 5 & $\begin{array}{ll}\text { Jun } 04 / \mathrm{Apr} 00 \\
0.00\end{array}$ & 150.0 & 129.0 & $\mathbf{C T}$ & Nat Gas & $\mathrm{P}$ \\
\hline & 6 & Jun 05/Apr 02 & 150.0 & 129.0 & $\overrightarrow{C T}$ & Nat Gas & $\mathbf{P}$ \\
\hline & 7 & Jun $06 / \mathrm{Apr} 02$ & 150.0 & 129.0 & $C W$ & WH & $\hat{\mathbf{p}}$ \\
\hline Louisville Gas \& Electric Co & 8 & Jun 07/Apr 03 & 150.0 & 129.0 & CT & Nat Gas & $\mathbf{P}$ \\
\hline 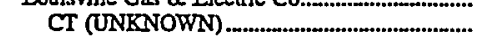 & & T1 030103 & 384.0 & $\begin{array}{r}326.4 \\
108\end{array}$ & & & \\
\hline & $\begin{array}{l}1 \\
2\end{array}$ & $\begin{array}{l}\text { JuI 03/Jul } 03 \\
\text { Jul 05/Jul 05 }\end{array}$ & $\begin{array}{l}128.0 \\
128.0\end{array}$ & 308.8 & $\begin{array}{l}\mathrm{GT} \\
\mathrm{GT}\end{array}$ & $\begin{array}{l}\text { Nat Gas } \\
\text { Nat Gas }\end{array}$ & $\stackrel{P}{\mathbf{P}}$ \\
\hline & 3 & JuI $07 / \mathrm{Jul} 07$ & 128.0 & 108.8 & $\mathrm{GT}$ & Nat Gas & $\mathbf{P}$ \\
\hline Louisiana. & & & 287.0 & 247.0 & & & \\
\hline Central Louisiana Elec Co Inc & & & 287.0 & 247.0 & & & \\
\hline Columbian (St Mary) & & May $00 /$ May 00 & 38.0 & 35.3 & ST & WH & $\mathbf{P}$ \\
\hline $\begin{array}{l}\text { Coughlin (Evangeline) } \\
\text { NA } 1 \text { (UNKNOWN) }\end{array}$ & $\begin{array}{r}8 \\
\text { NAI }\end{array}$ & $\begin{array}{l}\text { Aug 01/Jan 0] } \\
\text { Jan 03/En 00 }\end{array}$ & $\begin{array}{l}136.0 \\
113.0\end{array}$ & $\begin{array}{r}115.6 \\
96.1\end{array}$ & $\begin{array}{l}\text { GT } \\
\text { GT }\end{array}$ & $\begin{array}{l}\text { Nat Gas } \\
\text { Nat Gas }\end{array}$ & $\begin{array}{l}P \\
P\end{array}$ \\
\hline 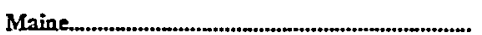 & & & 45.2 & 42.9 & & & \\
\hline 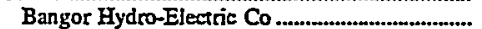 & & & 45.2 & 42.9 & & & \\
\hline 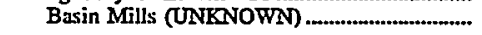 & 1 & Jan 0S/Apr 99 & 120 & 11.4 & $\mathrm{HY}$ & Water & $\mathbf{P}$ \\
\hline & 2 & Jan 05/Apr 99 & 12.0 & 11.4 & $\mathrm{HY}$ & Water & $\mathbf{P}$ \\
\hline & 3 & Jan 05/Apr 99 & 12.0 & 11.4 & $\mathrm{HY}$ & Water & $\mathbf{P}$ \\
\hline Milford (Penobseot) & 7 & Jan $05 J$ Jul 98 & 1.2 & 1.1 & $\mathrm{HY}$ & Water & $\vec{P}$ \\
\hline 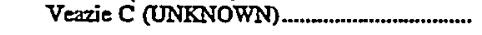 & 1 & Jan 0S/Apr 99 & 8.0 & 7.6 & $\mathrm{HY}$ & Water & $\vec{P}$ \\
\hline Maryland & & & $1,411.4$ & $1,212.8$ & & & \\
\hline 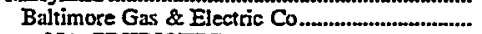 & & & $1,246.4$ & $1,069.8$ & & & \\
\hline NA (UNKNOWN) & NAI & Jun 02/Jun 0] & 215.7 & 183.3 & GT & $\mathrm{FO} 2$ & $\mathbf{P}$ \\
\hline 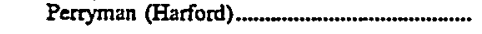 & 6 & Jun 01/Jun 00 & 131.4 & 113.0 & $\mathrm{CW}$ & WH & $\mathbf{P}$ \\
\hline & 7 & Jun 04/Jun 0] & 131.4 & 113.0 & $C W$ & WH & $\mathbf{P}$ \\
\hline & 61 & Jun 00/un 97 & 192.0 & 365.1 & $\mathbf{C T}$ & Nat Gas & $\mathbf{P}$ \\
\hline & 62 & Jun $01 /$ Jun 98 & 1920 & 165.1 & CT & Nat Gas & $\mathrm{P}$ \\
\hline & 71 & Jun 01/Jun 0] & 192.0 & $165 . j$ & $\overrightarrow{\mathrm{CT}}$ & Nat Gas & $\mathrm{P}$ \\
\hline & 72 & Jun 02/Jun 0] & 192.0 & 165.1 & CT & Nat Gas & $\mathrm{p}$ \\
\hline Easton Utilities Comm ..... & & & 10.0 & 9.8 & & & \\
\hline Easton 2 (Talbot)... & 27 & May 02Dec 95 & 5.0 & 4.9 & IC ${ }^{-}$ & FO2 & $\mathbf{p}$ \\
\hline & 28 & May 03/May 99 & 5.0 & 4.9 & IC & $\mathrm{FO} 2$ & $\overline{\mathrm{P}}$ \\
\hline $\begin{array}{l}\text { Potomac Electric Power Co } \\
\text { Dicketson (Montgomery) }\end{array}$ & & & 155.0 & 1333 & & & \\
\hline & NAI & Jun 04Dec 98 & 155.0 & 133.3 & $\mathrm{CW}$ & WH & $\mathbf{P}$ \\
\hline 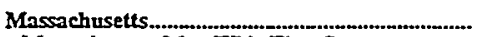 & & & 125.0 & 108.1 & & & \\
\hline Massachusetts Mun Whls Elec Co ...................... & & & 120.0 & 1032 & & & \\
\hline Srony Brook (Hampden) & **CT4 & Nov $04 /$ Nov 04 & 120.0 & 103.2 & $\mathbf{C T}$ & Nat Gas & $\mathbf{P}$ \\
\hline Nantucket Electric Co & & & 5.0 & 4.9 & & & \\
\hline Nantucket (Nantucket) ............................................ & $* * 16$ & Feb 98/Feb 98 & 25 & 2.4 & IC & FO2 & $\mathbf{v}$ \\
\hline
\end{tabular}

See footnotes at end of table. 
Table 23. Planned Generating Unit Additions at U.S. Electric Utilities by State, Company, and Plant, 1998 Through 2007

as of January 1, 1998 (Continued)

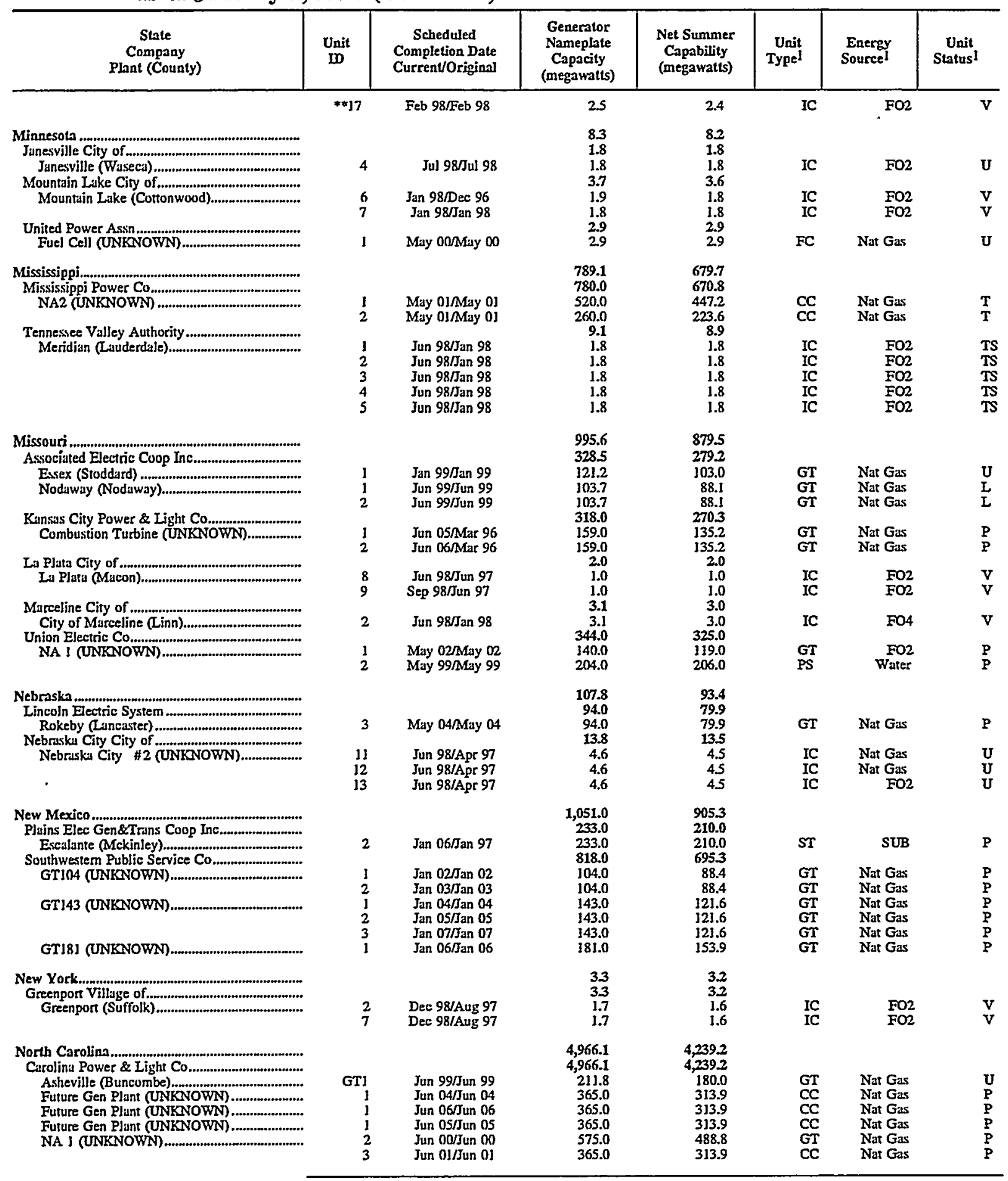

See footnoses at end of tuble. 
Table 23. Planned Generating Unit Additions at U.S. Electric Utilities by State, Company, and Plant, 1998 Through 2007 as of January 1, 1998 (Continued)

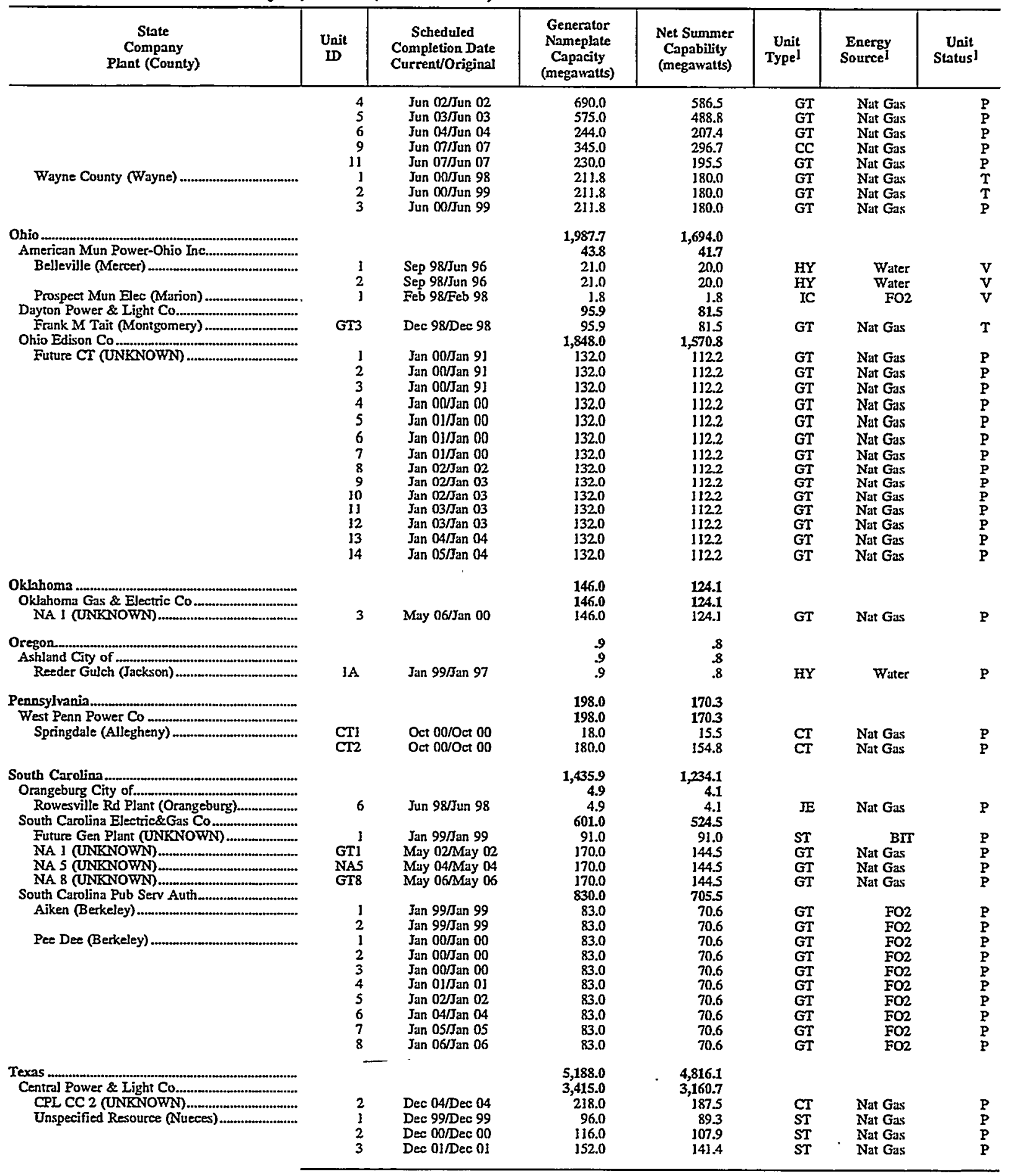

See footnotes at end of table. 
Table 23. Planned Generating Unit Additions at U.S. Electric Utilities by State, Company, and Plant, 1998 Through 2007 as of January 1, 1998 (Continued)

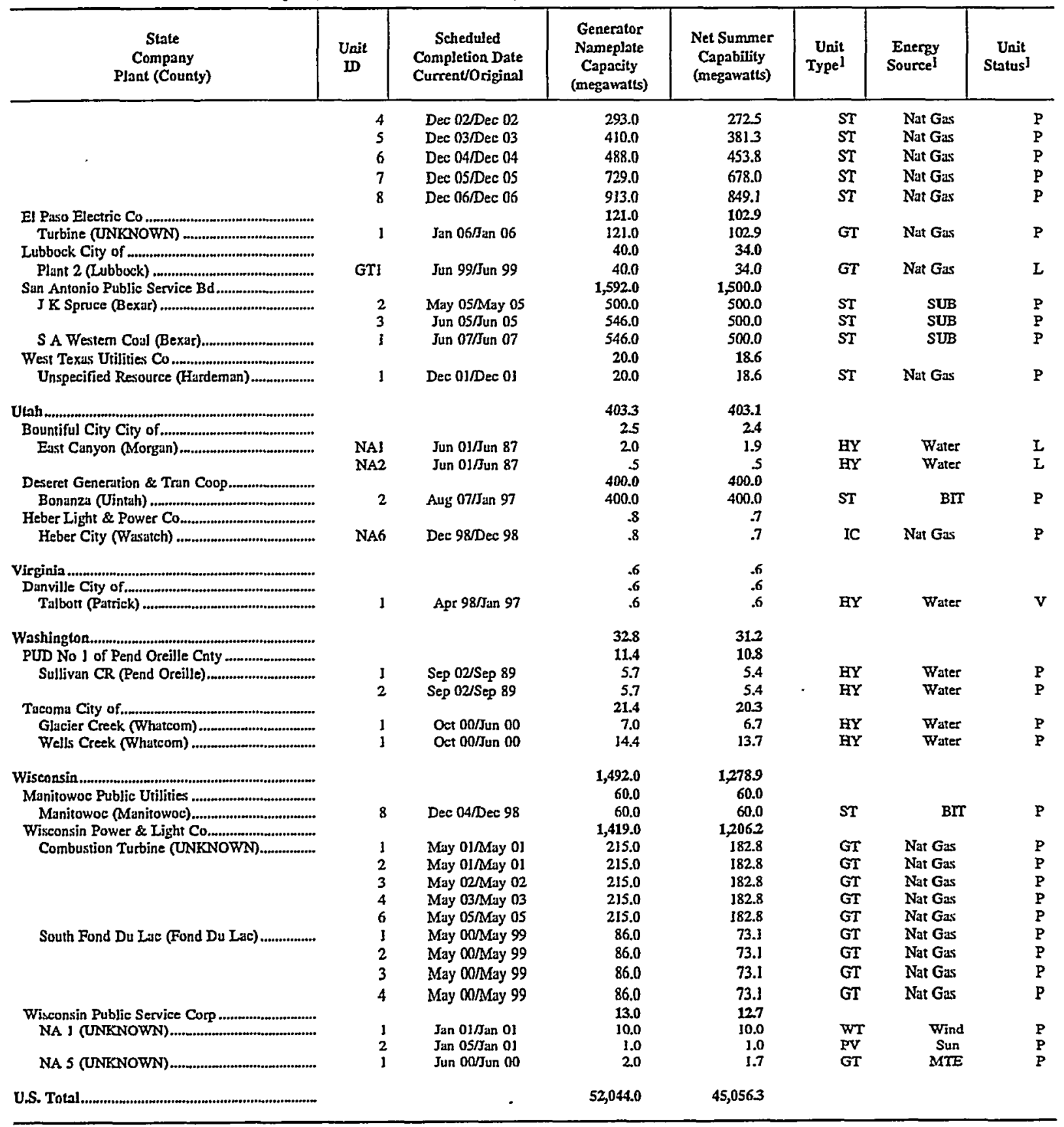

1 See Appendix B for codes.

* A jointly uwned unit. See Appendix C for the list of owners.

Notes: Totul may not equal the sum of components because of independent rounding. The Form EIA-860 was revised during 1995 to collect data as of January ! of the reporting year, where "reporting year" is the calendar year in which the report is required to be filed with the Energy Information Administration. These dati reflect the status of electric power plants/generators as of January l: however, dynamic data are based on occurrences in the previous calendar year (e.g., capabilities and energy sources based on test and consumption in the previous year). Source: Energy Information Administration, Fom EIA-860, "Annual Electric Generator Report." 
Table 24. Existing Capacity at U.S. Nonutility Power Producers by State, Owner and Facility, as of December 31, 1997

\begin{tabular}{|c|c|c|c|}
\hline State/Owner/Facility & $\begin{array}{l}\text { Nameplate } \\
\text { Capacity } \\
\text { (megawatts) }\end{array}$ & State/Company/Facility & $\begin{array}{l}\text { Nameplate } \\
\text { Capacity } \\
\text { (megawatts) }\end{array}$ \\
\hline $\begin{array}{l}\text { Alabama } \\
\text { Alabama Pine Pulp Co Inc } \\
\text { Alabama Pine Pulp Company, Incorporated }\end{array}$ & 69.0 & $\begin{array}{l}\text { Jabama (Continued) } \\
\text { U.S. Alliance Corp } \\
\text { U.S. Alliance Coosa Pines }\end{array}$ & 37.5 \\
\hline $\begin{array}{l}\text { Alabama River Pulp Co Inc } \\
\text { Alabama River Pulp Company }\end{array}$ & 48.0 & $\begin{array}{l}\text { Unjon Camp Corp } \\
\text { Union Camp Corporation - Prattville }\end{array}$ & 65.0 \\
\hline $\begin{array}{l}\text { Boise Casade Corporation } \\
\text { Boise Casade Pulp and Paper Mill Jackson Alabama }\end{array}$ & 18.0 & $\begin{array}{l}\text { Union Oil Co of Califomia } \\
\text { Unocal s Chunchula Plant \# I }\end{array}$ & 2.6 \\
\hline $\begin{array}{l}\text { Champion Intemational Corp } \\
\text { Courtland Mill }\end{array}$ & 126.4 & $\begin{array}{l}\text { USX Corp } \\
\text { Fairfield Works }\end{array}$ & 82.0 \\
\hline $\begin{array}{l}\text { Crestwood Corporation } \\
\text { Crestwood Corporation - Dothan }\end{array}$ & 9.7 & $\begin{array}{l}\text { Vintage Petroleum Inc. } \\
\text { Fumaton Treating Facility }\end{array}$ & 2.2 \\
\hline $\begin{array}{l}\text { Exxon Co USA } \\
\text { Big Escambia Creek Treating Facility } \\
\text { Mobile Bay Onshoce Treating Facility }\end{array}$ & $\begin{array}{l}3.8 \\
12.2\end{array}$ & $\begin{array}{l}\text { laska } \\
\text { Alyeska Seafoods Inc } \\
\text { Alyeska Seafoods, Incorporated }\end{array}$ & 5.9 \\
\hline $\begin{array}{l}\text { Fort James Corp. } \\
\text { Naheola Mill } \\
\text { Gulf States Paper Corp. } \\
\text { Gulf States Paper Corp. }\end{array}$ & $\begin{array}{l}78.4 \\
20.2\end{array}$ & $\begin{array}{c}\text { Arco Alaska Inc } \\
\text { Central Production Facility } \\
\text { Central Production Facility } \\
\text { Central Production Fucility } \\
\text { Lisburne Production Center } \\
\text { Seawater Treatment Plant }\end{array}$ & $\begin{array}{l}21.4 \\
21.4 \\
28.9 \\
35.4 \\
7 . j\end{array}$ \\
\hline $\begin{array}{l}\text { Gulf Statex Steel, Inc. } \\
\text { Gulf States Steel, Inc. } \\
\text { International Paper Co }\end{array}$ & 11.5 & $\begin{array}{l}\text { Icjele Seafouds, Inc. } \\
\text { Bering Star }\end{array}$ & 2.0 \\
\hline $\begin{array}{l}\text { Mobile Mill } \\
\text { Riverdale Mill }\end{array}$ & $\begin{array}{l}92.0 \\
91.3\end{array}$ & $\begin{array}{l}\text { Ketchikan Pulp Co } \\
\text { Ketchikan Pulp Company }\end{array}$ & 38.0 \\
\hline $\begin{array}{l}\text { Jefferson Smurfit Corp } \\
\text { Jefferson Smurfit Corporation }\end{array}$ & 38.9 & $\begin{array}{l}\text { Lake Colleen Enterprises Inc } \\
\text { Luke Colleen Enterprises Incorporated }\end{array}$ & 4.5 \\
\hline $\begin{array}{l}\text { Koppers Industries Inc } \\
\text { Woodward Coke Plant }\end{array}$ & 7.5 & $\begin{array}{l}\text { Offshore Systems, Inc. } \\
\text { Offshore Systems, Inc. }\end{array}$ & 1.4 \\
\hline $\begin{array}{l}\text { M.C. Dixon Lumber Co., Ine } \\
\text { M.C. Dixon Lumber Co., Inc. }\end{array}$ & 2.5 & $\begin{array}{l}\text { Ounalashka Corporation } \\
\text { American President Lines, Limited }\end{array}$ & 1.4 \\
\hline $\begin{array}{l}\text { MacMallan Bloedel Packaging } \\
\text { MacMillan Bloedel Packaging, Inc. }\end{array}$ & 76.5 & $\begin{array}{l}\text { Peter Pan Seafoods } \\
\text { King Cove }\end{array}$ & 2.6 \\
\hline $\begin{array}{l}\text { Mead Coated Board, Inc. } \\
\text { Mead Coated Board, Incorporated }\end{array}$ & 112.5 & $\begin{array}{l}\text { Tesoro Alaska Corp } \\
\text { Tesoro Alaskil Petroleum }\end{array}$ & 8.0 \\
\hline $\begin{array}{l}\text { Mobil Explor. \& Prod. SE Inc. } \\
\text { Mary Ann Gas Plant }\end{array}$ & 2.4 & $\begin{array}{l}\text { U S Air Force-Eielson AFB } \\
\text { Ejelson Air Force Base Central Heat }\end{array}$ & 32.5 \\
\hline $\begin{array}{l}\text { Mobile Energy Serv Co. L.L.C. ' } \\
\text { Mobile Energy Services Company, LL.C. }\end{array}$ & 106.9 & $\begin{array}{l}\text { U S Army-Ft Wainwright } \\
\text { Utility Plants Section }\end{array}$ & 22.5 \\
\hline $\begin{array}{l}\text { Scotch Lumber Company } \\
\text { Scotch Lumber Company }\end{array}$ & 2.5 & $\begin{array}{l}\text { U.S. Army } \\
\text { Fort Greely Power PJant }\end{array}$ & s.s \\
\hline $\begin{array}{l}\text { Shell Offshore Inc. } \\
\text { Shell Offshore Inc. Yellowhammer Plant }\end{array}$ & 3.4 & $\begin{array}{l}\text { Union Oil Co of Califomia } \\
\text { Anna Platform } \\
\text { Baker Platform }\end{array}$ & $\begin{array}{l}2.2 \\
3.0\end{array}$ \\
\hline Sloss Industries Inc & & Buce Platform & 2.0 \\
\hline $\begin{array}{l}\text { Sloss Industries Corporation } \\
\text { Transcontinental Gas Pipe Line } \\
\text { District 100-Trans. Gas Pipe Line Corp }\end{array}$ & 25.0 & $\begin{array}{l}\text { Dillon Platform } \\
\text { Granite Point Platform } \\
\text { Grayling Platform } \\
\text { Kenai Ammonia Facility } \\
\text { Monopod Platform }\end{array}$ & $\begin{array}{l}1.8 \\
2.2 \\
3.2 \\
23.3 \\
1.6\end{array}$ \\
\hline $\begin{array}{l}\text { U S Alliance Coosa Pinex Corp } \\
\text { U S Alliance Coosa Pines Corp }\end{array}$ & 89.0 & $\begin{array}{l}\text { Unisea Inc } \\
\text { Unisea Incorporated G-2 }\end{array}$ & 15.7 \\
\hline
\end{tabular}

See footnotes at end of table. 


\section{Table 24. Existing Capacity at U.S. Nonutility Power Producers by State, Owner and}

Facility, as of December 31, 1997 (Continued)

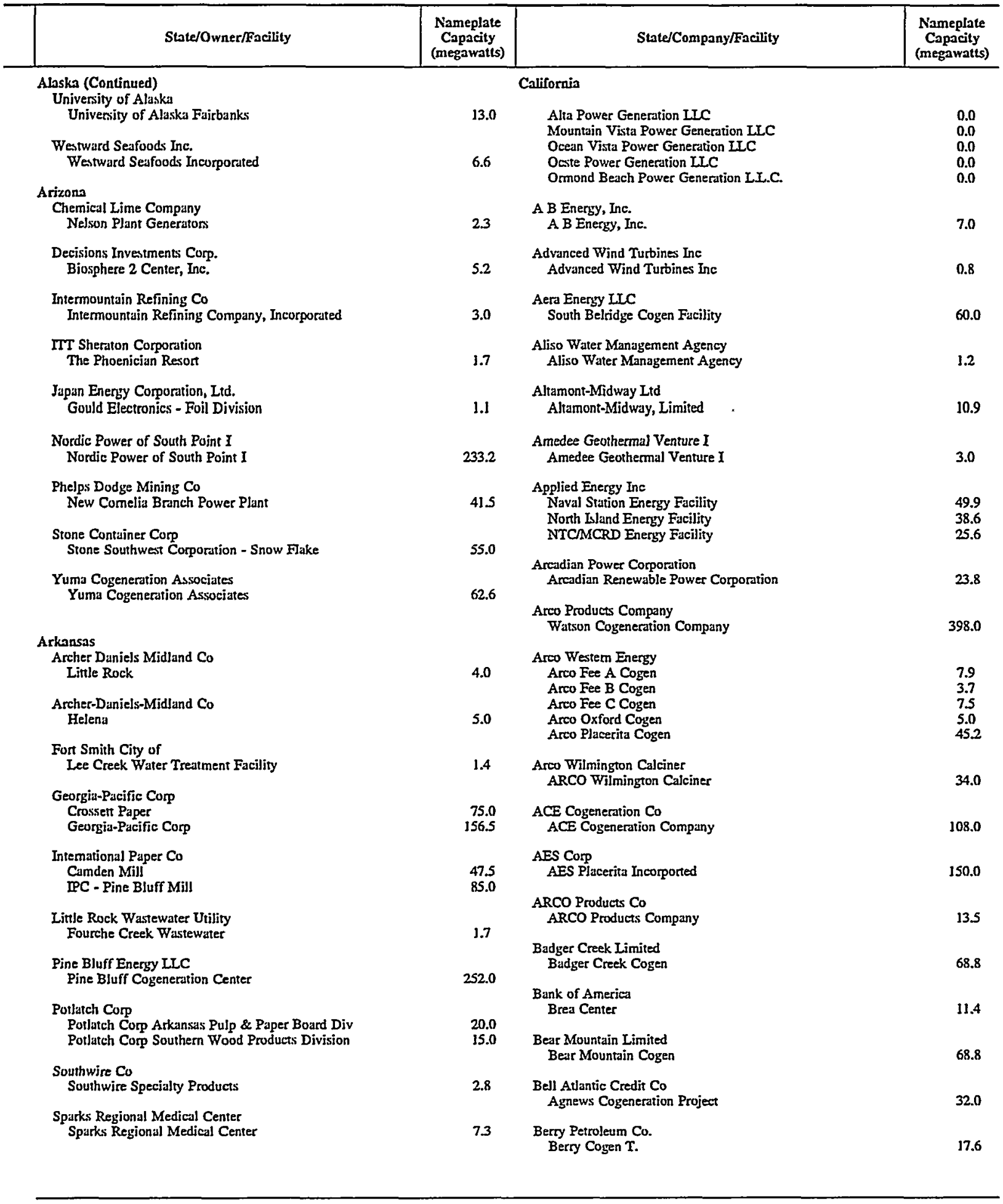

See footnotes at end of table. 


\section{Table 24. Existing Capacity at U.S. Nonutility Power Producers by State, Owner and}

Facility, as of December 31, 1997 (Continued)

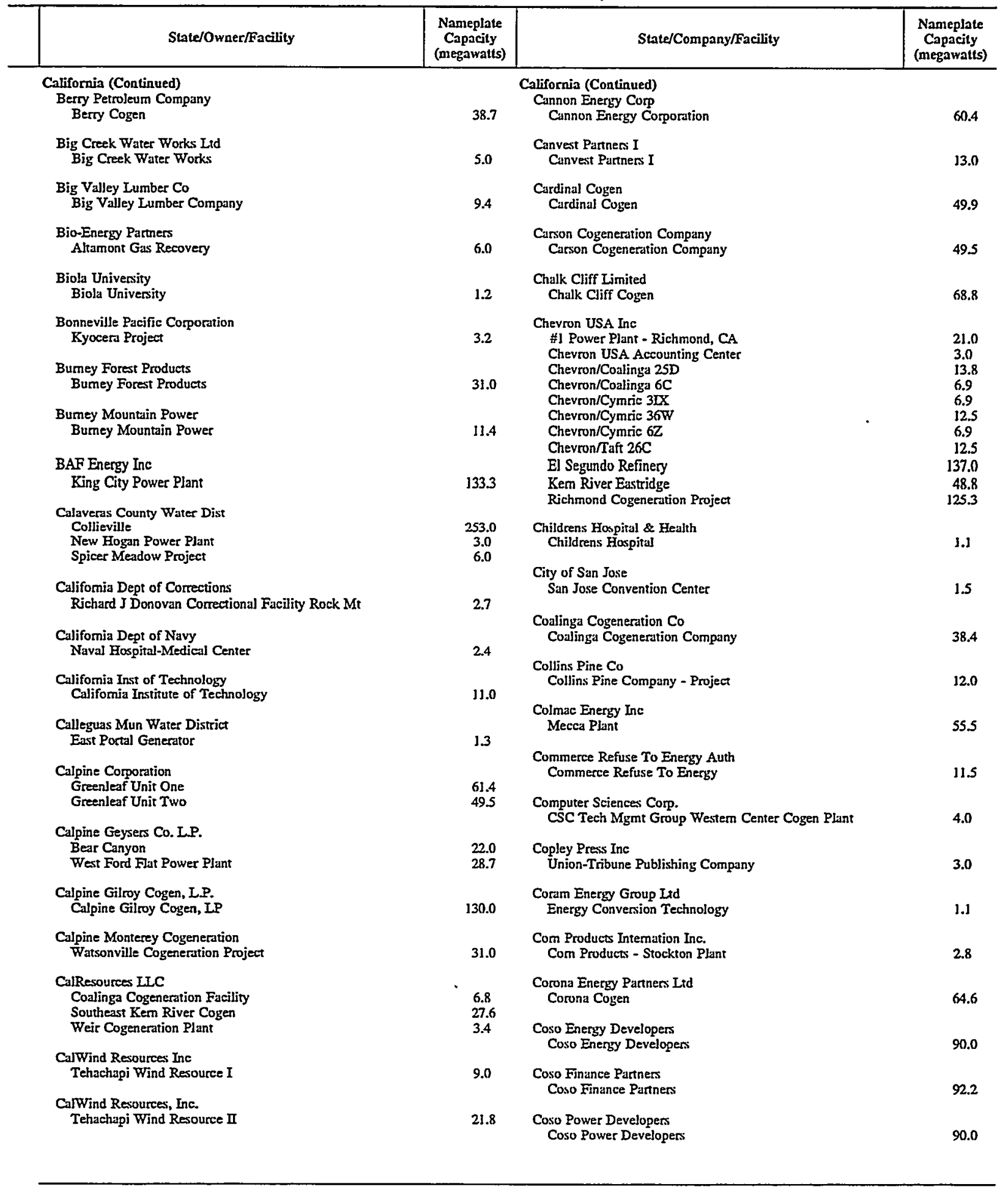

See footnoies at end of table. 
Table 24. Existing Capacity at U.S. Nonutility Power Producers by State, Owner and Facility, as of December 31, 1997 (Continued)

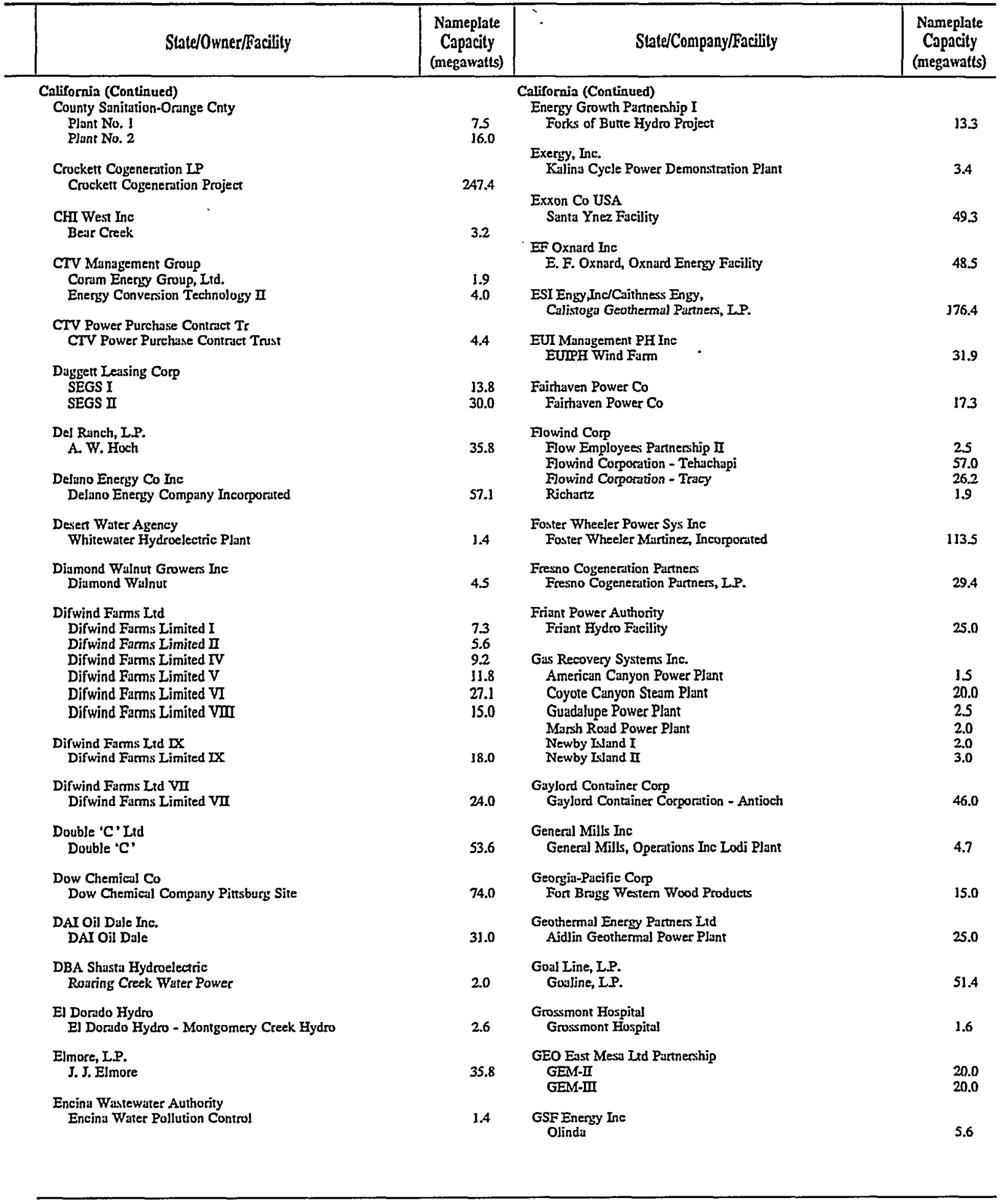

See footnotes at end of table. 
Table 24. Existing Capacity at U.S. Nonutility Power Producers by State, Owner and Facility, as of December 31, 1997 (Continued)

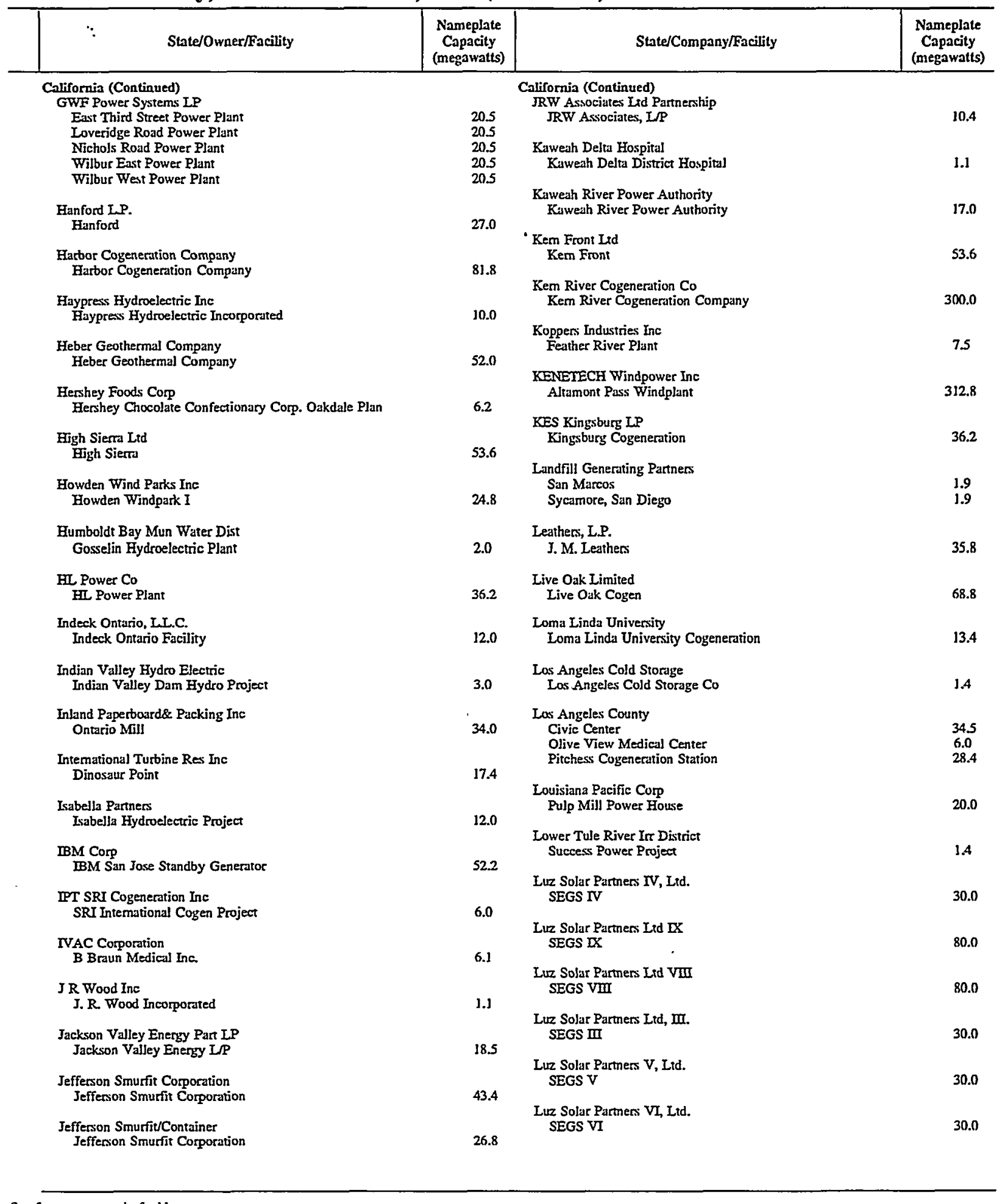

Sec footnotes at end of table. 
Table 24. Existing Capacity at U.S. Nonutility Power Producers by State, Owner and Facility, as of December 31, 1997 (Continued)

\begin{tabular}{|c|c|c|c|}
\hline State/Owner/Facility & $\begin{array}{l}\text { Nameplate } \\
\text { Capacity } \\
\text { (megawatts) }\end{array}$ & State/Company/Facility & $\begin{array}{c}\text { Nameplate } \\
\text { Capacity } \\
\text { (megawatts) }\end{array}$ \\
\hline $\begin{array}{l}\text { California (Continued) } \\
\text { Luz Solar Parmers VI, Ltd. } \\
\text { SEGS VI }\end{array}$ & 30.0 & $\begin{array}{l}\text { California (Continued) } \\
\text { Monterey Reg. Waste Mgnt Dist. } \\
\text { Marina Landfill Gas }\end{array}$ & 2.4 \\
\hline $\begin{array}{l}\text { LA County Sanitution Districts } \\
\text { Palos Verdes Gas-to-Energy Fucility } \\
\text { Puente Hills Energy Recovery } \\
\text { Spadra Lundfill Gas-to Energy } \\
\text { Total Energy Facilities }\end{array}$ & $\begin{array}{l}13.0 \\
54.2 \\
10.5 \\
25.0\end{array}$ & $\begin{array}{l}\text { Mother Energy Incorporated } \\
\text { Three Forks Hydroelectric Project } \\
\text { Mt Lassen Power } \\
\text { Mt. Lassen Power }\end{array}$ & $\begin{array}{l}1.3 \\
11.4\end{array}$ \\
\hline $\begin{array}{l}\text { LAX Airport } \\
\text { Centril Utility PJant }\end{array}$ & 8.0 & $\begin{array}{l}\text { Mr. Poso Cogeneration Co } \\
\text { Mr. Poso Cogeneration }\end{array}$ & 62.0 \\
\hline $\begin{array}{l}\text { M M Yolo Power ILC } \\
\text { M M Yolo Power LLC Facility }\end{array}$ & 2.6 & $\begin{array}{l}\text { MRWPCA } \\
\text { Monterey Regional Water Pollution Control Cogen }\end{array}$ & 1.7 \\
\hline $\begin{array}{l}\text { Madera-Chowchilla Power Auth } \\
\text { Site } 980+65\end{array}$ & 2.1 & $\begin{array}{l}\text { Nelson Creek Power Inc } \\
\text { Nelson Creek Power }\end{array}$ & 1.3 \\
\hline $\begin{array}{l}\text { Malacha Hydro Ltd Parmenhip } \\
\text { Muck Valley Hydroelectric }\end{array}$ & 29.9 & $\begin{array}{l}\text { Nevada Power Authority } \\
\text { Bowman }\end{array}$ & 3.6 \\
\hline $\begin{array}{l}\text { Mammoth Pacific IP } \\
\text { Mammoth-Pacific III }\end{array}$ & 15.0 & $\begin{array}{l}\text { New Charleston Power I, IP } \\
\text { Mesquite Resource Recovery Project }\end{array}$ & 17.9 \\
\hline $\begin{array}{l}\text { McKittrick Ltd } \\
\text { McKittrick Cogen }\end{array}$ & 68.8 & $\begin{array}{l}\text { North American Chemical Co } \\
\text { Argus Cogen Plant } \\
\text { westend Facility }\end{array}$ & $\begin{array}{l}55.0 \\
20.0\end{array}$ \\
\hline $\begin{array}{l}\text { Mega Renewables } \\
\text { Bidwell Ditch Project } \\
\text { Hatchet Creek Project }\end{array}$ & $\begin{array}{l}1.8 \\
6.9\end{array}$ & $\begin{array}{l}\text { North American Power Group } \\
\text { Ultrapower } 3 \text { - Blue Lake }\end{array}$ & 13.8 \\
\hline $\begin{array}{l}\text { Mendora Biomass Power Lłd } \\
\text { Mendota Biomass Power, Limited }\end{array}$ & 28.0 & $\begin{array}{l}\text { Northwind Energy, Inc } \\
\text { Northwind Energy, Incorporated }\end{array}$ & 13.1 \\
\hline $\begin{array}{l}\text { Mid Set Cogeneration Co } \\
\text { Mid-Set Cogeneration Company }\end{array}$ & 39.1 & $\begin{array}{l}\text { Nove Investments Inc } \\
\text { Nove Power PJant }\end{array}$ & 2.9 \\
\hline $\begin{array}{l}\text { Midsun Parmers, L.P. } \\
\text { Midsun }\end{array}$ & 27.0 & $\begin{array}{l}\text { Nuevo Energy Company } \\
\text { Dome Projett } \\
\text { Rincon Facility }\end{array}$ & $\begin{array}{l}6.1 \\
3.6\end{array}$ \\
\hline $\begin{array}{l}\text { Midway-Sunset Cogeneration Co } \\
\text { Midway Sunset Cogeneration Company }\end{array}$ & 234.0 & $\begin{array}{l}\text { Welport Lease Project } \\
\text { NAWP Inc. }\end{array}$ & 3.8 \\
\hline $\begin{array}{l}\text { Minnesota Methane } \\
\text { BKK Landfill }\end{array}$ & 6.5 & $\begin{array}{l}\text { Eust Winds Projects } \\
\text { NEO Corporation }\end{array}$ & 4.2 \\
\hline $\begin{array}{l}\text { Mobil Oil Corp } \\
\text { Torrance Refinery }\end{array}$ & 49.0 & NP Cogen, Inc & 0.6 \\
\hline $\begin{array}{l}\text { Modesto Energy Limited Prtmsp } \\
\text { Modesto Energy LP }\end{array}$ & 14.4 & O'Brien CA Couten Ied & 32.9 \\
\hline $\begin{array}{l}\text { Mogul Wind Corporation } \\
\text { Mogul Energy Corporation }\end{array}$ & 4.0 & $\begin{array}{l}\text { O'Brien CA Cogen Lid } \\
\text { OrBrien Califomia Cogen Limited } \\
\text { Oak Creek Energy System Ine II }\end{array}$ & 34.4 \\
\hline $\begin{array}{l}\text { Mojave Cogeneration Co } \\
\text { Mojave Cogeneration Company }\end{array}$ & 56.5 & $\begin{array}{l}\text { Oak Creek Energy Systems Incorporated } \\
\text { Ogden Energy }\end{array}$ & 24.0 \\
\hline $\begin{array}{l}\text { Mojave } 16 / 17 / 18 \\
\text { Mojave } 16 \\
\text { Mojave } 17 \\
\text { Mojave } 18\end{array}$ & $\begin{array}{l}30.0 \\
25.0 \\
30.0\end{array}$ & $\begin{array}{l}\text { Mammoth-Pacific II } \\
\text { Ogden Energy Group Inc. } \\
\text { Stanislaus Resource Recovery Facility }\end{array}$ & 15.0 \\
\hline $\begin{array}{l}\text { Monanto Company } \\
\text { Kelco Biopolymers Group of Monsanto Co, San Diego }\end{array}$ & 24.0 & $\begin{array}{l}\text { Ogden Energy Inc. } \\
\text { Mammoth-Pacific I } \\
\text { Ples I }\end{array}$ & $\begin{array}{l}10.0 \\
15.0\end{array}$ \\
\hline $\begin{array}{l}\text { Monterey Cnty Water Resc. Agcy } \\
\text { Nacimiento Hydro Project }\end{array}$ & 4.4 & $\begin{array}{l}\text { Oildale Cogenerution Prnr. LP } \\
\text { Oildale Cogen }\end{array}$ & 32.0 \\
\hline
\end{tabular}

See footnotes at end of table. 
Table 24. Existing Capacity at U.S. Nonutility Power Producers by State, Owner and Facility, as of December 31, 1997 (Continued)

\begin{tabular}{|c|c|c|c|}
\hline Stste/Owner/Facility & $\begin{array}{l}\text { Nameplate } \\
\text { Capacity } \\
\text { (niegawatts) }\end{array}$ & State/Company/Facility & $\begin{array}{l}\text { Nameplate } \\
\text { Capacity } \\
\text { (megrawatts) }\end{array}$ \\
\hline $\begin{array}{l}\text { California (Continued) } \\
\text { Olcese Water District } \\
\text { Rio Bravo Hydroelectric Project }\end{array}$ & 14.] & $\begin{array}{l}\text { California (Continued) } \\
\text { Rio Bravo Fresno } \\
\text { Rio Bravo Fresno }\end{array}$ & 28.0 \\
\hline $\begin{array}{l}\text { Ormesa Geothermal } \\
\text { Ormesa I }\end{array}$ & 31.2 & $\begin{array}{l}\text { Rio Bravo Jasmin } \\
\text { Rio Bravo Jasmin }\end{array}$ & 38.3 \\
\hline $\begin{array}{l}\text { Ormesa Geothermal II } \\
\text { Ormess Geothermal II }\end{array}$ & 24.0 & $\begin{array}{l}\text { Rio Bravo Poso } \\
\text { Rio Bravo Poso }\end{array}$ & 38.3 \\
\hline $\begin{array}{l}\text { Oroville Cogeneration IP } \\
\text { Oroville Cogeneration IP }\end{array}$ & 8.1 & $\begin{array}{l}\text { Rio Bravo Rocklin } \\
\text { Rio Bravo Rucklin }\end{array}$ & 28.0 \\
\hline $\begin{array}{l}\text { Oxnard City of } \\
\text { Oxnard Wastewater Treatment Plant }\end{array}$ & 1.5 & $\begin{array}{l}\text { Ripon Cugeneration Inc. } \\
\text { San Gabriel Facility }\end{array}$ & 36.0 \\
\hline $\begin{array}{l}\text { Pacific Lumber Co } \\
\text { The Pacific Lumber Company }\end{array}$ & 25.0 & $\begin{array}{l}\text { Ripon Cogeneration, Inc } \\
\text { Ripon Mill }\end{array}$ & 49.5 \\
\hline $\begin{array}{l}\text { Pacific Oroville Power Co } \\
\text { Pacific Oroville Power, Inc. }\end{array}$ & 18.8 & $\begin{array}{l}\text { Rockwell Intemational Corp } \\
\text { SCTI/ Power Pak }\end{array}$ & 26.9 \\
\hline $\begin{array}{l}\text { Pacific Recovery Corp } \\
\text { Otay } \\
\text { Oxnard } \\
\text { Salinas } \\
\text { Santa Clara }\end{array}$ & $\begin{array}{l}3.8 \\
5.6 \\
1.5 \\
1.5\end{array}$ & $\begin{array}{l}\text { RSD Power Partners L/P } \\
\text { San Diego Power \& Cooling Company } \\
\text { Saint Agnes Medical Center } \\
\text { Saint Agnes Medical Center }\end{array}$ & 2.6 \\
\hline $\begin{array}{l}\text { Pacific Ultrapower Chinese } \\
\text { Ultrapower Chinese Station }\end{array}$ & 25.0 & $\begin{array}{l}\text { Saint John 's Health Center } \\
\text { Saint John 's Health Center }\end{array}$ & 1.1 \\
\hline $\begin{array}{l}\text { Palm Sptings City of } \\
\text { Municipal Cogen Plant }\end{array}$ & 1.3 & $\begin{array}{l}\text { Salinas River Cogeneration Co } \\
\text { Salinas River Cogeneration Company }\end{array}$ & 38.9 \\
\hline $\begin{array}{l}\text { Palomar Memorial Hospital } \\
\text { Palomar Medical Center }\end{array}$ & 1.3 & $\begin{array}{l}\text { Salk Institute } \\
\text { Salk Institute }\end{array}$ & 1.3 \\
\hline $\begin{array}{l}\text { Paper Pak Products Inc } \\
\text { Park Pak Products }\end{array}$ & 1.4 & $\begin{array}{l}\text { Salton Sea PwiGen } \# 4 / F i s h \text { Lake } \\
\text { Salion Sea Unit } \# 4\end{array}$ & 51.0 \\
\hline $\begin{array}{l}\text { Point Arguello Pipeline Co } \\
\text { Gaviota Oil Plant }\end{array}$ & 17.5 & $\begin{array}{l}\text { Salton Sea PwrGeneration L.P \# } 1 \\
\text { Salton Sea Unit \#1 }\end{array}$ & 10.0 \\
\hline $\begin{array}{l}\text { Praxair Inc. } \\
\text { Linde Wilmington }\end{array}$ & 31.0 & $\begin{array}{l}\text { Salton Sea PwrGeneration I.P } \# 2 \\
\text { Salton Sea Unit } \# 2\end{array}$ & 20.0 \\
\hline $\begin{array}{l}\text { Procter \& Gamble Co } \\
\text { Oxnard } \\
\text { Sacramento }\end{array}$ & $\begin{array}{l}68.8 \\
21.1\end{array}$ & $\begin{array}{l}\text { Salton Sea PwrGeneration L.P \#3 } \\
\text { Salton Sea Unit } \# 3\end{array}$ & 54.0 \\
\hline $\begin{array}{l}\text { POSDEF Power Company LP } \\
\text { Pon of Stockton District Energy Facility }\end{array}$ & 50.0 & $\begin{array}{l}\text { San Anionio Community Hospital } \\
\text { San Antonio Community Hospital }\end{array}$ & 1.8 \\
\hline $\begin{array}{l}\text { Qualcomm Inc } \\
\text { Central Plant }\end{array}$ & 2.4 & $\begin{array}{l}\text { San Diego City of } \\
\text { Gas Utilization Facility } \\
\text { San Diego County Water Auth }\end{array}$ & 2.7 \\
\hline $\begin{array}{l}\text { Recot Inc } \\
\text { Recot Inc. Cogeneration PJant }\end{array}$ & 6.] & San Diego State University & 2.1 \\
\hline $\begin{array}{l}\text { Red Top Cogeneration Project } \\
\text { Red Top Cogeneration Project, IP }\end{array}$ & 3.6 & $\begin{array}{l}\text { San Diego State University } \\
\text { San Gabriel Hydroelectric Asso }\end{array}$ & 2.5 \\
\hline $\begin{array}{l}\text { Rhone-Poulene Inc } \\
\text { Martinez Regen Sulfuric Acid Plant } \\
\text { Rhone-Poujene Dominguez Plant } \\
\text { Ridgewood/Byron Power Parmers }\end{array}$ & $\begin{array}{l}4.0 \\
5.0\end{array}$ & $\begin{array}{l}\text { San Gabriel Hydroelectric Project } \\
\text { San Gabriel Valley Mun Wtr Dt } \\
\text { San Dimas Wash Generating Station }\end{array}$ & 5.0 \\
\hline Ridgewoud/Byron Power Partners L.P. & 6.5 & $\begin{array}{l}\text { San Gorgonio Wind Farms Inc } \\
\text { San Gorgonio Farms Wind Energy Power PJant }\end{array}$ & 33.7 \\
\hline
\end{tabular}

See footnotes at end of table. 
Table 24. Existing Capacity at U.S. Nonutility Power Producers by State, Owner and Facility, as of December 31, 1997 (Continued)

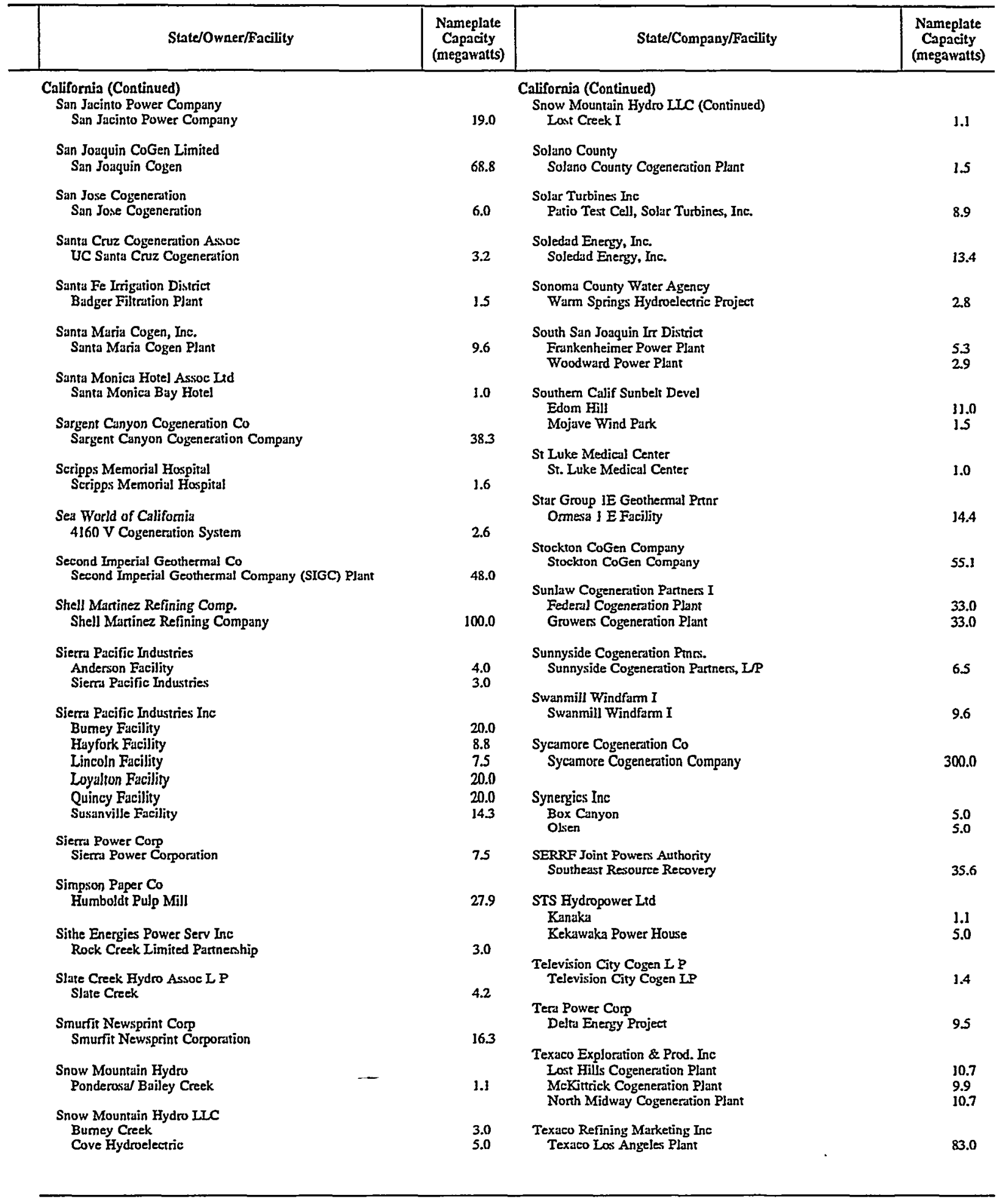

See footnotes at end of tuble. 
Table 24. Existing Capacity at U.S. Nonutility Power Producers by State, Owner and Facility, as of December 31, 1997 (Continued)

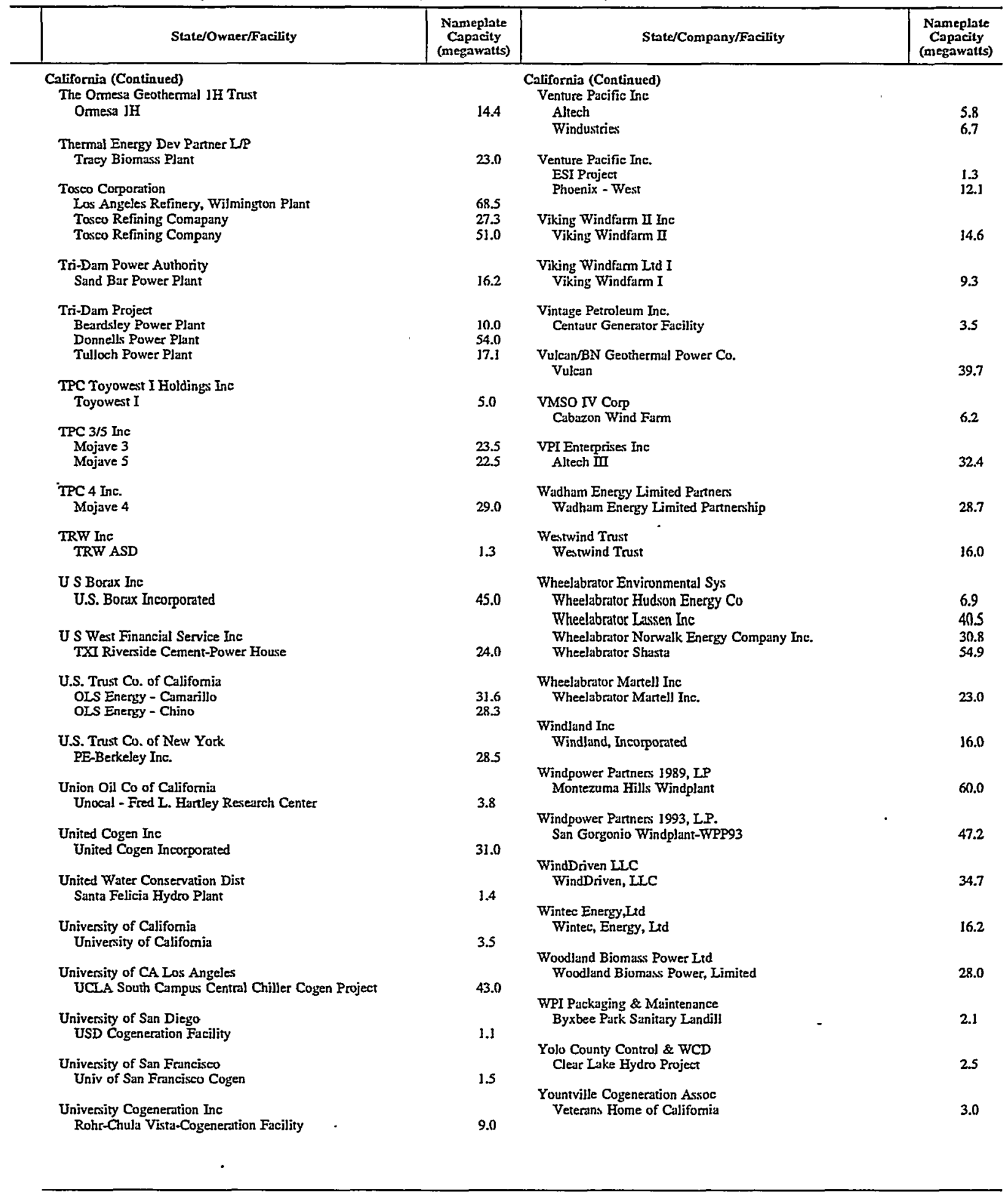

See footnotes at end of table. 
Table 24. Existing Capacity at U.S. Nonutility Power Producers by State, Owner and Facility, as of December 31, 1997 (Continued)

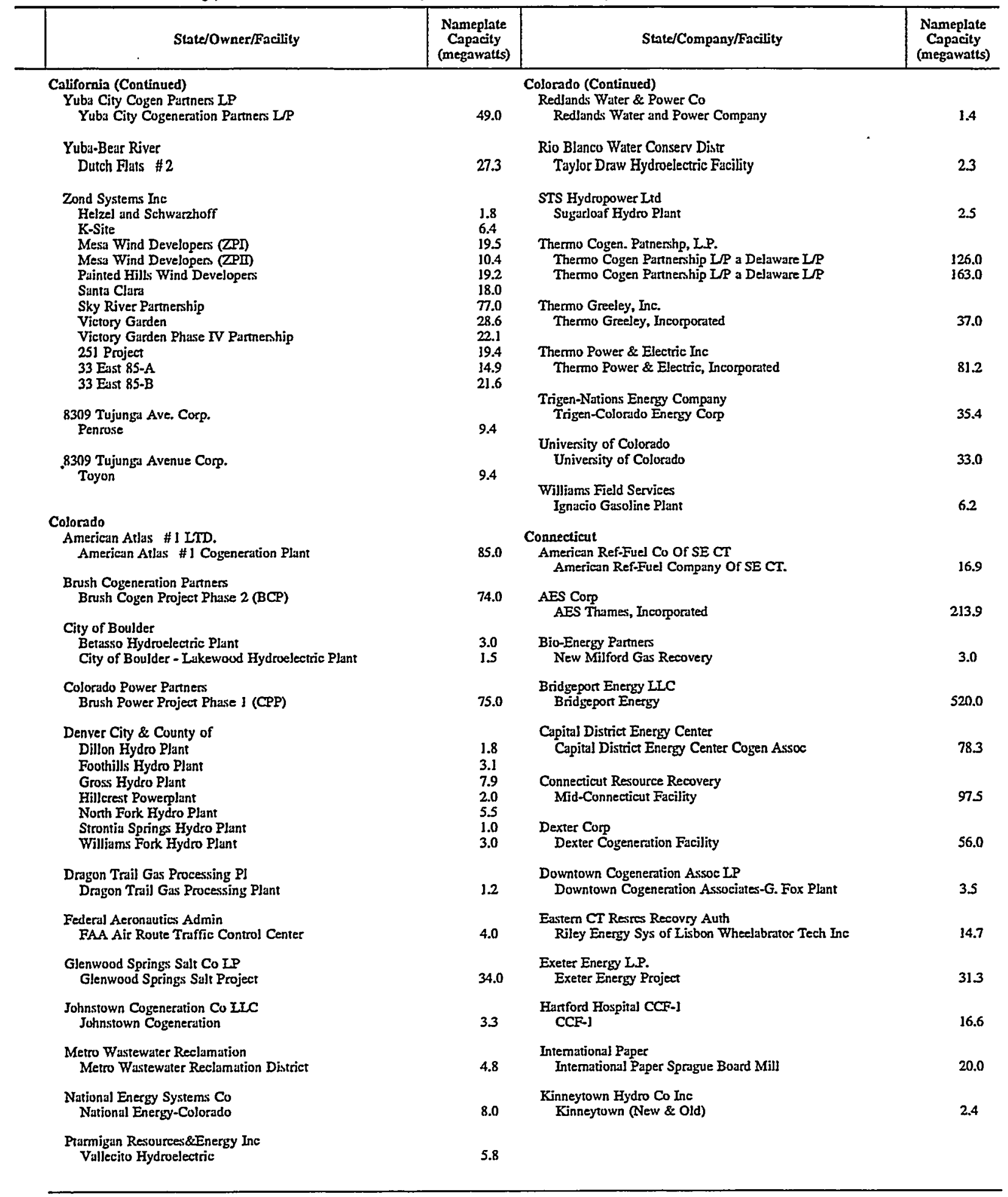

See footnotes at end of table. 


\section{Table 24. Existing Capacity at U.S. Nonutility Power Producers by State, Owner and}

Facility, as of December 31, 1997 (Continued)

\begin{tabular}{|c|c|c|c|}
\hline State/Owner/Facility & $\begin{array}{c}\text { Nameplate } \\
\text { Capacity } \\
\text { (megawatts) }\end{array}$ & State/Company/Facility & $\begin{array}{c}\text { Nameplate } \\
\text { Capacity } \\
\text { (megawatts) }\end{array}$ \\
\hline $\begin{array}{l}\text { Conneclicut (Continued) } \\
\text { McCallum Enter I Ltd Part } \\
\text { McCallum Enterprise I - Limited Partnership }\end{array}$ & 8.7 & $\begin{array}{l}\text { Florida (Continued) } \\
\text { Champion International Corp } \\
\text { Pensacola, Florida }\end{array}$ & 82.8 \\
\hline $\begin{array}{l}\text { Ogden Projects Inc } \\
\text { Bristol Resource Recovery Facility } \\
\text { Wallingford Resource Recovery Facility }\end{array}$ & $\begin{array}{l}16.3 \\
11.0\end{array}$ & $\begin{array}{l}\text { Citrus World Inc. } \\
\text { Cirrus World Inc. }\end{array}$ & 3.5 \\
\hline $\begin{array}{l}\text { Pfizer Inc } \\
\text { Pfizer, Incorporated }\end{array}$ & 25.0 & $\begin{array}{l}\text { City of Key West } \\
\text { Southermmost Waste To Energy Facility }\end{array}$ & 3.5 \\
\hline $\begin{array}{l}\text { Quinebaug Associates LLC } \\
\text { Quinebaug Five Mile Project }\end{array}$ & 2.4 & $\begin{array}{l}\text { City of Tampa } \\
\text { McKay Bay Facility }\end{array}$ & 22.2 \\
\hline $\begin{array}{l}\text { Resource Technology Corp. } \\
\text { Shelton Landfill Gas Recovery Elect Gen Facility }\end{array}$ & 1.8 & $\begin{array}{l}\text { Cutrale Citrus Juices USA Inc } \\
\text { Cutrale Citrus Juices USA Inc (Leesburg) }\end{array}$ & 3.6 \\
\hline $\begin{array}{l}\text { Southwire Co } \\
\text { Wyre Wynd Hydro }\end{array}$ & 2.7 & $\begin{array}{l}\text { Cutrale Citrus Juices USA, Inc } \\
\text { Cutrale Citrus Juices USA, Ine }\end{array}$ & 8.5 \\
\hline $\begin{array}{l}\text { Stone Container Corp } \\
\text { Stone Container Corporation - Uncusville }\end{array}$ & 2.8 & $\begin{array}{l}\text { CF Industries Inc } \\
\text { CFI Plant City Phosphate Complex }\end{array}$ & 40.5 \\
\hline $\begin{array}{l}\text { The Metropolitian District } \\
\text { Colebrook Hydroelectric }\end{array}$ & 3.0 & $\begin{array}{l}\text { De Soto Oil \& Gas, Inc. } \\
\text { Blackjack Creek Treating }\end{array}$ & 2.0 \\
\hline Goodwin Hydroelectric & 3.3 & $\begin{array}{l}\text { Energy Development Corp } \\
\text { Energy Development Corporation }\end{array}$ & 74.9 \\
\hline $\begin{array}{l}\text { United Technologies } \\
\text { United Technologies }\end{array}$ & 25.8 & $\begin{array}{l}\text { Farmland Hydro Ird Partner } \\
\text { Farmland Hydro, I/P }\end{array}$ & 38.2 \\
\hline $\begin{array}{l}\text { Wheelabrator Environmental Sys } \\
\text { Bridgepor Resco }\end{array}$ & 67.0 & $\begin{array}{l}\text { First Union National Bk of FL } \\
\text { Fist Union National Bank of Forida }\end{array}$ & 2.0 \\
\hline $\begin{array}{l}\text { Delaware } \\
\text { E I DuPont De Nemours \& Co } \\
\text { Seaford, Delaware Plant }\end{array}$ & 30.0 & $\begin{array}{l}\text { Forida State Hospital } \\
\text { Florida State Hospital/Rower Plant }\end{array}$ & 65 \\
\hline $\begin{array}{l}\text { General Chemical Corp } \\
\text { General Chemical Corp }\end{array}$ & 4.5 & $\begin{array}{l}\text { Ford Master Credit Company } \\
\text { Bay Revource Management Center }\end{array}$ & 13.6 \\
\hline $\begin{array}{l}\text { Star Enterprises } \\
\text { Delaware City Plant }\end{array}$ & 141.2 & $\begin{array}{l}\text { Gator Generating Co, Ltd Part } \\
\text { Osceola Power Limited Partnership }\end{array}$ & 65.0 \\
\hline $\begin{array}{l}\text { Florida } \\
\text { Anheuser-Busch Inc } \\
\text { Anheuser-Busch,Incorporated-Jacksonville Brewery }\end{array}$ & 8.7 & $\begin{array}{l}\text { Georgia-Pacific Corp } \\
\text { Palatka Operations }\end{array}$ & 87.5 \\
\hline $\begin{array}{l}\text { Aubumdale Power Partness I P } \\
\text { Aubumdale Power Parmes, Limited Partmership }\end{array}$ & 192.8 & $\begin{array}{l}\text { Hardee Power Partness Lld } \\
\text { Hardee Power Station }\end{array}$ & 383.5 \\
\hline $\begin{array}{l}\text { Baptist Memorial Hospital } \\
\text { Baptist Medical Center }\end{array}$ & 13.7 & $\begin{array}{l}\text { Hillsborough County } \\
\text { Hillsborough County Resource Recovery Facility }\end{array}$ & 29.0 \\
\hline $\begin{array}{l}\text { Bio-Energy Partners } \\
\text { CSL Gas Recovery }\end{array}$ & 15.0 & $\begin{array}{l}\text { Indiantown Cogeneration IP } \\
\text { Indiantown Cogeneration Facility }\end{array}$ & 330.0 \\
\hline $\begin{array}{l}\text { Buckeye Florida L/P } \\
\text { Buckeye Florida L/P }\end{array}$ & 44.4 & $\begin{array}{l}\text { IMC-Agrico Company } \\
\text { IMC-Agrico Company - New Wales Operations } \\
\text { IMC-Agrico Company - Nichols Operstions }\end{array}$ & $\begin{array}{l}68.5 \\
13.3\end{array}$ \\
\hline $\begin{array}{l}\text { Cargill Fertilizer Inc } \\
\text { Cargill Fertilizer, Inc. } \\
\text { Cargill Fertilizer, Inc. (Batow) }\end{array}$ & $\begin{array}{l}41.4 \\
82.0\end{array}$ & $\begin{array}{l}\text { IMC-Agrico Company - South Pierce Operations } \\
\text { Jefferson Smurit Corp } \\
\text { Jefferson Smurfit Corp }\end{array}$ & 118.4 \\
\hline $\begin{array}{l}\text { Cedar Bay Generating Co., L.P. } \\
\text { Cedar Bay Generating Company I/P }\end{array}$ & 285.0 & $\begin{array}{l}\text { Jeffersion Smurfint Corp } \\
\text { Jeffersion Smurfit Corporation-Jacksionvijle }\end{array}$ & 43.5 \\
\hline $\begin{array}{l}\text { Central Power and Lime, Inc. } \\
\text { Central Power and Lime, Incoporated }\end{array}$ & 125.0 & $\begin{array}{l}\text { John Hancock Mutual Life Ins. } \\
\text { Merritt Square Mall }\end{array}$ & 4.9 \\
\hline
\end{tabular}

See foomotes at end of table. 
Table 24. Existing Capacity at U.S. Nonutility Power Producers by State, Owner and Facility, as of December 31, 1997 (Continued)

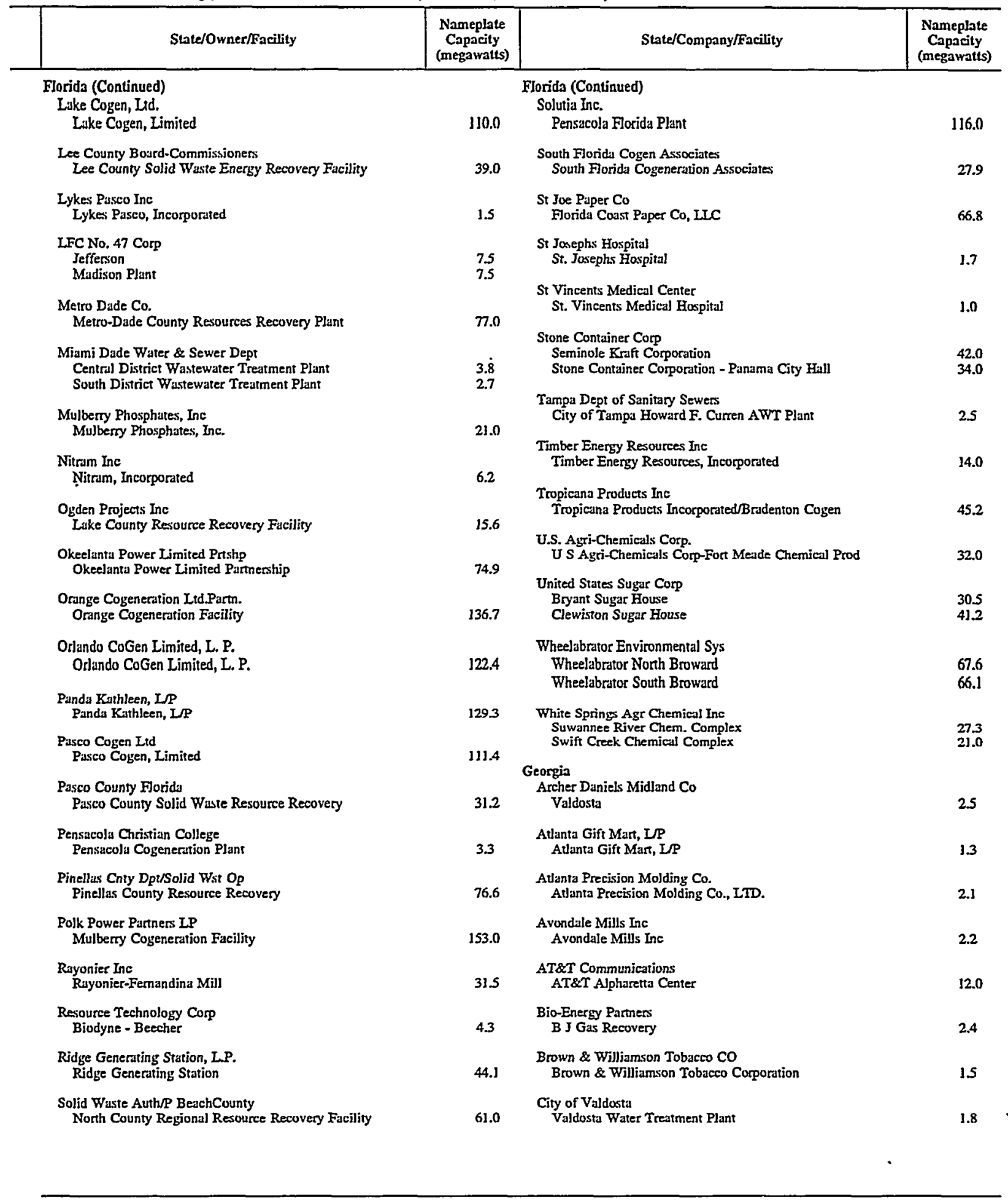

See footnotes at end of table. 
Table 24. Existing Capacity at U.S. Nonutility Power Producers by State, Owner and Facility, as of December 31, 1997 (Continued)

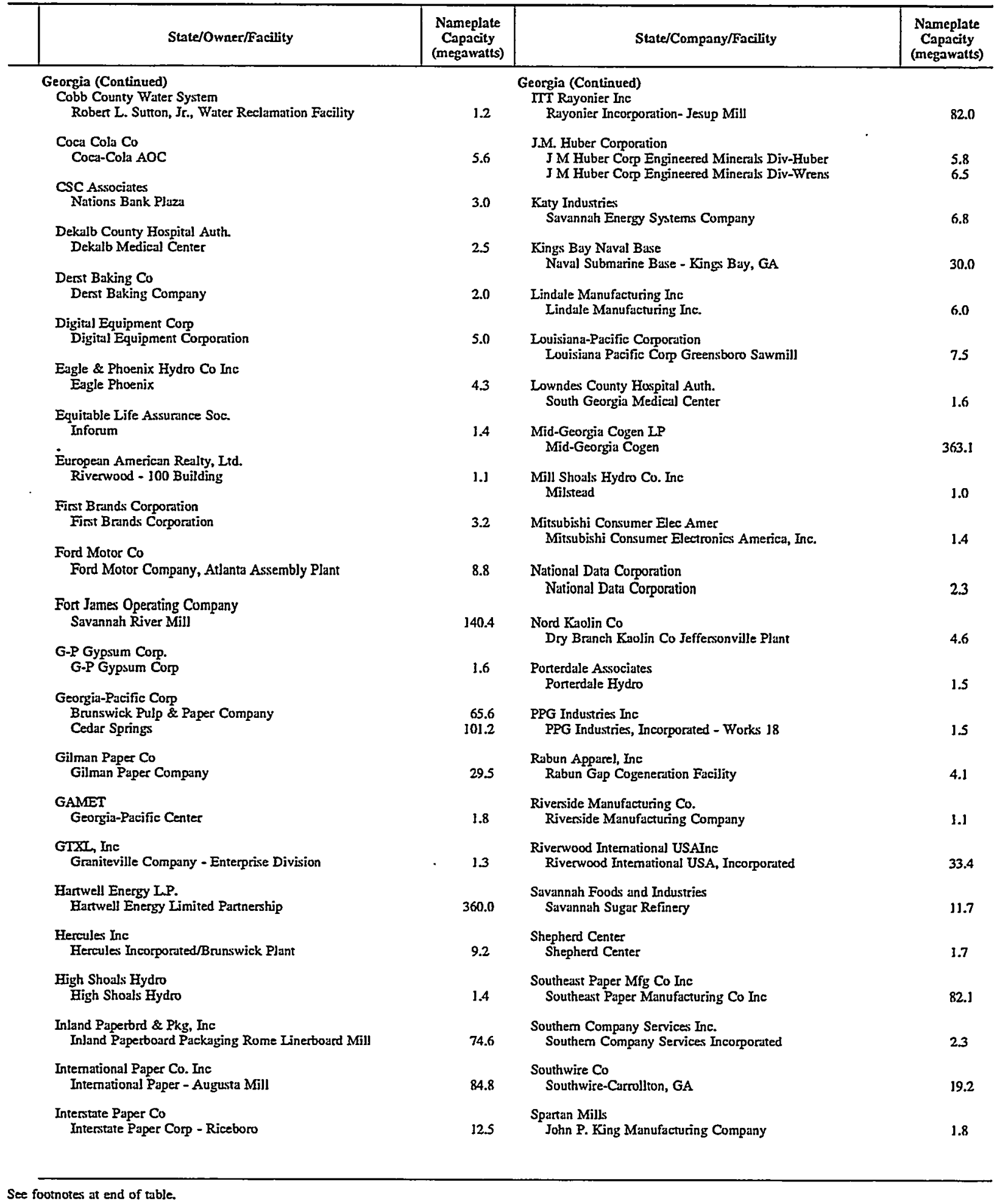

See footnotes at end of table. 
Table 24. Existing Capacity at U.S. Nonutility Power Producers by State, Owner and Facility, as of December 31, 1997 (Continued)

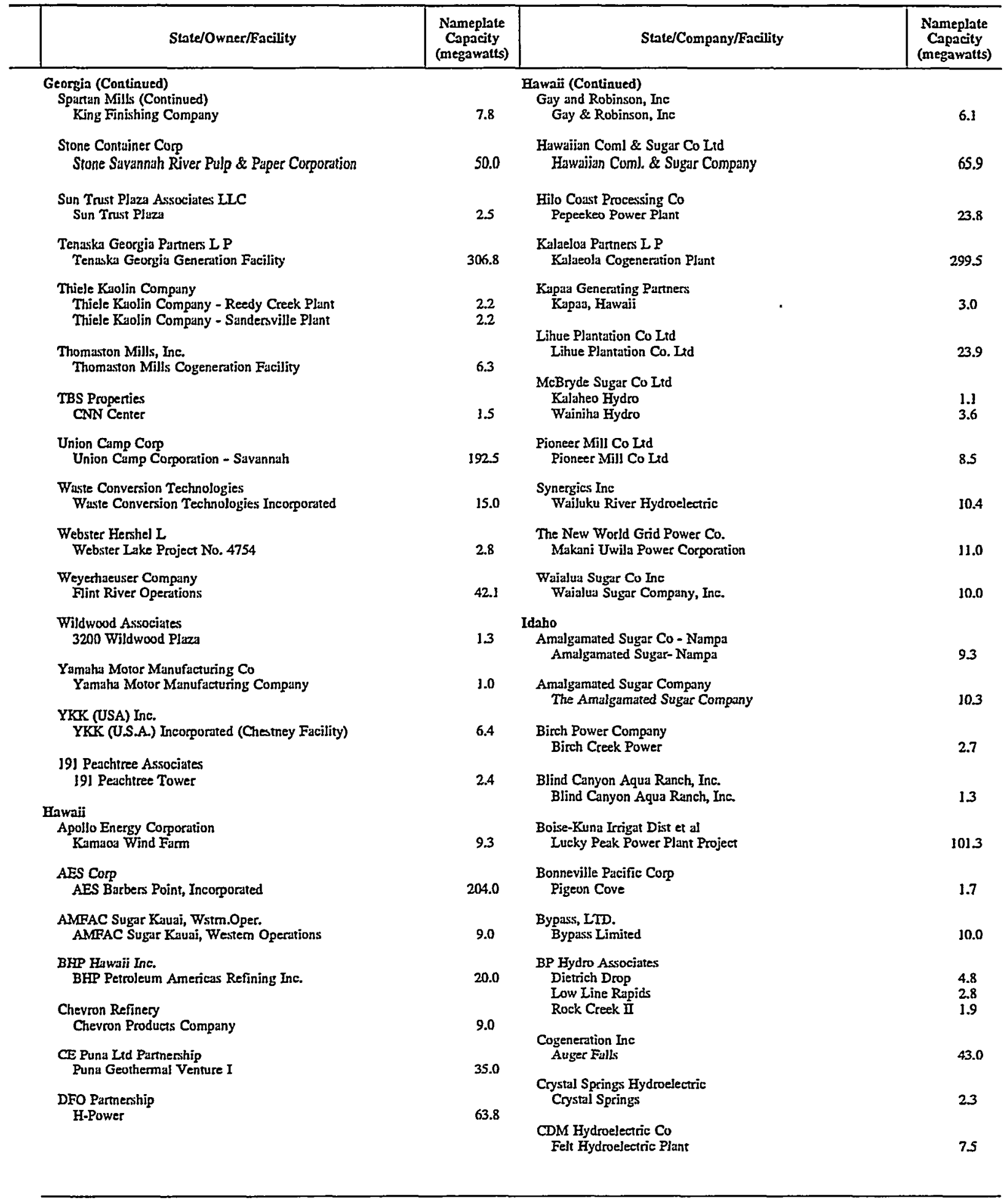

See footnotes at end of table. 


\section{Table 24. Existing Capacity at U.S. Nonutility Power Producers by State, Owner and}

Facility, as of December 31, 1997 (Continued)

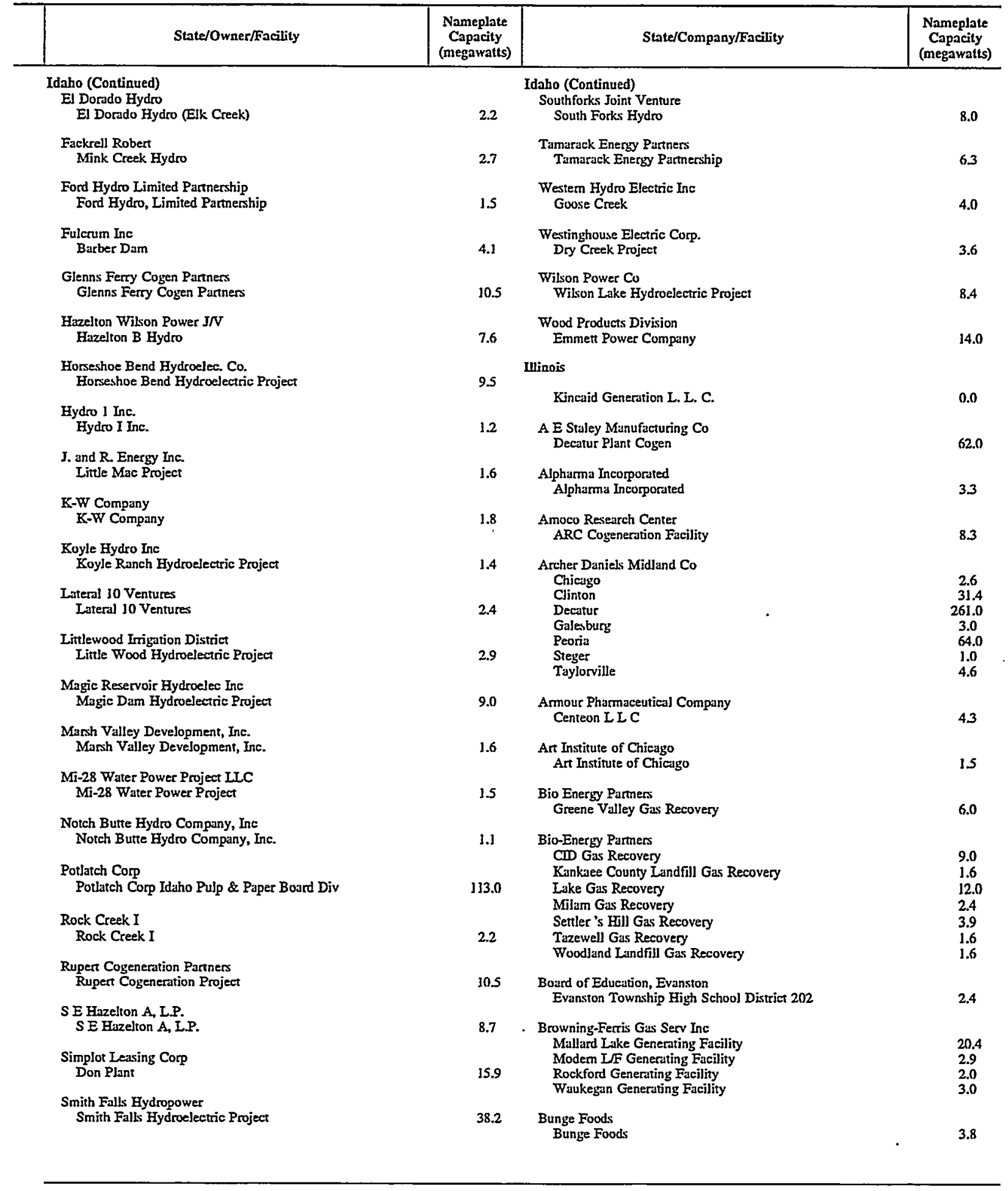

See footnotes at end of rable. 

Table 24. Existing Capacity at U.S. Nonutility Power Producers by State, Owner and
Facility, as of December 31, 1997 (Continued)

\begin{tabular}{|c|c|c|c|}
\hline State/Owner/Facility & $\begin{array}{c}\text { Nameplate } \\
\text { Capacity } \\
\text { (megawalts) }\end{array}$ & State/Company/Facility & $\begin{array}{c}\text { Nameplate } \\
\text { Capacity } \\
\text { (megawatts) }\end{array}$ \\
\hline $\begin{array}{l}\text { Ulinois (Continued) } \\
\text { City of Kankakee } \\
\text { Kankakee Hydruelectric Facility }\end{array}$ & 1.2 & $\begin{array}{l}\text { Ulinois (Continued) } \\
\text { Lahoff Gruin Co } \\
\text { Lauhoff Grain Company }\end{array}$ & 20.0 \\
\hline $\begin{array}{l}\text { Com Products International } \\
\text { Com Products-Illinois }\end{array}$ & 59.5 & $\begin{array}{l}\text { Little Co of Mary Huspital } \\
\text { Iittle Company of Mary Hospital }\end{array}$ & 4.0 \\
\hline $\begin{array}{l}\text { Cyprus Rod Chicago, Inc. } \\
\text { Cyprus Rod Chicago, Inc. }\end{array}$ & 2.3 & $\begin{array}{l}\text { LTV Steel Co Inc } \\
\text { ITV Steel-So. Chicago Works }\end{array}$ & 9.5 \\
\hline $\begin{array}{l}\text { CGE Ford Height, ILC } \\
\text { CGE Ford Heights Waste Tires to Energy Project }\end{array}$ & 23.5 & $\begin{array}{l}\text { M\&MMars Inc } \\
\text { M\&MNMats - Chicago }\end{array}$ & 3.5 \\
\hline $\begin{array}{l}\text { Dixon Marquetre } \\
\text { Dixon Marquetre }\end{array}$ & 14.1 & $\begin{array}{l}\text { Marathon Oil Co } \\
\text { Illinois Refining Division }\end{array}$ & 12.0 \\
\hline $\begin{array}{l}\text { Duraco Products, Incorporated } \\
\text { Duraco Products, Incorporated }\end{array}$ & 1.6 & $\begin{array}{l}\text { Martap Corporation } \\
\text { IT Cogeneration Facility }\end{array}$ & 8.0 \\
\hline $\begin{array}{l}\text { DuPage County Environmental } \\
\text { DuPage County Region } 9 \text { West Wastewater Treatment }\end{array}$ & 1.5 & $\begin{array}{l}\text { Metro Water Reclamation } \\
\text { Iockpon Powerhouse }\end{array}$ & 13.5 \\
\hline $\begin{array}{l}\text { Fox Merco Warer Reclamation } \mathrm{Di} \\
\text { Fox Merto Warer Reclamation District }\end{array}$ & 2.2 & $\begin{array}{l}\text { Mobil Oil Corp } \\
\text { Joliet Refinery }\end{array}$ & 39.6 \\
\hline $\begin{array}{l}\text { FSC Paper Co/Wisconsin Tissue } \\
\text { Alsip Paper Condominium Association }\end{array}$ & 8.6 & $\begin{array}{l}\text { Moose International } \\
\text { Mooseheart Power House }\end{array}$ & 2.0 \\
\hline $\begin{array}{l}\text { General Mills, Inc. } \\
\text { General Mills - West Chicago }\end{array}$ & 6.6 & $\begin{array}{l}\text { MWRD:W/SW Facility } \\
\text { Stickney Water Reclamation PJant }\end{array}$ & 3.0 \\
\hline $\begin{array}{l}\text { Hoffer Plasties } \\
\text { Hoffer Plastics }\end{array}$ & 7.2 & $\begin{array}{l}\text { Nalco Chemical Co } \\
\text { NALCO Chemical Company }\end{array}$ & 4.7 \\
\hline $\begin{array}{l}\text { Huey Forest Products } \\
\text { Tim Huey Comporation(DBA) - Huey Forest Products }\end{array}$ & 3.0 & $\begin{array}{l}\text { Northem Illinois Gas Co } \\
\text { Northem Ilinois Gas Company }\end{array}$ & 2.6 \\
\hline $\begin{array}{l}\text { Hydro-Op One Assocjates } \\
\text { Dayton Hydro }\end{array}$ & 3.6 & $\begin{array}{l}\text { Panduit Corporation } \\
\text { Panduit Corporation - Tinley Park }\end{array}$ & 3.5 \\
\hline $\begin{array}{l}\text { Ingersoll Milling } \\
\text { Ingersoll Milling Machine Company }\end{array}$ & 4.9 & $\begin{array}{l}\text { Pekin Paperboard Company IIP } \\
\text { Pekin Paperboard Company }\end{array}$ & 1.5 \\
\hline $\begin{array}{l}\text { Interstate Brands Co } \\
\text { Chicago Baking Co }\end{array}$ & 1.1 & $\begin{array}{l}\text { PPG Industries Inc } \\
\text { PPG Industries, Incorporated - Works } 14\end{array}$ & 4.8 \\
\hline $\begin{array}{l}\text { IMC Nitrogen Co. } \\
\text { Ime Nitrogen Co }\end{array}$ & 3.5 & $\begin{array}{l}\text { Resource Technology Corp } \\
\text { Biodyne - Congress } \\
\text { Biodyne - Pontiac }\end{array}$ & $\begin{array}{l}4.3 \\
1.8\end{array}$ \\
\hline $\begin{array}{l}\text { IVEX Corporation } \\
\text { IVEX Coporation }\end{array}$ & 3.8 & $\begin{array}{l}\text { Biodyne-Lansing } \\
\text { Biodyne-Lyons } \\
\text { Biodyne-Peoria }\end{array}$ & $\begin{array}{l}2.2 \\
4.5 \\
4.3\end{array}$ \\
\hline $\begin{array}{l}\text { Jacobs Energy Corporation } \\
\text { Jacobs Energy Corporation }\end{array}$ & 5.7 & $\begin{array}{l}\text { Biodyne-Springfield } \\
\text { Rock Tenn Company }\end{array}$ & 3.3 \\
\hline $\begin{array}{l}\text { Jeffersion Smurit Corp } \\
\text { Jefferson Smurtit Corporation (U.S.) }\end{array}$ & 12.5 & $\begin{array}{l}\text { Rock Tenn Company } \\
\text { Shell Wood River Refining Co. }\end{array}$ & 3.0 \\
\hline $\begin{array}{l}\text { John Deere Harvester Works Co } \\
\text { John Deere Harverter Works }\end{array}$ & 10.0 & $\begin{array}{l}\text { Shell Wood River Refining Company } \\
\text { Sherman Hospital }\end{array}$ & 20.0 \\
\hline $\begin{array}{l}\text { Klein Tools Inc } \\
\text { Klein Tools Incorporated - Chicago }\end{array}$ & 3.6 & $\begin{array}{l}\text { Sherman Hoxpital } \\
\text { Sisters of the Holy Family }\end{array}$ & 1.6 \\
\hline $\begin{array}{l}\text { Koppers Industries Inc } \\
\text { Chicago Plant }\end{array}$ & 7.5 & $\begin{array}{l}\text { Saint Mary of Nazareth Hospital Center } \\
\text { Sisters of Resurrection Hospl }\end{array}$ & 2.4 \\
\hline $\begin{array}{l}\text { KMSS Bakery Power Partners L P } \\
\text { Entenmann 's Co-Generation Facility }\end{array}$ & 1.6 & Resurrection Hospital & 1.5 \\
\hline
\end{tabular}

See footnotes at end of table. 


\section{Table 24. Existing Capacity at U.S. Nonutility Power Producers by State, Owner and Facility, as of December 31, 1997 (Continued)}

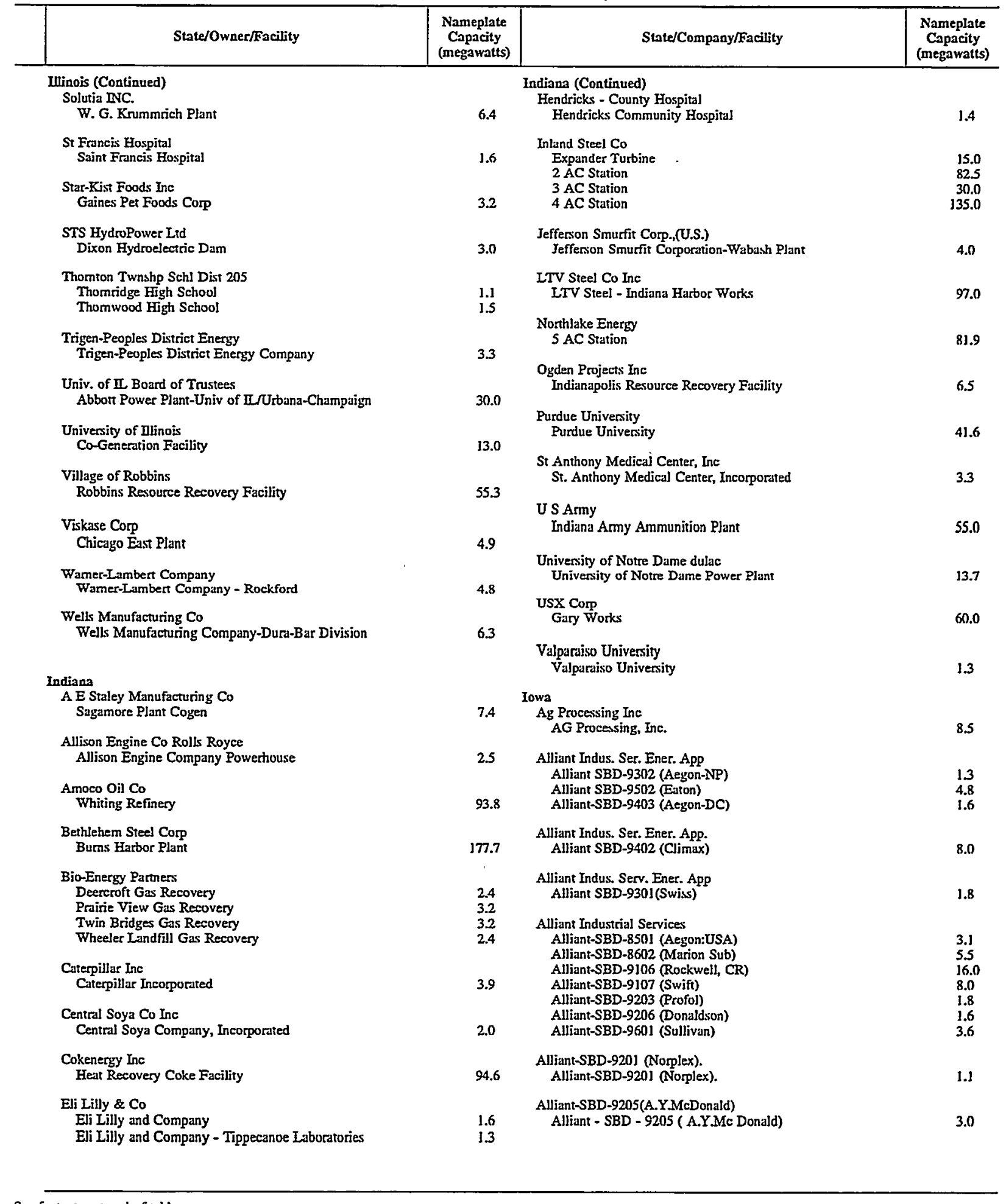

See footnotes at end of table. 
Table 24. Existing Capacity at U.S. Nonutility Power Producers by State, Owner and Facility, as of December 31, 1997 (Continued)

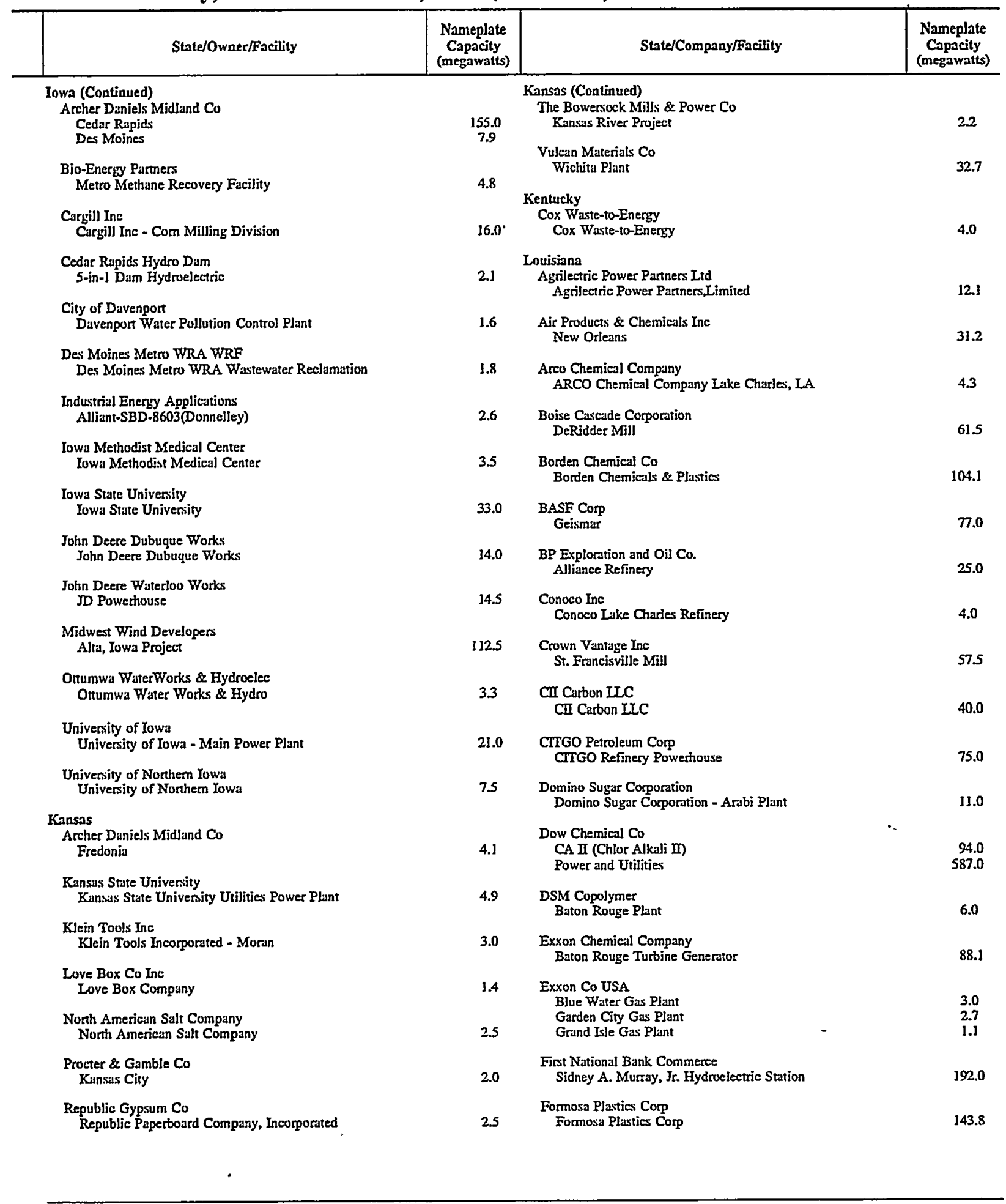

See footnotes at end of table. 


\section{Table 24. Existing Capacity at U.S. Nonutility Power Producers by State, Owner and}

Facility, as of December 31, 1997 (Continued)

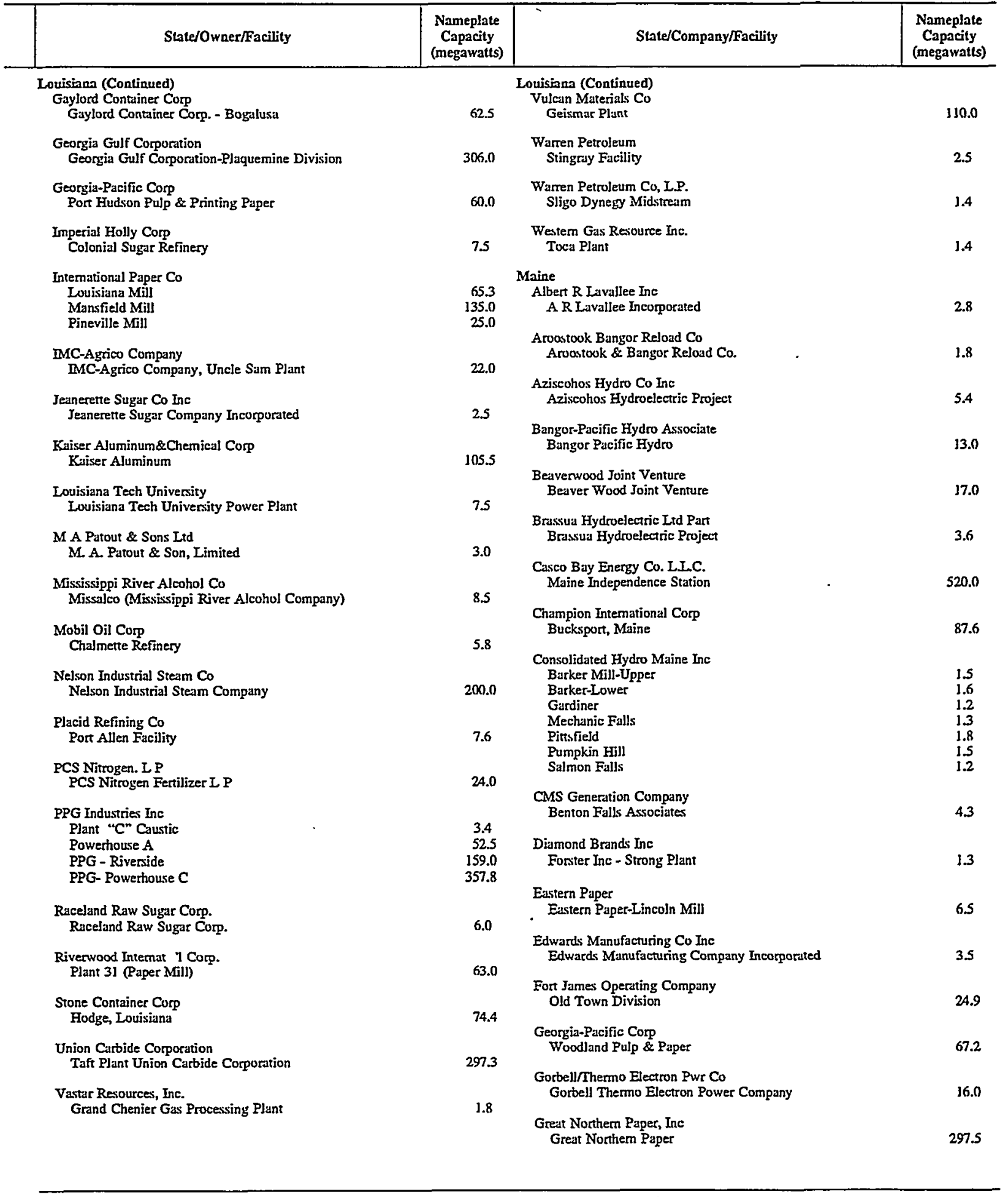

See footnotes at end of table. 
Table 24. Existing Capacity at U.S. Nonutility Power Producers by State, Owner and Facility, as of December 31, 1997 (Continued)

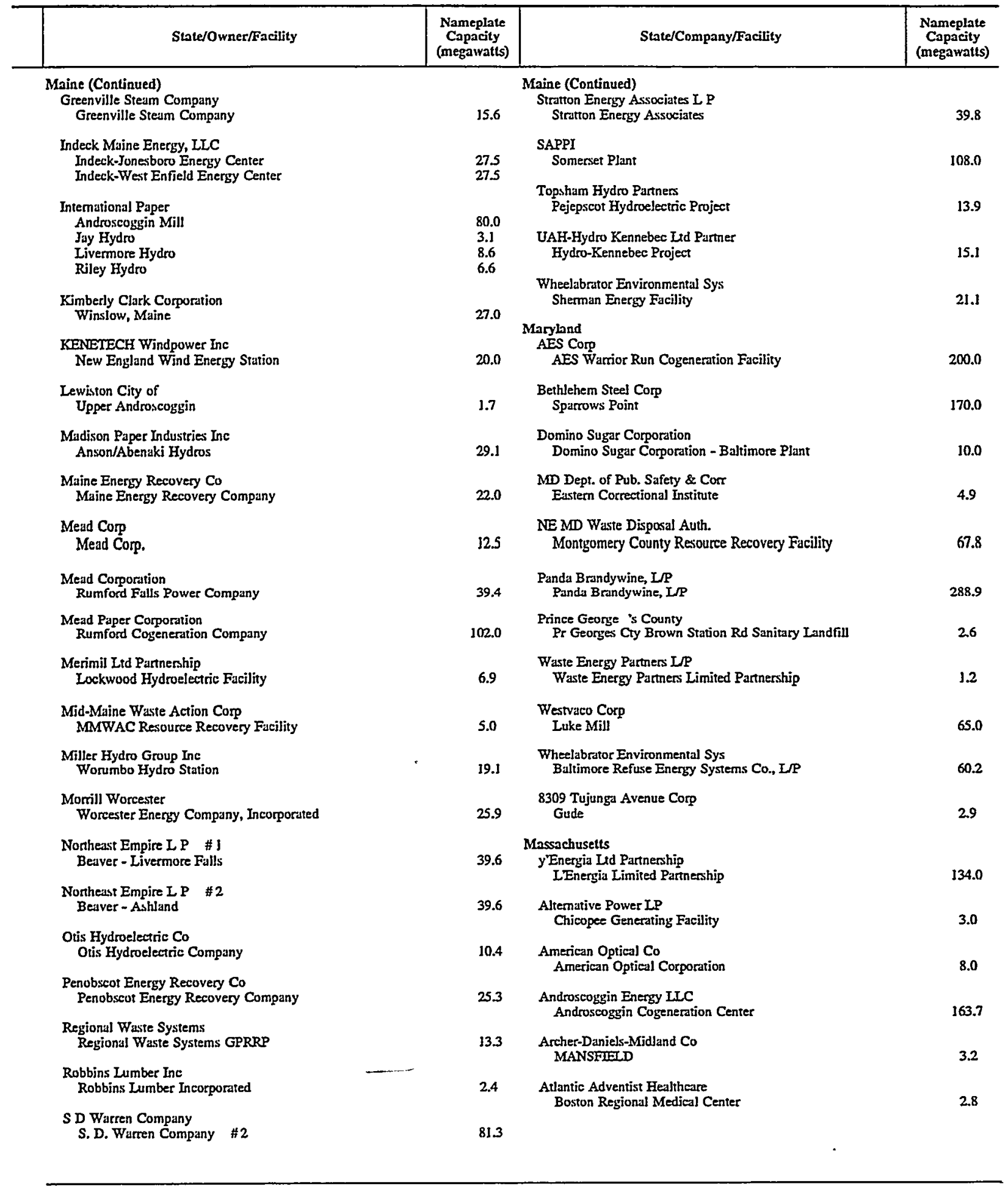

See footnotes at end of table. 


\section{Table 24. Existing Capacity at U.S. Nonutility Power Producers by State, Owner and}

Facility, as of December 31, 1997 (Continued)

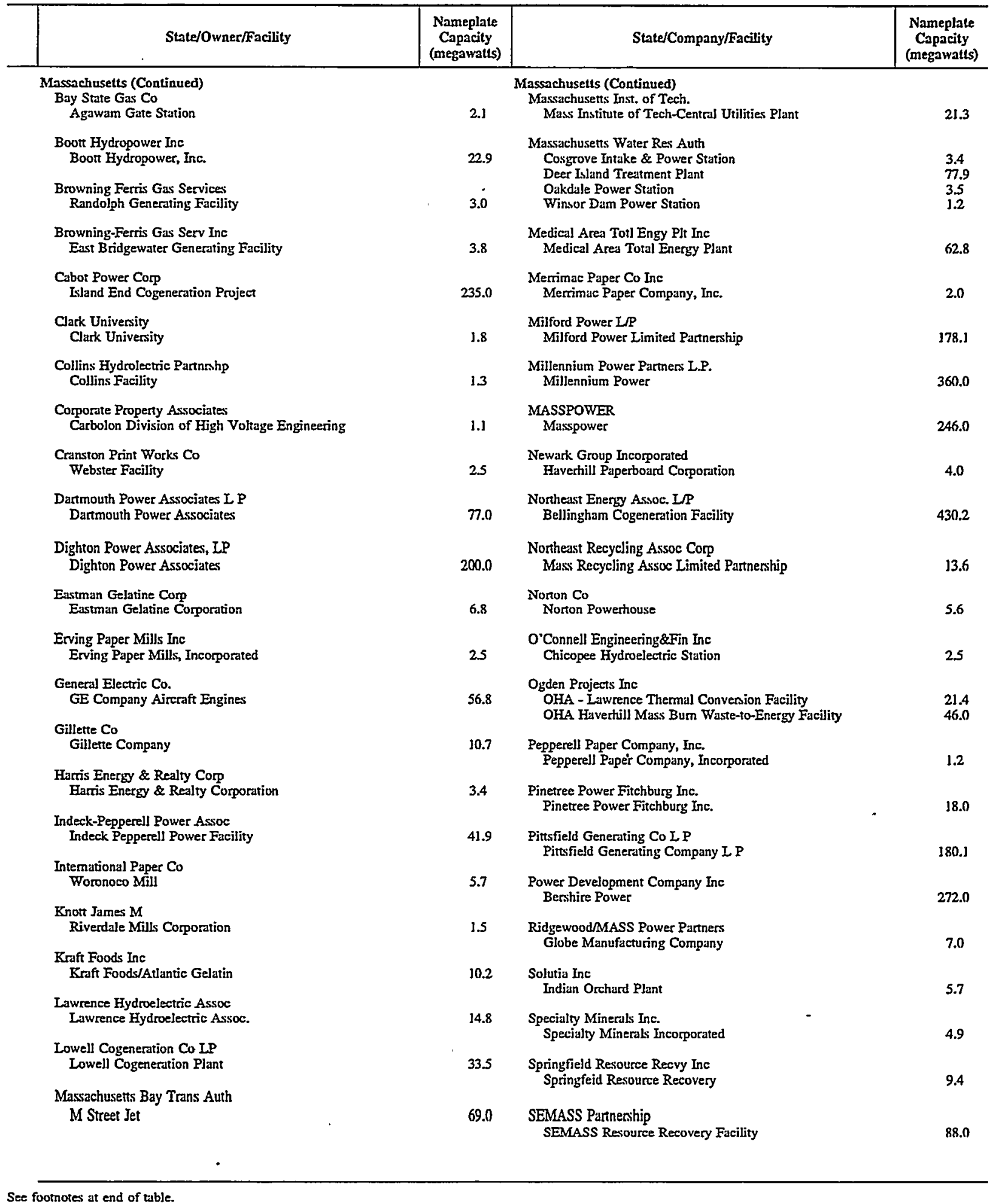

See footnotes at end of tuble. 
Table 24. Existing Capacity at U.S. Nonutility Power Producers by State, Owner and Facility, as of December 31, 1997 (Continued)

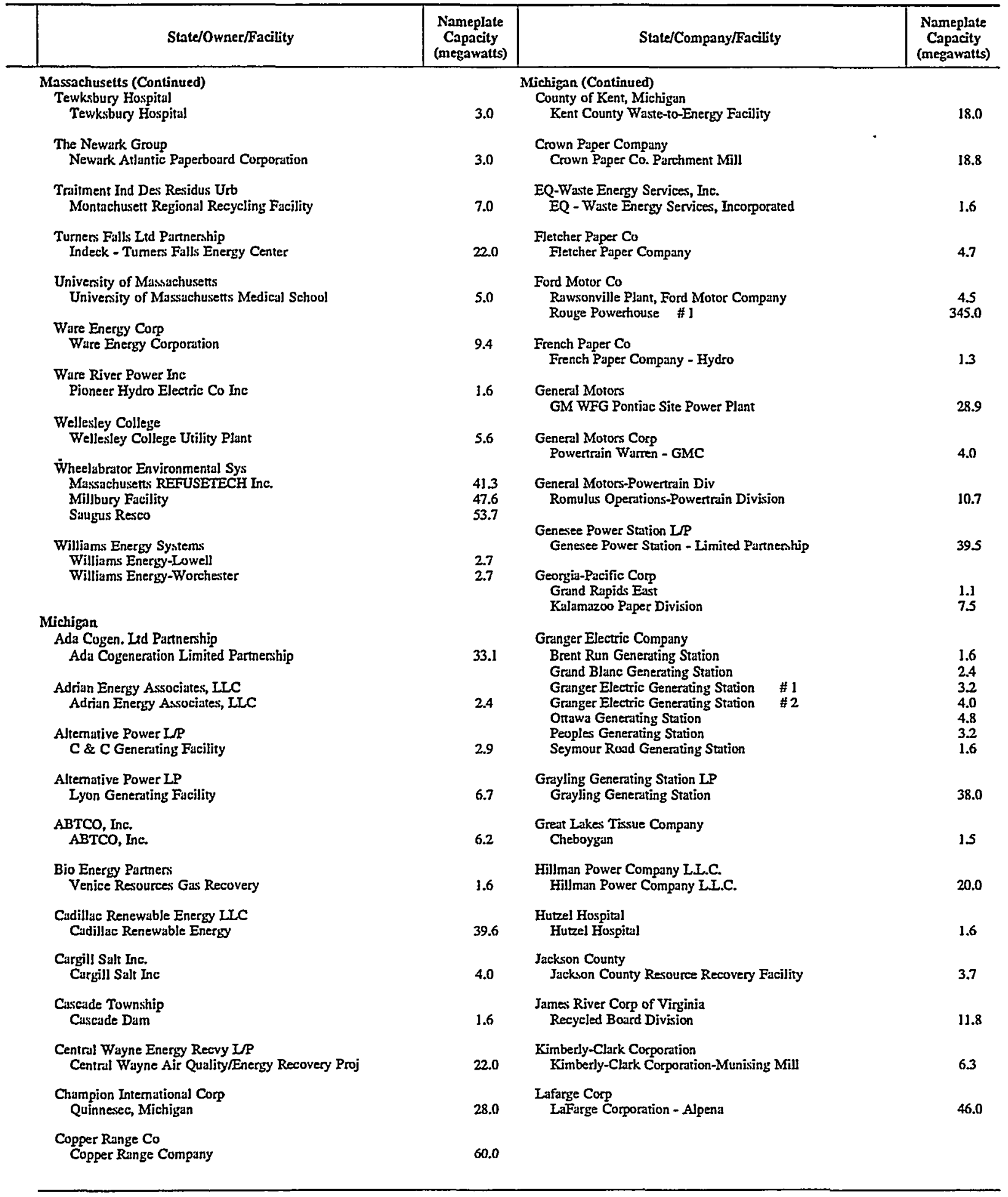

See footnotes at end of table. 


\section{Table 24. Existing Capacity at U.S. Nonutility Power Producers by State, Owner and}

Facility, as of December 31, 1997 (Continued)

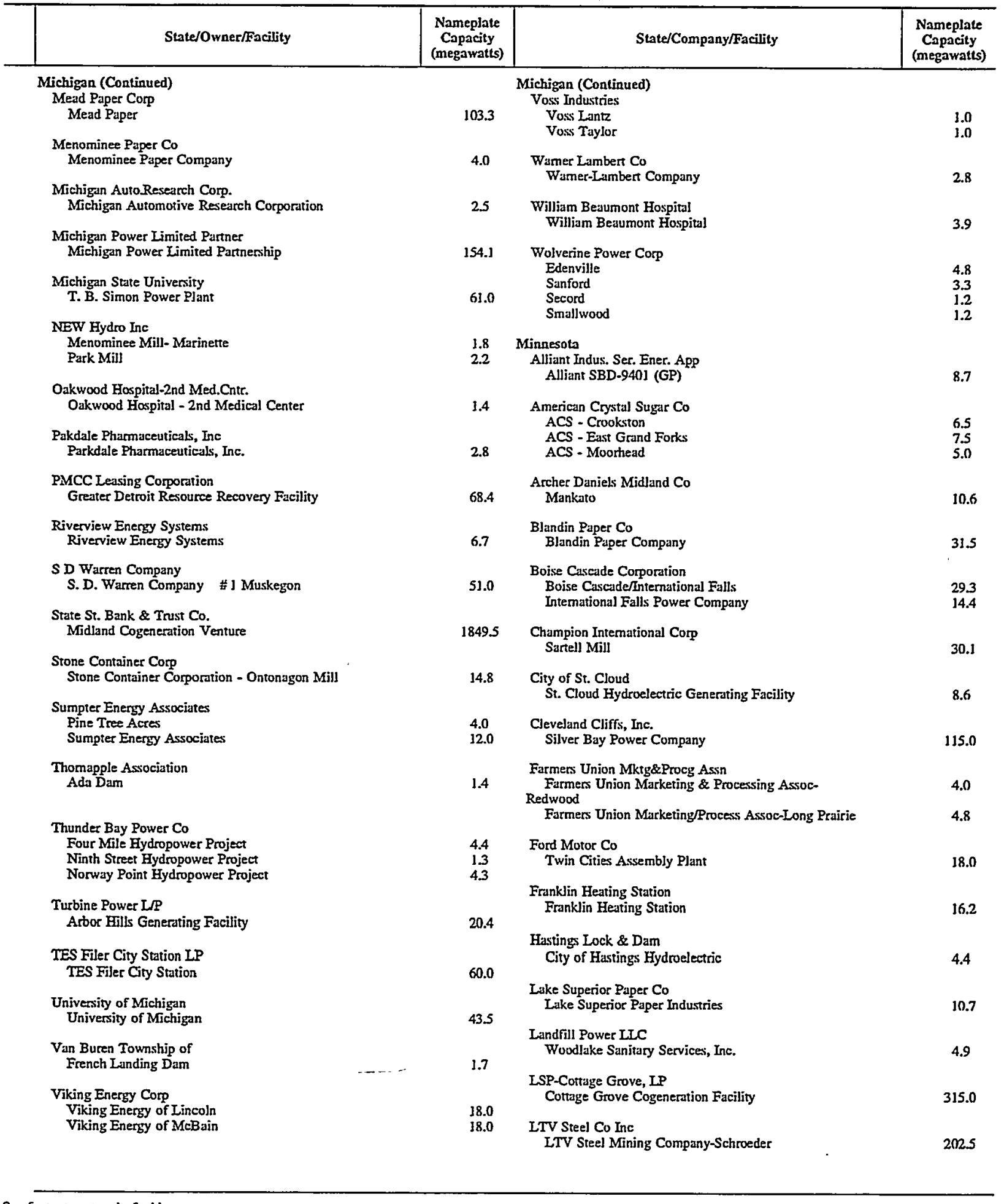

See footnotes at end of table. 


\section{Table 24. Existing Capacity at U.S. Nonutility Power Producers by State, Owner and}

Facility, as of December 31, 1997 (Continued)

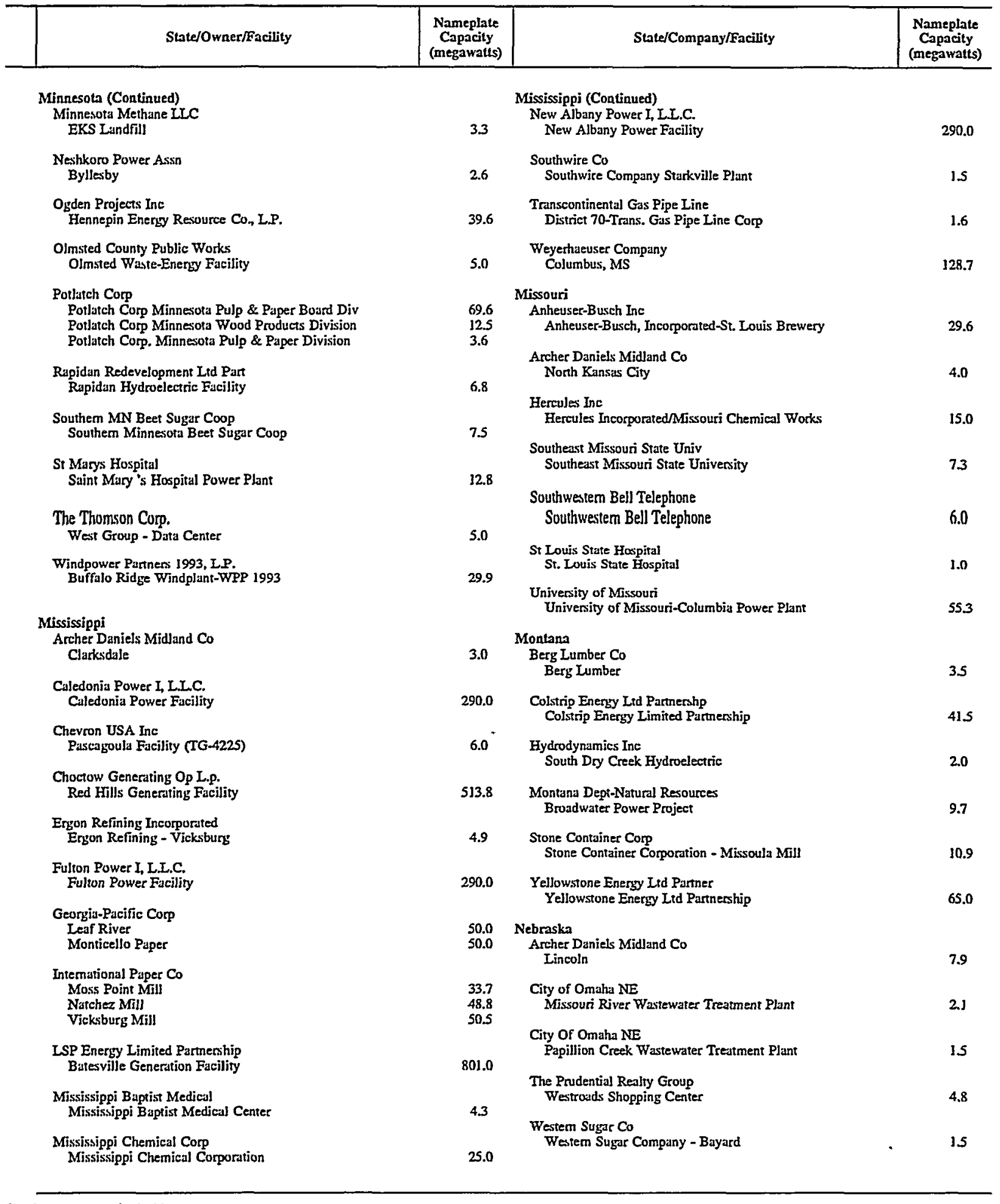

See foomotes at end of table: 
Table 24. Existing Capacity at U.S. Nonutility Power Producers by State, Owner and Facility, as of December 31, 1997 (Continued)

\begin{tabular}{|c|c|c|c|}
\hline State/Owner/Facility & $\begin{array}{c}\text { Nameplate } \\
\text { Capacity } \\
\text { (megawatts) }\end{array}$ & State/Company/Facility & $\begin{array}{c}\text { Nameplate } \\
\text { Capacity } \\
\text { (megawatts) }\end{array}$ \\
\hline $\begin{array}{l}\text { Nevada } \\
\text { Brady Power Partners } \\
\text { Brady Power Project }\end{array}$ & 26.8 & $\begin{array}{l}\text { Vew Hampshire } \\
\text { Baldwin Hydro Corp } \\
\text { Baldwin Dam }\end{array}$ & 4.5 \\
\hline $\begin{array}{l}\text { Cal Energy Company Inc } \\
\text { Desert Peak Power Plant }\end{array}$ & 11.0 & $\begin{array}{l}\text { Bio-Energy Corp } \\
\text { Bio Energy Corporation }\end{array}$ & 12.7 \\
\hline $\begin{array}{l}\text { Dixie Valley Power Partnership } \\
\text { Dixie Valley Geothermal }\end{array}$ & 25.0 & $\begin{array}{l}\text { Bio-Energy Partners } \\
\text { Turnkey Landfill Gas Recovery }\end{array}$ & 9.2 \\
\hline $\begin{array}{l}\text { Earth Power Resources, Inc. } \\
\text { Lee Hot Springs Power Project }\end{array}$ & 5.0 & $\begin{array}{l}\text { Briar Hydro Associates } \\
\text { Briar Hydro Assoc Penacook Upper Falls Facility } \\
\text { Briar Hydro Associate:/Rolfe Canal Facility }\end{array}$ & $\begin{array}{l}3.4 \\
4.3\end{array}$ \\
\hline $\begin{array}{l}\text { EJ Dorado Energy LLC } \\
\text { El Dorado Energy }\end{array}$ & 632.0 & $\begin{array}{l}\text { Bridgewater Power Co LP } \\
\text { Bridgewater Power Company L/P }\end{array}$ & 20.0 \\
\hline $\begin{array}{l}\text { Empire Limited Partmership } \\
\text { Empire Facility }\end{array}$ & 4.8 & $\begin{array}{l}\text { Clement Dam Development Inc } \\
\text { Clement Dam Development, Inc. }\end{array}$ & 2.4 \\
\hline $\begin{array}{l}\text { Far West Elec Energy Fund LP } \\
\text { Steamboat } 1\end{array}$ & 8.9 & $\begin{array}{l}\text { Consolidated Hydro NH Inc } \\
\text { EHC - West Hopkinton }\end{array}$ & 1.0 \\
\hline $\begin{array}{l}\text { Fish Lake Power Co } \\
\text { Fish Lake Geothermal Project }\end{array}$ & 22.0 & $\begin{array}{l}\text { Rollinsford } \\
\text { Crotched Mt Rehab Center }\end{array}$ & 1.5 \\
\hline $\begin{array}{l}\text { Las Vegas Cogeneration L.P. } \\
\text { Las Vegas Cogeneration Limited Partnership }\end{array}$ & 50.5 & Crotched Mt. Rehab Center & 1.5 \\
\hline $\begin{array}{l}\text { M. A. Hanna } \\
\text { CIMCO Nevada }\end{array}$ & 1.5 & $\begin{array}{l}\text { Crown Paper Company Ine } \\
\text { Berlin-Gotham } \\
\text { Dartmouth College }\end{array}$ & 44.6 \\
\hline $\begin{array}{l}\text { Nevada Cogeneration Assoc \#2 } \\
\text { Nevada Cogen Assoc } \quad \text { \#2 (Black Mtn. Co-Gen. Plant) }\end{array}$ & 107.2 & $\begin{array}{l}\text { Darmouth College Energy Plant } \\
\text { Dodge Falls Associates L P }\end{array}$ & 7.0 \\
\hline $\begin{array}{l}\text { Nevada Cogeneration Assoc \# } 1 \\
\text { Nevada Cogeneration Associates \# }\end{array}$ & 107.2 & Dodge Falls Associates & 5.0 \\
\hline $\begin{array}{l}\text { Nevada Sun-Peak LP } \\
\text { Nevada Sun-Peak Project }\end{array}$ & 210.0 & $\begin{array}{l}\text { Dunbarton Energy Partnes, I.P. } \\
\text { Durgin \& Crowell Iumber Co Inc }\end{array}$ & 1.0 \\
\hline $\begin{array}{l}\text { Oxbow Geothermal Corporation } \\
\text { Oxbow Geothermal Coporation - Dixie Valley/Fallon }\end{array}$ & 60.5 & $\begin{array}{l}\text { Durgin \& Crowell Lumber Co Inc } \\
\text { Durgin and Crowell Lumber Company, Inc. } \\
\text { Errol Hydroelectric Lid Part }\end{array}$ & 2.0 \\
\hline $\begin{array}{l}\text { Oxbow Power of Beowawe } \\
\text { Beowawe Geothermal Power Company }\end{array}$ & 17.0 & $\begin{array}{l}\text { Errol Hydroelectric Project } \\
\text { Foss Manufacturing Co Inc }\end{array}$ & 3.0 \\
\hline $\begin{array}{l}\text { Saguaro Power Co } \\
\text { Saguaro Power Company }\end{array}$ & 127.4 & Hampton Facility & 7.0 \\
\hline $\begin{array}{l}\text { Soda Iake Limited Parmership } \\
\text { Soda Lake Geothermal No. I \& II }\end{array}$ & 26.1 & $\begin{array}{l}\text { Franklin Industrial Complx Inc } \\
\text { Franklin Industrial Complex } \\
\text { General Electric Co }\end{array}$ & 2.3 \\
\hline $\begin{array}{l}\text { Star Group Stillwater I } \\
\text { Stillwater Facility }\end{array}$ & 21.0 & $\begin{array}{l}\text { GE Hydro Station } \\
\text { Gregg Falls Hydro Ascociates }\end{array}$ & 2.1 \\
\hline $\begin{array}{l}\text { Steamboat Development Corp } \\
\text { Steamboat II } \\
\text { Steamboat III }\end{array}$ & $\begin{array}{l}22.6 \\
22.6\end{array}$ & $\begin{array}{l}\text { Gregg Falls } \\
\text { Hemphill Power and Light Co } \\
\text { Hemphill Power and Light Company }\end{array}$ & 54.1 \\
\hline $\begin{array}{l}\text { TCID Hydro } \\
\text { New Lahontan }\end{array}$ & 4.0 & $\begin{array}{l}\text { Hillsborough Hydroelectric L P } \\
\text { Hillsborough (Hosiery) }\end{array}$ & 1.2 \\
\hline $\begin{array}{l}\text { Yankee Caithness Joint Vent IP } \\
\text { Steamboat Fills Geothermal Plant }\end{array}$ & 13.2 & $\begin{array}{l}\text { Hydro-Op One Associates } \\
\text { Milton Hydro }\end{array}$ & 1.6 \\
\hline $\begin{array}{l}\text { 1-A Enterpises } \\
\text { Steamboat IA Power Plant }\end{array}$ & 2.6 & $\begin{array}{l}\text { HDI Axsociates I } \\
\text { Iochmere Hydroejectric Plant }\end{array}$ & 1.2 \\
\hline
\end{tabular}

See footnotes at end of table. 


\section{Table 24. Existing Capacity at U.S. Nonutility Power Producers by State, Owner and}

Facility, as of December 31, 1997 (Continued)

\begin{tabular}{|c|c|c|c|}
\hline State/Owner/Facility & $\begin{array}{l}\text { Nameplate } \\
\text { Capacity } \\
\text { (megawatts) }\end{array}$ & State/Company/Facility & $\begin{array}{l}\text { Nameplate } \\
\text { Capacity } \\
\text { (megawatts) }\end{array}$ \\
\hline New Hampshire (Continued) & & New Jersey (Continued) & \\
\hline Marlborough Hydro Corp & & Aves Hamikon Inc & \\
\hline $\begin{array}{l}\text { Lower Village Water Power Project } \\
\text { Marlborough Hydro Corporation }\end{array}$ & $\begin{array}{l}1.3 \\
1.0\end{array}$ & Aves Hamilton, Incorporated & 3.0 \\
\hline Murphy Dam & 3.0 & $\begin{array}{l}\text { AT\&T Credit Corp } \\
\text { Kenilworth Energy Facility }\end{array}$ & 30.0 \\
\hline $\begin{array}{l}\text { Mascoma Hydro Corporation } \\
\text { Mascoma Hydro Corporation }\end{array}$ & 1.5 & $\begin{array}{l}\text { Beneficial Management Corp } \\
\text { Beneficial Management Corporation }\end{array}$ & 4.8 \\
\hline $\begin{array}{l}\text { Mine Fulls Lod Parnership } \\
\text { Fine Ful!s Lid. Partneship }\end{array}$ & 3.0 & $\begin{array}{l}\text { Bio-Energy Partners } \\
\text { Eusthampton Power Plant }\end{array}$ & 3.0 \\
\hline $\begin{array}{l}\text { Minnesota Methane ILC } \\
\text { Four Hills:Nashua Landfill }\end{array}$ & 3.1 & $\begin{array}{l}\text { Bristol-Myers Squibb Company } \\
\text { Bristol-Myers Squibb Company }\end{array}$ & 9.5 \\
\hline $\begin{array}{l}\text { New Hampshire Hydro Associates } \\
\text { New Hampshire Hydro Associates }\end{array}$ & 4.6 & $\begin{array}{l}\text { Camden Cogen L.P. } \\
\text { Comden Cogen I.P. }\end{array}$ & 157.0 \\
\hline $\begin{array}{l}\text { Newfound Hydroejectic Co } \\
\text { Newfound Hydroelectric Company }\end{array}$ & 1.5 & $\begin{array}{l}\text { Chambers Cogeneration IP } \\
\text { Chambers Cogeneration Limited Partnership }\end{array}$ & 285.0 \\
\hline $\begin{array}{l}\text { Pembroke Hydro Associates } \\
\text { Pembroke Hydro }\end{array}$ & 2.6 & $\begin{array}{l}\text { Cogen Technologies Linder Vent } \\
\text { Linden Cogen Plant }\end{array}$ & 761.6 \\
\hline $\begin{array}{l}\text { Pinetree Power Tumworth Inc. } \\
\text { Pinetree Power Tamworth Inc. }\end{array}$ & 25.0 & $\begin{array}{l}\text { Cogen Technologies NJ Venture } \\
\text { Bayonne Cogen Plant }\end{array}$ & 191.6 \\
\hline $\begin{array}{l}\text { Pinetree Power, Inc. } \\
\text { Pinetree Power, Incoporated }\end{array}$ & 37.6 & $\begin{array}{l}\text { Cross Roads Cogeneration Co } \\
\text { Intemational Crossroads }\end{array}$ & 11.7 \\
\hline $\begin{array}{l}\text { Plymouth Cogeneration L/P } \\
\text { PJymouth State College Cogeneration Facility }\end{array}$ & 1.3 & $\begin{array}{l}\text { CMS Generation Company } \\
\text { Lakewood Cogeneration, ISP }\end{array}$ & 238.5 \\
\hline $\begin{array}{l}\text { Pontook Operating Ird Partness } \\
\text { Pontook Hydroelectric Facility }\end{array}$ & 10.7 & $\begin{array}{l}\text { Eagle Point Cogen Partnership } \\
\text { Eagle Point Cogeneration }\end{array}$ & 225.0 \\
\hline $\begin{array}{l}\text { Seven Oaks Land Co Inc } \\
\text { Oak Ridge Station \#1 }\end{array}$ & $\$ 40.0$ & $\begin{array}{l}\text { Fiber Mark, Drbl Specialities } \\
\text { Fiber Mark - Technical Specialies Inc }\end{array}$ & 2.0 \\
\hline $\begin{array}{l}\text { Somersworth Hydropower Assoc } \\
\text { Somersworth (Lower Great Dam) }\end{array}$ & 13 & $\begin{array}{l}\text { Foster Wheeler Power Sys Inc } \\
\text { Camden Resource Recovery Facility }\end{array}$ & 34.0 \\
\hline $\begin{array}{l}\text { Thomas Hodgson \& Sons Inc } \\
\text { Thomas Hodgson \& Sons Incorporated }\end{array}$ & 1.9 & $\begin{array}{l}\text { Great Falls Hydroelectric Co } \\
\text { Great Falls Hydroelectric Project }\end{array}$ & 10.8 \\
\hline $\begin{array}{l}\text { Tillotson Rubber Co Inc } \\
\text { Tillotion Rubber Company, Incorporated }\end{array}$ & 1.5 & $\begin{array}{l}\text { Hercules Inc } \\
\text { Aqualon, A division of Hercules Incorporated }\end{array}$ & 4.5 \\
\hline $\begin{array}{l}\text { Velero USA Ine } \\
\text { Velcro USA, Incorporated }\end{array}$ & 4.4 & $\begin{array}{l}\text { Hoechst Marion Roussel } \\
\text { Hoechst Marion Roussel }\end{array}$ & 3.8 \\
\hline $\begin{array}{l}\text { Wausau Papers of New Hampshire } \\
\text { Wausau Papers of New Hampshire, Inc. }\end{array}$ & 6.5 & $\begin{array}{l}\text { Hoffmann LaRoche Ine } \\
\text { Hoffmann-La Roche Incorporated }\end{array}$ & 12.0 \\
\hline $\begin{array}{l}\text { Wheelabrator Environmental Sys } \\
\text { Claremont Facility } \\
\text { Concord Facility }\end{array}$ & $\begin{array}{l}4.5 \\
14.0\end{array}$ & $\begin{array}{l}\text { Homasote Co } \\
\text { Homasote Company }\end{array}$ & 2.3 \\
\hline $\begin{array}{l}\text { Whitefield Power \& Light Co } \\
\text { Whitefield Power and Light Co }\end{array}$ & 16.0 & $\begin{array}{l}\text { Hunterdon Cogeneration L.P. } \\
\text { Hunterdon Cogeneration Facility }\end{array}$ & 4.1 \\
\hline $\begin{array}{l}\text { New Jersey } \\
\text { Amer Ref-Fuel Co of Essex Cnt } \\
\text { American Ref-Fuel Company of Evisex County }\end{array}$ & 69.9 & $\begin{array}{l}\text { Kinsleys Landfill Inc } \\
\text { Kinsleys Landfill Inc. }\end{array}$ & 20 \\
\hline $\begin{array}{l}\text { Anheuset-Busch Inc } \\
\text { Anheuser-Busch, Inc. - Newark Brewery }\end{array}$ & 13.0 & $\begin{array}{l}\text { Lafayette Energy Partmen, L.P } \\
\text { Lafayette Energy Partners, L/P }\end{array}$ & 1.2 \\
\hline $\begin{array}{l}\text { Asbury Park Press, Inc. } \\
\text { Asbury Park Press, Incorporated }\end{array}$ & 1.3 & $\begin{array}{l}\text { Logan Generaring Company L.P. } \\
\text { Logan Generating Plant }\end{array}$ & 230.0 \\
\hline
\end{tabular}

See foutnotes at end of table. 
Table 24. Existing Capacity at U.S. Nonutility Power Producers by State, Owner and Facility, as of December 31, 1997 (Continued)

\begin{tabular}{|c|c|c|c|}
\hline State/Owner/Facility & $\begin{array}{l}\text { Nameplate } \\
\text { Capacity } \\
\text { (megawatis) }\end{array}$ & State/Company/Facility & $\begin{array}{c}\text { Nameplate } \\
\text { Capacity } \\
\text { (megawatts) }\end{array}$ \\
\hline $\begin{array}{l}\text { New Jersey (Continued) } \\
\text { Lowe Paper Co (Div of Simkins) } \\
\text { Lowe Paper Co (Division of Simkins Industries) }\end{array}$ & 3.0 & $\begin{array}{l}\text { New Jersey (Continued) } \\
\text { Schweitzer-Maudit Intem } \eta \text { Inc } \\
\text { Schweitzer-Mauduit Intemational Inc }\end{array}$ & 3.6 \\
\hline $\begin{array}{l}\text { M\&MMars Inc } \\
\text { M\&M/Mars }\end{array}$ & 10.3 & $\begin{array}{l}\text { Trigen-Trenton Energy Company } \\
\text { Trigen-Trenton Energy Company }\end{array}$ & 12.0 \\
\hline $\begin{array}{l}\text { Mercer County Improvement Auth } \\
\text { Mercer County Regional Resource Recovery Facility }\end{array}$ & 52.0 & $\begin{array}{l}\text { Union Carbide Corporation } \\
\text { Bound Brook Plant, Union Carbide Corporation }\end{array}$ & 5.5 \\
\hline $\begin{array}{l}\text { Merck \& Co Inc } \\
\text { Merck Rahway Power Plant }\end{array}$ & 10.8 & $\begin{array}{l}\text { Union County Utilities Auth } \\
\text { Union County Resource Recovery Facility }\end{array}$ & 44.0 \\
\hline $\begin{array}{l}\text { Milford Power Itd Partnership } \\
\text { Milford Power Limited Partnership }\end{array}$ & 36.5 & $\begin{array}{l}\text { University of M\&D-New Jersey } \\
\text { Univerity - Medicine/Dentistry }\end{array}$ & 10.5 \\
\hline $\begin{array}{l}\text { Mobil Oil Corp } \\
\text { Paulsboro Refinery }\end{array}$ & 57.0 & $\begin{array}{l}\text { Van Leer Chocolate Corp } \\
\text { Van Leer Chocolate Corporation }\end{array}$ & 3.3 \\
\hline $\begin{array}{l}\text { Montclair Cogen. Proj. Assoc. } \\
\text { Montclair Cogeneration Facility }\end{array}$ & 4.1 & $\begin{array}{l}\text { Vineland Cogeneration I/P } \\
\text { Vineland Cogeneration Plant }\end{array}$ & 53.0 \\
\hline $\begin{array}{l}\text { MCRC Renewable Power Partners } \\
\text { MCRC Renewable Power Partners, IP. }\end{array}$ & 10.0 & $\begin{array}{l}\text { Wheelabrator Environmental Sys } \\
\text { Wheelabrator Gloucester Company, L/P }\end{array}$ & 14.1 \\
\hline $\begin{array}{l}\text { Newark Bay Cogen. Part., L.P. } \\
\text { Newark Bay Cogeneration Project } \\
\text { North Jersey Assoc. IR }\end{array}$ & 135.0 & $\begin{array}{l}\text { New Mexico } \\
\text { Albuquerque Ciry of } \\
\text { Southside Water Reclamation Plant }\end{array}$ & 2.3 \\
\hline $\begin{array}{l}\text { Sayreville Cogeneration Facility } \\
\text { Novartis Pharmaceuticals Corp }\end{array}$ & 430.2 & $\begin{array}{l}\text { Cobisa-Person Limited Partners } \\
\text { Cobisa-Person Limited Parnership }\end{array}$ & 150.0 \\
\hline $\begin{array}{l}\text { Novartis Phamaceuticals } \\
\text { NRG Generating (Newark) }\end{array}$ & 28 & $\begin{array}{l}\text { Conoco Inc } \\
\text { San Juan Gas Processing Plant }\end{array}$ & 8.1 \\
\hline NRG Generating (Newark)Cugeneration Inc. & 64.6 & $\begin{array}{l}\text { El Paso Natural Gas Co } \\
\text { Blanco Compressor Station }\end{array}$ & 3.0 \\
\hline $\begin{array}{l}\text { NRG Generating (Newark) Cog. } \\
\text { NRG Generating (Padin) Cogeneration Inc. }\end{array}$ & 133.1 & $\begin{array}{l}\text { Giant Industries Arizona Ine } \\
\text { Ciniza Refinery }\end{array}$ & 6.0 \\
\hline $\begin{array}{l}\text { O'Brien Biogas IV IIC } \\
\text { O'Brien Bjogas IV IIC } \\
\text { Ocem County Utilities Auth }\end{array}$ & 9.5 & $\begin{array}{l}\text { Lordsburg Limited Partnership } \\
\text { Lordsburg Limited Partnership }\end{array}$ & 115.0 \\
\hline $\begin{array}{l}\text { Bayville Cented Facility } \\
\text { Ogden Projects Inc }\end{array}$ & 1.6 & $\begin{array}{l}\text { New Mexico State University } \\
\text { New Mexico State University }\end{array}$ & 4.8 \\
\hline $\begin{array}{l}\text { Warren Energy Resource Co } \\
\text { Passaic Valley Water Comm } \\
\text { Passaic Valley Water Commission }\end{array}$ & 13.0 & $\begin{array}{l}\text { Phelps Dodge Corp } \\
\text { Chino Mines Company } \\
\text { Hidalgo Smelter } \\
\text { Phelps Dodge Tyrone, Inc }\end{array}$ & $\begin{array}{l}64.0 \\
37.5 \\
45.4\end{array}$ \\
\hline $\begin{array}{l}\text { Pedricktown Cogeneration I/P } \\
\text { Pedricktown Cogeneration Plant }\end{array}$ & 134.6 & $\begin{array}{l}\text { Union Oil Co of Califomia } \\
\text { Molycorp Inc. Questa Division }\end{array}$ & 18.8 \\
\hline $\begin{array}{l}\text { Prime Energy LP } \\
\text { Prime Energy Limited Partnership }\end{array}$ & 79.0 & $\begin{array}{l}\text { University of New Mexico } \\
\text { CoGeneration Plant } \\
\text { Ford Utilities Center }\end{array}$ & $\begin{array}{l}2.5 \\
1.5\end{array}$ \\
\hline $\begin{array}{l}\text { Roche Vitamins } \\
\text { Roche Vitamins Inc. } \\
\text { Rowan Unjversity } \\
\text { Rowan University }\end{array}$ & 69.1 & $\begin{array}{l}\text { Williams Field Services } \\
\text { Milagro Cogeneration Plant } \\
\text { Williams Field Services Kutz Plant }\end{array}$ & $\begin{array}{l}60.8 \\
4.8\end{array}$ \\
\hline $\begin{array}{l}\text { RTC Properties, Incorporated } \\
\text { RTC Properties, Incorporated }\end{array}$ & 14.0 & $\begin{array}{l}\text { New York } \\
\text { Aetna Life \& Casualty } \\
\text { Moose River Coporation }\end{array}$ & 12.6 \\
\hline $\begin{array}{l}\text { Schering Corporation } \\
\text { Schering Corporation Cogeneration Facility }\end{array}$ & 3.8 & $\begin{array}{l}\text { Albany Cogeneration Assoc IP } \\
\text { Colonie Cogeneration Plant }\end{array}$ & 25.0 \\
\hline
\end{tabular}

See footnotes at end of table. 
Table 24. Existing Capacity at U.S. Nonutility Power Producers by State, Owner and Facility, as of December 31, 1997 (Continued)

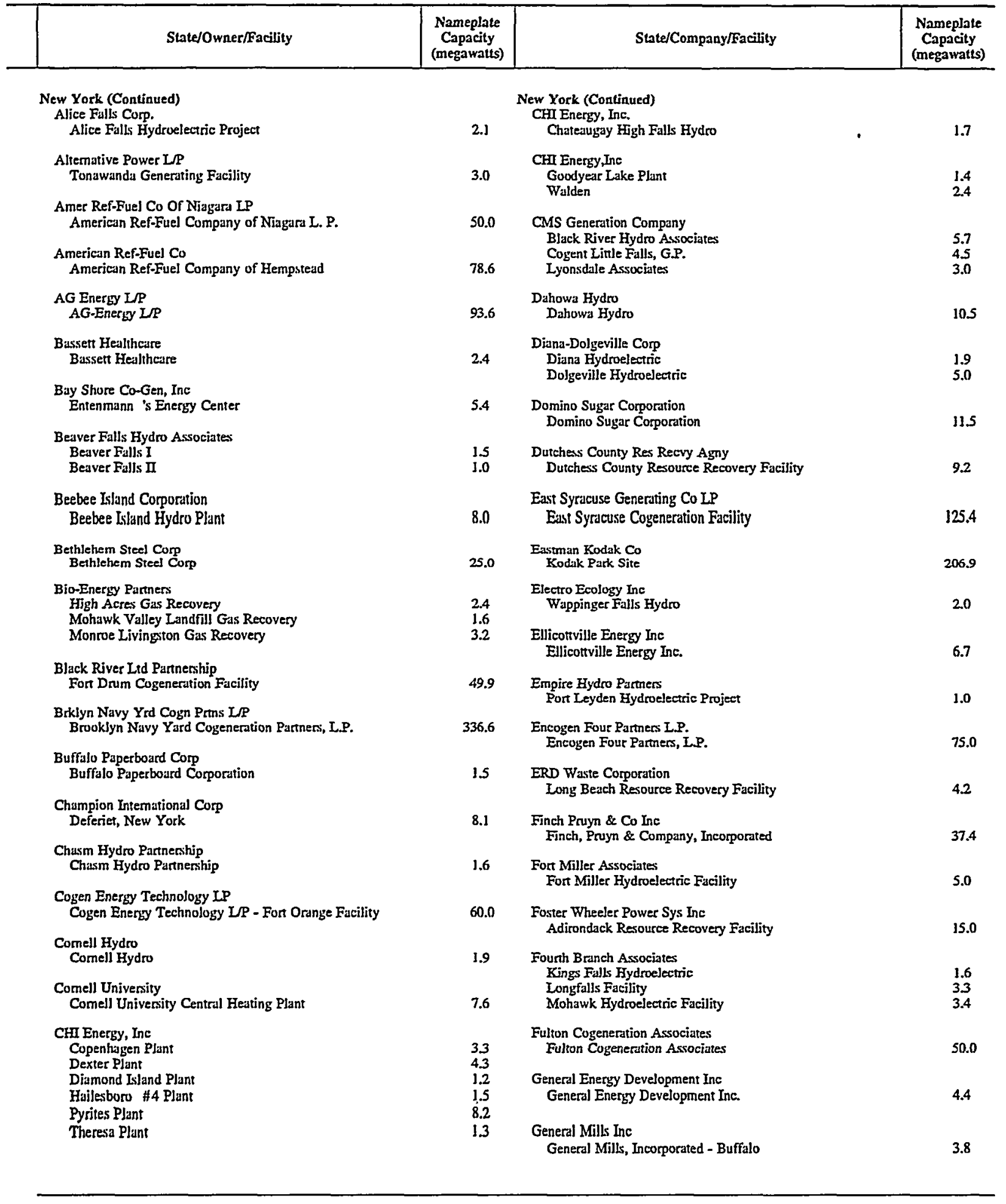

See footnotes at end of table. 


\section{Table 24. Existing Capacity at U.S. Nonutility Power Producers by State, Owner and}

Facility, as of December 31, 1997 (Continued)

\begin{tabular}{|c|c|c|c|}
\hline State/Owner/Facility & $\begin{array}{c}\text { Nameplate } \\
\text { Capacity } \\
\text { (megawatts) }\end{array}$ & State/Company/Facility & $\begin{array}{l}\text { Nameplate } \\
\text { Capacity } \\
\text { (megawatts) }\end{array}$ \\
\hline $\begin{array}{l}\text { New York (Continued) } \\
\text { Glen Park Associates } \\
\text { Glen Park Hydroelectric Project }\end{array}$ & 32.8 & $\begin{array}{l}\text { New York (Continued) } \\
\text { KES Chateaugay L P } \\
\text { KES Chateaugay Power Station }\end{array}$ & 19.7 \\
\hline $\begin{array}{l}\text { GPU International Inc } \\
\text { Onondaga Cogeneration }\end{array}$ & 105.9 & $\begin{array}{l}\text { KIAC Parmen: } \\
\text { Kennedy International Airporn Cogen Fucility }\end{array}$ & 121.1 \\
\hline $\begin{array}{l}\text { Hampshire Paper Co Ine } \\
\text { Humpshire Paper Company Ine. }\end{array}$ & 3.5 & $\begin{array}{l}\text { Lachute Hydro Co Inc } \\
\text { Lachute Hydro-Lower } \\
\text { Lichute Hydro-Upper }\end{array}$ & $\begin{array}{l}3.8 \\
4.9\end{array}$ \\
\hline $\begin{array}{l}\text { Harza Hydropower, Ine. } \\
\text { Philadelpitia Corporation }\end{array}$ & 3.6 & $\begin{array}{l}\text { Landfill Generating Partners } \\
\text { Orange County, New York }\end{array}$ & 3.0 \\
\hline $\begin{array}{l}\text { Hofstra University } \\
\text { Hofstra Univexity }\end{array}$ & 2.3 & $\begin{array}{l}\text { Little Falls Hydroelec Assoc } \\
\text { Little Falls Hydroelectric }\end{array}$ & 13.1 \\
\hline $\begin{array}{l}\text { Hollingworth \& Vose Co } \\
\text { Center Falls } \\
\text { Clark Mills Lower } \\
\text { Clarks Mill Upper }\end{array}$ & $\begin{array}{l}1.3 \\
1.1 \\
1.0\end{array}$ & $\begin{array}{l}\text { Lockport Energy Assoc. L/P } \\
\text { Lockport Energy Assoc I/P Lockport Cogen Facil }\end{array}$ & 209.6 \\
\hline $\begin{array}{l}\text { Hollow Dam Power Co } \\
\text { Hollow Dam Power Company }\end{array}$ & 1.0 & $\begin{array}{l}\text { Lower Saranac Hydro Partner IP } \\
\text { Lower Saranac Hydroelectric Faciliny } \\
\text { Lutheran Medical Center }\end{array}$ & 6.7 \\
\hline $\begin{array}{l}\text { Honeywell Farms, Inc } \\
\text { Honeywell Farms, Incorporated }\end{array}$ & 3.7 & Lutheran Medical Center & 1.6 \\
\hline $\begin{array}{l}\text { Fydrocarbon Generation Inc. } \\
\text { Hydrocatoon Generation Incorporation - Allegany }\end{array}$ & 2.0 & $\begin{array}{l}\text { Iyons Falls Pulp Inc } \\
\text { Iyons Falls Hydroelectric Incorporation }\end{array}$ & 12.1 \\
\hline $\begin{array}{l}\text { Indeck-Corinth Itd Partnership } \\
\text { Indeck-Corinth Energy Center }\end{array}$ & 147.0 & $\begin{array}{l}\text { Lyonsdale Energy L. P. } \\
\text { Iyonsdale Energy I/P }\end{array}$ & 21.2 \\
\hline $\begin{array}{l}\text { Indeck-Energy Serv Silver Sprg } \\
\text { Indeck-Silver Springs Energy Center }\end{array}$ & 56.7 & $\begin{array}{l}\text { LFG Energy Inc } \\
\text { LFG Energy Inc } \\
\text { LG\&E-Westmoreland Rensselaer }\end{array}$ & 6.5 \\
\hline $\begin{array}{l}\text { Indeck-Dion Ltd Partnership } \\
\text { Indeck-Dion Energy Center }\end{array}$ & 63.8 & $\begin{array}{l}\text { LG\&E-Westmoreland Rensselaer } \\
\text { LG\&E-Westmoreland Rensselaer }\end{array}$ & 103.9 \\
\hline $\begin{array}{l}\text { Indeck-Olean Led Partnership } \\
\text { Indeck Olean Energy Center }\end{array}$ & 90.7 & $\begin{array}{l}\text { Manufac. \& Traders Trust Co. } \\
\text { Kamine / Besicorp South Glens Falls L.P. } \\
\text { Kamine/Besicorp Carthage L.P. }\end{array}$ & $\begin{array}{l}63.0 \\
63.0\end{array}$ \\
\hline $\begin{array}{l}\text { Indeck-Oswego Iid Partnership } \\
\text { Indeck Oswego Energy Center }\end{array}$ & 57.6 & $\begin{array}{l}\text { Manufact. \& Traders Turst Co. } \\
\text { Kamine / Besicorp Natural Dam L.P. }\end{array}$ & 70.0 \\
\hline $\begin{array}{l}\text { Indeck-Yerkes Led Partnership } \\
\text { Indeck-Yerkes Energy Center }\end{array}$ & 60.0 & $\begin{array}{l}\text { Megan-Racine Axsociates } \\
\text { Cunton Cogeneration Facility }\end{array}$ & 50.0 \\
\hline $\begin{array}{l}\text { International Paper Co } \\
\text { Hudson River Mill } \\
\text { Ticonderoga Mill }\end{array}$ & $\begin{array}{l}38.4 \\
42.3\end{array}$ & $\begin{array}{l}\text { Mercy Medical Center } \\
\text { Mercy Medical Center }\end{array}$ & 1.3 \\
\hline $\begin{array}{l}\text { Islip Resource Recovery Agency } \\
\text { Mac Arthur Waste-to-Energy Facility }\end{array}$ & 11.5 & $\begin{array}{l}\text { Middle Falls Limited Partner } \\
\text { Middle Falls Hydroelectric } \\
\text { Middletown LFG Ltd }\end{array}$ & 2.3 \\
\hline $\begin{array}{l}\text { Jefferson County Indl Dev Agcy } \\
\text { Climax Energy Facility }\end{array}$ & 11.1 & $\begin{array}{l}\text { Middletown LFGLID Conversion, Site } 2 \text { \& } 3 \\
\text { Miller Brewing Co }\end{array}$ & 6.0 \\
\hline $\begin{array}{l}\text { KamineßBesicorp Allegany I P } \\
\text { Kimine / Besicorp Allegany L.P. }\end{array}$ & 74.4 & $\begin{array}{l}\text { Miller Brewing Company-Fulton Brewery } \\
\text { Moreau Manufacturing Corp }\end{array}$ & 5.5 \\
\hline $\begin{array}{l}\text { Kamine/Besicorp Beaver FallsIP } \\
\text { Kamine / Besicorp Beaver Falls L.P. }\end{array}$ & 107.8 & $\begin{array}{l}\text { Feeder Dam Hydro Plant } \\
\text { Mt. Ida Assuciates }\end{array}$ & 6.0 \\
\hline $\begin{array}{l}\text { Kamine/Besicorp Syracuse L P } \\
\text { Kamine/Besicorp Syracuse LP. }\end{array}$ & 102.7 & $\begin{array}{l}\text { Mt. Ida HydroeJectric } \\
\text { New York Methodist Hospital }\end{array}$ & 3.0 \\
\hline $\begin{array}{l}\text { Kings Park Psychiatric Center } \\
\text { Kings Park Psychiatric Center }\end{array}$ & 6.5 & New York Methodist Hospital & 1.9 \\
\hline
\end{tabular}


Table 24. Existing Capacity at U.S. Nonutility Power Producers by State, Owner and Facility, as of December 31, 1997 (Continued)

\begin{tabular}{|c|c|c|c|}
\hline State/Owner/Facility & $\begin{array}{c}\text { Nameplate } \\
\text { Capacily } \\
\text { (megawatts) }\end{array}$ & State/Company/Facility & $\begin{array}{c}\text { Nameplate } \\
\text { Capacity } \\
\text { (megawatts) }\end{array}$ \\
\hline $\begin{array}{l}\text { New York (Continued) } \\
\text { New York University } \\
\text { New York University Central PJant }\end{array}$ & 8.2 & $\begin{array}{l}\text { New York (Continued) } \\
\text { Salt City Energy Venture LP } \\
\text { Salt City Energy Venure, I/P }\end{array}$ & 90.6 \\
\hline $\begin{array}{l}\text { New York Zoological Society } \\
\text { Bronx Zoo }\end{array}$ & 4.0 & $\begin{array}{l}\text { Saranac Power Partners, L/P } \\
\text { Saranac Facility }\end{array}$ & 285.6 \\
\hline $\begin{array}{l}\text { Newport Hydro Associates } \\
\text { Newport Hydro }\end{array}$ & 1.8 & $\begin{array}{l}\text { Selkirk Cogen Partmess, L.P. } \\
\text { Selkirk Cogen Partmers, IP }\end{array}$ & 357.6 \\
\hline $\begin{array}{l}\text { Nissequoque Cogen Partners } \\
\text { Stony Brook Cogeneration Plant }\end{array}$ & 42.0 & $\begin{array}{l}\text { Seneca Energy Ine } \\
\text { Seneca Energy }\end{array}$ & 5.6 \\
\hline $\begin{array}{l}\text { North Shore Towens Apts Inc } \\
\text { North Shore Towess }\end{array}$ & 8.9 & $\begin{array}{l}\text { Seneca Power Parmers LP } \\
\text { Seneca Power Parmers, I/P }\end{array}$ & 67.4 \\
\hline $\begin{array}{l}\text { Nornhem Electric Power Co. LP } \\
\text { Hudson Falls Hydroelectric Project }\end{array}$ & 36.0 & $\begin{array}{l}\text { Sissonville Limited Partnershp } \\
\text { Sissonville Hydroelectric }\end{array}$ & 3.0 \\
\hline $\begin{array}{l}\text { NYC Energy Group LP } \\
\text { Nisa Cogeneration Facility }\end{array}$ & 36.0 & $\begin{array}{l}\text { Sithe/Independence Pwr PrtncLP } \\
\text { Sithe/Independence Station }\end{array}$ & 1305.5 \\
\hline $\begin{array}{l}\text { NYSD Ltd Partnership } \\
\text { New York State Dam Hydro }\end{array}$ & 11.4 & $\begin{array}{l}\text { Smithtown Energy Partners,L.P. } \\
\text { Smithtown Energy Partners, L.P. }\end{array}$ & 1.4 \\
\hline $\begin{array}{l}\text { Ogden Energy Group, Inc. } \\
\text { Huntington Resource Recovery Facility }\end{array}$ & 25.0 & $\begin{array}{l}\text { South Glens Falls IP } \\
\text { South Glens Falls Hydroejectric Project }\end{array}$ & 13.9 \\
\hline $\begin{array}{l}\text { Ogden Projects Inc } \\
\text { Babylon Resource Recovery Facility } \\
\text { Onondaga County Resource Recovery Facility }\end{array}$ & $\begin{array}{l}17.0 \\
39.5\end{array}$ & $\begin{array}{l}\text { South Oak Hospital } \\
\text { South Oaks Hospital }\end{array}$ & 1.3 \\
\hline $\begin{array}{l}\text { Oneida County Indl. Dev. Agcy. } \\
\text { Sterling Energy Facility }\end{array}$ & 65.3 & $\begin{array}{l}\text { St John 's Riverside Hospital } \\
\text { St. John 's Riverside Hospital } \\
\text { St. Mary's Hospital }\end{array}$ & 1.2 \\
\hline $\begin{array}{l}\text { Onondaga Energy Parner, L.P. } \\
\text { Onondaga Energy Parners, L.P. }\end{array}$ & 1.4 & Starrett City Inc & 1.2 \\
\hline $\begin{array}{l}\text { Oswego County } \\
\text { Oswego County Energy Recovery }\end{array}$ & 3.6 & $\begin{array}{l}\text { Starrett at Spring Creek Total Energy Plant } \\
\text { Stillwater Associates }\end{array}$ & 18.0 \\
\hline $\begin{array}{l}\text { Oswego Hydro Partner L/P } \\
\text { Phoenix Hydro Project }\end{array}$ & 3.2 & $\begin{array}{l}\text { Stillwater Reservoir Hydro } \\
\text { Stillwater Hydro Partners LP }\end{array}$ & 1.9 \\
\hline $\begin{array}{l}\text { Oxbow Power-N Tonawanda NY Inc } \\
\text { Oxbow Power of North Tonawanda, New York, Ine }\end{array}$ & 56.7 & $\begin{array}{l}\text { Stillwater Hydro Padthers LP } \\
\text { Stillwater Hydro Electric Project } \\
\text { Synergics Inc }\end{array}$ & 3.5 \\
\hline $\begin{array}{l}\text { Oyster Bay Energy Partmers, LP } \\
\text { Oyster Bay Energy Partners, L.P. }\end{array}$ & 2.0 & $\begin{array}{l}\text { Union Falls } \\
\text { Syracuse Power Company }\end{array}$ & 2.6 \\
\hline $\begin{array}{l}\text { Palmer Hydroelectric } \\
\text { Curtis Palmer Hydroelectric }\end{array}$ & 59.3 & $\begin{array}{l}\text { Syracuse Power Company } \\
\text { Tannery Istand Power Company }\end{array}$ & 5.6 \\
\hline $\begin{array}{l}\text { Power City Partners LP } \\
\text { Massena Energy Facility }\end{array}$ & 101.9 & The Fonda Group, Ine & 1.9 \\
\hline $\begin{array}{l}\text { Project Orange Associates L/P } \\
\text { Project Orange Associates, L/P }\end{array}$ & 98.0 & $\begin{array}{l}\text { The Fonda GroupNatural Dam Mill } \\
\text { Trafalgar Power Inc }\end{array}$ & 1.0 \\
\hline $\begin{array}{l}\text { Raquette Hydro Power Ltd } \\
\text { Hewittville Hydroelectrie } \\
\text { Unionville Hydro Proj 2499-NY }\end{array}$ & $\begin{array}{l}3.0 \\
3.0\end{array}$ & $\begin{array}{l}\text { Forestpor } \\
\text { Herkimer } \\
\text { Ogdensburg }\end{array}$ & $\begin{array}{l}3.4 \\
1.7 \\
3.8\end{array}$ \\
\hline $\begin{array}{l}\text { Ridgewood/Elmsford Power Part } \\
\text { Coca-Cola Bonling Company of New York }\end{array}$ & 1.9 & $\begin{array}{l}\text { Trigen-Nassau Energy Corp. } \\
\text { Trigen-Nassau Energy Corporation }\end{array}$ & 57.0 \\
\hline $\begin{array}{l}\text { Riverbay Corp } \\
\text { Riverbay Corporation }\end{array}$ & 6.0 & $\begin{array}{l}\text { TBG Cogen Partners } \\
\text { TBG Cogen }\end{array}$ & 84.0 \\
\hline
\end{tabular}

See foornotes at end of table. 
Table 24. Existing Capacity at U.S. Nonutility Power Producers by State, Owner and Facility, as of December 31, 1997 (Continued)

\begin{tabular}{|c|c|c|c|}
\hline State/Owner/Facility & $\begin{array}{c}\text { Nameplate } \\
\text { Capacity } \\
\text { (megawatts) }\end{array}$ & State/Company/Facility & $\begin{array}{c}\text { Nameplate } \\
\text { Capacity } \\
\text { (megawatts) }\end{array}$ \\
\hline $\begin{array}{l}\text { New York (Continued) } \\
\text { U S Gypsum Co } \\
\text { U S Gypsum - Oakfield }\end{array}$ & 5.8 & $\begin{array}{l}\text { Jorth Carolina (Continued) } \\
\text { Cogentrix of Rocky Mount Inc } \\
\text { Dwayne Collier Battle Cogeneration Facility }\end{array}$ & 114.8 \\
\hline $\begin{array}{l}\text { United Develop Grp-Niagara IP } \\
\text { UDG Niagara Falls Cogeneration Facility } \\
\text { United Supply Corp } \\
\text { Wartios }\end{array}$ & 86.0 & $\begin{array}{l}\text { Cogentrix Eastm Carolina Corp } \\
\text { Cogentrix Elizabethtown } \\
\text { Cogentrix Kenansville } \\
\text { Cogentrix Lumberton }\end{array}$ & $\begin{array}{l}34.7 \\
34.7 \\
34.7\end{array}$ \\
\hline $\begin{array}{l}\text { Valley Falls Associates } \\
\text { Valley Falls Hydroelectric Facility }\end{array}$ & 2.5 & $\begin{array}{l}\text { Com Products International } \\
\text { Com Products-Winston Salem }\end{array}$ & 8.4 \\
\hline $\begin{array}{l}\text { Victory Mills Co Ine } \\
\text { Victory Mills }\end{array}$ & 1.7 & $\begin{array}{l}\text { Cranston Print Works Co } \\
\text { Fletcher Facility }\end{array}$ & 3.0 \\
\hline $\begin{array}{l}\text { Warrensburg Hydro Pwr Lrd Part } \\
\text { Warrensburg Hydroelectric }\end{array}$ & 2.9 & DMON Intemational Inc & 2.2 \\
\hline $\begin{array}{l}\text { Watervliet City of } \\
\text { Hormanskill Hydro Project }\end{array}$ & 1.2 & DIMON Intemational Inc - Kinston & 1.0 \\
\hline $\begin{array}{l}\text { Wehran Landfill Energy Corp } \\
\text { Brookhaven Landfill Generating Facility }\end{array}$ & 3.7 & $\begin{array}{l}\text { E I DuPont De Nemours \& Co } \\
\text { Kinston, North Carolina plant }\end{array}$ & 15.5 \\
\hline $\begin{array}{l}\text { West Delaware Hydro Associatex } \\
\text { West Delaware Tunnel Plant }\end{array}$ & 7.5 & $\begin{array}{l}\text { FMC Corp - Lithium Division } \\
\text { FMC Lithium Division } \\
\text { Glaco WellJcome Ine }\end{array}$ & 10.0 \\
\hline $\begin{array}{l}\text { West End Dam Associates } \\
\text { West End Dam Hydroelectric Project }\end{array}$ & 4.5 & $\begin{array}{l}\text { Catalytica Pharmaceuticals Inc } \\
\text { Haw River Hydro Co }\end{array}$ & 6.5 \\
\hline $\begin{array}{l}\text { Westchester County IDA } \\
\text { Westchester Resco }\end{array}$ & 74.5 & Haw River Hydro Co & 1.5 \\
\hline $\begin{array}{l}\text { Wyeth Ayerst Lederle } \\
\text { Lederle Laboratories }\end{array}$ & 24.5 & $\begin{array}{l}\text { International Paper Co } \\
\text { International Paper, Riegelwood Mill } \\
\text { Kannapolis Energy Parners ILC }\end{array}$ & 58.3 \\
\hline $\begin{array}{l}\text { Zapco Energy Tactics Corp } \\
\text { Oceanside Landfil] }\end{array}$ & 4.3 & $\begin{array}{l}\text { Kannapolis Energy Partners } \\
\text { Kannapolis Energy Partners - Spencer }\end{array}$ & $\begin{array}{l}25.0 \\
3.5\end{array}$ \\
\hline $\begin{array}{l}\text { North Carolina } \\
\text { Archer Daniels Midland Co } \\
\text { Southport }\end{array}$ & 52.5 & $\begin{array}{l}\text { Lockville Hydropower Co } \\
\text { Lockville Hydropower Company }\end{array}$ & 1.3 \\
\hline $\begin{array}{l}\text { Avalon/H \& H Properties } \\
\text { Avalon/H \& H Properties }\end{array}$ & 1.4 & $\begin{array}{l}\text { Madison Hydro Partnen: } \\
\text { Madison Hydro Partners (Ivy Hydro) }\end{array}$ & 1.2 \\
\hline $\begin{array}{l}\text { BASF Corp } \\
\text { Enka }\end{array}$ & 16.3 & $\begin{array}{l}\text { Metropolitan Sewerage District } \\
\text { Metropolitan Sewerage District }\end{array}$ & $2.6^{\circ}$ \\
\hline $\begin{array}{l}\text { BCH Energy, Limited Partnership } \\
\text { BCH Energy, Limited Partnership }\end{array}$ & 18.2 & $\begin{array}{l}\text { Mills Shoals Hydro Co. Inc } \\
\text { High Shoals Hydro Incorporated }\end{array}$ & 3.7 \\
\hline $\begin{array}{l}\text { Carolina Energy IP } \\
\text { Carolina Energy Iimited Partmership }\end{array}$ & 8.5 & $\begin{array}{l}\text { New Hanover County } \\
\text { New Hanover County - Wastec }\end{array}$ & 30.4 \\
\hline $\begin{array}{l}\text { Carroll's Food Ine } \\
\text { Carroll's Food Ine }\end{array}$ & 2.5 & $\begin{array}{l}\text { Panda-Rosemary Limited Part. } \\
\text { Panda-Rosemary Limited Partnership }\end{array}$ & 180.0 \\
\hline $\begin{array}{l}\text { Champion Intemational Corp } \\
\text { Canton, North Carolina } \\
\text { Roanoke Rapids, North Carolina }\end{array}$ & $\begin{array}{l}52.5 \\
22.5\end{array}$ & $\begin{array}{l}\text { PCS Phosphate } \\
\text { PCS Phosphate Company, Inc. (e/k/a Texasgulf, Inc) }\end{array}$ & 39.9 \\
\hline $\begin{array}{l}\text { Cogentrix of } \mathrm{N} \text { Carolina Inc } \\
\text { Cogentrix Roxboro } \\
\text { Cogentrix Southport }\end{array}$ & $\begin{array}{r}54.2 \\
108.5\end{array}$ & $\begin{array}{l}\text { PPG Industries Inc } \\
\text { PPG Industries, Inc. Shelby, NC - Works } 52 \\
\text { R J Reynolds Tobacco Co } \\
\text { Bailey Utility Plant }\end{array}$ & 4.2 \\
\hline
\end{tabular}

See footnotes at end of table. 
Table 24. Existing Capacity at U.S. Nonutility Power Producers by State, Owner and Facility, as of December 31, 1997 (Continued)

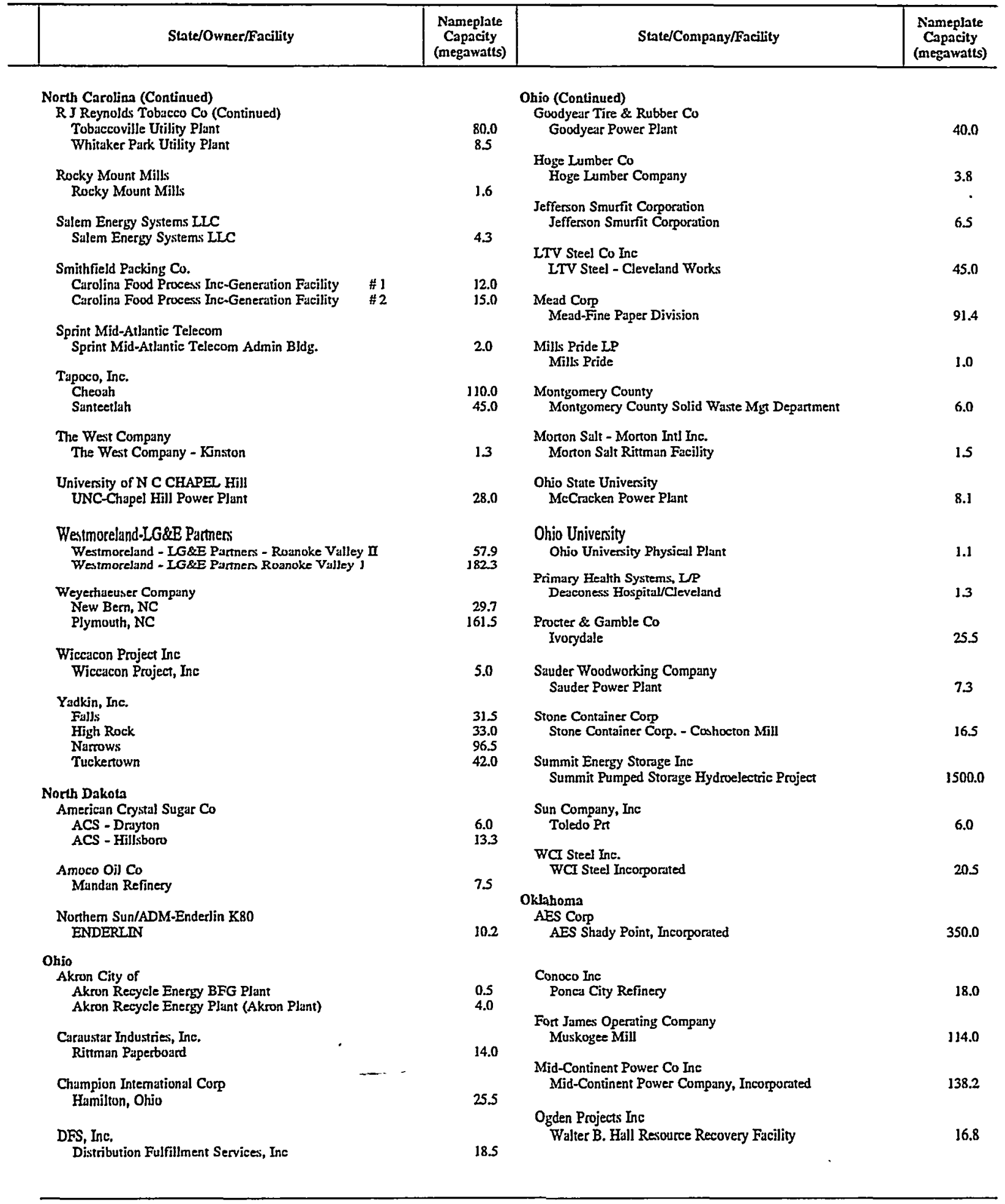

See footnotes at end of table. 


\section{Table 24. Existing Capacity at U.S. Nonutility Power Producers by State, Owner and}

Facility, as of December 31, 1997 (Continued)

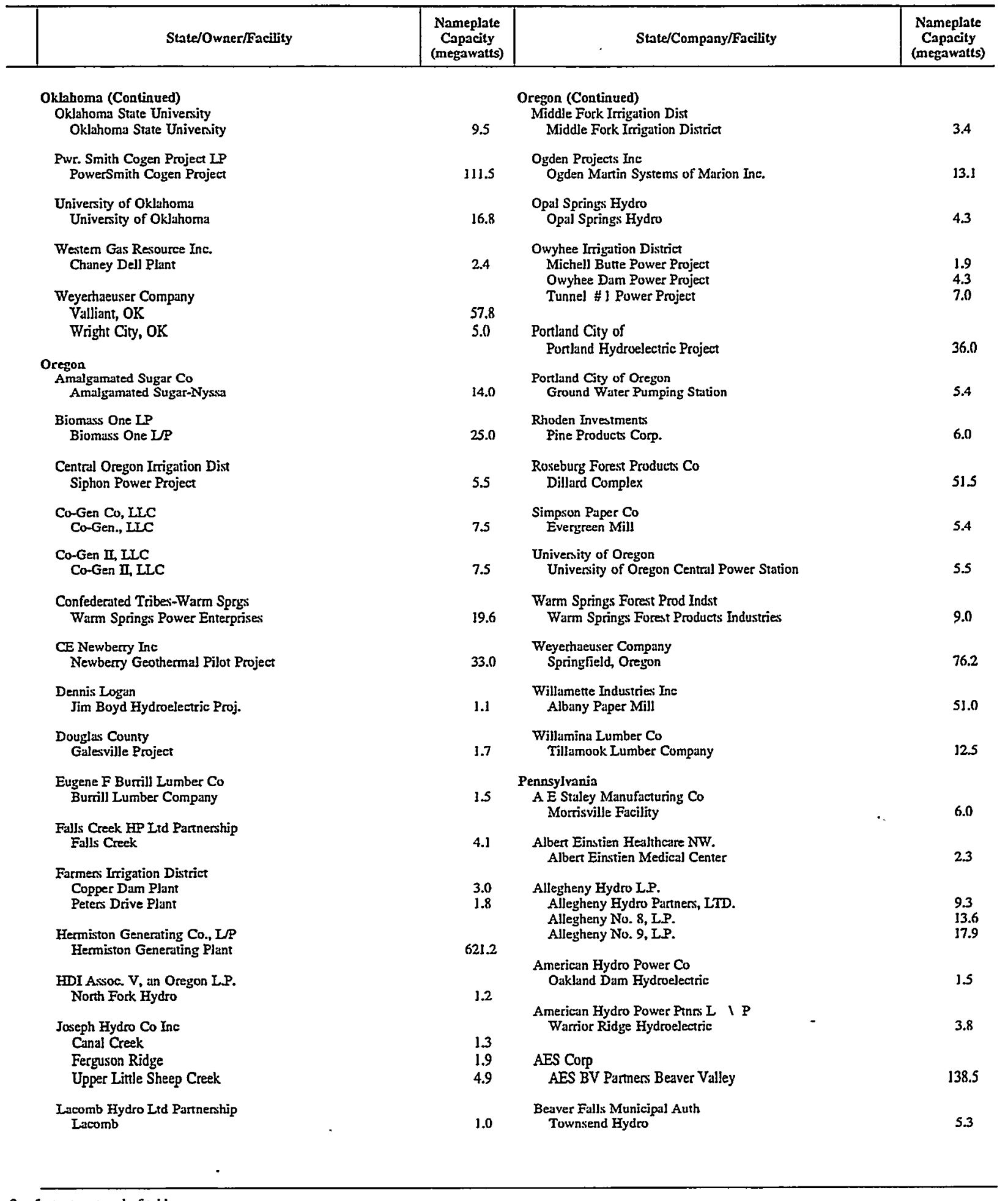

See footnotes at end of table. 
Table 24. Existing Capacity at U.S. Nonutility Power Producers by State, Owner and Facility, as of December 31, 1997 (Continued)

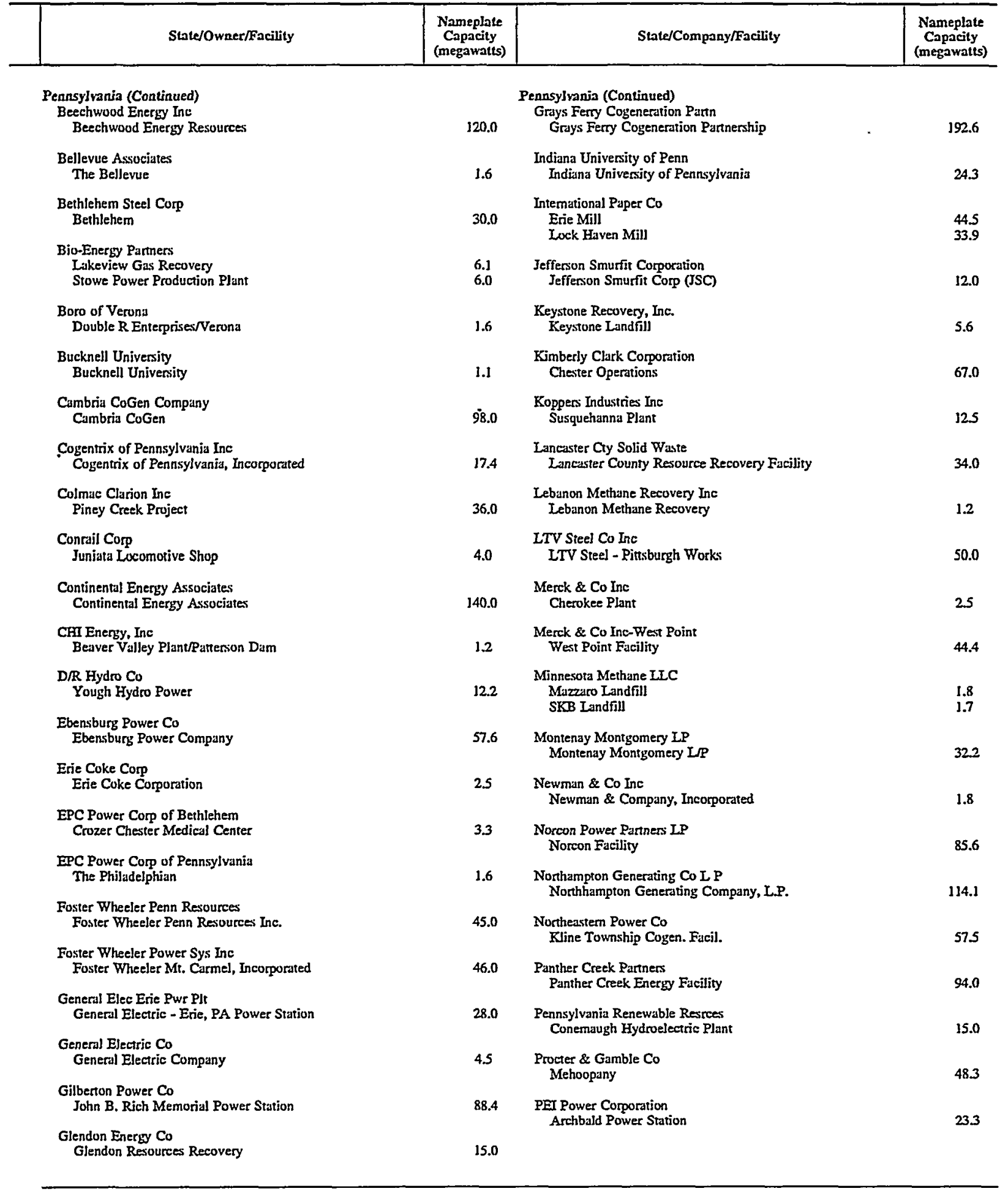

See footnotes at end of table. 
Table 24. Existing Capacity at U.S. Nonutility Power Producers by State, Owner and Facility, as of December 31, 1997 (Continued)

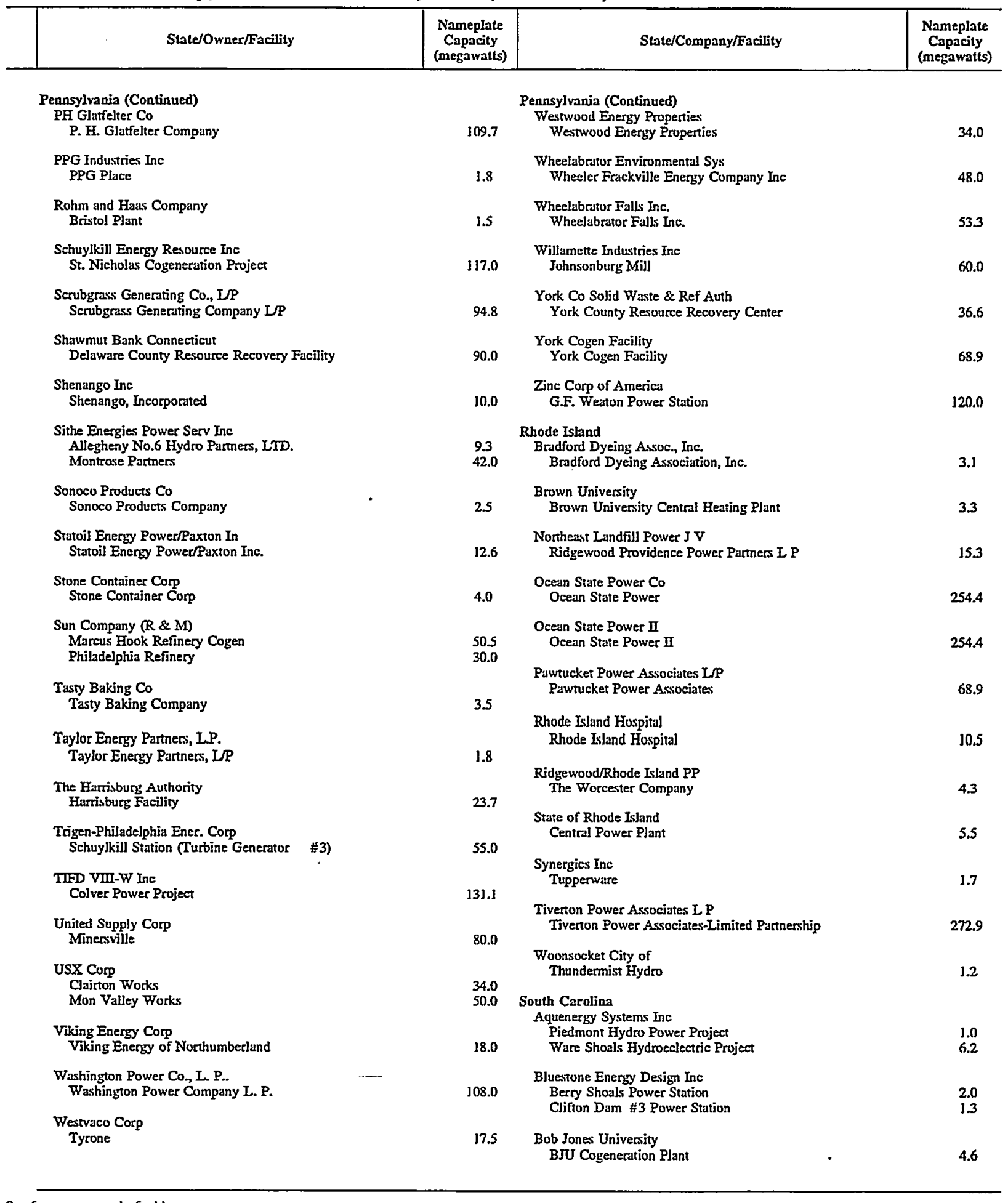

See foomotes at end of table. 
Table 24. Existing Capacity at U.S. Nonutility Power Producers by State, Owner and Facility, as of December 31, 1997 (Continued)

\begin{tabular}{|c|c|c|c|}
\hline State/Owner/Facility & $\begin{array}{l}\text { Nameplate } \\
\text { Capacity } \\
\text { (megawatts) }\end{array}$ & State/Company/Facility & $\begin{array}{c}\text { Nameplate } \\
\text { Capacity } \\
\text { (megawatts) }\end{array}$ \\
\hline $\begin{array}{l}\text { South Carolina (Continued) } \\
\text { Cherokee County Cogeneration } \\
\text { Cherokee County Cogeneration Partners, L P }\end{array}$ & 117.7 & $\begin{array}{l}\text { Cennessee (Continued) } \\
\text { Intertrade Holdings: Inc. } \\
\text { Intertrade Holdings Power Generation Plant }\end{array}$ & 40.0 \\
\hline $\begin{array}{l}\text { Cherokee Falls Associates } \\
\text { Cherokee Falls }\end{array}$ & $\cdot 4.4$ & $\begin{array}{l}\text { Memphis Hardwood Flooring Co } \\
\text { Memphis Hardwood Flooring Co. }\end{array}$ & 1.8 \\
\hline $\begin{array}{l}\text { E I DuPont De Nemours \& Co } \\
\text { May PJant }\end{array}$ & 30.0 & $\begin{array}{l}\text { Nashville Thermal Transfi Corp } \\
\text { Nashville Thermal Transfer Corporation }\end{array}$ & 7.2 \\
\hline $\begin{array}{l}\text { Foster Wheeler Power Sys Inc } \\
\text { Charleston Resource Recovery Facility }\end{array}$ & 13.8 & $\begin{array}{l}\text { Tapoco, Ine. } \\
\text { Calderwood } \\
\text { Chilhowee }\end{array}$ & $\begin{array}{r}121.5 \\
50.0\end{array}$ \\
\hline $\begin{array}{l}\text { Intemational Paper Co } \\
\text { Georgetown Mill }\end{array}$ & 95.7 & $\begin{array}{l}\text { Tenneco Packing } \\
\text { Tenneco Packaging Counce Mill }\end{array}$ & 35.0 \\
\hline $\begin{array}{l}\text { Pelzet Hydro Co Ine } \\
\text { Pelzer-Lower } \\
\text { Peizer-Upper }\end{array}$ & $\begin{array}{l}3.3 \\
2.0\end{array}$ & $\begin{array}{l}\text { Tennessee Eastman Division } \\
\text { Tenn Eastman Div, a Div of Eastman Chemical Co }\end{array}$ & 188.9 \\
\hline $\begin{array}{l}\text { Southwire Co } \\
\text { Gaston Copper Recycling Corp }\end{array}$ & 1.5 & $\begin{array}{l}\text { The University of Tennessee } \\
\text { UT Steam Plant }\end{array}$ & 5.0 \\
\hline $\begin{array}{l}\text { Spartanburg, Comm. Public Works } \\
\text { Spanumburg Water System }\end{array}$ & 1.0 & $\begin{array}{l}\text { Vadison Energy Corp } \\
\text { Vadison Energy Corporation }\end{array}$ & 20.0 \\
\hline $\begin{array}{l}\text { Stone Container Corp } \\
\text { Stone Container Corporation-Florence Mill }\end{array}$ & 107.6 & $\begin{array}{l}\text { Vanderbilt University } \\
\text { Vanderbilt University Power Plant }\end{array}$ & 11.0 \\
\hline $\begin{array}{l}\text { Union Camp Corp } \\
\text { Eastover Facility }\end{array}$ & 109.7 & $\begin{array}{l}\text { Willamette Industries } \\
\text { Willamette Industries-Kingsport Mill }\end{array}$ & 20.0 \\
\hline $\begin{array}{l}\text { Westvaco Corp } \\
\text { Charleston }\end{array}$ & 48.3 & $\begin{array}{l}\text { Aexas } \\
\text { Air Liquide America Corp. } \\
\text { Bayou Cogeneration Plant } \\
\text { Pt. Neches Plant }\end{array}$ & $\begin{array}{r}300.0 \\
43.0\end{array}$ \\
\hline $\begin{array}{l}\text { Tennessee } \\
\text { Arcadian Fertilizer, I/P } \\
\text { Areadian Fertilizer, LP }\end{array}$ & 25.0 & $\begin{array}{l}\text { Air Products \& Chemicals Ine } \\
\text { Pasadena }\end{array}$ & 4.1 \\
\hline $\begin{array}{l}\text { Averitt Lumber Company } \\
\text { Averitt Lumber Company }\end{array}$ & 3.8 & $\begin{array}{l}\text { Alcoid Alumina\&Chemicals L.L.C. } \\
\text { Pt. Comfort Operations }\end{array}$ & 42.8 \\
\hline $\begin{array}{l}\text { Bio-Energy Parners } \\
\text { Chestnut Ridge Gas Recovery }\end{array}$ & 3.2 & $\begin{array}{l}\text { Aluminum Co of America } \\
\text { Sandow }\end{array}$ & 363.0 \\
\hline $\begin{array}{l}\text { Bioten GP } \\
\text { Bioten Operations Inc }\end{array}$ & 5.0 & $\begin{array}{l}\text { Amoco Chemical Co } \\
\text { Chocolate Bayou PJant } \\
\text { Texas City Plant }\end{array}$ & $\begin{array}{l}41.0 \\
41.5\end{array}$ \\
\hline $\begin{array}{l}\text { Bowater Newsprint Calhoun Oper } \\
\text { Bowater Newsprint Calhoun Operdtions } \\
\text { Brownsville Power } \mathbf{L}, \text { LL.C. } \\
\text { Brownsville Peaking Power Plant }\end{array}$ & 290.0 & $\begin{array}{l}\text { Amoco Oil Co } \\
\text { Power Station } \# 3 \\
\text { Power Station } \# 4\end{array}$ & $\begin{array}{l}118.1 \\
191.1\end{array}$ \\
\hline $\begin{array}{l}\text { BASF Corp } \\
\text { Lowland }\end{array}$ & 20.3 & $\begin{array}{l}\text { Austin State Hospital } \\
\text { Austin State Hospital }\end{array}$ & 3.0 \\
\hline $\begin{array}{l}\text { Cargill Inc. } \\
\text { Com Wet Milling Plant }\end{array}$ & 29.8 & $\begin{array}{l}\text { AES Corp } \\
\text { AES Deepwater, Incorporated } \\
\text { ALTURA Energy ITD }\end{array}$ & 184.0 \\
\hline $\begin{array}{l}\text { E I DuPont De Nemours \& Co } \\
\text { Old Hickory Plant }\end{array}$ & 3.9 & Wasson CO2 Removal Plant & 23.4 \\
\hline $\begin{array}{l}\text { Gaylord Entertainment Company } \\
\text { Opryland USA }\end{array}$ & 4.6 & $\begin{array}{l}\text { ASARCO, Inc. } \\
\text { ASARCO, Inc. - El Paso, TX } \\
\text { Basis Petroleum Inc }\end{array}$ & 5.0 \\
\hline $\begin{array}{l}\text { Hartco Flooring Company } \\
\text { Hartco Flooring Company }\end{array}$ & 2.5 & $\begin{array}{l}\text { Basis Petroleum lnc } \\
\text { Basis - Texas City Refinety }\end{array}$ & 39.6 \\
\hline
\end{tabular}

See footnotes at end of table. 
Table 24. Existing Capacity at U.S. Nonutility Power Producers by State, Owner and Facility, as of December 31, 1997 (Continued)

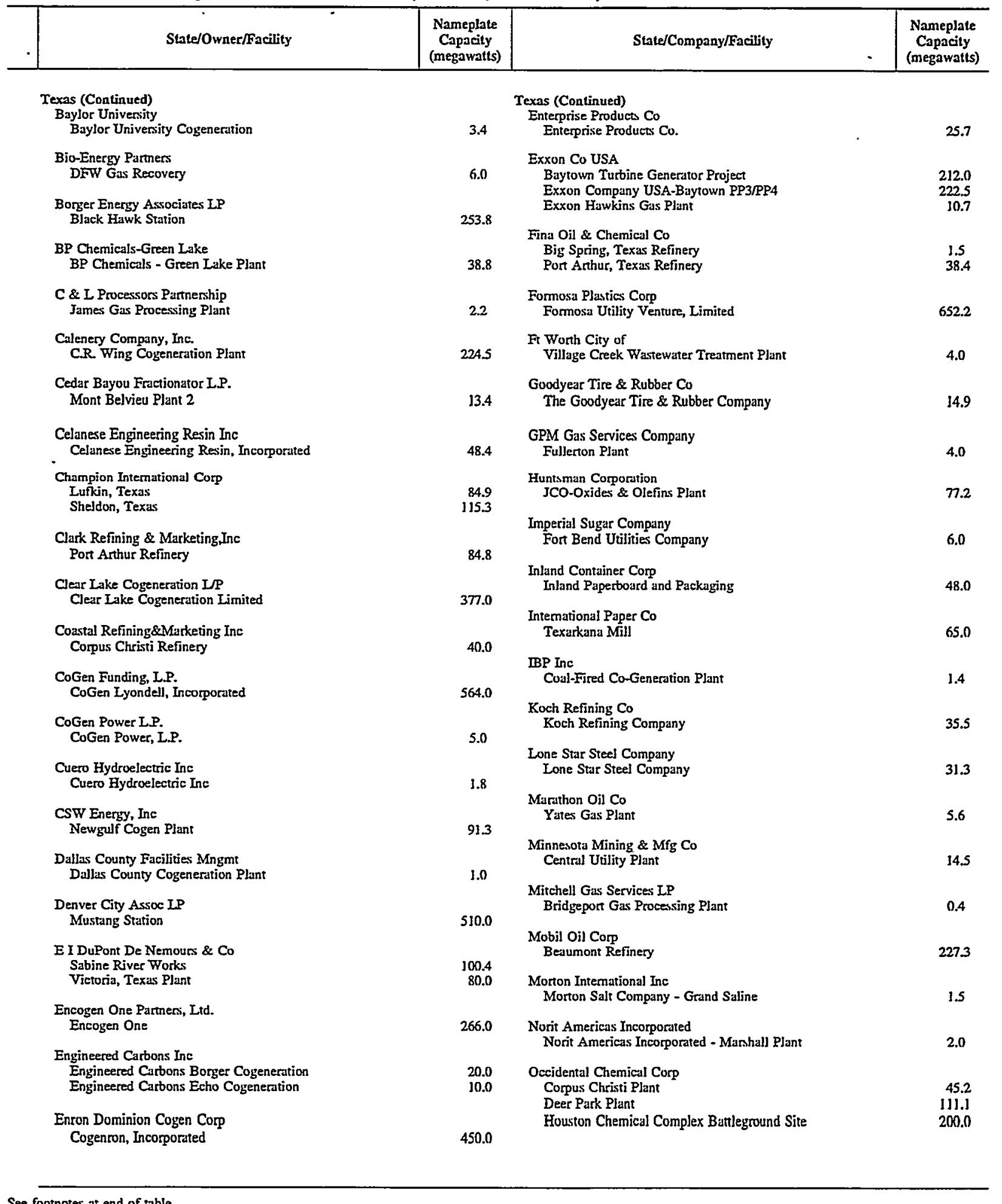

See footnotes at end of table. 
Table 24. Existing Capacity at U.S. Nonutility Power Producers by State, Owner and Facility, as of December 31, 1997 (Continued)

\begin{tabular}{|c|c|c|c|}
\hline State/Owner/Facility & $\begin{array}{l}\text { Nameplate } \\
\text { Capacity } \\
\text { (megawatts) }\end{array}$ & State/Company/Facility & $\begin{array}{c}\text { Nameplate } \\
\text { Capacity } \\
\text { (megawatts) }\end{array}$ \\
\hline $\begin{array}{l}\text { Texas (Continued) } \\
\text { Oyster Creek Limited } \\
\text { Oyster Creek Unit VIII }\end{array}$ & 498.0 & $\begin{array}{l}\text { Texas (Continued) } \\
\text { Texaco Exploration \& Prod.,Inc } \\
\text { Eust Vealmoor Gas Plant }\end{array}$ & 2.2 \\
\hline $\begin{array}{l}\text { Pasadena Cogeneration L P } \\
\text { Pasadena Power Plant }\end{array}$ & 260.9 & $\begin{array}{l}\text { Texas Petrochemicals Cotp } \\
\text { Texus Petrochemieals Corp }\end{array}$ & 35.0 \\
\hline $\begin{array}{l}\text { Phelps Dodge Corp } \\
\text { Phelps Dodge Refining Corporation }\end{array}$ & 19.8 & $\begin{array}{l}\text { The Carbide/Graphite Group,Inc } \\
\text { Seadrift Coke, IP. }\end{array}$ & 7.6 \\
\hline $\begin{array}{l}\text { PPG Industries Ine } \\
\text { PPG Industries, Incoporated - Works } \quad \# 4\end{array}$ & 5.1 & $\begin{array}{l}\text { The Dow Chemical Company } \\
\text { The Dow Chemical Company Texas Operations }\end{array}$ & 1500.2 \\
\hline $\begin{array}{l}\text { Reynolds Metals Co-Sherwin Plt } \\
\text { Reynolds Metals Company - Sherwin Plant }\end{array}$ & 39.0 & $\begin{array}{l}\text { The New World Power Corp } \\
\text { Big Spring Wind Farm }\end{array}$ & 34.3 \\
\hline $\begin{array}{l}\text { Rhone-Poulenc Ine } \\
\text { Rhone Poulenc Basic Chemical Company }\end{array}$ & 6.5 & $\begin{array}{l}\text { Ultramar Diamond Shamrock Corp } \\
\text { McKee Refinery }\end{array}$ & 2.0 \\
\hline $\begin{array}{l}\text { Rio Grande Sugar Growers Co } \\
\text { Rio Grunde Valley Sugar Growers, Incorporated }\end{array}$ & 7.5 & $\begin{array}{l}\text { Uncle Ben 's, Inc } \\
\text { Uncle Bens Incorporated }\end{array}$ & 1.4 \\
\hline $\begin{array}{l}\text { Rock-Tenn } \\
\text { Rock-Tenn, Daljas Mill }\end{array}$ & 6.3 & $\begin{array}{l}\text { Union Carbide Corporation } \\
\text { Seadrift Plant Union Carbide Corporation } \\
\text { Texas City PJant Union Carbide Corporation }\end{array}$ & $\begin{array}{r}133.0 \\
96.0\end{array}$ \\
\hline $\begin{array}{l}\text { S\&L Cogeneration Co } \\
\text { S \& L Cogenerution }\end{array}$ & 55.0 & $\begin{array}{l}\text { Union Oil Co of Califomia } \\
\text { North Riley }\end{array}$ & 3.0 \\
\hline $\begin{array}{l}\text { Shell Development Co } \\
\text { Shell Development Co Westhollow Research Center }\end{array}$ & 3.7 & $\begin{array}{l}\text { Union Pacific Resources Co. } \\
\text { East Texas Gas Plant }\end{array}$ & 2.6 \\
\hline $\begin{array}{l}\text { Shell Oil Co } \\
\text { Shell Deer Park }\end{array}$ & 255.0 & $\begin{array}{l}\text { University of Texas at Austin } \\
\text { University of Texas at Austin }\end{array}$ & 108.9 \\
\hline $\begin{array}{l}\text { Sid Richardson Carbon Co. LTD } \\
\text { Borger Plant }\end{array}$ & 37.5 & $\begin{array}{l}\text { University of Texas At Dallas } \\
\text { University of Texas at Dallas }\end{array}$ & 3.5 \\
\hline $\begin{array}{l}\text { Simpson Paper Co } \\
\text { Pasadena, Texas }\end{array}$ & 14.0 & $\begin{array}{l}\text { University of TX-San Antonio } \\
\text { University of Texas at San Antonio }\end{array}$ & 3.5 \\
\hline $\begin{array}{l}\text { Snider Industries, Inc. } \\
\text { Snider Industries, Incorporated }\end{array}$ & 5.0 & $\begin{array}{l}\text { Valero Refining Co } \\
\text { Valero Refinery }\end{array}$ & 72.2 \\
\hline $\begin{array}{l}\text { Solutia Inc } \\
\text { Chocolate Bayou Plant }\end{array}$ & 9.2 & $\begin{array}{l}\text { Valero Refining Company -Texas } \\
\text { Valero Refining Company - Texas Houston Refinery }\end{array}$ & 34.3 \\
\hline $\begin{array}{l}\text { Southwest Texas State Univ } \\
\text { Southwest Texas State University Cogen } \\
\text { Stue Enterprise } \\
\text { Port Anthur PJant }\end{array}$ & $\begin{array}{r}6.0 \\
135.4\end{array}$ & $\begin{array}{l}\text { Westem Gas Resource Inc. } \\
\text { Benedum Plant } \\
\text { Midkiff Plant } \\
\text { Perkins Plant }\end{array}$ & $\begin{array}{l}2.8 \\
3.6 \\
1.8\end{array}$ \\
\hline $\begin{array}{l}\text { Sweeny Cogeneration L/P } \\
\text { Sweeny Cogeneration Facility }\end{array}$ & 345.0 & $\begin{array}{l}\text { Westem Gas Resources Inc. } \\
\text { Edgewood Gas Plant }\end{array}$ & 3.0 \\
\hline $\begin{array}{l}\text { Temple-Inland Forest Prod Corp } \\
\text { Temple-Inland Forest Prod Corp-Bleached Paperboard }\end{array}$ & 50.1 & $\begin{array}{l}\text { Wichita Falls Energy Co Ltd } \\
\text { Wichita Falls Energy Company, Limited. }\end{array}$ & 80.0 \\
\hline $\begin{array}{l}\text { Tenaska Frontier Partners, LTD } \\
\text { Tenaska Frontier Generation Station }\end{array}$ & 549.6 & $\begin{array}{l}\text { William Marsh Rice University } \\
\text { Rice University }\end{array}$ & 7.1 \\
\hline $\begin{array}{l}\text { Tenaska III Inc } \\
\text { Tenaska III Texas Panners }\end{array}$ & 250.0 & $\begin{array}{l}\text { Windpower Partners j994, LP. } \\
\text { West Texas Windplant }\end{array}$ & 33.6 \\
\hline $\begin{array}{l}\text { Tenaska IV Texas Partners, Lid } \\
\text { Tenaska IV Texas Partners Lid (Cleburne Cogen) }\end{array}$ & 282.6 & $\begin{array}{l}\text { Utah } \\
\text { Geneva Steel } \\
\text { Geneva Steel }\end{array}$ & 50.0 \\
\hline $\begin{array}{l}\text { Tenet Hospital Limited } \\
\text { Pcovidence Memorial Hospital }\end{array}$ & 4.4 & $\begin{array}{l}\text { Lagoon Corp, Inc. } \\
\text { Lagoon Cogeneration Fucility }\end{array}$ & 3.0 \\
\hline
\end{tabular}

See footnotes at end of table. 
Table 24. Existing Capacity at U.S. Nonutility Power Producers by State, Owner and Facility, as of December 31, 1997 (Continued)

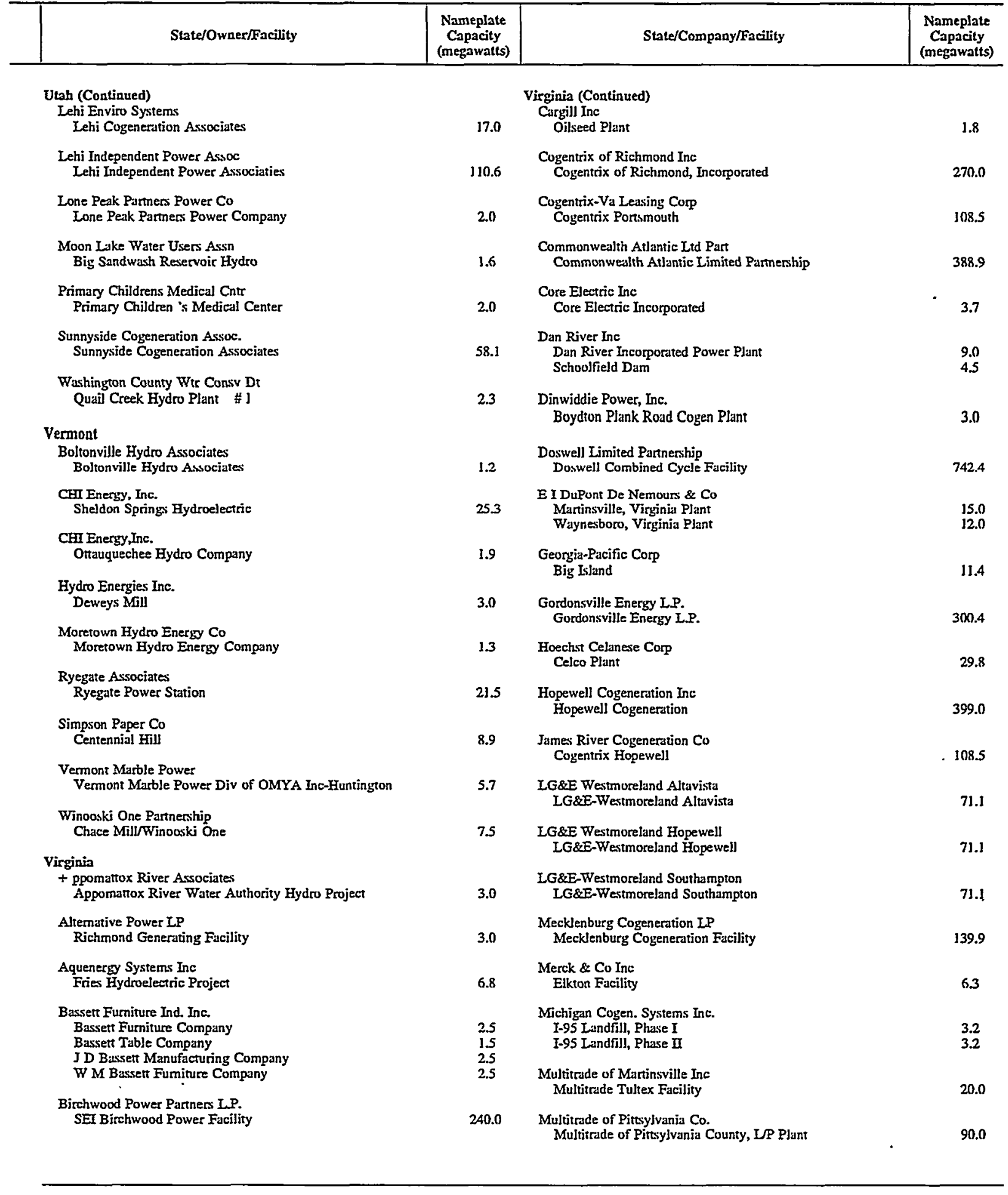

See footnotes at end of rable. 
Table 24. Existing Capacity at U.S. Nonutility Power Producers by State, Owner and Facility, as of December 31, 1997 (Continued)

\begin{tabular}{|c|c|c|c|}
\hline State/Owner/Facility & $\begin{array}{c}\text { Nameplate } \\
\text { Capacity } \\
\text { (megawatts) }\end{array}$ & State/Company/Facility & $\begin{array}{c}\text { Nameplate } \\
\text { Copacity } \\
\text { (negawatts) }\end{array}$ \\
\hline $\begin{array}{l}\text { Virginia (Continued) } \\
\text { Multitrade Group Inc } \\
\text { Multitrade Industrial Park Fucility }\end{array}$ & 20.0 & $\begin{array}{l}\text { Washington } \\
\text { Black Creek Hydro, Inc. } \\
\text { Black Creek }\end{array}$ & 3.7 \\
\hline $\begin{array}{l}\text { Navy Public Works Center } \\
\text { Refuse Derived Fuel Power Plant }\end{array}$ & 60.0 & $\begin{array}{l}\text { Calligan Hydro Ine } \\
\text { Calligan Creek }\end{array}$ & 5.4 \\
\hline $\begin{array}{l}\text { Ogden Energy Group, Inc. } \\
\text { I-95 Energy/Resource Recovery Facility }\end{array}$ & 124.0 & $\begin{array}{l}\text { Daishowa America Co Ltd } \\
\text { Dajshowa America Hydroelectric Ewha Facility } \\
\text { Daishowa America Hydroelectric Glines Facility }\end{array}$ & $\begin{array}{l}12.7 \\
14.9\end{array}$ \\
\hline $\begin{array}{l}\text { Ogden Projects Inc } \\
\text { Alexandria/Arlington Resource Recovery Facility }\end{array}$ & 29.0 & $\begin{array}{l}\text { Encogen Northwest L.P. } \\
\text { Encogen NW }\end{array}$ & 170.2 \\
\hline $\begin{array}{l}\text { Park 500 Philip Morris USA } \\
\text { Park 500 Philip Moris USA }\end{array}$ & 19.1 & $\begin{array}{l}\text { Hancock Hydro Ine } \\
\text { Hancock Creek }\end{array}$ & 6.3 \\
\hline $\begin{array}{l}\text { R.W, Power Partners L/P } \\
\text { R.W. Power Parners I/P - WeGen }\end{array}$ & 3.9 & $\begin{array}{l}\text { King Cnty Dept Nat Resources } \\
\text { West Point Treatment Plast }\end{array}$ & 3.9 \\
\hline $\begin{array}{l}\text { Rock-Tenn Co } \\
\text { Rock-Tenn Company }\end{array}$ & 2.0 & $\begin{array}{l}\text { Koma Kulshan Associates } \\
\text { Koma Kulshan Associates }\end{array}$ & 12.0 \\
\hline $\begin{array}{l}\text { Scott Wood Inc } \\
\text { Scott Wood Ine } \# 2\end{array}$ & 1.3 & $\begin{array}{l}\text { Longview Fibre Co } \\
\text { Longview Fibre Company }\end{array}$ & 135.0 \\
\hline $\begin{array}{l}\text { Scolt Wood Inc. } \\
\text { Scult Wood, Incorporated I }\end{array}$ & 1.4 & $\begin{array}{l}\text { March Point Cogeneration Co } \\
\text { March Point Cogeneration Company }\end{array}$ & 167.0 \\
\hline $\begin{array}{l}\text { Shoosmith Brothers Inc } \\
\text { Shoosmith Brothers, Incorporsted }\end{array}$ & 3.7 & $\begin{array}{l}\text { Omak Wood Products Inc } \\
\text { Omak Wood Products Incorporated }\end{array}$ & 12.5 \\
\hline $\begin{array}{l}\text { St. Luturent Paper Products Co. } \\
\text { St. Lusurent Paper Products Corp. }\end{array}$ & 106.7 & $\begin{array}{l}\text { Port Townsend Paper Corp. } \\
\text { Port Townsend Paper Corporation }\end{array}$ & 14.9 \\
\hline $\begin{array}{l}\text { Stone Container Corp } \\
\text { Stone Container Coporation - Hopewell Mill }\end{array}$ & 47.6 & $\begin{array}{l}\text { Recomp of Washington Ine } \\
\text { Recomp of Washington, Incorporated }\end{array}$ & 2.5 \\
\hline $\begin{array}{l}\text { Suffolk Energy Parners, L.P. } \\
\text { Suffolk Energy Partners, L.P. }\end{array}$ & 3.3 & $\begin{array}{l}\text { Reed, William G., Jr. } \\
\text { Lilliwaup Falls Generating Company }\end{array}$ & 1.8 \\
\hline $\begin{array}{l}\text { Synergics Inc } \\
\text { Emporia } \\
\text { Halifax }\end{array}$ & $\begin{array}{l}2.4 \\
1.8\end{array}$ & $\begin{array}{l}\text { Regional Disposal Co } \\
\text { Roosevelt Regional Landfill }\end{array}$ & 3.0 \\
\hline $\begin{array}{l}\text { U. S. Army } \\
\text { Radford Army Ammunition PJant }\end{array}$ & 24.0 & $\begin{array}{l}\text { Rocky Brook Hydroelectrie Ine } \\
\text { Rocky Brook Hydroelectric }\end{array}$ & 1.6 \\
\hline $\begin{array}{l}\text { Union Camp Corp } \\
\text { Franklin Fine Paper Division }\end{array}$ & 155.6 & $\begin{array}{l}\text { Sheep Creek Hydro Inc } \\
\text { Sheep Creek Hydro Incoporated }\end{array}$ & 1.7 \\
\hline $\begin{array}{l}\text { Vitginia Cogen Ine } \\
\text { Buker Equipment Facility }\end{array}$ & 3.5 & $\begin{array}{l}\text { Spokane City of } \\
\text { Upriver Dam Hydro Plant } \\
\text { Wheelabrator Spokane Incorporated }\end{array}$ & $\begin{array}{l}17.7 \\
26.0\end{array}$ \\
\hline $\begin{array}{l}\text { Vitginia Cogen II Ine } \\
\text { Handeraft Facility }\end{array}$ & 3.5 & $\begin{array}{l}\text { Sumas Cogeneration Co, L.P. } \\
\text { Sumas Cogeneration Company LP. }\end{array}$ & 125.5 \\
\hline $\begin{array}{l}\text { Virginia Cogen } \mathrm{m} \text {, Inc. } \\
\text { Byrd Press Cogeneration Facility }\end{array}$ & 2.5 & $\begin{array}{l}\text { SDS Lumber Co } \\
\text { Gorge Energy Div-SDS Lumber Company }\end{array}$ & 8.5 \\
\hline $\begin{array}{l}\text { Virginia Cogen rV, Inc. } \\
\text { Johnston-Willis Facility }\end{array}$ & 2.5 & $\begin{array}{l}\text { STS Hydropower Ltd } \\
\text { Hutchinson Creek }\end{array}$ & 4.0 \\
\hline $\begin{array}{l}\text { Westvaco Corp } \\
\text { Covington Facility }\end{array}$ & 97.5 & $\begin{array}{l}\text { Tenaska Washington Partners } \\
\text { Tenaska Washington Partners, L/P }\end{array}$ & 245.7 \\
\hline $\begin{array}{l}\text { Wythe Park Power Ine } \\
\text { WPP \#3 (Richmond Plant) } \\
\text { WPP\# I (Petersburg Plant) }\end{array}$ & $\begin{array}{l}3.0 \\
3.0\end{array}$ & $\begin{array}{l}\text { Twin Falls Hydro Associates LP } \\
\text { Twin Falls Hydro }\end{array}$ & 24.0 \\
\hline
\end{tabular}

See footnotes at end of table. 
Table 24. Existing Capacity at U.S. Nonutility Power Producers by State, Owner and Facility, as of December 31, 1997 (Continued)

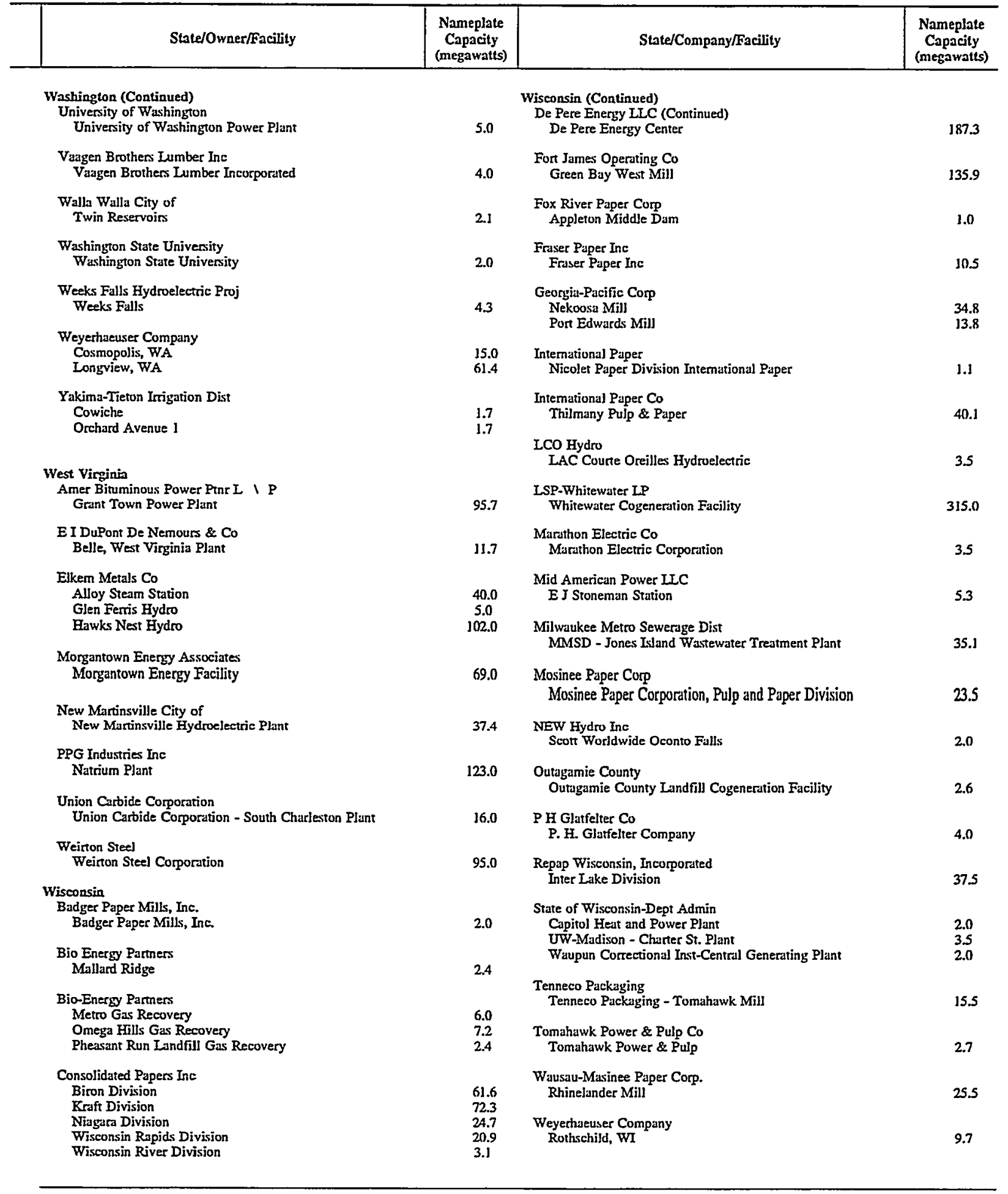

See footnotes at end of table. 
Table 24. Existing Capacity at U.S. Nonutility Power Producers by State, Owner and Facility, as of December 31, 1997 (Continued)

\begin{tabular}{|c|c|c|c|}
\hline State/Owner/Facility & $\begin{array}{c}\text { Nameplate } \\
\text { Capacity } \\
\text { (megawatts) }\end{array}$ & State/Company/Facility & $\begin{array}{c}\text { Nameplate } \\
\text { Capacity } \\
\text { (megawatts) }\end{array}$ \\
\hline $\begin{array}{l}\text { Wisconsin (Continued) } \\
\text { Winnebago County Solid Wist Mgt } \\
\text { Winnebago County Lindfill Gas Recovery }\end{array}$ & 3.2 & & \\
\hline $\begin{array}{l}\text { Wyoming } \\
\text { Amoco Production Co } \\
\text { Anschuz Ranch East } \\
\text { Beaver Creek } \\
\text { Elk Basin Gasoline Plant }\end{array}$ & $\begin{array}{l}50.6 \\
5.0 \\
2.5\end{array}$ & & \\
\hline $\begin{array}{l}\text { General Chemical Corp } \\
\text { General Chemical }\end{array}$ & 30.0 & & \\
\hline $\begin{array}{l}\text { Sincjair Oil Corp } \\
\text { Sinclait Oil Refinery }\end{array}$ & 3.4 & & \\
\hline $\begin{array}{l}\text { Swift Creek Power Co } \\
\text { Swift Creek Power Company }\end{array}$ & 1.5 & & \\
\hline $\begin{array}{l}\text { SF Phosphates Ltd Co } \\
\text { SF Phosphates Limited Company }\end{array}$ & 11.5 & & \\
\hline
\end{tabular}

Source: Energy Information Administration, Form EIA-867, "Annual Nonutility Power Producer Report." 



\section{Appendix A}

Technical Notes 


\section{Appendix A}

\section{Technical Notes}

\section{Sources of Data}

A synopsis of the data collection system used to prepare the Inventory of Power Plants in the United States is presented below. This synopsis reflects the Form EIA-860 data collection system, as of January 1, 1998.

The following are the primary changes that were made to the Form EIA-860 data collection during 1995, which were effective with the January 1, 1996 reporting. (For an update on the definitions of various codes, see Appendix B.)

- Data are reported as of January 1 of the reporting year, where reporting year is the calendar year in which the report is filed with the Energy Information Administration.

- Respondents were given the option to file directly with EIA or file through an agent of their choice.

- Schedule II - Power Plant Site Information: The requirements for elevation and type of cooling were eliminated.

- Schedule III - Generator Information: The requirements for service type, first electricity date, start-up fuels, third energy source, date of cancellation, and reasons for delay/cancellation were eliminated. The requirements for "mode of transportation of fuel" and "ownership type" were added.

\section{Form EIA-860, "Annual Electric Generator Report"}

The Form EIA-860 provides for the annual data collection of information pertaining to power plants owned and operated by electric utilities. The survey includes information on existing power plants and the 10-year plans for new plants, generating unit additions, modifications, and retirements. Data on Form EIA-860 are collected from all electric utilities in the United States that operate power plants or plan to operate a power plant within 10 years of the reporting year.

Instrument and Design History. The Form EIA-860 was implemented in January 1985 to collect data as of year-end 1984. The Federal Energy Administration Act of 1974 (Public Law 93-275) defines the legislative authority to collect these data.

Data Processing. Data on Form EIA-860 are collected from approximately 900 respondents. The forms are mailed to the respondents in November or December to collect data as of January 1 of the reporting year, where the reporting year is the calendar year in which the report is filed. Effective with the 1996 reporting, respondents have the option of filing Form EIA-860 directly with the EIA or through an agent--such as the respondent's regional electric reliability council. For the 1998 reporting, 689 respondents filed directly with the EIA and 191 respondents filed through their regional electric reliability council. Data reported through the regional electric reliability councils are submitted to the EIA electronically from the North American Electric Reliability Council (NERC). Forms filed directly with the EIA are due February 15 of the reporting calendar year. The submittal date of Form EIA- 860 by respondents who file through their agent is determined by the agent. Extensions for filing may be granted by the EIA, upon request.

Data for each respondent are preprinted from the applicable data base. Respondents are instructed to verify all preprinted data and to supply missing data. Processing of the data on Form EIA-860 is the responsibility of the Electric Power Division of the Office of Coal, Nuclear, Electric and Alternate Fuels. The system used to process data reported on Form EIA-860 was designed by this office. The data are manually edited before being keyed for automatic data processing. Computer programs containing additional edit checks are run. Respondents are contacted if nec- 
essary, to obtain correction or clarification of reported data, and to obtain missing data as a result of the manual and automated editing process.

Presentation. Data from Form EIA-860 are summarized in the Inventory of Power Plants in the United States. This report presents aggregate totals for electric utilities in the United States, by Federal region, NERC region, Census division, and State. The data are also used as input to publications and studies by other offices in the Department of Energy.

Information Collected. A summary of the four schedules contained in Form EIA-860 is presented below.

1. Schedule I - Identification and Certification: Respondent's mailing address; name and telephone number of contact person; and name and title of certifying official.

2. Schedule II - Power Plant Site Information: For each reported power plant, the following are specified: plant name; county location; State location; zipcode; name of cooling water source or source of water for hydroelectric power; and indicator of plant's cogeneration function.

3. Schedule III - Generator Information

a. For each existing generator (active and inactive), the following are specified: plant name; generator identification; prime mover; nameplate rating; date of initial commercial operation; energy sources used during the reporting year for the production of electricity; heat rate; net summer capability; and net winter capability; ownership identification; modes of transportation of fuel.

b. For each generator-scheduled for initial commercial operation within 10 years, the following are specified: plant name; generator identification; prime mover; nameplate rating; dates scheduled for initial commercial operation; proposed energy sources; and proposed net summer and net winter capabilities; ownership identification; modes of transportation of fuel.

c. Previously reported proposed generators that have been canceled or indefinitely postponed since the last reporting period are reported.

d. Ten-year plans for changes to existing generators are reported. These proposed changes include change in fuel, life extension, or repowering, and rerating. Additionally, proposed changes in the status of existing generators during the next 10 . years, including deactivation, change in ownership, retirement, and reactivation are reported.

e. Generators that have been retired during the reporting period and their date of retirement are reported.

4. Schedule IV - Ownership of Generators Jointly Owned or Exclusively Owned by Others: For operable generators and proposed new generators that are jointly owned, or for any generator that the respondent operates, but has 100 percent own- ership outside the operating company, the following are reported: plant name, generator identification, prime mover, each owner's name, and their percent ownership.

\section{Quality of Data}

The Office of Coal, Nuclear, Electric and Alternate Fuels (CNEAF) is responsible for routine data improvement and quality assurance activities. All operations of CNEAF are done in accordance with formal standards established by the Energy Information Administration (EIA). These standards are the guidelines for ensuring quality statistics. Data improvement efforts include verification of datakeyed input by automated computerized methods, editing by subject matter specialists, and followup on submissions by nonrespondents. The CNEAF supports the quality assurance efforts of the data collectors by providing advisory reviews of information requirements, and of proposed designs for new and revised data collection forms and systems. The actual performance of working data collection systems is validated once they are implemented. Respondents' computerized data files are checked to identify those who fail to respond to the survey. By law, nonrespondents may be fined or otherwise penalized for not filing an EIA data form as prescribed in the instructions. Before invoking the law, the EIA tries to obtain the required information by encouraging cooperation of nonrespondents.

\section{Updating and Editing of Data}

Automated systems used to edit data include both deterministic checks, in which records are checked for the presence of data in required fields, and statistical checks, in which the data are checked against a range of values based on historical data values and for logical or mathematical consistency with data elements reported in the source documents.

\section{CNEAF Data Revision Policy}

The Office of Coal, Nuclear, Electric and Alternate Fuels has adopted the following policy with respect to the revision and correction of recurrent data in energy publications:

1. Annual survey data collected by this office are published either as preliminary or final when first appearing in a data report. Data initially released as preliminary will be so noted in the report. These data will be revised, if necessary, and declared final in the next publication of the data.

2. All monthly and quarterly survey data collected by this office are published as preliminary. These data are revised only after the completion of the 
12-month cycle of the data. No revisions are made to the published data before this.

3. The magnitude of changes due to revisions experienced in the past will be included in the data reports, so that the reader can assess the accuracy of the data.

4. After data are published as final, corrections will be made only in the event of a greater than one percent difference at the national level. Corrections for differences that are less than the before-mentioned threshold are left to the discretion of the Office Director.

Data as of January 1,1997 at the NERC regional level were revised. The revised data are in the table below.

\begin{tabular}{|c|c|c|c|c|c|c|c|c|}
\hline \multirow{3}{*}{$\begin{array}{c}\text { NERC Region } \\
\text { Primary Energy } \\
\text { Source }\end{array}$} & \multicolumn{8}{|c|}{$\begin{array}{l}\text { Existing Capacity and Planned Capacity Additions at US. Electric Utilities, FRCC and SERC as of } \\
\text { January 1,1997 }\end{array}$} \\
\hline & \multicolumn{4}{|c|}{ Existing! } & \multicolumn{4}{|c|}{ Phnned Additions! 2} \\
\hline & $\begin{array}{l}\text { Number } \\
\text { of Units }\end{array}$ & $\begin{array}{c}\text { Generator } \\
\text { Namephte } \\
\text { (megawatts) }\end{array}$ & $\begin{array}{c}\text { Summer } \\
\text { Capability } \\
\text { (megawatts) }\end{array}$ & $\begin{array}{c}\text { Winter } \\
\text { Capability } \\
\text { (megawatts) }\end{array}$ & $\begin{array}{l}\text { Number } \\
\text { of Units }\end{array}$ & $\begin{array}{l}\text { Generator } \\
\text { Nameplate } \\
\text { (megratts) }\end{array}$ & $\begin{array}{l}\text { Summer } \\
\text { Capability } \\
\text { (megawatis) }\end{array}$ & $\begin{array}{c}\text { Winter } \\
\text { Capability } \\
\text { (megawatts) }\end{array}$ \\
\hline FRCC & 332 & 35,802 & 32,751 & 34,123 & 17 & 3,639 & 3,143 & 3,463 \\
\hline 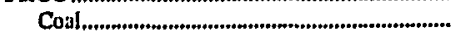 & 21 & 8,853 & 8,042 & 8,195 & 1 & 157 & 157 & 157 \\
\hline 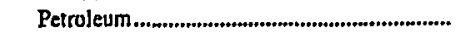 & 132 & 12,957 & 11,753 & 12,430 & - & - & - & - \\
\hline Gas,........, & 133 & 6,947 & 4,821 & 5,119 & 13 & 2,474 & 2,119 & 2,359 \\
\hline Wuter(Pumped Storage Hydroelectric) & 2 & 250 & 276 & 276 & - & - & - & - \\
\hline Water(Conventional Hydroelectric) ................ & 25 & 786 & 868 & 880 & 一 & 一 & 一 & 一 \\
\hline 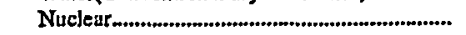 & 5 & 4,110 & 3,876 & 3,975 & - & - & - & - \\
\hline Wuste Heat ......................................................... & 14 & 1,897 & 3,114 & 3,248 & 3 & 1,008 & 867 & 948 \\
\hline 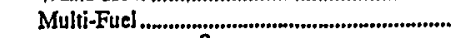 & 一 & - & - & - & 一 & - & - & 一 \\
\hline 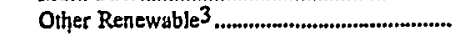 & - & - & - & - & 一 & - & 一 & - \\
\hline SERC & 1,136 & 134,708 & 125,079 & 127,666 & 58 & 8,824 & 7,556 & 8,564 \\
\hline Coal & 233 & 70,418 & 65,013 & 65,527 & 1 & 23 & 23 & 23 \\
\hline 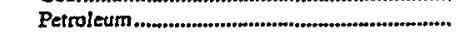 & 217 & 10,102 & 8,688 & 9.659 & 10 & 989 & 841 & 969 \\
\hline 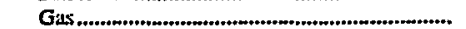 & 137 & 7,677 & 6,742 & 7,995 & 43 & 7,512 & 6,407 & 7,296 \\
\hline Water(Pumped Storage Hydroelectric) ........... & 28 & 6,382 & 6,384 & 6,384 & - & - & - & - \\
\hline Water(Conventional Hydroelectric)............... & 481 & 9,987 & 10,219 & 9,921 & 4 & 300 & 285 & 276 \\
\hline 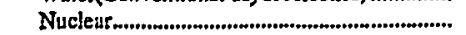 & 29 & 29,845 & 27,765 & 27,911 & - & - & - & - \\
\hline 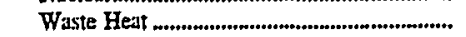 & 8 & 297 & 268 & 268 & - & 一 & - & - \\
\hline 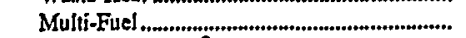 & - & - & - & - & - & 一 & - & - \\
\hline 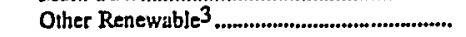 & 3 & $\approx$ & $*$ & * & - & - & 一 & 一 \\
\hline
\end{tabular}

1 NERC region totals are aggregates based on the assignment of units/capacity to the NERC region with which the utility operating the unit is associared.

2 Planned additions are for 1997 through 2006

3 Includes geothermal, biomuss (wood, wood waste, nonwood waste), solar, and wind.

* Less than 0.5 megawatts.

Notes: -NERC $=$ North American Electric Reliability Council. •See NERC Map in Appendix F. -The Form EIA-860 was revised during 1995 to collect duta as of January 1 of the reporting year, where "reporting year" is the calendar year in which the report is required to be filed with the Energy Information Administration. These data reflect the status of electric power plants/generators as of January l: however, dynamic data are based on oceurrences in the previous calendar year (e.g., capabilities and energy sources based on test and consumption in the previous year).

Source: Energy Information Administration, Form EIA-860, “Annual Electric Generator Report."

\section{Confidentiality of the Data}

Generally, data collected on Form EIA-860 as of January 1, 1998 are not confidential. However, specific heat rate data reported on the form will not be released to the public.

\section{Obtaining Copies of Data}

Upon EIA approval of the Inventory of Power Plants in the United States, the data become available for public use. Computer listings are obtained by submitting a written request to:

Energy Information Administration, EI-53 Forrestal Building

U.S. Department of Energy

Washington, DC 20585
These data are also available on machine-readable tapes. Tapes may be purchased by using Visa, MasterCard, or American Express cards, as well as money orders or checks payable to the National Technical Information Service (NTIS). Purchasers may also use NTIS and Government Printing Office depository accounts. To place an order, contact:

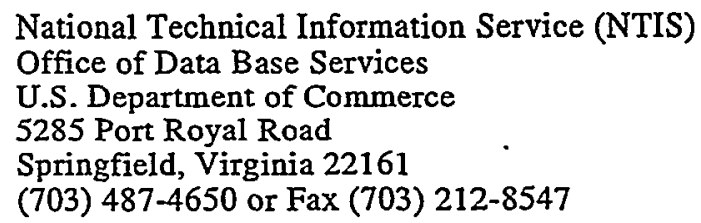

Personal computer diskette ( $31 / 2^{\prime \prime}$ or $51 / 4^{\prime \prime}$ ) may be purchased by using Visa or MasterCard, as well as money orders or checks payable to the U.S. Department of Energy. To place an order, contact:

Office of Scientific and Technical Information U.S. Department of Energy

Energy Information Administration/Inventory of Power Plants in the United States as of January I, 1998289 
Request Services

P.O. Box 62

Oak Ridge, Tennessee 37831

(615) 576-8401 or Fax (615) 576-2865

\section{Explanatory Notes}

\section{U.S. Aggregates}

Data from Form EIA-860 are submitted at the generator level. These data are then aggregated to provide totals by energy source (coal, petroleum, gas, water, nuclear, other) and geographic area (State, NERC region, Federal region, Census division). Additionally, at the national level data are aggregated to provide totals by prime mover.

\section{Generator Nameplate Capacity Versus Generator Capability}

Generator nameplate capacity is determined by the generator manufacturer under specified test conditions normally conducted at the factory. The manufacturer stamps the achieved test capacity on the metal nameplate attached to the generator. Generator capability, on the other hand, is determined by the utility operating the generator, and is based on historical performance of the generator and associated equipment. Generator nameplate capacity and generator capability generally differ from each other because the test conditions used to establish the nameplate rating differ from those normally encountered in daily power plant operations. Different steam working pressures and temperatures, capacity limitations of boilers, cooling systems, turbines, and environmental control equipment, different hydrogen pressures used to cool the generator, and reliability considerations cause discrepancies between nameplate and operating capacity.

Generator nameplate capacity reflects the capability of the generator to generate electricity without regard to electrical loads from associated equipment such as boilers, particulate collectors, flue gas desulfurization units, and plant lighting. Generator nameplate capacity is therefore the gross capacity of the equipment. Net capability refers to the ability of the generator to generate electric power, taking into consideration the electrical requirements of associated plant equipment. For example, the electricity to run flue gas desulfurization equipment comes from electricity generated at the plant. Net, therefore, refers to the electricity available to be sent offsite (for consumption) after plant electrical loads have been satisfied.

Net summer and net winter capability (the capacity of the generator that is generally achievable during the summer and winter months, respectively, after plant electrical requirements have been satisfied) is determined by the utility operating the generator on the basis of historical performance of the generator and associated equipment. The summer and winter figures are usually not the same because of the differences in ambient temperatures during each season. Power plant cooling capacity, an essential part of electric power generation, decreases as air and water temperatures increase. Summer capability is therefore generally lower than winter capability, because high summer temperatures can strain power plant cooling capacity to the extent that maximum electric power generation cannot be achieved. The statistics cited in the narrative in this publication are based on net summer capability, unless specified otherwise.

\section{Net Summer Capability and Net Winter Capability Estimates}

Estimated values for net summer capability and net winter capability for nonnuclear ${ }^{9}$ electric generating units were developed by use of a regression formula, using year-end 1992 data on net summer capability, net winter capability, and generator nameplate capacity of units in commercial operation during three intervals of time: 1940 or earlier, 1941 through 1980, and 1981 to present. A zero-intercept linear regression model with generator nameplate capacity as the regressor data was used since examination of the data shows that the intercepts are generally near zero. In all formulas,

the symbol, *, is an operator meaning multiplied by.

For nonnuclear units,

Net Summer/Winter Capability $=b *($ Nameplate
Capacity), where

b, represents the slope or factor by which nameplate capacity has to be multiplied to obtain a capability estimate, using this model,

$\sigma$, represents the standard error for $b$,

Generator Nameplate Capacity is expressed in kilowatts.

Net Summer Capability

$\mathrm{b}=.90, \sigma=.04,1940$ or earlier; $\mathrm{b}=.927, \sigma=$ $.002,1941-1980 ; b=.937, \sigma=.004,1981$ through present, for coal steam units (Unit Types, ST, AB, $\mathrm{CH}, \mathrm{PB}$ )

$\mathrm{b}=1.00, \sigma=.03,1940$ or earlier; $\mathrm{b}=.961, \sigma=$ $.002,1941-1980 ; b=.93, \sigma=.01,1981$ through present, for noncoal steam units (Unit Types, ST, $\mathrm{AB}, \mathrm{CH}, \mathrm{PB}$ )

9 Respondents report summer and winter capability and nameplate for all nuclear units. 
$\mathrm{b}=.856, \sigma=.003,1980$ or earlier; $\mathrm{b}=.85, \sigma=$ $.01,1981$ through present, for gas-turbine units (Unit Types, GT, JE)

$\mathrm{b}=.94, \sigma=.01,1940$ or earlier; $\mathrm{b}=.84, \sigma=.01$, $1941-1980 ; \mathrm{b}=.86, \sigma=.02,1981$ through present, for combined-cycle units (Unit Types, CA, CS, CW, CT, IG, CC)

$\mathrm{b}=.884, \sigma=.009,1940$ or earlier; $\mathrm{b}=.925, \sigma=$ $.002,1941-1980 ; b=.976, \sigma=.003,1981$ through present, for internal combustion units (Unit Type, IC)

$\mathrm{b}=.975, \sigma=.005,1940$ or earlier; $\mathrm{b}=1.034, \sigma=$ $.004,1941-1980 ; \mathrm{b}=.950, \sigma=.008,1981$ through present, for conventional and pipeline hydroelectric units (Unit Types, HY, HL)

$\mathrm{b}=.93, \sigma=.03,1940$ or earlier; $\mathrm{b}=1.03, \sigma=$ $.01,1941-1980 ; b=1.01, \sigma=.006,1981$ through present, for pumped-storage hydroelectric units (Unit Type, PS)

$\mathrm{b}=1$, for all other units (Unit Types, CE, FC, GE, $\mathrm{OC}, \mathrm{PV}, \mathrm{SS}, \mathrm{WT}$ ), where limited data are available.

Net Winter Capability

$\mathrm{b}=.88, \sigma=.05,1940$ or earlier; $\mathrm{b}=.934, \sigma=$ $.002,1941-1980 ; \mathrm{b}=.940, \sigma=.004,1981$ through present, for coal steam units (Unit Types, $\mathrm{ST}, \mathrm{AB}, \mathrm{CH}, \mathrm{PB}$ )

$\mathrm{b}=1.02, \sigma=.03,1940$ or earlier; $\mathrm{b}=.965, \sigma=$ $.002,1941-1980 ; b=.94, \sigma=.01,1981$ through present, for noncoal steam units (Unit Types, ST, $\mathrm{AB}, \mathrm{CH}, \mathrm{PB}$ )

$\cdot \mathrm{b}=1.023, \sigma=.004,1980$ or earlier; $\mathrm{b}=.98, \sigma=$ $.01,1981$ through present, for gas-turbine units (Unit Types, GT, JE)

$\mathrm{b}=1.02, \sigma=.03,1940$ or earlier; $\mathrm{b}=.96, \sigma=$ $.01,1941-1980 ; b=.94, \sigma=.02,1981$ through present, for combined-cycle units (Unit Types, $\mathrm{CA}, \mathrm{CS}, \mathrm{CW}, \mathrm{CT}, \mathrm{IG}, \mathrm{CC}$ )

$\mathrm{b}=.893, \sigma=.008,1940$ or earlier; $\mathrm{b}=.940, \sigma=$ $.002,1941-1980 ; b=.987, \sigma=.002,1981$ through present, for internal combustion units (Unit Type, IC)

$\mathrm{b}=.979, \sigma=.005,1940$ or earlier; $\mathrm{b}=1.026, \sigma=$ $.004,1941-1980 ; b=.92, \sigma=.01,1981$ through present, for conventional and pipeline hydroelectric units (Unit Types, HY, HL)

$\mathrm{b}=.96, \sigma=.05,1940$ or earlier; $\mathrm{b}=1.02, \sigma=$ $.01,1941-1980 ; b=1.03, \sigma=.01,1981$ through present, for pumped-storage hydroelectric units (Unit Type, PS)

$\mathrm{b}=1$, for all other units (Unit Types, CE, FC, GE, $O C, P V, S S, W T$ ), where limited data are available.

\section{Definitions of Terms}

\section{Existing Capacity/Existing Units}

Capacity/units that are existing, including those that are on standby and those that are out of service for an indefinite period of time.

\section{Planned Additions/Additional Units}

Capacity/units scheduled for initial commercial operation within 10 years of the reporting period of the publication, unless otherwise specified.

\section{Scheduled Completion}

Current/Original: For projected generating unit additions, the estimated date the unit is scheduled to start commercial operation, both the current date and the original scheduled date.

\section{Rounding Rules for Data}

Given an $\mathbf{n}$ digit number with $\mathbf{r}$ digits to the left of the decimal and $d+t$ digits in the fraction part, with $d$ being the place to which the number is to be rounded and $t$ being the remaining digits which will be truncated, this number is rounded to $\mathrm{r}+\mathrm{d}$ digits by adding 5 to the $(r+d+1)$ th digit when the number is positive or by subtracting 5 when the number is negative. The $t$ digits are then truncated at the $(r+d+1)$ th digit. The symbol for a rounded number truncated to zero is $(*)$.

\section{Use of the Glossary}

The terms in the Glossary have been defined for general use. Restrictions on the definitions as used in these data collection systems are included in each definition when necessary to define the terms as they are used in this report. 
Appendix B

\section{Table Codes}

and

References 
. 


\section{Appendix B}

\section{Table Codes and References}

\section{Table B1. Codes for Energy Sources}

\begin{tabular}{|c|c|}
\hline Code & Energy Source \\
\hline ANT,...................................................... & Anthracite Coal \\
\hline BFG ..................................................... & Blast-Fumace Gass \\
\hline 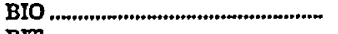 & Biomass (general) \\
\hline 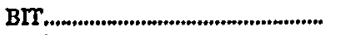 & Bituminous Coal \\
\hline 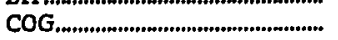 & Coke-Oven Gas \\
\hline Coal (COL),............................................. & Coal (general) \\
\hline 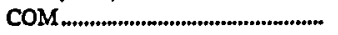 & Coal-Oil Mixture \\
\hline 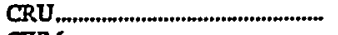 & Crude Oil \\
\hline CWM..................................................... & Coal-Water Mixture \\
\hline 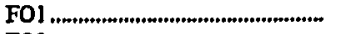 & No. 1 Fuel Oil \\
\hline FO2 2........................................................ & No. 2 Fuel Oil \\
\hline 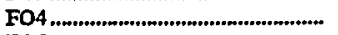 & No. 4 Fuel Oil \\
\hline 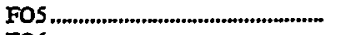 & No. 5 Fuel Oil \\
\hline FO6 ........................................................ & No. 6 Fuel Oil \\
\hline GAS........................................................... & Gas (general) \\
\hline 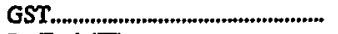 & Geothermal Steam \\
\hline Jet Fuel (JF) .......................................... & Jet Fuel \\
\hline 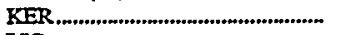 & Kerosene \\
\hline LIG ............................................................. & Lignite \\
\hline ING,........................................................ & Liquifred Natural Gas \\
\hline LPG............................................................ & Liquid Propane Gas \\
\hline MF.............................................................. & Multifueled \\
\hline MTE........................................................... & Methane \\
\hline MTH ……...................................................... & Methanol \\
\hline Nat Gas (NG) .............................................. & Natural Gas \\
\hline OT & Other \\
\hline 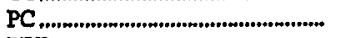 & Petroleum Coke \\
\hline 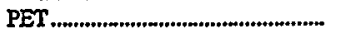 & Petroleum (general) \\
\hline 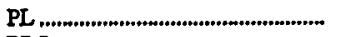 & Plutonium \\
\hline PRO & Propane \\
\hline 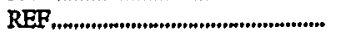 & Refuse, Bagasse, or any other nonwood waste \\
\hline 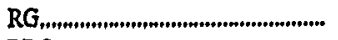 & Refinery Gas \\
\hline 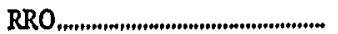 & Re-refined Motor Oil \\
\hline 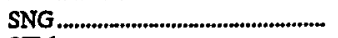 & Synthetic Natural Gas \\
\hline 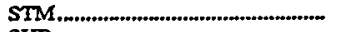 & Steam \\
\hline 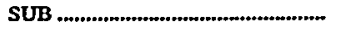 & Subbituminous Coal \\
\hline SUN (............................................................. & Sun \\
\hline TOP........................................................... & Top Crude Ois \\
\hline UR............................................................ & Uranium \\
\hline Water (WAT) ........................................ & Water \\
\hline 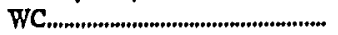 & Waste Coal (culm) \\
\hline WD & Wood or Wood Waste \\
\hline WH & Wasre Hear \\
\hline 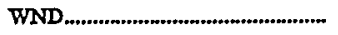 & Wind \\
\hline
\end{tabular}

Source: Energy Information Administration, Office of Cous, Nuclear, Electric and Altemate Fueb. 
Table B2. Cross Reference of Energy Sources to Codes

\begin{tabular}{|c|c|}
\hline Energy Source & Code \\
\hline 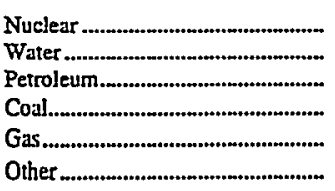 & $\begin{array}{l}\text { Uranium (UR), PL } \\
\text { Water (WAT) } \\
\text { RRO, FO1, FO2, FO4, FO5,FO6, CRU, Jet Fuel (JF), KER, TOP,PET, PC, MTH } \\
\text { COAL, BIT, SUB, ANT, LIG, WC } \\
\text { LNG, GAS, Nat Gas (NG), SNG, RG, BFG,COG, LPG, PRO } \\
\text { All other energy sources not specified above. }\end{array}$ \\
\hline
\end{tabular}

Source: Energy Information Administration, Office of Cual, Nuclear, Electric and Altemate Fuels.

Table B3. Codes for Generating Unit Type

\begin{tabular}{|c|c|}
\hline Code & Generating Unit Type \\
\hline $\begin{array}{l}C A \\
C E \\
C S\end{array}$ & $\begin{array}{l}\text { Atmospheric Fluidized Bed Combustion } \\
\text { Combined Cycle Steam Turbine with Supplementary Firing } \\
\text { Combined Cycle - Total Unit } \\
\text { Compressed Air Energy Storage } \\
\text { Steam Turbine, Common Header } \\
\text { Combined Cycle - Single Shaft } \\
\text { Combined Cycle Combustion Turbine } \\
\text { Combined Cycle Sream Turbine with Only Waste Heat Capability } \\
\text { Fuel Cell } \\
\text { Steam Turbine - Geothermal } \\
\text { Combustion (gas) Turbine } \\
\text { Hydraulic Turbine - Pipeline } \\
\text { Hydraulic Turbine - Conventional } \\
\text { Internal Combustion (diesel) } \\
\text { Integrated Coal Gasification Combined Cycle } \\
\text { Jet Engine } \\
\text { Steam Turbine - Boiling Water Nuclear Reactor } \\
\text { Steam Turbine - Graphite Nuclear Reactor } \\
\text { Steam Turbine - High Temperature Gas Nuclear Reactor } \\
\text { Steam Turbine - Prexsurized Water Nuclear Reactor } \\
\text { Ocean Thermal Turbine } \\
\text { Other } \\
\text { Pressurized Fluidized Bed Combustion } \\
\text { Hydraulic Turbine - Reversible (pumped storage) } \\
\text { Photovoltaic } \\
\text { Steam Turbine - Solar } \\
\text { Steam Turbine - Boiler } \\
\text { Wind Turbine }\end{array}$ \\
\hline
\end{tabular}

Source: Energy Information Administration, Office of Coal, Nuclear, Electric and Altemate Fuels. 
Table B4. Codes for Generating Unit Status

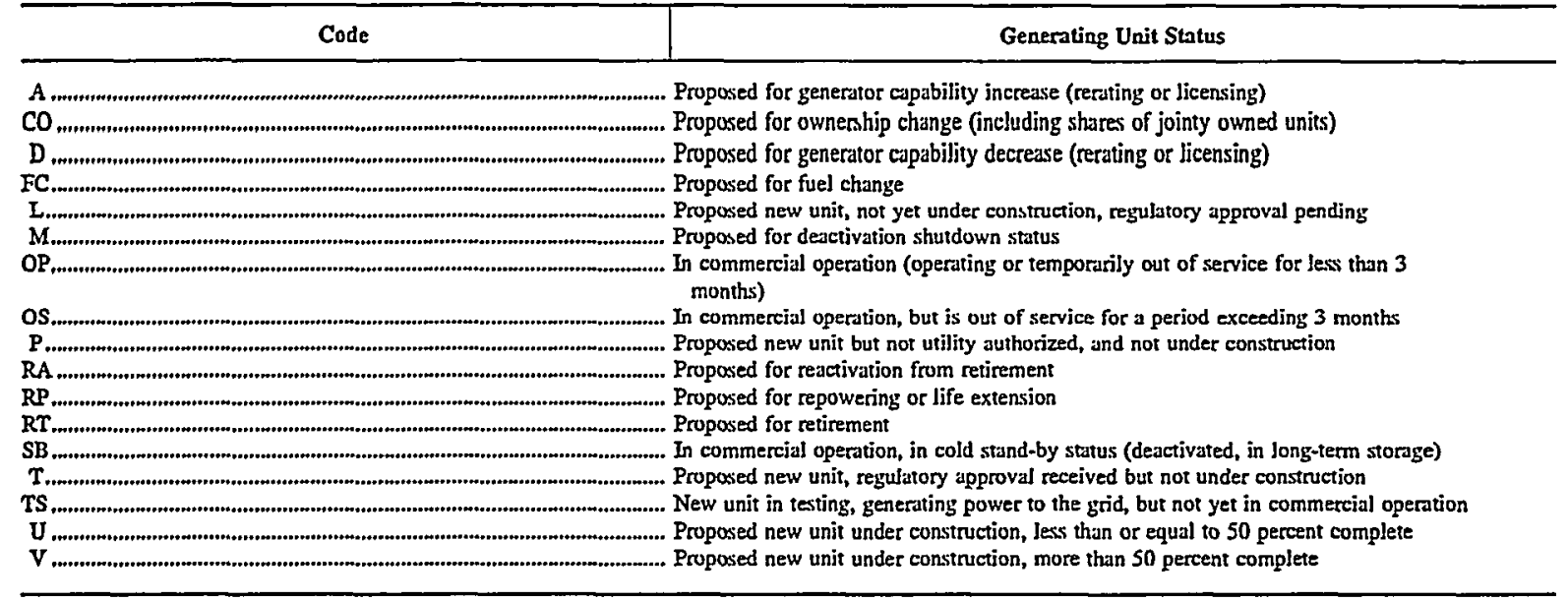

Source: Energy Information Administration, Office of Cos], Nuclear, Electric and Altemate Fuels. 
Table B5. Cross Reference of States to Federal Regions, NERC Regions, and Census Divisions

\begin{tabular}{|c|c|c|c|}
\hline State & Federal Region & NERC Region & Census Division \\
\hline Alabama & 4 & SERC & Eust South Central \\
\hline 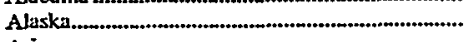 & 10 & ASCC & Pacific \\
\hline Arizona & 9 & wsCC & Mountain \\
\hline 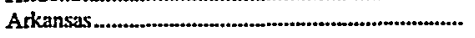 & 6 & SPP & West South Central \\
\hline Califomia & 9 & wsce & Pacjitic \\
\hline 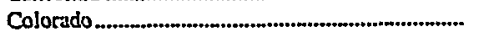 & 8 & wsCC & Mountain \\
\hline 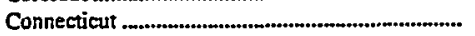 & 1 & NPCC & New England \\
\hline 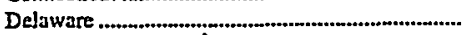 & 3 & MAAC & South Atlantic \\
\hline District of CoJumbial & 3 & MAAC & South Atlantic \\
\hline Forida & 4 & FRCC & South Atlantic \\
\hline 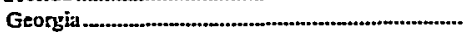 & 4 & SERC & South Atlantic \\
\hline 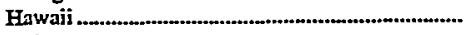 & 9 & HICC & Pacific \\
\hline Idaho & 10 & wsCC & Mountain \\
\hline 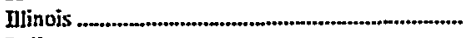 & 5 & MAIN & East North Central \\
\hline 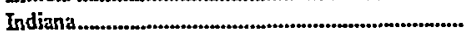 & 5 & ECAR & East North Central \\
\hline 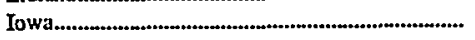 & 7 & MAPP & West North Central \\
\hline 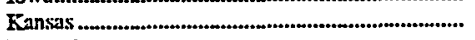 & 7 & SPP & West North Central \\
\hline 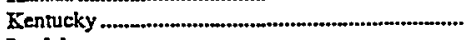 & 4 & ECAR, SERC & East South Central \\
\hline 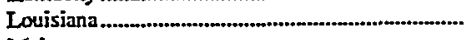 & 6 & SPP & West South Central \\
\hline 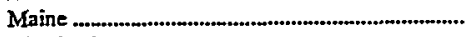 & 1 & NPCC & New England \\
\hline 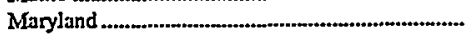 & 3 & MAAC, ECAR & South Allantic \\
\hline 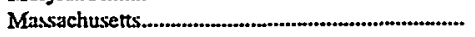 & 1 & $\mathrm{NPCC}$ & New England \\
\hline 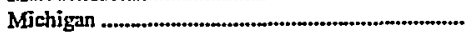 & 5 & ECAR, MAIN & East North Centeal \\
\hline 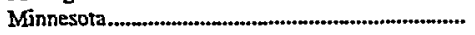 & 5 & MAPP & West Nonh Central \\
\hline 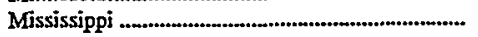 & 4 & SERC, SPP & East South Central \\
\hline Missouri & 7 & MAIN, SPP & West North Central \\
\hline Montana & 8 & WSCC, MAPP & Mountain \\
\hline 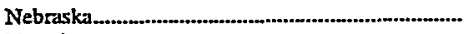 & 7 & MAPP, WSCC & West North Central \\
\hline Nevada & 9 & wscc & Mountsin \\
\hline 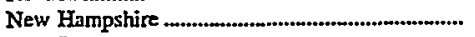 & 1 & NPCC & New England \\
\hline 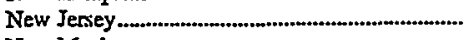 & 2 & MAAC & Middle Atlantic \\
\hline New Mexico & 6 & WSCC, SPP & Mountain \\
\hline 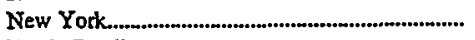 & 2 & NPCC & Middle Atlantic \\
\hline 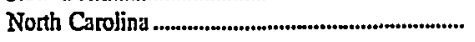 & 4 & SERC & South Atlantic \\
\hline North Dakota & 8 & MAPP & West North Central \\
\hline & 5 & ECAR & Eust North Central \\
\hline 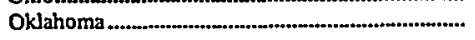 & 6 & SPP & West South Central \\
\hline Oregon & 10 & wsCC & Pacific \\
\hline 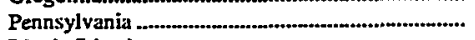 & 3 & MAAC, ECAR & Middle Atlintic \\
\hline 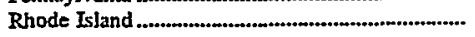 & ] & NPCC & New England \\
\hline 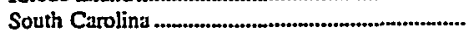 & 4 & SERC & South Atlantic \\
\hline South Dakota & 8 & MAPP, WSCC & West North Central \\
\hline 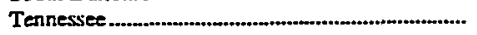 & 4 & SERC & Eust South Central \\
\hline 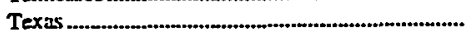 & 6 & ERCOT, SPP, WSCC & West South Central \\
\hline Utah. & 8 & WSCC & Mountain \\
\hline 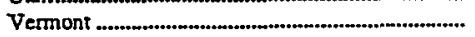 & 1 & $\mathrm{NPCC}$ & New England \\
\hline Virginia & 3 & SERC, ECAR, MAAC & South Atjantic \\
\hline 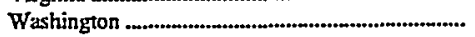 & 10 & WSCC & Pacific \\
\hline 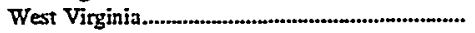 & 3 & ECAR & South Atlantic \\
\hline Wisconsin & 5 & MAIN, MAPP & East North Central \\
\hline 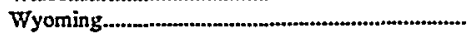 & 8 & WSCC & Mountain \\
\hline
\end{tabular}

1 Treated as a State in this publication.

NERC = North American Electric Reliability Councit

Source: Energy Information Administration, Office of Coal, Nuclear, Electric and Altemate Fuels. 


\title{
Appendix C
}

\author{
Jointly Owned \\ Electric \\ Generating \\ Units
}




\section{Appendix C}

\section{Jointly Owned Electric Generating Units}


Table C1. Jointly Owned Electric Generating Units by State, Company, and Plant, as of January 1, 1998

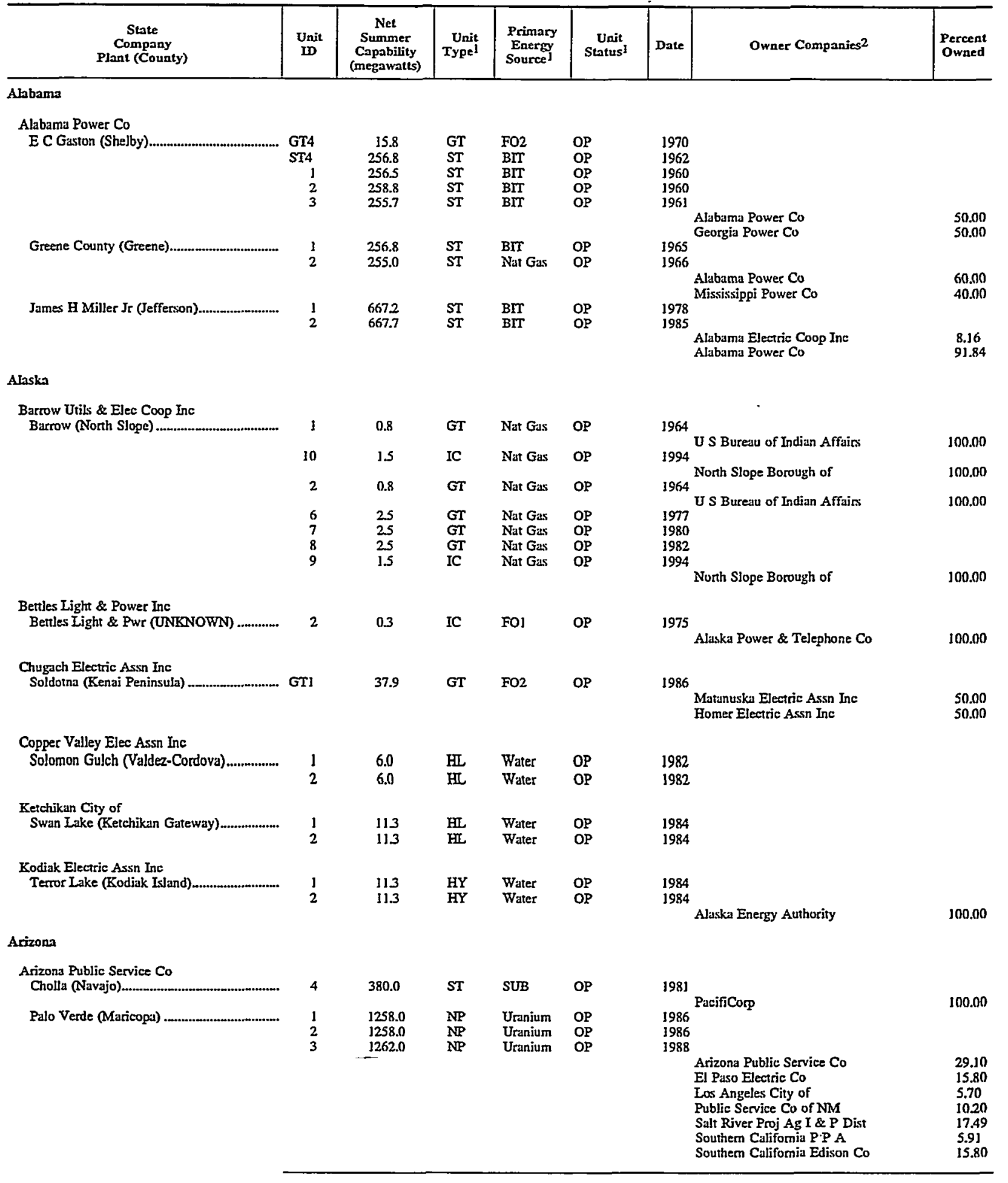

See foomotes at end of table. 
Table C1. Jointly Owned Electric Generating Units by State, Company, and Plant, as of January 1, 1998 (Continued)

\begin{tabular}{c|c|c|c|c|c|c|c|}
\hline $\begin{array}{c}\text { State } \\
\text { Company } \\
\text { Plant (County) }\end{array}$ & $\begin{array}{c}\text { Unit } \\
\text { ID }\end{array}$ & $\begin{array}{c}\text { Net } \\
\text { Cummer } \\
\text { (megawility }\end{array}$ & $\begin{array}{c}\text { Unit } \\
\text { Typel }\end{array}$ & $\begin{array}{c}\text { Primary } \\
\text { Energy } \\
\text { Sourcel }\end{array}$ & $\begin{array}{c}\text { Unit } \\
\text { Statusl }\end{array}$ & Date & Owner Companies2 \\
\hline
\end{tabular}

Arizona

Arizona Public Service Co Yucea (Yuma) ST]

75.0 ST Nat Gas $\quad$ OP

Imperial Irigation District

100.00

Salt River Proj Ag I \& P Dist

Navajo (Coconino)

NAVJ

NAV2

NAV2
NAV3

755.0
720.0

720.0
750.0

$\begin{array}{ll}\text { ST } & \text { SUB } \\ \text { ST } & \text { SUB } \\ \text { ST } & \text { SUB }\end{array}$

OP
OP
OP

1974
1975

1975
1976

Arizona Public Service Co Bureau of Reclamation

Los Angeles City of

Nevada Power Co

Salt River Proj Ag I \& P Dist

Tucson Electric Power Co

2430

21.20

11.30

,

Arkansas

Entergy Arkunsas Inc.

Independence (Independence)

Independence (thdependence)...........................

836.0

SUB

OP

White Bluff (Jeffersion)

815.0
844.0

ST

SUB

OP
OP

OP

1983

Arkansas Electric Coop Corp

Entergy Arkansas, Inc

Conway Corp

Jonesboro City of

Entergy Mississippi, Ine

Osceola City of

1984

West Memphis City of

21.70
7.50

Arkansas Electric Coop Corp

Conway Corp

Jonesboro City of

Entergy Mississippi, Inc

Osceola City of

West Memphis City of

Entergy Power Ine

1980
1981

Arkansas Electric Coop Corp

Entergy Arkansas, Inc

Conway Corp

Jonesboro City of

West Memphis City of

35.00

3150

2.00

5.00

25.00

0.50
1.00

35.00

2.00

5.00

25.00

0.50

1.00
31.50

Southwestem Electric Power Co

pint Creek (Benton)

ST

SUB

OP

1978

Arkansas Electric Coop Corp

Southwestem Electric Power Co

50.00

so.00

California

Califomia Dept-Wtr Rexources

W R Gianelli (Merced)...

$\begin{array}{ll}1 & 51.0 \\ 2 & 50.0 \\ 3 & 50.0 \\ 4 & 50.0 \\ 5 & 50.0 \\ 6 & 50.0 \\ 7 & 50.0 \\ 8 & 50.0\end{array}$

$\begin{array}{ll}\text { PS } & \text { Water } \\ \text { PS } & \text { Water } \\ \text { PS } & \text { Water } \\ \text { PS } & \text { Water } \\ \text { PS } & \text { Water } \\ \text { PS } & \text { Water } \\ \text { PS } & \text { Water } \\ \text { PS } & \text { Water }\end{array}$

$O P$
$O P$
$O P$
$O P$
$O P$
$O P$
$O P$
$O P$

1968
1968
1967
1967
1967
1967
1967
1967

Bureau of Reclamation
Califomia Dept-Wit Re

45.00
55.00

Modesto Irrigation District

New Hogan (Calaveras)

NA1
NA2

2.0

HY Water
HY Water

OP
OP

1986

Calaveras County Water Dist $\quad 100.00$

See foonotes at end of table.

Energy Information Administration/Inventory of Power Plants in the United States as of January 1, 1998303 
Table C1. Jointly Owned Electric Generating Units by State, Company, and Plant, as of January 1, 1998 (Continued)

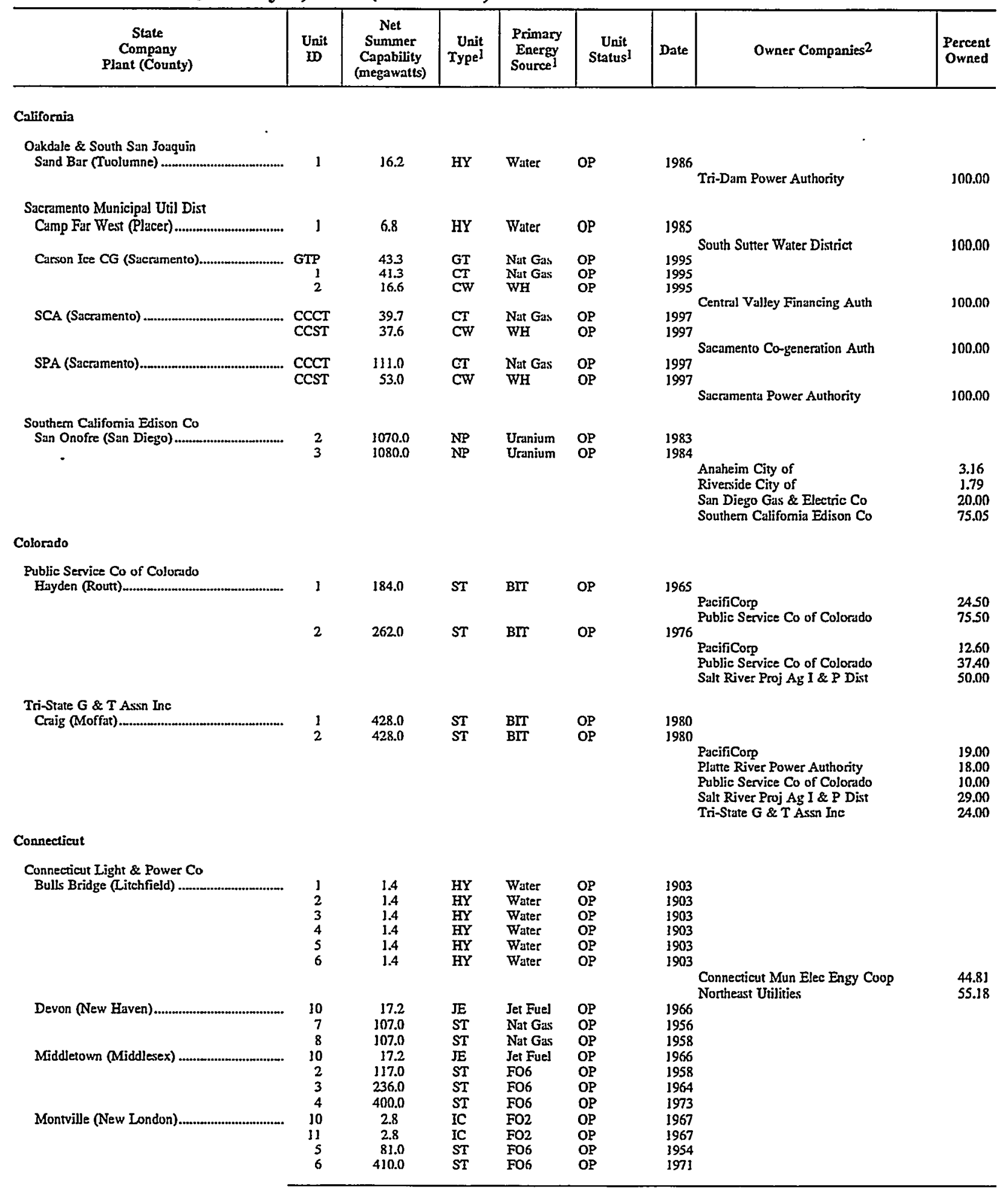

See footnotes at end of table. 
Table C1. Jointly Owned Electric Generating Units by State, Company, and Plant, as of January 1, 1998 (Continued)

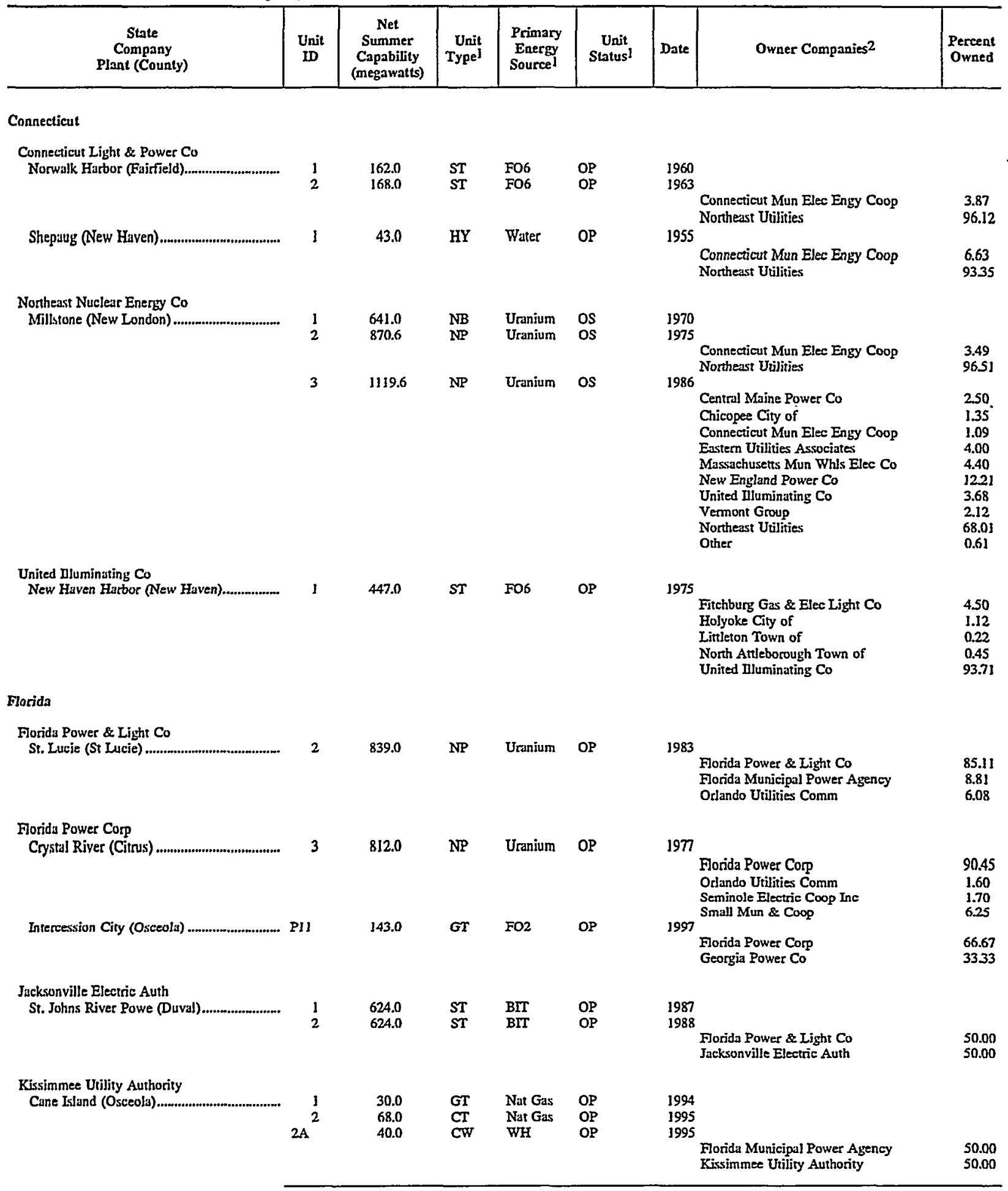

See footnotes at end of table. 
Table C1. Jointly Owned Electric Generating Units by State, Company, and Plant, as of January 1, 1998 (Continued)

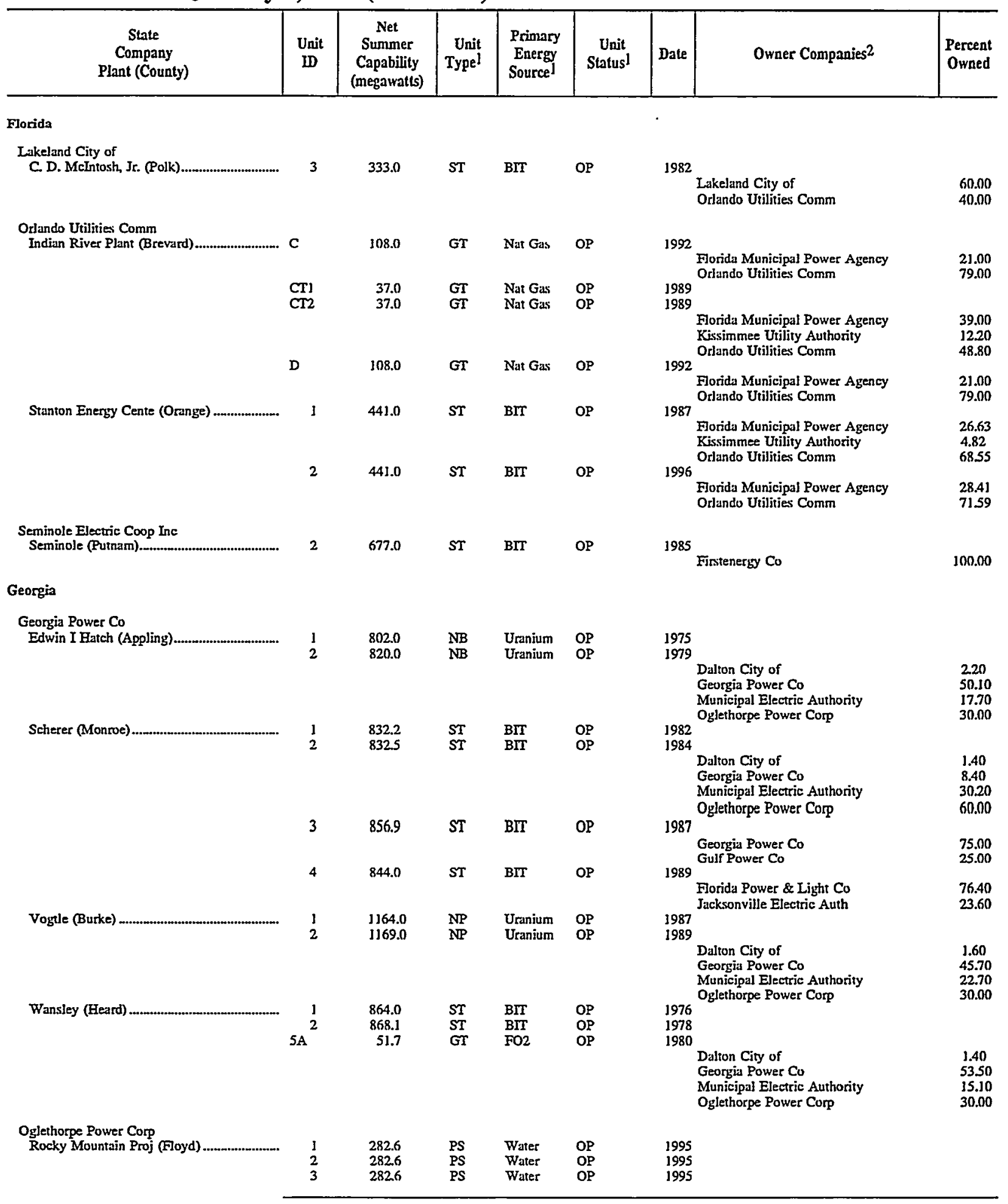

See footnotes at end of table. 
Table C1. Jointly Owned Electric Generating Units by State, Company, and Plant, as of January 1, 1998 (Continued)

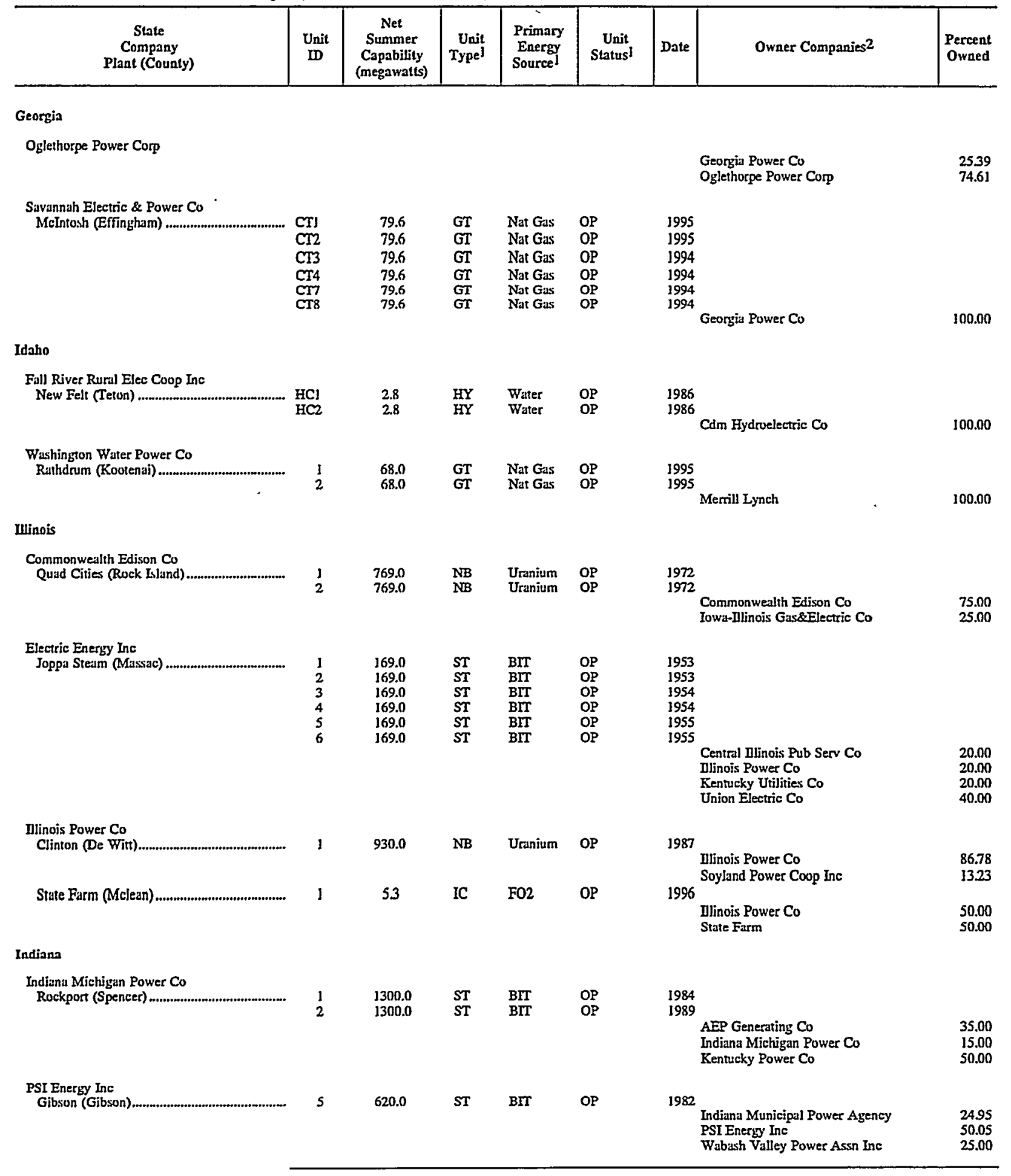

See footnotes at end of table. 
Table C1. Jointly Owned Electric Generating Units by State, Company, and Plant, as of January 1, 1998 (Continued)

\begin{tabular}{|c|c|c|c|c|c|c|c|c|}
\hline $\begin{array}{c}\text { State } \\
\text { Company } \\
\text { Plant (County) }\end{array}$ & $\begin{array}{l}\text { Unit } \\
\text { ID }\end{array}$ & $\begin{array}{c}\text { Net } \\
\text { Summer } \\
\text { Capability } \\
\text { (megawatts) }\end{array}$ & $\begin{aligned} \text { Unit } \\
\text { Typel }\end{aligned}$ & $\begin{array}{l}\text { Primary } \\
\text { Energy } \\
\text { Sourcel }\end{array}$ & $\begin{array}{c}\text { Unit } \\
\text { Stalus }\end{array}$ & Date & Owner Companies 2 & $\begin{array}{l}\text { Percent } \\
\text { Owned }\end{array}$ \\
\hline \multicolumn{9}{|l|}{ Indiana } \\
\hline $\begin{array}{l}\text { Southem Indiana Gas \& Elec Co } \\
\text { Warrick (Warrick)................. }\end{array}$ & 4 & 135.0 & ST & BIT & OP & 1970 & $\begin{array}{l}\text { Alcoa Generating Corp } \\
\text { Southem Indiana Gas \& Elec Co }\end{array}$ & $\begin{array}{l}50.00 \\
50.00\end{array}$ \\
\hline \multicolumn{9}{|l|}{ Iowa } \\
\hline \multirow[t]{2}{*}{$\begin{array}{l}\text { Central Iowa Power Coop } \\
\text { Fair Station (Muscatine)... }\end{array}$} & $\begin{array}{l}1 \\
2\end{array}$ & $\begin{array}{l}23.4 \\
41.0\end{array}$ & $\begin{array}{l}\text { ST } \\
\text { ST }\end{array}$ & $\begin{array}{l}\text { BIT } \\
\text { BIT }\end{array}$ & $\begin{array}{l}\text { OP } \\
\text { OP }\end{array}$ & $\begin{array}{l}1960 \\
1967\end{array}$ & $\cdot$ & \\
\hline & & & & & & & Eustern lowa Light\&Power Coop & 100.00 \\
\hline $\begin{array}{l}\text { IES Utilities Inc } \\
\text { Duane Amold (Linn) }\end{array}$ & 1 & 535.0 & NB & Uranium & OP & 1975 & $\begin{array}{l}\text { IES Utilities Inc } \\
\text { MidAmerican Energy Co }\end{array}$ & $\begin{array}{l}90.00 \\
10.00\end{array}$ \\
\hline $\begin{array}{l}\text { MidAmerican Energy Co } \\
\text { Council Bluffs (Pottawattamie) }\end{array}$ & 3 & 675.0 & ST & SUB & OP & 1978 & $\begin{array}{l}\text { Atlantic City of } \\
\text { Cedar Falls City of } \\
\text { IES Utilities Inc } \\
\text { MidAmerican Energy Co }\end{array}$ & $\begin{array}{l}2.50 \\
3.10 \\
11.50 \\
82.90\end{array}$ \\
\hline 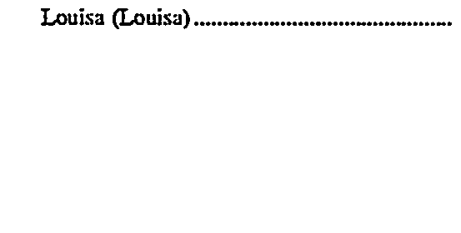 & 1 & 700.0 & ST & SUB & OP & $\begin{array}{l}1983 \\
1975\end{array}$ & $\begin{array}{l}\text { Central Iowa Power Coop } \\
\text { Eldridge City of } \\
\text { Geneseo City of } \\
\text { Harlan City of } \\
\text { Interstate Power Co } \\
\text { MidAmerican Energy Co } \\
\text { Tipton City of } \\
\text { Waverly City of }\end{array}$ & $\begin{array}{l}4.60 \\
0.50 \\
0.50 \\
0.80 \\
4.00 \\
88.00 \\
0.50 \\
1.10\end{array}$ \\
\hline Neal North (Woodbury) & & & & & & & $\begin{array}{l}\text { IES Utilities Inc } \\
\text { MidAmeriean Energy Co }\end{array}$ & $\begin{array}{l}28.00 \\
72.00\end{array}$ \\
\hline Neal South (Woodbury) & 4 & 624.0 & ST & SUB & OP & $\begin{array}{l}1979 \\
1981\end{array}$ & $\begin{array}{l}\text { Algona City of } \\
\text { Cedar Falls City of } \\
\text { Coon Rapids City of } \\
\text { Com Belt Power Coop } \\
\text { Interstute Power Co } \\
\text { MidAmerican Energy Co } \\
\text { Northwest Iowa Power Coop } \\
\text { Northwestem Public Service Co } \\
\text { Spencer City of } \\
\text { Webster City City of }\end{array}$ & $\begin{array}{l}2.94 \\
2.50 \\
0.52 \\
9.03 \\
25.53 \\
40.57 \\
5.02 \\
8.69 \\
1.21 \\
2.60\end{array}$ \\
\hline Otumwa (Wapello) & & & & & & & $\begin{array}{l}\text { IES Utilities Inc } \\
\text { MidAmerican Energy Co }\end{array}$ & $\begin{array}{l}48.00 \\
52.00\end{array}$ \\
\hline \multicolumn{9}{|l|}{ Kansas } \\
\hline \multirow[t]{2}{*}{$\begin{array}{l}\text { Kansas City Power \& Light Co } \\
\text { Lacygne (Linn) }\end{array}$} & $\begin{array}{l}1 \\
2\end{array}$ & $\begin{array}{l}688.0 \\
672.0\end{array}$ & $\begin{array}{l}\text { ST } \\
\text { ST }\end{array}$ & $\begin{array}{l}\text { SUB } \\
\text { SUB }\end{array}$ & $\begin{array}{l}\text { OP } \\
\text { OP }\end{array}$ & $\begin{array}{l}1973 \\
1977\end{array}$ & & \\
\hline & & & & & & & $\begin{array}{l}\text { Kansas City Power \& Iight Co } \\
\text { KG\&E a Westem Resources Co }\end{array}$ & $\begin{array}{l}50.00 \\
50.00\end{array}$ \\
\hline \multirow[t]{2}{*}{$\begin{array}{l}\text { KPL Westem Resources Co } \\
\text { Jeffrey EC (Pottawatomie) }\end{array}$} & $\begin{array}{l}1 \\
2 \\
3\end{array}$ & $\begin{array}{l}734.0 \\
734.0 \\
720.0\end{array}$ & $\begin{array}{l}\text { ST } \\
\text { ST } \\
\text { ST }\end{array}$ & $\begin{array}{l}\text { SUB } \\
\text { SUB } \\
\text { SUB }\end{array}$ & $\begin{array}{l}\text { OP } \\
\text { OP } \\
\text { OP }\end{array}$ & $\begin{array}{l}1978 \\
1980 \\
1983\end{array}$ & & \\
\hline & & & & & & & $\begin{array}{l}\text { UtiliCorp United } \\
\text { KG\&E a Westem Resources Co } \\
\text { KPL, a Westem Resources Co } \\
\text { UtiliCorp United Inc }\end{array}$ & $\begin{array}{l}20.00 \\
8.00 \\
64.00 \\
8.00\end{array}$ \\
\hline
\end{tabular}

See footnotes at end of table. 
Table C1. Jointly Owned Electric Generating Units by State, Company, and Plant, as of January 1, 1998 (Continued)

\begin{tabular}{|c|c|c|c|c|c|c|c|c|}
\hline $\begin{array}{c}\text { State } \\
\text { Company } \\
\text { Plant (County) }\end{array}$ & $\begin{array}{l}\text { Unit } \\
\text { ID }\end{array}$ & $\begin{array}{c}\text { Net } \\
\text { Summer } \\
\text { Capability } \\
\text { (megawatts) }\end{array}$ & $\begin{array}{r}\text { Unit } \\
\text { Type }\end{array}$ & $\begin{array}{l}\text { Primary } \\
\text { Energy } \\
\text { Sourcel }\end{array}$ & $\begin{array}{c}\text { Unit } \\
\text { Statusl }\end{array}$ & Date & Owner Companies 2 & $\begin{array}{l}\text { Percent } \\
\text { Owned }\end{array}$ \\
\hline \multicolumn{9}{|l|}{ Kansas } \\
\hline 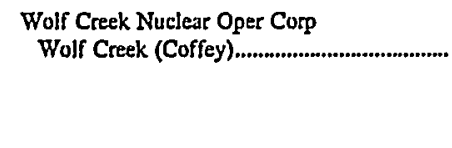 & $\mathbf{J}$ & 1163.0 & NP & Uranium & OP & 1985 & $\begin{array}{l}\text { Kansas City Power \& Light Co } \\
\text { KG\&E a Wextern Resources Co } \\
\text { Small Mun \& Coop }\end{array}$ & $\begin{array}{l}47.00 \\
47.00 \\
6.00\end{array}$ \\
\hline \multicolumn{9}{|l|}{ Kentucky } \\
\hline $\begin{array}{l}\text { Big Rivers Electric Corp } \\
\text { HMP\&L Station } 2 \text { (Henderson) }\end{array}$ & $\begin{array}{l}1 \\
2\end{array}$ & $\begin{array}{l}154.0 \\
161.0\end{array}$ & $\begin{array}{l}\text { ST } \\
\text { ST }\end{array}$ & $\begin{array}{l}\text { BIT } \\
\text { BIT }\end{array}$ & $\begin{array}{l}\text { OP } \\
\text { OP }\end{array}$ & $\begin{array}{l}3973 \\
1974\end{array}$ & Hendesson City Utility Comm & 100.00 \\
\hline 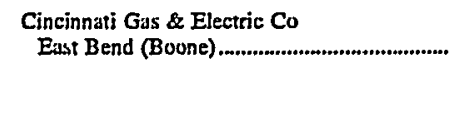 & 2 & 600.0 & ST & BIT & OP & 1981 & $\begin{array}{l}\text { Cincinnati Gas \& Electric Co } \\
\text { Dayton Power \& Light Co }\end{array}$ & $\begin{array}{l}69.00 \\
31.00\end{array}$ \\
\hline 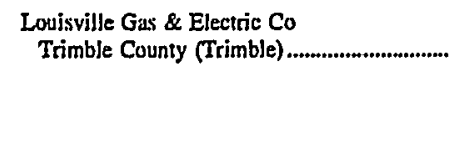 & 1 & 495.0 & ST & BIT & OP & 1990 & $\begin{array}{l}\text { Indiana Municipal Power Agency } \\
\text { Dlinois Municipal Elec Agency } \\
\text { Louisville Gas \& Electric Co }\end{array}$ & $\begin{array}{l}12.88 \\
12.12 \\
75.00\end{array}$ \\
\hline Louisinna & & & & & & & & \\
\hline $\begin{array}{l}\text { Cajun Electric Power Coop Inc } \\
\text { Big Cajun } 2 \text { (Pointe Coupee)......................... }\end{array}$ & 3 & 575.0 & ST & SUB & $O P$ & $\begin{array}{l}1981 \\
1983\end{array}$ & $\begin{array}{l}\text { Cajun Electric Power Coop Ine } \\
\text { Entergy Loujsiana, Inc } \\
\text { Cajun Electric Power Coop Ine } \\
\text { Louisiana Pacific Corp }\end{array}$ & $\begin{array}{l}58.00 \\
42.00 \\
58.00 \\
42.00\end{array}$ \\
\hline 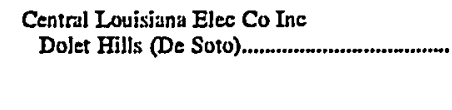 & 1 & 650.0 & ST & IIG & OP & 1986 & $\begin{array}{l}\text { Central Louisiuna Elec Co Ine } \\
\text { Southwestern Electric Power Co }\end{array}$ & $\begin{array}{l}50.00 \\
50.00\end{array}$ \\
\hline 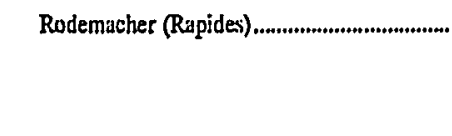 & 2 & 523.0 & ST & SUB & OP & 1982 & $\begin{array}{l}\text { Central Louisiana Elec Co Inc } \\
\text { Lafayette Public Power Auth } \\
\text { Louisiana Energy \& Power Auth }\end{array}$ & $\begin{array}{l}30.00 \\
50.00 \\
20.00\end{array}$ \\
\hline $\begin{array}{l}\text { Entergy Gulf States Inc. } \\
\text { Nelson (Calcasieu) }\end{array}$ & $\begin{array}{l}1 \\
2\end{array}$ & $\begin{array}{l}98.0 \\
98.0\end{array}$ & $\begin{array}{l}\text { ST } \\
\mathbf{S T}\end{array}$ & $\begin{array}{l}\text { Nat Gas } \\
\text { Nat Gas }\end{array}$ & $\begin{array}{l}O P \\
O P\end{array}$ & $\begin{array}{l}1959 \\
1956\end{array}$ & $\begin{array}{l}\text { Conoco Inc } \\
\text { Entergy Gulf States, Inc } \\
\text { Vista Energy Ltd Partnership } \\
\text { Citgo Petroleum Corp }\end{array}$ & $\begin{array}{l}36.10 \\
1.00 \\
13.40 \\
49.50\end{array}$ \\
\hline 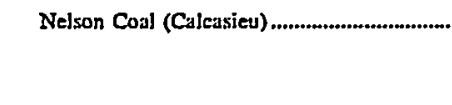 & 6 & 550.0 & ST & SUB & $O P$ & 1982 & $\begin{array}{l}\text { Entergy Gulf States, Ine } \\
\text { Sam Raybum Municipal Pwr Agny } \\
\text { Sam Raybum G \& T Inc }\end{array}$ & $\begin{array}{l}70.00 \\
20.00 \\
10.00\end{array}$ \\
\hline 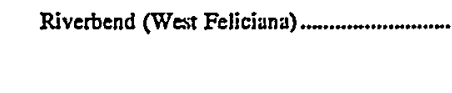 & 1 & 936.0 & NB & Uranium & OP & 1986 & $\begin{array}{l}\text { Cajun Electrie Power Coop Inc } \\
\text { Entergy Gulf States, Inc }\end{array}$ & $\begin{array}{l}30.00 \\
70.00\end{array}$ \\
\hline $\begin{array}{l}\text { Natchitoches City of } \\
\text { Natchitoches (Natchitoches) }\end{array}$ & $\begin{array}{r}10 \\
2 \\
8 \\
9\end{array}$ & $\begin{array}{l}25.5 \\
10.0 \\
6.0 \\
11.5\end{array}$ & $\begin{array}{l}\text { ST } \\
\text { IC } \\
\text { ST } \\
\text { ST }\end{array}$ & $\begin{array}{l}\text { Nat Gas } \\
\text { Nat Gas } \\
\text { Nat Gas } \\
\text { Nat Gas }\end{array}$ & $\begin{array}{l}\text { OP } \\
\text { OP } \\
\text { OP } \\
\text { OP }\end{array}$ & $\begin{array}{l}1972 \\
1942 \\
1962 \\
1966\end{array}$ & Lafayerte City of & 100.00 \\
\hline
\end{tabular}

See footnotes at end of table. 


\section{Table C1. Jointly Owned Electric Generating Units by State, Company, and Plant,}

as of January 1, 1998 (Continued)

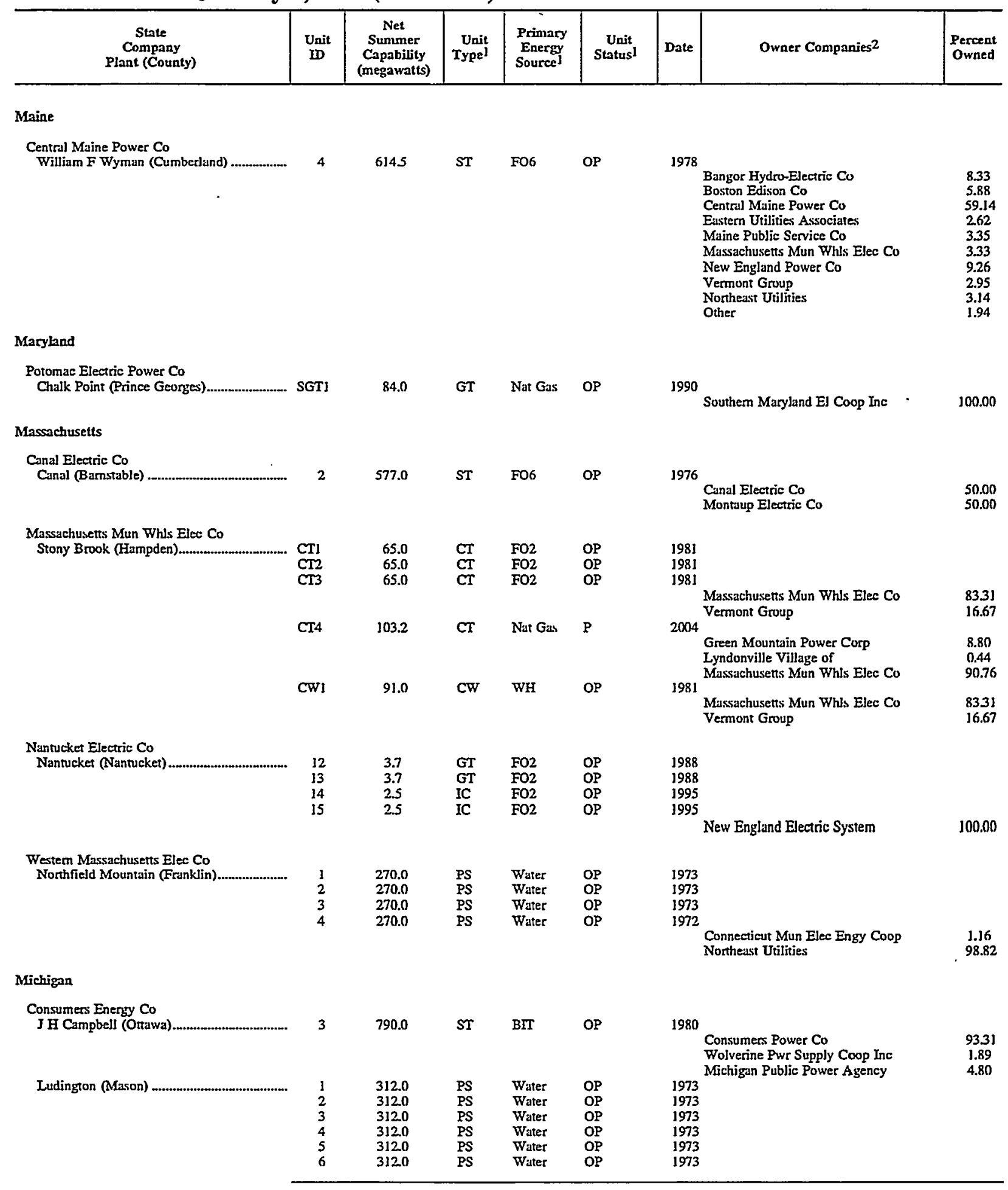

See footnotes at end of table. 
Table C1. Jointly Owned Electric Generating Units by State, Company, and Plant, as of January 1, 1998 (Continued)

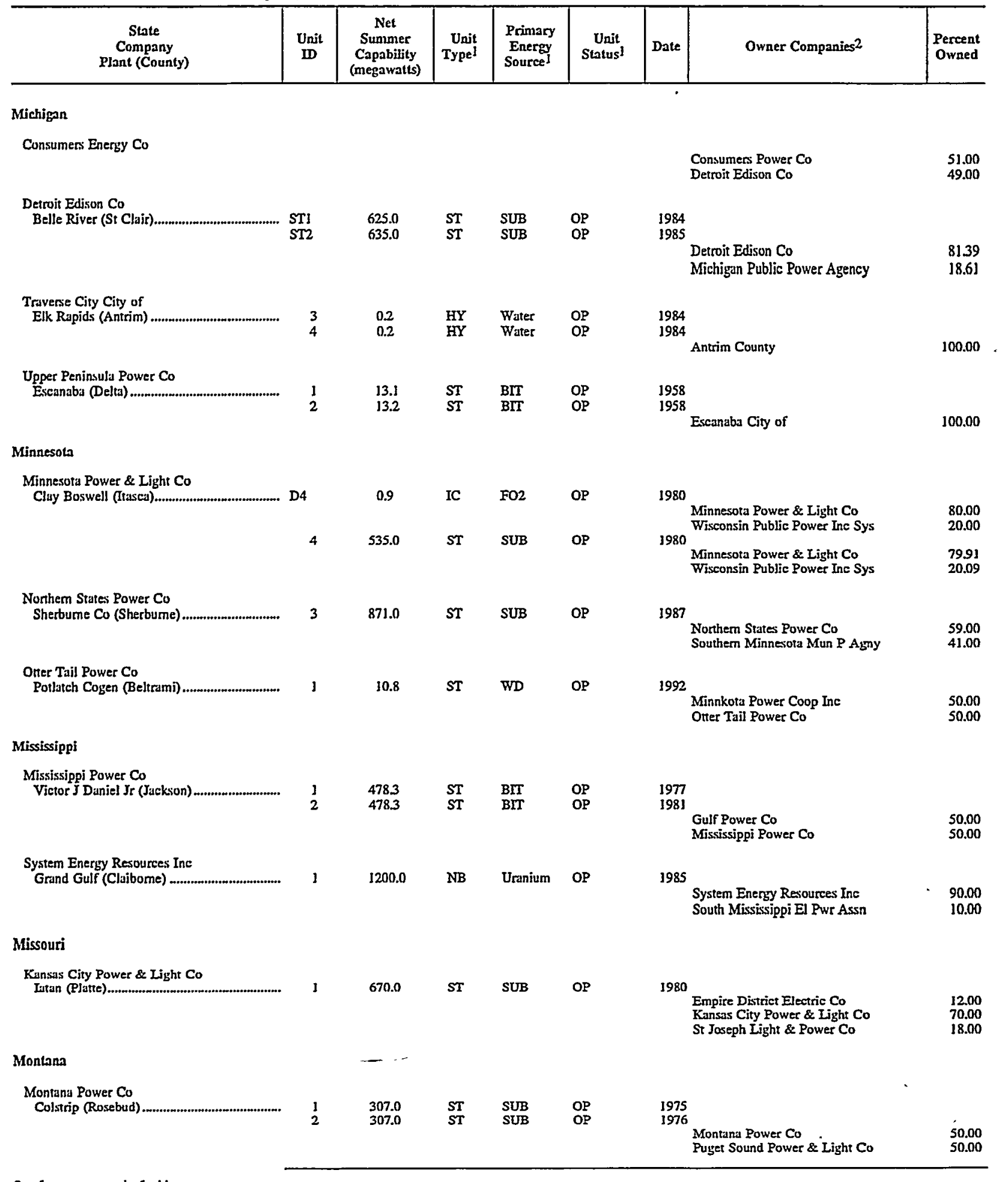

See footnotes at end of table. 
Table C1. Jointly Owned Electric Generating Units by State, Company, and Plant, as of January 1, 1998 (Continued)

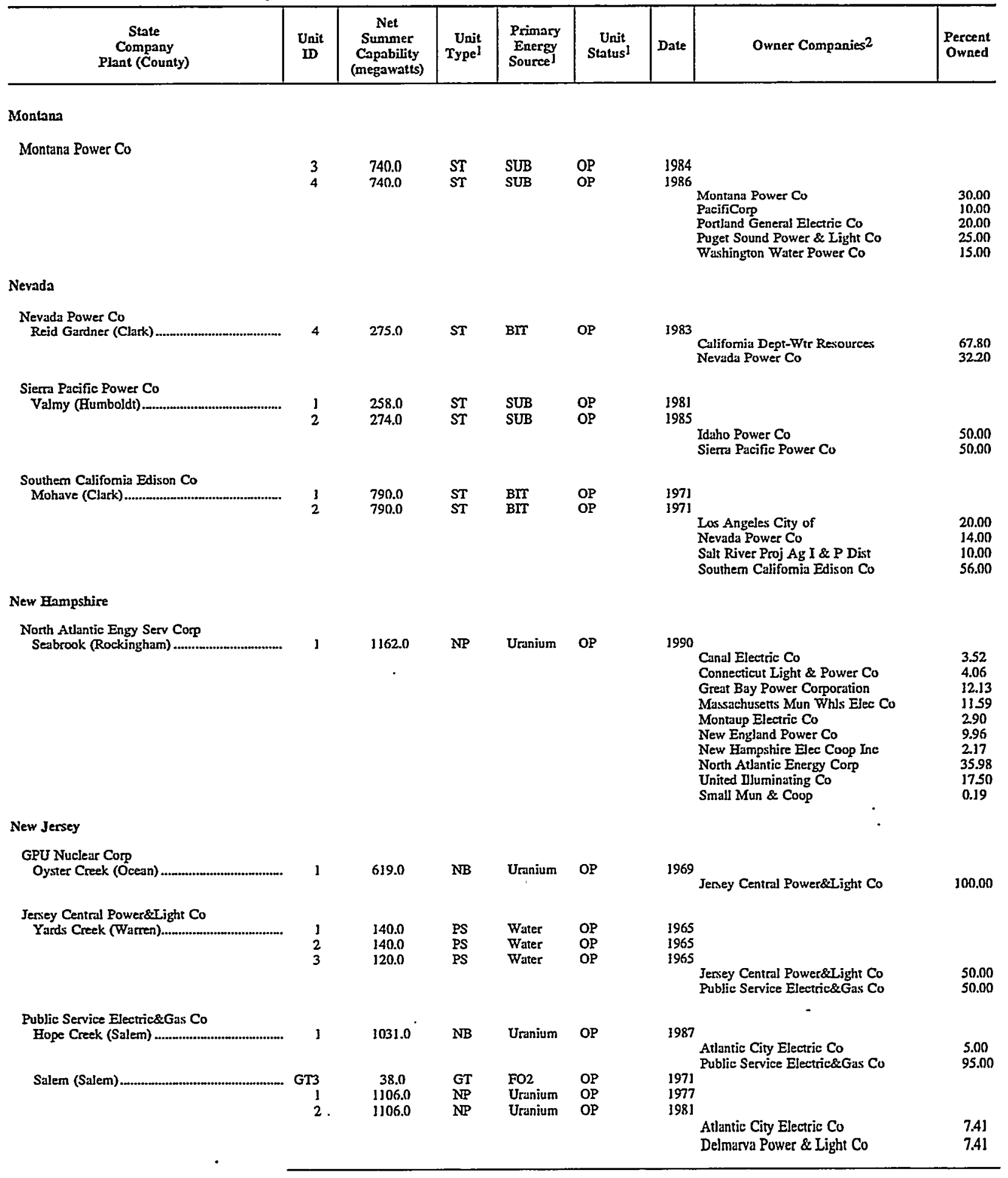

See footnotes at end of table. 
Table C1. Jointly Owned Electric Generating Units by State, Company, and Plant, as of January 1, 1998 (Continued)

\begin{tabular}{c|c|c|c|c|c|c|c|c|c|c|c|c|c|}
\hline $\begin{array}{c}\text { State } \\
\text { Company } \\
\text { Plant (County) }\end{array}$ & $\begin{array}{c}\text { Unit } \\
\text { ID }\end{array}$ & $\begin{array}{c}\text { Summer } \\
\text { Capability } \\
\text { (megawatts) }\end{array}$ & $\begin{array}{c}\text { Unit } \\
\text { Typel }\end{array}$ & $\begin{array}{c}\text { Primary } \\
\text { Energy } \\
\text { Sourcel }\end{array}$ & $\begin{array}{c}\text { Unit } \\
\text { Status }\end{array}$ & Date & Owner Companies2 \\
\hline
\end{tabular}

New Jersey

Public Service Electric\&Gas Co

Philadelphia Electric Co $\quad 4259$

Public Service Electric\&Gas Co $\quad 42.59$

New Mexico

Arizona Public Service Co
Four Comers (San Juan)...

$\begin{array}{llllll}4 & 740.0 & \text { ST } & \text { SUB } & \text { OP } & 1969 \\ 5 & 740.0 & \text { ST } & \text { SUB } & \text { OP } & 1970\end{array}$

Arizona Public Service Co $\quad 15.00$

El Paso Electric Co

Public Service Co of NM 13.00

Salt River Proj Ag I \& P Dist

Southem Califomia Edison Co $\quad 48.00$

Tueson Electric Power Co $\quad$ * 7.00

Public Service Co of NM

San Juan (San Juan)

New York

Central Hudion Gas \& Elec Corp

Roseton (Orance)

Cosp

$\begin{array}{lllll}1 & 316.0 & \text { ST } & \text { BIT } & \text { OP } \\ 2 & 312.0 & \text { ST } & \text { BIT } & \text { OP } \\ 3 & 488.0 & \text { ST } & \text { BIT } & \text { OP }\end{array}$

$\begin{array}{lllll}4 & 498.0 & \text { ST } & \text { BIT } & \text { OP }\end{array}$

1976

1973 Publie Service Co of NM

1979

Tueson Electric Power Co $\quad 50.00$

6.15

Banning City of $\quad 4.10$

Glendale City of

Imperial Irrigation Distriet

Public Service Co of NM

1982

Iri-State G \& T Assn Inc

Anaheim City of

Farmington City of $\quad 8.43$

Los Alamus County $\quad 7.23$

Public Service Co of NM

MSR Public Power Agency

Utsh Associated Mun Power Sys $\quad \mathbf{7 . 0 9}$

\begin{tabular}{|c|c|c|c|c|c|c|c|c|}
\hline & 2 & 605.3 & SI & FUn & UP & $19 / 4$ & $\begin{array}{l}\text { Central Hudson Gas \& Elec Corp } \\
\text { Consolidated Edison Co-NY Inc } \\
\text { Niagara Mohawk Power Corp }\end{array}$ & $\begin{array}{l}35.00 \\
40.00 \\
25.00\end{array}$ \\
\hline \multirow[t]{2}{*}{$\begin{array}{l}\text { Niugara Mohawk Power Corp } \\
\text { Beebee Island (Jefferson) }\end{array}$} & $\begin{array}{l}1 \\
2\end{array}$ & $\begin{array}{l}3.3 \\
3.3\end{array}$ & $\begin{array}{l}\mathrm{HY} \\
\mathrm{HY}\end{array}$ & $\begin{array}{l}\text { Water } \\
\text { Water }\end{array}$ & $\begin{array}{l}\text { OP } \\
\text { OP }\end{array}$ & $\begin{array}{l}1968 \\
1963\end{array}$ & & \\
\hline & & & & & & & $\begin{array}{l}\text { Ahistrom Development Corp } \\
\text { Niagara Mohawk Power Corp } \\
\text { Watertown City of }\end{array}$ & $\begin{array}{l}14.06 \\
82.84 \\
3.10\end{array}$ \\
\hline \multirow[t]{2}{*}{ Feeder Dam (Saratoga) } & $\begin{array}{l}1 \\
2 \\
3 \\
4 \\
5\end{array}$ & $\begin{array}{l}0.8 \\
0.8 \\
0.8 \\
0.8 \\
0.8\end{array}$ & $\begin{array}{l}\mathrm{HY} \\
\mathrm{HY} \\
\mathrm{HY} \\
\mathrm{HY} \\
\mathrm{HY}\end{array}$ & $\begin{array}{l}\text { Water } \\
\text { Water } \\
\text { Water } \\
\text { Water } \\
\text { Water }\end{array}$ & $\begin{array}{l}\text { OP } \\
\text { OP } \\
\text { OP } \\
\text { OP } \\
\text { OP }\end{array}$ & $\begin{array}{l}1924 \\
1924 \\
1924 \\
1924 \\
1924\end{array}$ & & \\
\hline & & & & & & & $\begin{array}{l}\text { Finch Pruyn \& Co Inc } \\
\text { Nagara Mohawk Power Corp }\end{array}$ & $\begin{array}{l}33.33 \\
66.67\end{array}$ \\
\hline 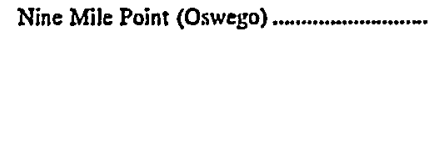 & 2 & 1136.5 & NB & Uranium & OP & 1988 & $\begin{array}{l}\text { Central Hudson Gas \& Elec Corp } \\
\text { Long Island Lighting Co } \\
\text { New York State Elee \& Gas Corp } \\
\text { Niagara Mohawk Power Corp } \\
\text { Rochester Gas \& Electric Corp }\end{array}$ & $\begin{array}{l}9.00 \\
18.00 \\
18.00 \\
41.00 \\
14.00\end{array}$ \\
\hline Oswego (Oswego) & r6 & 819.7 & ST & FO6 & OP & 1980 & & \\
\hline
\end{tabular}

See footnotes at end of table. 
Table C1. Jointly Owned Electric Generating Units by State, Company, and Plant, as of January 1, 1998 (Continued)

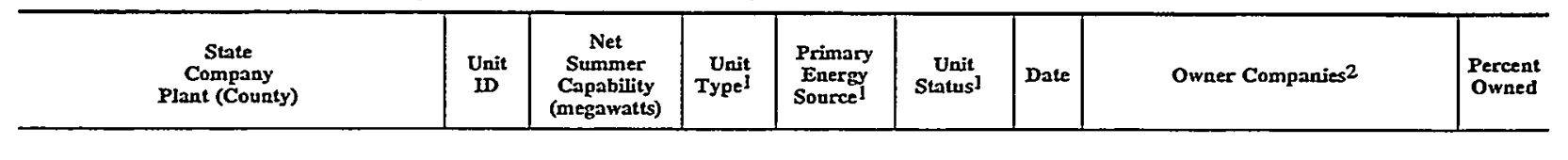

New York

Niagara Mohawk Power Corp

Orange \& Rockland Utils Inc

Bowline (Rockland).....

Inc

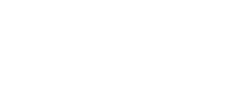

\begin{tabular}{|c|c|c|c|c|c|}
\hline & & & & $\begin{array}{l}\text { Niagara Mohawk Power Corp } \\
\text { Rochester Gas \& Electric Corp }\end{array}$ & $\begin{array}{l}76.00 \\
24.00\end{array}$ \\
\hline $\begin{array}{l}\text { ST } \\
\text { ST }\end{array}$ & $\begin{array}{l}\text { FO6 } \\
\text { Nat Gas }\end{array}$ & $\begin{array}{l}\text { OP } \\
\text { OP }\end{array}$ & $\begin{array}{l}1972 \\
1974\end{array}$ & & \\
\hline & & & & $\begin{array}{l}\text { Consolidated Edison Co-NY Inc } \\
\text { Orange \& Rockland Utils Inc }\end{array}$ & $\begin{array}{l}67.00 \\
33.00\end{array}$ \\
\hline
\end{tabular}

North Caroling

Carolina Power \& Light Co
Brunswick (Brunswick)

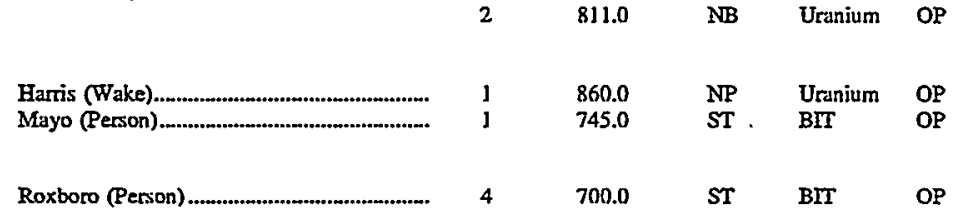

North Dakota

Coop Power Assn

Coal Creek (Mclean)

Minnkota Power Coop Inc

Milton R Young (Oliver)

Montana-Dakota Utilities Co

Coyote (Merces)

427.0 ST IIG OP

$\begin{array}{rrrr}537.0 & \text { ST } & \text { IIG } & \text { OP } \\ 542.0 & \text { ST } & \text { IIG } & \text { OP } \\ & & & \\ 1.2 & \text { IC } & \text { FO2 } & \text { OP }\end{array}$

1977

1975

Carolina Power \& Light Co

81.67

1987

North Carolina Eastem M P A

18.33

1983

Carolina Power \& Light Co

1980

North Carolina Eustern M P A

83.83

16.17

Carolina Power \& Light Co

North Carolina Eustem M P A

87.06

12.94

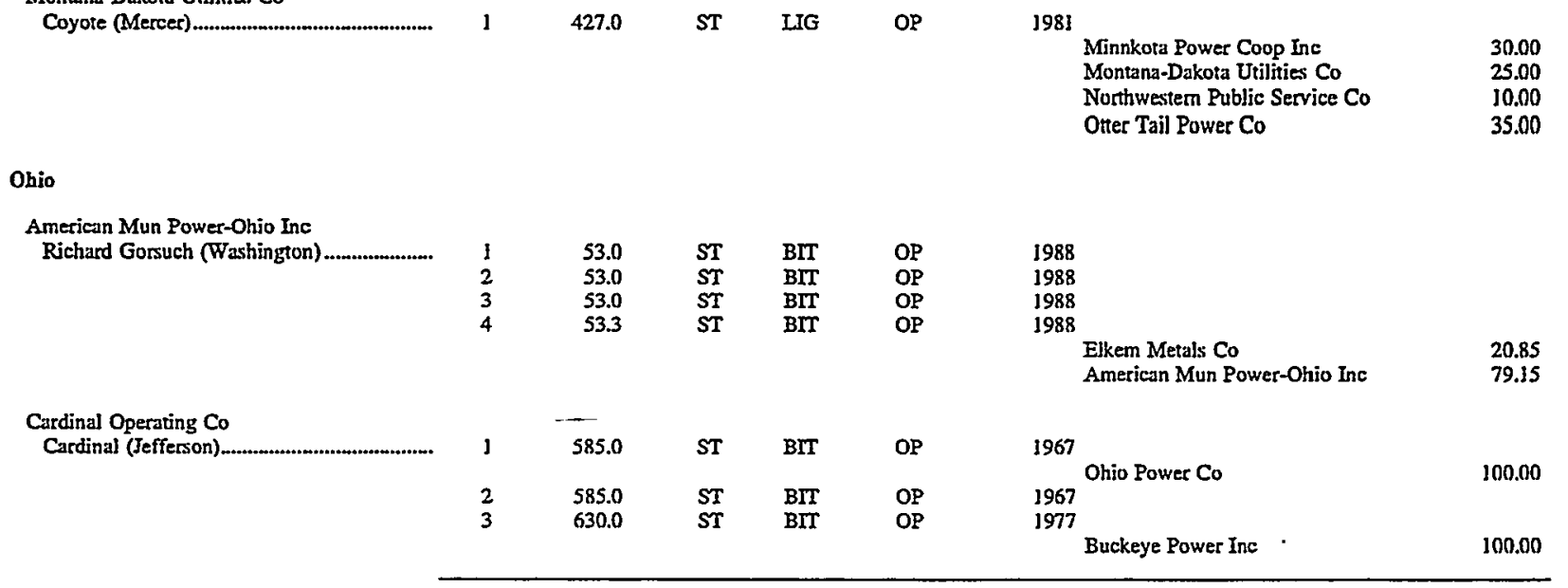

See footnotes at end of table. 
Table C1. Jointly Owned Electric Generating Units by State,.Company, and Plant, as of January 1, 1998 (Continued)

\begin{tabular}{|c|c|c|c|c|c|c|c|c|}
\hline $\begin{array}{c}\text { State } \\
\text { Company } \\
\text { Plant (County) }\end{array}$ & $\begin{array}{l}\text { Unit } \\
\text { ID }\end{array}$ & $\begin{array}{c}\text { Net } \\
\text { Summer } \\
\text { Capability } \\
\text { (megawatts) }\end{array}$ & $\begin{array}{r}\text { Unit } \\
\text { Type! }\end{array}$ & $\begin{array}{l}\text { Primary } \\
\text { Energy } \\
\text { Sourcel }\end{array}$ & $\begin{array}{c}\text { Unit } \\
\text { Status }\end{array}$ & Date & Owner Companies 2 & $\begin{array}{l}\text { Percent } \\
\text { Owned }\end{array}$ \\
\hline \multicolumn{9}{|l|}{ Ohio } \\
\hline \multirow[t]{2}{*}{$\begin{array}{l}\text { Cincinnati Gas \& Electric Co } \\
\text { Miami Fort (Hamilton) ..................................... }\end{array}$} & $\begin{array}{l}7 \\
8\end{array}$ & $\begin{array}{l}500.0 \\
500.0\end{array}$ & $\begin{array}{l}\text { ST } \\
\text { ST }\end{array}$ & $\begin{array}{l}\text { BIT } \\
\text { BIT }\end{array}$ & $\begin{array}{l}\text { OP } \\
\text { OP }\end{array}$ & $\begin{array}{l}1975 \\
1978\end{array}$ & & . \\
\hline & & & & & & & $\begin{array}{l}\text { Cincinnati Gas \& Electric Co } \\
\text { Dayton Power \& Light Co }\end{array}$ & $\begin{array}{l}64.00 \\
36.00\end{array}$ \\
\hline W H Zimmer (Cletmont) ......................................... & STI & 1300.0 & ST & BIT & OP & 1991 & $\begin{array}{l}\text { Cincinnati Gas \& Electric Co } \\
\text { Columbus Southem Power Co } \\
\text { Dayton Power \& Light Co }\end{array}$ & $\begin{array}{l}46.50 \\
25.40 \\
28.10\end{array}$ \\
\hline Walter C Beckjord (Clermont) ........................ & 6 & 414.0 & ST & BIT & OP & 1969 & $\begin{array}{l}\text { Cincinnati Gas \& Electric Co } \\
\text { Columbus Southem Power Co } \\
\text { Dayton Power \& Light Co }\end{array}$ & $\begin{array}{l}37.50 \\
12.50 \\
50.00\end{array}$ \\
\hline $\begin{array}{l}\text { Cleveland Electric Illum Co } \\
\text { Eustlake (Lake) }\end{array}$ & $s$ & 597.0 & ST & BIT & OP & 1972 & $\begin{array}{l}\text { Cleveland Electric Ilum Co } \\
\text { Duquesne Light Co }\end{array}$ & $\begin{array}{l}68.80 \\
31.20\end{array}$ \\
\hline 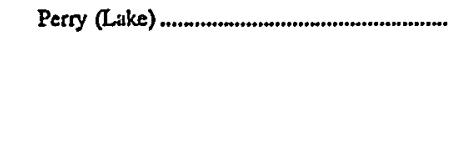 & 1 & 1169.0 & $\mathrm{NB}$ & Uranium & $\mathrm{OP}$ & 1987 & $\begin{array}{l}\text { Cleveland Electric Ilum Co } \\
\text { Duquesne Light Co } \\
\text { Ohio Edison Co } \\
\text { Toledo Edison Co }\end{array}$ & $\begin{array}{l}31.11 \\
13.74 \\
35.24 \\
19.91\end{array}$ \\
\hline $\begin{array}{l}\text { Columbus Southem Power Co } \\
\text { Conesville (Coshocton) }\end{array}$ & 4 & 780.0 & ST & BIT & OP & 1973 & $\begin{array}{l}\text { Cincinnati Gas \& Electric Co } \\
\text { Columbus Southem Power Co } \\
\text { Dayton Power \& Light Co }\end{array}$ & $\begin{array}{l}40.00 \\
43.50 \\
16.50\end{array}$ \\
\hline $\begin{array}{l}\text { Dayton Power \& Light Co } \\
\text { JM Stuat (Adams) }\end{array}$ & $\begin{array}{l}\text { D1 } \\
\text { D2 } \\
\text { D3 } \\
\text { D4 } \\
1 \\
2 \\
2 \\
3 \\
4\end{array}$ & $\begin{array}{c}2.5 \\
2.5 \\
2.5 \\
2.5 \\
585.0 \\
585.0 \\
585.0 \\
585.0\end{array}$ & $\begin{array}{l}\text { IC } \\
\text { IC } \\
\text { IC } \\
\text { IC } \\
\text { ST } \\
\text { ST } \\
\text { ST } \\
\text { ST }\end{array}$ & $\begin{array}{l}\text { FO2 } \\
\text { FO2 } \\
\text { FO2 } \\
\text { FO2 } \\
\text { BII } \\
\text { BII } \\
\text { BII } \\
\text { BIT }\end{array}$ & $\begin{array}{l}O P \\
O P \\
O P \\
O P \\
O P \\
O P \\
O P \\
O P\end{array}$ & $\begin{array}{l}1969 \\
1969 \\
1969 \\
1969 \\
1971 \\
1970 \\
1972 \\
1974\end{array}$ & & \\
\hline & & & & & & & $\begin{array}{l}\text { Cincinnati Gas \& Electric Co } \\
\text { Columbus Southem Power Co } \\
\text { Dayton Power \& Light Co }\end{array}$ & $\begin{array}{l}39.00 \\
26.00 \\
35.00\end{array}$ \\
\hline \multirow[t]{2}{*}{ 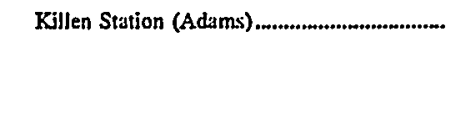 } & GT1 & $\begin{array}{r}18.0 \\
600.0\end{array}$ & $\begin{array}{l}\text { GT } \\
\text { ST }\end{array}$ & $\begin{array}{l}\text { FO2 } \\
\text { BIT }\end{array}$ & $\begin{array}{l}O P \\
O P\end{array}$ & $\begin{array}{l}1982 \\
1982\end{array}$ & & \\
\hline & & & & & & & $\begin{array}{l}\text { Cincinnati Gas \& Electric Co } \\
\text { Dayton Power \& Light Co }\end{array}$ & $\begin{array}{l}33.00 \\
67.00\end{array}$ \\
\hline \multicolumn{9}{|l|}{ Ohio Edison Co } \\
\hline 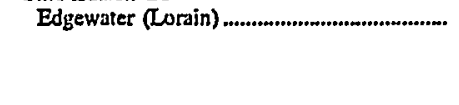 & $\begin{array}{l}\text { CTA } \\
\text { CIB }\end{array}$ & $\begin{array}{l}19.0 \\
19.0\end{array}$ & $\begin{array}{l}\text { GT } \\
\text { GT }\end{array}$ & $\begin{array}{l}\mathrm{FO} 2 \\
\mathrm{FO} 2\end{array}$ & $\begin{array}{l}\text { OP } \\
\text { OP }\end{array}$ & $\begin{array}{l}1973 \\
1973\end{array}$ & $\begin{array}{l}\text { Ohio Edison Co } \\
\text { Pennsylvania Power Co }\end{array}$ & $\begin{array}{l}86.00 \\
14.00\end{array}$ \\
\hline $\begin{array}{l}\text { Mad River (Clark) } \\
\text { Niles (Mahoning) } \\
\text { R E Burger (Belmunt) }\end{array}$ & $\begin{array}{l}\text { CTA } \\
\text { CIB } \\
\text { CTA } \\
\text { A1 } \\
\text { B1 } \\
\text { B2 } \\
\text { A1 } \\
\text { B1 } \\
\text { B2 } \\
\text { B3 } \\
\text { B4 }\end{array}$ & $\begin{array}{l}25.0 \\
25.0 \\
25.0 \\
2.0 \\
2.0 \\
3.0 \\
3.0 \\
3.0 \\
3.0 \\
2.0 \\
2.0\end{array}$ & $\begin{array}{l}\text { GT } \\
\text { GI } \\
\text { GT } \\
\text { IC } \\
\text { IC } \\
\text { IC } \\
\text { IC } \\
\text { IC } \\
\text { IC } \\
\text { IC } \\
\text { IC }\end{array}$ & $\begin{array}{l}\text { FO2 } \\
\text { FO2 } \\
\text { FO2 } \\
\text { FO2 } \\
\text { FO2 } \\
\text { FO2 } \\
\text { FO2 } \\
\text { FO2 } \\
\text { FO2 } \\
\text { FO2 } \\
\text { FO2 }\end{array}$ & $\begin{array}{l}O P \\
O P \\
O P \\
O P \\
O P \\
O P \\
O P \\
O P \\
O P \\
O P \\
O P\end{array}$ & $\begin{array}{l}1972 \\
1972 \\
1972 \\
1972 \\
1972 \\
1972 \\
1972 \\
1972 \\
1972 \\
1972 \\
1972\end{array}$ & & \\
\hline \multirow{2}{*}{ W H Sammis (Jefferson) ................................ } & & & & & & & $\begin{array}{l}\text { Ohio Edison Co } \\
\text { Pennsylvania Power Co }\end{array}$ & $\begin{array}{l}85.60 \\
14.40\end{array}$ \\
\hline & 7 & 600.0 & ST & BIT & OP & 1971 & Duquesne Light Co & 31.20 \\
\hline
\end{tabular}

See foutnotes at end of table. 
Table C1. Jointly Owned Electric Generating Units by State, Company, and Plant, as of January 1, 1998 (Continued)

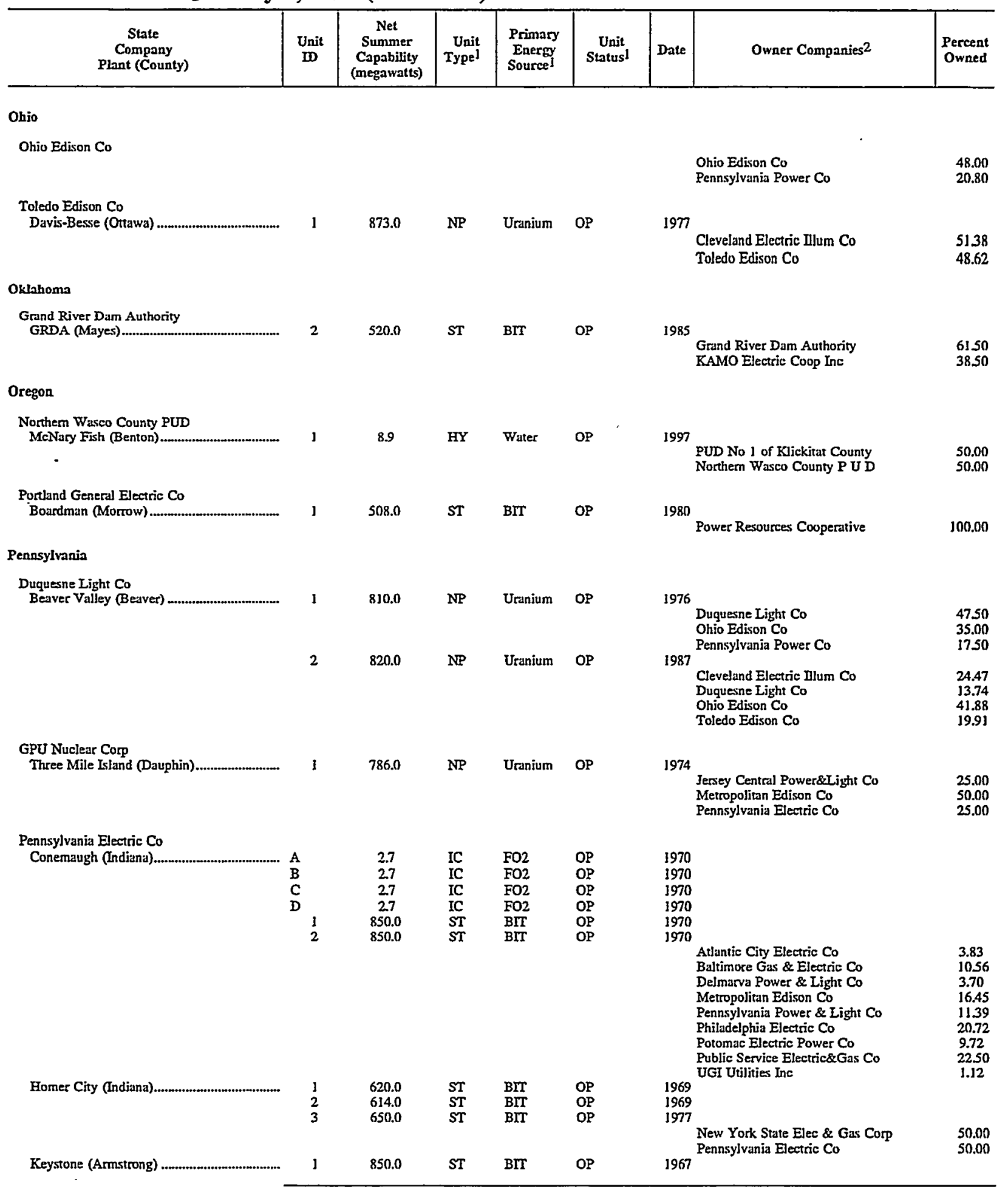

See footnotes at end of table. 
Table C1. Jointly Owned Electric Generating Units by State, Company, and Plant, as of January 1, 1998 (Continued)

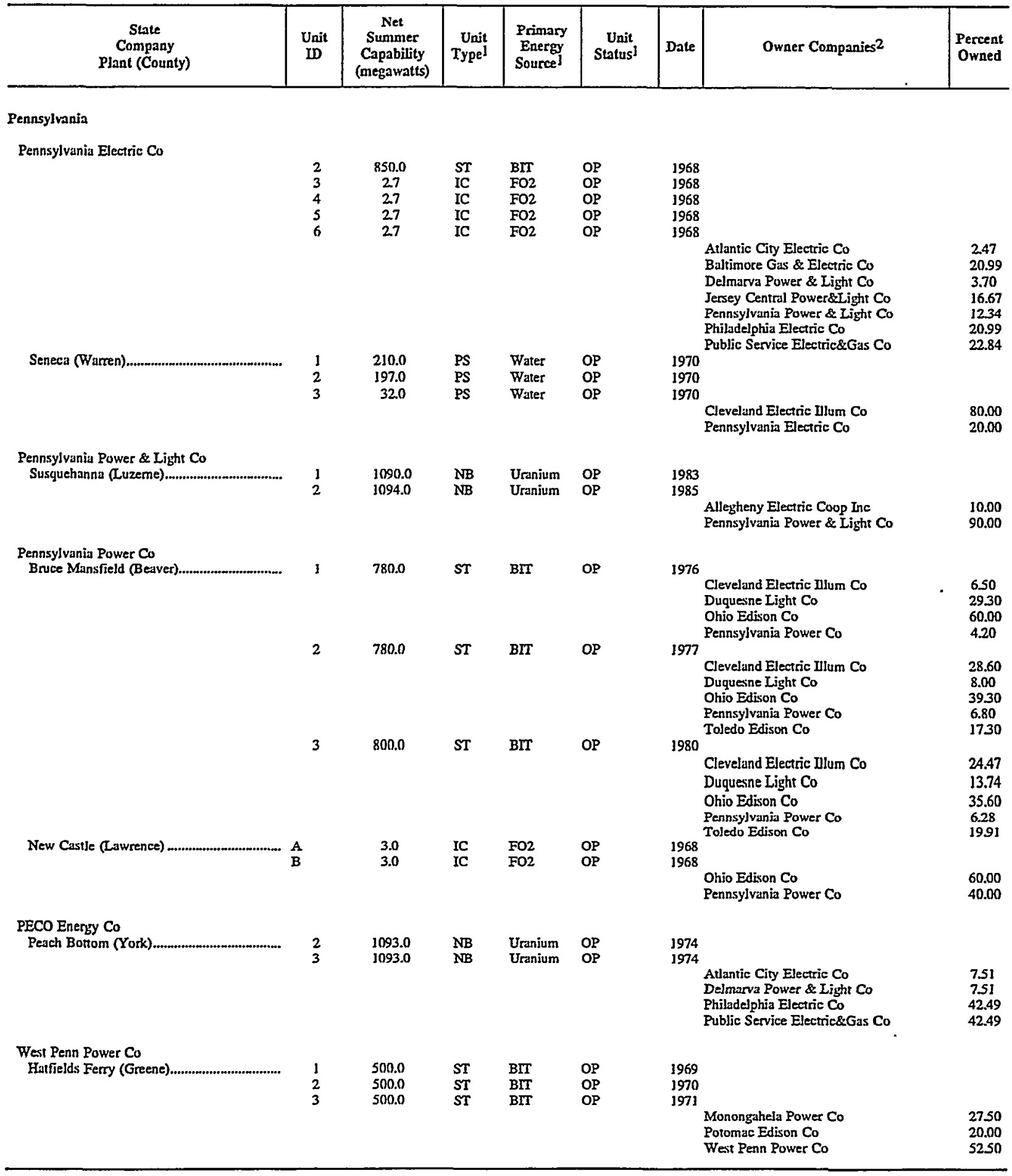

See footnotes at end of table. 
Table C1. Jointly Owned Electric Generating Units by State, Company, and Plant, as of January 1, 1998 (Continued)

\begin{tabular}{|c|c|c|c|c|c|c|c|c|}
\hline $\begin{array}{c}\text { State } \\
\text { Company } \\
\text { Plant (County) }\end{array}$ & $\begin{array}{l}\text { Unit } \\
\text { WD }\end{array}$ & $\begin{array}{c}\text { Net } \\
\text { Summer } \\
\text { Capability } \\
\text { (megawatts) }\end{array}$ & $\begin{array}{l}\text { Unit } \\
\text { Type! }\end{array}$ & $\begin{array}{l}\text { Primary } \\
\text { Energy } \\
\text { Sourcel }\end{array}$ & $\begin{array}{c}\text { Unit } \\
\text { Status }\end{array}$ & Date & Owner Companies 2 & $\begin{array}{l}\text { Percent } \\
\text { Owned }\end{array}$ \\
\hline \multicolumn{9}{|l|}{ South Carolina } \\
\hline 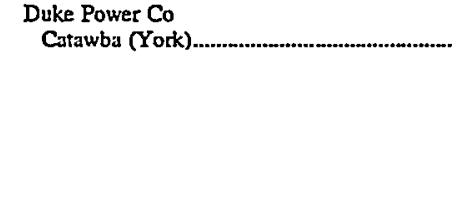 & 2 & $\begin{array}{l}1129.0 \\
1129.0\end{array}$ & $\mathbf{N P}$ & $\begin{array}{l}\text { Uranium } \\
\text { Uranium }\end{array}$ & OP & $\begin{array}{l}1985 \\
1986\end{array}$ & $\begin{array}{l}\text { Duke Power Co } \\
\text { North Carolina El Member Corp } \\
\text { Saluda River Electric Coop Inc } \\
\text { North Carolina Mun Power Agny } \\
\text { Piedmont Municipal Power Agny }\end{array}$ & $\begin{array}{l}25.00 \\
56.25 \\
18.75 \\
75.00 \\
25.00\end{array}$ \\
\hline 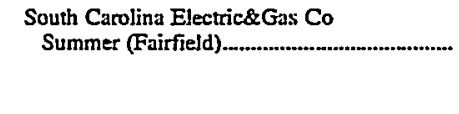 & 1 & 942.0 & NP & Uranium & OP & 1984 & $\begin{array}{l}\text { South Carolina Electric\&Gas Co } \\
\text { South Carolina Pub Serv Auth }\end{array}$ & $\begin{array}{l}66.67 \\
33.33\end{array}$ \\
\hline $\begin{array}{l}\text { South Carolina Pub Serv Auth } \\
\text { Dolphus M Grainger (Horry) } \\
\text { Fil................... }\end{array}$ & $\begin{array}{l}1 \\
2 \\
1\end{array}$ & $\begin{array}{l}85.0 \\
85.0 \\
20.0\end{array}$ & $\begin{array}{l}\text { ST } \\
\text { ST } \\
\text { GT }\end{array}$ & $\begin{array}{l}\text { BIT } \\
\text { BIT } \\
\text { FO2 }\end{array}$ & $\begin{array}{l}\text { OP } \\
\text { OP } \\
\text { OP }\end{array}$ & $\begin{array}{l}1966 \\
1966 \\
1973\end{array}$ & & \\
\hline St Stephen (Berkeley) & $\begin{array}{l}1 \\
2 \\
3\end{array}$ & $\begin{array}{l}28.0 \\
28.0 \\
28.0\end{array}$ & $\begin{array}{l}\mathrm{HY} \\
\mathrm{HY} \\
\mathrm{HY}\end{array}$ & $\begin{array}{l}\text { Water } \\
\text { Water } \\
\text { Water }\end{array}$ & $\begin{array}{l}\text { OP } \\
\text { OP } \\
\text { OP }\end{array}$ & $\begin{array}{l}1985 \\
1985 \\
1985\end{array}$ & $\begin{array}{l}\text { Central Electric Pwr Coop Inc } \\
\text { U S Amy Corps of Engineers }\end{array}$ & 100.00 \\
\hline \multicolumn{9}{|l|}{ South Dakota } \\
\hline $\begin{array}{l}\text { Black Hills Corp } \\
\text { Ben French (Pennington) }\end{array}$ & $\begin{array}{l}\text { GT] } \\
\text { GT2 } \\
\text { GT3 } \\
\text { GT4 }\end{array}$ & $\begin{array}{l}17.0 \\
17.0 \\
17.0 \\
17.0\end{array}$ & $\begin{array}{l}\text { GT } \\
\text { GT } \\
\text { GT }\end{array}$ & $\begin{array}{l}\text { FO2 } \\
\text { FO2 } \\
\text { FO2 } \\
\text { FO2 }\end{array}$ & $\begin{array}{l}O P \\
O P \\
O P \\
O P\end{array}$ & $\begin{array}{l}1977 \\
1977 \\
1978 \\
1979\end{array}$ & PacifiCorp & 300.00 \\
\hline $\begin{array}{l}\text { Missouri Basin Mun Power Agny } \\
\text { Watertown PP (Codington) }\end{array}$ & 1 & 42.2 & GT & FO2 & OP & 1978 & Westem Minnesota Mun Pwr Agny & 100.00 \\
\hline 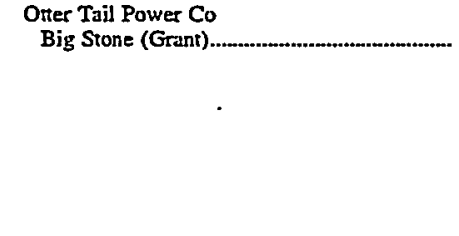 & D) & 445.8 & ST & SUB & OP & $\begin{array}{l}1975 \\
1975\end{array}$ & $\begin{array}{l}\text { Montana-Dakota Utilities Co } \\
\text { Nurthwestem Public Service Co } \\
\text { Otter Tail Power Co } \\
\text { Montana-Dakota Utilities Co } \\
\text { Northwestem Publie Service Co } \\
\text { Otter Tail Power Co }\end{array}$ & $\begin{array}{l}22.55 \\
20.59 \\
56.86 \\
\\
22.70 \\
23.40 \\
53.90\end{array}$ \\
\hline Texas & & & & & & & & \\
\hline $\begin{array}{l}\text { Entergy Gulf States Inc. } \\
\text { Toledo Bend (Newton) }\end{array}$ & $\begin{array}{l}\mathbf{I} \\
\mathbf{2}\end{array}$ & $\begin{array}{l}40.5 \\
40.5\end{array}$ & $\begin{array}{l}\text { HY } \\
\text { HY }\end{array}$ & $\begin{array}{l}\text { Water } \\
\text { Water }\end{array}$ & $\begin{array}{l}O P \\
O P\end{array}$ & $\begin{array}{l}1969 \\
1969\end{array}$ & $\begin{array}{l}\text { Sabine River Authority of LA } \\
\text { Heartland Energy Services }\end{array}$ & $\begin{array}{l}50.00 \\
50.00\end{array}$ \\
\hline 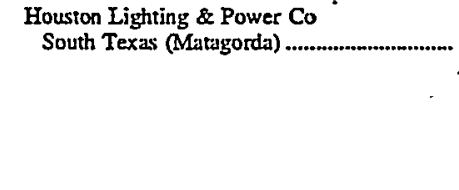 & $\begin{array}{l}1 \\
2\end{array}$ & $\begin{array}{l}1250.0 \\
1250.0\end{array}$ & $\begin{array}{l}\mathrm{NP} \\
\mathrm{NP}\end{array}$ & $\begin{array}{l}\text { Uranium } \\
\text { Uranium }\end{array}$ & $\begin{array}{l}O P \\
O P\end{array}$ & $\begin{array}{l}1988 \\
1989\end{array}$ & $\begin{array}{l}\text { Austin City of } \\
\text { Central Power \& Light Co } \\
\text { Houston Lighting \& Power Co } \\
\text { San Antonio City of }\end{array}$ & $\begin{array}{l}16.00 \\
25.20 \\
30.80 \\
28.00\end{array}$ \\
\hline $\begin{array}{l}\text { Lower Colorado River Authority } \\
\text { Fayette Power Prjc (Fayette)...................... }\end{array}$ & $\begin{array}{l}1 \\
2\end{array}$ & $\begin{array}{l}580.0 \\
580.0\end{array}$ & $\begin{array}{l}\text { ST } \\
\text { ST }\end{array}$ & $\begin{array}{l}\text { SUB } \\
\text { SUB }\end{array}$ & $\begin{array}{l}\text { OP } \\
\text { OP }\end{array}$ & $\begin{array}{l}1979 \\
1980\end{array}$ & $\begin{array}{l}\text { Austin City of } \\
\text { Lower Colorado River Authority }\end{array}$ & $\begin{array}{l}50.00 \\
50.00\end{array}$ \\
\hline
\end{tabular}

See footnotes at end of table. 
Table C1. Jointly Owned Electric Generating Units by State, Company, and Plant, as of January 1, 1998 (Continued)

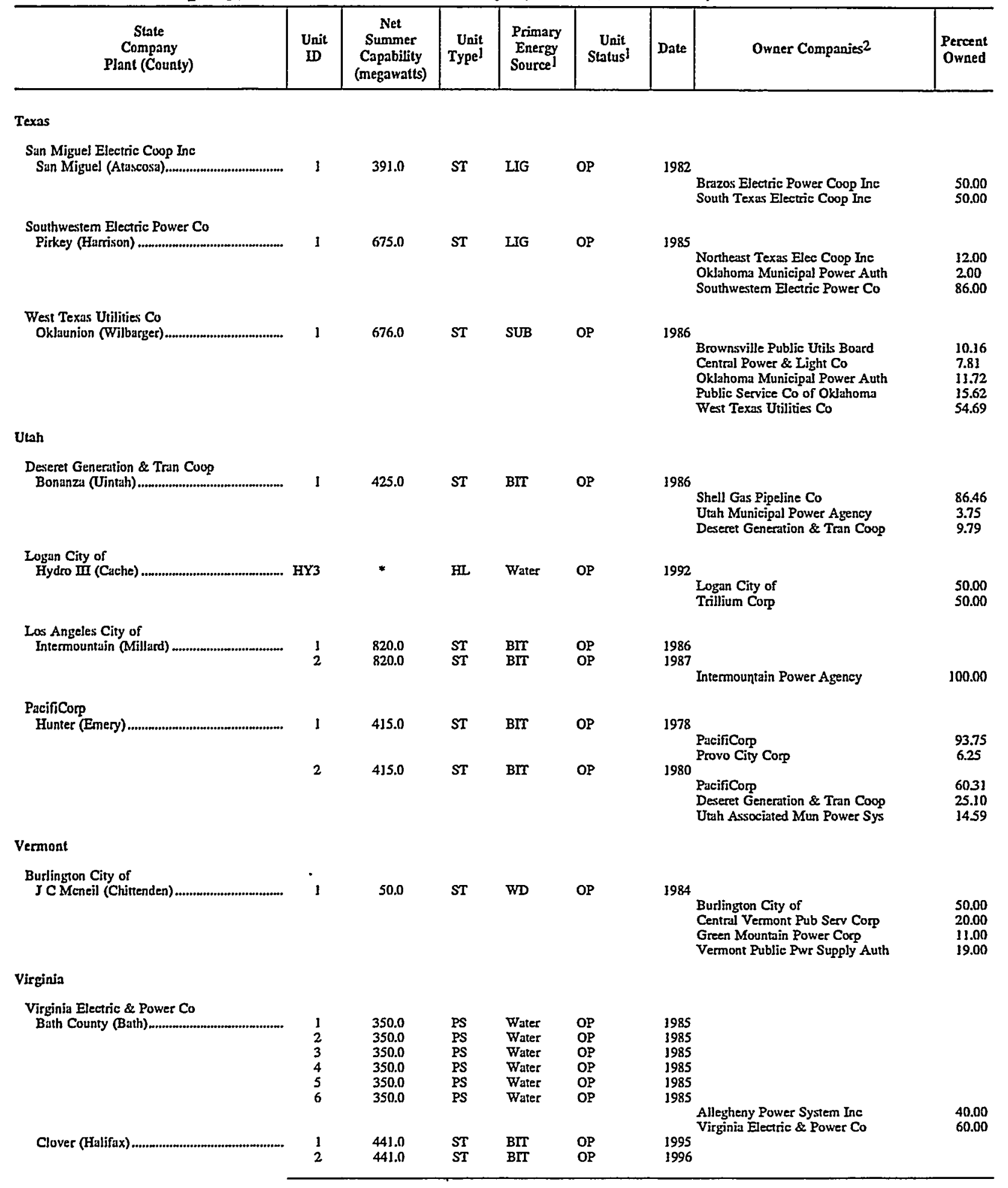

See footnotes at end of table. 
Table C1. Jointly Owned Electric Generating Units by State, Company, and Plant, as of January 1, 1998 (Continued)

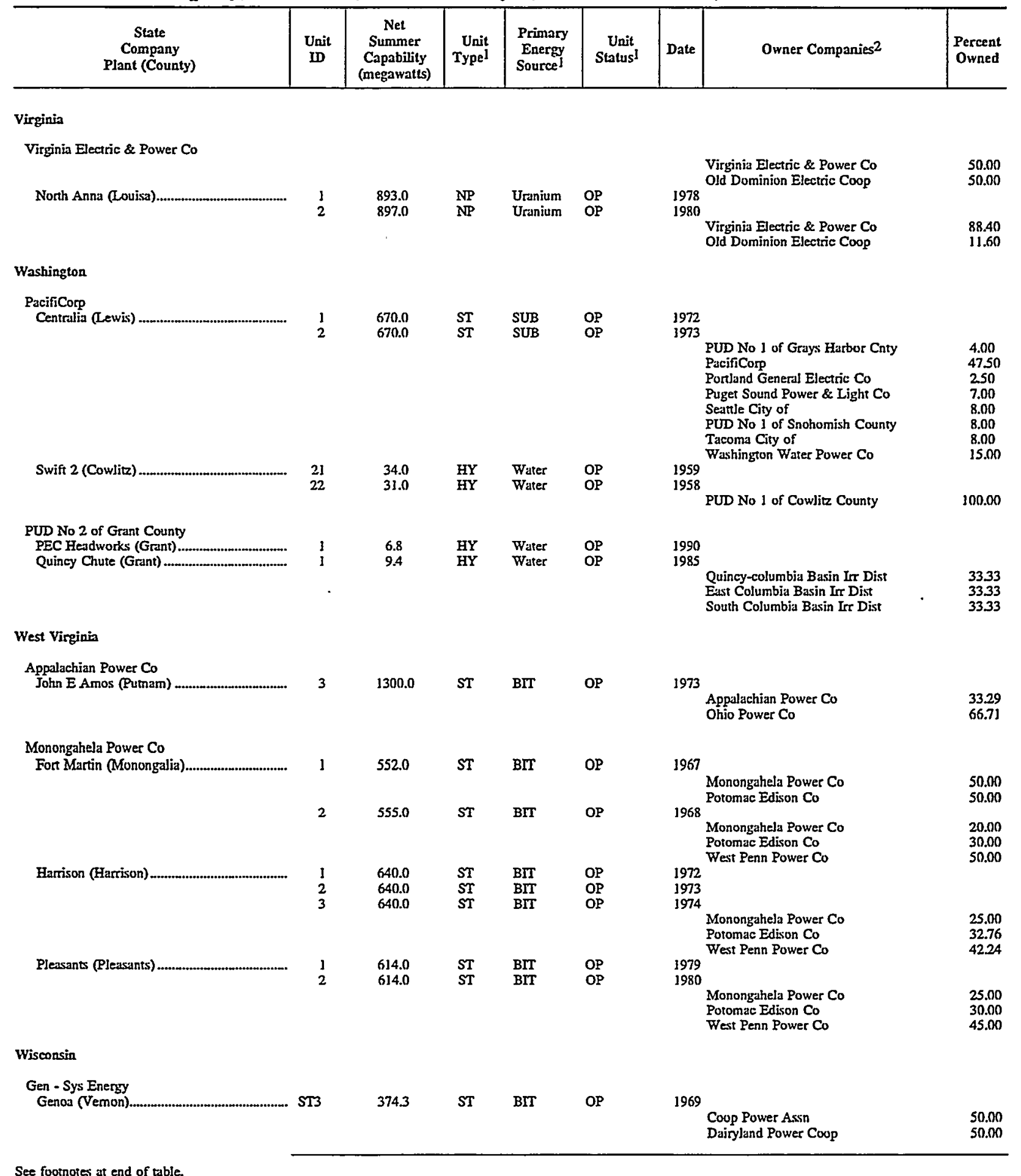


Table C1. Jointly Owned Electric Generating Units by State, Company, and Plant, as of January 1, 1998 (Continued)

\begin{tabular}{c|c|c|c|c|c|c|c|c|}
\hline $\begin{array}{c}\text { State } \\
\text { Company } \\
\text { Plant (County) }\end{array}$ & $\begin{array}{c}\text { Unit } \\
\text { ID }\end{array}$ & $\begin{array}{c}\text { Net } \\
\text { Summer } \\
\text { Capability } \\
\text { (megawatts) }\end{array}$ & $\begin{array}{c}\text { Unit } \\
\text { Typel }\end{array}$ & $\begin{array}{c}\text { Primary } \\
\text { Energy } \\
\text { Sourcel }\end{array}$ & $\begin{array}{c}\text { Unit } \\
\text { Status! }\end{array}$ & Date & Owner Companies ${ }^{2}$ \\
\hline
\end{tabular}

Wisconsin

Wisconsin Power \& Light Co

Columbja (Columbia)

Edgewater (Sheboygan) ...................................

Wisconsin Public Service Corp

Kewaunee (Kewaunee) .

West Marinette (Marinette)

33

Wyoming

Basin Electric Power Coop

Laramie R Station (PJatte)
82

498.0

2.1

GT

\section{5}

348.0

408.0

$N P$

Uranium

OP

OP

$\$ 50.0 \quad$ ST $\quad$ IIG $\quad$ OP

$\begin{array}{lllll}2 & 550.0 & \text { ST } & \text { BIT } & \text { OP } \\ 3 & 550.0 & \text { ST } & \text { BIT } & \text { OP }\end{array}$

1975

1978

Madison Gas \& Electric Co Wisconsin Power \& Iight Co 4620 1969

Wisconsin Public Service Corp $\quad 31.80$

Wisconsin Power \& Iight Co $\quad 68.20$ 1985

isconsin Public Service Corp

31.80

Wisconsin Electric Power $\mathrm{CO}$ Wisconsin Power \& Light Co $\quad 75.00$

1974

Madison Gas \& Electric Co $\quad 17.80$ Wisconsin Power \& Light Co $\quad 41.00$ 1993

Wisconsin Public Service Corp 4120

Marshfield City of $\quad 32.00$

Wisconsin Public Service Corp

1980

Basin Electio Power Coop

Lincoln Electric System

8.41

Missouri Basin Mun Power Agny $\quad 55.77$

Municipal Energy Agency of NE 1981

1982

Basin Electric Power Coop $\quad 4227$

Iincoln Electric System $\quad 12.76$

Missouri Basin Mun Power Agny $\quad 16.47$

Tri-State G \& T Assn Inc 24.13

Wyoming Municipal Power Agency

Feartand Consumers Power Dist 3.00

Pacificorp

Jim Bridger (Sweetwater) ............................. J J 520.0

520.0

520.0

520.0

$\begin{array}{ll}\text { ST } & \text { SUB } \\ \text { ST } & \text { SUB } \\ \text { ST } & \text { SUB } \\ \text { ST } & \text { SUB }\end{array}$

OP

OP 1974

OP $\quad 1975$

$\begin{array}{ll}\text { OP } & 1976 \\ \text { OP } & 1979\end{array}$

1979

daho Power Co

PacifiCorp 66.67

1978

Pacificorp 80.00

Black Hills Corp

Wyodak (Cumpbeil) ................................... $\quad 1 \quad 335.0 \quad$ ST $\quad$ SUB $\quad$ OP

See Appendix B for codes.

2 Includes owners or proposed owners that have 100 percent ownership but are not the operators or proposed operators of the unit.

* Less than 0.05 megawatts.

Notes: -Status OP means in commercial operation, active: OS means in commercial operation but out of service for an extended period: SB means in commercial operation, in cold standby or on reserve:P, $L$ and $T$ mean planned but not under construction:TS means construction complete, but not yet in commercial operation. The Form ElA-860 was revised during 1995 to collect data as of January 1 of the reporing year, where "reporting year" is the calendar year in which the report is required to be filed with the Energy Information Administration. These data reflect the satus of electric power plana/generators as of January !, 1998; however, dynamic data are based on occurrences in the previous calendar year (e.g., capabilities and energy sources based on test and consumption in the previous year).

Source: Energy Information Administration, Form EIA-86n, "Annual Electric Generator Report." 


\title{
Appendix D
}

\author{
U.S. Electric \\ Utility Plants
}




\section{U.S. Electric Utility Plants}

Table D1. U.S. Electric Utility Plants, as of January 1, 1998

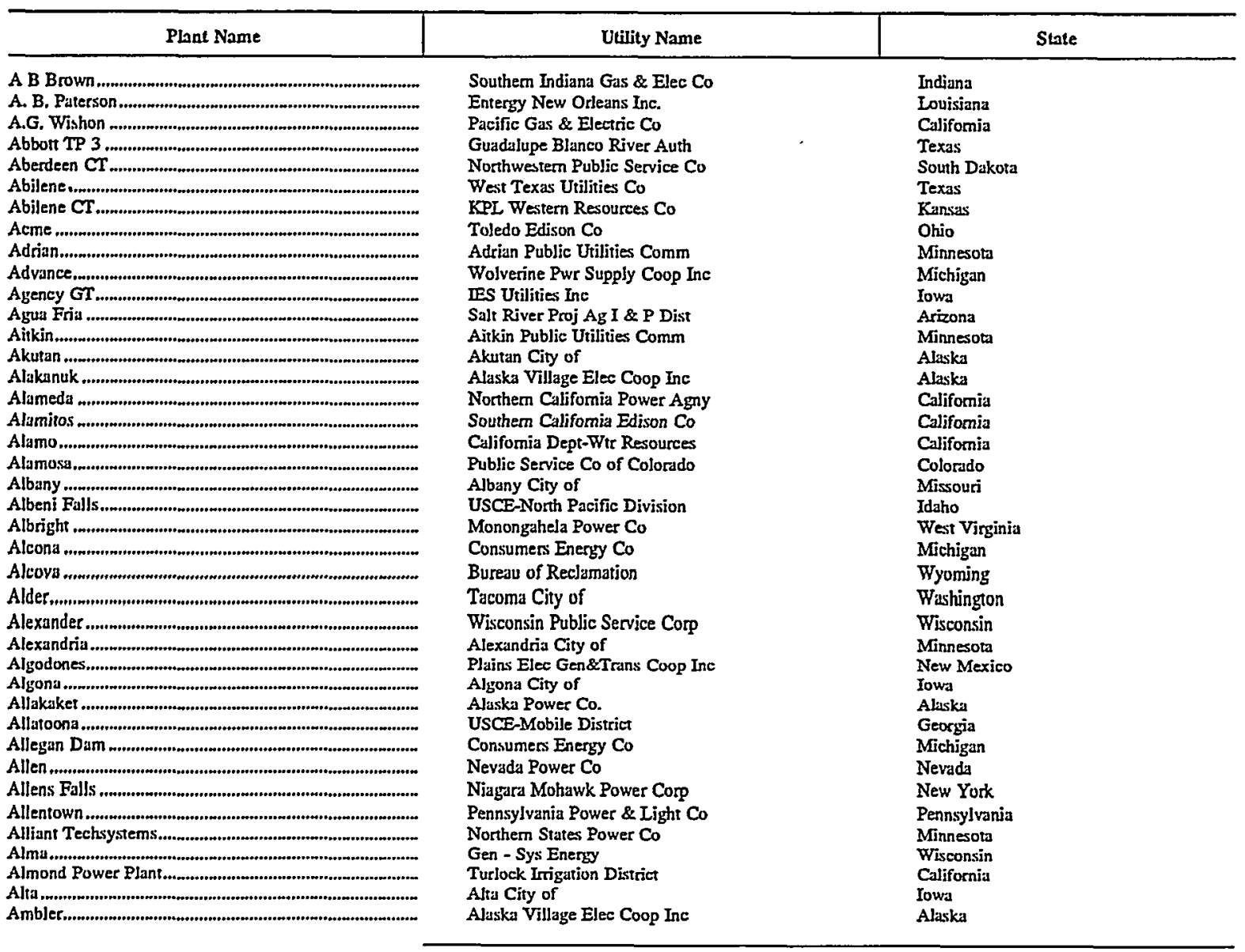

See footnotes at end of table. 
Table D1. U.S. Electric Utility Plants, as of January 1, 1998 (Continued)

\begin{tabular}{|c|c|c|}
\hline Plant Name & Utility Name & State \\
\hline 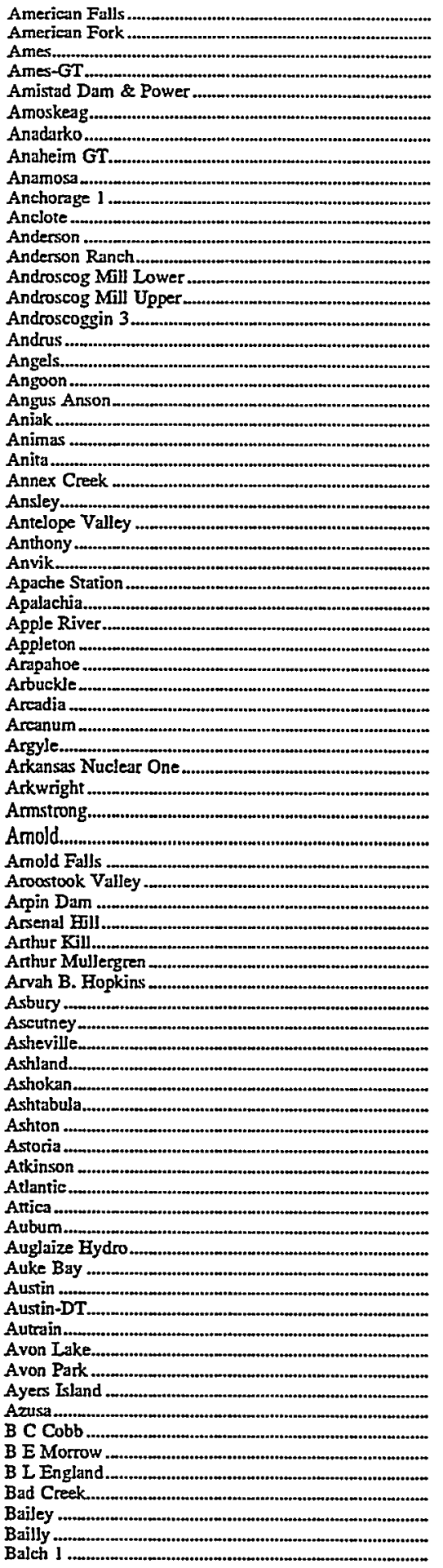 & 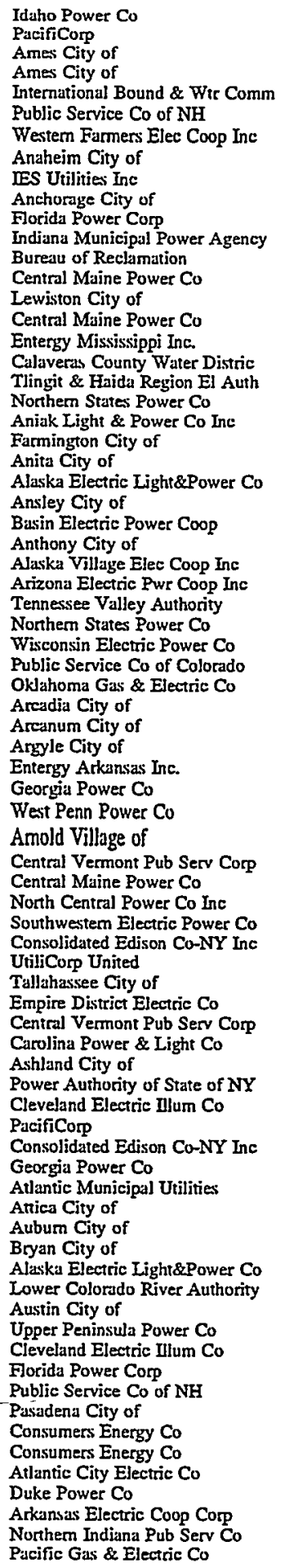 & 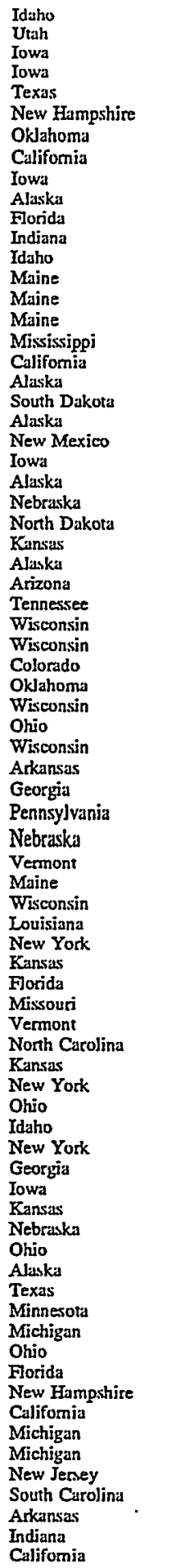 \\
\hline
\end{tabular}

See footnotes at end of table. 
Table D1. U.S. Electric Utility Plants, as of January 1, 1998 (Continued).

\begin{tabular}{|c|c|c|}
\hline Plant Name & Utility Name & Slate \\
\hline 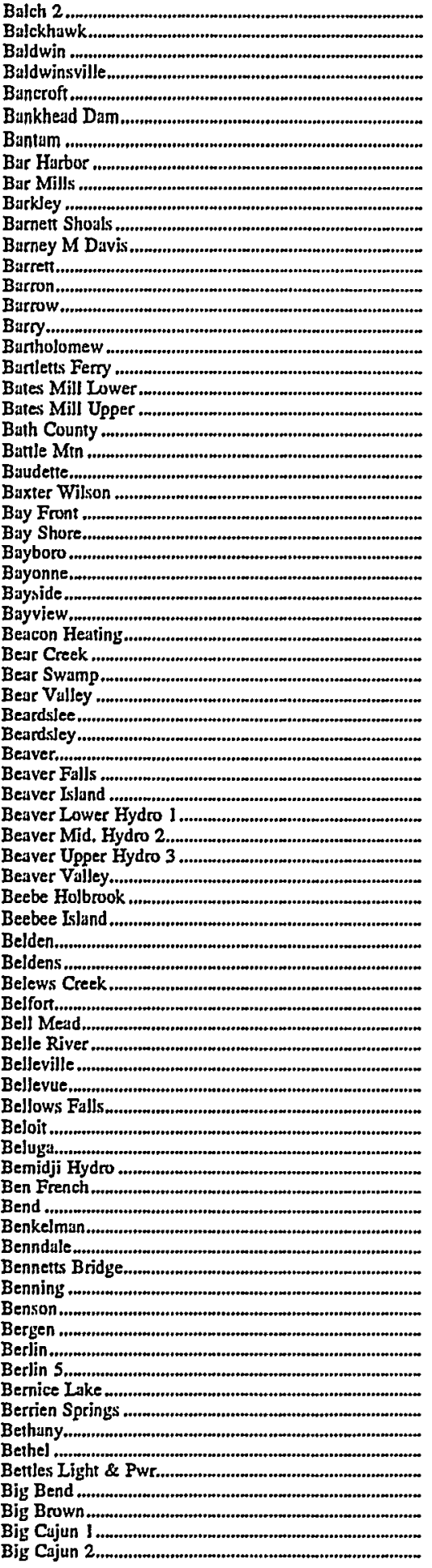 & 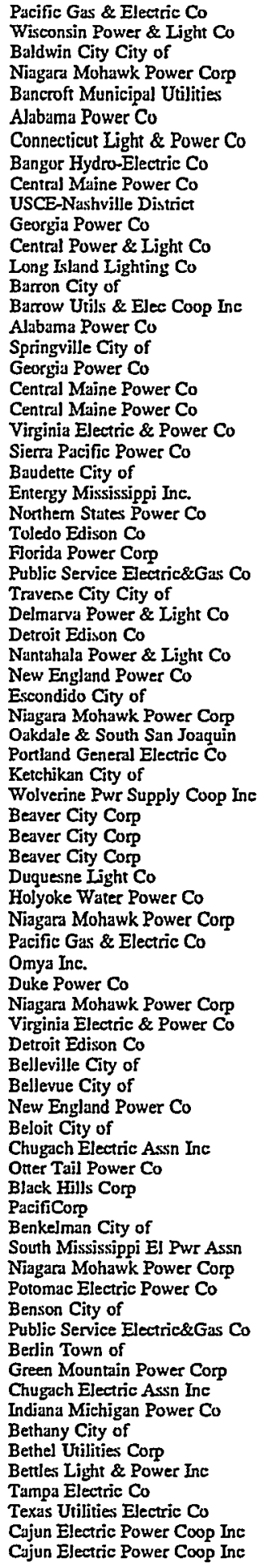 & 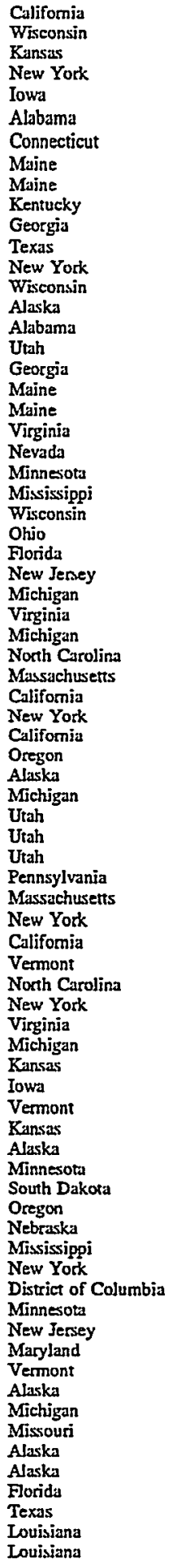 \\
\hline
\end{tabular}

See footnotes at end of table. 
Table D1. U.S. Electric Utility Plants, as of January 1, 1998 (Continued)

\begin{tabular}{|c|c|c|}
\hline Plant Name & Utility Name & State \\
\hline 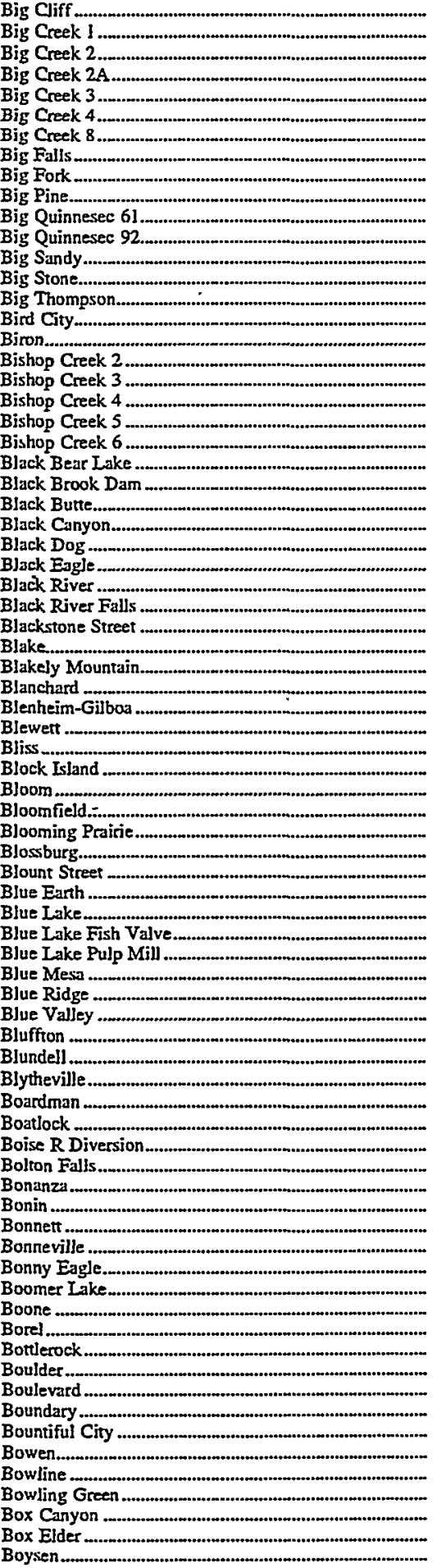 & 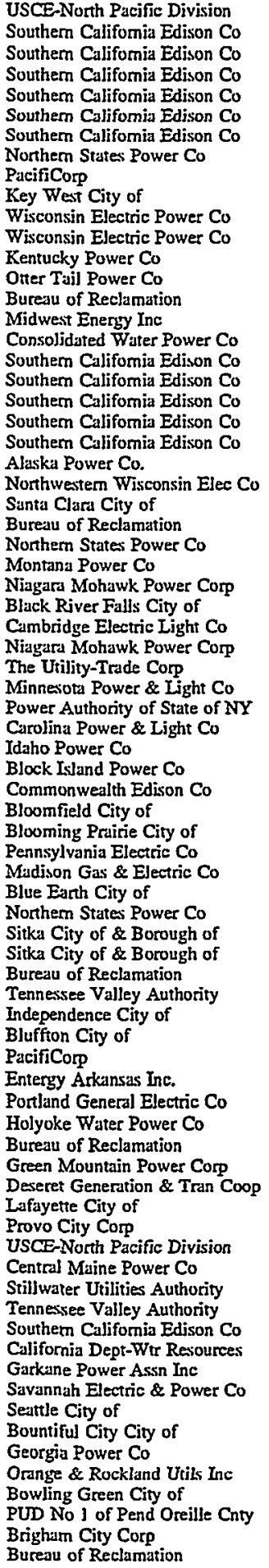 & 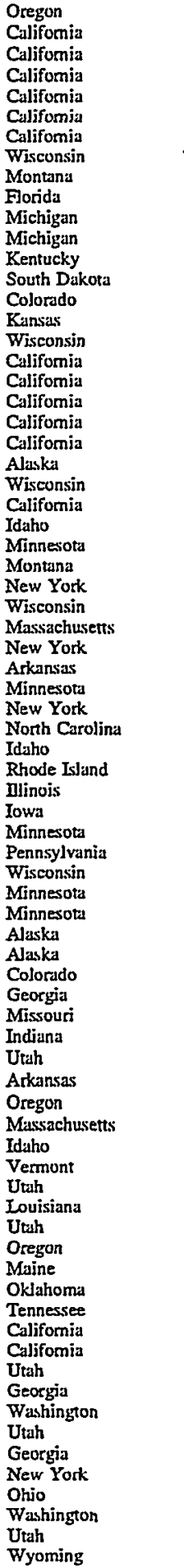 \\
\hline
\end{tabular}

See foomoies at end of table. 
Table D1. U.S. Electric Utility Plants, as of January 1, 1998 (Continued)

\begin{tabular}{|c|c|c|}
\hline Plant Name & Utility Name & State \\
\hline 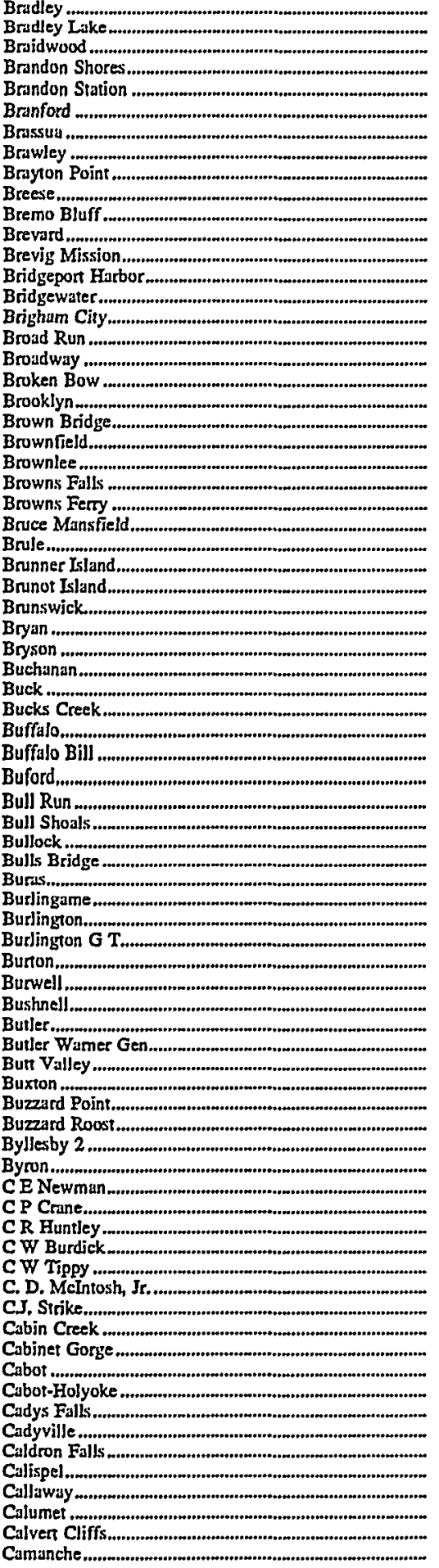 & 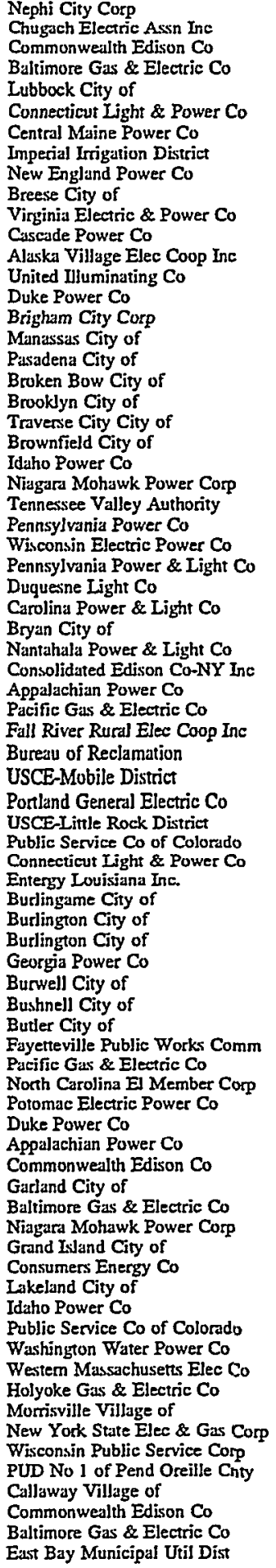 & 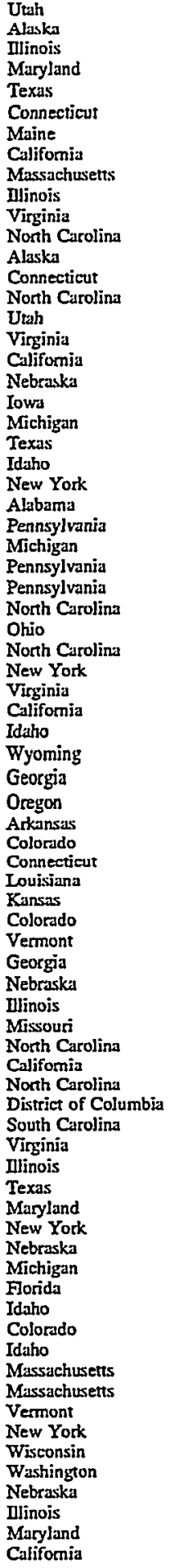 \\
\hline
\end{tabular}

See footnotes at end of table. 
Table D1. U.S. Electric Utility Plants, as of January 1, 1998 (Continued) .

\begin{tabular}{|c|c|c|c|}
\hline Plant Name & Utility Name & & State \\
\hline 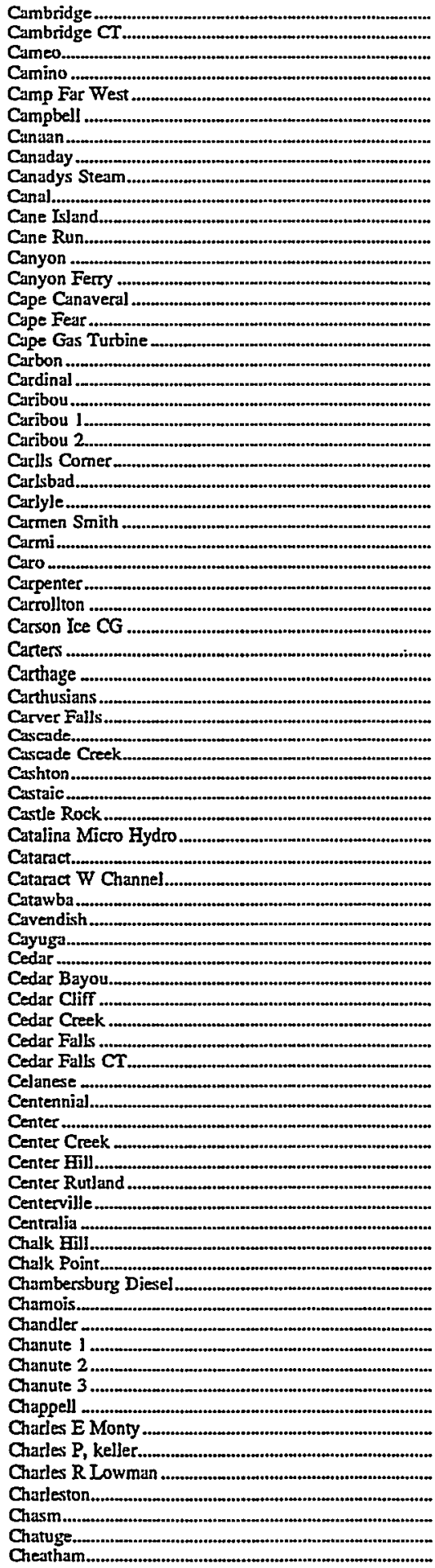 & 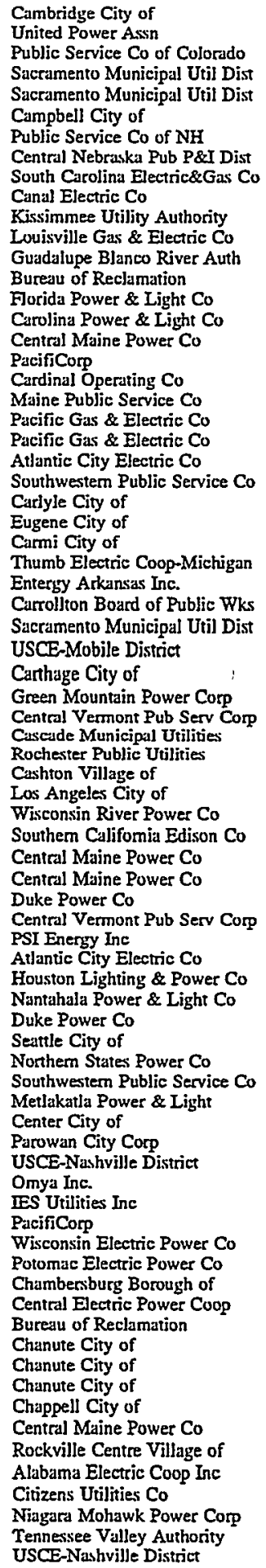 & 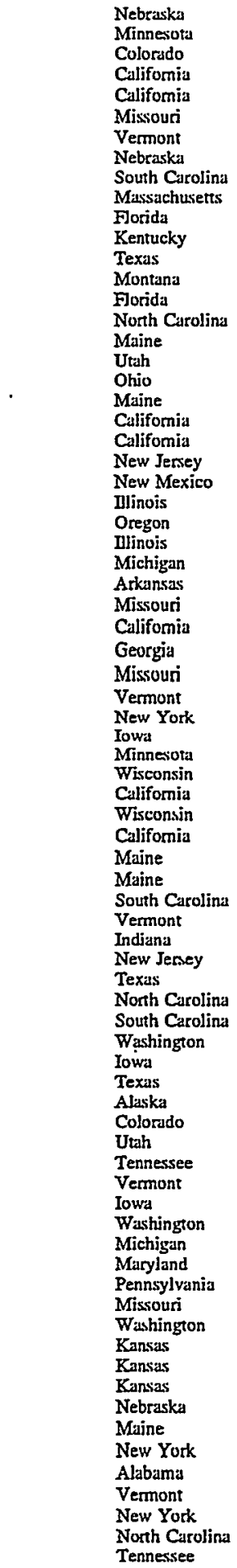 & \\
\hline
\end{tabular}

See foomotes at end of table. 
Table D1. U.S. Electric Utility Plants, as of January 1, 1998 (Continued)

\begin{tabular}{|c|c|c|}
\hline Plant Name & Utility Name & State \\
\hline 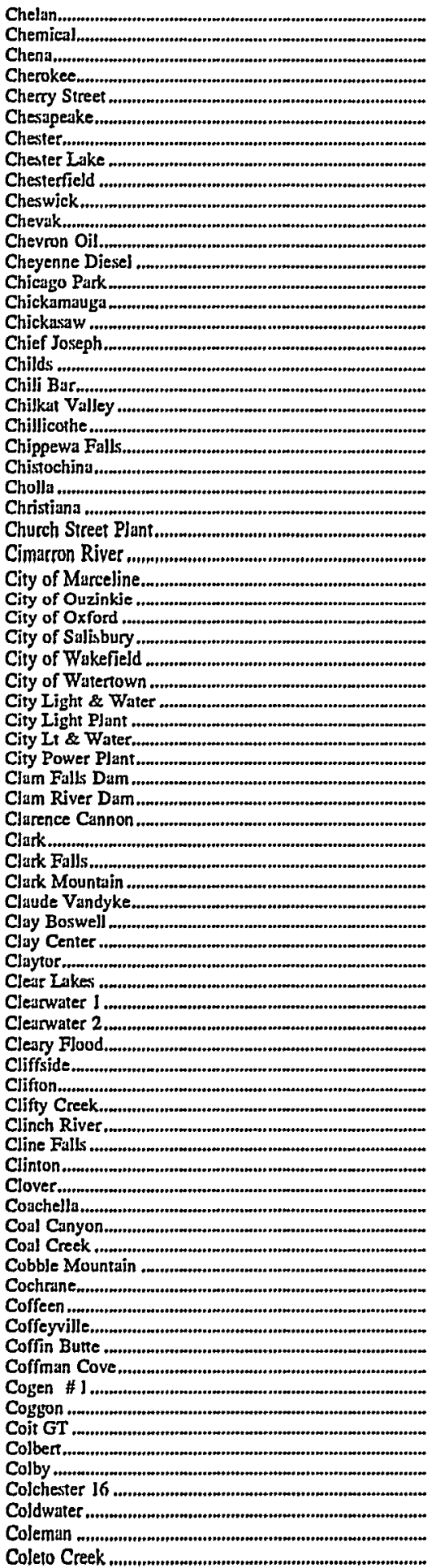 & 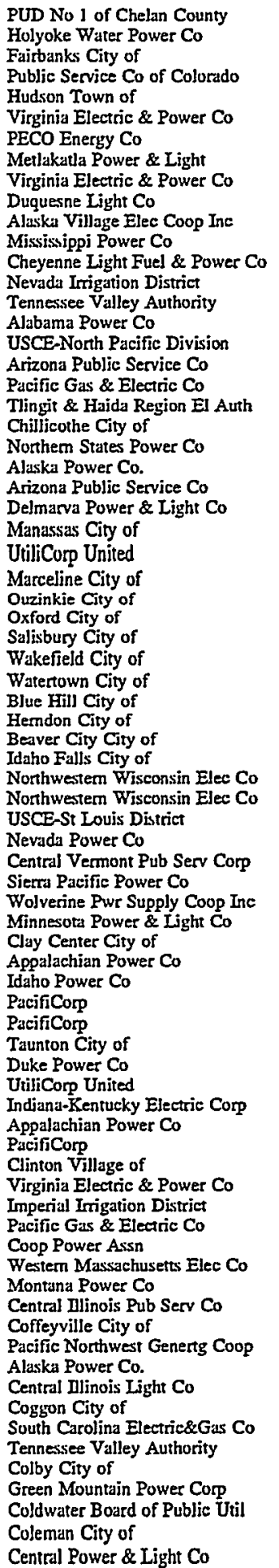 & 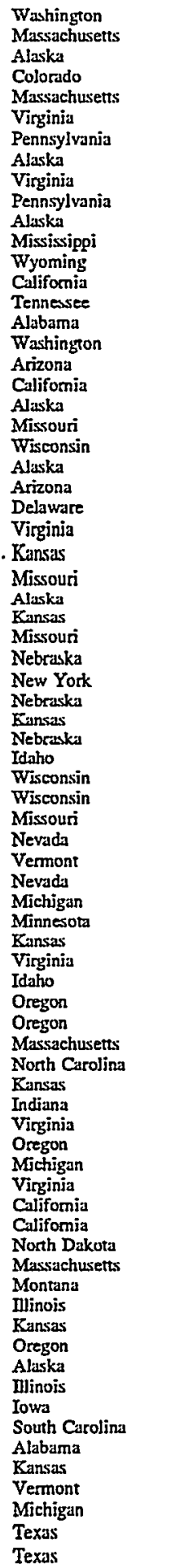 \\
\hline
\end{tabular}

See footnotes at end of table. 
Table D1. U.S. Electric Utility Plants, as of January 1, 1998 (Continued)

\begin{tabular}{|c|c|c|}
\hline Plant Name & Utility Name & State \\
\hline 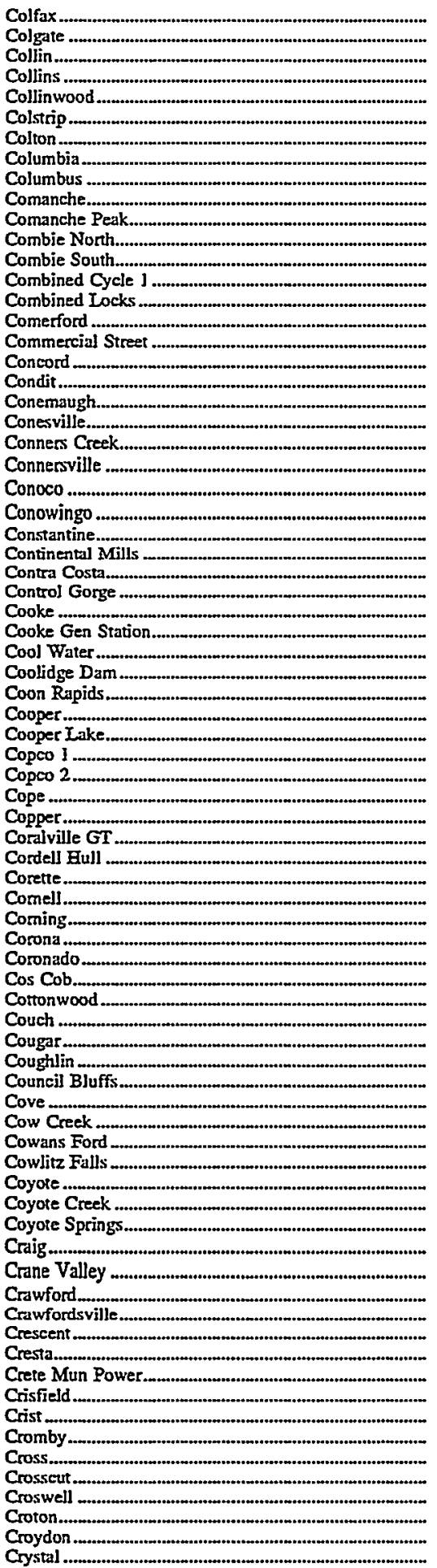 & 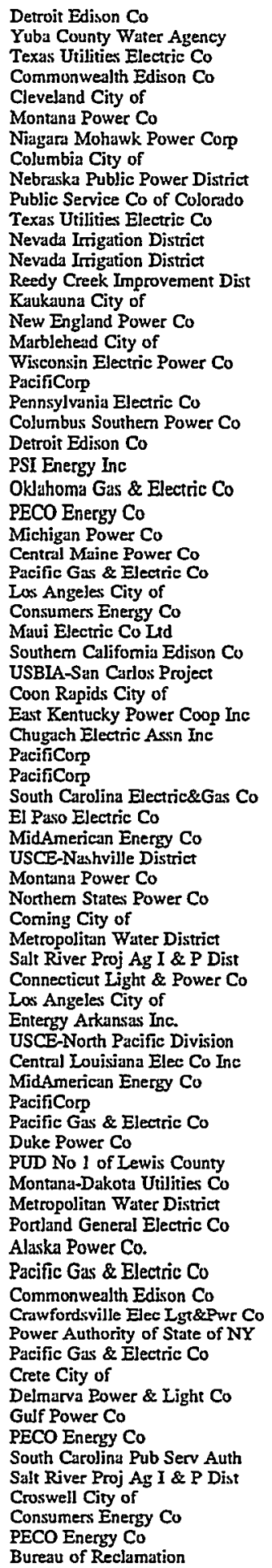 & 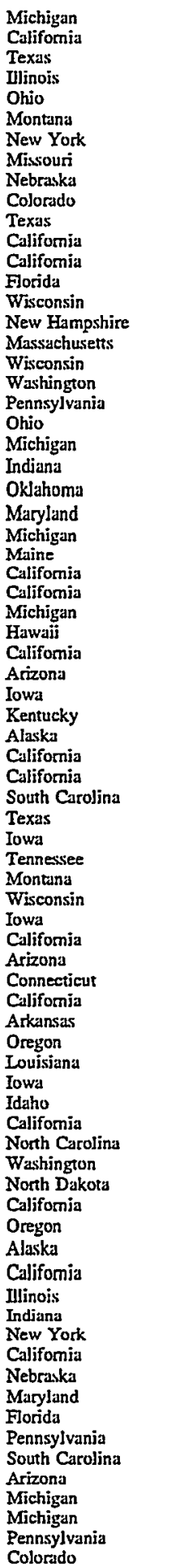 \\
\hline
\end{tabular}

See footnotes at end of table. 
Table D1. U.S. Electric Utility Plants, as of January 1, 1998 (Continued)

\begin{tabular}{|c|c|c|}
\hline Plant Name & Utility Name & Sente \\
\hline 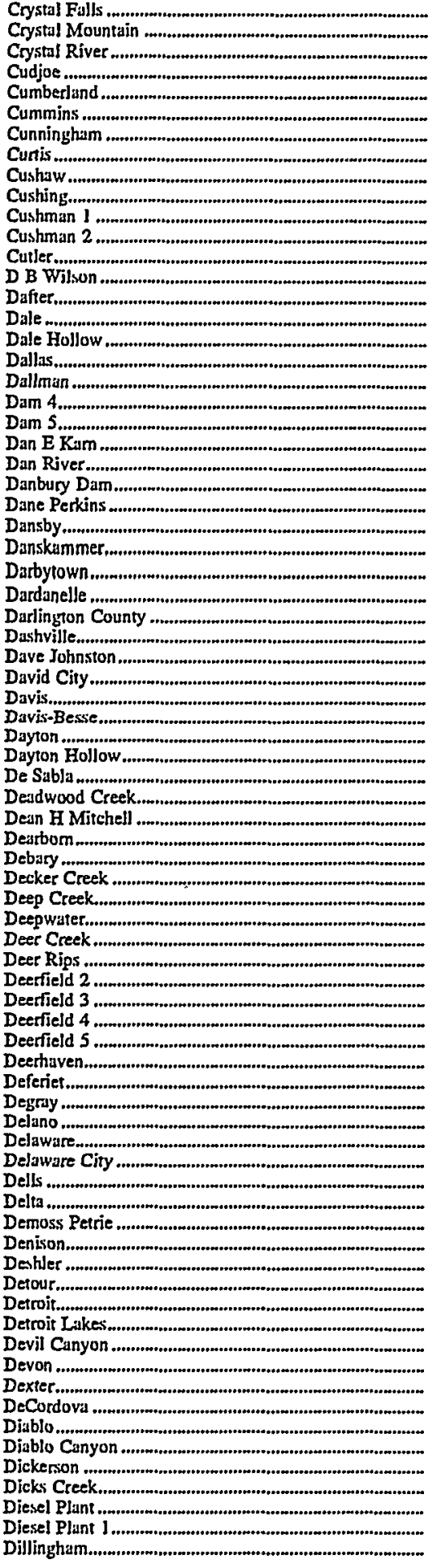 & 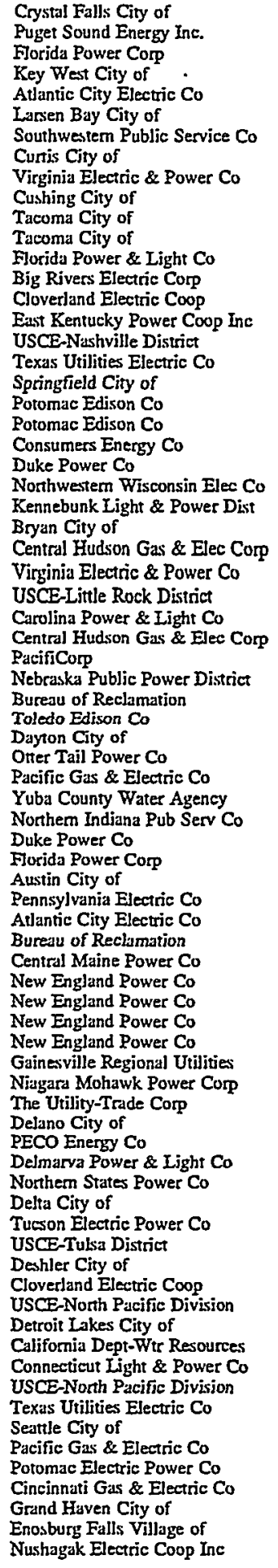 & 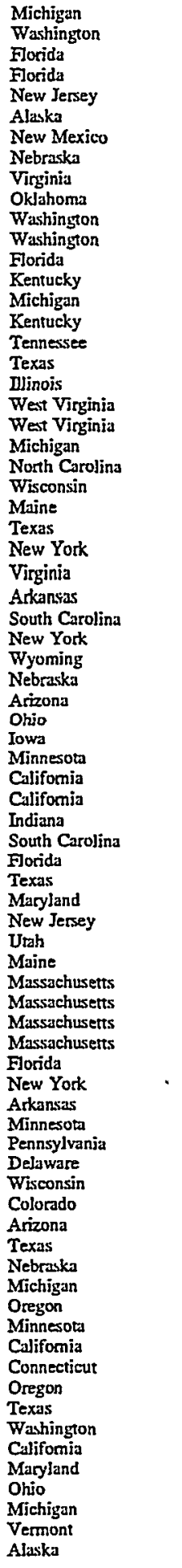 \\
\hline
\end{tabular}

See footnutes at end of table. 
Table D1. U.S. Electric Utility Plants, as of January 1, 1998 (Continued)

\begin{tabular}{|c|c|c|}
\hline Plant Name & Utility Name & State \\
\hline 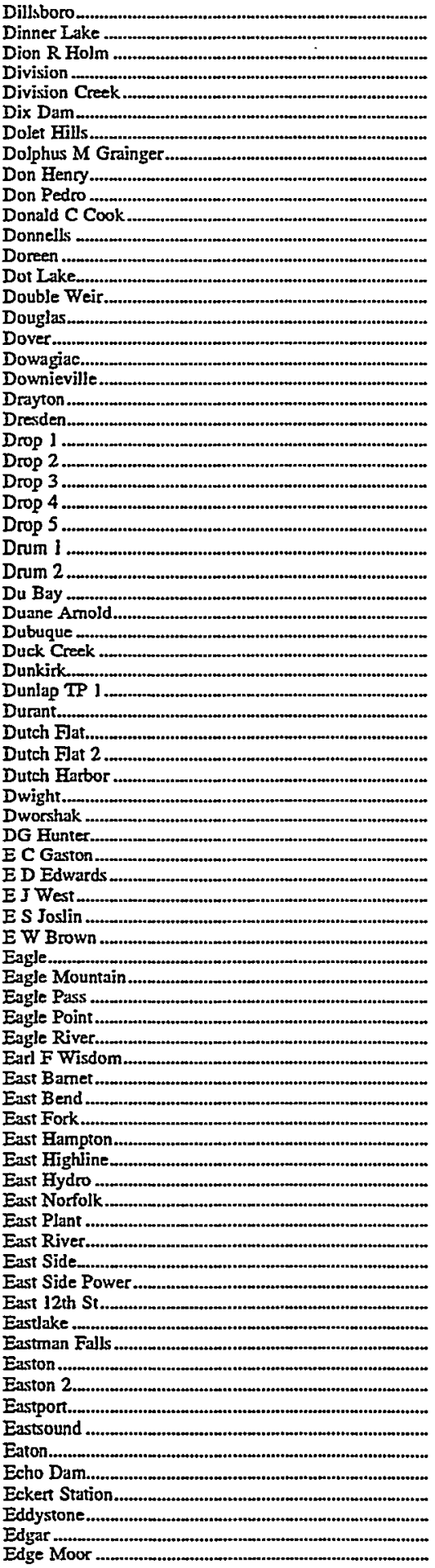 & 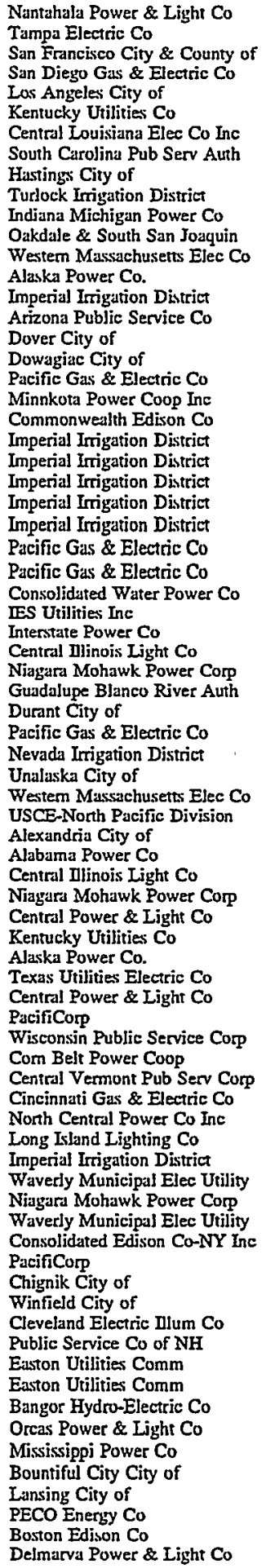 & 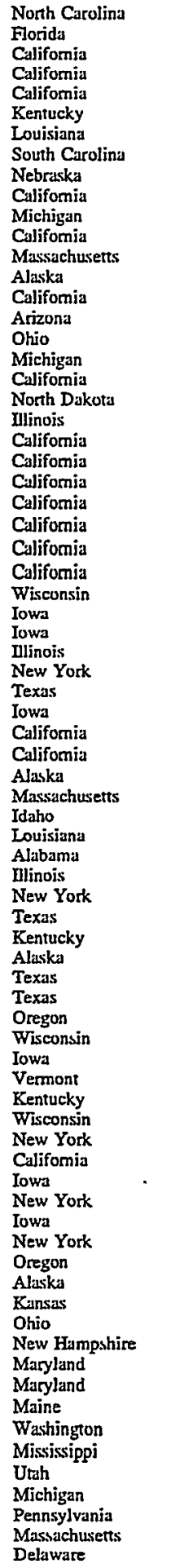 \\
\hline
\end{tabular}

See footnotes at end of table. 
Table D1. U.S. Electric Utility Plants, as of January 1, 1998 (Continued)

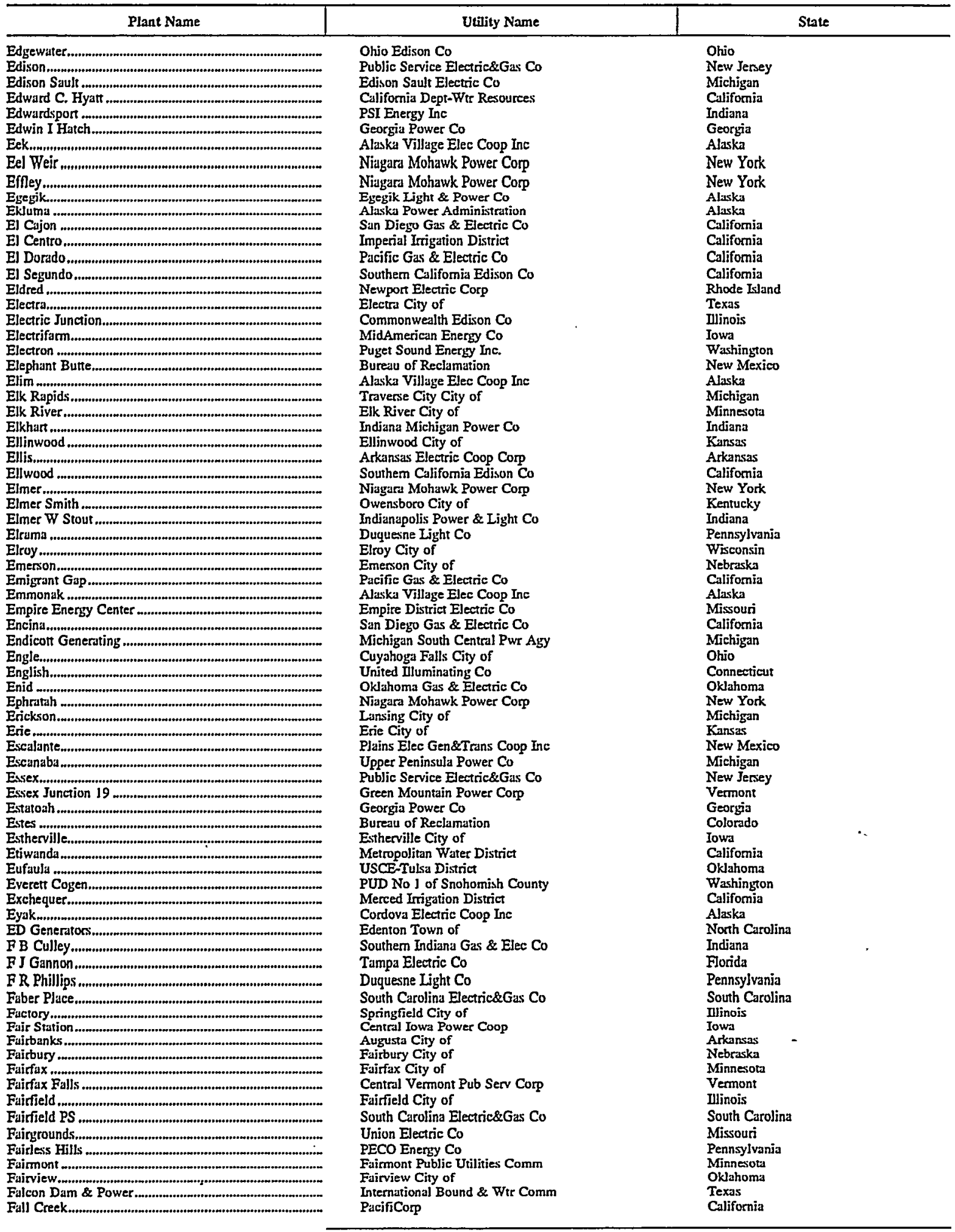

See foutnotes at end of table. 
Table D1. U.S. Electric Utility Plants, as of January 1, 1998 (Continued)

\begin{tabular}{|c|c|c|}
\hline Plant Name & Utility Name & State \\
\hline 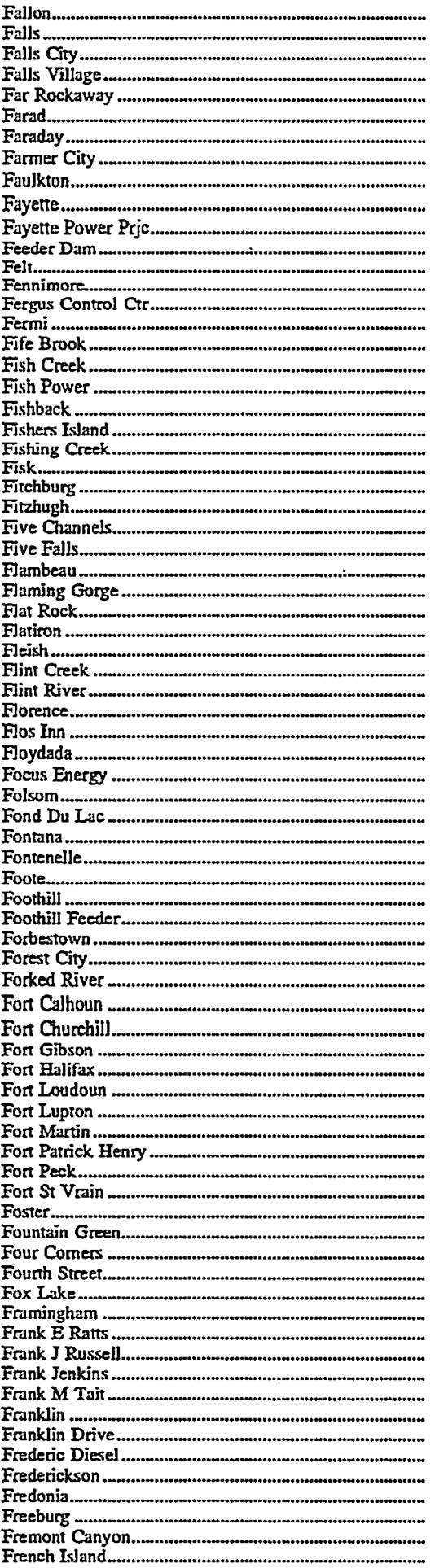 & 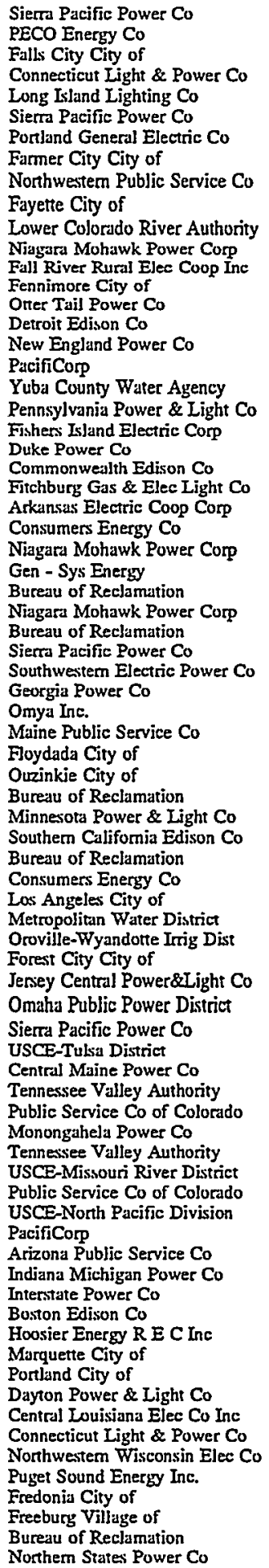 & 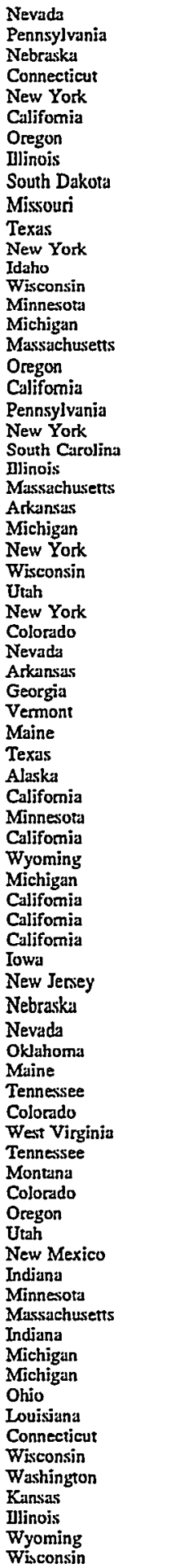 \\
\hline
\end{tabular}

See footnotes at end of table. 
Table D1. U.S. Electric Utility Plants, as of January 1, 1998 (Continued)

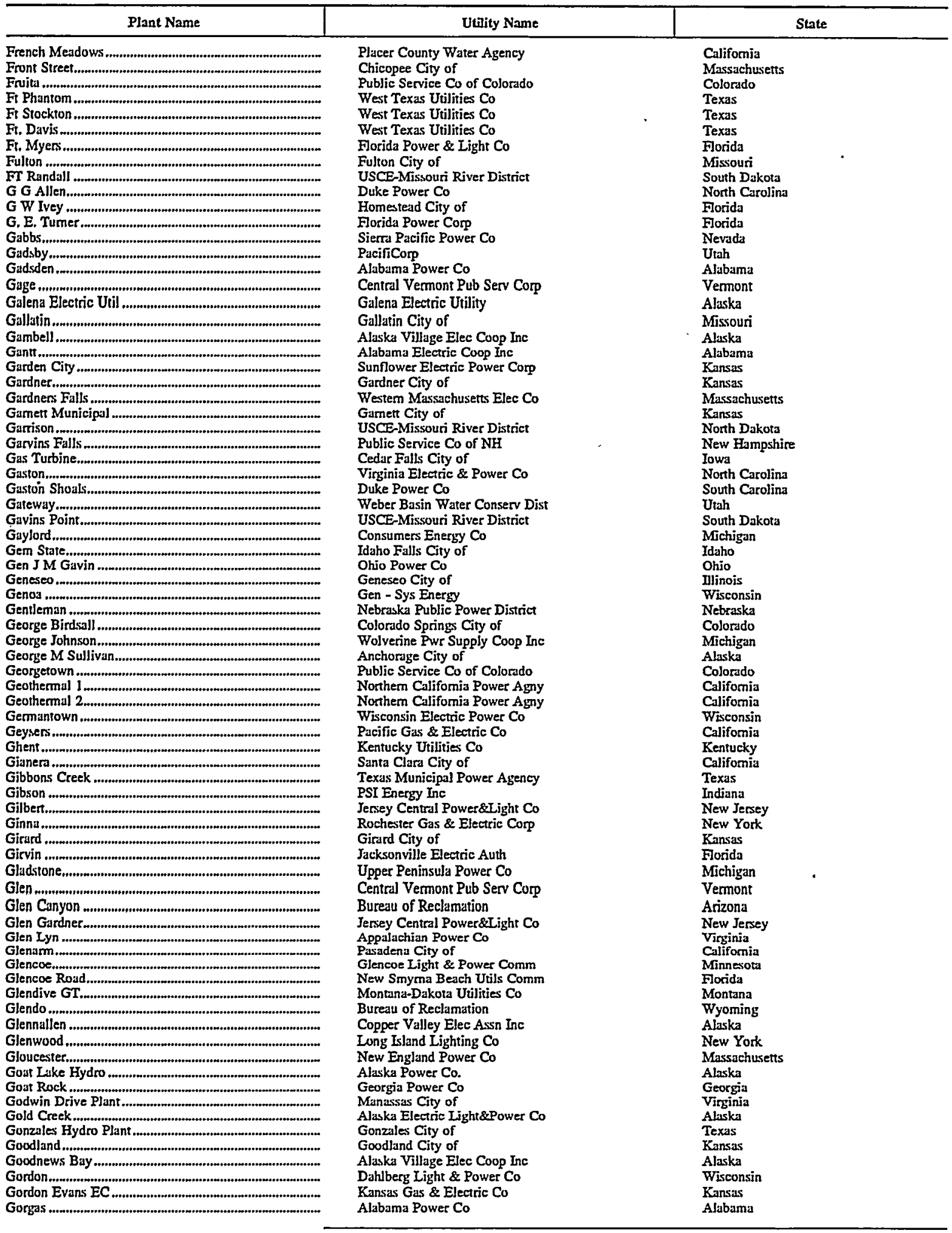

See footnotes at end of table. 
Table D1. U.S. Electric Utility Plants, as of January 1, 1998 (Continued)

\begin{tabular}{|c|c|c|}
\hline Plant Name & Utility Name & State \\
\hline 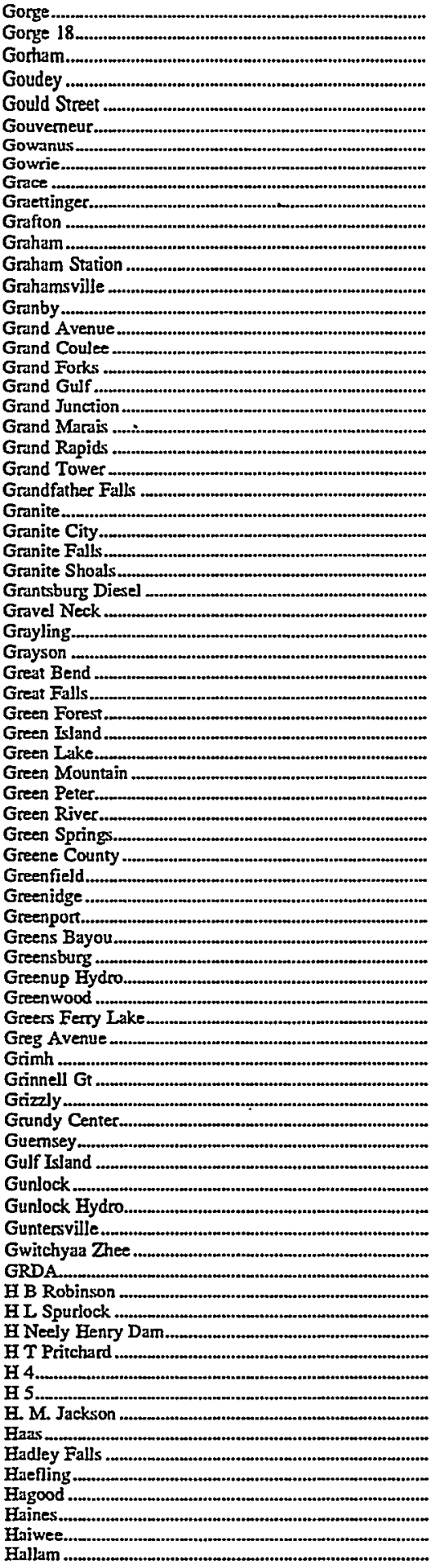 & 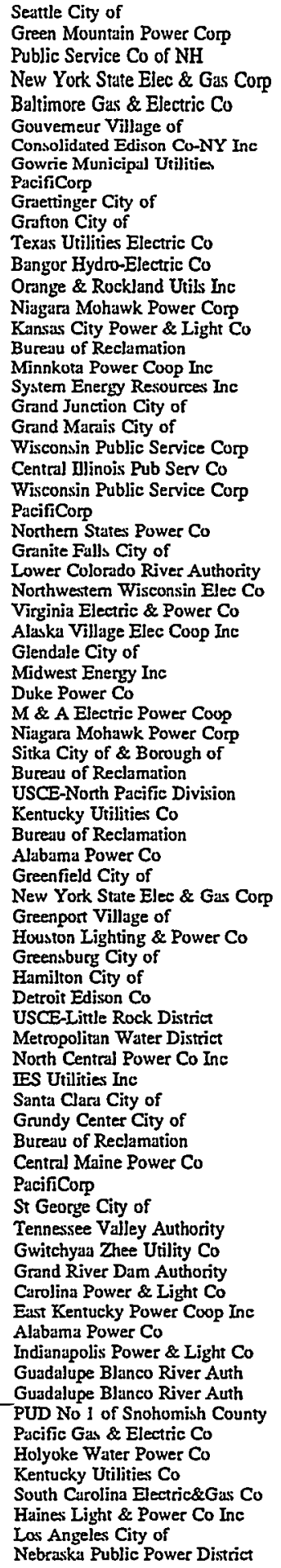 & 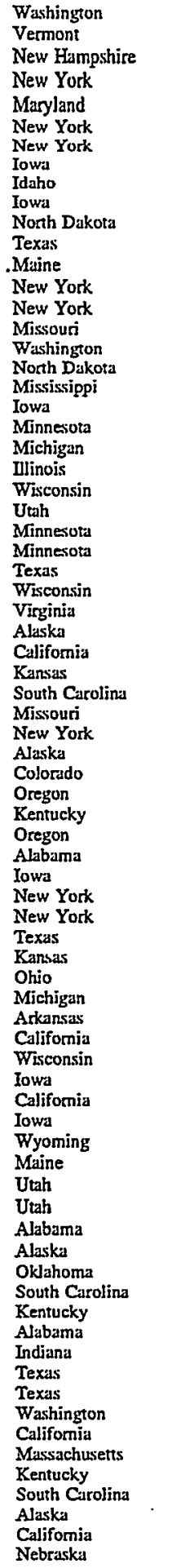 \\
\hline
\end{tabular}

See footnotes at end of rable. 
Table D1. U.S. Electric Utility Plants, as of January 1, 1998 (Continued) .

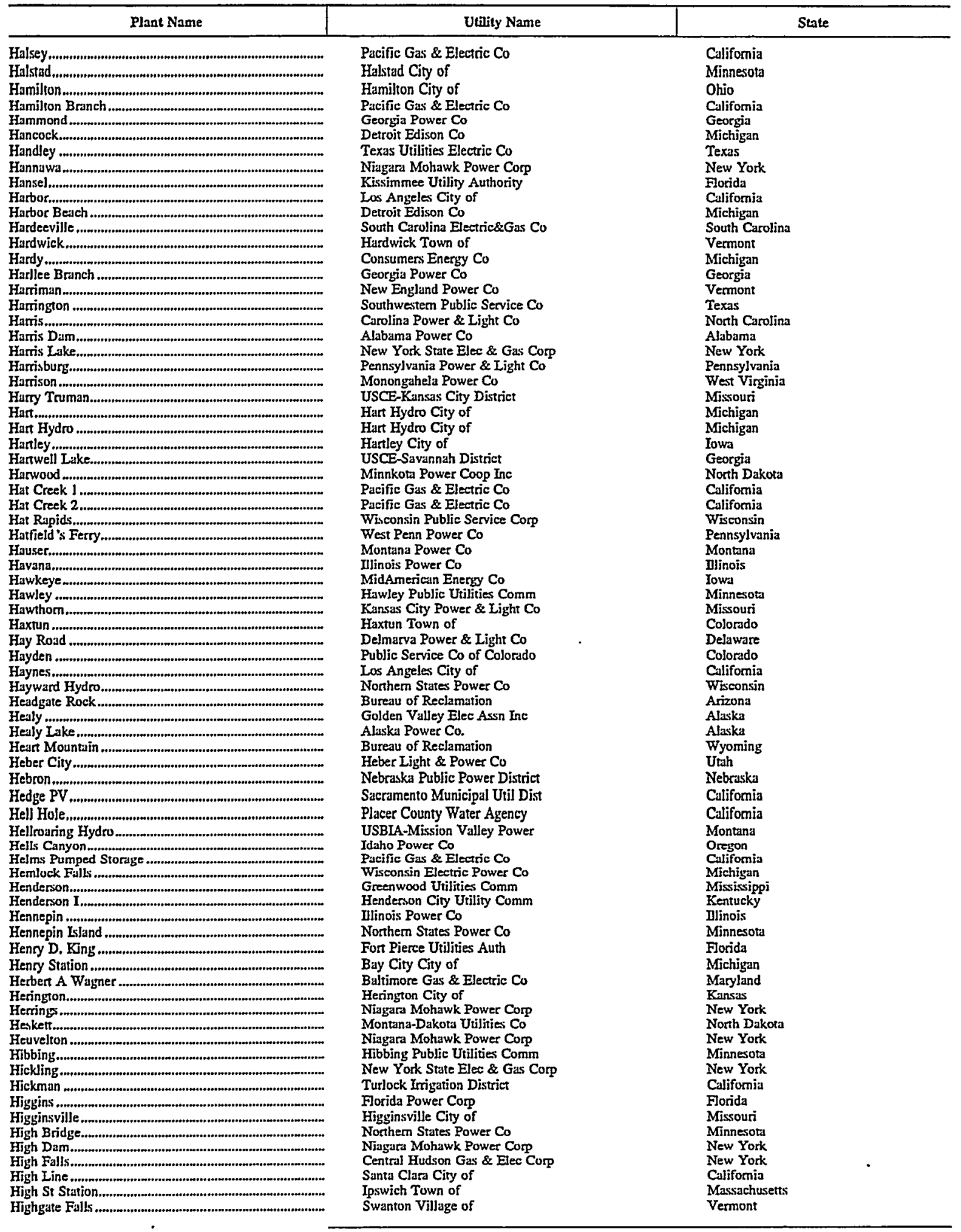

See foornotes at end of table. 
Table D1. U.S. Electric Utility Plants, as of January 1, 1998 (Continued)

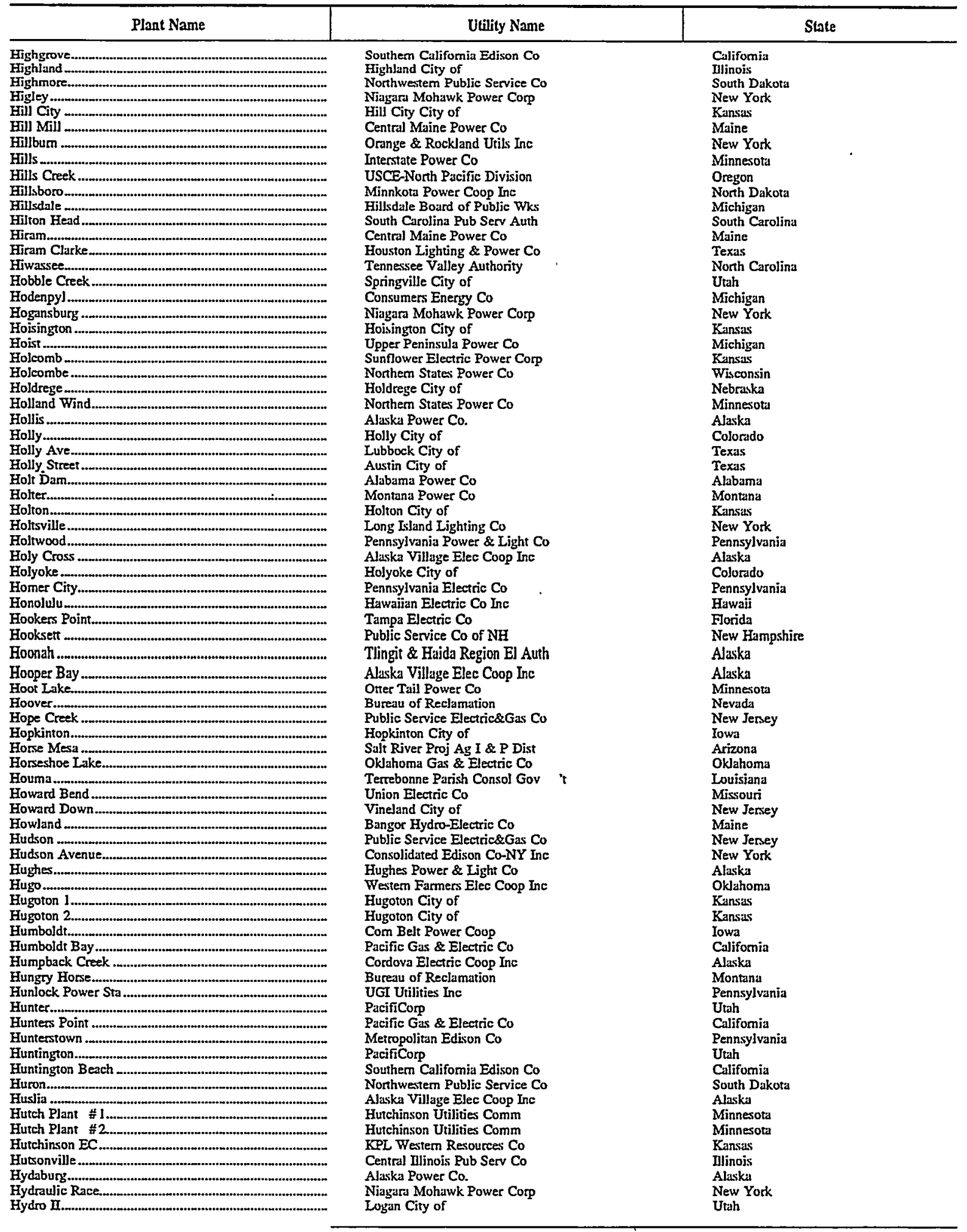

See footnotes at end of table. 
Table D1. U.S. Electric Utility Plants, as of January 1, 1998 (Continued)

\begin{tabular}{|c|c|c|}
\hline Plant Name & Utility Name & State \\
\hline 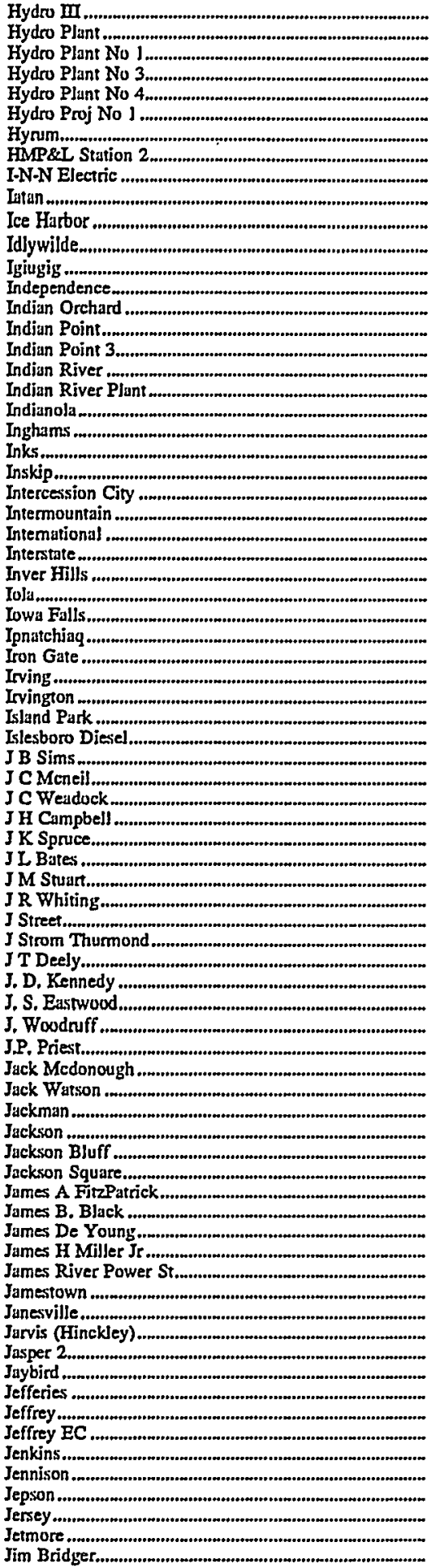 & 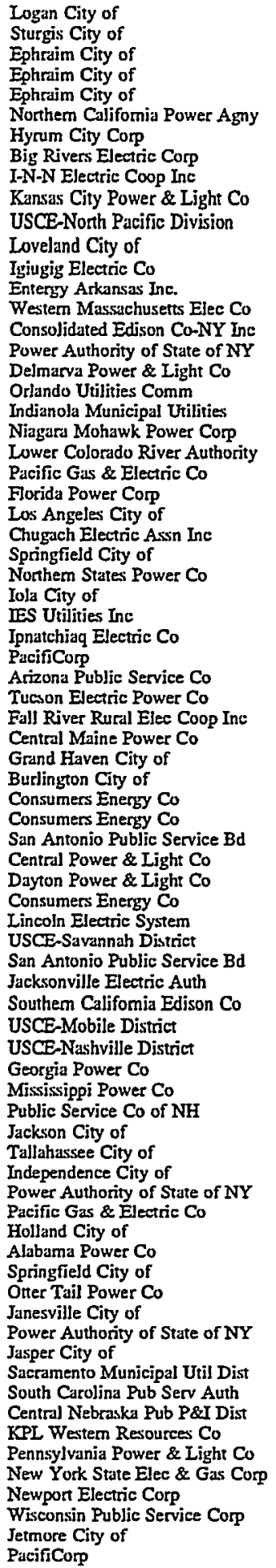 & 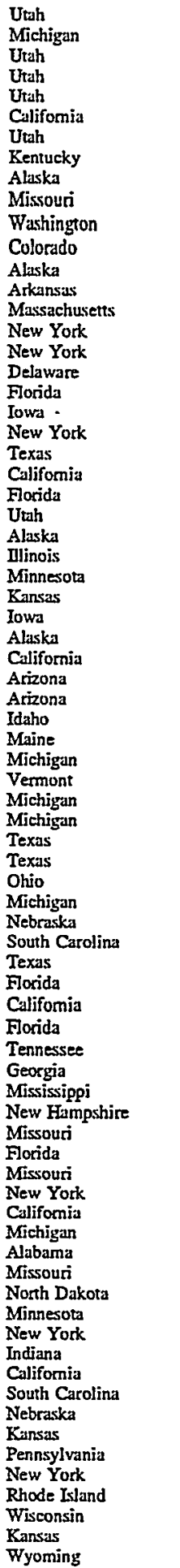 \\
\hline
\end{tabular}

See footnotes at end of table. 
Table D1. U.S. Electric Utility Plants, as of January 1, 1998 (Continued) .

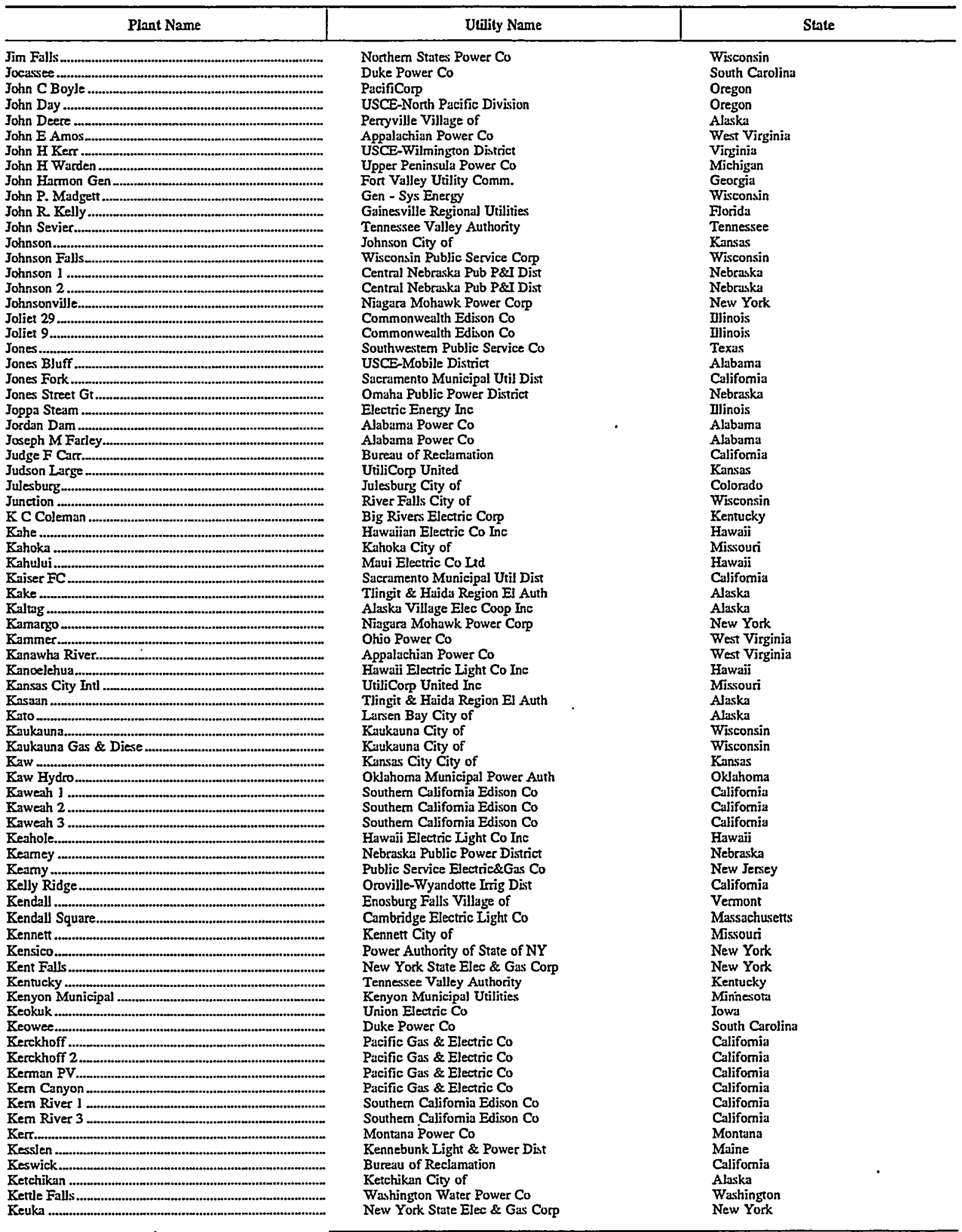

See footnotes at end of table. 
Table D1. U.S. Electric Utility Plants, as of January 1, 1998 (Continued)

\begin{tabular}{|c|c|c|}
\hline Plant Name & Utility Name & State \\
\hline 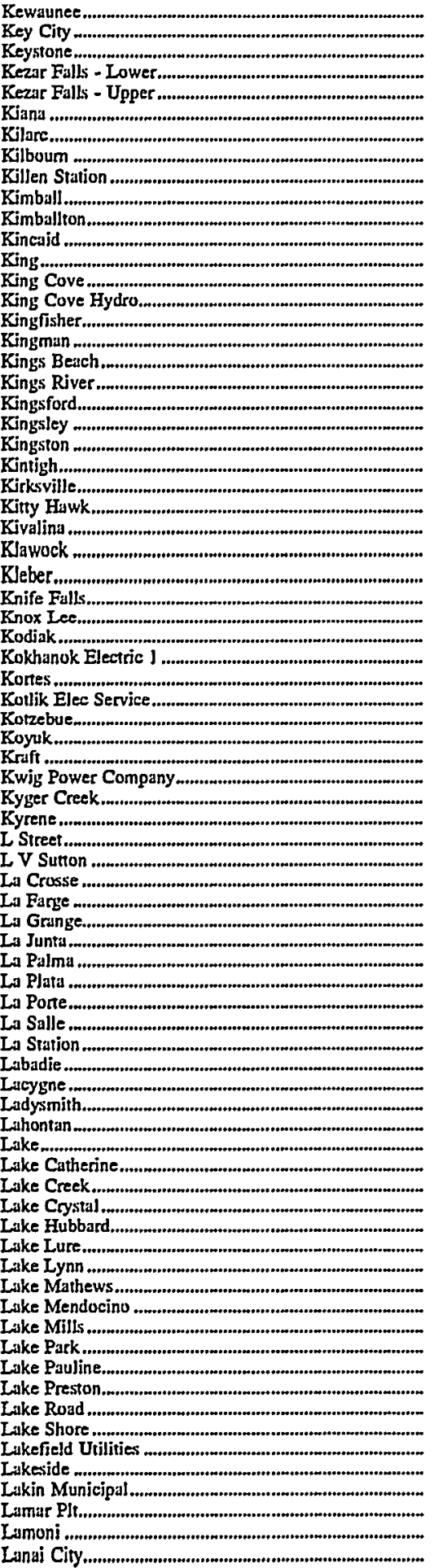 & 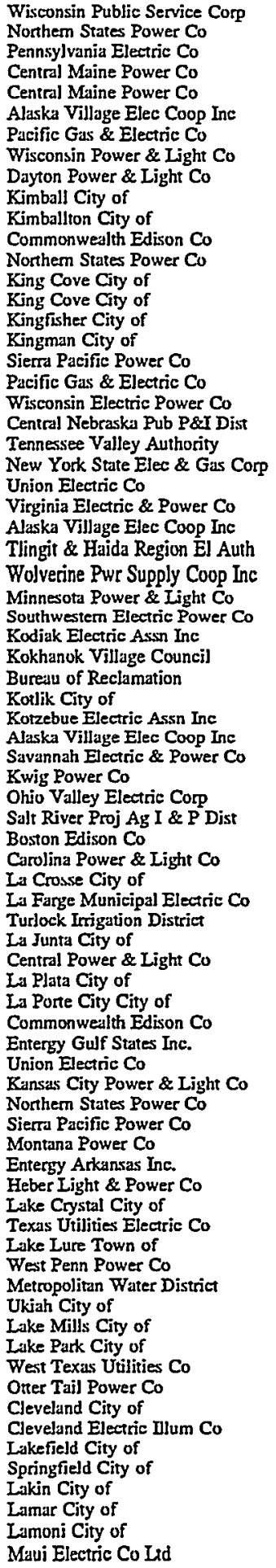 & 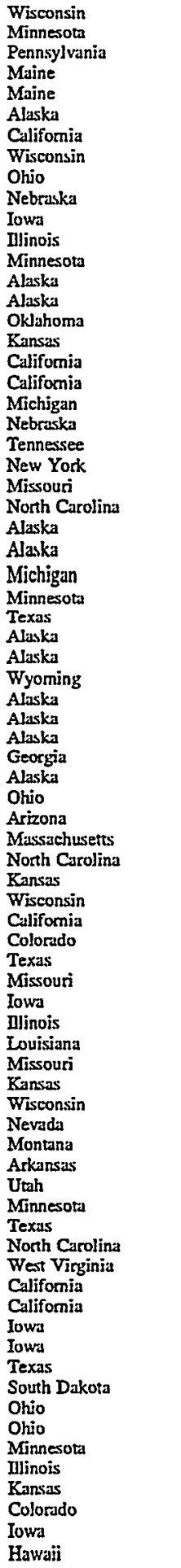 \\
\hline
\end{tabular}

See footnotes at end of table. 
Table D1. U.S. Electric Utility Plants, as of January 1, 1998 (Continued)

\begin{tabular}{|c|c|c|c|}
\hline Plant Name & Utility Name & State & \\
\hline 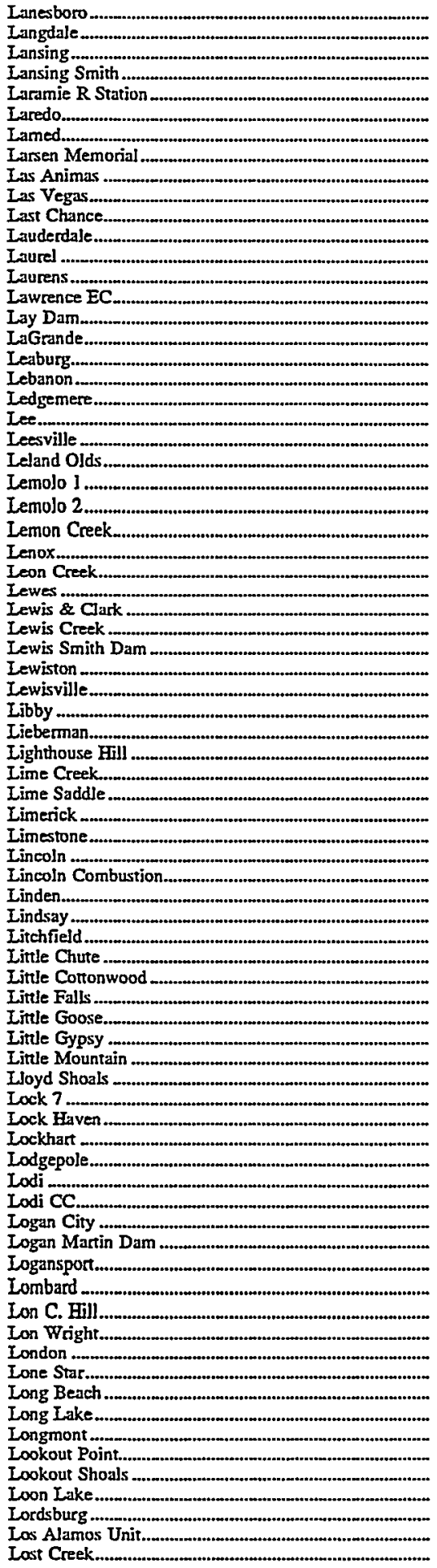 & 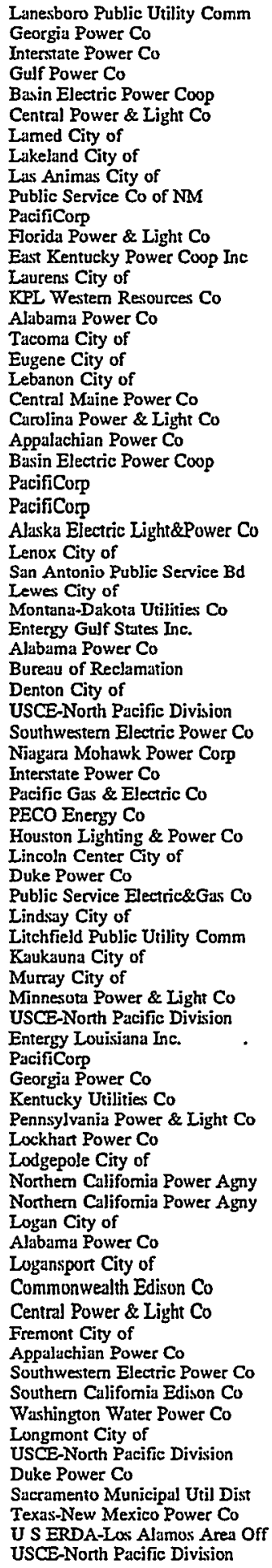 & 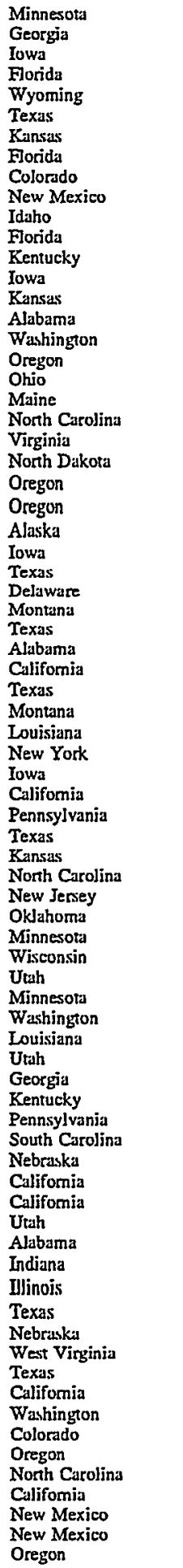 & • \\
\hline
\end{tabular}

See footnotes at end of table. 
Table D1. U.S. Electric Utility Plants, as of January 1, 1998 (Continued)

\begin{tabular}{|c|c|c|}
\hline Plant Name & Utility Name & State \\
\hline 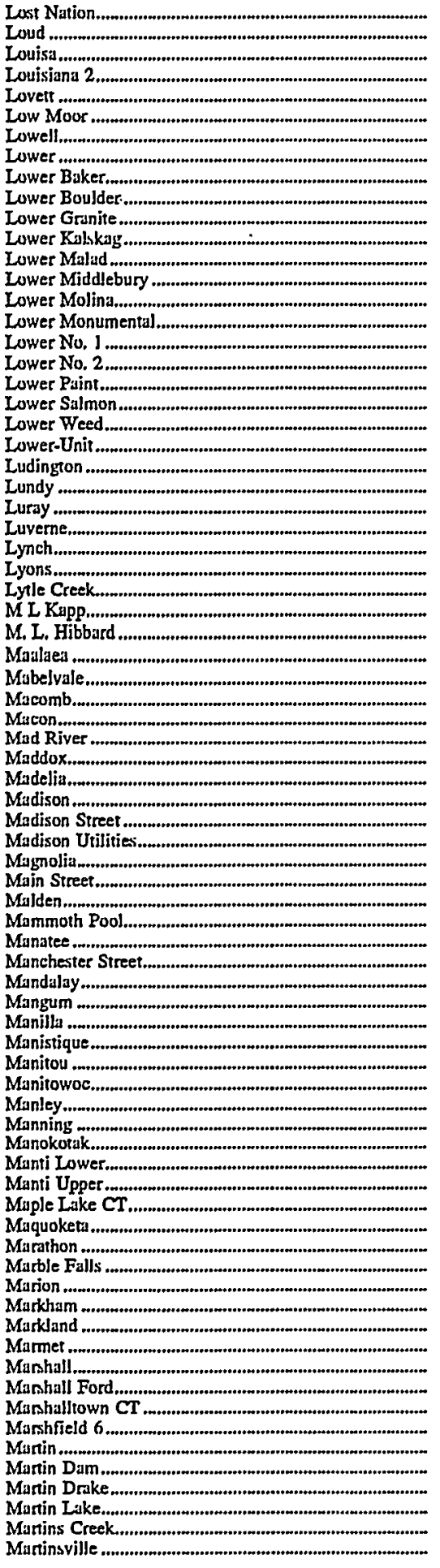 & 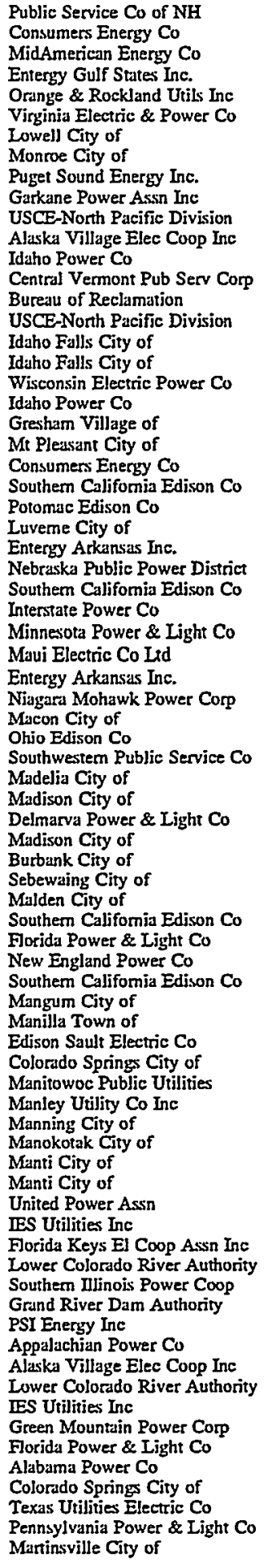 & 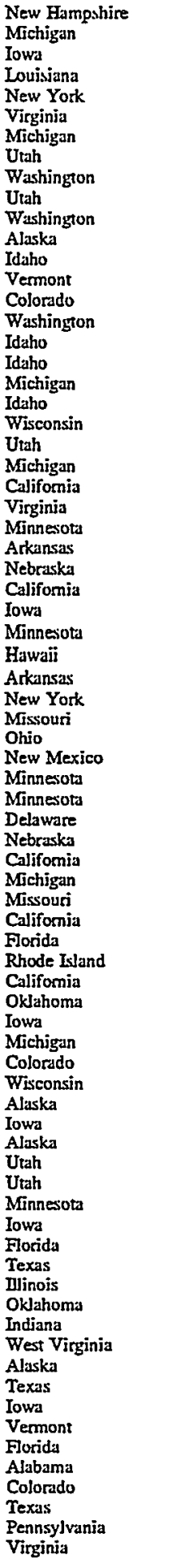 \\
\hline
\end{tabular}


Table D1. U.S. Electric Utility Plants, as of January 1, 1998 (Continued)

\begin{tabular}{|c|c|c|}
\hline Plant Name & Utility Name & State \\
\hline 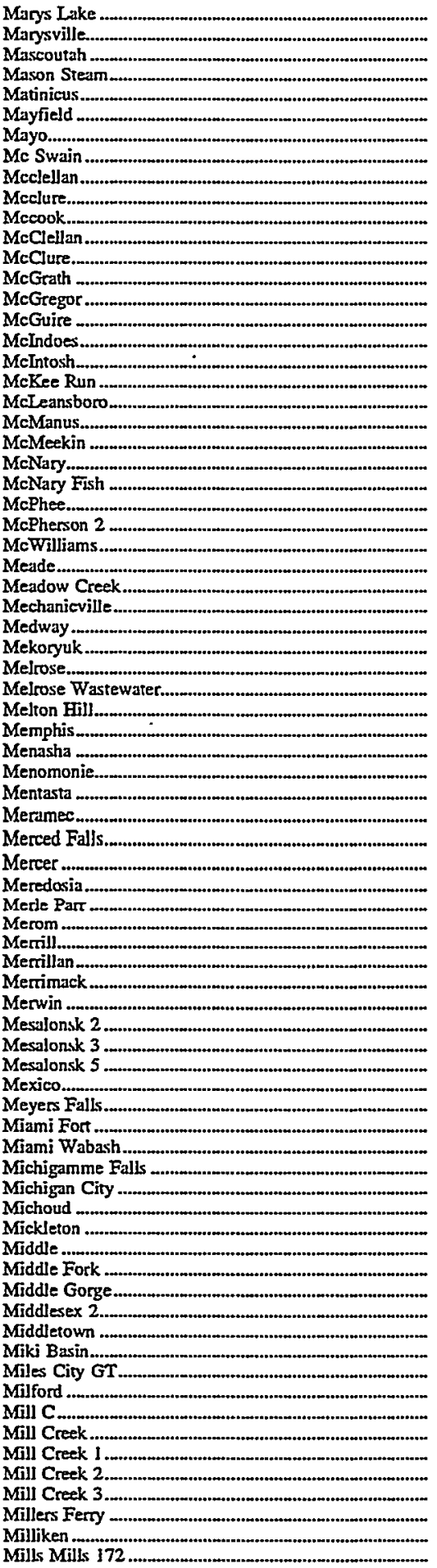 & 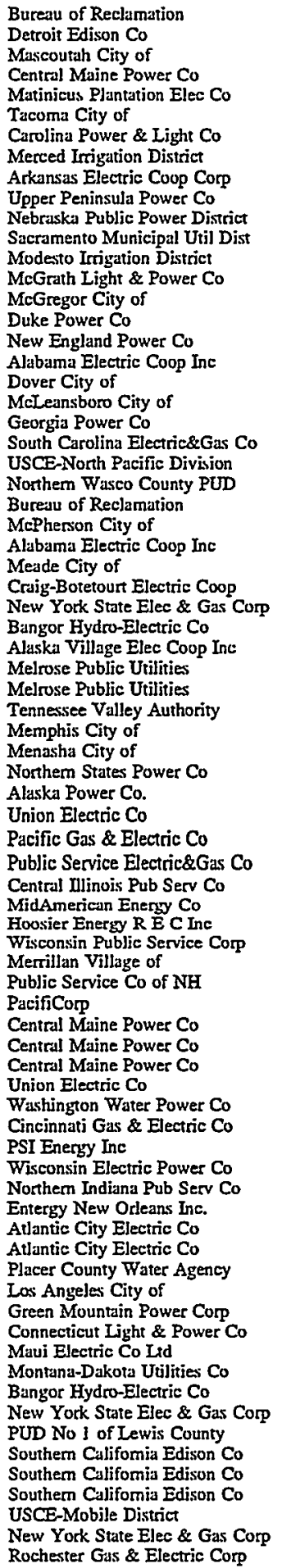 & 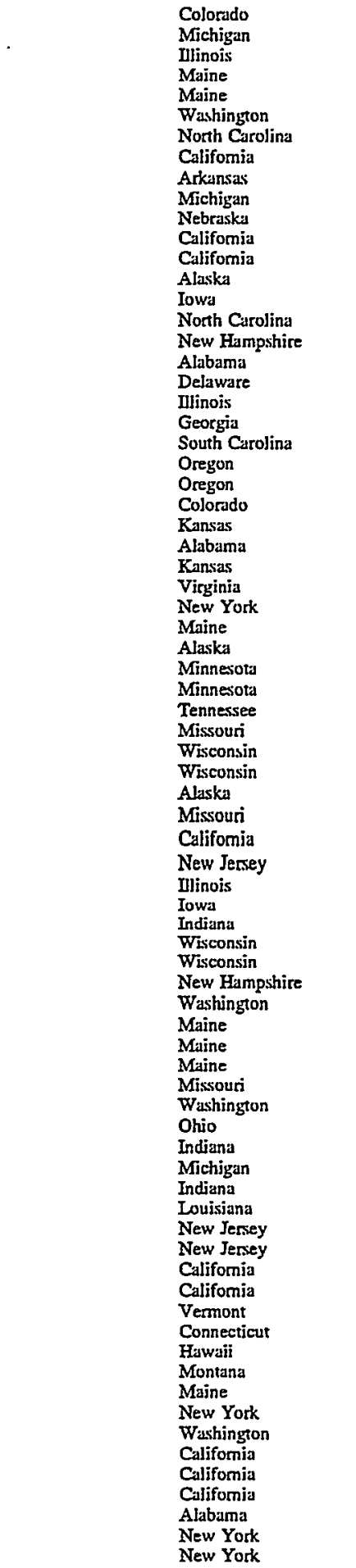 \\
\hline
\end{tabular}

See foomotes at end of table. 
Table D1. U.S. Electric Utility Plants, as of January 1, 1998 (Continued)

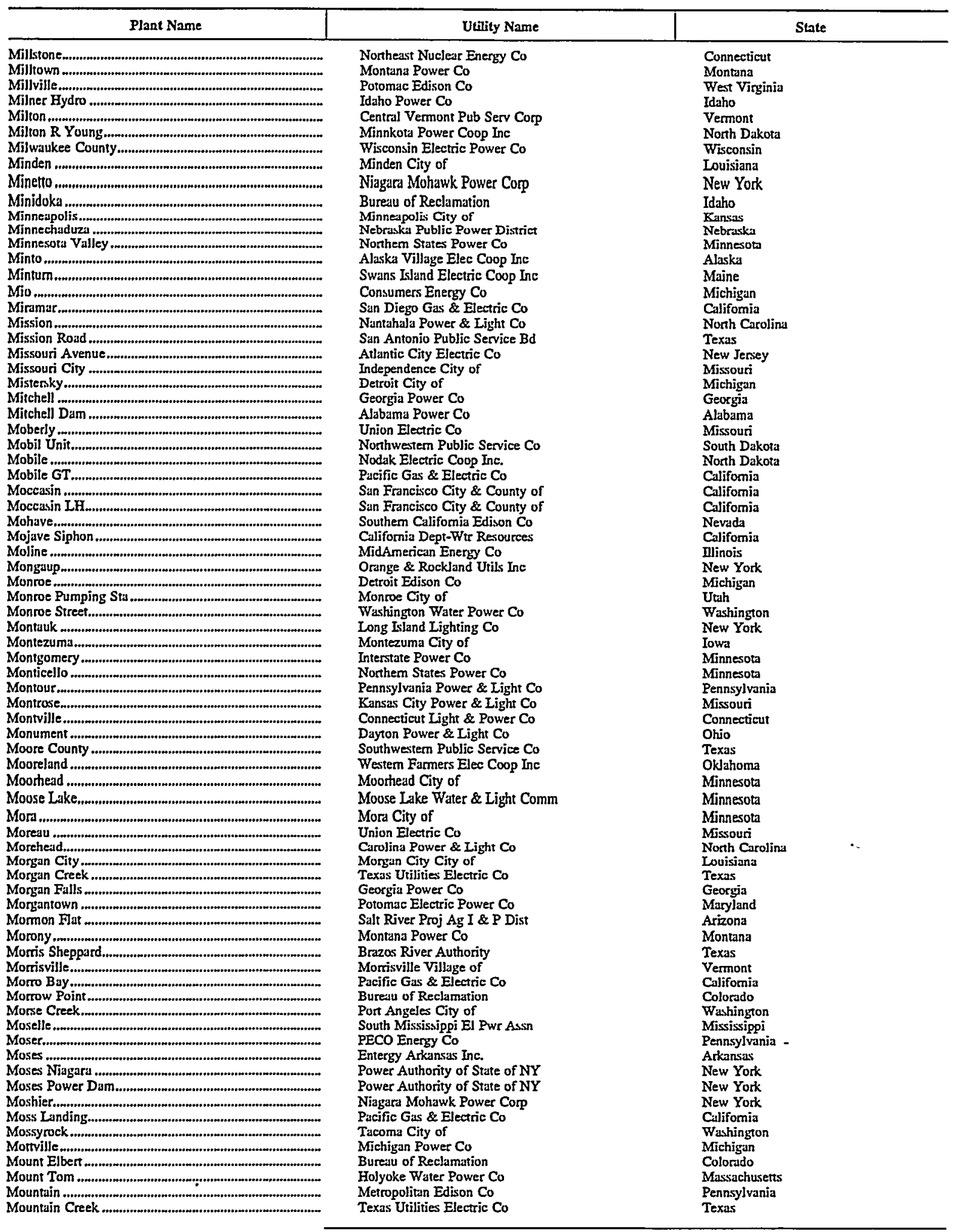

See footnotes at end of table. 
Table D1. U.S. Electric Utility Plants, as of January 1, 1998 (Continued)

\begin{tabular}{|c|c|c|}
\hline Plant Name & Utility Name & Slate \\
\hline 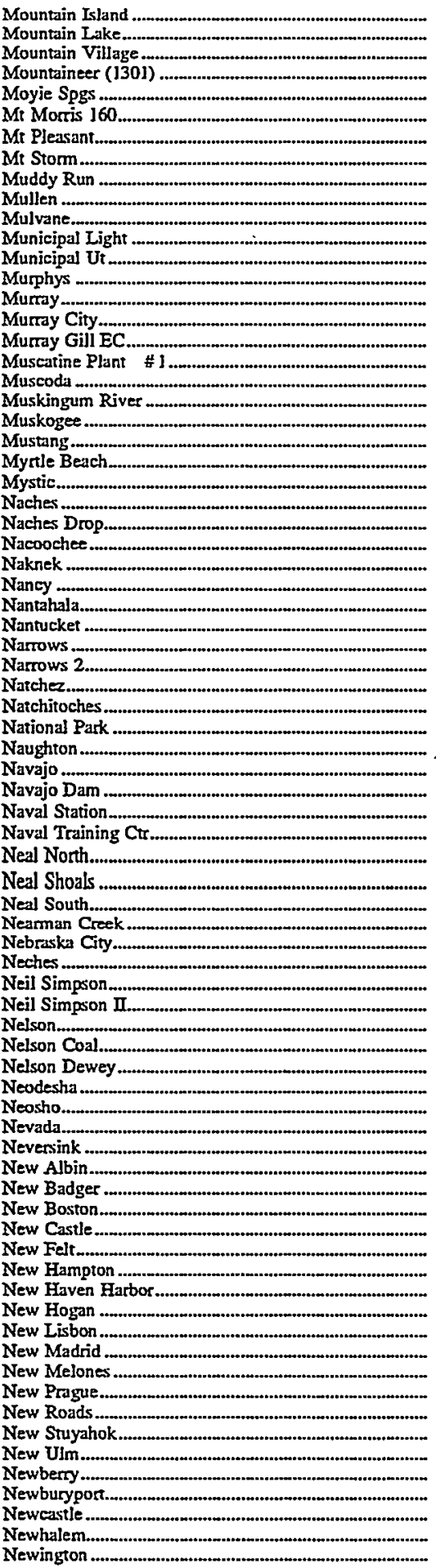 & 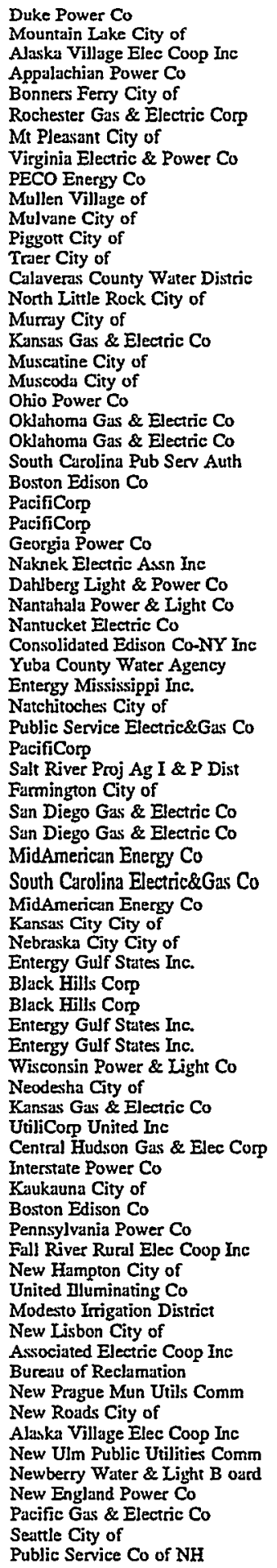 & 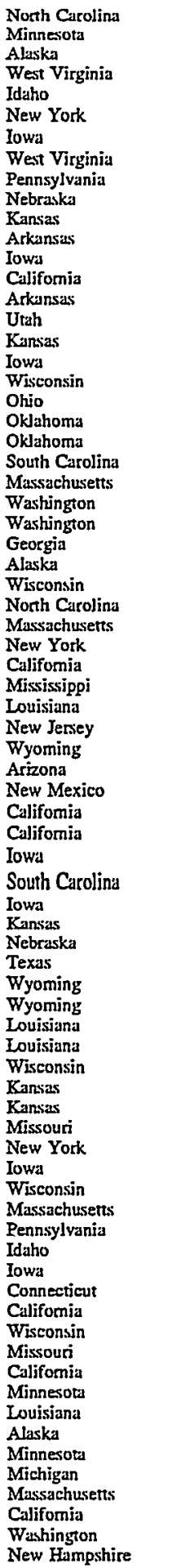 \\
\hline
\end{tabular}

See footnotes at end of table. 
Table D1. U.S. Electric Utility Plants, as of January 1, 1998 (Continued)

\begin{tabular}{|c|c|c|}
\hline Plant Name & Utility Name & State \\
\hline 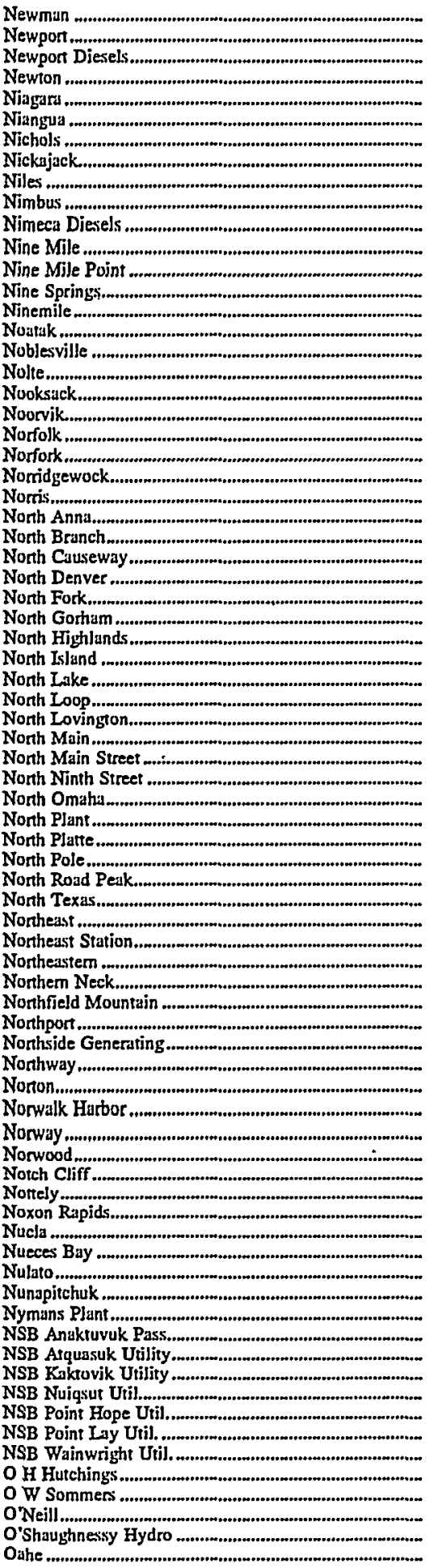 & 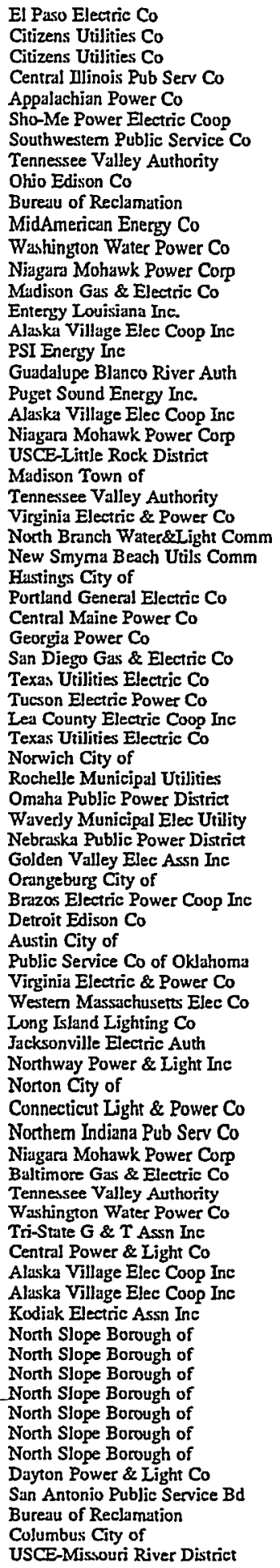 & 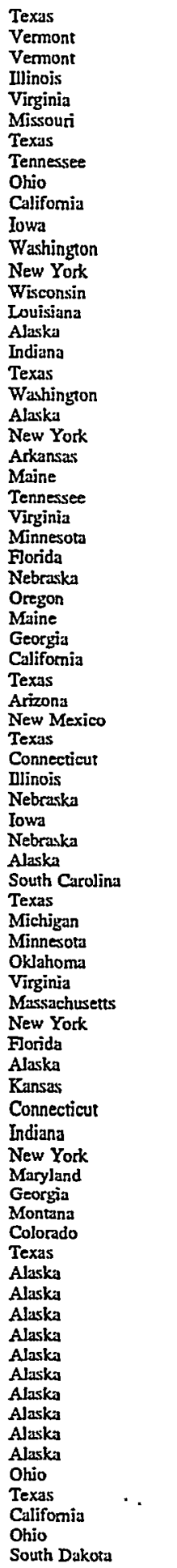 \\
\hline
\end{tabular}

See footnotes at end of table. 
Table D1. U.S. Electric Utility Plants, as of January 1, 1998 (Continued)

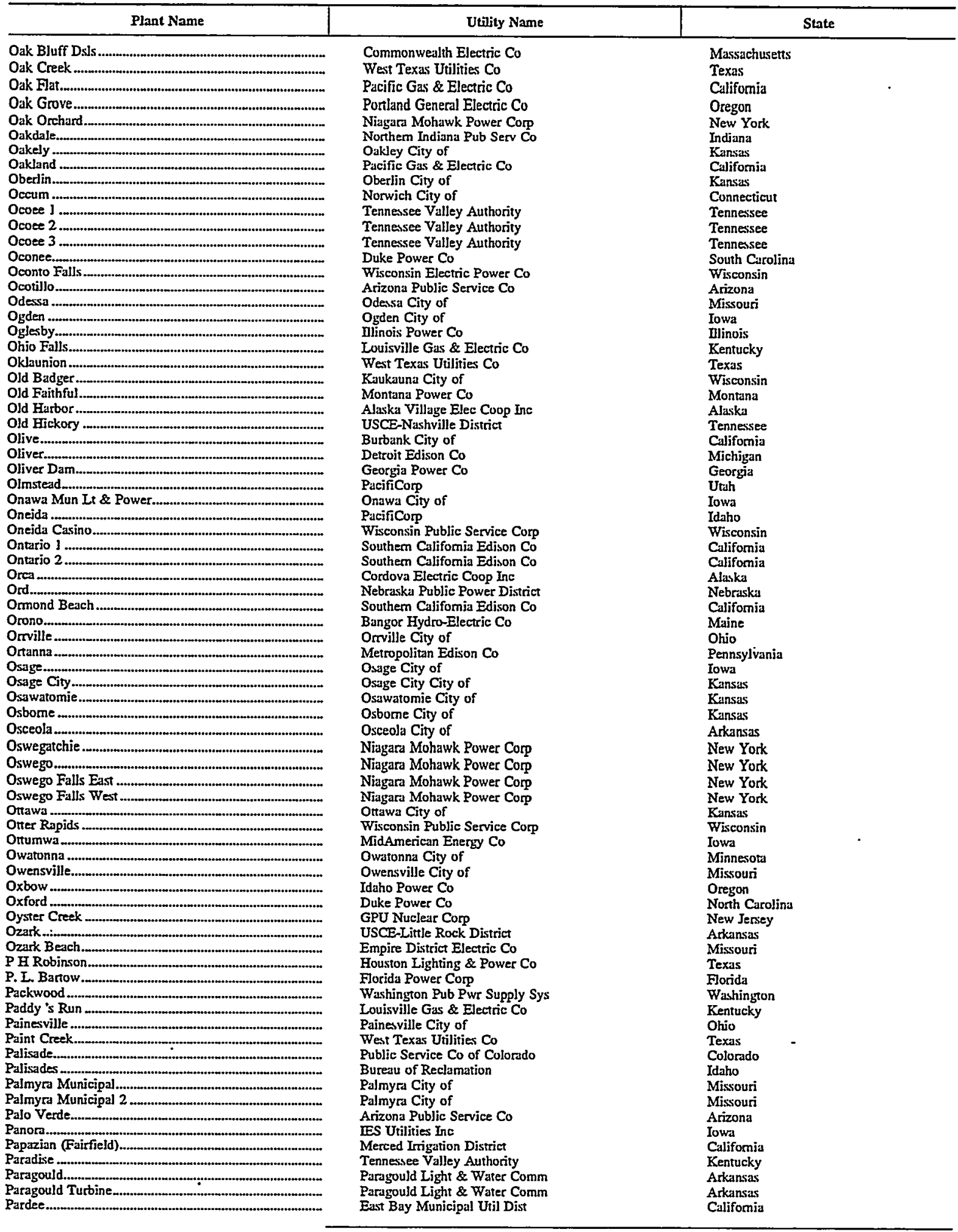

See footnotes at end of table. 
Table D1. U.S. Electric Utility Plants, as of January 1, 1998 (Continued)

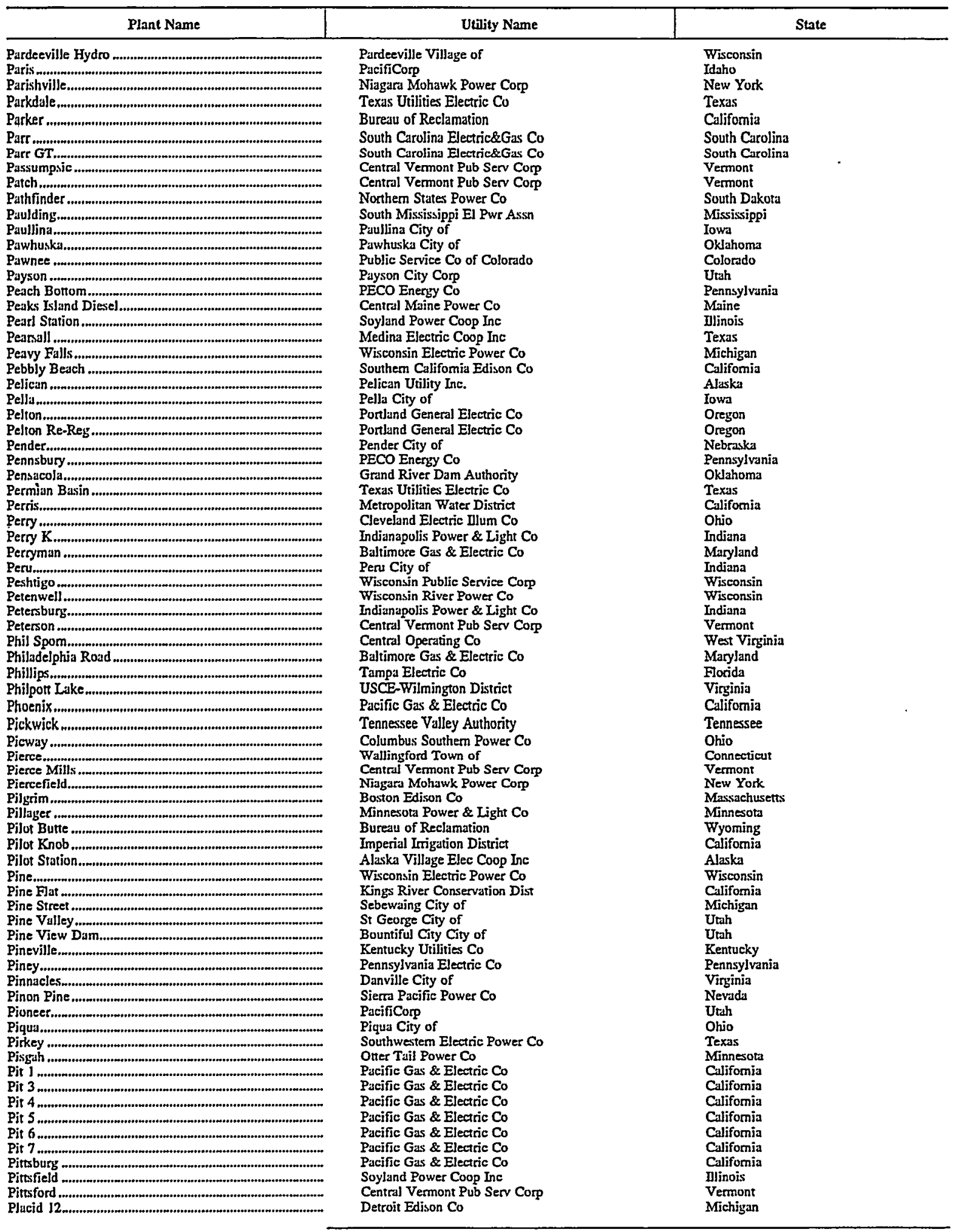

See footnotes at end of table. 
Table D1. U.S. Electric Utility Plants, as of January 1, 1998 (Continued)

\begin{tabular}{|c|c|c|}
\hline Plant Name & Utility Name & State \\
\hline 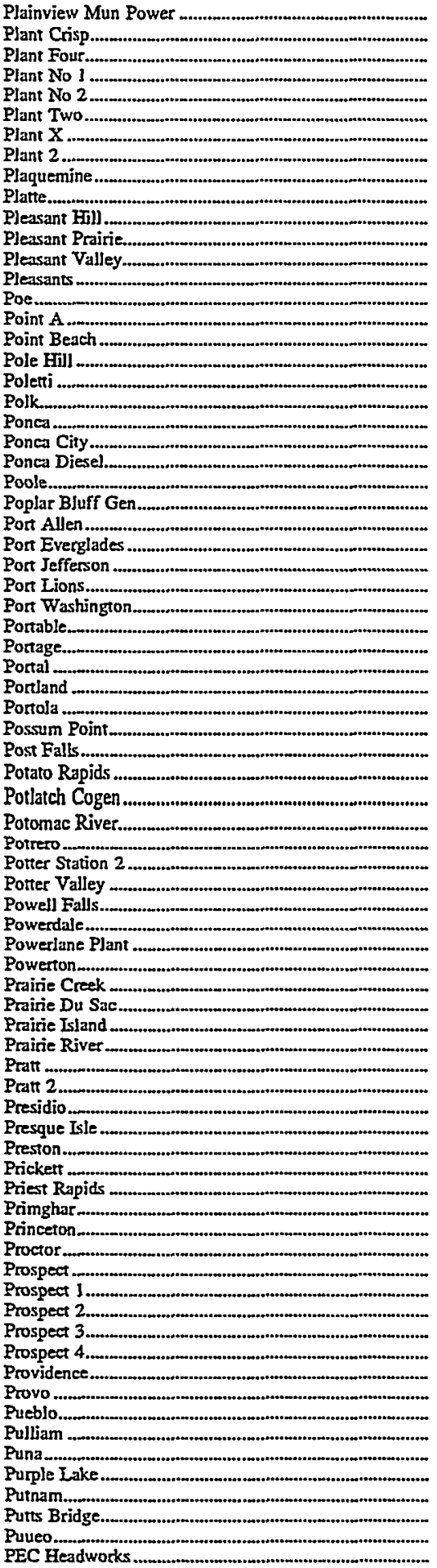 & 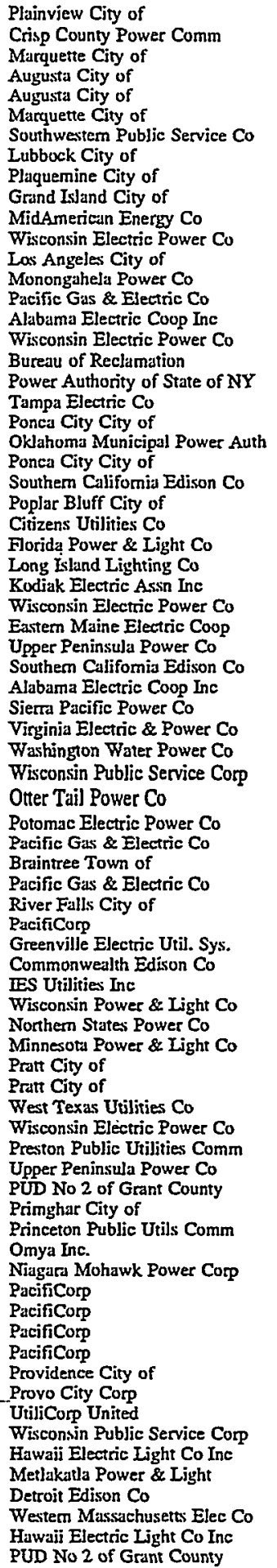 & 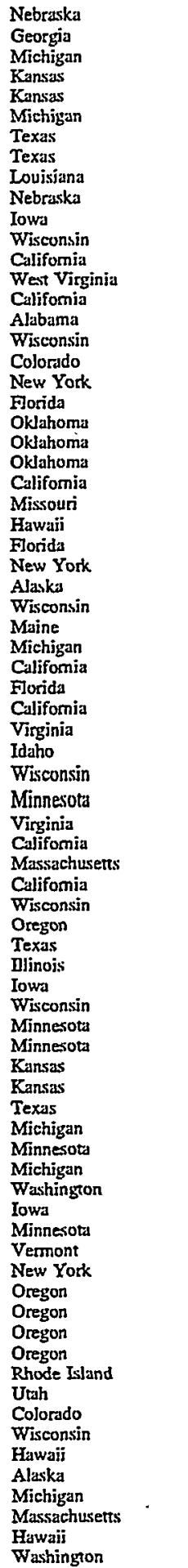 \\
\hline
\end{tabular}

See footnotes at end of table. 
Table D1. U.S. Electric Utility Plants, as of January 1, 1998 (Continued)

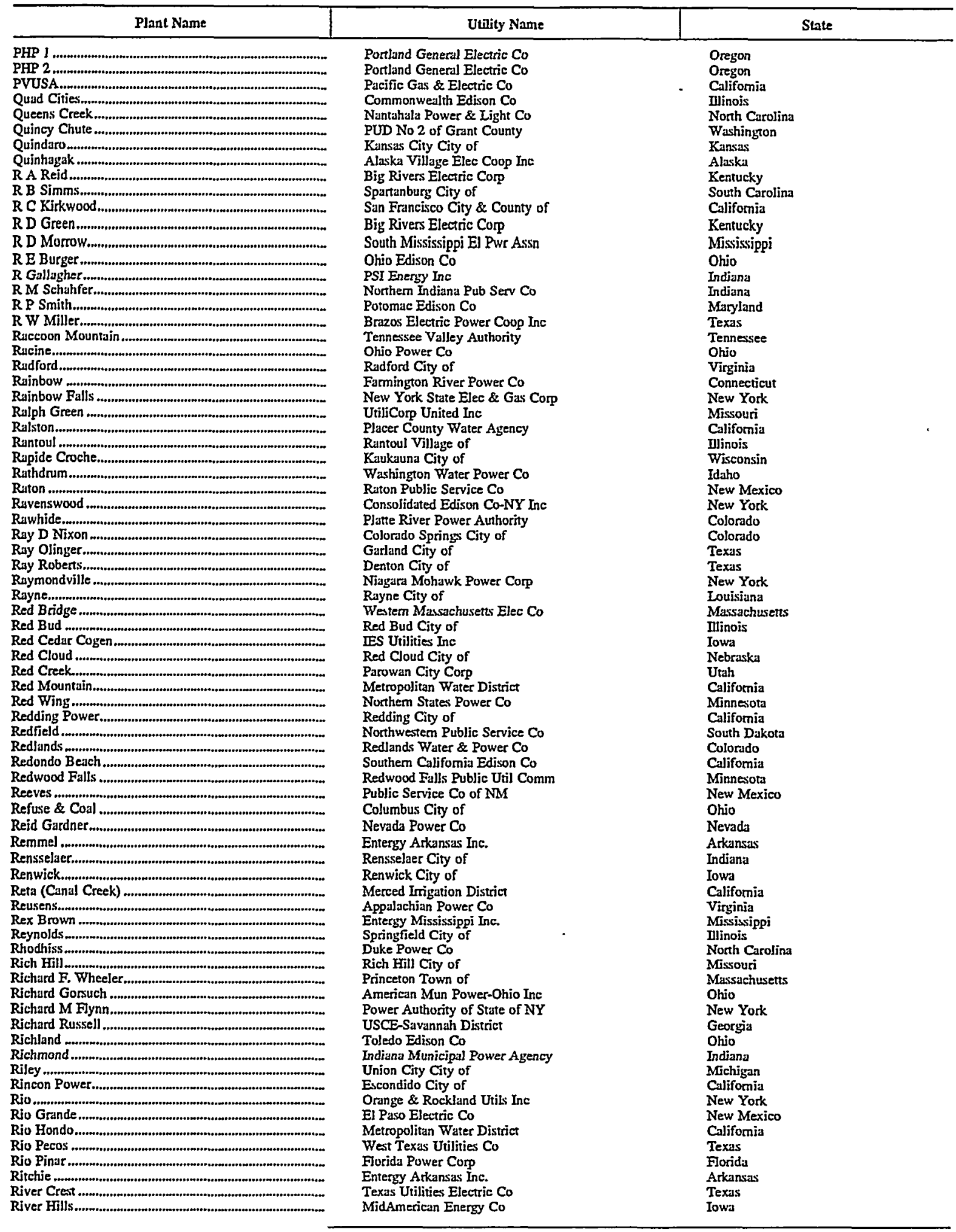

See footnotes at end of table. 
Table D1. U.S. Electric Utility Plants, as of January 1, 1998 (Continued) .

\begin{tabular}{|c|c|c|}
\hline Plant Name & Utility Name & State \\
\hline 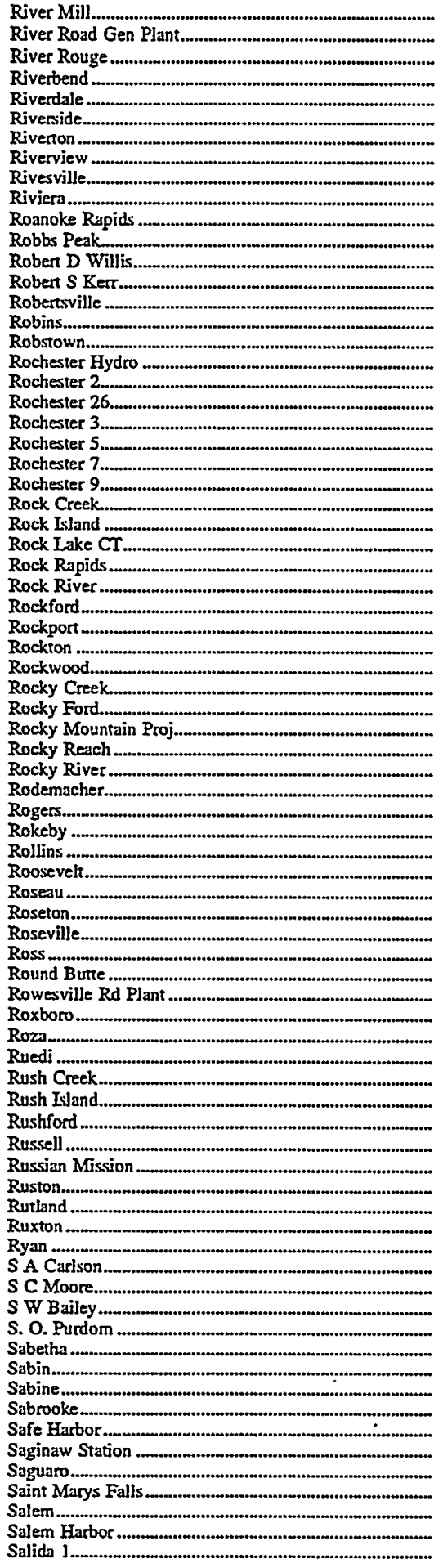 & 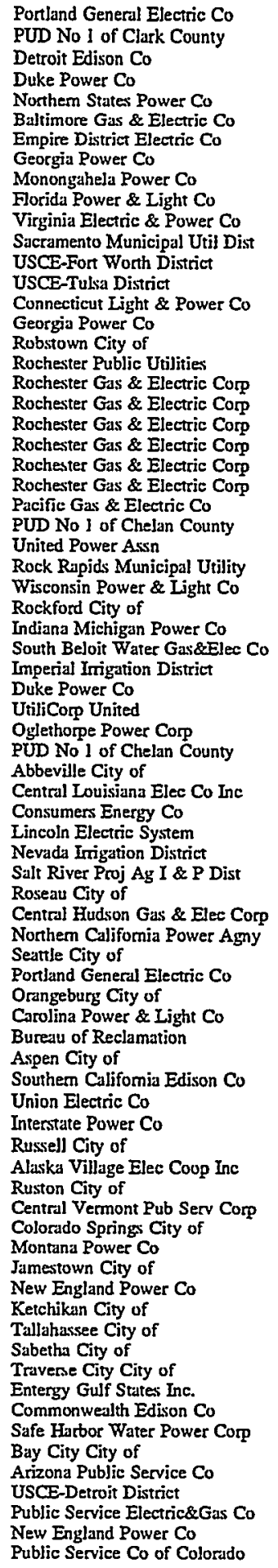 & 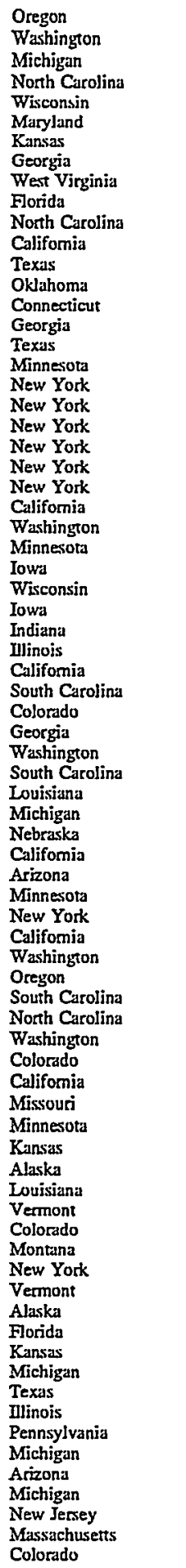 \\
\hline
\end{tabular}

See footnotes at end of table. 
Table D1. U.S. Electric Utility Plants, as of January 1, 1998 (Continued)

\begin{tabular}{|c|c|c|}
\hline Plant Name & Utility Name & State \\
\hline 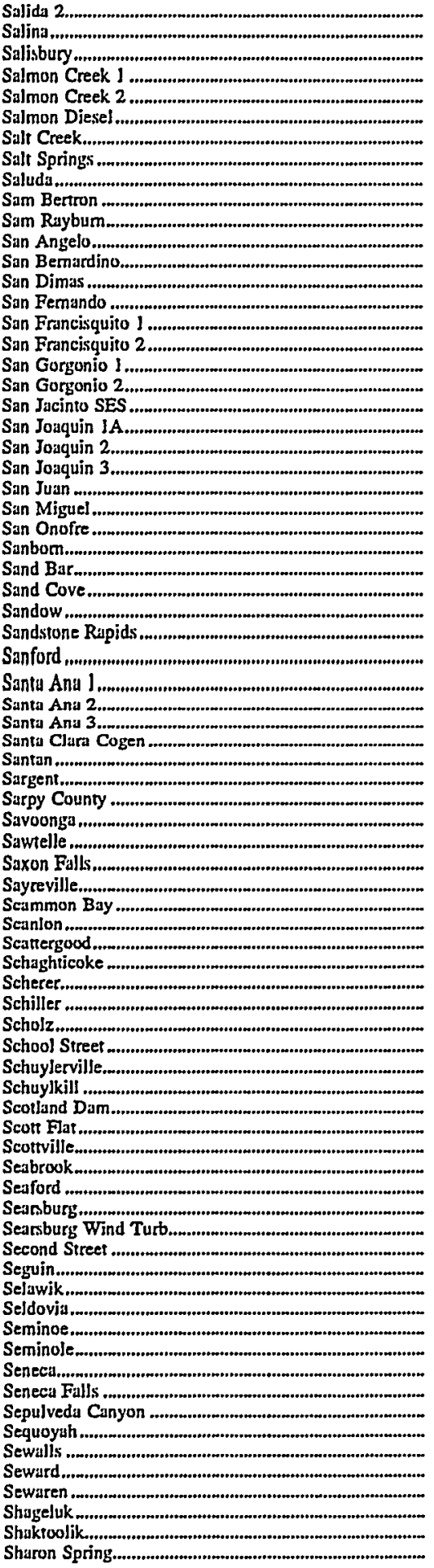 & 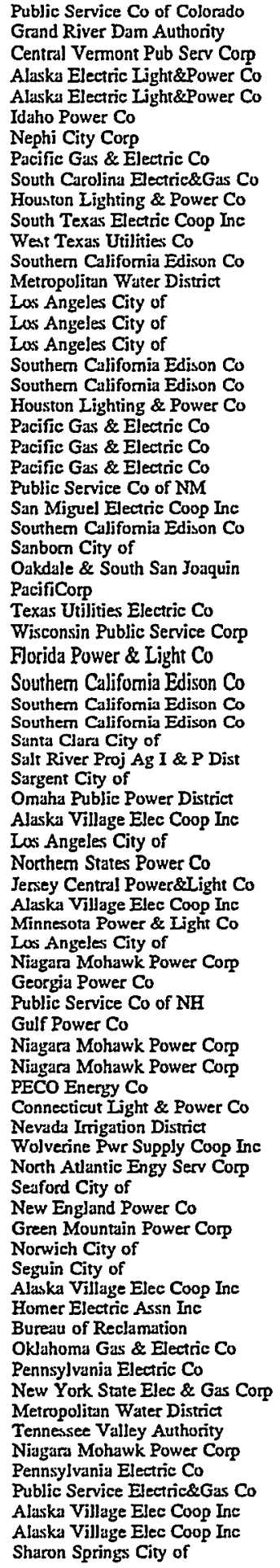 & 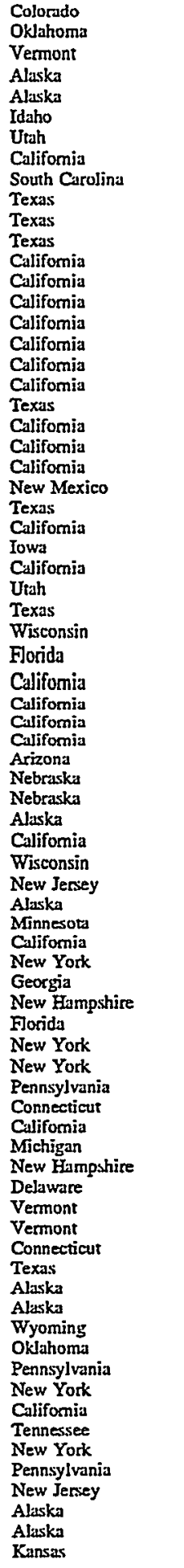 \\
\hline
\end{tabular}

See footnotes at end of table. 
Table D1. U.S. Electric Utility Plants, as of January 1, 1998 (Continued)

\begin{tabular}{|c|c|c|}
\hline Plant Name & Utility Name & State \\
\hline 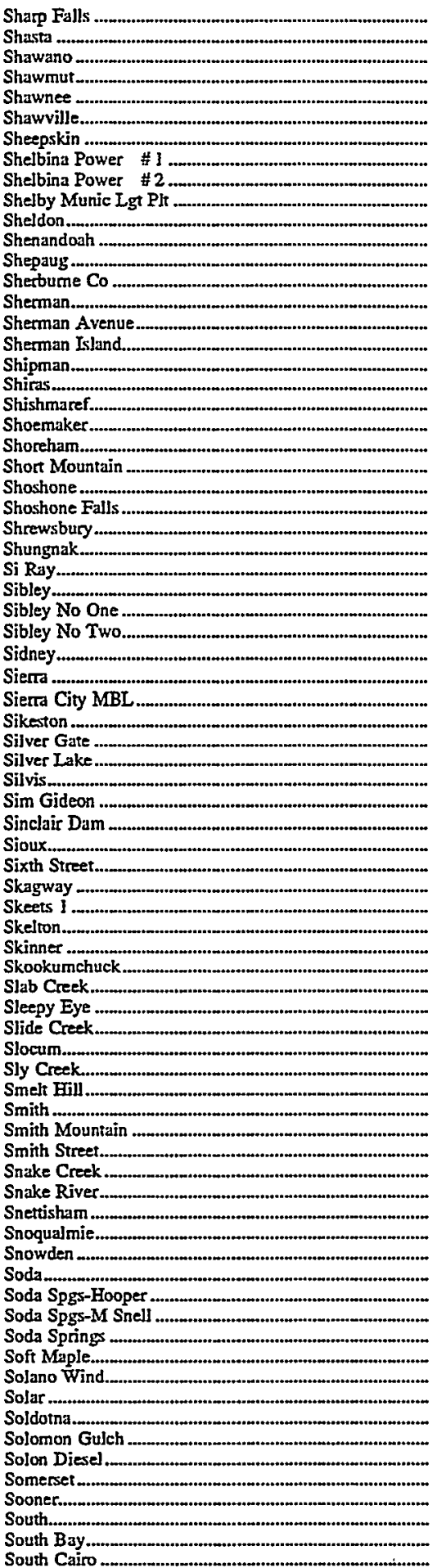 & 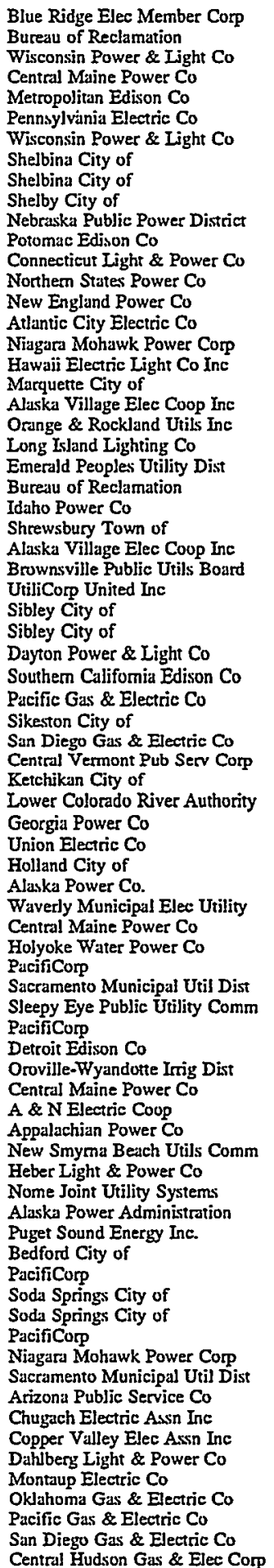 & 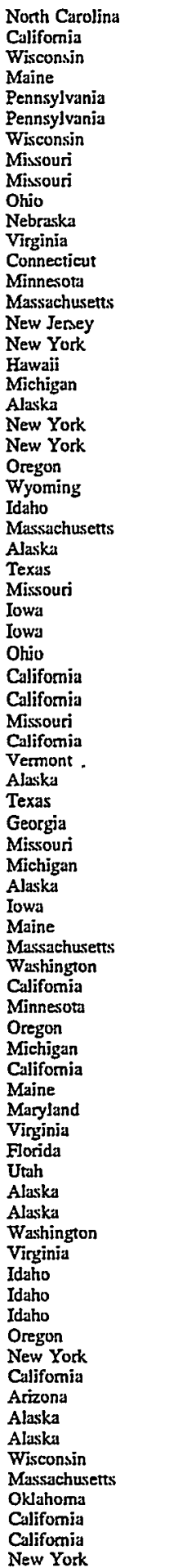 \\
\hline
\end{tabular}

See footnotes at end of table. 
Table D1. U.S. Electric Utility Plants, as of January 1, 1998 (Continued)

\begin{tabular}{|c|c|c|}
\hline Plant Name & Utility Name & State \\
\hline 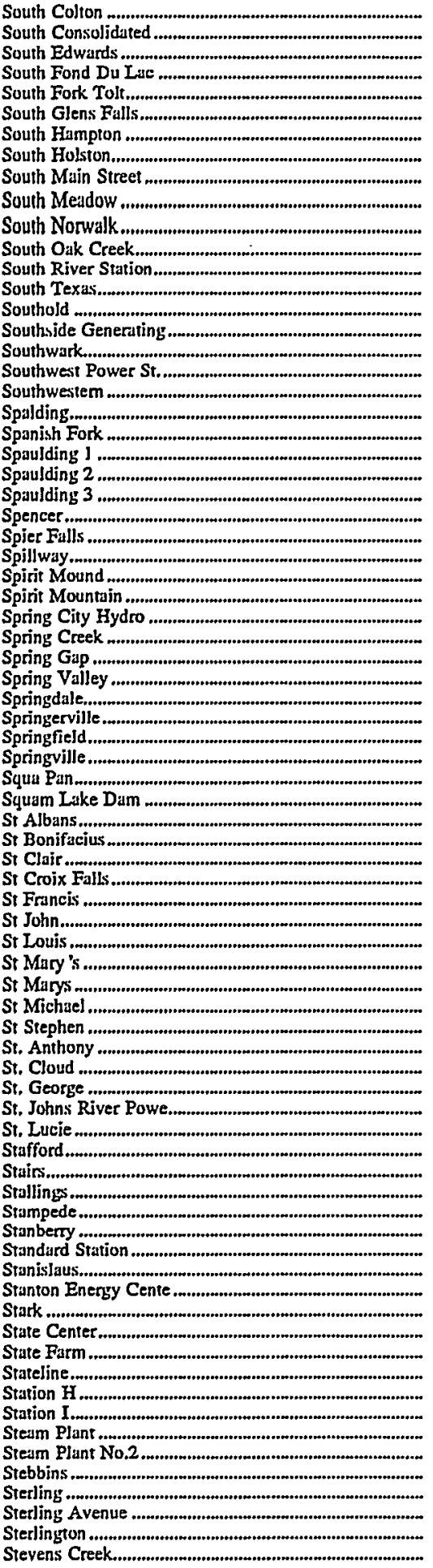 & 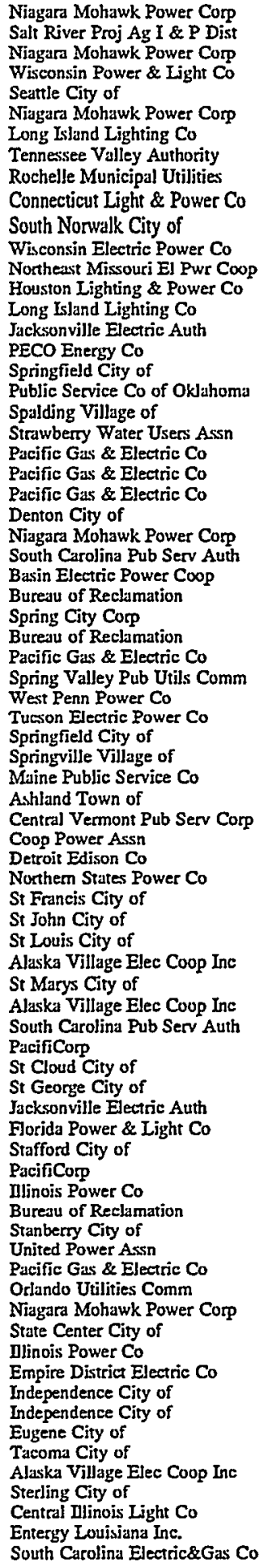 & 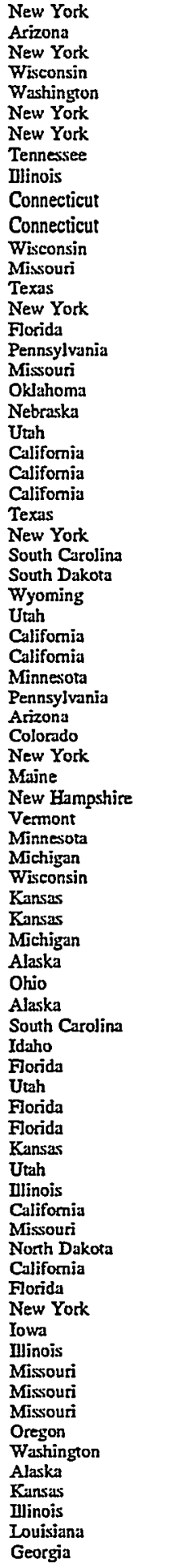 \\
\hline
\end{tabular}

See footnotes at end of tuble. 
Table D1. U.S. Electric Utility Plants, as of January 1, 1998 (Continued)

\begin{tabular}{|c|c|c|}
\hline Plant Name & Utility Name & State \\
\hline 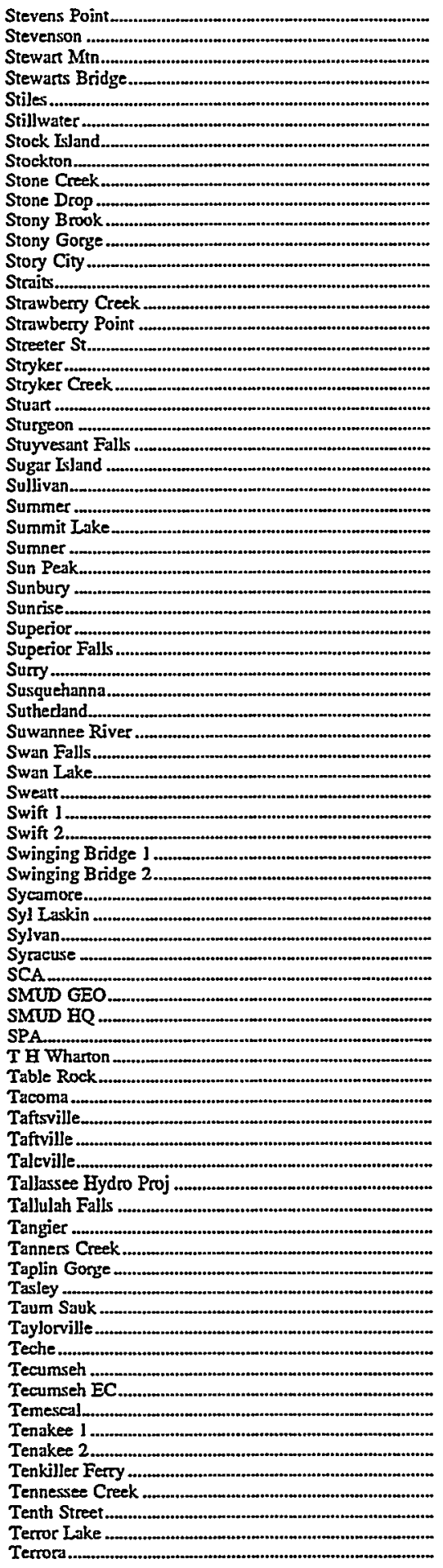 & 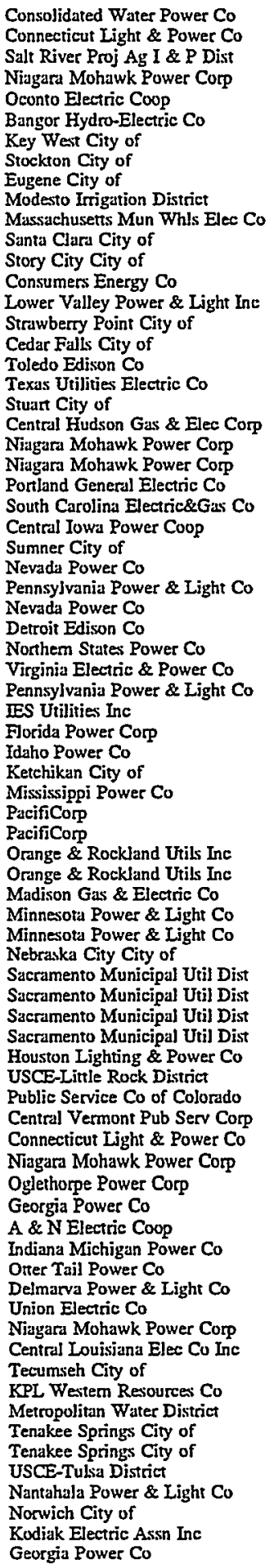 & 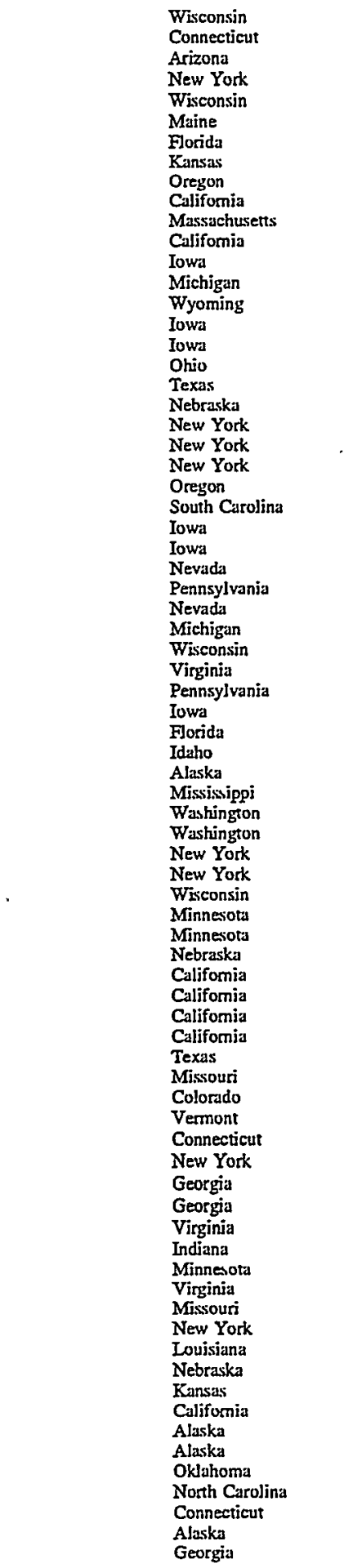 \\
\hline
\end{tabular}

See footnotes at end of table. 
Table D1. U.S. Electric Utility Plants, as of January 1, 1998 (Continued)

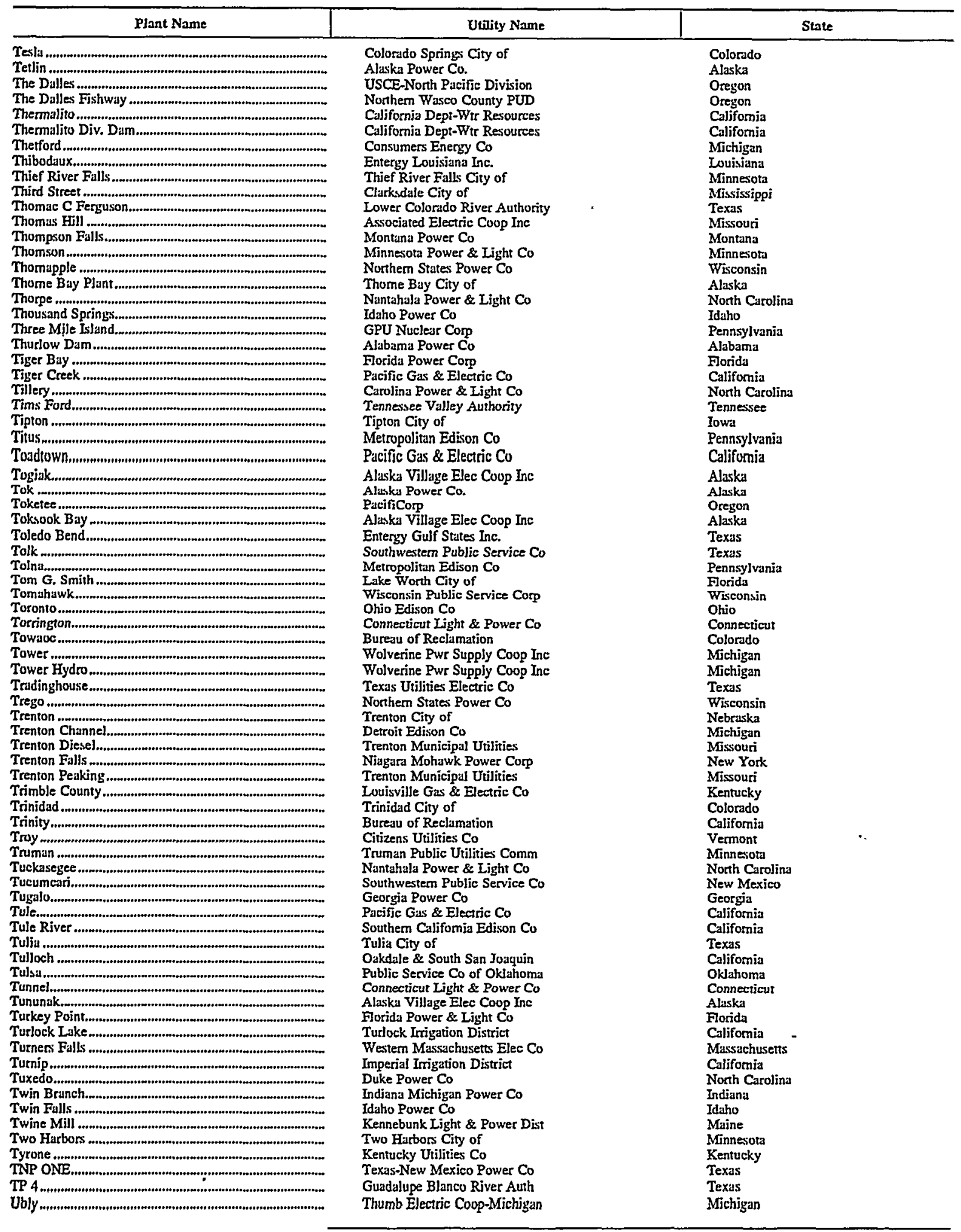

See footnotes at end of table. 
Table D1. U.S. Electric Utility Plants, as of January 1, 1998 (Continued)

\begin{tabular}{|c|c|c|c|}
\hline Plant Name & Utility Name & & \\
\hline 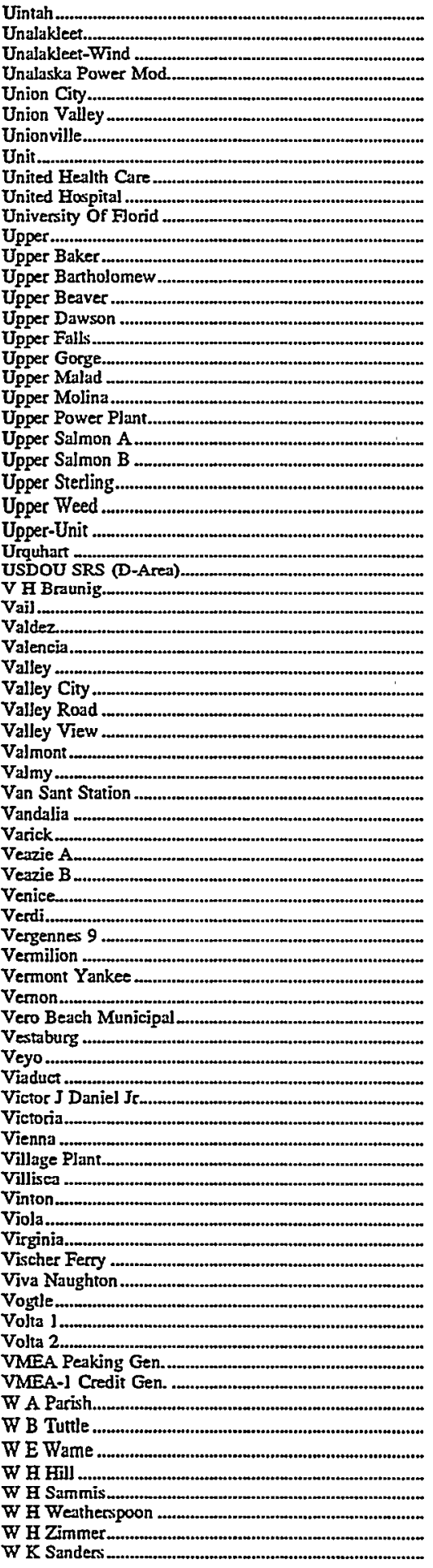 & 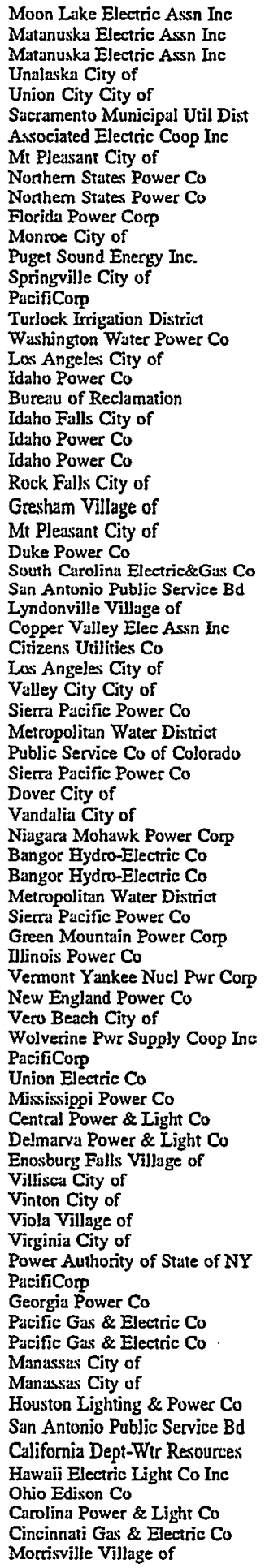 & 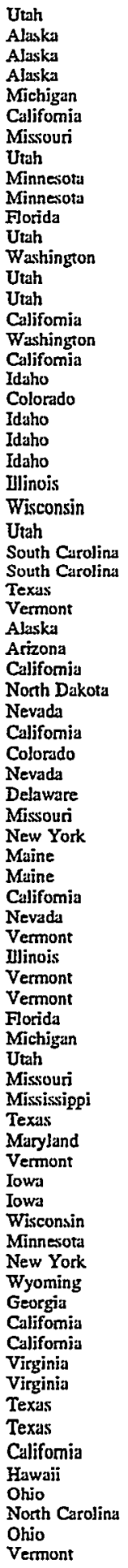 & • \\
\hline
\end{tabular}

See footnotes at end of table. 
Table D1. U.S. Electric Utility Plants, as of January 1, 1998 (Continued)

\begin{tabular}{|c|c|c|}
\hline Plant Name & Utility Name & State \\
\hline 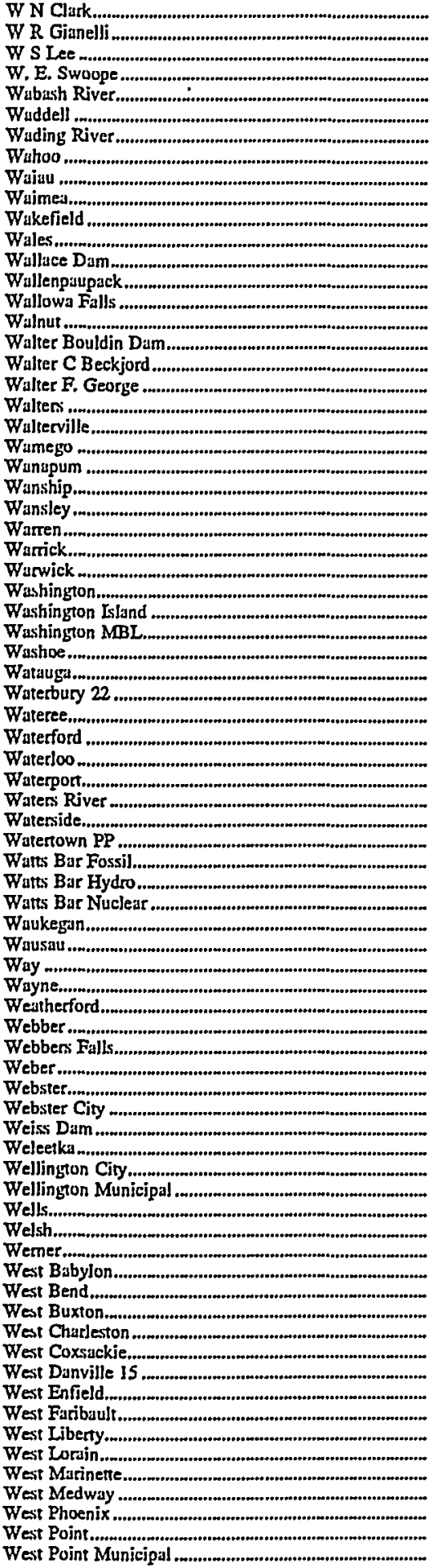 & 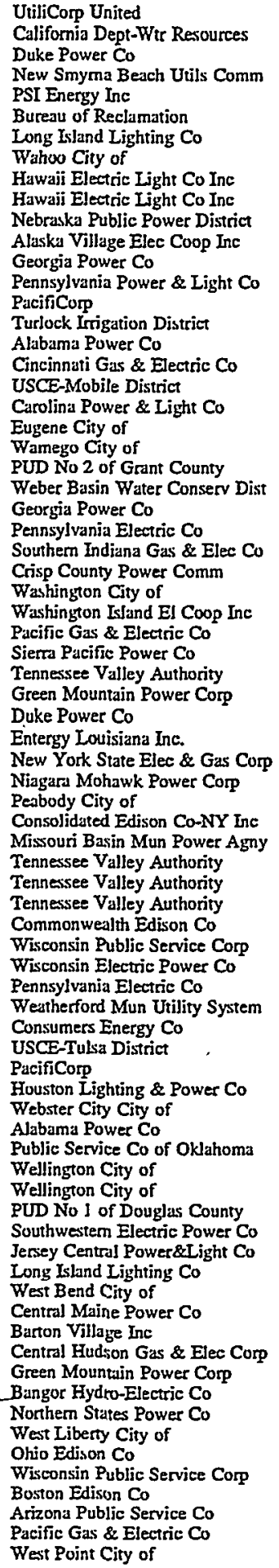 & 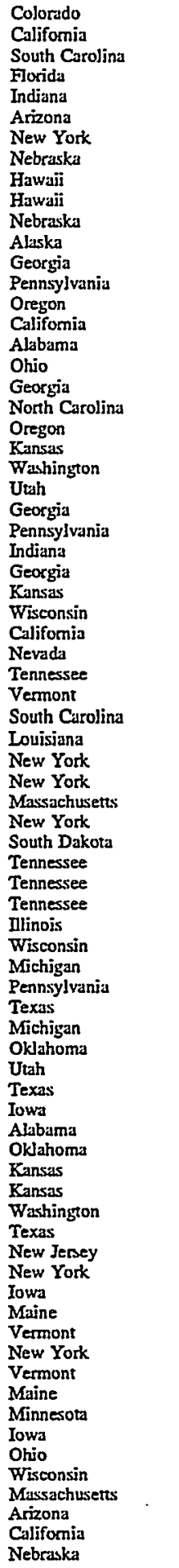 \\
\hline
\end{tabular}

See footnotes at end of table. 
Table D1. U.S. Electric Utility Plants, as of January 1, 1998 (Continued)

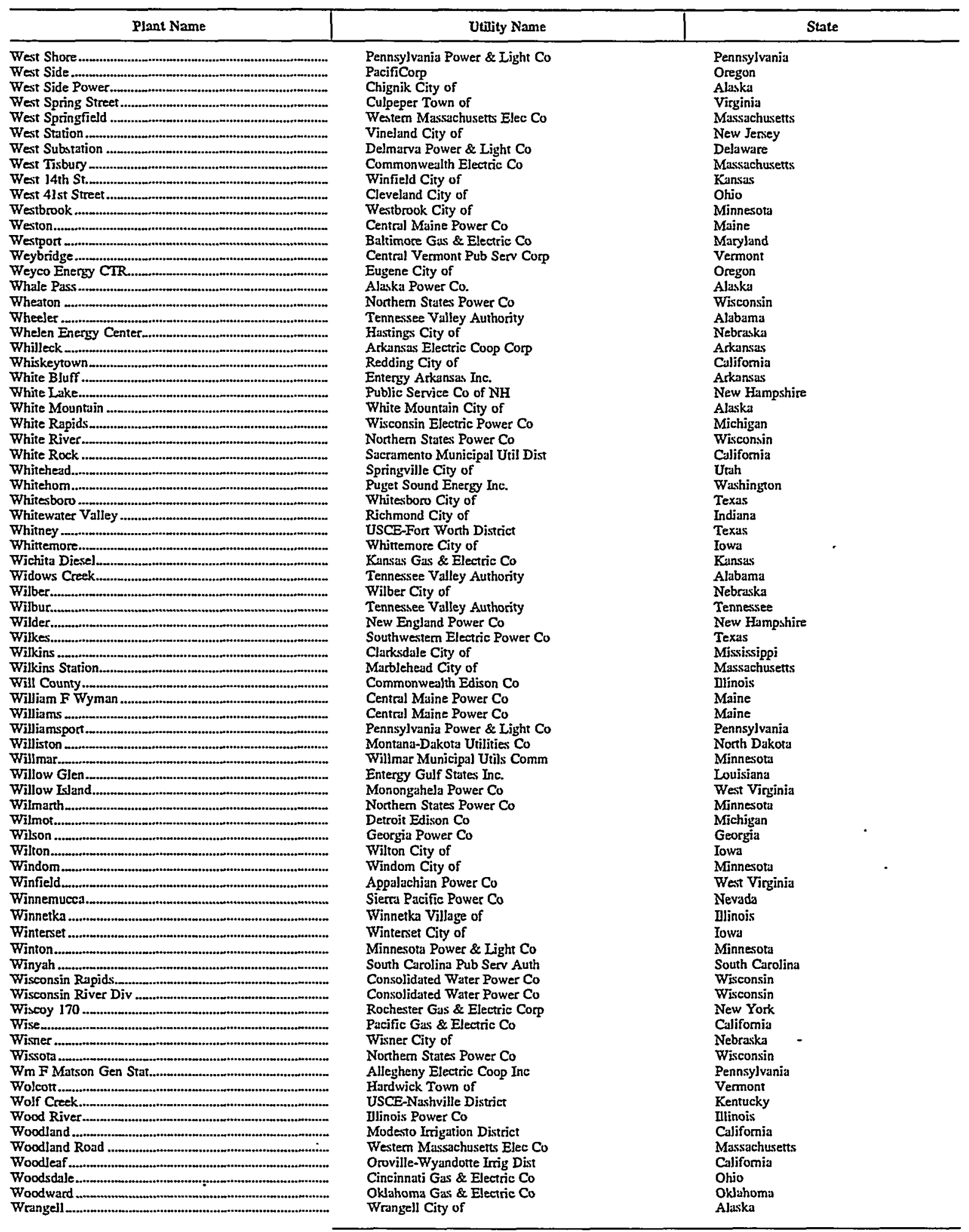

See footnores at end of tuble. 
Table D1. U.S. Electric Utility Plants, as of January 1, 1998 (Continued)

\begin{tabular}{|c|c|c|c|c|}
\hline Phant Name & Utility Name & & State & \\
\hline 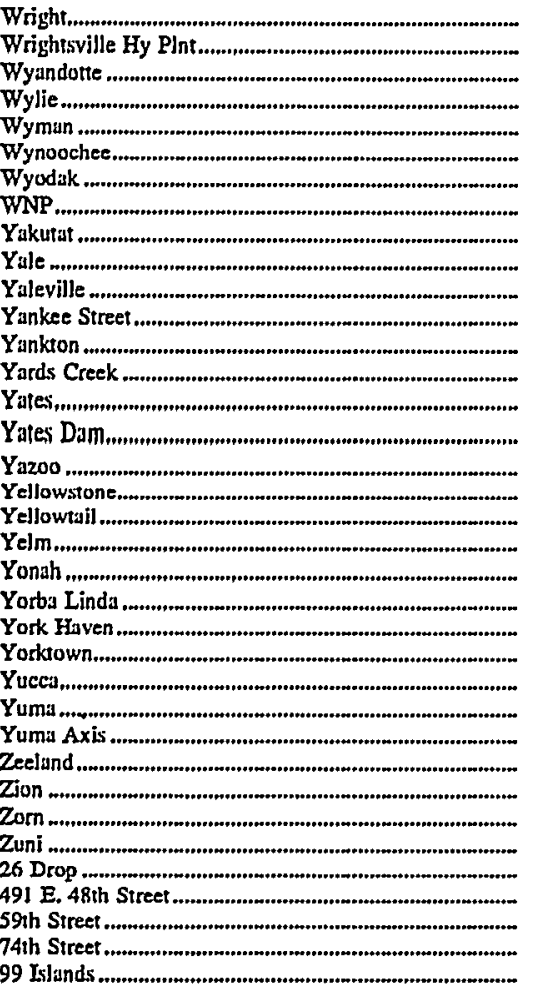 & $\begin{array}{l}\text { Greenwood Utilities Comm } \\
\text { Washington Electric Coop Ine } \\
\text { Wyandotte Municipal Serv Comm } \\
\text { Duke Power Co } \\
\text { Central Maine Power Co } \\
\text { Tacoma City of } \\
\text { PacifiCorp } \\
\text { Washington Pub Pwr Supply Sys } \\
\text { Yakutat Power Inc } \\
\text { PaciriCorp } \\
\text { Niagara Mohawk Power Corp } \\
\text { Dayton Power \& Light Co } \\
\text { Northwestern Public Service Co } \\
\text { Jersey Central Power\&Iight Co } \\
\text { Georgia Power Co } \\
\text { Alabama Power Co } \\
\text { Public Serv Comm of Yazoo City } \\
\text { Moon Iake Electric Assn Ine } \\
\text { Bureau of Reclamation } \\
\text { Centralia City of } \\
\text { Georgia Power Co } \\
\text { Metropolitan Water District } \\
\text { Metropolitan Edison Co } \\
\text { Virginia Electric \& Power Co } \\
\text { Arizona Public Service Co } \\
\text { Yuma City of } \\
\text { Imperial Irrigation District } \\
\text { Zeeland City of } \\
\text { Commonwealth Edison Co } \\
\text { Louisville Gas \& Electric Co } \\
\text { Public Service Co of Colorado } \\
\text { Sierta Pacific Power Co } \\
\text { Holjand City of } \\
\text { Consolidated Edison Co-NY Inc } \\
\text { Consolidated Edison Co-NY Inc } \\
\text { Duke Power Co }\end{array}$ & . & $\begin{array}{l}\text { Mississippi } \\
\text { Vermont } \\
\text { Michigan } \\
\text { South Carolina } \\
\text { Maine } \\
\text { Washington } \\
\text { Wyoming } \\
\text { Washington } \\
\text { Alaska } \\
\text { Washington } \\
\text { New York } \\
\text { Ohio } \\
\text { South Dakota } \\
\text { New Jersey } \\
\text { Georgia } \\
\text { Alabama } \\
\text { Mississippi } \\
\text { Utah } \\
\text { Montana } \\
\text { Washington } \\
\text { Georgia } \\
\text { California } \\
\text { Pennsylvania } \\
\text { Virginia } \\
\text { Arizona } \\
\text { Colorado } \\
\text { Arizuna } \\
\text { Michigan } \\
\text { yllinois } \\
\text { Kentucky } \\
\text { Colorado } \\
\text { Nevada } \\
\text { Michigan } \\
\text { New York } \\
\text { New York } \\
\text { South Carolina }\end{array}$ & " \\
\hline
\end{tabular}

Source: •Energy Information Administration, Form EIA-860, “Annual Electric Generator Repon.” 
Table D2. U.S. Electric Utility Plants by State, as of January 1, 1998

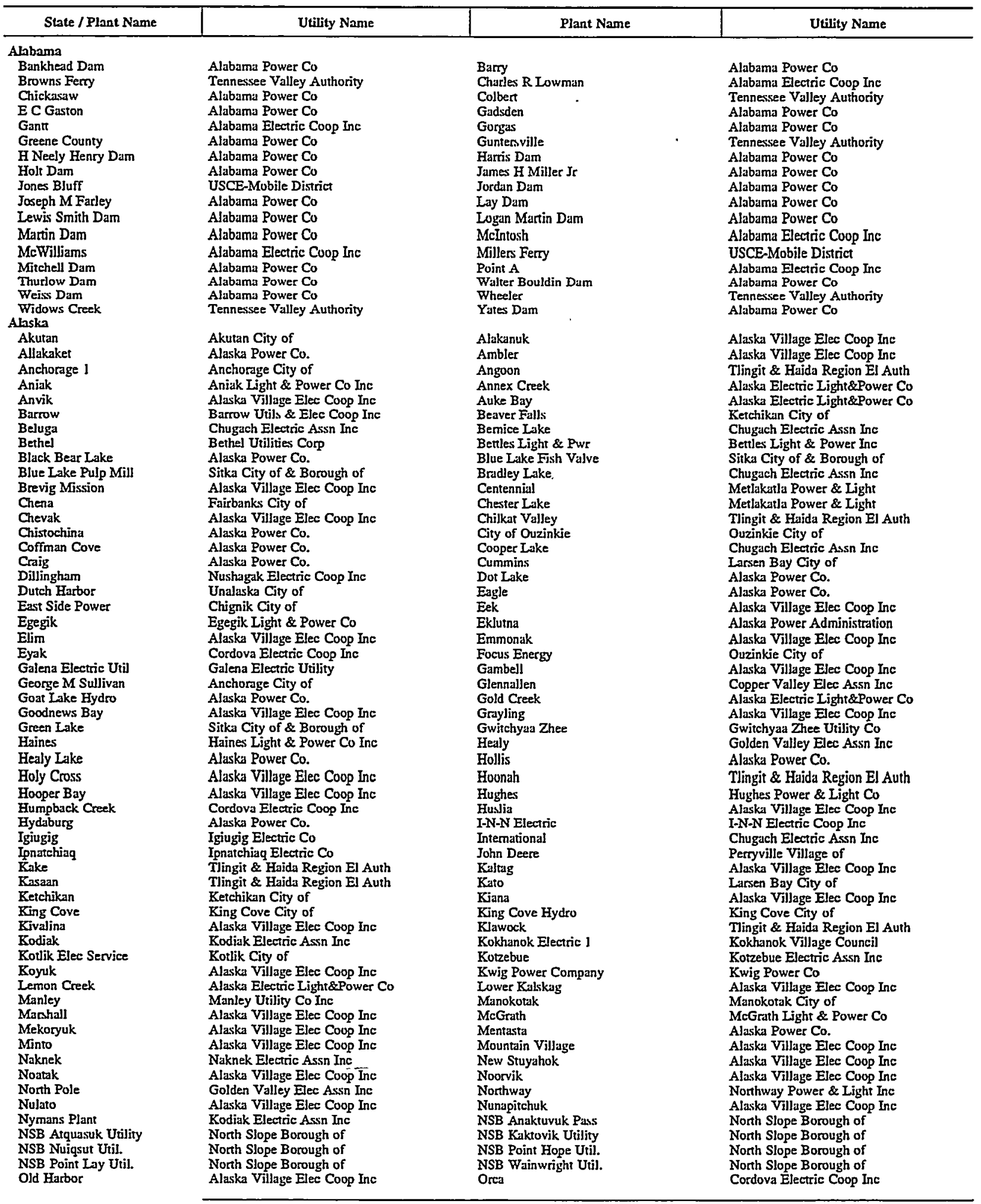

See footnotes at end of table. 
Table D2. U.S. Electric Utility Plants by State, as of January 1, 1998 (Continued)

\begin{tabular}{|c|c|c|c|}
\hline State / Plant Name & Utility Name & Plant Name & Utility Name \\
\hline $\begin{array}{l}\text { Pelican } \\
\text { Port Lions } \\
\text { Quinhagak } \\
\text { S W Bailey } \\
\text { Salmon Creek } 2 \\
\text { Scammon Bay } \\
\text { Seldovia } \\
\text { Shaktoolik } \\
\text { Shungnak } \\
\text { Skagway } \\
\text { Snettisham } \\
\text { Solomon Gulch } \\
\text { St Michsel } \\
\text { Swan Lake } \\
\text { Tenakee } 2 \\
\text { Tetlin } \\
\text { Togiak } \\
\text { Toksook Bay } \\
\text { Unalakeet } \\
\text { Unalaska Power Mod. } \\
\text { Wales } \\
\text { Whale Pass } \\
\text { Wrangell } \\
\text { Arizona }\end{array}$ & $\begin{array}{l}\text { Pelican Utility Inc. } \\
\text { Kodiak Electric Assn Inc } \\
\text { Alaska Village Elec Coop Inc } \\
\text { Ketchikan City of } \\
\text { Alaska Electric Light\&Power Co } \\
\text { Alaska Village Elec Coop Inc } \\
\text { Homer Electric Assn Inc } \\
\text { Alaska Village Elec Coop Inc } \\
\text { Alaska Village Elec Coop Inc } \\
\text { Alaska Power Co. } \\
\text { Alaska Power Administration } \\
\text { Copper Valley Elec Assn Inc } \\
\text { Alaska Village Elec Coop Inc } \\
\text { Ketchikan City of } \\
\text { Tenakee Springs City of } \\
\text { Alaska Power Co. } \\
\text { Alaska Village Elec Coop Inc } \\
\text { Alaska Village Elec Coop Inc } \\
\text { Matanuska Electric Assn Inc } \\
\text { Unalaska City of } \\
\text { Alaska Village Elec Coop Inc } \\
\text { Alaska Power Co. } \\
\text { Wrangell City of }\end{array}$ & $\begin{array}{l}\text { Pilot Station } \\
\text { Purple Iake } \\
\text { Russian Mission } \\
\text { Salmon Creek ] } \\
\text { Savoonga } \\
\text { Selawik } \\
\text { Shageluk } \\
\text { Shishmaref } \\
\text { Silvis } \\
\text { Snake River } \\
\text { Soldotna } \\
\text { St Mary's } \\
\text { Stebbins } \\
\text { Tenakee ] } \\
\text { Terror Lake } \\
\text { Thome Bay Plant } \\
\text { Tok } \\
\text { Tununak } \\
\text { Unalakleet-Wind } \\
\text { Valdez } \\
\text { West Side Power } \\
\text { White Mountain } \\
\text { Yakutat }\end{array}$ & $\begin{array}{l}\text { Alaska Village Elec Coop Inc } \\
\text { Metlakutla Power \& Light } \\
\text { Alaska Village Elec Coop Ine } \\
\text { Alaska Electric Light\&\&ower Co } \\
\text { Alaska Village Elec Coop Inc } \\
\text { Alaska Village Elec Coop Inc } \\
\text { Alaska Village Elec Coop Inc } \\
\text { Alaska Village Elec Coop Inc } \\
\text { Ketchikan City of } \\
\text { Nome Joint Utility Systems } \\
\text { Chugach Electric Assn Ine } \\
\text { Alaska Village Elec Coop Inc } \\
\text { Alaska Village Elec Coop Inc } \\
\text { Tenakee Springs City of } \\
\text { Kodiak Electric Assn Inc } \\
\text { Thome Bay City of } \\
\text { Alaska Power Co. } \\
\text { Alaska Viltage Elec Coop Inc } \\
\text { Matanuska Electric Assn Inc } \\
\text { Copper Valley Elec Assn Inc } \\
\text { Chignik City of } \\
\text { White Mountain City of } \\
\text { Yakutat Power Inc }\end{array}$ \\
\hline $\begin{array}{l}\text { Agua Fria } \\
\text { Childs } \\
\text { Coolidge Dam } \\
\text { Crosscut } \\
\text { Demoss Petrie } \\
\text { Glen Canyon } \\
\text { Horse Mesa } \\
\text { Irvington } \\
\text { Mormon Flat } \\
\text { North Loop } \\
\text { Palo Verde } \\
\text { Saguaro } \\
\text { Solur } \\
\text { Springerville } \\
\text { Valencia } \\
\text { West Phoenix } \\
\text { Yuma Axis }\end{array}$ & $\begin{array}{l}\text { Salt River Proj Ag I \& P Dist } \\
\text { Arizona Public Service Co } \\
\text { USBIA-San Carlos Project } \\
\text { Salt River Proj Ag I \& P Dist } \\
\text { Tucson Electric Power Co } \\
\text { Bureau of Reclamation } \\
\text { Salt River Proj Ag I \& P Dist } \\
\text { Tucson Electric Power Co } \\
\text { Salt River Proj Ag I \& P Dist } \\
\text { Tucson Electric Power Co } \\
\text { Arizona Public Service Co } \\
\text { Arizona Public Service Co } \\
\text { Arizona Public Service Co } \\
\text { Tucson Electric Power Co } \\
\text { Citizens Utilities Co } \\
\text { Arizona Public Service Co } \\
\text { Imperial Irrigation District }\end{array}$ & $\begin{array}{l}\text { Apache Station } \\
\text { Cholla } \\
\text { Coronado } \\
\text { Davis } \\
\text { Douglas } \\
\text { Headgate Rock } \\
\text { Irving } \\
\text { Kyrene } \\
\text { Navajo } \\
\text { Ocotillo } \\
\text { Roosevelt } \\
\text { Santan } \\
\text { South Consolidated } \\
\text { Stewart Min } \\
\text { Waddell } \\
\text { Yucea }\end{array}$ & $\begin{array}{l}\text { Arizona Electric Pwr Coop Inc } \\
\text { Arizona Public Service Co } \\
\text { Salt River Proj Ag I \& P Dist } \\
\text { Bureau of Reclamation } \\
\text { Arizona Public Service Co } \\
\text { Bureau of Reclamation } \\
\text { Arizona Public Service Co } \\
\text { Salt River Proj Ag I \& P Dist } \\
\text { Salt River Proj Ag I \& P Dist } \\
\text { Arizona Public Service Co } \\
\text { Salt River Proj Ag I \& P Dist } \\
\text { Salt River Proj Ag I \& P Dist } \\
\text { Salt River Proj Ag I \& P Dist } \\
\text { Salt River Proj Ag I \& P Dist } \\
\text { Bureau of Reclamation } \\
\text { Arizona Public Service Co }\end{array}$ \\
\hline Arkansas & & & \\
\hline $\begin{array}{l}\text { Arkansas Nuclear One } \\
\text { Blakely Mountain } \\
\text { Bull Shoals } \\
\text { Couch } \\
\text { Degray } \\
\text { Fajibanks } \\
\text { Flint Creck } \\
\text { Independence } \\
\text { Lynch } \\
\text { Mcclellan } \\
\text { Municipal Light } \\
\text { Norfork } \\
\text { Ozark } \\
\text { Paragould Turbine } \\
\text { Ritchje } \\
\text { White Bluff } \\
\text { California }\end{array}$ & $\begin{array}{l}\text { Entergy Arkansas Inc. } \\
\text { The Utility-Trade Corp } \\
\text { USCE-Little Rock District } \\
\text { Entergy Arkansas Inc. } \\
\text { The Utility-Trade Corp } \\
\text { Augrusta City of } \\
\text { Southwestem Electric Power Co } \\
\text { Entergy Arkansas Inc. } \\
\text { Entergy Arkansas Inc. } \\
\text { Arkansas Electric Coop Corp } \\
\text { Pjggott City of } \\
\text { USCE-Little Rock District } \\
\text { USCE-Little Rock District } \\
\text { Paragould Light \& Water Comm } \\
\text { Entergy Arkansas Inc. } \\
\text { Entergy Arkansas Inc. }\end{array}$ & $\begin{array}{l}\text { Bailey } \\
\text { Blytheville } \\
\text { Carpenter } \\
\text { Dardanelle } \\
\text { Ellis } \\
\text { Fitzhugh } \\
\text { Greers Ferry Lake } \\
\text { Lake Catherine } \\
\text { Mabelvale } \\
\text { Moses } \\
\text { Murray } \\
\text { Osceola } \\
\text { Paragould } \\
\text { Remmel } \\
\text { Whilleck }\end{array}$ & $\begin{array}{l}\text { Arkansas Electric Coop Corp } \\
\text { Entergy Arkansas Inc. } \\
\text { Entergy Arkansas Ine. } \\
\text { USCE-Linte Rock Distritt } \\
\text { Atkansas Electric Coop Corp } \\
\text { Arkansas Electric Coop Corp } \\
\text { USCE-Little Rock District } \\
\text { Entergy Arkansas Ine. } \\
\text { Entergy Arkansas Inc. } \\
\text { Entergy Arkansas Inc. } \\
\text { North Litule Rock City of } \\
\text { Osceola City of } \\
\text { Paragould Iight \& Water Comm } \\
\text { Entergy Arkansas Inc. } \\
\text { Arkansas Electric Coop Corp }\end{array}$ \\
\hline $\begin{array}{l}\text { A.G. Wiston } \\
\text { Alamitos } \\
\text { Almond Power Plant } \\
\text { Angels } \\
\text { Bulch 1 } \\
\text { Bear Valley } \\
\text { Belden } \\
\text { Big Creek } 2 \\
\text { Big Creek 3 } \\
\text { Bigg Creek } 8 \\
\text { Bishop Creek } 3 \\
\text { Bishop Creek } 5 \\
\text { Black Butre } \\
\text { Bottlerock } \\
\text { Broudway } \\
\text { Butt Valley } \\
\text { Camino }\end{array}$ & $\begin{array}{l}\text { Pacific Gas \& Electric Co } \\
\text { Southem Califomia Edison Co } \\
\text { TurJock Irigation District } \\
\text { Calaveras County Water Distric } \\
\text { Pacific Gas \& Electric Co } \\
\text { Escondido City of } \\
\text { Pacific Gas \& Electric Co } \\
\text { Southem Califomia Edison Co } \\
\text { Southem Califomia Edison Co } \\
\text { Southem Califomia Edison Co } \\
\text { Southem Califomia Edison Co } \\
\text { Southem Califomia Edison Co } \\
\text { Santa Clara City of } \\
\text { Califomia Dept-Wtr Resources } \\
\text { Pasadena City of } \\
\text { Pacific Gas \& Electric Co } \\
\text { Sacramento Municipal Util Dist }\end{array}$ & $\begin{array}{l}\text { Alameda } \\
\text { Alamo } \\
\text { Anaheim GT } \\
\text { Azusa } \\
\text { Balch } 2 \\
\text { Beardsley } \\
\text { Big Creek 1 } \\
\text { Big Creek 2A } \\
\text { Big Creek 4 } \\
\text { Bishop Creek } 2 \\
\text { Bishop Creek } 4 \\
\text { Bishop Creek } 6 \\
\text { Borel } \\
\text { Brawley } \\
\text { Bucks Creek } \\
\text { Camanche } \\
\text { Camp Far West }\end{array}$ & $\begin{array}{l}\text { Northem Califomia Power Agny } \\
\text { Califomia Dept-Wtr Resourees } \\
\text { Anaheim City of } \\
\text { Pasadena City of } \\
\text { Pacific Gas \& Electrie Co } \\
\text { Oakdale \& South San Joaquin } \\
\text { Southern Califomia Edison Co } \\
\text { Southem Califomia Edison Co } \\
\text { Southem Califomia Edison Co } \\
\text { Southem California Edison Co } \\
\text { Southem Califomia Edison Co } \\
\text { Southem Califomia Edison Co } \\
\text { Southem Califomia Edison Co } \\
\text { Imperial Irrigation District } \\
\text { Pacific Gas \& Electric Co } \\
\text { Eust Bay Municipal Util Dint } \\
\text { Sacramento Municipal Util Dist }\end{array}$ \\
\hline
\end{tabular}

Sec footnotes at end of table. 
Table D2. U.S. Electric Utility Plants by State, as of January 1, 1998 (Continued)

\begin{tabular}{|c|c|c|c|}
\hline State / Plant Name & Utility Name & Plant Name & Utility Name \\
\hline 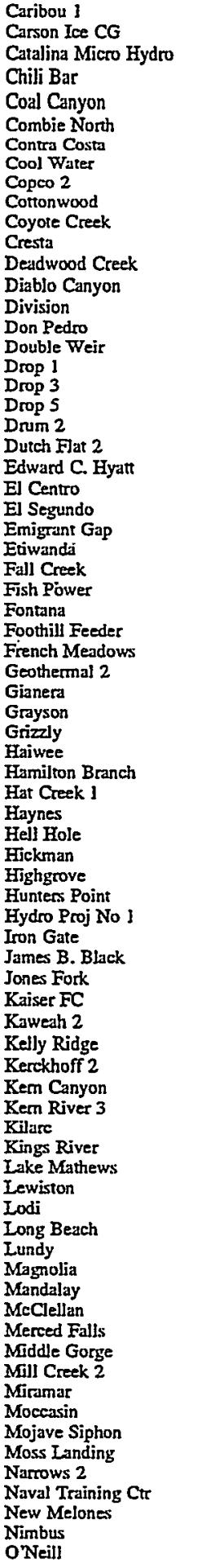 & 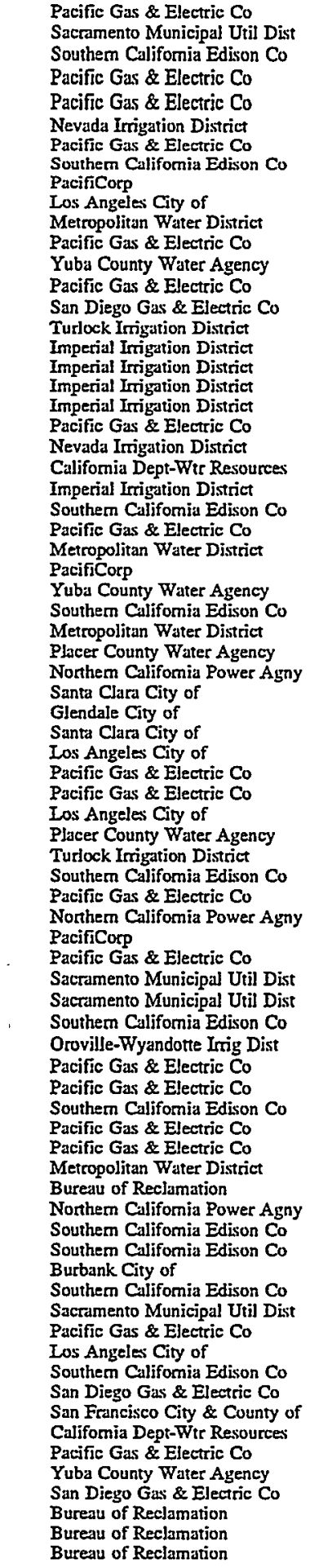 & 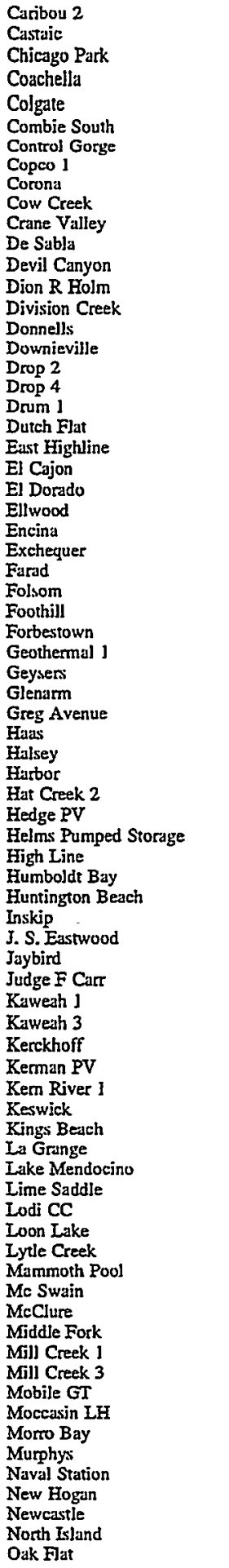 & 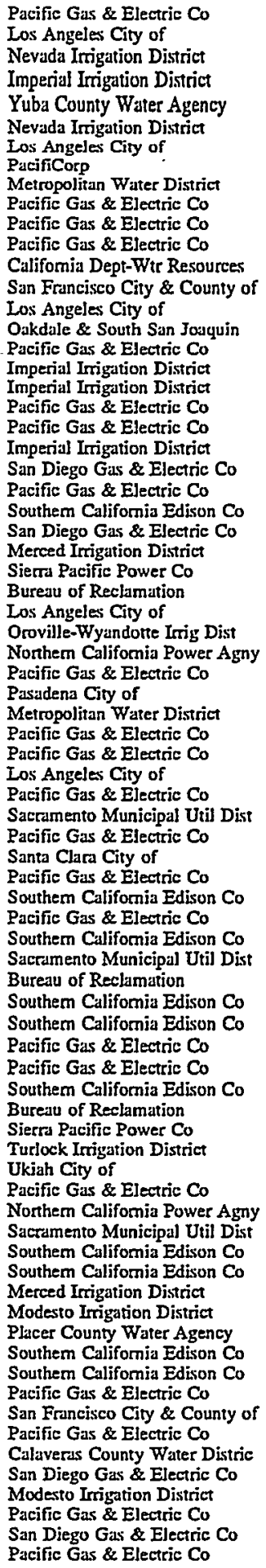 \\
\hline
\end{tabular}

See footnotes at end of table. 
Table D2. U.S. Electric Utility Plants by State, as of January 1, 1998 (Continued)

\begin{tabular}{|c|c|c|c|}
\hline State / Plant Name & Utility Name & Plant Name & Utility Name \\
\hline 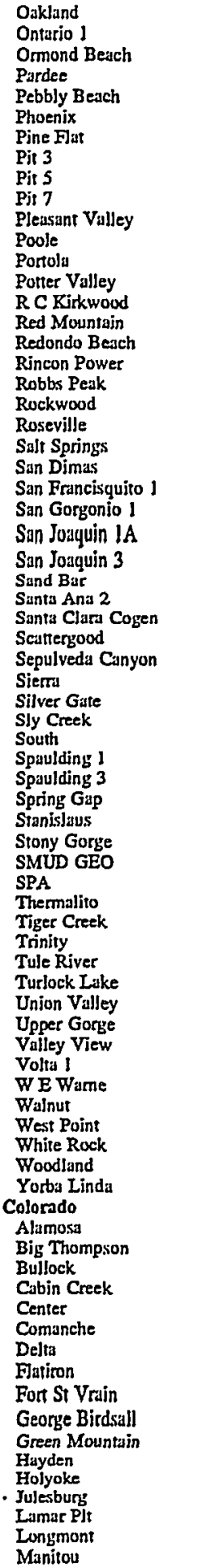 & 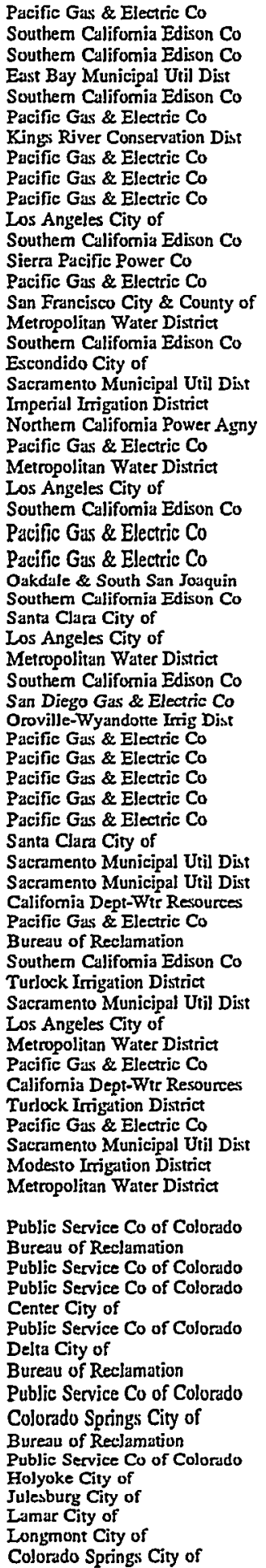 & 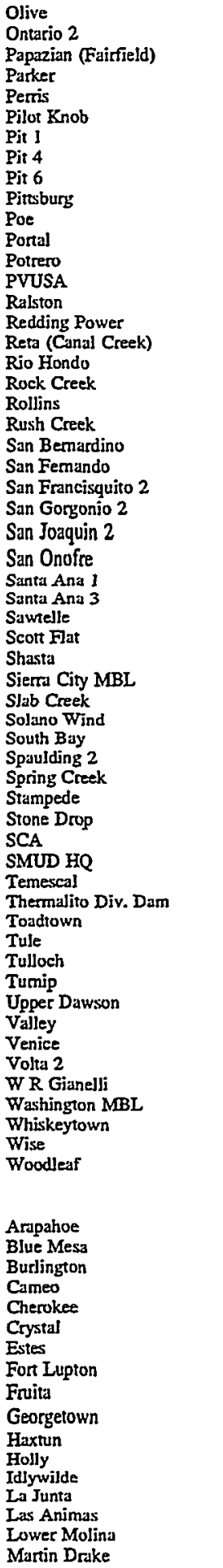 & 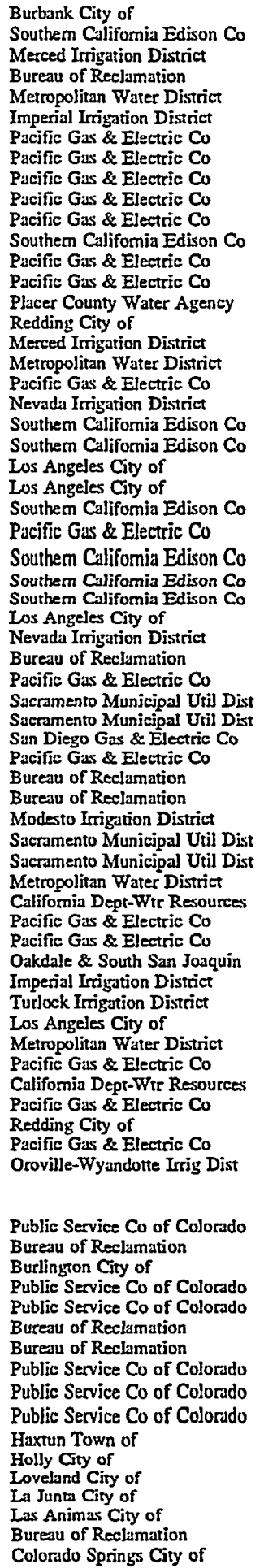 \\
\hline
\end{tabular}

See footnotes at end of table. 
Table D2. U.S. Electric Utility Plants by State, as of January 1, 1998 (Continued)

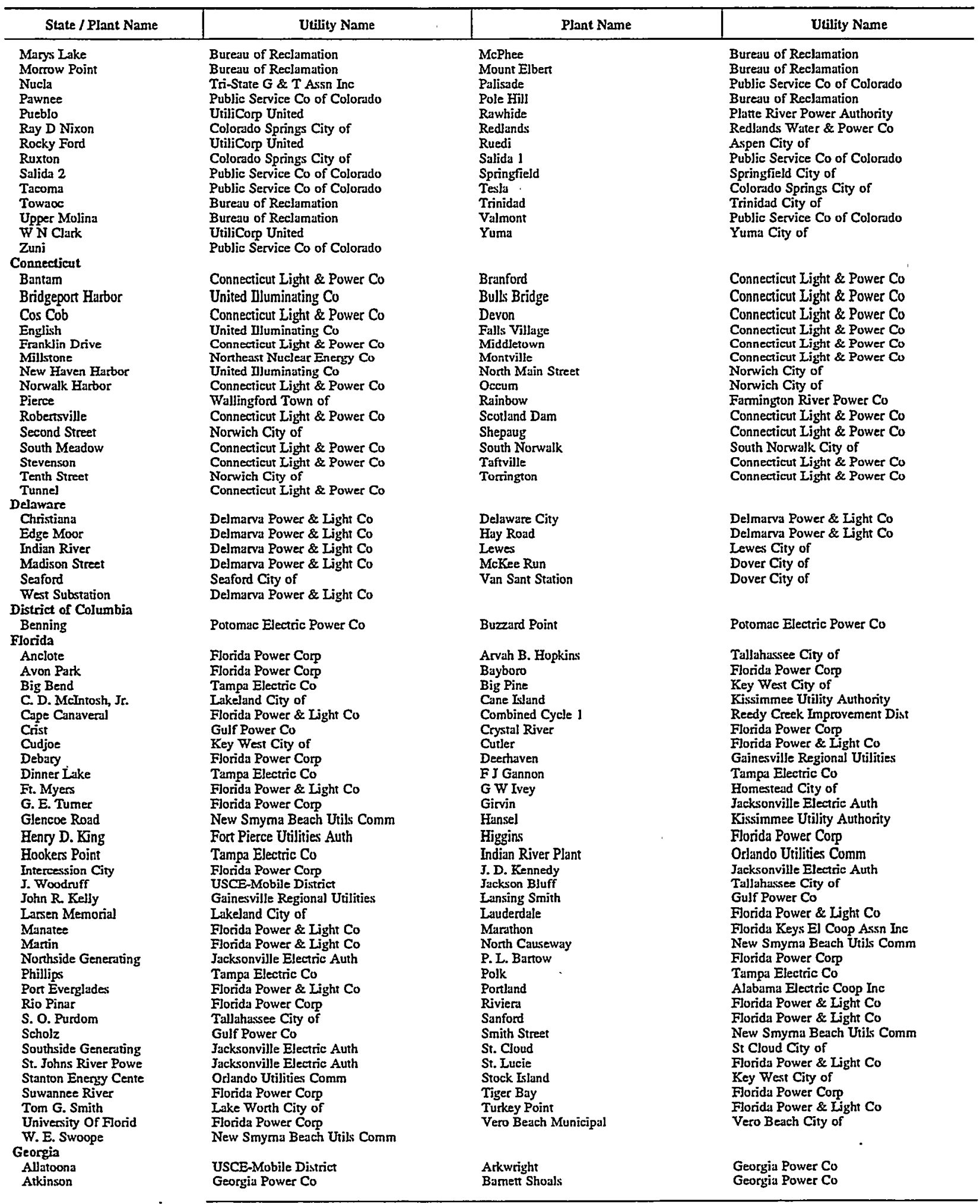

See footnotes at end of table. 
Table D2. U.S. Electric Utility Plants by State, as of January 1, 1998 (Continued)

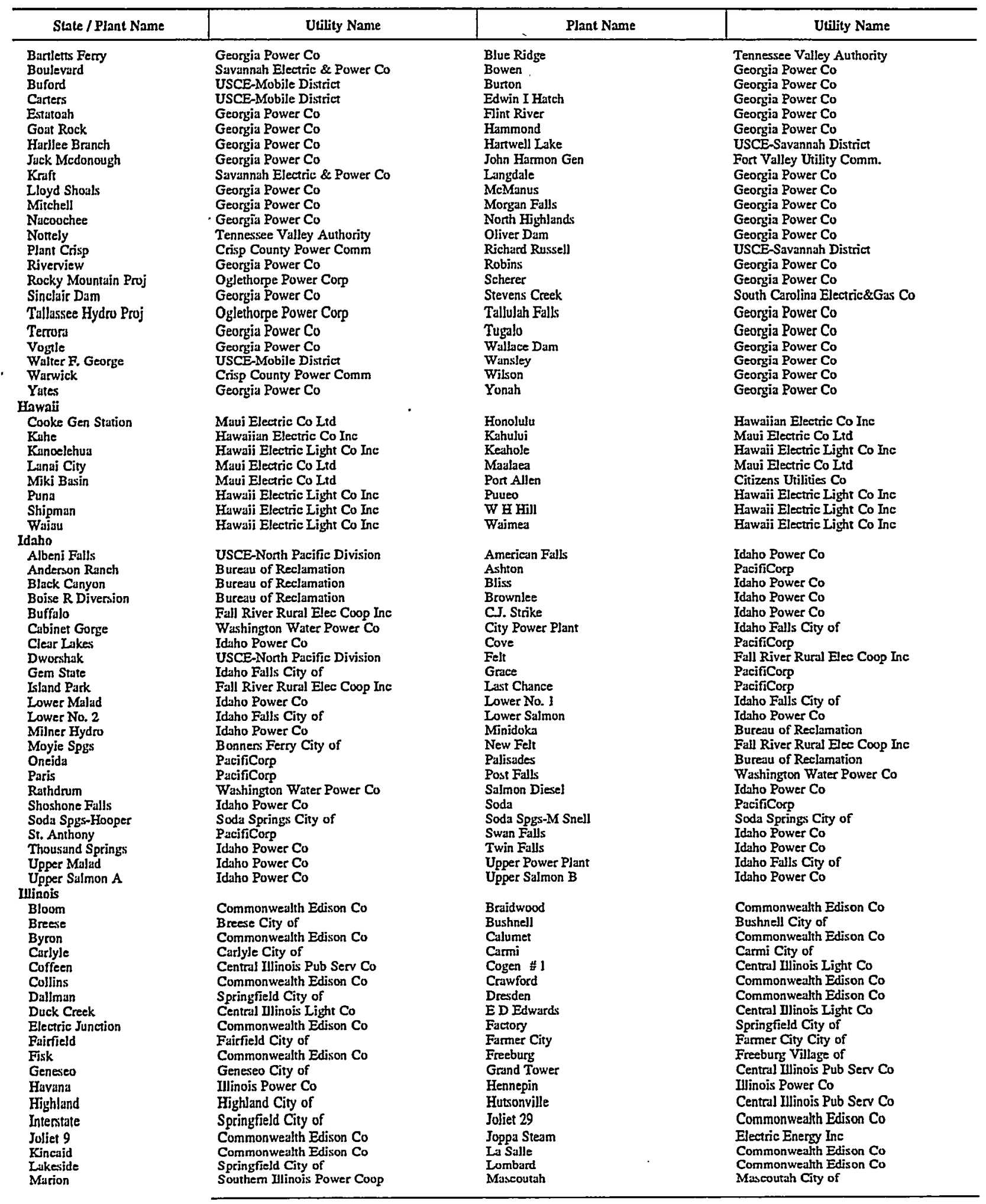

See footnotes at end of table. 
Table D2. U.S. Electric Utility Plants by State, as of January 1, 1998 (Continued)

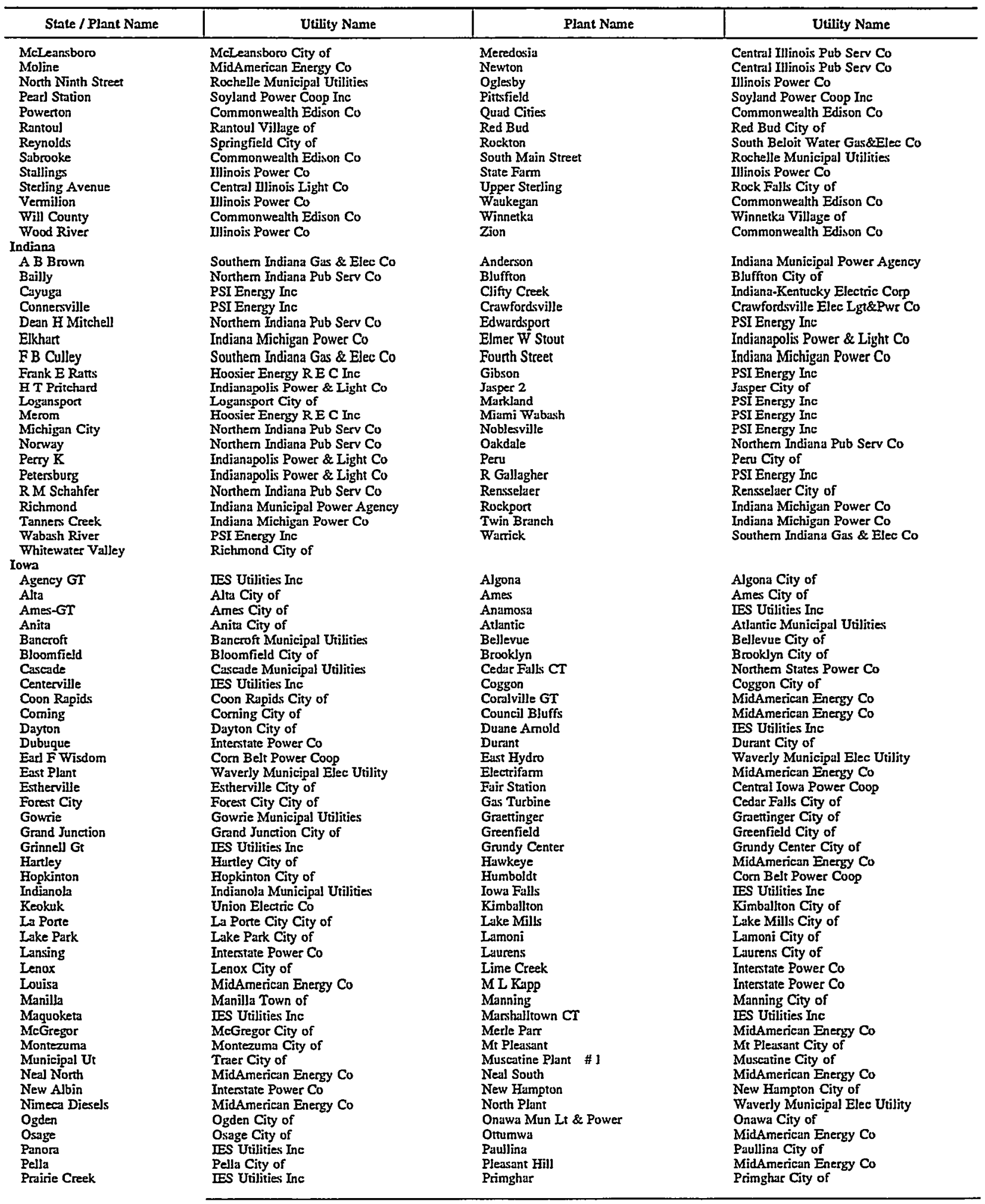

See footnotes at end of table. 
Table D2. U.S. Electric Utility Plants by State, as of January 1, 1998 (Continued)

\begin{tabular}{|c|c|c|c|}
\hline State / Plant Name & Utility Name & Plant Name & Utility Name \\
\hline $\begin{array}{l}\text { Red Cedar Cogen } \\
\text { River Hills } \\
\text { Rockford } \\
\text { Sibley No One } \\
\text { Skeets J } \\
\text { Story City } \\
\text { Streeter St } \\
\text { Sumner } \\
\text { Tipton } \\
\text { Vinton } \\
\text { West Bend } \\
\text { Whittemore } \\
\text { Winterset }\end{array}$ & $\begin{array}{l}\text { IES Utilities Inc } \\
\text { MidAmerican Energy Co } \\
\text { Rockford City of } \\
\text { Sibley City of } \\
\text { Waverly Municipal Elec Urility } \\
\text { Story City City of } \\
\text { Cedar Falls City of } \\
\text { Sumner City of } \\
\text { Tipton City of } \\
\text { Vinton City of } \\
\text { West Bend City of } \\
\text { Whittemore City of } \\
\text { Wintenset City of }\end{array}$ & $\begin{array}{l}\text { Renwick } \\
\text { Rock Rapids } \\
\text { Sanbom } \\
\text { Sibley No Two } \\
\text { State Center } \\
\text { Strawberry Point } \\
\text { Summit Lake } \\
\text { Sutherland } \\
\text { Villisea } \\
\text { Webster City } \\
\text { West Liberty } \\
\text { Wilton }\end{array}$ & $\begin{array}{l}\text { Renwick City of } \\
\text { Rock Rapids Municipal Utility } \\
\text { Sanbom City of } \\
\text { Sibley City of } \\
\text { State Center City of } \\
\text { Strawberry Point City of } \\
\text { Central lowa Power Coop } \\
\text { IES Utilities Inc } \\
\text { Villisca City of } \\
\text { Webster City City of } \\
\text { West Liberty City of } \\
\text { Wilton City of }\end{array}$ \\
\hline $\begin{array}{l}\text { Kansas } \\
\text { Abilene CT } \\
\text { Arthur Mullergren } \\
\text { Attica } \\
\text { Belleville } \\
\text { Bird City } \\
\text { Chanute ! } \\
\text { Chanute 3 } \\
\text { City of Oxford } \\
\text { Clay Center } \\
\text { Coffeyville } \\
\text { Erat J2th St } \\
\text { Erie } \\
\text { Garden City } \\
\text { Gamett Municipal } \\
\text { Goudland } \\
\text { Great Bend } \\
\text { Herington } \\
\text { Hoisington } \\
\text { Holton } \\
\text { Hugoton } 2 \\
\text { Iola } \\
\text { Jetrnore } \\
\text { Judson Large } \\
\text { Kingman } \\
\text { Lacygne } \\
\text { Lamed } \\
\text { Lincoln } \\
\text { Meade } \\
\text { Mulvane } \\
\text { Neurman Creek } \\
\text { Neosho } \\
\text { Oakely } \\
\text { Osage City } \\
\text { Osbome } \\
\text { Plant No I } \\
\text { Pratt } \\
\text { Quindaro } \\
\text { Russell } \\
\text { Sharon Spring } \\
\text { St John } \\
\text { Sterling } \\
\text { Tecumseh EC } \\
\text { Wushington } \\
\text { Wellington Municipal } \\
\text { Wichita Diesel }\end{array}$ & 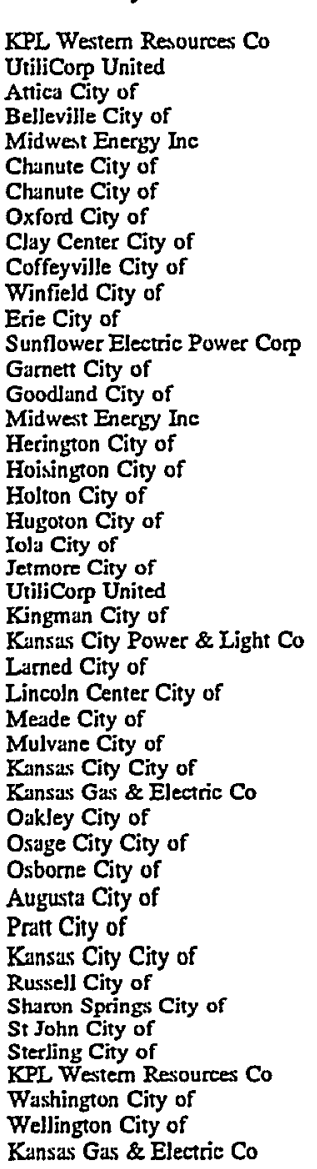 & $\begin{array}{l}\text { Anthony } \\
\text { Ashland } \\
\text { Baldwin } \\
\text { Beloit } \\
\text { Burlingame } \\
\text { Chanute 2 } \\
\text { Cimarron River } \\
\text { City Light Plant } \\
\text { Clifton } \\
\text { Colby } \\
\text { Ellinwood } \\
\text { Fredonia } \\
\text { Gardner } \\
\text { Girard } \\
\text { Gordon Evans EC } \\
\text { Greensburg } \\
\text { Hill City } \\
\text { Holcomb } \\
\text { Hugoton } 1 \\
\text { Hutchinson EC } \\
\text { Jefrey EC } \\
\text { Johnson } \\
\text { Kaw } \\
\text { La Croose } \\
\text { Lakin Municipal } \\
\text { Lawrence EC } \\
\text { McPherson } 2 \\
\text { Minneapolis } \\
\text { Murray Gill EC } \\
\text { Neodesha } \\
\text { Norton } \\
\text { Oberlin } \\
\text { Osawatomie } \\
\text { Ottawa } \\
\text { Plant No } 2 \\
\text { Pratt } 2 \\
\text { Riverton } \\
\text { Sabetha } \\
\text { St Franeis } \\
\text { Stafford } \\
\text { Stockton } \\
\text { Wamego } \\
\text { Wellington City } \\
\text { West IAth St. }\end{array}$ & 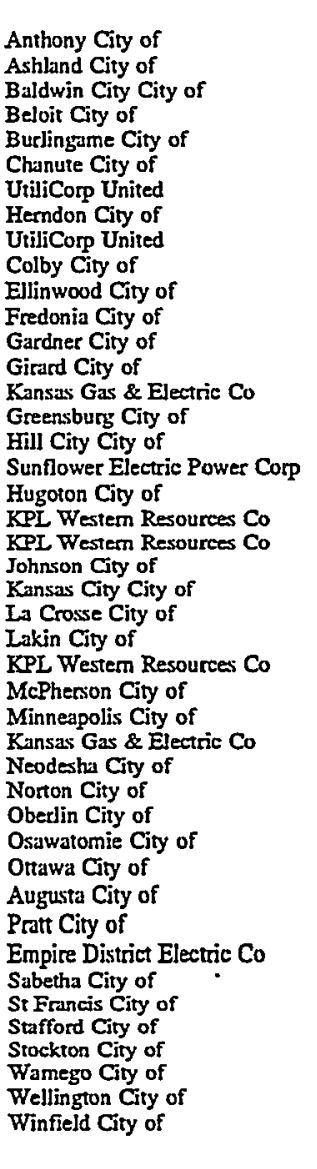 \\
\hline $\begin{array}{l}\text { Kentucky } \\
\text { Barkley } \\
\text { Cane Run } \\
\text { D B Wilson } \\
\text { Dix Dam } \\
\text { East Bend } \\
\text { Ghent } \\
\text { HL Spurlock } \\
\text { Henderson I } \\
\text { K C Coleman } \\
\text { Luurel } \\
\text { Ohio Falls } \\
\text { Paradise } \\
\text { R A Reid } \\
\text { Trimble County } \\
\text { Wolf Creek } \\
\text { Touisinna }\end{array}$ & $\begin{array}{l}\text { USCE-Nashville District } \\
\text { Louisville Gas \& Electric Co } \\
\text { Big Rivers Electric Corp } \\
\text { Kentucky Utilities Co } \\
\text { Cincinnati Gas \& Electric Co } \\
\text { Kentucky Utilities Co } \\
\text { East Kentucky Power Coop Inc } \\
\text { Henderson City Utility Comm } \\
\text { Big Rivers Electric Corp } \\
\text { East Kentucky Power Coop Inc } \\
\text { Louisville Gas \& Electric Co } \\
\text { Tennessee Valley Authority } \\
\text { Big Rivers Electric Cor } \\
\text { Louisville Gas \& Electric Co } \\
\text { USCE-Nashville District }\end{array}$ & $\begin{array}{l}\text { Big Sandy } \\
\text { Cooper } \\
\text { Dale } \\
\text { E W Brown } \\
\text { Elmer Smith } \\
\text { Green River } \\
\text { Haefling } \\
\text { HMP\&I Station } 2 \\
\text { Kennicky } \\
\text { Lock 7 } \\
\text { Paddy 's Run } \\
\text { Pineville } \\
\text { R D Green } \\
\text { Tyrone } \\
\text { Zom }\end{array}$ & $\begin{array}{l}\text { Kentucky Power Co } \\
\text { East Kentucky Power Coop Ine } \\
\text { Enst Kenrucky Power Coop Inc } \\
\text { Kentucky Utilities Co } \\
\text { Owensboro City of } \\
\text { Kentucky Utilities Co } \\
\text { Kentucky Utilities Co } \\
\text { Big Rivers Electric Corp } \\
\text { Tennessee Valley Authority } \\
\text { Kentucky Utilities Co } \\
\text { Louisville Gas \& Electric Co } \\
\text { Kentucky Utilities Co } \\
\text { Big Rivers Electric Corp } \\
\text { Kentucky Utilities Co } \\
\text { Louisville Gas \& Electric Co }\end{array}$ \\
\hline
\end{tabular}

See footnotes at end of table. 
Table D2. U.S. Electric Utility Plants by State, as of January 1, 1998 (Continued)

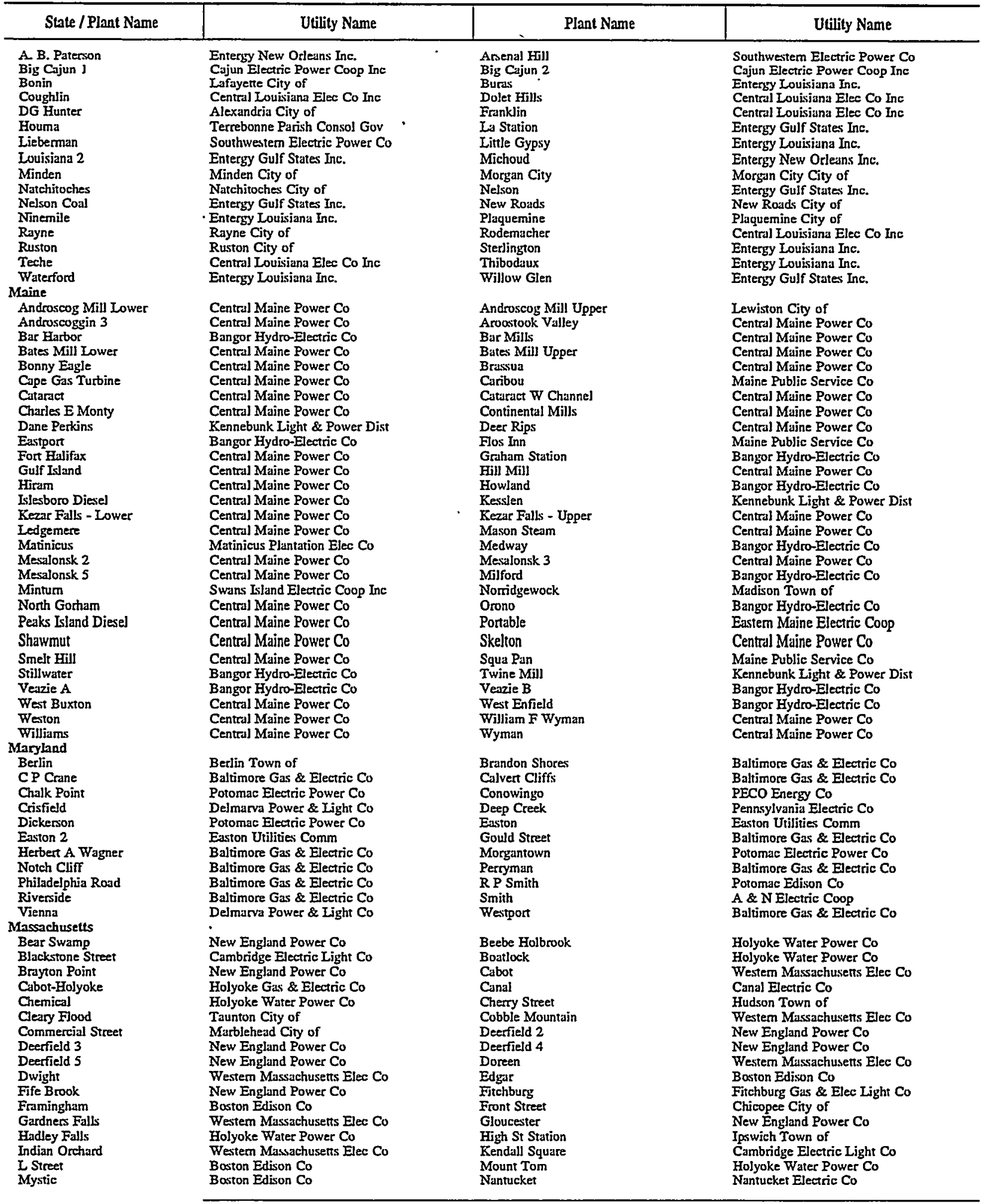

See footnotes at end of table. 
Table D2. U.S. Electric Utility Plants by State, as of January 1, 1998 (Continued)

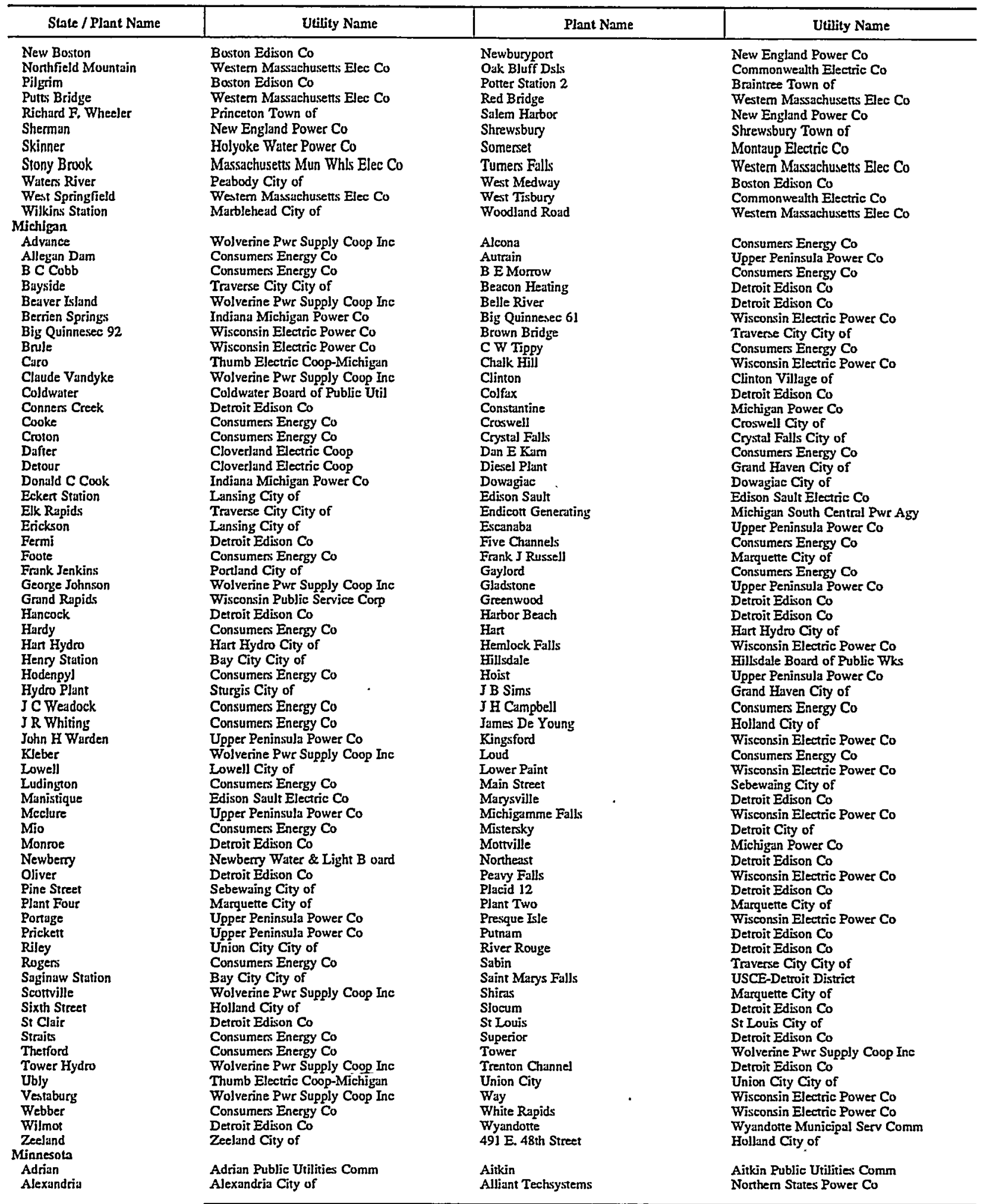

See footnotes at end of table. 
Table D2. U.S. Electric Utility Plants by State, as of January 1, 1998 (Continued)

\begin{tabular}{|c|c|c|c|}
\hline State / Plant Name & Utility Name & Plant Name & Utility Name \\
\hline $\begin{array}{l}\text { Austin-DT } \\
\text { Bemidji Hydro } \\
\text { Black Dog } \\
\text { Blooming Praiie } \\
\text { Blue Lake } \\
\text { Cascade Creek } \\
\text { Dayton Hollow } \\
\text { Detroit Lakes } \\
\text { Fairfax } \\
\text { Fergus Control Cre } \\
\text { Fox Iake } \\
\text { Grand Marais } \\
\text { Granite Falls } \\
\text { Hawley } \\
\text { Hibbing } \\
\text { Hills } \\
\text { Hoot Lake } \\
\text { Hutch Plant } \# 2 \\
\text { Janesville } \\
\text { Key City } \\
\text { Knife Falls } \\
\text { Lakefield Utilities } \\
\text { Litchficld } \\
\text { Luverne } \\
\text { Madelia } \\
\text { Maple Lake CT } \\
\text { Melrose Wastewater } \\
\text { Montgomery } \\
\text { Moorhead } \\
\text { Mora } \\
\text { New Prague } \\
\text { Norh Branch } \\
\text { Owatonna } \\
\text { Pisgah } \\
\text { Prairie Island } \\
\text { Preston } \\
\text { Red Wing } \\
\text { Rochester Hydro } \\
\text { Roseau } \\
\text { Scanlon } \\
\text { Sleepy Eye } \\
\text { St Bonifacius } \\
\text { Sylvan } \\
\text { Thief River Falls } \\
\text { Truman } \\
\text { United Health Care } \\
\text { Virginia } \\
\text { Westbrook } \\
\text { Wilmanth } \\
\text { Winton } \\
\text { Ting }\end{array}$ & $\begin{array}{l}\text { Austin Ciry of } \\
\text { Otter Tail Power Co } \\
\text { Northem States Power Co } \\
\text { Blooming Prairie City of } \\
\text { Northem States Power Co } \\
\text { Rochester Public Utilities } \\
\text { Orter Tail Power Co } \\
\text { Detroit Iakes City of } \\
\text { Fairfax City of } \\
\text { Orrer Tail Power Co } \\
\text { Interstate Power Co } \\
\text { Grand Marais City of } \\
\text { Granite Falls City of } \\
\text { Hawley Public Utilities Comm } \\
\text { Hibbing Public Utilities Comm } \\
\text { Interstate Power Co } \\
\text { Orter Tail Power Co } \\
\text { Hutchinson Utilities Comm } \\
\text { Janesville City of } \\
\text { Nonhem States Power Co } \\
\text { Minnesota Power \& Light Co } \\
\text { Lakefield City of } \\
\text { Lirehfield Public Utility Comm } \\
\text { Luveme City of } \\
\text { Madelia City of } \\
\text { United Power Assn } \\
\text { Melrose Public Utilities } \\
\text { Interstate Power Co } \\
\text { Moorhead City of } \\
\text { Mora City of } \\
\text { New Prague Mun Utils Comm } \\
\text { North Branch Water\&Light Comm } \\
\text { Owatonna City of } \\
\text { Otter Tail Power Co } \\
\text { Northem States Power Co } \\
\text { Preston Public Utilities Comm } \\
\text { Northem States Power Co } \\
\text { Rochester Public Utilities } \\
\text { Roseau City of } \\
\text { Minnesota Power \& Light Co } \\
\text { Sleepy Eye Public Utility Comm } \\
\text { Coop Power Assn } \\
\text { Minnesota Power \& Light Co } \\
\text { Thief River Falls City of } \\
\text { Truman Public Utilities Comm } \\
\text { Northem States Power Co } \\
\text { Virginia City of } \\
\text { Westbrook City of } \\
\text { Northem States Power Co } \\
\text { Minnesota Power \& Light Co }\end{array}$ & $\begin{array}{l}\text { Baudette } \\
\text { Benson } \\
\text { Blanchard } \\
\text { Blue Earth } \\
\text { Cambridge CT } \\
\text { Clay Boswell } \\
\text { Delano } \\
\text { Ejk River } \\
\text { Fairmont } \\
\text { Fond Du Lad } \\
\text { Glencoe } \\
\text { Granite City } \\
\text { Halstad } \\
\text { Hennepin Island } \\
\text { High Bridge } \\
\text { Holland Wind } \\
\text { Hutch PJant \# ] } \\
\text { Inver Hills } \\
\text { Kenyon Municipal } \\
\text { King } \\
\text { Lake Crystal } \\
\text { Lanesboro } \\
\text { Little Fall } \\
\text { M. L Hibbard } \\
\text { Madison } \\
\text { Melrose } \\
\text { Minnesota Valley } \\
\text { Monticello } \\
\text { Moose Lake } \\
\text { Mountain Lake } \\
\text { New Ulm } \\
\text { Northeast Station } \\
\text { Pillager } \\
\text { Potlatch Cogen } \\
\text { Prairie River } \\
\text { Princeton } \\
\text { Redwood Falls } \\
\text { Rock Lake CT } \\
\text { Rushford } \\
\text { Sherbume Co } \\
\text { Spring Valley } \\
\text { Sy] Linkin } \\
\text { Taplin Gorge } \\
\text { Thomson } \\
\text { Two Harbos } \\
\text { United Hospital } \\
\text { Weat Faribault } \\
\text { Willmar } \\
\text { Windom }\end{array}$ & $\begin{array}{l}\text { Baudette City of } \\
\text { Benson City of } \\
\text { Minnesota Power \& Light Co } \\
\text { Blue Eath City of } \\
\text { United Power Assn } \\
\text { Minnesota Power \& Light Co } \\
\text { Delano Ciry of } \\
\text { Elk River City of } \\
\text { Fajmont Public Utilities Comm } \\
\text { Minnesota Power \& Light Co } \\
\text { Glencoe Iight \& Power Comm } \\
\text { Northem Stutes Power Co } \\
\text { Halstad City of } \\
\text { Northem States Power Co } \\
\text { Northem States Power Co } \\
\text { Northem States Power Co } \\
\text { Hutchinson Utilities Comm } \\
\text { Northem States Power Co } \\
\text { Kenyon Municipal Utilities } \\
\text { Northem States Power Co } \\
\text { Like Crystal City of } \\
\text { Lanesboro Public Utility Comm } \\
\text { Minnesota Power \& Light Co } \\
\text { Minnesota Power \& Light Co } \\
\text { Madison City of } \\
\text { Melrose Public Utilities } \\
\text { Northem States Power Co } \\
\text { Northem States Power Co } \\
\text { Moose Luke Water \& Light Comm } \\
\text { Mountain Lake City of } \\
\text { New Ulm Public Utilities Comm } \\
\text { Austin City of } \\
\text { Minnesota Power \& Light Co } \\
\text { Otter Tail Power Co } \\
\text { Minnesota Power \& Light Co } \\
\text { Princeton Public Utils Comm } \\
\text { Redwood Falls Public Util Comm } \\
\text { United Power Assn } \\
\text { Interstate Power Co } \\
\text { Northem States Power Co } \\
\text { Spting Valley Pub Utils Comm } \\
\text { Minnesota Power \& Light Co } \\
\text { Otrer Tail Power Co } \\
\text { Minnesota Power \& Light Co } \\
\text { Two Harbors City of } \\
\text { Nothem States Power Co } \\
\text { Northem States Power Co } \\
\text { Willmar Municipal Utils Comm } \\
\text { Windom City of }\end{array}$ \\
\hline $\begin{array}{l}\text { Mississippi } \\
\text { Andrus } \\
\text { Benndale } \\
\text { Eaton } \\
\text { Henderson } \\
\text { Moselle } \\
\text { Paulding } \\
\text { Rex Brown } \\
\text { Third Street } \\
\text { Wilkins } \\
\text { Yazoo }\end{array}$ & $\begin{array}{l}\text { Entergy Mississippi Inc. } \\
\text { South Mississippi El Pwr Assn } \\
\text { Missirsippi Power Co } \\
\text { Greenwood Utilities Comm } \\
\text { South Mississippi El Pwr Assn } \\
\text { South Mississigpi El Pwr Assn } \\
\text { Entergy Mississippi Inc. } \\
\text { Clarksdale City of } \\
\text { Clarksdale City of } \\
\text { Public Serv Comm of Yazoo City }\end{array}$ & $\begin{array}{l}\text { Baxter Wilson } \\
\text { Chevron Oil } \\
\text { Grand Gulf } \\
\text { Jack Watson } \\
\text { Natchez } \\
\text { R D Morrow } \\
\text { Sweatt } \\
\text { Victor J Daniel Jr } \\
\text { Wright }\end{array}$ & $\begin{array}{l}\text { Entergy Mississippi Inc. } \\
\text { Mississippi Power Co } \\
\text { System Energy Resources Ine } \\
\text { Mississippi Power Co } \\
\text { Entergy Mississippi Inc. } \\
\text { South Mississippi El Pwr Assn } \\
\text { Mississippi Power Co } \\
\text { Mississippi Power Co } \\
\text { Greenwood Utilities Comm }\end{array}$ \\
\hline $\begin{array}{l}\text { Missouri } \\
\text { Albany } \\
\text { Bethany } \\
\text { Butler } \\
\text { Carrollton } \\
\text { Chamois } \\
\text { City of Marceline } \\
\text { Clarence Cannon } \\
\text { Empire Energy Center } \\
\text { Fayette } \\
\text { Gallatin } \\
\text { Green Forest } \\
\text { Hawthom } \\
\text { Howard Bend } \\
\text { Jackson }\end{array}$ & $\begin{array}{l}\text { Albany City of } \\
\text { Bethany City of } \\
\text { Butler City of } \\
\text { Carrollton Board of Public Wks } \\
\text { Central Electric Power Coop } \\
\text { Marceline City of } \\
\text { USCE-St Louis District } \\
\text { Empire District Electric Co } \\
\text { Fayete City of } \\
\text { Gallatin City of } \\
\text { M \& A Electric Power Coop } \\
\text { Ransas City Power \& Light Co } \\
\text { Union Electric Co } \\
\text { Jackson City of }\end{array}$ & $\begin{array}{l}\text { Asbury } \\
\text { Blue Valley } \\
\text { Campbell } \\
\text { Carthage } \\
\text { Chillicothe } \\
\text { City of Salisbury } \\
\text { Columbia } \\
\text { Fairgrounds } \\
\text { Fulton } \\
\text { Grand Avenue } \\
\text { Harry Truman } \\
\text { Higginsville } \\
\text { Iatan } \\
\text { Jackson Square }\end{array}$ & $\begin{array}{l}\text { Empire District Electric Co } \\
\text { Independence City of } \\
\text { Campbell City of } \\
\text { Carthage City of } \\
\text { Chillicothe City of } \\
\text { Salisbury City of } \\
\text { Columbia City of } \\
\text { Union Electric Co } \\
\text { Fulton City of } \\
\text { Kinsas City Power \& Light Co } \\
\text { USCE-Kansas City District } \\
\text { Figginsville City of } \\
\text { Kansas City Power \& Light Co } \\
\text { Independence City of }\end{array}$ \\
\hline
\end{tabular}

See footnotes at end of table. 
Table D2. U.S. Electric Utility Plants by State, as of January 1, 1998 (Continued)

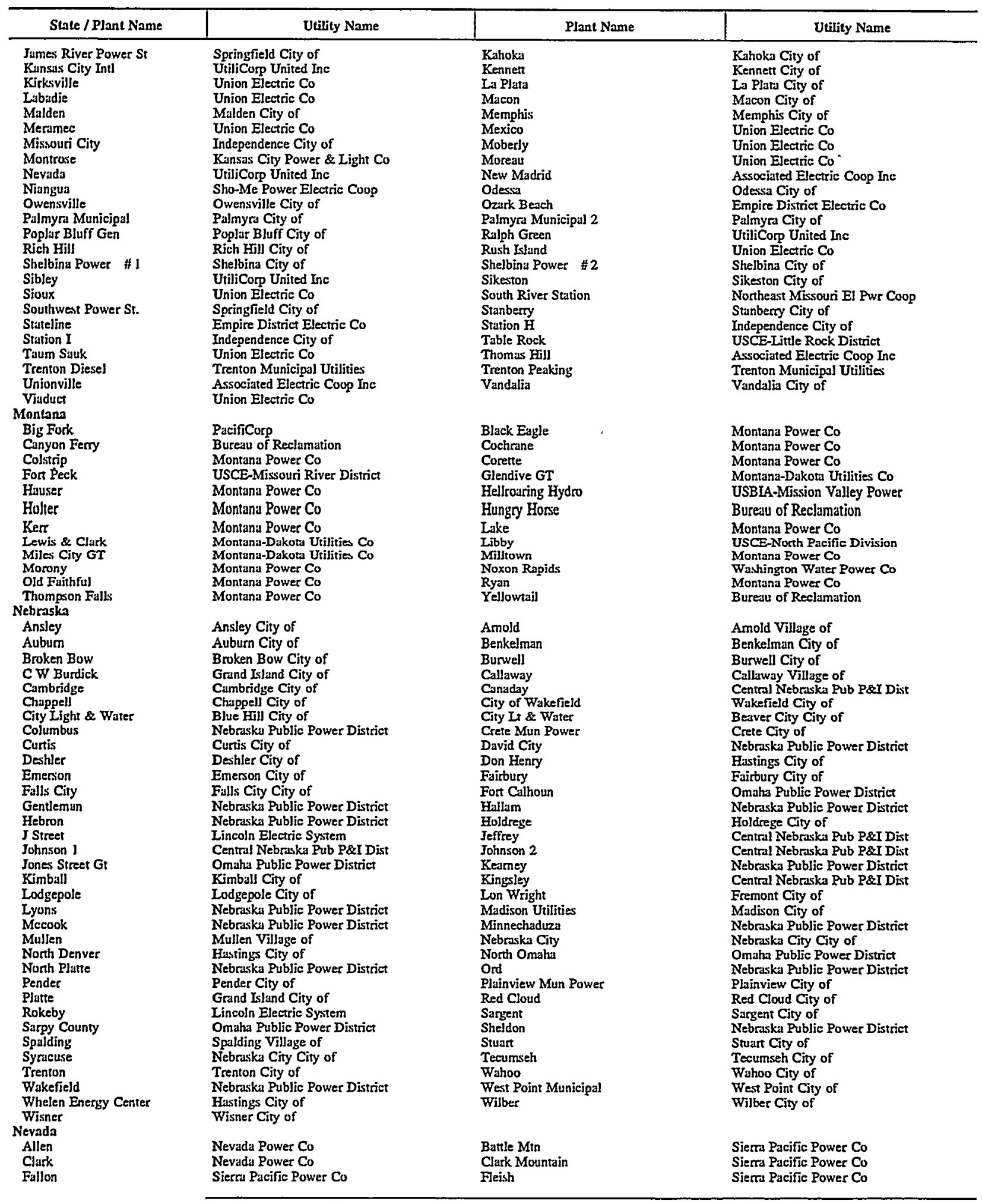

See foutnotes at end of tuble. 
Table D2. U.S. Electric Utility Plants by State, as of January 1, 1998 (Continued)

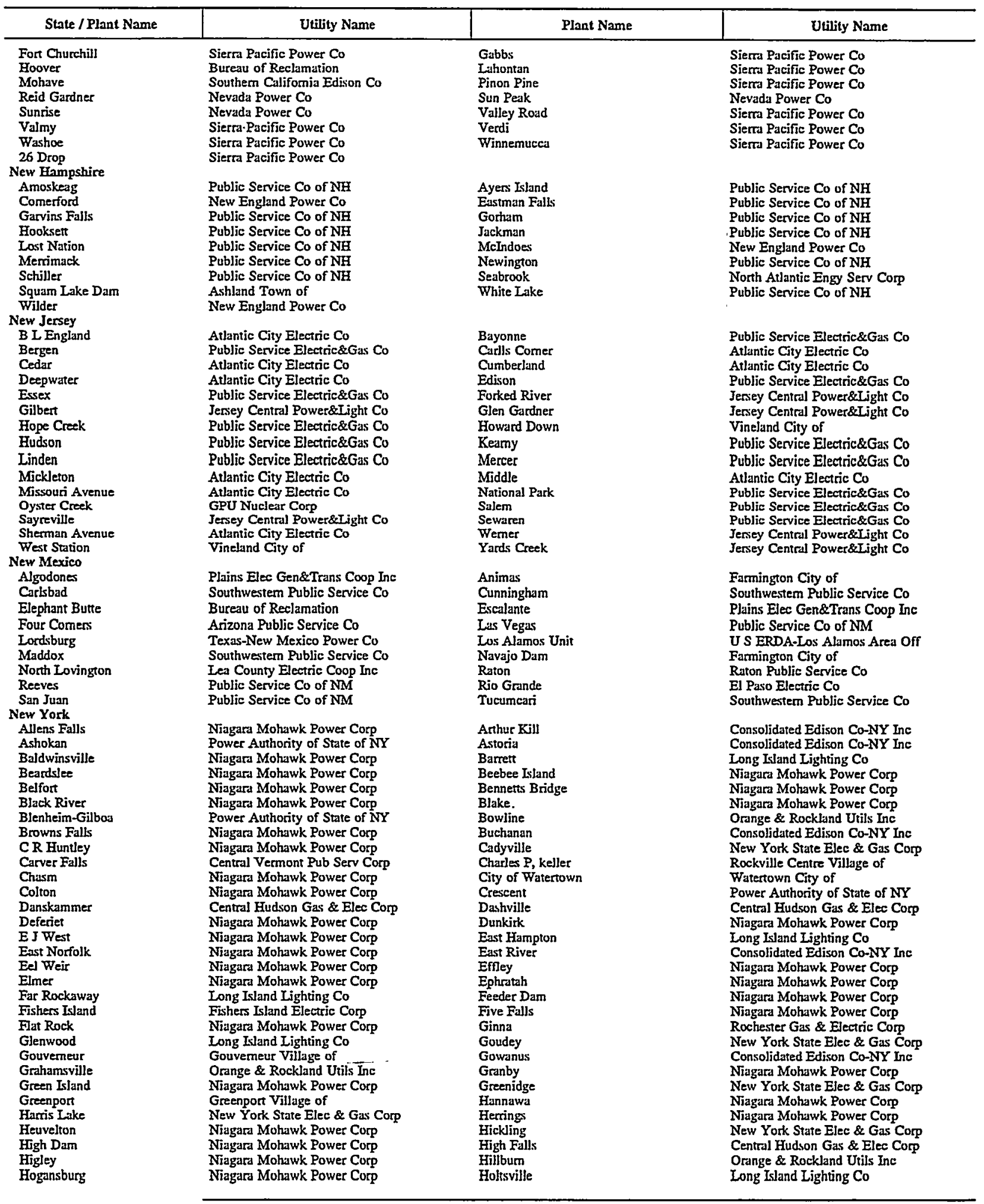

See footnotes at end of table. 
Table D2. U.S. Electric Utility Plants by State, as of January 1, 1998 (Continued)

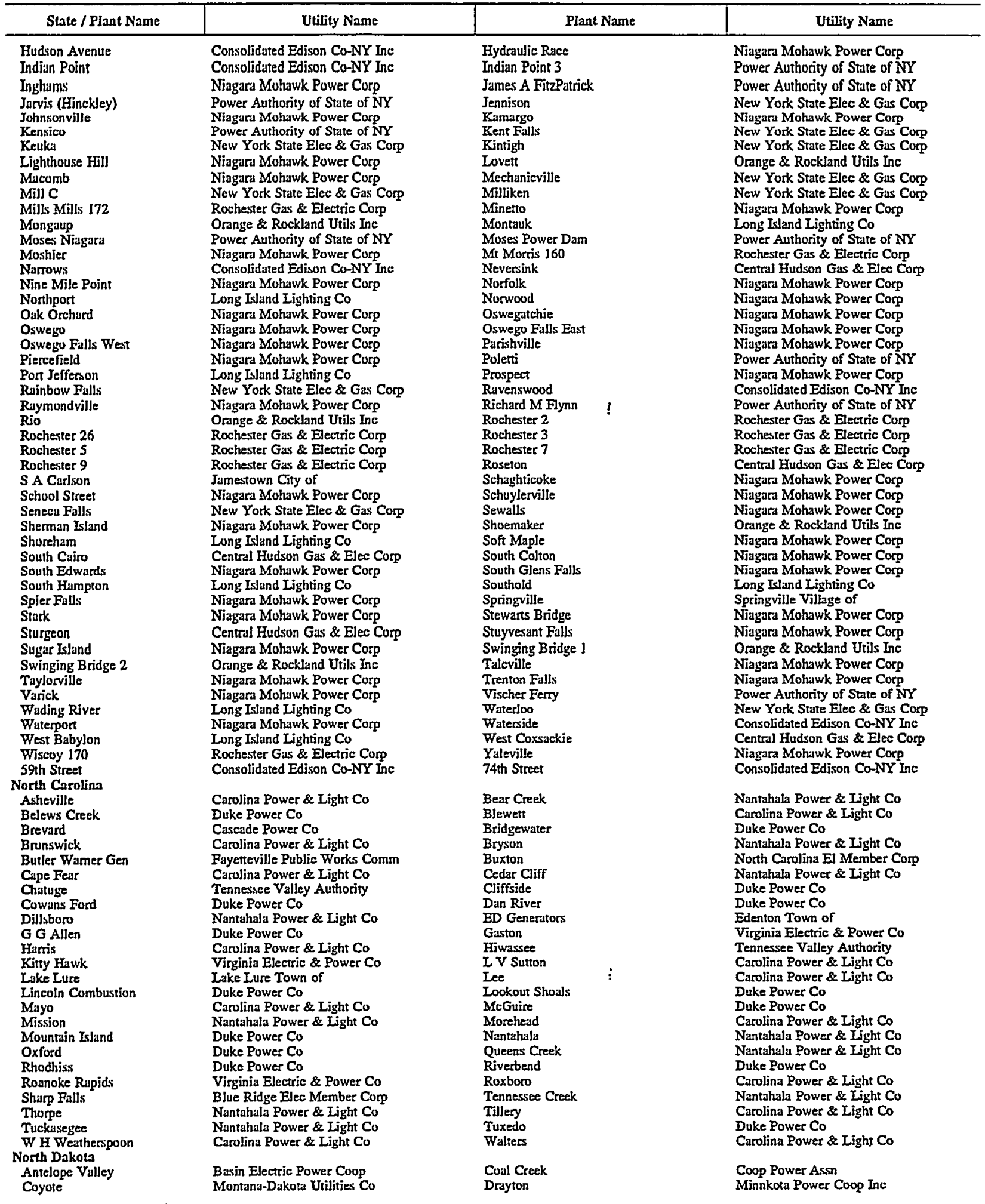

See footnotes at end of table. 
Table D2. U.S. Electric Utility Plants by State, as of January 1, 1998 (Continued)

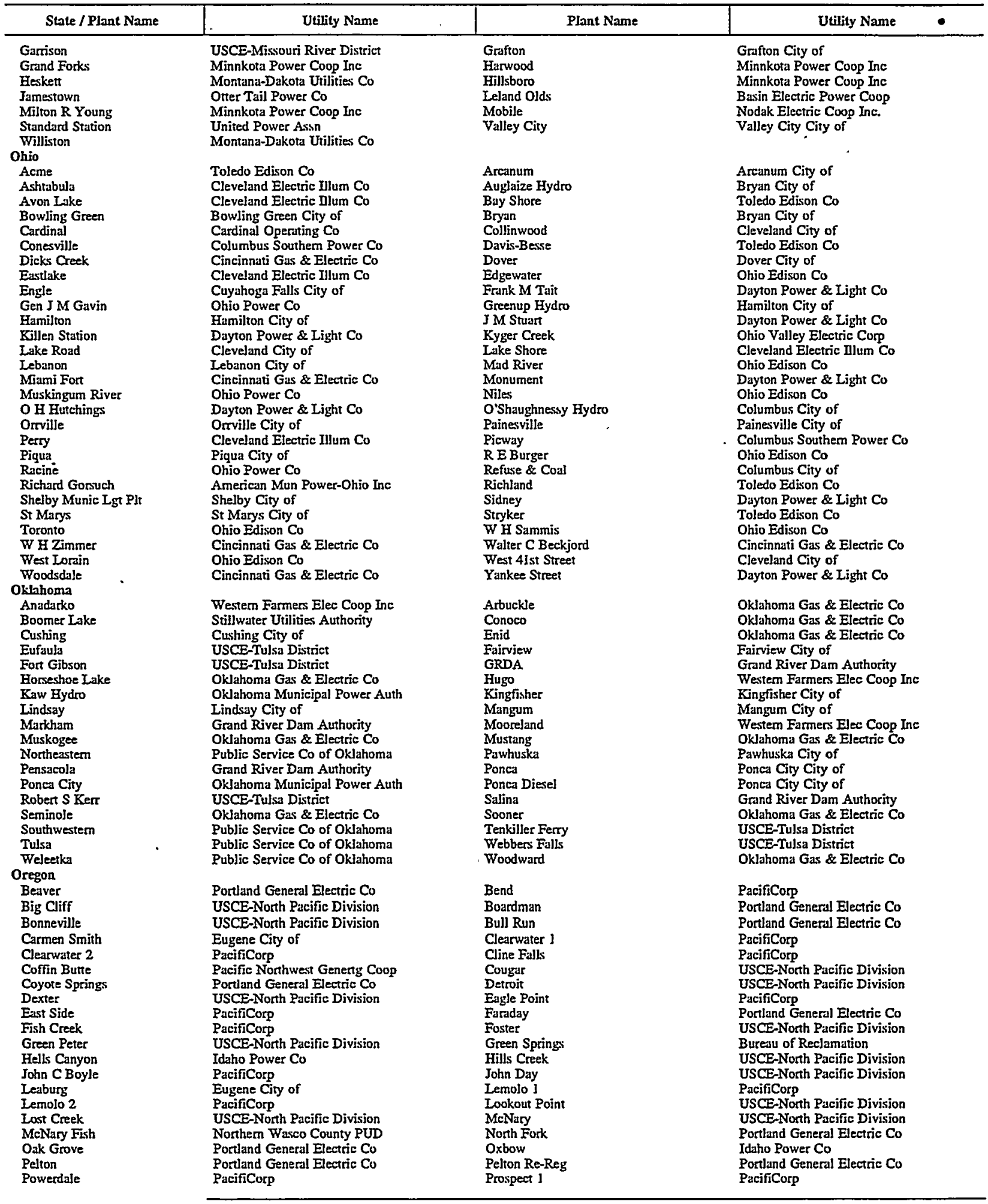

See footnotes at end of table. 
Table D2. U.S. Electric Utility Plants by State, as of January 1, 1998 (Continued)

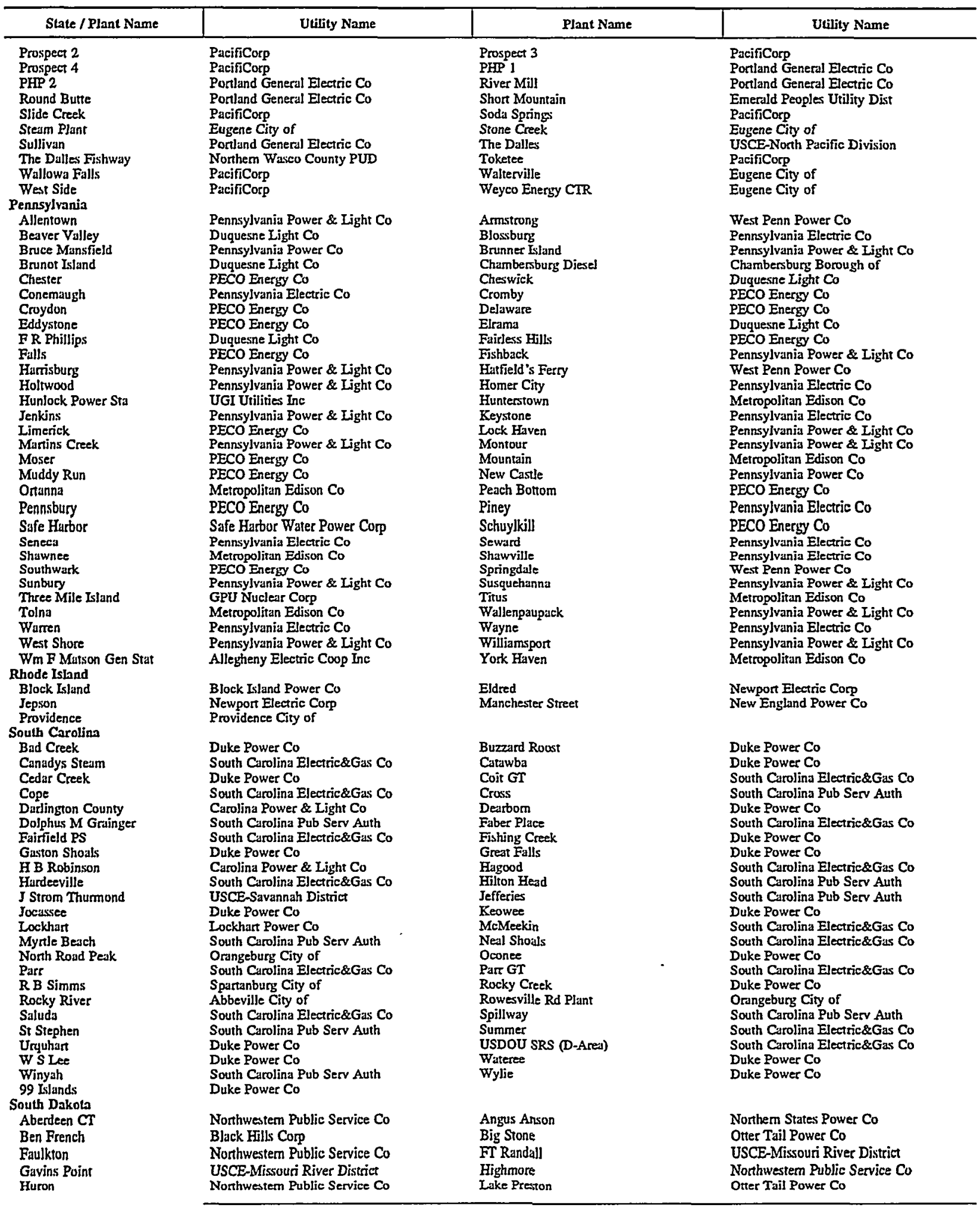

See footnotes at end of table. 
Table D2. U.S. Electric Utility Plants by State, as of January 1, 1998 (Contịnued)

\begin{tabular}{|c|c|c|c|}
\hline State / Plant Name & Utility Name & Plant Name & Utility Name \\
\hline $\begin{array}{l}\text { Mobil Unit } \\
\text { Pathfinder } \\
\text { Spirit Mound } \\
\text { Yankton }\end{array}$ & $\begin{array}{l}\text { Northwestem Public Service Co } \\
\text { Northem States Power Co } \\
\text { Basin Electric Power Coop } \\
\text { Northwestem Public Service Co }\end{array}$ & $\begin{array}{l}\text { Oahe } \\
\text { Redfield } \\
\text { Watertown PP }\end{array}$ & $\begin{array}{l}\text { USCE-Missouri River District } \\
\text { Northwestem Public Service Co } \\
\text { Missouri Basin Mun Power Agny }\end{array}$ \\
\hline \multicolumn{4}{|l|}{ Tennessee } \\
\hline Apalachia & Tennexsee Valley Authority & Boone & Tennessee Valley Authority \\
\hline Center Hill & USCE-Nashville District & Cheatham & USCE-Nashville District \\
\hline Chickamauga & Tennexsee Valley Authority & Cordell Hull & USCE-Nashville District \\
\hline Dale Hollow & USCE-Nashville District & Fort Loudoun & Tennessee Valley Authority \\
\hline Fort Patrick Henry & Tennessee Valley Authority & J.P. Priest & USCE-Nashville District \\
\hline John Sevier & Tennessee Valley Authority & Kingston & Tennessee Valley Authority \\
\hline Melton Hill & Tennessee Valley Authority & Nickajack & Tennexsee Valley Authority \\
\hline Norris & Tennessee Valley Authority & Ocoee I & Tennessee Valley Authority \\
\hline Ocoes 2 & Tennessee Valley Authority & Ocoee 3 & Tennessee Valley Authority \\
\hline Old Hickory & USCE-Nashville District & Pickwick & Tennessee Valley Authority \\
\hline Raccoon Mountain & Tennessee Valley Authority & Sequoyah & Tennessee Valley Authority \\
\hline South Holsion & Tennessee Valley Authority & Tims Ford & Tennessee Valley Authority \\
\hline Watauga & Tennessee Valley Authority & Watts Bar Fossil & Tennessee Valley Authority \\
\hline Watts Bar Hydro & Tennessee Valley Authority & Watts Bar Nuclear & Tennessee Valley Authority \\
\hline Wilbur & Tennessee Valley Authority & & \\
\hline \multicolumn{4}{|c|}{ - } \\
\hline Abbott TP 3 & Guadalupe Blanco River Auth & Abilene & West Texas Utilities Co \\
\hline Amistad Dam \& Power & Intemational Bound \& Wtr Comm & Austin & Lower Colorado River Authority \\
\hline Bamey M Davis & Central Power \& Light Co & Big Brown & Texas Utilities Electric Co \\
\hline Brandon Stazion & Lubbock City of & Brownfield & Brownfield City of \\
\hline C E Newman & Garland City of & Canyon " & Guadalupe Blunco River Auth \\
\hline & $\begin{array}{l}\text { Houston Lighting \& Power Co } \\
\text { Coleman City of }\end{array}$ & Celanese & Southwestem Public Service Co \\
\hline $\begin{array}{l}\text { Coleman } \\
\text { Collin }\end{array}$ & & $\begin{array}{l}\text { Coleto Creek } \\
\text { Comanche Peak }\end{array}$ & $\begin{array}{l}\text { Central Power \& Light Co } \\
\text { Texas Utilities Electric Co }\end{array}$ \\
\hline Copper & EJ Paso Electric Co & Dallas & Texas Utilities Electric Co \\
\hline Dansby & Bryan City of & Decker Creek & Austin City of \\
\hline Denison & USCE-Tulsa District & DeCordova & Texas Utilities Electric Co \\
\hline Dunlap TP J & Guadalupe Blanco River Auth & E S Joslin & Central Power \& Light Co \\
\hline Eagle Mountain & Texas Utilities Electric Co & Eagle Pass & Central Power \& Light Co \\
\hline Electra & Electra City of & Fulcon Dam \& Power & Intemational Bound \& Wtr Comm \\
\hline Fayette Power Prje & Lower Colorado River Authority & Floydada & Floydada City of \\
\hline Fi Phantom & West Texas Utilities Co & Ft Śtockton & West Texas Utilities Co \\
\hline Fr. Davis & West Texas Utilities Co & Gibbons Creek & Texas Municipal Power Agency \\
\hline Gonzales Hydro Plant & Gonzales City of & Graham & Texas Utilities Electric Co \\
\hline Granite Shoals & Lower Colorado River Authority & Greens Bayou & Houston Lighting \& Power Co \\
\hline H 4 & Guadalupe Blanco River Auth & H 5 & Guadalupe Blanco River Auth \\
\hline Handley & Texas Utilities Electric Co & Harrington & Southwestem Public Service Co \\
\hline Hiram Clarke & Houston Lighting \& Power Co & Holly Ave & Lubbock City of \\
\hline Holly Street & Austin City of & Inks & Lower Colorado River Authority \\
\hline J K Spruce & San Antonjo Public Service Bd & J I Bates & Central Power \& Light Co \\
\hline J T Deely & San Antonio Public Service Bd & Jones: & Southwertem Public Service Co \\
\hline Knox Iee & Southwertem Electric Power Co & La Palma & Central Power \& Light Co \\
\hline Lake Hubbard & Texas Utilities Electric Co & Lake Pauline & West Texass Utilities Co \\
\hline Laredo & Central Power \& Light Co & Leon Creek & Sun Antonio Public Service Bd \\
\hline Lewis Creek & Entergy Gulf States Inc. & Lewisville & Denton City of \\
\hline Limestone & Houston Lighting \& Power Co & Lon C. Hill & Central Power \& Light Co \\
\hline Lone Star & Southwestem Electric Power Co & Marble Falls & Lower Colorado River Authority \\
\hline Marshall Ford & Lower Colorado River Authority & Martin Lake & Texus Urilities Electric Co \\
\hline Mission Road & San Antonio Public Service Bd & "Moore County & Southwestem Public Service Co \\
\hline Morgan Creek & Texas Utilities Electric Co & Morris Sheppard & Brazos River Authority \\
\hline Mountain Creek & Texas Utilities Electric Co & Neches & Entergy Gulf States Inc. \\
\hline Newman & El Paso Electric Co & Nichols & Southwestem Public Service Co \\
\hline Nolte & Guadalupe Blanco River Auth & North Lake & Texas Utilities Electric Co \\
\hline North Main & Texas Uttilities Electrie Co & Nonth Texas & Brazos Electric Power Coop Inc \\
\hline Nueces Bay & Central Power \& Light Co & O W Sommers & San Antonio Public Service Bd \\
\hline Oak Creek & West Texas Utilities Co & Oklaunion & West Texas Utilities Co \\
\hline P H Robinson & Houston Lighting \& Power Co & Paint Creek & West Texas Utilities Co \\
\hline Parkdale & Texas Utilities Electric Co & Peanall & Medina Electric Coop Ine \\
\hline Permian Basin & Texas Utilities Electric Co & Pirkey & Southwestem Electric Power Co \\
\hline Plant $X$ & Southwestem Public Service Co & Plant 2 & Lubbock City of \\
\hline Powerlane Plant & Greenville Electric Util. Sys. & Presidio & West Texas Utilities Co \\
\hline $\mathrm{R}$ W Miller & Brazos Electric Power Coop Inc & Ray Olinger & Garland City of \\
\hline Ray Roberts & Denton City of & Rio Pecos & West Texas Utijities Co \\
\hline River Crest & Texas Utilities Electric Co & Robert D Willis & USCE-Fort Worth District \\
\hline Robstown & Robstown City of & Sabine & Entergy Gulf States Inc. \\
\hline Sam Bertron & Houston Lighting \& Power Co & Sam Raybum & South Texis Electric Coop Ine \\
\hline San Angelo & West Texas Utilities Co & San Jacinio SES & Houston Lighting \& Power Co \\
\hline San Miguel & San Miguel Electric Coop Inc & Sandow & Texas Utilities Electric Co \\
\hline Seguin & Seguin City of & Si Ray & Brownsville Public Utilis Board \\
\hline Sim Gideon & Lower Colorado River Authority & South Texas & Houston Iighting \& Power Co \\
\hline Spencer & Denton City of & Stryker Creek & Texas Utilities Electric Co \\
\hline
\end{tabular}

See footnotes at end of table. 
Table D2. U.S. Electric Utility Plants by State, as of January 1, 1998 (Continued)

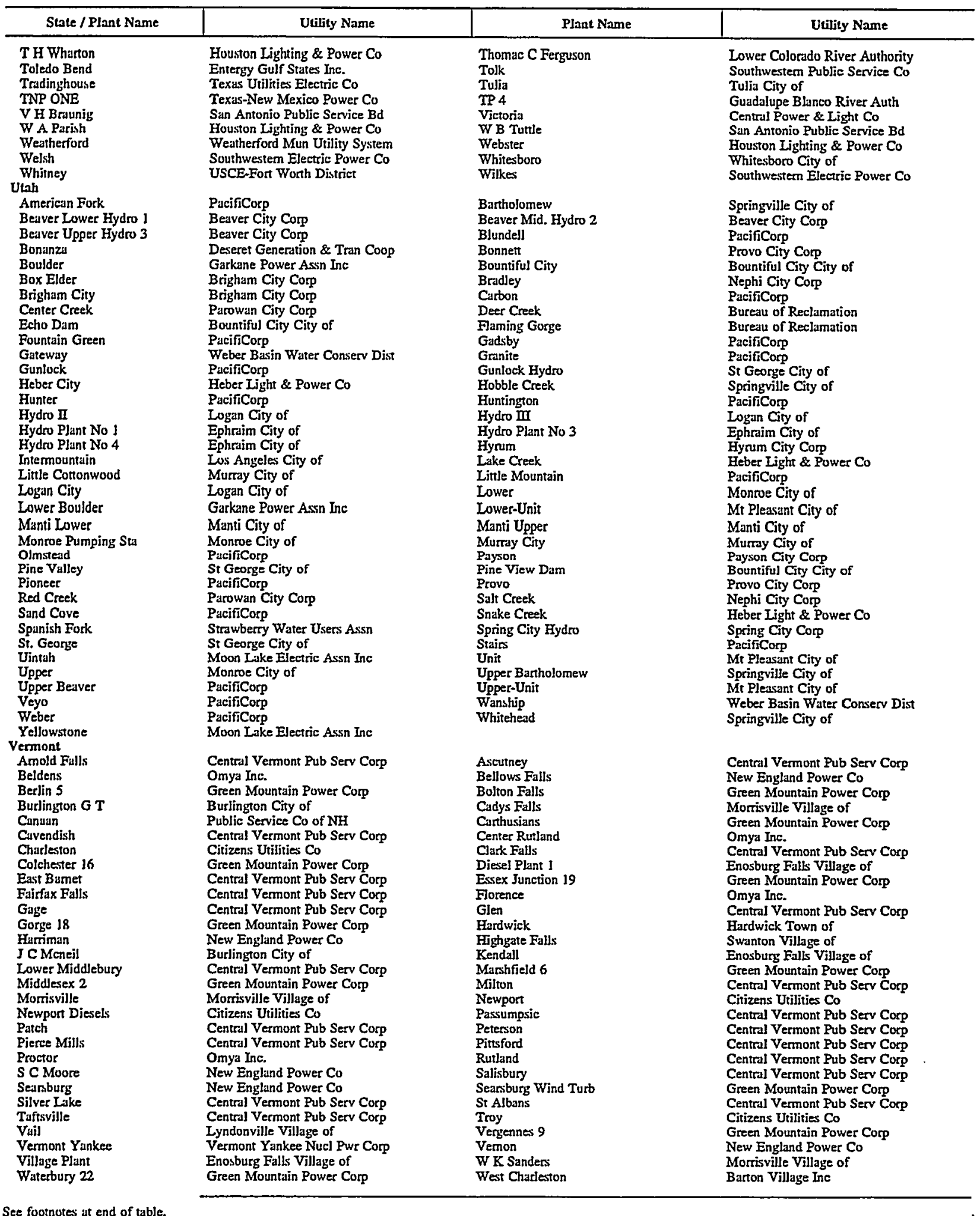


Table D2. U.S. Electric Utility Plants by State, as of January 1, 1998 (Continued)

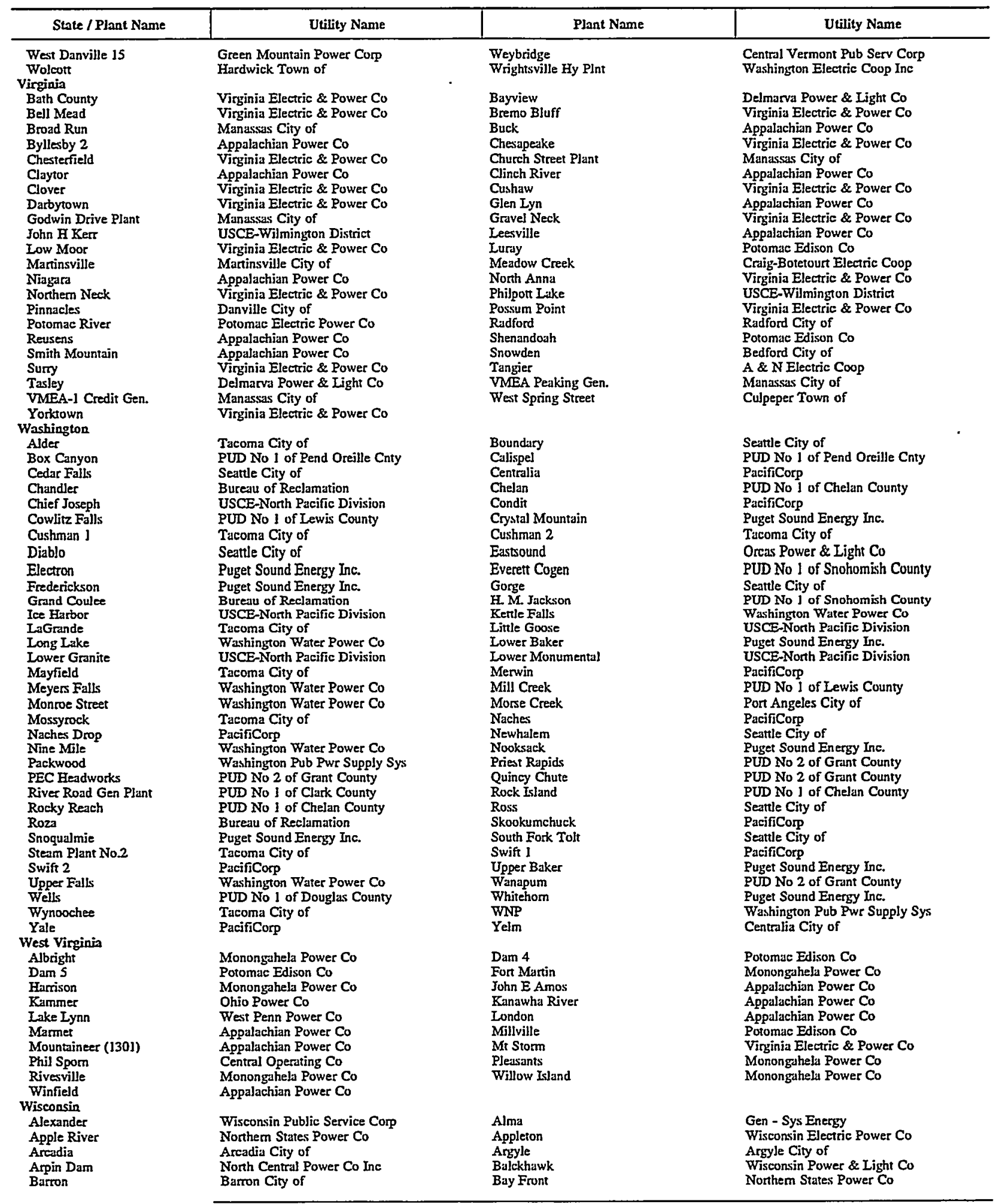

See footnotes at end of table. 
Table D2. U.S. Electric Utility Plants by State, as of January 1, 1998 (Continued)

\begin{tabular}{|c|c|c|c|}
\hline State / Plant Name & Utility Name & Plant Name & Utility Name \\
\hline $\begin{array}{l}\text { Big Falls } \\
\text { Black Brook Dam } \\
\text { Blount Street } \\
\text { Cashton } \\
\text { Chippewa Falls } \\
\text { Clam Rjver Dam } \\
\text { Concord } \\
\text { Danbury Dam } \\
\text { Du Bay } \\
\text { East Fork } \\
\text { Fennimore } \\
\text { Frederic Diesel } \\
\text { Genoa } \\
\text { Gordon } \\
\text { Grantsburg Diesel } \\
\text { Hat Rupids } \\
\text { Holcombe } \\
\text { Jim Falls } \\
\text { Johnson Falls } \\
\text { Katukauna } \\
\text { Kewaunee } \\
\text { La Farge } \\
\text { Lirte Chute } \\
\text { Manitowoc } \\
\text { Menomonie } \\
\text { Merrillan } \\
\text { Muscoda } \\
\text { Nelson Dewey } \\
\text { New Lisbon } \\
\text { Oconto Falls } \\
\text { Oneida Casino } \\
\text { Pardeeville Hydro } \\
\text { Petenwell } \\
\text { PJeasunt Prairie } \\
\text { Pon Washington } \\
\text { Powell Falls } \\
\text { Pulliam } \\
\text { Riverdale } \\
\text { Sandstone Rapids } \\
\text { Shawano } \\
\text { Solon Diesel } \\
\text { South Oak Creek } \\
\text { Stevens Point } \\
\text { Superior Falls } \\
\text { Thomapple } \\
\text { Trego } \\
\text { Viola } \\
\text { Wausau } \\
\text { Wheaton } \\
\text { Wisconsin Rapids } \\
\text { Wissota }\end{array}$ & $\begin{array}{l}\text { Northem States Power Co } \\
\text { Nurthwestem Wisconsin Elec Co } \\
\text { Madison Gas \& Electric Co } \\
\text { Cushton Village of } \\
\text { Northem Stutes Power Co } \\
\text { Northwestem Wisconsin Elec Co } \\
\text { Wisconsin Electrie Power Co } \\
\text { Northwestem Wisconsin Elec Co } \\
\text { Consolidated Water Power Co } \\
\text { North Centeal Power Co Ine } \\
\text { Fennimore City of } \\
\text { Northwestern Wisconsin Elec Co } \\
\text { Gen - Sys Energy } \\
\text { Dahlberg Light \& Power Co } \\
\text { Nurthwestem Wisconsin Elec Co } \\
\text { Wisconsin Public Service Corp } \\
\text { Northem States Power Co } \\
\text { Northem States Power Co } \\
\text { Wisconsin Public Service Corp } \\
\text { Kiukauna City of } \\
\text { Wisconsin Public Service Corp } \\
\text { La Farge Municipal Electric Co } \\
\text { Kaukauna City of } \\
\text { Manitowoc Public Utilities } \\
\text { Northem States Power Co } \\
\text { Merrillan Village of } \\
\text { Muscoda City of } \\
\text { Wisconsin Power \& Light Co } \\
\text { New Lisbon City of } \\
\text { Wisconsin Electric Power Co } \\
\text { Wisconsin Public Service Corp } \\
\text { Pardeeville Village of } \\
\text { Wisconsin River Power Co } \\
\text { Wisconsin Electric Power Co } \\
\text { Wisconsin Electric Power Co } \\
\text { River Falls City of } \\
\text { Wisconsin Public Service Corp } \\
\text { Northem States Power Co } \\
\text { Wisconsin Public Service Corp } \\
\text { Wisconsin Power \& Light Co } \\
\text { Dahlberg Light \& Power Co } \\
\text { Wisconsin Electric Power Co } \\
\text { Consolidated Water Power Co } \\
\text { Northem States Power Co } \\
\text { Northem States Power Co } \\
\text { Northem States Power Co } \\
\text { Viola Village of } \\
\text { Wisconsin Public Service Corp } \\
\text { Northem States Power Co } \\
\text { Consolidated Water Power Co } \\
\text { Northem States Power Co }\end{array}$ & $\begin{array}{l}\text { Biron } \\
\text { Black River Falls } \\
\text { Caldron Falls } \\
\text { Castle Rock } \\
\text { Clam Falls Dam } \\
\text { Combined Iocks } \\
\text { Comell } \\
\text { Dells } \\
\text { Eagle River } \\
\text { Elroy } \\
\text { Flambeau } \\
\text { French Island } \\
\text { Germantown } \\
\text { Grandfather Falls } \\
\text { Grimh } \\
\text { Hayward Hydro } \\
\text { Jersey } \\
\text { John P. Madgett } \\
\text { Junction } \\
\text { Kaukauna Gas \& Diese } \\
\text { Kilboum } \\
\text { Ladysmith } \\
\text { Lower Weed } \\
\text { Menasha } \\
\text { Merrill } \\
\text { Milwaukee County } \\
\text { Nancy } \\
\text { New Badger } \\
\text { Nine Springs } \\
\text { Old Badger } \\
\text { Otter Rapids } \\
\text { Peshtigo } \\
\text { Pine } \\
\text { Point Beach } \\
\text { Potato Rapids } \\
\text { Prairie Du Sac } \\
\text { Rapide Croche } \\
\text { Rock River } \\
\text { Saxon Falls } \\
\text { Sheepskin } \\
\text { South Fond Du Lac } \\
\text { St Croix Falls } \\
\text { Stiles } \\
\text { Sycamore } \\
\text { Tomahawk } \\
\text { Upper Weed } \\
\text { Washington Island } \\
\text { West Marinette } \\
\text { White River } \\
\text { Wisconsin River Div }\end{array}$ & 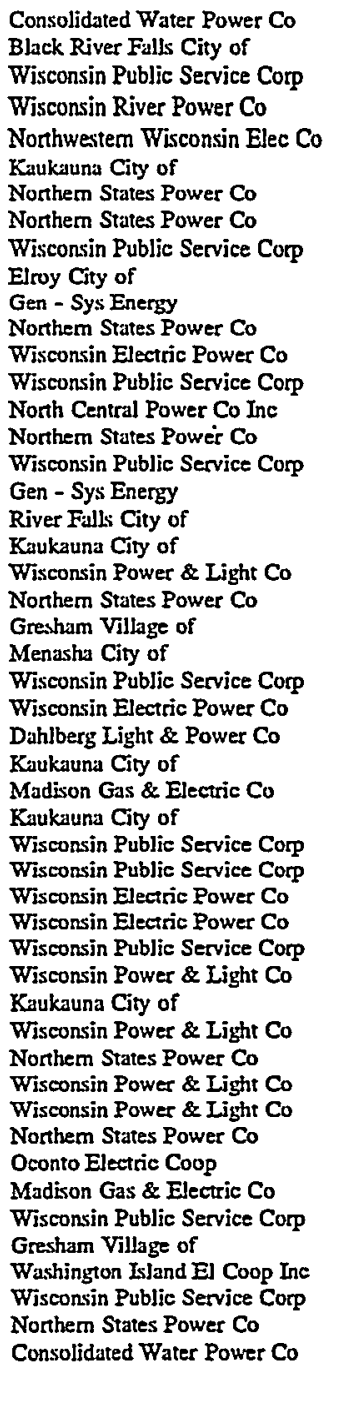 \\
\hline \multicolumn{4}{|l|}{ Wyoming } \\
\hline $\begin{array}{l}\text { Alcova } \\
\text { Buffalo Bill } \\
\text { Dave Johnston } \\
\text { Fremont Canyon } \\
\text { Guemsey } \\
\text { Jim Bridger } \\
\text { Laramie R Station } \\
\text { Neil Simpson } \\
\text { Pilot Butte } \\
\text { Shoshone } \\
\text { Strawberry Creek } \\
\text { Wyodak }\end{array}$ & $\begin{array}{l}\text { Bureau of Reclamation } \\
\text { Bureau of Reclamation } \\
\text { Pacificorp } \\
\text { Bureau of Reclamation } \\
\text { Bureau of Reclamation } \\
\text { PacifiCorp } \\
\text { Basin Electric Power Coop } \\
\text { Black Hills Corp } \\
\text { Bureau of Reclamation } \\
\text { Bureau of Reclamation } \\
\text { Lower Valley Power \& Light Ine } \\
\text { PacifiCorp }\end{array}$ & $\begin{array}{l}\text { Boysen } \\
\text { Cheyenne Diesel } \\
\text { Fontenelle } \\
\text { Glendo } \\
\text { Heart Mountain } \\
\text { Kortes } \\
\text { Naughton } \\
\text { Neil Simpson II } \\
\text { Seminoe } \\
\text { Spirit Mountain } \\
\text { Viva Naughton }\end{array}$ & $\begin{array}{l}\text { Bureau of Reclamation } \\
\text { Cheyenne Light Fuel \& Power Co } \\
\text { Bureau of Reclamation } \\
\text { Bureau of Reclamation } \\
\text { Bureau of Reclamation } \\
\text { Bureau of Reclamation } \\
\text { Pacificorp } \\
\text { Black Hills Corp } \\
\text { Bureau of Reclamation } \\
\text { Bureau of Reclamation } \\
\text { PacifiCorp }\end{array}$ \\
\hline
\end{tabular}

Source; •Energy Information Administration, Form EIA-860, “Annual Electric Generator Report." 
Table D3. U.S. Electric Utility Plants by Utility, as of January 1, 1998

\begin{tabular}{|c|c|c|c|}
\hline Utility / Plant Name & State & Utility / Plant Name & State \\
\hline 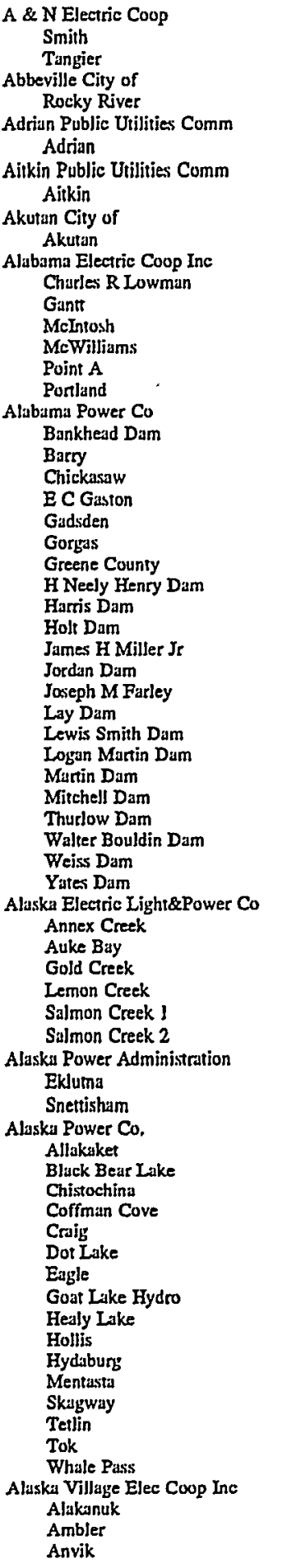 & 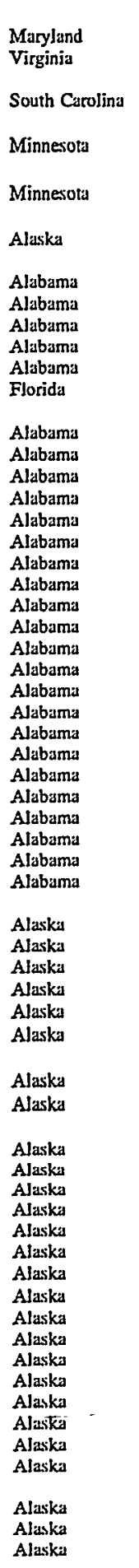 & 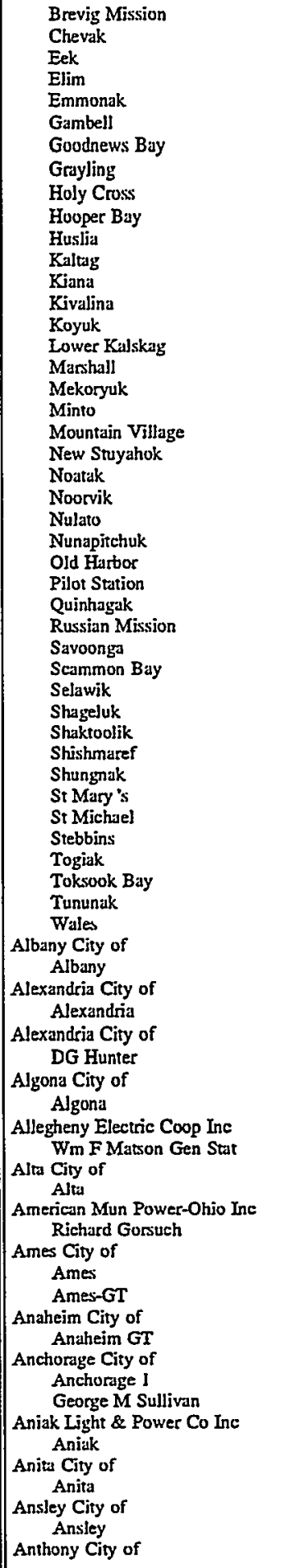 & 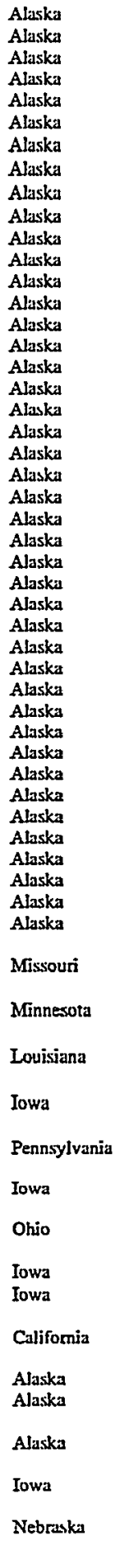 \\
\hline
\end{tabular}

See footnotes at end of table. 
Table D3. U.S. Electric Utility Plants by Utility, as of January 1, 1998 (Continued)

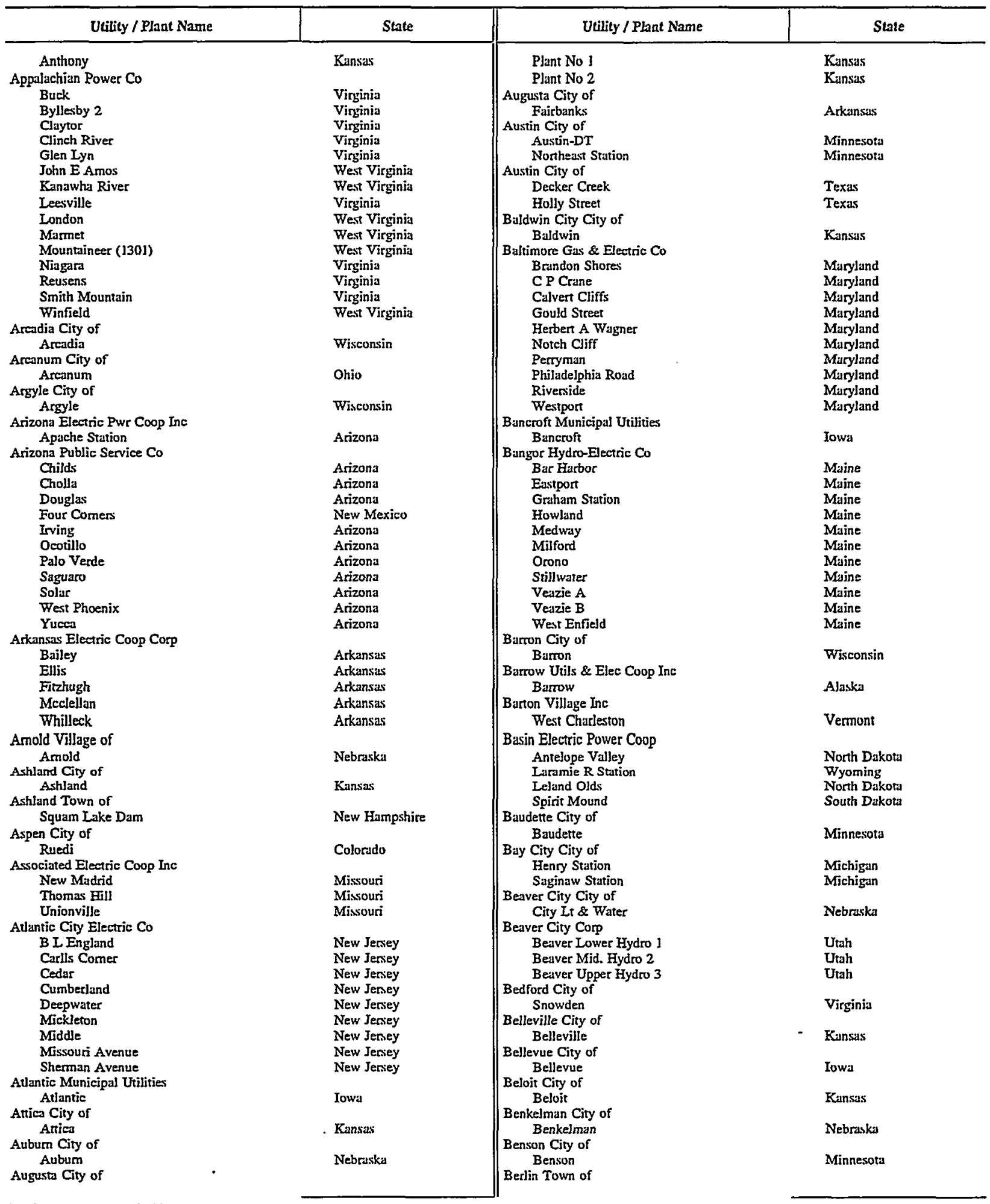

See footnotes at end of table. 
Table D3. U.S. Electric Utility Plants by Utility, as of January 1, 1998 (Continued)

\begin{tabular}{|c|c|c|c|}
\hline Utility / Plant Name & State & Utility / Phant Name & State \\
\hline $\begin{array}{c}\text { Berlin } \\
\text { Bethany Ciry of }\end{array}$ & Maryland & $\begin{array}{l}\text { Bryan City of } \\
\text { Dansby }\end{array}$ & Texas \\
\hline Bethany & Missouri & Burbank City of & 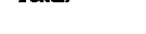 \\
\hline Bethel Utilities Corp & & Magnolia & Califomia \\
\hline Bethel & Alaska & Olive & Califomia \\
\hline Bettles Light \& Power Inc & & Bureau of Reclamation & \\
\hline Betrles Light \& Pwr & Alaska & Alcova & Wyoming \\
\hline Big Rivers Electric Corp & & Andersion Ranch & Iduho \\
\hline D B Wilson & Kentucky & Big Thompson & Colorado \\
\hline HMP\&L Stution 2 & Kentucky & Black Canyon & Idaho \\
\hline K C Coleman & Kentucky & Blue Mesa & Colorado \\
\hline RA Reid & Kentucky & Boise $R$ Diversion & Idaho \\
\hline R. D Green & Kentucky & Boysen & Wyoming \\
\hline Black Hills Corp & & Buffalo Bill & Wyoming \\
\hline Ben French & South Dakota & Canyon Ferry & Montana \\
\hline Neil Simpson & Wyoming & Chandler & Washington \\
\hline Neil Simpson II & Wyoming & Crystal & Colorado \\
\hline Black River Falls City of & & Davis & Arizona \\
\hline Black River Fallsi & Wisconsin & Deer Creek & Utah \\
\hline Block Island Power Co & & Elephant Butre & New Mexico \\
\hline Block Island & Rhode Island & Extes & Colorado \\
\hline Bloomfield City of & & Flaming Gorge & Utah \\
\hline Bloomfield & Iowa & Flatiron & Colorado \\
\hline Blooming Prairie City of & & Folsom & Califomia \\
\hline Blooming Prairie & Minnesota & Fontenelle & Wyoming \\
\hline Blue Earth City of & & Fremont Canyon & Wyoming \\
\hline Blue Earth & Minnesota & Glen Canyon & Añzona \\
\hline Blue Hill City of & & Glendo & Wyoming \\
\hline City Ijght \& Water & Nebraska & Grand Coulee & Washington \\
\hline Blue Ridge Elec Member Corp & & Green Mountain & Colurado \\
\hline Sharp Falls & North Carolina & Green Springs & Oregon \\
\hline Bluffion City of & & Guemsey & Wyoming \\
\hline Bluffton & Indiana & Headgate Rock & Anizona \\
\hline Bonners Ferty City of & & Heart Mountain & Wyoming \\
\hline Moyie Spgs & Idaho & Hoover & Nevada \\
\hline Boston Edison Co & & Hungry Horse & Montana \\
\hline Edgar & Massachusetts & Judge F Carr & Califomia \\
\hline Framingham & Massachusetts & Keswick & California \\
\hline L Street & Massachuserts & Kortes & Wyoming \\
\hline Mystic & Massachusetts & Lewiston & Califomia \\
\hline New Boston & Massachusetts & Lower Molina & Colorado \\
\hline Pilgtim & Massachusetts & Marys Lake & Colorado \\
\hline West Medway & Massachusetts & MePhee & Colorado \\
\hline Bouniful City City of & & Minidoka & Idaho \\
\hline Bountiful City & Utah & Morrow Point & Colorado \\
\hline Echo Dam & Utah & Mount Elbert & Colorado \\
\hline Pine View Dam & Utah & New Melones & Califomia \\
\hline Bowling Green City of & & Nimbus & California \\
\hline Bowling Green & Ohio & O'Neill & California \\
\hline Braintree Town of & & Palisades & Iduho \\
\hline Potter Stution 2 & Massachusetts & Parker & Califomia \\
\hline Brazos Electric Power Coop Inc & & Pilot Burte & Wyoming \\
\hline North Texas & Texas & Pole Hill & Colorado \\
\hline RW Miller & Texas & Roza & Washington \\
\hline Bruzos River Authority & & Seminoe & Wyoming \\
\hline Morris Sheppard & Texas & Shasta & Califomia \\
\hline Bresse City of & & Shoshone & Wyoming \\
\hline Breese & Illinois & Spirit Mountain & Wyoming \\
\hline Brighum City Corp & & Spring Creek & California \\
\hline Box Elder & Utah & Stampede & Califomia \\
\hline Brigham City & Utah & Towale & Colorado \\
\hline Broken Bow City of & & Trinity & California \\
\hline Broken Bow & Nebraska & Upper Molina & Colorado \\
\hline Brooklyn City of & & Waddell & Arizona \\
\hline Brooklyn & Iowa & Yellowtail & Montana \\
\hline Brownfield City of & & Butlingame City of & \\
\hline Brownfield & Texas & Burlingame & Kansas \\
\hline Brownsville Public Utils Board & & Burlington City of & \\
\hline $\begin{array}{l}\text { Si Rayy } \\
\text { Bryan City of }\end{array}$ & Texas & Burlingron G T & Vermont \\
\hline $\begin{array}{l}\text { Bryan City of } \\
\text { Auglaize Hydro }\end{array}$ & Ohio & J C Mcneil & Vermont \\
\hline $\begin{array}{l}\text { Augranze Hyaro } \\
\text { Bryan }\end{array}$ & Ohio & $\begin{array}{l}\text { Burlington City of } \\
\text { Burlington }\end{array}$ & Colorado \\
\hline
\end{tabular}

See footnotes ut end of table. 
Table D3. U.S. Electric Utility Plants by Utility, as of January 1, 1998 (Continued)

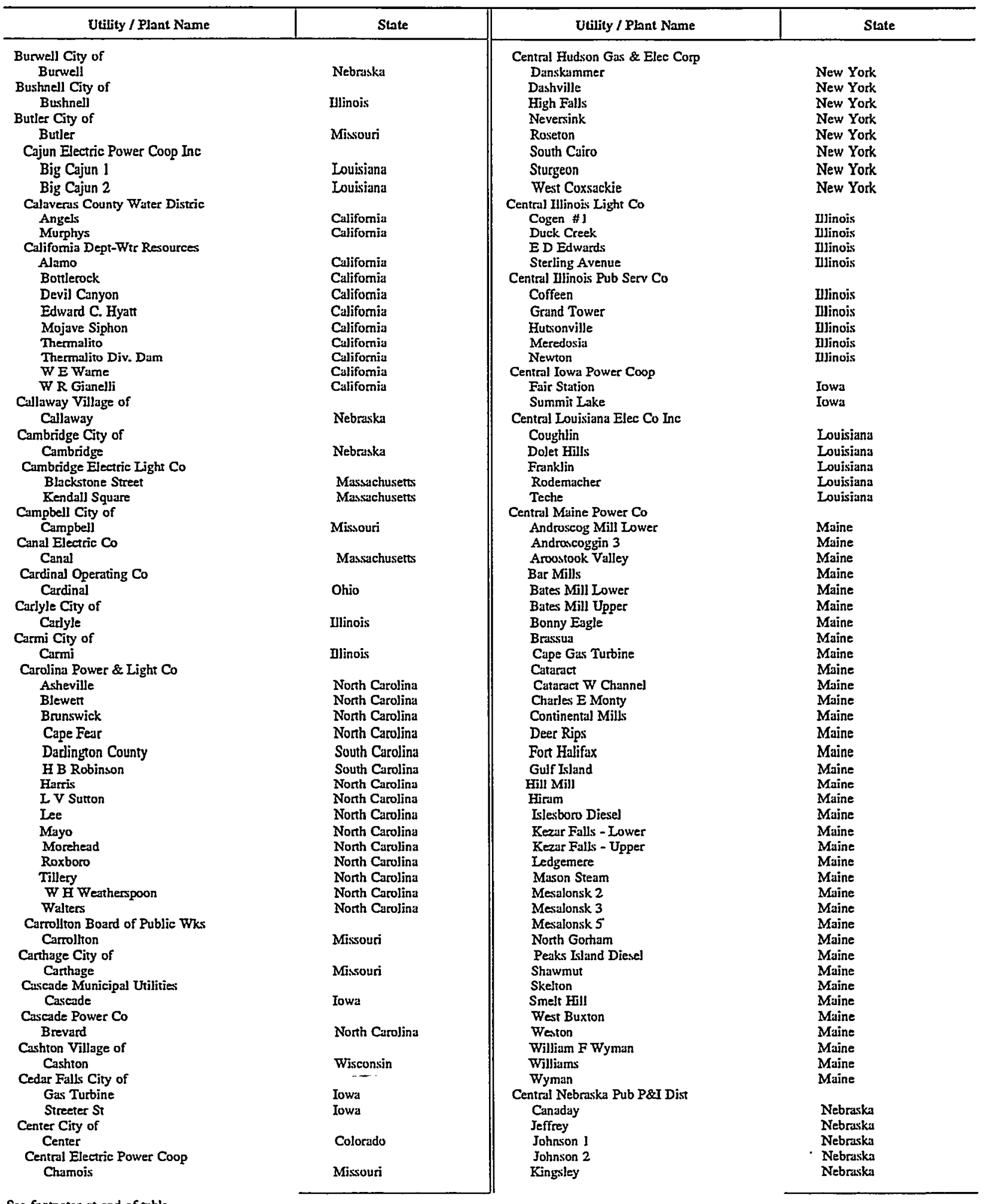


Table D3. U.S. Electric Utility Plants by Utility, as of Jannary 1, 1998 (Continued)

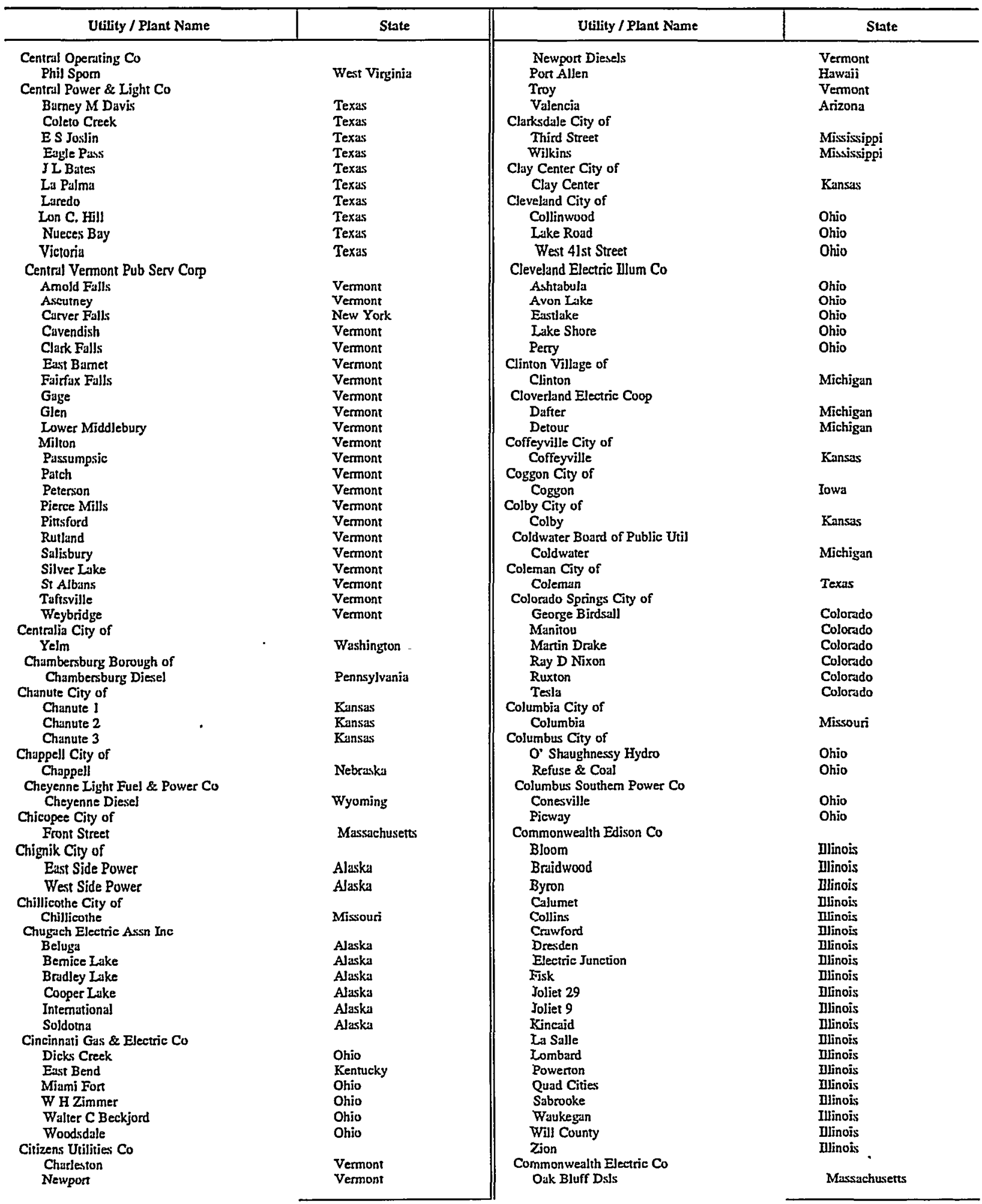

See footnotes at end of table. 
Table D3. U.S. Electric Utility Plants by Utility, as of January 1, 1998 (Continued)

\begin{tabular}{|c|c|c|c|}
\hline Utility / Plant Name & State & Utility / Plant Name & State \\
\hline West Tisbury & Massachusetts & Cordova Electric Coop Inc & \\
\hline Connecticut Light \& Power Co & & Eyak & Alaska \\
\hline Bantam & Connecticut & Humpbrack Creek & Alaska \\
\hline Branford & Connecticut & Orca & Alaska \\
\hline Bulls Bridge & Connecticut & Corn Belt Power Coop & \\
\hline $\mathrm{Cos} \mathrm{Cob}$ & Connecticut & Earl $F$ Wisdom & Iowa \\
\hline Devon & Connecticut & Humboldt & Lowa. \\
\hline Falls Village & Connecticut & Coming City of & \\
\hline Franklin Drive & Connecticut & Coming & Iowa \\
\hline Middletown & Connecticut & Craig-Butetour Electric Coop & \\
\hline Montville & Connecticut & Meadow Creek & Virginia \\
\hline Norwalk Harbor & Connecticut & Crawfordsville Elec Lgr\&Pwr Co & \\
\hline Robertsville & Connecticut & Crawfordsville & Indiana \\
\hline Scotland Dam . & Connecticur & Crere City of & \\
\hline $\begin{array}{l}\text { Shepaug } \\
\text { South Meadow }\end{array}$ & $\begin{array}{l}\text { Connecticut } \\
\text { Connecticut }\end{array}$ & $\begin{array}{l}\text { Crete Mun Power } \\
\text { Crisp County Power Comm }\end{array}$ & Nebraskil \\
\hline Stevenson & Connecticut & Plant Crisp & Georgia \\
\hline Tafwille & Connecticut & Warwick & Georgia \\
\hline Torrington & Connecticut & Croswell City of & \\
\hline Tunnel & Connecticut & Croswell & Michigan \\
\hline Consolidated Edison Co-NY Inc & & Crystal Falls City of & \\
\hline Arthur Ki]J & New York & Crystal Falls & Michigan \\
\hline Astoria & New York & Culpeper Town of & \\
\hline Buchanan & New York & West Spring Street & Virginia \\
\hline East River & New York & Curtis City of & \\
\hline Gowanus & New York & Curtis & Nebraska \\
\hline Hudson Avenue & New York & Cushing City of & \\
\hline Indian Point & New York & Cushing & Oklahoma \\
\hline Narrows & New York & Cuyahoga Falls City of & \\
\hline Ravenswood & New York & Engle & Ohio \\
\hline Waterside & New York & Dahlberg Light \& Power Co & \\
\hline $59 \mathrm{th}$ Street & New York & Gordon & Wisconsin \\
\hline 74th Street & New York & Nancy & Wisconsin \\
\hline Consolidated Water Power Co & & Solon Diesel & Wisconsin \\
\hline Biron & Wisconsin & Danville City of & \\
\hline Du Bay & Wisconsin & Pinnacles & Virginia \\
\hline Stevens Point & Wisconsin & Dayton City of & \\
\hline Wisconsin Rapids & Wisconsin & Dayton & Iowa \\
\hline Wisconsin River Div & Wisconsin & Dayton Power \& Light Co & \\
\hline Consumess Energy Co & & Frank M Tait & Ohio \\
\hline Alcona & Michigan & J M Stuart & Ohio \\
\hline Allegan Dam & Michigan & Killen Station & Ohio \\
\hline B C Cobb & Michigan & Monument & Ohio \\
\hline B E Morrow & Michigun & $\mathrm{O}$ H Hutchings & Ohio \\
\hline CW Tippy & Michigan & Sidney & Ohio \\
\hline Cooke & Michigan & Yankee Street & Ohio \\
\hline Croton & Michigan & Delano City of & \\
\hline Dan E Kam & Michigan & Delano & Minnesota \\
\hline Five Channels & Michigan & Delmarva Power \& Light Co & \\
\hline Foote & Michigan & Bayview & Virginja \\
\hline Gaylord & Michigan & Christiana & Delaware \\
\hline Hardy & Michigun & $\begin{array}{l}\text { Crisfield } \\
\text {. }\end{array}$ & Maryland \\
\hline Hodenpyl & Michigan & Delaware City & Delaware \\
\hline J C Weadock & Michigan & Edge Moor & Delaware \\
\hline J H Campbell & Michigan & Hay Road & Delaware \\
\hline IR Whiting & Michigan & Indian River & Delaware \\
\hline Loud & Michigan & Madison Street & Delaware \\
\hline Ludington & Michigan & Tasley & Virginia \\
\hline Mio & Michigan & Vienna & Maryland \\
\hline Rogers & Michigan & West Substution & Delaware \\
\hline Straits & Michigan & Dejta City of & \\
\hline Therford & Michigan & Delta & Colorado \\
\hline Webber & Michigan & Denton City of & \\
\hline Coon Rapids City of & & Lewisville & Texas \\
\hline Coon Rapids & Iowa & Ruly Roberts & Texas \\
\hline Coop Power Assn & & Spencer & Texas \\
\hline Coal Creek & North Dakota & Deseret Generation \& Tran Coop & \\
\hline St Bonifacius & Minnesota & Bonanza & Utah \\
\hline Copper Valley Elec Assn Inc & & Deshler City of & \\
\hline Glennallen & Alaskal & Deshler & Nebraskis \\
\hline Solomon Gulch & Alaska & Detroit City of & \\
\hline Valdez & Alanka & Mistersky & Michigan \\
\hline
\end{tabular}

See footnotes at end of table. 
Table D3. U.S. Electric Utility Plants by Utility, as of January 1, 1998 (Continued)

\begin{tabular}{|c|c|c|c|}
\hline Utility / Plant Name & State & Utility / Plant Name & State \\
\hline 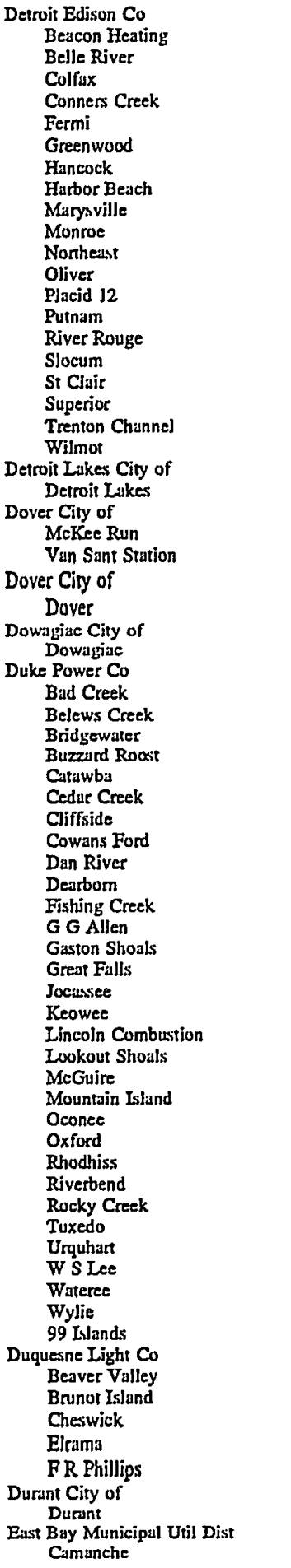 & 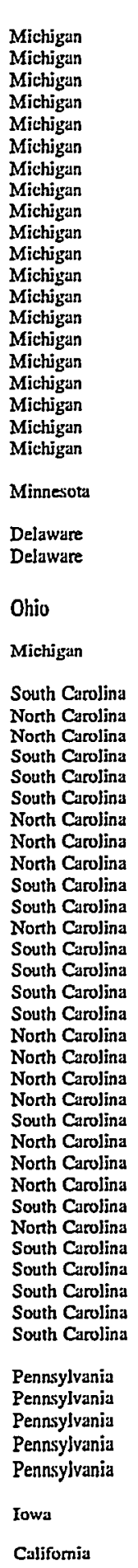 & 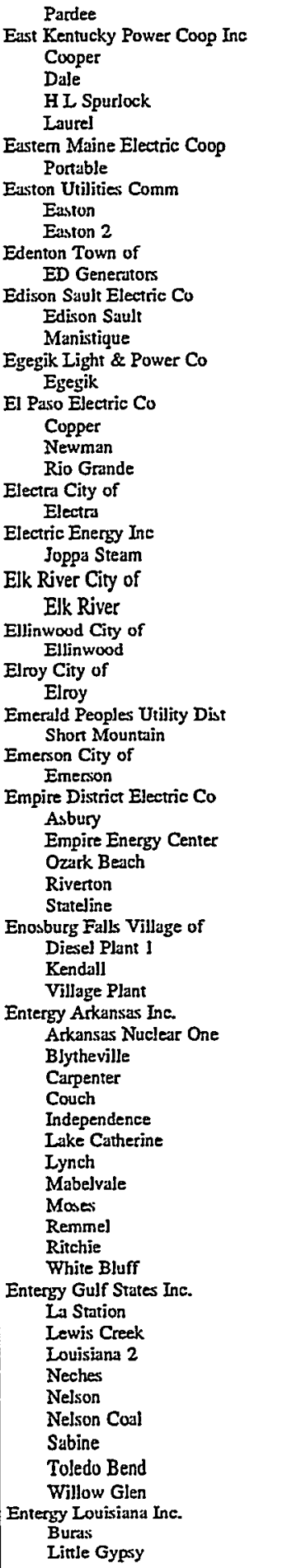 & 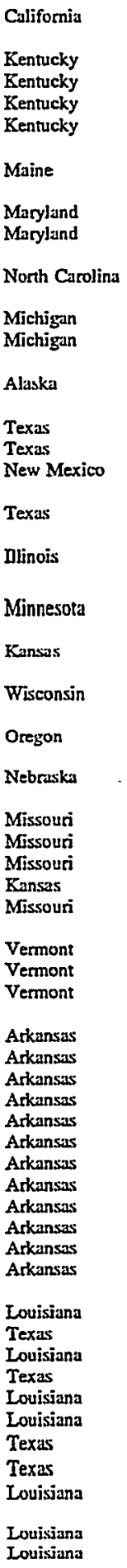 \\
\hline
\end{tabular}

See footnotes at end of table. 
Table D3. U.S. Electric Utility Plants by Utility, as of January 1, 1998 (Continued)

\begin{tabular}{|c|c|c|c|}
\hline Utility / Plant Name & State & Utility / Plant Name & State \\
\hline 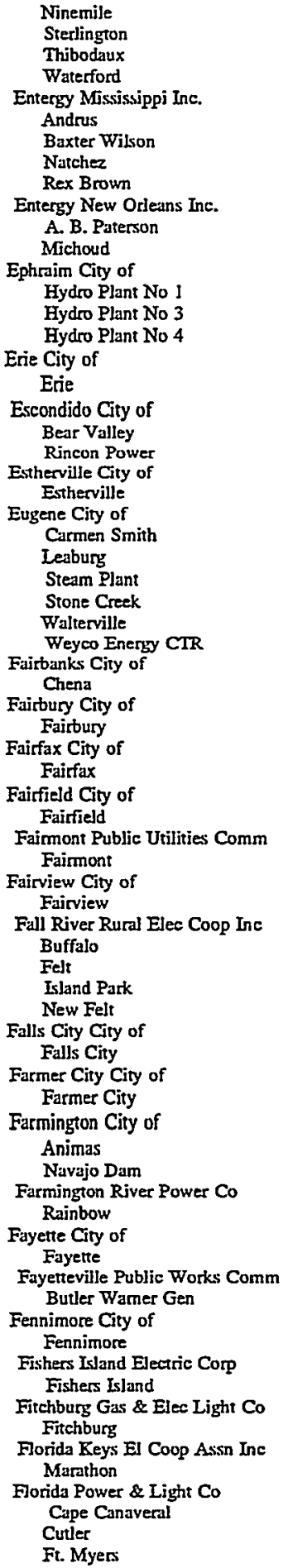 & 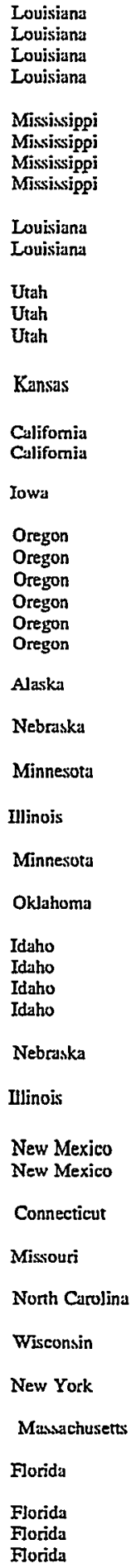 & 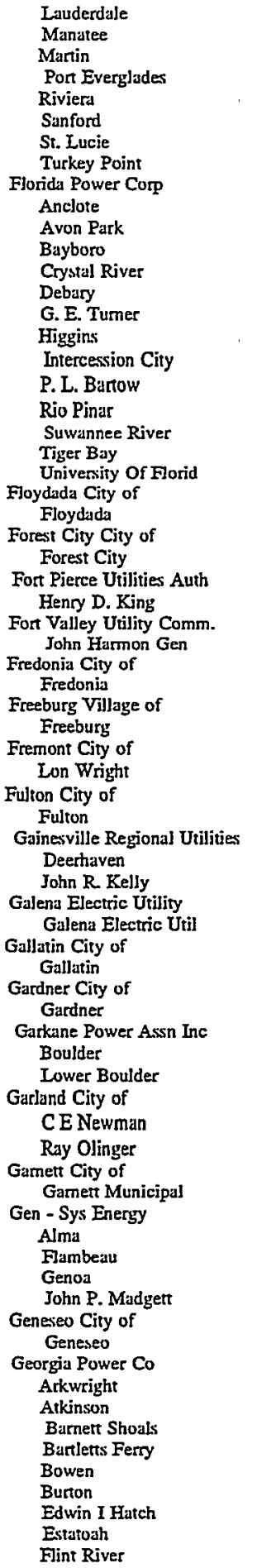 & 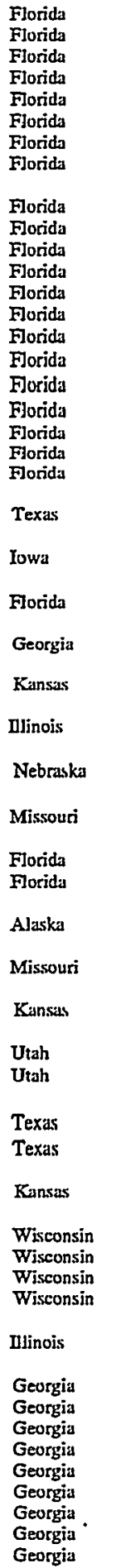 \\
\hline
\end{tabular}

See footnotes at end of table. 
Table D3. U.S. Electric Utility Plants by Utility, as of January 1, 1998 (Continued)

\begin{tabular}{|c|c|c|c|}
\hline Utility / Plant Name & State & Utility / Plant Name & State \\
\hline 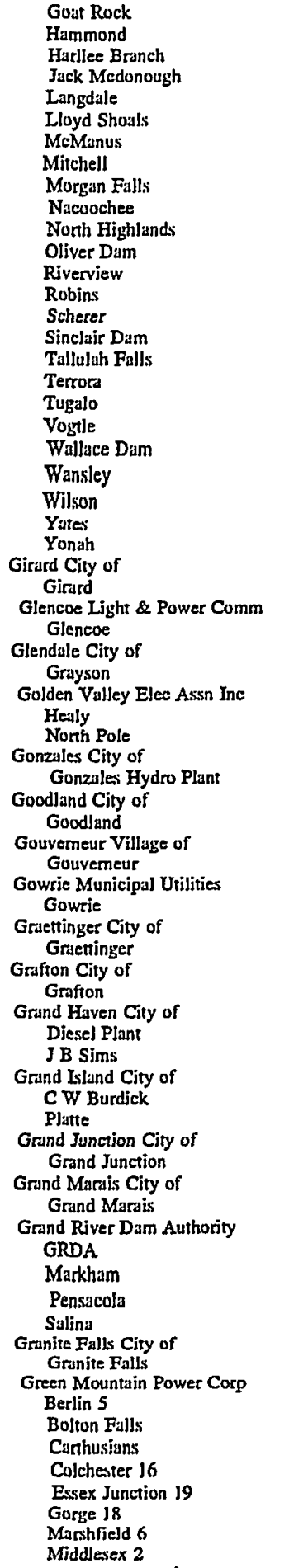 & $\begin{array}{l}\text { Georgia } \\
\text { Georgia } \\
\text { Georgia } \\
\text { Georgia } \\
\text { Georgia } \\
\text { Georgia } \\
\text { Georgia } \\
\text { Georgia } \\
\text { Georgia } \\
\text { Georgia } \\
\text { Georgia } \\
\text { Georgia } \\
\text { Georgia } \\
\text { Georgia } \\
\text { Georga } \\
\text { Georgia } \\
\text { Georgia } \\
\text { Georgia } \\
\text { Georgia } \\
\text { Georgia } \\
\text { Georgia } \\
\text { Georgia } \\
\text { Georgia } \\
\text { Georgia } \\
\text { Georgia } \\
\text { Kansas } \\
\text { Minnesota } \\
\text { Califomia } \\
\text { Alaska } \\
\text { Alaskia } \\
\text { Texas } \\
\text { Kansas } \\
\text { New York } \\
\text { Iowa } \\
\text { Iowa } \\
\text { Nornh Dakota } \\
\text { Machigan } \\
\text { Michigan } \\
\text { Nebraska } \\
\text { Nebraska } \\
\text { Iowa } \\
\text { Minnesota } \\
\text { OkJahoma } \\
\text { OkJahoma } \\
\text { OkJahoma } \\
\text { Oklahoma } \\
\text { Minnesota } \\
\text { Vemont } \\
\text { Vemonont } \\
\text { Vermont } \\
\text { Vermont } \\
\text { Vermont } \\
\text { Vermont } \\
\text { Vermont } \\
\text { Vermont }\end{array}$ & 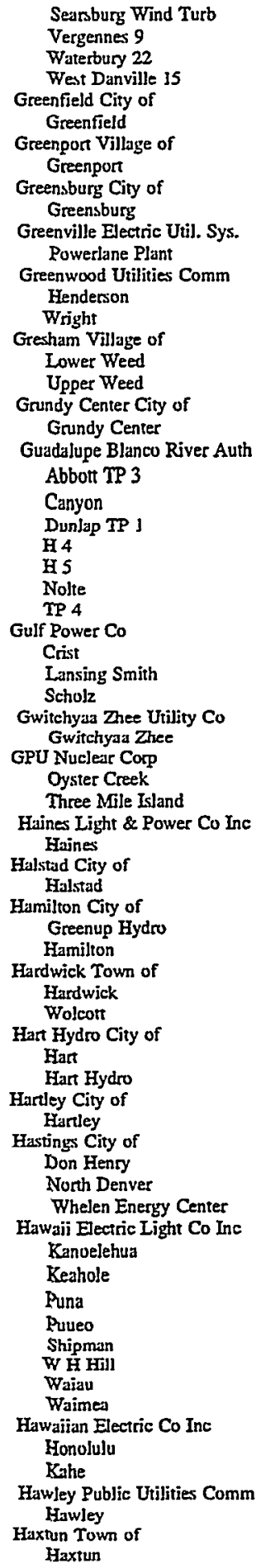 & $\begin{array}{l}\text { Florida } \\
\text { Florida } \\
\text { Forida } \\
\text { Aluska } \\
\text { New Jersey } \\
\text { Pennsylvania } \\
\text { Alaska } \\
\text { Minnesota } \\
\text { Ohio } \\
\text { Ohio } \\
\text { Vermont } \\
\text { Vermont } \\
\text { Michigan } \\
\text { Michigan } \\
\text { Iowa } \\
\text { Nebraska } \\
\text { Nebraska } \\
\text { Nebraska } \\
\text { Hawaji } \\
\text { Hawaji } \\
\text { Hawaii } \\
\text { Hawaij } \\
\text { Hawaij } \\
\text { Hawaij } \\
\text { Hawaii } \\
\text { Hawaii } \\
\text { Hawaii } \\
\text { Hawaii } \\
\text { Minnesota } \\
\text { Colorado }\end{array}$ \\
\hline
\end{tabular}

See footnotes at end of table. 
Table D3. U.S. Electric Utility Plants by Utility, as of January 1, 1998 (Continued)

\begin{tabular}{|c|c|c|c|}
\hline Utility / Plant Name & State & Utility / Plant Name & State \\
\hline 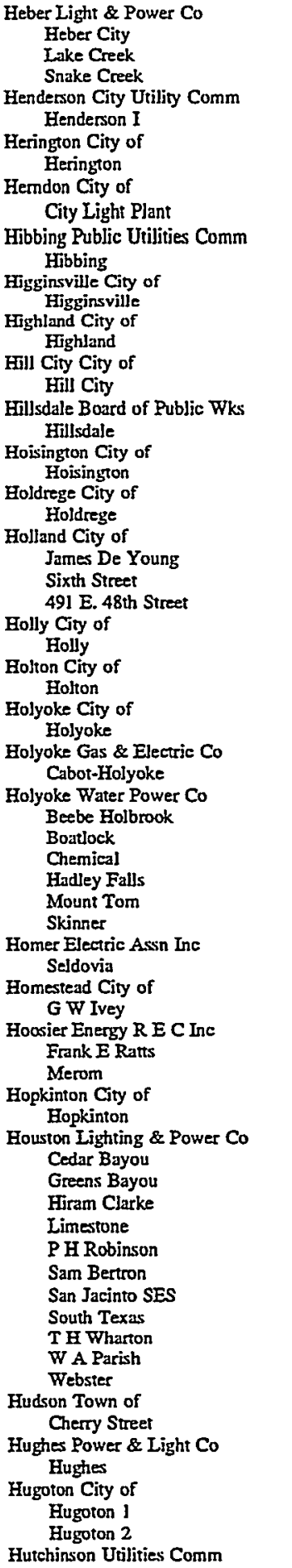 & $\begin{array}{l}\text { Utah } \\
\text { Utah } \\
\text { Utah } \\
\text { Kentucky } \\
\text { Kansas } \\
\text { Kansas } \\
\text { Minnesota } \\
\text { Missouri } \\
\text { Illinois } \\
\text { Kansas } \\
\text { Michigan } \\
\text { Kansas } \\
\text { Nebraska } \\
\text { Michigan } \\
\text { Michigan } \\
\text { Michigan } \\
\text { Colorado } \\
\text { Kansas } \\
\text { Texasas } \\
\text { Texas } \\
\text { Texas } \\
\text { Texas } \\
\text { Texasas } \\
\text { Massachuserts } \\
\text { Colorado } \\
\text { Alaska } \\
\text { Kassachuretts } \\
\text { Kansas } \\
\text { Kansas } \\
\text { Massachusetts } \\
\text { Massachusetts } \\
\text { Massachusetts } \\
\text { Massachusetts } \\
\text { Massachusetts } \\
\text { Mussachusetts } \\
\text { Alaska } \\
\text { Florida } \\
\text { Indiana } \\
\text { Toxas } \\
\text { Texas }\end{array}$ & 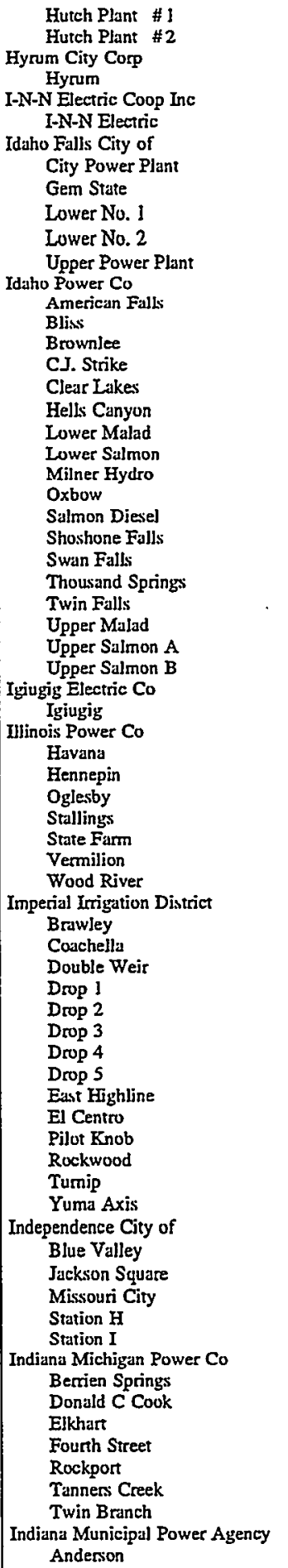 & $\begin{array}{l}\text { Utah } \\
\text { Alaska } \\
\text { Idaho } \\
\text { Idaho } \\
\text { Idaho } \\
\text { Idaho } \\
\text { Idaho } \\
\text { Idaho } \\
\text { Idaho } \\
\text { Idaho } \\
\text { Idaho } \\
\text { Idaho } \\
\text { Oregon } \\
\text { Idaho } \\
\text { Idaho } \\
\text { Idiaho } \\
\text { Oregon } \\
\text { Idaho } \\
\text { Iduho } \\
\text { Idaho } \\
\text { Idaho } \\
\text { Idaho } \\
\text { Idaho } \\
\text { Idaho } \\
\text { Idaho } \\
\text { Alaska } \\
\text { Illinois } \\
\text { Illinois } \\
\text { Illinois } \\
\text { Ilinois } \\
\text { Ilinois } \\
\text { Illinois } \\
\text { Illinois } \\
\text { Califomia } \\
\text { Califomia } \\
\text { Califomia } \\
\text { Califomia } \\
\text { Califomia } \\
\text { California } \\
\text { Califomia } \\
\text { Califomia } \\
\text { Califomia } \\
\text { Califomia } \\
\text { Califomia } \\
\text { Califomia } \\
\text { Califomia } \\
\text { Arizona } \\
\text { Missouri } \\
\text { Missouri } \\
\text { Missouri } \\
\text { Missouri } \\
\text { Missouri } \\
\text { Indiana } \\
\text { Indiana } \\
\text { Indiana } \\
\text { Indiana } \\
\text { Indiana } \\
\text { Indiana }\end{array}$ \\
\hline
\end{tabular}

See footnotes at end of table. 
Table D3. U.S. Electric Utility Plants by Utility, as of January 1, 1998 (Continued)

\begin{tabular}{|c|c|c|c|}
\hline Utility / Plant Name & State & Utility / Plant Name & State \\
\hline 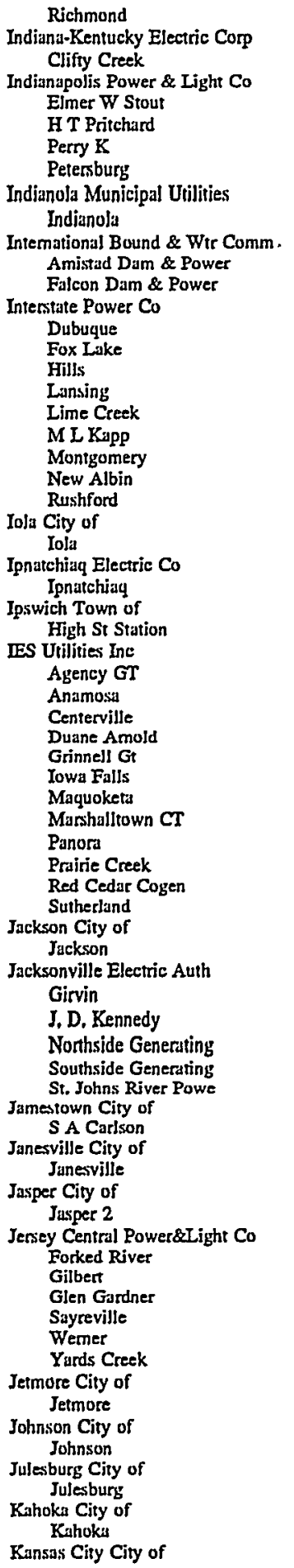 & 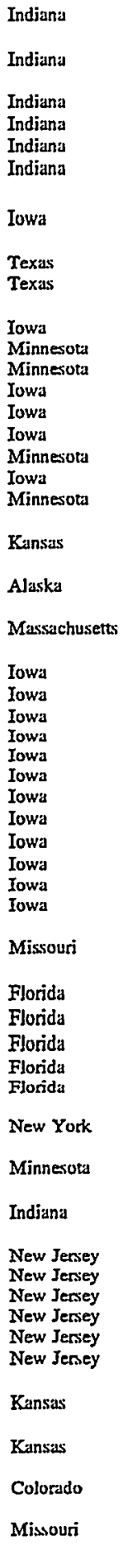 & 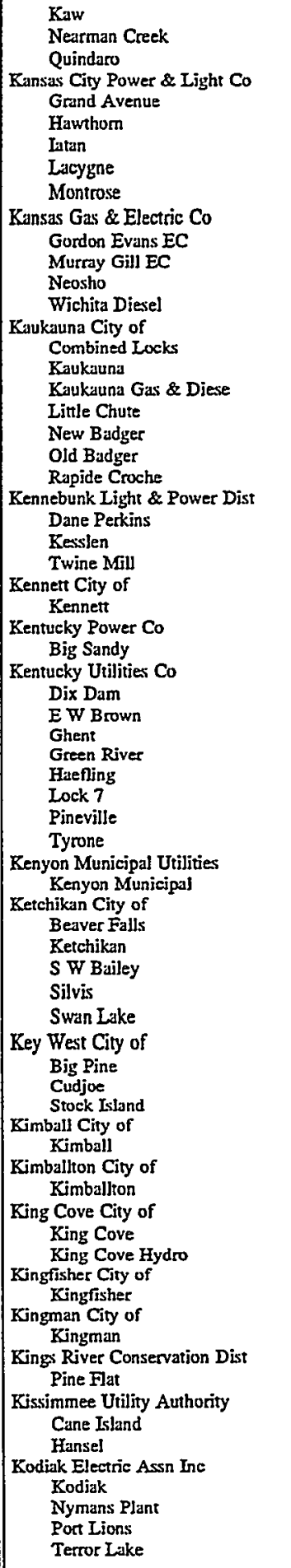 & 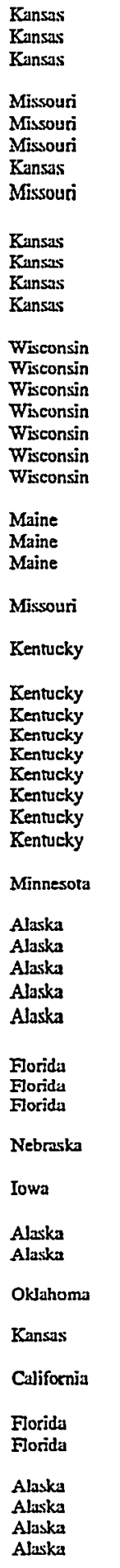 \\
\hline
\end{tabular}

See footnotes at end of table. 
Table D3. U.S. Electric Utility Plants by Utility, as of January 1, 1998 (Continued)

\begin{tabular}{|c|c|c|c|}
\hline Utifity / Plant Name & State & Utility / Phant Name & State \\
\hline 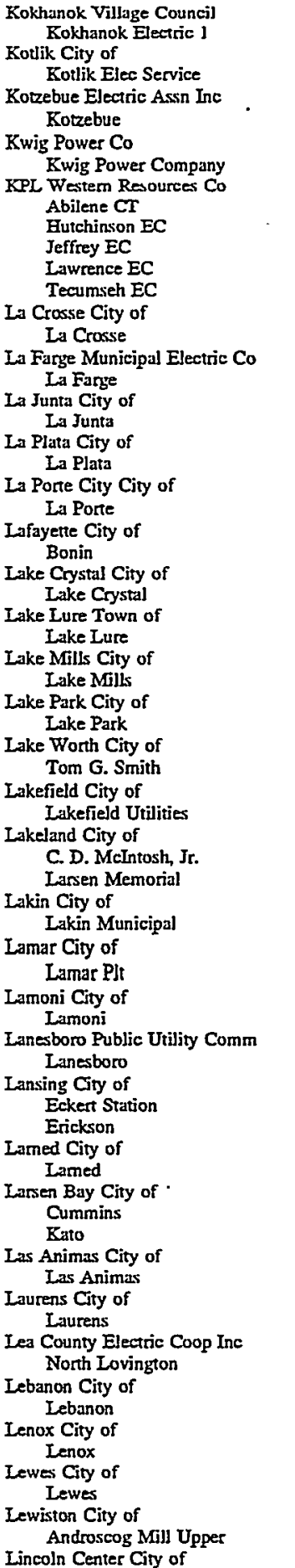 & 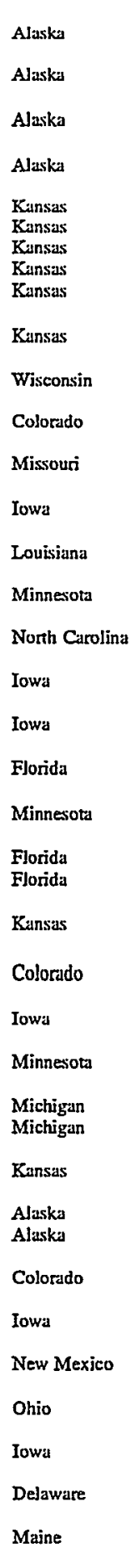 & 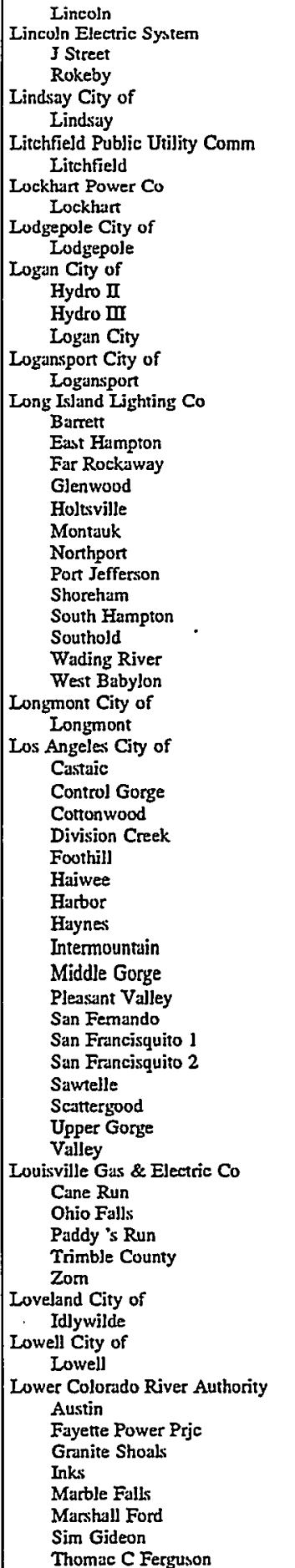 & 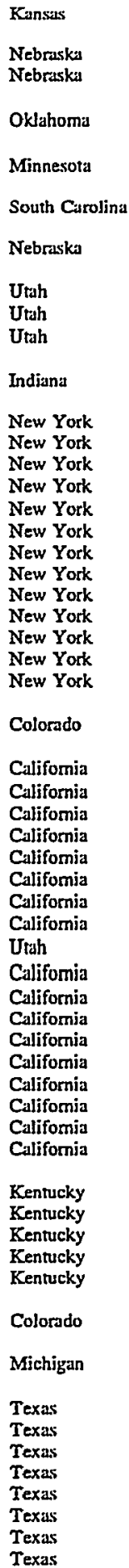 \\
\hline
\end{tabular}


Table D3. U.S. Electric Utility Plants by Utility, as of January 1, 1998 (Continued)

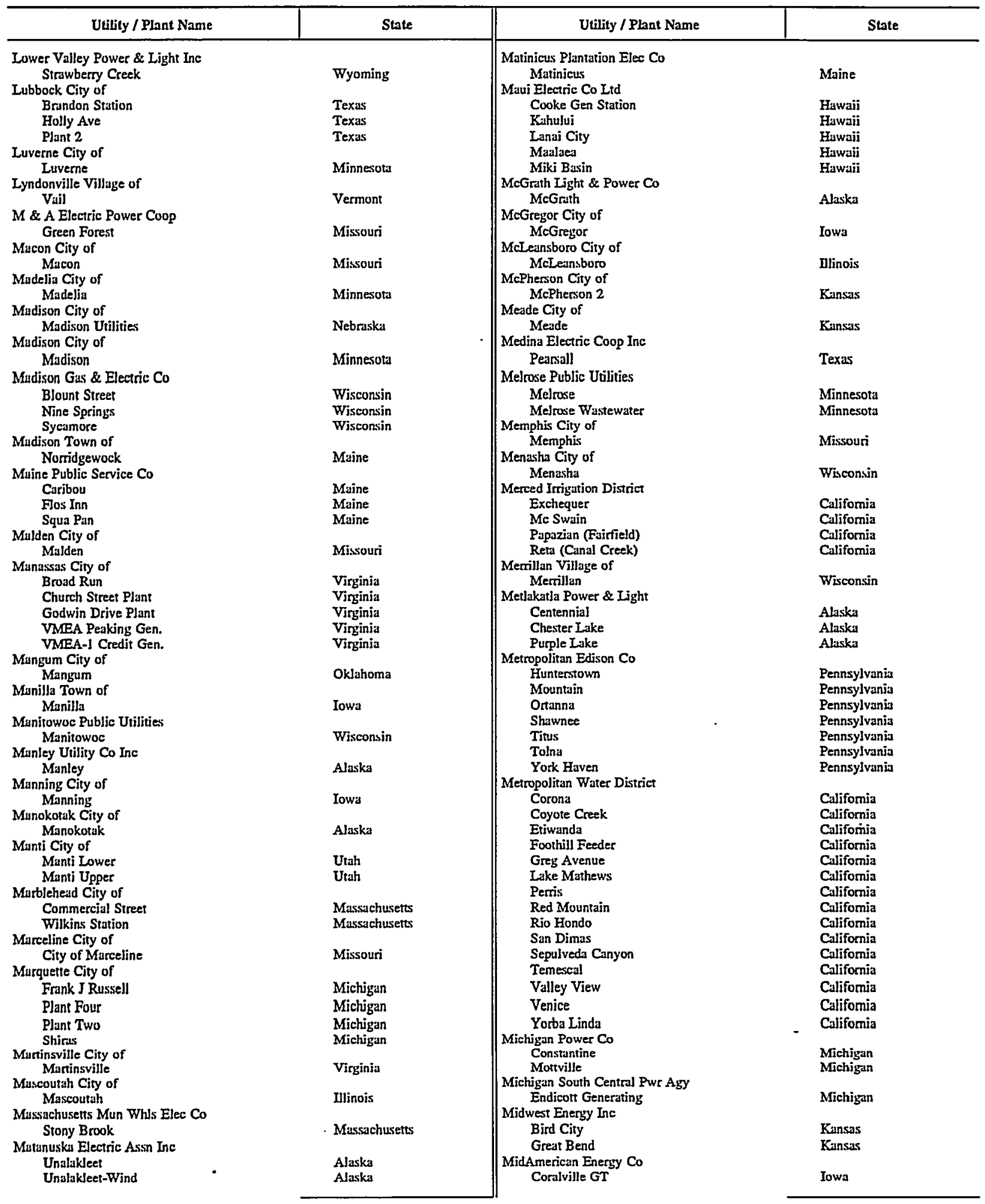

See foutnotes at end of table. 
Table D3. U.S. Electric Utility Plants by Utility, as of January 1, 1998 (Continued)

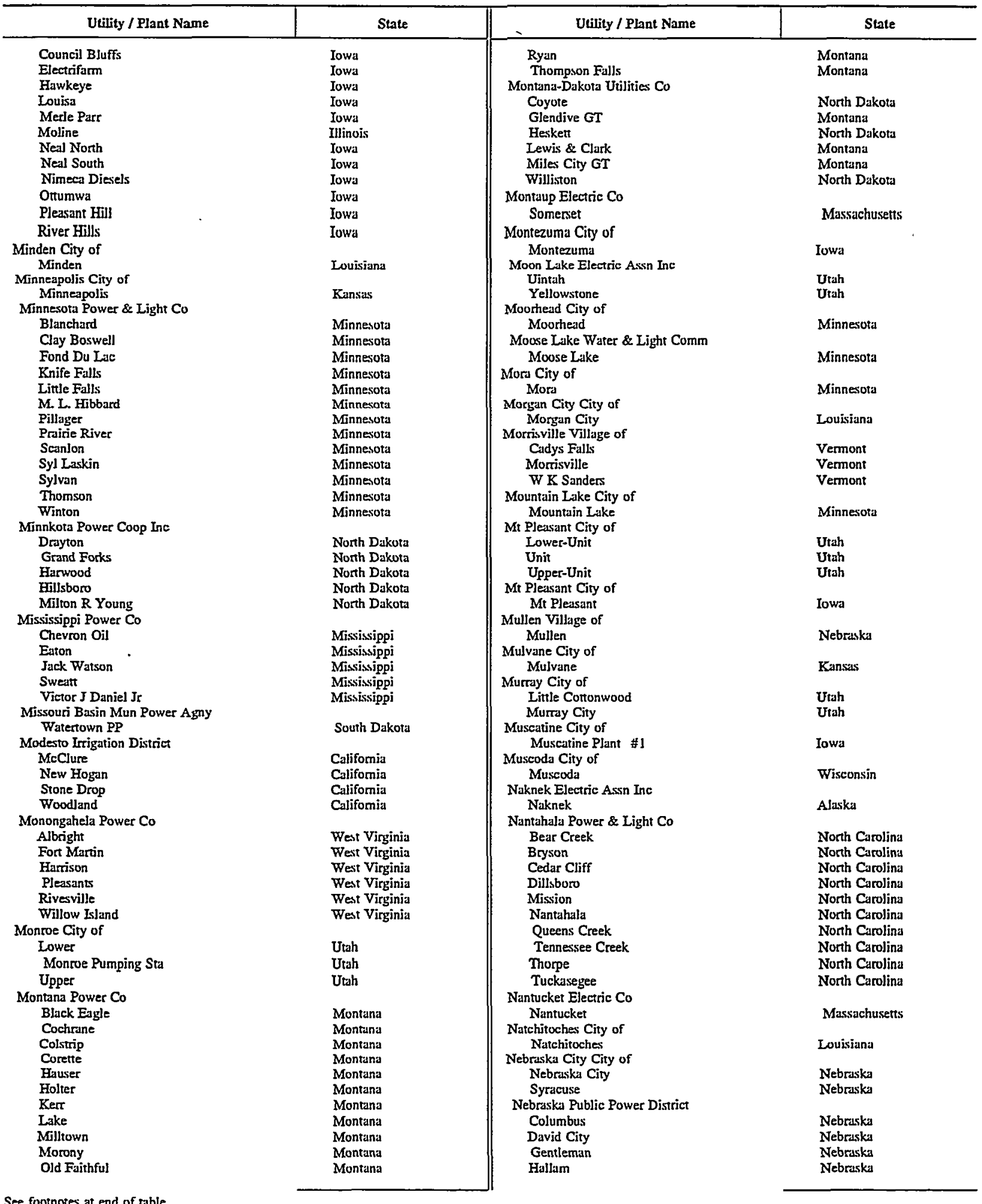

See footnotes at end of table. 
Table D3. U.S. Electric Utility Plants by Utility, as of January 1, 1998 (Continued)

\begin{tabular}{|c|c|c|c|}
\hline Utility / Plant Name & State & Utility / Pant Name & State \\
\hline 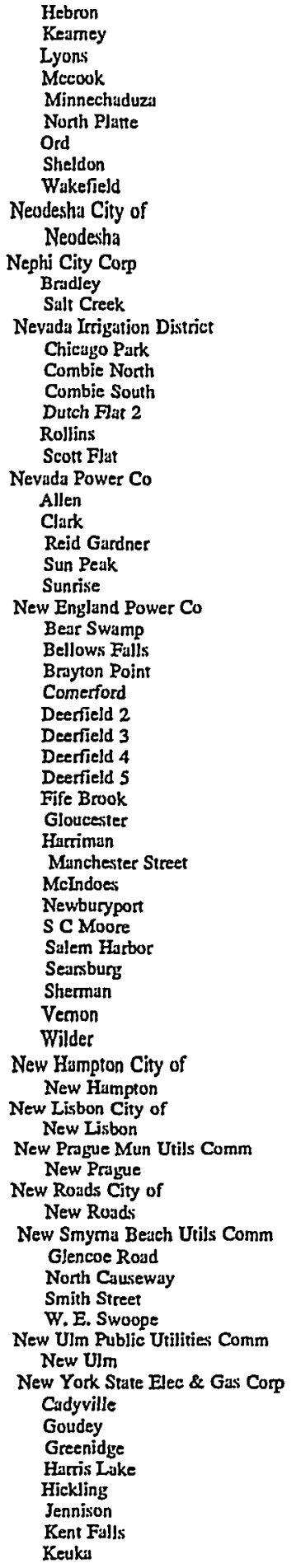 & 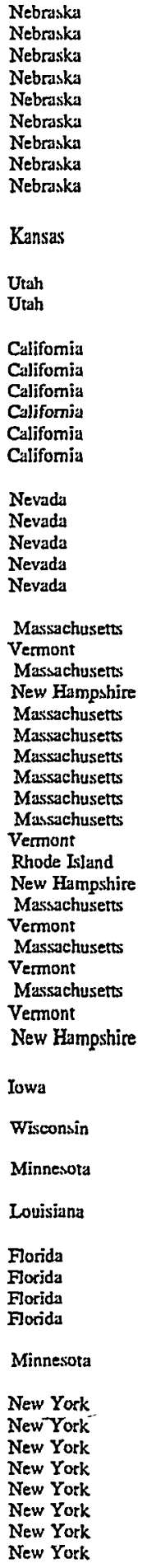 & 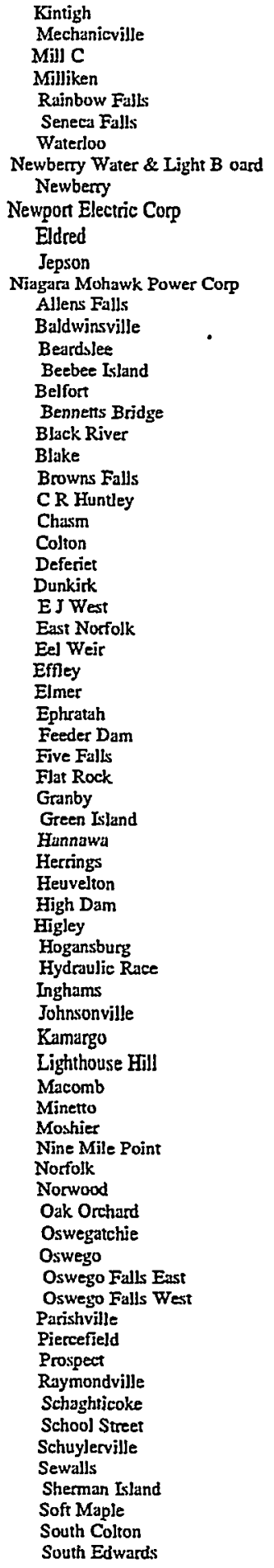 & $\begin{array}{l}\text { New York } \\
\text { New York } \\
\text { New York } \\
\text { New York } \\
\text { New York } \\
\text { New York } \\
\text { New York } \\
\text { New York } \\
\text { New York } \\
\text { New York } \\
\text { New York } \\
\text { New York } \\
\text { New York } \\
\text { New York } \\
\text { New York } \\
\text { New York } \\
\text { New York } \\
\text { New York } \\
\text { New York } \\
\text { New York } \\
\text { New York } \\
\text { New York } \\
\text { New York } \\
\text { New York } \\
\text { New York } \\
\text { New York } \\
\text { New York } \\
\text { New Yew York } \\
\text { New York } \\
\text { New York } \\
\text { New York } \\
\text { New York } \\
\text { New York York } \\
\text { New York } \\
\text { New York } \\
\text { New York } \\
\text { New York } \\
\text { New York } \\
\text { New York } \\
\text { New York } \\
\text { New Yowk York } \\
\text { New York } \\
\text { New York } \\
\text { New York } \\
\text { New York } \\
\text { New York } \\
\text { New York } \\
\text { New York } \\
\text { New York } \\
\text { New York } \\
\text { New York } \\
\text { New York } \\
\text { New York } \\
\text { New }\end{array}$ \\
\hline
\end{tabular}

See footnotes at end of table. 
Table D3. U.S. Electric Utility Plants by Utility, as of January 1, 1998 (Continued)

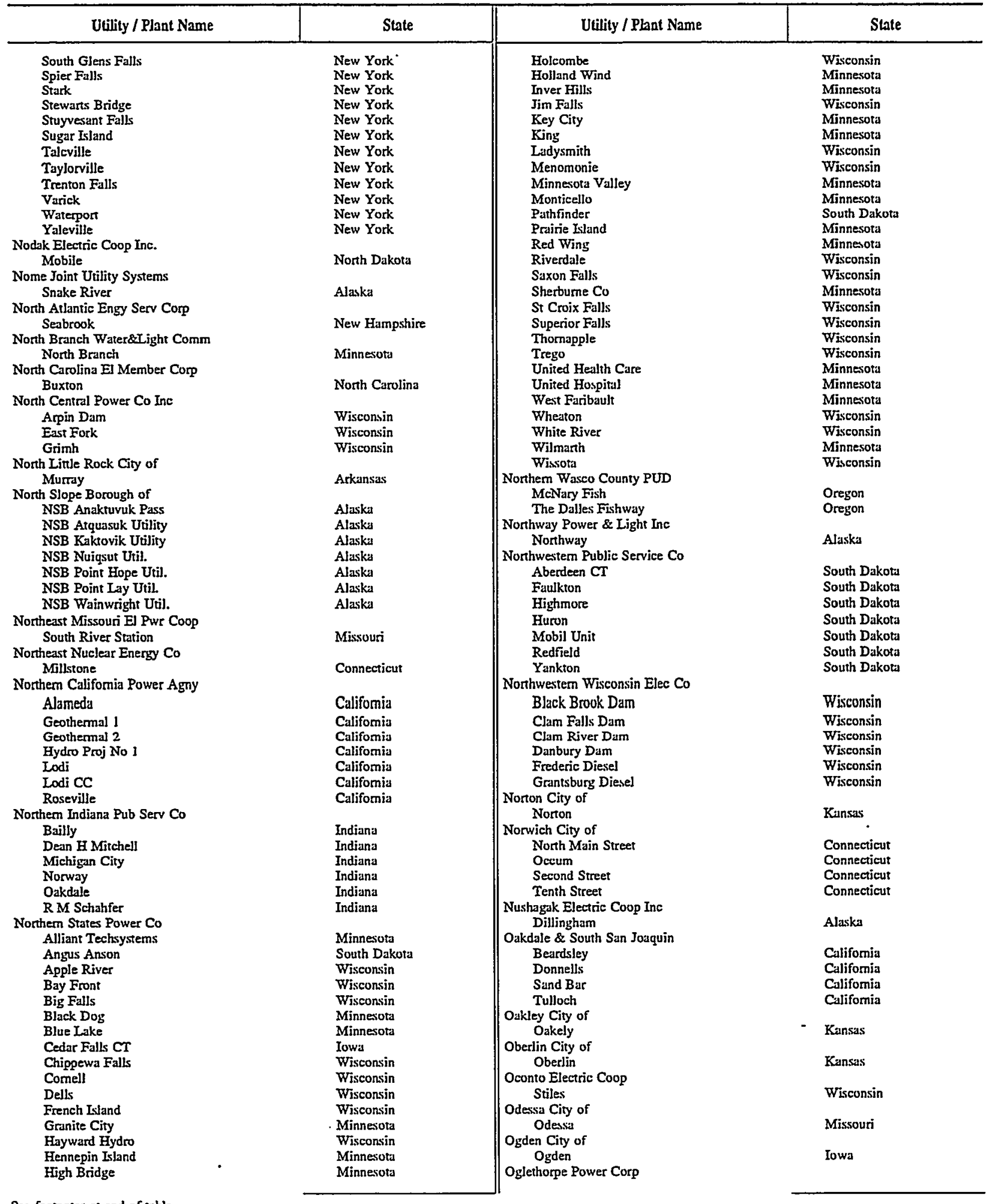

See footnotes at end of table. 
Table D3. U.S. Electric Utility Plants by Utility, as of January 1, 1998 (Continued)

\begin{tabular}{|c|c|c|c|}
\hline Utility / Piant Name & State & Utility / Phnt Name & State \\
\hline 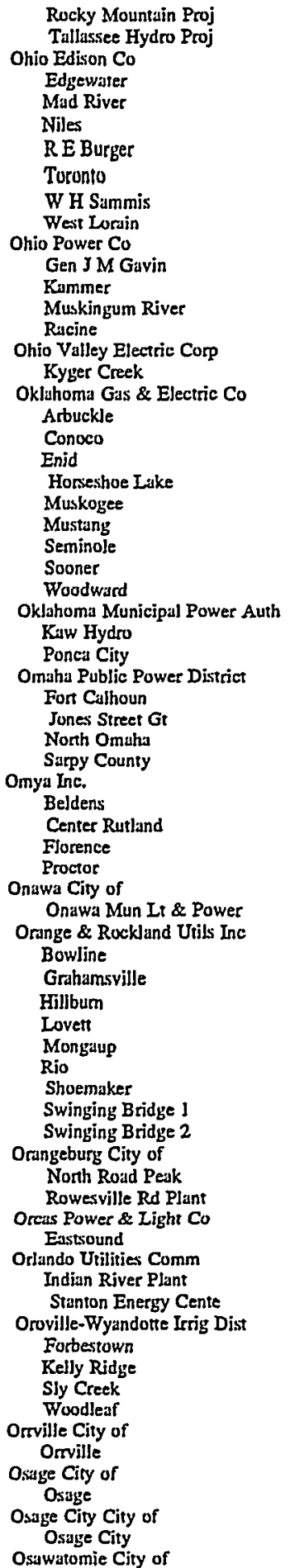 & $\begin{array}{l}\text { Georgia } \\
\text { Georgia } \\
\text { Ohio } \\
\text { Ohio } \\
\text { Ohio } \\
\text { Ohio } \\
\text { Ohio } \\
\text { Ohio } \\
\text { Ohio } \\
\text { Ohio } \\
\text { West Virginia } \\
\text { Ohio } \\
\text { Ohio } \\
\text { Ohio } \\
\text { Oklahoma } \\
\text { Oklahoma } \\
\text { OkJahoma } \\
\text { Oklahtoma } \\
\text { Oklahoma } \\
\text { Oklahoma } \\
\text { Oklahoma } \\
\text { Oklahoma } \\
\text { Oklahoma } \\
\text { Oklahoma } \\
\text { Oklahoma } \\
\text { Nebraska } \\
\text { Nebraska } \\
\text { Nebrskka } \\
\text { Nebraska } \\
\text { Vermont } \\
\text { Vermont } \\
\text { Vermont } \\
\text { Vermont } \\
\text { Iowa } \\
\text { New York } \\
\text { New York } \\
\text { New York } \\
\text { New York } \\
\text { New York } \\
\text { New York } \\
\text { New York } \\
\text { New York } \\
\text { New York } \\
\text { South Carolina } \\
\text { South Carolina } \\
\text { Washington } \\
\text { Forida } \\
\text { Furida } \\
\text { Califomia } \\
\text { Califomia } \\
\text { Califomia } \\
\text { Califomia } \\
\text { Ohio } \\
\text { Iowa } \\
\text { Kansas } \\
\end{array}$ & 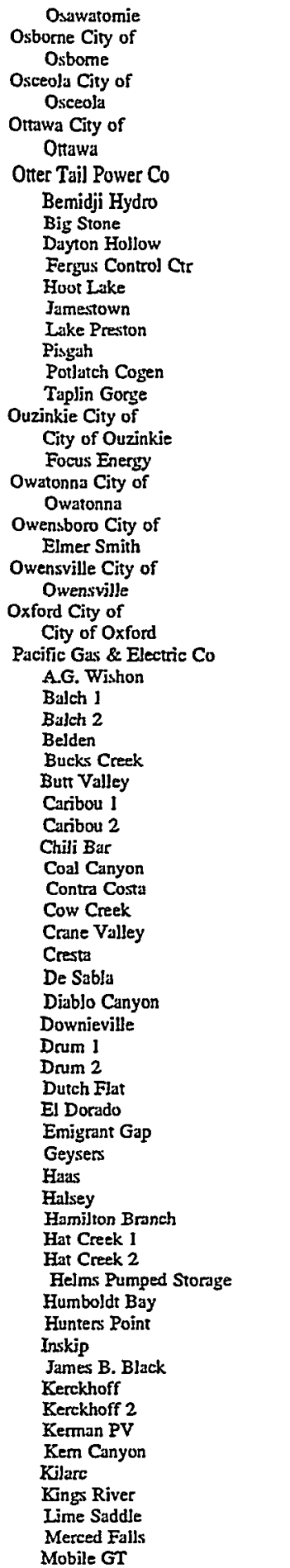 & 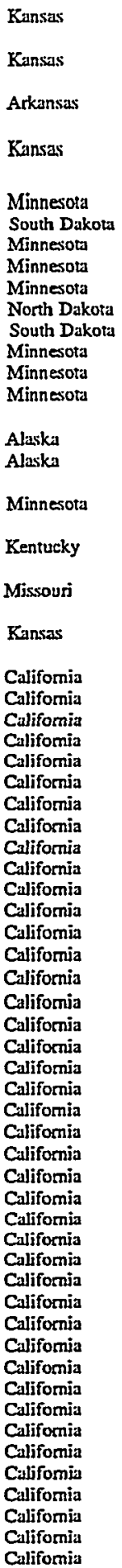 \\
\hline
\end{tabular}


Table D3. U.S. Electric Utility Plants by Utility, as of January 1, 1998 (Continued)

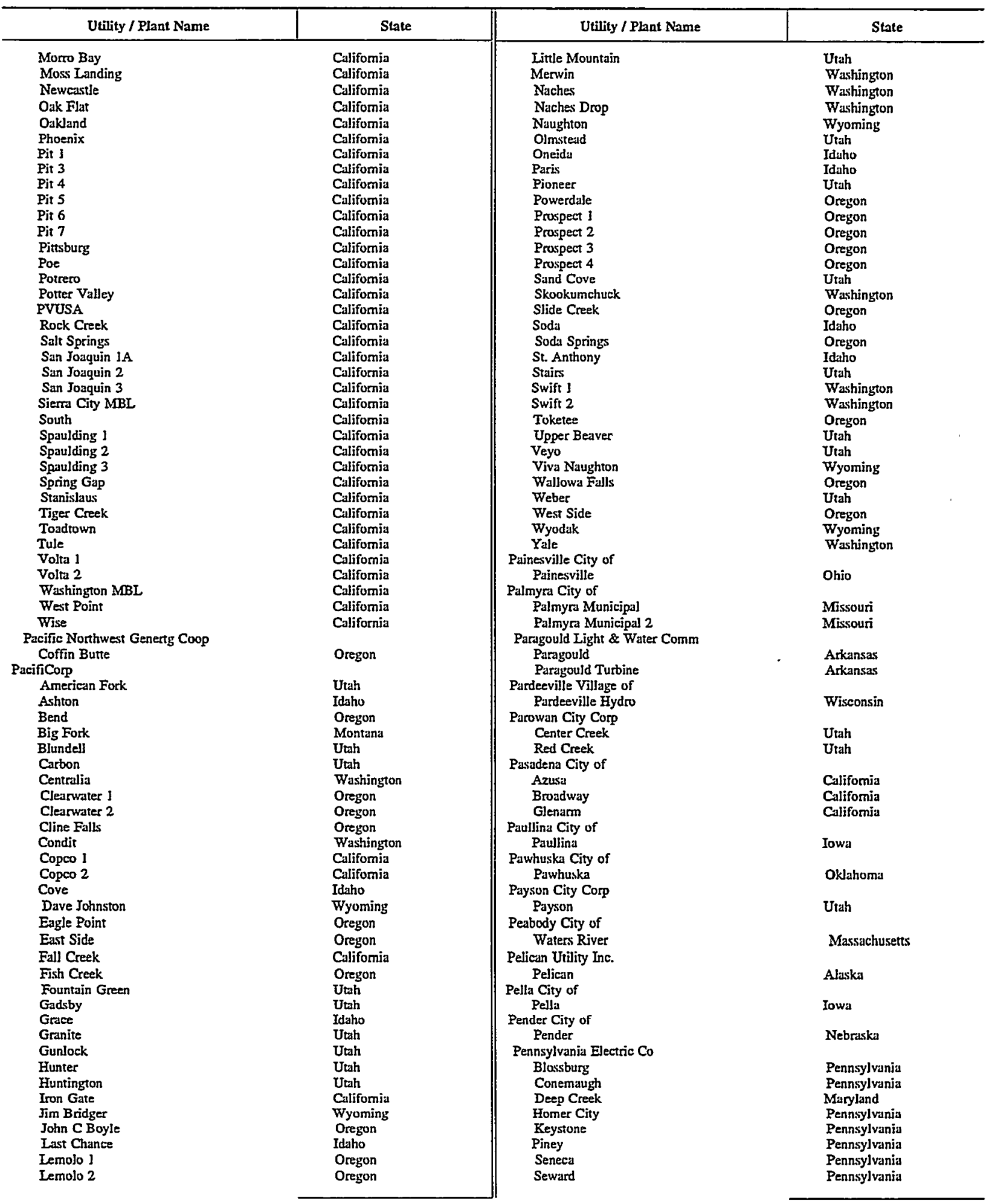

See footnotes at end of table. 
Table D3. U.S. Electric Utility Plants by Utility, as of January 1, 1998 (Continued)

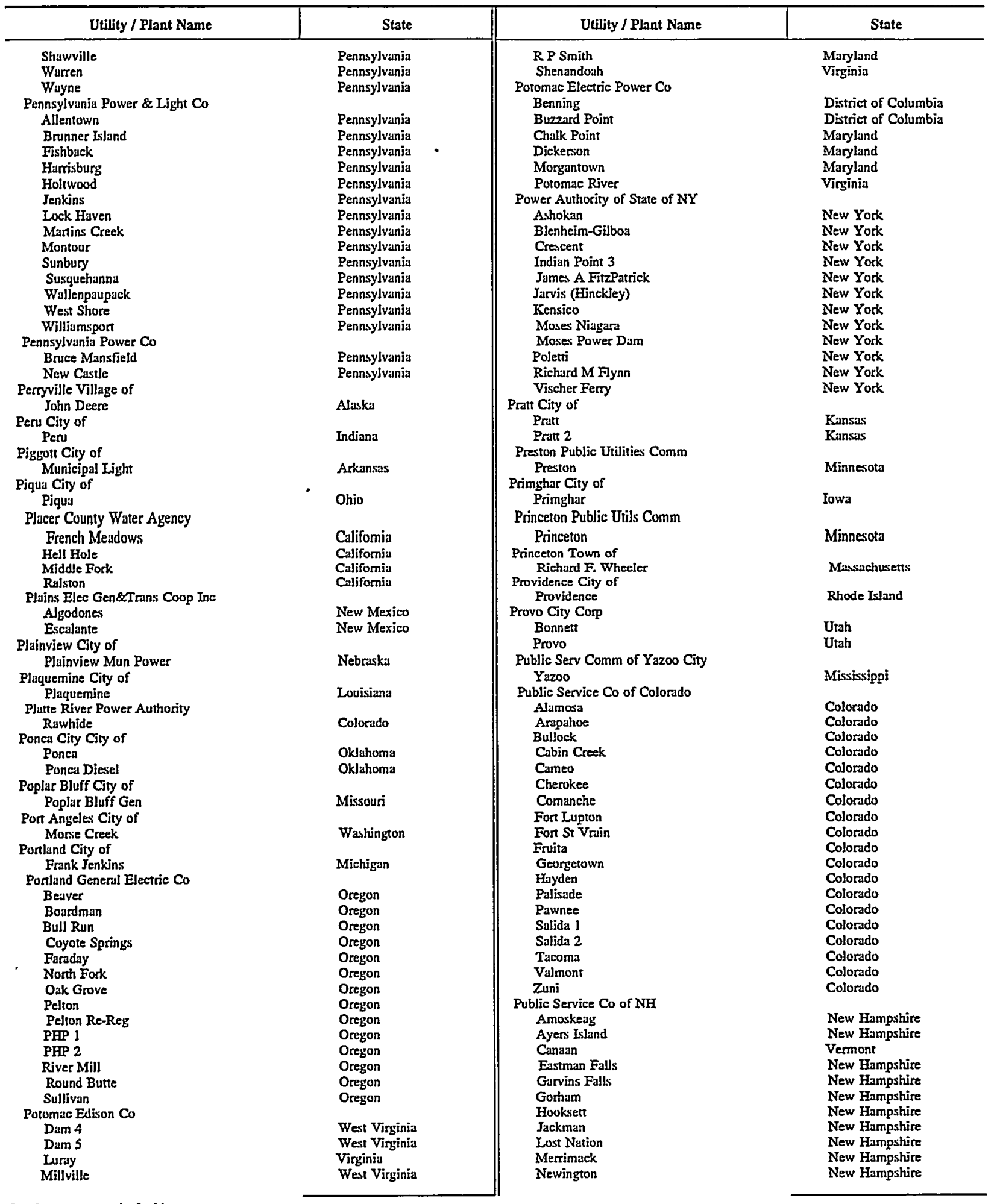

See footnotes at end of table. 
Table D3. U.S. Electric Utility Plants by Utility, as of January 1, 1998 (Continued)

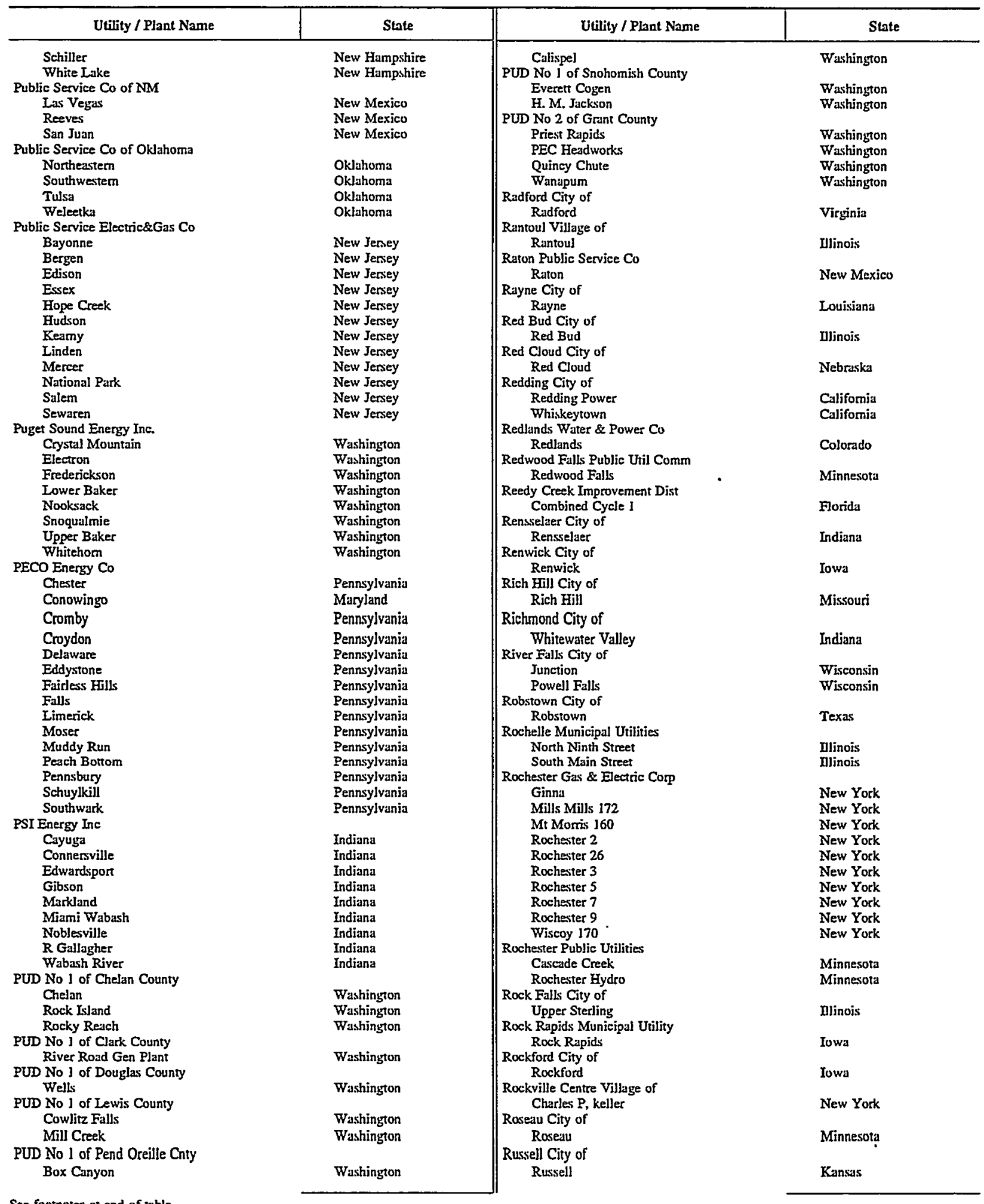


Table D3. U.S. Electric Utility Plants by Utility, as of January 1, 1998 (Continued)

\begin{tabular}{|c|c|c|c|}
\hline Utility / Plant Name & State & Utility / Plant Name & State \\
\hline 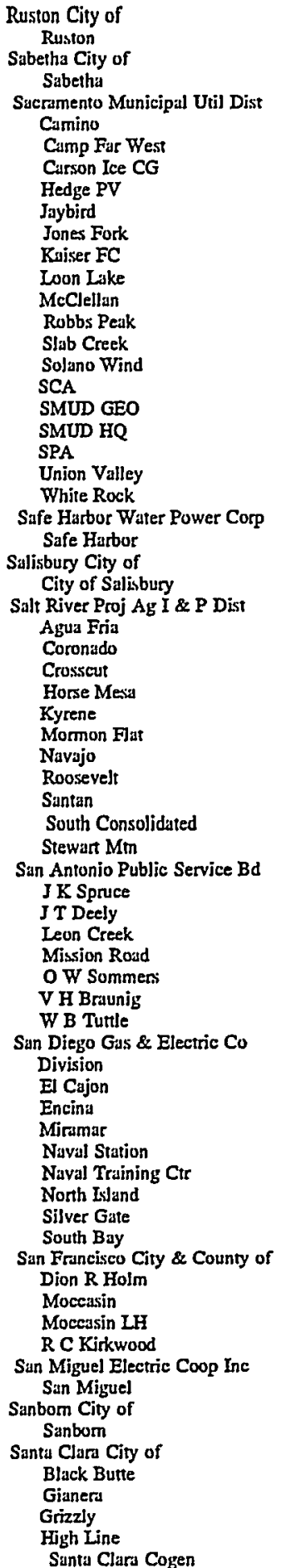 & 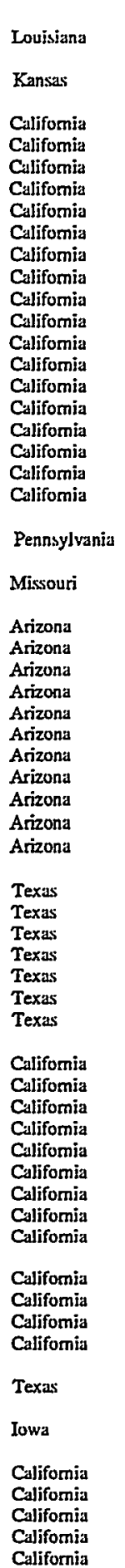 & 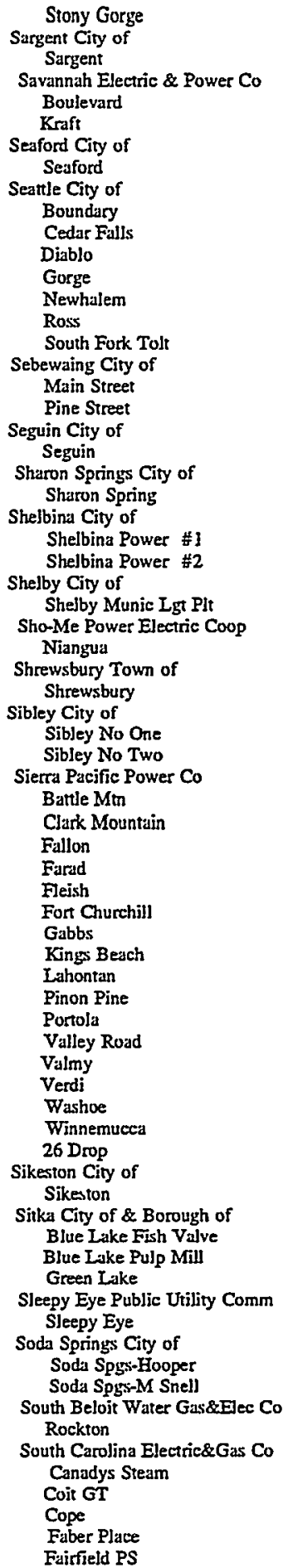 & 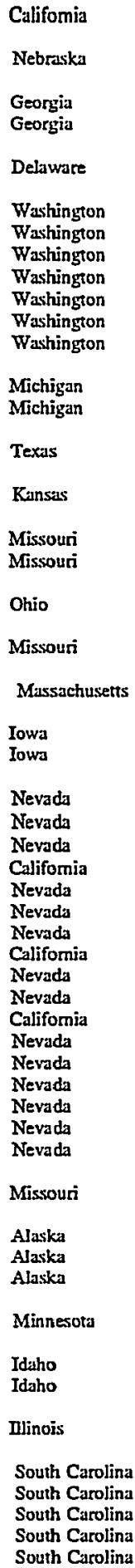 \\
\hline
\end{tabular}

See footnotes at end of table. 
Table D3. U.S. Electric Utility Plants by Utility, as of January 1, 1998 (Continued)

\begin{tabular}{|c|c|c|c|}
\hline Utility / Plant Name & State & Utility / PLant Name & Stale \\
\hline 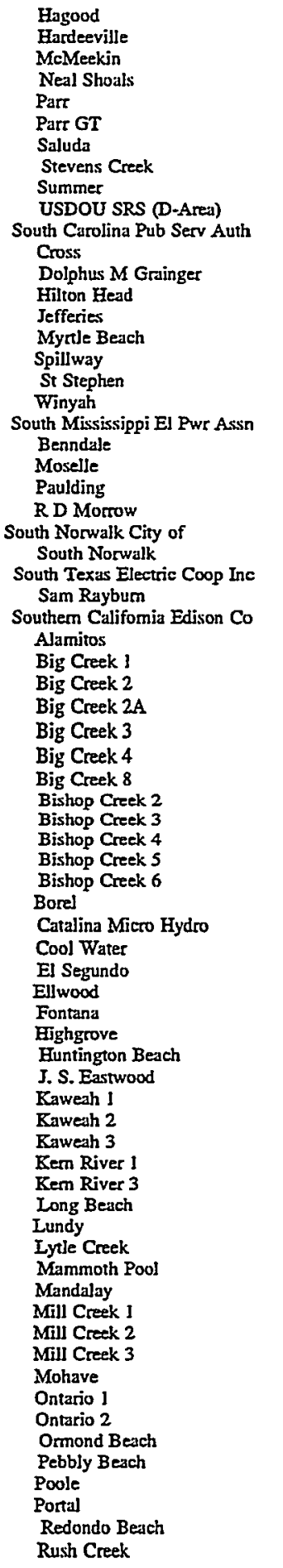 & 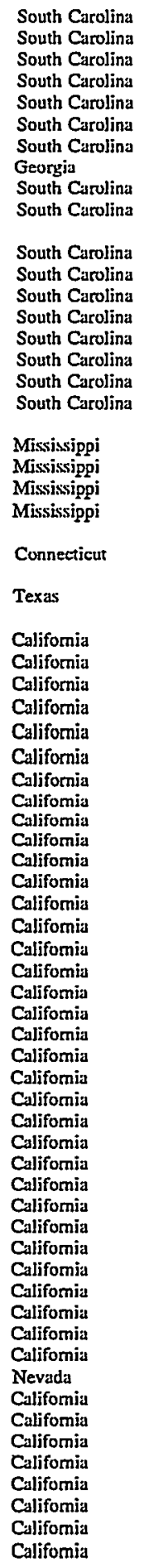 & 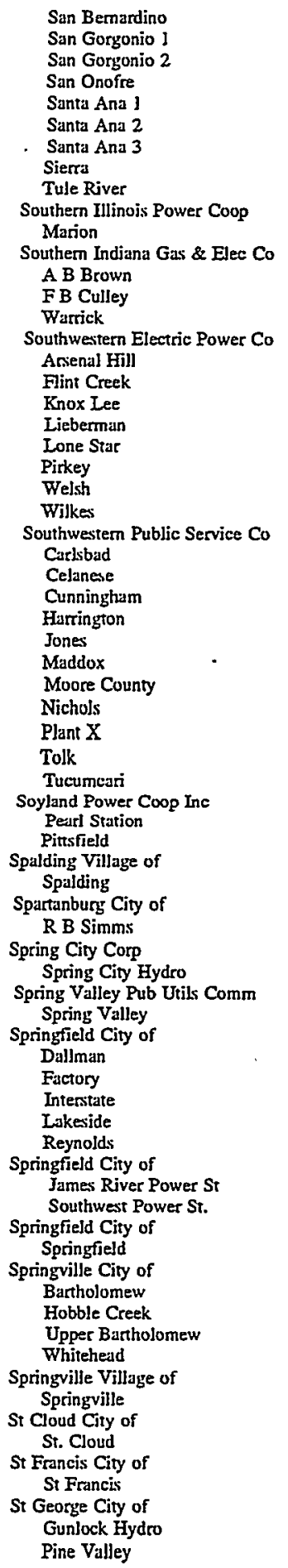 & 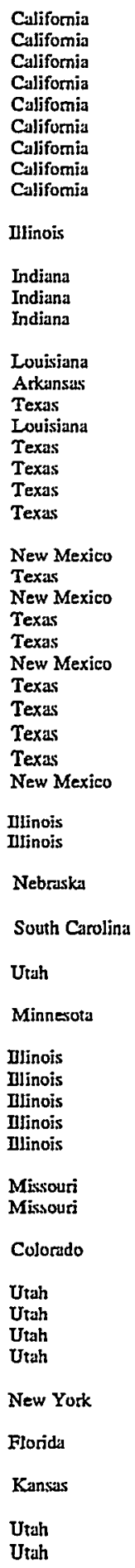 \\
\hline
\end{tabular}

See footnotes at end of table. 
Table D3. U.S. Electric Utility Plants by Utility, as of January 1, 1998 (Continued)

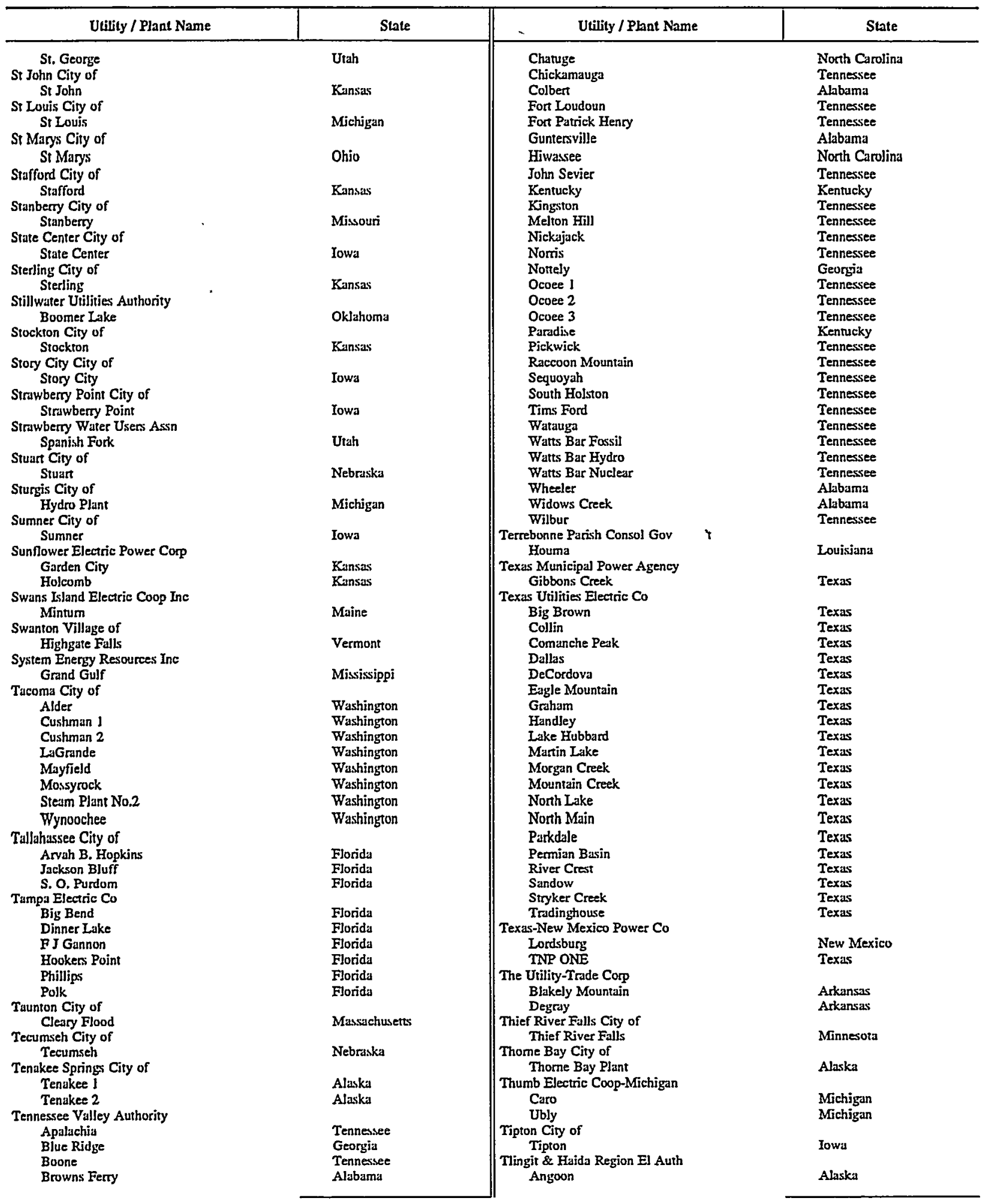

See footnotes at end of table. 
Table D3. U.S. Electric Utility Plants by Utility, as of January 1, 1998 (Continued)

\begin{tabular}{|c|c|c|c|}
\hline Utility / Plant Name & State & Utility / Phnt Name & State \\
\hline 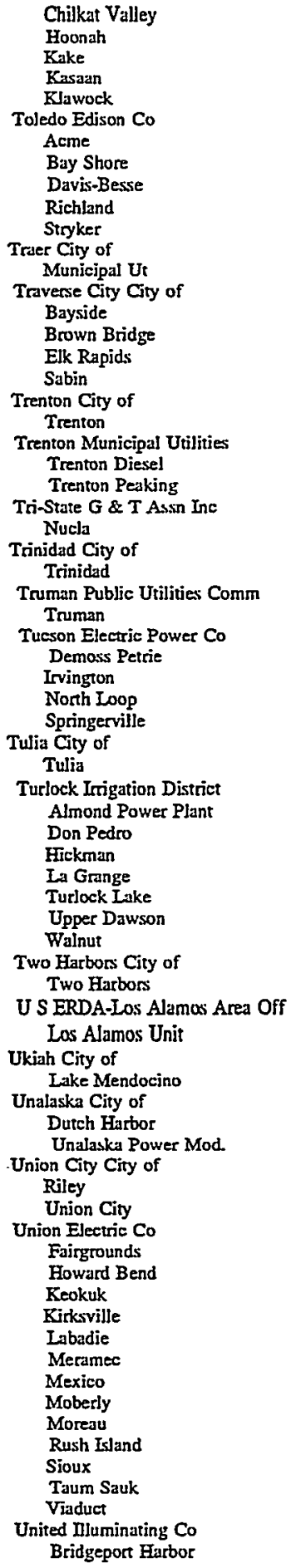 & 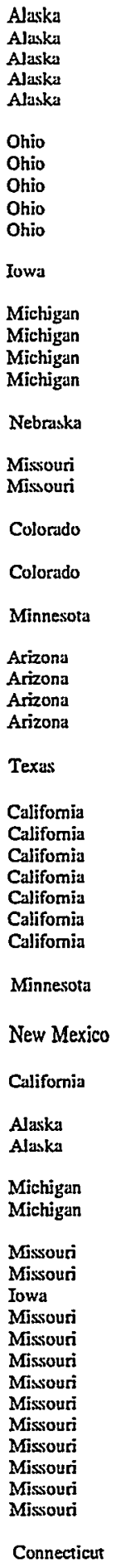 & 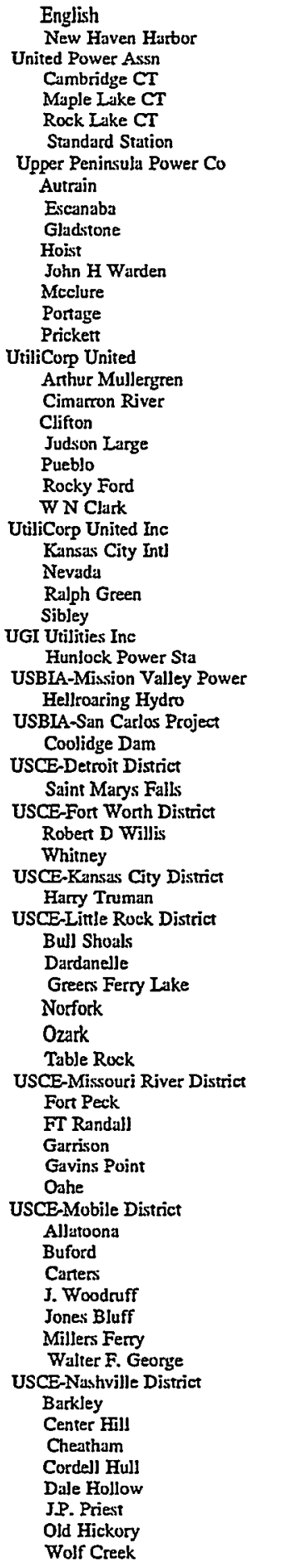 & $\begin{array}{l}\text { Michigan } \\
\text { Michigan } \\
\text { Michigan } \\
\text { Michigan } \\
\text { Michigan } \\
\text { Michigan } \\
\text { Michigan } \\
\text { Michigan } \\
\text { Kansas } \\
\text { Kansas } \\
\text { Kansas } \\
\text { Kansas } \\
\text { Colorado } \\
\text { Colorado } \\
\text { Colorado } \\
\text { Missouri } \\
\text { Missouri } \\
\text { Missouri } \\
\text { Missouri } \\
\text { Pennsylvania } \\
\text { Montana } \\
\text { Kentucky } \\
\text { Tennessee } \\
\text { Tennessee } \\
\text { Tennessee } \\
\text { Tennessee } \\
\text { Tennessee } \\
\text { Tennessee } \\
\text { Kentucky }\end{array}$ \\
\hline
\end{tabular}

See footnotes at end of table. 
Table D3. U.S. Electric Utility Plants by Utility, as of January 1, 1998 (Continued)

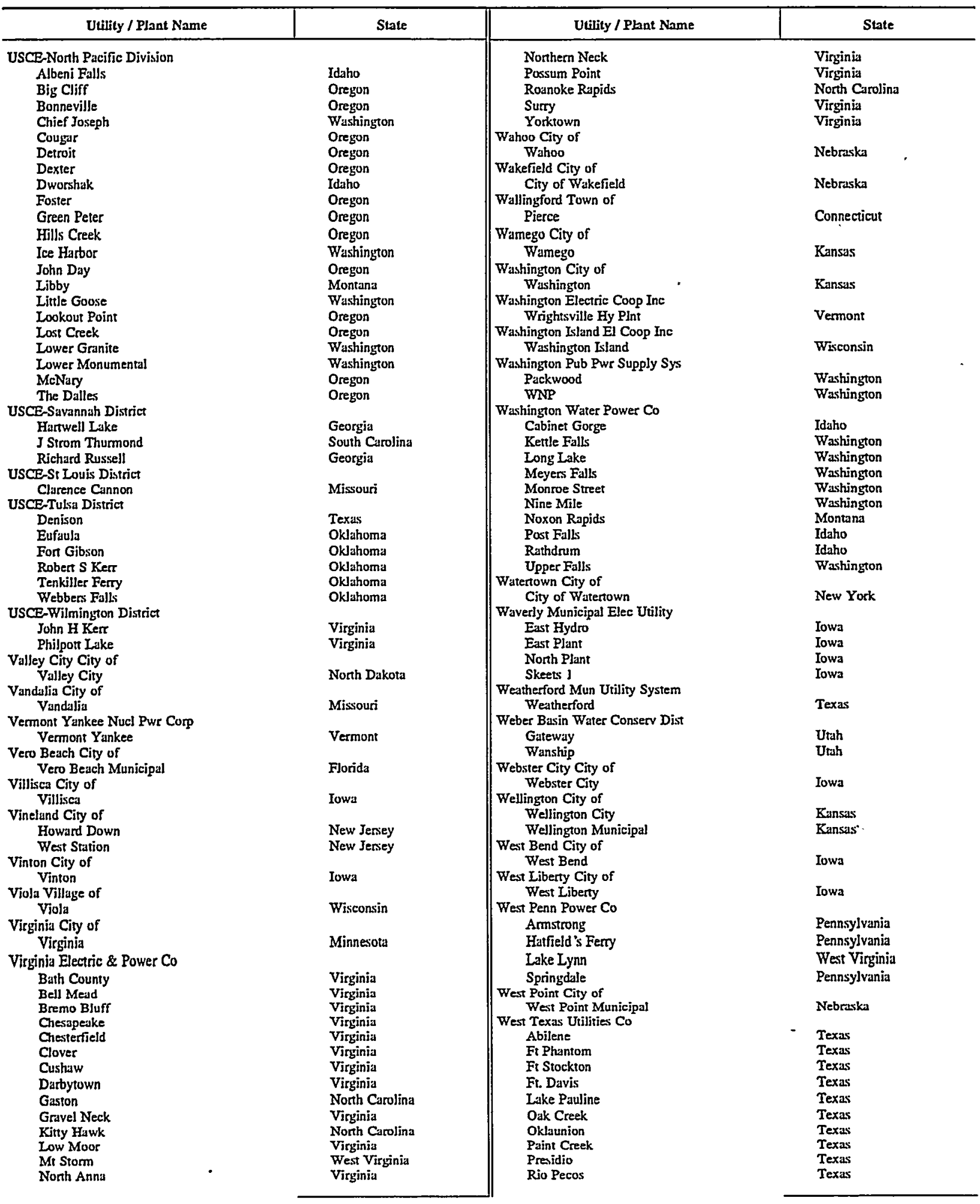

See footnotes at end of table. 
Table D3. U.S. Electric Utility Plants by Utility, as of January 1, 1998 (Continued)

\begin{tabular}{|c|c|c|c|}
\hline Utility / Phant Name & State & Utility / Plant Name & State \\
\hline 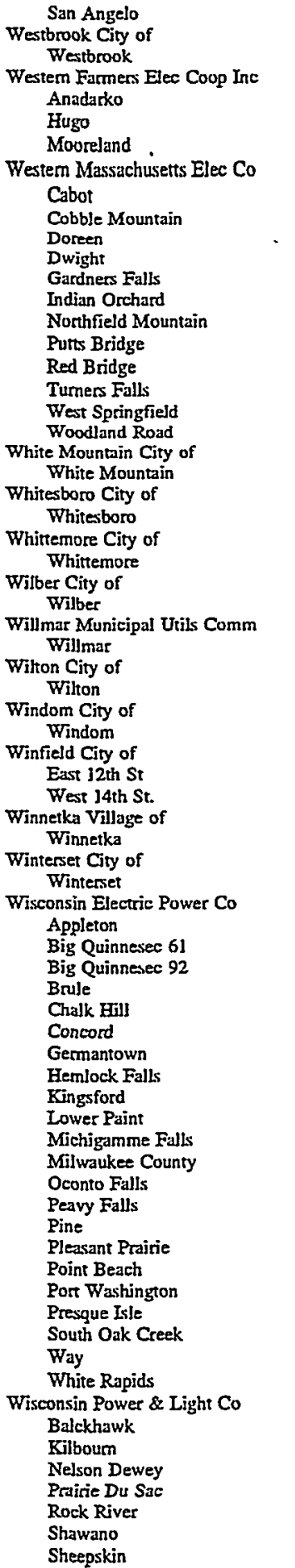 & 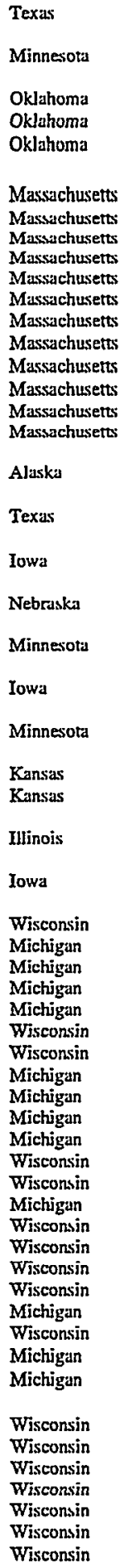 & 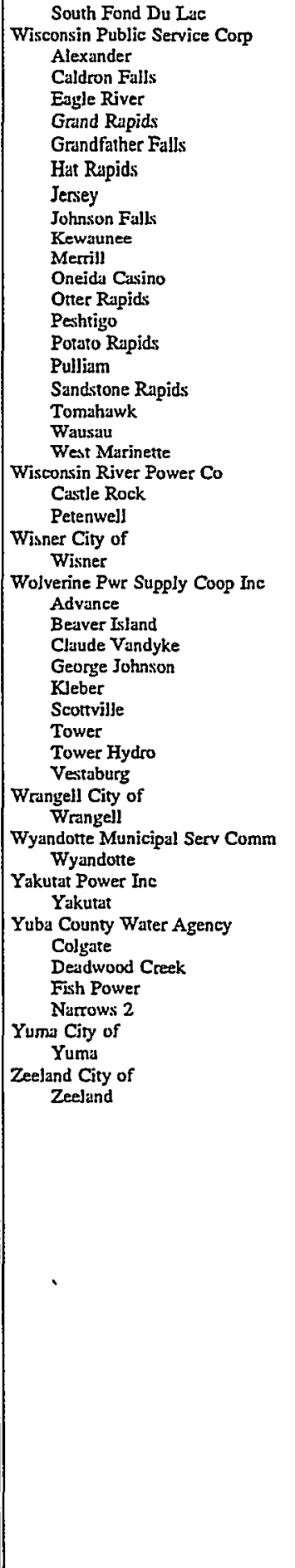 & $\begin{array}{l}\text { Wisconsin } \\
\text { Wisconsin } \\
\text { Wisconsin } \\
\text { Wisconsin } \\
\text { Michigan } \\
\text { Wisconsin } \\
\text { Wisconsin } \\
\text { Wisconsin } \\
\text { Wisconsin } \\
\text { Wisconsin } \\
\text { Wisconsin } \\
\text { Wisconsin } \\
\text { Wisconsin } \\
\text { Wisconsin } \\
\text { Wisconsin } \\
\text { Wisconsin } \\
\text { Wisconsin } \\
\text { Wisconsin } \\
\text { Wisconsin } \\
\text { Wisconsin } \\
\text { Wisconsin } \\
\text { Wisconsin } \\
\text { Nebraski } \\
\text { Michigan } \\
\text { Michigan } \\
\text { Michigan } \\
\text { Michigan } \\
\text { Michigan } \\
\text { Michigan } \\
\text { Michigan } \\
\text { Michigan } \\
\text { Michigan } \\
\text { Alaska } \\
\text { Michigan } \\
\text { Alaska } \\
\text { California } \\
\text { Califomia } \\
\text { Califomia } \\
\text { Califomia } \\
\text { Colado } \\
\text { Michigan }\end{array}$ \\
\hline
\end{tabular}

Source: •Energy Information Administration, Fom EIA-860, "Annual Electric Generator Repont." 


\section{Appendix E}

Plant-Level Statistics for

U.S. Electric

Utilities 


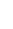




\section{Plant-Level Statistics for U.S. Electric Utilities}

Table E1. Number of Plants at U.S. Electric Utilities by Census Division and State, as of January 1, 1998

\begin{tabular}{|c|c|c|c|}
\hline $\begin{array}{l}\text { Census Division } \\
\text { State }\end{array}$ & $\begin{array}{c}\text { Numberl } \\
\text { of } \\
\text { Plants }\end{array}$ & $\begin{array}{c}\text { Census Division } \\
\text { State }\end{array}$ & $\begin{array}{c}\text { Numberl } \\
\text { of } \\
\text { Plants }\end{array}$ \\
\hline U.S. Total & 3,101 & East South Central. & 126 \\
\hline 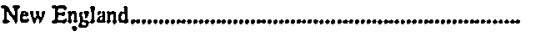 & 234 & Alabama...................................... & 35 \\
\hline 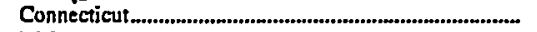 & 30 & Kentucky ............................. & 34 \\
\hline 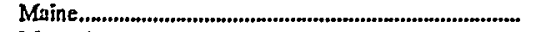 & 60 & Mississippi......................... & 20 \\
\hline 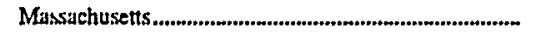 & 57 & Tennessee ............................. & 37 \\
\hline New Hampshire. & 18 & West South Central ...... & 247 \\
\hline 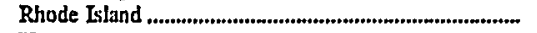 & 5 & 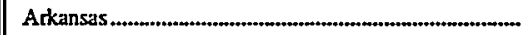 & 33 \\
\hline 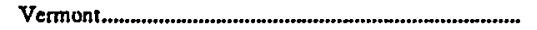 & 64 & Louisiana ............................... & 36 \\
\hline 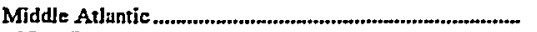 & 266 & Oklahoma ..................................... & 40 \\
\hline 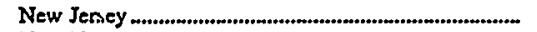 & 31 & 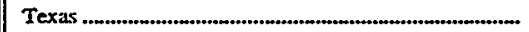 & 138 \\
\hline New York & 170 & Mountain & 315 \\
\hline 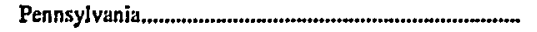 & 65 & Arizona & 34 \\
\hline 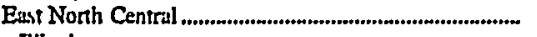 & 427 & Colorado & 66 \\
\hline 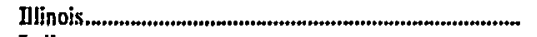 & 71 & Idaho & 47 \\
\hline Indiand & 41 & 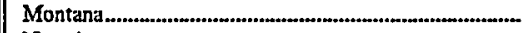 & 27 \\
\hline 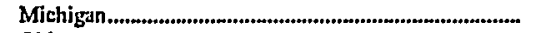 & 134 & Nevada & 22 \\
\hline 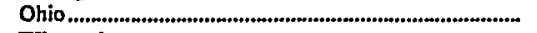 & 59 & 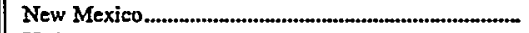 & 18 \\
\hline Wisconsin & 122 & Utah & 77 \\
\hline 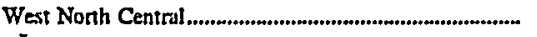 & 529 & Wyoming & 24 \\
\hline Iowa & 119 & Pacific Contiguous & 449 \\
\hline 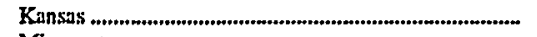 & 94 & Califomia & 316 \\
\hline Minnesota & [1] & Oregon & 61 \\
\hline Missouri,..., & 87 & Washington. & 72 \\
\hline Nebraska & 81 & Pacific Noncontiguous & 182 \\
\hline 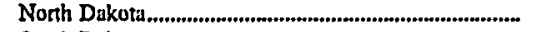 & 17 & 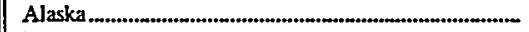 & 165 \\
\hline 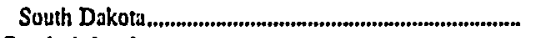 & 20 & 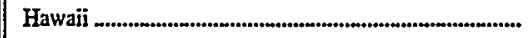 & 17 \\
\hline South Allantic & 326 & & \\
\hline 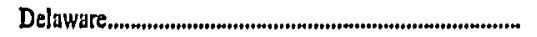 & 11 & & \\
\hline 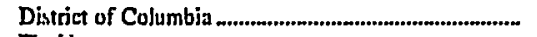 & 2 & & \\
\hline 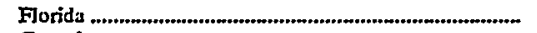 & 67 & & \\
\hline Georgia & 53 & & \\
\hline 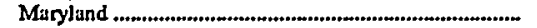 & 22 & & \\
\hline 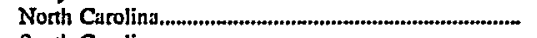 & 53 & & \\
\hline 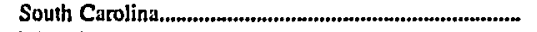 & 52 & & \\
\hline 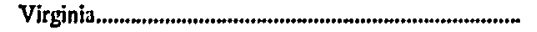 & 45 & & \\
\hline 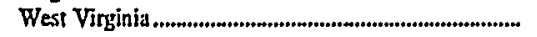 & 21 & & \\
\hline
\end{tabular}

I Each unique site reported by electric utilities, regardless of the number of prime mover types at that site is counted as a single plant. Note: Totals may not equal the sum of components because of independent rounding. Source: Energy Information Administration, Form EIA-860, “Annual Electric Generator Report." 
Table E2. Existing Capacity at U.S. Electric Utilities by Census Division, State, and Prime Mover, as of January 1, 1998

\begin{tabular}{|c|c|c|c|c|c|c|}
\hline \multirow[b]{2}{*}{$\begin{array}{c}\text { Census Division } \\
\text { State }\end{array}$} & \multicolumn{2}{|c|}{ Fossil Steam 1} & \multicolumn{2}{|c|}{ Nuclear } & \multicolumn{2}{|c|}{ Hydroelectric 2} \\
\hline & $\begin{array}{c}\text { Number } \\
\text { of } \\
\text { Plants }\end{array}$ & $\begin{array}{c}\text { Generator } \\
\text { Nameplate } \\
\text { Capacity } \\
\text { (megawatts) }\end{array}$ & $\begin{array}{c}\text { Number }{ }^{3} \\
\text { of } \\
\text { Plants }\end{array}$ & $\begin{array}{c}\text { Generator } \\
\text { Nameplate } \\
\text { Capacity } \\
\text { (megawatts) }\end{array}$ & $\begin{array}{c}\text { Number } \\
\text { of } \\
\text { Phants }\end{array}$ & $\begin{array}{c}\text { Generator } \\
\text { Nameplate } \\
\text { Capacity } \\
\text { (megawatts) }\end{array}$ \\
\hline US. Total & 841 & 480,644 & 67 & 107,632 & 1,264 & 91,872 \\
\hline 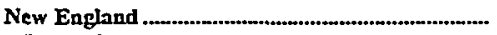 & 32 & 12,169 & 4 & 5,285 & 147 & 2,783 \\
\hline 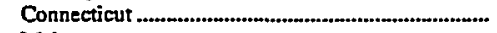 & 8 & 3,070 & ] & 2,824 & 14 & 132 \\
\hline 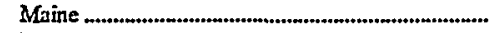 & 5 & 1,050 & - & - & 47 & 380 \\
\hline 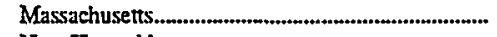 & 14 & 6,487 & 1 & 655 & 23 & 1,647 \\
\hline New Hampshire & 3 & 1,023 & 1 & 1,242 & 12 & 254 \\
\hline 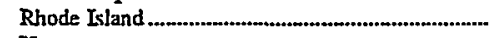 & 1 & 489 & $一$ & - & 1 & 2 \\
\hline 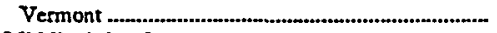 & 1 & 50 & 1 & 563 & so & 368 \\
\hline Middle Athntic & 71 & 45,511 & 13 & 19,328 & 120 & 7,435 \\
\hline 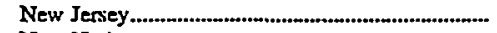 & 11 & 5,180 & 3 & 4,146 & 1 & 387 \\
\hline New York & 30 & 17,049 & 5 & 5,624 & 111 & 5,190 \\
\hline Pennsylvania & 30 & 23,282 & 5 & 9,557 & 8 & 1,858 \\
\hline East North Central & 142 & 88,905 & 14 & 21,746 & 144 & 3,006 \\
\hline Dlinois & 31 & 20,525 & 7 & 13,734 & 4 & 14 \\
\hline 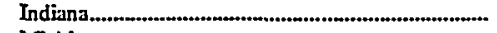 & 28 & 21,038 & - & - & 5 & 89 \\
\hline 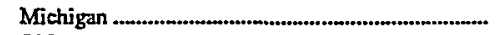 & 29 & 15,791 & 3 & 4,251 & 56 & 2,321 \\
\hline 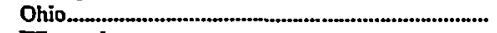 & 33 & 24,214 & 2 & 2,178 & 5 & 129 \\
\hline Wiseonsin & 21 & 7,337 & 2 & 1,583 & 74 & 452 \\
\hline 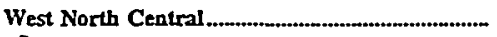 & 123 & 40,267 & 7 & 6,157 & 54 & 3,808 \\
\hline 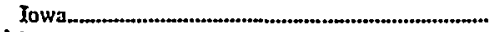 & 23 & 6,180 & 1 & 597 & 8 & 135 \\
\hline 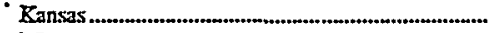 & 26 & 7,462 & 3 & 1,236 & - & - \\
\hline 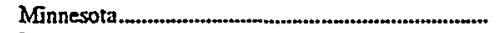 & 29 & 6,213 & 2 & 1,751 & 22 & 142 \\
\hline Missouri & 22 & 12,090 & ] & 1,236 & 8 & 1,100 \\
\hline Nebraska & 11 & 3,433 & 2 & 1,338 & 11 & 183 \\
\hline North Dakota & 9 & 4,313 & - & - & 1 & 517 \\
\hline South Dakota & 3 & 576 & 一 & - & 4 & 1,731 \\
\hline South Atlantic & 128 & 95,647 & 15 & 25,617 & 120 & 11,908 \\
\hline Delaware & 4 & 2,102 & 一 & - & - & - \\
\hline 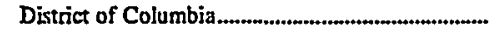 & 1 & 580 & - & 一 & - & - \\
\hline Forida & 45 & 28,452 & 3 & 4,110 & 2 & 42 \\
\hline 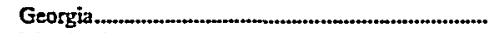 & 15 & 15,125 & 2 & 4,042 & 32 & 3,291 \\
\hline 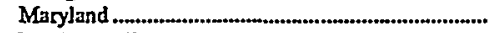 & 10 & 7,146 & 1 & 1,829 & 2 & 494 \\
\hline 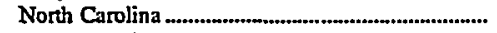 & 15 & 12,697 & 3 & 5,182 & 30 & 1,497 \\
\hline South Carolina & 13 & 6,503 & 4 & 6,799 & 25 & 3,423 \\
\hline Virginia & 11 & 8,004 & 2 & 3,655 & 22 & 3,060 \\
\hline 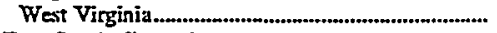 & 34 & 15,038 & 一 & - & 7 & 101 \\
\hline Enst South Central & S7 & 44,437 & $\mathbf{5}$ & 10,316 & 55 & 7,440 \\
\hline 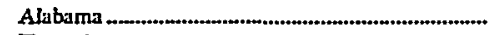 & 10 & 12,632 & 2 & 5,233 & 21 & 2,904 \\
\hline 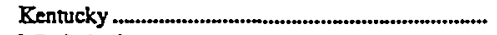 & 22 & 16,160 & 一 & - & 7 & 770 \\
\hline Mississippi & 17 & 5,625 & l & 1,373 & - & 一 \\
\hline 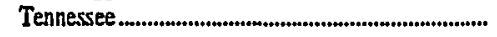 & 8 & 10,020 & 2 & 3,711 & 27 & 3,766 \\
\hline West South Central & 155 & 91,253 & 5 & 9,219 & 51 & 2,875 \\
\hline Arkansas _... & 11 & 6,427 & ] & 1,845 & 14 & 1,196 \\
\hline 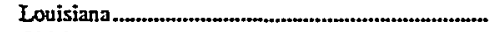 & 31 & 15,986 & 2 & 2,236 & 一 & - \\
\hline OkJahoma & 19 & 11,521 & - & - & 11 & 1,044 \\
\hline Texas & 94 & 57,319 & 2 & 5,139 & 26 & 634 \\
\hline Mountain & 75 & 35,394 & $\mathbf{1}$ & 4,210 & 193 & 10,396 \\
\hline 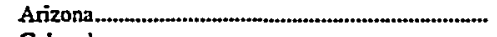 & 14 & 7,377 & ] & 4,210 & 14 & 2,893 \\
\hline 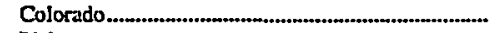 & 19 & 5,362 & 一 & - & 30 & 1,124 \\
\hline Idaho & - & - & - & - & 45 & 2,221 \\
\hline 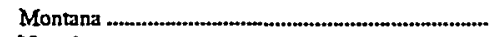 & 3 & 2,514 & - & - & 20 & 2,488 \\
\hline Nevada & 9 & 4,135 & - & - & 6 & 1,046 \\
\hline 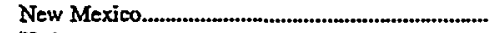 & 15 & 5,212 & 一 & 一 & 3 & 58 \\
\hline Utah & 7 & 4,720 & - & - & 60 & 273 \\
\hline Wyoming & 8 & 6,075 & - & - & 15 & 294 \\
\hline Pacifrc Contiguous & 47 & 25,569 & 3 & 5,755 & 347 & 41,848 \\
\hline 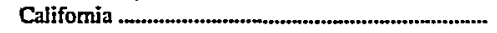 & -37 & 22,081 & 2 & 4,555 & 234 & 12,867 \\
\hline 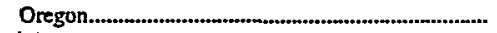 & 5 & 1,638 & - & - & 53 & 8,163 \\
\hline Washington & 5 & 1,851 & 1 & 1,200 & 60 & 20,819 \\
\hline 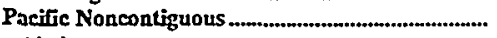 & 11 & 1,494 & - & - & 33 & 372 \\
\hline 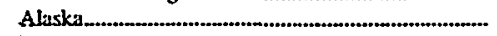 & 3 & 292 & - & - & 31 & 369 \\
\hline 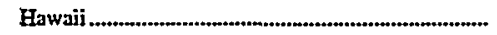 & 8 & 1,201 & 一 & - & 2 & 3 \\
\hline
\end{tabular}

Se footnotes at end of table. 
Table E2. Existing Capacity at U.S. Electric Utilities by Census Division, State, and Prime Mover, as of January 1, 1998 (Continued)

\begin{tabular}{|c|c|c|c|c|c|c|}
\hline \multirow[b]{2}{*}{$\begin{array}{l}\text { Census Division } \\
\text { State }\end{array}$} & \multicolumn{2}{|c|}{ Gas Turbine } & \multicolumn{2}{|c|}{ Internal Combustion } & \multicolumn{2}{|c|}{ Other 4} \\
\hline & $\begin{array}{c}\text { Number } 3 \\
\text { of } \\
\text { Plants }\end{array}$ & $\begin{array}{c}\text { Generator } \\
\text { Nameplate } \\
\text { Capacity } \\
\text { (megawatts) }\end{array}$ & $\begin{array}{c}\text { Number }{ }^{3} \\
\text { of } \\
\text { Phants }\end{array}$ & $\begin{array}{c}\text { Generator } \\
\text { Nameplate } \\
\text { Capacity } \\
\text { (megawatts) }\end{array}$ & $\begin{array}{c}\text { Number }{ }^{3} \\
\text { of } \\
\text { Plants }\end{array}$ & $\begin{array}{c}\text { Generator } \\
\text { Nameplate } \\
\text { Capacity } \\
\text { (megawatts) }\end{array}$ \\
\hline 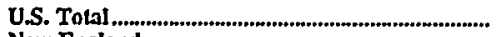 & 604 & 67,920 & 741 & 5,075 & 26 & 1,781 \\
\hline 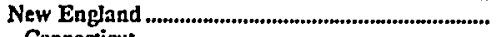 & 37 & 1,584 & 35 & 244 & 3 & 7 \\
\hline 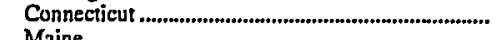 & II & 558 & 2 & 23 & - & - \\
\hline 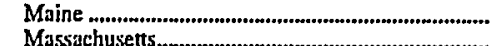 & 1 & 35 & 10 & 36 & - & - \\
\hline & 15 & 772 & 13 & 145 & 1 & $\star$ \\
\hline & 4 & 95 & - & $\bar{a}$ & - & 一 \\
\hline & $\overline{6}$ & - & 3 & 20 & - & - \\
\hline Vermont .., & 6 & 123 & 7 & 20 & 2 & 6 \\
\hline & 85 & 10,908 & 26 & 177 & - & - \\
\hline & 27 & 4,689 & 1 & 8 & 二 & 一 \\
\hline & $\begin{array}{l}28 \\
30\end{array}$ & $\begin{array}{l}4,097 \\
2,122\end{array}$ & $\begin{array}{l}14 \\
11\end{array}$ & $\begin{array}{r}103 \\
65\end{array}$ & 二 & 二 \\
\hline 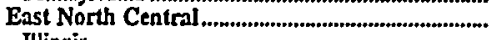 & 103 & 9,476 & 116 & 943 & $\overline{-}$ & - \\
\hline 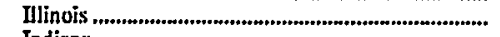 & 20 & 2,575 & 24 & 282 & - & - \\
\hline Indiand & 14 & 1,300 & 8 & 57 & - & - \\
\hline Michigan & 21 & 1,164 & 43 & 389 & - & - \\
\hline 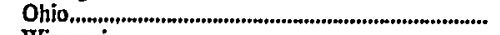 & 29 & 1,972 & 13 & 99 & 一 & - \\
\hline Wisconsin & 19 & 2,464 & 28 & 116 & 一 & - \\
\hline 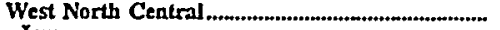 & 103 & 7,938 & 298 & 2,090 & 2 & $\star$ \\
\hline 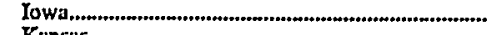 & 18 & 1,500 & 77 & 454 & $\bar{I}$ & * \\
\hline 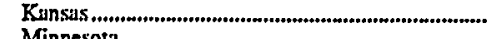 & 15 & 1,140 & 67 & 629 & - & - \\
\hline 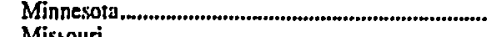 & 23 & 1,202 & 50 & 271 & 1 & * \\
\hline 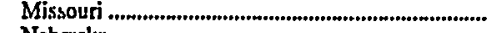 & 29 & 2,664 & 38 & 392 & 一 & - \\
\hline 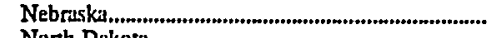 & 9 & 749 & 52 & 277 & 一 & 一 \\
\hline 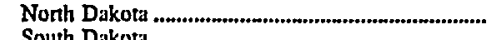 & 2 & 58 & 6 & 25 & 一 & 一 \\
\hline 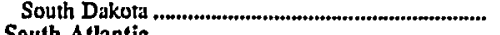 & 7 & 624 & 8 & 43 & - & - \\
\hline 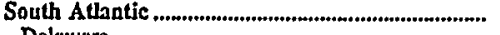 & 106 & 18,765 & 37 & 414 & 1 & * \\
\hline Delaware & 7 & 181 & 2 & 10 & 一 & - \\
\hline & $\begin{array}{r}1 \\
33\end{array}$ & 288 & $\overline{16}$ & $\overrightarrow{20}$ & & 一 \\
\hline 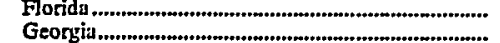 & $\begin{array}{l}33 \\
13\end{array}$ & $\begin{array}{l}7,545 \\
2,148\end{array}$ & $\begin{array}{r}16 \\
3\end{array}$ & $\begin{array}{r}229 \\
8\end{array}$ & - & 二 \\
\hline & 12 & $\begin{array}{l}2,148 \\
2,344\end{array}$ & $\frac{3}{5}$ & 80 & - & 二 \\
\hline 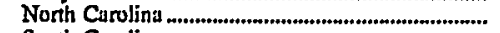 & 13 & 2,571 & 2 & 18 & - & - \\
\hline South Carolina & 17 & 2,050 & 2 & 15 & - & - \\
\hline Virginia & 9 & 1,620 & $\overline{7}$ & 55 & 1 & $*$ \\
\hline Weit Virginia & $I$ & 19 & - & - & - & - \\
\hline 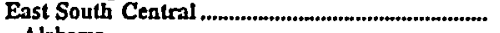 & 24 & 4,674 & 2 & 14 & - & - \\
\hline 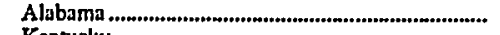 & 5 & 1,474 & - & 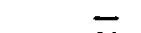 & - & - \\
\hline 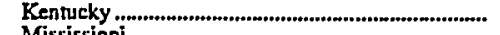 & 7 & 783 & 2 & 14 & - & - \\
\hline 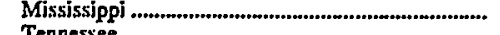 & 9 & 383 & 一 & - & - & - \\
\hline 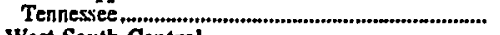 & 3 & 2,034 & - & - & - & - \\
\hline West South Central & 41 & 5,467 & 40 & 355 & 3 & 14 \\
\hline 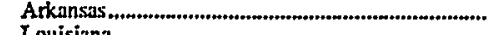 & 4 & 305 & 6 & 34 & - & - \\
\hline Louisiana & 4 & 176 & 6 & $7 \mathrm{~J}$ & - & - \\
\hline Oklahoma & 9 & 809 & 13 & 123 & - & - \\
\hline Texis & 24 & 4,177 & 15 & 128 & 3 & 14 \\
\hline 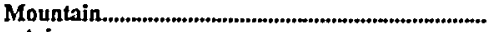 & 35 & 3,864 & 36 & 232 & 3 & 40 \\
\hline 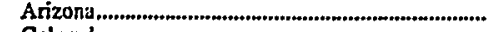 & 15 & 2,158 & 1 & 4 & 1 & $*$ \\
\hline 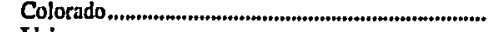 & 6 & 413 & 16 & 80 & - & - \\
\hline 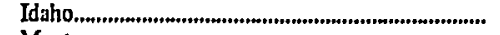 & 1 & 167 & 1 & 5 & - & - \\
\hline 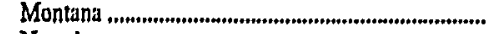 & 2 & 77 & 2 & 5 & - & - \\
\hline Nevada ,.,., & 6 & 690 & 6 & 30 & - & - \\
\hline 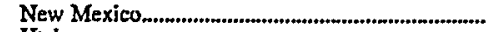 & 4 & 341 & 了 & 16 & - & - \\
\hline 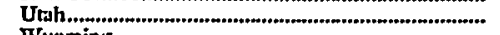 & 1 & 16 & 8 & 83 & 2 & 40 \\
\hline 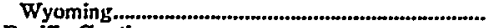 & - & - & I & 10 & - & - \\
\hline 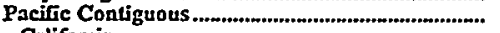 & 50 & 4,040 & 10 & 70 & 13 & 1,720 \\
\hline 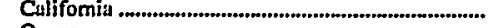 & 45 & 3,210 & 7 & 63 & 12 & 1,718 \\
\hline 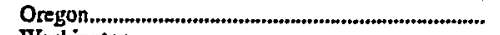 & 1 & 113 & 1 & 3 & J & 2 \\
\hline 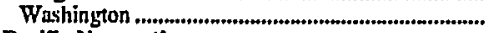 & 4 & 717 & 2 & 4 & - & 一 \\
\hline 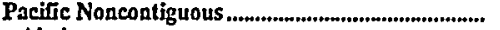 & 20 & 1,203 & 141 & 535 & $\mathbf{1}$ & * \\
\hline 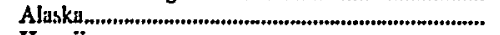 & 14 & 955 & 133 & 332 & 1 & $\star$ \\
\hline 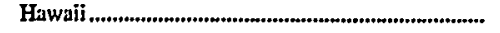 & 6 & 247 & 8 & 203 & - & - \\
\hline
\end{tabular}

- Less than 0.5 megawatts.

1 Includes plants that use coal, petroleum, gas, wood, refuse, or other nonwood waste. Includes a 248-megawatt combined cycle unit with an aggregate for the steam and gas turbine parts.

2 Includes both conventional and pumped storage.

3 Each type of prime mover at a site is counted as a separate plant.

4 Includes geothermal, wind, solar, 2 gas-fueled fuel cell units totaling 4 megawatts, one I3-megawatt expander turbine fueled by hot nitrogen, and 2 megawatrs fueled by landfill gas.

Notes: Totals may not equal the sum of components because of independent rounding.

Source: Energy Information Administration, Form ElA-860, "Annual Electrie Generator Report." 
Table E3. Existing Capacity at U.S. Electric Utilities by Class of Ownership, Census Division, and State, as of January 1, 1998 (Megawatts)

\begin{tabular}{|c|c|c|c|c|c|c|c|c|c|c|}
\hline \multirow[b]{2}{*}{$\begin{array}{c}\text { Census Division } \\
\text { State }\end{array}$} & \multicolumn{2}{|c|}{ Privately Owned } & \multicolumn{2}{|c|}{ Publicly Owned 1} & \multicolumn{2}{|c|}{ Federal } & \multicolumn{2}{|c|}{ Cooperative } & \multicolumn{2}{|c|}{ Other ${ }^{2}$} \\
\hline & $\begin{array}{c}\text { Generator } \\
\text { Nameplate } \\
\text { Capacity }\end{array}$ & $\begin{array}{c}\text { Net } \\
\text { Summer } \\
\text { Capability }\end{array}$ & $\begin{array}{c}\text { Generator } \\
\text { Nameplate } \\
\text { Capacity }\end{array}$ & $\begin{array}{c}\text { Net } \\
\text { Summer } \\
\text { Capability }\end{array}$ & $\begin{array}{c}\text { Generator } \\
\text { Nameplate } \\
\text { Capacity }\end{array}$ & $\begin{array}{c}\text { Net } \\
\text { Summer } \\
\text { Capabjlity }\end{array}$ & $\begin{array}{c}\text { Generator } \\
\text { Nameplate } \\
\text { Capacity }\end{array}$ & $\begin{array}{c}\text { Net } \\
\text { Summer } \\
\text { Capability }\end{array}$ & $\begin{array}{c}\text { Generator } \\
\text { Nameplate } \\
\text { Capacity }\end{array}$ & $\begin{array}{c}\text { Net } \\
\text { Summer } \\
\text { Capability }\end{array}$ \\
\hline 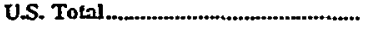 & 539,668 & 504,473 & 90,905 & 86,675 & 68,556 & 67,047 & 33,736 & 32,291 & 22,058 & 21,402 \\
\hline 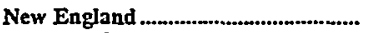 & 15,382 & 14,729 & 1,401 & 1,207 & - & - & 29 & 27 & 5,260 & 5,319 \\
\hline 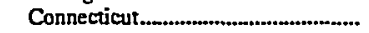 & 2,071 & 1,925 & 285 & 272 & - & - & - & - & 4,253 & 4,098 \\
\hline 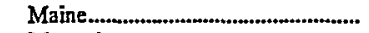 & 1,408 & 1,408 & 23 & 22 & - & - & 1 & l & 69 & 67 \\
\hline Massachusetts...................................... & 7,910 & 7,590 & 860 & 700 & - & - & - & - & 936 & 1,152 \\
\hline New Hampshire................................... & 2,441 & 2,350 & 146 & 137 & - & - & 27 & 25 & - & - \\
\hline 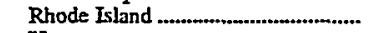 & 509 & 440 & - & - & - & - & - & 一 & 2 & 1 \\
\hline Vermont & 1,042 & 1,017 & 87 & 76 & - & - & 1 & ] & - & - \\
\hline Middle Atlantic....................................... & 75,615 & 70,006 & $\mathbf{7 , 4 8 8}$ & 7,259 & - & - & 252 & 226 & 3 & 2 \\
\hline New Jersey .......................................... & 14,313 & 13,592 & 98 & 92 & - & - & - & - & 一 & 一 \\
\hline 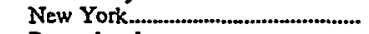 & 24,674 & 22,820 & 7,386 & 7,163 & - & - & - & - & 3 & 2 \\
\hline Pennsylvania ........................................... & 36,629 & 33,595 & 4 & 4 & - & - & 252 & 226 & - & - \\
\hline East North Central............................... & 114,501 & 104,970 & 4,782 & 4,499 & 18 & 20 & 4,313 & 4,212 & 462 & 432 \\
\hline 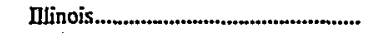 & 35,293 & 31,812 & 963 & 902 & - & - & 457 & 448 & 417 & 387 \\
\hline 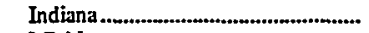 & 20,416 & 18,252 & 588 & 550 & - & - & 1,480 & 1,399 & - & - \\
\hline 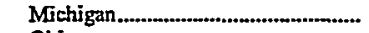 & $2 \mathrm{~J}, 890$ & 20,043 & 1,827 & 1,673 & 18 & 20 & 181 & 172 & 1 & 一 \\
\hline Ohio & 26,126 & 24,245 & 1,156 & 1,125 & - & 一 & 1,265 & 1,215 & 44 & 44 \\
\hline Wisconsin ....................................................... & 10,776 & 10,618 & 248 & 249 & - & - & 929 & 978 & 一 & - \\
\hline 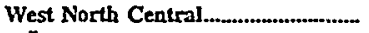 & 37,662 & 35,317 & 12,473 & 11,624 & 2,713 & 2,894 & $\mathbf{7 , 4 0 9}$ & 7,033 & 3 & 3 \\
\hline 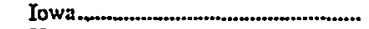 & 7,424 & 6,828 & 1,081 & 1,049 & - & - & 358 & 357 & 3 & 3 \\
\hline 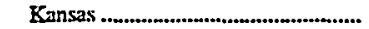 & 7,881 & 7,498 & $1,9] 7$ & 1,728 & - & - & 668 & 560 & - & - \\
\hline 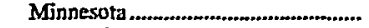 & 8,045 & 7,766 & 1,308 & 1,252 & - & - & 226 & 198 & - & - \\
\hline 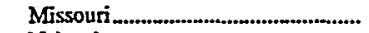 & 12,444 & 11,489 & 2,112 & 1,785 & 465 & 529 & 2,460 & 2,410 & - & - \\
\hline 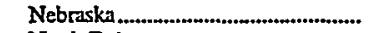 & - & - & 5,980 & 5,760 & - & - & - & - & - & - \\
\hline 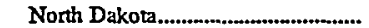 & 826 & 769 & 7 & 7 & 517 & 545 & 3,563 & 3,412 & - & - \\
\hline 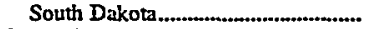 & 1,041 & 968 & 68 & 42 & 1,731 & 1,820 & 135 & 96 & - & - \\
\hline 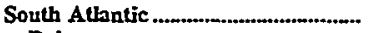 & 125,195 & 116,657 & 15,831 & 14,517 & 2,451 & 2,662 & 6,123 & 5,862 & 2,750 & 2,626 \\
\hline Delaware................................................ & 2,087 & 2,092 & 206 & 185 & - & - & - & - & - & - \\
\hline District of Columbia ............................ & 868 & 806 & - & - & - & - & - & - & - & - \\
\hline 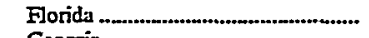 & 31,169 & 28,314 & 7,706 & 6,981 & 30 & 36 & 759 & 718 & 715 & 677 \\
\hline Georgia & 17,527 & 16,168 & 2,038 & 1,944 & 1,544 & 1,682 & 3,504 & 3,354 & - & - \\
\hline 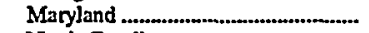 & 11,730 & 30,951 & 67 & 65 & - & - & 96 & 86 & 一 & - \\
\hline North Carolina.................................... & 20,563 & 19,688 & 1,003 & 935 & 379 & 413 & 15 & 15 & 4 & 4 \\
\hline 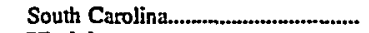 & 12,582 & 11,677 & 4,750 & 4,352 & 280 & 280 & 1,094 & 1,037 & 85 & 85 \\
\hline 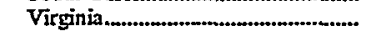 & 14,619 & 33,491 & 60 & 57 & 218 & 252 & 656 & 653 & 840 & 840 \\
\hline West Virginia ........................................ & 14,052 & 13,471 & - & - & $-\infty$ & - & - & - & 1,106 & 1,020 \\
\hline East South Central ............................... & 15,889 & 14,664 & 1,147 & 1,034 & 32,993 & 29,163 & 4,861 & 4,614 & 11,992 & 11,544 \\
\hline Alabama & 768 & 727 & - & $\rightarrow$ & 8,564 & 7,656 & 918 & 913 & 11,992 & $1], 544$ \\
\hline 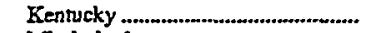 & 8,740 & 7,755 & 980 & 874 & 4,898 & 4,146 & 3,109 & 2,885 & - & - \\
\hline Mississippi & 6,380 & 6,182 & 167 & 160 & - & - & 833 & 816 & - & - \\
\hline 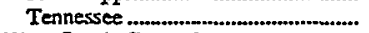 & - & - & - & - & 19,531 & 17,361 & - & - & - & - \\
\hline 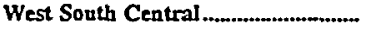 & 85,219 & 81,347 & 15,317 & 14,553 & 1,792 & 1,966 & 6,294 & 6,173 & 563 & 517 \\
\hline Arkansas & 6,594 & 6,373 & 368 & 355 & 1,021 & 1,148 & J,825 & 3,812 & - & - \\
\hline 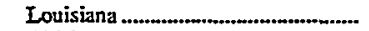 & 14,596 & 13,456 & 1,469 & 1,388 & - & - & 1,922 & 1,801 & 482 & 436 \\
\hline 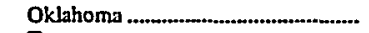 & 10,047 & 9,546 & 1,656 & 1,554 & 514 & 539 & 1,279 & 1,291 & - & - \\
\hline 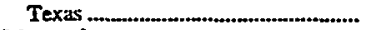 & 53,982 & 51,973 & 11,824 & 11,256 & 257 & 278 & 3,268 & 1,269 & 81 & 81 \\
\hline Mountain & 32,578 & 30,327 & 10,652 & 10,024 & 7,633 & 7,843 & 2,749 & 2,640 & 524 & s14 \\
\hline 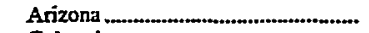 & 8,075 & 7,113 & 4,768 & 4,342 & 3,233 & 3,188 & 566 & 520 & - & - \\
\hline 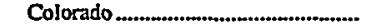 & 3,817 & 3,805 & 1,564 & $1,46]$ & 730 & 771 & 867 & 813 & - & - \\
\hline 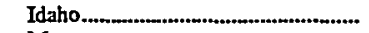 & $1,46]$ & $1,6] 7$ & 55 & 55 & 698 & 756 & 6 & 6 & 173 & 142 \\
\hline 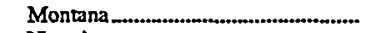 & 3,645 & 3,353 & - & - & 1,439 & 1,590 & - & - & - & - \\
\hline Nevada & 4,190 & 3,944 & 674 & 660 & 1,037 & 3,037 & - & - & - & 一 \\
\hline 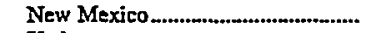 & 4,400 & 4,014 & 808 & 752 & 48 & 48 & 371 & 369 & - & - \\
\hline Utah & 2,572 & 2,383 & 1,891 & 1,879 & 157 & 157 & 159 & 153 & 352 & 372 \\
\hline 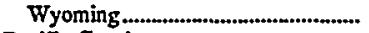 & 4,416 & 4,098 & 892 & 873 & 291 & 295 & 780 & 778 & - & - \\
\hline 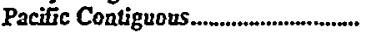 & 35,805 & 34,694 & 21,253 & 21,447 & 20,848 & 22,392 & 650 & 597 & 446 & 390 \\
\hline 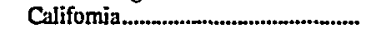 & 30,380 & 29,447 & 11,614 & 11,664 & 1,983 & 2,139 & 86 & 86 & 430 & 373 \\
\hline Oregon & 2,625 & 2,538 & 195 & 168 & 6,537 & 7,320 & 563 & 510 & - & - \\
\hline Washington.......................................... & 2,800 & 2,708 & 9,444 & 9,615 & 12,328 & 12,933 & 1 & 1 & 16 & 16 \\
\hline Pacifrc Noncontiguous.......................... & 1,823 & 1,762 & 560 & 513 & 108 & 108 & 1,057 & 906 & 56 & 56 \\
\hline 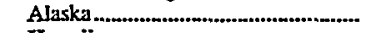 & 168 & 167 & 560 & 513 & 108 & 108 & 1,057 & 906 & 56 & 56 \\
\hline 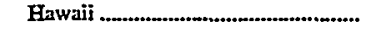 & \,65S & 1,595 & - & - & - & - & - & - & 一 & 一 \\
\hline
\end{tabular}

1 Includes municipalities, State projects, political subdivisions.

Includes nonutility power producers.

Nore: Total may not equal the sum of components becuuse of independent rounding.

Source: Energy Information Administration, Form ElA-860, "Annual Electric Generator Report." 


\title{
Appendix F
}

\author{
Maps
}


-

• 


\title{
Appendix F
}

\author{
Maps
}

Figure F1. North American Electric Reliability Council Regions for the Contiguous United States and Alaska

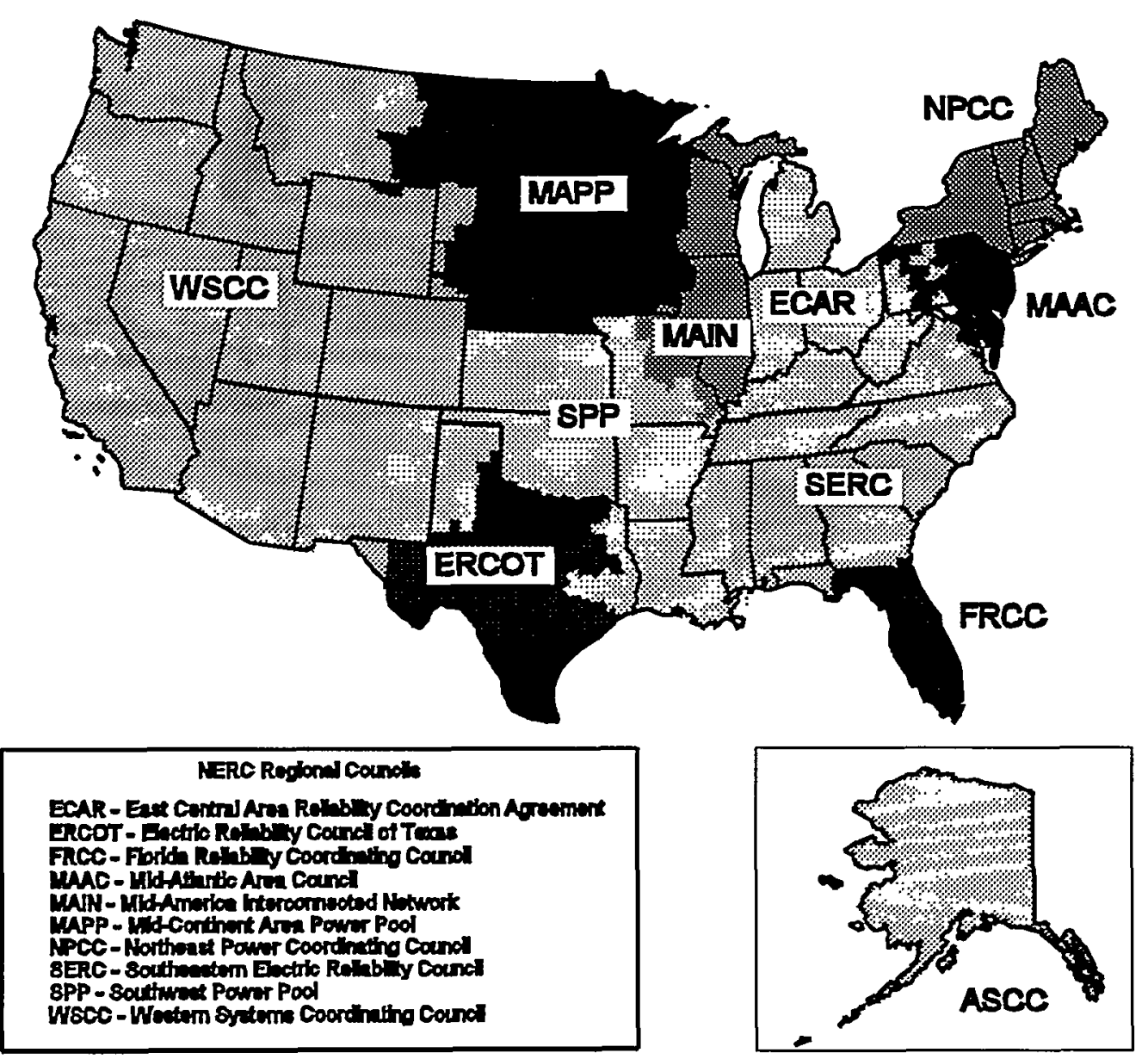

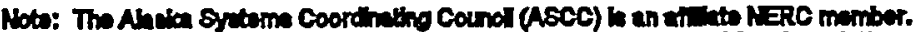

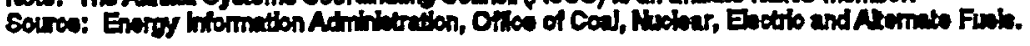


Figure F2. U.S. Federal Regions

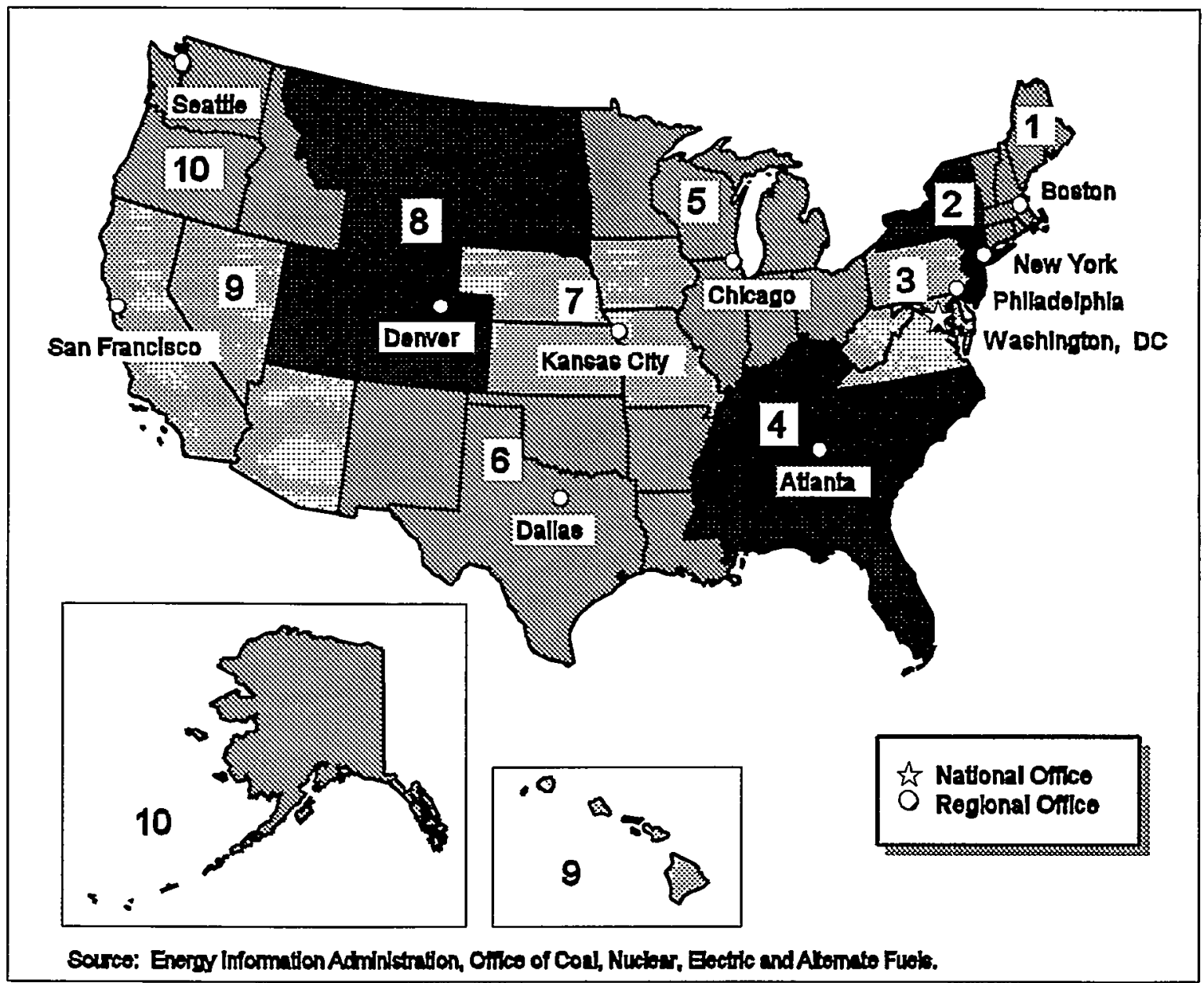


Figure F3. U.S. Census Regions and Divisions

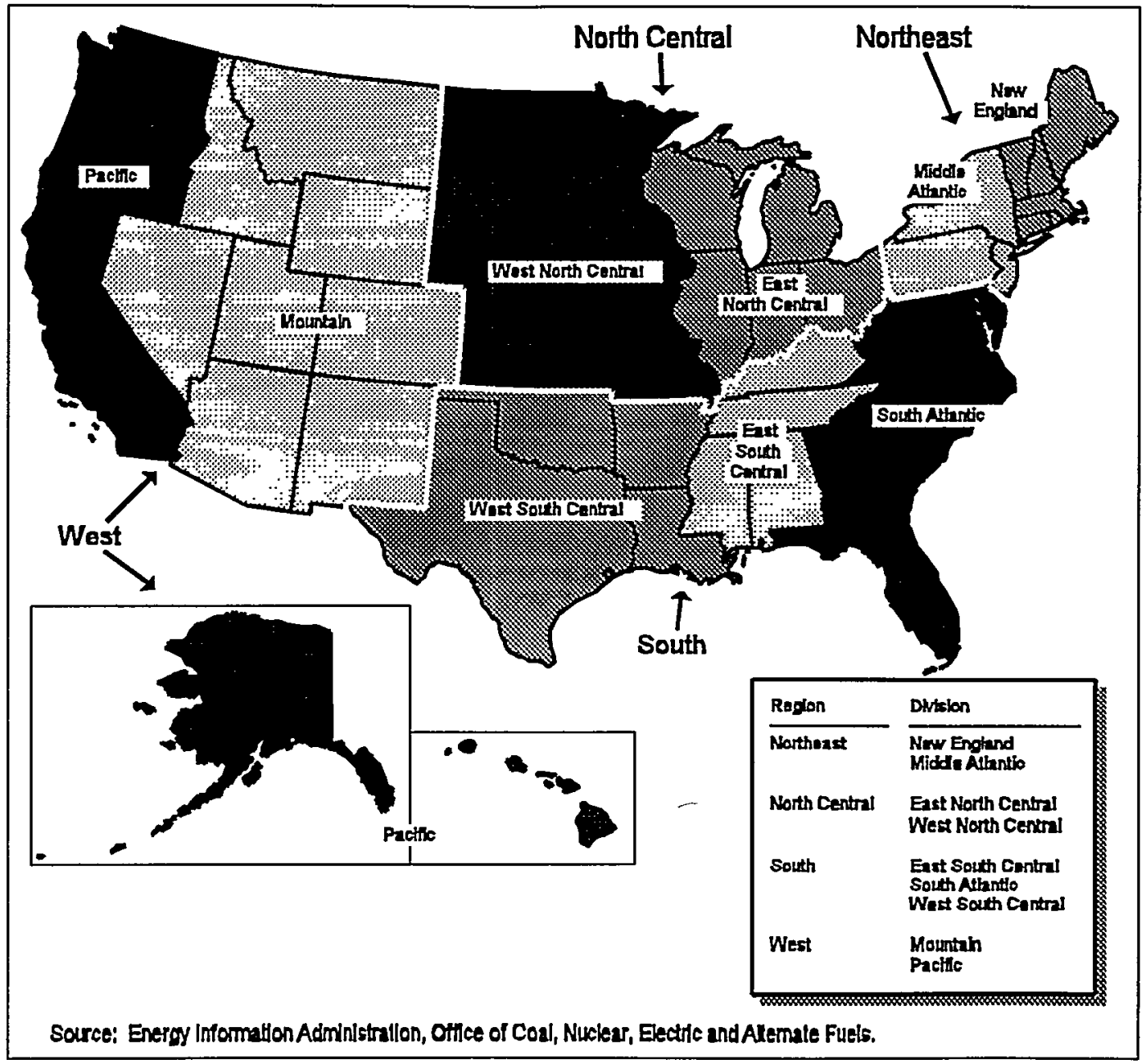




\section{Glossary}

Ampere: The unit of measurement of electrical current produced in a circuit by 1 volt acting through a resistance of $1 \mathrm{ohm}$. (See Current, Ohm, Volt.)

Anthracite: Anthracite, or hard coal, is the highest rank of economically useable coal. It is jet black with a high luster. The moisture content generally is less than 15 percent. Anthracite contains approximately 22 to 28 million Btu per ton as received and averages about 25 million $\mathrm{Btu}$ per ton. Its ignition temperature is approximately 925 to 970 degrees Fahrenheit. Virtually all of the anthracite mined is from northeastern Pennsylvania. It is used mostly for space heating and generating electricity.

Barrel: A volumetric unit of measure for crude oil and petroleum products equivalent to 42 U.S. gallons.

Baseload: The minimum amount of electric power delivered or required over a given period of time at a steady state. (See Baseload Plant.)

Baseload Capacity: The generating equipment normally operated to serve loads on a round-the-clock basis. (See Baseload, Baseload Plant.)

Baseload Plant: A plant, usually housing highefficiency steam-electric units, which is normally operated to take all or part of the minimum load of a system, and which consequently produces electricity at an essentially constant rate and runs continuously. These units are operated to maximize system mechanical and thermal efficiency and minimize system operating costs. (See Baseload.)

Biomass: Organic materials used as a source of energy. (See Other Generation.)

Bituminous Coal: Bituminous coal, or soft coal, is the most common coal. It is dense, black, often with well-defined bands of bright and dull material. Its moisture content usually is less than 20 percent. The heating value ranges from 19 to 30 million $B$ tu per ton as received and averages about 24 million Btu per ton. The ignition temperature ranges from about 700 to almost 900 degrees Fahrenheit. Bituminous coal is mined chiefly in the Appalachian and Interior coal fields. It is used for 'generating electricity, making coke, and space heating.

Blast Furnace: A furnace in which solid fuel (coke) is burned with an air blast to smelt iron ore.

Boiling-Water Reactor (BWR): A light-water reactor in which water, used as both coolant and moderator, is allowed to boil in the core. The resulting steam can be used directly to drive a turbine.
Btu (British Thermal Unit): A standard unit for measuring the quantity of heat energy equal to the quantity of heat required to raise the temperature of 1 pound of water by 1 degree Fahrenheit.

Capability: The maximum load that a generating unit, generating station, or other electrical apparatus can carry under specified conditions for a given period of time without exceeding approved limits of temperature and stress.

Capacity: The amount of electric power delivered or required for which a generator, turbine, transformer, transmission circuit, station, or system is rated by the manufacturer. (See Generator Nameplate Capacity.)

Capacity Factor: The ratio of the average load on the plant(s) for the period of time considered to the aggregate capacity of all the generating equipment installed in the plant(s).

Census Divisions: The nine geographic divisions of the United States established by the Bureau of the Census, U.S. Department of Commerce for statistical analysis. The boundaries of Census divisions coincide with State boundaries. In some cases, the Pacific Division is subdivided into the Pacific Contiguous and Pacific Noncontiguous areas.

Coal: A black or brownish-black solid combustible substance formed by the partial decomposition of vegetable matter without access to air. The rank of coal, which includes anthracite, bituminous coal, subbituminous coal, and lignite, is based on fixed carbon, volatile matter, and heating value. Coal rank indicates the progressive alteration from lignite to anthracite. Lignite contains approximately 9 to 17 million Btu per ton. The contents of subbituminous and bituminous coal range from 16 to 24 million Btu per ton and from 19 to 30 million Btu per ton, respectively. Anthracite contains approximately 22 to 28 million Btu per ton.

Cogeneration: The sequential or simultaneous process in which useful heat/steam is generated, used in a variety of process applications, and then directed into a turbine to generate electricity and/or mechanical work from the useful thermal energy still available for use. (See Generation, Energy.)

Coke: In general, a product made from bituminous coal and crude oil from which the volatile constituents have been driven off by heat, so that fixed carbon and ash are fused together. Coke, being largely carbon, is hard and porous, and is a desirable fuel in certain metallurgical industries. 
Combined Cycle: A cogeneration technology in which additional electricity is produced sequentially from the otherwise lost waste heat exiting from one or more gas-fired turbines. The exiting heat flow is routed to a exhaust-fired conventional boiler or to a heat recovery steam generator for utilization by a steam turbine in the production of electricity. This process increases the efficiency of an electric generating system by turning the rejected heat into thermal steam rather than discharging it into the atmosphere. (See Cogeneration, Turbine.)

Combined Hydroelectric Plant: A hydroelectric plant that uses both pumped water and natural streamflow for the production of power.

Combined Pumped-Storage Plant: A pumpedstorage hydroelectric power plant that uses both pumped water and natural streamflow to produce electricity.

Commercial Operation: A generating unit is said to be in commercial operation when control of the loading of the unit is turned over to the system dispatcher.

Consumption (Fuel): The amount of fuel used for gross generation, providing standby service and start-up and/or flame stabilization. (See Fuel.)

Conventional Hydroelectric Plant: A plant in which all of the power is produced from natural streamflow as regulated by available storage.

Crude Oil (including Lease Condensate): A mixture of hydrocarbons that existed in liquid phase in underground reservoirs and that remains liquid at atmospheric pressure after passing through surface separating facilities. Included are lease condensate and liquid hydrocarbons produced from tar sands, gilsonite, and.shale oil. Drip gases are also included, but topped crude oil (residual oil) and other unfinished oils are excluded. Liquids produced at natural gas processing plants and mixed with crude oil are likewise excluded where identifiable. (See Petroleum.)

Current: A flow of electrons in an electrical conductor. The strength or rate of movement of the electricity is measured in amperes. (See Ampere, Ohm, Volt.)

Demand: The rate at which electric energy is delivered to or by a system, part of a system, or piece of equipment, at a given instant or averaged over any designated period of time.

Design Electrical Rating (Capacity), Net: The nominal net electrical output of a nuclear unit, as specified by the utility for the purpose of plant design.

Distillate Fuel Oil: A general classification for one of the petroleum fractions produced in conventional distillation operations. It is used primarily for space heating, on-and-off-highway diesel engine fuel (including railroad engine fuel and fuel for agriculture machinery), and electric power generation. Included are products known as No. 1, No. 2, and No. 4 fuel oils; No. 1, No. 2, and No. 4 diesel fuels.

Electric Plant: A station containing prime movers, electric generators, and auxiliary equipment for converting mechanical, chemical, and/or fission energy into electric energy.

Electric Power Industry: The public, private, and cooperative electric utility systems of the United States taken as a whole. This includes all electric systems serving the public: regulated investor-owned electric utility companies; Federal power projects; State, municipal, and other government-owned systems, including electric public utility districts; electric cooperatives, including Generation and Transmission entities ("G and $T$ 'S"); jointly owned electric utility facilities, and electric utility facilities owned by a lessor and leased to an electric utility. Excluded from this list are the special purpose electric facilities or systems that do not offer service to the public.

Electric Power System: An individual electric power entity--a company, an electric cooperative, a public electric supply corporation like the Tennessee Valley Authority, a similar Federal department or agency like the Bonneville Power Administration, the Bureau of Reclamation or the Corps of Engineers, a municipally owned, electric department offering service to the public, or an electric public utility district (a "PUD "); also a jointly owned electric supply project such as the Keystone.

Electric Utility: A corporation, person, agency, authority, or other legal entity or instrumentality that owns and/or operates facilities within the United States, its territories, or Puerto Rico for the generation, transmission, distribution, or sale of electric energy, primarily for use by the public. An entity that solely operates qualifying facilities under the Public Utility Regulatory Policies Act of 1978 is not considered an electric utility.

Energy: The capacity for doing work as measured by the capability of doing work (potential energy) or the conversion of this capability to motion (kinetic energy). Energy has several forms, some of which are easily convertible and can be changed to another form useful for work. Most of the world's convertible energy comes from fossil fuels that are burned to produce heat that is then used as a transfer medium to mechanical or other means in order to accomplish tasks. Electrical energy is usually measured in kilowatthours, while heat energy is usually measured in British thermal units. (See Energy Source.)

Energy Source: The primary source that provides the power that is converted to electricity through chemical, mechanical, or other means. Energy sources include coal, petroleum and petroleum products, gas, water, uranium, wind, sunlight, geothermal, and other sources.

Fahrenheit: A temperature scale on which the boiling point of water is at 212 degrees above zero on the scale and the freezing point is at 32 degrees above zero at standard atmospheric pressure. 
Federal Region: In a Presidential directive issued in 1969, various Federal agencies (among them the currently designated Department of Health and Human Services, the Department of Labor, the Office of Economic Opportunity, and the Small Business Administration) were instructed to adopt a uniform field system of 10 geographic regions with common boundaries and headquarters cities. The action was taken to correct the evolution of fragmented Federal field organization structures that each agency or component created independently, usually with little reference to other agencies' arrangements. Most Federal domestic agencies or their components have completed realignments and relocations to conform to the Standard Federal Administration Regions (SFAR's) shown on the map at the end of this publication.

Forced Outage: The shutdown of a generating unit, transmission line or other facility, for emergency reasons or a condition in which the generating equipment is unavailable for load due to unanticipated breakdown. (See Outage.)

Fossil Fuel: Any naturally occurring organic fuel, such as coal, crude oil, and natural gas.

Fossil Fuel Plant: A plant using coal, petroleum, or gas as its source of energy.

Fuel: Any substance that can be burned to produce heat; also, materials that can be fissioned in a chain reaction to produce heat.

Fuel Cell: A device that produces electrical energy directly from the controlled electrochemical oxidation of the fuel. It does not contain an intermediate heat cycle, as do most other electrical generation techniques.

Gas: Includes natural gas, coke-oven gas, blastfurnace gas, and refinery gas. Manufactured gas is reported as natural gas on FERC Form 423. (See Natural Gas.)

Gas-Turbine Plant: A plant in which the prime mover is a gas turbine. A gas turbine consists typically of an axial-flow air compressor, one or more combustion chambers where liquid or gaseous fuel is burned and the hot gases are passed to the turbine; where the hot gases expand to drive the generator and then are used to run the compressor.

Generating Unit: An electric generator together with its prime mover.

Generation: The process of producing electric energy by transforming other forms of energy; also, the amount of electric energy produced, expressed in kilowatthours. (See Electric Plant, Energy.)

Generator: A machine that converts mechanical energy into electrical energy.

Generator Nameplate Capacity: The full-load continuous rating of a generator, prime mover, or other electrical equipment under specified conditions as designated by the manufacturer. Generator nameplate capacity is usually indicated on a nameplate attached physically to the equipment. Installed station capacity does not include auxiliary or house units.

Geothermal Energy: Energy from the internal heat of the earth may be residual heat, friction heat, or a result of radioactive decay. The heat is found in rocks and fluids at various depths and can be extracted by drilling and/or pumping.

Geothermal Plant: A plant in which the prime mover is a steam turbine. The turbine is driven either by steam produced from hot water or by natural steam that derives its energy from heat found in rocks or fluids at various depths beneath the surface of the earth. The energy is extracted by drilling and/or pumping.

Gigawatt (GW): One billion watts. (See Watt.)

Gigawatthour (GWh): One billion watthours. (See Watthour.)

Grid: The layout of an electrical distribution system.

Gross Generation: The total amount of electric energy produced by a generating station or stations, measured at the generator terminals. (See Generation, Electric Plant.)

Heat Rate: A measure of generating station thermal efficiency, generally expressed in Btu per net kilowatthour. It is computed by dividing the total Btu content of fuel burned for electric generation by the resulting net kilowatthour generation. (See Btu, British Thermal Unit.)

Heavy Oil: The fuel oils remaining after the lighter oils have been distilled off during the refining process. Except for start-up and flame stabilization, virtually all petroleum used in steam plants is heavy oil.

Horsepower: A unit for measuring the rate of work (or power) equivalent to 33,000 foot-pounds per minute or 746 watts. (See Watt.)

Hydroelectric Energy: The production of electricity from kinetic energy in flowing water. (See Energy.)

Hydroelectric Plant: A plant in which the turbine generators are driven by falling water.

Hydroelectric Power: The harnessing of flowing water to produce mechanical or electrical energy. (See Hydroelectric Energy, Hydroelectric Plant.)

Internal Combustion Plant: A plant in which the prime mover is an internal combustion engine. An internal combustion engine has one or more cylinders in which the process of combustion takes place, converting energy released from the rapid burning of a fuel-air mixture into mechanical energy. Diesel or gas-fired engines are the principal types used in electric plants. The plant is usually operated during periods of high demand for electricity. 
Kilowatt (kW): One thousand watts. (See Watt.)

Kilowatthour (kWh): One thousand watthours. (See Watthour.)

Life Extension: Investments made to maintain the operating status of an electric generating plant, into acceptable levels of availability and efficiency, beyond its originally anticipated retirement date.

Light Oil: Lighter fuel oils distilled off during the refining process. Virtually all petroleum used in internal combustion and gas-turbine engines is light oil.

Light-Water Reactor (LWR): A nuclear reactor that uses water as the primary coolant and moderator, with slightly enriched uranium as fuel. There are two types of commercial light-water reactor -- the boiling-water reactor (BWR) and the pressurized-water reactor (PWR).

Lignite: Lignite, the lowest rank of coal, is brownish black and has a high moisture content, sometimes as high as 45 percent. It tends to disintegrate when exposed to the weather. The heat content of lignite ranges from 9 to 17 million Btu per ton as received and averages about 14 million Btu per ton. The ignition temperature is approximately 600 degrees Fahrenheit. Lignite is mined in California, Louisiana, Montana, North Dakota, and Texas, and is used mainly to generate electricity in power plants that are relatively close to the mines.

Load (Electric): The amount of electric power delivered or required at any specific point or points on a system. The requirement originates at the energyconsuming equipment of the customers.

Load Management Technique: Utility demand management practices directed at reducing the maximum kilowatt demand on an electric system, and/or modifying the coincident peak demand of one or more classes of service to better meet the utility system capability for a given hour, day, week, season, or year. (See Demand, Load (Electric)).

Low-Power Testing: The period of time between a plant's initial fuel loading date and the issuance of its operating (Full Power) license. The maximum level of operation during this period is 5 percent of the unit's design thermal rating.

Maximum Demand: ' The greatest of all demands of the load that has occurred within a specified period of time.

Mcf: One thousand cubic feet.

Megawatt (MW): One million watts. (See Watt.)

Megawatthour (MWh): One million watthours. (See Watthour.)

MMcf: One million cubic feet.
Municipality: A city, county, irrigation district, drainage district, or a political subdivision or agency of a State competent under the laws thereof to carry on the business of developing, transmitting, or distributing power.

Natural Gas: A naturally occurring mixture of hydrocarbon and nonhydrocarbon gases found in porous geological formations beneath the earth's surface, often in association with petroleum. The principal constituent is methane.

Net Generation: Gross generation less plant use, measured at the high-voltage terminals of the station's step-up transformer. The energy required for pumping at pumped-storage plants is regarded as plant use and must be deducted from the gross generation. (See Generation, Electric Plant.)

Net Summer Capability: The steady hourly output which generating equipment is expected to supply to system load (exclusive of auxiliary) power as demonstrated by tests at the time of summer peak demand.

Net Winter Capability: The steady hourly output which generating equipment is expected to supply to system load exclusive of auxiliary power as demonstrated by test at the time of winter peak demand.

North American Electric Reliability Council (NERC): A council formed in 1968 by the electric utility industry to promote the reliability and adequacy of bulk power supply in the electric utility systems of North America. NERC consists of nine regional reliability councils and encompasses essentially all the power systems of the contiguous United States, Canada, and some in Mexico. The data summarized by NERC regions in this publication are limited to that portion applicable to the contiguous United States, thereby excluding that portion of NERC data applicable to Alaska, Hawaii, Canada, and Mexico. The NERC Regions are:

ECAR - East Central Area Reliability Coordination Agreement

$$
\begin{aligned}
& \text { ERCOT - Electric Reliability Council of Texas } \\
& \text { FRCC - Florida Reliability Coordinating Council } \\
& \text { MAIN - Mid-America Interconnected Network } \\
& \text { MAAC - Mid-Atlantic Area Council } \\
& \text { MAPP - Mid-Continent Area Power Pool } \\
& \text { NPCC - Northeast Power Coordinating Council } \\
& \text { SERC - Southeastern Electric Reliability Council } \\
& \text { SPP - Southwest Power Pool } \\
& \text { WSCC - Western Systems Coordinating Council. }
\end{aligned}
$$

Nuclear Fuel: Fissionable materials that have been enriched to such a composition that when placed in a nuclear reactor will support a self-sustaining fission chain reaction, producing heat in a controlled manner for process use.

Nuclear Power Plant: A plant in which the prime mover is a steam turbine. The steam used to drive the 
turbine is produced by a heat transfer from the reactor vessel during the period when the nuclear fuel is undergoing fission.

Nuclear Reactor: A device in which a fission chain reaction can be initiated, maintained, and controlled. Its essential components are a vessel containing a core with fissionable fuel, a moderator for the fission chain reaction, and a control system.

No. 1 Fuel Oil: A light distillate fuel oil intended for use in vaporizing pot-type burners. ASTM Specification D396 specifies for this grade maximum distillation temperatures of 400 degrees $F$. at the 10 -percent point and 550 degrees $F$. at the 90 -percent point, and kinematic viscosities between 1.4 and 2.2 centistokes at 100 degrees $F$.

No. 2 Fuel Oil: A distillate fuel oil for use in atomizing type burners for domestic heating or for moderate capacity commercial-industrial burner units. ASTM Specification D396 specifies for this grade distillation temperatures at the 90-percent point between 540 degrees and 640 degrees $F_{\text {., }}$ and kinematic viscosities between 2.0 and 3.6 centistokes at 100 degrees $F$.

No. 1 and No. 2 Diesel Fuel Oils: Distillate fuel oils used in compression-ignition engines, as given by ASTM Specification D975:

No. 1-D - A volatile distillate fuel oil with a boiling range between $300-575$ degrees $F$. and used in high-speed diesel engines generally operated under wide variations in speed and load. Includes type C-B diesel fuel used for city buses and similar operations. Properties are defined in ASTM Specifications D975.

No. 2-D - A gas-oil type of distillate of lower volatility with distillation temperatures at the 90-percent point between 540-640 degrees F. for use in high-speed diesel engines generally operated under uniform speed and load conditions. Includes Type R-R diesel fuel used for railroad locomotive engines, and $\mathrm{T}-\mathrm{T}$ for diesel-engine trucks. Properties are defined in ASTM Specification D975.

No. 4 Fuel Oil: A fuel oil for commercial burner installations not equipped with preheating facilities; used extensively in industrial plants. This grade is a blend of distillate fuel oil and residual fuel oil stocks that conform to ASTM Specification D396 or Federal Specification VV-F-815C; its kinematic viscosity is between 5.8 and 26.4 centistokes at 100 degrees $F$. Also included is No. 4-D, a fuel oil for low- and medium-speed diesel engines that conforms to ASTM Specification D975.

Ohm: The unit of measurement of electrical resistance. The resistance of a circuit in which a potential difference of 1 volt produces a current of 1 ampere. (See Ampere, Current, Volt.)

Oil: A mixture of hydrocarbons usually existing in the liquid state in natural underground pools or reservoirs. Gas is often found in association with oil. (See Crude Oil (Including Lease condensate), Petroleum.)
Operable: A unit is operable when it is available to provide power to the grid. For a nuclear unit, this is when it receives its full power amendment to its operating license from the Nuclear Regulatory Commission.

Other Gas: Includes manufactured gas, coke-oven gas, blast-furnace gas, and refinery gas. Manufactured gas is obtained by distillation of coal, by the thermal decomposition of oil, or by the reaction of steam passing through a bed of heated coal or coke. (See Natural Gas)

Other Generation: Electricity originating from these sources: biomass, fuel cells, geothermal heat, solar power, waste, wind, and wood.

Outage: The period during which a generating unit, transmission line, or other facility is out of service. (See Forced Outage, Scheduled Outage.)

Peak Load: The maximum load during a specified period of time.

Peak Load Plant: A plant usually housing old, lowefficiency steam units, gas turbines, diesels, or pumped-storage hydroelectric equipment normally used during the peak-load periods.

Peaking Capacity: Capacity of generating equipment normally operated during the hours of highest daily, weekly, or seasonal loads. Some generating equipment may be operated at certain times as peaking capacity and at other times to serve loads on a 'round-the-clock basis. (See Peak Load.)

Petroleum: A mixture of hydrocarbons existing in the liquid state found in natural underground reservoirs, often associated with gas. Petroleum includes Fuel Oil 2, 4, 5, 6, topped crude, kerosene, and jet fuel. (See Petroleum (Crude Oil.))

Petroleum Coke: A residue, high in carbon content and low in hydrogen, that is the final product of thermal decomposition in the condensation process in cracking. This product is reported as marketable coke or catalyst coke. The conversion factor is 5 barrels (of 42 U.S. gallons each) per short ton.

Petroleum (Crude Oil): A naturally occurring, oily, flammable liquid composed principally of hydrocarbons. Crude oil is occasionally found in springs or pools but usually is drilled from wells beneath the earth's surface.

Photovoltaic Cell: Device that produces electrical current by converting light or similar radiation. (See Other Generation.)

Plant: A station at which are located prime movers, electric generators, and auxiliary equipment for converting mechanical, chemical, and/or nuclear energy into electric energy. A station may contain more than one type of prime mover. Electric utility plants exclude stations that satisfy the definition of quali- 
fying facility under the Public Utility Regulatory Policies Act of 1978.

Plant Use: The electric energy used in the operation of a plant. Included in this definition is the energy required for pumping at pump-storage plants.

Plant-Use Electricity: The electric energy used in the operation of a plant. This energy total is subtracted from the gross energy production of the plant; for reporting purposes the plant energy production is then reported as a net figure. The energy required for pumping at pumped-storage plants is by definition subtracted, and the energy production for these plants is then reported as a net figure. (See Combined Pumped-Storage Plant, Pumped-Storage Hydroelectric Plant, Pure Pumped-Storage Hydroelectric Plant.)

Power: The rate at which energy is transferred, usually measured in watts. Also used for a measurement of capacity. (See Capacity, Energy, Watt.)

Power (Electrical): An electric measurement unit of power called a voltampere is equal to the product of one volt and one ampere. This is equivalent to $1 \mathrm{Watt}$ for a direct current system and a unit of of apparent power is separated into real and reactive power. Real power is the work-producing part of apparent power that measures the rate of supply of energy and is denoted as kilowatts (KW). Reactive power is the portion of apparent power that does no work and is referred to as kilovars; this type of power must be supplied to most types of magnetic equipment, such as motors, and is supplied by generator or by electrostatic equipment. Voltamperes are usually divided by 1,000 and called kilovoltamperes (kVA). Energy is denoted by the product of real power and the length of time utilized; this product is expressed as kilowatthours.

Pressurized-Water Reactor (PWR): A nuclear reactor in which heat is transferred from the core to a heat exchanger via water kept under high pressure, so that high temperatures can be maintained in the primary system without boiling the water. Steam is generated in a secondary circuit.

Prime Mover: The engine, turbine, water wheel, or similar machine that drives an electric generator.

Privately Owned Electric Utility: A class of ownership found in the electric power industry where the utility is regulated and authorized to achieve an allowed rate of return. (See Electric Power Industry.)

Production (Electric): Act or process of producing electric energy from other forms of energy; also, the amount of electric energy expressed in watthours (Wh).

Publicly Owned Electric Utility: A class of ownership found in the electric power industry. This group includes those utilities operated by municipalities, and State and Federal power agencies.

Public Utility Regulatory Policies Act of 1978: One part of the National Energy Act, PURPA contains measures designed to encourage the conservation of energy, more efficient use of resources, and equitable rates. Principal among these were suggested retail rate reforms and new incentives for production of electricity by cogenerators and users of renewable resources. The Commission has primary authority for implementing several key PURPA programs.

Pumped-Storage Hydroelectric Plant: A plant thit usually generates electric energy during peak-load periods by using water previously pumped into an elevated storage reservoir during off-peak periods when excess generating capacity is available to do so. When additional generating capacity is needed, the water can be released from the reservoir through a conduit to turbine generators located in a power plant at a lower level.

Pure Pumped-Storage Hydroelectric Plant: A plant that produces power only from water that has previously been pumped to an upper reservoir.

Renewable Energy Source: An energy source that is regenerative or virtually inexhaustible. Typical examples are wind, geothermal and water power. (See Other Generation.)

Repowering: Refurbishment of a plant by replacement of the combustion technology with a new combustion technology, usually resulting in better performance and greater capacity.

Residual Fuel Oil: The topped crude of refinery operation; includes No. 5 and No.6 fuel oils as defined in ASTM Specification D396 and Federal Specification VV-F-815C, Navy Special fuel oil as defined in Military Specification MIL-F-859E including Amendment 2 (NATO Symbol F-77), and Bunker C fuel oil. Residual fuel oil is used for the production of electric power, space heating, vessel bunkering, and various industrial purposes. Imports of residual fuel oil include "Imported Crude Oil Burned as Fuel."

Run-of-River Hydroelectric Plant: A low-head plant using the flow of a stream as it occurs, and having little or no reservoir capacity for storage. (See Hydroelectric Power.)

Scheduled Outage: The shutdown of a generating unit, transmission line, or other facility, for inspection or maintenance, in accordance with an advance schedule. (See Forced Outage, Outage.)

Short Ton: A unit of weight equal to 2,000 pounds.

Solar Energy: Energy produced from the sun's radiation.

Standby Facility: A facility that supports a utility system and is generally running under no-load. It is available to replace or supplement a facility normally in service. (See Standby Service, Outage.)

Standby Service: Support service that is available as needed to supplement a customer, a utility system, or to another utility if a schedule or an agreement 
authorizes the transaction. The service is not regularly used. (See Standby Facility, Outage.)

Station (Electric): A plant containing prime movers, electric generators, and auxiliary equipment for converting mechanical, chemical, and/or nuclear energy into electric energy.

Storage Hydroelectric Plant: A hydroelectric plant with reservoir storage capacity for power use.

Subbituminous Coal: Subbituminous coal, or black lignite, is dull black and generally contains 20 to 30 percent moisture. The heat content of subbituminous coal ranges from 16 to 24 million Btu per ton as received and averages about 18 million Btu per ton. Subbituminous coal, mined in the western coal fields, is used for generating electricity and space heating.

System (Electric): Physically connected generation, transmission, and distribution facilities operated as an integrated unit under one central management, or operating supervision.

Thermal: A term used to identify a type of electric generating station, capacity, capability, or output in which the source of energy for the prime mover is heat.

Turbine: A machine for generating rotary mechanical power from the energy in a stream of fluid (such as water, steam, or hot gas). Turbines convert the kinetic energy of fluids to mechanical energy through the principles of impulse and reaction, or a mixture of the two.

Uranium: A heavy, naturally radioactive, metallic element with atomic number 92 . The two isotopes that occur most frequently are Uranium-235 and Uranium-238. Uranium-235 is the only isotope existing in nature in any appreciable extent that is fissionable by thermal neutrons. Uranium is the basic raw material of nuclear energy. (See Nuclear Fuel.)

Volt: The unit of measurement of voltage, electrical force, or pressure. The electrical force that, if steadily applied to a circuit with a resistance of $1 \mathrm{ohm}$, will produce a current of 1 ampere. (See Ampere, Current, Ohm.)

Watt: The electrical unit of power. The rate of energy transfer equivalent to 1 ampere flowing under a pressure of 1 volt at unity power factor.

Watthour (Wh): An electrical energy unit of measure equal to 1 watt of power supplied to, or taken from, an electric circuit steadily for 1 hour.

Wind Energy: Energy produced by harnessing the force of the wind. In a wind energy conversion system such as a windmill, the energy of wind is used to turn the shaft of a generator, which in turn usually produces direct current. This direct current is usually converted to alternating current before being fed into a utility grid system. 